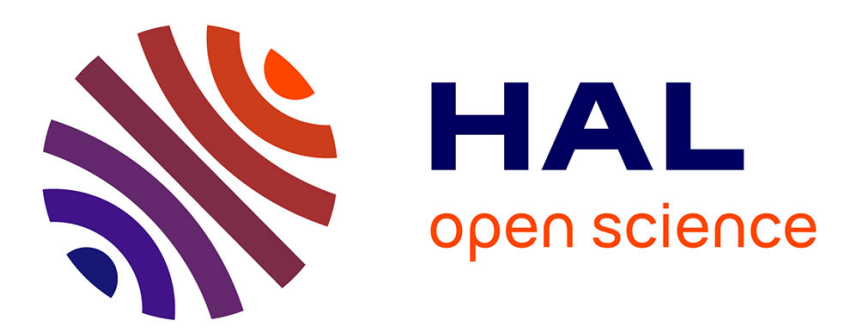

\title{
Community-based flood vulnerability index for urban flooding: understanding social vulnerabilities and risks \\ Mae Brigitt Bernadel Villordon
}

\section{To cite this version:}

Mae Brigitt Bernadel Villordon. Community-based flood vulnerability index for urban flooding: understanding social vulnerabilities and risks. Other. Université Nice Sophia Antipolis, 2014. English. NNT : 2014NICE4145 . tel-01128335

\section{HAL Id: tel-01128335 \\ https://theses.hal.science/tel-01128335}

Submitted on 9 Mar 2015

HAL is a multi-disciplinary open access archive for the deposit and dissemination of scientific research documents, whether they are published or not. The documents may come from teaching and research institutions in France or abroad, or from public or private research centers.
L'archive ouverte pluridisciplinaire HAL, est destinée au dépôt et à la diffusion de documents scientifiques de niveau recherche, publiés ou non, émanant des établissements d'enseignement et de recherche français ou étrangers, des laboratoires publics ou privés. 
Community-Based Flood Vulnerability Index for Urban Flooding: Understanding Social Vulnerabilities and Risks

\section{UNIVERSITE DE NICE-SOPHIA ANTIPOLIS ECOLE DOCTORALE STIC}

SCIENCES ET TECHNOLOGIES DE L'INFORMATION ET DE LA COMMUNICATION

$$
\text { THESE }
$$

pour l'obtention du grade de

\section{Docteur en Sciences}

de l'Université de Nice-Sophia Antipolis

Mention: Automatique, Traitement du Signal et des Images

présentée et soutenue par

Mae Brigitt Bernadel VILLORDON

\section{Community-Based Flood Vulnerability Index for Urban Flooding: Understanding Social Vulnerabilities and Risks}

Thèse dirigée par Philippe GOURBESVILLE

soutenue le 8 décembre 2014

Jury:

M. Manuel GOMEZ VALENTIN, Professeur UPC-Barcelone

Rapporteur

M. Shie Yui LIONG, Professeur-Deputy Director of Tropical Marine Science Institute

Rapporteur

M. Franco Siccardi, Professeur Université de Génes

Examinateur

M. Philippe Audra, Professeur-Polytech Nice Sophia/Université Nice Sophia Antipolis

Examinateur

Mme. Anny Cupo, Professeur-Polytech Nice Sophia/Université Nice Sophia Antipolis

Examinateur

M. Philippe Gourbesville, Professeur-Polytech Nice Sophia/Université Nice Sophia Antipolis

Directeur de thése

Université

nice

Sophia Antipolis
I-CiTy

Innovative CiTy Lab 
Community-Based Flood Vulnerability Index for Urban Flooding: Understanding Social Vulnerabilities and Risks

\section{ACKNOWLEDGEMENTS}

I am deeply thankful to God Almighty who has always been treating me so kind and so generous. For HIS unwavering love and blessings, I am grateful.

I extend my gratitude to the European Commission for Erasmus Mundus Mobility with Asia (EMMA Action 2) Lot 12: 2010-2362/001-001-EMA2 and to Silliman University to possibly carry out my PhD study here in Nice, France.

To Prof. Philippe Gourbesville whom I am also very grateful for the opportunity to work with him, for giving me space to do my studies, space to write and space to be. Forever, I will be grateful to you, thank you sir.

I am also thankful to Prof. Roy Olsen De Leon for his support and guidance in my studies, my colleagues Joan Tura and Prof. Michael Alcala for the data input and assisting me in my field work. Thank you to Rafael Vargas, Qiang Ma, Duong Vo, Mingxuan Du, Kim Lien and Jelena Batica who were kind and helpful enough to helped me improved my paper and for their cheerful company, thank you guys!

And to those wonderful people whom I have met during my stay in Europe, thank you for enriching my personal life. My time here has been a wonderful and beautiful journey. To mommy Ingrid M. Rosell thank you for the love and support. To all my dear friends back home, here and in other parts of the world, thank you for keeping me company through your letters, mails and postcards. Thank you.

Finally, I would like to express my deepest love and gratitude to my mother and sister for their constant love and support and the coming of my niece into this world is such a great joy and blessing. And to the greatest guru of all: life.

With love and thanks. 
Community-Based Flood Vulnerability Index for Urban Flooding: Understanding Social Vulnerabilities and Risks

Sujet de thèse en Français: Index de vulnérabilité sanitaire pour les crues urbaines: évaluation de la vulnérabilité sociale et des risques

\section{Résumé en Français}

Selon le World Risk Report publié par United Nations University Institute for Environment and Human Security, les Philippines occupent la troisème place mondiale pour l'exposition aux risques naturels. Un des risques majeurs est celui des inondatoons qui représente un défi pour la sécurité de sa population et le développement économique du pays. L'impact de ses inondations sur la santé publique des communautés en function deleur vulnérabilité sociale a été très peu étudié jusqu'à présent faute de données systématiques. Ce travail de recherceh se concentre sur ces aspect et propose une méthodologie pour évaluer la vulnérabilité sanitaire d'une population exposée à des inondations récurrentes. La methodologie est basée sur une évaluation de la connaissance, de l'attitude et des pratiques (KAP) des populations inondées et de leur résilience vis à vis de leur exposition à des pathogènes tels que E.coli, Leptospirosis and la dengue qui peuvent se développer à la suite d'un typhon. Des indicateurs communautaires ont été élaborés afin de caractériser les communautés. Ces indicateurs intègrent le profil socio-démographique, les conditions de logement, l'environnement physique ainsi que la gouvernance locale. Ces éléments sont importants pour évaluer le dégré de vulnérabilité sociale vis à vis du risque sanitaire afin de pouvoir ensuite intégrer ces éléments dans les outils de modélisation. Une investigation de terrain a été effectuée dans la ville de Dumaguete, Philippines, de mars 2013 à juillet 2013. Un total de 357 familles réparties dans 12 communautés ont été interrogés. L'analyse de ces données a permis de révéler une vulnérabilité synthétisée dans un indice (IVF) qui s'établi en moyenne à 39,34 \%. Le secteur de Barangay Tabuc-tubig présente un indice de $53,39 \%$ et s'avère le site le plus vulnérable. L'indice de vulnérabilité est basé sur 5 composants: hydroclimatique, social, économique, socio- comportementale et politico-administratif. Cette rapproche permet de caractériser l'état de vulnérabilité des communautés. Les résultats démontre que 
Community-Based Flood Vulnerability Index for Urban Flooding: Understanding Social Vulnerabilities and Risks

l'indice de vulnérabilité reste faible malgré des indicateurs d'exposition élevées. Ce résultat peut s'expliquer par la résilience élevée des communautés dans leurs stratégies d'adaptation lors des inondations. Cette recherche a permis de démontrer que Dans ce travail de recherche, l'indice de vulnérabilité est lié aux variables intervenant dans la caractérisation de la résilience. 


\section{ABSTRACT}

According to the World Risk Report released by the United Nations University Institute for Environment and Human Security, the Philippines is ranked third globally in terms of disaster risk. One of those disaster risks is flooding which poses a serious challenge to the development and the lives of the people. Public health risks and understanding social vulnerability are usually overlooked and undermined and only very little attention is given. Thus, this research work focuses on these aspects. This research was an exploratory step towards assessing vulnerability particularly to fluvial flooding. It was a rapid assessment of the Knowledge, Attitudes, and Practices (KAP) of the community people towards flood vulnerability and resilience and their exposure to microorganisms such as E.coli, Leptospirosis and the Dengue Fever mosquito which could pose an outbreak after a typhoon event. Appropriate community-based indicators were formulated and developed. Their socio-demographic profile, housing conditions, physical environment and governance were also included. These are important factors to be assessed in order to establish correlations and relationships in understanding social vulnerabilities and risks using local indicators which can be incorporated later in hydroinformatics. The survey was done from March 2013 to July 2013 to capture the dry and wet season for sampling. A total of 357 household respondents from the 12 communities and 30 respondents from the LGU and NGO were surveyed. Results of the study revealed an overall Flood Vulnerability Index (FVI) of $39.34 \%$. Barangay Tabuctubig (53.39\%) topping from all the 12 communities surveyed using the newly developed 36 community-based flood vulnerability indicators with its corresponding 5 major components namely; hydro-climatic, social, economic, socio-behavioral and the politicoadministrative. This research also reveals the most vulnerable communities from each of those 5 major components surveyed. It is interesting to note that Flood Vulnerability Index remains low in spite that the exposure indicators are high. The low FVI can be attributed to the community's high resilience in its coping and adaptation strategies. In this research work, the Flood Vulnerability Index is significantly sensitive to susceptibility and flood resilience variables. 
Community-Based Flood Vulnerability Index for Urban Flooding: Understanding Social Vulnerabilities and Risks

\section{TABLE OF CONTENTS}

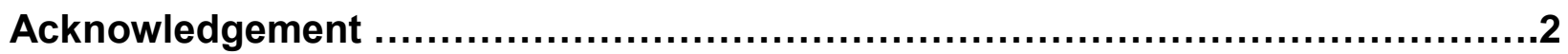

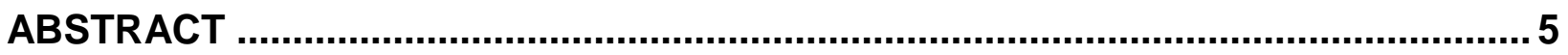

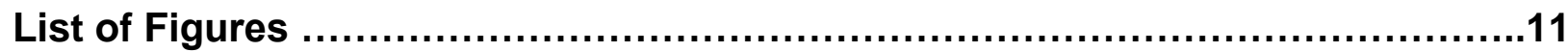

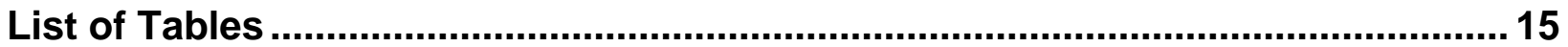

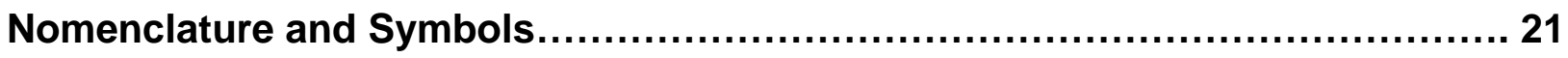

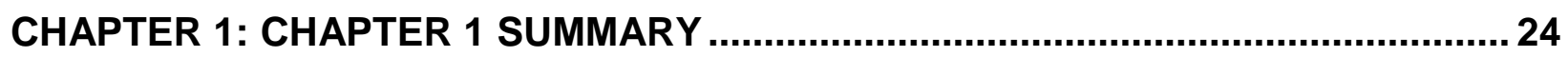

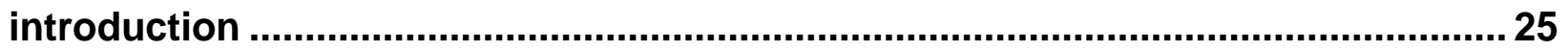

1.1 Approaches and Frameworks for Community-Based Flood Vulnerability Index

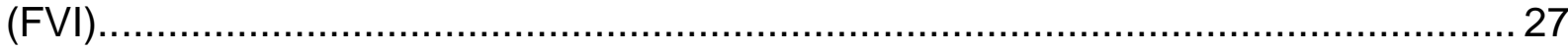

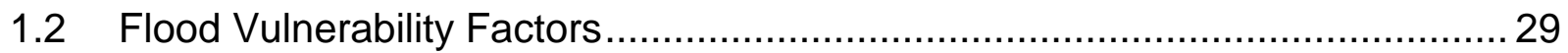

1.3 Identifying the Key Components and Indicators of the Developed Community-

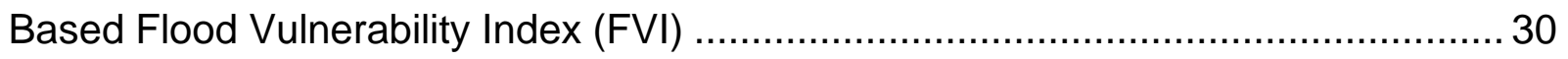

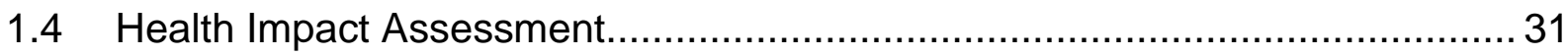

1.5 FLOOD RESILIENCE ADAPTATION STRATEGIES ASSESSMENT ............... 33

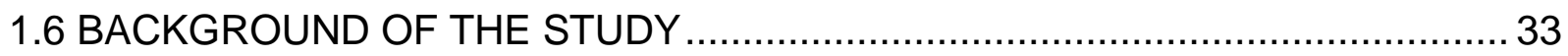

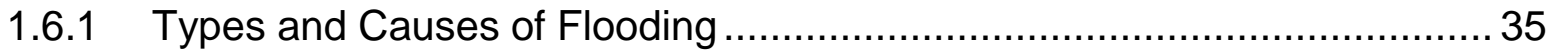

1.6.2 Natural Disasters: Storm and Flood Record Worldwide and in the

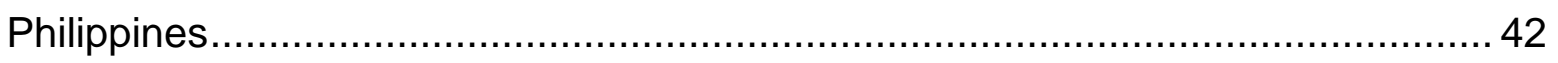

1.6.3 The Natural Disaster's Data in the Philippines from the 1900-2014 ......... 46

1.6.4 On the Health Impact Assessment: Disease Surveillance in the Philippines on Diarrhoea, Leptospirosis and Dengue Fever............................................... 51

1.7 STATE OF THE ART AND NEEDED IMPROVEMENTS …........................... 57

1.7.1 The Bündnis Entwicklung Hilft (Alliance Development Works) and United Nations University Institute for Environment and Human Security (UNU-EHS) ... 57

1.7.2 The United Nation Development Programme (UNDP) …........................ 58 
1.7.3 A Flood Vulnerability Index for Coastal Cities and Its Use in Assessing Climate Change Impacts. 58

1.7.4 The 2012 Philippine Disaster Report ................................................. 59

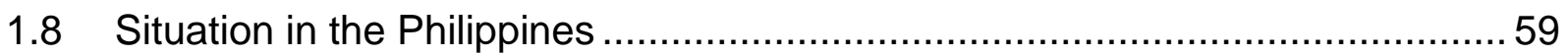

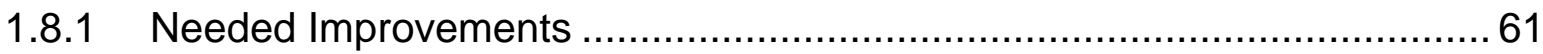

1.8.2 Significance for Developing of the Community-Based Vulnerability Index for

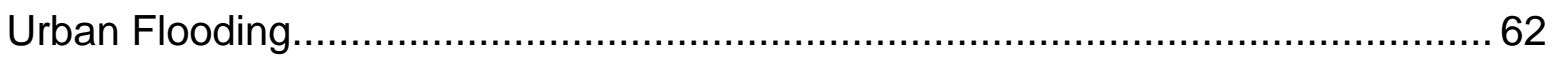

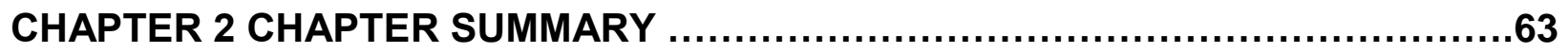

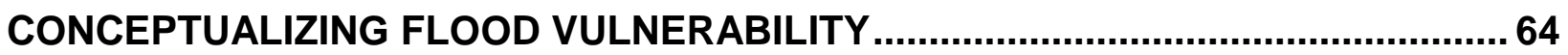

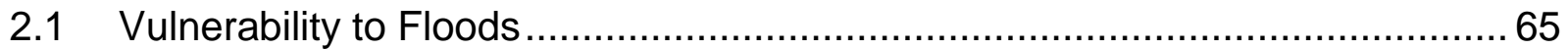

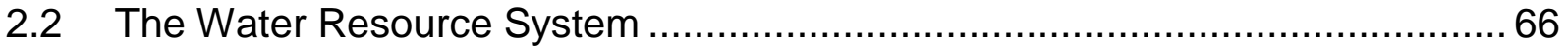

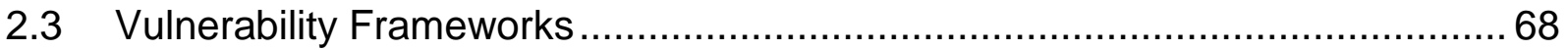

2.4 Global Risk and Vulnerability Indicators .................................................... 71

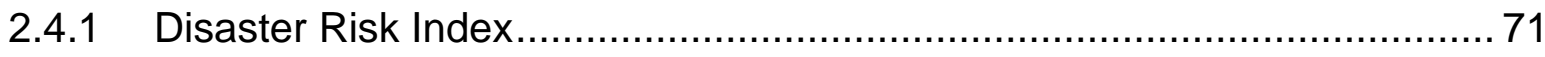

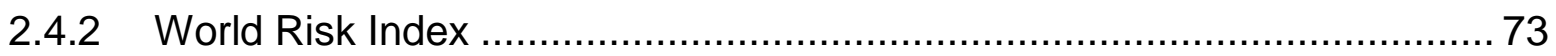

2.4.3 A Flood Vulnerability Index for Coastal Cities and Its Use in Assessing

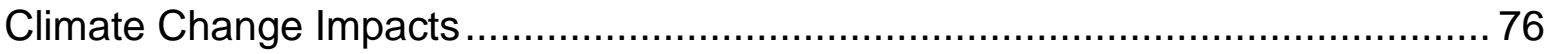

2.4.4 Existing Flood Vulnerability Index, Risk and Vulnerability Studies in the

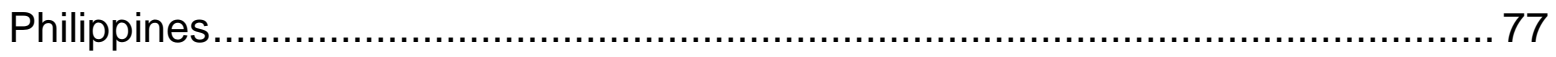

2.5 The Hyogo Framework for Action (HFA) (2005-2015) of the United Nations ... 79

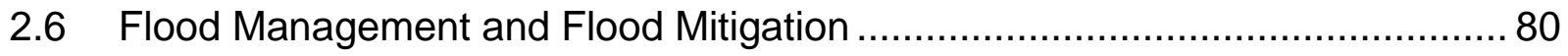

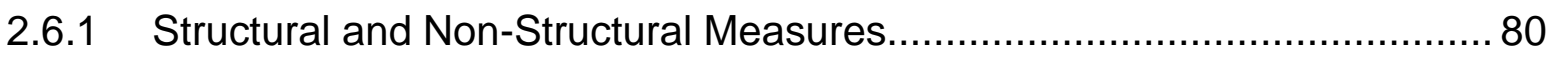

2.6.2 The Identified Emergency Evacuation Areas of Dumaguete City ............... 88

2.6.3 The Incident Command System of Dumaguete City ............................... 89

2.6.4 Institutional Working Arrangement........................................................ 90 
Community-Based Flood Vulnerability Index for Urban Flooding: Understanding Social Vulnerabilities and Risks

2.6.5 General Monitoring and Evaluation Framework..................................... 91

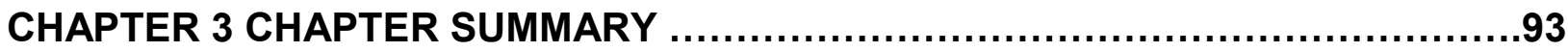

The Development of Community-Based Flood Vulnerability Framework: Its Components and Indicators for Urban Flooding ................................................ 94

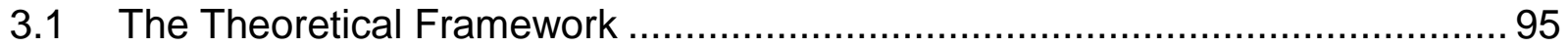

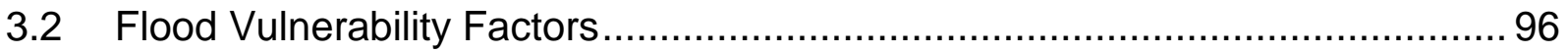

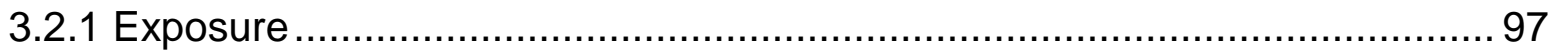

3.2.2 Susceptibility (Before the floods: Awareness and Preparedness) (During the floods: Dealing and Coping) .......................................................................... 97

3.2.3 Resilience (During: Handling and Coping) (After: Survive and

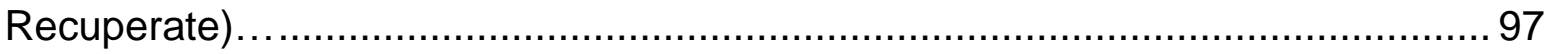

3.3 Identifying the Key Components and Indicators of Community-Based Flood

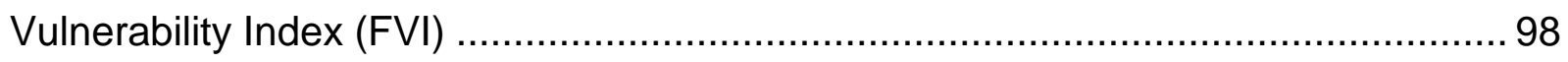

3.3.1 Hydro-Climatic Component............................................................... 99

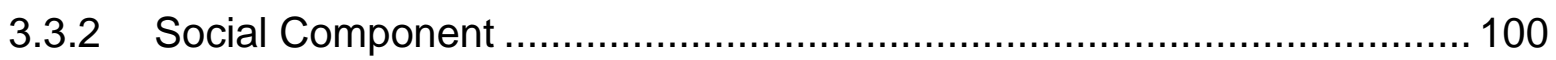

3.3.3 Economic Component ..................................................................... 100

3.3.4 Socio-Behavioral Component ….................................................... 100

3.3.5 Politico-Administrative Component ...................................................... 101

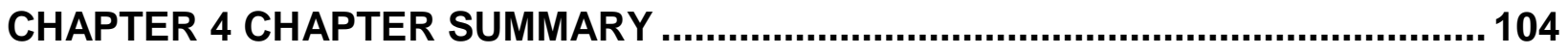

APPLICATION OF THE METHODOLOGY OF THE COMMUNITY-BASED FLOOD VULNERABILITY INDEX (FVI) FOR URBAN FLOODING:DATA COLLECTION AND

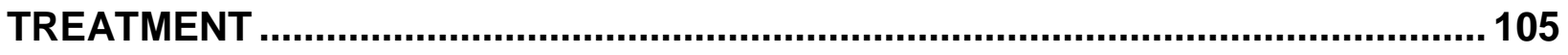

4.1 Community-Based Flood Vulnerability Index Methodology............................. 105

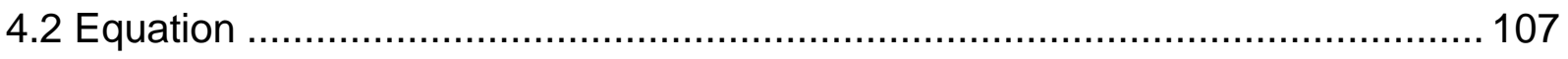

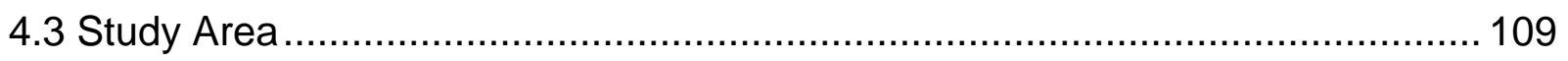

4.3.1 Dumaguete City, Negros Oriental Philippines ........................................ 112 
4.4 Community Profile 118

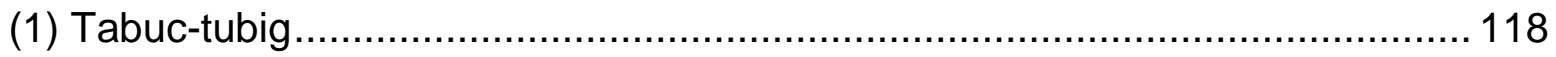

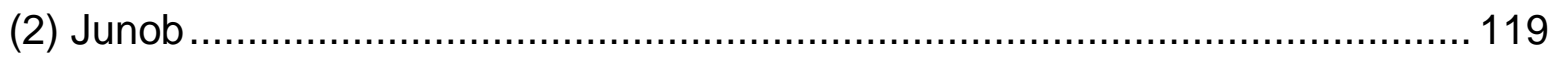

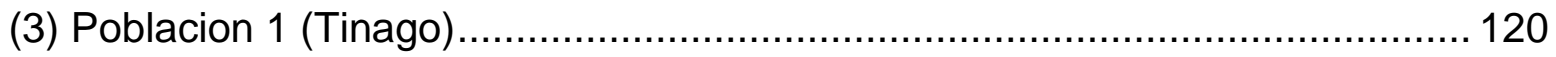

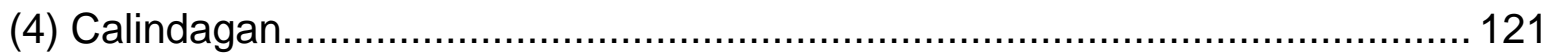

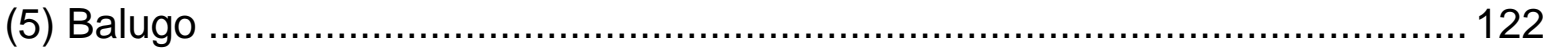

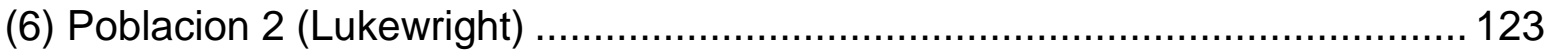

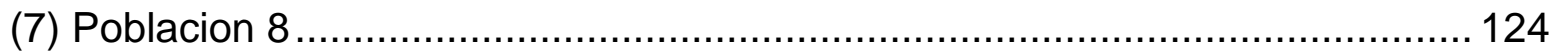

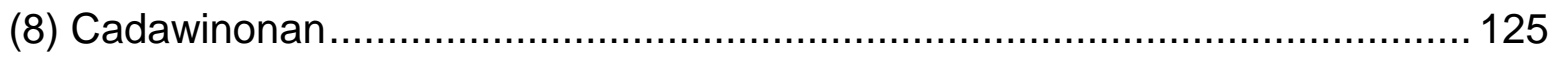

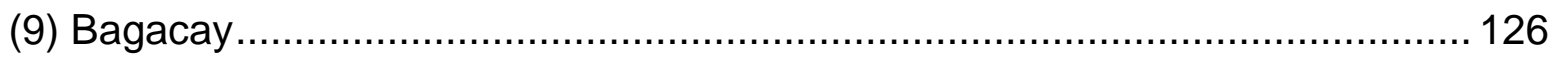

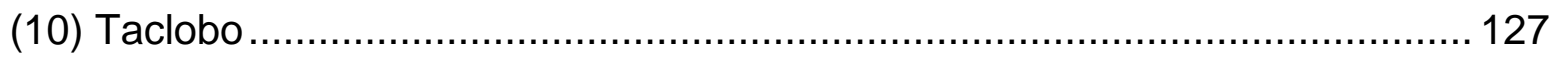

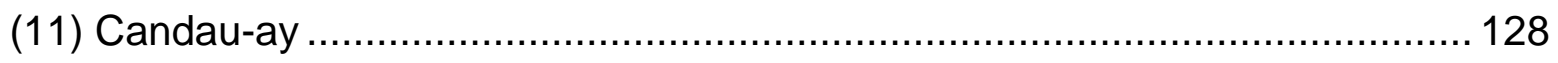

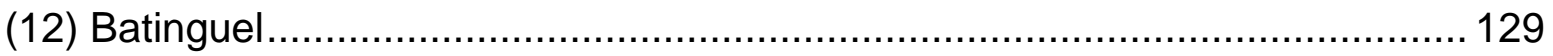

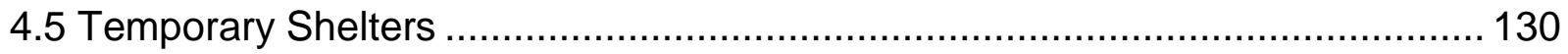

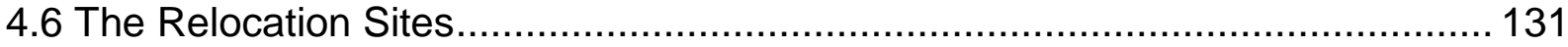

4.7 The Situation of the Most Recent Flooding Event in 2011 ........................ 132

4.8 Methodology for Hydrological Data of Banica River.............................. 133

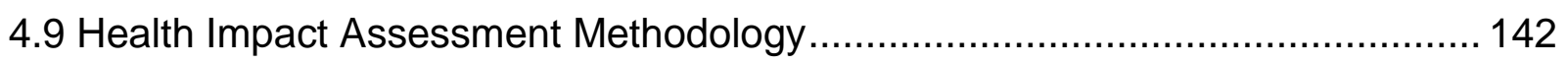

4.9.1 Sampling and Microbial Analyses .............................................. 144

4.10 E.coli Exposure of the 12 Communities .......................................... 150

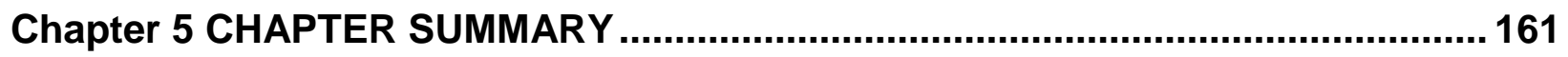

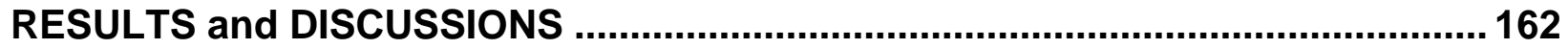

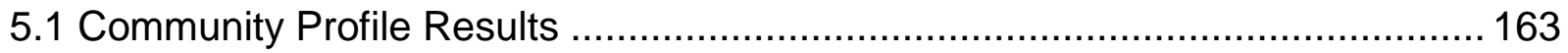

5.2 DETAILED ANALYSIS: Building Scale for Poblacion 2 (Barangay Lukewright) 198 
5.3 The Total E.coli counts (colony forming units or CFU's) per 100ml Water Sample during Dry and Wet Season from the Different Stations of the Banica River 213

5.4 The Overall Average E.coli counts per 100ml Water Sample during Dry and Wet Season from the Different Stations of the Banica River ........................................ 215

5.5 Assessment on Flood Resilience Adaptation Strategies in Dumaguete City Solicited from the Household Respondents of the 12 Communities ....................... 219 5.6 The Overall Results for the Flood Vulnerability Index (FVI) of Dumaguete City 233

5.7 The OVERALL Result from Assessment on Flood Resilience Adaptation Strategies 243

5.8 The OVERALL counts of E.coli (CFU's) per $100 \mathrm{~mL}$ water.............................. 244

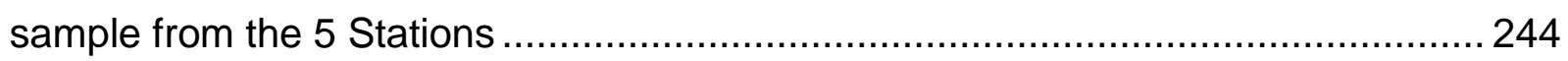

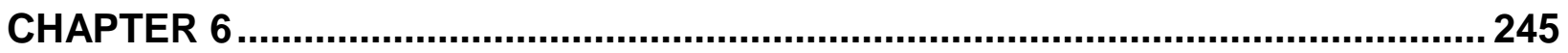

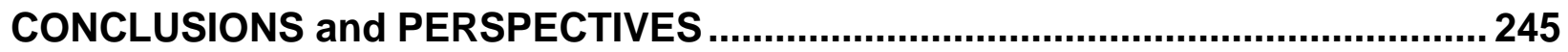

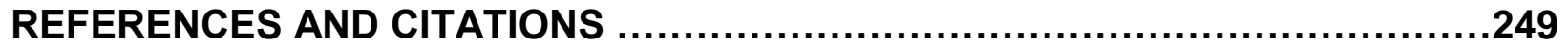

Appendix 1 English Household Survey Questionnaire ...................................253

Appendix 2 Visayan Household Survey Form Questionnaire ...........................267

Appendix 3 Survey Form Questionnaire Local Government Units (LGU's) and

Non-Governmental Organizations (NGO's) ..............................279

Appendix 4 Respondents Profile ............................................ 285

Appendix 5 Flood Resilience Knowledge ....................................... 345

Appendix 6 Environmental Microbial Health Risks: Knowledge ................... 408

Appendix 7 LGU's and NGO's Survey Results ..................................... 513

Appendix 8 Assessment on Flood Resilience and Health Program of the

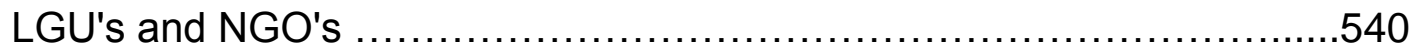




\section{List of Figures}

Figure 1-1: Community-Based Flood Vulnerability Framework: Based from SUST

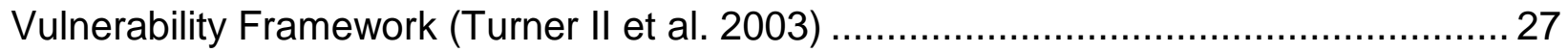

Figure 1-2: Community-Based Flood Vulnerability Components and Indicators ............ 28

Figure 1-3: Methodology Framework for Community-Based Flood Vulnerability Index for

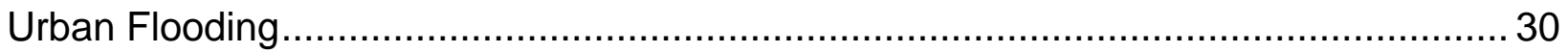

Figure 1-4: River Flood (Dumaguete City, Philippines) ….......................................... 37

Figure 1-5: Flash Flood (Dumaguete City, Philippines) …......................................... 38

Figure 1-6: Urban Floods (Manila, Philippines) ………............................................ 39

Figure 1-7: Coastal Floods (Iligan City, Philippines) .................................................. 40

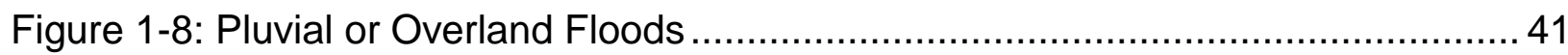

Figure 1-9: Number of Natural Disaster Reported 1900-2012 .................................. 43

Figure 1-10: Total Damages (\$US billion) Caused by Reported Natural Disasters 1900-

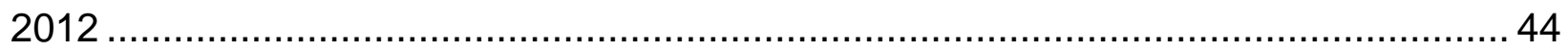

Figure 1-11: Number of Occurrence of Flood Disaster by Country: 1974-2003 ............ 45

Figure 1-12: Natural Disaster Occurrence Reported ................................................ 47

Figure 1-13: Percentage of Reported People Killed by Disaster Type ......................... 48

Figure 1-14: Percentage of Reported People Affected by Disaster Type ...................... 48

Figure 1-15: Estimated Economic Damages Reported by Disaster Type (US\$ X 1,000) 49

Figure 2-1: The Water Resource Systems (GRoWE, 2005) …................................. 66

Figure 2-2: a and b Water Resource System's Sub-System and its Interactions (van

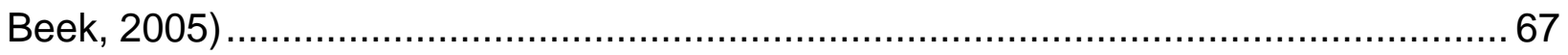

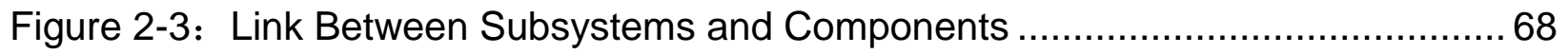

Figure 2-4: SUST Vulnerability Framework. Full Framework (Turner II et.al. 2003) .... 69

Figure 2-5: SUST Vulnerability Framework Detailed Framework (Turner II et al. 2003) 70

Figure 2-6: Based from SUST Vulnerability Framework (Turner II et al. 2003).............70 
Community-Based Flood Vulnerability Index for Urban Flooding: Understanding Social Vulnerabilities and Risks

Figure 2-7: Local Disaster Risk Reduction and Management Council (LDRRMC)

Structure. 83

Figure 2-8: Small to Medium Isolated Emergencies/Disaster Situations ....................... 85

Figure 2-9: LDRRMO Service Command Team Leaders and Members ....................... 87

Figure 2-10: LDRRMO Organizational Structure (for Large Scale Emergency,

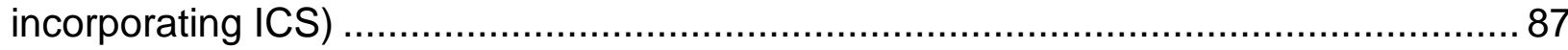

Figure 3-1: Community-Based Flood Vulnerability Components and Indicators ............ 95

Figure 4-1 Methodology Framework for Community-Based Flood Vulnerability Index for

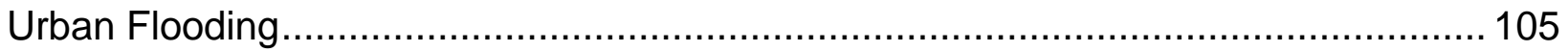

Figure 4-2: Map of the Philippines and my Study Site .............................................. 109

Figure 4-3: Flooding in Manila, Philippines............................................................. 111

Figure 4-4: Boundary Map of Dumaguete City, Philippines ...................................... 112

Figure 4-5: Elevation Map of Dumaguete City, Philippines …................................... 113

Figure 4-6: Banica and Okoy River Watershed Location Map................................... 114

Figure 4-7: Existing General Land Use Map ..................................................... 117

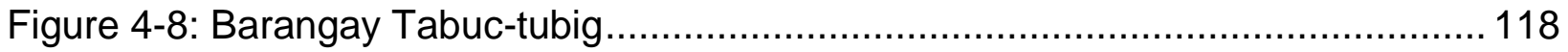

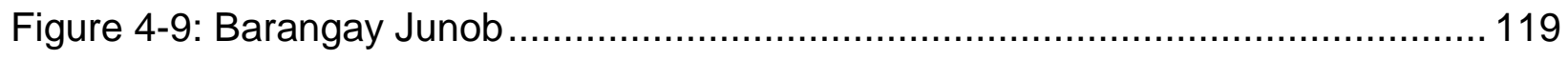

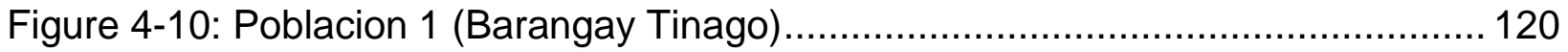

Figure 4-11: Barangay Calindagan ..................................................................... 121

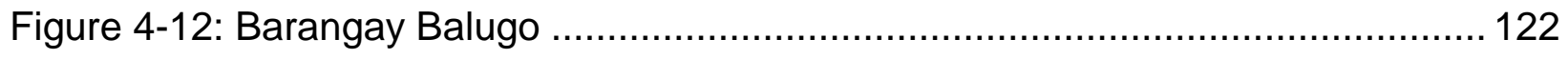

Figure 4-13: Poblacion 2 (Barangay Lukewright) ............................................... 123

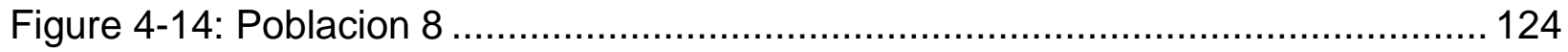

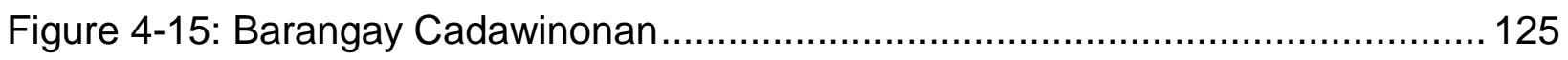

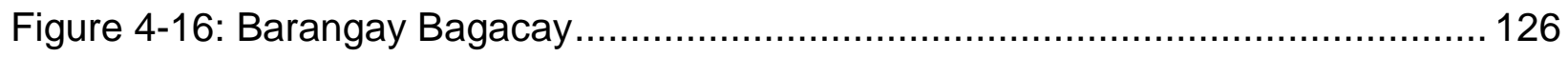

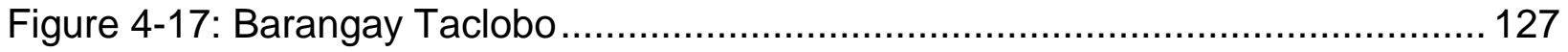

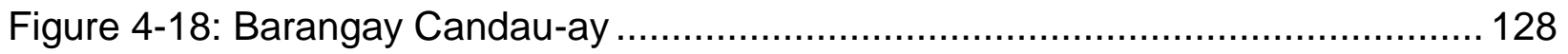

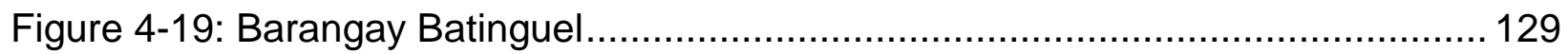

Figure 4-20: Temporary Shelters in Barangay Junob............................................... 130

Figure 4-21: Temporary Shelters in Barangay Bagacay .......................................... 130

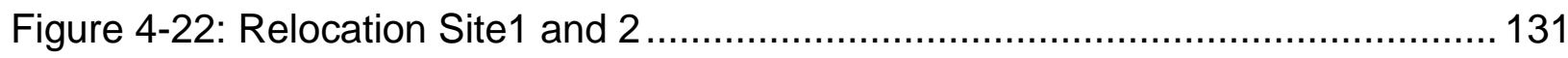


Figure 4-23: Flash Flood in Dumaguete City, Philippines 132

Figure 4-24: The Daily Activities of the Community People in Relation to Banica River

Figure 4-25: Station 1 (S1): City Pound Bridge, Barangay Balugo 134

Figure 4-26: Station 2 (S2): Smokey Mountain Overflow, Barangay Balugo and Candauay 135

Figure 4-27: Station 3 (S3): Barangay Candau-ay and Cadawinonan ....................... 136

Figure 4-28: Station 4 (S4): Barangay Taclobo Overflow ....................................... 137

Figure 4-29: Station 5 (S5) Colon Extension Overflow (Barangay Taclobo)................. 138

Figure 4-30: Station 6 (S6): Barangay Tabuc-tubig Bridge....................................... 139

Figure 4-31: Station 7 (S7): Barangay Calindagan Bridge .................................... 140

Figure 4-32: Station 8 (S8) Poblacion 1 (Tinago) Bridge ......................................... 142

Figure 4-33: EMB plate (left) positive for E.coli (greenish metallic sheeen) and EMB

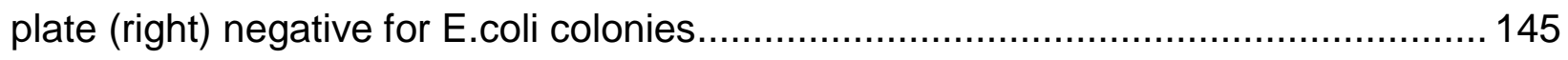

Figure 4-34: Upstream (S1): City Pound Bridge, Barangay Balugo .......................... 146

Figure 4-35: Midstream 1 (S3): Barangay Candau-ay and Cadawinonan Overflow.... 147

Figure 4-36: Midstream 2 (S5): Colon Extension Overflow, Barangay Taclobo .......... 148

Figure 4-37: Downstream 1 (S7): Barangay Tabuc-tubig Bridge.............................. 149

Figure 4-38: Downstream 2 (S8): Barangay Calindagan and Poblacion 1 ................. 150

Figure 5-1: Hydro-Climatic Component of Flood Vulnerability lindex of Poblacion 2 .. 198

Figure 5-2: Social Component of Flood Vulnerability lindex of Poblacion 2 ................ 200

Figure 5-3: Economic Components of Flood Vulnerability lindex of Poblacion 2 ........ 202

Figure 5-4: Socio-Behavioral Component of Flood Vulnerability lindex on Flood

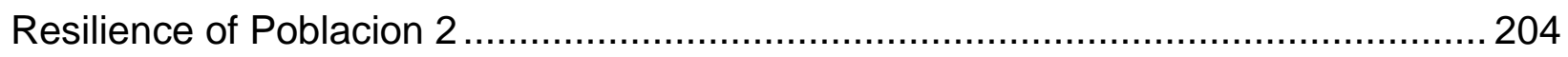

Figure 5-5: Socio-Behavioral Component of Flood Vulnerability Index on the Exposure of Microorganisms (E.coli, Leptospirosis, and Dengue Fever Mosquito of Pobalcion 2 206

Figure 5-6: Combined Socio-Behavioral Component of Flood Vulnerability lindex on Flood Resilience and Microorganisms of Poblacion 2 ............................................... 208 
Community-Based Flood Vulnerability Index for Urban Flooding: Understanding

Social Vulnerabilities and Risks

Figure 5-7: Politico-Administrative Component of Flood Vulnerability lindex of Poblacion 2 210

Figure 5-8: Hydro-Climatic Component on Flood Vulnerability Index $\quad \ldots \ldots \ldots \ldots \ldots . . . . .233$

Figure 5-9: Social Component on Flood Vulnerability Index ...........................235

Figure 5-10: Economic Component on Flood Vulnerability Index...................... 236

Figure 5-11: Socio-Behavioral Compnent on Flood Vulerability Index................... 237

Figure 5-12: Politico-Administrative Compnent on Flood Vulerability Index............ 238

Figure 5-13: Overall Flood Vulnerability Index for the 12 Communities.............. 240

Figure 5-14: The Flood Map of Dumaguete City, Philippines......................... 241

Figure 5-15: Flood Vulnerability Inded Sensitivity................................... 242 
Community-Based Flood Vulnerability Index for Urban Flooding: Understanding Social Vulnerabilities and Risks

\section{LIST OF TABLES}

Table 1-1: Top 10 Natural Disasters in the Philippines for the period 1900-2014 (Killed) 46

Table 1-2: Top 10 Natural Disasters in the Philippines for the period 1900-2014 (Affected) 46

Table 1-3: Average Disaster per Year Worldwide 47

Table 1-4: Timeline of Disaster Events in Dumaguete City, Negros Oriental Philippines. 50

Table 1-5: Ten (10) Leading Causes of Child Mortality Among 1-4 Years Old............... 54

Table 1-6: Ten (10) Leading Causes of Child Mortality Among 5-9 Years Old.............. 54

Table 1-7: Ten (10) Leading Causes of Child Mortality Among 10-14 Years Old.......... 55

Table 1-8: Top 10 Leading Causes of Morbidity in Dumaguete City in 2012................. 56

Table 1-9: Top 10 Leading Causes of Morbidity in Dumaguete City in 2011 ................. 56

Table 1-10: Top 10 Leading Causes of Morbidity in Dumaguete City in 2010................57

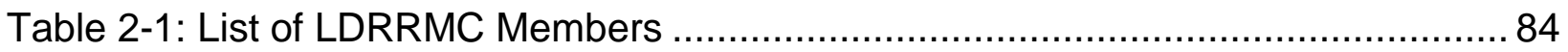

Table 3-1: Relationship Between Components and Indicators.................................. 103

Table 4-1: Population Profile and the Suggested Sample Size (SS) ........................ 106

Table 4-2: Hydrological Data of Banica River for Station 1 (S1) ............................... 134

Table 4-3: Hydrological Data of Banica River for Station 2 (S2) ............................... 135

Table 4-4: Hydrological Data of Banica River for Station 3 (S3) ............................... 136

Table 4-5: Hydrological Data of Banica River for Station 4 (S4) ............................... 137

Table 4-6: Hydrological Data of Banica River for Station 5 (S5) .............................. 138

Table 4-7: Hydrological Data of Banica River for Station 6 (S6) ............................... 139

Table 4-8: Hydrological Data of Banica River for Station 7 (S7) ............................. 140

Table 4-9: Hydrological Data of Banica River for Station 8 (S8)............................. 141

Table 4-10: E.coli counts during dry and wet season (March-July, 2013) Upstream: City

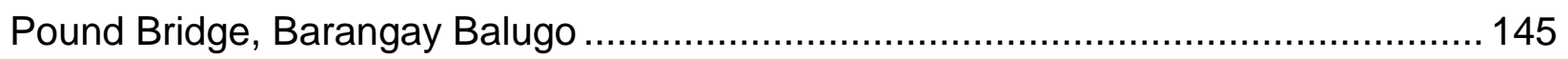

Table 4-11: E.coli counts during dry and wet season (March-July, 2013) Midstream 1: Barangay Candau-ay and Cadawinonan Overflow ................................................ 146 
Community-Based Flood Vulnerability Index for Urban Flooding: Understanding Social Vulnerabilities and Risks

Table 4-12: E.coli counts during dry and wet season (March-July, 2013) Midstream 2:

Colon Extension Overflow, Barangay Taclobo. 147

Table 4-13: E.coli counts during dry and wet season (March-July, 2013) Downstream 1: Tabuc-Tubig Bridge. 148

Table 4-14: E.coli counts during dry and wet season (March-July, 2013) Downstream 2: Barangay Calindagan and Tinago..... 149

Table 4-15: E.coli Exposure in Banica River through swimming/bathing (Tabuc-tubig) 150

Table 4-16: E.coli Exposure in Banica River through swimming/bathing (Junob) 151

Table 4-17: E.coli Exposure in Banica River through swimming/bathing (Poblacion 1) 151

Table 4-18: E.coli Exposure in Banica River through swimming/bathing (Calindagan) 151 Table 4-19: E.coli Exposure in Banica River through swimming/bathing (Poblacion 2) 152

Table 4-20: E.coli Exposure in Banica River through swimming/bathing (Balugo) ...... 152 Table 4-21: E.coli Exposure in Banica River through swimming/bathing (Poblacion 8) 152

Table 4-22: E.coli Exposure in Banica River through swimming/bathing (Cadawinonan) 153

Table 4-23: E.coli Exposure in Banica River through swimming/bathing (Bagacay) ... 153 Table 4-24: E.coli Exposure in Banica River through swimming/bathing (Taclobo) .... 154 Table 4-25: E.coli Exposure in Banica River through swimming/bathing (Candau-ay) 154 Table 4-26: E.coli Exposure in Banica River through swimming/bathing (Batinguel) .. 155 Table 4-27: E.coli Exposure in Banica River through immersing/washing of clothes (Tabuc-tubig) 155

Table 4-28: E.coli Exposure in Banica River through immersing/washing of clothes (Junob) 156

Table 4-29: E.coli Exposure in Banica River through immersing/washing of clothes (Poblacion 1) 156 
Community-Based Flood Vulnerability Index for Urban Flooding: Understanding Social Vulnerabilities and Risks

Table 4-30: E.coli Exposure in Banica River through immersing/washing of clothes

(Calindagan) 156

Table 4-31: E.coli Exposure in Banica River through immersing/washing of clothes (Balugo). 157

Table 4-32: E.coli Exposure in Banica River through immersing/washing of clothes (Poblacion 2) 157

Table 4-33: E.coli Exposure in Banica River through immersing/washing of clothes (Poblacion 8) 157

Table 4-34: E.coli Exposure in Banica River through immersing/washing of clothes (Cadawinonan) 158

Table 4-35: E.coli Exposure in Banica River through immersing/washing of clothes (Bagacay) 158

Table 4-36: E.coli Exposure in Banica River through immersing/washing of clothes (Taclobo) 159

Table 4-37: E.coli Exposure in Banica River through immersing/washing of clothes (Candau-ay) 159

Table 4-38: E.coli Exposure in Banica River through immersing/washing of clothes (Batinguel) 160

Table 5-1: Barangay Tabuc-Tubig FVI 161

Table 5-2: Barangay Junob FVI 168

Table 5-3: Poblacion 1 (Barangay Tinago) FVI 171

Table 5-4: Barangay Calindagan FVI 174

Table 5-5: Barangay Balugo FVI 178

Table 5-6: Poblacion 2 (Barangay Lukewright) FVI 181

Table 5-7: Poblacion 8 FVI. 184

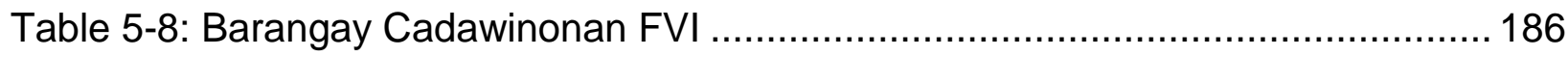

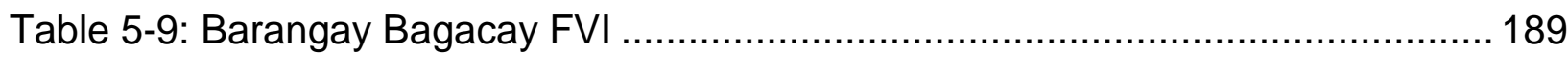

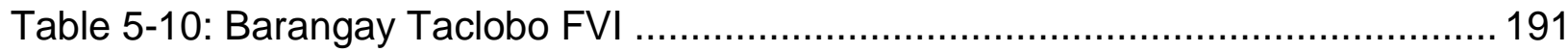

Table 5-11: Barangay Candau-ay FVI................................................................. 194

Table 5-12: Barangay Batinguel FVI .............................................................. 197 
Community-Based Flood Vulnerability Index for Urban Flooding: Understanding Social Vulnerabilities and Risks

Table 5-13: Hydro-Climatic Component of Flood Vulnerability Index of Poblacion 2 .. 199

Table 5-14: Social Component of Flood Vulnerability Index of Poblacion 2 ................ 201

Table 5-15: Economic Component of Flood Vulnerability Index of Poblacion 2 ........... 203

Table 5-16: Socio-Behavioral Component of Flood Vulnerability Index on Flood

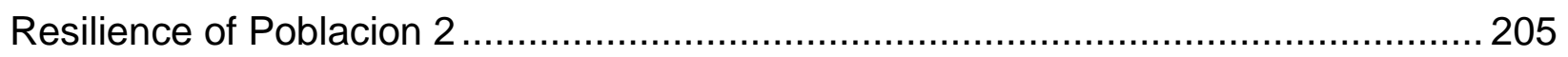

Table 5-17: Socio-Behavioral Component of Flood Vulnerability Index on the Exposure of Microorganisms (E.coli, Leptospirosis, Dengue Fever Mosquito) of Poblacion 2 .... 207 Table 5-18: Combined Socio-Behavioral on Resilience and Exposure to Microorganisms

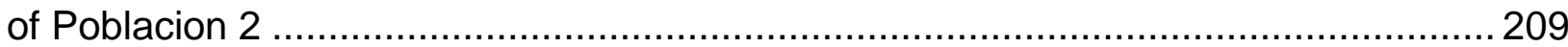

Table 5-19: Politico-Administrative Component of Flood Vulnerability Index of Poblacion 2 211

Table 5-20: Overall Flood Vulnerability Index for Poblacion 2 ................................. 212

Table 5-21: Total E.coli counts per 100mL for the month of March, 2013 .................. 213

Table 5-22: Total E.coli counts per 100mL for the month of April, 2013 .................... 213

Table 5-23: Total E.coli counts per 100mL for the month of May, 2013 ...................... 214

Table 5-24: Total E.coli counts per 100mL for the month of June, 2013 .................... 214

Table 5-25: Total E.coli counts per 100mL for the month of July, 2013 ...................... 215

Table 5-26: The Overall Average E.coli counts per $100 \mathrm{~mL}$ during dry and wet season for

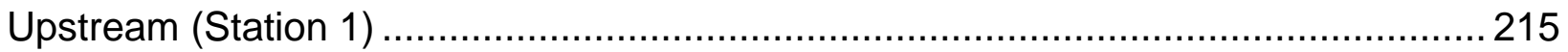

Table 5-27: The Overall Average E.coli count per 100mL during dry and wet season for

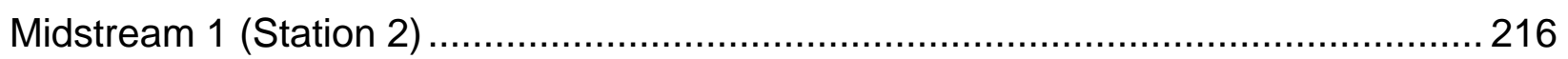
Table 5-28: The Overall Average E.coli counts per $100 \mathrm{~mL}$ during dry and wet season for

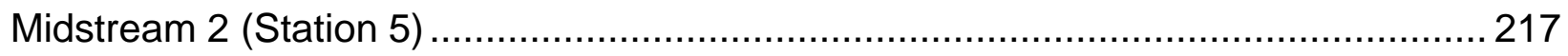

Table 5-29: The Overall Average E.coli counts per 100mL during dry and wet season for

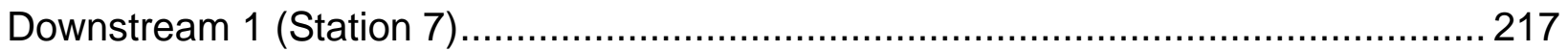

Table 5-30: The Overall Average counts per $100 \mathrm{~mL}$ during dry and wet season for

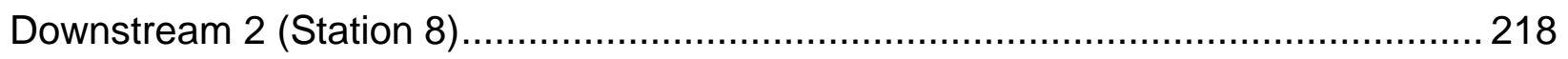

Table 5-31: Implementation and monitoring of the policies, plans and programs for the different natural calamities particularly typhoons and flooding events .........................219 
Table 5-32: Transparency and trustworthiness of the LGU's in terms of the facilitation and distribution of the budget and donations for the affected population in the

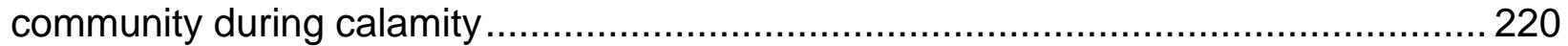

Table 5-33: Livelihood and financial aid for the community people to help them recover

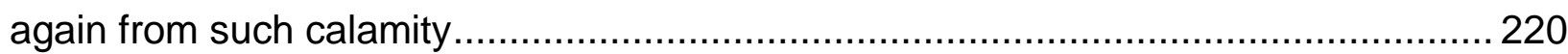

Table 5-34: Programmes and policies in saving and protecting the Banica River ....... 221 Table 5-35: Cooperation of the community people including you (household respondents) in protecting the Banica River......................................................... 222

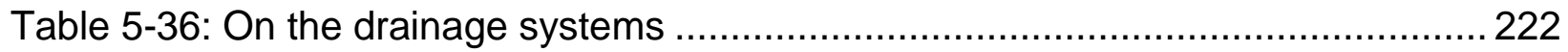

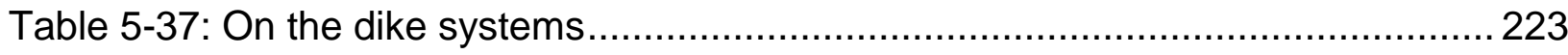

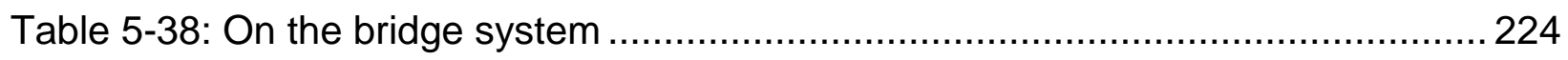

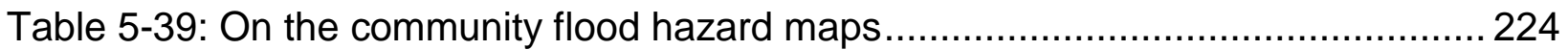

Table 5-40: The use of backhoe in cleaning the Banica river especially when normal

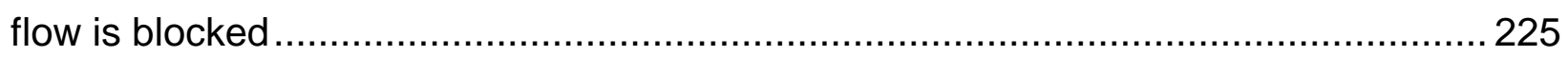

Table 5-41: Distribution of donations, goods and relief ......................................... 225

Table 5-42: Distribution of brochures and the information drive that would increase knowledge on the negative impacts from typhoon and flooding events for the purposes

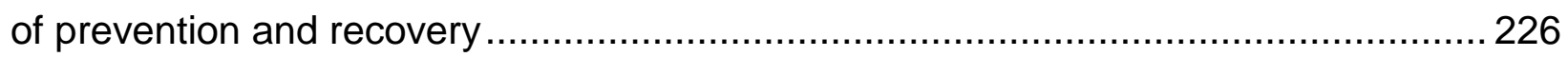

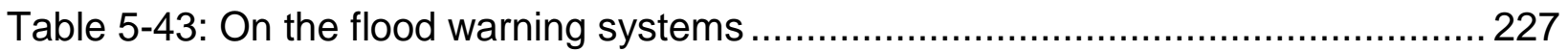

Table 5-44: Preparedness and flood drill activity in the community to increase resilience

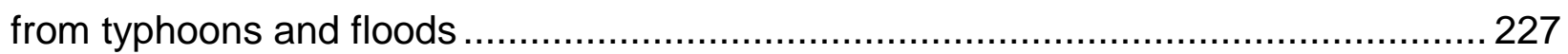

Table 5-45: Response and preparedness of the DRRMC, PDRRMC, and other NGO volunteers during rescue events 228

Table 5-46: The basic emergency and relief services such as food, water, sanitation, transportation, communication, medical help, provisional repairs of damaged properties

Table 5-47: Operation clean-up affected places, giving of insurances, claims, financial aids, traumatic and psychological stress debriefings.............................................. 229 Table 5-48: Relocation sites provided by the LGU's to those who were affected from the last flooding and to those who live in the flood prone area.......................................2 230 
Table 5-49: Health programmes for diarrhoae and Leptospirosis such as medical help, information drive and among others so outbreaks can be prevented 231 Table 5-50: Different prevention and control programmes for Dengue Fever infection such as fogging, chemical/biological control, information drive brochures, lectures, clean-up 231

Table 5-51: Assessment on Flood Resilience Adaptation Strategies solicited from the Local Government Units (LGU's) and the Non-Governmental Organizations (NGO's)

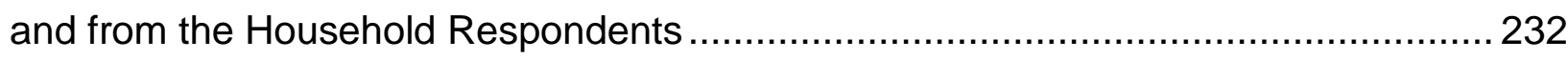
Table 5-52: Overall FVI and the FVI of the Five (5) Components ............................241 Table 5-53:Flood Vulnerability Index: Pearson Product Moment Correlation Matrix ( $r$ ) 242

Table 5-54: The OVERALL Result from Assessment on Flood Resilience Adaptation Strategies solicited from the Local Government Units (LGU's) and from the NonGovernmental Organizations (NGO's) 243

Table 5-55: The OVERALL counts of E.coli (CFU's) per 100mL water sample from the five (5) Stations 244 


\section{Nomenclature and Symbols}

The following nomenclature and symbols were used in this dissertation.

\section{ABBREVIATIONS}

AIS - Administrative and Institutional Subsystem

ACDV's - Accredited Community Disaster Volunteers

AGE - Acute Gastrointestinal Enteritis

AMSL - Above Mean Sea Level

BDCC - Barangay Disaster Coordinating Council

BDRRMCs - Barangay Disaster Risk Reduction Management Committee

BRW - Banica River Watershed

CaMReSC - Camp Management and Relief Service Command

CDCC - City Disaster Coordinating Council

CCFVI - Coastal Cities Flood Vulnerability Index

CDRRMC - City Disaster Risk Reduction and Management Council

CDRRMP - City Disaster Risk Reduction Management Plan

CFU's - Colony Forming Units

$\mathrm{CHO}$ - City Health Office

CRED - Centre for Research on the Epidemiology of Disasters

CSWDO - City Social Welfare office, Planning and Development Office

DANA-SC - Damage Assessment and Needs Analysis Service Command

DBM - Department of Budget and Management

DENR - Department of Environment and Natural Resources

DILG - Department of Interior and Local Government

DIPECHO - Disaster Preparedness European Commission's Humanitarian Aid

Department

$\mathrm{DOH}$ - Department of Health

DRI - Disaster Risk Index

DRR - Disaster Risk Reduction

DRRMF - Disaster Risk Reduction and Management Fund

EMB - Eosin-Methylene Blue agar

EMT - Emergency Management Team

EPA - Environment Protection Agency

EM-DAT - Emergency Events Data Base

EM-DAT: The OFDA/CRED International Disaster Database

EWSC - Early Warning Service Command

FVI - Flood Vulnerability Index

GDP - Gross Domestic Product

GIS - Geophysical Information System

GIZ - Deutsche Gesellschaft fur Internationale Zusammenarbeit

GPS - Global Positioning System

GRoWe - Global Research on Water-Based Economies 

Social Vulnerabilities and Risks

HFA - Hyogo Framework for Action

ICS - Incident Command System

IFRC - International Federation of Red Cross

IPCC - Intergovernmental Panel on Climate Change

ISDR - International Strategy for Disaster Reduction

KAP - Knowledge, Attitudes, and Practices

LDRRMC - Local Disaster Risk Reduction and Management Council of Dumaguete City

LDRRMO - Local Disaster Risk Reduction and Management Office

LDRRMP - Local Disaster Risk Reduction and Management Plan

LGU's - Local Government Units

MHSC - Medical and Health Service Command

MGB - Mines and Geosciences Bureau

MOA - Memorandum of Agreement

NDRRMC- National Disaster Risk Reduction and Management Council

NIA -National Irrigation Administration

NGO's - Non-Governmental Organizations

NOAA - National Oceanic and Atmospheric Administration

OFDA - Office of Foreign Assistance

PAGASA - The Philippine Atmospheric, Geophysical and Astronomical Services

PDRRM - Philippine Disaster Risk Reduction and Management

PDRRMC - Provincial Disaster Risk Reduction Management Council

RA - Republic Act

RRSC - Response and Rescue Service Command

SP -Sangguniang Panlalawigan

SUVFRU - Silliman Volunteer for Fire and Rescue Unit

UNEP - United Nations Environmental Programme

UNESCO-IHE - United Nations Educational, Scientific and Cultural OrganizationInstitute for Water Education

UNDP - United Nations Development Program

UNISDR - United Nations Office for Disaster Risk Reduction

UNU-EHS - United Nations University Institute for Environment and Human Security

WB - World Bank

WHO - World Health Organization 


\section{SYMBOLS}

AHDF - Attitude of Households on Dengue Fever

AHEC - Attitude of Households on E.coli

AHFR - Attitude of Households on Flood Resilience

AHL - Attitude of Households on Liptospirosis

EA - Educational Attainment

FF - Frequency of Flooding

$\mathrm{FI}$-Family Income

FVIc - Flood Vulnerability Index Combined (Flood Resilience and Microorganisms)

FVIfr - Flood Vulnerability Index for Flood Resilience

FVImqs - Flood Vulnerability Index for Microorganisms (E.coli, Liptospirosis, Dengue

Fever)

$\mathrm{G}$ - Governance

$\mathrm{HC}-$ Housing Conditions

$\mathrm{HF}$ - Height of Flooding

$\mathrm{HH}$ - Households

HNE -Houses Not on Elevated area

HNIS - Houses with No access to Improved Sanitation

HNIW - Houses with No access to Improved Water source

HPP - Health and Prevention of E.coli, Liptospirosis and Dengue Fever

HRF - Houses Reached by Flood

KHDF - Knowledge of Households on Dengue Fever

KHEC - Knowledge of Households on E.coli

KHFR - Knowledge of Households on Flood Resilience

$\mathrm{KHL}$ - Knowledge of Households on Liptospirosis

LUMSD - Land Use Management and Structural Design

NTY - Number of Typhoons per Year

ODAW - Open disposal of animal waste

PHDF - Practices of Households on Dengue Fever

PHEC - Practices of Households on E.coli

PHFR - Practices of Households on Flood Resilience

$\mathrm{PHL}$ - Practices of Households on Liptospirosis

PI -Property Insurance

PRAI - Post-Risk Assessment and Integration

PRV - Presence of Rats in the Vicinity

PWLV - Presence of Water-Logged areas in the Vicinity

RNRMP - River's Natural Resources and Natural Features Management and

Programme

RSP - Relocation Site Project

SCLP - Sustainable Community Livelihood Programme

SN - Social Networks

SS - Sample Size

UVR - Unwillingness to vacate and be relocated

WT - Water Treatment or Sterilization Practice 


\section{CHAPTER 1 INTRODUCTION \\ SUMMARY}

Chapter 1 is an introductory chapter where it gives a brief description of what this entire research work is all about. For instance, how the development of this community-based flood vulnerability index was formulated and how different it is from other similar studies; the respondents whom the survey was solicited from; in what way this research work is done in a more detailed manner compared to the previous and similar studies and how it is improved. Furthermore, glimpses illustration of previous and existing approaches and frameworks for flood vulnerability studies along with the proposed communitybased flood vulnerability index are also presented. The identified flood vulnerability factors, key components and indicators will also made mentioned in this chapter.

Apart from the surveys solicited for this developed community-based flood vulnerability index, a health impact assessment was also included in this research work and briefly presented here. Microbial hazards such as that of E.coli, Leptospirosis, and Dengue fever mosquito were identified and chosen as focus of the study. This particular environmental microbial hazard was characterized and noted. Exposure assessment and risk characterization were also considered and being made mention in this chapter. Alongside, flood resilience adaptation strategies assessment is also briefly presented. Much of this chapter reveals about historical records of natural disasters worldwide from 1900-2012 and of the Philippines that are of great importance in this research work. For the purpose of clarity, types and causes of floods were also clearly described and categorized. Reviews of relevant literature, reports, and surveillance data of focus and its impacts to human health are also presented.

Other similar studies on disaster risks, flood vulnerability and resilience index were also reviewed. The current situation in the Philippines in terms of disaster coordination and facilitation is also look into. Finally, the aim and purpose of this research work was laid down including the needed improvements and significance and its importance of why conducting this kind of research work are presented in the latter part of this chapter. 


\section{CHAPTER 1 INTRODUCTION}

The development of community-based flood vulnerability index (FVI) for urban flooding through using local components and indicators is important in generating a localizedbased flood vulnerability index that depicts a more realistic scenario of vulnerability and resilience indexes in a local, national and international setting. There have been a number of studies conducted in the past years that is similar to this but mostly revolves around national data or on a per country description but have neglected to include some of the important components which has theoretical and practical significance due to lack of relevant data from the community level. The gaps of knowledge for disaster risk, the lack of concerted actions from numerous players in the society during disaster recovery, and using community-based indicators is what this research work is trying to accomplish to address those gaps so we would have a thorough understanding why the community people are vulnerable or resilient in the first place.

Soliciting the responses from the individual household respondents themselves and the local government units (LGU's) from each of the communities involved and including those who are in the city and provincial disaster coordinating council office and the volunteers from the non-governmental organizations (NGO's) have been the sources of the actual community survey. It is very important to do an actual field survey so that a realistic scenario will be generated and projected.

This research work is done in a more detailed survey of which the improvement that this work has accomplished when it comes to addressing the socio-economic profile of the individual households, including their socio-behavioral approach in terms of the knowledge, attitudes, and practices towards flood vulnerability and resilience particularly on the items of hazards, risks, exposure, preparedness, response, recovery, coordination, and adaptation strategies. The socio-behavioral approach was conducted in a more detailed way by soliciting the community people's Knowledge, Attitudes and Practices (KAP) particularly on flood preparedness and health impacts and it is measured in terms of their exposure to E.coli, Leptospirosis and Dengue Fever particularly on the nature of these organisms, their mode of transmission, prevention, signs and symptoms, how fatal, treatment, and the financial cost of treatment. The hydro-climatic and politico-administrative components were also studied in detailed. Measuring the KAP of the respondents from preparedness to recovery, and as well as the KAP on the exposures of the microorganisms in focus would give us a clue how community people perceived in these kinds of phenomenon which are translated into 
their attitudes and practices before, during or after any catastrophic events such as typhoons and flooding.

There are five (5) flood vulnerability components and thirty-six (36) indicators that were developed in this work. Each of the indicators is belonging to a specific flood vulnerability component and to a particular flood vulnerability factors; namely exposure, susceptibility and resilience that would eventually produce community-based flood vulnerability index profile.

Apart from developing a community-based flood vulnerability index, this research work has also included a simple health impact assessment that is associated with the daily exposure of the community people in the river prior to, during and after flooding events. The health impact assessment includes microbial analysis through laboratory culture of E.coli from collected water samples from the river. The frequency of exposure and the possible amount of ingested contaminated water were also included. The KAP towards exposure to E.coli, Leptospirosis and Dengue fever mosquito completes the health impact assessment in this research work.

Moreover, this research work has also performed an assessment on the flood resilience adaptation strategy solicited from Local Government Units (LGU's) and the NonGovernmental Organizations (NGO's) and from the Household Respondents respectively to be able to have a holistic view and a comprehensive result of the different items that are significant in the overall understanding of social vulnerabilities and risks.

The approaches and frameworks of this community-based flood vulnerability index $(\mathrm{FVI})$, health impact assessment and flood resilience adaptation strategy assessment will be thoroughly discussed in the succeeding chapters, in the meantime an overview of these approaches and frameworks will be presented below 


\subsection{Approaches and Frameworks for Community-Based Flood Vulnerability Index (FVI)}

A system's vulnerability to hazards consists of (i) linkages to the broader human and biophysical (environmental) conditions and processes operating on the coupled system in question; (ii) perturbations and stressors/stresses that emerge from this conditions and processes; and (iii) the coupled human - environment system of concern in which vulnerability resides, including exposure and responses (i.e. coping, impacts, adjustments, and adaptation). It is seen that changes in the resilience can affect the susceptibility of a system and if we are careless with our actions, it can alter the whole system in ways that make it difficult to recover.

\section{Community-Based Flood Vulnerability Framework: Detailed Framework for Urban Flooding}

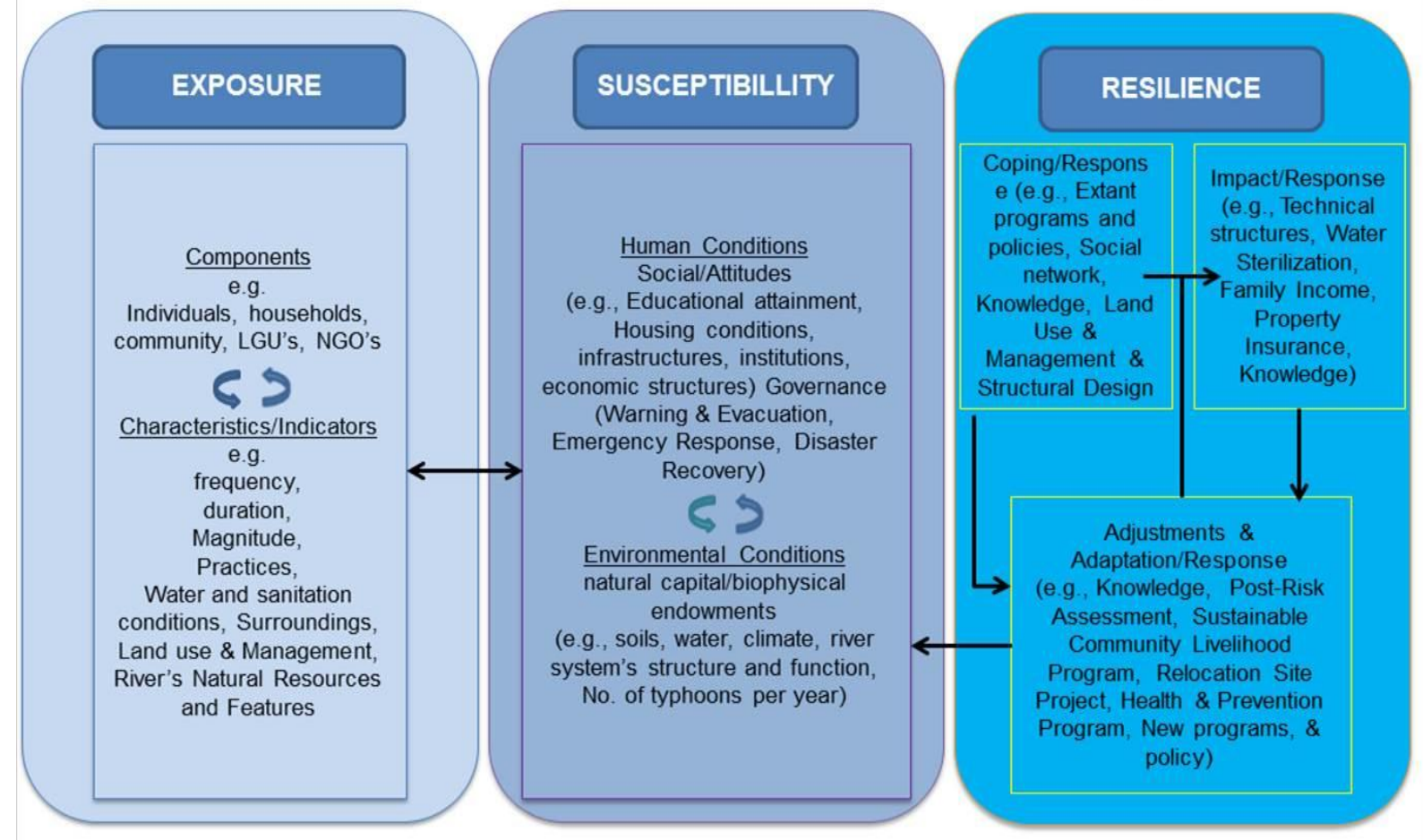

Figure 1-1: Community-Based Flood Vulnerability Framework: Based from SUST Vulnerability Framework (Turner II et al. 2003)

Figure 1-1 depicts the proposed version of "working framework" which is based from Turner's conceptual framework. The different components and indicators that were 

Social Vulnerabilities and Risks

used in this work are shown in the category (exposure, susceptibility, and resilience) to which it appropriately belonged to.

The theoretical framework is presented in the succeeding page along with its corresponding description and detailed discussions of the interplay of the different components and indicators in producing a community-based flood vulnerability index.

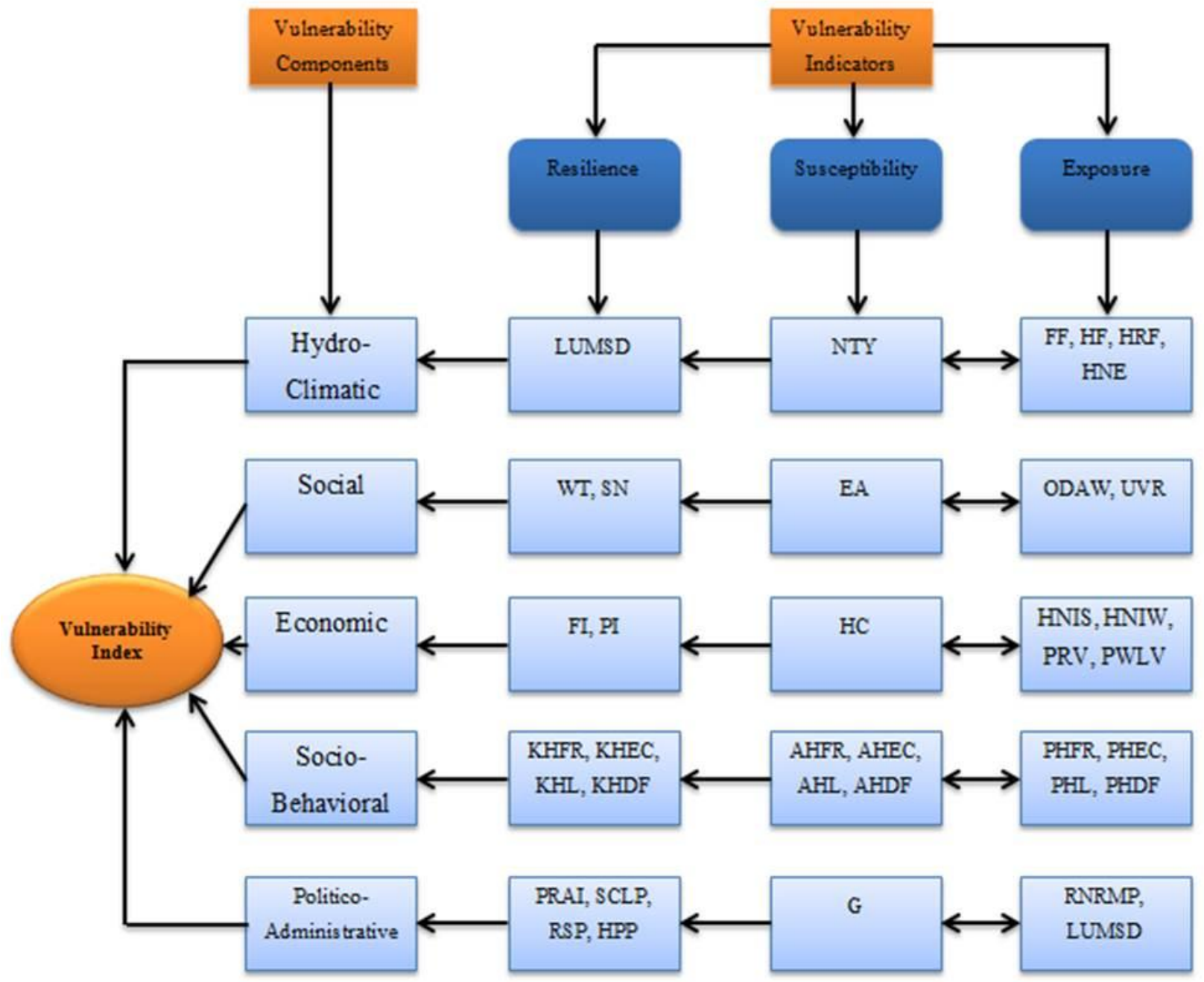

Figure 1-2: Community-Based Flood Vulnerability Components and Indicators

In this community-based flood vulnerability framework shown in figure 1-2, the researcher presented the relationship of the vulnerability components along with the three (3) vulnerability factors and its corresponding indicators on how it could influence vulnerability. The indicators are shown in a more detailed manner (see table 3.1) for the detailed description of the abbreviations used. A brief illustration is presented below while the detailed descriptions and discussions are found in the succeeding chapters. 


\subsection{Flood Vulnerability Factors}

This section provides an overview of the selected components and indicators in the development and calculation of the Community-Based Flood Vulnerability Index (FVI) for Dumaguete City, Negros Oriental Philippines. This research work was done locally among the twelve communities of Dumaguete City and the researcher has based the analysis to the following components: Hydro-Climatic, Social, Economic, SocioBehavioral and Politico-Administrative components which are general and relevant to the local level. The individual indicators of each of the components will be made mention below.

There are 3 important factors of vulnerability to consider all throughout the components which determine the vulnerability index. These factors are exposure, susceptibility and resilience. In addition, the concept of vulnerability will also be described below to facilitate a complete understanding of the interplay and influence of the indicators to the components and factors of vulnerability.

Vulnerability is considered as the extent of harm which can be expected under certain conditions of exposure, susceptibility, and resilience. More specifically in the case of floods, a system is susceptible to floods due to exposure in conjunction with its capacity/incapacity to be resilient, to cope, recover or adapt to the extent. Some of the exposed populations are protected from flooding by various structural and non-structural measures that are part of the resilience strategy. On the other hand, some of them have none, or only weak, flood defenses and the exposed populations are more often subject to flooding with the consequent disruption, economic loss and loss of life (Balica, S.F., Wright, N.G., and van der Meulen, F., 2012). In this research, vulnerability is the result of the interplay of the indicators in the exposure, susceptibility and resilience category.

By dividing the FVI into different components, such as hydro-climatic, social, economic, socio-behavioral, and politico-administrative and linking them with the factors of vulnerability (exposure, susceptibility, resilience) can help identify the weak and strong points of a certain community in terms of flood vulnerability and in that way, it helps to propose strategies for improvement and identifies which one is a priority. 


\subsection{Identifying the Key Components and Indicators of the Developed Community-Based Flood Vulnerability Index (FVI)}

This part deals with the description of the components and its indicators as used on the local scale to capture the aspects of exposure, susceptibility, and resilience as well as their aggregation to the Community-Based Flood Vulnerability Index. In this research work the indicators vary, a totally different indicators used but were chosen based on the same concept developed by the WorldRiskIndex Report and the study of Balica et.al (2012) on the development of Flood Vulnerability Index for Coastal City.

This research work is trying to fill those categories suggested by those studies that were not included in the global scale, for instance, indicators such as housing conditions; disaster preparedness and early warning; social networks; property insurance; Knowledge, Attitude, Practices (KAP) of respondents on flood resilience; and exposure to microorganisms such as that of E.coli, Leptospirosis and Dengue fever mosquito; the different adaptation strategies such as integration of post-risk assessments; sustainable community livelihood; relocation site projects and health programs for the prevention against diarrhoea, leptospirosis and dengue fever which are facilitated by the LGU's and as well as some NGO's. Figure 1-3 below shows the five components of this proposed community-based flood vulnerability index in producing flood vulnerability indexes, maps and profiles.

\section{Methodology of Community Based Flood Vulnerability Index (FVI) for Urban Flooding}

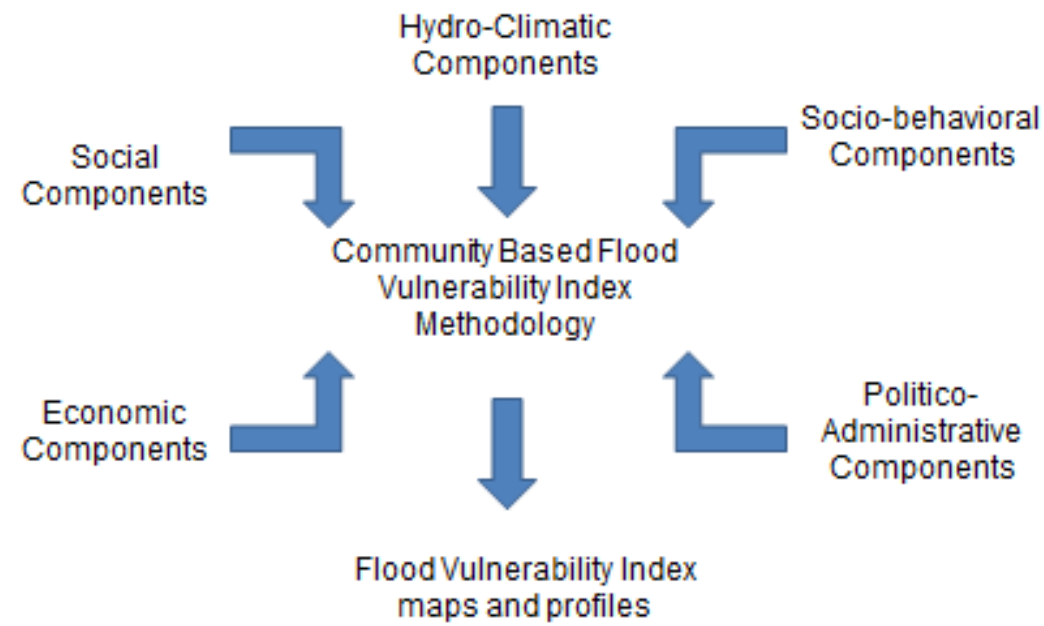

Figure 1-3: Methodology Framework for Community-Based Flood Vulnerability Index for Urban Flooding 
These five components have been linked with the three factors of vulnerability as shown in Table 3.1 The relationship of these factors and components should increase the robustness of the developed Community-Based FVI as it was also observed in the study of Balica et al. (2012). These five components are; hydro-climatic, social, economic, socio-behavioral, and politico-administrative and along with the thirty-six (36) indicators that were used and examined in computing for the community-based flood vulnerability index $(\mathrm{FVI})$ for Dumaguete City, Negros Oriental. By computing the FVI of the city, hotspots to flooding events with the corresponding strong and weak points will be identified and mapped. By doing so, this would serve as a tool to assist planners and policymakers in prioritising their areas of intervention and to provide useful information for awareness rising.

The development of this community-based FVI which is in the Philippines local context involved the interplay of factors within the water resource system in the event of flooding, a deductive approach was used to identify the best possible indicators based on the existing principles and conceptual framework (Chapter 2).

\subsection{Health Impact Assessment}

In a developing country like the Philippines and among others, outbreaks of certain diseases such as that of bacterial and viral in origin are common during and after a flooding event. Traumatic experiences are also observed during such events and to some extent exposure on a daily basis is also a common scenario. Their effects can be direct or indirect, immediate or long term. Health impact assessment is therefore important so as to address this issues which is usually have been overlooked. This research work has conducted a crude assessment on the presence of E.coli in the Banica river where the community people have the possibility of being exposed to.

Water samples were taken during dry and wet season for five (5) consecutive months. The frequencies of possible exposures were investigated including the activities that predisposed the respondents. The amount of ingested of contaminated water were also taking into account on a daily basis and during and after flooding events. The respondents were also asked if they have experienced diarrhoea, leptospirosis and dengue fever infection through memory recall. For Leptospirosis and Dengue fever cases, available health data from the city, provincial and national health agencies were solicited. Hydrological data such as uniform stream flow were also recorded to be able to be able to have a crude picture of the possible flow or stagnation of the organism in focus. Due to limited resources, a simple health impact assessment was done. 
In conducting a health impact assessment the European Commission's Directorate General on health and Consumer Affairs (SANCO) have formulated the following steps to harmonized risk assessment procedures and terminology. The four key steps are as follows (European Commission, 2000).
A. Hazard Identification
B. Hazard Characterization
C. Exposure Assessment
D. Risk Characterization

As mentioned in the CORFU project (CORFU FP7 Collaborative Research on Flood Resilience in Urban Areas: Health Impacts Model, 2014), the second step, hazard characterization, is sometimes referred to as Dose-response assessment. Moreover, these four steps have previously been described by the US National Academy of Science's earlier report on Risk Assessment for Federal Government ( National Academy of Sciences, 1983) and formed the US's Environmental Protection Agency's Risk Assessment and Management Paradigm. These four steps has been adopted and used but were conducted slightly different in this particular health impact assessment.

For hazard identification, E.coli, Leptospirosis and Dengue Fever cases were the chosen microorganisms to be assessed because of its common occurrence during and after flooding events. Usually, during and after flooding events cases of diarrhoea are in significant numbers. In some places, leptospirosis cases are also occurring. Dengue fever cases is also rampant during rainy or typhoon seasons. But, what is interesting to know is the people's vulnerability or resilience in terms of their knowledge, attitude and practices towards these microorganisms. These items have been addressed and solicited from the questionnaires administered to the household respondents.

In doing the hazard characterization, a dose-response assessment was not conducted but instead, results from surveys from the household respondents that indicates their experienced of being sick from any of the focus microorganisms were noted and counted. Top 10 leading causes of morbidity in the city and the country were solicited to counter-check the incidences and occurrences of those diseases.

Exposure assessment was conducted through survey questionnaires. Household respondents were asked if any member in the family has been exposed to E.coli, leptospirosis and dengue fever mosquito. The frequency of exposure to the river and the amount of possible ingestion of the contaminated water were asked and recorded. 
After gathering the relevant data from hazard identification, characterization and exposure, risk characterization is possible to be established. The level of risks and correlation to exposure in terms of the number of E.coli taken from the different sampling sites, and the number of diarrhoeal cases per community are mentioned in the results and discussion chapter. The step-by-step procedure and discussion is presented in the succeeding pages.

\subsection{FLOOD RESILIENCE ADAPTATION STRATEGIES} ASSESSMENT

Assessment on flood resilience adaptation strategies were also solicited from Local Government Units (LGU's) and the Non-Governmental Organizations (NGO's) and from the Household Respondents respectively. Issues on governance, sustainable community livelihood, the rivers natural resource and natural features management, land use and management and structural design, risk knowledge-post risk integration, warning and evacuation, emergency response, and disaster recovery were assessed in detailed. It is very important to conduct such assessment to be able to pinpoint the strengths and weaknesses of the program the government has initiated. Having an understanding of the current situation, what needs emphasis and focus, improvements will be given attention. Participation from the different players in the society is important to be able to have a holistic view and a comprehensive result of the different items that are significant in the overall understanding of the social vulnerabilities and risks.

\section{6 BACKGROUND OF THE STUDY}

According to the World Risk Report released by the United Nations University Institute for Environment and Human Security, the Philippines is ranked third globally in terms of disaster risk (United Nations University Institute for Environment and Human Security, 2011). Typhoon which usually followed by flooding in some areas is one of those disaster risk that is frequency occurring in the Philippines, twenty or more typhoons visits the country every year leaving devastations in many forms. It is a global phenomenon and due to climate change, this will continue. Urban fluvial flooding in particular caused havoc in many aspects in the society particularly to human health, infrastructure and the economy of the country. Moreover, it has become a usual scenario especially in underdeveloped and the developing countries. However, this phenomenon is also occurring in developed countries though less more frequent than those previous countries mentioned. Flooding poses a serious challenge to the economic development and the lives of the people particularly the residents of a rapidly 
expanding towns and cities in developing countries. Its causes are shifting and their impacts are accelerating against the backdrop of increasing demographics, urbanization trends and climate change. The current and projected levels of flood impacts give urgency to the need to make flood risk management in urban settlement a high priority on the political and policy agenda. It is therefore important to conduct studies related to vulnerability and resilience at the community level so issues on health and disaster risks will be addressed appropriately.

Public health risk in urban fluvial flooding are usually been overlooked, undermined and only very little attention is given. In Dumaguete City alone, there was no study similar to this that was conducted. This would therefore hopefully serve as a baseline study. Faecal pollution of water particularly human faecal sources are the most relevant source of human illnesses globally especially during flooding event and rainy season. Exposure and ingestion of faecally-contaminated water and other routes of transmission are responsible for a variety of diseases such as diarrhoea, leptospirosis, and bites from dengue mosquitoes which demands special attention. Diarrhoeal and other waterborne diseases still rank among the leading causes of morbidity worldwide and in the Philippines. According to the World Health Organization (WHO), each year diarrhoea kills around 760,000 children under the age of five and is the second leading cause of death among that age group. Worldwide, there are nearly 1.7 billion cases of diarrhoeal disease every year ( WHO, 2013). In the surveillance report of 2013 by the Department of Health (DOH) in the Philippines, a total of 1,174 leptospirosis cases have been reported nationwide from January 1, 2013 to September 17, 2013. This is $78.74 \%$ lower compared to the same period last year (5,522), ( $\mathrm{DOH}, 2013)$. A total of 117,658 dengue fever cases from January 1 to September 7, 2013 were reported nationwide. This is $5.25 \%$ lower compared to the same period last year's $(124,173)$ cases and mostly coming from regions $\mathrm{VI}$ and IV-A, $(\mathrm{DOH}, 2013)$. Though the figures of the surveillance report in 2013 were lower than the previous years, yet these recent statistics is still very alarming. Given this high incidences of diarrhoea, leptospirosis, and dengue fever cases, it is therefore important to conduct studies that would provide better understanding how each households perceives, relates and employs their attitudes and practices towards personal hygiene and protection, and to environmental sanitation.

According to the 2012 Philippines Disaster Report, a total of 471 natural and humaninduced disasters were reported in the Philippines in 2012 (CDRC, 2012). One thousand six hundred fifteen $(1,615)$ people were killed, and more than 2.8 million families or 12 million people were affected, and caused over Php 39.9 billion in economic damages. In terms of frequency, flood topped the list with 143 reported incidents, or $30 \%$ of the total number of disaster events monitored in 2012 . Given this 
high-risk status of the Philippines to hazards in general, it is surprising to find that there were very few comprehensive place-specific vulnerability and resilience assessments performed at the local level in the Philippines which accounts on social vulnerability specifically on how the community people respond to these kind of phenomenon and to the impacts of global warming. Such kinds of studies and assessment should be conducted so such gaps will be addressed properly. This study was an exploratory step towards assessing flood vulnerability and resilience, a rapid assessment of the Knowledge, Attitudes, and Practices (KAP) of the community people towards flood resilience, exposures to the different microorganisms that have health concern during and after a typhoon or flooding event. Environmental sanitation, the hydro-climatic components, including their socio-demographic profile and governance were also included in this study. These are important factors to be assessed in order to established correlations and relationships in understanding social vulnerabilities and its indicators so it can be incorporated in hydroinformatics. Determining flood vulnerability index varies from one country to another. There is no single gold standard used worldwide. Measuring vulnerability and resilience is important, it mirrors how well are the people adapting to climate change and its impacts, how are the resilience programs implemented and facilitated by the local government units. Perhaps it is also important to note that gauging vulnerability may have a number of different reasons but understanding the context of people's vulnerability to hazards and why they are vulnerable in the first place, seems to be more useful for making a difference in their lives.

\subsubsection{Types and Causes of Flooding}

Flood is usually due to several factors (Jha, A.K., et al., 2012). A combination of meteorological and hydrological such extreme precipitation and flows is one and human activity is another. Unplanned growth and development in floodplains or from the breach of a dam or the overtopping of an embankment may result to flooding when these structures failed to protect under extreme hydrological weather conditions. Among others are the influxes of people from rural areas to urban places that often settled in areas that are highly exposed to flooding. The lack of flood defense system, the improper implementation of land use and urban development that reduces the permeability of soil while increasing surface runoff coupled with poor drainage system, are one of the many reasons that increases the risk of flooding.

For the purpose of clarity, descriptions and categorizing of floods should be distinguished properly (Balica, S.F., Wright, N.G., and van der Meulen, F., 2012). As mentioned in their paper of which was based from the works of previous authors named as follows, a flood is "defined as a temporary condition of surface water be that be river, 
lake or sea in which the water level and or discharge exceeds a certain value, thereby escaping from its normal confines," this does not necessarily results in flooding (Douben, K.J., 2006). On the other hand, flooding is defined as the spilling over or failing of the normal limits for example river, lake, sea, stream or accumulation of water as a result of heavy precipitation through lack or exceeding of the discharge capacity of drains, or snow melt, dams or dikes break affecting areas which are normally not submerged (Douben, N. and Ratnayake, RMW., 2005).

Floods vary and are based on a combination of sources, causes and impacts. Based on such combinations, floods can be generally characterized into river (or fluvial) floods, pluvial (or overland) floods, coastal floods, groundwater floods or the failure of artificial water systems. Based on the speed of onset of flooding, floods are often described as flash floods, urban floods, semi-permanent floods, and slow rise floods. All the abovementioned floods can have severe impacts on urban areas - and thus be categorized as urban floods. It is important to understand both the cause and speed of onset of each type to understand their possible effects on urban areas and how to mitigate their impacts (Jha, A.K., et al., 2012).

In the recent decades facts have revealed the growing incidence of floods and flooding from many parts of the world which can be caused by climate change and global warming according to the reports of UNDP.

A distinction can be made between five different types of floods: river floods flash floods, urban floods and coastal floods, (MunichRe, 2007) is described briefly in the study of Balica et al. 2012 and here below are the detailed description along with other studies and reports.

\section{River floods or Fluvial Floods}

This type of flood occurs when the surface water runoff exceeds the capacity of natural or artificial channels to accommodate the flow. The excess water overflow the banks of the watercourse and spills out into the adjacent, low-lying floodplain areas (Balica, S.F., Wright, N.G., and van der Meulen, F., 2012).

The river such as the Mississippi in the United States or the Nile in North Africa and the Yangtze River Basin are typical places where fluvial flooding inundation to its floodplains occurs once every 20 years or so affecting millions of people, and causing economic losses of millions of dollars. 


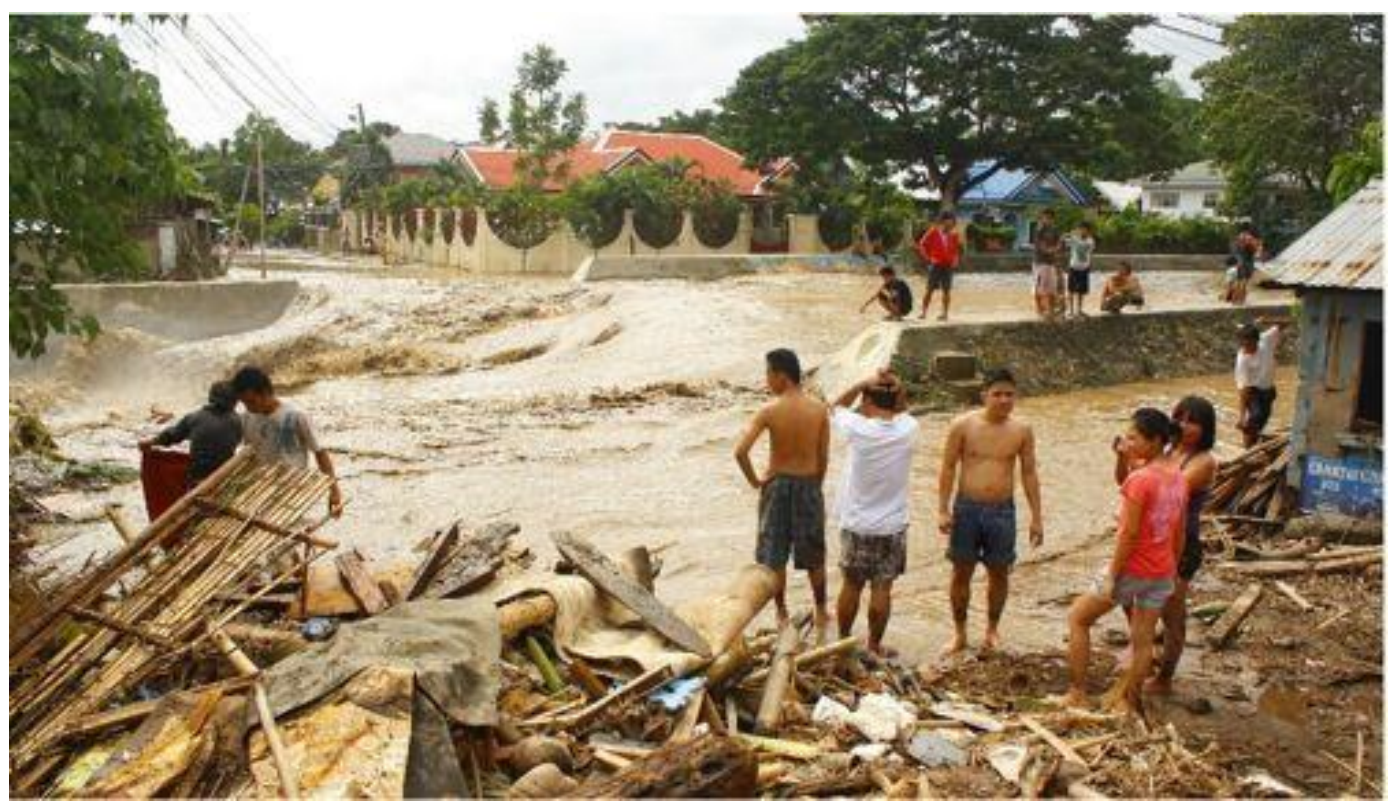

Figure 1-4: River Flood (Dumaguete City, Philippines)

This is a typical illustration of a river flood (Figure 1-4). Floods along rivers are a natural event and some occur seasonally during rainy season. River floods do not occur abruptly but build up gradually and are a result of copious rainfall usually continuing for a period of days over a large area. When the ground becomes saturated and cannot cope with infiltration, the rainwater flows directly into the rivers (Hoyt, G.W, and Langbein, W., 1955).

As a rule, they last from a few days to a few weeks and may vary in the extent of devastation depending on the topography of the river. River related flooding also brings indirect threats such as the spread of disease arising from contaminated food and water (Douben, K.J., 2006). 


\section{Flash Floods}

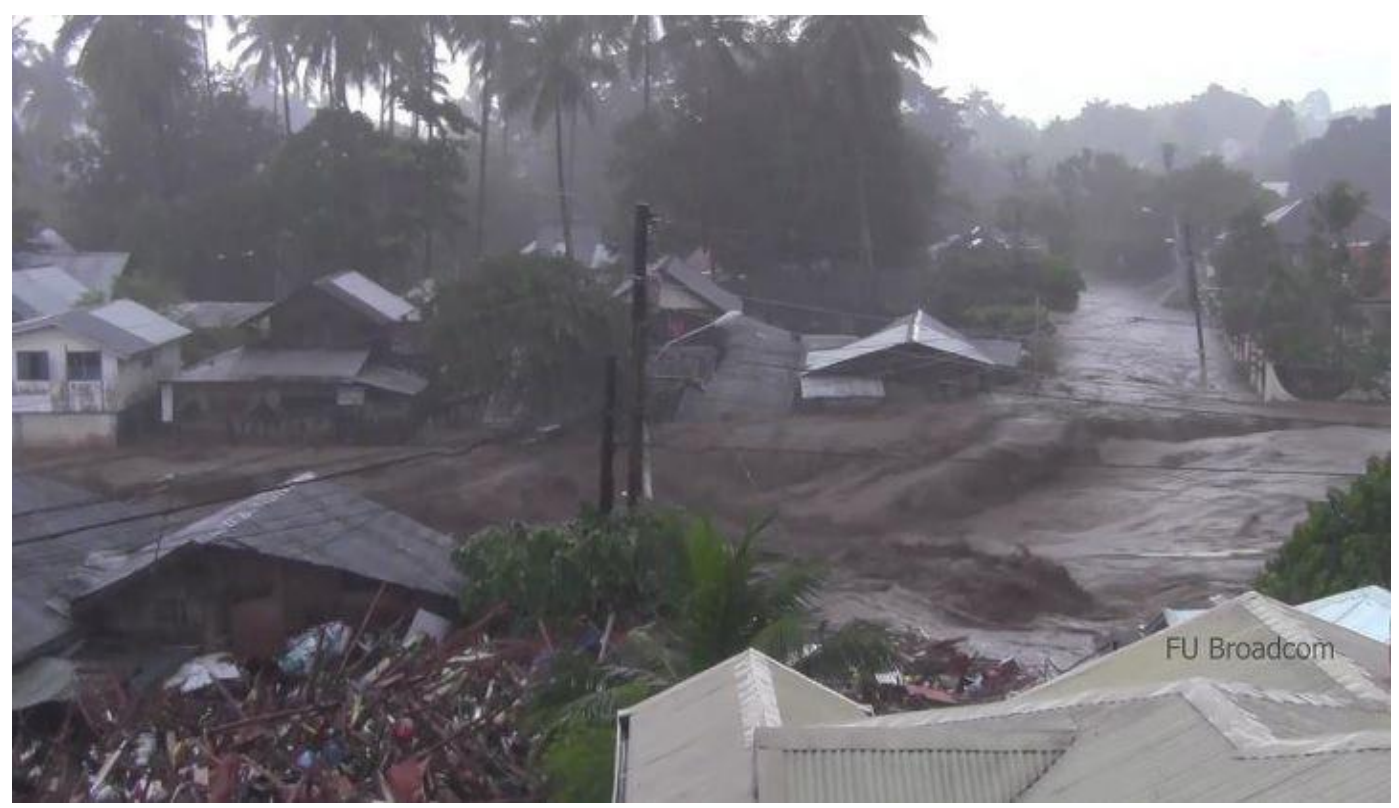

Figure 1-5: Flash Flood (Dumaguete City, Philippines)

Flash floods (Figure 1-5) are short-term inundations of small areas such as towns or parts of a city. They are caused by short periods of intense rain often occurring over a very small area and typically in conjunction with thunderstorms. When the river dikes or levees fails or washed out, the river flood waters are released to become a flash flood. They are the most deadly and damaging kind of floods because they happen without warning and delivers massive amounts of fast-moving water. Unfortunately, they are also the most common kind of flood. They are much shorter in duration than river floods. Most of the water disappears after a few hours (Perry, 2000).

As also defined by the International Federation of Red Cross (IFRC) and Red Crescent Societies, flash flood are sudden and extreme volume of water flow rapidly and cause inundation. Because of its rapid nature flash floods are difficult to forecast and give people little time to escape or to take food and other essentials with them (IFRC, 2014)

Flash flood is also defined by The US National Oceanic and Atmospheric Administration (NOAA) National Weather Service Manual in December 2012, as the one whose peak appears within six hours from the onset of a torrential rainfall (NOAA, 2014). Flash floods can be caused by local convective thunderstorms, or by the sudden release from an upstream impoundment created behind a dam, landslide, glacier or ice-jam. Factors that contribute to this type of flooding are, in addition to rainfall intensity and duration, surface conditions and the topography and slope of the receiving basin. Urban areas are notably susceptible to flash floods because a high percentage of their surfaces are 
composed of impervious streets, roofs, and car parking areas where runoff occurs very rapidly. Flash floods can be particularly dangerous because they occur suddenly and are difficult, if not impossible, to forecast. They typically affect a more localized area compared to other floods but can still caused serious damage as the water may be travelling at high speed and carrying large amounts of debris, including rocks, trees and cars.

In November 5, 1991 Ormoc region in the Philippines was inundated by Tropical Storm Uring. The city government recorded 4,922 deaths, 3,000 missing persons, 14,000 destroyed houses, and more than 600 million pesos worth of damaged property.

\section{Urban Floods}

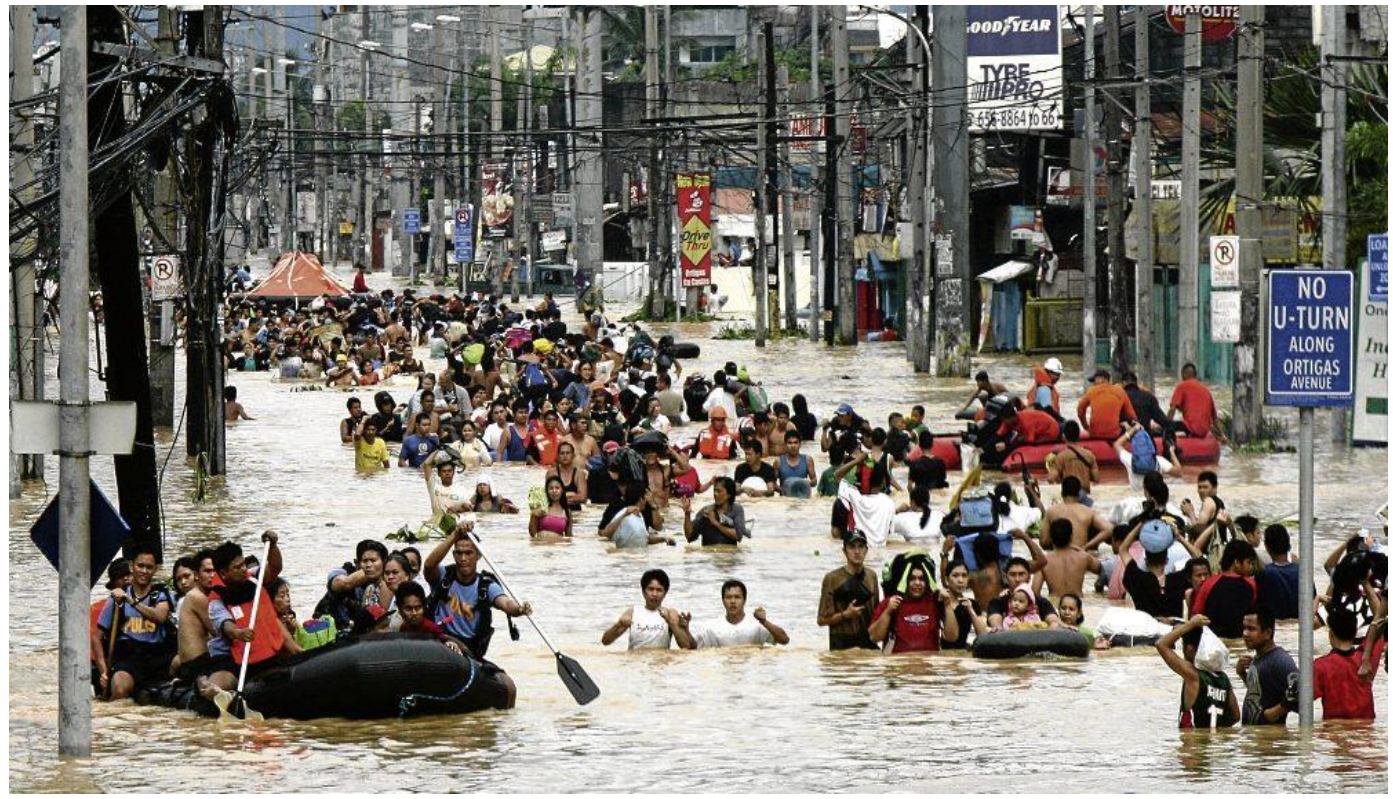

Figure 1-6: Urban Floods (Manila, Philippines)

As mentioned by Balica, et al (2012) in their paper, urban floods (Figure 1-6) are usually caused by extreme local rainfall combined with blocked drainage systems. This type of flooding depends on soil and typographical conditions and the quality of the drainage systems (Douben, K.J., 2006). These scenarios are the result of urban and sub-urban sprawl where developed land areas lose their ability to absorb rainfall. In a developing world where infrastructures and drainage systems are poor, the exposed population is more often subject to flooding unlike in developed countries, exposed populations are protected from flooding by various structural measures (e.g. UK, the Netherlands and Japan). People in developing countries have less capacity to adapt to change and are more vulnerable to environmental threats, floods and global change, just as they are more vulnerable to other stresses (UNEP, 2002). 
In the paper of Jha et al. (2012), it was made mention that urban floods are a growing issue of concern for both developed and developing nations. They cause damage to buildings, utility works, housing, household assets, income losses in industries and trade, loss of employment to daily earners or temporary workers, and interruption to transport systems. The damage caused by urban floods is on the rise. It is therefore important to understand the causes of and impacts different types of flooding have on urban areas. Urban floods typically stem from a complex combination of causes. The urban environment is subject to the same natural forces as the natural environment and the presence of urban settlements exacerbates the problem. Urban areas can be flooded by rivers, coastal floods, pluvial and groundwater floods and artificial system failures, urban floods are also caused by the effects of deficient or improper land use planning. Many urban areas are facing the challenge of increased urbanization with rising populations and high demands for land. While there are existing laws and regulations to control the construction of new infrastructure and the variety of building types, they are often not enforced properly owing to economic or political factors, or capacity or resource constraints. This leads to obstruction in the natural flow path of water, which causes floods. Unless there is awareness amongst residents and proper cooperation between decision makers, risk management authorities and the public in the process of flood risk management, it will be very difficult to control the deterioration of the global urban flood risk situation.

\section{Coastal Floods}

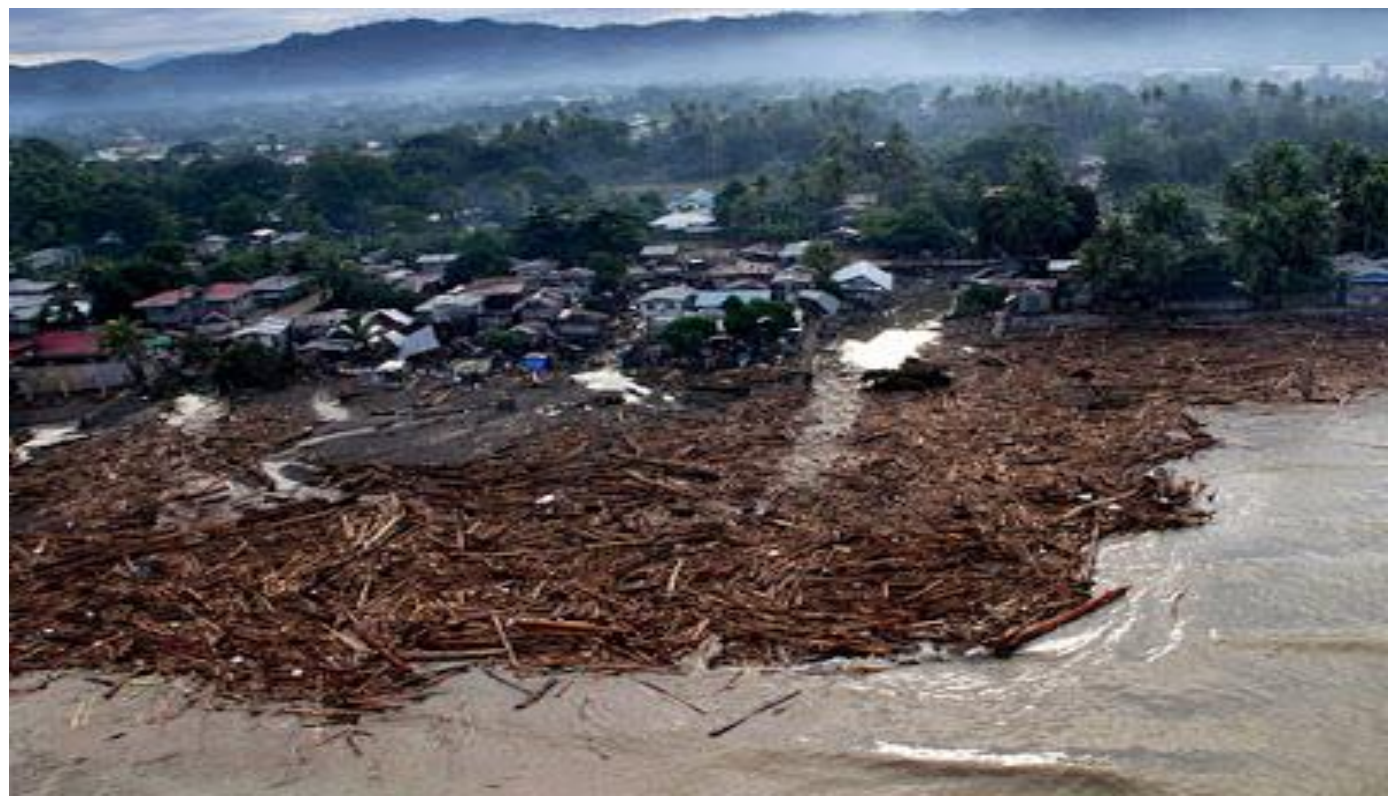

Figure 1-7: Coastal Floods (Iligan City, Philippines) 
Coastal floods can occur along the coast (Figure 1-7). Coastal floods usually occur when storms coincide with high tides and can also produce by sea waves called tsunamis, unusually giant tidal waves that are created by volcanoes or earthquakes in the ocean. Hurricanes and tropical storms can produce heavy rains, or drives ocean water into the land.

Again in the paper report of Jha et al. (2012) to the World Bank, coastal floods arise from incursion by the ocean or by sea water. They differ from cyclic high tides in that they result from an unexpected relative increase in sea level caused by storms or a tsunami (sometimes referred to as a tidal wave) caused by seismic activities. In the case of a storm or hurricane, a combination of strong winds that causes the surface water to pile up and the suction effects of low pressure inside the storm, creates a dome of water. If this approaches a coastal area, the dome may be forced towards the land; the increasing sea floor level typically found in inshore waters causes the body of water to rise, creating a wave that inundates the coastal zones. The storm surge usually causes the sea level to rise for a relatively short period of time of four to eight hours, but in some areas it might take much longer to recede to pre-storm levels. Coastal floods caused by tsunamis are less frequent than storm surges, but can also cause huge losses in low-lying coastal areas. The 2004 Indian Ocean Tsunami was caused by one of the strongest earthquakes ever recorded and affected the coasts around the ocean rim, killing hundreds of thousands of people in fourteen countries.

\section{Pluvial or Overland floods}

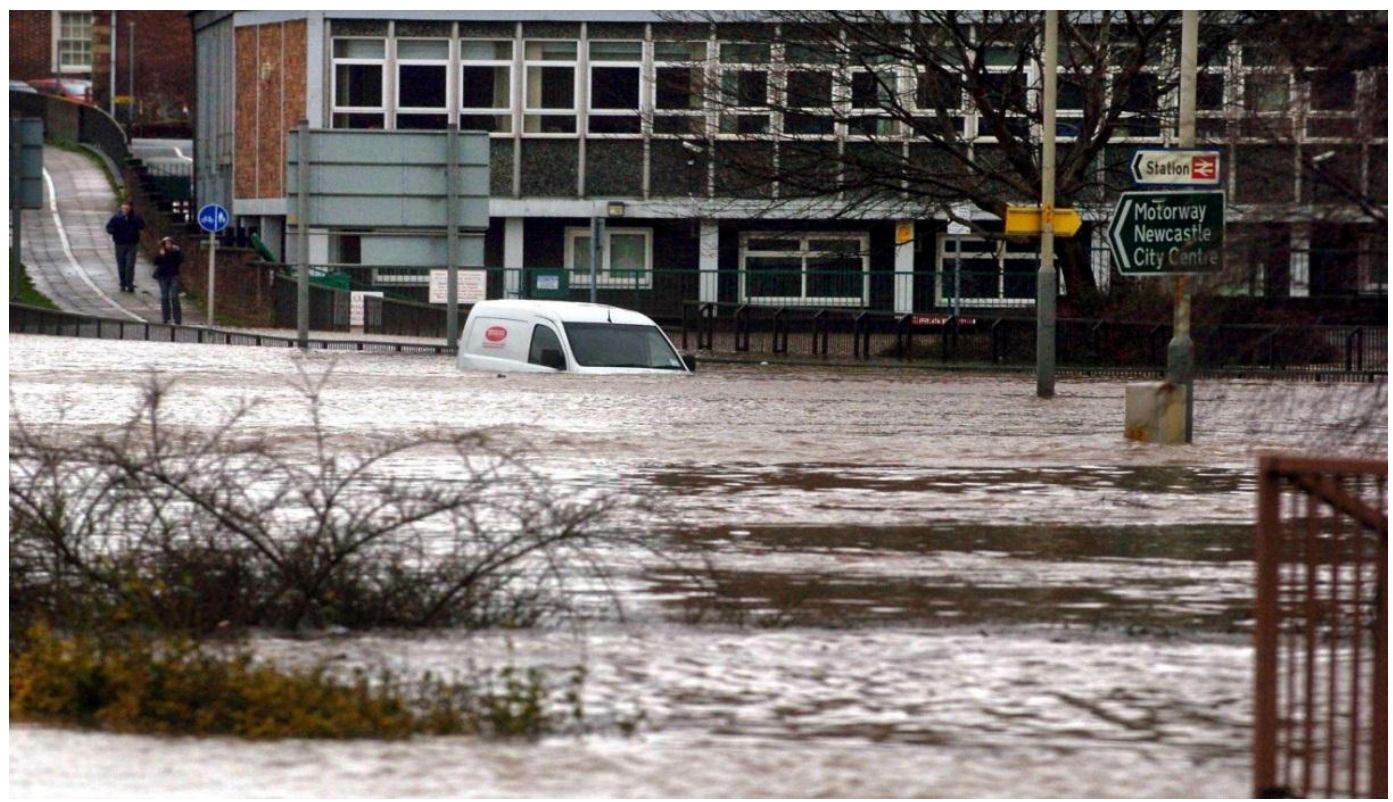

Figure 1-8: Pluvial or Overland Floods 
In the same paper, an account on pluvial floods also known as overland floods are caused by rainfall or snowmelt that is not absorbed into the land and flows over land and through urban areas before it reaches drainage systems or watercourses. This kind of flooding often occurs in urban areas as the lack of permeability of the land surface means that rainfall cannot be absorbed rapidly enough, flooding results. Pluvial floods are often caused by localized summer storms or by weather conditions related to unusually large low pressure areas. Characteristically, the rain overwhelms the drainage systems, where they exist, and flows over land towards lower-lying areas (Figure 1-8). These types of floods can affect a large area for a prolonged period of time: the 2007 floods in the Hull area in the UK were the result of prolonged rainfall onto previously saturated terrain which overwhelmed the drainage system and caused overland flooding in areas of the city outside the fluvial floodplain. Pluvial floods may also occur regularly in some urban areas, particularly in tropical climates, draining away quickly but happening very frequently, even daily, during the rainy season. The Philippines is no excused to be spared from this type of flooding. Every year when rainy season commence big and crowded cities such as Manila and Cebu can be flooded for the same reason mentioned above.

\subsubsection{Natural Disasters: Storm and Flood Record Worldwide and in the Philippines}

The information on natural disasters presented here is taken from EM-DAT: The OFDA/CRED International Disaster Database (EM-DAT, 2014). In order for a disaster to be entered into the data base at least one of the following criteria has to be fulfilled: 10 or more people reported killed; 100 people reported affected; a call for international assistance; declaration of state emergency.

For some natural disaster (particularly floods and droughts) there is no exact day or month for the event, and for other disasters (particularly pre-1974) the available record of the disaster does not provide an exact day or month. 

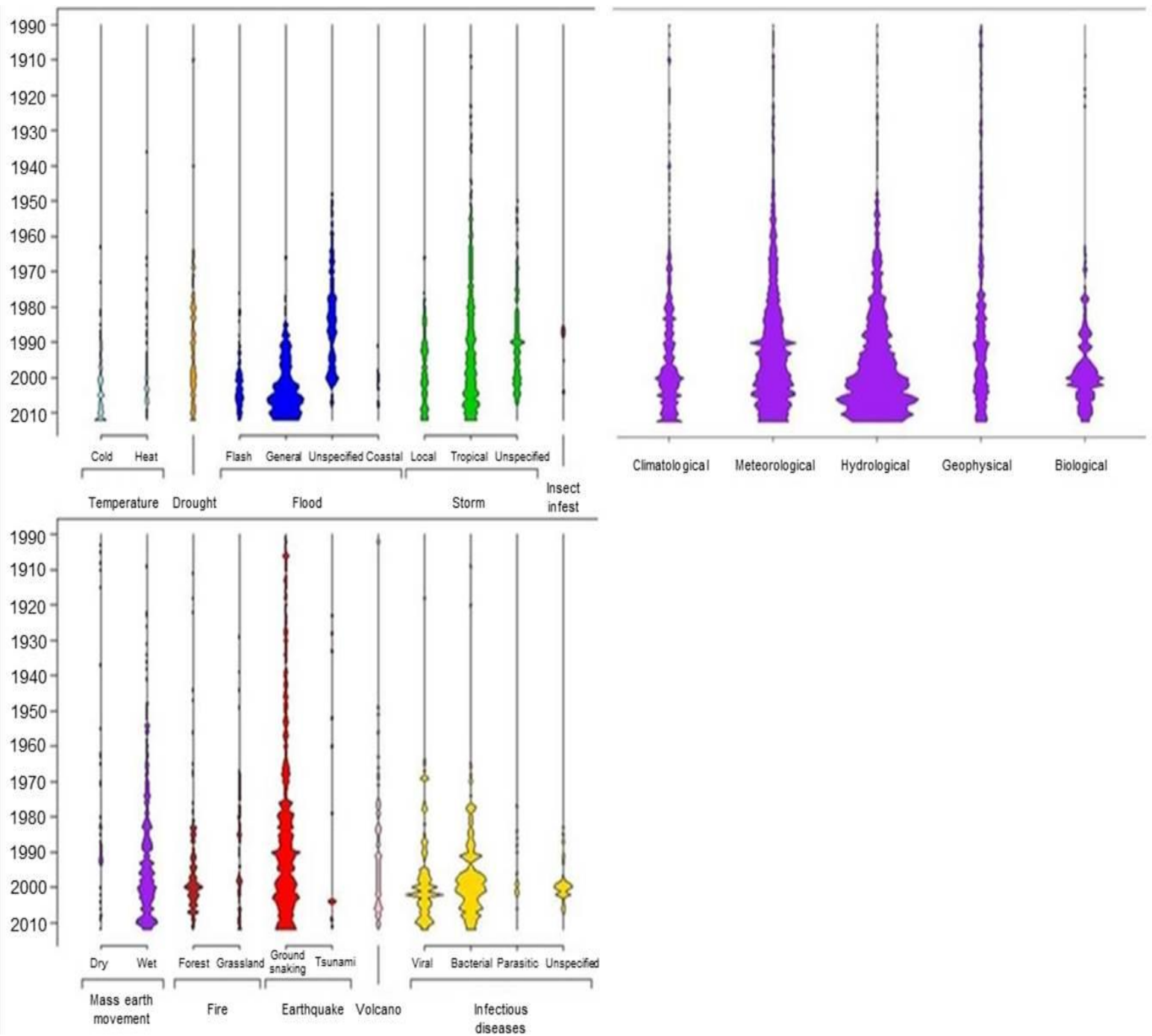

Figure 1-9: Number of Natural Disaster Reported 1900-2012

Figure 1-9: Shows the number of natural disaster reported from 1900 until 2012 particularly those of hydrological and meteorological in nature showed an increasing number of occurrences for the last three decades (1990-2010).

As illustrated in Figure 1-9, flood of all types but of particularly of the general type accounts a huge increase in terms of occurrence for the last three decades (1990-2010) and along with earthquake and infectious diseases of those particularly caused by bacteria and virus. 


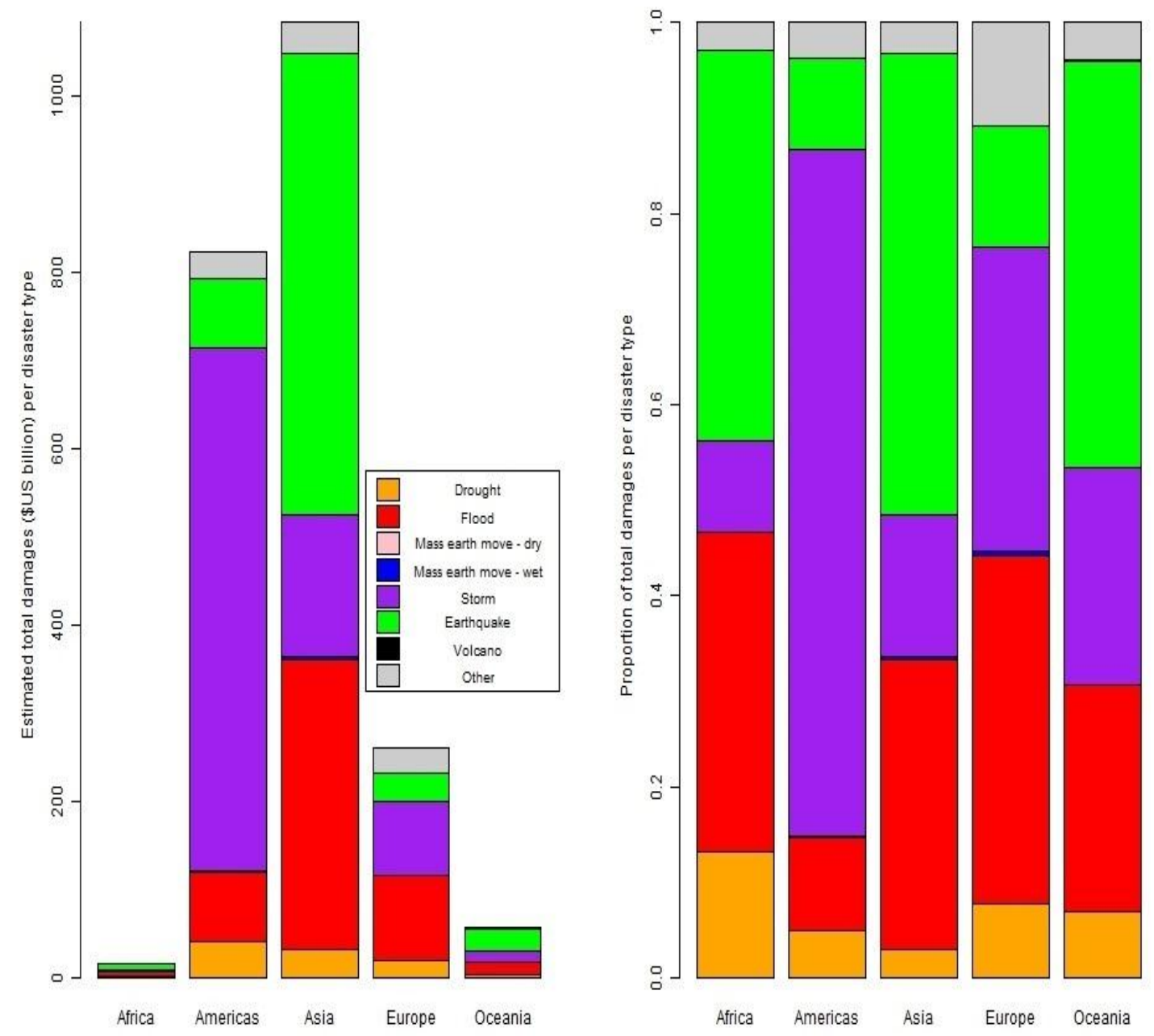

Figure 1-10: Total Damages (\$US billion) Caused by Reported Natural Disasters 1900-2012

Figure 1-10 shows the total economic damages in US billion dollars from the different continents in the world (Africa, Americas, Asia, Europe, and Oceania) caused by the different natural disasters (Drought, Flood, Mass earth move-dry, Mass earth move-wet, Storm, Earthquake, Volcano and Others) from 1900-2012. Earthquake, floods and storm topped the list in Asia when it comes to total economic damages. Earthquake, flood and drought topped in Africa. In the Americas, storm, flood and earthquake topped the list. While in Europe, flood, storm and earthquake topped on the list. In the Oceania, earthquake, flood and storm are the natural disasters that topped on the list respectively. 
Number of Occurrences of Flood Disasters by Country:

1974-2003
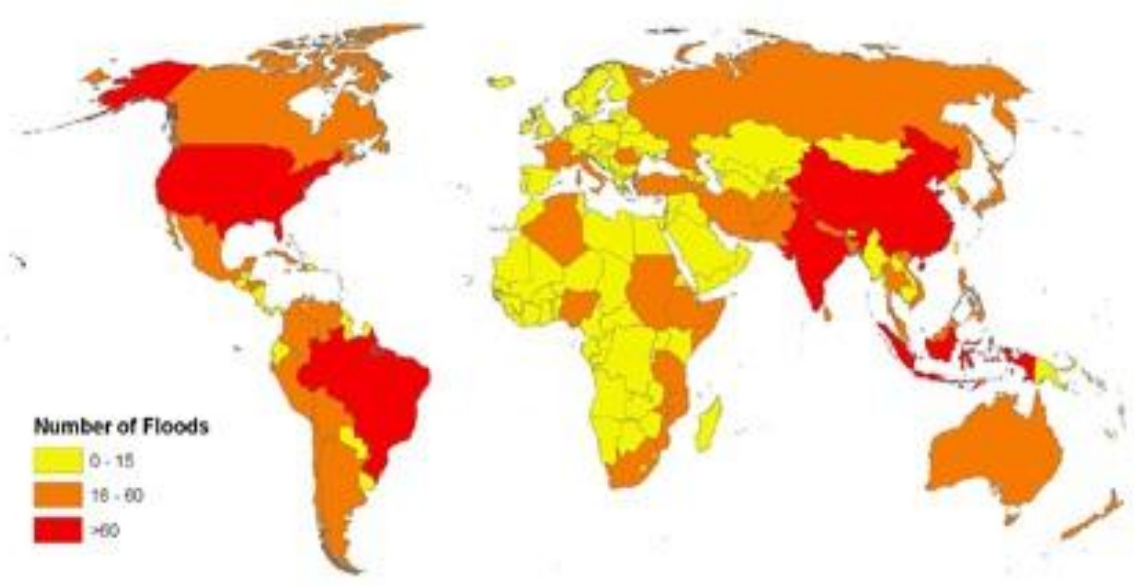

Figure 1-11: Number of Occurrence of Flood Disaster by Country: 1974-2003

The number of occurrences of flood disasters by country from 1974 to 2003 is shown in this map (Figure 1-11). The Philippines falls within the 16-60 flood occurrences from 1974-2003 when it comes to flood disaster among other neighboring countries such as Viet Nam, Thailand, Japan, South Korea and Australia. Russia, Pakistan, Afghanistan, Iran, Turkey, Italy, France, Algeria, some countries in Africa, Latin America and North America are also between 16-60 occurrences. On the other hand, China, India, Brazil, United States of America, Alaska, and some parts of Indonesia and Papua New Guinea topped the list with more than 60 occurrences of flood disasters from 1974-2003. 
Community-Based Flood Vulnerability Index for Urban Flooding: Understanding Social Vulnerabilities and Risks

\subsubsection{The Natural Disaster's Data in the Philippines from the 1900-2014}

Table 1-1: Top 10 Natural Disasters in the Philippines for the period 1900-2014

\begin{tabular}{|c|c|c|}
\hline Disaster & Date & No. Killed \\
\hline Storm & $08 / 11 / 2013$ & 7986 \\
\hline Earthquake (seismic activity) & $16 / 08 / 1976$ & 6000 \\
\hline Storm & $05 / 11 / 1991$ & 5956 \\
\hline Earthquake (seismic activity) & $16 / 07 / 1990$ & 2412 \\
\hline Storm & $04 / 12 / 2012$ & 1901 \\
\hline Storm & $29 / 11 / 2004$ & 1619 \\
\hline Storm & $13 / 10 / 1970$ & 1551 \\
\hline Storm & $15 / 12 / 2011$ & 1439 \\
\hline Storm & $01 / 09 / 1984$ & 1399 \\
\hline Storm & $30 / 11 / 2006$ & 1399 \\
\hline
\end{tabular}

Most of the natural disasters in the Philippines that has been recorded from 1900-2014 has been dominated by storm when it comes to the number of people affected from that disaster. As depicted in Table 1-1. The most recent and probably the most devastating storm that hits the country as far as record is concern is Typhoon Haiyan (local name Yolanda) that displaced about 16.1 million people (Table 1-2). A flood that struck in August of 2012 has also affects about 4.4 million people.

Table 1-2: Top 10 Natural Disasters in the Philippines for the period 1900-2014

\begin{tabular}{|l|c|r|}
\hline Disaster & Date & No. Total Affected \\
\hline Storm & $08 / 11 / 2013$ & $16,106,807$ \\
\hline Storm & $04 / 12 / 2012$ & $6,246,664$ \\
\hline Storm & $12 / 11 / 1990$ & $6,159,569$ \\
\hline Storm & $24 / 09 / 2009$ & $4,901,763$ \\
\hline Storm & $21 / 06 / 2008$ & $4,785,460$ \\
\hline Storm & $29 / 09 / 2009$ & $4,478,491$ \\
\hline Flood & $06 / 08 / 2012$ & $4,451,725$ \\
\hline Storm & $21 / 10 / 1998$ & $3,902,424$ \\
\hline Storm & $27 / 09 / 2006$ & $3,842,406$ \\
\hline Storm & $20 / 11 / 1973$ & $3,400,024$ \\
\hline
\end{tabular}

Storm Haiyan (local name Yolanda) also topped the list when it comes to economic damage cost. A 10 billion US dollar cost was the total damaged caused by Yolanda. In August 2013, torrential monsoon rains brings flood in most parts of Manila and the National Capital Region due to heavy downpours brought by the Habagat or Southwest 
monsoon. The economic damage amounted to 2.1 million US dollars. The rest of the economic damages are mostly caused by storm with one exception, the earthquake that struck in July of 1990.

The following figures and statistics are data related to human and economic losses from disasters that have occurred between 1980 and 2010 from EM-DAT: The OFDA/CRED International Disaster Database.

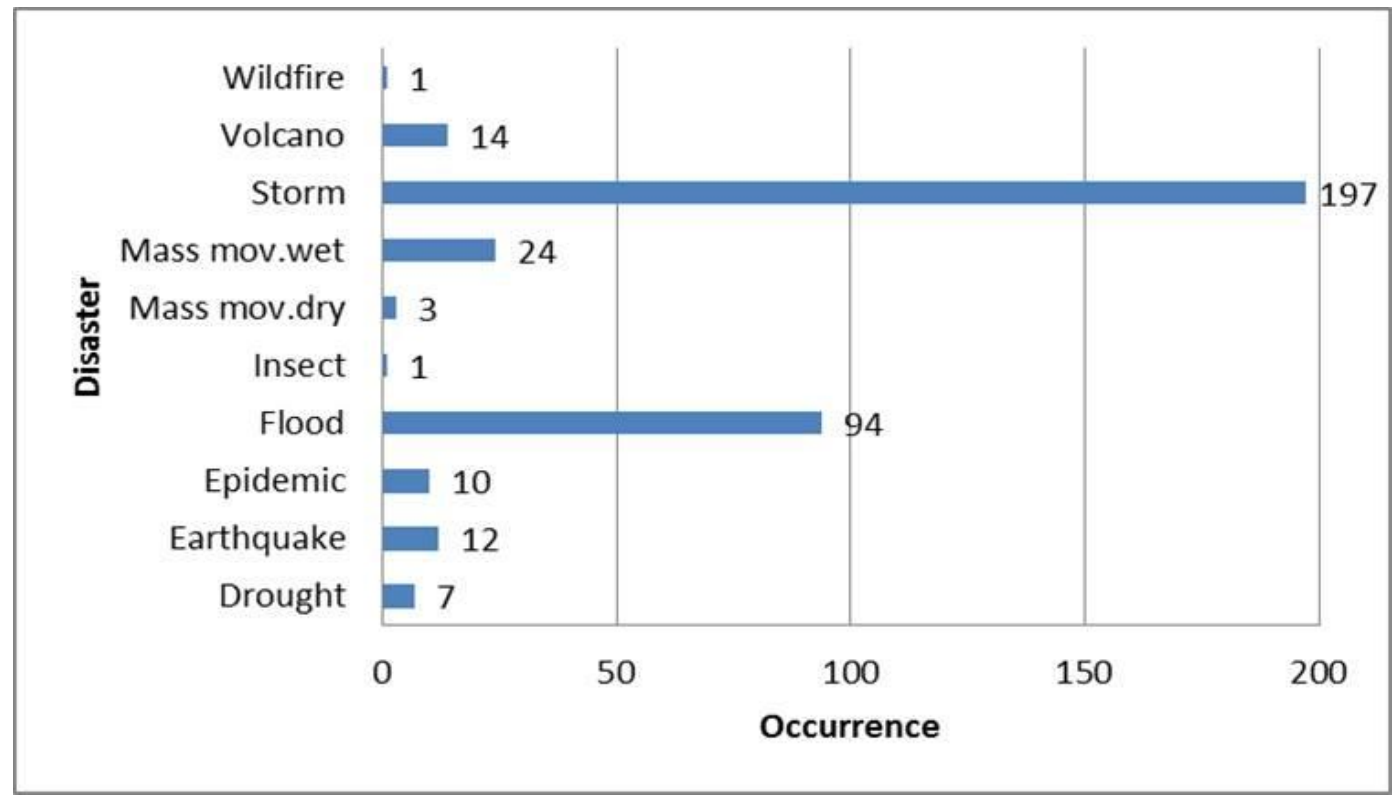

Figure 1-12: Natural Disaster Occurrence Reported

This graph (Figure 1-12) depicts storm as the most number of occurrences (197) followed by floods (94), and mass movement-wet (24) respectively from 1980-2010.

Table 1-3: Average Disaster per Year Worldwide

\begin{tabular}{|l|r|}
\hline Disaster & Annual Disaster \\
\hline Drought & 0.23 \\
\hline Earthquake & 0.39 \\
\hline Epidemic & 0.32 \\
\hline Extreme temp & - \\
\hline Flood & 3.03 \\
\hline Insect infestation & 0.03 \\
\hline Mass movement dry & 0.10 \\
\hline Mass movement wet & 0.77 \\
\hline Volcano & 0.45 \\
\hline Storm & 6.35 \\
\hline Wildfire & 0.03 \\
\hline
\end{tabular}


Community-Based Flood Vulnerability Index for Urban Flooding: Understanding Social Vulnerabilities and Risks

As seen in Table 1-3, storm and flood are the leading disasters per year worldwide, 6.35 and 3.03 on average per year.

Statistics by Disaster Type

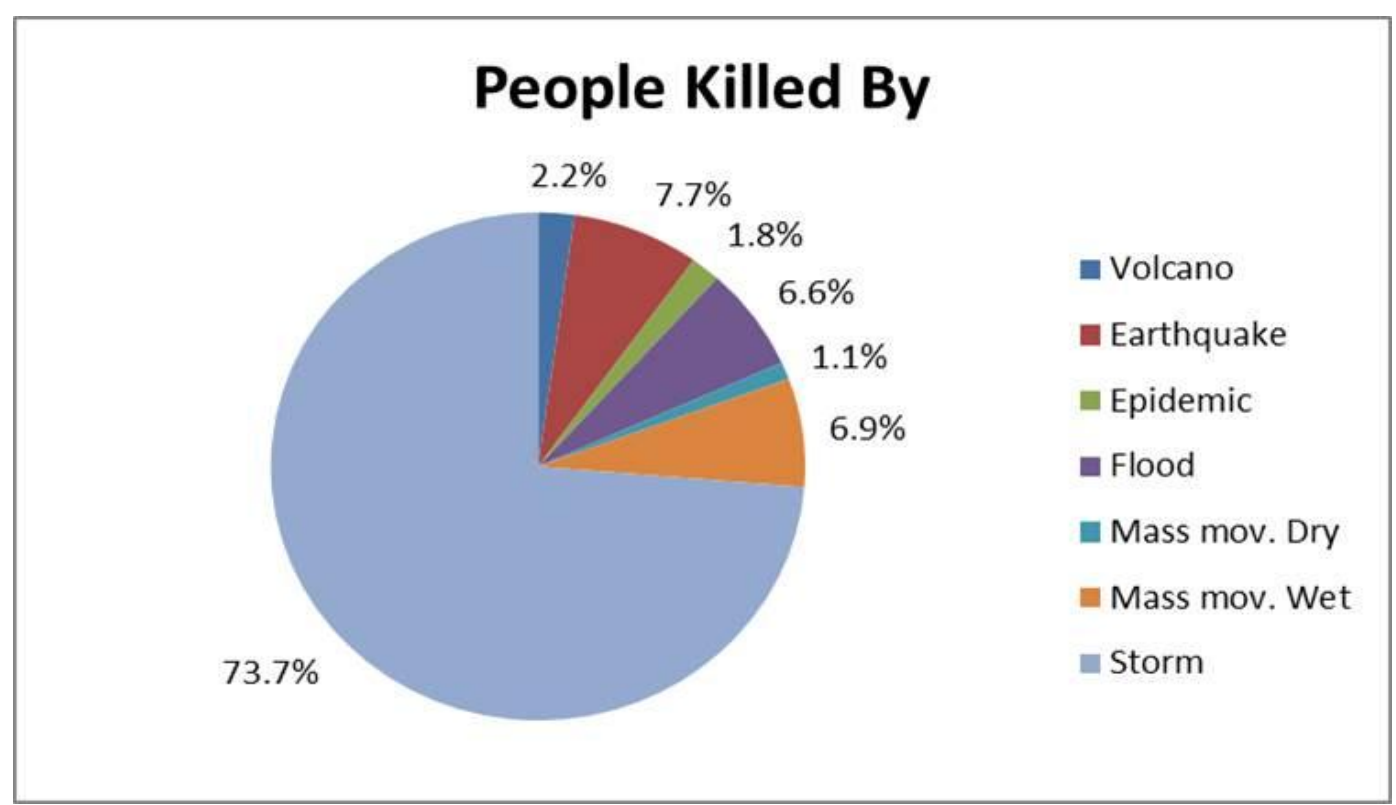

Figure 1-13: Percentage of Reported People Killed by Disaster Type

Figure 1-13. In terms of disaster type, storm (73.7\%) tops the list on the percentage of people killed, followed by earthquake $(7.7 \%)$, mass movement-wet $(6.9 \%)$ and flood $(6.6 \%)$ respectively on a per annual basis.

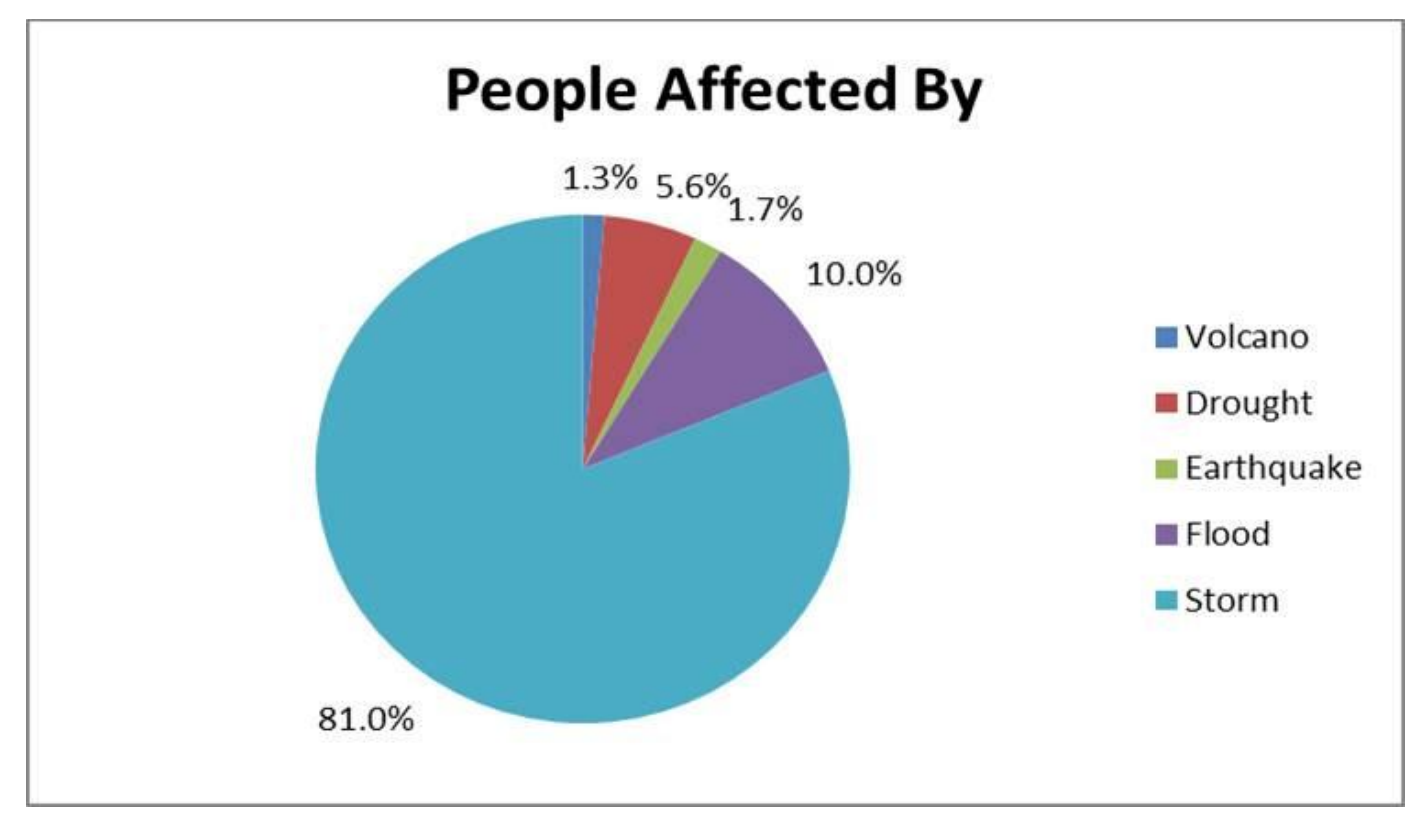

Figure 1-14: Percentage of Reported People Affected by Disaster Type 

Social Vulnerabilities and Risks

On the basis of the percentage of reported people affected by disaster type (Figure 1$14)$, storm $(81 \%)$ still top the list followed by flood $(10 \%)$ and drought $(5.6 \%)$ which is not the case of people reported killed by these disaster types on a per annual basis.

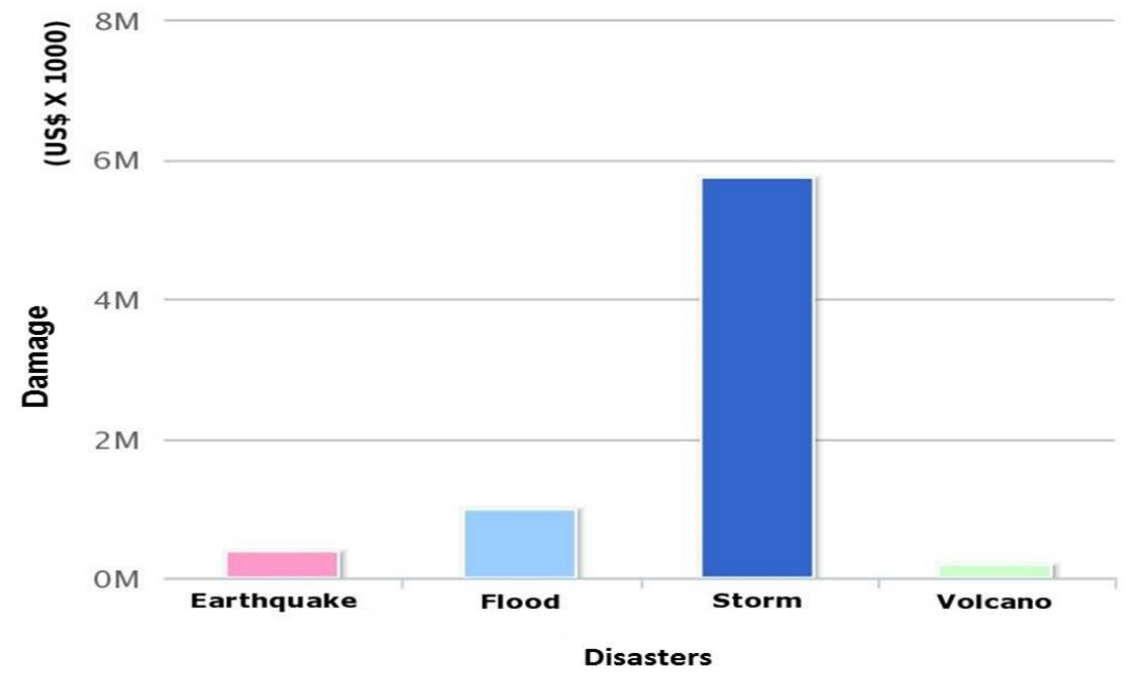

Figure 1-15: Estimated Economic Damages Reported by Disaster Type (US $\$$ X 1,000)

The same pattern is observed in Figure 1-15. Storm ranks first (nearly 6 million) in terms of economic damages reported by disaster type in US dollars. Flood follows about 1.5 million US dollars on a per annual basis. 
Community-Based Flood Vulnerability Index for Urban Flooding: Understanding

\section{Social Vulnerabilities and Risks}

Table 1-4: Timeline of Disaster Events in Dumaguete City, Negros Oriental Philippines.

\begin{tabular}{|c|c|c|c|c|c|c|c|}
\hline $\begin{array}{l}\text { Type of } \\
\text { Hazards/ } \\
\text { Disasters }\end{array}$ & $\begin{array}{l}\text { Typhoon } \\
\text { RUPING }\end{array}$ & $\begin{array}{l}\text { Northeast } \\
\text { Monsoon }\end{array}$ & Northeast Monsoon & Typhoon SENDONG & $\begin{array}{l}\text { Storm Surge along coastal } \\
\text { Brgys: Mangnao, Calindagan, } \\
\text { Brgy 1, Looc, Piapi and } \\
\text { Bantayan }\end{array}$ & Typhoon PABLO & Typhoon AURING \\
\hline $\begin{array}{l}\text { Date of } \\
\text { Occurren- } \\
\text { ces }\end{array}$ & Nov-90 & Dec-08 & Feb-09 & Dec 16, 2011 & Perennial & Dec 4, 2012 & Jan 3, 2013 \\
\hline $\begin{array}{l}\text { Impact } \\
\text { and } \\
\text { Strength }\end{array}$ & $\begin{array}{l}\text { Signal \# } \\
3\end{array}$ & $\begin{array}{l}\text { Heavy } \\
\text { Rainfall }\end{array}$ & $\begin{array}{l}\text { Heavy Rainfall - } \\
240 \mathrm{~mm} ; 9 \\
\text { Barangays; } 1000 \\
\text { families affected }\end{array}$ & $\begin{array}{l}\text { Typhoon Signal \# 2; } 21 \\
\text { Barangays; } 4,017 \text { families } \\
\text { affected }\end{array}$ & High tide and surges & Signal \# 3 & Signal \# 1 \\
\hline \multirow[b]{2}{*}{$\begin{array}{l}\text { Injured/ } \\
\text { Casualties }\end{array}$} & \multirow[b]{2}{*}{ No Data } & \multirow[b]{2}{*}{ No Data } & \multirow[b]{2}{*}{ None } & 4 deaths from floods & \multirow[b]{2}{*}{ None } & Zero Casualty & Zero Casualty \\
\hline & & & & 1 electricuted; Injured - 468 & & $\begin{array}{l}21 \text { injured; } 1,350 \text { families } \\
\text { affected }\end{array}$ & $\begin{array}{l}\text { Less than } 10 \\
\text { persons (health } \\
\text { problem); Less than } \\
20 \text { injured }\end{array}$ \\
\hline \multirow{2}{*}{$\begin{array}{l}\text { Property } \\
\text { Damage }\end{array}$} & \multirow{2}{*}{$\begin{array}{l}40 \\
\text { houses } \\
\text { totally } \\
\text { dama- } \\
\text { ged }\end{array}$} & \multirow{2}{*}{ No Data } & \multirow{2}{*}{$\begin{array}{l}60 \text { houses totally } \\
\text { damaged }\end{array}$} & 392 Houses totally damaged & Light material Houses & $\begin{array}{l}\text { Houses: } 72 \text { totally } \\
\text { damaged; } 1,278 \text { partially } \\
\text { damaged }\end{array}$ & $\begin{array}{l}\text { Life Raft, Life vest, } \\
\text { Ropes }\end{array}$ \\
\hline & & & & 740 partially damaged & & Cost $P 7,830,000$ & $\begin{array}{l}\text { Boat (Zamboanga } \\
\text { Ferry Incident) etc. } \\
\text { Cost P500,000 }\end{array}$ \\
\hline \multirow[t]{2}{*}{$\begin{array}{l}\text { Infrastruc- } \\
\text { ture } \\
\text { Damage }\end{array}$} & \multirow[t]{2}{*}{ No Data } & \multirow[t]{2}{*}{$\begin{array}{l}\text { Damaged } \\
\text { roads and } \\
\text { spillways. }\end{array}$} & Damaged roads, & $\begin{array}{l}\text { Damaged roads, } 4 \text { spillways, } \\
\text { Calabnugan bridge; } \\
\text { disrupted water and power } \\
\text { supply; }\end{array}$ & \multirow[t]{2}{*}{ Seawalls damaged/eroded } & Electrical Facilities & \multirow[t]{2}{*}{ Sea port P300,000 } \\
\hline & & & $\begin{array}{l}4 \text { spillways, } \\
\text { Calabnugan bridge }\end{array}$ & $\begin{array}{l}\text { Destruction of river control } \\
\text { dikes; }\end{array}$ & & $\begin{array}{l}\text { 300+ Electric poles down; } \\
\text { P215,600 }\end{array}$ & \\
\hline \multirow{2}{*}{$\begin{array}{l}\text { Agricultu- } \\
\text { ral } \\
\text { Damage }\end{array}$} & \multirow{2}{*}{ No Data } & \multirow{2}{*}{ No Data } & \multirow{2}{*}{$\begin{array}{l}\text { P500,000 worth of } \\
\text { Agricultural damage }\end{array}$} & $\begin{array}{l}\text { P1.1 Million.; Farmland - } \\
12.5 \text { has; Fisheries - } 1 \text { has }\end{array}$ & \multirow{2}{*}{ None } & $\begin{array}{l}\text { P 1,247,000; Rice } 8.4 \text { has.; } \\
5,120 \text { fruit trees; Mango 13, } \\
\text { Coconut 20; Corn } 4 \text { has. }\end{array}$ & \multirow{2}{*}{ None } \\
\hline & & & & $\begin{array}{l}\text { Brgy Banilad - About } 200 \\
\text { kilos of tilapia and milkfish } \\
\text { washed out. }\end{array}$ & & $\begin{array}{l}\text { Vegetables } 1,000 \text { sqm, } \\
\text { Banana } 8.4 \text { has; Fruit trees } \\
1,000 ; \text { Total area } 21.9 \text { has. }\end{array}$ & \\
\hline \multirow{4}{*}{$\begin{array}{l}\text { Environ- } \\
\text { mental } \\
\text { Damaged }\end{array}$} & \multirow{4}{*}{ No Data } & \multirow{4}{*}{ No Data } & \multirow{4}{*}{$\begin{array}{l}\text { Trees along Banica } \\
\text { River uprooted. }\end{array}$} & $\begin{array}{l}\text { Trees along Banica River } \\
\text { uprooted; }\end{array}$ & \multirow{4}{*}{ None } & \multirow{4}{*}{358 trees uprooted } & \multirow{4}{*}{ None } \\
\hline & & & & $\begin{array}{l}\text { Siltation of Banica } \\
\text { River;Change in river } \\
\text { channel; }\end{array}$ & & & \\
\hline & & & & $\begin{array}{l}\text { Erosion and destruction of } \\
\text { river banks; }\end{array}$ & & & \\
\hline & & & & $\begin{array}{l}\text { Siltation of sea floor and } \\
\text { covering of sea grass. }\end{array}$ & & & \\
\hline $\begin{array}{l}\text { Estimated } \\
\text { Amount of } \\
\text { Damaged }\end{array}$ & No Data & No Data & P 25Million & P 60Million & 0 & P 40Million & P 915,000 \\
\hline
\end{tabular}



Social Vulnerabilities and Risks

This table above (Table 1-4) shows the different disaster that hit Dumaguete City for the past three (3) decades.

On December 17, 2011 almost $50 \%$ of the entire population of the city was affected by floods brought about by Typhoon SENDONG. Total estimated damages from the typhoon on infrastructures, agricultural crops and livestock, livelihoods, lifelines and properties was around 60 million pesos as recorded by the Local Disaster Risk Reduction and Management Council (LDRRMC) of Dumaguete City.

Almost a year later, Typhoon PABLO struck Dumaguete City on December 4, 2012. The typhoon hit with maximum sustained winds of 175 kilometers per hour that day at around $5 \mathrm{pm}$ and the force of the wind was very strong that it tore away sheets of metal from the roofs of houses as well as boards and signage's from private establishments and stores. More than 300 electrical post and over 300 trees were toppled that blocked most road networks around the city, resulting in a total power black-out that lasted more than a week. With the heavy rains and strong winds, agricultural crops and fruit bearing trees were uprooted and wiped out. More than 1,400 families were affected, 73 houses totally damaged and over 1,300 homes considered partially damaged. Again the total cost of damage from Typhoon PABLO was estimated around 40 million pesos.

\subsubsection{On the Health Impact Assessment: Disease Surveillance in the Philippines on Diarrhoea, Leptospirosis and Dengue Fever}

A review of the relevant literature, reports and surveillance data on the health impacts of floods has been identified and presented below. As mentioned and identified from the corfu project, the first and perhaps the most obvious health impact of flooding is the direct risk to human life through direct contact with deep and fast flowing floodwaters. This can result in the loss of life and physical injuries. The risks of death and injuries are often exacerbated by the presence of debris within the floodwater, and mitigated by effective flood warning and evacuation procedures. The greatest burden of mortality comes from drowning, heart attacks, hypothermia, trauma, and vehicle-related accidents.

A second type of impact caused by flooding is the risk to human health that results from the diseases and illness. These illnesses can be subdivided into several categories, depending on the types of pathogens that cause them and how they are transmitted.

The first major type of illness is that of faecal-oral diseases. These can include diarrhoeal diseases, which can result from the ingestion of specific pathogens. These pathogens include viruses, bacteria and protozoans. The second type of illnesses or diseases caused by flooding are the vector borne diseases, typically transmitted by 
mosquitoes. These can include malaria, which is caused by a parasitic Protist (a type of microorganism), and Dengue Fever which is caused by the Dengue virus. Other than vector-borne diseases transmitted by mosquitoes, there are diseases that are borne by other carriers. Leptospirosis (or Weil's Disease) is caused by a bacterial pathogen and transmitted by rodents. The pathogen is excreted into floodwaters. Leptospirosis causes a range of symptoms including fever, headaches and vomiting as well as liver and kidney damage. The psychological impacts of flooding can be very significant and longlasting. Flooding can lead to common mental health disorders such as depression, anxiety, sleeplessness and irritability.

This research work has only focused on the most common health impacts that are commonly occurring in the Philippines and these include diarrhoea, leptospirosis, and dengue fever cases respectively.

As described by the World Health Organization, diarrhoea is the passage of three or more loose or liquid stools per day (or more frequent passage than is normal for an individual). Diarrhoea is usually a symptom of an infection of the intestinal tract which can be caused by a variety of bacterial, viral and parasitic organisms. Infection is spread through a contaminated food or drinking water, or from person-to-person as a result of poor hygiene. According to the World Health Organization, each year diarrhea kills around 760,000 children under the age of five and is the second leading cause of death among that age group. Worldwide, there are nearly 1.7 billion cases of diarrheal disease every year (WHO, 2013).

Leptospirosis is another disease in focus of this research work. Leptospirosis is zoonotic disease caused by the pathogenic Leptospires of the genus Leptospira. It has a worldwide distribution but endemic mainly in humid subtropical and tropical countries. It is transmitted through contact of mucus membranes or (broken) skin with water (swimming or immersion), moist soil or vegetation contaminated with the urine of infected animals; occasional infection occurs through ingestion/inhalation of food/droplet aerosols of fluids contaminated by urine. The incubation usually lasts about 10 days (2 to 30 days). The usual presentation is an acute febrile illness with headache, myalgia (particularly calf muscle) and prostration. In the surveillance report of 2013 by the Department of Health (DOH) in the Philippines, a total of 1,174 leptospirosis cases have been reported nationwide from January 1, 2013 to September 17, 2013. This is $78.74 \%$ lower compared to the same period last year $(5,522)$. Most of the cases were from the following regions: National Capital Region or NCR (17.80\%), VI (17.22\%), III (15.16\%), Region 11 (11.41\%) and Region II (8.94\%). Ages of cases reported ranged from 2 to 83 years old (median $=30$ years old) and majority $(86.1 \%)$ of the cases were male. The 

Social Vulnerabilities and Risks

most affected (27.17\%) is the age group higher than 40 years old. Of all the cases reported, there were 86 reported deaths (CFR 7.33\%), (DOH, 2013).

On the other hand, dengue fever is transmitted by the bite of a mosquito infected with one of the four dengue virus serotypes. It is a febrile illness that affects infants, young children and adults with symptoms appearing 3-14 days after the infected bite. Dengue is not transmitted directly from person-to-person and symptoms range from mild fever, to incapacitating high fever, with severe headache, pain behind the eyes, muscle and joint pain, and rash. For the dengue fever cases, the $\mathrm{DOH}$ has reported a total of 117,658 cases from January 1 to September 7, 2013 nationwide. This is $5.25 \%$ lower compared to the same period last year's $(124,173)$ cases and most of the cases were coming from regions VI (14.82\%), IV-A(13.98\%), Region VII( 9.38\%), XII (7.98\%), III $(7.82 \%)$. Ages of cases ranged from less than 1 month old to 98 years old (median= 12.83 years) and majority of the cases were male (52.9\%). Most of the cases $(40.03 \%)$ belonged to the $1-10$ years age group. There were 433 reported deaths (CFR $0.37 \%$ ) from these reported cases. Though the figures of the surveillance report in 2013 were lower than the previous years, yet these recent statistics is still very alarming $(\mathrm{DOH}$, 2013).

In the case of diarrhoea, it is not part of the surveillance of diseases monitored by the Department of Health $(\mathrm{DOH})$ in the Philippines but is recorded as part of the top ten (10) leading causes of child mortality from year 2000 to 2010 along with dengue fever. Diarrhoea and other gastroenteritis of presumed infectious origin is usually in the top 5 leading causes of child mortality among 1 to 4 years old age bracket. Here below is the latest available data from $\mathrm{DOH}$ official website. 
Community-Based Flood Vulnerability Index for Urban Flooding: Understanding Social Vulnerabilities and Risks

Table 1-5: Ten (10) Leading Causes of Child Mortality Among 1-4 Years Old.

\begin{tabular}{|l|c|c|c|c|}
\hline \multirow{2}{*}{ Cause } & \multicolumn{4}{c|}{$\mathbf{1 - 4}$ Years } \\
\cline { 2 - 5 } & Male & Female & $\begin{array}{c}\text { Both } \\
\text { Sexes }\end{array}$ & Rate \\
\hline 1. Pneumonia & 1,073 & 978 & 2,051 & 223 \\
\hline $\begin{array}{l}\text { 2. Diarrhoeas and gastroenteritis of } \\
\text { presumed infectious origin }\end{array}$ & 482 & 334 & 816 & 9.3 \\
\hline 3. Congenital anomalies & 409 & 388 & 797 & 9.1 \\
\hline 4. Septicemia & 251 & 231 & 482 & 5.5 \\
\hline 5. Other diseases of the nervous system & 246 & 212 & 458 & 5.2 \\
\hline 6. Accidental drowning and submersion & 296 & 159 & 455 & 5.2 \\
\hline $\begin{array}{l}\text { 7. Dengue Fever and Dengue- } \\
\text { haemorrhagic fever }\end{array}$ & 195 & 223 & 418 & 4.7 \\
\hline 8. Chronic lower respiratory diseases & 213 & 202 & 415 & 4.7 \\
\hline 9. Meningitis & 179 & 154 & 333 & 3.8 \\
\hline 10. Leukemia & 148 & 91 & 239 & 2.7 \\
\hline
\end{tabular}

N.B: Rate per 100,000 population of corresponding age-group

In the top 10 leading causes of mortality among 1-4 years old in 2010 (Table 1-5) pneumonia tops the list. Diarrhoea and gastroenteritis of presumed infectious origin which are one of the microorganisms concern on this research ranked second on the list while dengue fever and dengue-hemorrhagic fever ranks $7^{\text {th }}$. However, leptospirosis infection is not among the top 10.

Table 1-6: Ten (10) Leading Causes of Child Mortality Among 5-9 Years Old.

\begin{tabular}{|l|c|c|c|c|}
\hline \multirow{2}{*}{ Cause } & \multicolumn{4}{c|}{ 5-9 Years } \\
\cline { 2 - 5 } & Male & Female & $\begin{array}{l}\text { Both } \\
\text { Sexes }\end{array}$ & Rate \\
\hline 1. Pneumonia & 334 & 282 & 616 & 5.9 \\
\hline 2. Dengue Fever \& Dengue-haemorrhagic fever & 211 & 328 & 539 & 5.2 \\
\hline 3. Accidental drowning and submersion & 299 & 159 & 458 & 4.4 \\
\hline 4. Other diseases of nervous system & 177 & 155 & 332 & 3.2 \\
\hline 5. Transport accidents & 198 & 107 & 305 & 2.9 \\
\hline 6. Congenital anomalies & 159 & 126 & 285 & 2.7 \\
\hline 7. Leukemia & 137 & 111 & 248 & 2.4 \\
\hline 8. Meningitis & 123 & 80 & 203 & 2.0 \\
\hline 9. Septicemia & 90 & 80 & 170 & 1.6 \\
\hline $\begin{array}{l}\text { 10. Diarrhoeas and gastroenteritis of presumed } \\
\text { origin }\end{array}$ & 87 & 77 & 164 & 1.6 \\
\hline
\end{tabular}

N.B: Rate per 100,000 population of corresponding age-group 

Social Vulnerabilities and Risks

For children 5-9 years old (Table 1-6), the leading causes of child mortality is still pneumonia topping the list. Dengue fever and dengue-hemorrhagic fever went up on the second rank while diarrhoea and gastroenteritis of presumed infectious origin went down to bottom 10. Leptospirosis infection is still not on the list.

Table 1-7: Ten (10) Leading Causes of Child Mortality Among 10-14 Years Old.

\begin{tabular}{|c|c|c|c|c|}
\hline \multirow[b]{2}{*}{ Cause } & \multicolumn{4}{|c|}{ 10-14 Years } \\
\hline & Male & Female & $\begin{array}{l}\text { Both } \\
\text { Sexes }\end{array}$ & Rate \\
\hline 1. Pneumonia & 233 & 195 & 428 & 4.4 \\
\hline 2. Accidental drowning and submersion & 212 & 140 & 352 & 3.6 \\
\hline 3. Other diseases of nervous system & 150 & 116 & 266 & 2.7 \\
\hline 4. Transport accidents & 172 & 77 & 249 & 2.5 \\
\hline 5. Congenital anomalies & 130 & 114 & 244 & 2.5 \\
\hline 6. Dengue Fever and Dengue-haemorrhagic fever & 111 & 102 & 213 & 2.2 \\
\hline 7. Chronic rheumatic heart disease & 86 & 106 & 192 & 2.0 \\
\hline 8. Leukemia & 94 & 82 & 176 & 1.8 \\
\hline 9. Septicemia & 92 & 78 & 170 & 1.7 \\
\hline 10. Nephritis nephrotic syndrome and neph & 95 & 67 & 162 & 1.7 \\
\hline
\end{tabular}

N.B: Rate per 100,000 population of corresponding age-group

For children 10-14 years old (Table 1-7), pneumonia still ranked first. Dengue fever and dengue-hemorrhagic fever is on the $6^{\text {th }}$ ranked. On the other hand, diarrhoea and gastroenteritis of presumed infectious origin is out of the list. Still, leptospirosis infection remained not on the top 10 .

Also found in the succeeding tables below (Tables 8, 9 and 10) are the top ten (10) leading causes of morbidity in Dumaguete City from 2012, 2011 and 2010 respectively. The top 10 leading causes of mortality were not included in this paper because the disease of concern were not in the top 10 list so the researcher opted not to show it here for it bears no significance.

Dengue Fever and Diarrhea/AGE (acute gastrointestinal enteritis) which are part of the target diseases in this study are on the top ten leading causes of morbidity in Dumaguete City in 2012. Dengue fever is in the top 4 and diarrhoea is on the top 5 respectively. Leptospirosis which is also part of the diseases concern in this study is not on the top 10. There were 827 cases of dengue fever in 2012 and 647 diarrhoeal cases. 
Community-Based Flood Vulnerability Index for Urban Flooding: Understanding Social Vulnerabilities and Risks

Table 1-8: Top 10 Leading Causes of Morbidity in Dumaguete City in 2012

\begin{tabular}{|l|r|r|}
\hline \multicolumn{1}{|c|}{ Cause } & Number & Rate/100, 000 Population \\
\hline 1. URTI & 11,315 & $8,275.31$ \\
\hline 2. Bronchitis/Bronchial Asthma & 1,323 & 967.59 \\
\hline 3. Pneumonia & 828 & 605.56 \\
\hline 4. Dengue Fever & 827 & 604.83 \\
\hline 5. Diarrhoea/AGE & 647 & 473.19 \\
\hline 6. Animal Bites & 633 & 462.95 \\
\hline 7. Wound All Types & 566 & 413.95 \\
\hline 8. Viral Infection & 528 & 386.16 \\
\hline 9. Hypertension & 509 & 372.26 \\
\hline 10. UTI & 391 & 285.96 \\
\hline
\end{tabular}

Dengue fever was not in the top 10 leading causes of morbidity in Dumaguete City in 2011 while diarrhea/AGE (acute gastrointestinal enteritis) was in the top 4 (Table 1-8). Leptospirosis was not also in the top 10 in 2011.

Table 1-9: Top 10 Leading Causes of Morbidity in Dumaguete City in 2011

\begin{tabular}{|l|r|r|}
\hline \multicolumn{1}{|c|}{ Cause } & Number & \multicolumn{1}{c|}{$\begin{array}{c}\text { Rate/100, 000 } \\
\text { Population }\end{array}$} \\
\hline 1. URTI & 13,281 & $9,951.07$ \\
\hline $\begin{array}{l}\text { 2. Bronchitis/Bronchial } \\
\text { Asthma }\end{array}$ & 2,589 & $1,939.86$ \\
\hline 3. Pneumonia & 1,902 & $1,425.11$ \\
\hline 4. Diarrhoea/AGE & 931 & 697.57 \\
\hline 5. Hypertension & 556 & 416.59 \\
\hline 6. Dental Carries & 483 & 361.9 \\
\hline 7. Wound All Types & 467 & 349.91 \\
\hline 8. Animal Bites & 381 & 285.47 \\
\hline 9. PTB & 311 & 233.02 \\
\hline 10. Tension Headache & 249 & 186.57 \\
\hline
\end{tabular}

The disease of concern such as diarrhea/AGE, and dengue fever were in the top 10 leading causes of morbidity in Dumaguete City in 2010. The former was on the top 4 while the latter was in top 6 respectively (Table 1-9). Leptospirosis was also not in the top 10 in 2010. 
Community-Based Flood Vulnerability Index for Urban Flooding: Understanding Social Vulnerabilities and Risks

Table 1-10: Top 10 Leading Causes of Morbidity in Dumaguete City in 2010

\begin{tabular}{|l|c|r|}
\hline \multicolumn{1}{|c|}{ Cause } & Number & $\begin{array}{c}\text { Rate/100, 000 } \\
\text { Population }\end{array}$ \\
\hline 1. URTI & 10,438 & 8012.59 \\
\hline 2. Bronchitis & 4,327 & 3321.56 \\
\hline 3. Pneumonia & 1,550 & 1189.84 \\
\hline 4.Diarrhoea/AGE & 1,312 & 1007.14 \\
\hline 5. Wounds & 748 & 574.19 \\
\hline 6. Dengue Fever & 490 & 376.14 \\
\hline 7. Hypertension & 466 & 357.72 \\
\hline 8. UTI & 457 & 350.81 \\
\hline 9. SVI & 417 & 320.1 \\
\hline 10. Animal Bites & 360 & 276.35 \\
\hline
\end{tabular}

It has been observed that the disease in focus, particularly diarrhoea and dengue fever were always on the top 10 when it comes to leading causes of morbidity in Dumaguete City and in the national surveillance data (Table 1-10). Though leptospirosis cases were not on the top 10 leading causes of morbidity but outbreaks in some areas of the country particularly during rainy season and flooding events are significantly high with over a 1000 cases nationwide. Thus, it is therefore important to give attention on these diseases.

\subsection{STATE OF THE ART AND NEEDED IMPROVEMENTS}

Several studies on disaster risk, flood vulnerability and resilience index have been conducted worldwide. Here is a brief review.

\subsubsection{The Bündnis Entwicklung Hilft (Alliance Development Works) and United Nations University Institute for Environment and Human Security (UNU-EHS)}

The Bündnis Entwicklung Hilft (Alliance Development Works), the UNU-EHS in Bonn, Germany has developed the WorldRiskIndex in 2011and calculated the risk values for 173 countries worldwide (United Nations University Institute for Environment and Human Security, 2011). The WorldRiskIndex in this report was measured on the basis of four components namely; exposure to natural hazards or a climatic stimulus, susceptibility, coping and adaptive capacities. According to this report, the Philippines ranked 3rd among those highest with a score of $24.32 \%$ on the disaster risk from all the 173 countries surveyed. However, this report did not include some of the important component which has theoretical and practical significance due to lack of relevant data. 

Social Vulnerabilities and Risks

These four sub-categories are, housing situation, social networks, disaster preparedness/early warning and adaptation strategies were not integrated into the overall calculation of the WorldRisklndex in 2011 which are deemed to be relevant and significant. Thus, this research study focuses on these items and among others so we would have a thorough understanding why the community people are vulnerable or resilient in the first place.

\subsubsection{The United Nation Development Programme (UNDP)}

In 2004, the United Nation Development Programme (UNDP) also published a Global Report on Reducing Disaster Risk: A Challenge for Development. Countries with low Gross Domestic Product (GDP) per capita, low local density of population and high physical exposure were associated with high levels of risk in floods (UNDP, 2004). Part of the recommendations from this report is to address the gaps in knowledge for disaster risk assessment. A clear understanding of the depth and extent of hazard, vulnerability and disaster loss are primary steps towards a concerted and coordinated global action in disaster risk reduction along with appropriate governance and risk indexing from sub-regional areas which in turned encourages the researcher to consider these components at the local level. It is very important and vital to address these gaps in knowledge for disaster risk and vulnerability assessment. Measuring the KAP of the respondents from preparedness to recovery, and as well as the KAP on the exposures of the microorganisms in focus would give us a clue how community people perceived in these kinds of phenomenon which are translated into their attitudes and practices before, during or after any catastrophic events such as typhoons and flooding.

\subsubsection{A Flood Vulnerability Index for Coastal Cities and Its Use in Assessing Climate Change Impacts}

A flood vulnerability index for coastal cities was developed by Balica, et al. in 2012 using the system's components namely, the hydro-geological component, socioeconomic and the politico-administrative components. It has been conducted to nine cities around the world (Balica, S.F., Wright, N.G., and van der Meulen, F., 2012). However, indicators in the socio-economic components such as the detailed description of the households in terms of their educational attainment, housing conditions, social networks, family income and property insurances were not included which are parts of the susceptibility and resilience category. Moreover, the knowledge, attitudes and practices of the households were also not taken into consideration which could also influence the vulnerability of those target population. In this same way, some indicators for the politico-administrative components such as good governance, sustainable community livelihood and among others should have been included. Thus, this research 
Community-Based Flood Vulnerability Index for Urban Flooding: Understanding Social Vulnerabilities and Risks

work focuses and gives attention to these factors and indicators in developing this community-based flood vulnerability index for urban flooding.

\subsubsection{The 2012 Philippine Disaster Report}

The 2012 Philippines Disaster Report presents information on disasters that occurred in the Philippines in 2012 and a review of the major disaster that occurred within the country for the past decade. According to this report, compared to the 2011 data, 2012 posed a $9 \%$ increase in the number of disaster events recorded (CDRC, 2012). Reviewing the figures of the extent of devastation of the different natural disasters that has occurred in the Philippines in recent years particularly that of flooding and typhoon events, the researcher has been taking considerations on how vulnerable or resilient the community people are. It is very important to conduct studies that would give us a comprehensive view why the same scenario of devastation and sometimes even worse than the previous one is repeating. Is our government serious about implementing those measures, do we have enough resources and equipment and training, are our communities responsive, have we done something with our infrastructures that would make it resilient, and why is recovery is too inefficient and too slow in most cases, these and many other similar concerns were addressed in this research work.

\subsection{Situation in the Philippines}

In May 27, 2010, former President Gloria Macapagal Arroyo signed into law the Disaster Risk Reduction and Management Act of 2010 or RA 10121, to amend the three-decade Presidential Decree 1566, the old Disaster Management Law of the Philippines. RA 10121 institutionalizes the Disaster Risk Reduction and Management system not only in the National Government but also to all local government units in the country. In 2011, the Dumaguete City Council passed Sangguniang Panglungsod (SP) Resolution No. 118, Ordinance No. 63 Series of 2011 which established the Local Disaster Risk Reduction and Management Office (LDRRMO) to strengthen the effectiveness of the various protective and emergency services in the City. The LDRRMO is the coordinator of all activities and actions related to disaster risk management and is also an operational unit responsible for functions and services not presently performed or not adequately performed by existing units, offices and organizations. In spite that the Philippines has a very good National and Local Disaster Risk Reduction and Management Council Structure yet there have been cases where emergency response and disaster recovery during and after a typhoon or flooding had experienced some delays due to some political issues or gaps among concerted actions from numerous 

Social Vulnerabilities and Risks

actors across multiple sectors. It is important to know why such gaps exists thus soliciting surveys from LGU's and NGO's is a way of connecting these gaps. Concerted actions and coordination among authorities at all levels (national, provincial, municipal and community) and among other partners are critical to ensure that the resources are mobilized accordingly. On the other hand, most assessments conducted by the Local Disaster Risk Reduction and Management Council (LDRRMC) were mainly focused on the damage of physical structures, height of flood, number of families affected and deaths. There were no thorough assessments in terms of how vulnerable and resilient the community people in terms of their perception and action towards flood preparedness, response, recovery and their response to adaptation strategies.

Most studies on vulnerability and resilience revolves around national data or on a per country description but fails to cover some of the important components from the local settings, for instance, survey on housing conditions which are not included in the computation in global assessment because of insufficient data, very time-consuming and cost-intensive but they should have been included in the susceptibility component because they are highly significant. Also, items like disaster preparedness and early warning, social network and adaptation strategies should also be taken into account because of their high significance in the component. Other items that influence the occurrence of disease outbreaks were also incorporated which are believed to be highly significant in the resilience and vulnerability index at the community level. Furthermore, the community people's knowledge, attitude, and practices (KAP) towards flood resilience and disease outbreaks were gauge to be able to have a thorough assessment.

Through this research work, the Flood Vulnerability Index of Dumaguete City will be established. Vulnerable communities will be identified and map. But what is even more important is for us to understand why the community people are vulnerable in the first place. This research will allow us to pinpoint the weak and strong points of the sociobehavioral and politico-administrative components particularly on the perception and behavior of the community people in their way of coping and adapting to the effects of global warming and its impact. The aim of this research work is to improve the limitation of the previous WorldDisasterlndex and other similar studies by developing new indicators and components for Flood Vulnerability Index that will be useful in the community level.

Urban flooding poses a serious challenge to development and the lives of the people. This natural phenomenon caused havoc in many aspects in the society particularly to human health, infrastructure and the economy of the country. Moreover, public health 
risk in urban pluvial flooding is usually overlooked and undermined and only very little attention is given. According to the World Risk Report released by the United Nations University Institute for Environment and Human Security, the Philippines is ranked third globally in terms of disaster risk as mentioned earlier on this research paper. Given this high-risk status of the Philippines to hazards in general, it is therefore important to conduct studies related to risk and vulnerability so issues on health and disaster risk will be addressed appropriately.

This research work will be conducted to assess the vulnerability of selected communities in Dumaguete City, Philippines in terms of flood resilience and their exposures to E.coli, leptospirosis and the dengue fever mosquito through questionnaire surveys from the households of the target community. The Knowledge, Attitudes, Practices or KAP of the respondents will be solicited. Survey questionnaires from the LGU's and NGO's will also be conducted to get the overall picture of the Flood Resilience and Health Program in the community. Finally, mapping of flood vulnerable communities of Dumaguete City will be generated, and a simple flood map of Dumaguete City will also be produced.

\subsubsection{Needed Improvements}

The aims of this research work are as follows:

1. To improve the limitation of the previous WorldDisasterlndex and other similar studies by developing new components and indicators for Flood Vulnerability Index (FVI) that will be useful in the community level, the nation and the general world as a whole.

2. To establish the relationship between Flood Vulnerability Index (FVI), susceptibility and resilience variables.

3. To produce flood vulnerability maps, health risk maps and profiles and flood map which can be used in the early warning system protocols.

Specifically this research work wants to know the overall Flood Vulnerability Index (FVI) of Dumaguete City, Negros Oriental and the individual FVI of each of the 12 communities. Through this work, the most and the least vulnerable communities in Dumaguete City in terms of the different components and indicators used in the FVI will be revealed. The level of governance in Dumaguete City in addressing natural disaster particularly on typhoons and flooding in terms of the benchmarks that were used will also be made known. The overall assessment on flood resilience and health program of the Local Government Units (LGU's) and Non-Governmental Organizations (NGO's) 

Social Vulnerabilities and Risks

has also been conducted. Lastly, this work allows us to understand why the community people are vulnerable in the first place.

\subsubsection{Significance for Developing of the Community-Based Vulnerability Index for Urban Flooding}

Flooding causes widespread devastation, economic damages and loss of human lives. It is a global phenomenon and due to climate change, this phenomenon will continue. It is very important that the community people are aware of its impacts but it is even more important that they are resilient to this phenomenon. Thus, it is important to know their level of awareness and vulnerability to the different risks and impacts of urban fluvial flooding.

In this regard, the findings of this research work will be considered significant. Specifically, to the community people, the local government units, the nongovernmental organizations and the stakeholders which are the main players and who can significantly benefit from the result of this work in various ways. By determining the vulnerability to urban fluvial flooding of selected communities in Dumaguete City, the researcher would be able to get the overall picture of the level of vulnerability and resilience in the community which in turn can provide an objective and scientific basis for risk management decisions, guide decision making, priority setting and resource allocation in health, environmental disaster management, and provide a rational basis for implementation and policy development.

It would also help establish correlations and relationships between the implementation and facilitation of the flood risk management and resilience program in the said community. Thus, it is vital to understand interplay of these factors, in doing so, areas with greater risks will be identified and map and appropriate risk management measures for the given community will be facilitated. The importance of measuring vulnerability and developing indicators is to reduce social vulnerability and build resilience and to help communities strengthen their resilience against climate change. 


\section{CHAPTER 2 \\ CONCEPTUALIZING FLOOD VULNERABILITY}

\section{SUMMARY}

This second chapter presents and discusses in details about the previous and existing approaches and frameworks for flood vulnerability studies. Describing and conceptualizing flood vulnerability in a more concrete way. This chapter also illustrates the interrelationships and complexity of the water resource system with an understanding point of view so that better decisions will be made and a holistic approach will be attained in maintaining sustainability. The proposed community-based flood vulnerability framework for urban flooding is introduced.

Disaster risk index developed by the United Nations Development Programme (UNDP) is presented in this chapter along with the world risk index report in 2012 by the United Nations University Institute for Environment and Human Security were made mentioned in this chapter. Moreover, a flood vulnerability index for coastal cities and its use in assessing climate change impacts is also presented as one of the basis of formulating this proposed community-based flood vulnerability index. To add further stronghold of this research work, it is back up with a few existing flood vulnerability index, risk, and vulnerability studies in the Philippines similar but totally of different focus, components and indicators.

Flood management and flood mitigation program of Dumaguete City through the information shared by city of Dumaguete and the Local Disaster Risk Reduction and Management Office and Staff is presented here in a more or less brief and concise manner. For example, the structural and non-structural measures; the LDRRMC structure; LDRRMO Organizational Structure; the identified emergency evacuation areas of Dumaguete City and its incident command system; the city's institutional working arrangement; and lastly the general monitoring and evaluation of framework is in detailed. 


\section{CHAPTER 2 \\ CONCEPTUALIZING FLOOD VULNERABILITY}

As described by the United Nations Office for Disaster Risk Reduction (UNISDR), vulnerability is the characteristics and circumstances of a community system or asset that make it susceptible to the damaging effects of a hazard. As there are many aspects of vulnerability, arising from various physical, social, economic, and environmental factors, this definition identifies vulnerability as a characteristic of the element of interest in this case, the community which is independent of its exposure. The concept tries to understand which of the factors is more relevant to community vulnerability (UNISDR, 2007).

There have been several attempts to define and capture the meaning of vulnerability over the last twenty years. The use of the term varies among disciplines and scientific research areas. For instance, the International Federation of Red Cross (IFRC) defines vulnerability as the diminished capacity of an individual or group to anticipate, cope with, resist and recover from the impact of a natural or man-made hazard. The concept is relative and dynamic (IFRC, 2014).

The Intergovernmental Panel on Climate Change (IPCC) in its Third Assessment Report in Climate Change 2001, described vulnerability as the function of the sensitivity of a system to changes in climate (the degree to which the system will respond to a given change in climate including beneficial and harmful effects). In its framework, a highly vulnerable system would be a system that is very sensitive to modest changes in climate, where the sensitivity includes the potential for substantial harmful effects, and for which the ability to adapt is severely constrained. Resilience is the flip side of vulnerability-a resilient system or population is not sensitive to climate variability and change and has the capacity to adapt (IPCC, 2001).

A Flood Vulnerability Index for Coastal Cities and Its Use in Assessing Climate Change Impacts considered vulnerability as the extent of harm which can be expected under certain conditions of exposure, susceptibility, and resilience. More specifically in the case of floods, a system is susceptible to floods due to exposure in conjunction with its capacity/incapacity to be resilient, to cope, recover or adapt to the extent. Some of the exposed populations are protected from flooding by various structural and non-structural measures that are part of the resilience strategy. On the other hand, some of them have none, or only weak, flood defenses and the exposed populations are more often subject 

Social Vulnerabilities and Risks

to flooding with the consequent disruption, economic loss and loss of life (Balica, S.F., Wright, N.G., and van der Meulen, F., 2012).

In this research, vulnerability is the result of the interplay of the vulnerability indicators in the exposure, susceptibility and resilience category which will be discussed in the succeeding pages.

\subsection{Vulnerability to Floods}

The definition of vulnerability mentioned above differs from definition to definition depending on the type of hazards exposed on a particular community or society. One of which gave a definition of vulnerability to a particular hazard like climate change. IPCC from its latest Fifth Assessment Report on Climate Change 2013 defines vulnerability as the propensity or predisposition to be adversely affected. Furthermore, vulnerability encompasses a variety of concepts and elements including sensitivity or susceptibility to harm and lack of capacity to cope and adapt (IPCC, 2014).

The World Bank has made a list of the five main threats arising from climate change namely, droughts, floods, storms, rising sea levels, and greater uncertainty in agriculture (World Bank, 2009). Four of the world's poorest nations top the list of the 12 countries at the higher risks. Bangladesh heads the list of countries most at risk of flooding. Increasing glacial melt from the Himalayan ranges as a result of rising global temperatures is set to swell the Ganges and Brahmaputra rivers and their hundreds of tributaries, flooding 30-70 percent of the country each year as the water makes its way to the Bay of Bengal in the south, where the coast is also vulnerable to flooding from rising sea levels. On the other hand, the Philippines, a middle-income country in Southeast Asia consisting of over 7,000 islands, leads the list of nations most in danger of facing frequent and more intense storms.

In the United Nations Convention on Climate Change, the paper Climate Change: Impacts, Vulnerabilities and Adaptation in Developing Countries released this report. In Asia, the principal impacts of climate change on health will be on epidemics of malaria, dengue, and other vector-borne diseases (Martens, 1999). The global burden of climate change-attributable diarrhoea and malnutrition are already the largest in the world in Southeast Asian countries including Bangladesh, Bhutan, India, Maldives, Myanmar and Nepal in 2000. Illness and death are expected to increase from diarrhoeal diseases due to drought and flooding, and are also expected from increased amounts of cholera bacteria in coastal waters (United Nations Framework Convention on Climate Climate, 2007). 


\subsection{The Water Resource System}

According to the Global Research on Water-Based Economies, management of water resource systems poses risks to the economic, social and environmental well-being of communities, regions, nations and ultimately the global world. It is of national and international interest to identify and evaluate economically viable, socially acceptable and environmentally conscious water management strategies to sustain this important region as well as other world water and agricultural resources (GRoWE, 2005).

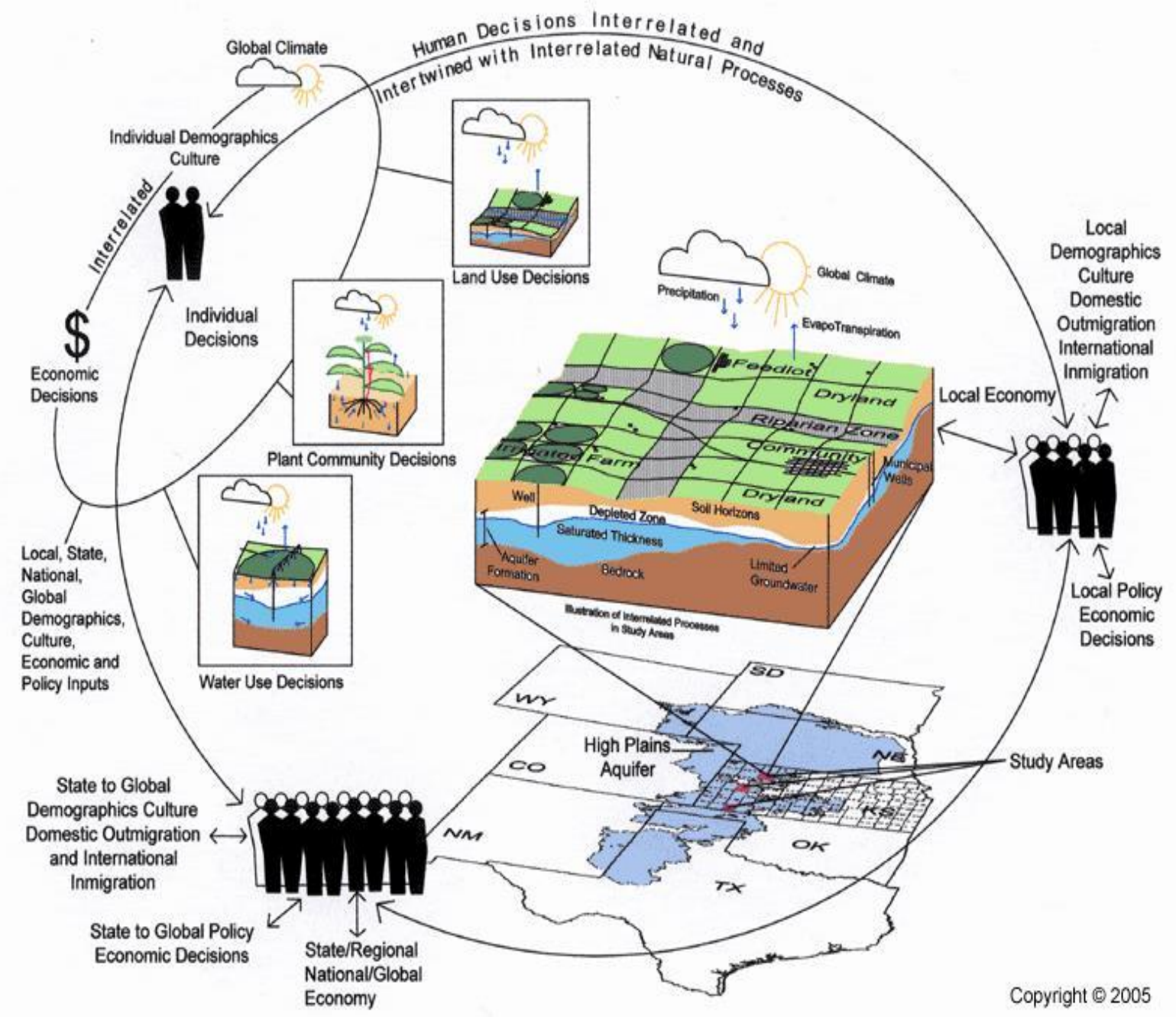

Figure 2-1: The Water Resource Systems (GRoWE, 2005)

Figure 2-1 illustrates the interrelationships, complexity and reach of management decisions related to water use and water related issues at the individual level, local, regional, national and ultimately to the global level. The interplay of the different players 

Social Vulnerabilities and Risks

in the society, from the individual decisions to international economic policy and decisions are crucial in maintaining the sustainability of the water resource system.

Understanding this interrelated and complexity in the water resource system is important so that better decisions will be made for managing the water resource system.
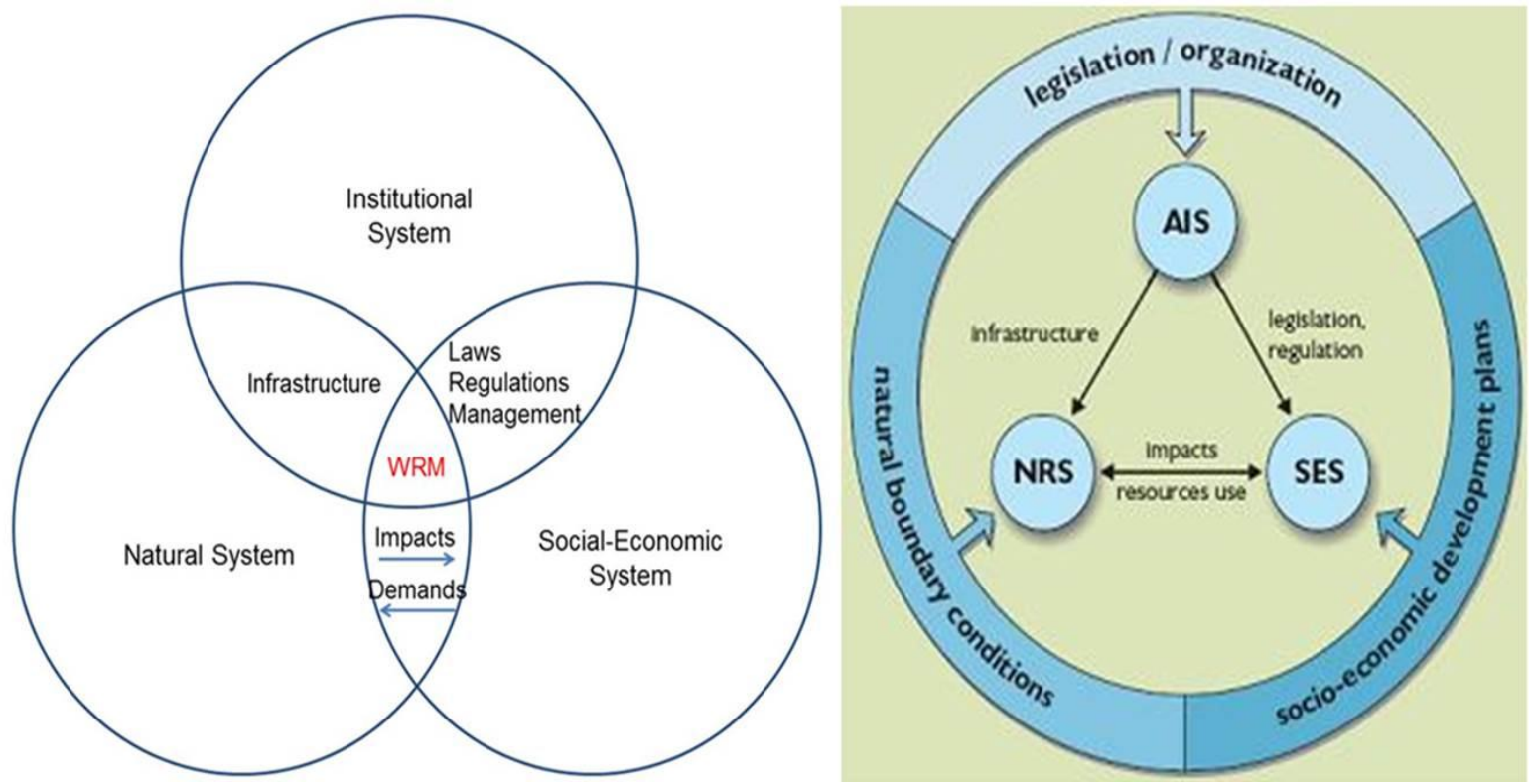

Figure 2-2: a and b Water Resource System's Sub-System and its Interactions (van Beek, 2005)

According to the Flood Vulnerability Index developed by the UNESCO-IHE, the system approach aims to identify the interactions of different actors or components within certain defined boundaries. This approach is considered holistic in understanding complex processes.

The three interdependent subsystems in the water resources system are identified (Van Beek, E. and Loucks, D.P., 2005). Figures 2-2 a and b illustrates their interaction, consisting of:

A. The natural river subsystem NRS, in which the physical, chemical and biological processes take place

B. The socio-economic subsystem SES, which includes the societal (human) activities related to the use of the natural river system

C. The administrative and institutional subsystem, AIS of administration, legislation and regulation, where the decision and planning and management processes take place. 

Social Vulnerabilities and Risks

Floods can be considered as a disruption in a normal functioning of a water resource system. There are three main systems that are affected by floods, with boundaries depending on the scale: the river basin system, the sub-catchment system and the urban system where the different players in the society are part of.

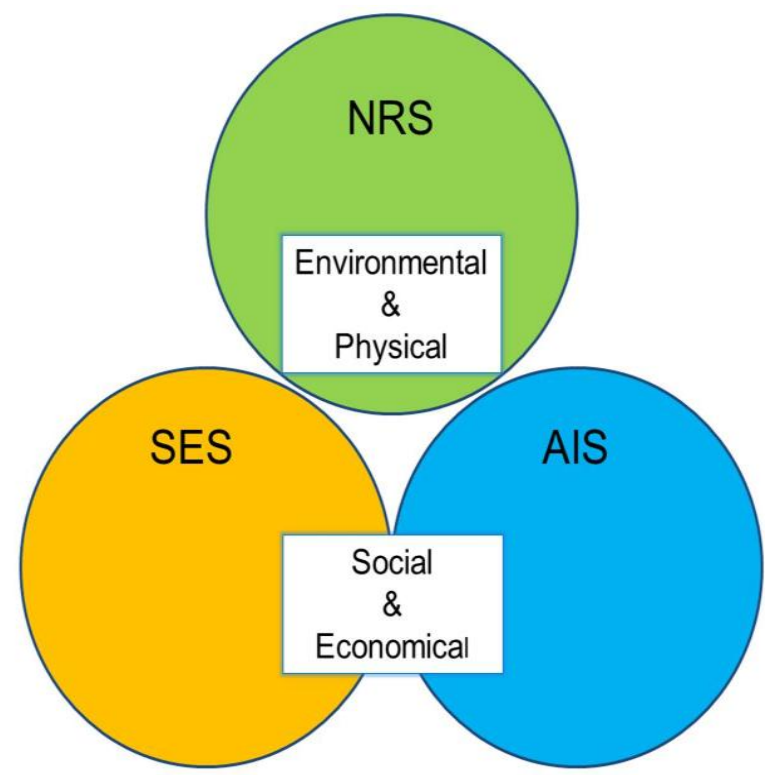

Figure 2-3: Link Between Subsystems and Components

Figure 2-3 illustrates the links between the subsystems and components. The components are assessed by different indicators to understand the vulnerability of the system to floods. The components are: social, economic, environmental and physical. Flooding distress these four components of the water resources system, each of them belong to one of the subsystems described before, and their interactions affect the possible short term and long term damages.

\subsection{Vulnerability Frameworks}

The conceptual framework (Figures 2.4 and 2.5) considered representative for the global environmental change community primarily due to its focus on the coupled human-environment systems (Turner, B.L. et al, 2003). The illustration of this framework is well described and explained by Ciurean et al. According to them, Turner's conceptual framework definition of vulnerability encompasses exposure, sensitivity and resilience (Ciurean, R.L. et al, 2013). Exposure contains a set of components (i.e. threatened elements: individuals, households, states, ecosystem, etc.) subjected to damage and characteristics of the threat (frequency, magnitude, duration). The sensitivity is determined by the human (social capital and endowments) and environmental (natural capital or biophysical endowments) conditions of the system 

Social Vulnerabilities and Risks

which influence its resilience. The last component is enhanced through adjustments and adaptation. A system's vulnerability to hazards consists of (i) linkages to the broader human and biophysical (environmental) conditions and processes operating on the coupled system in question; (ii) perturbations and stressors/stresses that emerge from this conditions and processes; and (iii) the coupled human - environment system of concern in which vulnerability resides, including exposure and responses (i.e. coping, impacts, adjustments, and adaptation). It is seen that changes in the resilience can affect the susceptibility of a system and if we are careless with our actions, it can alter the whole system in ways that make it difficult to recover.

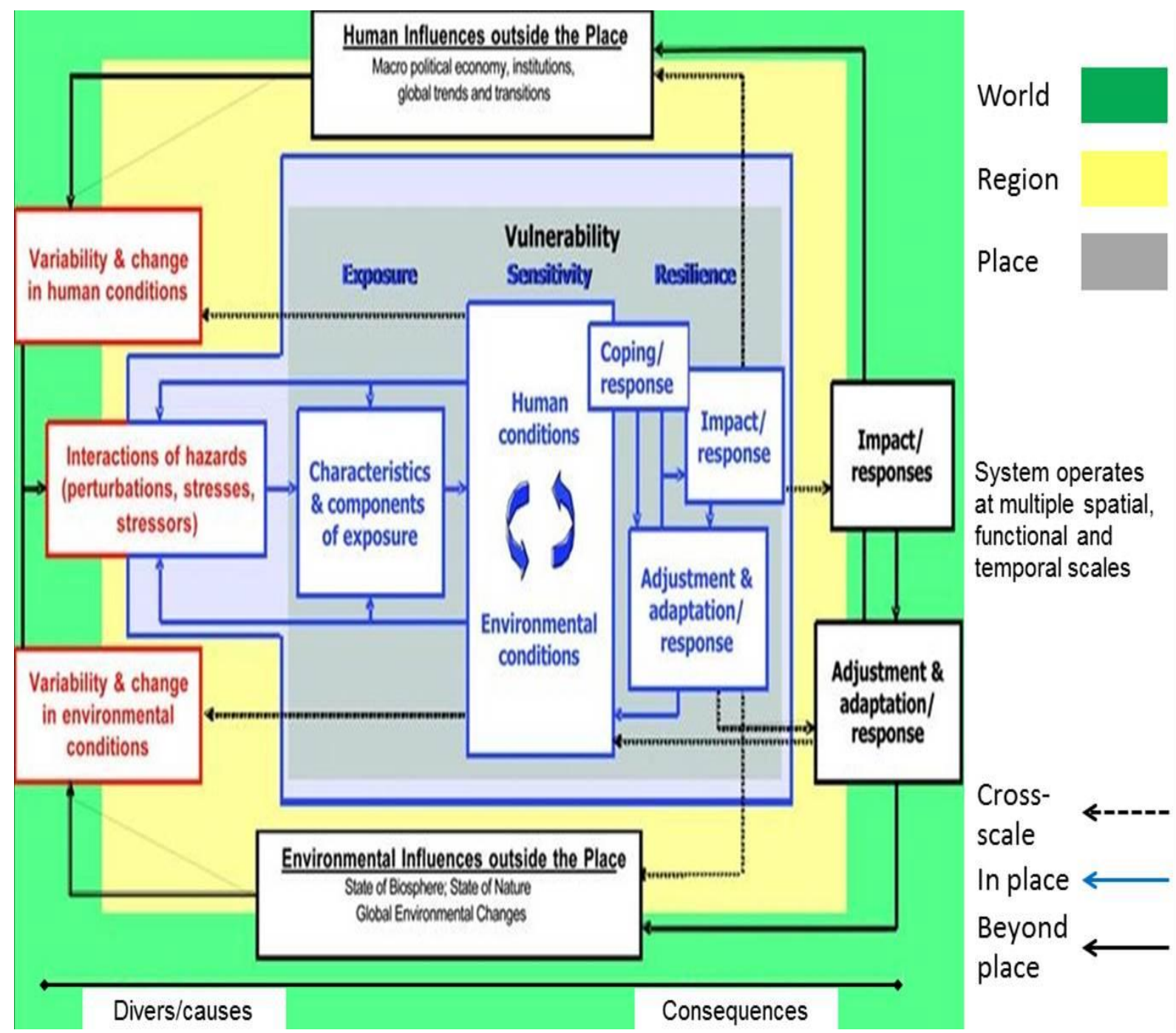

Figure 2-4: SUST Vulnerability Framework. Full Framework (Turner II et.al. 2003) 


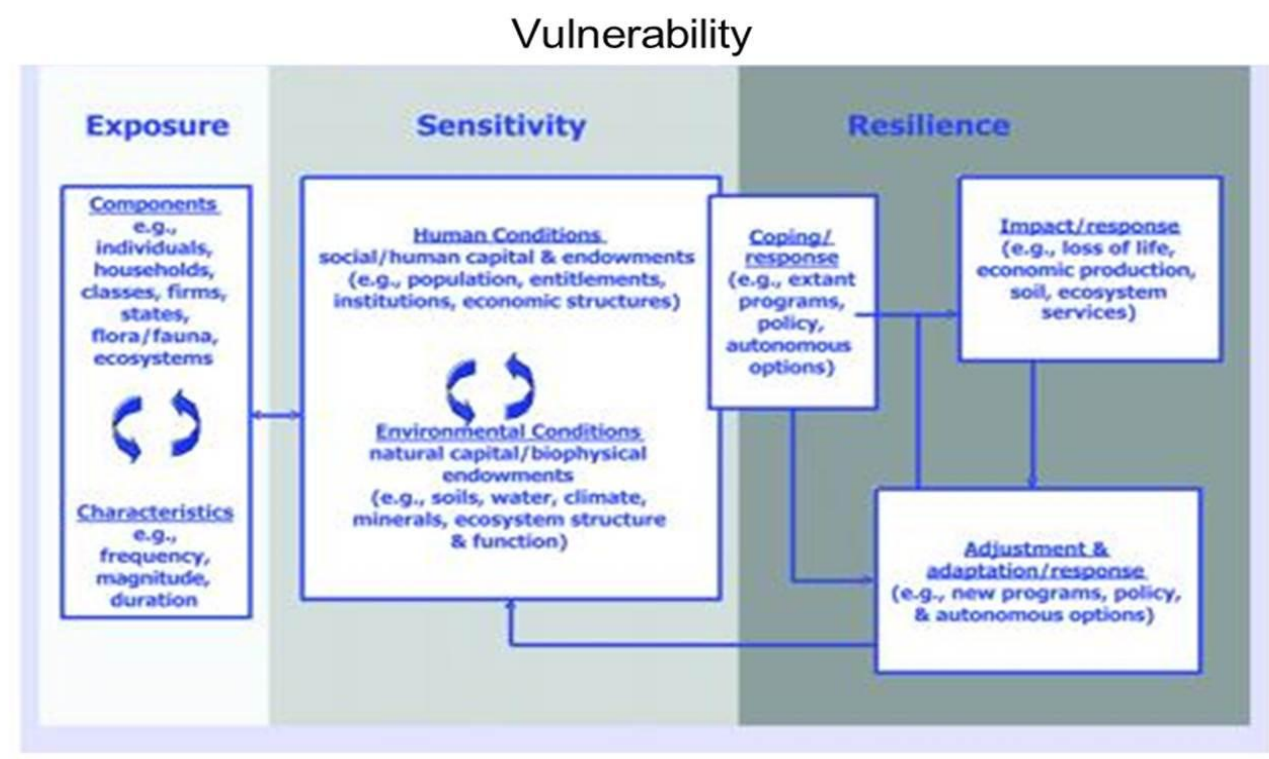

Figure 2-5: SUST Vulnerability Framework Detailed Framework (Turner II et al. 2003)

\section{Community-Based Flood Vulnerability Framework: Detailed Framework for Urban Flooding}

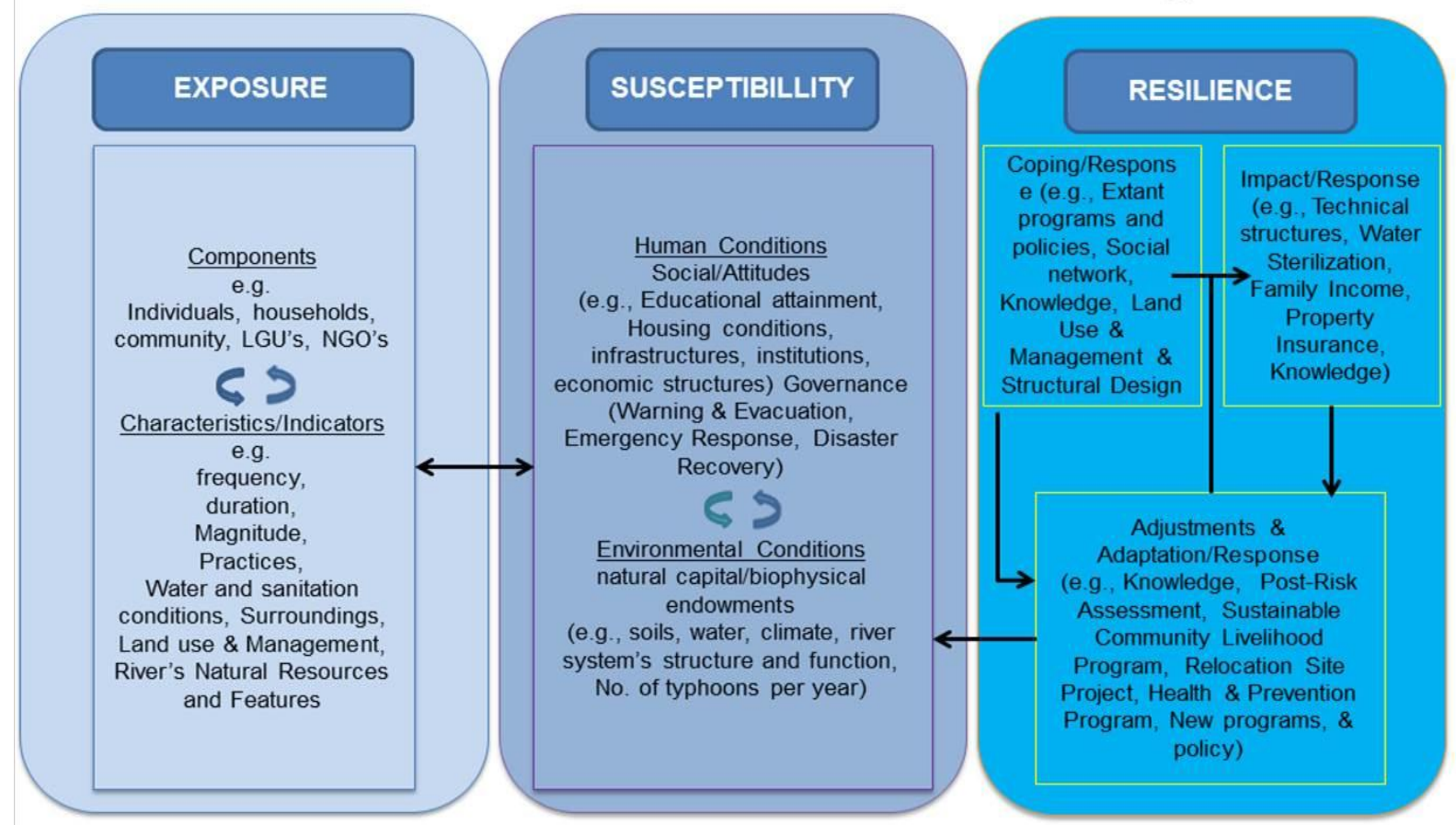

Figure 2-6: Based from SUST Vulnerability Framework (Turner II et al. 2003) 

Social Vulnerabilities and Risks

Figure 2.6 depicts the proposed version of "working framework" which is based from Turner's conceptual framework. The different components and indicators that were used in this study are shown in the category (exposure, sensitivity, and resilience) to which it appropriately belonged to.

\subsection{Global Risk and Vulnerability Indicators}

\subsubsection{Disaster Risk Index}

The United Nations Development Programme (UNDP) Bureau for Crisis Prevention and Recovery has developed the Disaster Risk Index on its global report on Reducing Disaster Risk: A Challenge for Development published in 2004. In this Disaster Risk Index (DRI), countries are indexed for each hazard type according to their degree of physical exposure, their degree of relative vulnerability and their degree of risk (UNDP, 2004).

The key steps involved in producing the DRI were:

A. Calculation of Physical Exposure

The DRI identified the areas exposed to each of the four hazards (earthquakes, tropical cyclones, floods and droughts) and the population living in these areas to arrive at a calculation of physical exposure for each country. This is the average number of people exposed to a hazard event in a given year. Physical exposure for each hazard was mapped in a Geophysical Information System (GIS). In the DRI, physical exposure is expressed both in absolute terms (the number of people exposed in a country) and in relative terms (the number exposed per million people).

B. Calculation of Relative Vulnerability

The DRI has used the number of people actually killed by each hazard type in each country as a proxy for manifest risk. The DRI, therefore, was able to calculate the relative vulnerability of a country to a given hazard by dividing the number of people killed by the number exposed. When more people are killed with respect to the number exposed, the relative vulnerability to the hazard in question is higher. 
C. Calculation of Vulnerability Indicators

The DRI then examined the manifest risk for each hazard type against a bundle of social, economic, and environmental indicators through statistical analysis using multiple logarithmic regression model. A total of 26 variables selected through expert opinion were available as global datasets and analyzed for each hazard type. These enabled the selection of those vulnerability indicators that were most associated with risk for each hazard type.

The formula and method for estimating risk and vulnerability in the development of DRI by UNDP is represented in the following simplified equation:

$$
\text { Risk }=\text { Hazard } x \text { Population } x \text { Vulnerability }
$$

Where:

Risk $=$ is the risk (number of killed people)

Hazard = is the hazard, which depends on the frequency and strength of a given hazard

Population $=$ is the population living in a given exposed area

Vulnerability $=$ is the vulnerability and depends on the socio-political-economical context of this population

Hazard multiplied by the population was used to calculate physical exposure.

The formula for risk evaluation using physical exposure is shown below:

$$
\text { Risk }=\text { Physical Exposure } x \text { Vulnerability }
$$

Where:

Physical Exposure $=$ is the physical exposure, i.e. the frequency and severity multiplied by exposed population

The risk indicators can be expressed in different ways (e.g. by the number of people killed, percentage killed or the percentage killed as compared to the exposed population).

Part of these indicators was considered in my study particularly on literacy rate and people with access to improve water supply as illustrated in Table 3.1.

The DRI has its limitations.

A. The DRI represents the risks of deaths because reliable data on other aspects of disaster risks (people affected, economic impacts) is not available in global level 
disaster databases. Thus, the DRI only represents risks to loss of life and cannot be inferred to represent other physical, social, and economic aspects of risk.

B. The DRI does not represent risk associated with small-scale and everyday disasters. DRI utilizes publicly available global data on disaster impact available for large and medium-scale disaster events, defined as those involving more than 10 deaths, 100 affected and/or a call for international assistance.

C. The DRI only represents the primary hazard events associated with earthquakes, tropical cyclones and floods. Local impacts were not considered in the DRI such as landslides, debris flow, sea surges and flooding brought about by tropical cyclones.

D. The DRI represents disaster risk in the period of 1980-2000 because it was considered that access to information before that period was less reliable. This, however, weights the work in favour of countries that suffered catastrophic disaster events with large loss of life in the two decades under analysis and against countries that suffered such events in the 1970's, for instance, but not since then.

E. The DRI test vulnerability indicators are from available global datasets. This implies that there may be other variables that potentially might help build a better correlation with risk such as the availability of direct indicators of national vulnerability. Small difference in the vulnerability indicator figures can mask major changes in disaster risk.

F. The DRI does not include indicators on disaster risk management and reduction which can be used as an initial level analysis of the comparative effectiveness of competing risk reduction strategies (including a do-nothing option).

After examining these limitations of this DRI, the researcher has considered those direct indicators and data that are with local significance and availability.

\subsubsection{World Risk Index}

The WorldRiskReport 2012 was developed jointly by scientists and development experts. The calculation of the Index, which the United Nations University Institute for Environment and Human Security, Bonn (UNU-EHS), has been commissioned to perform by the Alliance Development Works, was carried out via the four components: (United Nations University Institute for Environment and Human Security, 2011). 
A. Exposure towards natural hazards such as earthquakes, cyclones, flooding, drought and sea level rise.

B. Susceptibility depending on infrastructure, nutrition, housing situation and economic framework conditions.

C. Coping capacities depending on governance, disaster preparedness and early warning, medical services and social and material coverage.

D. Adaptive capacities relating to forthcoming natural events, to climate change and to other challenges.

The term exposure refers to entities (population, built-up area, infrastructure component, environmental areas) being exposed to the effects of one or more natural hazards (earthquakes, cyclones, droughts and floods). In the WorldRisklndex, exposure relates to the annual average number of individuals who are potentially exposed to hazard events. In this regard, the frequency of hazards is also taken into account. Additionally, the number of people who are considered who would potentially be affected by the sea level rising by one meter. To calculate exposure to earthquakes, cyclones, floods and droughts, the Physical Exposure data of the PREVIEW-Global Risk Data Platform (http://preview.grid.unep.ch/) of the United Nations Environmental Program (UNEP) has been used. These include the number of people per approx. 20 square kilometers who are exposed on average to the above-mentioned natural hazards per country and per year (UNEP, 2014).

Susceptibility generally refers to the likelihood of harm, loss and disruption in an extreme event triggered by a natural hazard. Thus susceptibility describes structural characteristics and framework conditions of a society. The following five sub-categories which outline the living situation and living conditions in a country, have been chosen to represent susceptibility: "public infrastructure", "housing conditions", "nutrition", "poverty and dependencies", "economic capacity and income distribution". Housing conditions are an important factor in defining susceptibility. However, they have so far not been included in Index calculations owing to a lack of global data. While data and methods do exist to assess housing conditions, such surveys have so far only been carried out for a few cities worldwide owing to the high time and cost effort involved so that presently, no sufficient information is available for this.

Coping and coping capacities comprise various abilities of societies and exposed elements (for example critical infrastructure such as nuclear power stations) to minimize negative impacts of natural hazards and climate change through direct action and the 

Social Vulnerabilities and Risks

resources available. Coping capacities encompass measures and abilities that are immediately available to reduce harm and damages in the occurrence of an event. The five sub-categories of coping capacities ("government and authorities", "disaster preparedness and early warning", "medical services", "social networks", "material coverage") and the indicators used together with their weighting factors are included. Due to their high importance, the sub-categories "disaster preparedness and early warning" and "social networks" are included in the coping capacities component. However, no global data referring to them is available. Hence it has so far not been possible to establish them in the Index. To calculate the WorldRisklndex, the opposite value, i.e. the lack of coping capacities, has been used, which results from the value 1 minus the coping capacities.

In contrast to coping, adaptation is understood as a long-term process that also includes structural changes (Birkmann, 2010). In addition, adaptation encompasses measures and strategies dealing with and attempting to address the negative impacts of natural hazards and climate change in the future. Five sub-categories have been chosen for calculation that described capacities for a long-term adaptation and change within a society: "education and research", "gender equity", "environmental status/ecosystem protection", "adaptation strategies" and "investment". Owing to insufficient global data, the five sub-categories and the eleven selected indicators as well as their corresponding weightings are selected except for the sub-category of adaptation strategies could not be integrated into the calculations either. In analogy to the coping capacities, the lack of adaptive capacities is included in the WorldRisklndex.

The WorldRisklndex is a tool to assess the disaster risk that a society or country is exposed to by external and internal factors. This index identifies global disaster hotspots. This report has calculated the individual risk values of the 173 countries worldwide. The Index focuses attention on the people, countries and regions, precisely because the emergence of disasters is crucially determined by domestic social factors. Thus, the WorldRiskIndex is based on the core understanding that a society's disaster risk is influenced by its structure, processes and framework conditions, which in turn may be affected by natural events and the effects of climate change. The concept of the Index stresses that not only the magnitude of frequency of a natural event but indeed also the social, economic and ecological factors characterizing a country essentially determine whether a natural hazard can turn into a disaster.

The formula for computing the World Disaster Risk Index is shown below and is based on twenty eight indicators: 
Where:

$$
\text { WorldRisklndex }=\text { Exposure } \times \text { Vulnerability }
$$

WorldRisklndex $=$ is the product of exposure and vulnerability

Exposure $=$ is the population or entities exposed to the different natural hazards (e.g. earthquakes, storms, droughts, sea level rise)

Vulnerability $=$ is the result of the combination of the lack of coping and adaptive capacities which comprises the susceptibility components.

For better comprehension, the individual indices have been transformed into percentage values and classified with the aid of the quantile method integrated into the ArcGIS10 software packet. The five classes calculated contain the same number of cases and are translated into a qualitative classification of "very high - high - medium low - very low". The WorldRiskIndex has also its limitations. Owing to insufficient global data, this report have not included the following indicators such as housing conditions, disaster preparedness and early warning, social networks, and adaptation strategies in the calculations in the WorldRisklndex in spite that it has theoretical and practical significance. Thus, this research study focuses on these items and among others so we would have a thorough understanding why the community people are vulnerable or resilient in the first place.

\subsubsection{A Flood Vulnerability Index for Coastal Cities and Its Use in Assessing Climate Change Impacts}

This Flood Vulnerability Index for Coastal Cities was developed by (Balica, S.F., Wright, N.G., and van der Meulen, F., 2012) considering the system approach identified previously by (Van Beek, E. and Loucks, D.P., 2005). Balica et al. uses the hydrogeological, socio-economic, and politico-administrative components. Nineteen (19) appropriate indicators out of the thirty (30) indicators from the World Bank data set, 2001, (Gornitz, 1990), (McLaughlin, 2010) and (Cutter, 2003) were chosen and administered to nine cities around the world.

The CCFVI of each coastal component in this study was computed based on the general Flood Vulnerability Index formula:

$$
F V I=\frac{E \times V}{R}
$$

Where:

$\mathrm{FVI}=$ is the Flood Vulnerability Index

$\mathrm{E}=$ Exposure

$\mathrm{V}=$ Vulnerability

$\mathrm{R}=$ Resilience 
The general formula for $\mathrm{FVI}$ is computed by categorising the indicators to the factors to which they belong (exposure (E), susceptibility (S) and resilience (R)) (Cendrero, 1997). The indicators of exposure and susceptibility are multiplied and then divided by the resilience indicators, because indicators representing exposure and susceptibility increase the flood vulnerability and are therefore placed in the numerator. The resilience indicators decrease flood vulnerability and are thus part of the denominator.

\subsubsection{Existing Flood Vulnerability Index, Risk and Vulnerability Studies in the Philippines}

As mentioned by Balica et al. 2012 in their paper, an existing Flood Vulnerability Index (FVI) by Connor \& Hiroki in 2005 which presented a methodology to calculate a FVI for river basins, using eleven indicators divided in four components (Climate (C), Hydrogeological $(\mathrm{H})$, Socio-Economic (S), and the Counter measures (M) component), (Connor, 2005). The methodology was tested on the river basin in Japan were there's accessibility to enough information. The index uses two sub-indices for its computation; the human index which corresponds to the social effects of floods; and the material effects which cover the economic effects of floods. The weights of the indicators were presented with the following equation:

$$
\mathrm{FVI}=\mathrm{C}+\mathrm{H}+\mathrm{S}-\mathrm{M}
$$

Where:

$\mathrm{FVI}=$ is the Flood Vulnerability Index

$\mathrm{C}=$ is the Climate component

$\mathrm{H}=$ is the Hydro-geological component

$\mathrm{S}=$ is the Socio-economic components

$\mathrm{M}=$ is the Counter measure component

The purpose of the FVI is to serve as a tool for assessing flood risk due to climate change in relation to underlying socio-economic conditions and management policies. This methodology was also administered in 18 river basins in the Philippines where some indicators were added or changed because of the lack of information.

A number of vulnerability and risk assessments have been conducted in the Philippines over these past few years. For instance, the Manila Observatory released the vulnerability and risk maps which give a national overview of risk and vulnerability susceptibility aggregated at the provincial level. The aim of the project (Mapping Philippine Vulnerability to Environmental Disasters) was to identify areas in the country 

Social Vulnerabilities and Risks

that are of high vulnerability and risk to environmental disasters. Hazards and disasters are mapped and analyzed using Geographic Information Systems (GIS), environmental modeling tools and spatial databases. The categories used in identifying vulnerability and risks in this study are climate/weather-related, geophysical, ecological and anthropogenic (Manila Observatory, 2005). However, national-scale flooding or the likelihood to flooding has not been addressed in this study.

A study on Measuring Social Vulnerability to Build Resilience to Environmental Hazards in the Philippines was published in 2012. In this study, the author measured social vulnerability by using social vulnerability index (SoVI) from census of population and housing which was based from the works of Cutter et al, in 2003b. As census data can be acquired at the detail of the individual in the Philippines, it is possible then to aggregate this information at the barangay levels. In his study, the SoVI indicators are a composite of variables from census data that described the inherent vulnerability of a population, for instance age (children or elderly), gender, ethnicity, employment and housing characteristics. This census-based SoVI was incorporated in the methods of mapping risk assessments. However, this study only includes those categories mentioned above (Ignacio, J.A.F, and Henry, S., 2013). The knowledge, attitude and practices among community people towards resilience have not been included in this study which could also give an indication of how these communities will be affected.

As pointed out by Ignacio in his paper, another related study was done by Fano, J., 2010, who combined natural and social factors in establishing a Philippine flood risk index at the provincial level by using fifteen (15) indicators (Fano, J. , 2010). His work was largely based on the work of (Kannami, Y., 2008) who developed a global countrybased flood risk index. In the study conducted by Fano, the 15 indicators that are needed generate for the five (5) indexes namely; hazard, exposure, basic vulnerability, capacity (hard countermeasures), and capacity (soft countermeasures) are readily available at the provincial level but down to the municipal and barangay level (the smallest basic unit of governance in the Philippines) is next to impossible because those data do not exist. Thus, a flood risk index that is at the barangay (community) level which are space-specific is highly limited. Again, in this study the social indicators are very limited and few. A thorough survey or information which has practical significance and bearing in flood risk indexes was not achieved. The social indicators in this study only includes, annual poverty threshold index, human development index, literacy rate, education indicator and access to information indicator which are all at the provincial level and not by per household information. 

Social Vulnerabilities and Risks

Another study was conducted by Acosta-Michlik in 2005 where she developed a static vulnerability assessment to global environmental change among farmers in the Philippines. This study uses socio-economic and biophysical indicators. Eighteen (18) attributes or indicators were used in this study. The vulnerabilities of which are captured by the differences in their social, economic, institutional and environmental structure at a given point in time. The exposure units are usually the geographical areas. The methods follow three approaches-indicator based, profile-based and agent-based. Under this approach, composite vulnerability indices are derived from aggregating socio-economic and ecological indicators using methods of indiscriminate aggregation, fuzzy logic, and weighted indicators which are useful for identifying vulnerable countries, regions or communities (Acosta-Michlik, L. and Espaldon, V., 2005).

The different studies mentioned above has become the guiding pattern of this research study but using different indicators and components which are community-based and is appropriate for Philippine context. Vulnerability study is not a new science. Different vulnerability indicators in particular have been used in several studies such as that of risk and vulnerability assessment studies in many different fields. Understanding and using the appropriate indicator for a particular study can complement and draw out the correct functioning of a system or group and why they are vulnerable in the first place.

\subsection{The Hyogo Framework for Action (HFA) (2005-2015) of the United Nations}

The HFA is a 10-year plan to make the world safer from natural disasters. It was endorsed by the UN General Assembly in the Resolution A/RES/60/195 following the World Disaster Reduction Conference in Kobe, Hyogo, Japan in 2005. According to UNISDR, the Hyogo Framework for Action (HFA) is the first plan to explain, describe and detail the work that is required from all different sectors and actors to reduce disaster losses. It was developed and agreed on with the many partners needed to reduce disaster risk - governments, international agencies, disaster experts and many others - bringing them into a common system of coordination. The HFA outlines five priorities for action, and offers guiding principles and practical means for achieving disaster resilience. Its goal is to substantially reduce disaster losses by 2015 by building the resilience of nations and communities to disasters. This means reducing loss of lives and social, economic, and environmental assets when hazards strike (UNSDR, 2005).

Its outcome can be achieve by its strategic goals namely; the integration of disaster risk reduction into sustainable development policies and planning; development and 

Social Vulnerabilities and Risks

strengthening of institutions, mechanisms and capacities to build resilience to hazards; and the systematic incorporation of risk reduction approaches into the implementation of emergency preparedness, response and recovery programmes. To be able to achieve these strategies goals, priorities for action must be carried over.

The Hyogo Framework ensures that disaster risk reduction (DRR) is a national and a local priority with a strong institutional basis for implementation; identify, assess and monitor disaster risks and enhance early warning; use knowledge, innovation and education to build a culture of safety and resilience at all levels; reduce the underlying risk factors; and strengthen disaster preparedness for effective response at all levels. Cross-cutting issues must also be addressed such as that of multi-hazard approach, gender perspective and cultural diversity, community and volunteer participation, and capacity building and technology transfer.

In order to achieve the goals and act upon the priorities identified in this Framework, the following tasks (see the details from the given reference from the previous page) have been identified to ensure implementation and follow-up by States, regional and international organizations in collaboration with civil society and other stakeholders. The ISDR partners, in particular the Inter-agency Task Force on Disaster Reduction and secretariat, are requested to assist in implementing this Framework for Action.

\subsection{Flood Management and Flood Mitigation}

\subsubsection{Structural and Non-Structural Measures}

As described by the United Nations Office for Disaster Risk Reduction (UNISDR), flood risk management is about maximizing both social and economic resilience against flooding (UNISDR, 2007). This can be done by protecting and working with the environment in a way which is fair and affordable both at the present time and in the future. As part of risk management, assessments and analysis, and implementation of strategies and specific actions to control and reduce risks are performed. This is a systemic approach and practice of managing uncertainty in lessening the adverse impact of floods and other related disasters to minimize harm and loss.

Resilience to flooding can be increased through a variety of measures, including structural (flood defense such as dams, barrages, levees, dikes, and other forms of channeling, etc. that reduce the impacts of floods to the population and infrastructure to flood prone areas), non-structural (flood warning, floodplain storage, flood event management) and, most commonly, an optimum combination of the two. 

Social Vulnerabilities and Risks

Non-structural measures, such as preparedness, response, legislature, financing, environmental impact assessment, reconstruction and rehabilitation planning, and their component techniques, contribute directly towards reducing losses of life and damage to property. Other mitigating actions include reducing physical vulnerability, reducing vulnerability of the economy, and strengthening the social structure of the community. These actions can be undertaken at individual, community, and state levels. Nongovernmental organizations, voluntary, and socio-cultural organizations may also play an important role in this respect (Andjekovic, I., 2001).

Dumaguete City has no particular flood management and flood mitigation program but it is incorporated in the city's disaster risk reduction management plan. All data, figures and tables used on this concept are borrowed and quoted from the unpublished 5-Year Local Disaster Risk Reduction and Management Plan (LDRRMP) which was developed by the City Government of Dumaguete City, Negros Oriental and its constituents through the Dumaguete City Local Disaster Risk Reduction and Management Office (LDRRMO) with technical assistance provided by Deutsche Gesellschaft fur Internationale Zusammenarbeit (GIZ) Gmbt and funding support of DIPECHO $8^{\text {th }}$ Action Call of the European Commission, the basis for founding the City Disaster Risk Reduction Management Plan (CDRRMP) was when former President Gloria Macapagal Arroyo signed into law the Disaster Risk Reduction and Management Act of 2010 or Republic Act (RA) 10121 in May 27, 2010 to amend the three-decade Presidential Decree 1566, the old Disaster Management Law of the Philippines (Dumaguete City Local Disaster Risk Reduction and Management Office (LDRRMO), 2013). RA 10121 institutionalizes the Disaster Risk Reduction and Management system not only in the National Government but also to all local government units in the country. One of the important features of this new law is the comprehensive utilization of the $5 \%$ Calamity Fund which is now the Disaster Risk Reduction and Management Fund (DRRMF). Under the old law the whole 5\% Calamity Fund could only be utilized when there was a declaration of a state of calamity. Now under Section 21 of RA 10121, 70\% of the LDRRM Fund can be used for pre-disaster activities thereby giving LGU's a more proactive approach in disaster risk reduction (NDRRMC-DBM-DILG Joint Memorandum Circular No. 2013-1, dated March 25, 2013). RA 10121 requires the establishment of a Local Disaster Risk Reduction and Management Office (LDRRMO) in every Province, City and Municipality. In order for the LGU's to be efficient and effective in the utilization of the LDRRM Fund, the law now also requires them to formulate a comprehensive DRRM Plan which it shall implement together with local partners and stakeholders as basis for the disbursement of the fund (Par. 1 of Sec. 21 of RA 10121). Hence, this CDRRM Plan was formulated. 

Social Vulnerabilities and Risks

Section 11 of RA 10121 states that, the existing City Disaster Coordinating Council (CDCC) shall henceforth be known as the City Disaster Risk Reduction and Management Council (CDRRMC). The Barangay Disaster Coordinating Council (BDCC) shall cease to exist and its power and functions shall henceforth be assumed by the existing Barangay Development Council.

In 2011, the Dumaguete City Council passed SP Resolution No. 118, Ordinance No. 63 Series of 2011 which established the Local Disaster Risk Reduction and Management Office (LDRRMO) to strengthen the effectiveness of the various protective and emergency services in the City. The LDRRMO is the coordinator of all activities and actions related to disaster risk management and is also an operational unit responsible for functions and services not presently performed or not adequately performed by existing units, offices and organizations. To date this ordinance is waiting for its approval at the Provincial Board of Negros Oriental pending clarification from DBM on the question of funding source and from the Civil Service Commission on filling up the positions of the LDRRMO as mandated by RA 10121.

The structural composition (Figure 2.7) of the Dumaguete City Disaster Risk Reduction and Management Council shall be headed by the City Mayor. Members of LDRRMC are divided into four committees namely; 1) Disaster Preparedness Committee, 2) Disaster Response Committee, 3) Disaster Mitigation and Prevention Committee and 4) Rehabilitation and Recovery Committee. Just like the structure of NDRRMC, the specific membership of every committee were identified not as individual members but rather per LGU department to ensure the continuity of the programs being identified in this 5-year LDRRM Plan. According to the LDRRMC it is very strategic to identify the committee members as per LGU department compared to appointing individuals, because people in the LGU departments will come and go but the department will remain even if a new set of political leaders will be elected every elections. Table 2.1 highlights the members of the LDRRMC per committee. 
Community-Based Flood Vulnerability Index for Urban Flooding: Understanding Social Vulnerabilities and Risks

\section{Dumaguete City Local Disaster Risk Reduction and Management Council (LDRRMC) STRUCTURE}

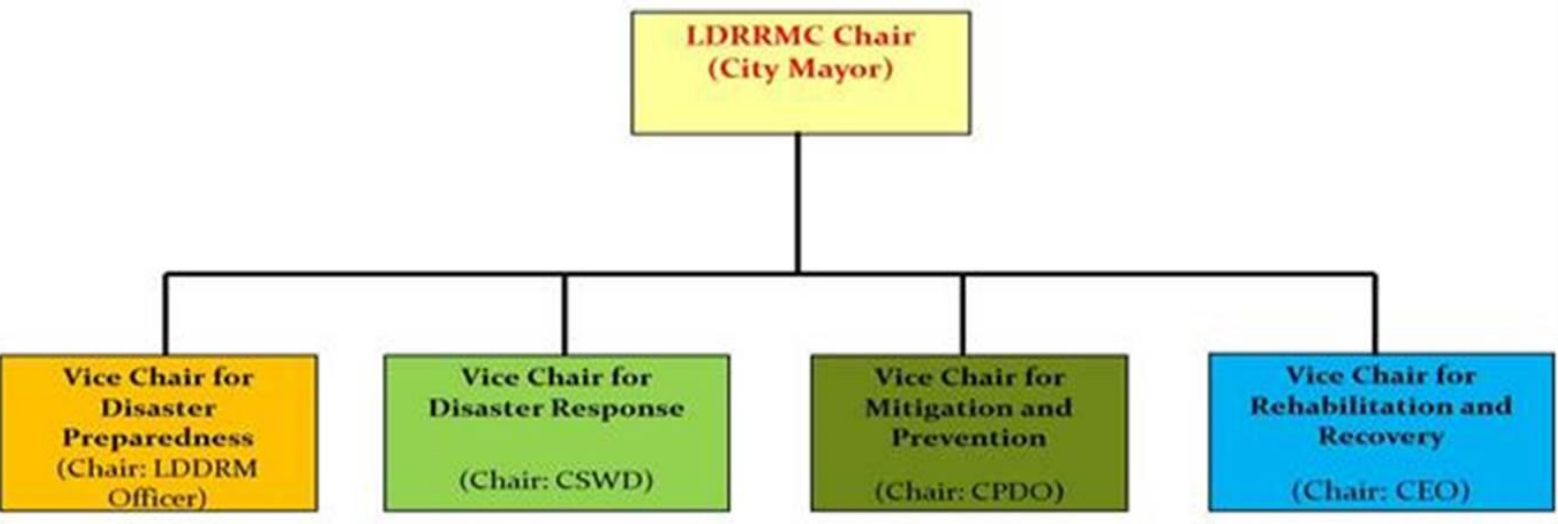

Figure 2-7: Local Disaster Risk Reduction and Management Council (LDRRMC) Structure 
Community-Based Flood Vulnerability Index for Urban Flooding: Understanding Social Vulnerabilities and Risks

Table 2-1: List of LDRRMC Members

\begin{tabular}{|c|c|c|}
\hline LDRRMC Committees & & DARTMENT AND INSTITUTION MEMBERS \\
\hline \multirow{8}{*}{$\begin{array}{l}\text { 1. Disaster Preparedness } \\
\text { Committee }\end{array}$} & Chair: & - $\quad$ LDRRM Office / Rescue 348 \\
\hline & Members: & - City Social Welfare and Development (CSWD) Office \\
\hline & & - $\quad$ Philippine Red Cross (PRC) \\
\hline & & - $\quad$ Department of Interior and Local Government (DILG) \\
\hline & & - Public Information Office (PIO) \\
\hline & & - Association of Barangay Captains (ABC) Pres. \\
\hline & & - $\quad$ Department of Education (DepEd) \\
\hline & & - Negros Oriental Hotels and Restaurants Association \\
\hline \multirow{11}{*}{$\begin{array}{l}\text { 2. Disaster Response } \\
\text { Committee }\end{array}$} & Chair: & - City Social Welfare and Development (CSWD) Office \\
\hline & Members & - City Budget Office (CBO) \\
\hline & & - $\quad$ City Accounting Office (CAO) \\
\hline & & - City Treasurer's Office (CTO) \\
\hline & & - $\quad$ Philippine National Police (PNP) \\
\hline & & - Bureau of Fire Protection (BFP) \\
\hline & & - Rescue 348 \\
\hline & & - City Traffic Management Office (CTMO) \\
\hline & & - $\quad$ Armed Forces of the Philippines (AFP) \\
\hline & & - $\quad$ Philippine Coast Guard (PCG) \\
\hline & & - Negros Oriental Chamber of Commerce \\
\hline \multirow{8}{*}{$\begin{array}{l}\text { 3. Disaster Mitigation and } \\
\text { Prevention Committee }\end{array}$} & Chair: & - City Planning and Development Office (CPDO) \\
\hline & Members & $\begin{array}{l}\text { - City Environment and Natural Resources Office } \\
\text { (CENRO) }\end{array}$ \\
\hline & & - City Veterinary Office (CVO) \\
\hline & & - $\quad$ City Health Office $(\mathrm{CHO})$ \\
\hline & & - Office of City Agriculturist (OCA) \\
\hline & & - Silliman University (SU) \\
\hline & & - Foundation University (FU) \\
\hline & & - Negros Oriental State University (NORSU) \\
\hline \multirow{10}{*}{$\begin{array}{l}\text { 4. Rehabilitation and } \\
\text { Recovery Committee }\end{array}$} & Chair: & - City Engineering Office (CEO) \\
\hline & Members & - General Services office (GSO) \\
\hline & & - City Social Welfare and Development (CSWD) Office \\
\hline & & - Gender and Development (GAD) Office \\
\hline & & - City Legal Office (CLO) \\
\hline & & - $\quad$ Local Contractors Association (LCA) \\
\hline & & $\begin{array}{l}\text { - Philippine Institute of Civil Engineers (PICE) - Negros } \\
\text { Oriental }\end{array}$ \\
\hline & & - Negros Oriental Electric Cooperative (NORECO) \\
\hline & & - St. Paul University \\
\hline & & - $\quad$ Philippine Maritime Academy (PMA) \\
\hline
\end{tabular}




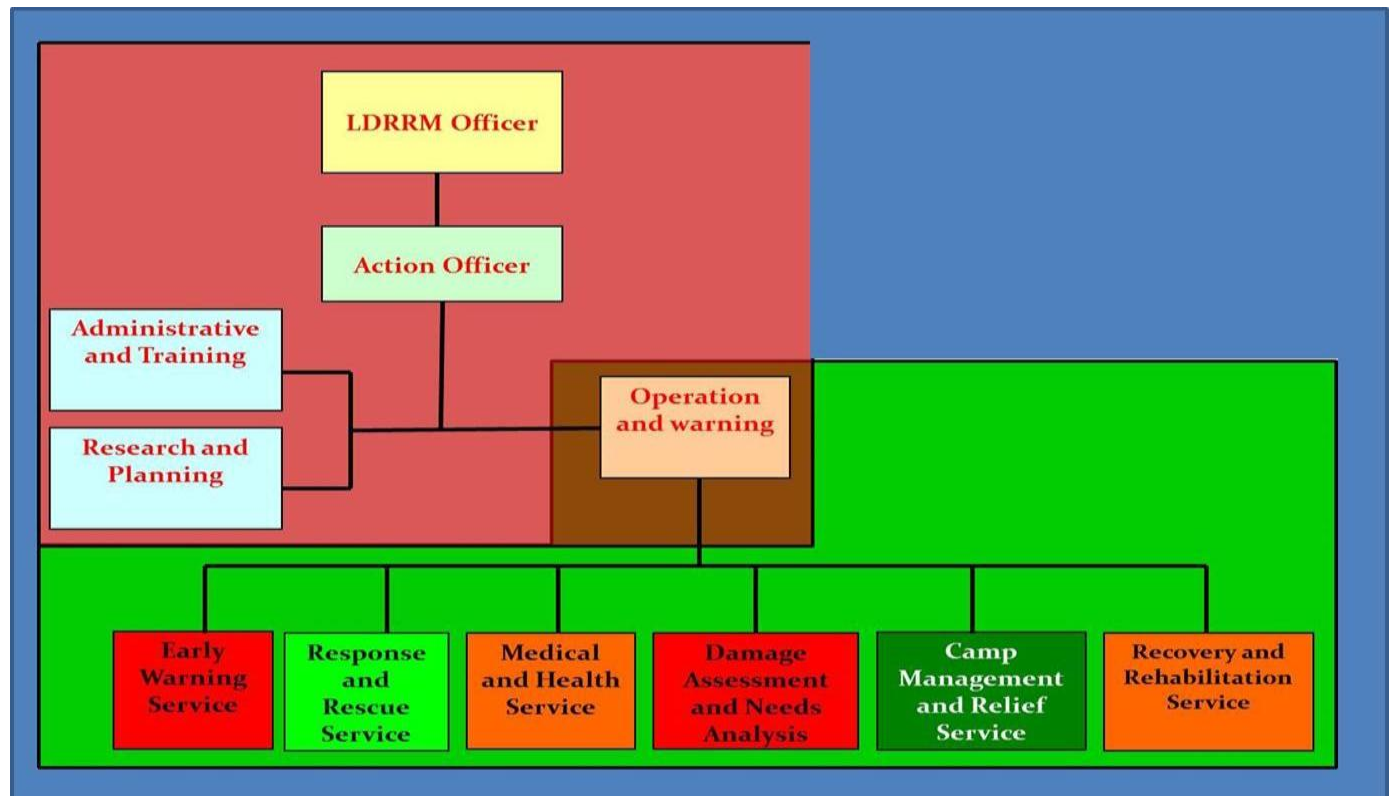

Figure 2-8: Small to Medium Isolated Emergencies/Disaster Situations

When a disaster situation occurs and can be classified as a relatively small or medium emergency with an anticipated minimal amount of possible damage and affected population, this structure in figure 2.8 will serve as the working structure of the Local Disaster Risk Reduction and Management Office (LDRRMO) of Dumaguete City. The City Mayor or the Local Disaster Risk Reduction and Management Officer will act as the Head of the Emergency Management Team (EMT). The Administrative and Training Officer together with the Research and Planning Officer will serve as Secretariat and Administrative support to the Operations and Warning Desk. The Deputy/Action Officer and the Operations and Warning Officer shall be responsible for the defining and execution of the Emergency/Disaster Operations or Contingency plan of the LDRRMO, in coordination with the Action Service Commands which are the following:

A. Early Warning Service Command ( EWSC) - The EWSC shall be headed by the ABC President with the Barangay Captains and SK Chairpersons of the 30 Barangays of Dumaguete City, Local PNP and the City Public Information Office as institutional or department members.

B. Response and Rescue Service Command (RRSC) - The RRSC shall be headed by the Dumaguete City Rescue 348 with the assistance of One Rescue Team, Philippine Red Cross, Silliman Fire Brigade, BFP, PNP, Philippine Army, Chinese Volunteers, Philippine Coast Guard, ENRO and the City Engineering Office as the Institutional/ Department Members. 
C. Medical and Health Service Command (MHSC) - This service command shall be headed by the City Health Office as service command Team Leader. The members of MHSC are the City Veterinary Office, Philippine Medical Association (Dumaguete Chapter) and the Philippine Nursing Association (Dumaguete Chapter).

D. Damage Assessment and Needs Analysis Service Command (DANA-SC) DANA-SC shall be headed by the City Administrator's Office as Team Leader with the assistance of the City Planning and development Office (CPDO), Office of the City Agriculturist (OCA), City Veterinary Office, and the Philippine Institute of Civil Engineers as members.

E. Camp Management and Relief Service Command (CaMReSC) - CaMReSC team leader is the City Social Welfare and Development Office (DCSWDO) with PNP and DepED as service command members.

F. Recovery and Rehabilitation Service Command (RRSC) - This service command shall be headed by the City Engineering Office as team leader, with the City Accounting Office, NORECO, GSO, ENRO DCWD and the TELCOs as service command members.

The above mentioned departments and institutions were objectively chosen by the LDRRMC of Dumaguete City based on the related function of their office or group, and qualifying capabilities such as skills and expertise, knowledge, and experience relative to the requirements needed for the LDRRMO Action Service Command. Below is the illustration of the members of Dumaguete City LDRRMO Action Service Command (Figure 2.9). 


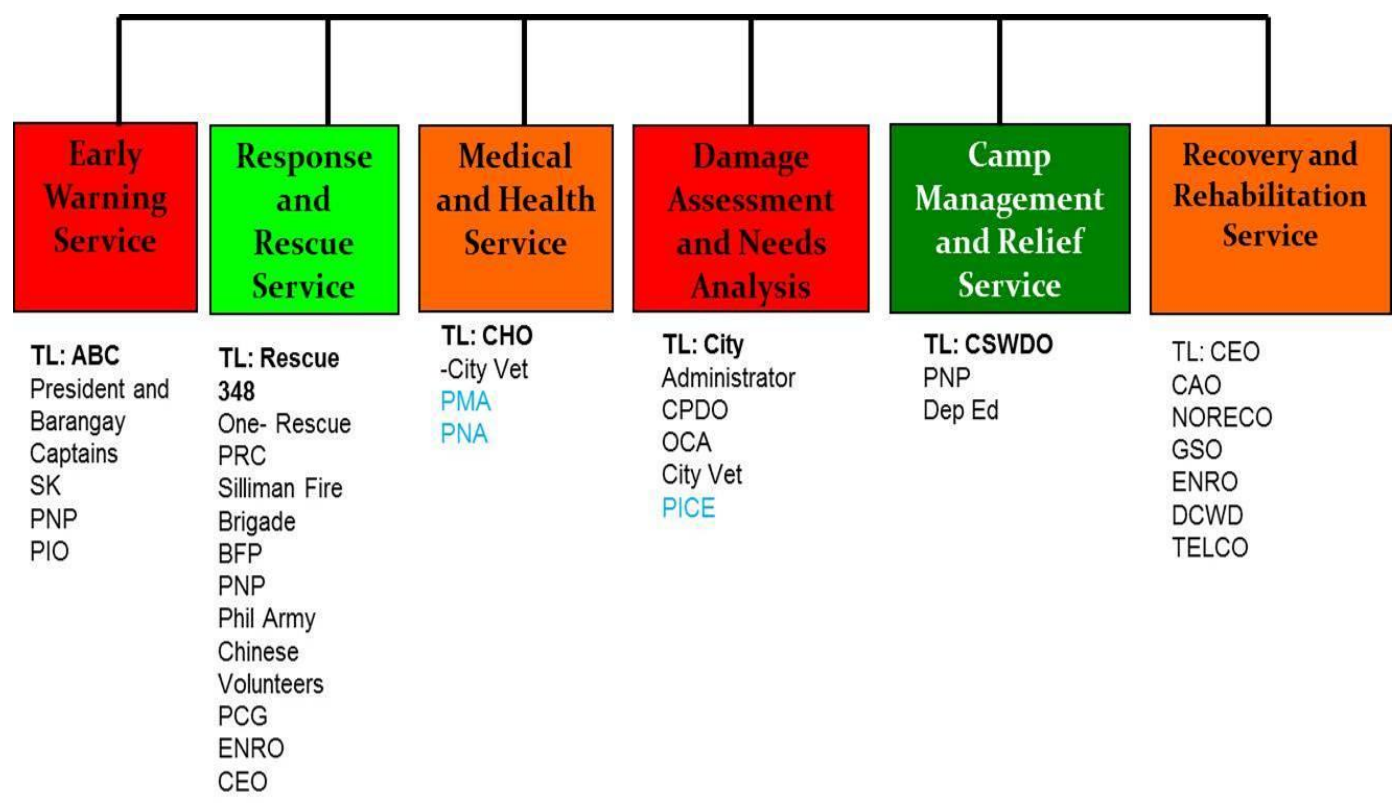

Figure 2-9: LDRRMO Service Command Team Leaders and Members

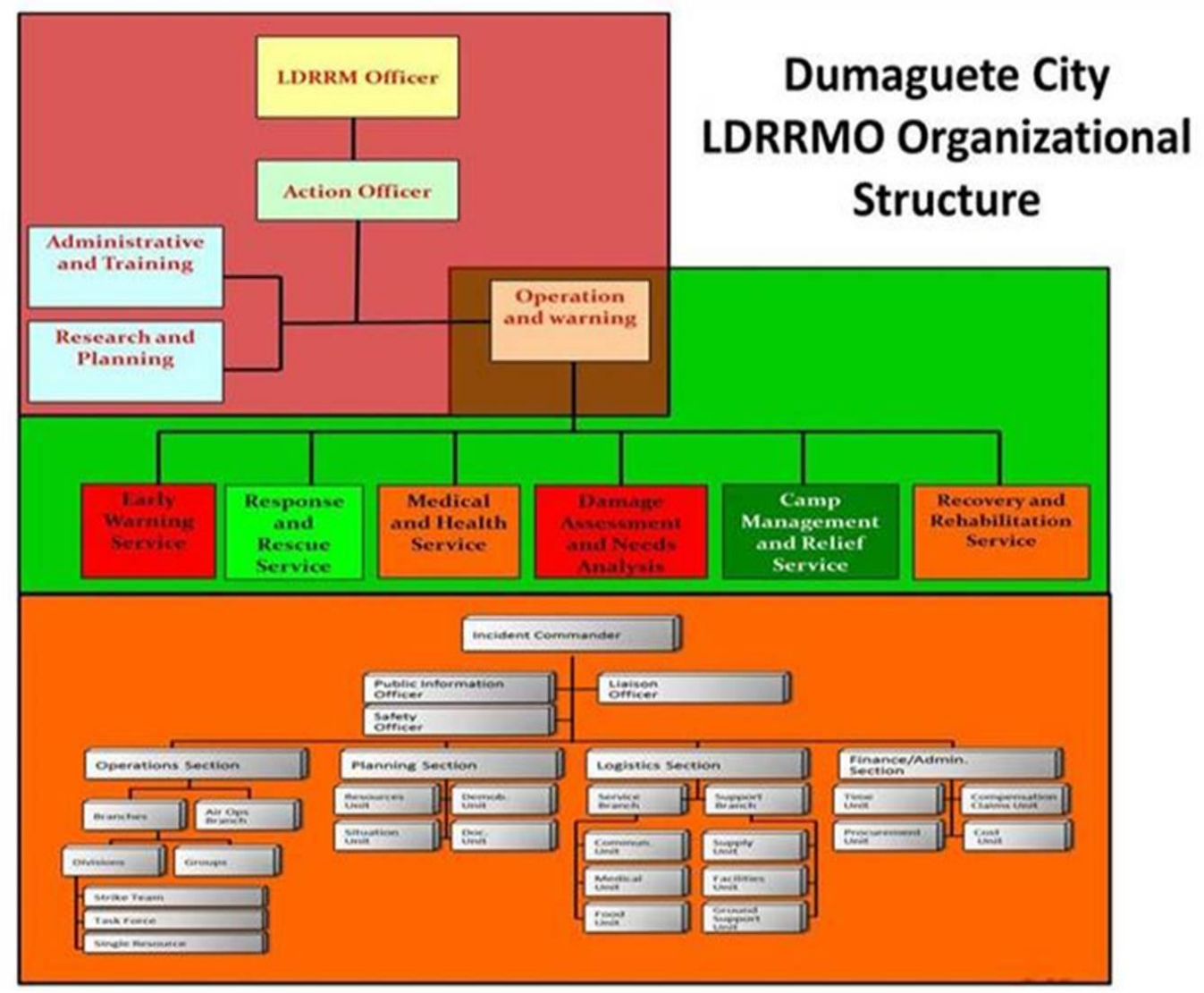

Figure 2-10: LDRRMO Organizational Structure (for Large Scale Emergency, incorporating ICS) 

Social Vulnerabilities and Risks

Typical examples of Large scale and/or Complex Emergency/Disaster situations is the occurrence of events such as Tropical Storm SENDONG in December 2011, the February 2012 Guihulngan Earthquake, Tropical Storm PABLO in December 2012, or as may be determined by the LDRRM Council. In Emergency/Disaster situations like this the LDRRMC members have agreed that the adoption and incorporation of the Incident Command System (ICS) as shown in figure 2.10, will be more effective because of its modular structure and adaptability to any rapidly expanding situation, especially with multi-agency participation, and therefore highly functional and will serve as the working structure that will be applied by the LDRRMC/O in Dumaguete City.

The Incident Command System (ICS), with its Incident Command Post near the vicinity of the incident site, and its Incident Management Team under the direction of the Incident Commander, will be operating under the guidance and directive of the Operations Center managed by the LDRRM Council with the City Mayor as Chairman and Over-all Head. The Operations Center will provide the necessary logistical and manpower support to the entire operations of the Incident Management Team.

The LDRRM Officer may be designated by the City Mayor as the Incident Commander, or as the case may be like Sea incidents (Coast Guard), Fire (BFP), Terroristic threats like bombing, chemical or biological (PNP or AFP) etc. such individual or officer of any government office/agency whose background, training, expertise or experience highly qualifies him for that specific incident to be the Incident Commander of the whole operations of the Incident Management Team. In which case, the LDRRM Officer, due to his familiarity with the locality and local organizational set-up, can ably support the designated Incident Commander by being the deputy IC.

The LDRRM Officer, whether designated as Incident Commander or deputy to the IC, shall be responsible for the deployment of personnel of the Action Service Command, or the Department/Institutional service command team leaders and members to various posts as will be required and necessary within the ICS organizational structure. The LDRRM officer shall also ensure that all instructions are clear and well disseminated to everyone concerned as well as provide regular report to the Incident Commander, or as the Incident Commander himself, to the LDRRM Council at the Operations Center.

\subsubsection{The Identified Emergency Evacuation Areas of Dumaguete City}

In compliance with RA 10121 and Memorandum Circulars on Disaster Risk Reduction issued by the Department of Interior and Local Government (DILG), Dumaguete City 
through its Local Disaster Risk Reduction and Management Office (LDRRMO) have identified possible evacuation areas in preparation for a worst case scenario happening. According to the LDRRMO Dumaguete City has a population of around 25,000 families/households. With an assumption that $20 \%$ of the population will be affected in a worst case scenario, 5,000 families will have to be evacuated. Taking into account each family will require a minimum of 8 square meter living space, a total of 4 hectares $(5,000$ families $\times 8$ square meter $=40,000$ square meter) will be critically needed as evacuation site.

Surely lacking this huge area requirement at present, the LDRRM Council has settled on a solution of accounting of all available spaces in all private and public schools, the private sector, and the 30 barangays in the city with facilities such as Gymnasiums \& Halls, Ball fields \& covered Courts, Classrooms, Churches \& Chapels, Barangay halls \& Government buildings, and other such similar places which have been flood free in the past and assessed to be relatively safe and secure as evacuation sites in the near future.

The LDRRM Office through the mandate of the LDRRM Council shall establish and maintain a strong link and coordination with school heads, barangay captains as well as heads of institutions and the private sector, and if possible execute a memorandum of agreement (MOA) between the city and these entities to ensure that utilization of such facilities will be granted during emergencies.

\subsubsection{The Incident Command System of Dumaguete City}

Defining the Incident Command System of Dumaguete City will be critical to avoid confusion among the key players in disaster response and will greatly help the LDRRMO and BDRRMCs to facilitate a systematic and orderly response operations when a calamity strikes. The ICS of the city will be divided into two Emergency Command Protocols, 1) The Barangay Emergency Command Protocol and 2) City-wide Emergency Command Protocol.

A. The Barangay Emergency Command Protocol - When a disaster strikes in a barangay the responsibility to take lead in the response operations lies with the Barangay Captain, to be assisted by the Barangay Disaster Risk Reduction and Management Committee. All support groups coming from the city and other areas responding to the emergency in the barangay should report first to the Barangay Captain for proper briefing and instructions before any response operation can be initiated by the group. The BDRRMC will as soon as practicable 

Social Vulnerabilities and Risks

conduct Damage Assessment and Needs Analysis of the disaster and the information gathered will be the official report to be submitted to LDRRMO for proper action. The BDRRMC will also initiate the establishment of a Command Post or Operations Center, if necessary, to have an organized and effective response.

B. The City-wide Emergency Command Protocol - When two or more barangays are affected by an Emergency/Disaster situation, the responsibility for immediate response at all levels rest with the LDRRM Office. The LDRRM Officer or the City Mayor will act as the Incident Commander and Dumaguete City Rescue 348 will immediately initiate the Emergency Command Protocol and coordinate the medical, rescue and evacuation procedures to be assisted by the City Health Office (CHO), City Social Welfare office, Planning and Development Office (CSWDO), Philippine National Police, Bureau of Fire, Red Cross, Dep't of Education, the BDRRMCs concerned, and other agencies tasks with the capability to respond and assist in such an emergency. The City Administrator's Office, as head of DANA-SC of the LDRRMO, will conduct the Damage Assessment and Needs Analyses that will serve as the official documentation/report of the city, to be submitted to the Sangguniang Panglungsod for the declaration of a State of Calamity if necessary, and to the higher authorities for assistance of any kind.

\subsubsection{Institutional Working Arrangement}

There shall be mutual cooperation among and between the LDRRMO, other city departments such as CSWDO, OCA, CEO, CHO CPDO, CENRO among others, and DepED, BDRRMCs and Accredited Community Disaster Volunteers in the implementation of this comprehensive 5-Year LDRRM Plan.

Quarterly or semi-annual Plans and Progress reports of LDRRM activities shall likewise be made to the City Council and other funding partners for information, technical and management guidance.

The LDRRMC shall actively participate in and support local policy proposals, including discussions and decisions relative to formulation, amendment and/or modifications of local policies pertinent to local disaster risk reduction especially in three core programs namely: disaster prevention, mitigation and preparedness.

Accountability for the regular reporting system to the public and concerned officials belongs to the LDRRM Officer. 

Social Vulnerabilities and Risks

\subsubsection{General Monitoring and Evaluation Framework}

Monitoring and evaluation is the process of gathering, filing, accessing and analyzing information that will enable the City Mayor as LDRRM Council Chairman, to determine the progress of the implementation of the LDRRM Plan, and make timely decisions to ensure that progress is maintained according to schedules and targets.

The public dissemination of the outputs of monitoring and evaluation activities enhances transparency in management.

The LDRRMO shall be primarily responsible in carrying out monitoring and evaluation activities that will be reviewed by the LDRRM Council as the overseeing body of the city for Disaster Risk Reduction and Management and Climate Change Adaptation program. The LDRRM Office shall submit a semi-annual report to the LDRRMC and to the City Mayor informing them of the status of implementation of the approved LDRRM programs and projects for the period.

The 5-year LDRRM Plan (2013 - 2017) of Dumaguete City focuses on the 4 core programs namely: 1) Disaster Prevention - focuses on health, public awareness, research and structural component of Disaster Risk Reduction and Management; 2) Disaster Mitigation and Climate Change Adaptation - aims to protect the environment, physical infrastructure construction and rehabilitation; 3) Vulnerability Reduction - gives emphasis on the installation and sustaining the existing initiative of localized early warning system, enhancing and upgrading DRRM related equipment; 4) Disaster Preparedness and Response - focuses on two aspects. First, upgrading the internal system and second, the organizational development of LDRRMC and LDRRMO.

The members of the LDRRMC shall be strengthened organizationally and technically to ensure their effectiveness in overseeing the LDRMM Plan of the City and provide direction to the LDRRM Office and its staff.

In the meantime that the Local Disaster Risk Reduction and Management Office (LDRRMO) is lacking in key personnel as prescribed under RA 10121 due to the question of the source of funding, the LDRRM Office of Dumaguete City thru initiatives fully supported by the Mayor has managed to utilize volunteers to carry out the tasks of day-to-day operations and implementation of its Comprehensive Disaster Risk Reduction and Management Plan.

The Accredited Community Disaster Volunteers (ACDV's), as what the PDRRM Law prescribed, shall be properly organized and eventually institutionalized through the close monitoring of the Barangay Disaster Risk Reduction and Management Committee 
(BDRRMC) with the technical assistance and close supervision of the LDRRMO and Barangay Development Council.

Looking at the organizational structure and command of the Local Disaster Risk Reduction and Management Council (LDRRMC), the Local Disaster Risk Reduction and Management Office (LDRRMO) and the 5-year LDRRM Plan (2013 - 2017) of Dumaguete City, the city is seemed to be well organized and well prepared for any natural calamity. 


\section{CHAPTER 3 THE DEVELOPMENT OF COMMUNITY-BASED FLOOD VULNERABILITY FRAMEWORK: ITS COMPONENTS AND INDICATORS FOR URBAN FLOODING SUMMARY}

The development of the proposed community-based flood vulnerability index for urban flooding will be discussed and presented thoroughly in this chapter. The major five (5) vulnerability components and thirty-six (36) indicators are illustrated in the theoretical framework and the interplay of these factors show how it could influence vulnerability.

The major five components namely: hydro-climatic, social, economic, socio-behavioral, and politico-administrative alongside linking them with the factors of vulnerability (exposure, susceptibility, resilience) and indicators in producing a vulnerability index. The hydro-climatic component being hazard dependent, local indicators were identified and considered since they have a direct interaction on this component. The social and economic component, as part of the socio-economic system may predispose these certain groups and to be able to determine the individual's vulnerability appropriate indicators were used. While the socio-behavioral component is one added component in this research work not found in many studies of flood vulnerability index. This is a very important component to consider because the interplay of these indicators influences the actual and direct effects of flooding and disease outbreaks. Lastly, the politicoadministrative component is as equally as important as the other components. It is very important to know how far the government has done its preventive, adaptive and coping measures in facing the different challenges of climate change.

The factors of vulnerability in this chapter are properly defined and illustrated with its corresponding entities of indicators in this study. Vulnerability is defined within the local context and within the concept of this study to be able to have a full understanding of this research work. Exposure is a factor of vulnerability whose selection of subindicators was based primarily on the local threats that exposed its entities. Susceptibility is another factor of vulnerability, and in this paper it defines susceptibility as the likelihood or those that influence the probabilities of being harmed at times of hazardous floods. While resilience the third factor, is composed of the coping and adaptive capacities of the community. The indicators that were used in this research work clarify the ability of the system to persist if exposed to a certain hazards by recovering during and after the flood event.

The relationship between flood vulnerability components, indicators and factors are presented in Table 3.1 


\section{CHAPTER 3 \\ THE DEVELOPMENT OF COMMUNITY-BASED FLOOD VULNERABILITY FRAMEWORK: ITS COMPONENTS AND INDICATORS FOR URBAN FLOODING}

The development of community-based flood vulnerability index for urban flooding through using local components and indicators is important in generating a localizedbased flood vulnerability index that depicts a more realistic scenario of vulnerability and resilience indexes in a local, national and international setting.

Soliciting the responses from the individual household respondents themselves and the local government units (LGU's) from each of the communities involved and including those who are in the city and provincial disaster coordinating council office and the volunteers from the non-governmental organizations (NGO's) have been the sources of the actual community survey. It is very important to do an actual field survey so that a realistic scenario will be generated and projected.

This research work is done in a more detailed survey, of which the improvement that this work has accomplished when it comes to addressing the socio-economic profile of the individual households, including their socio-behavioral approach in terms of the knowledge, attitudes, and practices towards flood vulnerability and resilience particularly on the items of hazards, risks, exposure, preparedness, response, recovery, coordination, and adaptation strategies. The socio-behavioral approach was conducted in a more detailed way by soliciting the community people's Knowledge, Attitudes and Practices (KAP) particularly on flood preparedness and health impacts and it is measured in terms of their exposure to E.coli, Leptospirosis and Dengue Fever particularly on the nature of these organisms, their mode of transmission, prevention, signs and symptoms, it is fatal, treatment, and the financial cost of treatment. The hydro-climatic and politico-administrative components were also studied in detailed. Measuring the KAP of the respondents from preparedness to recovery, and as well as the KAP on the exposures of the microorganisms in focus and would give us a clue how community people perceived in these kinds of phenomenon which are translated into their attitudes and practices before, during or after any catastrophic events such as typhoons and flooding.

There are five (5) flood vulnerability components and thirty-six (36) indicators that were developed in this work. Each of the indicators is belonging to a specific flood 

Social Vulnerabilities and Risks

vulnerability component and to a particular flood vulnerability factors; namely exposure, susceptibility and resilience that would eventually produce flood vulnerability index profile.

The theoretical framework is presented below along with its corresponding description and detailed discussions of the interplay of the different components and indicators in producing a community-based flood vulnerability index.

\subsection{The Theoretical Framework}

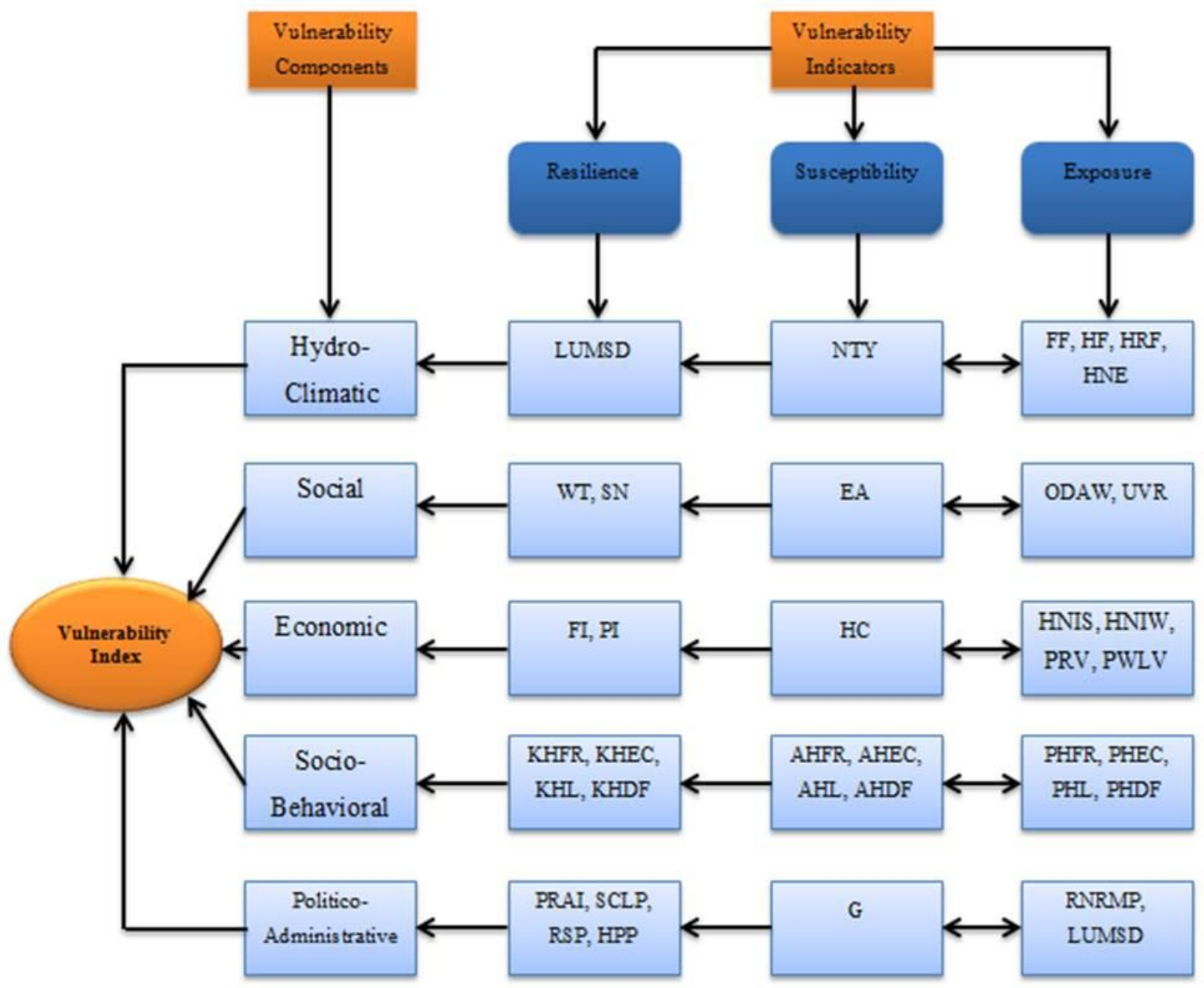

Figure 3-1: Community-Based Flood Vulnerability Components and Indicators

In this theoretical framework for vulnerability (Figure 3-1), the researcher presented the relationship of the vulnerability components along with the three (3) vulnerability factors and its corresponding indicators on how it could influence vulnerability. The indicators 

Social Vulnerabilities and Risks

are shown in a more detailed manner (see table 3.1 below) for the detailed description of the abbreviations used. The detailed descriptions and discussions are as follows.

\subsection{Flood Vulnerability Factors}

This section provides an overview of the selected components and indicators in the development and calculation of this Community-Based Flood Vulnerability Index (FVI) for Dumaguete City, Negros Oriental Philippines. This study was done locally among the twelve communities of Dumaguete City and the researcher has based the analysis to the following components: Hydro-Climatic, Social, Economic, Socio-Behavioral and Politico-Administrative components which are general and relevant to the local level. The individual indicators of each of the components will be mentioned below.

There are 3 important factors of vulnerability to consider all throughout the components which determine the vulnerability index. These factors are exposure, susceptibility and resilience. In addition, the concept of vulnerability will also be described below to facilitate a complete understanding of the interplay and influence of the indicators to the components and factors of vulnerability.

Vulnerability is considered as the extent of harm which can be expected under certain conditions of exposure, susceptibility, and resilience. More specifically in the case of floods, a system is susceptible to floods due to exposure in conjunction with its capacity/incapacity to be resilient, to cope, recover or adapt to the extent. Some of the exposed populations are protected from flooding by various structural and non-structural measures that are part of the resilience strategy. On the other hand, some of them have none, or only weak, flood defenses and the exposed populations are more often subject to flooding with the consequent disruption, economic loss and loss of life (Balica, S.F., Wright, N.G., and van der Meulen, F., 2012). In this research, vulnerability is the result of the interplay of the indicators in the exposure, susceptibility and resilience category.

By dividing the FVI into different components, such as hydro-climatic, social, economic, socio-behavioral, and politico-administrative and linking them with the factors of vulnerability (exposure, susceptibility, resilience) can help identify the weak and strong points of a certain community in terms of flood vulnerability and in that way, it helps to propose strategies for improvement and identifies which one is a priority. 

Social Vulnerabilities and Risks

\subsubsection{Exposure}

Exposure in its core meaning in natural hazard research refers to entities exposed and prone to be affected by a hazard event. These entities include persons, resources, infrastructure, production, goods, services or ecosystems and coupled social-ecological systems (United Nations University Institute for Environment and Human Security, 2011).

The selection for the sub-indicators for exposure was based primarily on the local threats that exposed the household respondents to river flooding and possible disease outbreak that goes with it. Within the Flood Vulnerability Index, exposure is related to the likelihood of acquiring and being affected by such phenomenon. The exposure factor considered those indicators that explained how those entities mentioned above are exposed to flood events. The actual practices of the people prior and during the flooding events, the established land use and structural design, and the infrastructures mirror the exposure of certain populations to flooding events.

\subsubsection{Susceptibility (Before the floods: Awareness and Preparedness) (During the floods: Dealing and Coping)}

Generally, susceptibility is understood as the likelihood of suffering harm and damages in case of the occurrence of a natural hazard (United Nations University Institute for Environment and Human Security, 2011). In this study, susceptibility relates to system and individual characteristics, including the individual level of education, housing conditions, their attitude regarding the risk that they live with (before the flood), the institutions that are involved in mitigating and reducing the effects of the hazards and the existence of possible measures, like flood hazard maps and early warning systems to be used during the floods.

This paper defines susceptibility as the elements exposed within the system, which influences the probabilities of being harmed at times of hazardous floods. The indicators that were used here evaluate the sensitivity of the element or entities at risks.

\subsubsection{Resilience (During: Handling and Coping) (After: Survive and Recuperate)}

Resilience is the capacity of any kind of system, community, society or environment, potentially exposed to hazards to adapt to any change, by resisting or modifying itself, in order to maintain or to achieve an acceptable level of functioning and structure (Pelling, 2003). Resilience is therefore analyzed through a political, administrative, environmental 

Social Vulnerabilities and Risks

and social organizational evaluation (Di Mauro, 2006). In this study, the resilience factor is composed of the coping capacities and adaptive capacities of the individuals, communities and the government that may contribute in reducing the impacts of river flooding and disease outbreaks, and the transformation of societies and socioecological systems for long term adaptation to negative impacts of natural hazards and climate change through direct actions and resources. The indicators that were used here clarify the ability of the system to persist if exposed to certain hazards by recovering during and after the flood event.

\subsection{Identifying the Key Components and Indicators of Community- Based Flood Vulnerability Index (FVI)}

This part deals with the description of the components and its indicators as used on the local scale to capture the aspects of exposure, susceptibility, and resilience as well as their aggregation to the local Community-Based Flood Vulnerability Index. In this study the indicators vary, a totally different indicators used but were chosen based on the same concept developed by the WorldRisklndex Report and the study of Balica et.al (2012) on the development of Flood Vulnerability Index for Coastal City.

This research work is trying to fill those categories that were suggested by those earlier studies that were not included in the global scale, for instance, indicators such as housing conditions; disaster preparedness and early warning; social networks; property insurance; Knowledge, Attitude, Practices (KAP) of respondents on flood resilience; and exposure to microorganisms such as that of E.coli, Leptospirosis and Dengue fever mosquito; the different adaptation strategies such as integration of post-risk assessments; sustainable community livelihood; relocation site projects and health programs for the prevention against diarrhea, leptospirosis and dengue fever which are facilitated by the LGU's and as well as some NGO's.

These five components have been linked with the three factors of vulnerability as shown in Table 3.1 The relationship of these factors and components should increase the robustness of the developed urban FVI as it was also observed in the study of Balica et al. (2012). Thirty-six (36) indicators were used and examined in computing the community-based flood vulnerability index (FVI) for Dumaguete City, Negros Oriental.

By computing the FVI of the city, hotspots to flooding events with the corresponding strong and weak points to vulnerability and resilience will be identified and mapped. By 

Social Vulnerabilities and Risks

doing so, this would serve as a tool to assist planners and policymakers in prioritizing their areas of intervention and to provide useful information for awareness rising.

The development of this community-based FVI which is in the Philippines' local context involved the interplay of factors within the water resource system in the event of flooding, a deductive approach was used to identify the best possible indicators based on the existing principles and conceptual framework (Chapter 2).

\subsubsection{Hydro-Climatic Component}

In spite that the hydro-climatic component is part of the natural river system as being hazard dependent, the following indicators were considered since they have a direct interaction on this component. The hydro-climatic component includes the frequency and height of flooding, the houses reached by flood waters and those houses that were not located on elevated areas near the river are all the indicators for this component that comprise the exposure factor of vulnerability. The frequency of flooding is measured as (every month, every 4 months, every 6 months, every year, sometimes, rarely or never). While the height of flooding is measured as (ankle level, knee, waist, and shoulder high, above the head, roof high and beyond the roof); the number of houses reached by flood and those that are not on elevated area were also accounted for.

The average number of typhoons that passes through the country is 20 but not all of it passes through the Visayan region, thus, in this case only $50 \%$ of the total number of typhoons is being considered (susceptibility).

The land use management and structural design (resilience factor) is highly taken into consideration being a positive measure and influences the vulnerability of the area in one way or another. Effective land use and structural design that complement environmental, economic, and community goals and reduce risks from hazards. This includes: how well are the land use policies and building standards that incorporate measures to reduce risks from hazards and protect sensitive habitats are established, monitored, and enforced such as urban planning; how well are the critical infrastructures such as the increasing capacity of our drainage system, good run-off volume control on open retention basin, in-line basins, off-site basins, on-site storage, dry ponds, the efficiency of our dike and bridge systems; how well are the developers and communities incorporate risk reduction into the location and design of structure particularly on existing spatial planning, flood risk adaptive to land use, building regulations, building codes, zoning ordinances, and how established is our education, outreach, and training programs to improve compliance with land use policies and building standards. 

Social Vulnerabilities and Risks

\subsubsection{Social Component}

The social component is part of the socio-economic system which can determine the individual's vulnerability in terms of its social status. The indicators in this component may predispose these certain groups to what extent they will be affected. The social component is pertaining to the educational attainment, it is rated from elementary level education, elementary graduate, high school level, vocational, college level, college graduate up to graduate school respectively which helps determine the susceptibility; social networks among neighborhoods such as helping each other in times of natural calamity; and the water treatment practice during such events are the indicators for resilience; while those factors that may predispose them to certain vulnerability such as open disposal of animal waste and the unwillingness to vacate from the hazard area comprise the exposure factor.

\subsubsection{Economic Component}

The economic component is also part of the socio-economic system which can determine the individual's vulnerability in terms of its economic status. The indicators in this component may also predispose these certain groups and to what extent they will be affected. But, it can also be a positive source of fast recovery from a previous calamity if a household has a very stable financial status.

The economic component in this study looks into the housing conditions of the households, such as whether it is made of concrete, wood, cartoon, steel, galvanized iron, bricks, tiles, nipa materials, or just coconut leaves, plastic materials and salvage materials (susceptibility); a family income of Php3000-10,000 pesos and if they have made their properties insured (resilience factor); on the other hand, factors that may predispose them to certain vulnerability such as no access to improved sanitation and water sources, presence of rats around the area and water logged in the vicinity is the exposure factor.

\subsubsection{Socio-Behavioral Component}

This component is an added component not found in many studies on flood vulnerability index. The researcher believed that it is equally important to study the household respondent's knowledge, attitude and practices (KAP) related to these events. The household respondent's KAP predisposes them to the cause and effects of this phenomenon. From what they know (knowledge-resilience) on flood resilience such as on the items of hazards, risks, exposure, preparedness, response, recovery, coordination, and adaptation strategies; also on their knowledge on E.coli, Leptospirosis 

Social Vulnerabilities and Risks

and Dengue Fever in terms of its nature, mode of transmission, prevention, signs and symptoms, how fatal it is, treatment and the financial coast of treatment.

How they perceived or what is their opinion and general view (attitude-susceptibility) to such kind of environmental threat by using the same items above but asked in a different way.

For the practices or what they actually do (practices-exposure) is also using the same items but presented in a different way. These items of indicators are very important to consider because the interplay of these factors influences the actual and direct effects of flooding and the occurrence of possible disease outbreaks. For the details of the items on this component and indicators it can be found in the appendix of this paper.

\subsubsection{Politico-Administrative Component}

The politico-administrative component is as important as the other components and this includes land use management and structural design; and the rivers natural resources and natural features management and program, these comprises the indicators for exposure. The local government's governance including those from the national and other NGO's are also included (susceptibility) which could affect the extent of vulnerability in the area.

The governance particularly includes warning and evacuation; emergency response; disaster recovery; and how well are the community development policies, plans, and programs were implemented and monitored; how accessible are the basic services such as water, transportation, communication, security, health services and evacuation centers to all sectors of society; how well are the participatory collaboration mechanisms among different sectors ad various levels of government used to managed for resilience; how transparent, accountable, and available are the technical and financial support mechanisms to support planned community actions for resilience; and how good are we with our risk reduction efforts. Along with these indicators, the government's adaptation capacities are highly considered because of their strong influences to the extent of vulnerability. It is important to know how far the government has done its adaptive and coping measures in facing the different impacts of climate change.

Post-risk assessment and integration is the first indicator for resilience and it is about how leadership and community members are aware of hazards and risk information is utilized when making decisions and implementing them during and after a particular calamity and this includes (how well are the flood hazard risks assessments completed 

Social Vulnerabilities and Risks

and routinely updated; how comprehensive is the flood hazard risk assessments to incorporate risks to all elements of resilience; how well is the community participation in the hazard risk assessment process; how well are the information from risk assessment is accessible and utilized by the community and government). Communities are engaged in diverse and environmentally sustainable livelihoods that are resistant to hazards and this composes for the sustainable community livelihood which is the second indicator for resilience and this includes (how well is our development policies and plans in building social capital and skills for economic diversity and self-reliance; how is the availability of diverse and environmentally sustainable livelihood in the community; how well is our social and cultural networks in promoting self-reliant communities so it would have the capacity to provide support to disaster-stricken areas; how well is out technical services offered and financial resources in promoting stable and robust economies, reducing vulnerabilities to hazards, and aids in disaster recovery. The third indicator for resilience factor is the relocation site project and the fourth is the health and prevention programs for E.coli, Leptospirosis and Dengue fever infection are all part of the adaptive measures (resilience) for long term adaptation.

The relationship between flood vulnerability components, indicators and factors is illustrated in Table 3.1 below. The availability of data, the importance of certain indicators and the condition that all FVIs computed must be made dimensionless for the purposes of comparison that would lead to the formulation of the equations for each vulnerability component. 
Community-Based Flood Vulnerability Index for Urban Flooding: Understanding

\section{Social Vulnerabilities and Risks}

Table 3-1: Relationship Between Components and Indicators

\begin{tabular}{|c|c|c|c|}
\hline \multirow{2}{*}{$\begin{array}{l}\text { Flood Vulnerability } \\
\text { Components }\end{array}$} & \multicolumn{3}{|l|}{ Vulnerability Indicators } \\
\hline & Exposure & Susceptibility & Resilience \\
\hline $\begin{array}{l}\text { A. Hydro- Climatic } \\
\text { Components }\end{array}$ & $\begin{array}{l}\text { A. Frequency of Flooding (FF) } \\
\text { B. Height of flooding (HF) } \\
\text { C. Houses reached by floods (HRF) } \\
\text { D. Houses not on elevated area (HNE) }\end{array}$ & $\begin{array}{l}\text { A. Number of Typhoons per year } \\
(50 \%)(\text { NTY) }\end{array}$ & $\begin{array}{l}\text { A. Land Use Management And } \\
\text { Structural Design (LUMSD) }\end{array}$ \\
\hline $\begin{array}{l}\text { B. Social } \\
\text { Components }\end{array}$ & $\begin{array}{l}\text { A. Open disposal of animal waste (ODAW) } \\
\text { B. Unwillingness to vacate and be relocated ( UVR) }\end{array}$ & $\begin{array}{l}\text { A. Educational Attainment (High } \\
\text { School Level and below) (EA) }\end{array}$ & $\begin{array}{l}\text { A. Water Treatment or Sterilization } \\
\text { Practice (WT) } \\
\text { B. Social Networks (SN) }\end{array}$ \\
\hline $\begin{array}{l}\text { C. Economic } \\
\text { Components }\end{array}$ & $\begin{array}{l}\text { A. Houses with NO access to improved sanitation (HNIS) } \\
\text { B. Houses with NO access to an improved water source (HNIW) } \\
\text { C. Presence of rats in the vicinity (PRV) } \\
\text { D. Presence of water logged areas in the vicinity (PWLV) }\end{array}$ & $\begin{array}{l}\text { A. Housing Conditions (semi- } \\
\text { concrete, tent light materials, and } \\
\text { plastic materials) }(\mathrm{HC})\end{array}$ & $\begin{array}{l}\text { A. Family Income }(3000-10,000)(\mathrm{FI}) \\
\text { B. Property Insurance (PI) }\end{array}$ \\
\hline \multirow{4}{*}{$\begin{array}{l}\text { D. Socio- Behavioral } \\
\text { Components }\end{array}$} & $\begin{array}{l}\text { A. PRACTICES of households on flood resilience (hazards, risks, } \\
\text { exposure, preparedness, response, recovery, coordination, } \\
\text { adaptation strategies) (PHFR) }\end{array}$ & $\begin{array}{l}\text { A. ATTITUDE of households on flood } \\
\text { resilience (hazards, risks, exposure, } \\
\text { preparedness, response, recovery, } \\
\text { coordination, adaptation strategies) } \\
\text { (AHFR) }\end{array}$ & $\begin{array}{l}\text { A. KNOWLEDGE of households on } \\
\text { flood resilience (hazards, risks, } \\
\text { exposure, preparedness, response, } \\
\text { recovery, coordination, adaptation } \\
\text { strategies) (KHFR) }\end{array}$ \\
\hline & $\begin{array}{l}\text { B. PRACTICES of households on E.coli (nature of E.coli, mode of } \\
\text { transmission, prevention, signs and symptoms, it is fatal, } \\
\text { treatment, financial cost of treatment) (PHEC) }\end{array}$ & $\begin{array}{l}\text { B. ATTITUDE of households on E.coli } \\
\text { (nature of E.coli, mode of } \\
\text { transmission, prevention, signs and } \\
\text { symptoms, it is fatal, treatment, } \\
\text { financial cost of treatment) (AHEC) }\end{array}$ & $\begin{array}{l}\text { B. KNOWLEDGE of households on } \\
\text { E.coli (nature of E.coli, mode of } \\
\text { transmission, prevention, signs and } \\
\text { symptoms, it is fatal, treatment, } \\
\text { financial cost of treatment) (KHEC) }\end{array}$ \\
\hline & $\begin{array}{l}\text { C. PRACTICES of households on Leptospirosis (same factors with } \\
\text { letter } \mathrm{B} \text { above) (PHL) }\end{array}$ & $\begin{array}{l}\text { C. ATTITUDE of households on } \\
\text { Leptospirosis (same factors w/letter B } \\
\text { above) (AHL) }\end{array}$ & $\begin{array}{l}\text { C. KNOWLEDGE of households on } \\
\text { Leptospirosis (same factors w/ letter B } \\
\text { above) (KHL) }\end{array}$ \\
\hline & $\begin{array}{l}\text { D. PRACTICES of households on Dengue Fever (same factors } \\
\text { with letter B above) (PHDF) }\end{array}$ & $\begin{array}{l}\text { D. ATTITUDE of households on } \\
\text { Dengue Fever (same factors with letter } \\
\text { B above) (AHDF) }\end{array}$ & $\begin{array}{l}\text { D. KNOWLEDGE of households on } \\
\text { Dengue Fever (same factors with letter } \\
\text { B above) (KHDF) }\end{array}$ \\
\hline \multirow{3}{*}{$\begin{array}{l}\text { E. Politico- } \\
\text { Administrative } \\
\text { Components }\end{array}$} & \multirow[t]{3}{*}{$\begin{array}{l}\text { A. The River's Natural Resources \& Natural Features } \\
\text { Management and Program (RNRMP) }\end{array}$} & \multirow{3}{*}{$\begin{array}{l}\text { A. Governance (Warning and } \\
\text { Evacuation, Emergency Response, } \\
\text { Disaster Recovery) (G) }\end{array}$} & $\begin{array}{l}\text { A. Post-risk Assessment and } \\
\text { Integration (PRAI) } \\
\text { B. Sustainable Community Livelihood } \\
\text { Programme. (SCLP) }\end{array}$ \\
\hline & & & C. Relocation Site Project (RSP) \\
\hline & & & $\begin{array}{l}\text { D. Health \& Prevention Program of } \\
\text { E.coli, Leptospirosis \& DF (HPP) }\end{array}$ \\
\hline
\end{tabular}




\section{CHAPTER 4 \\ APPLICATION OF THE METHODOLOGY OF THE COMMUNITY-BASED FLOOD VULNERABILITY INDEX (FVI) FOR URBAN FLOODING: DATA COLLECTION AND TREATMENT}

\section{SUMMARY}

This part of the paper shows the methodology and application of the proposed community-based flood vulnerability index (FVI) for urban flooding. The collection of data and treatment are presented in tables, maps, photos and formulated equations.

A total of 357 household respondents were surveyed from 12 communities and 30 respondents from the local government units and non-governmental organizations were also solicited from the survey respectively. The calculation of the proposed communitybased flood vulnerability index is based on the accepted general flood vulnerability index formula.

The study site is presented in maps with its boundaries, population, elevation, land use, and the watershed location of the Banica River where these communities lies. A brief community profile of the 12 communities that were involved. Temporary shelters and relocation site are also presented to have a glimpse of the actual scenario of the study area. Situation of the most recent flooding event in 2011 and the daily activities of the community people in relation to the river are shown in photographic images.

The methodology for hydrological data is briefly discussed and crudely done due to unavailability of data and sources. The hydrological data are gathered two times during the dry months of March and the wet months of July and simply for the purposes of bacterial correlations of actual exposures and incidences of diarrhoea from the community people surveyed. The results are shown in tables and the locations for the different stations are presented in maps and photos. The health impact assessment methodology in terms of sampling and microbial analyses is also briefly presented in this chapter. For the laboratory culture, EMB agar was used and aseptic techniques were observed all throughout the procedure. The E.coli counts and exposure are presented in tables. An example of a positive and negative bacterial culture is also shown in photos. Exposures in terms of the amount of water swallowed in activities like swimming/bathing/washing in the river and exposures during and after flooding events are look into. 


\section{CHAPTER 4 \\ APPLICATION OF THE METHODOLOGY \\ OF THE COMMUNITY-BASED FLOOD VULNERABILITY INDEX (FVI) FOR URBAN FLOODING: DATA COLLECTION AND TREATMENT}

\subsection{Community-Based Flood Vulnerability Index Methodology}

The first task of this research was to review the different research work, survey and literature about vulnerability index with the purpose of identifying which indices must be included and added in this study. After which the most relevant components have been recognized from the previous studies, a revision of such components were done to be able to have a holistic approach which can be used for local data and on a per country basis shown in figure 4-1 below. The next step was to identify the main indicators that mirror vulnerability to urban flooding. Identifying these different indicators will facilitate the development of equations for the Community-Based Flood Vulnerability Index (FVI). The different indicators were then categorized under exposure, susceptibility and resilience factors. The FVI must have different indicators for the different components and factors which are grouped appropriately. Such indicators must have a direct, indirect or both impacts on vulnerability of the area of study.

Methodology of Community Based Flood Vulnerability Index (FVI)

for Urban Flooding

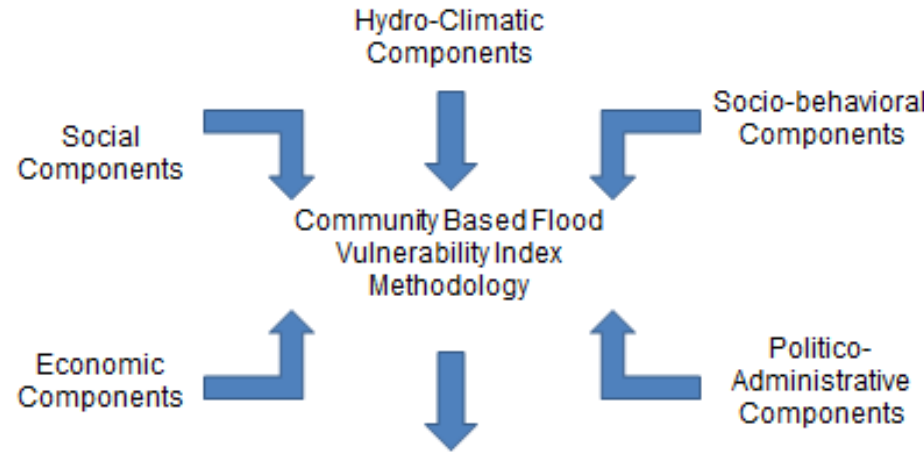

Flood Vulnerability Index

maps and profiles

Figure 4-1 Methodology Framework for Community-Based Flood Vulnerability Index for Urban Flooding 
Community-Based Flood Vulnerability Index for Urban Flooding: Understanding Social Vulnerabilities and Risks

Table 4-1: Population Profile and the Suggested Sample Size (SS)

\begin{tabular}{|l|c|c|c|c|c|c|c|c|}
\hline Community & $\begin{array}{c}\text { Affected } \\
\text { Population }\end{array}$ & $\begin{array}{c}\text { No. of } \\
\mathrm{HH}\end{array}$ & $\begin{array}{c}\text { Affected } \\
\text { Pop. }\end{array}$ & $\begin{array}{l}\text { Affected } \\
\mathrm{HH}\end{array}$ & $\begin{array}{l}\text { No. } \\
\mathrm{HH} \\
(\%)\end{array}$ & $\begin{array}{l}\text { Sample } \\
\text { Size }\end{array}$ & $\begin{array}{l}\text { A HH } \\
\text { SS }\end{array}$ & $\begin{array}{l}\text { NA } \\
\text { HH } \\
\text { SS }\end{array}$ \\
\hline Candauay & 6000 & 1200 & 4550 & 910 & 23.68 & 88 & 67 & 21 \\
\hline Junob & 900 & 180 & 870 & 174 & 3.55 & 13 & 13 & 0 \\
\hline Bagacay & 2170 & 434 & 1700 & 340 & 8.57 & 32 & 25 & 7 \\
\hline Balugo & 1115 & 223 & 160 & 32 & 4.40 & 16 & 2 & 14 \\
\hline Batinguel & 2355 & 471 & 1905 & 381 & 9.30 & 34 & 28 & 7 \\
\hline Taclobo & 4510 & 902 & 1960 & 392 & 17.80 & 66 & 29 & 37 \\
\hline Tabuctubig & 500 & 100 & 420 & 84 & 1.97 & 7 & 6 & 1 \\
\hline Polacion 8 & 2000 & 400 & 1800 & 360 & 7.89 & 29 & 26 & 3 \\
\hline Cadawinonan & 1605 & 321 & 900 & 198 & 6.34 & 24 & 14 & 9 \\
\hline Calindagan & 1500 & 300 & 1200 & 240 & 5.92 & 22 & 18 & 4 \\
\hline Poblacion 1 & 1530 & 306 & 600 & 120 & 6.04 & 22 & 9 & 14 \\
\hline Poblacion 2 & 1150 & 230 & 1070 & 214 & 4.54 & 17 & 16 & 1 \\
\hline Total & 25335 & 5067 & 17135 & 3445 & 100.00 & 371 & 252 & 119 \\
\hline
\end{tabular}

A total of 357 household respondents instead of 371 from the 12 communities (Table 41) and 30 respondents from the Local Government Units (LGU's) and NonGovernmental Organizations (NGO's) in Dumaguete City Philippines were surveyed through sets of questionnaires and interviews from March 2013 to July 2013. The population being considered consists of households who are situated in areas reported to have experienced fluvial flooding in the past few years. Using the Slovin's formula:

Where:

$$
\mathrm{n}=\mathrm{N} /\left(1+\mathrm{N} \mathrm{e}^{2}\right)
$$

$\mathrm{n}=$ number of samples

$\mathrm{N}=$ total population

$\mathrm{E}^{2}=$ margin of error

( $=0.05 \%$ if $95 \%$ confidence level or $+5 \%$ error to be used) the desired sample size $(n)$ for a total population of $5067(\mathrm{~N})$ is 371 (http://www.statisticshowto.com/how-to-useslovins-formula/). The distribution of the number of samples to be taken per community is based on the proportion (\%) of the number of households per community to the total number of households. The distribution of the number of samples to be taken for the affected $(\mathrm{A})$ and not affected (NA) households $(\mathrm{HH})$ or families are based on the proportion (\%) of the affected and not affected households per community. The sample size of 357 household respondents is still within the $95 \%$ confidence level.

The Community-Based Flood Vulnerability Index is calculated using appropriate indicators from the five components namely: hydro-climatic, social, economic, sociobehavioral, and the politico-administrative components shown in Figure 4.1. While Table 

Social Vulnerabilities and Risks

3.1 shows the relationship between components and their corresponding indicators (Chapter 3). The selection of the indicators relates among other things, to the aspects of the Hyogo Framework for Action (2005-2015) of the United Nations (Chapter 2). The respondents evaluated none of the suggested variables as irrelevant but some were, of course, judged more important than others. However, after thorough weighing of the variables, for most cases, not significantly different from equal weights hence, the researchers decided to use equal weights in many of the components at the moment and to reassess the weighting of the indicators at a potential later project stage, within the process of fully testing the proposed index.

Depending on the nature of the answer to the question, each question was given a corresponding score. For questions that require a yes or no answer: $Y e s=1, \mathrm{No}=0$. For questions that require very lightly, lightly, seriously and very seriously answer: very lightly $=1$, lightly $=2$, seriously $=3$, very seriously $=4$. For questions that require

excellent, very well, good, poor and very poor answer: excellent $=5$, very well $=4$, good $=3$, poor $=2$, very poor $=1$. To determine the composite score which is expressed in percent, the sum of the item scores were divided by the highest possible score and then multiplied by 100 .

The data were summarized per barangay (the smallest political/community unit in the Philippines) in frequency tables and their corresponding relative frequencies (\%) as well the average of scores whenever appropriate. Variations in responses are expressed as standard deviation.

\subsection{Equation}

For the calculation of this Community- Based Flood Vulnerability Index (FVI), each of the components (hydro-climatic, social, economic, socio-behavioral, and politicoadministrative) is computed based on the general flood vulnerability index (FVI) formula (Eq. 1).

$$
F V I=\frac{E^{*} S}{R}
$$

The general formula for $\mathrm{FVI}$ is computed by categorizing the indicators to the factors to which they belong (exposure $(E)$, susceptibility $(S)$ and resilience $(R)$. The indicators of exposure and susceptibility are multiplied and then divided by the resilience indicators, because indicators representing exposure and susceptibility increase the flood 

Social Vulnerabilities and Risks

vulnerability and are therefore placed in the numerator. The resilience indicators decrease flood vulnerability and are thus part of the denominator (Cendrero, 1997).

The Flood Vulnerability Index (FVI) for the hydro-geological, social, economic, sociobehavioral and politico-administrative components are expressed as follows (Equations 2-9) and equations 10 and 10' the formula for computing the overall FVI. Refer to Table 3.1 for the abbreviations used for the indicators used for the individual formula for the different components.

$$
\begin{aligned}
& \mathrm{FVI}_{\text {hydro-climatic }}=f \frac{\mathrm{FF}, \mathrm{HF}, \mathrm{HRF}, \mathrm{HNE}{ }^{*} \mathrm{NTY}}{\mathrm{LUMSD}} \\
& \mathrm{FVI}_{\text {social }}=f \frac{\mathrm{ODAW}, \mathrm{UVR}{ }^{*} \mathrm{EA}}{\mathrm{WT}, \mathrm{SN}} \\
& \mathrm{FVI}_{\text {economic }}=f \frac{\mathrm{HNIS}, \mathrm{HNIW}, \mathrm{PRV}, \mathrm{PWLV}{ }^{*} \mathrm{HC}}{\mathrm{FI}, \mathrm{PI}} \\
& \mathrm{FVI}_{\text {socio-behavioral on flood resilience }}=f \frac{\mathrm{PHFR}{ }^{*} \text { AHFR }}{\mathrm{KHFR}} \\
& \mathrm{FVI}_{\text {socio-behavioral on } \mathrm{E} \text {. coli }=} f \frac{\mathrm{PHEC} * \text { AHEC }}{\mathrm{KHEC}} \\
& \mathrm{FVI}_{\text {socio-behavioral on Leptospirosis }}=f \frac{\mathrm{PHL}{ }^{*} \mathrm{AHL}}{\mathrm{KHL}} \\
& \mathrm{FVI}_{\text {socio-behavioral on Dengue fever }}=f \frac{\mathrm{PHDF}^{*} \mathrm{AHDF}}{\mathrm{KHDF}} \\
& \mathrm{FVI}_{\text {politico-administrative }}=f \frac{\mathrm{RNRMP}, \mathrm{LUMSD}{ }^{*} \mathrm{G}}{\mathrm{PRAI}, \mathrm{SCLP}, \mathrm{RSP}, \mathrm{HPP}} \\
& \text { Overall FVI }=\frac{\text { Hydro-climatic }+ \text { Social }+ \text { Economic }+ \text { Socio-Behavioral }+ \text { Politico-Administrative }}{5} \\
& \left.\left(\frac{P H F R * A H F R}{K H F R}\right)+\left(\frac{P H E C * A H E C}{K H E C}\right)+\left(\frac{P H L * A H L}{K H L}\right)+\left(\frac{P H D F * A H D F}{K H D F}\right)+\left(\frac{R N R M P, L U M S D * G}{P R A I, S C L P, R S P, H P P}\right)\right\}
\end{aligned}
$$

The integrated Flood Vulnerability Index is a method to combine multiple aspects of a system into one number. On a global perspective, the results will be presented in values between $0 \%$ and $100 \%$ for better comprehension: $100 \%$ being the highest vulnerability 

Social Vulnerabilities and Risks

found in the samples studied and $0 \%$ the lowest vulnerability. The community-based flood vulnerability index percentile ratings are as follows with its corresponding interpretation: $0-19 \%$ very low; $20-39 \%$ low; $40-59 \%$ medium; $60-79 \%$ high; $80-100 \%$ very high vulnerability. Here is how the community-based flood vulnerability index will be interpreted: A very low flood vulnerability index indicates that the community is very well prepared for a flood event. A low flood vulnerability index also indicates that the community is well prepared for a flood event. A medium flood vulnerability index indicates that more work could be done to improve the resilience in this category. A high flood vulnerability index indicates that the community should pay specific attention to this category and should make efforts to address the areas of high vulnerability rating. A very high flood vulnerability index indicates that the community should really pay specific attention to this category and should make more efforts to address the areas of very low rating.

Regardless if the community/city has a HIGH, MEDIUM, or LOW Flood Vulnerability Index, one should learn about and investigate the weaknesses identified during the process.

\subsection{Study Area}

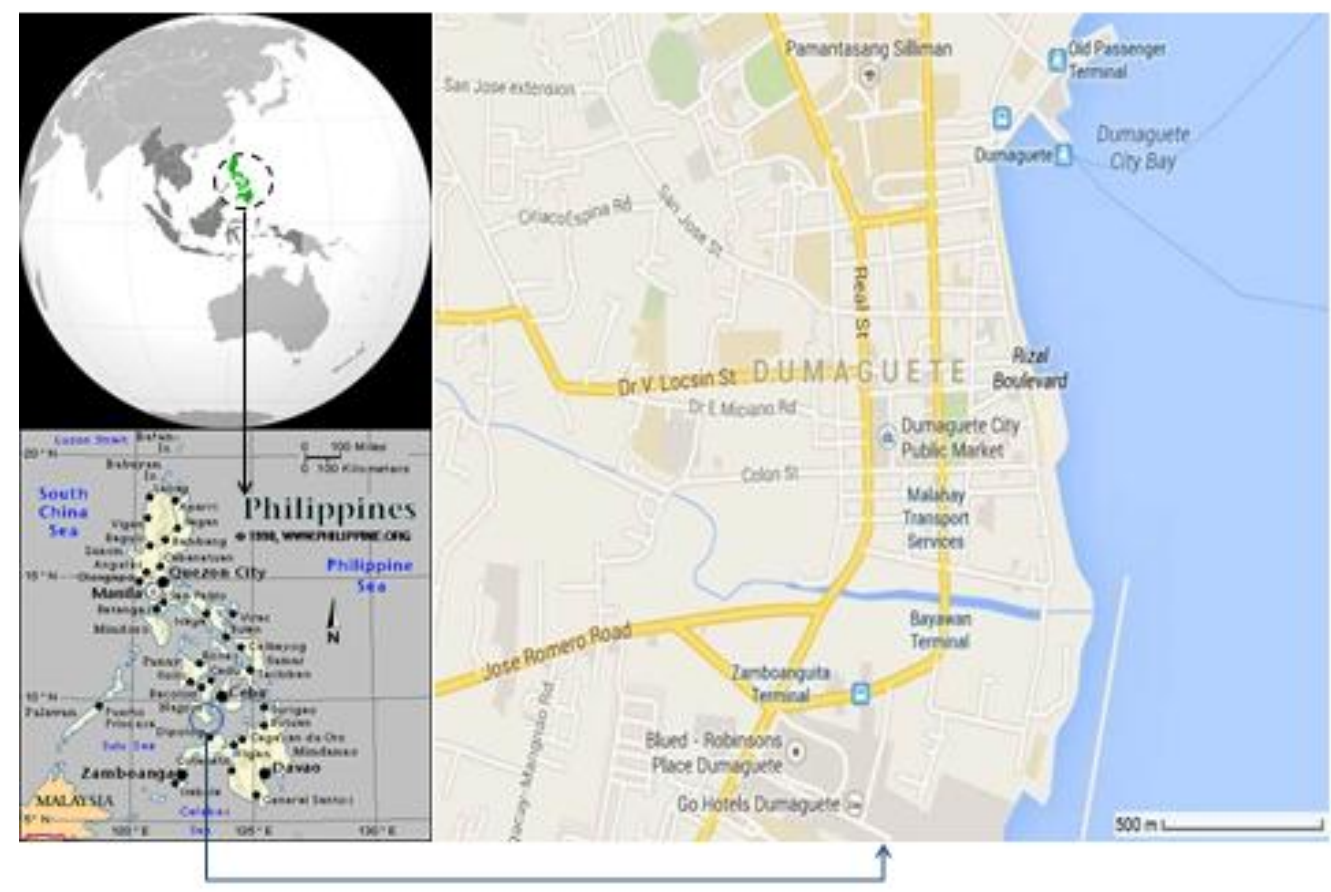

Figure 4-2: Map of the Philippines and the Study Site 

Social Vulnerabilities and Risks

\section{Country background: The Philippines}

The Philippines (Figure 4-2) is an archipelago with a total discontinuous coastline of 32,400 kilometers, the longest in the world. Being in the Pacific Rim, the Philippines is a hot spot for natural hazard occurrences. It is highly prone to storm surges and riverine flooding, caused by storms and other environmental degradation. This is due to the fact that an average of 20 tropical cyclones passes yearly through the Philippine area and about nine of them crossed land. Flooding usually occurs in the low- lying coastal areas. The eastern side of the country is subject to heavy rains during the Northeast Monsoon season (November to February), while the western side during the Southwest Monsoon season (from May to September). The Southwest Monsoon season coincides with the typhoon season as well.

The Philippines, is an archipelago of some 7,100 islands, only 2000 of which are inhabited, lies in the Pacific Ocean off the coast of Southeast Asia between latitudes $5^{\circ}$ and $21^{\circ}$ North and longitudes $117^{\circ}$ and $127^{\circ}$ East. Of the total land area of 300,000 $\mathrm{km} 2$, the 11 largest islands contain $94 \%$ of the total with the two largest, Luzon and Mindanao, accounting for approximately 66. The country's nearest neighbours are Taiwan to the north, Eastern Malaysia and Brunei to the southwest, and Indonesia to the south.

The islands are home to over 94.04 million people with a population density of 294 persons $/ \mathrm{km} 2$ but this is unevenly distributed throughout the islands. The population is evenly split between urban and rural and the largest urban centre is the capital Manila. Topographically, the Philippines are part of a western Pacific arc system that is characterized by active volcanoes, earthquakes and frequent seismic activity. The islands typically have narrow coastal plains with sand beaches and numerous swiftrunning streams, but few open onto spacious lowlands or large plains. With a tropical marine climate, the country is hot and humid year-round and is dominated by a rainy season and a dry season. The summer monsoon brings heavy rains and dangerous storms to most of the archipelago from May to October, whereas the winter monsoon brings cooler and drier air from December to February. Most of the lowland areas are hot and dusty from March to May, but even at this time, however, temperatures rarely rise above $37^{\circ} \mathrm{C}$, and mean annual sea-level temperatures rarely fall below $27^{\circ} \mathrm{C}$. Droughts and flooding from typhoons are common and annual rainfall varies from as much as $5000 \mathrm{~mm}$ in the mountainous east coast section of the country to less than $1000 \mathrm{~mm}$ in some of the sheltered valleys. This abundant rainfall is distributed unevenly 
across the country, but although there is a high degree of variability from place to place, groundwater levels are generally high, and streams flow continuously.

\section{Water resources and supply}

Freshwater storage capacity and the high rate of precipitation theoretically assure the Philippines of an adequate supply of freshwater for its agricultural, industrial and domestic uses. Approximately $70 \%$ of the land area of the Philippines is considered as watershed areas (lakes, springs, and streams), comprising over 400 river basins and with an annual average rainfall of over $2,500 \mathrm{~mm}$, there are ample, dependable surface run-off and ground water resources.

\section{Water and health}

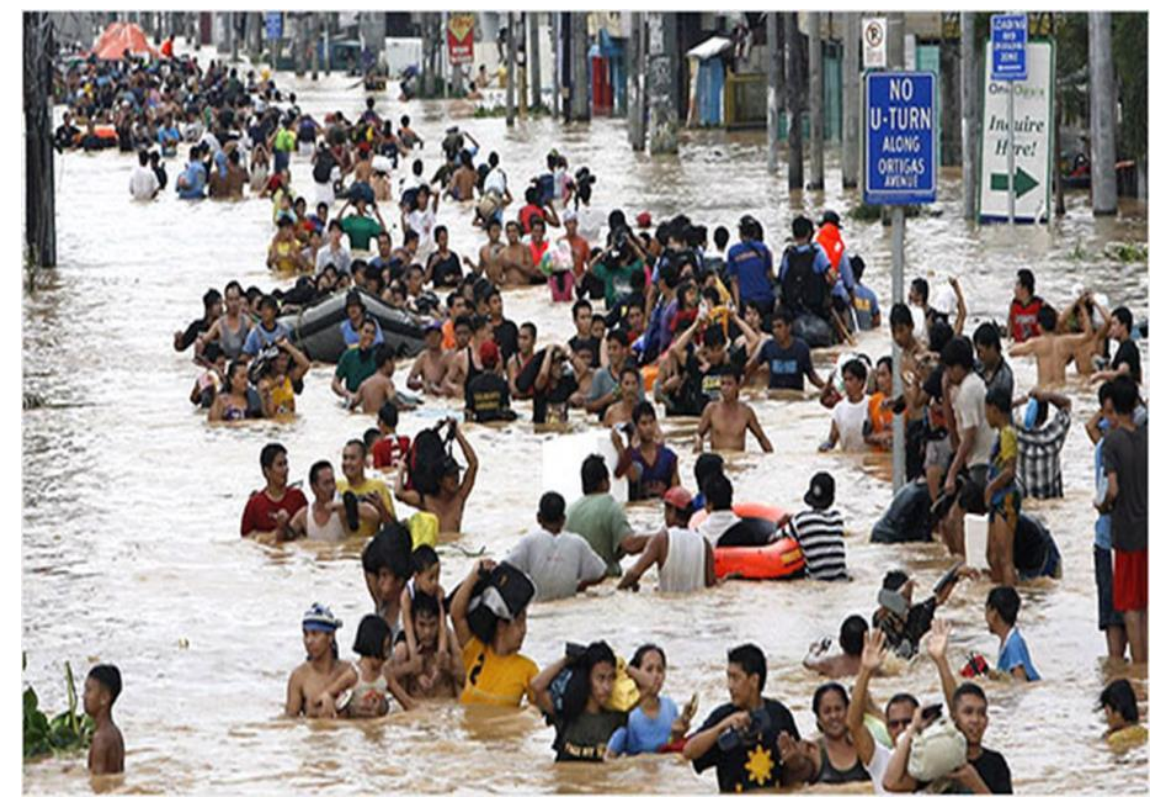

Figure 4-3: Flooding in Manila, Philippines

There have been numerous large epidemics of waterborne diseases throughout the country, particularly of cholera and typhoid fever during the 1990's. While diarrhoea remains the number one cause of illness in all age groups, the decline in the incidence of cases is accompanied by reports to the National Epidemiology Centre (DOH) of significant reduction in the number of food-borne and water-borne infection outbreaks in the past years. Investigations of these disease outbreaks have identified contaminated sources of drinking water, improper disposal of human waste and unsanitary food handling practices as the main causes. Figure 4-3 above depicts the possibility of acquiring such infections mentioned above. 
Diarrhoea and other waterborne diseases still rank among the leading causes of morbidity and mortality in the Philippines. The incidence rate for these diseases is high as 1,997 per 100,000 population while mortality rate is 6.7 per 100,000 populations. A total of 2,471 leptospirosis cases were reported nationwide from January 1 to August 18,2012 . This is $62.35 \%$ higher compared to the same time period last year $(1,522)$. Cases were high in morbidity week 1 due to flash flood in Cagayan de Oro. Most of the cases were from the following regions: Region X (37.5\%), Region VI (18.4\%) and NCR (9.1\%). 51,597 dengue cases were reported nationwide from January 1 to July 14 , 2012. This is $16.43 \%$ higher compared to the same time period last year $(44,315)$. Most of the cases were from the following regions: National Capital Region (22.24\%), Region IV-A (14.08\%) and Region III (13.65\%), (DOH, 2012).

\subsubsection{Dumaguete City, Negros Oriental Philippines}

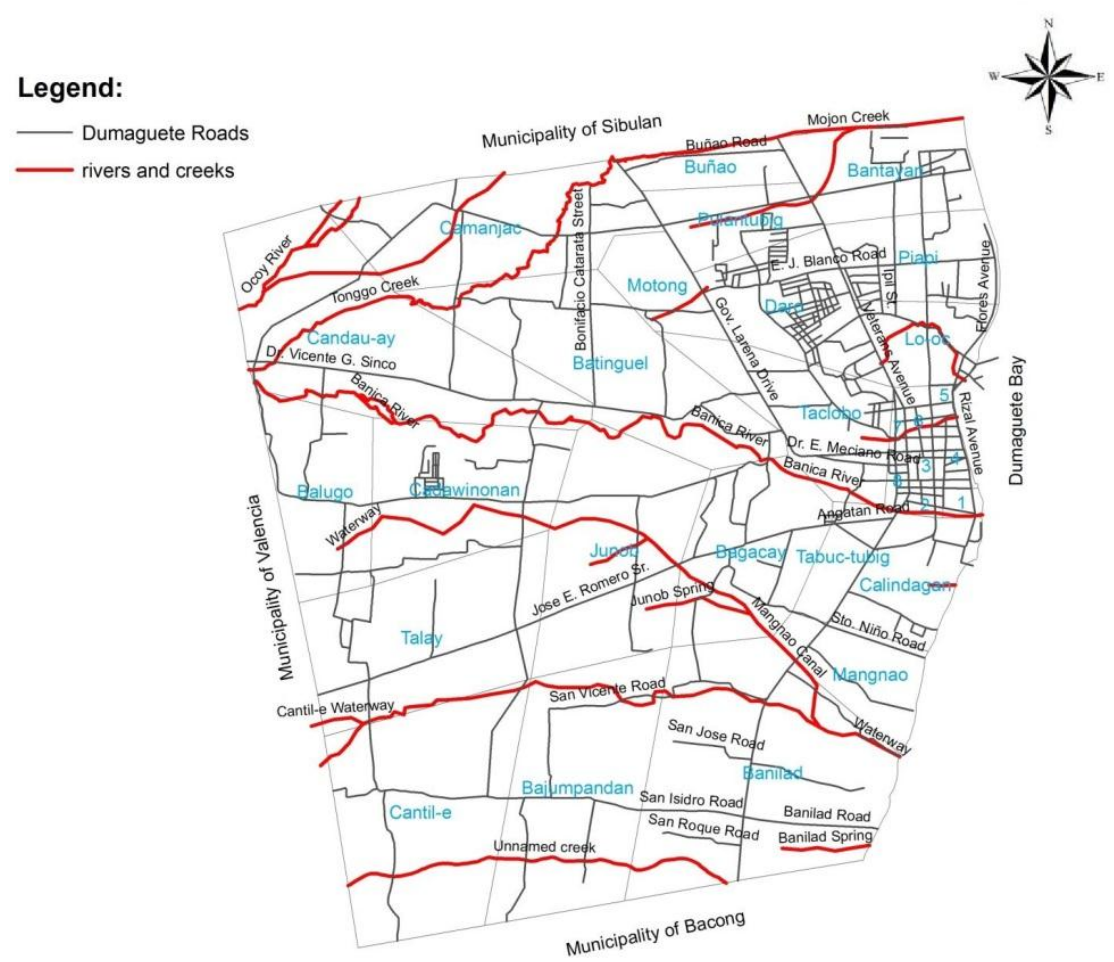

Figure 4-4: Boundary Map of Dumaguete City, Philippines

The city of Dumaguete is classified as a second class city. Dumaguete City, the capital of Negros Oriental is located 9 degrees 18 minutes 28 seconds north latitude and 123 degrees 18 minutes 28 seconds east longitude. It is bounded on the north by the municipality of Sibulan, on the south by Bacong, in the west by Valencia, and on the east by Tañon Strait and Mindanao Sea (Figure 4-4). 

Social Vulnerabilities and Risks

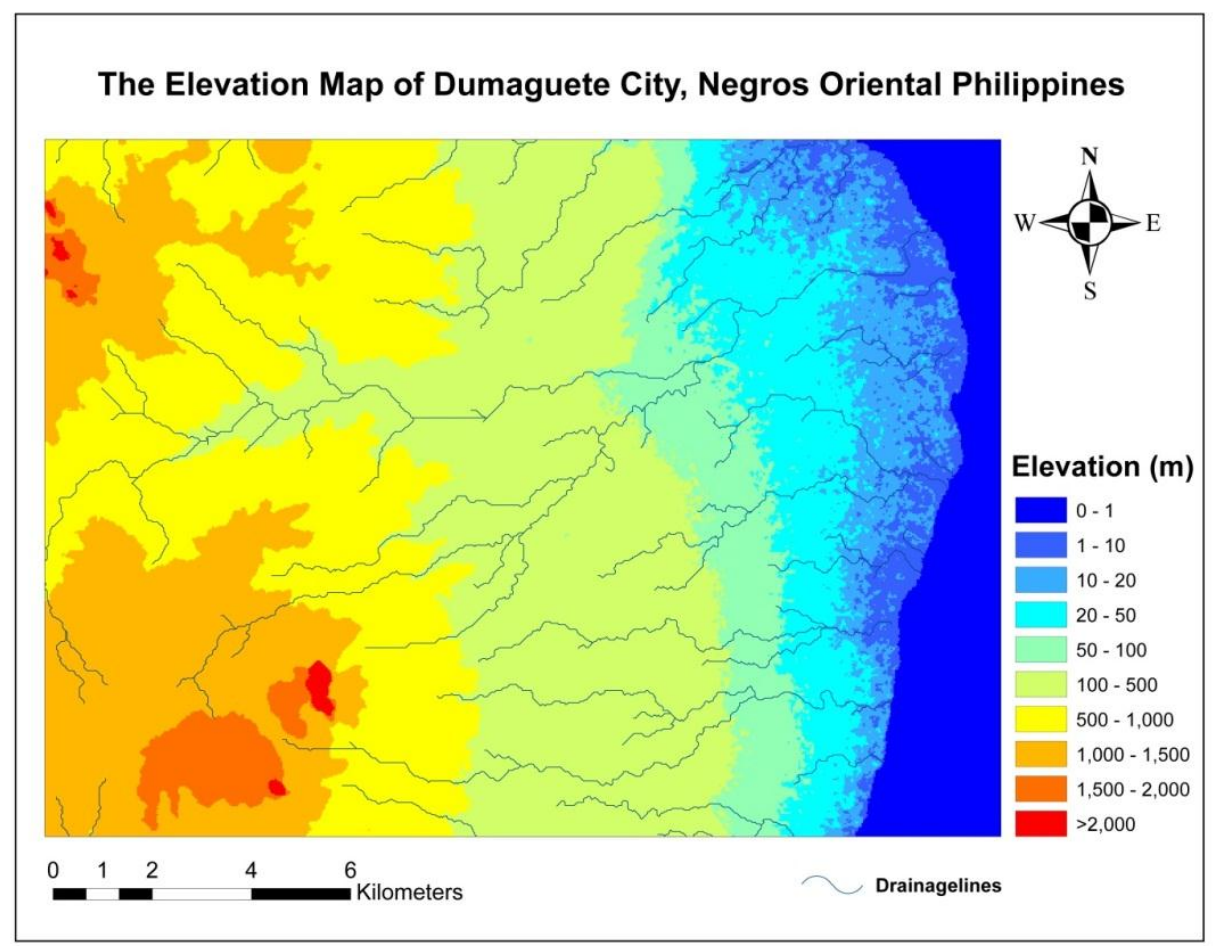

Figure 4-5: Elevation Map of Dumaguete City, Philippines

The total area of Dumaguete City is approximately 3,426 hectares with an estimated population of 120,883 according to the 2010 population census report. Its smallest barangay is Barangay 4 with an area of only 511 hectares, while the biggest barangay is Barangay Banilad with 362.71 hectares. Of the province's 20 municipalities and 5 cities, Dumaguete City is the smallest in terms of land area. The City's topography is generally flat from 2 to 6 kilometers from the shoreline (Figure 4-5). It's slope gently upwards to the adjoining municipality of Valencia. The highest ground elevation is located at the boundary of the municipality of Valencia, about 100 meters above mean sea level. About $93 \%$ of the land has slopes of less than $3 \%$. The remaining areas have $3 \%$ to $5 \%$ slope.

From the soil survey of Dumaguete City, the city's soil type consist of San Miguel-Taal Complex, San Miguel Fine Sandy Loam, Dauin Sandy Loam and Isabela Clay, found only in the Barangays of Looc, Piapi, and Bantayan, is characteristically black, coarse, powdery and loose. Dumaguete City has two seasons, namely; the dry and wet seasons. The wet season covers the period from June to November, and the dry season starts from December to May, the hottest being April and May. The average maximum temperature is 34.31 Degrees celcius and the average minimum temperature is 22.85 Degrees celcius for the past years. The relative humidity of the locality for the 

Social Vulnerabilities and Risks

past years was $78.75 \%$ with the month of December registering the highest. (Dumaguete City Planning and Development Office, 2000)

Dumaguete City has 30 Barangays, 8 of which belonged to the Poblacion area. Out of the 30 Barangays, 12 were chosen as the study sites which include Barangay TabucTubig, Junob, Poblacion 1 (Tinago), Calindagan, Balugo, Poblacion 2 (Lukewright), Pobalcion 8, Cadawinonan, Bagacay, Taclobo, Candauy-ay, and Batinguel (Figure 44).

The Bio-physical Features of Banica River Watershed

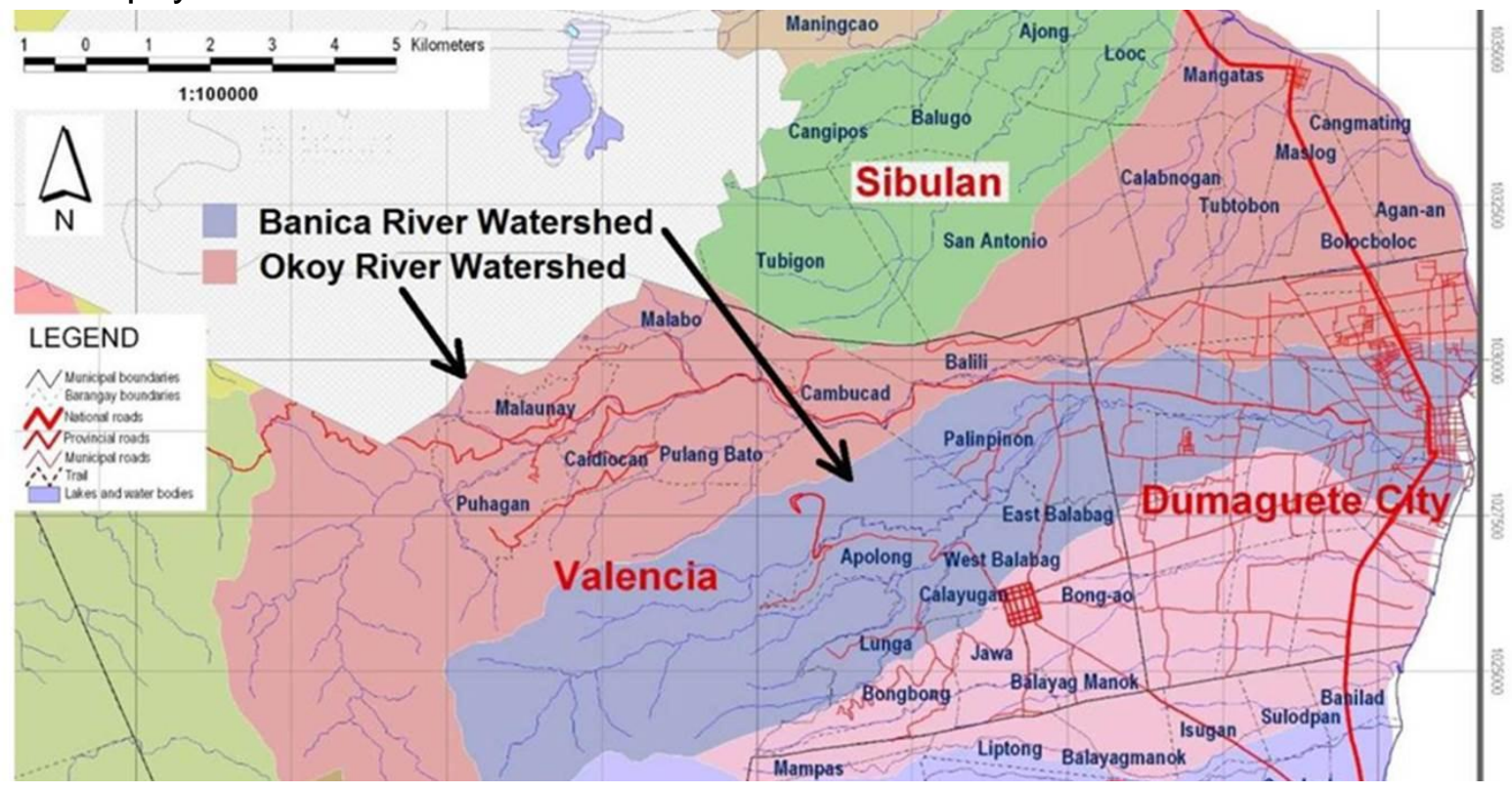

Figure 4-6: Banica and Okoy River Watershed Location Map

Topography

Banica River Watershed (BRW) forms elongated channel from the mouth of Banica River in Dumaguete City to Casaroro Falls in Valencia. The main tributary creeks and rivers of Banica River are Apolong, Bunao Diyot, Kaipuhan and Maite, among others (Figure 4-6). Banica River itself is approximately 18 kilometers long from the coastline to Casaroro Falls. The difference in elevation from Dumaguete's shoreline to the peak of the watershed is 1,580 meters. In Dumaguete, the slope ranges from $1 \%$ to $5 \%$, rapidly increases and then rises steeply westward beyond the Valencia poblacion. At the upper watershed, the slopes are much steeper at $172 \mathrm{~m} / \mathrm{km}$. Thirty eight percent $(38 \%)$ of the BRW have slopes from 18 to $50 \%$ where forest vegetation is found. About fifty percent $(50 \%)$ of the total area of BRW have elevations from 0 to $100 \mathrm{~m}$ and about $40 \%$ have 

Social Vulnerabilities and Risks

elevations from 300m or greater (Figure 4-5). The straight course of Banica River and high gradient signify a short residence time for surface runoff and hence, a great risk and occurrence of flashfloods and riverbed drying.

At the Dumaguete-Valencia boundary in Barangay Balugo, the watershed is approximately 2.0 kilometers wide. The river becomes slower as the gradient decreases and discharges at Poblacion 1 (Tinago) just south of the Dumaguete poblacion into the Mindanao Sea.

The Okoy River watershed, which is actually an allied watershed of Banica River system, drains down to a catchment area of roughly $72 \mathrm{sq} \mathrm{km}$. Okoy River runs for about 27 kilometers. Similar to Banica, its headwaters are located in the town of Valencia, its course passes partly through Dumaguete City at Barangays Candau-ay and Camanjac and eventually discharges to the Mindanao Sea through the town of Sibulan. Headwaters elevation is around $1,200 \mathrm{~m}$ (3,900ft) AMSL with a general average river slope of 0.04 .

\section{Flow and Uses of Banica River}

In the BRW are found numerous small watersheds and streams contributing to the flow of Banica River. The flow of Banica River into the lowland is drastically reduced when the National Irrigation Administration (NIA) irrigation system withdraws its full design rate of 300 liters per second in the dry summer months. In the summer months sections of Banica River in Balugo, Candau-ay, and Cadawinonan are dry for months. At the poblacion where river discharges to the seas, the river during this period is dry and seawater flows inward about one kilometer into the river channel.

There is a big difference in the flow measurements between Candau-ay and Batinguel sections of Banica River, which is attributed to high infiltration rates in Batinguel section. The waters of Banica River and its tributaries are used for irrigation, recreation, laundry, and bathing of both humans and animals. In the upper watershed in Valencia, water is diverted to fill two public and private swimming pools but subsequently discharged back to the river. At Barangay Apolong in Valencia some distance below the swimming area, a greater percentage of water from Banica River are diverted for irrigation purposes. In the lowlands, the water is mainly used for bathing and laundry purposes.

A few years ago, the river water at the upper reaches of the water system was classified by DENR as Class A. However, its present uses would rule out its classification as high 

Social Vulnerabilities and Risks

quality surface water (Institutionalization of the Rehabilitation of Banica River Watershed, 2000).

As per geophysical features of the two watersheds, flooding can be characterized as rapid onset (Flash flood) at the upstream to midstream part, becoming moderate at its lower sections. Obvious manifestation of flood response is the river channels' slope and the channel bed which is composed mainly of boulders at the upstream portion, and large rocks and stones, to cobblestones at the midstream part. Interviews conducted in some places revealed that river level rises are quite rapid particularly at the upstream and midstream portions. Also floods lasted for just a few hours at many areas for both watersheds as was observed during the passage of Tropical Storm SENDONG in 2011.

\section{Land Characteristics}

There are basically two types of soil in the BRW, namely: clay to sandy clay loam in the upper watershed and sandy loam in the lowlands. In the lowlands, soil is slightly susceptible to erosion but in the uplands, there are pockets wherein soils are highly, moderately and slightly susceptible to erosion.

\section{Land Use}

The land uses of the two LGU's show contrasting utilization. Valencia is predominantly agricultural and timberland with small areas for residential use. Within the BRW in Valencia, land is used mainly for agriculture and social reforestation. While Dumaguete City is considered as $100 \%$ urbanized, approximately $22.5 \%$ of its land in the southern portion of the city is considered as protected prime agricultural land. Its main uses are agriculture, residential, commerce and institutional. As illustrated in Figure 4-7 below, the built up areas are in the poblacion (centre areas) while outside the poblacion area there are still open spaces/idle lots making Dumaguete City not a crowded place. 


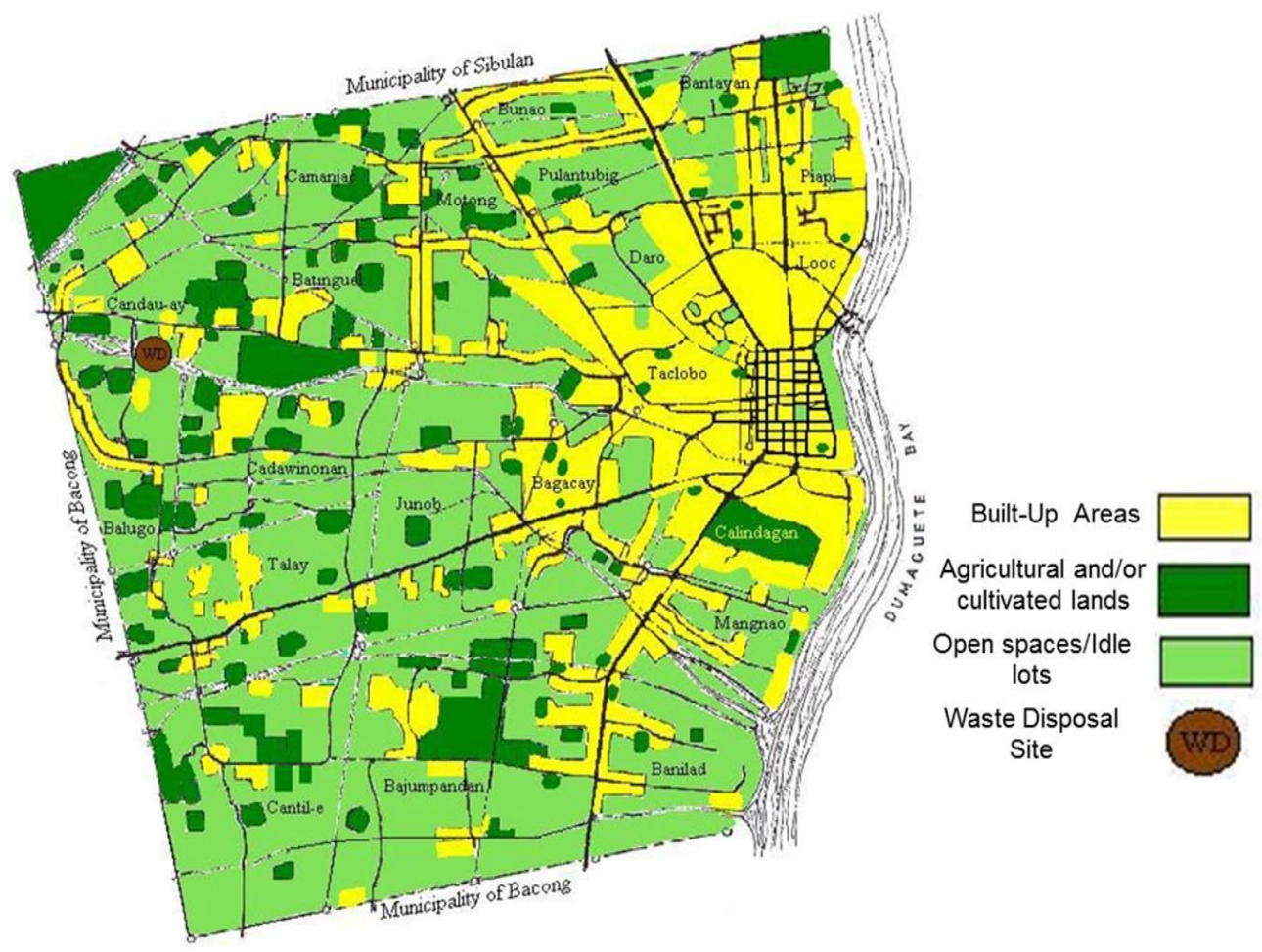

Figure 4-7: Existing General Land Use Map

According to the Local Disaster Risk Reduction and Management Council (LDRRMC) of Dumaguete City, on February 07, 2009, the effects of Amihan produced a low pressure area (LPA) with heavy rainfall which caused a major flooding in Dumaguete City affecting 12 barangays of the City, namely: Tabuc-tubig, Bagacay, Junob, Cadawinonan, Batinguel, Candau-ay, Balugo, Taclobo, Poblacion 8, Bunao, Camanjac and Poblacion 2. The main reason why the flood became devastating was the occurrence of heavy rainfall which happened during high tide which causes a massive increased of flood water level to an estimated height of 1 meter or higher in some areas. Based on the disaster timeline result of the LDRRMC, 60 houses were totally damaged and around 1000 families were affected. Infrastructure and agricultural damage was significant, and based on the report made by the city LDRRMO the flood cost around 25 million pesos worth of damage to the city.

Like many coastal cities and municipalities in the Philippines, Dumaguete City is now frequently visited by typhoons particularly in the months from October to February where the northeast monsoon is passing through the entire province of Negros Oriental. From 2011 up to the present, three significant typhoons passed through the city and the province which brought with it significant damage to the area. 

Social Vulnerabilities and Risks

\subsection{Community Profile}

A brief description of the 12 communities in Dumaguete City, Negros Oriental that were studied are described below. These communities were chosen because they are located along the Banica River that flows into the city. History of the flood events in Dumaguete City has showed that these communities have experienced such flooding phenomenon. A quick assessment conducted by The MGB-Region VII in February 25, 2006 and a more recent assessment was conducted by the Local Disaster Risk Reduction Management Office (LDRRMO) from the most recent flash flood/flooding event caused by Typhoon Sendong (International name: Washi) in December 17, 2011 were incorporated in the community profile.

\section{(1) Tabuc-tubig}
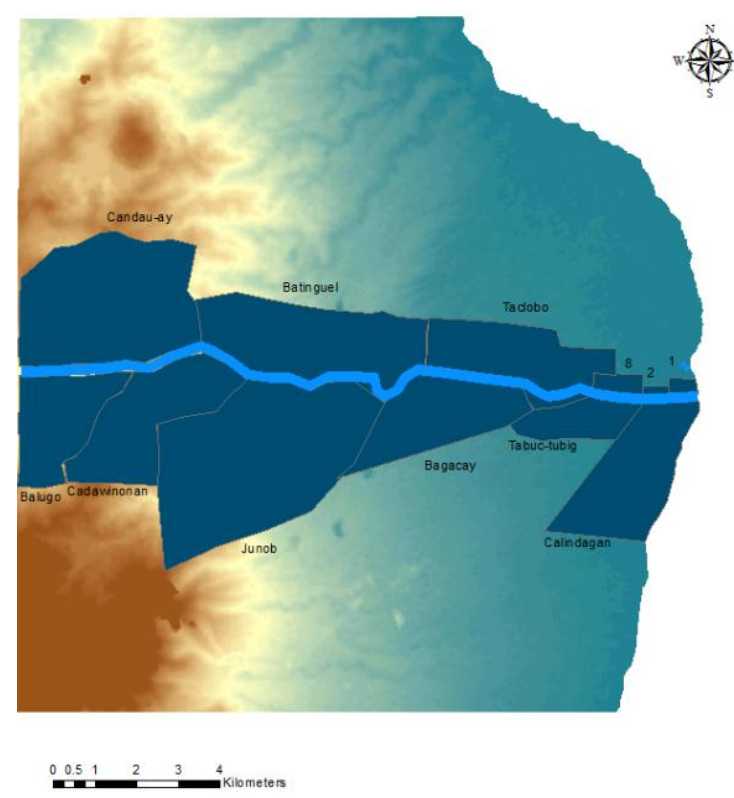

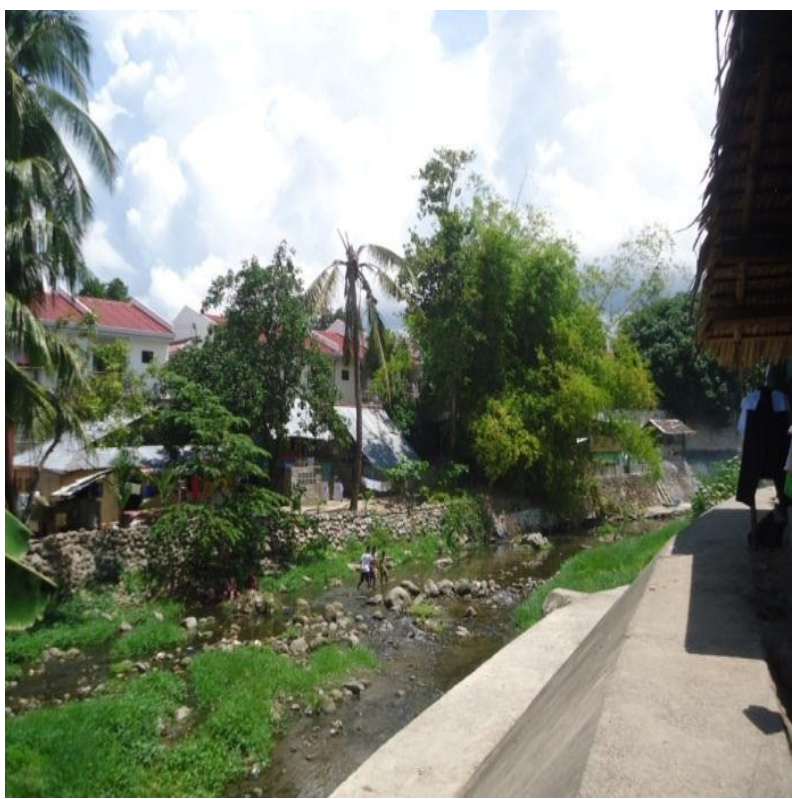

Figure 4-8: Barangay Tabuc-tubig

Barangay Tabuc-tubig (Figure 4-8) has an area of .4068sq.km and a population of 1684 people as of the 2010 Population census with 100 household. According to the last human and social capital community assessment by the Local Disaster Risk Reduction Management Office (LDRRMO), there are only five hundred exposed individual (500) from entire community population and 420 of the exposed population were affected during the most recent flash flood in December 17, 2011 caused by Typhoon Sendong (International name: Washi). Eighty four (84) households were affected. Eighty-four percent $(84 \%)$ of the population was affected. A flood water level of $0.7 \mathrm{~m}$ has flooded the community covering about $(30 \%)$ of the area. As observed in this photo, there are a number of houses built along the river banks whose flood barrier were not enough to 
contain such huge volume of water during heavy rains and typhoon seasons. Eight (8) respondents were surveyed from this community.

(2) Junob

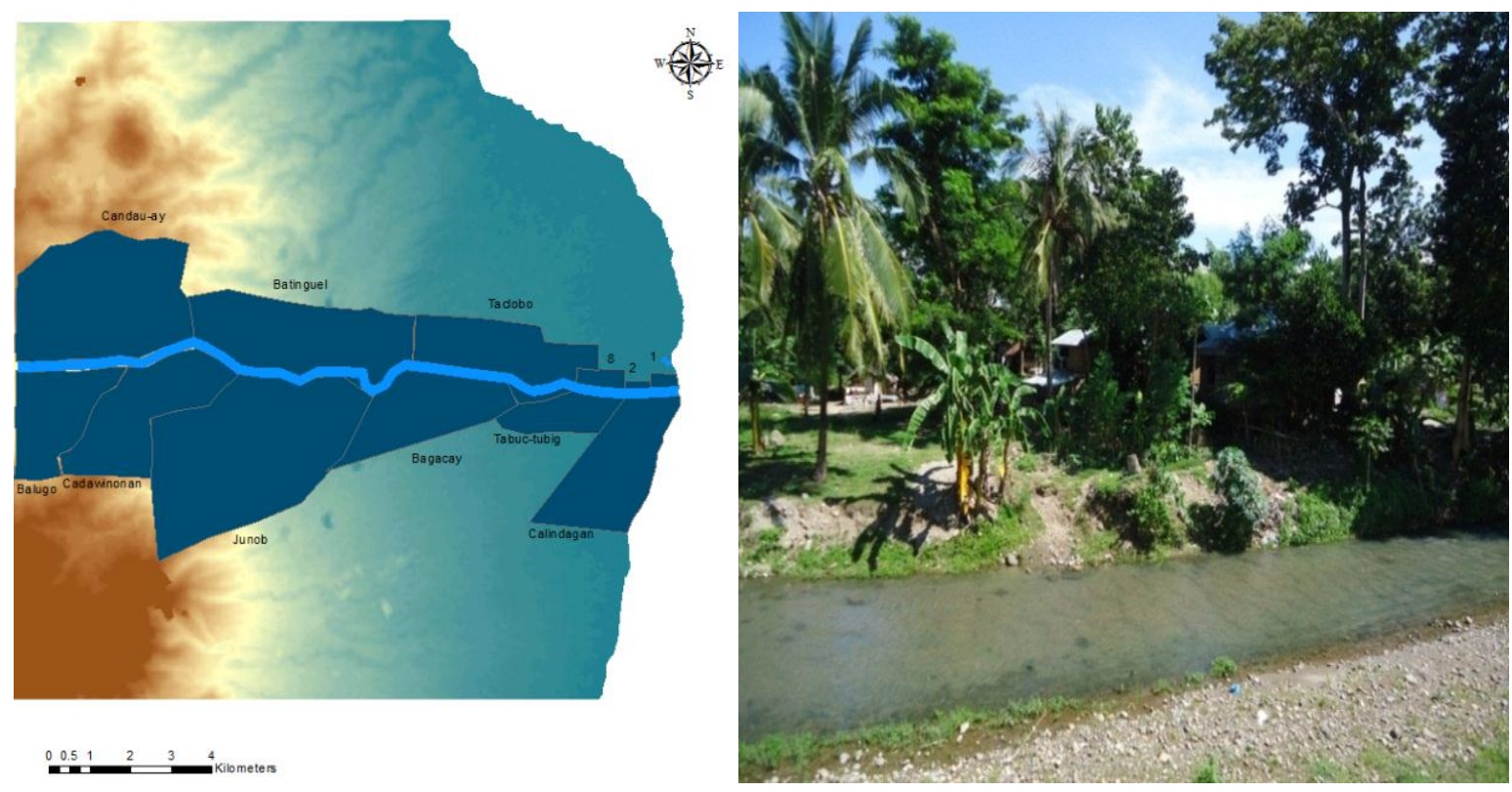

Figure 4-9: Barangay Junob

This community (Figure 4-9) has a total population of 6054 with180 households and only 900 are the exposed individual. This barangay (community) has an area of $2.2536 \mathrm{sq} . \mathrm{km}$. It is the second largest barangay in terms of land area. In that same assessment, one hundred seventy four (174) households were affected. Ninety-seven percent $(97 \%)$ of the exposed population was affected. A flood water level of $0.5 \mathrm{~m}$ flooded the community about (10\%) of the area. Barangay Junob is outside the Poblacion area. It is not a built-up area but there are spaces along the river that were not protected with dike system making some of the houses more vulnerable. As seen in this photo, these houses are built in the flood plain area which can easily be reached by over-spilling water from the river. Fourteen (14) respondents were surveyed from this community. 
(3) Poblacion 1 (Tinago)

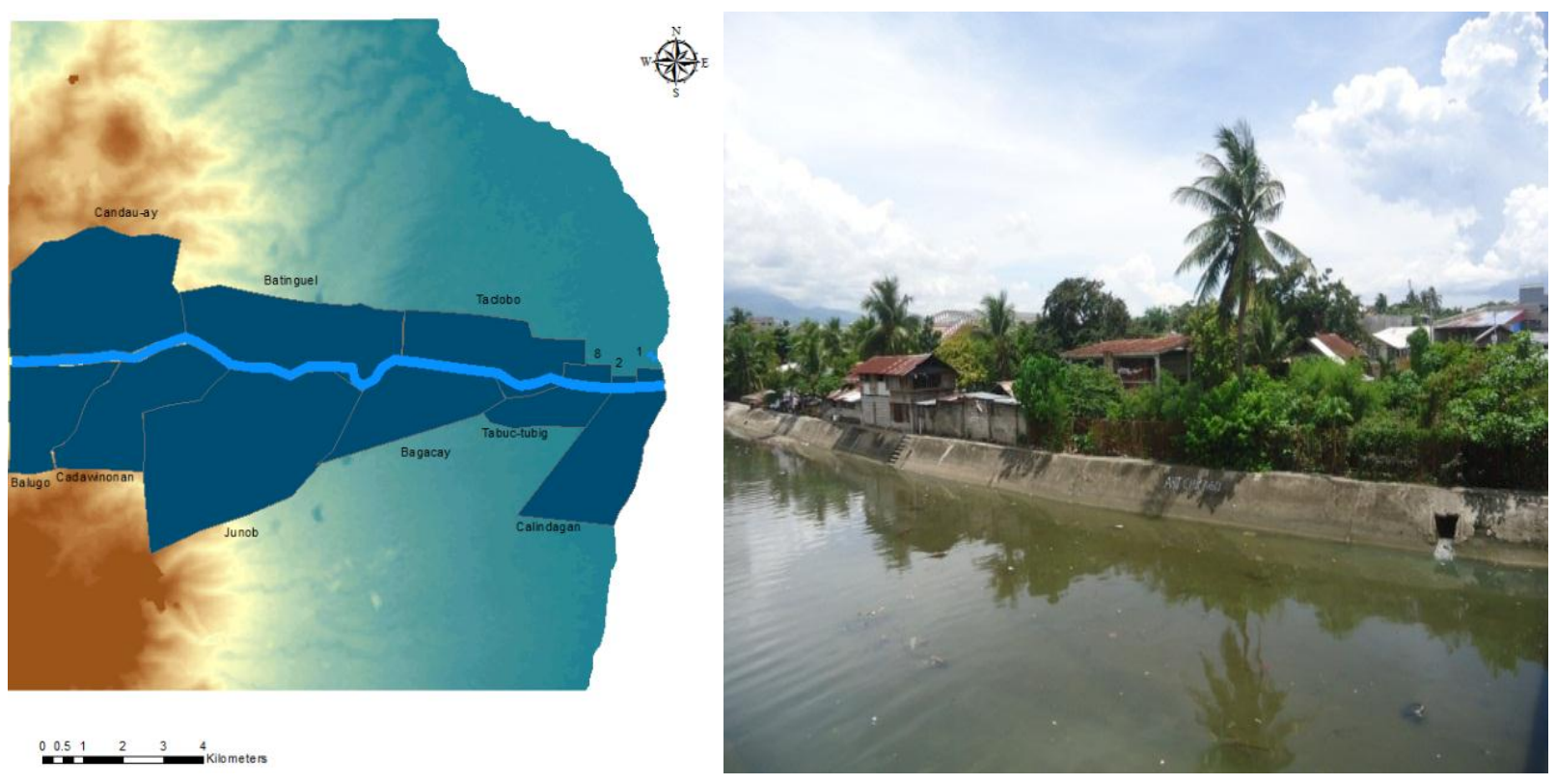

Figure 4-10: Poblacion 1 (Barangay Tinago)

The land area of Poblacion 1(Tinago) is 0.0801 sq.km (Figure 4-10). It has a total population of 2170 and 1530 are the exposed population. There are three hundred six (306) households in this community. One hundred twenty (120) of the households were affected from the last flooding events affecting about thirty-nine percent (39\%) of the exposed population. In February 25, 2006 the Mines and Geosciences Bureau (MGBRegion VII) conducted a geo-hazard survey and based from their results Dumaguete City is vulnerable to flooding. A low flood depth of up to $0.5 \mathrm{~m}$ was recorded but rarely experienced in Purok Ubos. This community is the first barangay located immediately after the mouth (delta) of the river from the shoreline. It is observed in this photo that during high tide, the seawater generally reached this part of the river. Flowing rubbish are frequently observed as well. The dike system lines the entire stretch but not high enough to protect from flowing waters during unprecedented events. Twenty-two (22) respondents were asked from this community. 


\section{(4) Calindagan}

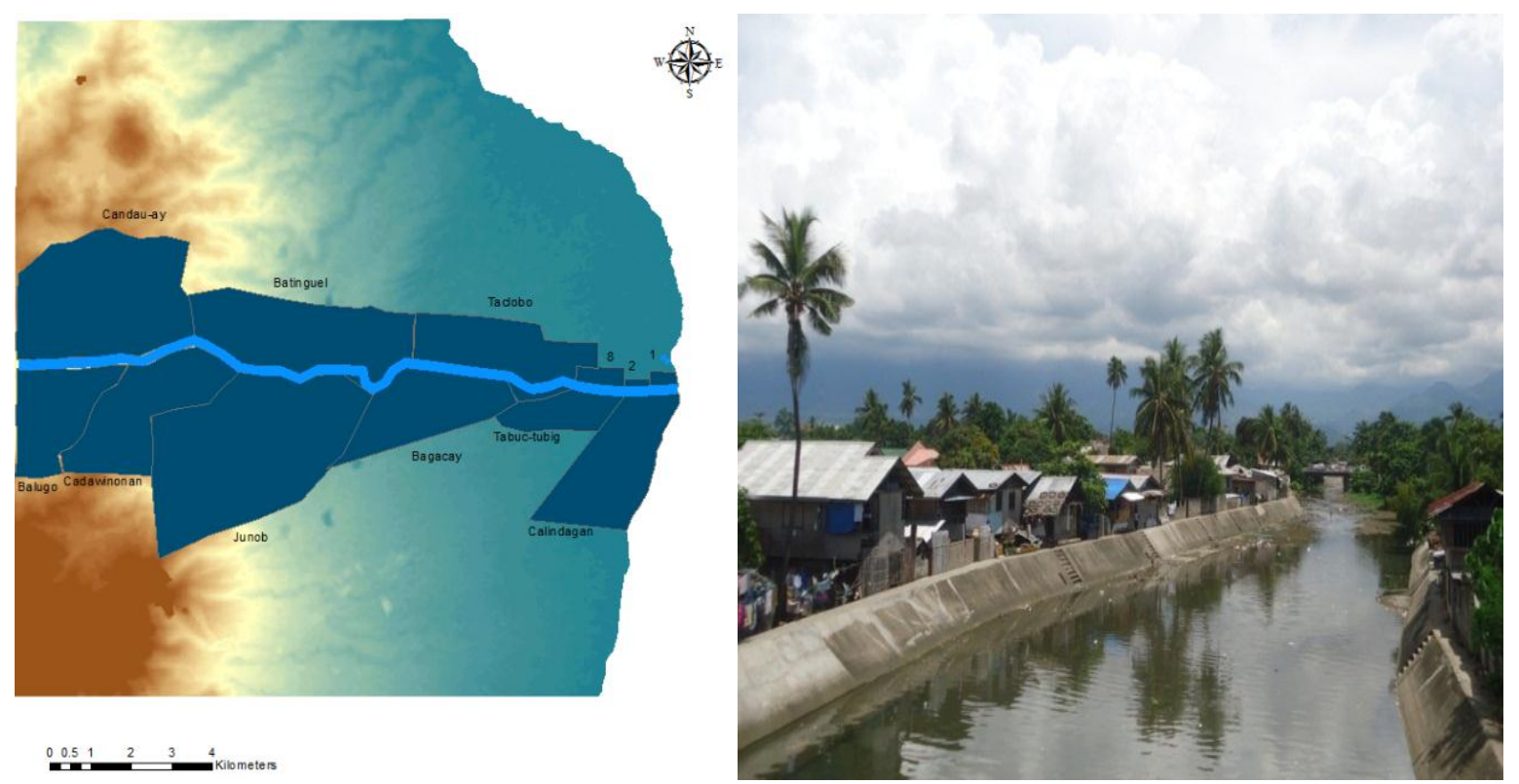

Figure 4-11: Barangay Calindagan

Barangay Calindagan (Figure 4-11) has an area of $0.8457 \mathrm{sq} . \mathrm{km}$ and has 8,056 total population with three hundred (300) households. One thousand five hundred (1500) are the exposed individuals. Two hundred forty (240) of the households were affected from the last flash flood event, affecting eighty percent (80\%) of the exposed population. According to the survey conducted by MGB-Region VI, a flash flood with high turbidity can rarely occur in Barangay Calindagan. In addition, a low flood depth of up to $0.5 \mathrm{~m}$ is seasonally experienced in this barangay. Purok Sampaguita and Purok Orchid had experienced $1 \mathrm{~m}$ depth floodwaters along the river bank and that is considerably high. Storm surge during typhoon Ruping (about 14 years ago) has devastated the houses that were along the coast. Forty (40) houses were totally damaged. Like its neighbouring barangay (Poblacion 1), Calindagan is also often seen with floating rubbish and some of the household drainage exits to the river. There are twenty-three (23) respondents from Calindagan that were surveyed. 
(5) Balugo
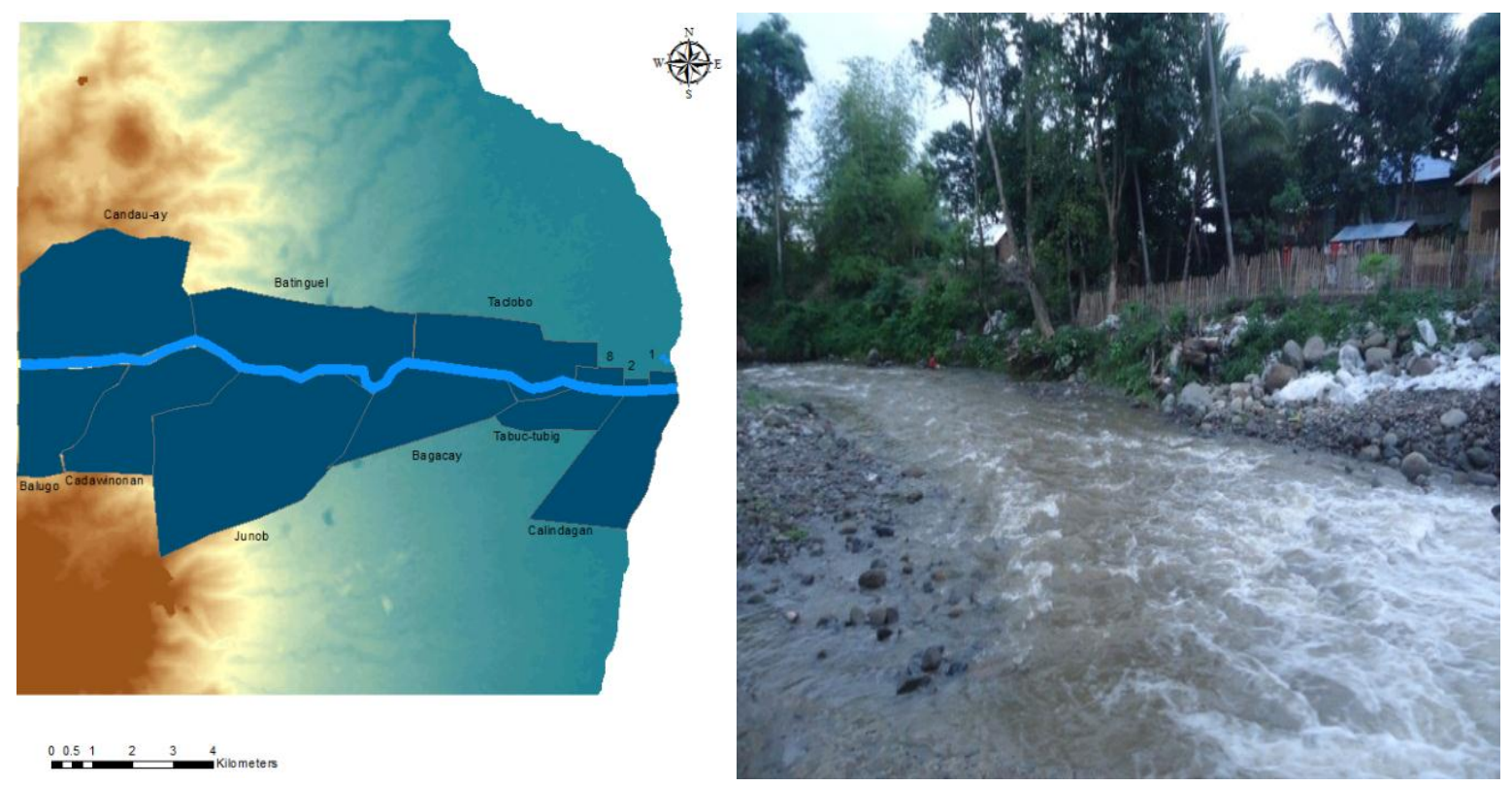

Figure 4-12: Barangay Balugo

Barangay Balugo (Figure 4-12) has a land area of $1.3184 \mathrm{sq} . \mathrm{km}$. This community has a total population of 2980 with one thousand one hundred fifteen (1015) exposed individual. There are two hundred twenty three households (223) in this community and thirty two (32) households were affected in the last flooding events. Only about fourteen percent $(14 \%)$ of the exposed population of the community was affected. Ten percent $(10 \%)$ of the entire area was flooded. From the records conducted by the MGB-Region VII in 2006, a flash flood with low turbidity occurs along this barangay affecting eighteen (18) households. Less number of houses are located near the river bank. Rather, most houses in Balugo are located further inland which is more elevated, thus less vulnerable in terms of exposure. Seventeen (17) respondents were solicited from Balugo. 
(6) Poblacion 2 (Lukewright)
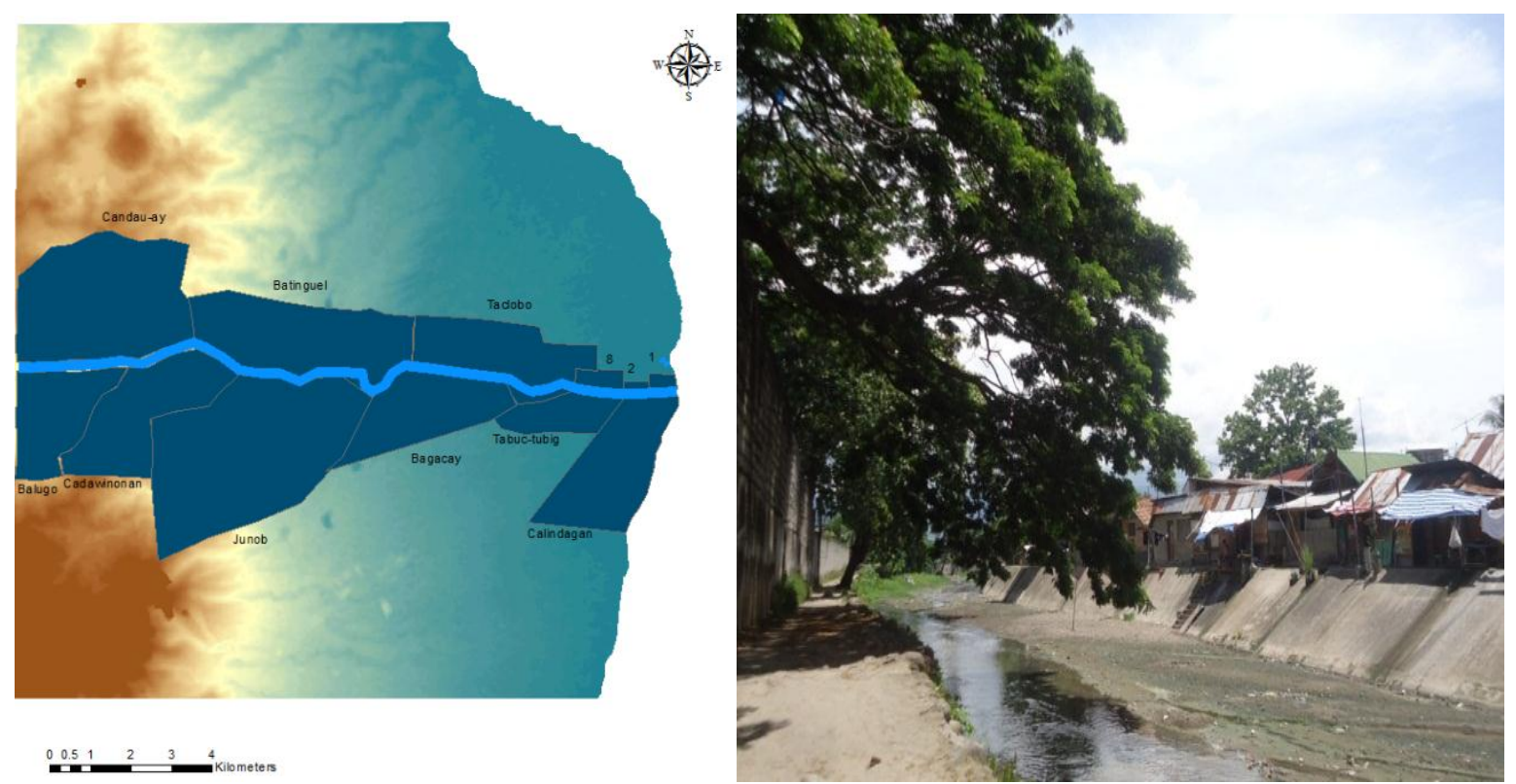

Figure 4-13: Poblacion 2 (Barangay Lukewright)

Poblacion 2 (Figire 4-13) has a land area of .0524sq.km and is second smallest in terms of land area among the 12 communities surveyed and has a total population of 1,305. This community has the smallest population among the 12 communities studied. One thousand one hundred fifty $(1,150)$ are the exposed individual. There are two hundred thirty (230) households. Two hundred fourteen (214) of the households were the affected from the last flooding. Ninety-three percent (93\%) of the population was affected. The flood water level has reached to about $0.6 \mathrm{~m}$, and twenty percent $(20 \%)$ of the community area was flooded. As observed in this photo, houses are immediately located on the river banks with low flood barrier system (dikes). Floating rubbish were observed especially further downstream. Fifteen (15) respondents were surveyed from Poblacion 2. 


\section{(7) Poblacion 8}

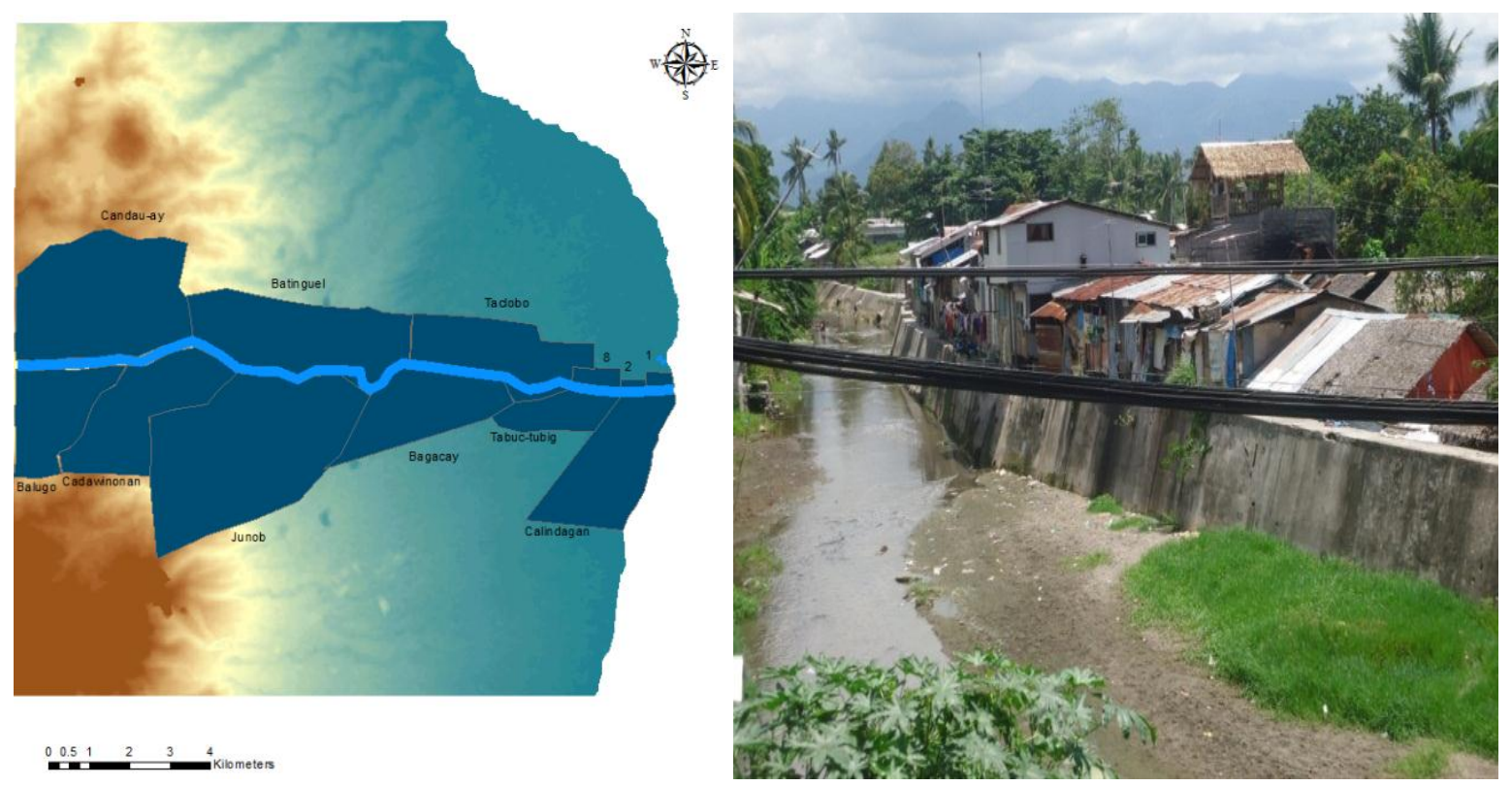

Figure 4-14: Poblacion 8

Poblacion 8(Figure 4-14) has a land area of .0623sq.km with two thousand three hundred sixty three $(2,363)$ people living in Poblacion 8 and 2000 of which are the exposed individuals. There were 1800 people affected during the last flash flood and there are 400 households in this community. Three hundred sixty (360) of the households were affected leading to ninety percent (90\%) affected population. Forty-five percent $(45 \%)$ of the area was flooded with waters up to $0.8 \mathrm{~m}$ in depth. Poblacion 8 is second most flooded among the 12 communities surveyed. As seen in this photo, houses are located immediately on the river banks and most houses are located on low lying area behind the dike system. Some parts of the flood barrier have been lowered through deposition of soil and sediments overtime making it easier for the flood water to overspill. Thirty (30) respondents were surveyed from this community. 
(8) Cadawinonan

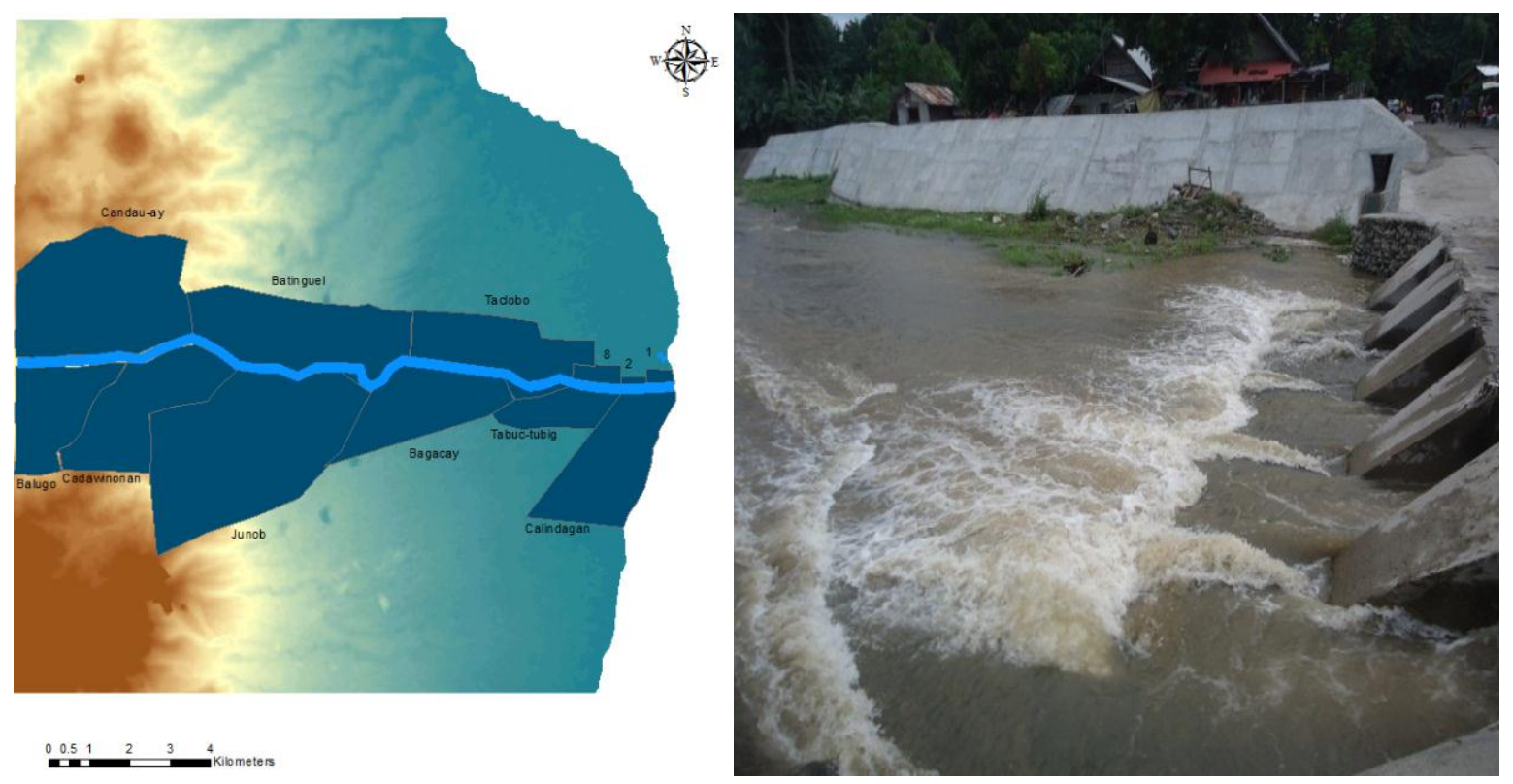

Figure 4-15: Barangay Cadawinonan

Cadawinonan (Figure 4-15) has 4,892 population in an area of $1.7028 \mathrm{sq} . \mathrm{km}$. One thousand six hundred five (1605) of which are the exposed individual. There are three hundred twenty-one (321) households were one hundred ninety-eight (198) of which were affected in the last flooding event. Sixty-two (62\%) of the population was affected. During the flood event, a $0.6 \mathrm{~m}$ flood water level spread the area. Twenty-five percent $(25 \%)$ of the area was flooded. In spite that the flood barriers are quite high enough but some areas were not completely built with the dike system thus flood water escaped from those open areas. The low lying overflow must have also contributed to the blockage of rushing water pushing it to the open side. This area is the location of one of the housing project area of the city. There are more or less 100 houses which are located immediately after the dikes system making it more vulnerable to exposure. Sand-gravel activity is active in this part of the river. Twenty-five respondents were solicited from Barangay Cadawinonan. 
(9) Bagacay
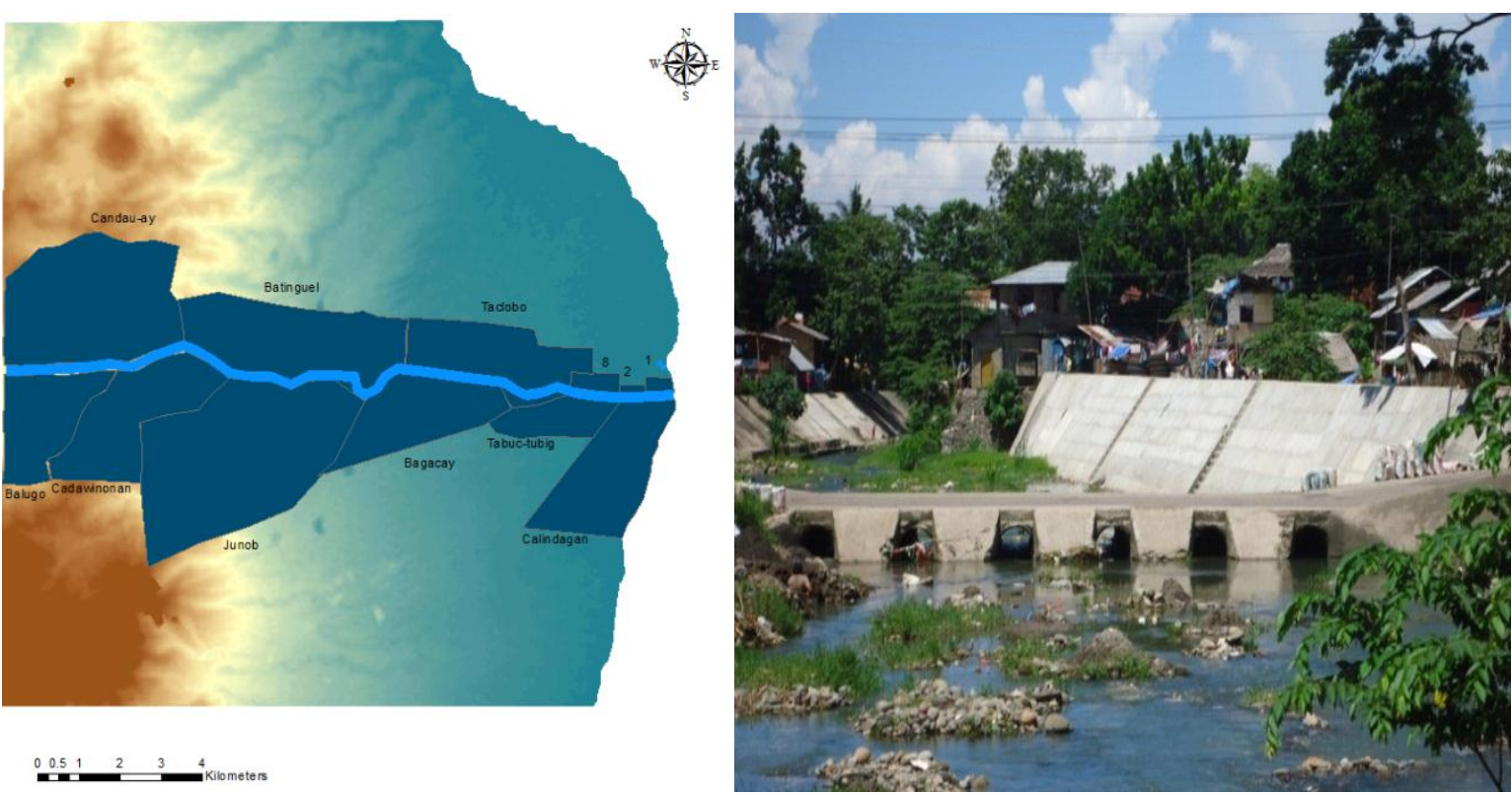

Figure 4-16: Barangay Bagacay

Bagacay (Figure 4-16) has an area of 1.6021 sq. km with a population of 8,266 . Two thousand one hundred seventy $(2,170)$ of which are the exposed individuals. There are four hundred thirty-four (434) families. In the last flooding event, three hundred forty (340) families were affected leading to seventy-eight percent $(78 \%)$ of the population was affected. The flood water level was up to $0.5 \mathrm{~m}$, flooding ten percent $(10 \%)$ of the area. Not all the river banks in Barangay Bagacay were built with dike system. Other areas are open and expose to the rushing flood water spreading during flash floods. The overflow structure may also contribute to the blockage of rushing waters spreading to the open spaces eventually reaching the nearby houses. As observed in this photo, sand gravel activity is active in this part of the river. Thirty (30) respondents were surveyed from Bagacay. 
(10) Taclobo

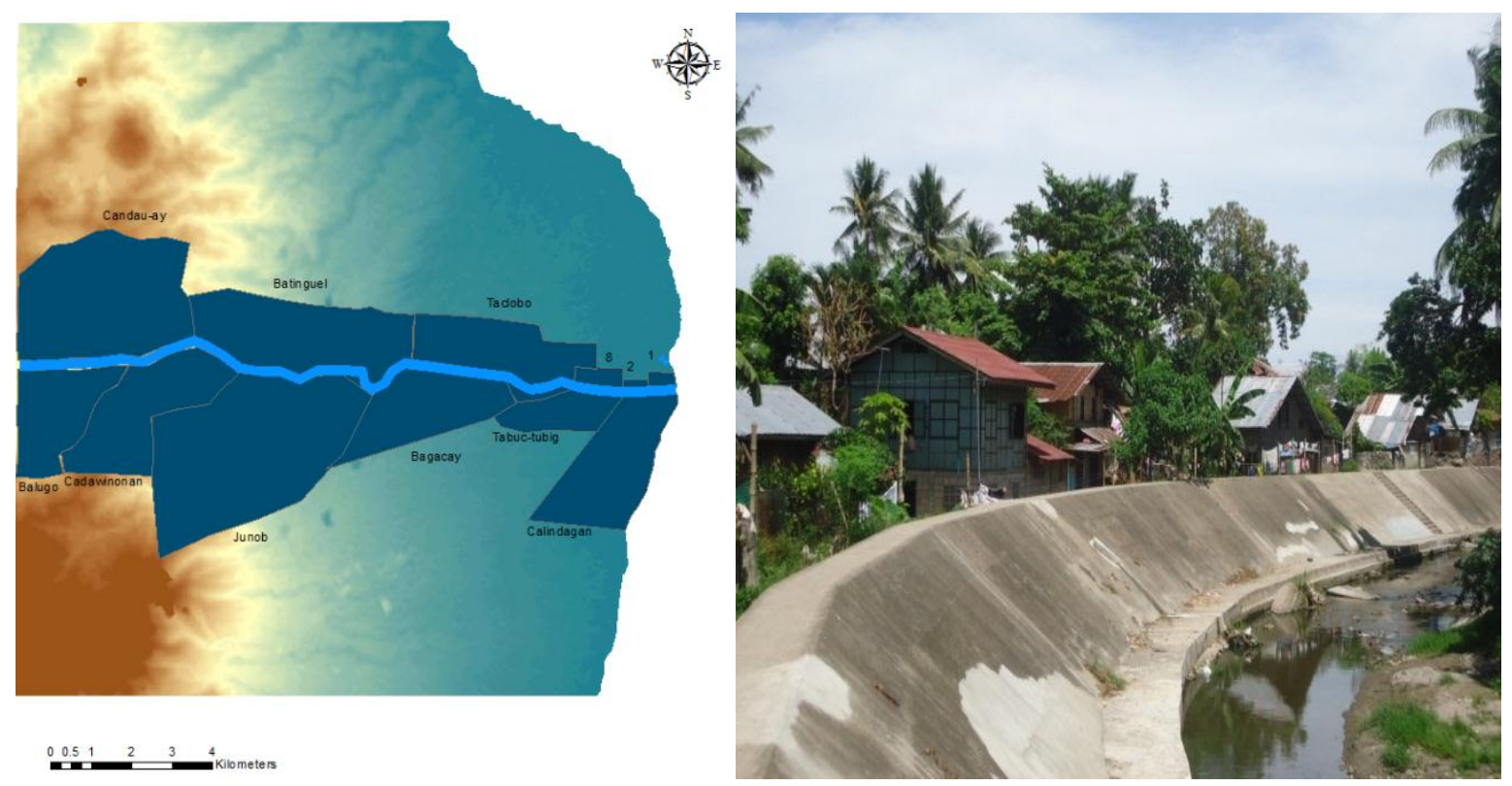

Figure 4-17: Barangay Taclobo

The land area of Barangay Taclobo (Figure 4-17) is 1.2931sq.km and with a population of 9,691 and four thousand five hundred ten $(4,510)$ individuals are the exposed. There are nine hundred two (902) families in this community. Three hundred ninety two (392) families were affected from the last flooding affecting forty-three percent $(43 \%)$ of the population. The flood waters reaches up to $0.5 \mathrm{~m}$ and fifteen percent $(15 \%)$ of the area was flooded. The entire stretch of Barangay Taclobo on this side of the river is lined with dike system but during the last flash flood the flood waters go beyond this flood barriers spreading to the houses nearby. The opposite side of the river has experienced a more devastating effect because it is not built with flood barriers (dike system) and it is located in much lower area than what is seen here on the photo. The low structure overflow may also have contributed in the over spilling of the rushing water. There were sixty-three (63) respondents interviewed from Taclobo. 
(11) Candau-ay

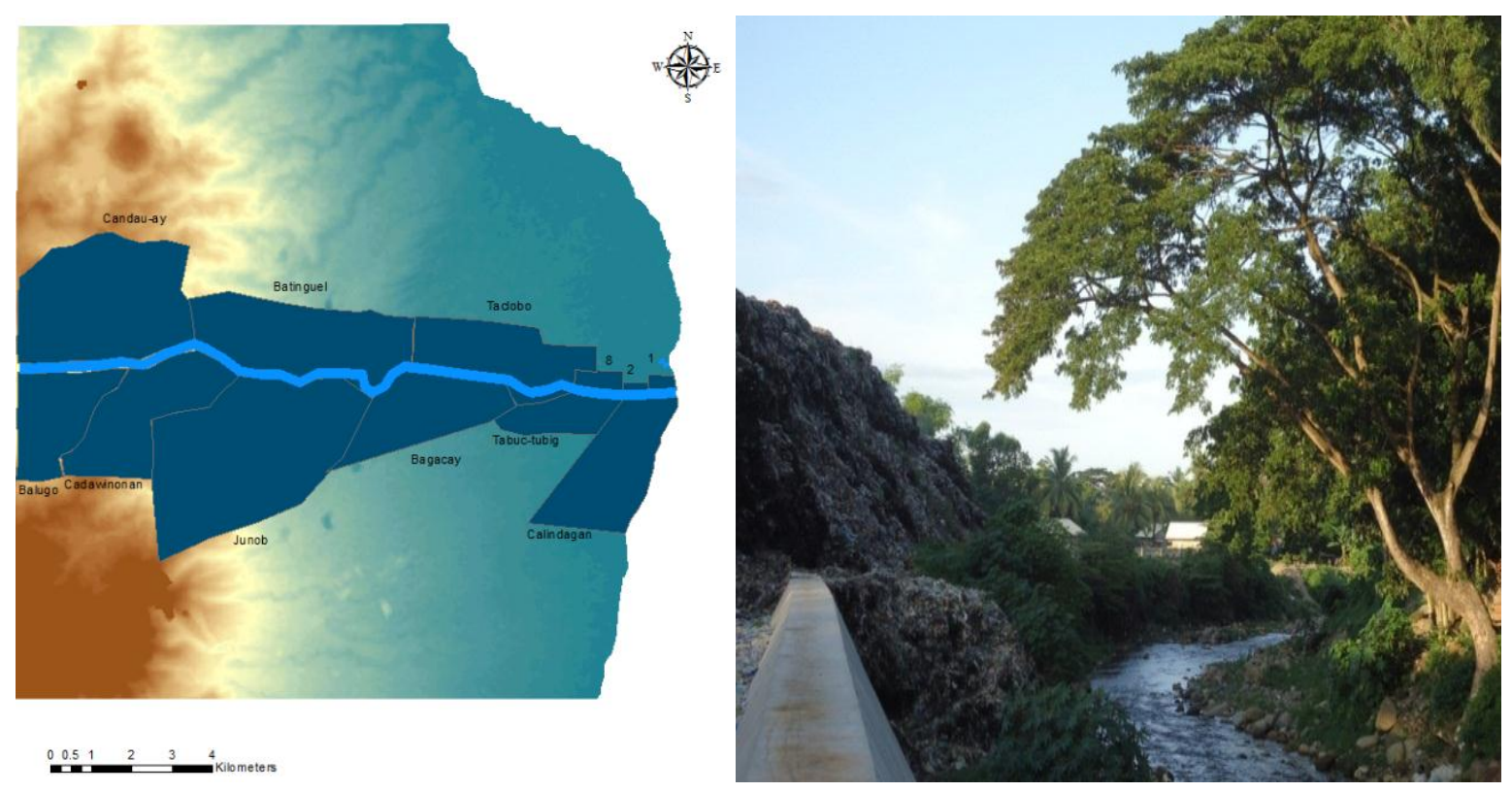

Figure 4-18: Barangay Candau-ay

Candau-ay (Figure 4-18) has 2.7370 sq.km area with a population of 6,583 and six thousand (6000) individuals are exposed. There are one thousand two hundred $(1,200)$ families. Nine hundred ten (910) families were affected out of the one thousand two hundred $(1,200)$. Seventy-six percent of the population was affected from the last flooding event. The flood water level reaches up to a meter $(1 \mathrm{~m})$ covering a $50 \%$ flooded area. The flood barriers of Barangay Candau-ay are in patches, not the entire stretch is lined with dike systems. There is also a government housing project in this community that were located adjacent to the river banks which was the most affected during the last flooding. The low level structure of overflow (bridge system) may have also contributed to the blockage of rushing flood water which spreads to the open spaces and reaching the surrounding houses. Seventy-two (72) respondents were surveyed from Cadawinonan. It has the most number of respondents among the 12 chosen communities. 
(12) Batinguel

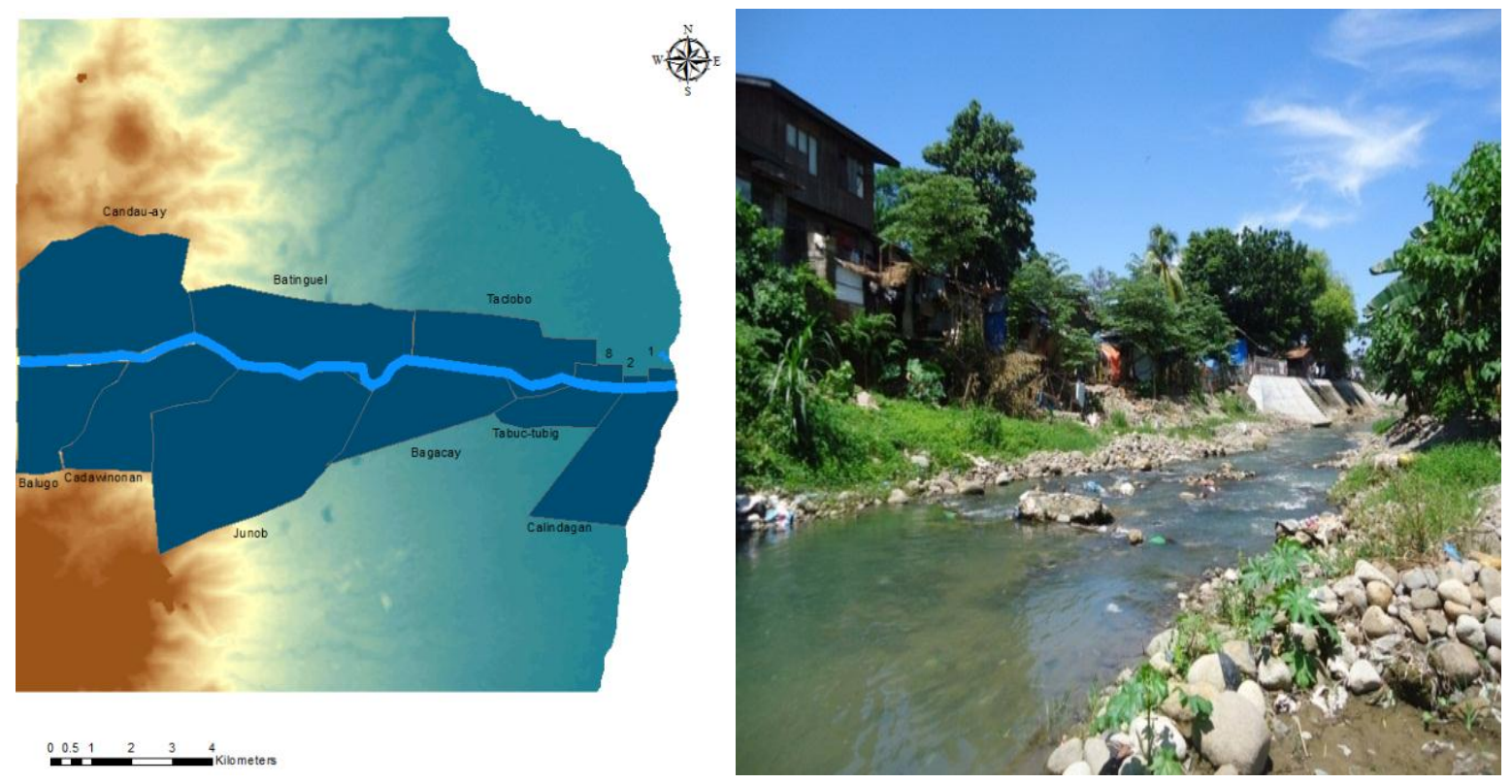

Figure 4-19: Barangay Batinguel

A total of 2.1691sq.km is the land area of Batinguel (Figure 4-19). This community has a population of 8,148 and two thousand three hundred fifty five (2355) individuals are exposed. There are four hundred seventy one (471) families. Out of the 471 families, three hundred eighty one (381) families were affected from the last flooding event affecting eighty one percent $(81 \%)$ of the entire population. Barangay Batinguel was also highly affected because the entire river bank was not built with flood barriers and houses are immediately located along the river banks. There were thirty-eight (38) respondents from Batinguel that were surveyed. 


\subsection{Temporary Shelters}

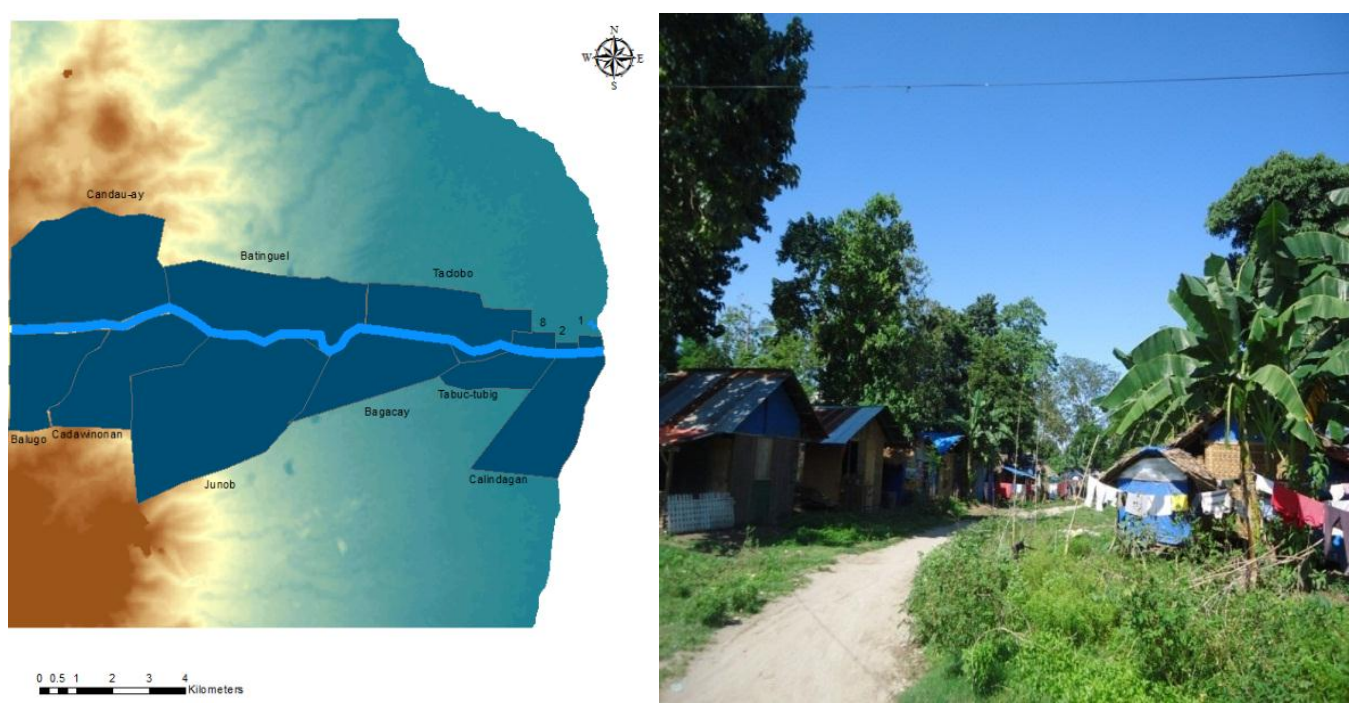

Figure 4-20: Temporary Shelters in Barangay Junob

This is one typical example of a temporary shelter (Figure 4-20). This is a temporary shelter put up by Barangay Junob aided by both the local and national government after the flash flood event in December, 2011. When the researcher of this study was conducting a fieldwork in April of 2013 this temporary shelter was still standing as seen in this photo. The affected families were still waiting for the local government's advice for settlement, and it's been 2 years of waiting (more or less) from that calamity.

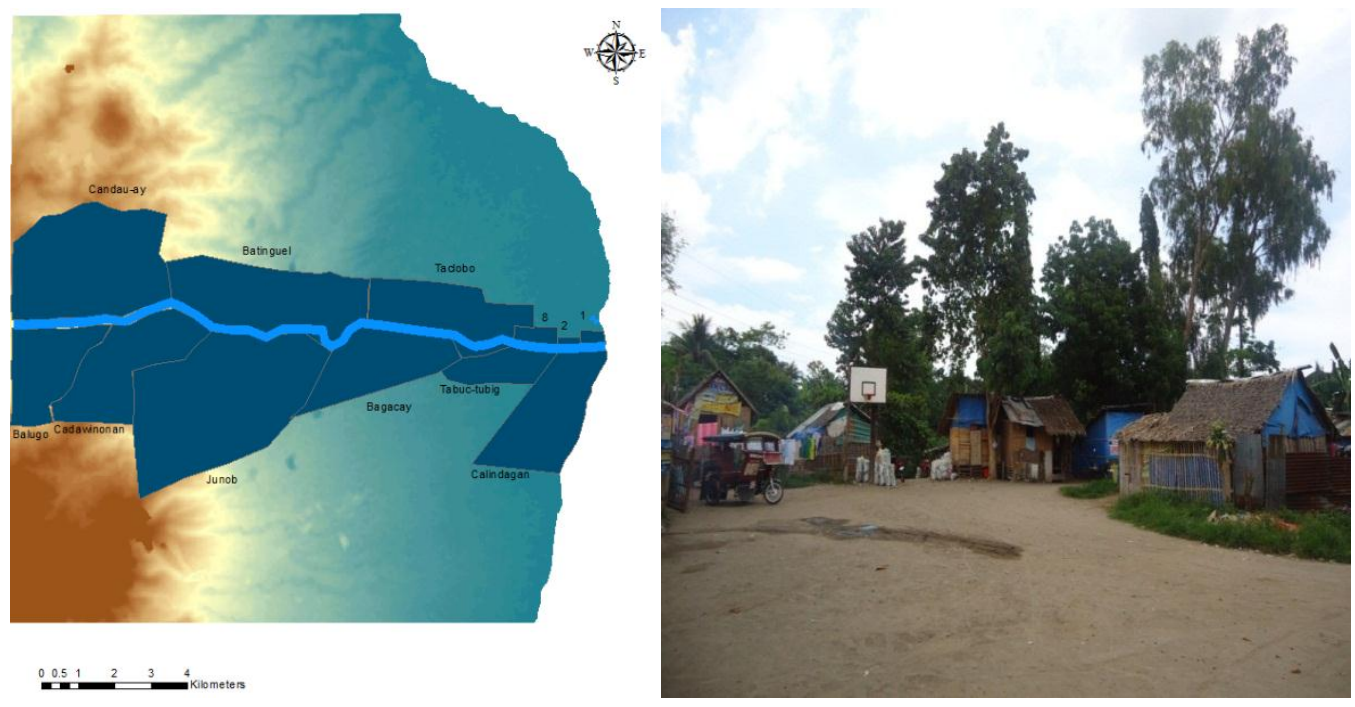

Figure 4-21: Temporary Shelters in Barangay Bagacay 

Social Vulnerabilities and Risks

This is another typical temporary shelter among the affected barangays in the city. This one is located in Barangay Bagacay (Figure 4-21) who was one of the most affected communities from the December 2011 flooding event. These temporary shelters were also there during the researcher's fieldwork in April of 2013 and are located just immediately after the river banks located at the back of these houses as seen in this photo. Affected families were waiting for settlement provided by both from the local government (LGU's) or the Nongovernmental organizations (NGO's) of the city.

\subsection{The Relocation Sites}

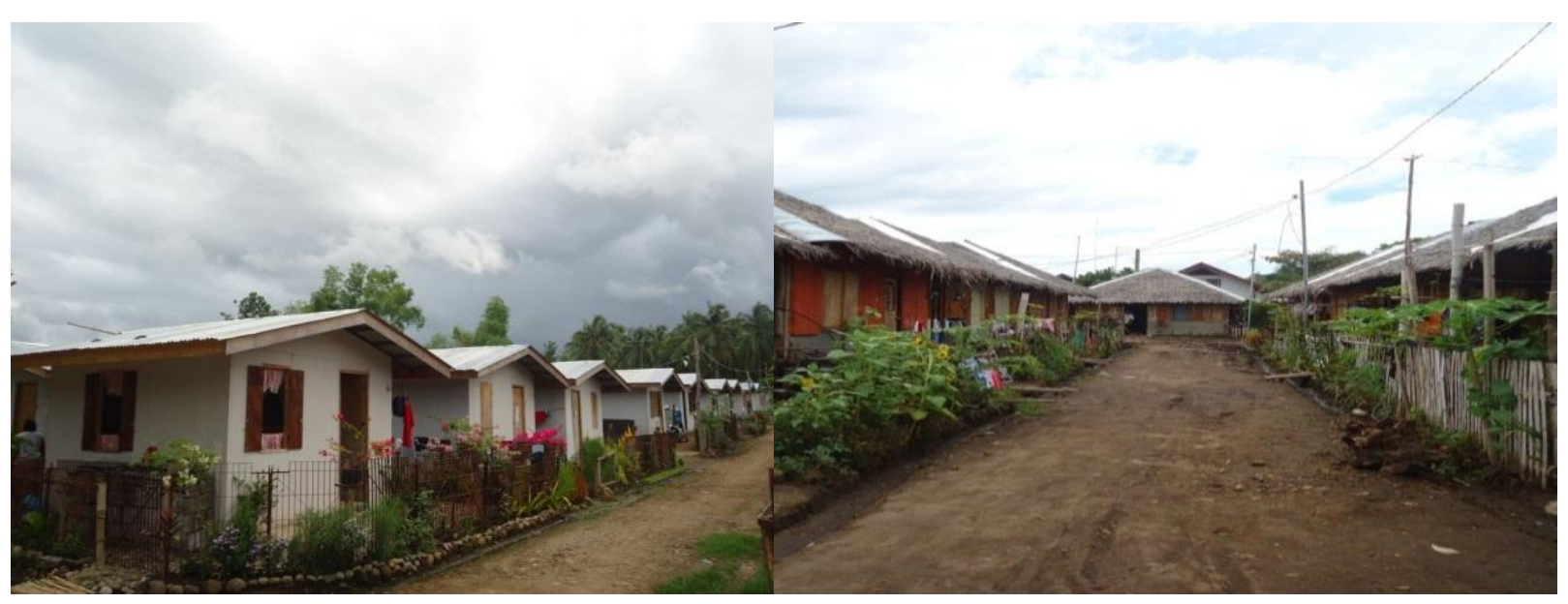

Figure 4-22: Relocation Site1 and 2

These are the two relocation sites (Figure 4-22) provided to those who were affected from the flash flood in December 2011. This was organized by a local Nongovernmental Organization (NGO) headed by the Parish community in Dumaguete City and by the LGU's of the city. There are more or less 200 of these relocation houses provided, though still not enough to provide those who were homeless after that calamity. It's a pretty decent place to stay and the community people are making it clean, pleasing and healthy to live in. Distance from livelihood and the city centre are some of the respondent's comments but having a nice and safer place to live in is better than nothing. These relocation sites are actually side by side to each other. 


\subsection{The Situation of the Most Recent Flooding Event in 2011}

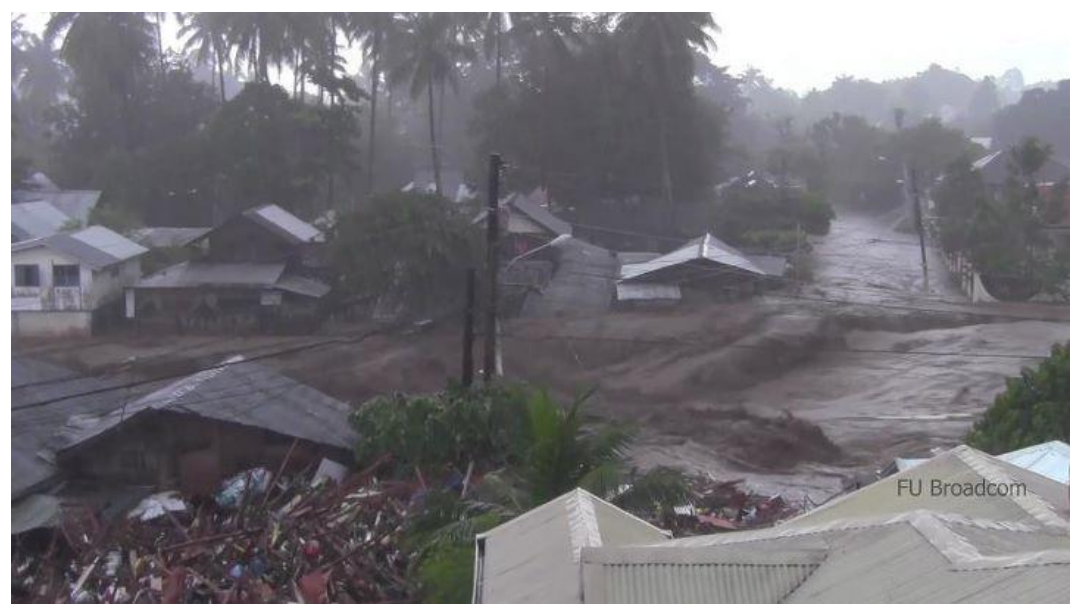

Figure 4-23: Flash Flood in Dumaguete City, Philippines

This was the scenario during the flashflood in December 17, 2011 that hits Dumaguete City (Figure 4-23). This location is from both Barangay Taclobo and Bagacay with the river separating the two communities from two sides. Houses and people were washed away. As depicted in this photo, the rushing water was so strong, carrying debris along with it. It's composed of muddy rushing water. In some houses the water was as high as the roof level and for some houses it was beyond the rooftop. This was probably one of the most damaging flash flood that occurred in the city from the 1900's up to these recent years. These residents are located obviously in the flood plains of Banica River. Figure 4-24 below shows the daily activities of the community people in relation to the Banica River in Dumaguete City, Negros Oriental.

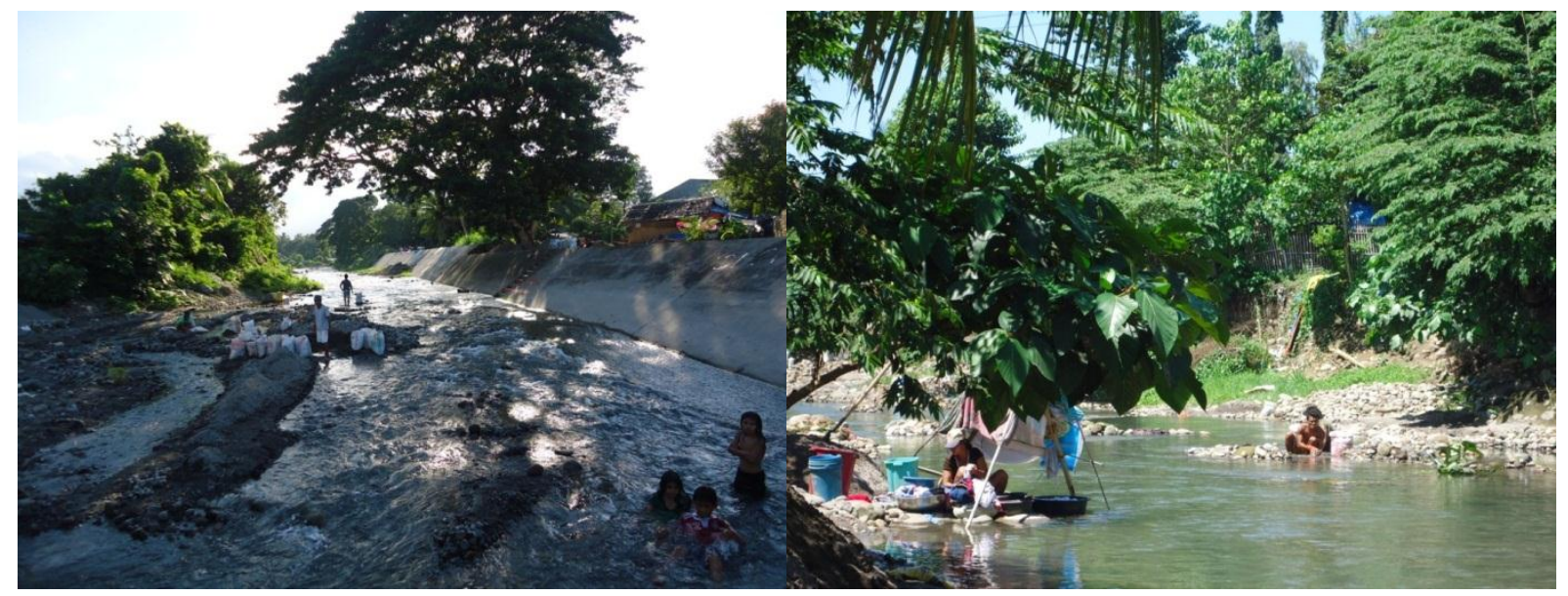

Figure 4-24: The Daily Activities of the Community People in Relation to Banica River 


\subsection{Methodology for Hydrological Data of Banica River}

The researcher conducted a crude geo-hydrological survey during the dry season (April, 30,2013 ) and during the wet season period (July 11, 2013) to be able to have first-hand information since there is no available information on these items published or unpublished. This would give us a bird's eye view of the river of which data can later be used for bacterial loading analysis and for other hydrological studies.

Stream flow is a function of water volume and velocity. Stream flow, or discharge, is the volume of water that moves over a designated point over a fixed period of time. It is often expressed as cubic meter per second $\left(\mathrm{m}^{3} / \mathrm{sec}\right)$. The flow of a stream is directly related to the amount of water moving off the watershed into the stream channel. It is affected by weather, increasing during rainstorms and decreasing during dry periods. It also changes during different seasons of the year, decreasing during the summer months when evaporation rates are high and shoreline vegetation is actively growing and removing water from the ground.

Calculating flow involves solving an equation that examines the relationship among several variables including stream cross-sectional area, stream length, and water velocity. One way to measure flow is to solve the following equation:

Where:

$$
\text { Flow }(\mathrm{Q})=\mathrm{A} \times \mathrm{V}
$$

$A=$ area of the stream (stream width multiplied by average water depth).

$\mathrm{V}=$ velocity (distance divided by time)

This formula was used in this research since the shape of the channel is roughly rectangle. 

Social Vulnerabilities and Risks

As seen in table 4-2, there is a difference in flow during dry and wet season. The flow during dry season is $0.20 \mathrm{~m}^{3} /$ second and $0.17 \mathrm{~m}^{3} /$ second in the wet season, respectively. There is also a difference observed in the water depth from $21.67 \mathrm{~cm}$ to $31.33 \mathrm{~cm}$. Figure 4-25 shows the location site for the hydrological data for station 1.

Table 4-2: Hydrological Data of Banica River for Station 1 (S1)

\begin{tabular}{|c|c|c|}
\hline STATION 1 (S1) & (DRY SEASON) & (WET SEASON) \\
\hline \multirow{2}{*}{ City Pound Bridge Barangay Balugo } & $30-A p r-13$ & $11-\mathrm{Jul}-13$ \\
& W $=18.24 \mathrm{~m}$ & W=18.24m \\
\hline DRY season & D1 $=24.0 \mathrm{~cm}$ & D1 $=34.0 \mathrm{~cm}$ \\
Flow $(\mathrm{Q})=\mathrm{A} \times \mathrm{V}$ & $\mathrm{D} 2=25.0 \mathrm{~cm}$ & $\mathrm{D} 2=31.0 \mathrm{~cm}$ \\
$0.20 \mathrm{~m}^{3} / \mathrm{s}$ & D3 $=16.0 \mathrm{~cm}$ & D3 $=29.0 \mathrm{~cm}$ \\
& Ave. depth: $21.67 \mathrm{~cm}$ & Ave. depth: $31.33 \mathrm{~cm}$ \\
\hline WET season & F1 $=62.79 \mathrm{~s}$ & $\mathrm{~F} 1=56.91 \mathrm{~s}$ \\
Flow $(\mathrm{Q})=\mathrm{A} \times \mathrm{V}$ & F2 $=44.38 \mathrm{~s}$ & F2 $=124.46 \mathrm{~s}$ \\
$0.17 \mathrm{~m}^{3} / \mathrm{s}$ & F3 $=64.26 \mathrm{~s}$ & F3 $=121.59 \mathrm{~s}$ \\
& Ave. flow: $57.14 \mathrm{~s}$ & Ave. flow: $100.99 \mathrm{~s}$ \\
\hline
\end{tabular}
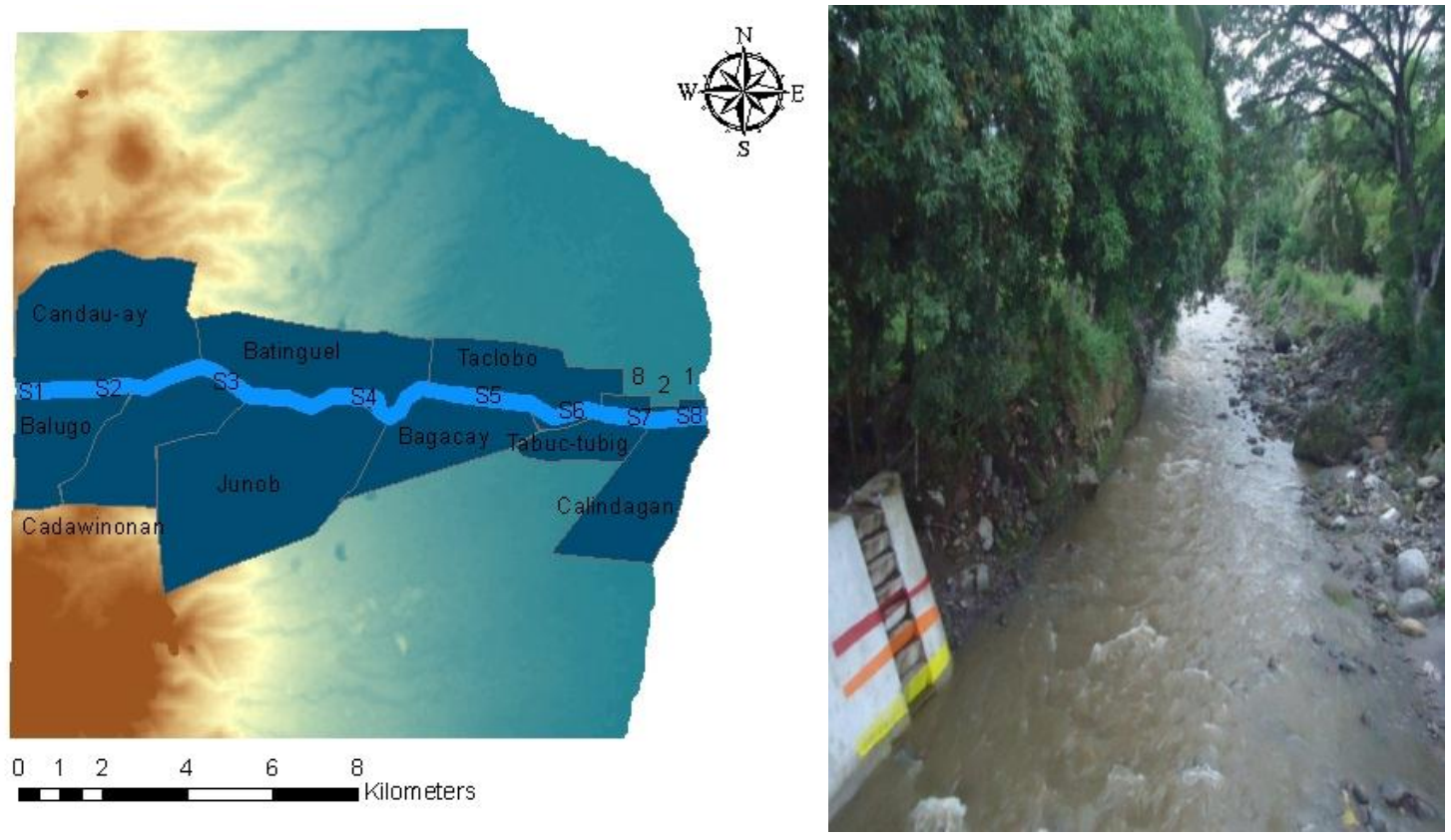

Figure 4-25: Station 1 (S1): City Pound Bridge, Barangay Balugo 

Social Vulnerabilities and Risks

The same pattern is observed for station 2 (Figure 4-26), there is a significant difference of the water flow during dry and wet season. A reading of $0.43 \mathrm{~m}^{3} /$ second is observed during dry season and $0.64 \mathrm{~m}^{3} / \mathrm{second}$ for the wet season. The water depth also rises from $24.67 \mathrm{~cm}$ in the dry season to $29.67 \mathrm{~cm}$ in the wet season as seen in Table $4-3$ below.

Table 4-3: Hydrological Data of Banica River for Station 2 (S2)

\begin{tabular}{|c|c|c|}
\hline STATION 2 (S2) & (DRY SEASON) & (WET SEASON) \\
\hline Smokey Mountain Overflow Brgy. Candau-ay \& Balugo & $30-$ Apr-13 & $11-\mathrm{Jul}-13$ \\
& $\mathrm{~W}=19.50 \mathrm{~m}$ & W $=19.50 \mathrm{~m}$ \\
\hline DRY season & $\mathrm{D} 1=20.0 \mathrm{~cm}$ & $\mathrm{D} 1=21.0 \mathrm{~cm}$ \\
Flow $(\mathrm{Q})=\mathrm{A} \times \mathrm{V}$ & $\mathrm{D} 2=25.0 \mathrm{~cm}$ & $\mathrm{D} 2=29.0 \mathrm{~cm}$ \\
$0.43 \mathrm{~m}^{3} / \mathrm{s}$ & $\mathrm{D} 3=29.0 \mathrm{~cm}$ & D3 $=39.0 \mathrm{~cm}$ \\
& Ave. depth: $24.67 \mathrm{~cm}$ & Ave. depth: $29.67 \mathrm{~cm}$ \\
\hline WET season & $\mathrm{F} 1=34.51 \mathrm{~s}$ & $\mathrm{~F} 1=28.14 \mathrm{~s}$ \\
Flow $(\mathrm{Q})=\mathrm{A} \times \mathrm{V}$ & $\mathrm{F} 2=34.93 \mathrm{~s}$ & $\mathrm{~F} 2=22.19 \mathrm{~s}$ \\
$0.64 \mathrm{~m}^{3} / \mathrm{s}$ & $\mathrm{F} 3=32.62 \mathrm{~s}$ & $\mathrm{~F} 3=30.94 \mathrm{~s}$ \\
& Ave. flow: $34.02 \mathrm{~s}$ & Ave. flow: $27.09 \mathrm{~s}$ \\
\hline
\end{tabular}
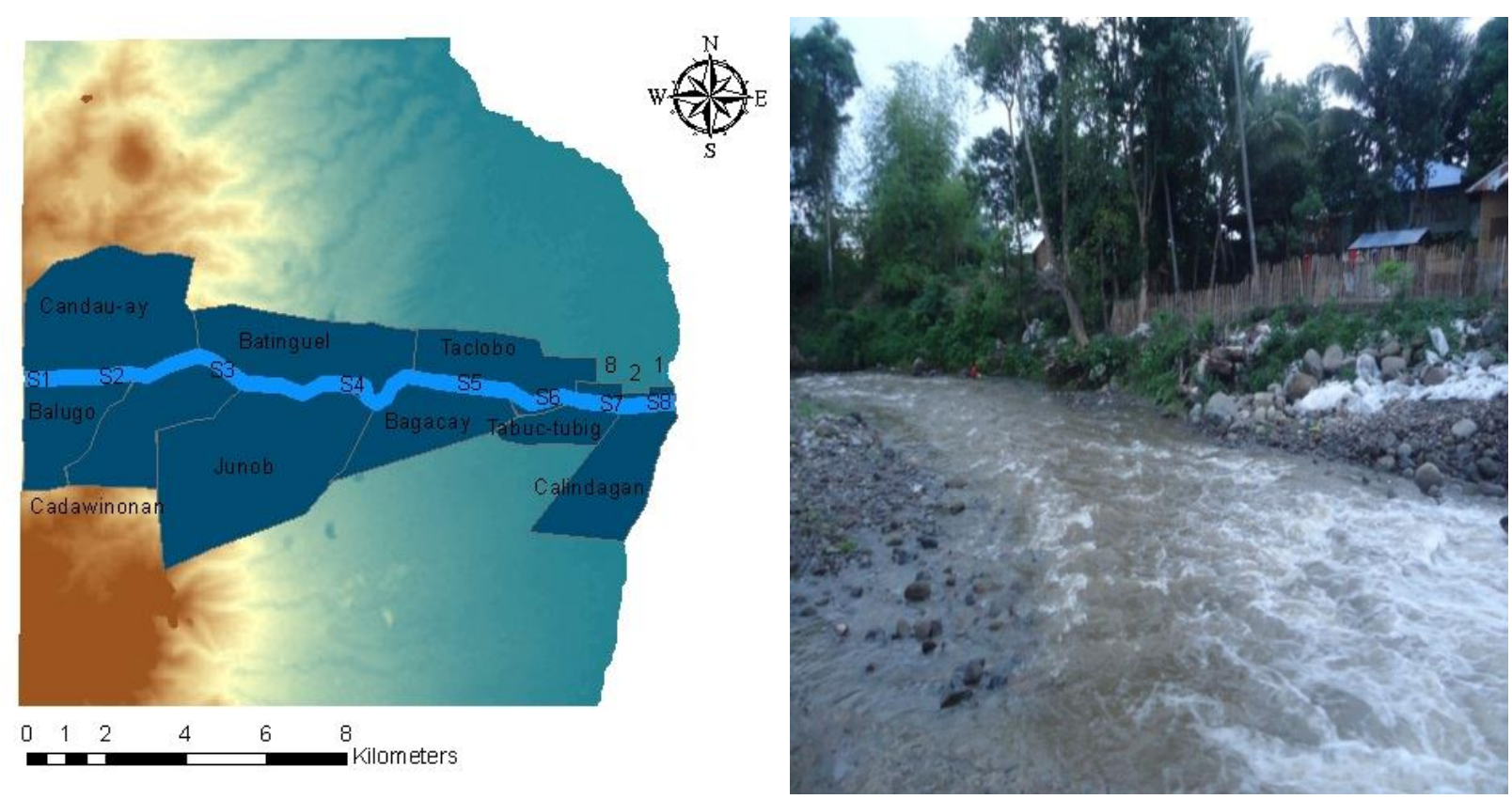

Figure 4-26: Station 2 (S2): Smokey Mountain Overflow, Barangay Balugo and Candau-ay 

Social Vulnerabilities and Risks

For station 3 (Table 4-4) and (Figure 4-27), not much difference is observed both the flow and water depth during the time of survey. From $0.25 \mathrm{~m}^{3} / \mathrm{second}$ to $0.33 \mathrm{~m}^{3} / \mathrm{second}$ stream flow in the dry and wet season respectively. Water depth increase is also very negligible from $15 \mathrm{~cm}$ to $15.67 \mathrm{~cm}$ rise in the wet season.

Table 4-4: Hydrological Data of Banica River for Station 3 (S3)

\begin{tabular}{|c|c|c|}
\hline STATION 3 (S3) & (DRY SEASON) & (WET SEASON) \\
\hline Barangay Cadawinonan - Candau-ay Overflow & $\begin{array}{c}\text { 30-Apr-13 } \\
W=20.95 m\end{array}$ & $\begin{array}{c}11-\mathrm{Jul}-13 \\
\mathrm{~W}=20.95 \mathrm{~m}\end{array}$ \\
\hline $\begin{array}{c}\text { DRY season } \\
\text { Flow }(Q)=A \times V \\
0.25 \mathrm{~m}^{3} / \mathrm{s}\end{array}$ & $\begin{array}{c}\mathrm{D} 1=12.0 \mathrm{~cm} \\
\mathrm{D} 2=16.0 \mathrm{~cm} \\
\mathrm{D} 3=17.0 \mathrm{~cm} \\
\text { Ave. depth: } 15 \mathrm{~cm}\end{array}$ & $\begin{aligned} & \mathrm{D} 1=15.0 \mathrm{~cm} \\
& \mathrm{D} 2=20.0 \mathrm{~cm} \\
& \mathrm{D} 3=12.0 \mathrm{~cm} \\
& \text { Ave. depth: } 15.67 \mathrm{~cm}\end{aligned}$ \\
\hline $\begin{array}{c}\text { WET season } \\
\text { Flow }(\mathrm{Q})=\mathrm{A} \times \mathrm{V} \\
0.33 \mathrm{~m}^{3} / \mathrm{s}\end{array}$ & $\begin{array}{c}F 1=40.32 \mathrm{~s} \\
F 2=38.50 \mathrm{~s} \\
F 3=27.72 \mathrm{~s} \\
\text { Ave. flow: } 35.51 \mathrm{~s}\end{array}$ & $\begin{array}{c}F 1=34.51 \mathrm{~s} \\
F 2=33.81 \mathrm{~s} \\
F 3=30.94 \mathrm{~s} \\
\text { Ave. flow: } 33.09 \mathrm{~s}\end{array}$ \\
\hline
\end{tabular}
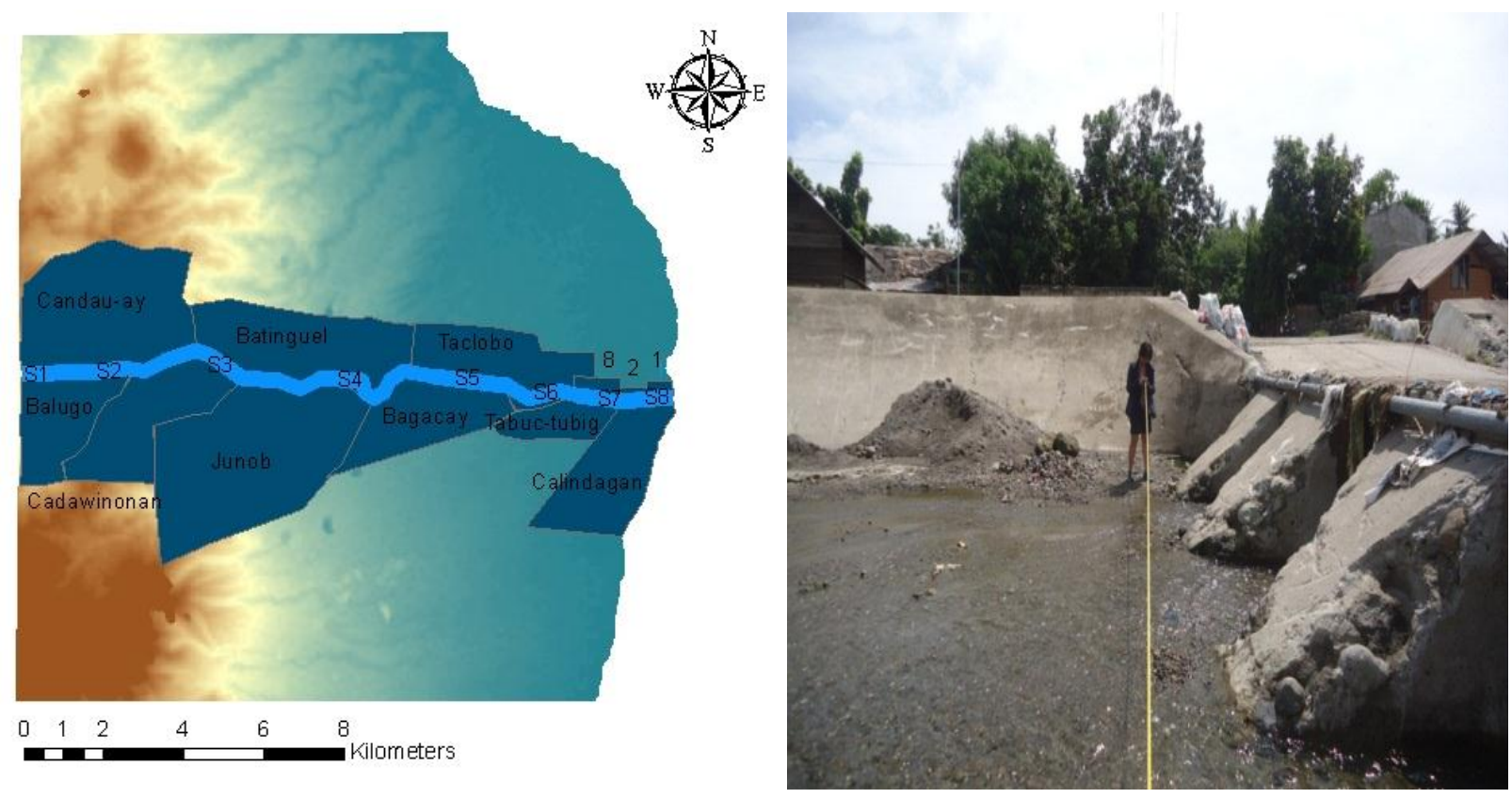

Figure 4-27: Station 3 (S3): Barangay Candau-ay and Cadawinonan 

Social Vulnerabilities and Risks

As depicted in table 4-5, increase of water flow during the dry and wet season is observed. From $0.38 \mathrm{~m}^{3} /$ second in the dry season to $0.61 \mathrm{~m}^{3} /$ second in the wet season. Water depth is also increasing from $28.43 \mathrm{~cm}$ to $45.67 \mathrm{~cm}$ respectively. Figure $4-28$ shows the location for station 4 for this hydrological data.

Table 4-5: Hydrological Data of Banica River for Station 4 (S4)

\begin{tabular}{|c|c|c|}
\hline STATION 4 (S4) & (DRY SEASON) & (WET SEASON) \\
\hline Barangay Taclobo Overflow & $\begin{array}{c}\text { 30-Apr-13 } \\
\mathrm{W}=18.95 \mathrm{~m}\end{array}$ & $\begin{array}{c}11-\mathrm{Jul}-13 \\
\mathrm{~W}=18.95 \mathrm{~m}\end{array}$ \\
\hline $\begin{array}{c}\text { DRY season } \\
\text { Flow }(Q)=A \times V \\
0.38 \mathrm{~m}^{3} / \mathrm{s}\end{array}$ & $\begin{array}{c}\text { D1 }=25.0 \mathrm{~cm} \\
\text { D2 }=57.0 \mathrm{~cm} \\
\text { D3 }=3.3 \mathrm{~cm} \\
\text { Ave. depth: } 28.43 \mathrm{~cm}\end{array}$ & $\begin{aligned} & \mathrm{D} 1=80.0 \mathrm{~cm} \\
& \mathrm{D} 2=35.0 \mathrm{~cm} \\
& \mathrm{D} 3=22.0 \mathrm{~cm} \\
& \text { Ave. depth: } 45.67 \mathrm{~cm}\end{aligned}$ \\
\hline $\begin{array}{c}\text { WET season } \\
\text { Flow }(\mathrm{Q})=\mathrm{A} \times \mathrm{V} \\
0.61 \mathrm{~m}^{3} / \mathrm{s}\end{array}$ & $\begin{array}{c}F 1=42.49 \mathrm{~s} \\
F 2=38.08 \mathrm{~s} \\
F 3=56.98 \mathrm{~s} \\
\text { Ave. flow: } 45.85 \mathrm{~s}\end{array}$ & $\begin{array}{c}F 1=50.12 \mathrm{~s} \\
F 2=28.21 \mathrm{~s} \\
F 3=49.21 \mathrm{~s} \\
\text { Ave. flow: } 42.51 \mathrm{~s}\end{array}$ \\
\hline
\end{tabular}
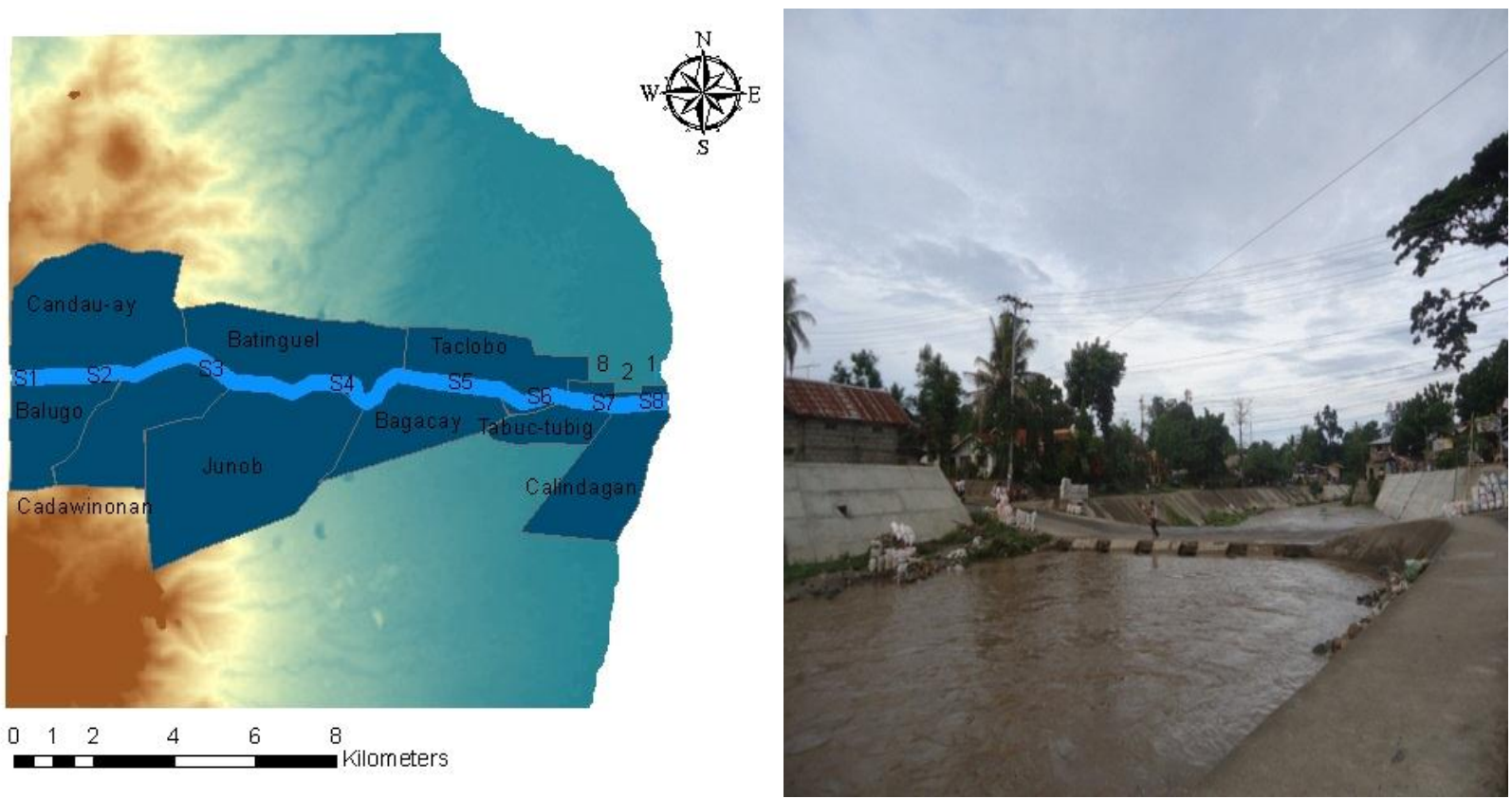

Figure 4-28: Station 4 (S4): Barangay Taclobo Overflow 

Social Vulnerabilities and Risks

In table 4-6, a difference of water flow is observed from $0.32 \mathrm{~m}^{3} /$ second to $0.58 \mathrm{~m}^{3} / \mathrm{second}$ in the wet season. Water depth increase is also observed from $23 \mathrm{~cm}$ to $29.67 \mathrm{~cm}$ in the wet season. Figure $4-29$ shows the location site for obtaining the hydrological data for station 5 .

Table 4-6: Hydrological Data of Banica River for Station 5 (S5)

\begin{tabular}{|c|c|c|}
\hline STATION 5 (S5) & (DRY SEASON) & (WET SEASON) \\
\hline Colon Extension Overflow Barangay Taclobo & $30-$ Apr -13 & $11-\mathrm{Jul}-13$ \\
& W $=19.70 \mathrm{~m}$ & W $=19.70 \mathrm{~m}$ \\
\hline DRY season & D1 $=21.0 \mathrm{~cm}$ & D1 $=41.0 \mathrm{~cm}$ \\
Flow $(\mathrm{Q})=\mathrm{A} \times \mathrm{V}$ & $\mathrm{D} 2=28.0 \mathrm{~cm}$ & D2 $=25.0 \mathrm{~cm}$ \\
$0.32 \mathrm{~m}^{3} / \mathrm{s}$ & D3 $=20.0 \mathrm{~cm}$ & D3 $=23.0 \mathrm{~cm}$ \\
& Ave. depth: $23 \mathrm{~cm}$ & Ave. depth: $29.67 \mathrm{~cm}$ \\
\hline WET season & $\mathrm{F} 1=34.02$ & F1 $=34.93 \mathrm{~s}$ \\
Flow $(\mathrm{Q})=\mathrm{A} \times \mathrm{V}$ & $\mathrm{F} 2=27.65 \mathrm{~s}$ & $\mathrm{~F} 2=25.69 \mathrm{~s}$ \\
$0.58 \mathrm{~m}^{3} / \mathrm{s}$ & F3 $=67.62 \mathrm{~s}$ & F3 $=33.11 \mathrm{~s}$ \\
& Ave. flow: $43.10 \mathrm{~s}$ & Ave. flow: $31.24 \mathrm{~s}$ \\
\hline
\end{tabular}

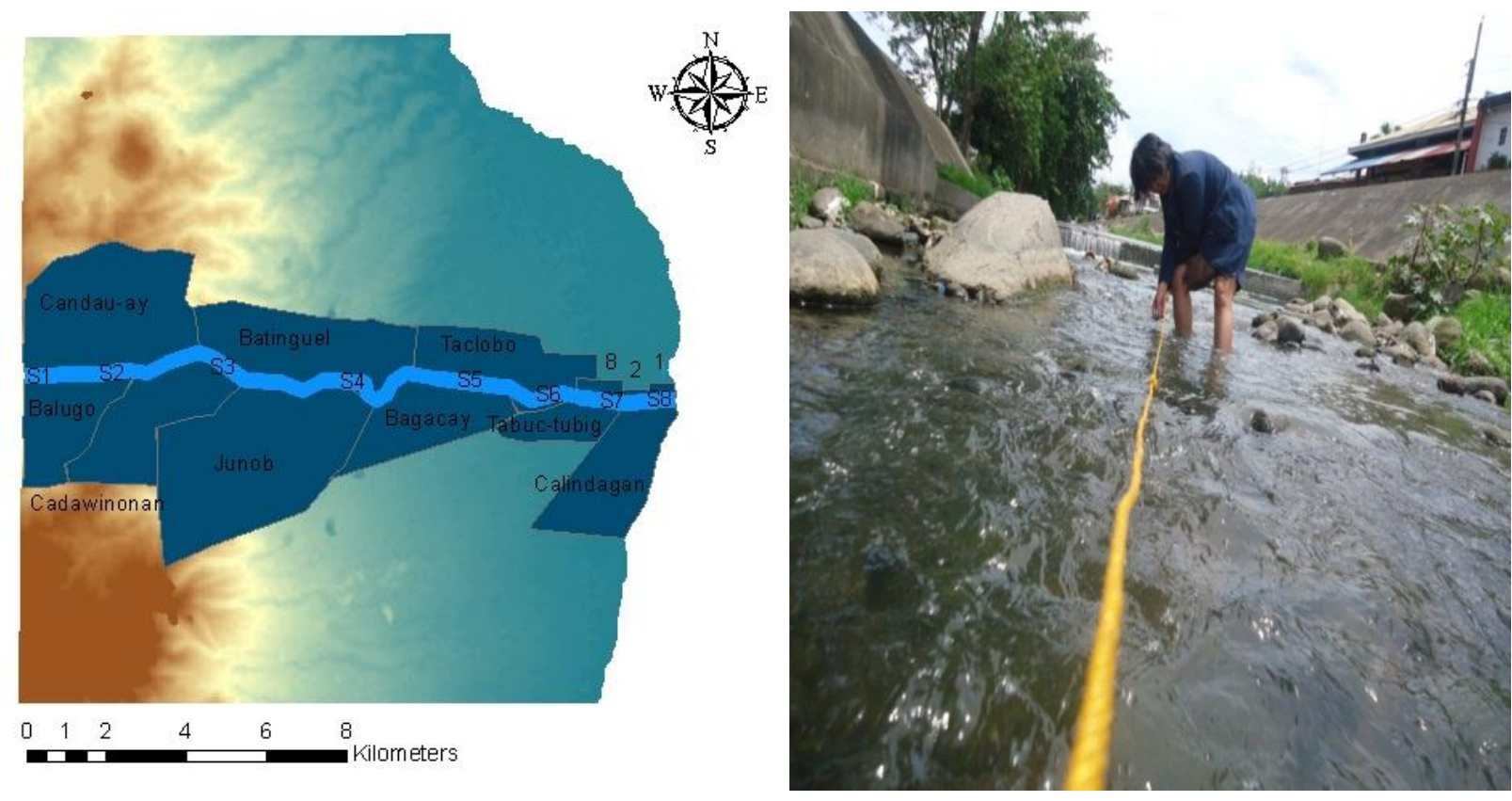

Figure 4-29: Station 5 (S5) Colon Extension Overflow (Barangay Taclobo) 

Social Vulnerabilities and Risks

For station 6 (Figure 4-30), a difference in water flow is also observable as the season changes from dry to wet, from $0.50 \mathrm{~m}^{3} /$ second to $0.49 \mathrm{~m}^{3} /$ second respectively. There is a very slight decrease of flow during the wet season. Water depth also increases from $16 \mathrm{~cm}$ to $22.33 \mathrm{~cm}$ respectively as shown in Table 4-7.

Table 4-7: Hydrological Data of Banica River for Station 6 (S6)

\begin{tabular}{|c|c|c|}
\hline STATION 6 (S6) & (DRY SEASON) & (WET SEASON) \\
\hline \multirow{2}{*}{ Barangay Tabuc-tubig Bridge } & $30-$ Apr-13 & $11-\mathrm{Jul}-13$ \\
& W $=43.70 \mathrm{~m}$ & W $=43.75 \mathrm{~m}$ \\
\hline DRY season & D1 $=14.0 \mathrm{~cm}$ & D1 $=14.0 \mathrm{~cm}$ \\
Flow (Q) $=$ A x V & D2 $=23.0 \mathrm{~cm}$ & D2 $=24.0 \mathrm{~cm}$ \\
$0.50 \mathrm{~m}^{3} / \mathrm{s}$ & D3 $=11.0 \mathrm{~cm}$ & D3 $=29.0 \mathrm{~cm}$ \\
& Ave. depth: $16 \mathrm{~cm}$ & Ave. depth: $22.33 \mathrm{~cm}$ \\
\hline WET season & F1 $=38.50 \mathrm{~s}$ & F1 $=58.24 \mathrm{~s}$ \\
Flow $(\mathrm{Q})=$ A x V & F2 $=56.07 \mathrm{~s}$ & F2 $=45.57 \mathrm{~s}$ \\
$0.49 \mathrm{~m}^{3} / \mathrm{s}$ & F3 $=42.49 \mathrm{~s}$ & F3 $=62.72 \mathrm{~s}$ \\
& Ave. flow: $45.69 \mathrm{~s}$ & Ave. flow: $55.52 \mathrm{~s}$ \\
\hline
\end{tabular}
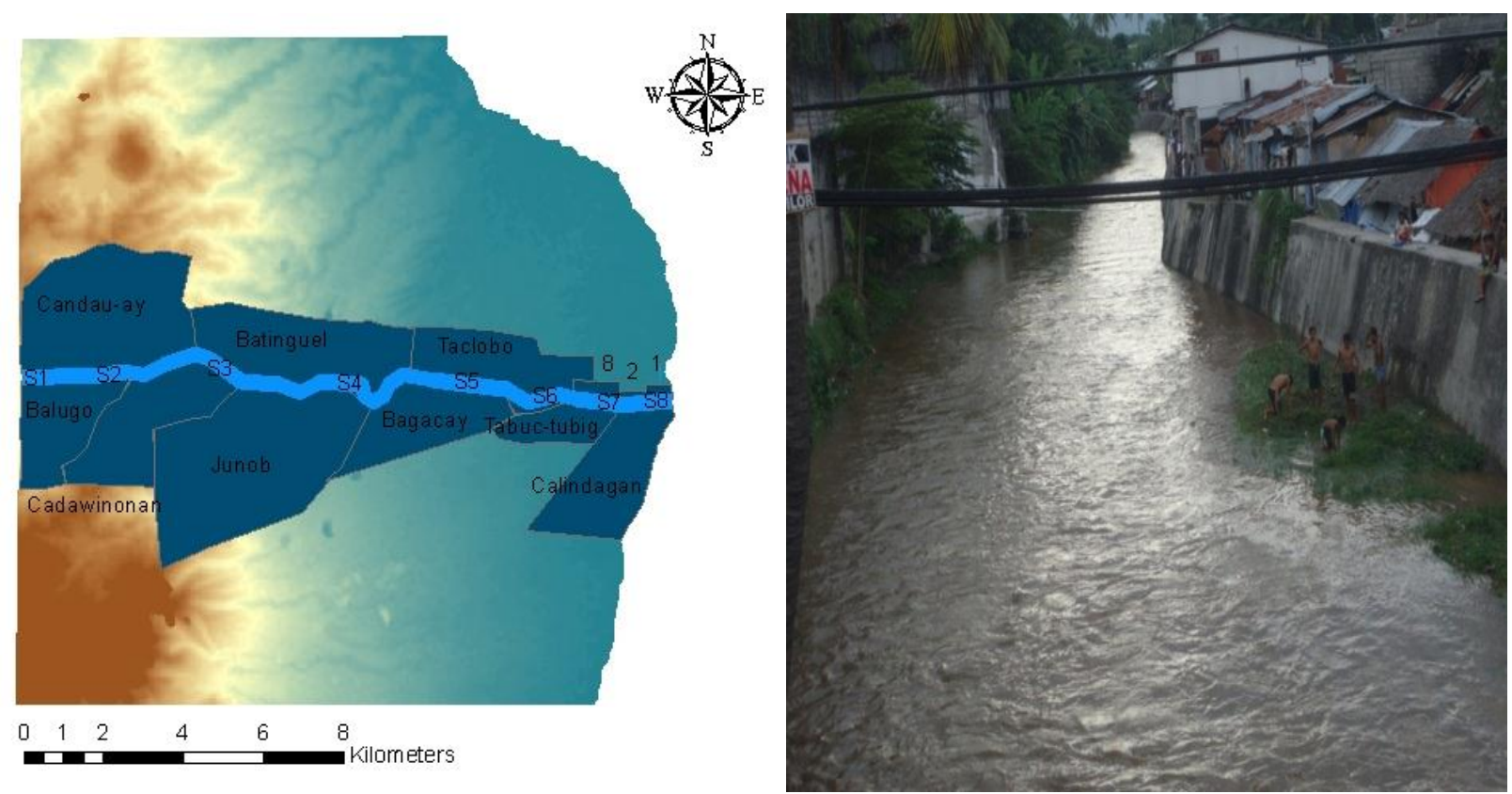

Figure 4-30: Station 6 (S6): Barangay Tabuc-tubig Bridge 

Social Vulnerabilities and Risks

There was a big difference in the water flow when it was conducted (Figure 4-31). It was high tide at that time. The water depth was $35 \mathrm{~cm}$ and the water was flowing $2.40 \mathrm{~m}^{3} /$ second respectively. In the wet season which was surveyed at low tide, the water depth was only $12.33 \mathrm{~cm}$ and the water was flowing at a rate of $0.10 \mathrm{~m}^{3} / \mathrm{second}$ compared to when it was a high tide time during the dry season (Table 4-8).

Table 4-8: Hydrological Data of Banica River for Station 7 (S7)

\begin{tabular}{|c|c|c|}
\hline STATION 7 & (DRY SEASON) & (WET SEASON) \\
\hline $\begin{array}{c}\text { Barangay Calindagan } \\
\text { Bridge }\end{array}$ & $\begin{array}{c}\text { 30-Apr-13 } \\
\text { HIGH TIDE time } \\
\text { W }=20.20 \mathrm{~m}\end{array}$ & $\begin{array}{l}11-\mathrm{Jul}-13 \\
\mathrm{~W}=20.10 \mathrm{~m}\end{array}$ \\
\hline $\begin{array}{c}\text { DRY season } \\
\text { Flow }(\mathrm{Q})=\mathrm{A} \times \mathrm{V} \\
2.40 \mathrm{~m}^{3} / \mathrm{s}\end{array}$ & $\begin{array}{c}\text { D1 }=30.0 \mathrm{~cm} \\
\mathrm{D} 2=25.0 \mathrm{~cm} \\
\mathrm{D} 3=50.0 \mathrm{~cm} \\
\text { Ave. depth: } 35 \mathrm{~cm}\end{array}$ & $\begin{array}{c}\mathrm{D} 1=12.0 \mathrm{~cm} \\
\mathrm{D} 2=18.0 \mathrm{~cm} \\
\mathrm{D} 3=7.0 \mathrm{~cm} \\
\text { Ave. depth: } 12.33 \mathrm{~cm}\end{array}$ \\
\hline $\begin{array}{c}\text { WET season } \\
\text { Flow }(\mathrm{Q})=\mathrm{A} \times \mathrm{V} \\
0.10 \mathrm{~m}^{3} / \mathrm{s}\end{array}$ & $\begin{array}{c}F 1=9.52 \mathrm{~s} \\
F 2=8.33 \mathrm{~s} \\
F 3=8.26 \mathrm{~s} \\
\text { Ave. flow: } 8.70 \mathrm{~s}\end{array}$ & $\begin{array}{c}F 1=73.64 \mathrm{~s} \\
F 2=63.63 \mathrm{~s} \\
F 3=62.79 \mathrm{~s} \\
\text { Ave. flow: } 66.69 \mathrm{~s}\end{array}$ \\
\hline
\end{tabular}
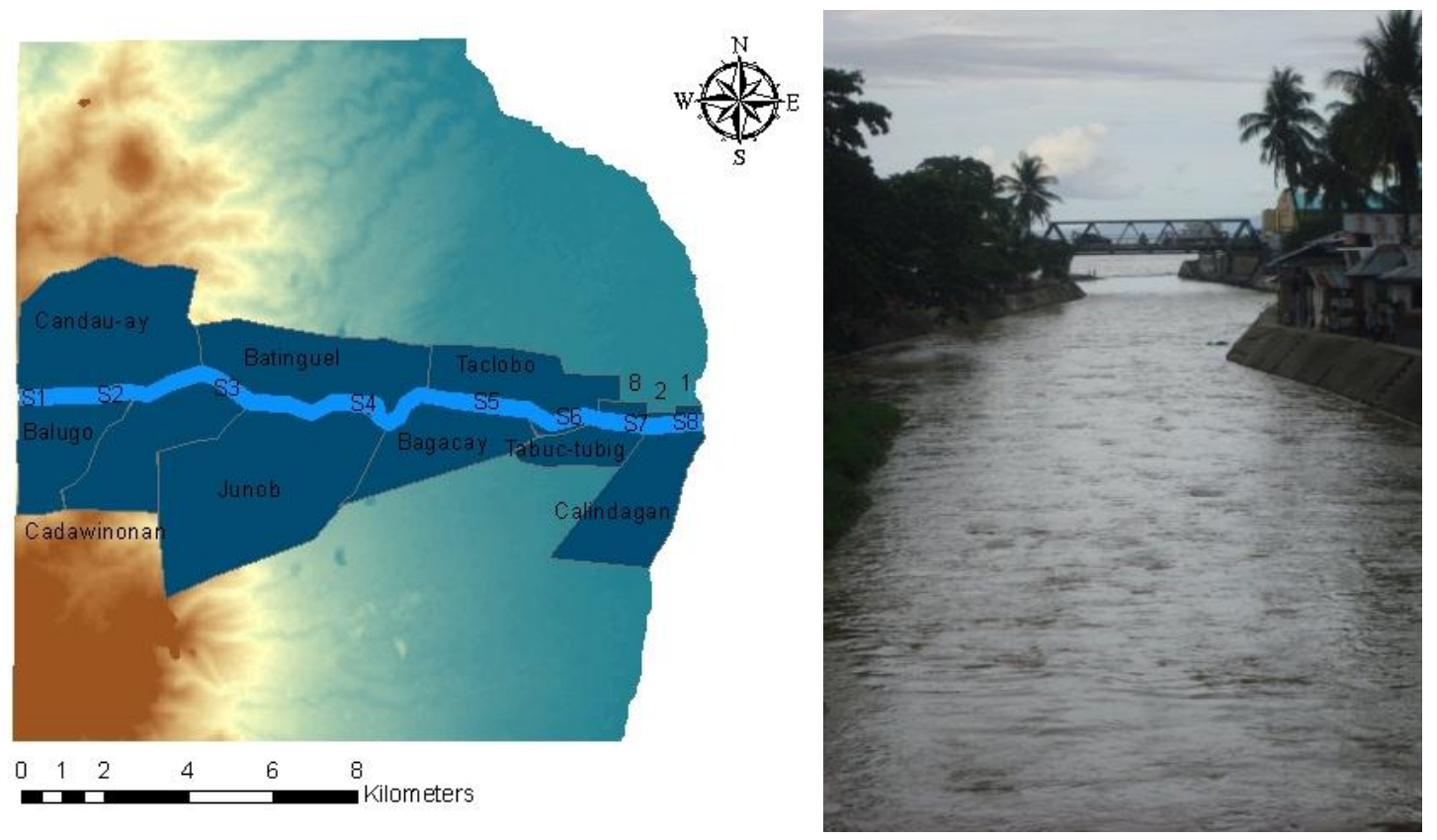

Figure 4-31: Station 7 (S7): Barangay Calindagan Bridge 

Social Vulnerabilities and Risks

Station 8 is located very near the delta or the mouth of the river and when it is high tide, water coming from the Mindanao sea moves inward up to several meters from the river's mouth along the shore (Figure 4-32). Some articles and unpublished studies of the Banica river has mentioned that during high tide, sea water can move inland stretching about half a kilometer from the delta. As shown below (Table 4-9), the water depth rises from $18.33 \mathrm{~cm}$ during low tide in the wet season to $57.13 \mathrm{~cm}$. The water flow during high tide in the dry season is $-0.01 \mathrm{~m} 3 /$ second (backflow) due to incoming seawater while $0.11 \mathrm{~m}^{3} /$ second at low tide in the wet season.

Table 4-9: Hydrological Data of Banica River for Station 8 (S8)

\begin{tabular}{|c|c|c|}
\hline STATION 8 & (DRY SEASON) & (WET SEASON) \\
\hline \multirow{2}{*}{ Barangay Tinago Bridge } & $\begin{array}{c}\text { 30-Apr-13 } \\
\text { HIGH TIDE time } \\
\text { W }=36.00 \mathrm{~m}\end{array}$ & $\begin{array}{c}11-\mathrm{Jul}-13 \\
\text { W }=20.90 \mathrm{~m}\end{array}$ \\
\hline DRY season & D1 $=140.00 \mathrm{~cm}$ & D1 $=11.00 \mathrm{~cm}$ \\
Flow $(Q)=$ A $\times$ V & D2 $=80.00 \mathrm{~cm}$ & D2 $=20.00 \mathrm{~cm}$ \\
$0.04 \mathrm{~m}^{3} / \mathrm{s}$ BACKFLOW & D3 $=90.00 \mathrm{~cm}$ & D3 $=24.0 \mathrm{~cm}$ \\
& Ave. depth: $57.13 \mathrm{~cm}$ & Ave. depth: $18.33 \mathrm{~cm}$ \\
\hline WET season & F1 $=100.66 \mathrm{~s} \mathrm{BF}$ & F1 $=112.28 \mathrm{~s}$ \\
Flow $(Q)=$ A $\times$ V & F2 $=163.73 \mathrm{~s} \mathrm{BF}$ & F2 $=89.32 \mathrm{~s}$ \\
$0.11 \mathrm{~m}^{3} / \mathrm{s}$ & F3 $=263.90 \mathrm{~s} \mathrm{BF}$ & F3 $=130.13 \mathrm{~s}$ \\
& Ave. flow: $-176.10 \mathrm{~s}$ & Ave. flow: $110.58 \mathrm{~s}$ \\
\hline
\end{tabular}




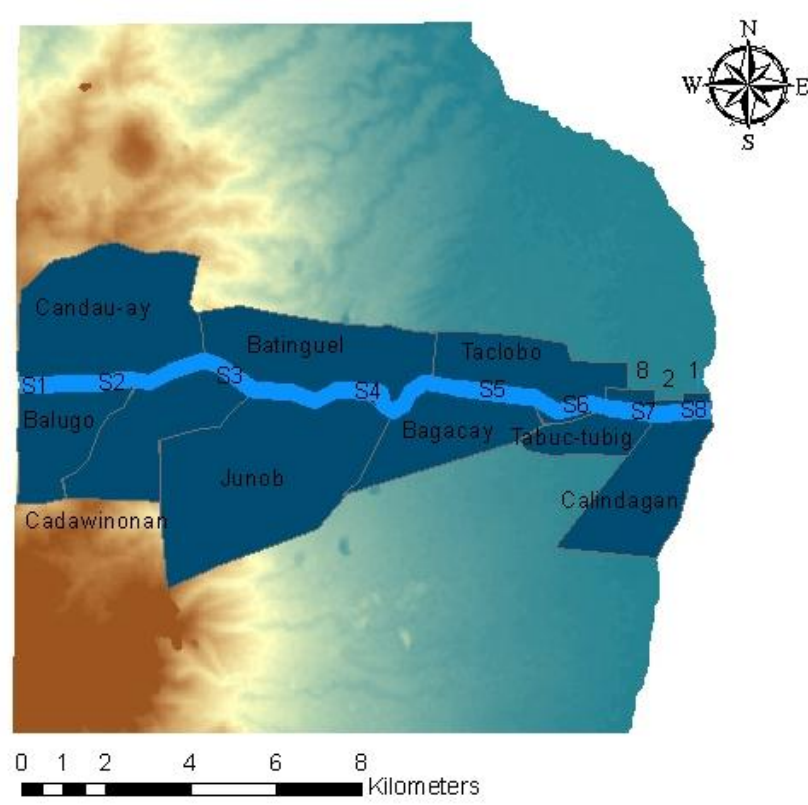

Figure 4-32: Station 8 (S8) Poblacion 1 (Tinago) Bridge

\subsection{Health Impact Assessment Methodology}

The health impact assessment was conducted through bacterial culture of E.coli, survey questionnaires (frequency of exposure and amount of ingestion of contaminated water from exposure), literature review and surveillance data.

In conducting health impact assessment, the four key steps are used and directly quoted as follows: (European Commission, 2000).

A. Hazard Identification - The identification of a risk source(s) capable of causing adverse effect(s)/event(s) to humans or the environment species, together with a qualitative description of the nature of these effect(s)/event(s).

B. Hazard Characterization - The quantitative or semi-quantitative evaluation of the nature of the adverse health effects to humans and/or the environment following exposure to a risk source(s). This must, where possible, include a dose/response assessment.

C. Exposure Assessment - The quantitative or semi-quantitative evaluation of the likely exposure of humans and/or the environment to risk sources from one or more media. 

Social Vulnerabilities and Risks

D. Risk Characterization - The quantitative or semi-quantitative estimate, including attendant uncertainties, of the probability of occurrence and severity of adverse effect(s)/event(s) in a given population under defined exposure conditions based on hazard identification, hazard characterisation and exposure assessment.

These steps will be conducted slightly differently depending on the particular health impact that is being considered.

For hazard identification, E.coli, leptospirosis and dengue fever cases were the chosen microorganisms to be assessed because of its common occurrence during and after flooding events. Usually, during and after flooding events cases of diarrhoea are in significant numbers. In some places, leptospirosis cases are also occurring. Dengue fever cases is also rampant during rainy or typhoon seasons. But, what is interesting to know is the people's vulnerability or resilience in terms of their knowledge, attitude and practices towards these microorganisms. These items have been addressed solicited from the questionnaires administered to the household respondents.

In doing the hazard characterization, a dose-response assessment was not conducted but instead, results from surveys from the household respondents that indicates their experienced of being sick from any of the focus microorganisms were noted and counted. Top 10 leading causes of morbidity in the city and the country were solicited to counter-check the incidences and occurrences of those diseases.

Exposure assessment was conducted through survey questionnaires. Household respondents were asked if any member in the family has been exposed to E.coli, leptospirosis and dengue fever. The frequency of exposure to the river and the amount of possible ingestion of the contaminated water were asked and recorded.

After gathering the relevant data from hazard identification, characterization and exposure, risk characterization is possible to establish. The level of risks and correlation to exposure in terms of the number of the number of E.coli taken from the different sampling sites, and the number of diarrheal cases per community are mentioned in the results and discussion chapter. 

Social Vulnerabilities and Risks

\subsubsection{Sampling and Microbial Analyses}

The researcher has conducted a five month E.coli counts on a monthly basis from March 2013 to July 2013. There were five (5) stations were the water samples were collected and nine (9) replicates in each sampling sites. These sampling sites include the following; upstream (City Pound Bridge, Barangay Balugo), midstream 1(Barangay Candau-ay and Cadawinonan Overflow), midstream 2 (Colon Extension Overflow, Barangay Taclobo), downstream 1 (Tabuc-tubig Bridge), and downstream 2 (Barangay Calindagan and Tinago) respectively.

E.coli which is among the coliforms is a good indicator organism to use for assessing surface water microbial contamination. They are not generally pathogenic but their presence indicates fecal contamination in the water. The cultivation of E.coli in this study uses the Eosin-Methylene Blue (EMB) agar which is one of the most efficient differential media for E.coli. The water samples from each site were taken between 8 o'clock and 11 o'clock in the morning and were processed immediately after.

During the water sampling collection, the bottle was plunged into the river about 3-4 inches (wrist level) below the surface water and then the bottle was turn into where the current was and waiting for it to be filled. After which, the bottle was brought out from the river and some water were poured out leaving an inch of air space. This was repeated in all of the 5 sampling sites. Since the proximity to the university laboratory is near and the time of collection is quick, all samples were immediately examined within 3-4 hours. Refrigeration and cold temperature during transport was not necessary. All the necessary data field information was recorded.

For the laboratory culture of E. coli, EMB agar was used and aseptic technique was observed all throughout the procedure. The spread plate technique was employed for the determination of E.coli bacteria. A ten-fold dilution series was prepared from the contaminated river water sample with $9 \mathrm{ml}$ sterile distilled water in each test tube replicates. From that set up, $0.1 \mathrm{ml}$ of dilution was spread onto the surface of EMB agar plates. The EMB agar plates were then incubated for 24 hours to get the results. Positive plates showing E.coli colonies were showing greenish metallic sheen on the surface which was easy to identify and count (Figure 4-33). E.coli bacteria were counted per plate (shown in the succeeding tables below) and then calculated per 100ml using this formula below (Environmental Protection Agency or EPA, 2012). The overall results will be presented in chapter 5 . 


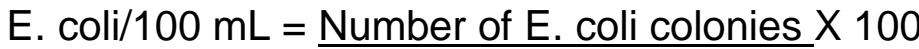 \\ Volume of sample $(\mathrm{mL})$}

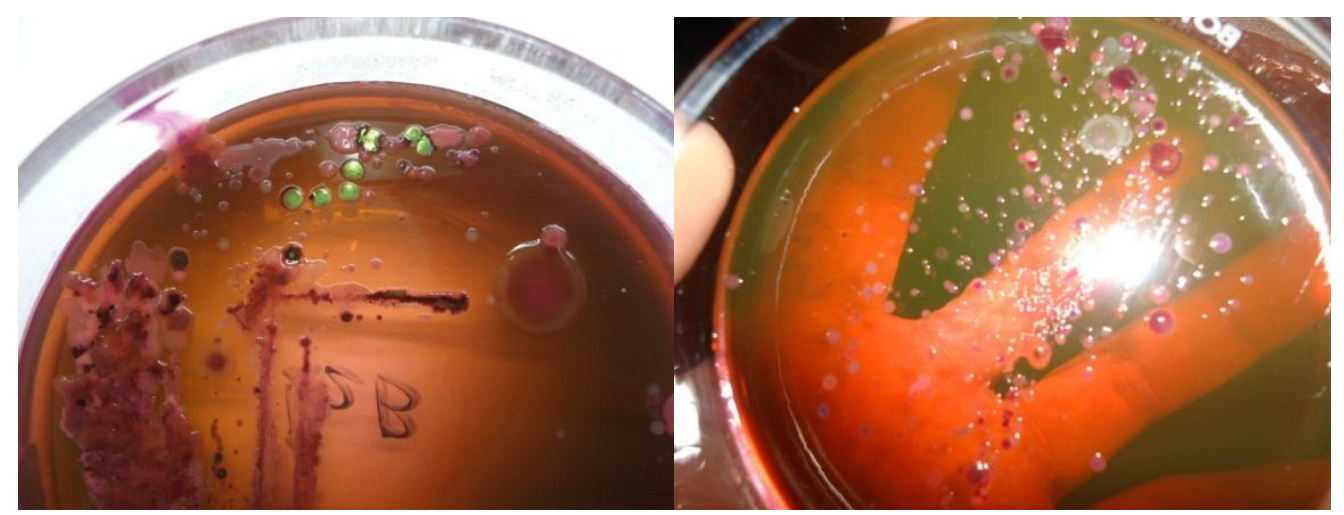

Figure 4-33: EMB plate (left) positive for E.coli (greenish metallic sheeen) and EMB plate (right) negative for E.coli colonies

Table 4-10: E.coli counts during dry and wet season (March-July, 2013) Upstream: City Pound Bridge, Barangay Balugo

\begin{tabular}{|l|r|r|r|r|r|}
\hline & $20-M a r-$ & 11-Apr- & 29-May- & 25-Jun- & 17-Jul- \\
\hline \multirow{3}{*}{ Upstream1A } & 13 & 13 & 13 & 13 & 13 \\
\cline { 2 - 6 } & 0 & 17 & 0 & 0 & 0 \\
\cline { 2 - 6 } & 0 & 0 & 0 & 0 & 0 \\
\hline \multirow{3}{*}{ Upstream1B } & 0 & 0 & 0 & 21 & 0 \\
\cline { 2 - 6 } & 0 & 0 & 0 & 0 & 0 \\
\cline { 2 - 6 } & 3 & 0 & 0 & 0 & 0 \\
\hline \multirow{3}{*}{ Upstream1C } & 0 & 0 & 0 & 0 & 0 \\
\cline { 2 - 6 } & 0 & 0 & 0 & 0 & 0 \\
\cline { 2 - 6 } & 0 & 3 & 0 & 0 & 0 \\
\hline
\end{tabular}

As shown in table 4-10, the E.coli counts in the upstream were both very negligible especially during the dry season and some isolated counts of 21 and 20 during the wet season respectively. The upper stream sampling is located in Station 1-City Pound Bridge, Barangay Balugo (Figure 4-34). Generally, the water in this part of the river is usually clean and clear and surrounded with trees. 

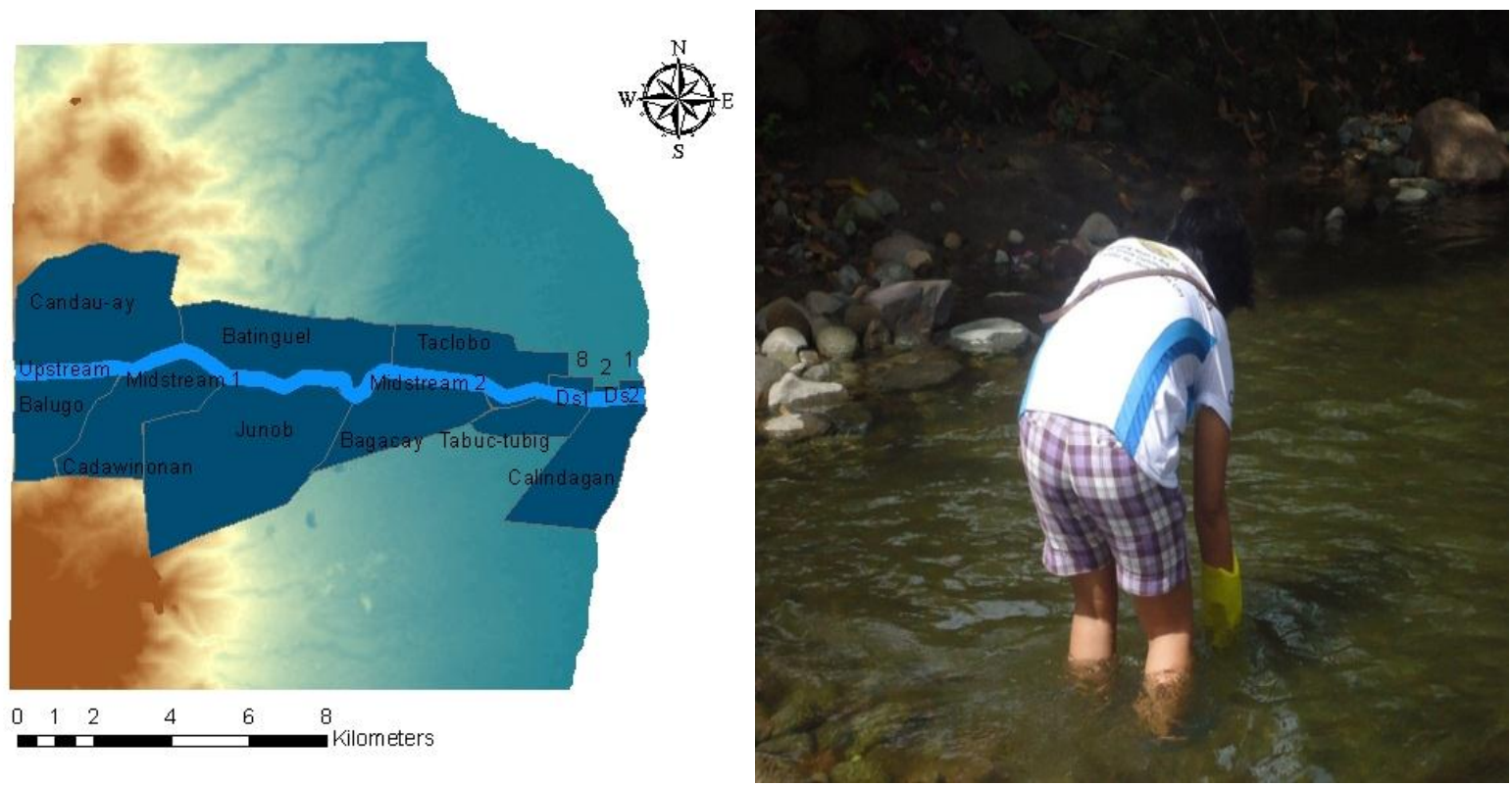

Figure 4-34: Upstream (S1): City Pound Bridge, Barangay Balugo

Table 4-11: E.coli counts during dry and wet season (March-July, 2013) Midstream 1: Barangay Candauay and Cadawinonan Overflow

\begin{tabular}{|c|r|r|r|r|r|}
\hline & 20-Mar- & 11-Apr- & 29-May- & 25-Jun- & 17-Jul- \\
\hline \multirow{3}{*}{$\begin{array}{c}\text { Midstream } \\
\text { 1A }\end{array}$} & 13 & 13 & 13 & 13 & 13 \\
\cline { 2 - 6 } & 17 & 0 & 0 & 0 & 0 \\
\cline { 2 - 6 } & 3 & 0 & 0 & 0 & 1 \\
\hline \multirow{3}{*}{$\begin{array}{c}\text { Midstream } \\
1 B\end{array}$} & 0 & 0 & 0 & 0 & 1 \\
\cline { 2 - 6 } & 12 & 1 & 0 & 0 & 1 \\
\hline \multirow{3}{*}{$\begin{array}{c}\text { Midstream } \\
\text { 1C }\end{array}$} & 3 & 0 & 5 & 0 & 0 \\
\cline { 2 - 6 } & 0 & 3 & 0 & 0 & 0 \\
\cline { 2 - 6 } & 3 & 1 & 0 & 1 & 1 \\
\hline
\end{tabular}

It rained the night before the March 20 sampling day for E.coli. As observed from table 4-11, March 20 sampling showed more E,coli counts than those done in other months including the wet months of June and July were it didn't rain the day before the sampling time. Figure 4-35 shows the location of Midstream 1 sampling area. 

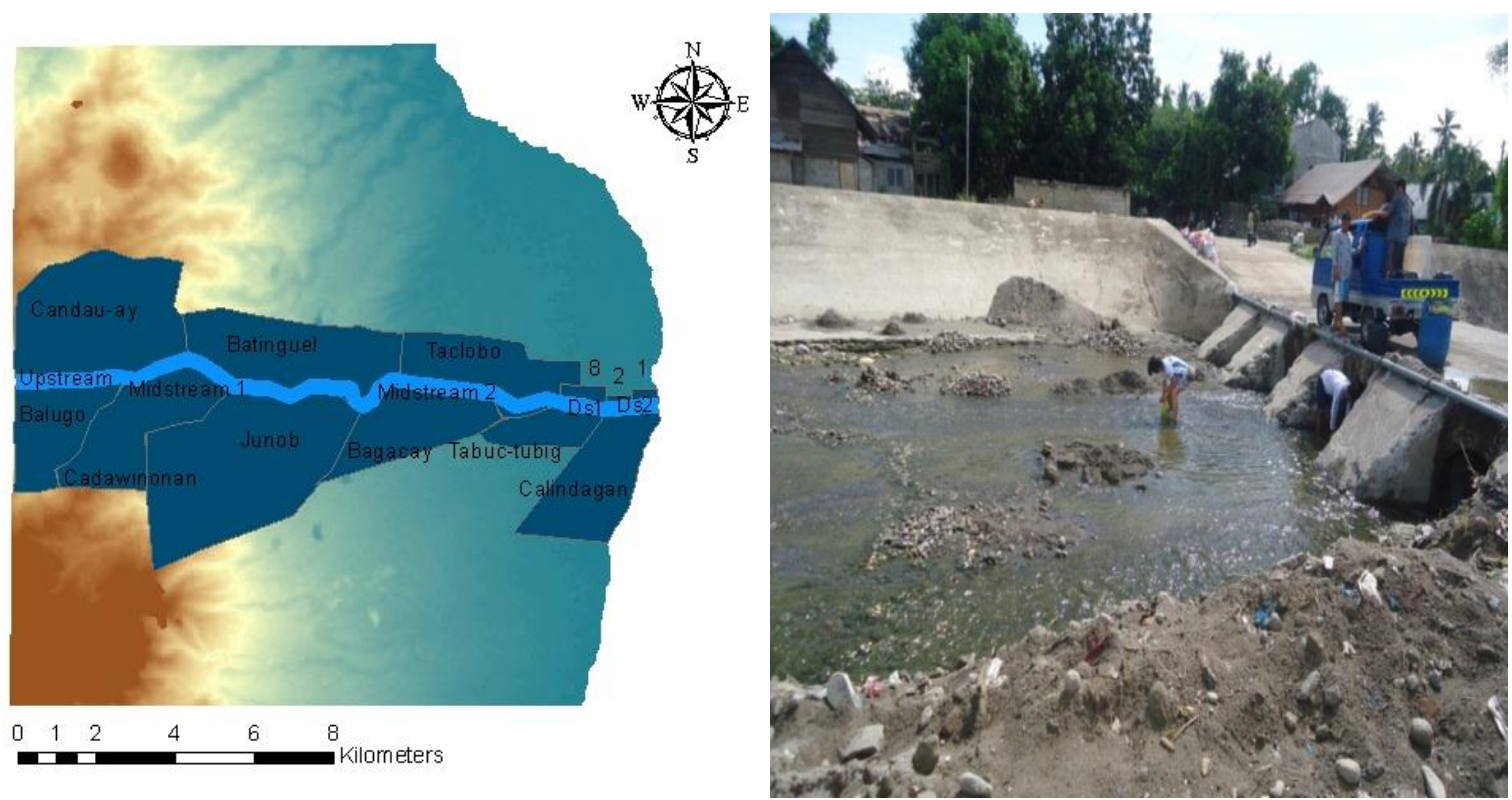

Figure 4-35: Midstream 1 (S3): Barangay Candau-ay and Cadawinonan Overflow

Table 4-12: E.coli counts during dry and wet season (March-July, 2013) Midstream 2: Colon Extension Overflow, Barangay Taclobo

\begin{tabular}{|c|r|r|r|r|r|}
\hline & 20-Mar- & 11 -Apr- & 29-May- & 25-Jun- & 17-Jul- \\
\hline \multirow{3}{*}{$\begin{array}{c}\text { Midstream } \\
\text { 2A }\end{array}$} & 7 & 13 & 13 & 13 & 13 \\
\cline { 2 - 6 } & 3 & 1 & 0 & 0 & 9 \\
\cline { 2 - 6 } & 5 & 35 & 4 & 0 & 0 \\
\hline \multirow{3}{*}{$\begin{array}{c}\text { Midstream } \\
\text { 2B }\end{array}$} & 0 & 19 & 0 & 0 & 0 \\
\cline { 2 - 6 } & 7 & 14 & 8 & 1 & 0 \\
\hline \multirow{3}{*}{$\begin{array}{c}\text { Midstream } \\
\text { 2C }\end{array}$} & 9 & 11 & 0 & 0 & 5 \\
\cline { 2 - 6 } & & 3 & 2 & 0 & 0 \\
\cline { 2 - 6 } & 4 & 10 & 1 & 0 & 0 \\
\hline
\end{tabular}

E.coli counts were higher in the months of April and March of 2013 when the collection was done (Table 4-12). It rained the night before March 20 and July 17 sampling collection. The high counts in midstream 2 was consistent with the high counts of downstream 1 and 2 where it is densely populated along the river banks and some open drainage system were observed directly connected the river. Figure 4-36 shows the location of Midstream 2. 

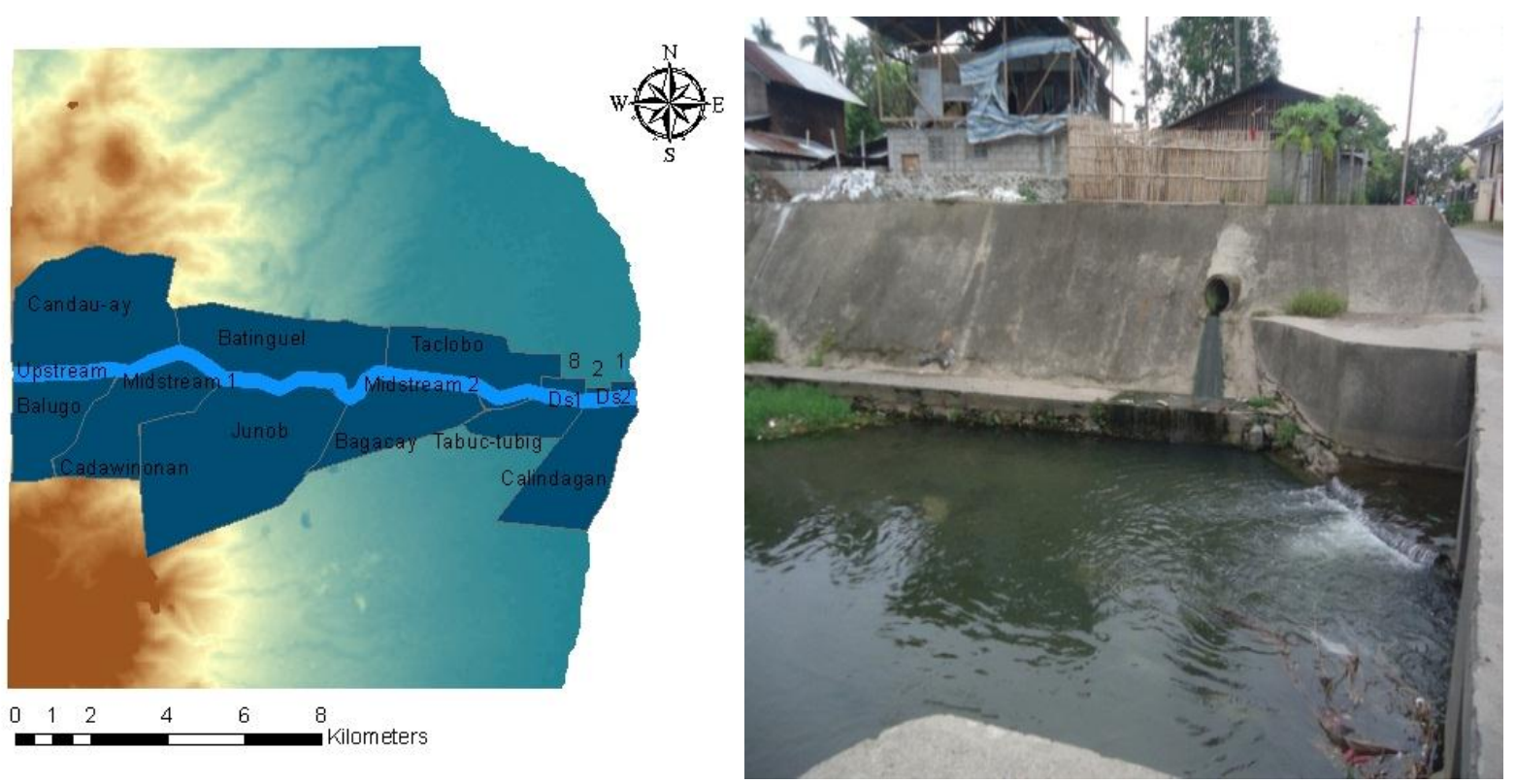

Figure 4-36: Midstream 2 (S5): Colon Extension Overflow, Barangay Taclobo

Table 4-13: E.coli counts during dry and wet season (March-July, 2013) Downstream 1: Tabuc-Tubig Bridge

\begin{tabular}{|c|r|r|r|r|r|}
\hline & 20-Mar- & 11-Apr- & 29-May- & 25-Jun- & 17-Jul- \\
\hline \multirow{3}{*}{ Downstream } & 13 & 13 & 13 & 13 & 13 \\
1A & 66 & 3 & 15 & 0 & 0 \\
& 34 & 13 & 12 & 0 & 15 \\
\hline \multirow{3}{*}{ Downstream } & 47 & 30 & 8 & 0 & 7 \\
1B & 45 & 0 & 50 & 0 & 16 \\
& 16 & 9 & 25 & 0 & 12 \\
Downstream & 23 & 12 & 0 & 0 & 6 \\
1C & 15 & 8 & 15 & 1 & 0 \\
& 16 & 0 & 14 & 0 & 0 \\
\hline
\end{tabular}

The E.coli count in this area is consistently high in most months even during the dry months of March to May. In the wet months of July the counts was also high except for the month of June as seen in Table 4-13. Some open drainage systems were also observed. Figure 4-37 belows shows the location for Downstream 1. 

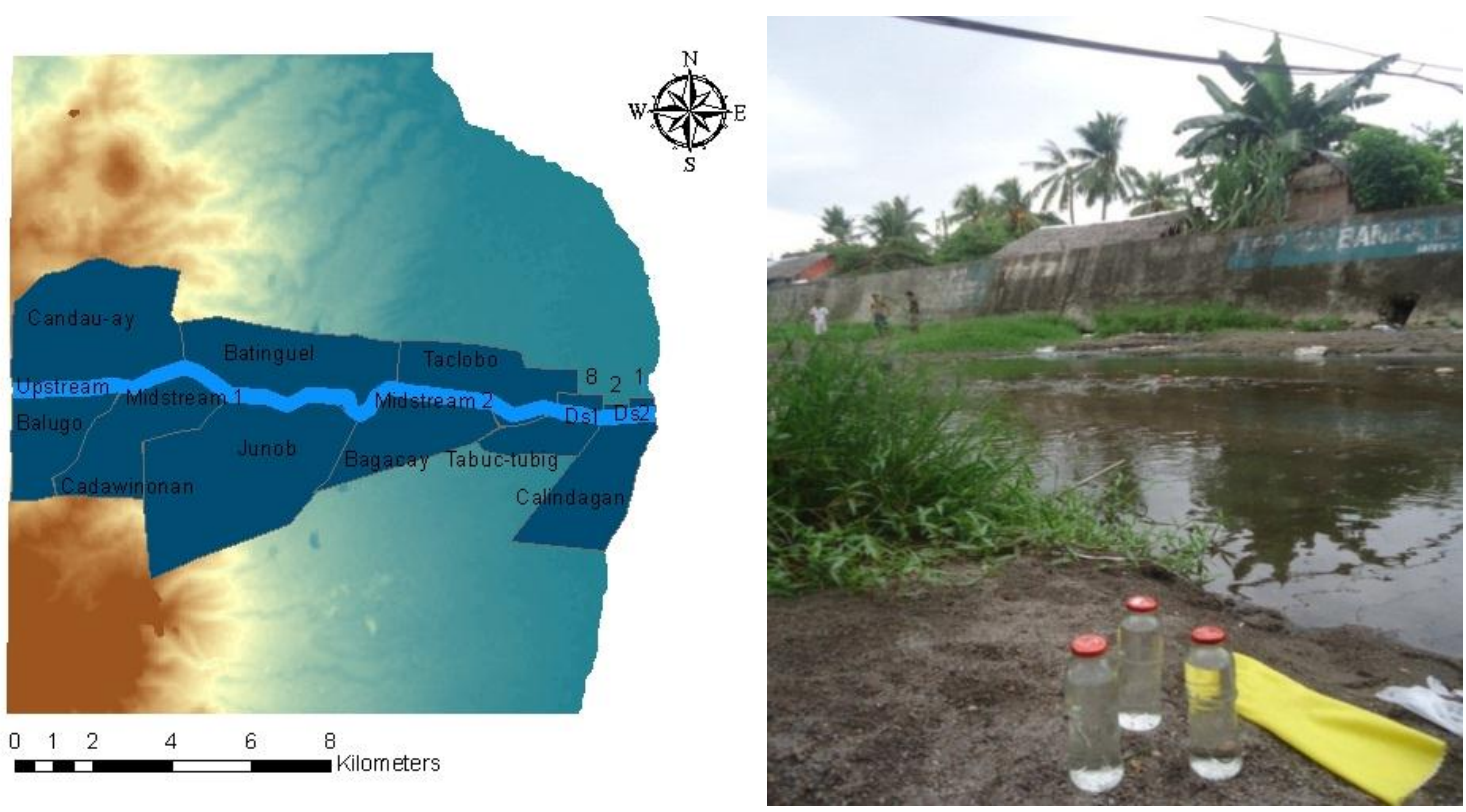

Figure 4-37: Downstream 1 (S7): Barangay Tabuc-tubig Bridge

Table 4-14: E.coli counts during dry and wet season (March-July, 2013) Downstream 2: Barangay Calindagan and Tinago

\begin{tabular}{|c|r|r|r|r|r|}
\hline & 20 -Mar- & 11 -Apr- & 29-May- & 25-Jun- & 17-Jul- \\
\hline \multirow{3}{*}{$\begin{array}{c}\text { Downstream } \\
2 \mathrm{~A}\end{array}$} & 33 & 13 & 13 & 13 & 13 \\
\cline { 2 - 6 } & 33 & 45 & 11 & 0 & 0 \\
\cline { 2 - 6 } & 15 & 20 & 8 & 15 & 0 \\
\hline \multirow{3}{*}{$\begin{array}{c}\text { Downstream } \\
\text { 2B }\end{array}$} & 25 & 45 & 5 & 3 & 1 \\
\cline { 2 - 6 } & 33 & 34 & 6 & 12 & 0 \\
\hline \multirow{3}{*}{$\begin{array}{c}\text { Downstream } \\
\text { 2C }\end{array}$} & 17 & 28 & 0 & 21 & 0 \\
\cline { 2 - 6 } & 60 & 7 & 30 & 3 & 1 \\
\cline { 2 - 6 } & 62 & 5 & 25 & 28 & 0 \\
\hline
\end{tabular}

The most downstream part of the river is located in Barangay Calindagan and Tinago and has the most number of E.coli counts which was consistent all throughout the dry and wet season except for the month of July (Table 4-14). A few open drainage systems were observed along this stretch of the river. This part somehow acts as the catchment of all the contaminants coming from the mid-and-upper stream of the river (Figure 4-38). 

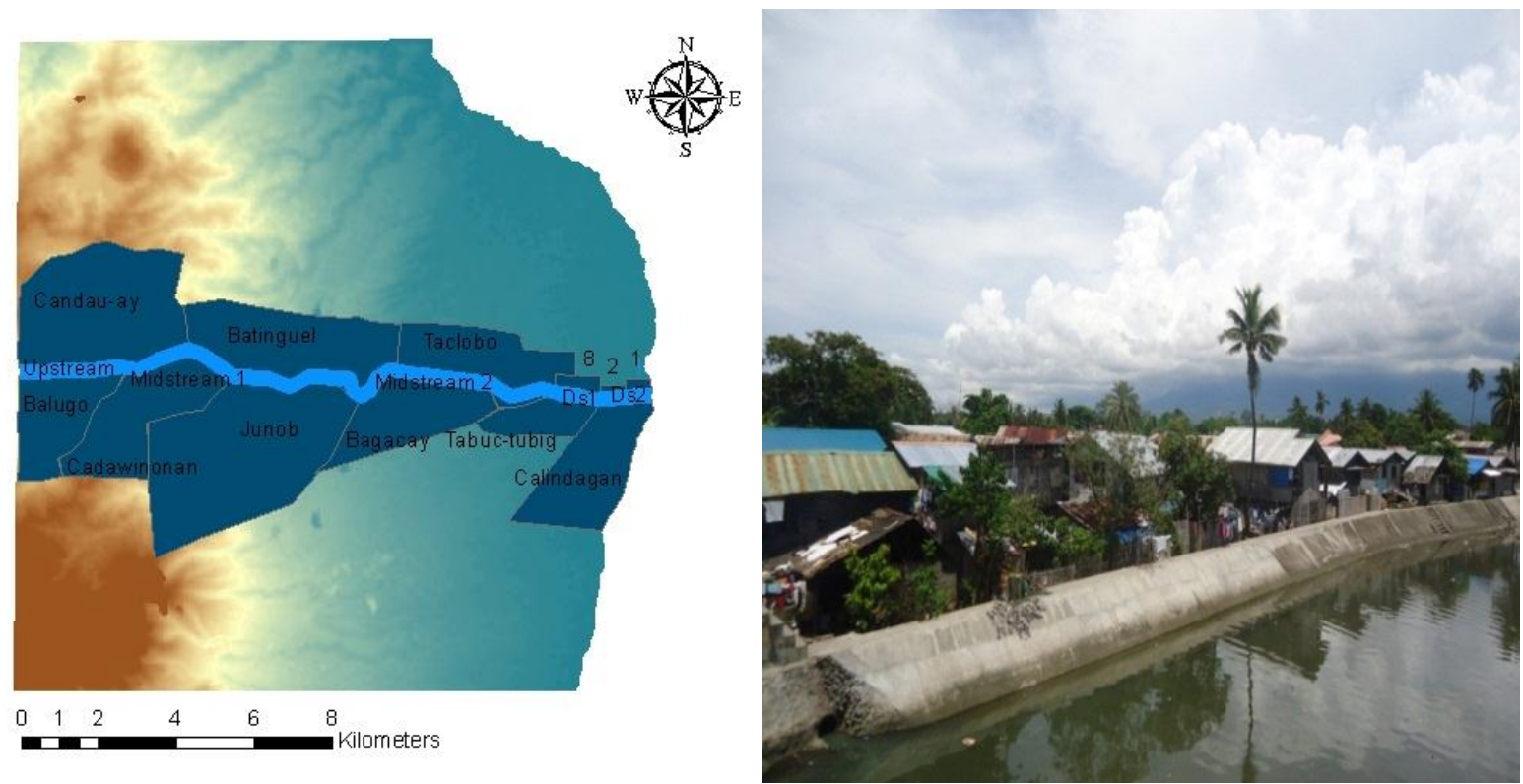

Figure 4-38: Downstream 2 (S8): Barangay Calindagan and Poblacion 1

\subsection{E.coli Exposure of the 12 Communities}

The succeeding tables present the E.coli exposure of the 12 communities in terms of the frequency of exposure (swimming or bathing in the river, immersing into the river and the washing of clothes in the river) and the possible amounts of water swallowed during such exposure. By soliciting this information, we may be able to understand the correlation between possible infection or outbreaks in the future.

Table 4-15: E.coli Exposure in Banica River through swimming/bathing (Tabuc-tubig)

\begin{tabular}{|ccc|}
\hline $\begin{array}{c}\text { Community } \\
\text { Tabuc- } \\
\text { tubig }\end{array}$ & Swimming/Bathing in the River & water swallowed \\
\hline 1 & Every week & Full shot glass \\
\hline
\end{tabular}

Out of the 8 household respondents in Barangay Tabuc-tubig, one (1) is showing exposure to E.coli through swimming/bathing in the river, swallowing a full shot glass amount of river water (Table 4-15). 
Community-Based Flood Vulnerability Index for Urban Flooding: Understanding Social Vulnerabilities and Risks

Table 4-16: E.coli Exposure in Banica River through swimming/bathing (Junob)

\begin{tabular}{|c|c|c|}
\hline $\begin{array}{c}\text { Community } \\
\text { Junob }\end{array}$ & $\begin{array}{c}\text { Frequency of } \\
\text { Swimming/Bathing in the River }\end{array}$ & $\begin{array}{c}\text { Amount of } \\
\text { water swallowed }\end{array}$ \\
\hline 1 & Very rarely & Half shot glass \\
\hline 2 & Everyday & Half shot glass \\
\hline 3 & Very rarely & Half spoonful \\
\hline 4 & Everyday & Half spoonful \\
\hline 5 & Very rarely & Half spoonful \\
\hline 6 & Very rarely & Full shot glass \\
\hline
\end{tabular}

Six (6) out of 14 respondents from Junob were exposed to E.coli though mostly rarely and 2 were exposed almost every day. Amount of river water swallowed ranged from a half-spoon to half-shot glass upon exposure (Table 4-16).

Table 4-17: E.coli Exposure in Banica River through swimming/bathing (Poblacion 1)

\begin{tabular}{|c|c|c|}
\hline Community & $\begin{array}{c}\text { Frequency of } \\
\text { Swimming/Bathing in the } \\
\text { River }\end{array}$ & Amount of \\
water swallowed
\end{tabular}

Only 3 out of 22 household respondents from Poblacion 1 (Table 4-17) were exposed to swimming/bathing in the river very rarely and of different amount of water swallowed, from spoonful to full shot and more than a full shot glass.

Table 4-18: E.coli Exposure in Banica River through swimming/bathing (Calindagan)

\begin{tabular}{|c|c|c|}
\hline $\begin{array}{l}\text { Community } \\
\text { Calindagan }\end{array}$ & $\begin{array}{c}\text { Frequency of } \\
\text { Swimming/Bathing in the } \\
\text { River }\end{array}$ & $\begin{array}{c}\text { Amount of } \\
\text { water swallowed }\end{array}$ \\
\hline 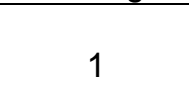 & Everyday & $\begin{array}{c}\text { More than a full shot } \\
\text { glass }\end{array}$ \\
\hline 2 & Very rarely & $\begin{array}{c}\text { More than a full shot } \\
\text { glass }\end{array}$ \\
\hline
\end{tabular}

Two (2) of the 23 household respondents (Table 4-18) claimed to have been exposed to E.coli through swimming/bathing in the river every day and very rarely with the same amount of water swallowed upon exposure (more than a full shot glass). 
Community-Based Flood Vulnerability Index for Urban Flooding: Understanding Social Vulnerabilities and Risks

Table 4-19: E.coli Exposure in Banica River through swimming/bathing (Poblacion 2)

\begin{tabular}{|c|c|c|}
\hline $\begin{array}{c}\text { Community } \\
\text { Poblacion } \\
2\end{array}$ & Frequency of & Amount of \\
\hline 1 & Swimming/Bathing in the River & water swallowed \\
\hline 2 & Twice a week & Half spoonful \\
\hline 3 & Very rarely & Spoonful \\
\hline
\end{tabular}

Three (3) out of 15 (Table 4-19) were exposed from here and variedly in terms of frequency (every day, twice a week, very rarely) and swallowed the river water about (spoonful, and half spoonful) of it.

Table 4-20: E.coli Exposure in Banica River through swimming/bathing (Balugo)

\begin{tabular}{|c|c|c|}
\hline $\begin{array}{c}\text { Community } \\
\text { Balugo }\end{array}$ & $\begin{array}{c}\text { Frequency of } \\
\text { Swimming/Bathing in the River }\end{array}$ & $\begin{array}{c}\text { Amount of } \\
\text { water swallowed }\end{array}$ \\
\hline 1 & Everyday & Half spoonful \\
\hline 2 & Everyday & Half spoonful \\
\hline 3 & Everyday & Half spoonful \\
\hline 4 & Everyday & Spoonful \\
\hline 5 & Twice a week & Spoonful \\
\hline
\end{tabular}

There were 5 out of the 17 respondents (Table 4-20) from Barangay Balugo that were exposed through swimming/bathing in the river almost every day and mostly have ingested from half spoonful to spoonful of water from the river respectively.

Table 4-21: E.coli Exposure in Banica River through swimming/bathing (Poblacion 8)

\begin{tabular}{|c|c|c|}
\hline $\begin{array}{c}\text { Community } \\
\text { Poblacion } \\
8\end{array}$ & Frequency of & Amount of \\
\hline 1 & Swimming/Bathing in the River & water swallowed \\
\hline 2 & Every other day & Half a shot glass \\
\hline 3 & Everyday & Full shot glass \\
\hline 4 & Everyday & Half spoonful \\
\hline 5 & Everyday & More than a full shot glass \\
\hline 6 & Every other day & Spoonful \\
\hline 7 & Every other day & Spoonful \\
\hline 8 & Every week & Full shot glass \\
\hline 9 & Very rarely & Half spoonful \\
\hline 10 & Very rarely & Half a shot glass \\
\hline
\end{tabular}



Social Vulnerabilities and Risks

Quite a number of respondents from Poblacion 8 (Table 4-21) were exposed through swimming/bathing in the river at different frequencies (from every day to every other day, every week and to some very rarely) of exposure. The amounts of water ingested varied from (half spoonful to a spoonful, half shot glass to a full shot glass and to more than a full shot glass) of river water.

Table 4-22: E.coli Exposure in Banica River through swimming/bathing (Cadawinonan)

\begin{tabular}{|c|c|c|}
\hline $\begin{array}{c}\text { Community } \\
\text { Cadawinonan }\end{array}$ & $\begin{array}{c}\text { Frequency of } \\
\text { Swimming/Bathing in the } \\
\text { River }\end{array}$ & $\begin{array}{c}\text { Amount of } \\
\text { water swallowed }\end{array}$ \\
\hline 1 & Very rarely & Spoonful \\
\hline 2 & Very rarely & Full shot glass \\
\hline 3 & Every week & $\begin{array}{c}\text { More than a full shot } \\
\text { glass }\end{array}$ \\
\hline 4 & Very rarely & Half a shot glass \\
\hline 5 & Very rarely & Half a shot glass \\
\hline 6 & Very rarely & Full shot glass \\
\hline
\end{tabular}

Six (6) out of 25 respondents (Table 4-22) have been exposed to swimming/bathing in the river very rarely and one claimed for an every week exposure. The amounts of water swallowed also varied (spoonful, half shot to full shot and more than a full shot glass) from each individual exposed.

Table 4-23: E.coli Exposure in Banica River through swimming/bathing (Bagacay)

\begin{tabular}{|c|c|c|}
\hline $\begin{array}{c}\text { Community } \\
\text { Bagacay }\end{array}$ & $\begin{array}{c}\text { Frequency of } \\
\text { Swimming/Bathing in the River }\end{array}$ & $\begin{array}{c}\text { Amount of } \\
\text { water swallowed }\end{array}$ \\
\hline 1 & Very rarely & Half spoonful \\
\hline 2 & Very rarely & More than a full shot glass \\
\hline 3 & Very rarely & Half a shot glass \\
\hline 4 & Very rarely & Spoonful \\
\hline 5 & Everyday & Half spoonful \\
\hline 6 & Everyday & Half a shot glass \\
\hline 7 & Every week & Half spoonful \\
\hline 8 & Very rarely & Spoonful \\
\hline
\end{tabular}

There were 8 out of 30 of the respondents (Table 4-23) from Bagacay that were exposed through swimming/bathing in the river mostly rarely, then two claimed for every day and one claimed for every week. The ingestion of the water from the river also 
Community-Based Flood Vulnerability Index for Urban Flooding: Understanding Social Vulnerabilities and Risks

varies (half spoonful, spoonful, half a shot glass, to more than a full shot glass) were swallowed upon exposure.

Table 4-24: E.coli Exposure in Banica River through swimming/bathing (Taclobo)

\begin{tabular}{|c|c|c|}
\hline $\begin{array}{c}\text { Community } \\
\text { Taclobo }\end{array}$ & $\begin{array}{c}\text { Frequency of } \\
\text { Swimming/Bathing in the River }\end{array}$ & $\begin{array}{c}\text { Amount of } \\
\text { water swallowed }\end{array}$ \\
\hline 1 & Everyday & Half spoonful \\
\hline 2 & Very rarely & Full shot glass \\
\hline 3 & Very rarely & Half spoonful \\
\hline 4 & Everyday & Half spoonful \\
\hline 5 & Every other day & Half spoonful \\
\hline 6 & Every week & Half spoonful \\
\hline 7 & Very rarely & More than a full shot glass \\
\hline 8 & Very rarely & Full shot glass \\
\hline 9 & Every week & Spoonful \\
\hline 10 & Everyday & Spoonful \\
\hline 11 & Very rarely & Hulf spoonful \\
\hline 12 & Very rarely & Full shot glass \\
\hline 13 & Very rarely & \\
\hline
\end{tabular}

Out of 63 respondents from Barangay Taclobo, 13 of which were exposed to E.coli through swimming/bathing in the river at different times (every day, every other day, every week, and mostly very rarely). The amount of water ingested also varies (half spoonful, spoonful, half shot glass, full shot glass, and more than a full shot glass) respectively, (Table 4-24).

Table 4-25: E.coli Exposure in Banica River through swimming/bathing (Candau-ay)

\begin{tabular}{|c|c|c|}
\hline $\begin{array}{c}\text { Community } \\
\text { Candau-ay }\end{array}$ & $\begin{array}{c}\text { Frequency of } \\
\text { Swimming/Bathing in the River }\end{array}$ & $\begin{array}{c}\text { Amount of } \\
\text { water swallowed }\end{array}$ \\
\hline 1 & Everyday & Half spoonful \\
\hline 2 & Everyday & More than a full shot glass \\
\hline 3 & Very rarely & Spoonful \\
\hline 4 & Twice a week & Full shot glass \\
\hline 5 & Very rarely & Half shot glass \\
\hline 6 & Twice a week & Half shot glass \\
\hline 7 & Everyday & Spoonful \\
\hline 8 & Very rarely & Spoonful \\
\hline
\end{tabular}



Social Vulnerabilities and Risks

Only 8 out of 72 household respondents from Candau-ay (Table 4-25) claimed to have been exposed to E.coli through swimming/bathing in the river at different frequencies (every day, every other day, every week, but mostly very rarely). The amount of water ingested also varies (half spoonful, spoonful, half shot glass, full shot glass and more than a full shot glass) respectively.

Table 4-26: E.coli Exposure in Banica River through swimming/bathing (Batinguel)

\begin{tabular}{|c|c|c|}
\hline $\begin{array}{c}\text { Community } \\
\text { Batinguel }\end{array}$ & $\begin{array}{c}\text { Frequency of } \\
\text { Swimming/Bathing in the River }\end{array}$ & $\begin{array}{c}\text { Amount of } \\
\text { water swallowed }\end{array}$ \\
\hline 1 & Very rarely & Half spoonful \\
\hline 2 & Everyday & Half spoonful \\
\hline 3 & Everyday & Spoonful \\
\hline 4 & Everyday & Half spoonful \\
\hline 5 & Everyday & Half spoonful \\
\hline 6 & Everyday & Half spoonful \\
\hline 7 & Everyday & Half shot glass \\
\hline 8 & Very rarely & Spoonful \\
\hline 9 & Everyday & Full shot glass \\
\hline 10 & Every week & Half shot glass \\
\hline 11 & Every other day & Half spoonful \\
\hline 12 & Everyday & Full shot glass \\
\hline 13 & Very rarely & Spoonful \\
\hline 14 & Very rarely & Spoonful \\
\hline
\end{tabular}

Almost half (14) of the 38 respondents in Batinguel (Table 4-26) claimed to have been exposed to E.coli through swimming/bathing in the river at different frequencies (every other day, every week, and very rarely but mostly claimed to have been exposed every day). The amount of water swallowed also varies respectively (half spoonful, spoonful, half shot glass, full shot glass).

Table 4-27: E.coli Exposure in Banica River through immersing/washing of clothes (Tabuc-tubig)

\begin{tabular}{|c|c|c|}
\hline $\begin{array}{c}\text { Community } \\
\text { Tabuc-tubig }\end{array}$ & $\begin{array}{c}\text { Frequency of immersing or } \\
\text { Washing of clothes in the River }\end{array}$ & $\begin{array}{c}\text { Amount of } \\
\text { water swallowed }\end{array}$ \\
\hline 1 & Every week & 0 \\
\hline
\end{tabular}

One (1) out of eight (8) from Barangay Tabuc-tubig (Table 4-27) was exposed to E.coli through washing of clothes in the river every week but no ingestion of water was involved. 
Community-Based Flood Vulnerability Index for Urban Flooding: Understanding Social Vulnerabilities and Risks

Table 4-28: E.coli Exposure in Banica River through immersing/washing of clothes (Junob)

\begin{tabular}{|c|c|c|}
\hline $\begin{array}{c}\text { Community } \\
\text { Junob }\end{array}$ & $\begin{array}{c}\text { Frequency of immersing or } \\
\text { Washing of clothes in the River }\end{array}$ & $\begin{array}{c}\text { Amount of } \\
\text { water swallowed }\end{array}$ \\
\hline 1 & Very rarely & 0 \\
\hline 2 & Everyday & 0 \\
\hline 3 & Everyday & 0 \\
\hline 4 & Everyday & 0 \\
\hline 5 & Everyday & 0 \\
\hline 6 & Twice a week & 0 \\
\hline
\end{tabular}

There were 6 out of 14 respondents from Junob (Table 4-28) were exposed through washing of clothes in the river that happens mostly every day, and for one respondent it happens twice a week and the other one very rarely. No amount of water was ingested.

Table 4-29: E.coli Exposure in Banica River through immersing/washing of clothes (Poblacion 1)

\begin{tabular}{|c|c|c|}
\hline $\begin{array}{c}\text { Community } \\
\text { Poblacion 1 }\end{array}$ & $\begin{array}{c}\text { Frequency of immersing or } \\
\text { Washing of clothes in the River }\end{array}$ & $\begin{array}{c}\text { Amount of } \\
\text { water swallowed }\end{array}$ \\
\hline 1 & Every other day & 0 \\
\hline 2 & Very rarely & 0 \\
\hline
\end{tabular}

Two (2) out of 14 respondents (Table 4-29) were exposed through washing of clothes in the river (every other day and very rarely) basis and no amount of water was swallowed.

Table 4-30: E.coli Exposure in Banica River through immersing/washing of clothes (Calindagan)

\begin{tabular}{|c|c|c|}
\hline $\begin{array}{c}\text { Community } \\
\text { Calindagan }\end{array}$ & $\begin{array}{c}\text { Frequency of immersing or } \\
\text { Washing of clothes in the River }\end{array}$ & $\begin{array}{c}\text { Amount of } \\
\text { water swallowed }\end{array}$ \\
\hline 1 & Everyday & 0 \\
\hline
\end{tabular}

Only 1 is exposed from Calindagan out of the 23 respondents in washing clothes in the river which happens every day and the possible of ingestion of water was zero (0) (Table 4-30). 
Community-Based Flood Vulnerability Index for Urban Flooding: Understanding Social Vulnerabilities and Risks

Table 4-31: E.coli Exposure in Banica River through immersing/washing of clothes (Balugo)

\begin{tabular}{|c|c|c|}
\hline $\begin{array}{c}\text { Community } \\
\text { Balugo }\end{array}$ & $\begin{array}{c}\text { Frequency of immersing or } \\
\text { Washing of clothes in the River }\end{array}$ & $\begin{array}{c}\text { Amount of } \\
\text { water swallowed }\end{array}$ \\
\hline 1 & Everyday & 0 \\
\hline 2 & Everyday & 0 \\
\hline 3 & Very rarely & 0 \\
\hline 4 & Every week & 0 \\
\hline 5 & Twice a week & 0 \\
\hline
\end{tabular}

Five (5) of the 17 respondents washed their clothes in the river making them exposed to E.coli (Table 4-31). The washing of clothes is (every day, twice a week, every week and very rarely). Ingestion of water from the river is zero (0).

Table 4-32: E.coli Exposure in Banica River through immersing/washing of clothes (Poblacion 2)

\begin{tabular}{|c|c|c|}
\hline $\begin{array}{c}\text { Community } \\
\text { Poblacion 2 }\end{array}$ & $\begin{array}{c}\text { Frequency of immersing or } \\
\text { Washing of clothes in the River }\end{array}$ & $\begin{array}{c}\text { Amount of } \\
\text { water swallowed }\end{array}$ \\
\hline 1 & Never & 0 \\
\hline 2 & Never & 0 \\
\hline 3 & Never & 0 \\
\hline
\end{tabular}

None out of 15 respondents from Poblacion 2 washed their clothes in the river (Table 432).

Table 4-33: E.coli Exposure in Banica River through immersing/washing of clothes (Poblacion 8)

\begin{tabular}{|c|c|c|}
\hline $\begin{array}{c}\text { Community } \\
\text { Poblacion 8 }\end{array}$ & $\begin{array}{c}\text { Frequency of immersing or } \\
\text { Washing of clothes in the River }\end{array}$ & $\begin{array}{c}\text { Amount of } \\
\text { water swallowed }\end{array}$ \\
\hline 1 & Twice a week & 0 \\
\hline 2 & Every other day & 0 \\
\hline 3 & Everyday & 0 \\
\hline 4 & Every week & 0 \\
\hline 5 & Every week & 0 \\
\hline 6 & Everyday & 0 \\
\hline 7 & Very rarely & 0 \\
\hline
\end{tabular}



Social Vulnerabilities and Risks

There were 7 out of 30 respondents from Poblacion 8 (Table 4-33) who washed their clothes in the river at different frequencies (every day, every week, every other day, twice a week and very rarely). Ingestion of water from the river is none.

Table 4-34: E.coli Exposure in Banica River through immersing/washing of clothes (Cadawinonan)

\begin{tabular}{|c|c|c|}
\hline $\begin{array}{c}\text { Community } \\
\text { Cadawinonan }\end{array}$ & $\begin{array}{c}\text { Frequency of immersing or } \\
\text { Washing of clothes in the River }\end{array}$ & $\begin{array}{c}\text { Amount of } \\
\text { water swallowed }\end{array}$ \\
\hline 1 & Twice a week & 0 \\
\hline 2 & Every week & 0 \\
\hline 3 & Very rarely & 0 \\
\hline 4 & Every week & 0 \\
\hline
\end{tabular}

Cadawinonan has 25 household respondents but only 4 were exposed to E.coli (through washing of clothes in the river (every week, twice a week, and very rarely) and with no ingestion of water from the river (Table 4-34).

Table 4-35: E.coli Exposure in Banica River through immersing/washing of clothes (Bagacay)

\begin{tabular}{|c|c|c|}
\hline $\begin{array}{c}\text { Community } \\
\text { Bagacay }\end{array}$ & $\begin{array}{c}\text { Frequency of immersing or } \\
\text { Washing of clothes in the River }\end{array}$ & $\begin{array}{c}\text { Amount of } \\
\text { water swallowed }\end{array}$ \\
\hline 1 & Very rarely & 0 \\
\hline 2 & Every other day & 0 \\
\hline 3 & Very rarely & 0 \\
\hline 4 & Very rarely & 0 \\
\hline 5 & Twice a week & 0 \\
\hline 6 & Every week & \\
\hline
\end{tabular}

Bagacay has 30 household respondents but only 6 (Table 4-35) has been exposed to E.coli through washing their clothes in the river (very rarely, twice a week, every other day, and every week). There was no ingestion of water from the river. 
Community-Based Flood Vulnerability Index for Urban Flooding: Understanding Social Vulnerabilities and Risks

Table 4-36: E.coli Exposure in Banica River through immersing/washing of clothes (Taclobo)

\begin{tabular}{|c|c|c|}
\hline $\begin{array}{c}\text { Community } \\
\text { Taclobo }\end{array}$ & $\begin{array}{c}\text { Frequency of immersing or } \\
\text { Washing of clothes in the River }\end{array}$ & $\begin{array}{c}\text { Amount of } \\
\text { water swallowed }\end{array}$ \\
\hline 1 & Everyday & 0 \\
\hline 2 & Everyday & 0 \\
\hline 3 & Twice a week & 0 \\
\hline 4 & Very rarely & 0 \\
\hline 5 & Very rarely & 0 \\
\hline 6 & Every week & 0 \\
\hline 7 & Very rarely & 0 \\
\hline 8 & Very rarely & 0 \\
\hline 9 & Everyday & 0 \\
\hline 10 & Twice a week & 0 \\
\hline 11 & Very rarely & 0 \\
\hline
\end{tabular}

Taclobo has sixty-three (63) household respondents but only 11 (Table 4-36) has claimed to be exposed by E.coli through washing their clothes in the river on the following frequencies (very rarely, every week, twice a week, and every day). The amount of water swallowed from the river is none.

Table 4-37: E.coli Exposure in Banica River through immersing/washing of clothes (Candau-ay)

\begin{tabular}{|c|c|c|}
\hline $\begin{array}{c}\text { Community } \\
\text { Candau-ay }\end{array}$ & $\begin{array}{c}\text { Frequency of immersing or } \\
\text { Washing of clothes in the River }\end{array}$ & $\begin{array}{c}\text { Amount of } \\
\text { water swallowed }\end{array}$ \\
\hline 1 & Every other day & 0 \\
\hline 2 & Everyday & 0 \\
\hline 3 & Everyday & 0 \\
\hline 4 & Every week & 0 \\
\hline 5 & Very rarely & 0 \\
\hline 6 & Very rarely & 0 \\
\hline 7 & Very rarely & 0 \\
\hline 8 & Everyday & 0 \\
\hline 9 & Everyday & \\
\hline
\end{tabular}

Barangay Candau-ay has seventy-two (72) household respondents with only 9 respondents (Table 4-37) have claimed to be exposed to E.coli through washing their clothes in the river on the following basis (very rarely, every week, every other day and every day). The amount of possible water swallowed is zero (0). 
Community-Based Flood Vulnerability Index for Urban Flooding: Understanding Social Vulnerabilities and Risks

Table 4-38: E.coli Exposure in Banica River through immersing/washing of clothes (Batinguel)

\begin{tabular}{|c|c|c|}
\hline $\begin{array}{c}\text { Community } \\
\text { Batinguel }\end{array}$ & $\begin{array}{c}\text { Frequency of immersing or } \\
\text { Washing of clothes in the River }\end{array}$ & $\begin{array}{c}\text { Amount of } \\
\text { water swallowed }\end{array}$ \\
\hline 1 & Very rarely & 0 \\
\hline 2 & Everyday & 0 \\
\hline 3 & Every week & 0 \\
\hline 4 & Every week & 0 \\
\hline 5 & Everyday & 0 \\
\hline 6 & Every other day & 0 \\
\hline 7 & Twice a week & 0 \\
\hline 8 & Twice a week & 0 \\
\hline 9 & Twice a week & 0 \\
\hline 10 & Every other day & 0 \\
\hline 11 & Very rarely & 0 \\
\hline 12 & Twice a week & 0 \\
\hline 13 & Everyday & 0 \\
\hline 14 & Everyday & \\
\hline & & 0 \\
\hline
\end{tabular}

There are thirty-eight (38) household respondents of Barangay Batinguel and almost half of the respondents (14) have been exposed to E.coli (Table 4-38) through washing their clothes in the river on the following basis (very rarely, twice a week, every other day, every day). The ingestion of the water from the river is none (0). 


\section{CHAPTER 5 \\ RESULTS AND DISCUSSION}

\section{SUMMARY}

This chapter presents the results of this research work. It is presented in tables and maps for better understanding with the corresponding discussions and analysis. The individual results of the twelve (12) communities selected as the study area for the application of the Community-Based Flood Vulnerability Index (FVI) for urban flooding, and the process of data collection will be presented, discussed and analyzed. An indepth case study of Poblacion 2 (Lukewright) will also be presented for better comprehension and analysis of the developed community-based flood vulnerability index within a particular community. The cases and results of each of the community will be presented in a detailed manner and finishing it with the overall results of the FVI of Dumaguete City, Negros Oriental Philippines in maps and profiles.

It is very important to do an actual field survey for the data collection in order to be able to see the feasibility of the developed community-based flood vulnerability index for urban flooding in terms of the flood vulnerability components and indicators used. Through soliciting the responses of the different respondents involved in this work, a more detailed perspective and realistic scenario will be generated based from the components and indicators that were formulated.

The total, average, and overall counts of E.coli are also revealed in this chapter. The individual results and overall results on the assessment on flood resilience adaptation strategies in Dumaguete City that were solicited from the household respondents of the twelve (12) communities and from the local government units (LGU's) and the nongovernmental organizations (NGO's) are shown.

This chapter will pinpoint the strengths and weakness of each of the twelve (12) communities studied in detailed based from the results gathered from the proposed community-based flood vulnerability index for urban flooding and why in the first place such a particular community is more vulnerable or resilient than the others. In this way, we would be able to understand fully why they are vulnerable and at risk in the first place. 


\section{CHAPTER 5 \\ RESULTS AND DISCUSSIONS}

This chapter presents the results of this research work. It is presented in tables and maps for better understanding with the corresponding discussions and analysis. The individual results of the twelve (12) communities selected as the study area for the application of the Community-Based Flood Vulnerability Index (FVI) for urban flooding, and the process of data collection will be presented, discussed and analyzed. An indepth case study of Poblacion 2 (Lukewright) will also be presented for better comprehension and analysis of the developed community-based flood vulnerability index. The cases and results will be presented in a detailed manner and finishing it with the overall results of the FVI of Dumaguete City, Negros Oriental Philippines.

It is very important to do an actual field survey for the data collection in order to be able to see the feasibility of the developed community-based flood vulnerability index for urban flooding in terms of the flood vulnerability components and indicators used. Through soliciting the responses of the different respondents involved in this work, a more detailed perspective and realistic scenario will be generated based from the components and indicators that were formulated.

This chapter will also discuss the general problems or limitations encountered in the development and application of the community-based flood vulnerability components and indicators. The accuracy of the data and the possible strengths and weaknesses of the identified indicators will also be looked into through testing the methodology. Lastly, this chapter will pinpoint the weaknesses in details as to why in the first place a particular community is more vulnerable than others. 

Social Vulnerabilities and Risks

\subsection{Community Profile Results}

(1) Barangay Tabuc-tubig

Barangay Tabuc-tubig's hydro-climatic Flood Vulnerability Index (FVI) is $74.19 \%$ as shown in Table 5-1 which indicates a high vulnerability in this particular component. The high vulnerability is due to high exposure in terms of the frequency of flooding $(60.00 \%)$ experienced in this community. Frequency of flooding is expected every year where $(70.00 \%)$ of the population is exposed per year. Though, $30.00 \%$ of the population surveyed claimed that flooding only happens sometimes. The height of flood water experienced in this community was as high as the roof top, and in some areas it is above the head and to some about shoulder high where $(20.00 \%),(30.00 \%),(10.00 \%)$ of the population have experienced such respectively amounting to $60.00 \%$. However, $40.00 \%$ from the surveyed household did not indicate the level of flood water in their area for some reasons. Sixty percent $(60.00 \%)$ of the households are reached by floods every year and only $50.00 \%$ of the households are located in an elevated area.

The number of typhoons on average per year that passes through the country is 20 . Since not all typhoons passes through Dumaguete City, only $50.00 \%$ of the typhoons are accounted and considered as a significant and a safe number and is used in the entire research work. It is important to note that whenever there is a tropical depression (TD) or a low pressure area (LPA) it usually brings rains that last for hours which can predispose to flooding. Thus, $50.00 \%$ is a safe number to be used for the possibility of.

The community's land use and management and structural design (LUMSD) as part of its resilience effort is only $38.75 \%$. This indicates a low efficiency when it comes to implementation, thus owing to low resilience and a high vulnerability in terms of these indicators.

The social FVI is $39.13 \%$. Open disposal of animal waste is widely observed (90.00\%) from the population. All households that were surveyed are willing to vacate into a new relocation site when advised by the government. They have acknowledged that they are located in a high risk area and they opt to vacate for safety reasons. Educational attainment of most households is only $(50.00 \%)$ which plays as a critical predisposing factor. The resilience factor that includes water treatment sterilization and social network is $20.00 \%$ and $95.00 \%$ respectively. The low range of water treatment sterilization resilience effort should be given attention so future disease outbreak that are water-borne can be prevented. 

Social Vulnerabilities and Risks

The economic FVI of Barangay Tabuc-tubig is $100.00 \%$ which is showing a high vulnerability in this item. All the households have good access to improved sanitation. Unfortunately, there is still $50.00 \%$ of this community that has no access to improved water source. Presence of rats in the community is highly observed $(100.00 \%)$ and $(90.00 \%)$ of the population live nearby the presence of water logged areas in the vicinity. Most of the housing conditions, only (50.00\%) is capable to withstand from strong winds and water invasion during heavy rains and flooding. Forty percent $(40.00 \%)$ of most households have family income that is around $3000-1000$ per month while $20.00 \%$ of the population has an income that is below 3,000.00 pesos and the other $20.00 \%$ has an income of more than $10,000.00$ pesos and the remaining $20.00 \%$ did not indicate their income resources. All families that were surveyed in this community did not have their properties insured $(0.00 \%)$.

The socio-behavioral $\mathrm{FVI}$ is $3.96 \%$ which is a very low vulnerability. It is a good indication that the community will not suffer from the risks and effects of flooding and the possible disease outbreak during and after any natural calamity. The vulnerability index in terms of the knowledge, attitude and practices that predisposed the household to any flooding event and disease outbreaks that may be caused by E.coli, Leptospirosis and Dengue Fever mosquito is considerably low giving its exposure vulnerability to $22.83 \%$, while susceptibility is only $13.35 \%$, and resilience effort is very good $(76.99 \%)$ respectively. However, it is important to note that only $30.00 \%$ of the household knew if there are flood hazard maps available in their community. And only $43.48 \%$ is aware of the negative impacts of flooding. Personal coping mechanism of the people to forget about the previous unfortunate incident brought about by flooding is to seek for counseling, by not mentioning about it or forgetting the unfortunate event and staying calm.

The politico-administrative $\mathrm{FVI}$ is $49.69 \%$, which is medium range vulnerability. The exposure vulnerability is $65.63 \%$, considerably high which could be due to poor attention for the river's natural resources and natural features management and program $(70.00 \%)$ and inefficient implementation of land use and management and structural design (61.25\%). On the other hand, the susceptibility is $52.11 \%$ (governance) and the resilience effort is $63.25 \%$. The resilience effort includes; post-risk assessment and integration (42.50\%), sustainable community livelihood program $(37.50 \%)$, relocation site project $(86.00 \%)$ and the health and prevention program for E.coli, leptospirosis and dengue fever mosquito (87.00\%) respectively. 

Social Vulnerabilities and Risks

The overall FVI for Barangay Tabuc-tubig is $53.39 \%$ which is in medium range vulnerability. However, it should be noted that only $10.00 \%$ of the effort accounts for protecting and maintaining the river and its natural features and only $20.00 \%$ of the community people are actively engaging in planning and implementing the river resource management activities. Participation of the community people and LGU's should be encouraged. Forty percent $(40.00 \%)$ is the transparency, accountability, and availability of technical and financial support mechanisms to support planned community actions for resilience and $40.00 \%$ is invested in the risk reduction effort carried by the LGU's. Furthermore, only $30.00 \%$ of the land use policies and building standards are incorporated to reduce risks from hazards and to protect sensitive habitats. Only $38.00 \%$ of the developers and communities incorporate the risk reduction effort into the location and design of structures. From that, only $30.00 \%$ followed the building codes, and $20.00 \%$ followed the zoning ordinances and $20.00 \%$ of resilience efforts for education, outreach, training programs to improve compliance with land use policies and building standards are achieved. Forty percent $(40.00 \%)$ is achieved in the development policies and plans in building social capital skills for economic diversity and self-reliance. There is only $30.00 \%$ availability of diverse and environmentally sustainable livelihood in the community which may have an impact during recovery of any natural calamity. The technical and financial resources in promoting self-reliant communities so it would have the capacity to provide support to disaster-stricken areas and in promoting robust economies, to reduce vulnerability to hazards and aid in disaster recovery is $40.00 \%$ respectively. Also, only $30.00 \%$ of flood hazard risk assessments are completed and routinely updated, and $30.00 \%$ indicates how comprehensive is our flood risk assessments in incorporating risks to all elements of resilience. The community is $40.00 \%$ ready when it comes to community warning and evacuation systems, policies, plans and procedures in place and capable of alerting vulnerable population in a timely manner. When it comes to the availability of technical services offered and financial resources to support the recovery process such as that of damage assessment facilitating claim procession, reconstruction, charitable funds, and social therapeutic measures is only $40.00 \%$. Special attention must be given to this weak points so that the community will be strengthened and resilient to whatever natural calamity particularly to flooding and typhoon. Barangay Tabuc-tubig's assessment on flood resilience and health programs implemented by the government is $81.10 \%$ which is a very high score indicating a very good performance. Though, the dike and drainage systems scored among the lowest $(62.00 \%$ and $64.00 \%$ respectively). 
Community-Based Flood Vulnerability Index for Urban Flooding: Understanding Social Vulnerabilities and Risks

Table 5-1: Barangay Tabuc-Tubig FVI

\begin{tabular}{|c|c|c|c|c|c|c|c|}
\hline \multirow[b]{2}{*}{ COMPONENTS } & \multicolumn{2}{|c|}{ EXPOSURE } & \multicolumn{2}{|c|}{ SUSCEPTIBILITY } & \multicolumn{2}{|c|}{ RESILIENCE } & \multirow{2}{*}{$\begin{array}{r}\text { FVI } \\
(\%)\end{array}$} \\
\hline & Indicators & $(\%)$ & Indicators & $(\%)$ & Indicators & $(\%)$ & \\
\hline \multirow{4}{*}{ A. HYDRO-CLIMATIC } & A. FF & 60.00 & \multirow[t]{4}{*}{ A. NTY } & \multirow[t]{4}{*}{50.00} & \multirow[t]{4}{*}{ A. LUMSD } & \multirow[t]{4}{*}{38.75} & \multirow[t]{4}{*}{74.19} \\
\hline & B. HF & 60.00 & & & & & \\
\hline & C. HRF & 60.00 & & & & & \\
\hline & D. HNE & 50.00 & & & & & \\
\hline \multirow{2}{*}{ B. SOCIAL } & A. ODAW & 90.00 & \multirow[t]{2}{*}{ A. EA } & \multirow[t]{2}{*}{50.00} & A. WT & 20.00 & \multirow[t]{2}{*}{39.13} \\
\hline & B. UVR & 0.00 & & & B. SN & 95.00 & \\
\hline \multirow{4}{*}{ C.ECONOMIC } & A. HNIS & 0.00 & \multirow[t]{4}{*}{ A. $\mathrm{HC}$} & \multirow[t]{4}{*}{50.00} & A. FI & 40.00 & \multirow[t]{4}{*}{100.00} \\
\hline & B. HNIW & 50.00 & & & B. PI & 0.00 & \\
\hline & C. PRV & 100.00 & & & & 20.00 & \\
\hline & D. PWLV & 90.00 & & & & & \\
\hline \multirow{4}{*}{ D.SOCIO-BEHAVIORAL } & A. PHFR & 24.48 & A. AHFR & 20.62 & A. KHFR & 80.79 & \multirow[t]{4}{*}{3.96} \\
\hline & B. PHEC & 14.28 & B. AHEC & 16.11 & B. KHEC & 75.72 & \\
\hline & C. PHL & 25.30 & C. $\mathrm{AHL}$ & 11.39 & C. KHL & 75.72 & \\
\hline & D. PHDF & 27.27 & D. AHDF & 5.28 & D. KHDF & 75.72 & \\
\hline \multirow{4}{*}{$\begin{array}{c}\text { E. POLITICO- } \\
\text { ADMINISTRATIVE }\end{array}$} & A. RNRMP & 70.00 & \multirow[t]{4}{*}{ A. $\mathrm{G}$} & \multirow[t]{4}{*}{52.11} & A. PRAI & 42.50 & \multirow[t]{4}{*}{49.69} \\
\hline & B. LUMSD & 61.25 & & & B. SCLP & 37.50 & \\
\hline & & & & & C. RSP & 86.00 & \\
\hline & & & & & D. HPP & 87.00 & \\
\hline
\end{tabular}

(2) Barangay Junob

Barangay Junob's hydro-climatic Flood Vulnerability Index (FVI) is $42.58 \%$ as shown in Table 5-2 indicating medium range vulnerability. Its medium range vulnerability is attributed to effective land use and structural design $(71.56 \%)$ that complement environmental, economic, and community goals that reduced risks from hazards. In spite that there is high exposure in terms of the number of houses reached by floods $(81.25 \%)$, and $56.25 \%$ of the houses are not on elevated area but since the resilience item on land use management and structural design (LUMSD) is high thus the hydroclimatic vulnerability is lowered. Frequency of flooding is expected every year according to $70.00 \%$ of the household surveyed though $30.00 \%$ says they only experience it sometimes. Flood waters are generally from the knee level and as high as beyond the roof from the last flooding event and this was experienced by $50.00 \%$ of the household surveyed. The highest height of floodwater experienced in this community is as high as above the head where $(25.00 \%)$ of them has experienced and some $(18.75 \%)$ claimed as high as the roof top. 
The social FVI is $13.59 \%$. Open disposal of animal waste is observed $(50.00 \%)$ from the population. Some $12.50 \%$ are not willing to vacate their residence because of the proximity of their source of livelihood and they also have learned how to secure their property when an anticipation of incoming untoward events such as typhoon and flooding. The educational attainment of most households is only (31.25\%) which is considerably low thus constant and continuous public awareness should be facilitated. The resilience factor that includes water treatment sterilization and social network is good and very high indicating $56.25 \%$ and $87.5 \%$ respectively.

The economic FVI of Junob is $100 \%$. All houses surveyed have good access to improved sanitation however, $25.00 \%$ among the surveyed population has no access to improved water source. Presence of rats in the community is highly observed $(93.75 \%)$ and $(25.00 \%)$ of the households lived in the presence of water logged. Most of the housing conditions, only (18.75\%) is capable to withstand from strong winds and water invasion. Most households (31.25\%) have family income that is around 3000-1000 per month. All families surveyed in this community did not have their properties insured $(0.00 \%)$.

The socio-behavioral $\mathrm{FVI}$ is $13.25 \%$. The socio-behavioral vulnerability index is very low in terms of the knowledge, attitude and practices that may predisposed the household to the impacts of any flooding event and disease outbreaks that may be caused by E.coli, Leptospirosis and Dengue Fever mosquito. Exposure vulnerability is $37.32 \%$, while susceptibility is only $26.26 \%$, and resilience factor is high $(73.95 \%)$ respectively. But, it is important to note the practices (52.64\%) that may predispose the community people to leptospirosis outbreak particularly on wearing protective sturdy shoes/boots during typhoons and flooding. Also, only $37.50 \%$ of the households surveyed have knowledge about the availability of flood hazard maps in their community. It is important that community people must be aware of the flood hazard maps for them to have a priori knowledge of the flood hazard area. With regards to drills on early warning system only $31.25 \%$ is aware about it. Awareness of these matters should be improved.

The politico-administrative $\mathrm{FVI}$ is $13.43 \%$. The exposure vulnerability is $30.47 \%$ with a considerably low exposure because of active management of river's natural resources and natural features management and program, sustained environmental services and livelihoods that reduces risks from flood hazards thus the exposure index value is $28.44 \%$ and $32.50 \%$ for the land use and management and structural design. Susceptibility is $30.78 \%$ (governance) and the resilience factor is $69.81 \%$. The resilience effort includes; post-risk assessment and integration $(71.25 \%)$, sustainable 

Social Vulnerabilities and Risks

community livelihood program $(62.50 \%)$, relocation site project $(73.60 \%)$ and the health and prevention program for E.coli, leptospirosis and dengue fever mosquito (71.90\%) respectively.

The overall FVI for Barangay Junob is $36.57 \%$ indicating a low vulnerability. However, the availability of technical (services offered) and financial resources to support the recovery process particularly on the insurance scheme scored the lowest $(20.00 \%)$. If this can be improve in the future then Barangay Junob would even have a much lower vulnerability. Barangay Junob's assessment on flood resilience and health programs implemented by the government is $64.38 \%$ which is a considerably high score indicating a good performance. However, the use of backhoe in cleaning the Banica river especially when the normal flow is blocked and the dike system scored among the lowest $(57.60 \%$ and $48.80 \%)$ respectively.

Table 5-2: Barangay Junob FVI

\begin{tabular}{|c|c|c|c|c|c|c|c|}
\hline \multirow[b]{2}{*}{ COMPONENTS } & \multicolumn{2}{|c|}{ EXPOSURE } & \multicolumn{2}{|c|}{ SUSCEPTIBILITY } & \multicolumn{2}{|c|}{ RESILIENCE } & \multirow{2}{*}{$\frac{\text { FVI }}{(\%)}$} \\
\hline & Indicators & $(\%)$ & Indicators & $(\%)$ & Indicators & $(\%)$ & \\
\hline \multirow{4}{*}{ A. HYDRO-CLIMATIC } & A. FF & 56.25 & \multirow[t]{4}{*}{ A. NTY } & \multirow[t]{4}{*}{50.00} & \multirow[t]{4}{*}{ A. LUMSD } & \multirow[t]{4}{*}{71.56} & \multirow[t]{4}{*}{42.58} \\
\hline & B. HF & 50.00 & & & & & \\
\hline & C. HRF & 81.25 & & & & & \\
\hline & D. HNE & 56.25 & & & & & \\
\hline \multirow{2}{*}{ B. SOCIAL } & A. ODAW & 50.00 & \multirow[t]{2}{*}{ A. EA } & \multirow[t]{2}{*}{31.25} & A. WT & 56.25 & \multirow[t]{2}{*}{13.59} \\
\hline & B. UVR & 12.50 & & & B. SN & 87.50 & \\
\hline \multirow{4}{*}{ C.ECONOMIC } & A. HNIS & 0.00 & \multirow[t]{4}{*}{ A. $\mathrm{HC}$} & \multirow[t]{4}{*}{81.25} & A. FI & 31.25 & \multirow[t]{4}{*}{100.00} \\
\hline & B. HNIW & 25.00 & & & B. PI & 0.00 & \\
\hline & C. PRV & 93.75 & & & & 15.63 & \\
\hline & D. PWLV & 25.00 & & & & & \\
\hline \multirow{4}{*}{ D.SOCIO-BEHAVIORAL } & A. PHFR & 22.21 & A. AHFR & 30.98 & A. KHFR & 69.02 & \multirow[t]{4}{*}{13.25} \\
\hline & B. PHEC & 32.36 & B. AHEC & 24.68 & B. KHEC & 75.32 & \\
\hline & C. PHL & 52.54 & C. $\mathrm{AHL}$ & 24.68 & C. $\mathrm{KHL}$ & 75.72 & \\
\hline & D. PHDF & 42.05 & D. AHDF & 24.68 & D. KHDF & 75.72 & \\
\hline \multirow{4}{*}{$\begin{array}{l}\text { E. POLITICO- } \\
\text { ADMINISTRATIVE }\end{array}$} & A. RNRMP & 28.44 & \multirow[t]{4}{*}{ A. $G$} & \multirow[t]{4}{*}{30.78} & A. PRAI & 71.25 & \multirow[t]{4}{*}{13.43} \\
\hline & B. LUMSD & 32.50 & & & B. SCLP & 62.50 & \\
\hline & & & & & C. RSP & 73.60 & \\
\hline & & & & & D. HPP & 71.90 & \\
\hline
\end{tabular}



Social Vulnerabilities and Risks

\section{(3) Poblacion 1 (Barangay Tinago)}

Barangay Tinago's hydro-climatic Flood Vulnerability Index $(\mathrm{FVI})$ is $60.15 \%$ as shown in Table 5-3 indicating high range vulnerability. This can be attributed to high exposure (75.00\%) index. Flooding is expected every year as experienced by $72.72 \%$ of the household surveyed. Some $27.28 \%$ expressed that it rarely and never happens. The level of flood water that was experienced by the community people is from ankle to shoulder high and $95.45 \%$ of them have experienced such. Most of the floodwater is knee high (36.36\%). In spite that there is a considerably high exposure in terms of the number of houses reached by floods (59.09\%), and $72.73 \%$ of the houses are not on elevated area but since the resilience item on land use management and structural design (LUMSD) is quite high (62.34\%) particularly on having efficient dike and bridge systems $(80.00 \%$ for both respectively) may have helped reduce the risks from over spilling waters.

The social $\mathrm{FVI}$ is $17.65 \%$. Open disposal of animal waste is observed (68.18\%) from the population. A considerable percent of $31.82 \%$ is not willing to vacate. The household perceived their area as no threat, there was no relocation site provided, the lack of trust to the LGU and the rest did not specify their reasons. Exposure index is $50.00 \%$ respectively. The educational attainment of most households is $27.28 \%$ which is quite low and may play as a critical predisposing factor. The resilience factor that includes water treatment sterilization and social network is both high indicating $77.27 \%$ and $77.30 \%$ respectively giving an overall resilience of $77.29 \%$ on these items.

The economic FVI for Poblacion 1 is also $100 \%$. There is still $4.55 \%$ with no access to improved sanitation and $18.19 \%$ of the community population with no access to improved water source. Presence of rats in the community is highly observed (100.00\%) and $(63.64 \%)$ of the household live near the presence of water logged areas in the vicinity. About $45.46 \%$ of most houses are susceptible to the effects of flooding and typhoons. Most households (27.27\%) have a family income that is around 3000-1000 per month and some families (13.64\%) in this community have their properties insured.

The socio-behavioral $\mathrm{FVI}$ is $13.12 \%$. The socio-behavioral vulnerability index of Poblacion 1 is also very low in terms of the knowledge, attitude and practices that may predisposed the household to any flooding event and disease outbreaks that may be caused by E.coli, Leptospirosis and Dengue Fever mosquito. Exposure vulnerability is $28.82 \%$, while susceptibility is only $33.25 \%$, and resilience is very good $(73.02 \%)$ respectively. However, some aspects are needed to be considered, for instance $31.32 \%$ are not aware about the availability of flood hazard maps in their community. It is very 

Social Vulnerabilities and Risks

important that community people should be aware on this to increase resilience and decrease vulnerability. There is also less awareness (45.45\%) on the limitation and level of protection offered by the flood barriers such as the dike system and the drainage system in the community. Only $40.91 \%$ of the surveyed household had heard about the presence of flood early warning system and $50.00 \%$ were aware about the lectures on early warning system. Furthermore, only $45.45 \%$ know about the adaptation strategies adapted in the community. Thus, there is a need to increase the awareness on this matter to increase the capacity of the community people to adapt. There is less participation (31.82\%) in the early warning system lectures from the community and less drill participation (31.82\%) related to evacuation and response as well. Also, only $45.45 \%$ have been given or have attended some debriefing session of the past flooding and $45.45 \%$ have attended to some discussions of lessons learned from the past flooding. About $59.09 \%$ have less contact to the communities located in the upstream area of the river (Balugo or Valencia) to give updates of the water level in the river. Contacts and coordination between communities should be enhanced to facilitate the sharing of information and updates of the water level condition so people in the downstream will be made alert. And only $50.00 \%$ have participated in the adaptation strategies facilitated by the LGU's which is again should be encouraged so people will be more adapted and resilient.

The politico-administrative $\mathrm{FVI}$ is $22.18 \%$. The exposure vulnerability is $37.58 \%$ with a considerably low exposure because of active management of river's natural resources and natural features management and program and the land use and management and structural design is also well facilitated. On the other hand, the susceptibility vulnerability is $40.00 \%$ (governance) and the resilience factor is $67.78 \%$. The resilience effort includes: post-risk assessment and integration (68.13\%), sustainable community livelihood program (57.50\%), relocation site project $(73.60 \%)$ and the health and prevention program for E.coli, leptospirosis and dengue fever mosquito (71.90\%) respectively. The overall $\mathrm{FVI}$ of Poblacion 1 is $42.62 \%$ which is considerably medium range vulnerability. However, sustainable community livelihood $(50.00 \%)$ should be made more available to the community; insurance scheme $(30.00 \%)$ to support the recovery process should also be given attention and likewise for traumatic and psychological stress debriefings. 
Community-Based Flood Vulnerability Index for Urban Flooding: Understanding Social Vulnerabilities and Risks

Table 5-3: Poblacion 1 (Barangay Tinago) FVI

\begin{tabular}{|c|c|c|c|c|c|c|c|}
\hline \multirow[b]{2}{*}{ COMPONENTS } & \multicolumn{2}{|c|}{ EXPOSURE } & \multicolumn{2}{|c|}{ SUSCEPTIBILITY } & \multicolumn{2}{|c|}{ RESILIENCE } & \multirow{2}{*}{$\begin{array}{c}\text { FVI } \\
(\%)\end{array}$} \\
\hline & Indicators & $(\%)$ & Indicators & $(\%)$ & Indicators & $(\%)$ & \\
\hline \multirow{4}{*}{ A. HYDRO-CLIMATIC } & A. FF & 72.72 & \multirow[t]{4}{*}{ A. NTY } & \multirow[t]{4}{*}{50.00} & \multirow[t]{4}{*}{ A. LUMSD } & \multirow[t]{4}{*}{62.34} & \multirow[t]{4}{*}{60.15} \\
\hline & B. HF & 95.45 & & & & & \\
\hline & C. HRF & 59.09 & & & & & \\
\hline & D. HNE & 72.73 & & & & & \\
\hline \multirow{2}{*}{ B. SOCIAL } & A. ODAW & 68.18 & \multirow[t]{2}{*}{ A. EA } & \multirow[t]{2}{*}{27.28} & A. WT & 77.27 & \multirow[t]{2}{*}{17.65} \\
\hline & B. UVR & 31.82 & & & B. SN & 77.30 & \\
\hline \multirow{4}{*}{ C.ECONOMIC } & A. HNIS & 4.55 & \multirow[t]{4}{*}{ A. $\mathrm{HC}$} & \multirow[t]{4}{*}{45.46} & A. $\mathrm{FI}$ & 27.27 & \multirow[t]{4}{*}{100.00} \\
\hline & B. HNIW & 18.19 & & & B. PI & 13.64 & \\
\hline & C. PRV & 100.00 & & & & & \\
\hline & D. PWLV & 63.64 & & & & & \\
\hline \multirow{4}{*}{ D.SOCIO-BEHAVIORAL } & A. PHFR & 33.11 & A. AHFR & 20.60 & A. KHFR & 65.29 & \multirow[t]{4}{*}{13.12} \\
\hline & B. PHEC & 16.35 & B. AHEC & 18.18 & B. KHEC & 75.60 & \\
\hline & C. PHL & 32.32 & C. $\mathrm{AHL}$ & 16.79 & C. $\mathrm{KHL}$ & 75.60 & \\
\hline & D. PHDF & 33.51 & D. AHDF & 13.76 & D. KHDF & 75.60 & \\
\hline \multirow{4}{*}{$\begin{array}{c}\text { E. POLITICO- } \\
\text { ADMINISTRATIVE }\end{array}$} & A. RNRMP & 37.66 & \multirow[t]{4}{*}{ A. $\mathrm{G}$} & \multirow[t]{4}{*}{40.00} & A. PRAI & 68.13 & \multirow[t]{4}{*}{22.18} \\
\hline & B. LUMSD & 37.50 & & & B. SCLP & 57.50 & \\
\hline & & & & & C. RSP & 73.60 & \\
\hline & & & & & D. HPP & 71.90 & \\
\hline Total Average FVI & & & & & & & 42.62 \\
\hline
\end{tabular}

(4) Barangay Calindagan

Barangay Calindagan's hydro-climatic Flood Vulnerability Index (FVI) is $37.76 \%$ as shown in Table 5-4 indicating a low vulnerability in this component. This can be due to its high resilience $(87.81 \%)$ when it comes to efficient land use and management and structural design. The household that were surveyed had experienced flooding every year about $26.09 \%$ of them while $(73.90 \%)$ of them claimed that flooding only happens rarely/sometimes or never. However, $(26.09 \%)$ claimed that flooding occurs every year in the area. The level of flood water experienced by the community people is from ankle high to above the head, $86.96 \%$ of them had experienced respectively. Generally the flood water is ankle high (39.13\%). In spite that there is a considerably high exposure in terms of the number of houses reached by floods (69.57\%), and $82.61 \%$ of the houses are not on elevated area but since the resilience item on (LUMSD) has been carried out effectively $(87.81 \%)$ particularly having an efficient dike $(80.00 \%)$ and bridge systems $(100.00 \%)$ which may have helped reduce the risks from over spilling waters. 

Social Vulnerabilities and Risks

The social FVI is $22.27 \%$. Open disposal of animal waste is observed (56.00\%) from the population. There is $17.39 \%$ who are not willing to vacate because there was no relocation site allotted for them, the proximity to their livelihood is big a consideration for them to stay, and they have learned to secure their property in the anticipation of certain calamity, while others did not specify their reasons for not acceding to vacate. These two items give an exposure index of $36.70 \%$ respectively. The educational attainment of most households is (47.82\%) which is not very high and which may plays as a critical predisposing factor. The resilience factor that includes water treatment sterilization and social network is both high indicating $69.57 \%$ and $88.04 \%$ respectively.

The economic FVI for Barangay Calindagan is $48.24 \%$. There is still $4.25 \%$ of the community population with no access to improved sanitation and also $4.25 \%$ with no access to improved water source. Presence of rats in the community is highly observed $(100.00 \%)$ and $(60.87 \%)$ of the population lived in the presence of water logged areas in the vicinity. $34.68 \%$ of most houses are susceptible to the effects of flooding and typhoons. Most households (52.17\%) have a family income that is around 3000-1000 per month and some families in this community have their properties insured $(8.70 \%)$.

The socio-behavioral FVI is $7.10 \%$. However, the socio-behavioral vulnerability index of Barangay Calindagan is also low in terms of the knowledge, attitude and practices that may predisposed the household to any flooding event and disease outbreaks that may be caused by E.coli, Leptospirosis and Dengue Fever mosquito. Exposure vulnerability is $29.58 \%$, while susceptibility is only $17.91 \%$, and resilience is very good $(74.62 \%)$ respectively. But it is important to note that practices items for Leptospirosis that may predispose the community people is $(40.87 \%)$. Efforts to increase good practices towards preventing leptospirosis must be given attention. Furthermore, only $34.78 \%$ are aware that their area is a flood hazard zone and is of high risk. Only $34.78 \%$ know the capacity of flood and just $4.45 \%$ are aware about the availability of flood hazard maps in their community. $30.43 \%$ of the surveyed population is aware of the limitation and level of protection of the flood control barriers. Barangay Calindagan has very low scores in terms of preparedness. For instance, only $17.39 \%$ have heard about the presence of flood early warning system in their community, and $17.39 \%$ knows how to interpret it, $17.39 \%$ as well for those who are aware about lectures on early warning system, and $8.70 \%$ awareness about drills on early warning system conducted in the community and $21.74 \%$ knows about the information drive on flood prevention that were spread in the community. There are only $26.09 \%$ who have been given or have attended some debriefing session of the past flooding event and $34.78 \%$ have attended to some discussions of lessons learned from the past flooding event as well. On the other hand, 

Social Vulnerabilities and Risks

in terms of recovery, only $17.39 \%$ knows how to conduct oneself in the evacuation centers, and only $21.74 \%$ are aware about the different programs initiated by the LGU in times of calamity. Moreover, only $21.74 \%$ are aware that the emergency response team and the rest of the units are at work in a coordinated manner. Same $24.74 \%$ knows the standard operating procedure during response and evacuation events. Lastly, only $8.70 \%$ knows about the adaptation strategies adapted in their community. Looking at these figures, it urges to improve public awareness about the aforementioned items to facilitate knowledge and awareness and coordination among them.

The politico-administrative FVI is $1.47 \%$. Among all the 12 communities surveyed, Barangay Calindagan is the least vulnerable in terms of politico-administrative. The exposure vulnerability is only $13.60 \%$ with a considerably very low exposure because of active management of river's natural resources and natural features management and program and efficient implementation of LUMSD which are both considerably high. On the other hand, the susceptibility is only $8.22 \%$ (governance) and the resilience factor is $76.29 \%$. The resilience factor includes: post-risk assessment and integration (88.75\%), sustainable community livelihood program $(80.00 \%)$, relocation site project $(68.60 \%)$ and the health and prevention program for E.coli, Leptospirosis and dengue fever mosquito $(67.80 \%)$ respectively.

The overall FVI for Barangay Calindagan is $23.37 \%$ which is a considerably low vulnerability. Although the overall FVI of Barangay Calindagan is generally low it is very important to give attention to the aforementioned items that scored very low that may predispose the community people to the effects of flooding and possible disease outbreaks. Its low vulnerability is mainly because of very high and good scores in the politico-administrative items that pulled up the scores of the other components and indicators but if you examined closely and in a more detailed manner in terms of its knowledge, attitude and practices to every items of exposure, preparedness, and adaptation strategies, the results are low. Thus, it should be given a priority to increase the community people's awareness on these items. 
Community-Based Flood Vulnerability Index for Urban Flooding: Understanding Social Vulnerabilities and Risks

Table 5-4: Barangay Calindagan FVI

\begin{tabular}{|c|c|c|c|c|c|c|c|}
\hline \multirow[b]{2}{*}{ COMPONENTS } & \multicolumn{2}{|c|}{ EXPOSURE } & \multicolumn{2}{|c|}{ SUSCEPTIBILITY } & \multicolumn{2}{|c|}{ RESILIENCE } & \multirow{2}{*}{$\frac{\text { FVI }}{(\%)}$} \\
\hline & Indicators & $(\%)$ & Indicators & $(\%)$ & Indicators & $(\%)$ & \\
\hline \multirow{4}{*}{ A. HYDRO-CLIMATIC } & A. FF & 26.09 & A. NTY & 50.00 & A. LUMSD & 87.81 & 37.76 \\
\hline & B. HF & 86.96 & & & & & \\
\hline & C. HRF & 69.57 & & & & & \\
\hline & D. HNE & 82.61 & & & & & \\
\hline \multirow{2}{*}{ B. SOCIAL } & A. ODAW & 56.00 & A. EA & 47.82 & A. WT & 69.57 & 22.27 \\
\hline & B. UVR & 17.39 & & & B. SN & 88.04 & \\
\hline \multirow{4}{*}{ C.ECONOMIC } & A. HNIS & 4.25 & A. $\mathrm{HC}$ & 24.68 & A. $\mathrm{FI}$ & 52.17 & 48.24 \\
\hline & B. HNIW & 4.25 & & & B. PI & 8.70 & \\
\hline & C. PRV & 100.00 & & & & & \\
\hline & D. PWLV & 60.87 & & & & & \\
\hline \multirow{4}{*}{ D.SOCIO-BEHAVIORAL } & A. PHFR & 21.09 & A. AHFR & 26.09 & A. KHFR & 55.71 & 7.10 \\
\hline & B. PHEC & 29.07 & B. AHEC & 21.98 & B. KHEC & 80.92 & \\
\hline & C. PHL & 40.87 & C. $\mathrm{AHL}$ & 16.43 & C. $\mathrm{KHL}$ & 80.92 & \\
\hline & D. PHDF & 27.27 & D. AHDF & 7.13 & D. KHDF & 80.92 & \\
\hline \multirow{4}{*}{$\begin{array}{c}\text { E. POLITICO- } \\
\text { ADMINISTRATIVE }\end{array}$} & A. RNRMP & 12.19 & A. G & 8.22 & A. PRAI & 88.75 & 1.47 \\
\hline & B. LUMSD & 15.00 & & & B. SCLP & 80.00 & \\
\hline & & & & & C. RSP & 68.60 & \\
\hline & & & & & D. HPP & 67.80 & \\
\hline Total Average FVI & & & & & & & 23.37 \\
\hline
\end{tabular}

(5) Barangay Balugo

Barangay Balugo's hydro-climatic Flood Vulnerability Index $(\mathrm{FVI})$ is $37.03 \%$ as shown in Table 5-5 indicating a low vulnerability in this component. The resilience item for land use and management and structural design (LUSMD) is 38.44\%, also quite low. Among the household surveyed, $29.41 \%$ have experienced flooding every year in this area. Though (64.70\%) of the surveyed household claimed that flooding only happens rarely/sometimes, while the rest did not specify. The community people $(88.23 \%)$ have experience flooding from ankle high to roof high. But, most of the population surveyed only experienced flood waters that are ankle level except from the last flash flood where some have experienced as high as the roof tops (5.88\%) because Barangay Balugo is basically located in an elevated area except to a few houses which are directly located from the river banks. In spite that there is a considerably medium range vulnerability to exposure in terms of the number of houses reached by floods $(58.82 \%)$, and only $5.88 \%$ of the houses are not on elevated area thus lowering the exposure vulnerability in spite that the resilience item is low. 

Social Vulnerabilities and Risks

The social $\mathrm{FVI}$ is $38.21 \%$. Open disposal of animal waste is observed (58.82\%) from the population. There is $11.76 \%$ who are not willing to vacate, giving an exposure index of $35.29 \%$ respectively. The reason not to vacate was simply because the household perceived their area as no threat to extreme effects of flooding while the rest did not specify their reasons. The educational attainment of most households is $(63.70 \%)$ which is quite high. The resilience factor that includes water treatment sterilization and social network are $47.06 \%$ and $70.59 \%$ respectively. Water treatment sterilization must be further encouraged to prevent possible disease outbreak during and after a natural calamity.

The economic FVI for Barangay Balugo is $100.00 \%$. There is still $5.88 \%$ of the community population with no access to improved sanitation and $5.88 \%$ as well with no access to improved water source. Presence of rats in the community is highly observed $(88.24 \%)$ and $(29.41 \%)$ of the population lived in the presence of water logged areas in the vicinity. Among the families surveyed, $76.47 \%$ of their houses are susceptible to the effects of flooding and typhoons. Most households (47.06\%) have a family income that is around 3000-1000 per month and none of the families surveyed have their properties insured.

The socio-behavioral $\mathrm{FVI}$ is $10.15 \%$. The socio-behavioral vulnerability index of Barangay Balugo is also low in terms of the knowledge, attitude and practices that may predisposed the household to any flooding event and disease outbreaks that may be caused by E.coli, Leptospirosis and Dengue Fever mosquito. Exposure vulnerability is $36.55 \%$, while susceptibility is only $19.68 \%$, and resilience is very good $(70.84 \%)$ respectively. But it is important to note that practices items for Leptospirosis and Dengue Fever mosquito that may predispose the community people is in the medium range vulnerability $(43.91 \%$ and $41.68 \%)$ respectively. Efforts to increase good practices towards preventing leptospirosis and dengue fever outbreak must be given attention. It must also be noted that only $11.76 \%$ are aware about the availability of flood hazard map in their community. Also, $47.06 \%$ are aware of the limitation and level of protection of the flood control barriers. And $23.53 \%$ knows when what particular time of the year flooding can possibly occur. Like the other communities, $47.06 \%$ of the household surveyed have heard about the presence of flood early warning system, $41.18 \%$ knows how to interpret it, 29. $41 \%$ were aware about if there were any lectures on early warning systems, $17.65 \%$ were aware if there were any drills on early warning systems in their community, $41.18 \%$ knows the location of the evacuation centers, $41.18 \%$ knows the standard operating procedure during response and evacuation events and $47.06 \%$ knows the adaptation strategies adapted by their community. 

Social Vulnerabilities and Risks

Furthermore, only $17.65 \%$ have participated in an early warning system lectures in the community and $23.53 \%$ have participated in the drills related to evacuation and response. There is only $17.65 \%$ have been given or have attended some debriefing session of the past flooding event and $35.29 \%$ have attended some discussions of lessons learned from the past flooding event. Again, these aforementioned items of indicators must be given attention so proper coordination and facilitation of programs and improving awareness will be facilitated and realized.

The politico-administrative $\mathrm{FVI}$ is $56.19 \%$. Among all the 12 communities surveyed, Barangay Balugo has the highest vulnerability in terms of politico-administrative. The exposure vulnerability (57.03\%) is border between medium and high vulnerability. The exposure items which predisposes the management of river's natural resources and natural features management and program to flooding is $(61.56 \%)$ and $(52.50 \%)$ for the LUMSD which are both considerably high and in the medium range vulnerability. On the other hand, the susceptibility is $57.39 \%$ (governance) and the resilience factor is $58.25 \%$ which is not high. The resilience efforts include; post-risk assessment and integration $(42.50 \%)$, sustainable community livelihood program $(47.50 \%)$, relocation site project $(76.40 \%)$ and the health and prevention program for E.coli, Leptospirosis and dengue fever mosquito $(66.60 \%)$ respectively.

The overall FVI for Barangay Balugo is $48.32 \%$ which is considerably medium vulnerability. It is important to note the following items with low scores so it can be improved. The governance in terms of the transparency, accountability and the availability of technical and financial support mechanisms to support planned community actions for resilience is only $40.00 \%$. For its sustainable community livelihood for instance, the technical and financial resources in promoting self-reliant communities so it would have the capacity to provide support to driven-stricken areas is also $40.00 \%$. The RNRMP particularly on how actively engaged the community in planning and implementing river resource management activity is only $30.00 \%$ and how well the community and local government value and invest in management and conservation to sustain the river's natural resources and natural features is $40.00 \%$. For how well the critical infrastructures constructed to address risks from priority hazards is $45.00 \%$. Also, for how well are the developers and communities have incorporate risk reduction into location and design structure particularly existing spatial planning, flood risk adaptive to land use, building regulations, building codes, zoning ordinances and how established is the education, outreach, and training programs to improve compliance with land use policies and building standards are as follows, $40.00 \%$, $40.00 \%, 20.00 \%, 20.00 \%, 20.00 \%$, and $40.00 \%$ respectively. The post-risk assessment 

Social Vulnerabilities and Risks

integration particularly on how well are the flood risk assessments completed and routinely updated; how comprehensive is the flood risk assessments to incorporate risks to all elements of resilience; how well the community participates in the hazard risk assessment process, the accessibility and utilization of the evacuation centers are as follows, $40.00 \%, 40.00 \%, 40.00 \%$, and $40.00 \%$ respectively. For warning and evacuation items, particularly on how well the community flood warning system is in place and maintained is $30.00 \%$ and how well the community evacuation infrastructure in place and maintained is $40.00 \%$; how prepared the community to respond to hazard warning with appropriate actions is $30.00 \%$, and the availability of the technical (service offered) and financial resources in maintaining and improving warning and evacuation systems is also $30.00 \%$ respectively. When it comes to disaster recovery particularly on how well us the disaster recovery process was monitored, and improved at periodic intervals is $40.00 \%$, the availability of technical (services offered) and financial resources to support the recovery process particularly on reconstruction and social therapeutic measures is $40.00 \%$, and $40.00 \%$ respectively. In here, it is observed that there are several items that needed to be improved and be given attention in spite that the overall $\mathrm{FVI}$ is in a medium range (48.32\%). It appears that the households and families in Barangay Balugo is a bit reluctant with their participation in the community activities such as on the early warning lectures, discussions and drills probably because they perceived their area as less threat with flooding for it is located in a more elevated location. The community people also respond less with appropriate actions to hazard warning for the same reason. It is important to instill in the minds of the households the readiness and anticipation and cooperation to avoid significant impact in the future if untoward events such as that of flooding and typhoon. There is a need to improve and increase community awareness and involvement so they will be more ready and resilient in the case of natural calamities. There is also a lot to improve in the governance aspect so vulnerability will be lowered and resilience will be increase. Regardless of the vulnerability index of $48.32 \%$ one must remember that Barangay Balugo is located on the verge of the Banica river along its banks. 
Community-Based Flood Vulnerability Index for Urban Flooding: Understanding Social Vulnerabilities and Risks

Table 5-5: Barangay Balugo FVI

\begin{tabular}{|c|c|c|c|c|c|c|c|}
\hline \multirow[b]{2}{*}{ COMPONENTS } & \multicolumn{2}{|c|}{ EXPOSURE } & \multicolumn{2}{|c|}{ SUSCEPTIBILITY } & \multicolumn{2}{|c|}{ RESILIENCE } & \multirow{2}{*}{$\begin{array}{r}\text { FVI } \\
(\%)\end{array}$} \\
\hline & Indicators & $(\%)$ & Indicators & $(\%)$ & Indicators & $(\%)$ & \\
\hline \multirow{4}{*}{ A. HYDRO-CLIMATIC } & A. FF & 29.41 & A. NTY & 50.00 & A. LUMSD & 38.44 & 37.03 \\
\hline & B. HF & 88.23 & & & & & \\
\hline & C. HRF & 58.82 & & & & & \\
\hline & D. HNE & 5.88 & & & & & \\
\hline \multirow{2}{*}{ B. SOCIAL } & A. ODAW & 58.82 & A. EA & 63.70 & A. WT & 47.06 & 38.21 \\
\hline & B. UVR & 11.76 & & & B. SN & 70.59 & \\
\hline \multirow{4}{*}{ C.ECONOMIC } & A. HNIS & 5.88 & A. $\mathrm{HC}$ & 76.47 & A. FI & 47.06 & 100.00 \\
\hline & B. HNIW & 5.88 & & & B. PI & 0.00 & \\
\hline & C. PRV & 88.24 & & & & & \\
\hline & D. PWLV & 29.41 & & & & & \\
\hline \multirow{4}{*}{ D.SOCIO-BEHAVIORAL } & A. PHFR & 31.41 & A. AHFR & 26.10 & A. KHFR & 50.91 & 10.15 \\
\hline & B. PHEC & 29.18 & B. AHEC & 18.79 & B. KHEC & 77.48 & \\
\hline & C. PHL & 43.91 & C. $\mathrm{AHL}$ & 19.28 & C. $\mathrm{KHL}$ & 77.48 & \\
\hline & D. PHDF & 41.68 & D. AHDF & 14.54 & D. KHDF & 77.48 & \\
\hline \multirow{4}{*}{$\begin{array}{c}\text { E. POLITICO- } \\
\text { ADMINISTRATIVE }\end{array}$} & A. RNRMP & 61.56 & A. $G$ & 57.39 & A. PRAI & 42.50 & 56.19 \\
\hline & B. LUMSD & 52.50 & & & B. SCLP & 47.50 & \\
\hline & & & & & C. RSP & 76.40 & \\
\hline & & & & & D. HPP & 66.60 & \\
\hline Total Average FVI & & & & & & & 48.32 \\
\hline
\end{tabular}

(6) Poblacion 2 (Barangay Lukewright)

Barangay Lukewright's hydro-climatic Flood Vulnerability Index (FVI) is $67.14 \%$ as shown in Table 5-6 indicating a high vulnerability in this component. The resilience item for land use and management and structural design (LUSMD) is $54.69 \%$, which is medium range. About $43.75 \%$ of the household surveyed claimed that flooding occurs every year in the area. However, $56.25 \%$ claimed that flooding only happens sometimes/rarely. All families surveyed (100.00\%) have experience flooding from ankle high to roof high though most of them have experienced flood waters that are as high as above the head $(25.00 \%)$ and as low as the ankle level (25.00\%) because Poblacion 2 is basically located in an a lower area except to a few houses that were located on an elevated area. Vulnerability to exposure in terms of the number of houses reached by floods (87.50\%) which is very high, and $62.50 \%$ of the houses are not on elevated area thus increasing the exposure vulnerability to $(73.44 \%)$ in spite that the resilience item is in the medium range. 

Social Vulnerabilities and Risks

The social $\mathrm{FVI}$ is $9.30 \%$. Open disposal of animal waste is observed $(62.50 \%)$ from the population. There is $37.50 \%$ who are not willing to vacate, because there was no relocation site provided for them and the proximity to their livelihood is also a major consideration. The exposure index is $50.00 \%$ respectively. The educational attainment of most households is only (12.50\%) which is very low and which plays as a critical predisposing factor in understanding and awareness it has to be made sure that whatever information drive regarding resilience and adaptation must be made sure that it has been delivered to the community people. The resilience factor that includes water treatment sterilization and social network is both high indicating $62.50 \%$ and $71.88 \%$ respectively.

The economic FVI for Poblacion 2 is $94.77 \%$. All the surveyed households of the community are with access to improved water source and improved sanitation. Presence of rats in the community is highly observed $(93.75 \%)$ and $(37.50 \%)$ of the population lived in the presence of water logged areas in the vicinity. Most houses $(81.25 \%)$ are susceptible to the effects of flooding and typhoons. Most households $(50.00 \%)$ have a family income that is around $3000-1000$ per month and only $(6.25 \%)$ of the families surveyed have their properties insured.

The socio-behavioral $\mathrm{FVI}$ is $25.59 \%$. The socio-behavioral vulnerability index of Poblacion 2 is also low in terms of the knowledge, attitude and practices that may predisposed the household to any flooding event and disease outbreaks that may be caused by E.coli, Leptospirosis and Dengue Fever mosquito. Exposure vulnerability is $29.76 \%$, while susceptibility is $68.62 \%$, which is quite high and resilience items are very good $(79.81 \%)$ respectively. It is important to note that attitude items for E.coli, Leptospirosis and Dengue Fever mosquito that may predispose the community people is in a high vulnerability range $(81.20 \%, 84.90 \%$ and $88.63 \%$ respectively). Efforts to increase good attitude towards preventing E.coli, leptospirosis and dengue fever outbreak must be given special attention. When it comes to knowledge, only $43.75 \%$ of the households are aware of lectures on early warning system in their community, and $37.50 \%$ are aware on the drills on early warning system in their community and only $50.00 \%$ of them knew about the different programs of the LGU in times calamities. For items on practices, only $43.75 \%$ wore sturdy shoes (boots) during typhoon and flooding. Only $31.25 \%$ have participated in the early warning system lecture and $25.00 \%$ have participated in drills related to evacuation and response. Furthermore, $37.50 \%$ have attended some debriefing session of the past flooding event and also $37.50 \%$ have attended to some discussions of lessons learned from the past flooding event and $37.50 \%$ as well have participated to any adaptation strategies facilitated by the LGU's. 
Community-Based Flood Vulnerability Index for Urban Flooding: Understanding Social Vulnerabilities and Risks

The politico-administrative $\mathrm{FVI}$ is $45.83 \%$. The exposure vulnerability is $(48.91 \%)$ a medium vulnerability range. The exposure items which predisposes the management of river's natural resources and natural features management and program to flooding is (45.31\%) and (52.50\%) for the LUMSD which are both in the medium range vulnerability. On the other hand, susceptibility is $52.39 \%$ (governance) and the resilience vulnerability is $55.91 \%$. The resilience effort includes; post-risk assessment and integration (51.25\%), sustainable community livelihood program (40.00\%), relocation site project $(66.20 \%)$ and the health and prevention program for E.coli, leptospirosis and dengue fever mosquito (66.20\%) respectively.

The overall FVI for Poblacion 2 is $48.53 \%$ which is considerably medium vulnerability. Some of the things that should be given attention to in the aspect of governance in Poblacion 2 is the accessibility of the basic services provided for instance, transportation service during calamity has only $40.00 \%$ availability and the health services provided is also $40.00 \%$. The transparency, accountability, and availability of technical and financial support system to support planned community actions for resilience and the risk reduction effort is $40.00 \%$ and $40.00 \%$ respectively. In terms of sustainable community livelihood, particularly on the developed policies and plans in building social capital and skill for economic diversity and self-reliance is also $40.00 \%$ while the availability of diverse and environmentally sustainable livelihood in the community is only $20.00 \%$. For the rivers' natural resources and natural features' management on how actively engaged are the community people in planning and implementing river resource management activities is only $40.00 \%$. For land use and management and structural design with respect to how the developers and communities incorporate risk reduction into the location and design of structures particularly on flood risk adaptive to land use is only $30.00 \%$. The post-risk assessment integration in terms of how well the information from the risk assessment accessibility and utilized by the community and government particularly on the availability of flood hazard maps is $40.00 \%$. In terms of emergency response, the on-going training and educating responders for the preparedness activities such as that of drills and simulations is only $40.00 \%$. In the disaster recovery, the disaster recovery process, monitoring, and improving at periodic intervals is $40.00 \%$ achieved. $40.00 \%$ also goes to how well the pre-established disaster recovery coordination mechanism at international, national, and local levels. Lastly, the availability of the technical (services offered) and financial resources to support the recovery process such as the insurance scheme, reconstruction, charitable funds, social therapeutic measures, rescue equipment and tools, and the traumatic/psychological stress debriefings are: $40.00 \%, 40.00 \%, 40.00 \%$, $40.00 \%, 40.00 \%$, and $20.00 \%$ respectively. As seen from these figures, there are a lot 
Community-Based Flood Vulnerability Index for Urban Flooding: Understanding Social Vulnerabilities and Risks

of things to improve in Poblacion 2 and it has to be addressed to improve their adaptive and resilience capacity.

Table 5-6: Poblacion 2 (Barangay Lukewright) FVI

\begin{tabular}{|c|c|c|c|c|c|c|c|}
\hline \multirow[b]{2}{*}{ COMPONENTS } & \multicolumn{2}{|c|}{ EXPOSURE } & \multicolumn{2}{|c|}{ SUSCEPTIBILITY } & \multicolumn{2}{|c|}{ RESILIENCE } & \multirow{2}{*}{$\begin{array}{l}\text { FVI } \\
(\%) \\
\end{array}$} \\
\hline & Indicators & $(\%)$ & Indicators & $(\%)$ & Indicators & $(\%)$ & \\
\hline A. HYDRO-CLIMATIC & $\begin{array}{l}\text { A. FF } \\
\text { B. HF } \\
\text { C. HRF } \\
\text { D. HNE }\end{array}$ & $\begin{array}{r}43.75 \\
100.00 \\
87.50 \\
62.50\end{array}$ & A. NTY & 50.00 & A. LUMSD & 54.69 & 67.14 \\
\hline B. SOCIAL & $\begin{array}{l}\text { A. ODAW } \\
\text { B. UVR }\end{array}$ & $\begin{array}{l}62.50 \\
37.50 \\
\end{array}$ & A. EA & 12.50 & $\begin{array}{l}\text { A. WT } \\
\text { B. SN }\end{array}$ & $\begin{array}{l}62.50 \\
71.88 \\
\end{array}$ & 9.30 \\
\hline C.ECONOMIC & $\begin{array}{l}\text { A. HNIS } \\
\text { B. HNIW } \\
\text { C. PRV } \\
\text { D. PWLV }\end{array}$ & $\begin{array}{r}0.00 \\
0.00 \\
93.75 \\
37.50 \\
\end{array}$ & A. $\mathrm{HC}$ & 81.25 & $\begin{array}{l}\text { A. } \mathrm{FI} \\
\text { B. } \mathrm{PI}\end{array}$ & $\begin{array}{r}50.00 \\
6.25\end{array}$ & 94.77 \\
\hline D.SOCIO-BEHAVIORAL & $\begin{array}{l}\text { A. PHFR } \\
\text { B. PHEC } \\
\text { C. PHL } \\
\text { D. PHDF }\end{array}$ & $\begin{array}{l}30.31 \\
23.51 \\
27.13 \\
38.07 \\
\end{array}$ & $\begin{array}{l}\text { A. AHFR } \\
\text { B. AHEC } \\
\text { C. AHL } \\
\text { D. AHDF }\end{array}$ & $\begin{array}{l}19.73 \\
81.20 \\
84.90 \\
88.63 \\
\end{array}$ & $\begin{array}{l}\text { A. KHFR } \\
\text { B. KHEC } \\
\text { C. KHL } \\
\text { D. KHDF }\end{array}$ & $\begin{array}{l}67.21 \\
84.01 \\
84.01 \\
84.01\end{array}$ & 25.59 \\
\hline $\begin{array}{l}\text { E. POLITICO- } \\
\text { ADMINISTRATIVE }\end{array}$ & $\begin{array}{l}\text { A. RNRMP } \\
\text { B. LUMSD }\end{array}$ & $\begin{array}{l}45.31 \\
52.50\end{array}$ & A. G & 52.39 & $\begin{array}{l}\text { A. PRAI } \\
\text { B. SCLP } \\
\text { C. RSP } \\
\text { D. HPP } \\
\end{array}$ & $\begin{array}{l}51.25 \\
40.00 \\
66.20 \\
66.20 \\
\end{array}$ & 45.83 \\
\hline Total Average FVI & & & & & & & 48.53 \\
\hline
\end{tabular}

(7) Poblacion 8

Poblacion 8's hydro-climatic Flood Vulnerability Index (FVI) is $82.07 \%$ as shown in Table 5-7 indicating a very high vulnerability in this component. The resilience item for land use and management and structural design (LUSMD) is only $43.59 \%$, which is medium range. Among the household surveyed, $48.27 \%$ claimed that they experienced flooding every year, the least. Though $(51.73 \%)$ of them claimed that flooding only happens sometimes/rarely. Most of the population surveyed experienced flood waters from ankle level to beyond the roof from the past flooding where $27.59 \%$ of them had experienced it above the head this is because most of the houses in Poblacion 8 is basically located in a lower area and the river water spills over the dike system during the last flooding event and there were many houses located immediately immediately after the flood barrier system (dike). Vulnerability to exposure in terms of the number of 

Social Vulnerabilities and Risks

houses reached by floods (82.76\%) is very high, and $65.52 \%$ of the houses are not on elevated area thus increasing the exposure vulnerability to $(71.55 \%)$ in spite that the resilience item is in the medium range (43.59\%).

The social FVI is $16.49 \%$. Open disposal of animal waste is observed (34.48\%) from the population though not highly observed which is a good thing. There is $20.00 \%$ who are not willing to vacate because there was no relocation site provided for them, some do not perceived living there as a threat; and due to proximity to the source of their livelihood while others did not specify their personal reasons. The exposure index is $27.24 \%$ respectively. The educational attainment of most households is $(48.28 \%)$ which is medium range and may play as a critical predisposing factor. The resilience factor that includes water treatment sterilization and social network is indicating both a very high resilience $82.76 \%$ and $76.73 \%$ respectively.

The economic FVI for Poblacion 8 is $92.43 \%$. Among the surveyed households of the community, there is still $3.45 \%$ with no access to improved sanitation while all of the surveyed households are with access to improved water source. Presence of rats in the community is highly observed $(96.55 \%)$ and $(41.38 \%)$ of the population lived in the presence of water logged areas in the vicinity which could be a predisposing factor for dengue fever mosquito outbreak. $58.62 \%$ of most houses are susceptible to the effects of flooding and typhoons. Most households (37.93\%) have a family income that is around $3000-1000$ per month and only $(6.90 \%)$ of the families surveyed have their properties insured.

The socio-behavioral $\mathrm{FVI}$ is $9.53 \%$. The socio-behavioral vulnerability index of Poblacion 8 is low in terms of the knowledge, attitude and practices that may predisposed the household to any flooding event and disease outbreaks that may be caused by E.coli, Leptospirosis and Dengue Fever mosquito. Exposure vulnerability is $34.75 \%$, while susceptibility is $21.21 \%$, and resilience items are very good $(77.30 \%)$ respectively. But it is important to note that practice items particularly for Leptospirosis that may predispose the community people is in medium range vulnerability $40.33 \%$. Efforts to increase good practice towards preventing leptospirosis and outbreak must be given attention. Wearing of sturdy shoes (boots) during typhoon and flooding is less practice $(31.03 \%)$ thus it should be encouraged.

The politico-administrative $\mathrm{FVI}$ is $42.85 \%$. The exposure vulnerability $(50.55 \%)$ is in a medium vulnerability range. The exposure items which predisposes the management of river's natural resources and natural features management and program to flooding is 

Social Vulnerabilities and Risks

(43.59\%) and (57.50\%) for the LUMSD which are both in the medium range vulnerability. On the other hand, the susceptibility is $54.00 \%$ (governance) and the resilience vulnerability is $63.70 \%$ which is a bit higher. The resilience items include; post-risk assessment and integration (59.38\%), sustainable community livelihood program $(47.50 \%)$, relocation site project $(74.40 \%)$ and the health and prevention program for E.coli, leptospirosis and dengue fever mosquito (73.50\%) respectively.

The overall FVI for Poblacion 8 is $48.6 \%$ which is considerably medium vulnerability. However, some items must be considered and be given further attention for instance sustainable community livelihood in terms of its availability in a diverse and environmentally sustainable livelihood is $40.00 \%$. Protecting and maintaining our river and its natural features to reduce risks from flood hazards; how actively engaged the community in planning and implementing river resource management activities; how well the community and local government value and invest in management and conservation to sustain our river's natural resources and natural features is $40.00 \%$, $40.00 \%, 40.00 \%$ respectively. $40.00 \%$ as well for how well the land use policies and building standard that incorporate measures to reduce risks from hazards and protect sensitive habitats are established, monitored, and enforced and $40.00 \%$ as well for zoning ordinances that were incorporated to reduce risk into the location implemented by the developers and communities. For warning and evacuation, how well the community flood warning system is in place and maintained is $40.00 \%$. The community people is only $40.00 \%$ prepared to respond to hazard warnings with appropriate actions and $40.00 \%$ are the on-going training in preparedness activities such as drills and simulations to educate responders. In the aspect of disaster recovery, $30.00 \%$ is for the availability of technical services offered and financial resources to support recovery process particularly on insurance scheme. Conducting traumatic/psychological stress debriefing is $40.00 \%$. 
Community-Based Flood Vulnerability Index for Urban Flooding: Understanding Social Vulnerabilities and Risks

Table 5-7: Poblacion 8 FVI

\begin{tabular}{|c|c|c|c|c|c|c|c|}
\hline \multirow[b]{2}{*}{ COMPONENTS } & \multicolumn{2}{|c|}{ EXPOSURE } & \multicolumn{2}{|c|}{ SUSCEPTIBILITY } & \multicolumn{2}{|c|}{ RESILIENCE } & \multirow{2}{*}{$\begin{array}{r}\text { FVI } \\
(\%)\end{array}$} \\
\hline & Indicators & $(\%)$ & Indicators & $(\%)$ & Indicators & $(\%)$ & \\
\hline \multirow{4}{*}{ A. HYDRO-CLIMATIC } & A. FF & 48.27 & A. NTY & 50.00 & A. LUMSD & 43.59 & 82.07 \\
\hline & B. HF & 89.65 & & & & & \\
\hline & C. HRF & 82.76 & & & & & \\
\hline & D. HNE & 65.52 & & & & & \\
\hline \multirow{2}{*}{ B. SOCIAL } & A. ODAW & 34.48 & A. EA & 48.28 & A. WT & 82.76 & 16.49 \\
\hline & B. UVR & 20.00 & & & B. SN & 76.73 & \\
\hline \multirow{4}{*}{ C.ECONOMIC } & A. HNIS & 3.45 & A. $\mathrm{HC}$ & 58.62 & A. FI & 37.93 & 92.43 \\
\hline & B. HNIW & 0.00 & & & B. PI & 6.90 & \\
\hline & C. PRV & 96.55 & & & & & \\
\hline & D. PWLV & 41.38 & & & & & \\
\hline \multirow{4}{*}{ D.SOCIO-BEHAVIORAL } & A. PHFR & 29.02 & A. AHFR & 29.74 & A. KHFR & 75.60 & 9.53 \\
\hline & B. PHEC & 29.65 & B. AHEC & 23.18 & B. KHEC & 77.87 & \\
\hline & C. PHL & 40.33 & C. $\mathrm{AHL}$ & 22.13 & C. $\mathrm{KHL}$ & 77.87 & \\
\hline & D. PHDF & 39.00 & D. AHDF & 9.77 & D. KHDF & 77.87 & \\
\hline \multirow{4}{*}{$\begin{array}{c}\text { E. POLITICO- } \\
\text { ADMINISTRATIVE }\end{array}$} & A. RNRMP & 43.59 & A. $G$ & 54.00 & A. PRAI & 59.38 & 42.85 \\
\hline & B. LUMSD & 57.50 & & & B. SCLP & 47.50 & \\
\hline & & & & & C. RSP & 74.40 & \\
\hline & & & & & D. HPP & 73.50 & \\
\hline Total Average FVI & & & & & & & 48.67 \\
\hline
\end{tabular}

(8) Barangay Cadawinonan

Barangay Cadawinonan's hydro-climatic Flood Vulnerability Index (FVI) is $43.75 \%$ as shown in Table 5-8 indicating medium range vulnerability in this component. The resilience item for land use and management and structural design (LUSMD) is only $58.28 \%$. The surveyed household $(32.00 \%)$ claimed that flooding occurs every year in the area. Though $(52.00 \%)$ of the surveyed household claimed that flooding only happens sometimes/rarely. $76.00 \%$ of the community people surveyed have experience flooding from ankle high to above the head level of floodwater though generally the water is ankle level because Barangay Cadawinonan is basically located in a higher elevation compared to those near the center of the city. Vulnerability to exposure in terms of the number of houses reached by floods $(60.00 \%)$ which is high and only $36.00 \%$ of the houses are not on elevated area thus the exposure vulnerability is in the medium range $(51.00 \%)$. 

Social Vulnerabilities and Risks

The social $\mathrm{FVI}$ is $28.03 \%$. Open disposal of animal waste is observed (56.00\%) from the population. There is $20.00 \%$ who are not willing to vacate. Most of them did not specify their reasons but for some, it is for sentimental reasons and for others said they are more ready and more alert for the next undesirable event. The exposure index is $38.00 \%$ respectively. The educational attainment of most households is $(52.00 \%)$ which plays as a critical predisposing factor. The resilience factor that includes water treatment sterilization and social network is indicating both a high and very high resilience $60.00 \%$ and $81.00 \%$ respectively.

The economic FVI for Barangay Cadawinonan is $27.79 \%$. All the surveyed households have access to improved sanitation. But, there is still $16.00 \%$ with no access to improved water source. Presence of rats in the community is highly observed $(84.00 \%)$ and $(32.00 \%)$ of the population lived in the presence of water logged areas in the vicinity which could be a predisposing factor for dengue fever mosquito outbreak. $32.00 \%$ of most houses are susceptible to the effects of flooding and typhoons. Most households (48.00\%) have a family income that is around 3000-1000 per month and $(28.00 \%)$ of the families surveyed have their properties insured.

The socio-behavioral $\mathrm{FVI}$ is $11.45 \%$. The socio-behavioral vulnerability index of Barangay Cadawinonan is low in terms of the knowledge, attitude and practices that may predisposed the household to any flooding event and disease outbreaks that may be caused by E.coli, Leptospirosis and Dengue Fever mosquito. Exposure vulnerability is $33.05 \%$, while susceptibility is $23.61 \%$, which is low and resilience items are good (68.14\%) respectively. It is important to maintain such good knowledge, attitude and practices that may predispose the community people from any disease outbreak and to any untoward events from flooding and typhoon. It's good to see that at least half $(50.00 \%)$ among surveyed household have attended some debriefing session and some discussions of lessons learned from the past flooding event. Among 12 communities, Barangay Cadawinonan has seen being actively involved though more participation $(45.83 \%)$ should be encouraged to attend and get involved in the adaptation strategies facilitated by the LGU's.

The politico-administrative $\mathrm{FVI}$ is $22.50 \%$. The exposure vulnerability is $(34.61 \%)$. In the exposure items which predisposes the management of river's natural resources and natural features management and program to flooding is $(41.72 \%)$ and $(27.50 \%)$ for the LUMSD which are in the medium and low range vulnerability respectively. On the other hand, the susceptibility is $45.44 \%$ (governance) and the resilience vulnerability is $69.90 \%$ which is a bit higher. Resilience activities includes; post-risk assessment and 
integration $(61.88 \%)$, sustainable community livelihood program $(62.50 \%)$, relocation site project $(76.80 \%)$ and the health and prevention program for E.coli, leptospirosis and dengue fever mosquito $(78.40 \%)$ respectively.

The overall FVI for Barangay Cadawinonan is $26.70 \%$ which is considerably a low vulnerability. However, it is important to consider the land use and management and structural design particularly on the efficiency of dike safety system which needs improvement in this community $(40.00 \%)$. In terms of disaster recovery, insurance scheme should be improved $(20.00 \%)$, the damage assessment facilitating claim procession (30.00\%) should likewise be improved and conducting traumatic/psychological stress debriefing $(40.00 \%)$ should also be given attention.

Table 5-8: Barangay Cadawinonan FVI

\begin{tabular}{|c|c|c|c|c|c|c|c|}
\hline \multirow[b]{2}{*}{ COMPONENTS } & \multicolumn{2}{|c|}{ EXPOSURE } & \multicolumn{2}{|c|}{ SUSCEPTIBILITY } & \multicolumn{2}{|c|}{ RESILIENCE } & \multirow{2}{*}{$\begin{array}{r}\text { FVI } \\
(\%) \\
\end{array}$} \\
\hline & Indicators & $(\%)$ & Indicators & $(\%)$ & Indicators & $(\%)$ & \\
\hline \multirow{4}{*}{ A. HYDRO-CLIMATIC } & A. FF & 32.00 & \multirow[t]{4}{*}{ A. NTY } & \multirow[t]{4}{*}{50.00} & \multirow[t]{4}{*}{ A. LUMSD } & \multirow[t]{4}{*}{58.28} & \multirow[t]{4}{*}{43.75} \\
\hline & B. HF & 76.00 & & & & & \\
\hline & C. HRF & 60.00 & & & & & \\
\hline & D. HNE & 36.00 & & & & & \\
\hline \multirow{2}{*}{ B. SOCIAL } & A. ODAW & 56.00 & \multirow[t]{2}{*}{ A. EA } & \multirow[t]{2}{*}{52.00} & A. WT & 60.00 & \multirow[t]{2}{*}{28.03} \\
\hline & B. UVR & 20.00 & & & B. SN & 81.00 & \\
\hline \multirow{4}{*}{ C.ECONOMIC } & A. HNIS & 0.00 & \multirow[t]{4}{*}{ A. $\mathrm{HC}$} & \multirow[t]{4}{*}{32.00} & A. FI & 48.00 & \multirow[t]{4}{*}{27.79} \\
\hline & B. HNIW & 16.00 & & & B. PI & 28.00 & \\
\hline & C. PRV & 84.00 & & & & & \\
\hline & D. PWLV & 32.00 & & & & & \\
\hline \multirow{4}{*}{ D.SOCIO-BEHAVIORAL } & A. PHFR & 31.26 & A. AHFR & 21.00 & A. KHFR & 70.71 & \multirow[t]{4}{*}{11.45} \\
\hline & B. PHEC & 28.77 & B. AHEC & 27.67 & B. KHEC & 67.28 & \\
\hline & C. PHL & 35.81 & C. AHL & 30.44 & C. KHL & 67.28 & \\
\hline & D. PHDF & 36.36 & D. AHDF & 15.33 & D. KHDF & 67.28 & \\
\hline \multirow{4}{*}{$\begin{array}{c}\text { E. POLITICO- } \\
\text { ADMINISTRATIVE }\end{array}$} & A. RNRMP & 41.72 & \multirow[t]{4}{*}{ A. $\mathrm{G}$} & \multirow[t]{4}{*}{45.44} & A. PRAI & 61.88 & \multirow[t]{4}{*}{22.50} \\
\hline & B. LUMSD & 27.50 & & & B. SCLP & 62.50 & \\
\hline & & & & & C. RSP & 76.80 & \\
\hline & & & & & D. HPP & 78.40 & \\
\hline Total Average FVI & & & & & & & 26.70 \\
\hline
\end{tabular}


(9) Barangay Bagacay

Barangay Bagacay's hydro-climatic Flood Vulnerability Index (FVI) is $50.37 \%$ as shown in Table 5-9 indicating medium range vulnerability in this component. The resilience item for land use and management and structural design (LUSMD) is only 56.25. Among the household surveyed, $46.67 \%$ claimed that flooding occurs every year in the area and $53.33 \%$ of the surveyed household claimed that flooding only happens sometimes/rarely. However, $83.43 \%$ of the community people surveyed have experience flooding from ankle high to above the head flood water level. The above the head flood water level was experienced by $26.67 \%$ of the household which registers the highest among the level of floodwaters. The level of flood water in Barangay Bagacay that was experienced by the people is basically because many houses are located in an area where there is no dike system and not in an elevated area. Vulnerability to exposure in terms of the number of houses reached by floods $(76.67 \%)$ which is high and $20.00 \%$ of the houses are not on elevated area. Exposure vulnerability is (56.67\%).

The social FVI is $18.08 \%$. Open disposal of animal waste is observed (53.33\%) from the population. There is $13.33 \%$ who are not willing to vacate because primarily there was no relocation site provided to those who needs it, they have learned to secure their property, and due to proximity to the source of their livelihood. The exposure index is $38.33 \%$ respectively. The educational attainment of most households is $(40.00 \%)$. The resilience factor that includes water treatment sterilization and social network is indicating both have high resilience $66.67 \%$ and $80.84 \%$ respectively.

The economic FVI for Barangay Bagacay is $100.00 \%$. Among the surveyed households of the community, all have good access to improved sanitation while $46.67 \%$ of the surveyed households do not have good access to water source. Presence of rats in the community is highly observed (93.33\%) and (53.33\%) of the population lived in the presence of water logged areas in the vicinity which could be a predisposing factor for dengue fever mosquito outbreak. $73.34 \%$ of most houses are susceptible to the effects of flooding and typhoons which is a high vulnerability. Most households (46.67\%) have a family income that is around $3000-1000$ per month and (13.33\%) of the families surveyed have their properties insured.

The socio-behavioral $\mathrm{FVI}$ is $15.72 \%$. The socio-behavioral vulnerability index of Barangay Bagacay is also very low in terms of their knowledge, attitude and practices that may predisposed the household to any flooding event and disease outbreaks that may be caused by E.coli, Leptospirosis and Dengue Fever mosquito. Exposure vulnerability is $39.12 \%$, while susceptibility is $28.33 \%$, which is low and resilience items 

Social Vulnerabilities and Risks

are good $(70.49 \%)$ respectively. It is important to maintain such good knowledge, attitude and practices that may predispose the community people from any disease outbreak and untoward events from flooding and typhoon. However, it is important to note that good practice particularly to leptospirosis and dengue fever mosquito should be encouraged so vulnerability of such will be keep constant if not lowered. Only $40.00 \%$ were aware about drills on early warning system carried in the community and only $43.33 \%$ practice to use sturdy shoes during typhoons and flooding. Just $40.00 \%$ of the households in Barangay Bagacay participated in the early warning lectures in the community and $26.67 \%$ of them have had participated the drills related to evacuation and response. Attention must be focus on these items to avoid uncoordinated and undesirable actions during calamities. Very few of them (26.67\%) have contacts from community people in the upper stream area of the river such as in Barangay Balugo and Valencia to update them with the floodwater level. Communication and coordination in this matter should be enhanced. Unfortunately, only $16.67 \%$ have been given or have attended some debriefing sessions of the past flooding event. Only $43.33 \%$ have participated to any adaptation strategies facilitated by LGU's.

The politico-administrative $\mathrm{FVI}$ is $21.93 \%$. The exposure vulnerability is $(36.88 \%)$. The exposure items which predisposes the management of river's natural resources and natural features management and program to flooding is $(43.75 \%)$ and $(30.00 \%)$ for the LUMSD which are in the medium and low range vulnerability respectively. On the other hand, the susceptibility is $40.78 \%$ (governance) and the resilience vulnerability is $68.58 \%$ which is a bit higher. Resilience efforts include; post-risk assessment and integration $(78.13 \%)$, sustainable community livelihood program $(67.50 \%)$, relocation site project $(54.40 \%)$ and the health and prevention program for E.coli, Leptospirosis and dengue fever mosquito $(74.30 \%)$ respectively.

The overall FVI for Barangay Bagacay is $41.22 \%$ which is considerably in medium range vulnerability. However, in the aspect of very efficient bridge system, it is only $40.00 \%$. The overflow bridge between Barangay Taclobo and Barangay Bagacay should be worked out and be replaced with better bridge system so river and flood waters will have easy flow from uphill to downhill rather than cause blockage due to poor overflow bridge system. Zoning ordinances must also be strictly implemented to avoid casualties from people living close by the river banks. Those are among the top priorities that needs special attention. 
Community-Based Flood Vulnerability Index for Urban Flooding: Understanding Social Vulnerabilities and Risks

Table 5-9: Barangay Bagacay FVI

\begin{tabular}{|c|c|c|c|c|c|c|c|}
\hline \multirow[b]{2}{*}{ COMPONENTS } & \multicolumn{2}{|c|}{ EXPOSURE } & \multicolumn{2}{|c|}{ SUSCEPTIBILITY } & \multicolumn{2}{|c|}{ RESILIENCE } & \multirow{2}{*}{$\begin{array}{r}\text { FVI } \\
(\%)\end{array}$} \\
\hline & Indicators & $(\%)$ & Indicators & $(\%)$ & Indicators & $(\%)$ & \\
\hline \multirow{4}{*}{ A. HYDRO-CLIMATIC } & A. FF & 32.00 & A. NTY & 50.00 & A. LUMSD & 58.28 & 50.37 \\
\hline & B. HF & 76.00 & & & & & \\
\hline & C. HRF & 60.00 & & & & & \\
\hline & D. HNE & 36.00 & & & & & \\
\hline \multirow{2}{*}{ B. SOCIAL } & A. ODAW & 56.00 & A. EA & 52.00 & A. WT & 60.00 & 18.08 \\
\hline & B. UVR & 20.00 & & & B. SN & 81.00 & \\
\hline \multirow{4}{*}{ C.ECONOMIC } & A. HNIS & 0.00 & A. $\mathrm{HC}$ & 32.00 & A. FI & 48.00 & 100.00 \\
\hline & B. HNIW & 16.00 & & & B. PI & 28.00 & \\
\hline & C. PRV & 84.00 & & & & & \\
\hline & D. PWLV & 32.00 & & & & & \\
\hline \multirow{4}{*}{ D.SOCIO-BEHAVIORAL } & A. PHFR & 31.26 & A. AHFR & 21.00 & A. KHFR & 70.71 & 15.72 \\
\hline & B. PHEC & 28.77 & B. AHEC & 27.67 & B. KHEC & 67.28 & \\
\hline & C. PHL & 35.81 & C. $\mathrm{AHL}$ & 30.44 & C. KHL & 67.28 & \\
\hline & D. PHDF & 36.36 & D. AHDF & 15.33 & D. KHDF & 67.28 & \\
\hline \multirow{4}{*}{$\begin{array}{c}\text { E. POLITICO- } \\
\text { ADMINISTRATIVE }\end{array}$} & A. RNRMP & 41.72 & A. $G$ & 45.44 & A. PRAI & 61.88 & 21.93 \\
\hline & B. LUMSD & 27.50 & & & B. SCLP & 62.50 & \\
\hline & & & & & C. RSP & 76.80 & \\
\hline & & & & & D. HPP & 78.40 & \\
\hline Total Average FVI & & & & & & & 41.22 \\
\hline
\end{tabular}

(10) Barangay Taclobo

Barangay Bagacay's hydro-climatic Flood Vulnerability Index $(\mathrm{FVI})$ is $55.31 \%$ as shown in Table 5-10 indicating medium range vulnerability in this component. The resilience item for land use and management and structural design (LUSMD) is only $46.25 \%$, which is medium range as well. Among the surveyed household, $30.16 \%$ claimed that flooding occurs every year in the area. $55.55 \%$ of the rest claimed that flooding only happens sometimes/rarely. $76.20 \%$ of the community people surveyed have experience flooding from ankle level to above the head and roof high. Though generally most households surveyed (34.92\%) have experienced flooding at ankle level floodwaters only except from the last flash flood event. The low level of floodwaters in ordinary days in Barangay Taclobo is basically because most of the houses along the river banks are located in an area where there is a good dike system. Vulnerability to exposure in terms of the number of houses reached by floods (47.62\%) and $50.79 \%$ of the houses are not on elevated area thus the exposure vulnerability is only in the medium range (51.19\%). 

Social Vulnerabilities and Risks

The social $\mathrm{FVI}$ is $23.93 \%$. Open disposal of animal waste is observed (96.83\%) from the population. There is $20.63 \%$ who are not willing to vacate because no relocation site provided for them, they perceived their area as no threat to flooding, for some it for sentimental reasons, the flood barriers (dikes) are still in place and intact, and they are not ready to move into a new place while the rest did not specify their reasons why. The exposure index is $58.73 \%$ respectively. The educational attainment of most households is $(30.16 \%)$ which is very low and which may play as a critical predisposing factor. The resilience factor that includes water treatment sterilization and social network is indicating both a high and very high resilience $73.02 \%$ and $75.00 \%$ respectively.

The economic FVI for Barangay Taclobo is $39.75 \%$. Among the surveyed households of the community, there is still $4.76 \%$ that have no access to improved sanitation and $17.46 \%$ of the surveyed households do not have good access to improved water source. Presence of rats in the community is observed $(49.21 \%)$ and $(49.21 \%)$ of the population lived in the presence of water logged areas in the vicinity which could be a predisposing factor for dengue fever mosquito outbreak. $40.79 \%$ of most houses are susceptible to the effects of flooding and typhoons which should be considered. Most households (44.44\%) have a family income that is around 3000-1000 per month and $(17.46 \%)$ of the families surveyed have their properties insured.

The socio-behavioral FVI is $6.88 \%$. The socio-behavioral vulnerability index of Barangay Taclobo is low in terms of the knowledge, attitude and practices that may predisposed the household to any flooding event and disease outbreaks that may be caused by E.coli, Leptospirosis and Dengue Fever mosquito. Exposure vulnerability is $22.72 \%$, while susceptibility is $22.12 \%$, which is low and resilience items are good $(73.07 \%)$ respectively. It is important to maintain such good knowledge, attitude and practices that may prevent the community people from any disease outbreak and untoward events from flooding and typhoon. Only $45.90 \%$ are aware about lectures on early warning system in the community and $32.79 \%$ were aware about drills on early warning system. Furthermore, only $36.07 \%$ have been given or attended some debriefing session from the past flooding event and $40.98 \%$ have attended to some discussions of lesson learned from the past flooding event. Moreover, only $40.98 \%$ have participated in the adaptation strategies the local government unit (LGU's) have implemented.

The politico-administrative $\mathrm{FVI}$ is $33.26 \%$. The exposure vulnerability is (48.13\%). The exposure items which predisposes the management of river's natural resources and natural features management and program to the effects of flooding is $(53.75 \%)$ and $(42.50 \%)$ for the LUMSD which are in the medium and low range vulnerability 

Social Vulnerabilities and Risks

respectively. On the other hand, the susceptibility is $44.44 \%$ (governance) and the resilience factor is $63.68 \%$ which is a bit higher. Resilience effort includes; post-risk assessment and integration $(57.50 \%)$, sustainable community livelihood program $(57.50 \%)$, relocation site project $(68.20 \%)$ and the health and prevention program for E.coli, leptospirosis and dengue fever mosquito (71.50\%) respectively.

The overall FVI for Barangay Taclobo is $31.83 \%$ which is considerably a low vulnerability. However, there is a need to improve in terms of the efficiency of the dike system (40.00\%) and the bridge or overflow system (40.00\%) respectively. The bridge overflow system in Barangay Taclobo blocks the river water or floodwaters during heavy rains instead of facilitating faster flow because of how it was built. Also, there is a need to establish well our education, outreach, and training programs to improve compliance with land use policies and building standards to more resilient and adaptive.

Table 5-10: Barangay Taclobo FVI

\begin{tabular}{|c|c|c|c|c|c|c|c|}
\hline \multirow[b]{2}{*}{ COMPONENTS } & \multicolumn{2}{|c|}{ EXPOSURE } & \multicolumn{2}{|c|}{ SUSCEPTIBILITY } & \multicolumn{2}{|c|}{ RESILIENCE } & \multirow{2}{*}{$\begin{array}{r}\mathrm{FVI} \\
(\%) \\
\end{array}$} \\
\hline & Indicators & $(\%)$ & Indicators & (\%) & Indicators & $(\%)$ & \\
\hline \multirow{4}{*}{ A. HYDRO-CLIMATIC } & A. FF & 30.16 & \multirow[t]{4}{*}{ A. NTY } & \multirow[t]{4}{*}{50.00} & \multirow[t]{4}{*}{ A. LUMSD } & \multirow[t]{4}{*}{46.25} & \multirow[t]{4}{*}{55.31} \\
\hline & B. $\mathrm{HF}$ & 76.20 & & & & & \\
\hline & C. HRF & 47.62 & & & & & \\
\hline & D. HNE & 50.79 & & & & & \\
\hline \multirow{2}{*}{ B. SOCIAL } & A. ODAW & 96.83 & \multirow[t]{2}{*}{ A. EA } & \multirow[t]{2}{*}{30.16} & A. WT & 73.02 & \multirow[t]{2}{*}{23.93} \\
\hline & B. UVR & 20.63 & & & B. SN & 75.00 & \\
\hline \multirow{4}{*}{ C.ECONOMIC } & A. HNIS & 4.76 & \multirow[t]{4}{*}{ A. $\mathrm{HC}$} & \multirow[t]{4}{*}{40.79} & A. $\mathrm{FI}$ & 44.44 & \multirow[t]{4}{*}{39.75} \\
\hline & B. HNIW & 17.46 & & & B. PI & 17.46 & \\
\hline & C. PRV & 49.21 & & & & & \\
\hline & D. PWLV & 49.21 & & & & & \\
\hline \multirow{4}{*}{ D.SOCIO-BEHAVIORAL } & A. PHFR & 30.28 & A. AHFR & 27.93 & A. KHFR & 64.93 & \multirow[t]{4}{*}{6.88} \\
\hline & B. PHEC & 22.88 & B. AHEC & 22.84 & B. KHEC & 75.78 & \\
\hline & C. PHL & 23.59 & C. AHL & 23.59 & C. KHL & 75.78 & \\
\hline & D. PHDF & 14.11 & D. AHDF & 14.11 & D. KHDF & 75.78 & \\
\hline \multirow{4}{*}{$\begin{array}{l}\text { E. POLITICO- } \\
\text { ADMINISTRATIVE }\end{array}$} & A. RNRMP & 53.75 & \multirow[t]{4}{*}{ A. $G$} & \multirow[t]{4}{*}{44.00} & A. PRAI & 57.50 & \multirow[t]{4}{*}{33.26} \\
\hline & B. LUMSD & 42.50 & & & B. SCLP & 57.50 & \\
\hline & & & & & C. RSP & 68.20 & \\
\hline & & & & & D. HPP & 71.50 & \\
\hline Ttotal Average FVI & & & & & & & 31.83 \\
\hline
\end{tabular}



Social Vulnerabilities and Risks

(11) Barangay Candau-ay

Barangay Candau-ay's hydro-climatic Flood Vulnerability Index (FVI) is $49.18 \%$ as shown in Table 5-11 indicating medium range vulnerability in this component. The resilience item for land use and management and structural design (LUSMD) is 68.13. About $40.28 \%$ of the household surveyed claimed that flooding occurs every year in the area though $51.39 \%$ of them claimed that flooding only happens sometimes/rarely. $91.67 \%$ of the community people surveyed have experience flooding from ankle high to roof high. Though generally most households surveyed $(25.00 \%)$ have experienced flooding at waist level floodwaters. The level of floodwater in Barangay Candau-ay is basically because some of houses are located in an area where there is no dike system protecting them from spilling running floodwaters. Vulnerability to exposure in terms of the number of houses reached by floods (81.94\%) which is very high, and $54.17 \%$ of the houses are not on elevated area thus the exposure vulnerability is considerably high $(67.02 \%)$ thus should be given special attention by completing the dike system in those areas.

The social $\mathrm{FVI}$ is $24.48 \%$. Open disposal of animal waste is observed (58.34\%) from the population. $33.33 \%$ of those surveyed are not willing to vacate because no relocation site provided, they are not ready to move to a new place, they perceived their place as no threat to the effects of flooding, due to proximity to the source of their livelihood, they have learned to secure their property, and for some it is for sentimental reasons while the rest did not specify their reasons. The exposure index is $45.84 \%$ respectively. The educational attainment of most households is (38.89\%) which is very low and which may play as a critical predisposing factor. The resilience factor that includes water treatment sterilization and social network is indicating both a high and very high resilience $69.44 \%$ and $76.39 \%$ respectively.

The economic FVI for Barangay Candau-ay is 52.30\%. Among the surveyed households of the community, there is still $(4.17 \%)$ that have no access to improved sanitation and $11.11 \%$ of the surveyed households do not have good access to improved water source. Presence of rats in the community is highly observed $(86.11 \%)$ and $(44.44 \%)$ of the population lived in the presence of water logged areas in the vicinity which could be a predisposing factor for dengue fever mosquito outbreak. $45.83 \%$ of most houses are susceptible to the effects of flooding and typhoons which should be considered. Most households (47.22\%) have a family income that is around $3000-1000$ per month and (16.67\%) of the families surveyed have their properties insured. 

Social Vulnerabilities and Risks

The socio-behavioral $\mathrm{FVI}$ is $13.51 \%$. The socio-behavioral vulnerability index of Barangay Candau-ay is low in terms of the knowledge, attitude and practices that may predisposed the household to any flooding event and disease outbreaks that may be caused by E.coli, Leptospirosis and Dengue Fever mosquito. Exposure vulnerability is $37.44 \%$, while susceptibility is $27.87 \%$, which is low and resilience items are good (77.21\%) respectively. It is important to maintain such good knowledge, attitude and practices that will prevent the community people from any disease outbreak and untoward events from flooding and typhoon. Furthermore, it is important to consider the practices $(42.71 \%)$ of the community people, if this can be improve so much the better to avoid dengue fever outbreak in the future. Also, only $38.89 \%$ have been given or have attended a debriefing session from the past flooding event. It is very important that the community people should receive debriefing sessions to help them cope from the unfortunate event. Only $43.06 \%$ have participated in an adaptation strategies implemented by the local government units (LGU's) which is also important for people's awareness and participation to create a coordinated flow of implementing the programs and rescue and recovery actions.

The politico-administrative $\mathrm{FVI}$ is $16.06 \%$. The exposure vulnerability is $(29.69 \%)$. The exposure items which predisposes the management of river's natural resources and natural features management and program to the effects of flooding is $(31.87 \%)$ and $(27.50 \%)$ for the LUMSD which are in the medium and low range vulnerability respectively. On the other hand, the susceptibility is $36.83 \%$ (governance) and the resilience vulnerability is $68.07 \%$. Resilience efforts include; post-risk assessment and integration $(71.88 \%)$, sustainable community livelihood program $(65.00 \%)$, relocation site project $(65.60 \%)$ and the health and prevention program for E.coli, Leptospirosis and dengue fever mosquito $(69.80 \%)$ respectively.

The overall FVI for Barangay Candau-ay is $31.11 \%$ which is considerably low vulnerability. Barangay Candau-ay has spoken. The availability of our technical (services offered) and financial resources to support the recovery process particularly on the insurance scheme, damage assessment facilitating claim procession, reconstruction, charitable funds, and social therapeutic measures are as follows $0.00 \%$, $0.00 \%, 0.00 \%, 0.00 \%$ and $30.00 \%$ respectively. There is much work to be done here to help the community people recover fast and better. 
Community-Based Flood Vulnerability Index for Urban Flooding: Understanding Social Vulnerabilities and Risks

Table 5-11: Barangay Candau-ay FVI

\begin{tabular}{|c|c|c|c|c|c|c|c|}
\hline \multirow[b]{2}{*}{ COMPONENTS } & \multicolumn{2}{|c|}{ EXPOSURE } & \multicolumn{2}{|c|}{ SUSCEPTIBILITY } & \multicolumn{2}{|c|}{ RESILIENCE } & \multirow{2}{*}{$\begin{array}{r}\text { FVI } \\
(\%)\end{array}$} \\
\hline & Indicators & $(\%)$ & Indicators & $(\%)$ & Indicators & $(\%)$ & \\
\hline \multirow{4}{*}{ A. HYDRO-CLIMATIC } & A. FF & 40.28 & A. NTY & 50.00 & A. LUMSD & 68.13 & 49.18 \\
\hline & B. HF & 91.67 & & & & & \\
\hline & C. HRF & 81.94 & & & & & \\
\hline & D. HNE & 54.17 & & & & & \\
\hline \multirow{2}{*}{ B. SOCIAL } & A. ODAW & 58.34 & A. EA & 38.89 & A. WT & 69.44 & 24.48 \\
\hline & B. UVR & 33.33 & & & B. SN & 76.39 & \\
\hline \multirow{4}{*}{ C.ECONOMIC } & A. HNIS & 4.17 & A. $\mathrm{HC}$ & 45.83 & A. FI & 69.44 & 52.30 \\
\hline & B. HNIW & 11.11 & & & B. PI & 76.39 & \\
\hline & C. PRV & 86.11 & & & & & \\
\hline & D. PWLV & 44.44 & & & & & \\
\hline \multirow{4}{*}{ D.SOCIO-BEHAVIORAL } & A. PHFR & 35.91 & A. AHFR & 30.38 & A. KHFR & 66.66 & 13.51 \\
\hline & B. PHEC & 33.36 & B. AHEC & 31.33 & B. KHEC & 80.72 & \\
\hline & C. PHL & 37.76 & C. $\mathrm{AHL}$ & 31.91 & C. $\mathrm{KHL}$ & 80.72 & \\
\hline & D. PHDF & 42.71 & D. AHDF & 17.86 & D. KHDF & 80.72 & \\
\hline \multirow{4}{*}{$\begin{array}{c}\text { E. POLITICO- } \\
\text { ADMINISTRATIVE }\end{array}$} & A. RNRMP & 31.87 & A. $G$ & 36.83 & A. PRAI & 71.88 & 16.06 \\
\hline & B. LUMSD & 27.50 & & & B. SCLP & 65.00 & \\
\hline & & & & & C. RSP & 65.60 & \\
\hline & & & & & D. HPP & 69.80 & \\
\hline Total Average FVI & & & & & & & 31.11 \\
\hline
\end{tabular}

(12) Barangay Batinguel

Barangay Batinguel's hydro-climatic Flood Vulnerability Index (FVI) is $62.73 \%$ as shown in Table 5-12 indicating medium range vulnerability in this component. The resilience item for land use and management and structural design (LUSMD) is $61.88 \%$, which is quite good. $68.42 \%$ of the household surveyed claimed that flooding occurs every year in the area. Some $28.39 \%$ of them claimed that flooding only happens sometimes/rarely. $92.10 \%$ of the community people surveyed have experience flooding from ankle level to beyond the roof from the past flooding. Though generally most households surveyed (23.68\%) have experienced flooding at waist level floodwaters. The level of flood water in Barangay Batinguel is at different range basically because some houses are located in an area where there is a dike system, while others are living in an exposed area and some in an elevated but many are located in a flat area. Vulnerability to exposure in terms of the number of houses reached by floods $(81.58 \%)$ which is very high, and $68.42 \%$ of the houses are not on elevated area thus the 
Community-Based Flood Vulnerability Index for Urban Flooding: Understanding Social Vulnerabilities and Risks

exposure vulnerability is considerably high $(77.63 \%)$ thus should be given special attention.

The social FVI is $6.08 \%$. Open disposal of animal waste is observed (60.53\%) from the population. There is $34.21 \%$ who are not willing to vacate because there was no relocation site provided for them, they perceived their area as no threat to flooding, the flood barrier structures (dike system) are still intact, proximity to the source of their livelihood, for some sentimental reasons and while the others did not specify their reasons. The exposure index is $47.37 \%$ respectively. The educational attainment of most households is only $(9.21 \%)$ which is very low and which may play as a critical predisposing factor. The resilience factor that includes water treatment sterilization and social network is indicating both a high and very high resilience $69.44 \%$ and $76.39 \%$ respectively.

The economic FVI for Barangay Batinguel is $100.00 \%$. Among the surveyed households of the community, there is still $2.63 \%$ that have no access to improved sanitation and $21.05 \%$ of the surveyed households do not have good access to improved water source which is a higher than the rest of the communities. Presence of rats in the community is highly observed $(92.11 \%)$ and $(42.11 \%)$ of the population lived in the presence of water logged areas in the vicinity which could be a predisposing factor for dengue fever mosquito outbreak. $76.31 \%$ of most houses are highly susceptible to the effects of flooding and typhoons which should be considered. Most households (39.47\%) have a family income that is around 3000-1000 per month and $(5.26 \%)$ of the families surveyed have their properties insured.

The socio-behavioral FVI is $8.76 \%$. The socio-behavioral vulnerability index of Barangay Taclobo is low in terms of the knowledge, attitude and practices that may predisposed the household to any flooding event and disease outbreaks that may be caused by E.coli, Leptospirosis and Dengue Fever mosquito. Exposure vulnerability is $33.48 \%$, while susceptibility is $19.53 \%$, which is low and resilience items are good $(74.63 \%)$ respectively. It is important to maintain such good knowledge, attitude and practices that may prevent the community people from any disease outbreak and untoward events from flooding and typhoon. However, it is important to consider the practices towards Leptospirosis outbreak (41.21\%) to keep it low. In terms of knowledge and awareness, only $42.11 \%$ are aware about the availability of flood hazard maps in their community. Only $50.00 \%$ are aware about lectures on early warning system conducted in their community. About $42.11 \%$ are aware on the drills on early warning system facilitated in their community. In terms of the people's practices, $47.37 \%$ have participated in the 

Social Vulnerabilities and Risks

early warning system lectures in their community. $50.00 \%$ have participated in drills related to evacuation and response. Proper information dissemination must be carried over to the rest of the community people so everyone will be alert and aware of the different response and recovery strategy of the LGU's. Barangay Batinguel has $47.37 \%$ in terms of neighborhood association or support members in terms of need during flooding. Only $44.74 \%$ have contacts from other communities in the upper stream (Balugo, Valencia) to keep them inform about the floodwater level before it would reach down the lower parts of the river.

The politico-administrative $\mathrm{FVI}$ is $21.10 \%$. The exposure vulnerability is $(37.81 \%)$. The exposure items which predisposes the management of river's natural resources and natural features management and program to flooding is (38.12\%) and $(37.50 \%)$ for the LUMSD which are in the medium and low range vulnerability respectively. On the other hand, susceptibility is $35.83 \%$ (governance) and the resilience factor is 64.45 . Resilience efforts include; post-risk assessment and integration (67.50\%), sustainable community livelihood program $(65.00 \%)$, relocation site project $(61.60 \%)$ and the health and prevention program for E.coli, leptospirosis and dengue fever mosquito (63.70\%) respectively. The overall $\mathrm{FVI}$ for Barangay Batinguel is $39.73 \%$ which is considerably low vulnerability. 
Community-Based Flood Vulnerability Index for Urban Flooding: Understanding Social Vulnerabilities and Risks

Table 5-12: Barangay Batinguel FVI

\begin{tabular}{|c|c|c|c|c|c|c|c|}
\hline \multirow[b]{2}{*}{ COMPONENTS } & \multicolumn{2}{|c|}{ EXPOSURE } & \multicolumn{2}{|c|}{ SUSCEPTIBILITY } & \multicolumn{2}{|c|}{ RESILIENCE } & \multirow{2}{*}{$\begin{array}{r}\text { FVI } \\
(\%)\end{array}$} \\
\hline & Indicators & $(\%)$ & Indicators & $(\%)$ & Indicators & $(\%)$ & \\
\hline \multirow{4}{*}{ A. HYDRO-CLIMATIC } & A. FF & 68.42 & A. NTY & 50.00 & A. LUMSD & 61.88 & 62.73 \\
\hline & B. HF & 92.10 & & & & & \\
\hline & C. HRF & 81.58 & & & & & \\
\hline & D. HNE & 68.42 & & & & & \\
\hline \multirow{2}{*}{ B. SOCIAL } & A. ODAW & 60.53 & A. EA & 9.21 & A. WT & 71.05 & 6.08 \\
\hline & B. UVR & 34.21 & & & B. SN & 72.37 & \\
\hline \multirow{4}{*}{ C.ECONOMIC } & A. HNIS & 2.63 & A. $\mathrm{HC}$ & 76.31 & A. FI & 39.47 & 100.00 \\
\hline & B. HNIW & 21.05 & & & B. PI & 5.26 & \\
\hline & C. PRV & 92.11 & & & & & \\
\hline & D. PWLV & 42.11 & & & & & \\
\hline \multirow{4}{*}{ D.SOCIO-BEHAVIORAL } & A. PHFR & 27.97 & A. AHFR & 27.38 & A. KHFR & 72.03 & 8.76 \\
\hline & B. PHEC & 30.05 & B. AHEC & 20.47 & B. KHEC & 75.49 & \\
\hline & C. PHL & 41.21 & C. $\mathrm{AHL}$ & 20.25 & C. $\mathrm{KHL}$ & 75.49 & \\
\hline & D. PHDF & 34.69 & D. AHDF & 10.01 & D. KHDF & 75.49 & \\
\hline \multirow{4}{*}{$\begin{array}{c}\text { E. POLITICO- } \\
\text { ADMINISTRATIVE }\end{array}$} & A. RNRMP & 38.12 & A. $G$ & 35.83 & A. PRAI & 67.50 & 21.10 \\
\hline & B. LUMSD & 37.50 & & & B. SCLP & 65.00 & \\
\hline & & & & & C. RSP & 61.60 & \\
\hline & & & & & D. HPP & 63.70 & \\
\hline Total Average FVI & & & & & & & 39.73 \\
\hline
\end{tabular}




\subsection{DETAILED ANALYSIS: Building Scale for Poblacion 2 (Barangay Lukewright)}

Here is a brief view of the household respondents in Poblacion 2 (Barangay Lukewright) in reference to their location from the river and their vulnerability index to the different components. Households were solicited for their answers with the corresponding flood vulnerability components. This study opted to do a detailed case study to have a closer look how each household differs their outlooks and perceptions in the different components and indicators of urban flood vulnerability index giving us an in-depth understanding of the community. To cover the entire community, adjacent households were assumed to have the same data values from the ones that were actually surveyed.

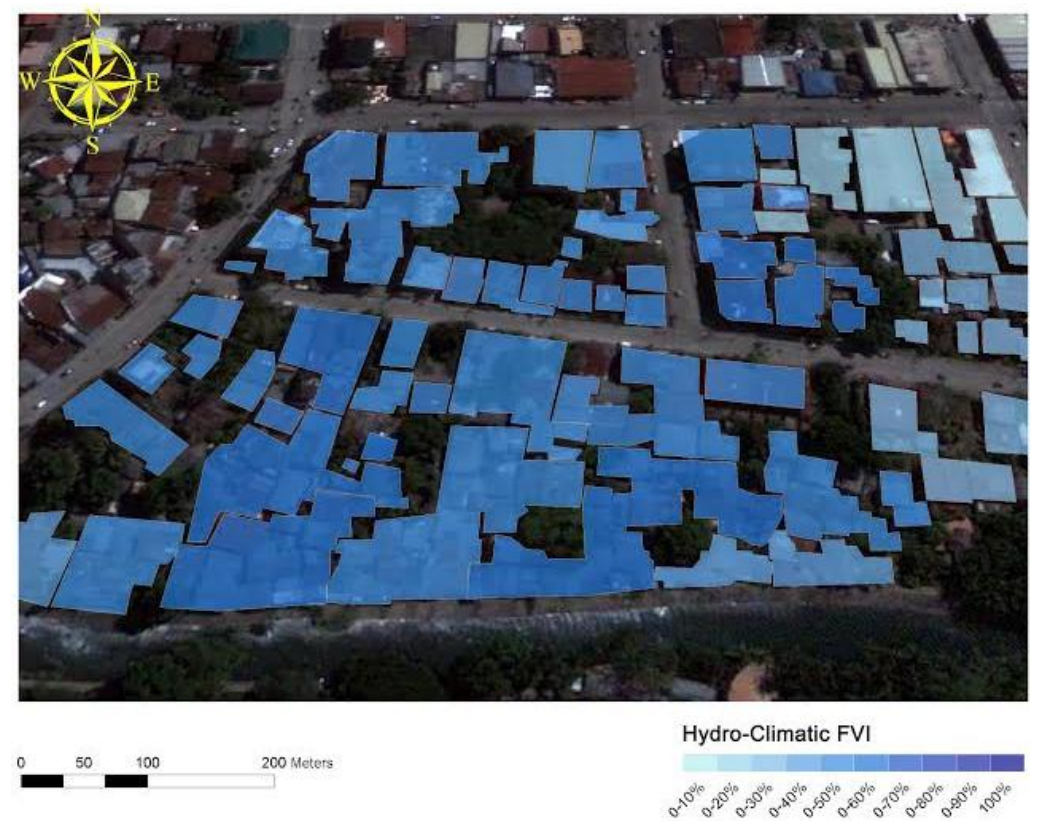

Figure 5-1: Hydro-Climatic Component of Flood Vulnerability Index of Poblacion 2

In the hydro-climatic flood vulnerability index $(\mathrm{FVI})$, parts of its components for the vulnerability indicators are as follows: the frequency of flooding, height of flooding, houses reached by floods, and houses not on elevated area are all part of the exposure indicator. The number of typhoons per year $(50 \%)$ is the susceptibility indicator. While the land use and management and structural design stands for its resilience indicator. 
Community-Based Flood Vulnerability Index for Urban Flooding: Understanding Social Vulnerabilities and Risks

Table 5-13: Hydro-Climatic Component of Flood Vulnerability Index of Poblacion 2

\begin{tabular}{|c|c|c|c|}
\hline RANK & Longitude $\left({ }^{\circ} \mathrm{E}\right)$ & Latitude $\left({ }^{\circ} \mathrm{N}\right)$ & $\begin{array}{c}\text { Hydro-Climatic FVI } \\
(\%)\end{array}$ \\
\hline 1 & 9.30243 & 123.30566 & 76.32 \\
\hline 1 & 9.30243 & 123.30566 & 76.32 \\
\hline 3 & 9.30206 & 123.30713 & 75.92 \\
\hline 4 & 9.30236 & 123.30687 & 73.06 \\
\hline 5 & 9.30214 & 123.30539 & 72.65 \\
\hline 6 & 9.30240 & 123.30631 & 60.61 \\
\hline 7 & 9.30215 & 123.30671 & 60.82 \\
\hline 7 & 9.30225 & 123.30518 & 58.37 \\
\hline 9 & 9.30218 & 123.30819 & 57.55 \\
\hline 10 & 9.30227 & 123.30591 & 49.80 \\
\hline 11 & 9.30236 & 123.30713 & 47.98 \\
\hline 12 & 9.30207 & 123.30830 & 45.83 \\
\hline 13 & 9.30323 & 123.30870 & 43.67 \\
\hline 14 & 9.30235 & 123.30552 & 43.26 \\
\hline 15 & 9.30169 & 123.30669 & 37.37 \\
\hline 16 & 9.30206 & 123.30713 & 34.69 \\
\hline 17 & 9.30276 & 123.30651 & 11.84 \\
\hline 18 & 9.30288 & 123.30656 & \\
\hline
\end{tabular}

Figure 5-1 and Table 5-13 shows the the Hydro-Climatic FVI of Poblacion 2 (Barangay Lukewright) indicating a considerably high vulnerability, $76.32 \%$ being the highest and $11.84 \%$ for its lowest rating. Those households that are in the lower left portion of the map depicted with dark blue colors are those households that are highly vulnerable in terms of the number of flooding incidences that they have experienced for these past few years. Many of the houses were reached by flood waters as high as their roof tops during the flash floods in 2011 and 2012 respectively were it rained for several hours. Most of the houses that were immediately located after the flood barrier (dike system) were not in an elevated ground thus spill over of river floods easily reached to the doorsteps of these houses. While those that were on the opposite side of the main road (upper part of the map) shown in light colored blue are located in elevated areas thus floodwaters do not usually reached to these houses. The land use and management and structural design along these areas were not strictly implemented and followed by the residence of this community and the constructed flood protection barriers (dike system) have underestimated the possible volume of floodwaters during such events. In this results, it can be observed that households of the same community have different experiences in terms of the hydro-climatic factors. Clearly, those houses located closeby the river are the ones highly affected when it comes to hydro-climatic 

Social Vulnerabilities and Risks

components and those that are located farther away and in an elevated area are less likely to be affected as shown in the map and table above.

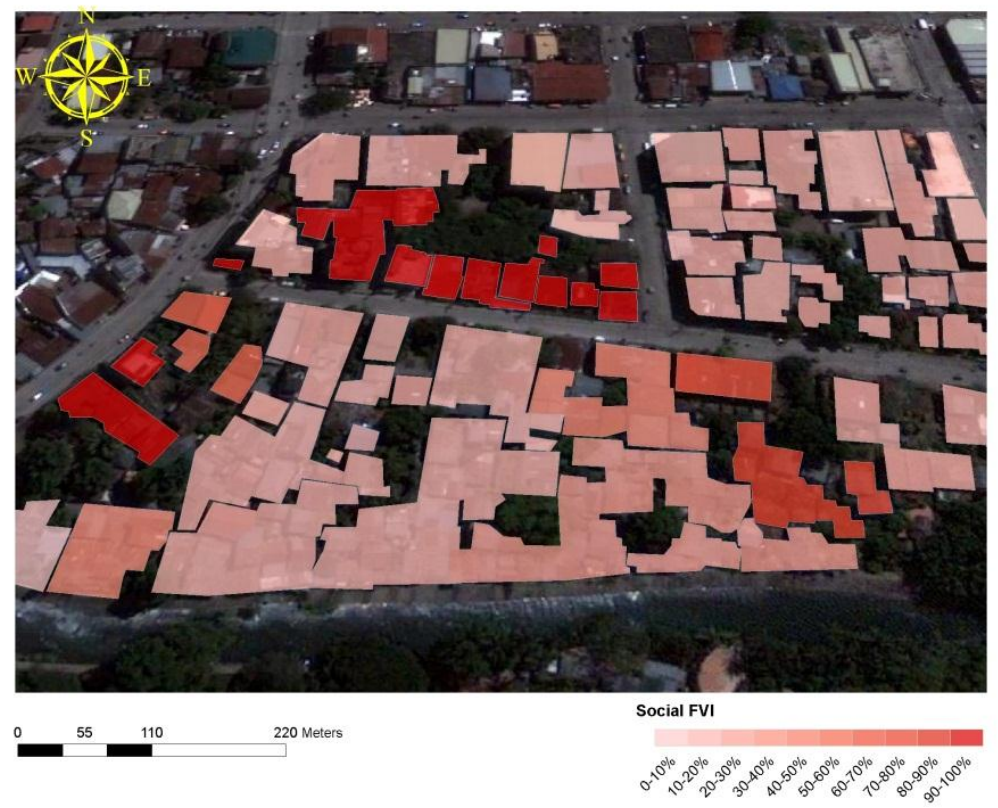

Figure 5-2: Social Component of Flood Vulnerability Index of Poblacion 2

For the social flood vulnerability index $(\mathrm{FVI})$ it includes the open disposal of animal waste and unwillingness to vacate (exposure indicator). The educational attainment is the susceptibility indicator. On the other hand, water treatment/sterilization practice and its social network reflects it resilience capacity. 
Community-Based Flood Vulnerability Index for Urban Flooding: Understanding Social Vulnerabilities and Risks

Table 5-14: Social Component of Flood Vulnerability Index of Poblacion 2

\begin{tabular}{|c|c|c|c|}
\hline RANK & Longitude $\left({ }^{\circ} \mathrm{E}\right)$ & Latitude $\left({ }^{\circ} \mathrm{N}\right)$ & Social FVI $(\%)$ \\
\hline 1 & 9.30206 & 123.30713 & 100.00 \\
\hline 1 & 9.30235 & 123.30552 & 100.00 \\
\hline 1 & 9.30276 & 123.30651 & 100.00 \\
\hline 4 & 9.30206 & 123.30713 & 73.33 \\
\hline 5 & 9.30236 & 123.30713 & 66.67 \\
\hline 6 & 9.30243 & 123.30566 & 53.32 \\
\hline 7 & 9.30214 & 123.30539 & 39.99 \\
\hline 8 & 9.30236 & 123.30687 & 33.33 \\
\hline 9 & 9.30215 & 123.30671 & 27.27 \\
\hline 10 & 9.30169 & 123.30669 & 20.51 \\
\hline 11 & 9.30227 & 123.30591 & 16.67 \\
\hline 12 & 9.30218 & 123.30819 & 14.10 \\
\hline 13 & 9.30323 & 123.30870 & 10.26 \\
\hline 14 & 9.30288 & 123.30656 & 10.26 \\
\hline 14 & 9.30240 & 123.30631 & 10.25 \\
\hline 16 & 9.30243 & 123.30566 & 10.25 \\
\hline 16 & 9.30207 & 123.30830 & 5.13 \\
\hline 18 & 9.30225 & 123.30518 & \\
\hline
\end{tabular}

Figure 5-2 and Table 5.14 reveals the Social FVI. Generally, 12 out of 18 household respondents that were surveyed (light colored pink shade) showed low to medium range Social FVI while 6 among those household respondents (dark pink shade) are showing a very high social vulnerability index. This can attributed to their refusal to vacate apparently because there was no relocation site provided for them. Another two major contributing factor to its considerably high vulnerability is due to high open disposal of animal waste practice and low level of educational attainment among the respondents. More than half of the respondents do not have a good educational background which can be a predisposing factor if information drive are not delivered well to each household in the community. Almost all of the respondents dispose their animal waste on the ground which considerably added to the high social flood vulnerability index of Poblacion 2 respectively. 


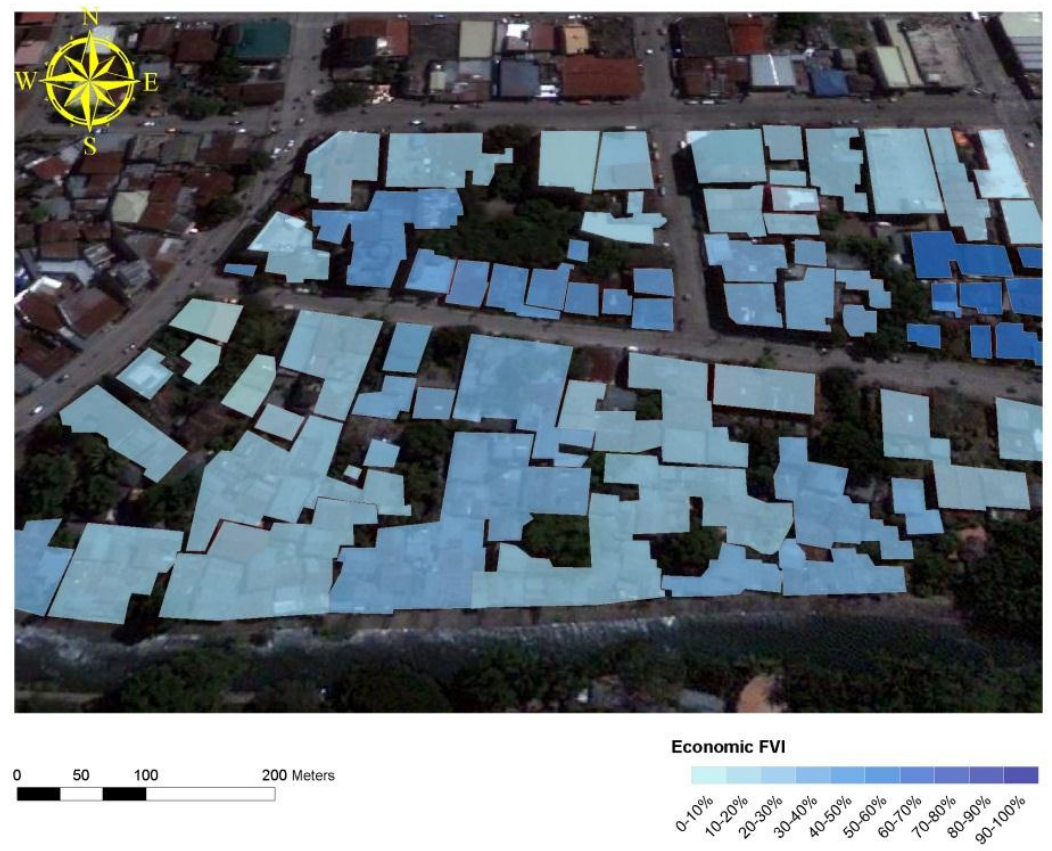

Figure 5-3: Economic Component of Flood Vulnerability Index of Poblacion 2

The economic flood vulnerability index (FVI) component for Poblacion 2 (Lukewright) includes houses with no access to improved sanitation, houses with no access to improved water source, presence of rats in the vicinity, presence of waterlogged areas in the vicinity (exposure indicator); the housing condition which could be semi-concrete, tent light materials, and plastic materials (susceptibility indicator); family income between 3000-10,000 pesos and property insurance (resilience indicator). 
Community-Based Flood Vulnerability Index for Urban Flooding: Understanding Social Vulnerabilities and Risks

Table 5-15: Economic Component of Flood Vulnerability Index of Poblacion 2

\begin{tabular}{|c|c|c|c|}
\hline RANK & Longitude $\left.^{\circ} \mathrm{E}\right)$ & Latitude $\left({ }^{\circ} \mathrm{N}\right)$ & Economic FVI $(\%)$ \\
\hline 1 & 9.30218 & 123.30819 & 59.99 \\
\hline 2 & 9.30206 & 123.30669 & 40.00 \\
\hline 3 & 9.30276 & 123.30651 & 36.00 \\
\hline 4 & 9.30169 & 123.30669 & 30.00 \\
\hline 4 & 9.30240 & 123.30631 & 30.00 \\
\hline 6 & 9.30206 & 123.30713 & 24.00 \\
\hline 6 & 9.30243 & 123.30566 & 24.00 \\
\hline 8 & 9.30225 & 123.30518 & 22.50 \\
\hline 9 & 9.30235 & 123.30552 & 18.00 \\
\hline 10 & 9.30214 & 123.30539 & 15.00 \\
\hline 10 & 9.30236 & 123.30687 & 15.00 \\
\hline 10 & 9.30236 & 123.30713 & 15.00 \\
\hline 10 & 9.30288 & 123.30656 & 15.00 \\
\hline 10 & 9.30207 & 123.30830 & 15.00 \\
\hline 10 & 9.30323 & 123.30870 & 12.00 \\
\hline 16 & 9.30227 & 123.30591 & 12.00 \\
\hline 16 & 9.30215 & 123.30671 & 6.00 \\
\hline 18 & 9.30243 & 123.30566 & \\
\hline
\end{tabular}

Figure 5-3 and Table 5.15 showed the Economic FVI of the household respondent surveyed in Poblacion 2 (Barangay Lukewright). The Economic FVI is relatively low where 16 out of the 18 respondents and those immediate adjacent to it (very light shade of blue to lighter shades) the values are ranging from $6.00 \%$ to $36.00 \%$ which falls in the low vulnerability range. While $40.00 \%$ and $59.99 \%$ are in the medium range vulnerability (more lighter blue shade). The medium range vulnerability can be accounted to a favorable high family income which follows good housing conditions, with access to good sanitation and improved water source among these respondents. Almost all of them have their property insured. In spite that there are presence of water logged areas in the vicinity and visibility of rats in the surroundings which could attribute to health hazards particularly of dengue fever and leptospirosis outbreak, yet, since they have good income and housing conditions, the vulnerability index is lowered at a minimal level. The disparity of values is quite high (6.00\% to $59.99 \%)$ but generally, the results between households are in a close range. 


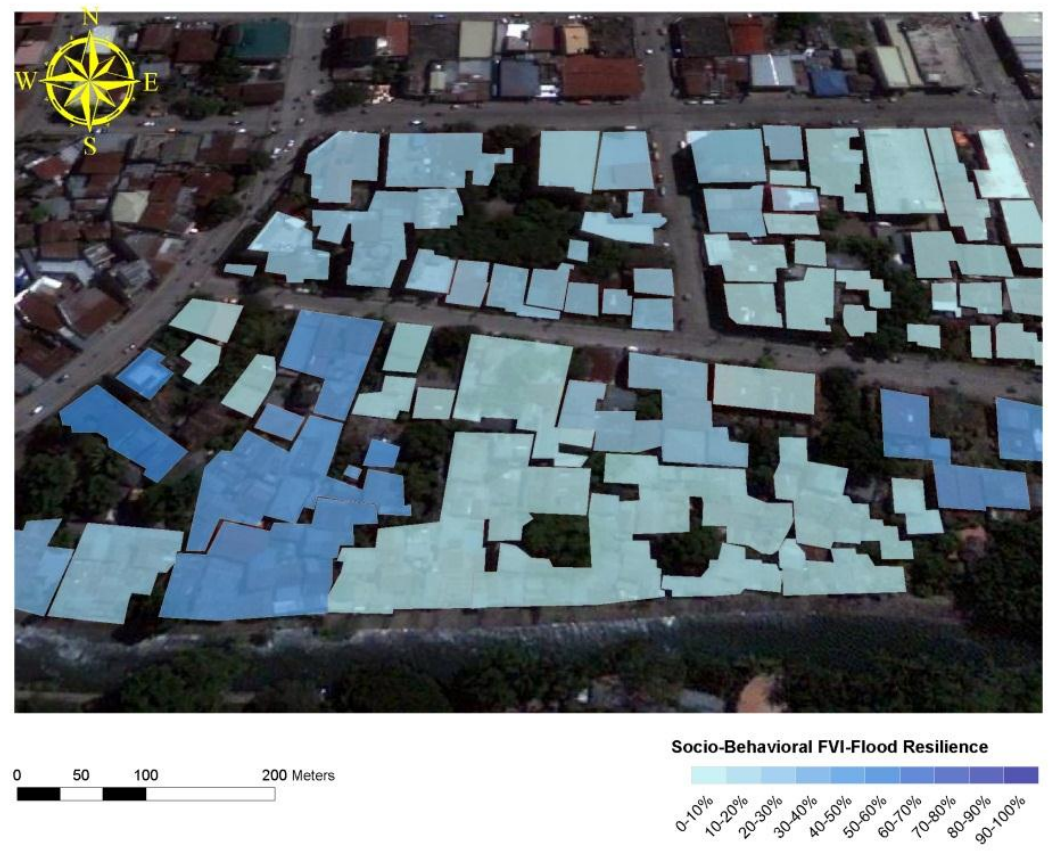

Figure 5-4: Socio-Behavioral Component of Flood Vulnerability Index of Poblacion 2

The socio-behavioral FVI of Poblacion 2 particularly on flood resilience includes the following items: practices of households on flood resilience in terms of its hazards, risks, exposure, preparedness, response, recovery, coordination, and adaptation strategies (exposure indicators); attitude of households in terms of the same items on hazards, risks, exposure, preparedness, response, recovery, coordination, and adaptation strategies (susceptibility indicators); and lastly, the knowledge of the household respondents in terms of the same items on hazards, risks, exposure, preparedness, response, recovery, coordination, and adaptation strategies (resilience indicators) in preparation to any natural calamity to occur particularly on typhoons and flooding before, during and after it happened. It is very important to have a closer and detailed investigation on these items so that strengths and weaknesses can be easily identified and addressed to. 
Community-Based Flood Vulnerability Index for Urban Flooding: Understanding Social Vulnerabilities and Risks

Table 5-16: Socio-Behavioral Component of Flood Vulnerability Index on Flood Resilience of Poblacion 2

\begin{tabular}{|c|c|c|c|}
\hline RANK & ${\text { Longitude }\left({ }^{\circ} \mathrm{E}\right)}$ & Latitude $\left({ }^{\circ} \mathrm{N}\right)$ & Socio-Behavioral FVIfr \\
\hline 1 & 9.30235 & 123.30552 & 42.58 \\
\hline 2 & 9.30207 & 123.30830 & 33.34 \\
\hline 3 & 9.30227 & 123.30591 & 31.02 \\
\hline 4 & 9.30225 & 123.30518 & 24.56 \\
\hline 5 & 9.30206 & 123.30713 & 22.40 \\
\hline 6 & 9.30276 & 123.30651 & 18.42 \\
\hline 7 & 9.30288 & 123.30656 & 18.31 \\
\hline 8 & 9.30214 & 123.30539 & 16.86 \\
\hline 9 & 9.30236 & 123.30687 & 7.68 \\
\hline 10 & 9.30206 & 123.30713 & 5.73 \\
\hline 11 & 9.30215 & 123.30671 & 5.51 \\
\hline 12 & 9.30243 & 123.30566 & 5.37 \\
\hline 13 & 9.30236 & 123.30713 & 4.66 \\
\hline 14 & 9.30243 & 123.30566 & 2.61 \\
\hline 15 & 9.30169 & 123.30669 & 0.00 \\
\hline 16 & 9.30240 & 123.30631 & 0.00 \\
\hline 16 & 9.30218 & 123.30819 & 0.00 \\
\hline 16 & 9.30323 & 123.30870 & \\
\hline
\end{tabular}

Figure 5-4 and Table 5.16 is the Socio-Behavioral FVI for flood resilience of Poblacion 2 (Lukewright). The vulnerability index is from very low to low result values of $0.00 \%$ to $33.34 \%$ respectively (very light shades of blue to lighter shades of blue), with one household registering a medium vulnerability index (42.58\%) shown in a more lighter shade of blue in the map. It is good thing to see that these household respondents are more or less ready for any flooding scenario as its vulnerability index is from low to medium range Their knowledge, attitude and practices towards hazard, risks, exposure, preparedness, response, recovery, coordination, and adapatation strategies are more or less good. The overall score for the knowledge aspect in terms of what to do is very high. However, there is a need to increase the attitude and practice aspect in order to be well coordinated specially during and after the each events so that no the same mistakes will be repeated in the future. Attitude and practices, especially the latter is very significant for that is how the actual response of the households during and after such calamities thus it has to be strengthened. 


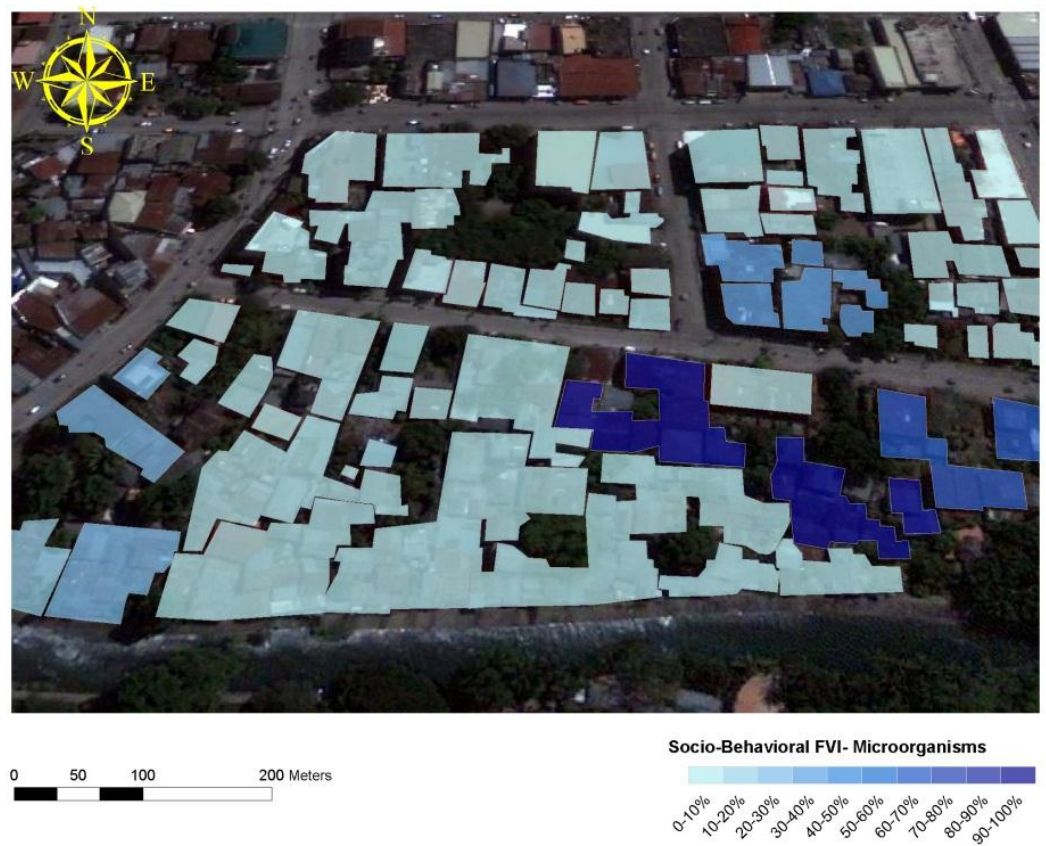

Figure 5-5: Socio-Behavioral on Flood Vulnerability Index on the Exposure of Microorganisms (E.coli, Leptospirosis, and Dengue Fever Mosquito of Pobalcion 2

The socio-behavioral FVI of Poblacion 2 (Lukewright) on the knowledge, attitude and practices of household respondents in predisposing to certain microorganisms such as those of E.coli, Leptospirosis and Dengue fever mosquito which may increase in incidences during and after a flooding or typhoon events. This component includes the following vulnerability indicators: practices in terms of the nature of E.coli, Leptospirosis, and Dengue fever, its mode of transmission, prevention, signs and symptoms, fatality, treatment and the financial cost of treatment (exposure indicators); attitude of households in terms of the same items above (susceptibility indicators); and the knowledge of households in terms of the same items mentioned above (resilience indicators). 
Community-Based Flood Vulnerability Index for Urban Flooding: Understanding Social Vulnerabilities and Risks

Table 5-17: Socio-Behavioral Components on Flood Vulnerability Index on the Exposure of Microorganisms (E.coli, Leptospirosis, Dengue Fever Mosquito) of Poblacion 2

\begin{tabular}{|c|c|c|c|}
\hline RANK & Longitude $\left({ }^{\circ} \mathrm{E}\right)$ & Latitude $\left({ }^{\circ} \mathrm{N}\right)$ & Socio-Behavioral FVImqs \\
\hline 1 & 9.30236 & 123.30687 & 100.00 \\
\hline 2 & 9.30206 & 123.30713 & 99.98 \\
\hline 3 & 9.30207 & 123.30830 & 66.91 \\
\hline 4 & 9.30243 & 123.30566 & 31.04 \\
\hline 5 & 9.30235 & 123.30552 & 25.23 \\
\hline 6 & 9.30214 & 123.30539 & 21.09 \\
\hline 7 & 9.30225 & 123.30518 & 16.08 \\
\hline 8 & 9.30236 & 123.30713 & 8.74 \\
\hline 9 & 9.30288 & 123.30656 & 8.72 \\
\hline 10 & 9.30169 & 123.30669 & 7.34 \\
\hline 11 & 9.30206 & 123.30713 & 5.55 \\
\hline 12 & 9.30276 & 123.30651 & 2.71 \\
\hline 13 & 9.30218 & 123.30819 & 1.75 \\
\hline 14 & 9.30243 & 123.30566 & 1.04 \\
\hline 15 & 9.30227 & 123.30591 & 0.00 \\
\hline 15 & 9.30215 & 123.30671 & 0.00 \\
\hline 15 & 9.30240 & 123.30631 & 0.00 \\
\hline 15 & 9.30323 & 123.30870 & 0.00 \\
\hline
\end{tabular}

Figure 5-5 and Table 5-17 shows the Socio-Behavioral FVI of Poblacion 2 for dealing with the microorganisms that are usually involved during flooding event (E.coli, Leptospirosis and the Dengue Fever mosquitoes). Three (3) of the respondents are showing a high to a very high vulnerability $66.91 \%, 99.98 \%$, and $100.00 \%$ respectively (light to dark shade of blue in the map) in terms of dealing these microorganisms that may predispose the community people. While generally most households indicating very low to low vulnerability. The practice items scored very high in terms of its exposure to these microorganisms but with low susceptibility attitude scores thus owing to generally low vulnerability with only two registering very high vulnerability index, $100 \%, 99.98 \%$ respectively. The knowledge items (resilience) also garnered better scores thus gives a good combination lowering its vulnerability index. But, it must be noted that the practice items are of high vulnerability particularly on the exposure items of indicators. This identified weakness must be given attention proper attention so outbreaks of such kind will be at minimum if not prevented to happen in the future. 


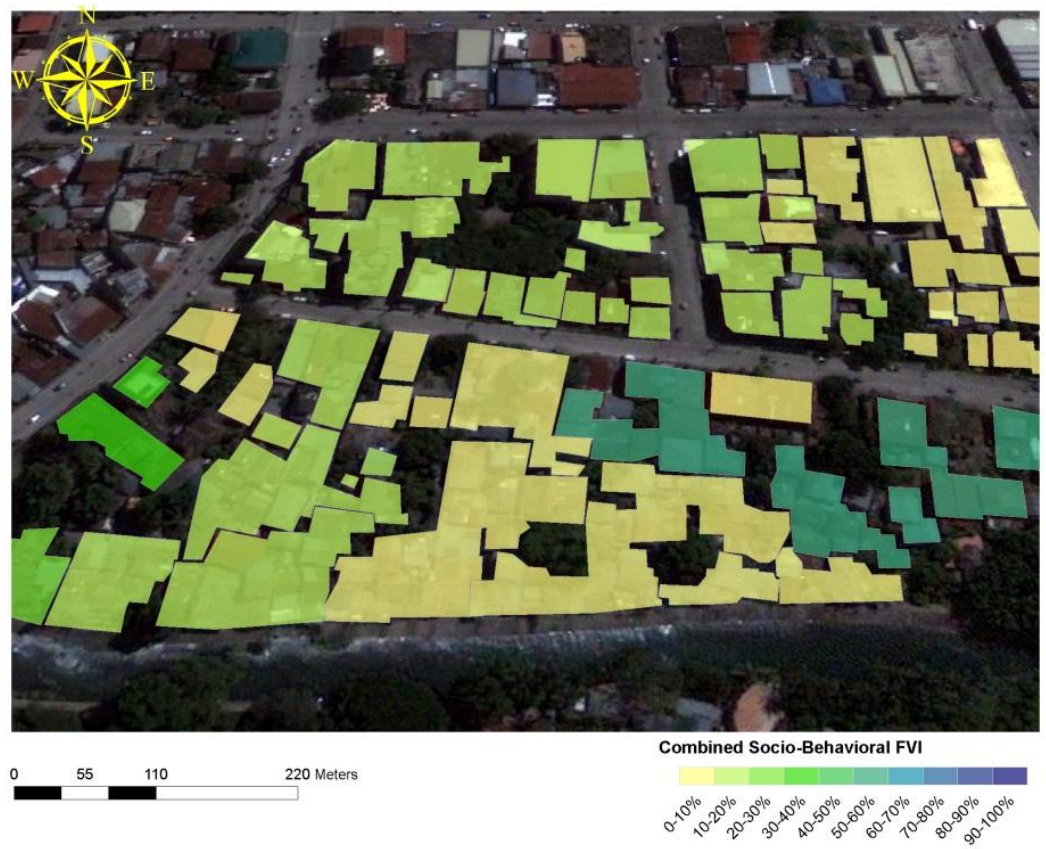

Figure 5-6: Combined Socio-Behavioral Components on Flood Vulnerability Index on Flood Resilience and Microorganisms of Poblacion 2

The combined socio-behavioral FVI of Poblacion 2 includes the following items: practices of households on flood resilience in terms of its hazards, risks, exposure, preparedness, response, recovery, coordination, and adaptation strategies (exposure indicators); attitude of households in terms of the same items mentioned above (susceptibility indicators); and lastly, the knowledge of the household respondents in terms of the same items (resilience indicators) in preparation to any natural calamity to occur particularly on typhoons and flooding before, during and after it happened. Then, the practices in terms of the nature of E.coli, Leptospirosis, and Dengue fever, its mode of transmission, prevention, signs and symptoms, fatality, treatment and the financial cost of treatment (exposure indicators); attitude of households in terms of the same items above (susceptibility indicators); and the knowledge of households in terms of the same items mentioned above (resilience indicators). 
Community-Based Flood Vulnerability Index for Urban Flooding: Understanding Social Vulnerabilities and Risks

Table 5-18: Combined Socio-Behavioral Components on Flood Resilience Index on Flood Resilience and Exposure to Microorganisms of Poblacion 2

\begin{tabular}{|c|c|c|c|}
\hline RANK & Longitude $\left({ }^{\circ} \mathrm{E}\right)$ & Latitude $\left({ }^{\circ} \mathrm{N}\right)$ & Socio-Behavioral FVIc \\
\hline 1 & 9.30236 & 123.30687 & 55.36 \\
\hline 2 & 9.30206 & 123.30713 & 53.83 \\
\hline 3 & 9.30207 & 123.30830 & 50.13 \\
\hline 4 & 9.30235 & 123.30552 & 33.91 \\
\hline 5 & 9.30225 & 123.30518 & 20.32 \\
\hline 6 & 9.30214 & 123.30539 & 18.98 \\
\hline 7 & 9.30243 & 123.30566 & 17.85 \\
\hline 8 & 9.30227 & 123.30591 & 15.51 \\
\hline 9 & 9.30206 & 123.30713 & 13.98 \\
\hline 10 & 9.30288 & 123.30656 & 10.57 \\
\hline 11 & 9.30276 & 123.30651 & 7.06 \\
\hline 12 & 9.30236 & 123.30713 & 4.98 \\
\hline 13 & 9.30169 & 123.30669 & 3.28 \\
\hline 14 & 9.30243 & 123.30566 & 2.87 \\
\hline 15 & 9.30215 & 123.30671 & 0.88 \\
\hline 16 & 9.30218 & 123.30819 & 0.00 \\
\hline 17 & 9.30240 & 123.30631 & 0.00 \\
\hline 17 & 9.30323 & 123.30870 & \\
\hline
\end{tabular}

Figure 5-6 and Table 5.18 shows the combination results of Socio-Behavioral FVI for flood resilience and dealing with the microorganisms associated in flooding in Poblacion 2 (Lukewright). The vulnerability index for this combination of items are ranging from very low to medium $(0.00 \%$ to $33.91 \%)$ shown in pale yellow to light green shade in the map and three with high vulnerability index of $(55.36 \%, 53.83 \%, 50.13 \%)$ shown in greenish blue shade respectively. It is therefore important to keep at low range the vulnerability indicators that would predispose community people in the effects of flooding during and after the event so that serious negative impacts will be prevented and at the same time recovery will be attained in the soonest time as possible before the next calamity beset in which such case is a common scenario in the Philippines or in some other region in the world where this kind of calamities are more common. The same is true to the knowledge, attitude and practices (KAP) of the community people in dealing those microorganisms before, during and after each flooding events. 

Social Vulnerabilities and Risks

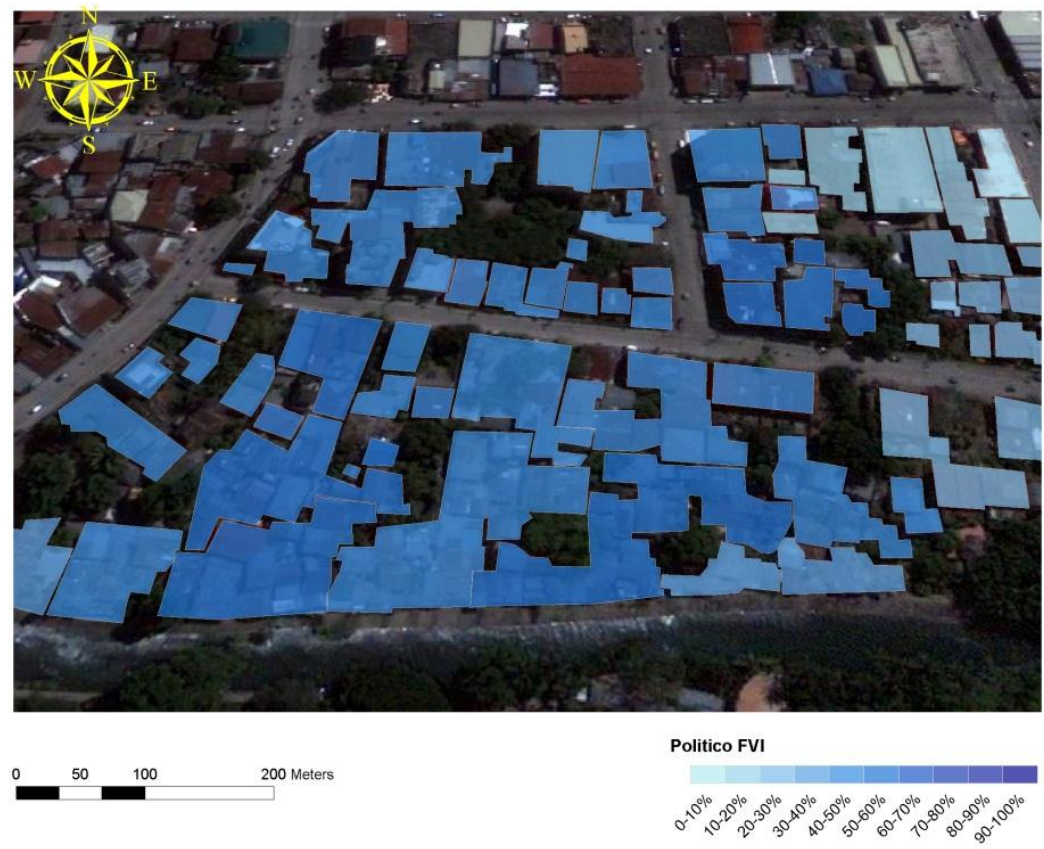

Figure 5-7: Politico-Administrative Components on Flood Vulnerability Index of Poblacion 2

The Politico-administrative FVI of Poblacion 2 (Barangay Lukewright) include the following items: land use and management and structural design, the river's natural resources and natural features management and program (exposure indicator); governance which includes warning and evacuation, emergency response, and disaster recovery (susceptibility indicators); post-risk assessment and integration, sustainable community livelihood program, relocation site project, and the health and prevention program for E.coli, Leptospirosis, and Dengue fever mosquito (resilience indicators). The Local government units (LGU's) proper and maximum facilitation of the different programs of the national government is very important for it will also determines the fate of the community people in terms of how they would response, the available help and resources that they could have during the event, and how fast they could recover from the previous event before the next one comes. 
Community-Based Flood Vulnerability Index for Urban Flooding: Understanding Social Vulnerabilities and Risks

Table 5-19: Politico-Administrative Component on Flood Resilience Index of Poblacion 2

\begin{tabular}{|c|c|c|c|}
\hline RANK & Longitude $\left({ }^{\circ} \mathrm{E}\right)$ & Latitude $\left({ }^{\circ} \mathrm{N}\right)$ & $\begin{array}{c}\text { Politico-Administrative } \\
\mathrm{FVI} \%\end{array}$ \\
\hline 1 & 9.30206 & 123.30713 & 57.76 \\
\hline 2 & 9.30243 & 123.30566 & 51.91 \\
\hline 2 & 9.30215 & 123.30671 & 51.91 \\
\hline 4 & 9.30227 & 123.30591 & 50.21 \\
\hline 5 & 9.30214 & 123.30539 & 47.17 \\
\hline 6 & 9.30206 & 123.30713 & 47.14 \\
\hline 6 & 9.30236 & 123.30687 & 47.14 \\
\hline 6 & 9.30236 & 123.30713 & 47.14 \\
\hline 9 & 9.30276 & 123.30651 & 45.73 \\
\hline 9 & 9.30288 & 123.30656 & 43.73 \\
\hline 11 & 9.30243 & 123.30566 & 43.17 \\
\hline 11 & 9.30240 & 123.30631 & 41.99 \\
\hline 13 & 9.30235 & 123.30552 & 39.81 \\
\hline 14 & 9.30169 & 123.30669 & 39.81 \\
\hline 15 & 9.30225 & 123.30518 & 25.85 \\
\hline 16 & 9.30207 & 123.30830 & 21.53 \\
\hline 17 & 9.30218 & 123.30819 & 15.03 \\
\hline 18 & 9.30323 & 123.30870 & \\
\hline
\end{tabular}

Figure 5-7 and Table 5.19 shows the Politico-Administrative FVI of Poblacion 2. The Politico-Administrative FVI in this community is generally in the medium high $(41.99 \%$ to $57.76 \%$ ) while 4 of the respondents are in the low range and one in the very low range (the different shades of blue from lighter to darker mirrors the degree of vulnerability from low to high as shown in the map) respectively. It is practically consistent within those ranges of vulnerability index. Thus, there is a need to look into consideration of some of the governmental program such as that of the strict and serious implementation of land use and management and structural design; strict observance and serious support to the river's natural resources and natural features and management program. Lastly, the governance itself in terms of the up to date giving of warning and evacuation before a flooding event occurs, and also particularly in facilitating disaster recovery particularly on the availability of techinical services offered and financial resources to support recovery process of the affected households while they are still in the evacuation centers or in the temporary shelters. In addition to that, coordination among those involved were not facilitated properly. This is one of the major weak points in terms of governance that must be addressed seriously. 
Community-Based Flood Vulnerability Index for Urban Flooding: Understanding Social Vulnerabilities and Risks

Table 5-20: Overall Flood Vulnerability Index for Poblacion 2

\begin{tabular}{|c|c|c|c|}
\hline RANK & Longitude $\left({ }^{\circ} \mathrm{E}\right)$ & Latitude $\left({ }^{\circ} \mathrm{N}\right)$ & Overall FVI \\
\hline 1 & 9.30206 & 123.30713 & 49.05 \\
\hline 2 & 9.30206 & 123.30713 & 45.09 \\
\hline 3 & 9.30169 & 123.30669 & 44.48 \\
\hline 4 & 9.30235 & 123.30552 & 43.63 \\
\hline 5 & 9.30243 & 123.30566 & 35.64 \\
\hline 6 & 9.30243 & 123.30566 & 35.45 \\
\hline 7 & 9.30227 & 123.30591 & 33.11 \\
\hline 8 & 9.30225 & 123.30518 & 31.86 \\
\hline 9 & 9.30214 & 123.30539 & 28.82 \\
\hline 10 & 9.30215 & 123.30671 & 28.18 \\
\hline 11 & 9.30236 & 123.30687 & 27.03 \\
\hline 12 & 9.30236 & 123.30687 & 26.95 \\
\hline 13 & 9.30276 & 123.30651 & 22.94 \\
\hline 14 & 9.30288 & 123.30656 & 22.01 \\
\hline 15 & 9.30240 & 123.30631 & 21.22 \\
\hline 16 & 9.30218 & 123.30819 & 17.63 \\
\hline 17 & 9.30207 & 123.30830 & 12.42 \\
\hline 18 & 9.30323 & 123.30870 & \\
\hline
\end{tabular}

Table 5-20 shows the overall rating of Flood Vulnerability Index for Poblacion 2 (Barangay Lukewright) from the 18 households that were surveyed respectively. The lowest vulnerability is $12.42 \%$. While the highest vulnerability index for this community is $49.05 \%$ which falls in the medium range vulnerability. If we look at the results, the disparity in terms of how they percieved and value preparedness and cooperation between households are on the same trend. Yet, there have been some weak points from the different components and indicators that were mentioned and discussed above that needs a practical consideration and must be addressed accordingly in order to lower more the vulnerability index among these households and in that way they will become more resilient and will have that sense of readiness in every natural calamity particularly of typhoons and flooding that may beset the place. 


\subsection{The Total E.coli counts (colony forming units or CFU's) per $100 \mathrm{ml}$ Water Sample during Dry and Wet Season from the Different Stations of the Banica River}

Table 5-21: Total E.coli counts per 100mL for the month of March, 2013

\begin{tabular}{|c|c|}
\hline Sampling Sites & E.coli Counts in 3/20/2013 \\
\hline Upstream & $444 / 100 \mathrm{~mL}$ \\
\hline Midstream 1 & $5667 / 100 \mathrm{~mL}$ \\
\hline Midstream 2 & $4556 / 100 \mathrm{~mL}$ \\
\hline Downstream 1 & $31667 / 100 \mathrm{~mL}$ \\
\hline Downstream 2 & $34222 / 100 \mathrm{~mL}$ \\
\hline Overall Average & $15311 / 100 \mathrm{~mL}$ \\
\hline
\end{tabular}

As shown in table 5-21, downstream 2 (Barangay Calindagan and Tinago) registers the highest total E.coli counts for the month of March, 2013 followed by downstream 1 (Tabuc-tubig Bridge), midstream 1 (Barangay Candau-ay and Cadawinonan Overflow), midstream 2 (Colon Extension Overflow, Barangay Taclobo) and upstream (City Pound Bridge, Barangay Balugo) respectively. It is important to note that midstream 1 has higher counts than midstream 2 which is located much further down the river. The overall average of the E.coli counts per $100 \mathrm{~mL}$ for the month of March is 15,311 cfu's/100 $\mathrm{mL}$. It is also important to note that it rained the night before the sampling day thus it is observed from this table that the E.coli counts were higher compared to other months were it was not raining the night or day before the water sampling schedule.

Table 5-22: Total E.coli counts per 100mL for the month of April, 2013

\begin{tabular}{|c|c|}
\hline Sampling Sites & E.coli Counts in 4/11/2013 \\
\hline Upstream & $2222 / 100 \mathrm{~mL}$ \\
\hline Midstream 1 & $667 / 100 \mathrm{~mL}$ \\
\hline Midstream 2 & $11222 / 100 \mathrm{~mL}$ \\
\hline Downstream 1 & $10000 / 100 \mathrm{~mL}$ \\
\hline Downstream 2 & $21667 / 100 \mathrm{~mL}$ \\
\hline Overall Average & $9156 / 100 \mathrm{~mL}$ \\
\hline
\end{tabular}

For the month of April, downstream 2 (Barangay Calindagan and Tinago) has the highest counts per $100 \mathrm{~mL}$ followed by midstream 2 (Colon Extension Overflow, Barangay Taclobo), downstream 1 (Tabuc-tubig Bridge), upstream (City Pound Bridge, Barangay Balugo), and midstream 1 (Barangay Candau-ay and Cadawinonan Overflow) 

Social Vulnerabilities and Risks

respectively. During this sampling, upstream has significantly higher count (Table 5-22) than midstream 1 which is located further down the river. There was a light rain the night before and that same morning when water sampling was conducted thus again higher counts are observed than those of other months were it did not rain prior to the collection. The rain has probably drained the fecal materials from the nearby surroundings thus showing a high counts during the sampling.

Table 5-23: Total E.coli counts per $100 \mathrm{~mL}$ for the month of May, 2013

\begin{tabular}{|c|c|}
\hline Sampling Sites & E.coli Counts in 5/29/2013 \\
\hline Upstream & $0 / 100 \mathrm{~mL}$ \\
\hline Midstream 1 & $556 / 100 \mathrm{~mL}$ \\
\hline Midstream 2 & $1667 / 100 \mathrm{~mL}$ \\
\hline Downstream 1 & $16556 / 100 \mathrm{~mL}$ \\
\hline Downstream 2 & $10778 / 100 \mathrm{~mL}$ \\
\hline Overall Average & $5911 / 100 \mathrm{~mL}$ \\
\hline
\end{tabular}

The water sampling in May showed that downstream 1 (Tabuc-tubig Bridge) has the highest E.coli counts per $100 \mathrm{~mL}$ followed by downstream 2 (Barangay Calindagan and Tinago), midstream 2 (Colon Extension Overflow, Barangay Taclobo), midstream 1 (Barangay Candau-ay and Cadawinonan Overflow) and upstream (City Pound Bridge, Barangay Balugo) respectively as shown in Table 5-23. The upper and midstream part of the river stay consistent to have lower counts of E.coli in that part of the river. The zero (0) count does not necessarily mean zero bacteria but it simply means that the number of bacteria per $100 \mathrm{~mL}$ is undetectable thus it registered zero or no growth of colonies. As expected, there should be less E.coli in the upper stream portion of the river because there are few houses located immediately after the river banks and the water also appears very clear and clean although presence of animals were observed but no open drainage that is directly dispose into the river system. This part of the river looks pristine compared to those areas in the lower portion of the Banica River.

Table 5-24: Total E.coli counts per 100mL for the month of June, 2013

\begin{tabular}{|c|c|}
\hline Sampling Sites & E.coli Counts in 6/25/2013 \\
\hline Upstream & $0 / 100 \mathrm{~mL}$ \\
\hline Midstream 1 & $111 / 100 \mathrm{~mL}$ \\
\hline Midstream 2 & $111 / 100 \mathrm{~mL}$ \\
\hline Downstream 1 & $16556 / 100 \mathrm{~mL}$ \\
\hline Downstream 2 & $12889 / 100 \mathrm{~mL}$ \\
\hline Overall Average & $5933 / 100 \mathrm{~mL}$ \\
\hline
\end{tabular}



Social Vulnerabilities and Risks

For the month of June, the E.coli counts from upstream (City Pound Bridge, Barangay Balugo) down to midstream 1 (Barangay Candau-ay and Cadawinonan Overflow) and midstream 2 (Colon Extension Overflow, Barangay Taclobo) were considerably low per $100 \mathrm{~mL}$ water sample. The downstream areas such as downstream 1 (Tabuc-tubig Bridge) and downstream 2 (Barangay Calindagan and Tinago) remained consistent with its higher counts respectively as shown in Table 5.24.

Table 5-25: Total E.coli counts per $100 \mathrm{~mL}$ for the month of July, 2013

\begin{tabular}{|c|c|}
\hline Sampling Sites & E.coli Counts in 7/17/2013 \\
\hline Upstream & $0 / 100 \mathrm{~mL}$ \\
\hline Midstream 1 & $556 / 100 \mathrm{~mL}$ \\
\hline Midstream 2 & $3111 / 100 \mathrm{~mL}$ \\
\hline Downstream 1 & $6333 / 100 \mathrm{~mL}$ \\
\hline Downstream 2 & $444 / 100 \mathrm{~mL}$ \\
\hline Overall Average & $2089 / 100 \mathrm{~mL}$ \\
\hline
\end{tabular}

The month of July has the lowest E.coli counts among all the 5 consecutive months of water sampling. Though, it is still considerably high when compared to the acceptable value of at-risk concentration levels at a one-time concentration or sampling which is 235 CFU's or E.coli colonies/ $100 \mathrm{~mL}$ set by the Environmental Protection Agency (Environmental Protection Agency or EPA, 2012). Downstream 1 (Tabuc-tubig Bridge) showed the highest counts followed by midstream 2 (Colon Extension Overflow, Barangay Taclobo). Upstream has zero (0) counts which simply means the number of E.coli is undetectable at this particular volume and concentration. The overall average total count is $2089 / 100 \mathrm{~mL}$ (Table 5.25 ).

\subsection{The Overall Average E.coli counts per 100ml Water Sample during Dry and Wet Season from the Different Stations of the Banica River}

Table 5-26: The Overall Average E.coli counts per 100mL during dry and wet season for Upstream (Station 1)

\begin{tabular}{|c|c|}
\hline Sampling Period & E.coli Counts in Upstream \\
\hline $20-$ Mar-13 & $444 / 100 \mathrm{~mL}$ \\
\hline $11-$ Apr-13 & $2222 / 100 \mathrm{~mL}$ \\
\hline $29-$ May-13 & $0 / 100 \mathrm{~mL}$ \\
\hline $25-J u n-13$ & $0 / 100 \mathrm{~mL}$ \\
\hline $17-J u l-13$ & $0 / 100 \mathrm{~mL}$ \\
\hline Overall Average & $533 / 100 \mathrm{~mL}$ \\
\hline
\end{tabular}



Social Vulnerabilities and Risks

For upstream 1 (City Pound Bridge, Barangay Balugo), it registered the highest counts $(2222 / 100 \mathrm{~mL})$ for the month of April and followed by the month of March and the rest of the three remaining months (May, June, July) were all zero (0) counts but this doesn't mean that there were no E.coli in the water but it simply implies that the numbers were too small to be detected at this particular dilution and volume. The average of E.coli counts in this station is 533cfu's $/ 100 \mathrm{~mL}$ (Table 5-26) above the standard counts for safe recreational water which is 235 cfu's set by the Environmental Protection Agency (EPA). The upstream station is with few houses along the river and no open drainage that is connected to the river. Presence of animals were observed though nearby. The water in station 1 is much clearer and cleaner by visual inspection compared to other sites.

Table 5-27: The Overall Average E.coli count per 100mL during dry and wet season for Midstream 1 (Station 2)

\begin{tabular}{|c|c|}
\hline Sampling Period & E.coli Counts in Midstream 1 \\
\hline 20-Mar-13 & $5667 / 100 \mathrm{~mL}$ \\
\hline 11-Apr-13 & $667 / 100 \mathrm{~mL}$ \\
\hline 29-May-13 & $556 / 100 \mathrm{~mL}$ \\
\hline 25-Jun-13 & $111 / 100 \mathrm{~mL}$ \\
\hline 17-Jul-13 & $556 / 100 \mathrm{~mL}$ \\
\hline Overall Average & $1511 / 100 \mathrm{~mL}$ \\
\hline
\end{tabular}

The month of March registered the highest counts of E.coli (5667 cfu's/100 mL) for midstream 1 (Barangay Candau-ay and Cadawinonan Overflow) followed by the months of April, May, July and June respectively. The average count for the entire 5 months of sampling is $1511 \mathrm{cfu}$ 's $/ 100 \mathrm{~mL}$ which is way higher than the set values for recreational waters which is $235 \mathrm{cfu}$ 's $/ 100 \mathrm{~mL}$. The E.coli count for the month of June (111 cfu's/100 $\mathrm{mL}$ ) (Table 5-27) is lower than the $235 \mathrm{cfu}$ 's $/ 100 \mathrm{~mL}$ set by EPA. This station is lined with houses along the river banks and domesticated and farm animals were observed in the vicinity. In addition, this area is less than a kilometer from the dumping site of Dumaguete City located along the river bank where all sorts of rubbish are dumped. Possible seepage and contamination may have been introduced into the river contributing to its high counts. 
Community-Based Flood Vulnerability Index for Urban Flooding: Understanding Social Vulnerabilities and Risks

Table 5-28: The Overall Average E.coli counts per 100mL during dry and wet season for Midstream 2 (Station 5)

\begin{tabular}{|c|c|}
\hline Sampling Period & E.coli Counts in Midstream 2 \\
\hline 20 -Mar-13 & $4556 / 100 \mathrm{~mL}$ \\
\hline 11 -Apr-13 & $11222 / 100 \mathrm{~mL}$ \\
\hline $29-$ May-13 & $1667 / 100 \mathrm{~mL}$ \\
\hline $25-J u n-13$ & $1667 / 100 \mathrm{~mL}$ \\
\hline 17-Jul-13 & $3111 / 100 \mathrm{~mL}$ \\
\hline Overall Average & $4445 / 100 \mathrm{~mL}$ \\
\hline
\end{tabular}

For station 3 or midstream 2 (Colon Extension Overflow, Barangay Taclobo) the highest counts $(11,222$ cfu's $/ 100 \mathrm{~mL})$ was in the month of April followed by March, July, May and June respectively. The average count for the entire 5 months of sampling is 4445 cfu's $/ 100 \mathrm{~mL}$ (Table 5-28) which is generally high than the set standard of $235 \mathrm{cfu}$ 's/100 $\mathrm{mL}$ by the EPA. Station 3 covers 2 big communities namely Barangay Batinguel and Barangay Taclobo with several houses located along the river banks, open drainage system were observed and end up into the Banica River. The water looks murky, dirty and polluted visually compared to stations 2 and 1 .

Table 5-29: The Overall Average E.coli counts per 100mL during dry and wet season for Downstream 1 (Station 7)

\begin{tabular}{|c|c|}
\hline Sampling Period & E.coli Counts in Downstream 1 \\
\hline $20-M a r-13$ & $31667 / 100 \mathrm{~mL}$ \\
\hline $11-A p r-13$ & $10000 / 100 \mathrm{~mL}$ \\
\hline 29-May-13 & $16556 / 100 \mathrm{~mL}$ \\
\hline 25-Jun-13 & $111 / 100 \mathrm{~mL}$ \\
\hline 17-Jul-13 & $6333 / 100 \mathrm{~mL}$ \\
\hline Overall Average & $12933 / 100 \mathrm{~mL}$ \\
\hline
\end{tabular}

Downstream 1 (Tabuc-tubig Bridge) or station 4 is second in terms of highest and average counts of E.coli among all the stations sampled. The highest count is 31667 cfu's $/ 100 \mathrm{~mL}$ in the month of March followed by the month of May (16556 cfu's/100mL), April (10000 cfu's/100 mL), July (6333/100 mL) and June (111cfu's/100 mL) respectively. The month of June in this station also registered a lower count of 111 cfu's/100 mL (Table 5-29) which is lower than the standard set by EPA (235 cfu's/ mL). The average count for the entire 5 months of sampling is very high $(12,933$ cfu's/100 $\mathrm{mL}$ ). Downstream 1 has also several houses along the river banks and open drainage system that drains into the river is highly observed. Domesticated animals were also 

Social Vulnerabilities and Risks

observed in the vicinity. The water in the river is also much dirtier, muddy and polluted as compared to the three upper stations (upstream, midstream 1 and 2) respectively.

Table 5-30: The Overall Average counts per 100mL during dry and wet season for Downstream 2 (Station 8)

\begin{tabular}{|c|c|}
\hline Sampling Period & E.coli Counts in Downstream 2 \\
\hline 20-Mar-13 & $34222 / 100 \mathrm{~mL}$ \\
\hline 11-Apr-13 & $21667 / 100 \mathrm{~mL}$ \\
\hline 29-May-13 & $10778 / 100 \mathrm{~mL}$ \\
\hline 25-Jun-13 & $12889 / 100 \mathrm{~mL}$ \\
\hline 17-Jul-13 & $444 / 100 \mathrm{~mL}$ \\
\hline Overall Average & $16000 / 100 \mathrm{~mL}$ \\
\hline
\end{tabular}

Downstream 2 (Barangay Calindagan and Tinago) or station 5 has the highest E.coli counts (34222 cfu's/100 mL) among all the 5 stations sampled. It also has the highest average counts for the 5 consecutive months sampling period $(16,000 \mathrm{cfu}$ 's $/ 100 \mathrm{~mL})$. The month of March registered the highest counts followed by the month of April, June, May, and July respectively (Table 5.30). The counts are incredibly high compared to the acceptable safe counts set by EPA which is 235 cfu's $/ 100 \mathrm{~mL}$ water sample. It was observed that along downstream 2 there were several houses located along the river banks and with many open drainage system drained into the river. Domesticated animals were also observed in the area. The water is much more polluted, muddy and murky, from all the rest of the sampling sites. Furthermore, stagnation in some areas due to rubbish and accumulation of sediments in some areas of the river were observed. In addition, during high tide phenomenon, a reverse flow stagnate the outgoing flow from the river which may accumulate the floating bacteria such as E.coli and other pollutants before it is released into the sea. Thus, this could be the possible explanation why downstream 2 had the highest E.coli counts from the rest of the sampling area. 

Social Vulnerabilities and Risks

\subsection{Assessment on Flood Resilience Adaptation Strategies in Dumaguete City Solicited from the Household Respondents of the 12 Communities}

This research work has made some assessment on the flood resilience adaptation strategies implemented in Dumaguete City, Negros Oriental. There are 20 questions given to the 357 household respondents from the 12 communities surveyed that relates on resilience adaptation strategy of the city. Table 5-31 to table 5-50 are the results of their responses to each of the items.

Table 5-31: Implementation and monitoring of the policies, plans and programs for the different natural calamities particularly typhoons and flooding events

\begin{tabular}{|l|r|}
\hline COMMUNITY & $\%$ \\
\hline Tabuc-tubig & 88.00 \\
\hline Batinguel & 76.30 \\
\hline Poblacion 2 & 76.24 \\
\hline Poblacion 1 & 75.44 \\
\hline Bagacay & 75.32 \\
\hline Calindagan & 72.94 \\
\hline Cadawinonan & 72.80 \\
\hline Taclobo & 71.74 \\
\hline Balugo & 73.00 \\
\hline Candau-ay & 70.82 \\
\hline Junob & 70.00 \\
\hline Poblacion 8 & 68.96 \\
\hline Overall Average & 74.30 \\
\hline
\end{tabular}

In terms of implementation and monitoring of the policies, plans, and programs particularly on typhoon and flooding, Barangay Tabuc-tubig gave the highest score $(88.00 \%)$ indicating that it is well implemented and monitored. On the other hand, Poblacion 8 gave the lowest score (68.96\%) among the 12 communities though it is still a favorable score. The overall average score given for this item is $74.30 \%$ which is favorably high (Table 5-31). 
Community-Based Flood Vulnerability Index for Urban Flooding: Understanding Social Vulnerabilities and Risks

Table 5-32: Transparency and trustworthiness of the LGU's in terms of the facilitation and distribution of the budget and donations for the affected population in the community during calamity

\begin{tabular}{|l|r|}
\hline COMMUNITY & $\%$ \\
\hline Tabuc-tubig & 92.00 \\
\hline Poblacion 1 & 69.08 \\
\hline Cadawinonan & 68.80 \\
\hline Taclobo & 66.60 \\
\hline Junob & 62.50 \\
\hline Poblacion 8 & 62.06 \\
\hline Bagacay & 62.00 \\
\hline Candau-ay & 60.56 \\
\hline Batinguel & 60.52 \\
\hline Calindagan & 60.00 \\
\hline Poblacion 2 & 57.60 \\
\hline Balugo & 52.94 \\
\hline Overall Average & 64.56 \\
\hline
\end{tabular}

The transparency and trustworthiness of the LGU's in terms of the facilitation and distribution of the budget and donations for the affected population in the community during calamity scored generally high (Table 5-32) with Barangay Tabuc-tubig indicating $92.00 \%$ on its assessment while Barangay Balugo scored $52.94 \%$ for this item. The overall average score is $64.56 \%$ which indicates a good score though generally most of the communities the scoring is from $52.00 \%$ to $69.00 \%$ respectively.

Table 5-33: Livelihood and financial aid for the community people to help them recover again from such calamity

\begin{tabular}{|l|r|}
\hline COMMUNITY & $\%$ \\
\hline Tabuc-tubig & 76.00 \\
\hline Poblacion 1 & 69.08 \\
\hline Poblacion 8 & 65.50 \\
\hline Bagacay & 64.00 \\
\hline Cadawinonan & 62.50 \\
\hline Taclobo & 61.58 \\
\hline Junob & 61.24 \\
\hline Candau-ay & 60.82 \\
\hline Batinguel & 59.46 \\
\hline Calindagan & 58.26 \\
\hline Poblacion 2 & 56.24 \\
\hline Balugo & 46.24 \\
\hline Overall Average & 61.74 \\
\hline
\end{tabular}



Social Vulnerabilities and Risks

For the livelihood and financial support for the affected communities, the score is generally lower than the previous items with Barangay Balugo giving $46.24 \%$ on its assessment which is below $50.00 \%$. While Barangay Tabuc-tubig gave $76.00 \%$ respectively. The range of the scoring is within $46.00 \%$ to $76.00 \%$ (Table 5-33). If we look at the transparency and trustworthiness score in Table 5.32, the scoring range is more or less within the same bracket.

Table 5-34: Programmes and policies in saving and protecting the Banica River

\begin{tabular}{|l|r|}
\hline COMMUNITY & $\%$ \\
\hline Tabuc-tubig & 74.20 \\
\hline Poblacion 1 & 70.90 \\
\hline Batinguel & 70.52 \\
\hline Cadawinonan & 70.00 \\
\hline Poblacion 8 & 69.28 \\
\hline Bagacay & 67.34 \\
\hline Taclobo & 65.80 \\
\hline Calindagan & 64.54 \\
\hline Candau-ay & 63.04 \\
\hline Junob & 61.24 \\
\hline Poblacion 2 & 60.00 \\
\hline Balugo & 48.22 \\
\hline Overall Average & 65.42 \\
\hline
\end{tabular}

Generally, the scores for the programs and policies in saving and protecting the Banica River are high. With Barangay Balugo giving the lowest assessment (48.22\%) and Barangay Tabuc-tubig giving the highest assessment score (74.20\%). In spite that this item receives a favorable score among the 12 communities, it was sad to observe that programs and policies in saving and protecting the Banica River is not well implemented and well respected by the community people (Table 5.34). The open drainage system that ends up in the river, the throwing of garbage into the river, and some illegal activities along the river such as small scale quarrying is visible. 
Community-Based Flood Vulnerability Index for Urban Flooding: Understanding Social Vulnerabilities and Risks

Table 5-35: Cooperation of the community people including you (household respondents) in protecting the Banica River

\begin{tabular}{|l|r|}
\hline COMMUNITY & \% \\
\hline Tabuc-tubig & 86.00 \\
\hline Batinguel & 75.78 \\
\hline Poblacion 1 & 75.22 \\
\hline Cadawinonan & 72.80 \\
\hline Calindagan & 71.30 \\
\hline Taclobo & 71.10 \\
\hline Poblacion 8 & 70.34 \\
\hline Candau-ay & 70.26 \\
\hline Junob & 70.00 \\
\hline Poblacion 2 & 68.74 \\
\hline Bagacay & 68.66 \\
\hline Balugo & 67.04 \\
\hline Overall Average & 72.27 \\
\hline
\end{tabular}

The cooperation of the community people in protecting the river is generally high. Barangay Tabuc-tubig is again topping the list and Barangay Balugo also consistently on the bottom list giving low scores among the 12 communities though in this item, $67.04 \%$ is considerably high (Table $5-35$ ). Unfortunately, that cooperation is not very visible in some areas though in some communities, others are trying their best to keep the river clean by cleaning and removing stagnated garbage. The researcher has personally witnessed such activity in Poblacion 8.

Table 5-36: On the drainage systems

\begin{tabular}{|l|r|}
\hline COMMUNITY & $\%$ \\
\hline Poblacion 1 & 70.90 \\
\hline Poblacion 8 & 65.52 \\
\hline Bagacay & 65.72 \\
\hline Calindagan & 65.22 \\
\hline Cadawinonan & 64.80 \\
\hline Tabuc-tubig & 64.00 \\
\hline Poblacion 2 & 63.76 \\
\hline Taclobo & 63.48 \\
\hline Candau-ay & 62.64 \\
\hline Batinguel & 62.62 \\
\hline Balugo & 51.76 \\
\hline Junob & 48.76 \\
\hline Overall Average & 62.43 \\
\hline
\end{tabular}



Social Vulnerabilities and Risks

The assessment of the drainage system along the river banks varies from $48.76 \%$ to $70.90 \%$. Barangay Junob gave the lowest assessment score $(48.76 \%)$ while Poblacion 1 gave the highest assessment score (Table 5-36). It is surprising to note that those communities near the city center and downstream find it favorable to have that kind of open drainage system that ends in the river. Most communities located in the mid and upstream of the river are more conscious about this open drainage system except for Barangay Cadawinonan which happens to give a positive score of $64.80 \%$ on this item. Ocular visits proved the upstream to be much cleaner and much preserved than those in the downstream part of the Banica River.

Table 5-37: On the dike systems

\begin{tabular}{|l|r|}
\hline COMMUNITY & $\%$ \\
\hline Poblacion 1 & 74.54 \\
\hline Bagacay & 71.34 \\
\hline Cadawinonan & 70.40 \\
\hline Batinguel & 68.42 \\
\hline Calindagan & 68.18 \\
\hline Poblacion 8 & 66.42 \\
\hline Poblacion 2 & 65.00 \\
\hline Balugo & 64.70 \\
\hline Junob & 63.76 \\
\hline Taclobo & 63.18 \\
\hline Candau-ay & 62.22 \\
\hline Tabuc-tubig & 62.00 \\
\hline Overall Average & 66.68 \\
\hline
\end{tabular}

The flood barrier system (dike system) of Dumaguete City is protecting some areas and communities in the city but not the whole stretch of the river is built with these flood barriers. There are open spaces with exposed households who are basically living in the flood plains. In some areas the dike system is well maintained and is still functioning though the city government is trying to make this as a priority by putting up and filling up a dike system in those open spaces where there's exposed population. Generally the assessment score for the dike system of the city is favorable $(62.00 \%$ to $74.54 \%)$ respectively with an overall average score of $66.68 \%$ (Table $5-37$ ). 
Community-Based Flood Vulnerability Index for Urban Flooding: Understanding Social Vulnerabilities and Risks

Table 5-38: On the bridge system

\begin{tabular}{|l|r|}
\hline COMMUNITY & $\%$ \\
\hline Tabuc-tubig & 84.00 \\
\hline Poblacion 1 & 80.90 \\
\hline Poblacion 8 & 72.14 \\
\hline Cadawinonan & 70.40 \\
\hline Bagacay & 70.00 \\
\hline Calindagan & 69.56 \\
\hline Poblacion 2 & 67.50 \\
\hline Batinguel & 66.84 \\
\hline Junob & 66.26 \\
\hline Taclobo & 63.18 \\
\hline Candau-ay & 61.94 \\
\hline Balugo & 61.34 \\
\hline Overall Average & 69.51 \\
\hline
\end{tabular}

There are three good and high bridge system in the city and are shared with the following Barangays; Poblacion 1, Calindagan, Poblacion 2, Tabuc-tubig, and Poblacion 8. The rest are overflow-bridges seen among the rest of the communities. It is built in a very low height and causes blockage during flooding events or rainy season. Basically, the assessment score is very high ranging from $61.34 \%$ to $84.00 \%$ respectively, with an overall average score of $69.51 \%$ (Table $5-38$ ).

Table 5-39: On the community flood hazard maps

\begin{tabular}{|l|r|}
\hline COMMUNITY & $\%$ \\
\hline Poblacion 1 & 71.42 \\
\hline Tabuc-tubig & 71.00 \\
\hline Cadawinonan & 70.40 \\
\hline Poblacion 8 & 69.68 \\
\hline Calindagan & 66.94 \\
\hline Balugo & 65.10 \\
\hline Poblacion 2 & 65.00 \\
\hline Bagacay & 64.82 \\
\hline Taclobo & 61.62 \\
\hline Junob & 60.00 \\
\hline Batinguel & 60.00 \\
\hline Candau-ay & 57.46 \\
\hline Overall Average & 65.29 \\
\hline
\end{tabular}

Barangay Candau-ay was the pilot community for the flood drill activity preparedness conducted last June, 2013. But, surprisingly the community people seemed to be not so 
aware about their community flood map with only $57.46 \%$ assessment score (Table 539). The researcher has seen and has procured the said flood map. There is a need of proper dissemination of information to the entire community so that community people will be more aware and will be more prepared.

Table 5-40: The use of backhoe in cleaning the Banica River especially when normal flow is blocked

\begin{tabular}{|l|r|}
\hline COMMUNITY & $\%$ \\
\hline Tabuc-tubig & 78.00 \\
\hline Bagacay & 64.42 \\
\hline Poblacion 8 & 63.44 \\
\hline Cadawinonan & 63.20 \\
\hline Calindagan & 61.72 \\
\hline Poblacion 1 & 60.90 \\
\hline Taclobo & 59.68 \\
\hline Candau-ay & 58.88 \\
\hline Balugo & 58.82 \\
\hline Junob & 57.50 \\
\hline Batinguel & 54.22 \\
\hline Poblacion 2 & 52.50 \\
\hline Overall Average & 61.11 \\
\hline
\end{tabular}

With regards to the use of backhoe in cleaning the Banica river when the normal flow is blocked, the assessment score is favorably high ranging from $52.50 \%$ to $78.00 \%$ and an overall average score of $61.11 \%$ respectively (Table $5-40$ ). The city government is quite quick enough to clean up the river after every flooding episode to facilitate normal flow before the next flooding event besets.

Table 5-41: Distribution of donations, goods and relief

\begin{tabular}{|l|r|}
\hline COMMUNITY & $\%$ \\
\hline Tabuc-tubig & 88.00 \\
\hline Cadawinonan & 68.80 \\
\hline Poblacion 8 & 68.28 \\
\hline Poblacion 1 & 68.20 \\
\hline Junob & 65.00 \\
\hline Taclobo & 64.76 \\
\hline Bagacay & 63.34 \\
\hline Candau-ay & 62.22 \\
\hline Poblacion 2 & 60.00 \\
\hline Batinguel & 57.90 \\
\hline Balugo & 56.26 \\
\hline Calindagan & 55.66 \\
\hline Overall Average & 64.87 \\
\hline
\end{tabular}



Social Vulnerabilities and Risks

This item has also received a good and positive score assessment ranging from $55.66 \%$ to $88.00 \%$ and with an overall average score of $64.87 \%$ respectively. However, during the survey the researcher has received some negative claims and comments from the household respondents of Barangay Batinguel and Poblacion 2 claiming that the distribution of donations, goods and relief were not fairly and appropriately distributed. There were those who were badly affected (for example, houses that were completely damaged and wash away) that did not received a fair share while those that were only partially affected have received more than what they are supposed to received. Those household respondents have all pointed out political reasons as the main culprit for such uneven distribution of aid.

Table 5-42: Distribution of brochures and the information drive that would increase knowledge on the negative impacts from typhoon and flooding events for the purposes of prevention and recovery

\begin{tabular}{|l|r|}
\hline COMMUNITY & $\%$ \\
\hline Tabuc-tubig & 82.00 \\
\hline Poblacion 8 & 73.10 \\
\hline Poblacion 1 & 70.00 \\
\hline Cadawinonan & 70.00 \\
\hline Calindagan & 68.70 \\
\hline Taclobo & 68.26 \\
\hline Junob & 67.50 \\
\hline Bagacay & 67.34 \\
\hline Candau-ay & 66.46 \\
\hline Batinguel & 65.26 \\
\hline Balugo & 64.70 \\
\hline Poblacion 2 & 60.00 \\
\hline Overall Average & 68.61 \\
\hline
\end{tabular}

It seems that the distribution of brochures and the information drive that would increase knowledge on the negative impacts from typhoon and flooding events for the purposes of prevention and recovery is well disseminated among the 12 communities surveyed. The assessment scores were high ranging from $60.00 \%$ to $82.00 \%$ and with an overall average score of $68.61 \%$ respectively (Table 5-42). Again, in some aspects of information drive such as that of community flood maps, it has to be made tangible to the community people so that they will have a thorough understanding of the preparedness and resilience strategies conducted by the city and barangay government units. 
Community-Based Flood Vulnerability Index for Urban Flooding: Understanding Social Vulnerabilities and Risks

Table 5-43: On the flood warning systems

\begin{tabular}{|l|r|}
\hline COMMUNITY & $\%$ \\
\hline Tabuc-tubig & 82.20 \\
\hline Cadawinonan & 75.84 \\
\hline Poblacion 8 & 73.10 \\
\hline Poblacion 1 & 70.90 \\
\hline Balugo & 70.60 \\
\hline Calindagan & 70.44 \\
\hline Poblacion 2 & 68.76 \\
\hline Taclobo & 65.40 \\
\hline Candau-ay & 65.00 \\
\hline Junob & 65.00 \\
\hline Bagacay & 64.66 \\
\hline Batinguel & 64.32 \\
\hline Overall Average & 69.69 \\
\hline
\end{tabular}

At the moment, there is no concrete presence of a flood warning device that is put up nearby to these 12 communities. Word of mouth, traditional warning noises and mobile connection among community officials served as warning systems. Some painted water level signals are written on the walls of the dike system in some areas like those found in Barangay Candau-ay, Balugo, and Cadawinonan that gives hint for the community people for emergency evacuation. Unfortunately, not all communities are as equipped and as well coordinated. The assessment score on this item (Table 5-43) is very favorable $(69.69 \%)$.

Table 5-44: Preparedness and flood drill activity in the community to increase resilience from typhoons and floods

\begin{tabular}{|l|r|}
\hline COMMUNITY & $\%$ \\
\hline Tabuc-tubig & 84.00 \\
\hline Cadawinonan & 70.84 \\
\hline Poblacion 8 & 68.28 \\
\hline Poblacion 1 & 67.62 \\
\hline Calindagan & 66.08 \\
\hline Bagacay & 66.00 \\
\hline Poblacion 2 & 65.00 \\
\hline Junob & 64.00 \\
\hline Taclobo & 63.22 \\
\hline Candau-ay & 63.88 \\
\hline Batinguel & 58.94 \\
\hline Balugo & 58.82 \\
\hline Overall Average & 66.39 \\
\hline
\end{tabular}



Social Vulnerabilities and Risks

The assessment score on the preparedness and flood drill activity in the community to increase resilience from typhoons and floods is also very favorable except to a few communities like Barangay Batinguel and Balugo (58.94\% and 58.82\%) respectively (Table 5-44). After this survey was conducted, Barangay Candau-ay along with Barangay Balugo a major flood preparedness drill was initiated by the local government and the barangay officials last June 2013.

Table 5-45: Response and preparedness of the DRRMC, PDRRMC, and other NGO volunteers during rescue events

\begin{tabular}{|l|r|}
\hline COMMUNITY & $\%$ \\
\hline Bagacay & 84.28 \\
\hline Balugo & 81.18 \\
\hline Poblacion 8 & 80.72 \\
\hline Tabuc-tubig & 80.00 \\
\hline Calindagan & 77.40 \\
\hline Candau-ay & 77.22 \\
\hline Poblacion 2 & 77.14 \\
\hline Taclobo & 75.86 \\
\hline Cadawinonan & 75.66 \\
\hline Junob & 75.00 \\
\hline Batinguel & 74.22 \\
\hline Poblacion 1 & 72.40 \\
\hline Overall Average & 77.59 \\
\hline
\end{tabular}

This particular item on the response and preparedness of the DRRMC, PDRRMC and other NGO volunteers during rescue events garnered a very high scores indicating that these rescue groups are doing well in their rescue efforts. The scores were all generally high from all the 12 communities surveyed ranging from $72.40 \%$ to $84.28 \%$ and with an overall average of $77.59 \%$ respectively (Table $5-45$ ). 

Social Vulnerabilities and Risks

Table 5-46: The basic emergency and relief services such as food, water, sanitation, transportation, communication, medical help, provisional repairs of damaged properties

\begin{tabular}{|l|r|}
\hline COMMUNITY & $\%$ \\
\hline Tabuc-tubig & 82.00 \\
\hline Poblacion 8 & 79.32 \\
\hline Balugo & 77.64 \\
\hline Cadawinonan & 76.80 \\
\hline Bagacay & 75.34 \\
\hline Candau-ay & 75.00 \\
\hline Poblacion 1 & 73.64 \\
\hline Taclobo & 72.70 \\
\hline Poblacion 2 & 72.00 \\
\hline Calindagan & 71.30 \\
\hline Batinguel & 69.48 \\
\hline Junob & 61.26 \\
\hline Overall Average & 73.87 \\
\hline
\end{tabular}

The basic emergency and relief services such as food, water, sanitation, transportation, communication, medical help, provisional repairs of damaged properties were also been well distributed during emergency and post-calamity situations. The assessment scores were favorably high from $61.26 \%$ to $82.00 \%$ and with an overall average score of $73.87 \%$ respectively (Table $5-46$ ).

Table 5-47: Operation clean-up affected places, giving of insurances, claims, financial aids, traumatic and psychological stress debriefings

\begin{tabular}{|l|r|}
\hline COMMUNITY & $\%$ \\
\hline Tabuc-tubig & 90.00 \\
\hline Poblacion 8 & 73.80 \\
\hline Poblacion 1 & 72.72 \\
\hline Cadawinonan & 72.00 \\
\hline Candau-ay & 69.72 \\
\hline Taclobo & 68.58 \\
\hline Bagacay & 66.66 \\
\hline Junob & 65.00 \\
\hline Balugo & 64.70 \\
\hline Poblacion 2 & 63.76 \\
\hline Batinguel & 63.16 \\
\hline Calindagan & 62.60 \\
\hline Overall Average & 69.39 \\
\hline
\end{tabular}

Although these items have received a favorable high scores (Table 5-47) ranging from $62.60 \%$ to $90.00 \%$ respectively yet there are some household respondents who claimed 

Social Vulnerabilities and Risks

that the distribution of claims and financial aids and the psychological debriefings were not enough and not well facilitated. There is a need of psychological debriefings that has to be given to affected households to minimize the trauma that they have experienced. Financial aids from the government and donating agencies must be made sure that it has reached those community people that were affected.

Table 5-48: Relocation sites provided by the LGU's to those who were affected from the last flooding and to those who live in the flood prone area

\begin{tabular}{|l|r|}
\hline COMMUNITY & $\%$ \\
\hline Tabuc-tubig & 86.00 \\
\hline Cadawinonan & 76.60 \\
\hline Balugo & 76.48 \\
\hline Poblacion 8 & 74.48 \\
\hline Poblacion 1 & 73.64 \\
\hline Calindagan & 68.70 \\
\hline Taclobo & 68.26 \\
\hline Poblacion 2 & 66.26 \\
\hline Candau-ay & 65.56 \\
\hline Junob & 63.76 \\
\hline Batinguel & 61.58 \\
\hline Bagacay & 54.48 \\
\hline Overall Average & 69.65 \\
\hline
\end{tabular}

The assessment scores for the relocation sites provided by the LGU's to those who were affected from the last flooding and to those who live in the flood prone area is high (54.548\% to $86.00 \%$ ) as shown in Table 5-48. Two relocation sites were provided by the city government and by a non-governmental organization that provided 200 houses more or less. For those who have received were very lucky but there were still a few who have not been relocated and would like to be relocated in a safer place. They have been staying in those temporary houses/tents two years after the flash flood and still waiting to be relocated but unfortunately, the city government has no place for them at the moment. Long term plans and goals must be a priority of the city and making sure in the implementation of building codes and illegal settlers along the river banks must be strictly implemented and followed to avoid such an unfortunate events. 

Social Vulnerabilities and Risks

Table 5-49: Health programmes for diarrhoae and Leptospirosis such as medical help, information drive and among others so outbreaks can be prevented

\begin{tabular}{|l|r|}
\hline COMMUNITY & $\%$ \\
\hline Tabuc-tubig & 86.00 \\
\hline Cadawinonan & 78.40 \\
\hline Poblacion 8 & 71.12 \\
\hline Poblacion 1 & 70.90 \\
\hline Bagacay & 70.66 \\
\hline Taclobo & 67.94 \\
\hline Calindagan & 66.96 \\
\hline Poblacion & 66.26 \\
\hline Junob & 66.26 \\
\hline Candau-ay & 66.12 \\
\hline Batinguel & 64.74 \\
\hline Balugo & 63.54 \\
\hline Overall Average & 69.91 \\
\hline
\end{tabular}

Health programs for diarrhea and Leptospirosis such as medical help, information drive and among others so outbreaks can be prevented were well facilitated and disseminated in the communities as seen in these assessment scores $(63.54 \%$ to $86.00 \%$ ) respectively (Table 5-49). However, there were 161 cases of diarrhea and 8 cases of leptospirosis among the household respondents that were surveyed. Moreover, diarrhea is also part of the top 10 leading causes of morbidity in Dumaguete City from 2010-2012 respectively (Table 1.8, 1.9, and 1.10). Leptospirosis is not on the top 10.

Table 5-50: Different prevention and control programmes for Dengue Fever infection such as fogging, chemical/biological control, information drive brochures, lectures, clean-up

\begin{tabular}{|l|r|}
\hline COMMUNITY & $\%$ \\
\hline Tabuc-tubig & 88.00 \\
\hline Cadawinonan & 78.40 \\
\hline Bagacay & 78.00 \\
\hline Poblacion 8 & 75.86 \\
\hline Taclobo & 74.92 \\
\hline Candau-ay & 73.34 \\
\hline Poblacion 1 & 72.72 \\
\hline Junob & 72.50 \\
\hline Balugo & 69.42 \\
\hline Calindagan & 68.70 \\
\hline Poblacion 2 & 66.26 \\
\hline Batinguel & 62.64 \\
\hline Overall Average & 73.40 \\
\hline
\end{tabular}



Social Vulnerabilities and Risks

The assessment on the different prevention and control programs for Dengue Fever infection such as fogging, chemical/biological control, information drive brochures, lectures, clean-up were also well facilitated and implemented in the communities. The assessment scores were very high ranging from $(62.64 \%$ to $88.00 \%)$ respectively (Table 5-50). In spite of these efforts, there were 67 cases of dengue fever among the community households that were surveyed. In addition, dengue fever is also part of the city's top 10 leading causes of morbidity in Dumaguete City for the year 2010 and 2012 respectively (Table 1.8 and table 1.10 ).

Table 5-51: Assessment on Flood Resilience Adaptation Strategies solicited from the Local Government Units (LGU's) and the Non-Governmental Organizations (NGO's) and from the Household Respondents

\begin{tabular}{|l|c|}
\hline \multicolumn{1}{|c|}{ Flood Resilience Adaptation Strategies with the Corresponding Respondents } & $\%$ \\
\hline A. Governance & 65.89 \\
Local Government Units (LGU's) and Non-Governmental Organizations (NGO's) Respondents & 70.54 \\
Household Respondents & \\
\hline B. Sustainable Community Livelihood & 59.33 \\
Local Government Units (LGU's) and Non-Governmental Organizations (NGO's) Respondents & 61.74 \\
Household Respondents & \\
\hline C. The River's Natural Resource and Natural Features' Management & 60.33 \\
Local Government Units (LGU's) and Non-Governmental Organizations (NGO's) Respondents & 68.85 \\
Household Respondents & \\
\hline D. Land Use and Management and Structural Design & 59.98 \\
Local Government Units (LGU's) and Non-Governmental Organizations (NGO's) Respondents & 66.21 \\
Household Respondents & \\
\hline E. Risks Knowledge-Post Risk Assessment Integration & 63.17 \\
Local Government Units (LGU's) and Non-Governmental Organizations (NGO's) Respondents & 68.17 \\
\hline Household Respondents & \\
\hline
\end{tabular}

Generally the assessment score on flood resilience adaptation strategies that were solicited from the Local Government Units (LGU's) and the Non-Governmental Organizations (NGO's) and from the household respondents were high except for the items on disaster recovery (57.47\%) as shown in Table 5-51 that needs to be improved and facilitated accordingly in the community level. 

Social Vulnerabilities and Risks

This section below presents the overall results and discussions of the study. It is presented in tables and maps for better understanding with the corresponding discussions and analysis. The overall results of the twelve (12) communities selected as the research area for the application of the Community-Based Flood Vulnerability Index (FVI) for urban flooding will be presented, discussed and analyzed in a detailed manner and finishing it with the overall results of the FVI in Dumaguete City, Negros Oriental Philippines.

\subsection{The Overall Results for the Flood Vulnerability Index (FVI) of Dumaguete City}

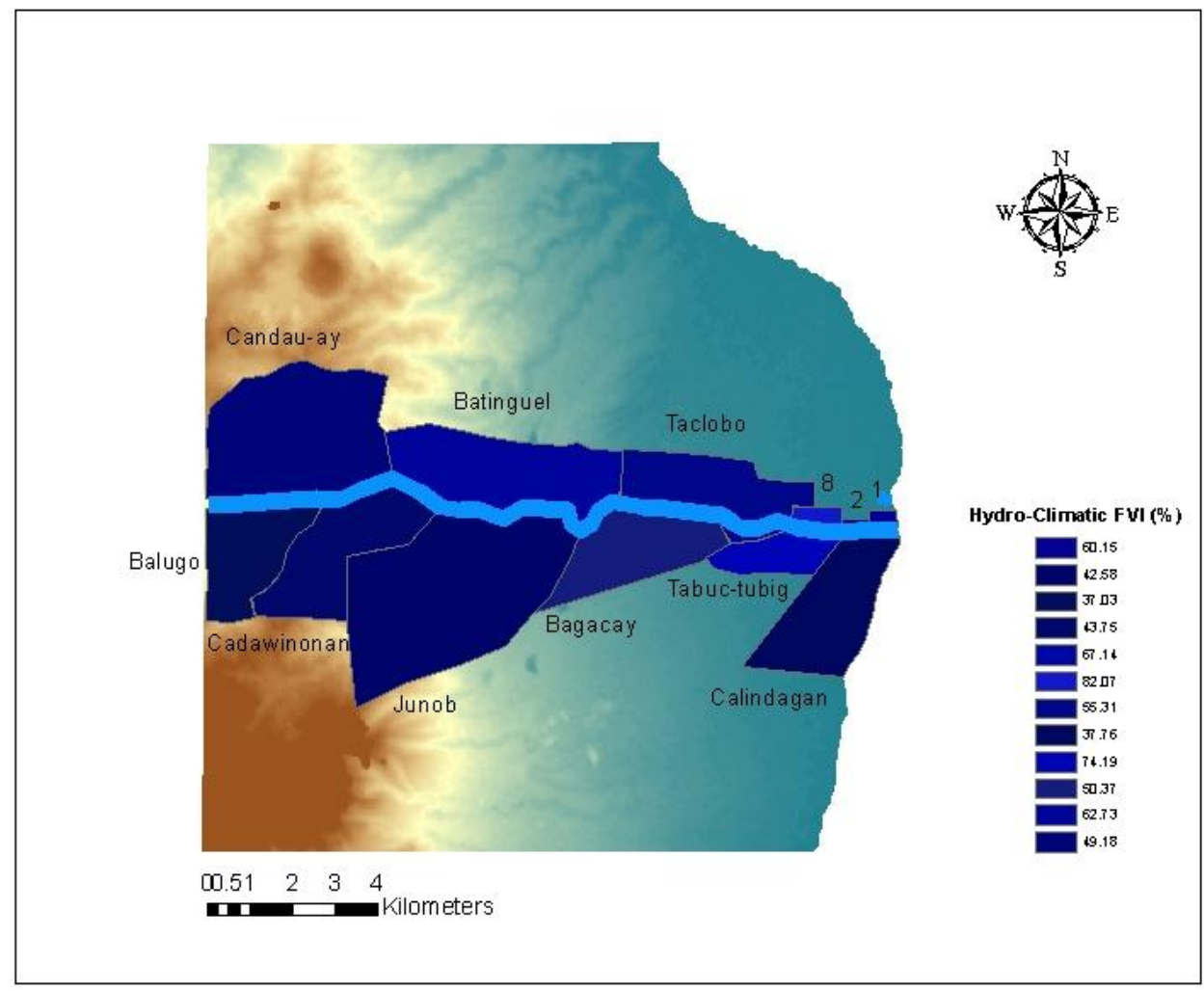

Figure 5-8: Hydro-Climatic Component of Flood Vulnerability Index

The values of the hydro-climatic component and its indicators were used for Equation 2 as described in chapter 4 . In this study, the researcher included susceptibility and resilience in computing for the hydro-climatic component simply because the susceptibility and resilience factors influence the extent of vulnerability to these kinds of exposures thus it is considered in this research work. The result of the hydro-climatic $\mathrm{FVI}$ is shown in Table 5.52 in the succeeding pages. Six (6) indicators were used to determine the hydro-climatic FVI values. After examining the hydro-climatic 

Social Vulnerabilities and Risks

components, it can be seen that Poblacion $8(82.07 \%)$ is the most vulnerable as shown in Figure 5-8 above. This can be attributed to a slightly lower values in the land use and management and structural design as part of its resilience strategies wherein the other leading communities for instance Batinguel, ranks first in terms of exposure it has a slightly higher values for its the land use and management and structural design thus in the overall vulnerability index for hydro-climatic component it only ranks $4^{\text {th }}$. Tabuc-tubig and Poblacion 2 (Lukewright) follows next to Poblacion 8 respectively. Those who are in the top 3 follows the same pattern wherein, the land use and management and structural design values are low to medium and with very high exposures in terms of the height of flooding and the number of houses reached by floods. Poblacion 1 (Tinago) ranks $5^{\text {th }}$ with a very high exposure to floods in terms of height in flooding but has a high value in the land use and management and structural design (resilience) thus putting it in a much lower vulnerability. The least vulnerable communities are Barangay Balugo (37.03\%) and Calindagan (37.76\%). However, this does not imply that these communities are not vulnerable to fluvial flooding. All these communities have already been subject to urban river flooding for the past years with loss of lives and significant cost of damaged from properties. Its reason for its least vulnerability is attributed to low exposure to floodwaters wherein most houses of Balugo community were situated on an elevated area while Calindagan has very high values for the land use and management and structural design. 


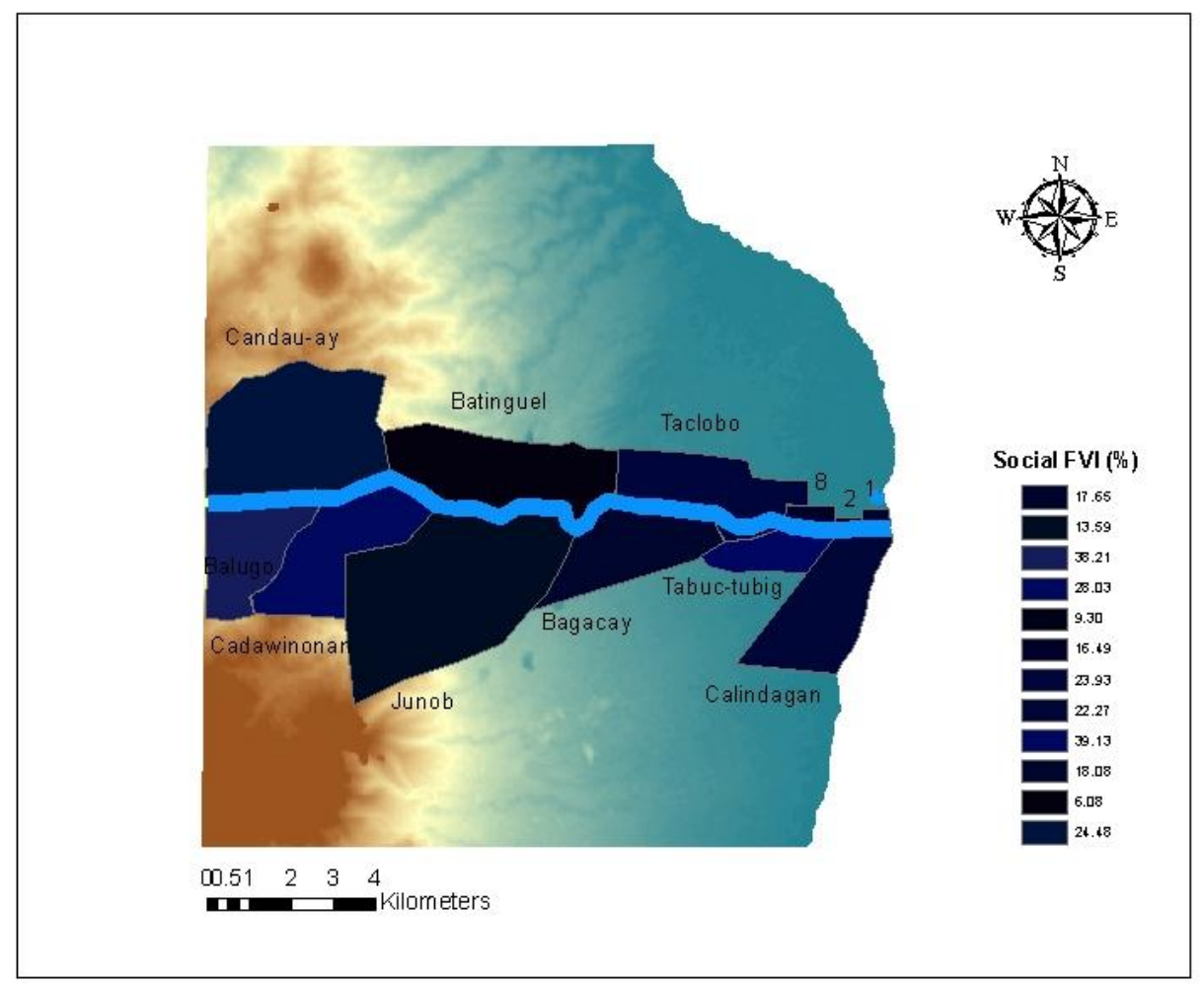

Figure 5-9: Social Component of Flood Vulnerability Index

The values of the social component indicators were used for Equation 3, as described in chapter 4. The results of the social component are shown in Table 5-52. There are five indicators from this component, belonging to all factors of vulnerability, but assigned correspondingly as exposure factor, susceptibility and resilience factors and were used to determine the social FVI values. These indicators include the following: open disposal of animal waste, unwillingness to vacate and be relocated, educational attainment (high school level and below), water treatment or sterilization practice, and social networks. These 5 indicators have an effect on flood exposure and possible disease outbreak before, during and after any flood event which is another major focus of this study. Using these indicators, Tabuc-tubig (39.13\%) stands out to be the most vulnerable to possible disease outbreak due to its high values of practice in open disposal of animal waste $(95.00 \%)$ and with very low values for water treatment or sterilization practice (20.00\%).

Barangays Balugo and Cadawinonan follow respectively. Unwillingness to vacate with extremely low values makes Balugo vulnerable to future urban river flooding and with similar reasons for Cadawinonan. Batinguel and Poblacion 2 (Lukewright) are the least 

Social Vulnerabilities and Risks

vulnerable to fluvial flooding when it comes to social component for the following reasons: the scores for water treatment practices and social networks among their neighborhoods are very good and with a very high educational attainment. Poblacion 2 (Lukewright) follows the same pattern of results. Communities along the river have high social resilience as depicted in Figure 5-9.

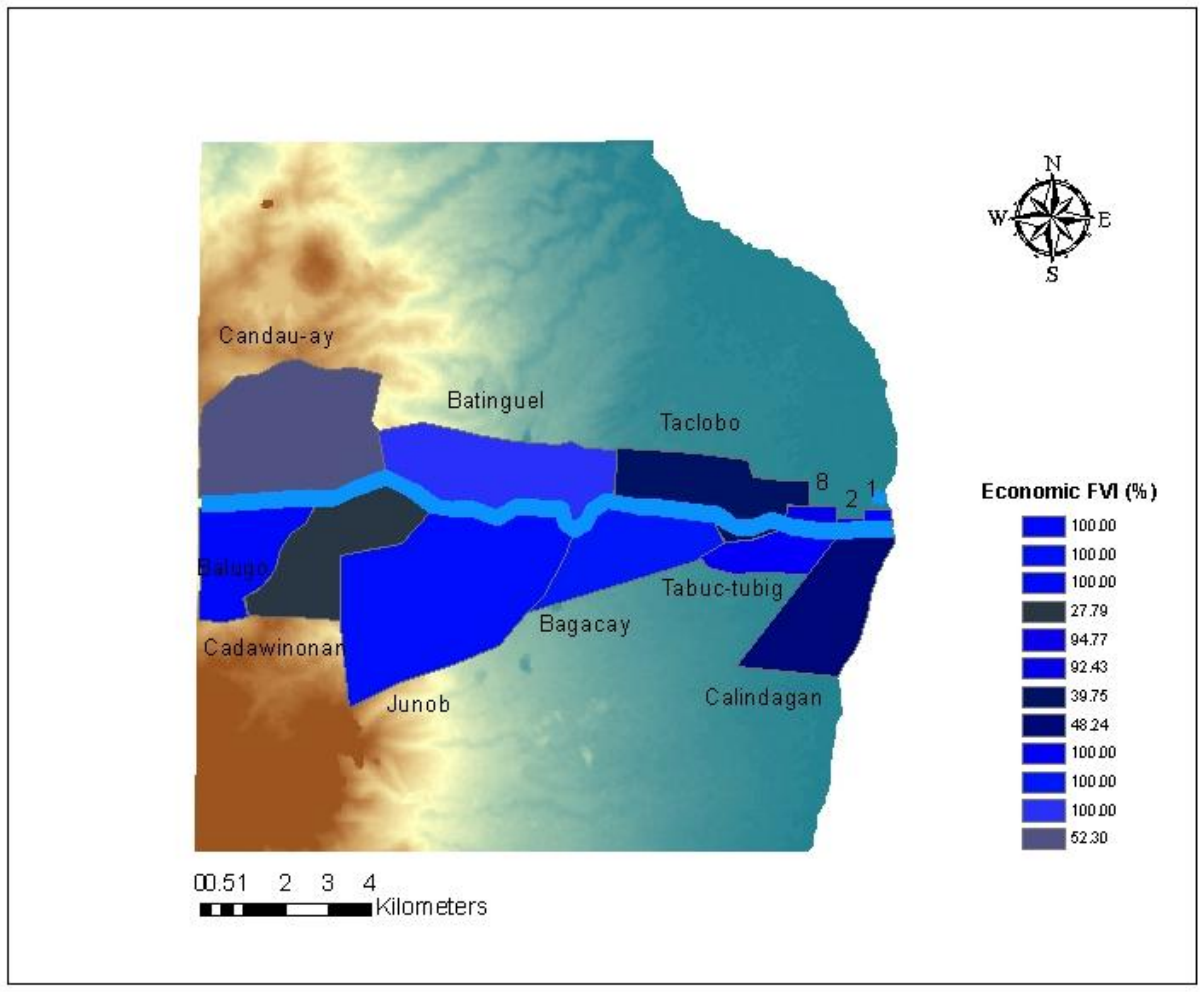

Figure 5-10: Economic Component of Flood Vulnerability Index

The economic FVI values were computed using its indicators, and were used in equation 4 , as described in chapter 4 . The results of the economic components are shown in Table 5-52.There are seven (7) indicators in this category and were assigned accordingly as exposure indicators, susceptibility and resilience indicators and were used to compute for the economic FVI. The indicators are the following; houses with no access to improved sanitation and no access to improved water source, presence of rats in the vicinity, and presence of water logged in the area are part of the exposure factors. While housing conditions comprise the susceptibility indicator. Family income and property insurance are placed in the resilience factor.

This component and indicators has an impact in the vulnerability of the community people in terms of their exposure to the different risks factors but at the same time, the 

Social Vulnerabilities and Risks

susceptibility and resilience factors also determines their overall vulnerability, thus it is important to look at the interplay of these factors on how they affect each other.

Using the economic components, communities like Tabuc-tubig, Junob, Poblacion 1, Balugo, Bagacay, Batinguel, Poblacion 2 (Lukewright) and Poblacion 8, all of them are highly vulnerable with a $100.00 \%, 94.77 \%$, and $92.43 \%$ scores respectively for their $\mathrm{FVI}$ in the economic components (Figure 5-10). Mainly, these can all be attributed to dirty environments (presence of rats in the vicinity), poor housing conditions, low income and no insurance for property in most cases. Barangay Candau-ay, Calindagan, Taclobo and Cadawinonan are the least vulnerable communities in terms of economic components. These communities have good housing conditions, fairly good family income and have their property insured.

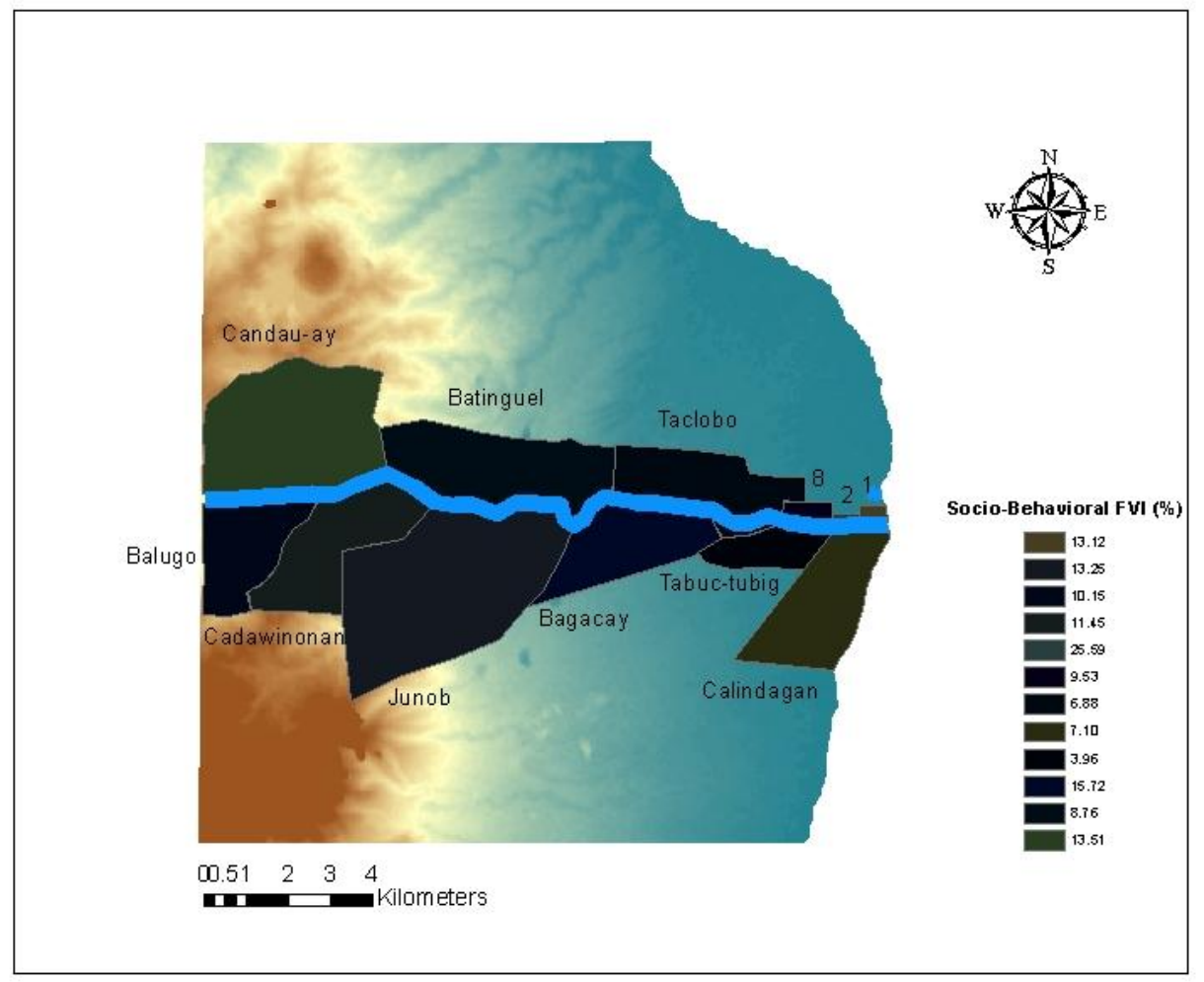

Figure 5-11: Socio-Behavioral Component of Flood Vulnerability Index

There are 12 indicators for the socio-behavioral component. The values were computed using Equation 5-8 described in chapter 4 and the results are shown in Table 5-52. Using these indicators Barangay 2 (Lukewright) with a score of $25.59 \%$ is the most vulnerable when it comes to KAP of flood resilience and KAP of prevention and management of diseases from E.coli, Leptospirosis and Dengue Fever. It is followed by 
Bagacay and Candau-ay respectively. In spite that Barangay 2 showed a very high knowledge score (resilience) yet still ranks to be the most vulnerable due to high bad attitude (susceptibility) scores which is $(68.62 \%)$. It follows the same pattern for those next in rank except that it's bad practice (exposure) rather than attitude that scores high in those cases. On the other hand, the least vulnerable community is Tabuc-tubig (3.96\%) followed by Taclobo and Calindagan respectively (Figure 5-11). The common pattern for this is usually, knowledge (resilience) score is sufficiently high and with extremely low bad attitude (susceptibility) or extremely low bad practices (exposure) against flood resilience and in the exposure of those diseases associated with flooding.

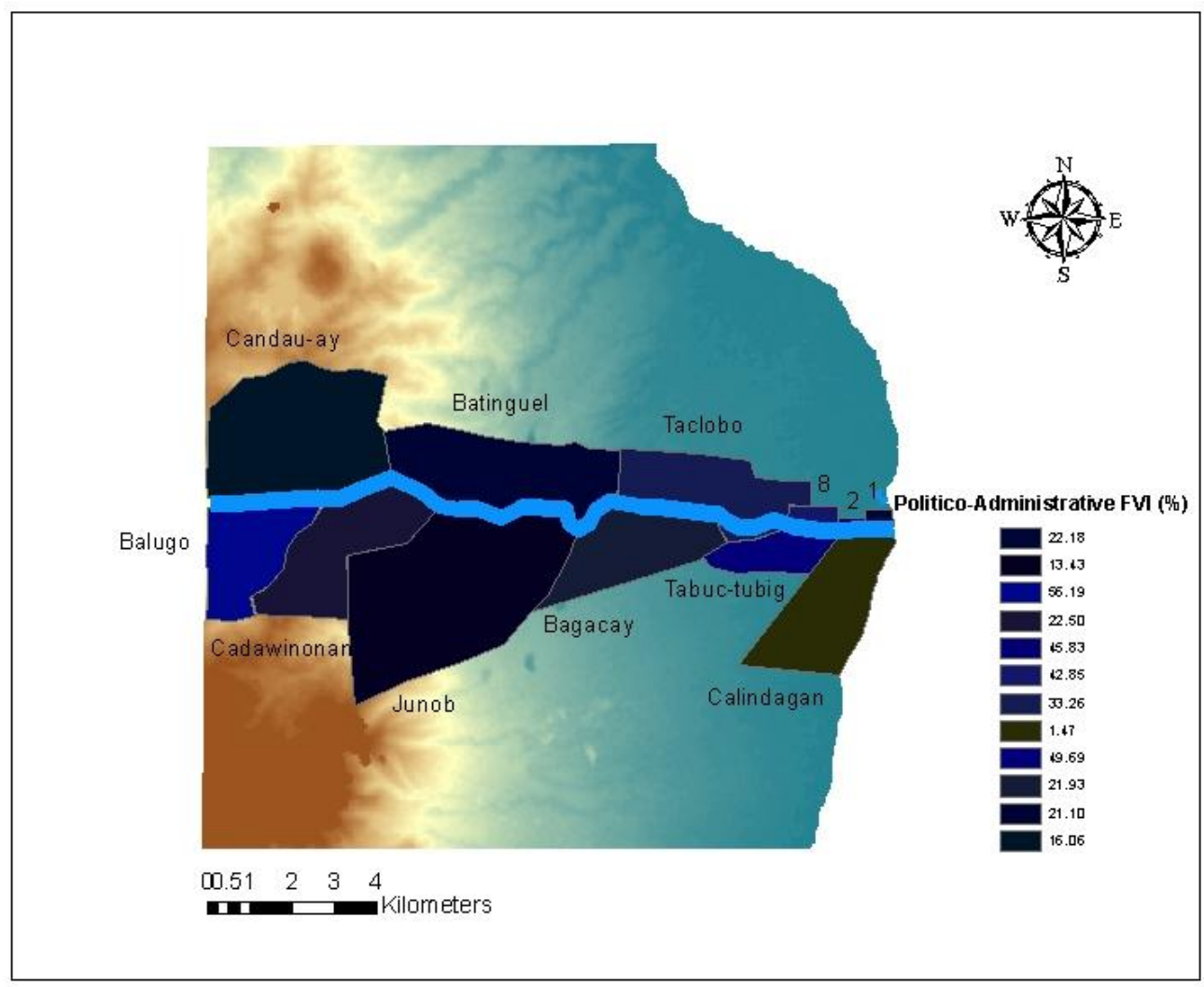

Figure 5-12: Politico-Administrative Component of Flood Vulnerability Index

The politico-administrative component of this study shows the involvement of institutional organizations in the flood management process, including those policies and programs that were laid prior to any catastrophic events and its long term adaptation strategies. These institutional organizations are composed of the following: the LGU's from each of the communities studied, the Local Disaster Risk Reduction Management Council (LDRRMC) of the City, the Provincial Disaster Risk Reduction 

Social Vulnerabilities and Risks

Management Council (PDRRMC) of the Province of Negros Oriental and some of the NGO's in Dumaguete City, namely; the Silliman Volunteer for Fire and Rescue Unit (SUVFRU), One Rescue EMS, the GIZ, and the CNDR-SMART. The computation of the values uses Equation 9 described in chapter 4.

As seen in Table 5-52, the most vulnerable politico-administrative is Barangay Balugo (56.19\%) followed by Tabuc-tubig and Poblacion 2 respectively. This is due to low resilience score in some of the indicators under this component, like for instance, the post-risk assessment and integration (42.50\%) and sustainable community livelihood $(47.50 \%)$ and it follows the same for Tabuc-tubig and Barangay 2 where the lowest score for sustainable community livelihood (resilience) is $37.50 \%$ respectively. The latter 2 Barangays were consistent as they are highly exposed to flood hazards (hydroclimatic component) ranking $2^{\text {nd }}$ and $3^{\text {rd }}$ respectively. Surprisingly Balugo ranks the least exposed community in terms of flood hazard and its hydro-climatic component due to its high elevation from the river banks it ranks to be the most vulnerable when it comes to politico-administrative components simply because it also ranks second (57.03\%) for its exposure indicator and low resilience scores. Barangay Calindagan is the least vulnerable to this component with very high scores $(76.29 \%)$ on its resilience strategies. Moreover, it also has good governance score (91.78\%), thus making it the least vulnerable community when it comes to the politico-administrative components. Junob and Candau-ay follows respectively. Junob shows low exposure scores with good governance and high resilience. Same is true to Barangay Candau-ay it follows the same pattern with Barangay Junob respectively as all shown in Figure 5-12. 


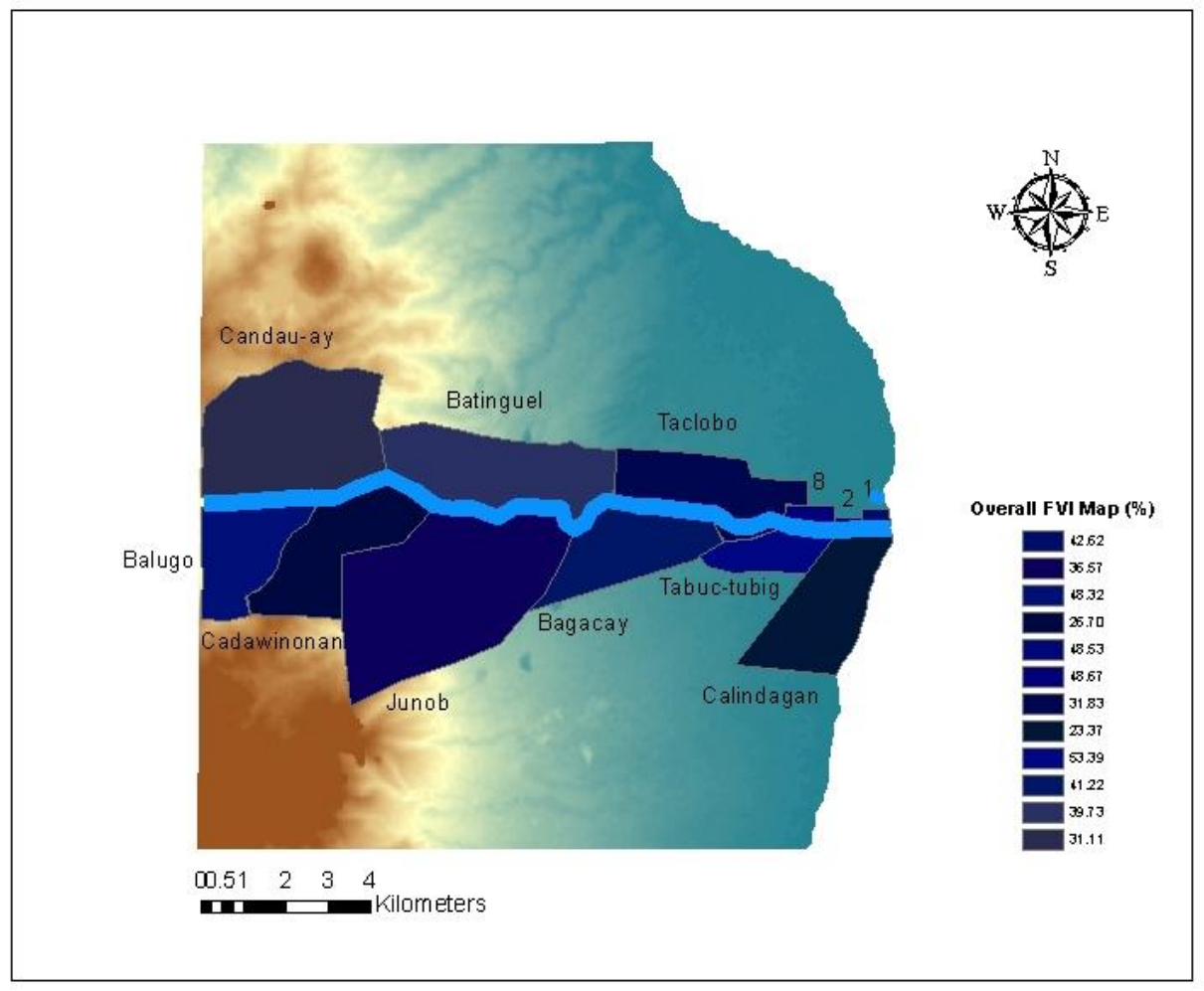

Figure 5-13: Overall Flood Vulnerability Index for the 12 Communities

Figure 6-6 and Table 5-52 shows the Overall Flood Vulnerability Index (FVI) of the twelve communities examined (39.34\%). Tabuc-tubig is the most vulnerable to urban river floods (53.39\%). Its vulnerability is owing to its high vulnerability index in economic and hydro-climatic components and low resilience to the latter. Poblacion 8 ranks 2nd in the overall result mainly because it has very high vulnerability to exposure (hydroclimatic factors). Barangay 2 (Lukewright) is next in line. It has high vulnerability to hydro-climatic exposure and politico-administrative components. Though the sociobehavioral is relatively low in vulnerability but it is still significant considering that it ranks highest in that component among the twelve communities. Barangay Balugo ranks 4th mainly because of high economic vulnerability and low resilience to hydro-climatic exposures and significantly higher in the politico-administrative index. Poblacion 1 (Tinago) is rank 5th, Bagacay on the 6th whom both similarly owing to high economic vulnerability, but for Bagacay it is significantly higher than the rest in terms of sociobehavioral component vulnerability. Batinguel ranks 7th, largely due to its very high economic vulnerability index and considerably high in the hydro-geological exposure factors. Junob is on the 8th rank owing to its high economic vulnerability. Taclobo is on the 9th rank, showing a considerable vulnerability in hydro-climatic exposure. Barangay 

Social Vulnerabilities and Risks

Candau-ay, Cadawinonan and Calindagan are the least vulnerable among the twelve communities respectively (Figure 5-13). All these three latter communities have very good resilience in most of the components examined.

Table 5.52: Overall FVI and the FVI of each the Five (5) Components

\begin{tabular}{|l|r|r|r|r|r|r|}
\hline Community & $\begin{array}{c}\text { OVERALL } \\
\mathrm{FVI}\end{array}$ & $\begin{array}{c}\text { Hydro- } \\
\text { Climatic FVI }\end{array}$ & $\begin{array}{c}\text { Social } \\
\mathrm{FVI}\end{array}$ & $\begin{array}{c}\text { Economi } \\
\text { C FVI }\end{array}$ & $\begin{array}{c}\text { Socio- } \\
\text { Behavioral } \\
\mathrm{FVI}\end{array}$ & $\begin{array}{c}\text { Politico- } \\
\text { Administrative } \\
\mathrm{FVI}\end{array}$ \\
\hline Tabuc-tubig & $53.39 \%$ & $74.19 \%$ & $39.13 \%$ & $100 \%$ & $3.96 \%$ & $49.69 \%$ \\
\hline Junob & $36.57 \%$ & $42.58 \%$ & $13.59 \%$ & $100.00 \%$ & $13.25 \%$ & $13.43 \%$ \\
\hline $\begin{array}{l}\text { Poblacion } \\
\text { (Tinago) }\end{array}$ & $42.62 \%$ & $60.15 \%$ & $17.65 \%$ & $100 \%$ & $13.12 \%$ & $22.18 \%$ \\
\hline Calindagan & $23.37 \%$ & $37.76 \%$ & $22.27 \%$ & $48.24 \%$ & $7.10 \%$ & $1.47 \%$ \\
\hline Balugo & $48.32 \%$ & $37.03 \%$ & $38.21 \%$ & $100.00 \%$ & $10.15 \%$ & $56.19 \%$ \\
\hline $\begin{array}{l}\text { Poblacion } \\
\text { (Lukewright) }\end{array}$ & $48.53 \%$ & $67.14 \%$ & $9.30 \%$ & $94.77 \%$ & $25.59 \%$ & $45.83 \%$ \\
\hline Poblacion 8 & $48.67 \%$ & $82.07 \%$ & $16.49 \%$ & $92.43 \%$ & $9.53 \%$ & $42.85 \%$ \\
\hline Cadawinonan & $26.70 \%$ & $43.75 \%$ & $28.03 \%$ & $27.79 \%$ & $11.45 \%$ & $22.50 \%$ \\
\hline Bagacay & $41.22 \%$ & $50.37 \%$ & $18.08 \%$ & $100.00 \%$ & $15.72 \%$ & $21.93 \%$ \\
\hline Taclobo & $31.83 \%$ & $55.31 \%$ & $23.93 \%$ & $39.75 \%$ & $6.88 \%$ & $33.26 \%$ \\
\hline Candau-ay & $31.11 \%$ & $49.18 \%$ & $24.48 \%$ & $52.30 \%$ & $13.51 \%$ & $16.06 \%$ \\
\hline Batinguel & $39.73 \%$ & $62.73 \%$ & $6.08 \%$ & $100.00 \%$ & $8.76 \%$ & $21.10 \%$ \\
\hline
\end{tabular}

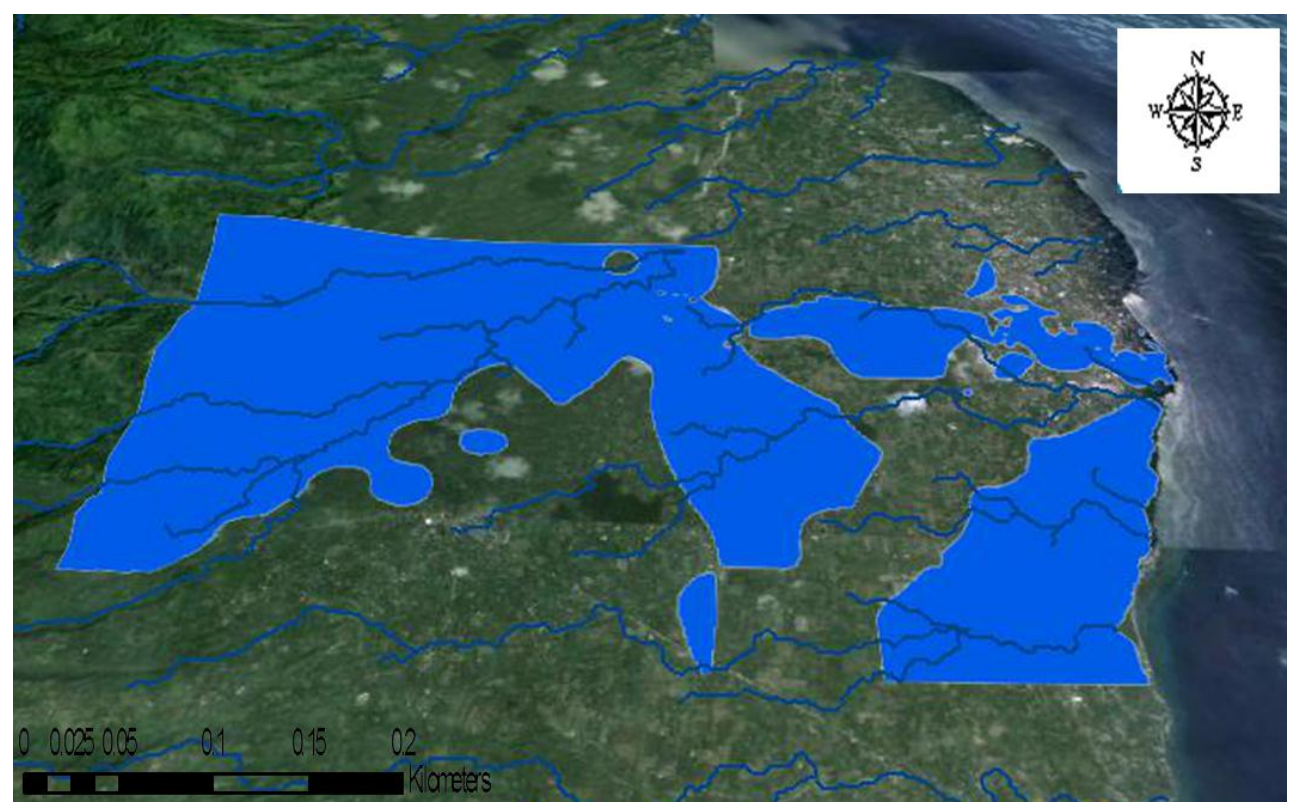

Figure 5-14: The Flood Map of Dumaguete City, Philippines 

Social Vulnerabilities and Risks

This is a very crude and simple flood map of Dumaguete City (Figure 5-14) generated from the history accounts of those household respondents that have experienced flooding for the past three years and from the 6 hour one month rainfall data. The blue colour indicates the spread of flooding from an overspill of Banica River and its tributaries around. Due to very limited data available the researcher has only generated this simple flood plan.

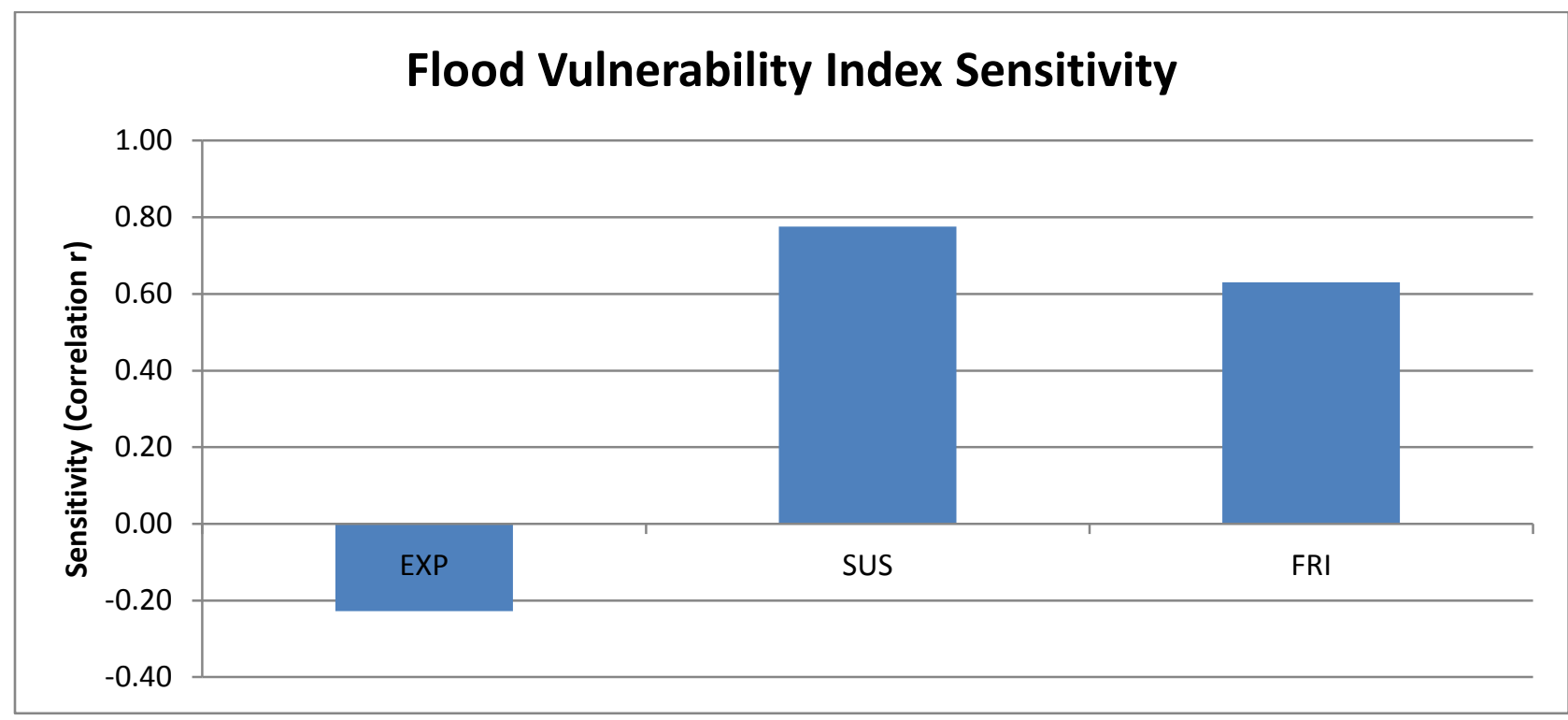

Figure 5-15: Flood Vulnerability Index Sensitivity

Table 5-53: Flood Vulnerability Index: Pearson Product Moment Correlation Matrix ( $r$ )

\begin{tabular}{|l|c|c|c|c|}
\hline & FVI & EXP & \multicolumn{1}{c|}{ SUS } & \multicolumn{1}{c|}{ FRI } \\
\hline Flood Vulnerability Index (FVI) & & -0.2281 & 0.7760 & 0.6305 \\
\hline Exposure (EXP) & -0.2281 & & -0.1747 & 0.6054 \\
\hline Susceptibility (SUS) & 0.7760 & -0.1747 & & 0.5024 \\
\hline Flood Resilience Index(FRI) & 0.6305 & 0.6054 & 0.5024 & \\
\hline
\end{tabular}

The mark values are correlation values $(r)$ that are significant (at alpha $=0.05$ ) as shown in Table 5-53. The Flood Vulnerability Index in this study is significantly sensitive to susceptibility and flood resilience variables as shown in Figure 5-15. 


\subsection{The OVERALL Result from Assessment on Flood Resilience Adaptation Strategies}

The overall result from the Assessment on Flood Resilience Adaptation Strategies Solicited from the Local Government Units (LGU's) and the Non-Governmental Organizations (NGO's) and from the Household Respondents is $64.43 \%$ shown in Table 5-54 which is generally high but special attention must be given to some of the items under disaster recovery particularly on availability of technical (services offered) and financial resources to support the recovery process.

Table 5.54: The OVERALL Result from Assessment on Flood Resilience Adaptation Strategies solicited from the Local Government Units (LGU's) and from the Non-Governmental Organizations (NGO's)

\begin{tabular}{|l|c|}
\hline ASSESSMENT on Flood Resilience Adaptation Strategies & $\%$ \\
\hline A. Governance & 68.22 \\
\hline B. Sustainable Community Livelihood & 60.54 \\
\hline C. The River's Natural Resource and Natural Features' Management & 64.59 \\
\hline D. Land Use and Management and Structural Design & 63.10 \\
\hline E. Risks Knowledge-Post Risk Assessment Integration & 65.67 \\
\hline F. Warning and Evacuation & 65.93 \\
\hline G. Emergency Response & 69.93 \\
\hline H. Disaster Recovery & 57.47 \\
\hline Overall & 64.43 \\
\hline
\end{tabular}




\subsection{The OVERALL counts of E.coli (CFU's) per $100 \mathrm{~mL}$ water sample from the 5 Stations}

Downstream 2 (Barangay Calindagan and Tinago) and Downstream 1 (Tabuc-tubig Bridge) that covers Poblacion 8, and parts of Barangay Taclobo (Table 5-55) correlates with the number of diarrhoeal cases among the household respondents. Poblacion 8 tops the list with $65.52 \%$ diarrhoeal cases, followed by Barangay Batinguel with $63.16 \%$ cases and Poblacion 1 with 54.55\% diarrhoeal cases respectively.

Table 5-55: The OVERALL counts of E.coli (CFU's) per $100 \mathrm{~mL}$ water sample from the five (5) Stations

\begin{tabular}{|l|c|}
\hline Stations & Colony Forming Units (CFU's) \\
\hline Upstream & $533 / 100 \mathrm{~mL}$ \\
\hline Midstream 1 & $1511 / 100 \mathrm{~mL}$ \\
\hline Midstream 2 & $4445 / 100 \mathrm{~mL}$ \\
\hline Downstream 1 & $12933 / 100 \mathrm{~mL}$ \\
\hline Downstream 2 & $16000 / 100 \mathrm{~mL}$ \\
\hline OVERALL Average & $7084 / 100 \mathrm{~mL}$ \\
\hline
\end{tabular}




\section{CHAPTER 6 CONCLUSIONS AND PERSPECTIVES}

The results of the Flood Vulnerability Index $(\mathrm{FVI})$ of the 5 components and the overall $\mathrm{FVI}$ are summarized in Table 5.52. Thirty-six (36) local indicators have been formulated for the five (5) components that fit and suit in in the local context. A new Flood Vulnerability Index (FVI) for Dumaguete City was developed in this study that incorporates the hydro-climatic and socio-economic components. Perspectives of the community people in terms of their knowledge, attitude, and practices towards flood resilience and adaptation, hygiene practices against E.coli, Leptospirosis and Dengue Fever mosquito exposure were included for the socio-behavioral component. Furthermore, the politico-administrative component was also included since it could have a profound effect in all of these components in the long run.

The Overall Flood Vulnerability Index (FVI) for Dumaguete City is $39.34 \%$ (Table 5-52) which could be considered medium range vulnerability. Among the 12 communities studied, Barangay Tabuc-tubig is the most vulnerable (53.39\%). Its high vulnerability is due to high FVI in hydro-climatic exposure and economic components. Moreover, it has low resilience in terms of adaptation strategies for adapting urban flooding. On the other hand, Barangay Calindagan is the least vulnerable $(23.37 \%)$ owing to very good politico-administrative and socio-behavioral components. The most exposed community in terms of the hydro-climatic component is Poblacion $8(82.07 \%)$ and the least exposed is Barangay Balugo (37.03\%) respectively. The 12 communities have different vulnerabilities among the five (5) components and thirty-six (36) local indicators used. However, what is true to all, the Flood Vulnerability Index in this study is significantly sensitive to susceptibility and flood resilience variables.

The assessment score solicited from the Local Government Units (LGU's) and the Nongovernmental Organization (NGO's) themselves is favorably good (64.43\%) with regards to the level of governance in facilitating the flood resilience strategies and adaptation in the city, however, there is a need to prioritise on some of the items under disaster recovery which scored the lowest (57.47\%) among the items surveyed. These items are pertaining to the availability of technical (services offered) and financial resources to support the recovery process particularly on insurance scheme, conducting traumatic/psychological stress debriefings, damage assessment facilitating claim procession, distribution of charitable funds, and on social therapeutic measures which helps and support in the recovery process. Apart from these intangible (non-structural) matters, reconstruction, the land use management and structural design must be 

Social Vulnerabilities and Risks

seriously and strictly implemented. Attention must also be given on these items, the building code regulation and zoning ordinances, flood risk adaptive to land use, and improving of flood barriers structures such as bridges and dike systems to achieved long term solutions.

There were 20 items related to flood resilience and adaptation strategy that were assessed in this study and were administered to the household respondents found in chapter 5 (pages 214-227) revealing different results though generally favorable but with with some exceptions in some items that need special attention to improve it better. For instance, the transparency and trustworthiness of the LGU's in terms of the facilitation and distribution of the budget and donations for the affected population in the community during calamity, it must have been given appropriately to those affected households in the community. Another item that needs attention is the livelihood and financial aid for the community people to help them recover again from any calamity before another one strikes. The programs and policies in saving and protecting the Banica River must also be given attention before it gets worse and before the damage would be irreversible. The open drainage system that ends into the river is also another serious form of pollution that has to be addressed, and likewise the practice of dumping garbage into the river by the people living along the river banks must also be stopped. The regular use of backhoe in cleaning up the river especially when normal flow is blocked should also be facilitated to avoid further blockage and stagnation when rainy season comes or before any flooding episode happens and as well as post-flooding events. Proper and equal distribution of donations, goods, and relief must be given on time, appropriately and efficiently. Relocation sites must be provided to those who were affected and to those who live in the flood prone area if financial resources are available.

This study has also included the examination of the presence of E.coli in the river for the period of 5 months covering both the dry and wet season (March to July). It was observed from the collected water samples, the E.coli counts (cfu's) in Banica river is significantly high $(15,311 \mathrm{cfu}$ 's $/ 100 \mathrm{~mL}$ ) in the month of March 2013 compared to the $235 \mathrm{cfu}$ 's/100 mL set by the Environmental Agency (EPA). Among the five (5) sampling stations, Downstream 2 (Barangay Calindagan and Tinago) has the highest E.coli counts $(34,222$ cfu's $/ 100 \mathrm{~mL})$ with an overall average of $16,000 \mathrm{cfu}$ 's $/ 100 \mathrm{~mL}$. Therefore, there is an urgent need to address this problem to avoid further contamination and disease outbreak in the future especially that $41.46 \%$ of the household surveyed are exposed to the river on a regular basis in activities such as immersing/washing of clothes and swimming/bathing in the river. Furthermore, 
Downstream 2 (Barangay Calindagan and Tinago) and Downstream 1 (Tabuc-tubig Bridge) that covers Poblacion 8, and parts of Barangay Taclobo correlates with the number of diarrheal cases among the household respondents. Poblacion 8 tops the list with $65.52 \%$ diarrheal cases, followed by Barangay Batinguel with $63.16 \%$ cases and Poblacion 1 with $54.55 \%$ diarrheal cases respectively.

The average flow of Banica river reveals some areas with slow and reverse flow (chapter 4) during high tide that may stagnate the floating bacteria and other pollutants that may possibly cause harm to the community people particularly of Poblacion 1 (Tinago), Calindagan, Poblacion 2 (Lukewright), Poblacion 8 and Tabuc-Tubig respectively.

The conclusion of this study covers five aspects and advantages:

(1) The Community-Based Flood Vulnerability Index (FVI) Methodology and Use. The advantage of developing this community-based FVI can make the community and the government aware of the different vulnerabilities that each community has and at the same time, this can be used as a network of knowledge to learn from each other and to increase the resilience of each community and which progress needs to be prioritised. With the FVI, the impacts can be predicted in different scenarios. In this way, it helps policymakers, environmental, water and disaster agencies to define what measurements must be taken and possible appropriation of funds for adaptation and reduction of flood vulnerability in urban areas will be allocated. The FVI is a powerful tool for mapping of vulnerable areas in the city.

(2) Baseline of Community-based Flood Vulnerability Index. Using the thirty-six (36) local indicators one can clearly compare the vulnerabilities of communities in a thorough perspective which can later be used between cities and countries of similar societies. The focus of doing this study is more of a holistic approach rather than just a political per se. No published studies have been conducted similar to this in Dumaguete City where a thorough survey using local-based indicators vulnerability approach that includes: individual exposure, the magnitude and frequency of flood; the community people's vulnerability perception; and the resilience and adaptation approach. Thus, this study would serve as a baseline study for Dumaguete City, and a Vulnerability Flood Index (FVI) for urban flooding.

(3) Involvement of Local Authority, Stakeholders and Community. For a FVI to be widely accepted, local authorities, stakeholders, community people and the non-governmental 

Social Vulnerabilities and Risks

agencies has to be involved in the weighting of the indicators which this study has accomplished. It is only through this involvement that the interconnectedness of several indicators and local specificities will be thoroughly captured and presented. For programs and adaptation strategies to be well facilitated and implemented, collaboration among them is crucial and important so proper response will be appropriately achieved.

(4) Sensitivity of Flood Vulnerability Index. The Flood Vulnerability Index in this study is significantly sensitive to susceptibility and flood resilience variables. Precisely, the community people are vulnerable in the first place because of these variables. After an in-depth study of this newly developed Community-Based Flood Vulnerability Index $(\mathrm{FVI})$ for Dumaguete City, there is a need to increase awareness towards adaptation measures by raising anticipatory mentality of the local population towards flood preparedness and adaptation strategies; a change of behavior towards caring for the environment; and a sense of awareness in the importance of good hygiene practices; and the collaboration between the LGU's, multiple stakeholders, local and international organizations and the community people must be realized so measurements that would lessen the vulnerability and impact would be undertaken.

(5) Future Extension of the Proposed Methodology. As this study deals particularly on community-based indicators methodology in producing a flood vulnerability index, for future studies, an interdisciplinary approach by bringing engineering and social approaches together is recommended to help in assessing flood vulnerable areas or other types of natural calamities. Using the ideal components and indicators that addressed to the current status of the community people in terms of their vulnerability and resilience to flooding is important to be able to have a more realistic scenario that is at the community level. Once these components are identified and established, then later this can be utilized as part of the criteria for hydrological models that will incorporate both structural and social vulnerabilities. It is important to incorporate these community-based flood vulnerability components and indicators so that a holistic approach and results will be obtained. In this way, vulnerability and resilience assessments in hydrological models or in a socio-economic approach will be more meaningful and comprehensive. In doing so, such issues will be analyzed in different aspects. 


\section{REFERENCES AND CITATIONS}

Acosta-Michlik, L. and Espaldon, V. (2005). Assessing Vulnerability of Selected Farming Communities in the Philippines Based on a Behavioral Model of Agent's Adaptation to Global Environmental Change.

Andjekovic, I. (2001). International Hydrological Programme Guidelines on NonStructural Measures in Urban Flood Management. IHP-V Techinical Documents in Hydrology No. 50.

Balica, S.F., Wright, N.G., and van der Meulen, F. (2012). A Flood Vulnerability Index for Coastal Cities and Its Use in Assessing Climate Change Impacts.

Birkmann, J. (2010). "Assessing Vulnerability in the Context of Multiple Stressors".

CDRC. (2012). Citizen's Disaster Response Center. The 2012 Philippines Disaster Report.

Cendrero, A. (1997). A Procedure for Assessing the Environmental Quality of Coastal Areas for Planning and Management.

Ciurean, R.L., Schröter D. and Glade T. (2013). Conceptual Frameworks of Vulnerability Assessments.

Connor, R. F., and Hiroki, K. (2005). Development of a Method for Assesing Flood Vulnerability. Water Science Technology, 61-70.

Cutter, S. B. (2003). Social Vulnerability to Environmental Hazards. Social Sciences Quarterly 84 (2), 242-261.

Di Mauro, C. (2006). Regional vulnerability map for supporting policy definitions and implementations. ARMONIA conference " multi-hazards: challenges for risk assessment, mapping and management". Barcelona.

DOH. (2013). Department of Health: Dengue Fever Surveillance Report. Philippines.

DOH. (2013). Department of Health: Leptospirosis Surveillance Report. Philippines.

Douben, K.J. (2006). Characteristics of River Floods and Flooding: A Global Overview, 1985-2003. Irrigation and Drain. 
Community-Based Flood Vulnerability Index for Urban Flooding: Understanding Social Vulnerabilities and Risks

Douben, N. and Ratnayake, RMW. (2005). Characterstics Data on River Floods: Facts and Figures. In Floods from Defense to Management, Symposium Papers, van Beek E, Taal (eds). London, UK: Taylor and Francis Group.

Dumaguete City Local Disaster Risk Reduction and Management Office (LDRRMO).

(2013). 5-Year Local Disaster Risk Reduction and Management Plan (LDRRMP).

Dumaguete City Planning and Development Office. (2000). Unpublished.

EM-DAT. (2014). The OFDA/CREED International Disaster Database.

Environmental Protection Agency or EPA. (2012).

European Commission. (2000). First report on the harmonisation of risk assessment procedures, Brussels. DG Health and Consumer Protection, European Commission.

Fano, J. . (2010). Establishment of Flood Risk Index by Province Based on Natural and Social Factors.

Gornitz, V. (1990). Vulnerability of the East Coast, USA to Failure Sea Level Rise. Journal of Coastal Research, 201-237.

GRoWE. (2005). Global Research on Water-Based Economies. Water Resource System Issue.

Hammond, Michael and Ole, Mark. (2014). CORFU FP7 Collaborative Research on Flood Resilience in Urban Areas: Health Impacts Model.

Hoyt, G.W, and Langbein, W. (1955). Floods. New Jersey: Princeton University Press.

http://www.statisticshowto.com/how-to-use-slovins-formula/. (n.d.).

IFRC. (2014). Internation Federation of Red Cross and Red Crescent Societies. What is Vulnerability?

IFRC. (2014). International Federation of red Cross amd Red Crescent Societies. Hydrological Hazards: General Floods and Flashfloods.

Ignacio, J.A.F, and Henry, S. (2013). Assessing Changes in Village-Level Social Vulnerability Based on Census Data.

Institutionalization of the Rehabilitation of Banica River Watershed. (2000).

IPCC. (2001). The International Panel on Climate Change. Third Assessment Report in Climate Change. 
Community-Based Flood Vulnerability Index for Urban Flooding: Understanding Social Vulnerabilities and Risks

Intergovernmental Panel on Climate Change: Fifth Assessment Report on Climate Change 2013. (2014).

Jha, AK, et al. (2012). Cities and Flooding. A Guide to Integrated Urban Flood Risk Management for the 21st Century.

Kannami, Y. (2008). Establishment of Country-Based Flood Risk Index.

Manila Observatory. (2005). Mapping Philippine Vulnerability to Environmental Disasters.

Martens, P. K. (1999). Climate Change and Future Populations at Risk of Malaria. Global Environmental Change.

McLaughlin, S. a. (2010). A Multi-Scale Coastal Vulnerability Index: A Tool for Coastal Managers? . Environmental Hazards: Human and Policy Dimensions Vollume 9, 233-246.

MunichRe. (2007). Flooding and Insurance, Munich Reinsurance Company.

National Academy of Sciences. (1983). Risks Assessment in the Federal Government: Managing the Process. Washington DC: National Academy Press.

NOAA. (2014). The US National Oceanic and Atmospheric Administration. National Weather Seervice.

Pelling, M. (2003). The Vulnerability of Cities: Natural Disaster and Social Resilience. UK: Earthscan Publications.

Perry, C. (2000). Significant Floods in the United States During the 20th Century-USGS Measures a Century of Floods.

Turner, B.L. et al. (2003). A Framework for Vulnerability Analysis in Sustainability Science.

UNDP. (2004). United Nation Development Programme. A Global Report Reducing Disaster Risk: A Challenge for Development.

UNEP. (2002). Global Environmental Outlook. London, UK: Earthscan.

UNEP. (2014). United Nations Environmental Programme. PREVIEW-Globl Risk Data Platform.

UNISDR. (2007). United Nations Office for Disaster Risk Reduction. Terminology on $D R R$. 
United Nations Framework Convention on Climate Climate. (2007). Climate Change: Impacts, Vulnerabilities and Adaptation in Developing Countries.

United Nations University Institute for Environment and Human Security. (2011). UN World Risk Index: Governance and Civil Society.

UNSDR. (2005). United Nations Office for Disaster Risk Reduction. The Hyogo Framework for Action (HFA) 2005-2015 of the United Nations.

Van Beek, E. and Loucks, D.P. (2005). Water Resources Systems Planning and Management.

WHO. (2013). World Health Organization: Media Center Factsheets.

World Bank. (2009). The World Bank Environment Depertment. Convenient Solutions to an Inconvenient Truth: Ecosystem-Bsed Approaches to Climate Change. 
Community-Based Flood Vulnerability Index for Urban Flooding: Understanding Social Vulnerabilities and Risks

\section{APPENDICES}

\section{Appendix 1 ENGLISH HOUSEHOLD SURVEY FORM QUESTIONNAIRE}

In this appendix the following form of questionnaires used in the survey is presented as follows:

1. Data of the household respondents on its socio-demographic profile, socioeconomic, physical and social environment

2. Knowledge, Attitude, and Practices (KAP) on Community Flood Resilient Assessment

3. KAP of Household Respondents on Environmental Microbial Health Risks (E. coli, Leptospira spp., Dengue Fever Mosquito)

4. Assessment on Flood Resilience \& Health Program of the Local Government Units and NGO's

Questionnaire No: GPS Location

Data of Household Respondents on its Socio-Demographic Profile, Physical and Social Environment

\begin{tabular}{|c|c|}
\hline $\begin{array}{l}\text { Name of the Community: } \\
\text { Name of Zone : }\end{array}$ & $\begin{array}{l}\text { Were you victims of the last typhoon/flooding Sendong? } \\
\qquad \ldots \text { Yes/No }\end{array}$ \\
\hline Number of family members: & Name (OPTIONAL) \\
\hline Number of extended family members: & Female/Male \\
\hline $\begin{array}{l}\text { Number of Female and Male in the Family: } \\
\text { Your level of Educational Attainment: }\end{array}$ & $\begin{array}{l}\text { Was there any one from the family members who had } \\
\text { experienced DIARRHEA especially during rainy, typhoon or } \\
\text { flooding seasons__ Yes/No } \\
\text { If Yes, how many have experienced it? }\end{array}$ \\
\hline $\begin{array}{l}\text { Was there any one from the family members who had } \\
\text { experienced DENGUE especially during rainy, typhoon or } \\
\text { flooding seasons _es/No } \\
\text { If Yes, how many have experienced it? }\end{array}$ & $\begin{array}{l}\text { Was there any one from the family members who had } \\
\text { experienced LIPTOSPIROSIS especially during rainy, } \\
\text { typhoon or flooding seasons __ Yes/No } \\
\text { If Yes, how many have experienced it? }\end{array}$ \\
\hline
\end{tabular}




\section{Community-Based Flood Vulnerability Index for Urban Flooding: Understanding Social Vulnerabilities and Risks}

\section{SOCIO-ECONOMIC}

1. Occupational background of the respondent or anyone working in the family. Please put a check mark on the choices below.

Fisherman __ Skilled worker __ Laborer/Helper __ Saleslady/Salesman __ Public Employee __ Private Employee __Pedicab/Easyride Driver __Private Driver __ Laundry Others, pls. specify

2. Estimated Monthly Income from all sources of livelihood. Please put a check mark on the choices below. Below $3000 \_3001-10,000 \_10,001$ above Others, pls. specify

3. Do you own your residential place, both the house and lot? __ Yes __ No __ Just the House __ Just the Lot

4. Is your housing property insured? __ Yes _ No

5. What construction material is your house mostly made of? Please put a check mark on the choices below.

Concrete __ Wood __ Cartoon __ Steel __ Galvanized Iron _ Coconut leaves__ Nipa material __ Plastic Bricks _ Tiles _ Salvage materials Others, pls. specify

\section{PHYSICAL ENVIRONMENT}

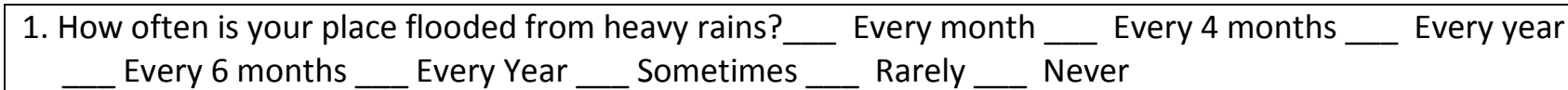

2. Did it reach inside your home? _Yes _ No

3. How high was the flood waters in your immediate surrounding have reached?

Ankle high __ Knee high __ Waist high __ Shoulder high __ Above the head __ Roof high _ B Beyond the roof Others, pl. specify

4. Is the immediate surroundings of your home clean? _ Yes _ No

5. Are there water logged areas in your surroundings? __ Yes __ No

6. Are there open sewage or canals in your surroundings? _ Yes _ No

7. Is your house situated near a river, creek/pond or coastal? Write down your answer

8. Is your house located in an elevated area? __ Yes __ No

9. Location where adult/child member of the household usually go to defecate: _ In your own latrine

In a neighbors latrine

Public latrine

On the ground

In a water body

Anywhere

Others, pls. specify

10. What type of latrine do you have at home?__ Water-sealed __ Antipolo type __ Pour flush

We don't have a latrine Others, pls. specify

11. Where do you dispose your household water waste? _ Into the septic tank _ Brgy. drainage _ Into the pit Anywhere Others, pls. specify

12. Where do you dispose your household solid waste?___ Garbage collected by LGU ground __ Burning __ Throwing into the river Others, pls. specify

Composting __ Burying in the

13. Do you practice segregation? __Yes _ No

14. Major source of drinking water at home during ordinary days:

Communal faucet

House to house connection __ Spring

Well

River Water pump Commercial

water seller dispensers__ Bottled water from industries

Others pls. specify

15. Major source of drinking water at home during heavy rains or flooding:

Communal faucet __ House to house connection __ Spring _

Commercial water seller dispensers

Bottled water from industries

Donations __ Well __ River Water pump

16. Do you think your source of drinking water is clean? __ Yes __No 


\section{Community-Based Flood Vulnerability Index for Urban Flooding: Understanding Social Vulnerabilities and Risks}

\begin{tabular}{|c|}
\hline $\begin{array}{l}\text { 17. How is your drinking water treated or sterilize? ___ Boiling in less than } 10 \text { minutes __ Boiling in } 10 \text { minutes } \\
\text { Chlorination __ Settling __ Filter__ Nothing } \quad \text { Others, pls. specify _ }\end{array}$ \\
\hline 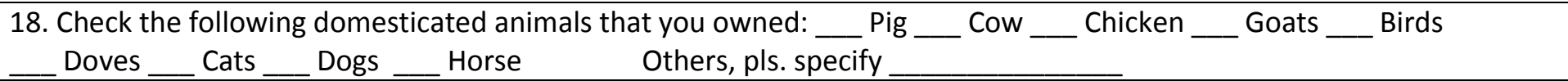 \\
\hline 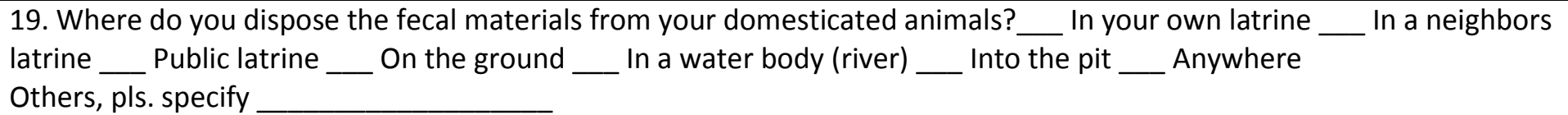 \\
\hline $\begin{array}{l}\text { 20. What are the domesticated animals you have observed from your neighbor's vicinity? _ Pig __ Cow _ _ Chicken } \\
\text { Goats _Birds _ Doves___ Cats _ _ Dogs__ Horse } \quad \text { Others, pls. specify _ }\end{array}$ \\
\hline 21. Is it permitted to raise domesticated animals in your vicinity? __ Yes _ No \\
\hline 22. Have you seen rats roaming around your vicinity? __ Yes _ N No \\
\hline 23. Have you seen rats roaming around your neighbor's vicinity? __ Yes __ No \\
\hline 24. Have you seen domesticated animals without an owner roaming outside your vicinity? _ Yes __ No \\
\hline $\begin{array}{l}\text { 25. What sanitation and hygiene programs you have heard before? } \ldots \text { About water safety __ Environmental sanitation } \\
\text { Garbage Segregation } \\
\text { The right way of washing of hands with soap and water __ Owning a latrine }\end{array}$ \\
\hline 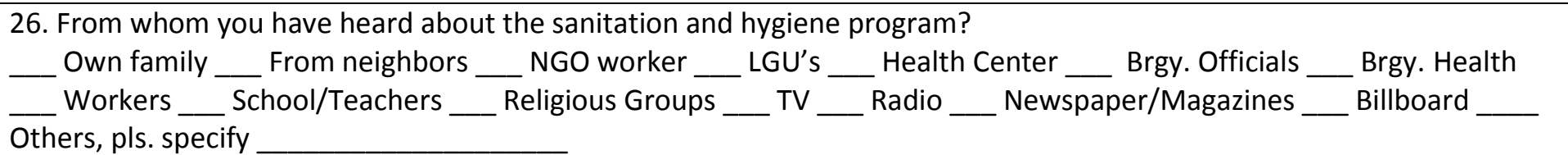 \\
\hline
\end{tabular}

\section{SOCIAL ENVIRONMENT}

\section{Are you friends with your neighbors? __ Yes _ No}

2. Are you willing to help your neighbor if in need of your help during or after heavy rains or flooding?

Yes No

3. Were there any health related meetings held in your place every now and then? Yes No Did you participate on this? __ Yes __ No

4. Have you observed your neighbors helping each other in whatever way they can during typhoon and flooding events?__ Yes _ No

5. If your house is very near from the river (about 5-10 meters) do you know that you can be at risk of flooding? Yes No

If the government would advice that your area is no longer safe, are you willing to vacate your place? _ _ Yes No If your answer is YES, then why? Give your reasons If your answer is NO, then why? Give your reasons 


\title{
Community-Based Flood Vulnerability Index for Urban Flooding: Understanding Social Vulnerabilities and Risks
}

\author{
KAP on Community Flood Resilient Assessment
}

On the KNOWLEDGE OF HOUSEHOLD RESPONDENTS on Flood Resilience in terms of the following

items:

\begin{tabular}{|c|c|}
\hline Items & Questions \\
\hline HAZARDS (harms) & $\begin{array}{l}\text { 1. Are you aware that your area is a flood hazard zone and you are at high risks? __ Yes __ No } \\
\text { 2. Do you know the nature and capacity of floods? _ Yes__ No } \\
\text { 3. Have you experienced flooding in this area and still continue to live here? __ Yes _ No } \\
\text { 4. Have you seen presence of overloaded drainage infrastructures during heavy rains/typhoons } \\
\text { and have seen its potential risks? } \\
\text { 5. Have you seen debris from all kinds during and after flooding? ___ Yes__ No } \\
\text { 6. Do you know if there are flood hazard maps available for your locality? }\end{array}$ \\
\hline RISKS (likelihood) & $\begin{array}{l}\text { 1. Are you aware that flooding can occur during and after heavy downpour? } \\
\text { 2. Are you aware of the limitation and level of protection of the flood control barriers? } \\
\text { 3. Do you know what time of the year flooding can usually occur? } \\
\text { 4. Do you think It can also happen at any time and one just needs to be ready all the time? } \\
\text { Yes__ No }\end{array}$ \\
\hline EXPOSURE & $\begin{array}{l}\text { 1. Are you aware of the negative impacts of flooding? (injury, infection, death, and loss of } \\
\text { property) Yes_ No } \\
\text { 2. Have you or anyone in the household have been exposed to flooding before? Y Yes__ No } \\
\text { 3. Have you or anyone in the household have been injured from the previous flooding? } \\
\text { 4. Have you or anyone in the household have been sick during or after flooding/rainy season? } \\
\text { 5. Have your household have experienced loss of love ones due to flooding and the impacts it } \\
\text { has brought such as injury and infection? } \\
\text { 6. Have you lost any of your property from the previous flooding? Y Yes No No }\end{array}$ \\
\hline PREPAREDNESS & 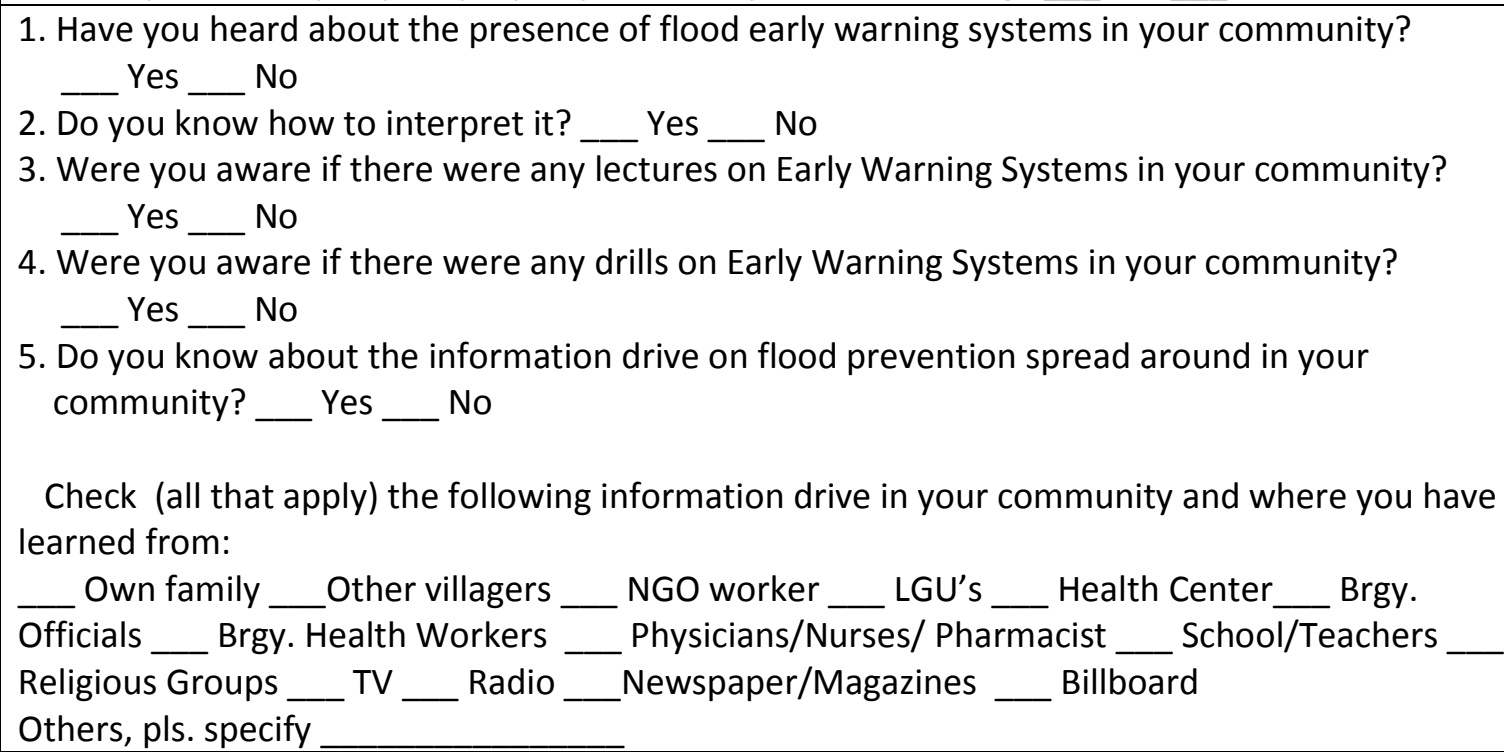 \\
\hline RESPONSE & 1. Are you aware that we have a local emergency response group in our community and city? \\
\hline
\end{tabular}


Community-Based Flood Vulnerability Index for Urban Flooding: Understanding Social Vulnerabilities and Risks

\begin{tabular}{|c|c|}
\hline & 2. $\overline{\text { Do you know }}_{\text {Ye }}^{\text {No }}$ the locations of the evacuation centers? __ Yes \\
\hline RECOVERY & $\begin{array}{l}\text { 1. Do you know how to conduct yourself in the evacuation centers? } \\
\text { (proper hygiene and sanitation).__ Yes }{ }_{\text {No }} \text { No } \\
\text { 2. Are you aware of the different programs of the local government in times of calamities? } \\
\text { Yes_ No }\end{array}$ \\
\hline COORDINATION & $\begin{array}{l}\text { 1. Are you aware that the emergency response team and the rest of the units work in a } \\
\text { coordinated manner? Yes__ No } \\
\text { 2. Do you know the Standard Operating Procedures during response and evacuations events } \\
\text { so coordination is facilitated? Yes__ No }\end{array}$ \\
\hline $\begin{array}{l}\text { ADAPTATION } \\
\text { STRATEGIES }\end{array}$ & 1. Do you know any adaptation strategies adapted in your community? __ Yes __ No \\
\hline
\end{tabular}

How much importance (ATTITUDE) did you give for the following items: Put a check mark on the lines of your choices.

a. HAZARDS

Very Lightly Lightly Seriously Very Seriously

(e.g. flood prone area)

b. RISKS

(e.g. low and inefficient dike and overflow bridges, clogged and overloaded drainage systems)

c. EXPOSURE

(e.g. by not vacating the place, watching the flash flood and running waters, picking up debris while flooding, immersing in flood waters without proper gears, drinking unsafe water)

d. PREPAREDNESS

(e.g. awareness of the flood early warning systems, attending lectures and drills on early warning systems)

e. RESPONSE

(e.g. readiness, cooperation with the emergency team, constant and regular TV, radio, online, text messages monitoring, and checking the water level closely)

f. RECOVERY

(e.g staying in the evacuation centers while not safe yet, staying away from clearing area so delays will be prevented, early reporting of damage so basic needs can be facilitated, cooperation in the evacuation centers, immediate repair of damage at home, food and water safety, attend debriefing sessions and go to doctors for check-up in case one is sick from the family)

g. COORDINATION

(e.g. cooperation to the programs facilitated $\overline{\text { by LGU's, sharing one's knowledge on flood }}$ preparedness, and continuous support and cooperation to the LGU's)

h. ADAPTATION STRATEGIES

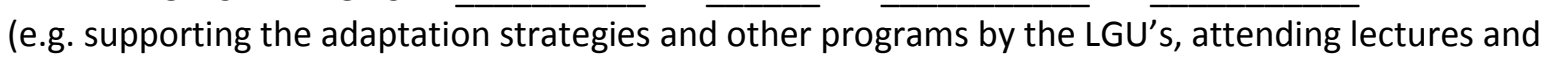
drills, and applying what was learned from these programs) 
Community-Based Flood Vulnerability Index for Urban Flooding: Understanding Social Vulnerabilities and Risks

On the PRACTICES of HOUSEHOLD RESPONDENTS on Flood Resilience in terms of the following items:

\begin{tabular}{|c|c|}
\hline ITEMS & Questions \\
\hline \multirow[t]{2}{*}{ HAZARDS } & $\begin{array}{l}\text { 1. If you know that your house is in a flood prone area, would you still continue to } \\
\text { live here? Y Yes__ No } \\
\text { If your answer is YES, then why. Give your reason }\end{array}$ \\
\hline & If your answer is YES, then why. Give your reason \\
\hline RISKS & $\begin{array}{l}\text { 1. Do you consider or give importance to the hazards involved in flooding? } \\
\text { 2. Do you consider or give importance to the risks involved in flooding? }\end{array}$ \\
\hline EXPOSURE & $\begin{array}{l}\text { 1. Do you wear protective clothing (raincoat) and sturdy shoes( boots) during typhoons and } \\
\text { flooding? Yes No } \\
\text { 2. Would you immediately evacuate to designated areas when a flood warning announcement } \\
\text { is given by those in authority? } \\
\text { 3. Would you tend to watch and stay near the flowing water while flooding? } \\
\text { 4. Would you tend to pick up floating and stocked debris during flooding? Yes }\end{array}$ \\
\hline PREPAREDNESS & 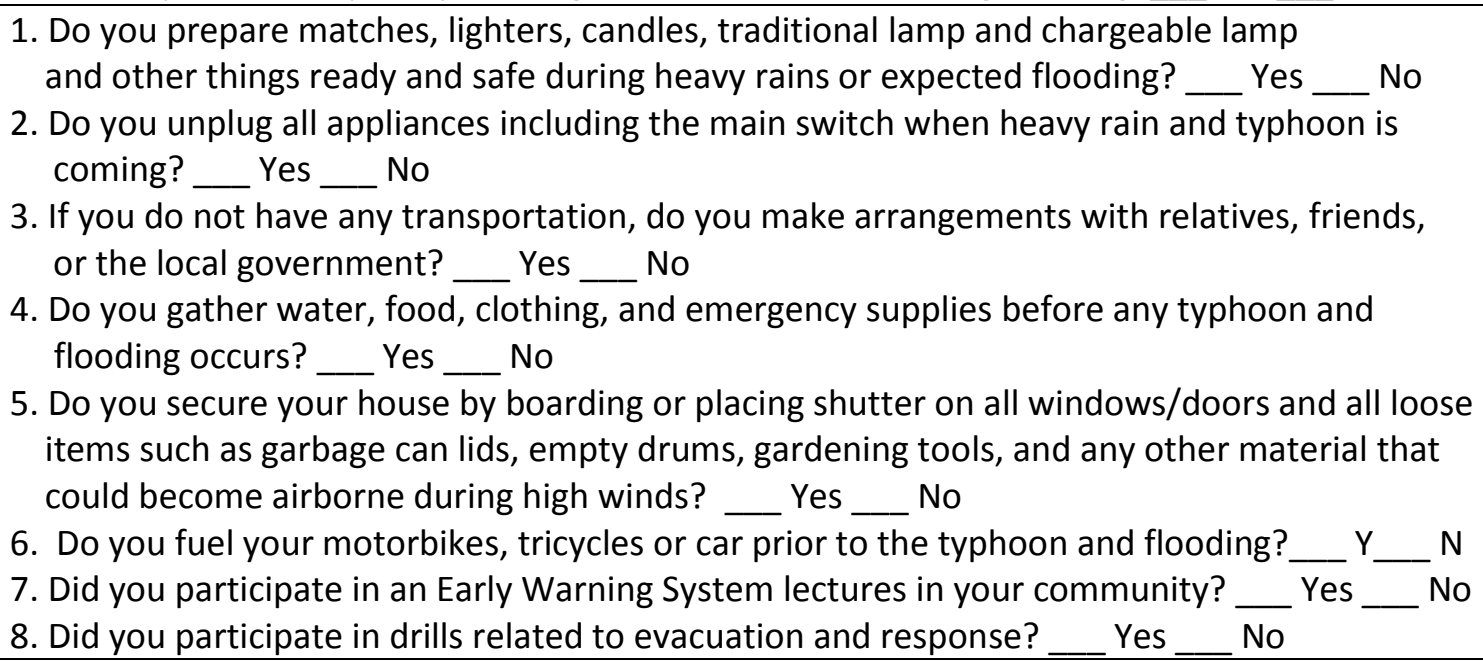 \\
\hline RESPONSE & $\begin{array}{l}\text { 1. Are you always alert all the time for possible flooding especially if it rains hard for several } \\
\text { hours? Yes No } \\
\text { 2. Do you listen to the radio, watch the TV, read the newspaper, keep track online updates and } \\
\text { mobile text messages and call authorities (local officials and city/prov. Rescue Headquarters) } \\
\text { for further information and warning during heavy rains, typhoons and flooding events? } \\
\text { Yes No } \\
\text { 3. Do you have neighborhood associations or support members in times of need during } \\
\text { flooding? Yes No } \\
\text { 4. Do you check from time to time the water levels of the river near you whenever there is a } \\
\text { heavy rain? Y Yes No No } \\
\text { 5. Do you have contacts from people further up to your area (Balugo or Valencia) so you will } \\
\text { know the water levels there? Yes_ No }\end{array}$ \\
\hline
\end{tabular}


Community-Based Flood Vulnerability Index for Urban Flooding: Understanding Social Vulnerabilities and Risks

\begin{tabular}{|c|c|}
\hline & $\begin{array}{l}\text { 6. Would you be ready to cooperate if local officials and rescue operations directing evacuation } \\
\text { routes? _ Yes__ No }\end{array}$ \\
\hline RECOVERY & 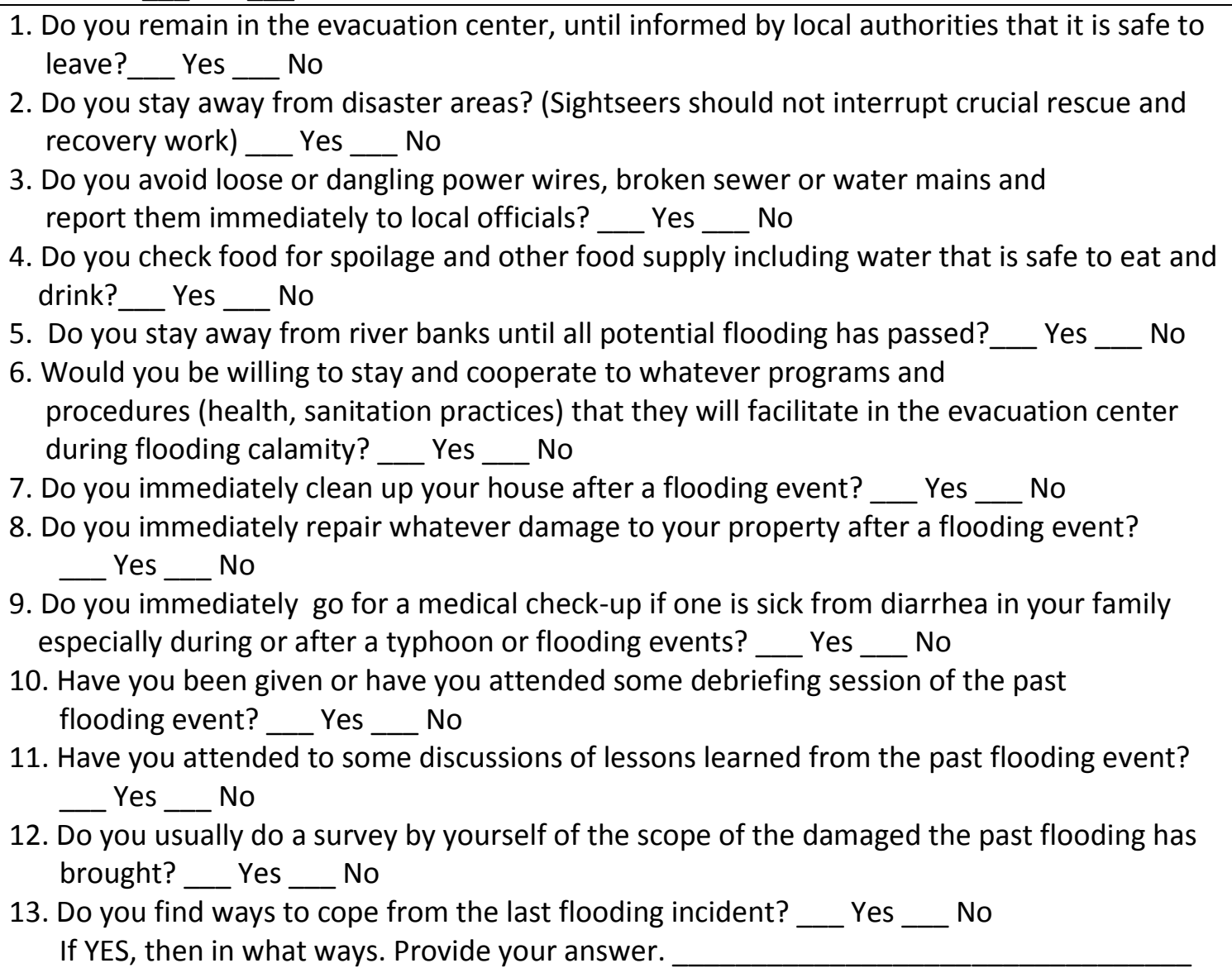 \\
\hline COORDINATION & $\begin{array}{l}\text { 1. Do you cooperate with the coordination procedures of the local government for the } \\
\text { resilience program in your community? Yes_ No } \\
\text { 2. Would you share your information to your neighbors about your knowledge of an issued } \\
\text { flood warning? Yes_ No }\end{array}$ \\
\hline $\begin{array}{l}\text { Adaptation } \\
\text { Strategies }\end{array}$ & $\begin{array}{l}\text { 1. Are you in favor of whatever adaptation strategies the local government is implementing or } \\
\text { in planned? } \\
\text { 2. Have you participated to any adaptation strategies facilitated by the LGU's? } \\
\text { 3. Have you applied what you have learned from the adaptation strategies? }\end{array}$ \\
\hline
\end{tabular}


Community-Based Flood Vulnerability Index for Urban Flooding: Understanding Social Vulnerabilities and Risks

\author{
KAP of Household Respondents on Environmental Microbial Health Risks \\ (E. coli, Leptospira spp., Dengue Fever Mosquito)
}

KNOWLEDGE on Environmental Microbial Health Risks

\title{
Questions
}

1. Have you heard about the following bacteria and virus:

Escherichia coli or E. coli? __ Yes No

Leptospira spp.?

Yes

No

Dengue Fever causing mosquito? ___es __ No

2. Have you heard about that there are bad and dangerous bacteria in water? __ Yes _ No

3. Are you aware that E. coli, Leptospira spp. \& Dengue Fever mosquito can be deadly? __ Yes__ No

4. Do you know how the following bacteria and virus can be transmitted?

E. coli __ Yes __ No

If your answer is YES, please check the items below that you think is the mode of transmission:

failure to wash hands thoroughly with soap and water following contact with animals or animal waste

drinking contaminated water

swimming in water even with very low levels of sewage contamination

accidental ingestion of contaminated water

Leptospira spp. __ Yes _ No

If your answer is YES, please check the items below that you think is the mode of transmission:

walking barefoot in flood waters; contacts of mucous membranes or broken skin with water (swimming or

immersion) contaminated with the urine of infected animals

swimming in water

wading in flood waters

Dengue Fever causing mosquito Yes No

If your answer is YES, please check the items below that you think is the mode of transmission:

mosquito bite infected from Aedes spp.

5. Have you heard that infections brought about by these bacteria and virus can be prevented? Yes No

If your answer is yes, check the items below that you think can help in the prevention of infection?

E.coli

washing of hands thoroughly with soap and water prohibiting animals near bodies of water boiling of water at 100 degrees celcius for 10 minutes avoid swimming in fecally contaminated waters treating water with chlorine

\section{Leptospirosis spp.}

avoid contact with flood waters by swimming or immersion with an open wound

use of sturdy boots during heavy rains and flooding

avoid walking barefoot

securing the environment free from its reservoir and fecal contamination 


\section{Dengue Fever Causing Mosquito}

mosquito control (eradicate mosquitoes as possible)

solid waste management (proper disposal of waste)

chemical control

improvement of water supply and storage (putting all unused containers upside down)

modification of man-made larval habitats (discourage presence of water-logged areas)

biological control (use of larvivoparous fish) personal protection (use of insect repellent and appropriate clothing)

6. Do you know the signs and symptoms of E.coli infection? __ Yes _ No

If your answer is yes, check the items below that you think are the signs and symptoms.

_ severe abdominal cramps watery diarrhea vomiting Fever severe neurological complications sometimes bloody diarrhea HUS (acute visceral failure, hemolytic anemia)

Do you know the signs and symptoms of Leptospirosis infection? _ Yes _ No

If your answer is yes, check the items below that you think are the signs and symptoms.

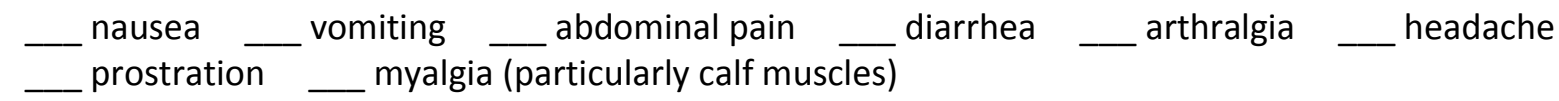

Do you know the signs and symptoms of Dengue Fever infection? __ Yes _ No

If your answer is yes, check the items below that you think are the signs and symptoms.

high fever of acute onset hemorrhagic manifestations (presence of spots on the body)

_ hepatomegally __ bleeding __ shock myalgia and arthralgia (severe joint and muscle pain)

L lymphadenopathy nausea and vomiting pain in eyeballs pain in back, body and joints severe headache _ colds and $\mathrm{fl}$

7. Do you know how E. coli infection, Liptospira spp. and Dengue Fever infection can be fatal? Yes No

8. Do you know that E. coli, Leptospira spp. \& Dengue Fever mosquito can also be treated? Yes _ No

9. Where did you get your sources of information on E. coli infection, Liptospira spp. and Dengue Fever infection? Pls. check items below for your answers.

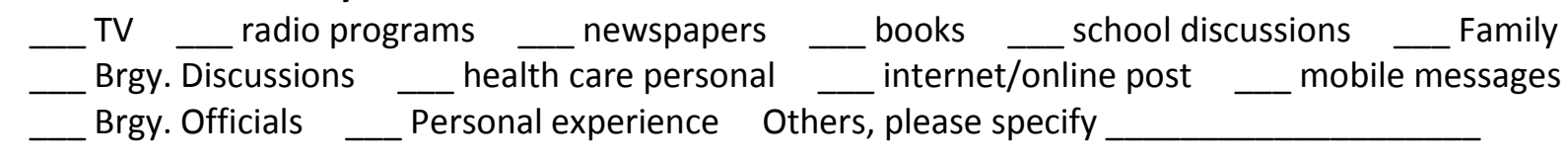

How much importance (ATTITUDE) did you give for the following items regarding on E. coli infections:

Put a check mark on the lines of your choices.
a. The Nature of E.coli
b. MODE of TRANSMISSION
c. PREVENTION
d. SIGNS and SYMPTOMS

Very Lightly Lightly Seriously Very Seriously 
e. It is FATAL

f. TREATMENT

g. FINANCIAL cOSt of TREATMENT

h. The INFECTION itself

i. Information Drive

How much importance (ATTITUDE) did you give for the following items regarding on Leptospirosis infections: Put a check mark on the lines of your choices.

Very Lightly Lightly Seriously Very Seriously
a. The Nature of Liptospirosis
b. MODE of TRANSMISSION
c. PREVENTION
d. SIGNS and SYMPTOMS
e. It is FATAL
f. TREATMENT
g. FINANCIAL cOSt of TREATMENT
h. The INFECTION itself
i. Information Drive
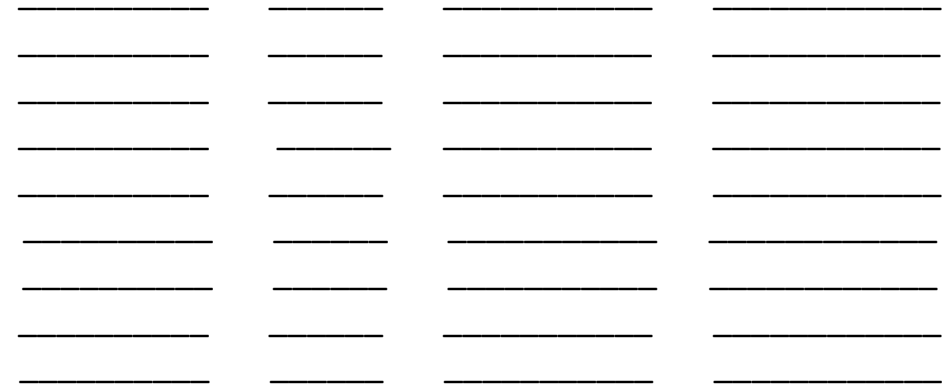

How much importance (ATTITUDE) did you give for the following items regarding on Dengue Fever infections: Put a check mark on the lines of your choices.

\section{Very Lightly Lightly Seriously Very Seriously}
a. The Nature of Dengue Fever
b. MODE of TRANSMISSION
c. PREVENTION
d. SIGNS and SYMPTOMS
e. It is FATAL
f. TREATMENT
g. FINANCIAL cOSt of TREATMENT
h. The INFECTION itself
i. Information Drive
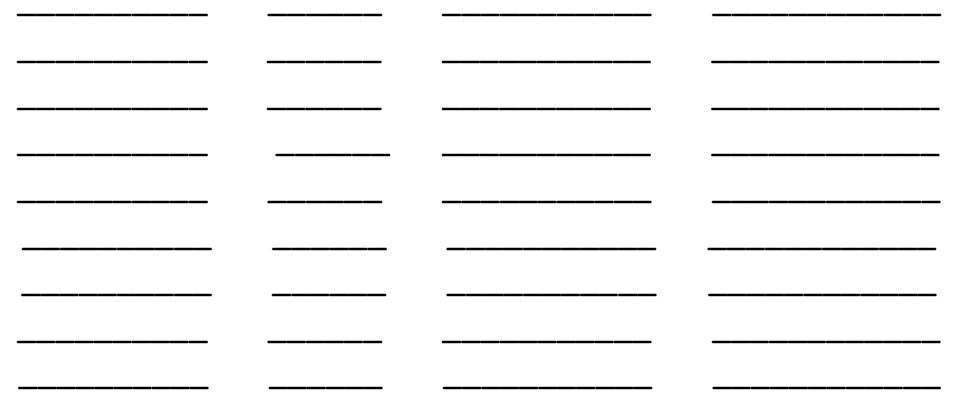

On the PRACTICES of HOUSEHOLD RESPONDENTS regarding on $E$. coli infection in terms of the following items.

Questions

1. Do you or other members in the family go swimming or bathing in the river? Yes No or Deep Well How often? Everyday Every other day Twice a week Every week Very rarely Never

Were there any chances that you have accidentally swallowed the water from the river? Yes No 


\section{Community-Based Flood Vulnerability Index for Urban Flooding: Understanding Social Vulnerabilities and Risks}

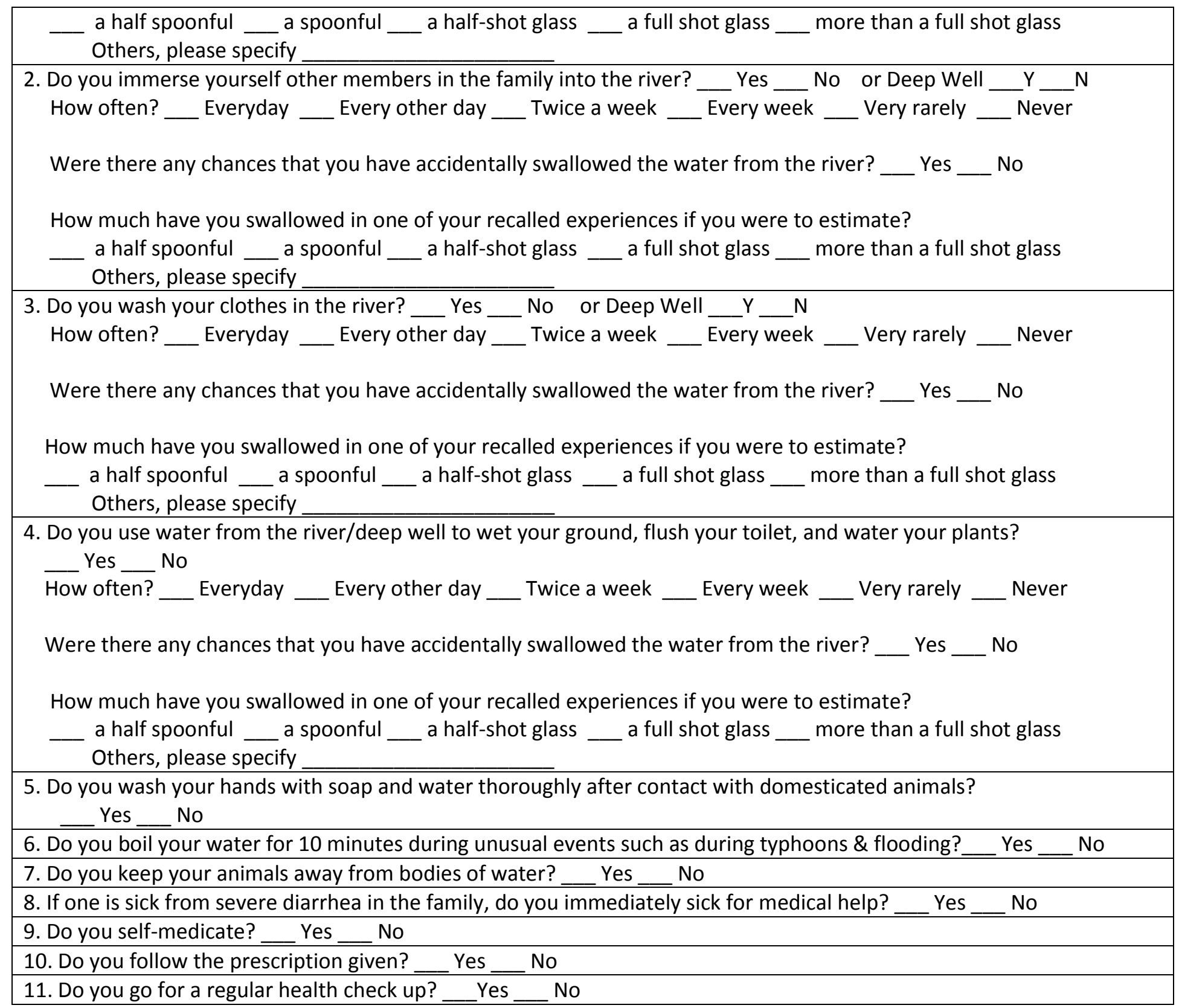

\section{On the PRACTICES of HOUSEHOLD RESPONDENTS regarding on Leptospirosis infection in terms of the}

following items.

Similar Questions for Leptospirosis Infection from E.coli questions(Numbers 1-4)

1. If one is sick from severe fever in the family, do you immediately sick for medical help? __ Yes __ No

2. Do you use rubber boots during heavy rains, typhoons or flooding? __ Yes _ No

3. Do you take Doxycyline antibiotics as prevention during rainy or flooding season? __ Yes __ No 


\section{Community-Based Flood Vulnerability Index for Urban Flooding: Understanding Social Vulnerabilities and Risks}

On the PRACTICES of HOUSEHOLD RESPONDENTS regarding on Dengue Fever infection in terms of the following items.

1. Do you clean your immediate surroundings and empty from the following usual mosquito breeding sites? Yes No

If your answer is yes, check the items below that correspond to your answer.

flower pot hardened soil of potted plants collar of toilet bowl gully trap roof gutter flower pot plate scupper drain abandoned water tank

2. Do you clean your immediate surroundings and empty from the following unusual/uncommon mosquito breeding Sites? Yes No

If your answer is yes, check the items below that correspond to your answer.

tree hole plant axil aircon tray BBQ pit canvass sheet

discarded receptacles such as:

tire plastic caps coconut shells empty bottles cans buckets jars blocked roof gutters _tarps __ drums

3. Do you make sure that your home is airy, bright, and safe from moisture? __ Yes _ No

4. Do you have fixed net on doors and windows? Yes No No

5. Do you close the overhead tanks after using? __ Yes __ No __ Not applicable

6. Do you keep your water in water containers for a week? __ Yes __ No

7. Do you let water to accumulate inside and outside your home?

8. Do you let water to stay in the flower pots or vases for a week?

Yes

No

9. Have you had fogging activities in your home or community? _ Yes _ No

10. Have you had apply chemical control against larval stages of dengue mosquitoes?

11. Have you had apply biological control against larval stages of dengue mosquitoes?

\section{Assessment on Flood Resilience \& Health Program of the Local Government Units and NGO's} In your own perspective and views based from your own personal experiences, and from what you have seen and heard from reliable sources how would you rate the programs of the LGU and NGO. Please put a check mark on the lines provided that reflect your choices.

\section{Excellent Very Well Good Poor Very Poor}

1. The implementation and monitoring of the policies, plans, and programs for the different natural calamities particularly typhoon and flooding events.

2. The transparency and trustworthiness of the LGU in terms of the facilitation and distribution of the budget and donations for the affected population in the community.

3. For the livelihood or financial aid for the community people to recover again from such calamity. 
4. For the programs and policies in saving and protecting the BANICA River.

5. The cooperation of the community people including you in protecting the Banica river.

6. The drainage systems

7. The dike systems

8. The bridge systems

9. The flood hazard maps

10. The use of backhoe in cleaning the Banica river especially when the normal flow is blocked.

11. The distribution of donations, goods and relief.

12. The distribution of brochures and the information drive that would increase knowledge on the negative impacts from typhoon and flooding events for the purposes of prevention and recovery.

13. Flood early warning systems

14. Preparedness and drill to increase resilience from typhoons and floods.

15. The response and preparedness

of the DRRMC, PDRRMC and other NGO volunteers during rescue events.

16. The basic emergency and

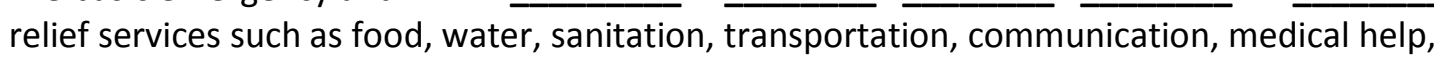
provisional repairs of damaged properties.

17. The operation clean-up of affected places, giving of insurances, claims, financial aids, traumatic and psychological stress debriefings.

18. The relocation sites provided by the LGU's to those who were affected from the last flooding and to those who live in the flood prone area. 

Social Vulnerabilities and Risks

19. The health programs for diarrhea and Liptospirosis such as medical help, information drive and among others so outbreaks can be prevented.

20. The different prevention and control programs for Dengue Fever infection such as fogging, chemical/biological control, information drive brochures, lectures, clean-up and other similar means at the community level. 
Community-Based Flood Vulnerability Index for Urban Flooding: Understanding Social Vulnerabilities and Risks

\section{Appendix 2 Visayan HOUSEHOLD SURVEY FORM QUESTIONNAIRE}

For the details of items for appendix 2, the lists are the same in appendix 1.

Questionnaire No: GPS Location

Data of Household Respondents on its Socio-Demographic Profile, Physical and Social Environment

\begin{tabular}{|c|c|}
\hline $\begin{array}{l}\text { Ngalan sa Barangay: } \\
\text { Ngalan sa Purok: }\end{array}$ & $\begin{array}{l}\text { Nabiktima ba kamo sa niaging Baha nga Sendong? } \\
\qquad \_ \text {Yes/No __ }\end{array}$ \\
\hline $\begin{array}{l}\text { Pila mo kabuok tanan sa Pamilya: } \\
\text { Pila Kabuok ang mga Ni-ipon Ninvo: }\end{array}$ & Imong Ngalan (OPTIONAL) \\
\hline & Imong Edad: \\
\hline $\begin{array}{l}\text { Pila Kabuok Babayi ug Lalaki sa Pamilya : } \\
\qquad \text { _ Babayi/Lalaki___ } \\
\text { Unsang Grado Imong Nakab-ot : }\end{array}$ & $\begin{array}{l}\text { Sa tibuok nimongbanay, aduna bay nakasulay nag } \\
\text { DIARRHEA or KALIBANGA hilabi na sa panahon sa ulan- } \\
\text { ulan, bagyo ug baha?__ Yes/No } \\
\text { Kung Yes, Pila man kabuok nakasulay na }\end{array}$ \\
\hline $\begin{array}{l}\text { Sa tibuok nimong banay, aduna bay nakasulay nag sakit nga } \\
\text { DENGUE FEVER hilabi na sa panahon sa ulan-ulan, bagyo ug } \\
\text { baha?__ Yes/No _ _ } \\
\text { Kung Yes, Pila man kabuok nakasulay na }\end{array}$ & $\begin{array}{l}\text { Sa tibuok nimong banay, aduna bay nakasulay nag sakit nga } \\
\text { LIPTOSPIROSIS (sakit nga gikan sa ihi sa ilaga) hilabi na sa } \\
\text { panahon sa ulan-ulan, bagyo ug baha?__ Yes/No } \\
\text { Kung Yes, Pila man kabuok nakasulay na }\end{array}$ \\
\hline
\end{tabular}

\section{SOCIO-ECONOMIC}

1. Unsay imong trabaho or trabaho sa imong bana or Anak? Palihug ug check kung asa sa ilalom ang imong mga tubag. Mananagat __ Skilled worker __ Laborer/Helper __ Tindera ___ Sa Gobyerno __ Private Employee Pedicab/ Easyride___ Private Driver__Labandera_Isulat kung wala diri

2. Estimate nga income sa Pamilya matag Bulan gikan sa tanan ninyong ma income. Ubos $3000 \ldots$ _ Gikan sa 3001 hangtud 10,000 __ Sobra sa 10,001 Isulat kung wala diri

3. Inyoha ba kining ma-ong balay ug yuta nga inyong gipuy-an karon? _ Yes _ No _ _ Ang Balay ra __ Ang yuta ra 4. Insured ba kining inyong balay? __ Yes _ No

5. Unsa nga construction material ang gigamit sa imong balay? Puedeng daghan ang imong tubag. Palihug ug acheck asa. Concrete __ Kahoy __ Karton __ Steel __ Galvanized Iron __ Coconut leaves__ Nipa material Plastic _ Bricks_Tiles_ Salvage materials_ Isulat kung wala diri 


\section{Community-Based Flood Vulnerability Index for Urban Flooding: Understanding Social Vulnerabilities and Risks}

\section{PHYSICAL ENVIRONMENT}

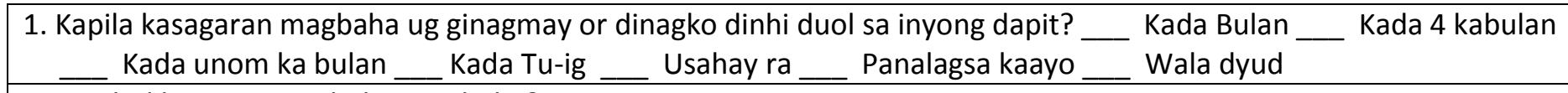

2. Nisulod ba sa inyong balay ang baha? _Y Yes _ No

3. Kung magbaha dinhi, unsa ka taas kasagaran? __ Sa may ti-il ra __ Sa may tuhod __ Sa may hawak __ Sa may abaga Lapaw sa ulo __ Abot sa atop___ Lapaw pas atop Ibutang kung wala dinhi ang imong tubag

4. Limpyo ba kasagaran ang iyong palibot? __ Yes __ No

5. Aduna bay mga basa-basa nga lugar dapit dinhi _. Yes _ No

6. Aduna bay mga abre nga kanal dinhi? __Yes __No

7. Ang imong balay duol ba ug suba? Basa-basa? Creek/Pond? Dagat? Isulat imong tubag

8. Ang imong balay nahimutang ba sa taas-taas nga dapit? __ Yes _ No

9. Asa kasagaran malibang inyong anak o sakop? __ Sa inyong kasilyas __ Kasilyas sa silingan __ Sa publiko nga kasilyas __ Sa yuta __ Sa suba __ Bisan asa_ lbutang kung wala dinhi ang imong tubag

10. Unsay klase/type sa inyong kasilyas? __ Water-sealed __ Antipolo type __ Pour flush _ WALA mi Kasilyas Ibutang kung wala dinhi ang imong tubag

11.Asa kasagaran paingun inyong tubig nga hinugas, tubig nga gikan sa banyo? _ Paingun sa septic tank __ Sa Brgy. drainage __ Sa yuta __ Sa dalan_lbutang kung wala dinhi ang imong tubag

12. Asa ninyo kasagaran ginalabay inyong basura? __ Garbage truck collected by LGU __ Composting __ llubong sa yuta __ Ginasunog___ Gilabay sa suba_ lbutang kung wala dinhi ang imong tubag

13. Nag segregate ba kamo o wala ba ninyo ginasagulsagol ang inyong mga basura? ___ Yes __ No

14. Asa gikan ang inyong tubig nga imnunon sa matag adlaw? __ gripo sa Barangay __ Gripo sa balay __ Tubod

Atabay __ Suba __ Sa bomba __ Gapalit gikan sa commercial water seller dispensers

Gapalit ug bottled water from industries___ lbutang kung wala dinhi ang imong tubag

15. Asa gikan ang inyong tubig nga imnunon sa matag sa timpong ting ululan, bagyo o baha?

__ gripo sa Barangay ___ Gripo sa balay __ Tubod__ Donations__ Atabay __ Suba __ Sa bomba __ Gapalit gikan sa commercial water seller dispensers _ Gapalit ug bottled water from industries

Ibutang kung wala dinhi ang imong tubag

16. Para nimo, limpyo ba kaayo ang maong tubig nga inyong gina-inom ug safe ba kini? __ Yes __No

17. Giunsa ninyo pag sterize inyong tubig nga imnunon? ___ Pagpabukal nga dili kaabot ug 10 minutes ug 10 minutes __ Pagbutang ug Chlorine Gpa settle lang Gamit ug filter Wala

Ibutang kung wala dinhi ang imong tubag

18. Asa dinhi ang mga hayop nga inyong buhi? Baboy __ Baka __ Manok __ Kanding Langgam Salapati Iring __ Iro__ Kabayo_ Ibutang kung wala dinhi ang imong tubag

19. Asa ninyo kasagaran ginalabay ang mga tae sa hayop nga inyong buhi? __ Sa inyong kasilyas Kasilyas sa silingan Sa publiko nga kasilyas __ Sa yuta __ Sa suba Bisan asa Ibutang kung wala dinhi ang imong tubag

20. Unsay mga kasagarang hayop ang buhi sa inyong silingan? __ Baboy __ Baka __ Manok __ Kanding __ Langgam Kalapati __ Iring __ Iro __ Kabayo_ Ibutang kung wala dinhi ang imong tubag

21. Gitugutan ra ba sa inyong lugar ang pagpamuhi aning maong mga hayop? __ Yes__ No

22. Nakita kabag ilaga dinhis inyong lugar? __ Yes __ No

23. Nakita kabag ilaga sa inyong silingan? _ Yes _ No

24. Kita ka bag mga hayop nga nagsuroy suroy nga walay tag-iya? __ Yes _ No

25. Unsay mga programaha nga kabahin sa panglawas ug palibot ang imong naduggan nga gihimo sa Barangay ? Kabahin kung unsaon pag sigurado nga limpyo ang tubig Kabahin sa Sanitisyon sa palibot 


\section{Community-Based Flood Vulnerability Index for Urban Flooding: Understanding Social Vulnerabilities and Risks}

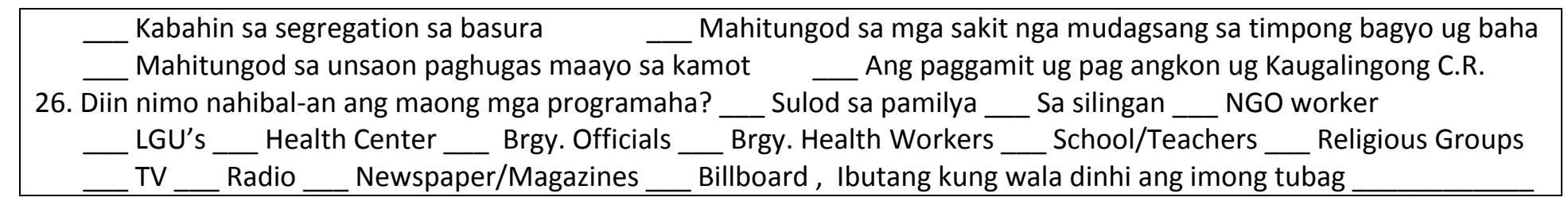

SOCIAL ENVIRONMENT

\begin{tabular}{|c|}
\hline 1. Maayo ba inyong relasyon sa imong silingan, in good terms or friends ba mo? \\
\hline 2. Andam ba ka nga mutabang sa imong silingan hilabi na sa panahon sa bagyo ug baha? \\
\hline $\begin{array}{l}\text { 3. Aduna bay mga health meetings or activities nga ginahimo sa Barangay dinhi sa inyong lugar? __ Yes _ _ No } \\
\mathrm{Ni} \text { apil ka ba sa maong activity? __ Yes__ No }\end{array}$ \\
\hline 4. Nakita ba nimo ang panagtinabangay sa imong silingan panahon sa kalamidad sama sa bagyo ug baha? __ Yes \\
\hline $\begin{array}{l}\text { 5. Kung ang imong balay duol kaayo sa suba (mga 5-10 metros gikan sa suba) nasayod ka ba nga puede kang maabot sa } \\
\text { baha? Y Yes__ No } \\
\text { Kung muingon ang gobyerno nga dili kini safe ang imong lugar, andam ka ba nga mo biya niini? ___ Yes__ No } \\
\text { Kung imong tubag Yes, ngano }\end{array}$ \\
\hline
\end{tabular}

\section{KAP on the Community Flood Resilient Assessment}

On the KNOWLEDGE OF HOUSEHOLD RESPONDENTS on Flood Resilience in terms of the following items:

\begin{tabular}{|c|c|}
\hline Items & Questions \\
\hline HAZARDS (harms) & $\begin{array}{l}\text { 1.Nasayod ka ba nga kining imong gipuy-an nasulod sa flood hazard zone ug puede kang maabot sa } \\
\text { baha? _ Yes__ No } \\
\text { 2. Nasayod ka ba sa capasidad ug puedeng mahimo sa baha? __ Yes __ No } \\
\text { 3. Nakasulay naba kamo ug baha dinhing dapita, apan padayon ra gihapun kamo ug puyo dinhi? } \\
\text { 4.Naka saksi ka ba nga napuno ang mga drainage sytem ug nahibalo nga peligro ka na ilabi na kung } \\
\text { timpong bagyo o kusog ug dugay nga ulan? Yes__ No } \\
\text { 5. Kita ka ba sa mga lain-laing anod gikan sa baha ug ang peligro niini? ___ Yes__ No } \\
\text { 6. Nahibalo ka ba nga adunay flood hazard map sa inyong lugar? __ Yes __ No }\end{array}$ \\
\hline RISKS (likelihood) & $\begin{array}{l}\text { 1.Nasayod ka ba nga puedeng mo baha kada nay kusog nga ulan or inanay apan dugay nga undang } \\
\text { nga ulan? } \\
\text { 2. Nasayod ka ba sa limitasyon kung asa ra kutob ang puedeng ika protektar sa maong mga flood } \\
\text { control barriers or sagang sa baha sama sa dike ug overflow bridges? } \\
\text { 3. Kahibalo ka ba kung unsang mga bulana kasagaran mo baha? Yes __ No __ No } \\
\text { 4. Sa imong panglantaw, ang baha puedeng mahitabo walay gipiling bulan or panahon maong } \\
\text { kinahanglan igmat sa tanang panahon? }\end{array}$ \\
\hline EXPOSURE & $\begin{array}{l}\text { 1. Nasayod ka ba sa mga negatibong epekto sa baha sama sa injury, infection, makamatay, maka } \\
\text { hanaw sa atong kabtangan? __ Yes _ No } \\
\text { 2. Aduna na bay nakasulay ninyo ug sinati ug baha?_ Yes__ No } \\
\text { 3. Aduna na bay nakasulay sa imong banay nga injured o nasamad tungod sa baha?__ Yes__ No } \\
\text { 4. Aduna na bay nakasulay sa imong banay nga nag sakit tungod sa bagyo ug baha? __ Yes__ No }\end{array}$ \\
\hline
\end{tabular}




\section{Community-Based Flood Vulnerability Index for Urban Flooding: Understanding Social Vulnerabilities and Risks}

\begin{tabular}{|c|c|}
\hline & $\begin{array}{l}\text { 5. Nakasulay na ba kamo nga nawad-an ug banay tungod sa baha ug bagyo? }{ }_{\text {6. Nakasulay nab a kamo nga nawad-an sa inyong mga butang or balay tungod sa baha? }} \text { No } \\
\text { Yes_ No }\end{array}$ \\
\hline PREPAREDNESS & 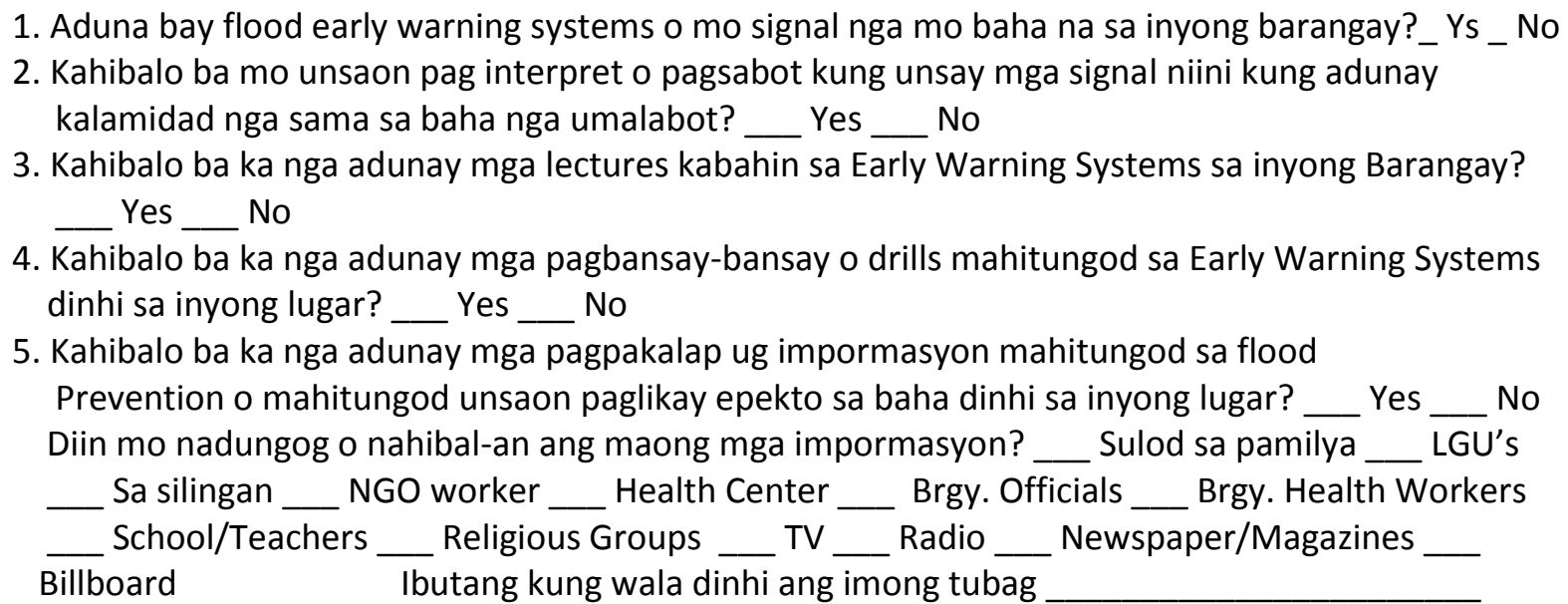 \\
\hline RESPONSE & $\begin{array}{l}\text { 1. Nasayod ba kamo nga duna kitay mga local emergency response group dinhi sa atong lugar hilabi } \\
\text { asa panahon sa mga kalamidad?__ Yes__ No } \\
\text { 2. Kahibalo ba mo kung asa nahimutang ang mga evacuation centers? __ Yes__ No }\end{array}$ \\
\hline RECOVERY & $\begin{array}{l}\text { 1. Kahibalo ba mo unsay angay nga buhaton kung ato-a na sa mga evacuation centers sama sa } \\
\text { maayong pag-atiman sa lawas o pag mintenar sa limpyo nga palibot? Yes __ No } \\
\text { 2. Nasayod ka ba sa mga lain-laing programa nga gitagana sa gobyerno hilabi na sa panahon sa } \\
\text { kalamidad, sama sa baha? _ Yes__ No }\end{array}$ \\
\hline COORDINATION & $\begin{array}{l}\text { 1.Nasayod ka ba nga ang mga emergency response team ug ubang mga organisayon coordinated } \\
\text { ilang pag facilitate sa panahon sa baha ug uban pang kalimidad? Yes No No } \\
\text { 2. Nasayod ka ba sa Standard Operating Procedures o angay nga buhaton panahon sa rescue ug pag } \\
\text { evacuate aron hapsay ug dali ang pag facilitate niini? __ Yes __ No }\end{array}$ \\
\hline $\begin{array}{l}\text { ADAPTATION } \\
\text { STRATEGIES }\end{array}$ & $\begin{array}{l}\text { 1. Nakadungog baka kabahin sa mga adaptation strategies or mga programa aron mahilayo o } \\
\text { maprotektaran kita sa mga kalamidad? Yes __ No }\end{array}$ \\
\hline
\end{tabular}

Unsay imong paghatag ug IMPORTANSYA (Attitude) kabahin sa mga sumusunod nga items:

Palihug ug butangi ug check ang linya sa imong tubag.

$\begin{array}{llll}\text { Gibaliwala } & \text { Medyo } & \text { Medyo } & \text { Giseryoso } \\ \text { Kaayo } & \text { Gibaliwala } & \text { Seryoso } & \text { Kaayo }\end{array}$

a. HAZARDS

(ex. baha-unon ang imong lugar ug peligro kini)

b. RISKS

(ex. mubo ra ang dike system, overflow bridges, bara nga mga drainage system o kanal so mag-igmat)

\section{c. EXPOSURE}

(ex. pagdili pag biya sa lugar, pag lantaw o saksi sa gahaguros nga baha, pagpamulot sa mga anod, pagtampisaw sa baha nga walay boots, ang dili pag sigurado sa seguridad sa tubig nga imnonon)

\section{d. PREPAREDNESS}

(ex. ang pag igmat sa mga sinyales sa early warning systems, pag apil sa mga lecture ug bansay-bansay mahitangod sa early warning system) 


\section{Community-Based Flood Vulnerability Index for Urban Flooding: Understanding}

Social Vulnerabilities and Risks

e. RESPONSE

(ex. kanunay ka bang alerto sa, andam nga mo kooperar sa mga emergency response team, kanunay nga nag monitor sa radio, $T V$, online, text messages, ug pag susi sa level sa tubig sa suba)

\section{f. RECOVERY}

(ex. muhawa lang sa evacuatin centers o sa balay kung safe na, dili mo disturb sa clearing area aron dili maka delay sa operasyon, magpahibalo dayon sa LGU's sa mga na damage aron nga ma repair dayon ang mga basic services sama sa kuryente, tubig ug uban pa, mo kooperar sa angay nga buhaton samtang naa sa evacuation centers, manglimpyo ug ayuhon dayon ang mga naguba nga property sa balay, seguraduhon nga limpyo ug safe ang mga tubig ug pagkaon, mo attend sa mga debriefing kabahin sa epekto sa baha, magpa check-up kung nasakit sa maong panahon)

\section{g. COORDINATION}

(ex. Pag kooperar sa programa sa LGU's mahitungod sa baha, pag pa ambit sa nahibal-an, kanunayong pag lambigit sa LGU aron updated sa mga bag-ong kalambu-an.

\section{h. ADAPTATION STRATEGIES}

(ex. Uyon ka bas a mga programa nga gihimo sa LGU's sama sa adaptation strategies aron mukunhod ang mga negatibong epekto sa baha, pag attend sa maong mga kalihokan, pag apply sa mga nahibal-an gikan sa maong kalihokan)

Mga PRACTICES nga adunay kalambigitan sa mga sumusunod nga items:

\begin{tabular}{|c|c|}
\hline Items & Questions \\
\hline HAZARDS & $\begin{array}{l}\text { 1. Kung nasayod ka nga ang imong balay nahimutang sa flood prone area o puedeng maabot sa } \\
\text { baha, o nabaha na, mupadayon ra ba ka sa pag puyo gihapun dinhi? } \\
\text { NGANO MANG Yes imong tubag or NGANON MANG No ang imong tubag? Palihug ug sulat sa imong } \\
\text { rason. }\end{array}$ \\
\hline RISKS & $\begin{array}{l}\text { 1. Imo bang gitagaan ug importantsya ang mga hazard o delikadong puedeng mahitabo sa baha? } \\
\text { 2. Imo bang gitagaan ug importantsya ang mga risk o risgo nga puedeng maka pa grabeh sa baha? } \\
\text { Yes__ No }\end{array}$ \\
\hline EXPOSURE & $\begin{array}{l}\text { 1. Nag gamit ba kamo ug raincoat, boots or sapatos sa panahon sa bagyo ug baha? _ Yes __ No } \\
\text { 2. Andam ba kamo nga mo evacuate sa mga evacuation centers kung adunay abiso? _ Yes _ No } \\
\text { 3. Mupadu-ol ba kamo sa baha ug maglantaw ni-ini samtang nagahitabo? __ Yes _ No } \\
\text { 4. Puluton ba ninyo ang mga anod samtang nag baha pa? _ Yes__ No }\end{array}$ \\
\hline PREPAREDNESS & 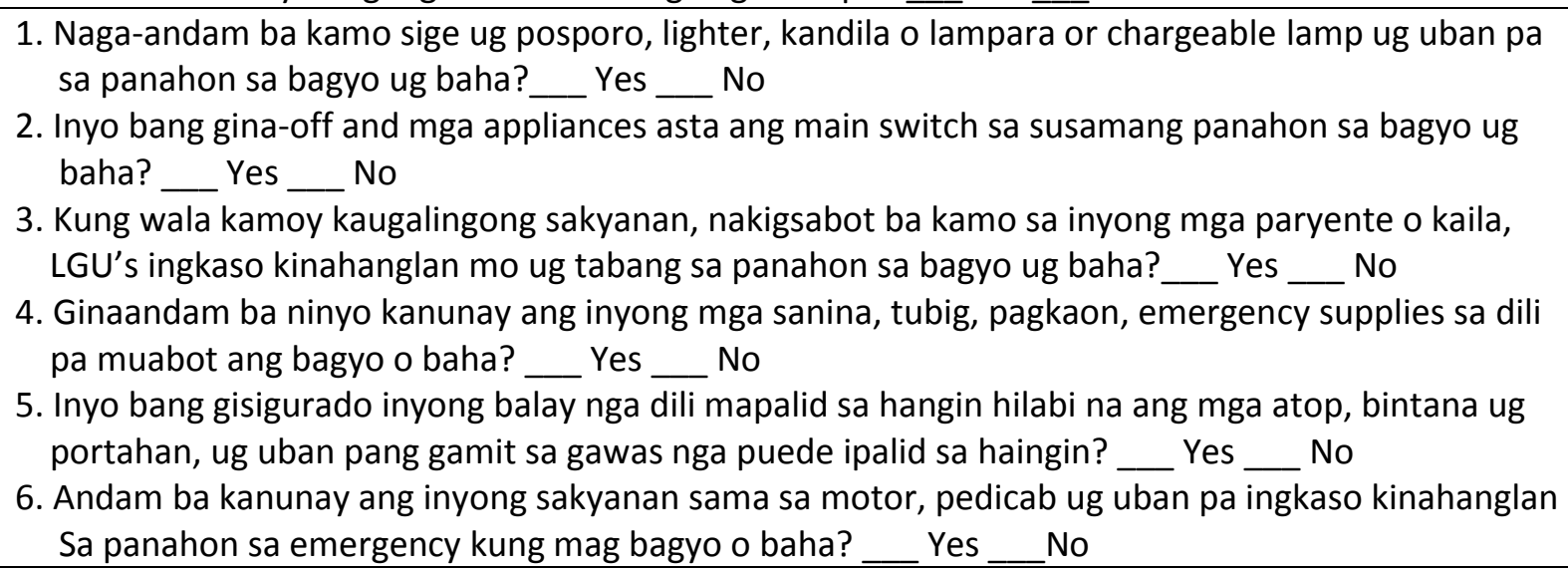 \\
\hline
\end{tabular}




\section{Community-Based Flood Vulnerability Index for Urban Flooding: Understanding}

Social Vulnerabilities and Risks

\begin{tabular}{|c|c|}
\hline & 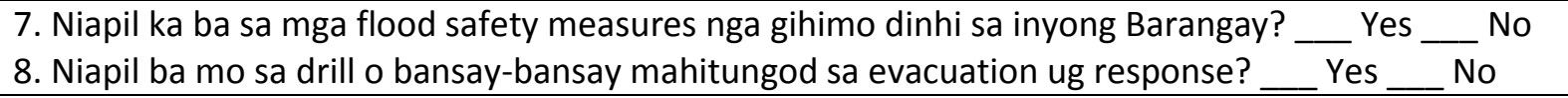 \\
\hline RESPONSE & $\begin{array}{l}\text { 1. Andam ba kamo kanunay sa baha hilabi na kung magsigeg ulan ug dugay or adunay bagyo?_ } \mathrm{Y}_{-} \mathrm{N} \\
\text { 2. Kanunay ba kamong nagmonitor sa radio, TV, , newspaper, online updates, mobile text messages, } \\
\text { or manawag sa LGU's ug provincial response team panahon sa bagyo o baha aron ma updated sa } \\
\text { mga angay nga buhaton?_ Yes__ No } \\
\text { 3. Aduna ba kamoy mga organisayon sa Barangay nga maoy puede tawagon panahon sa bagyo o } \\
\text { baha?_Yes__ No } \\
\text { 4. Naga obserbar ka ba kanunay sa level sa tubig sa suba labi na kung panahon sa bagyo ug baha? } \\
\text { 5. Aduna ba kamoy kontak nga kaila sa Valencia o Balugo aron mahibalo dayon kung unsa nay level } \\
\text { sa atubig ug unsa nay dagan sa baha?_ Yes__ No } \\
\text { 6. Andam ba kamo nga mo kooperar sa LGU emergency response team kung kinahanglan ng mo } \\
\text { evacuate sa inyong lugar? Y Yes_ No }\end{array}$ \\
\hline RECOVERY & 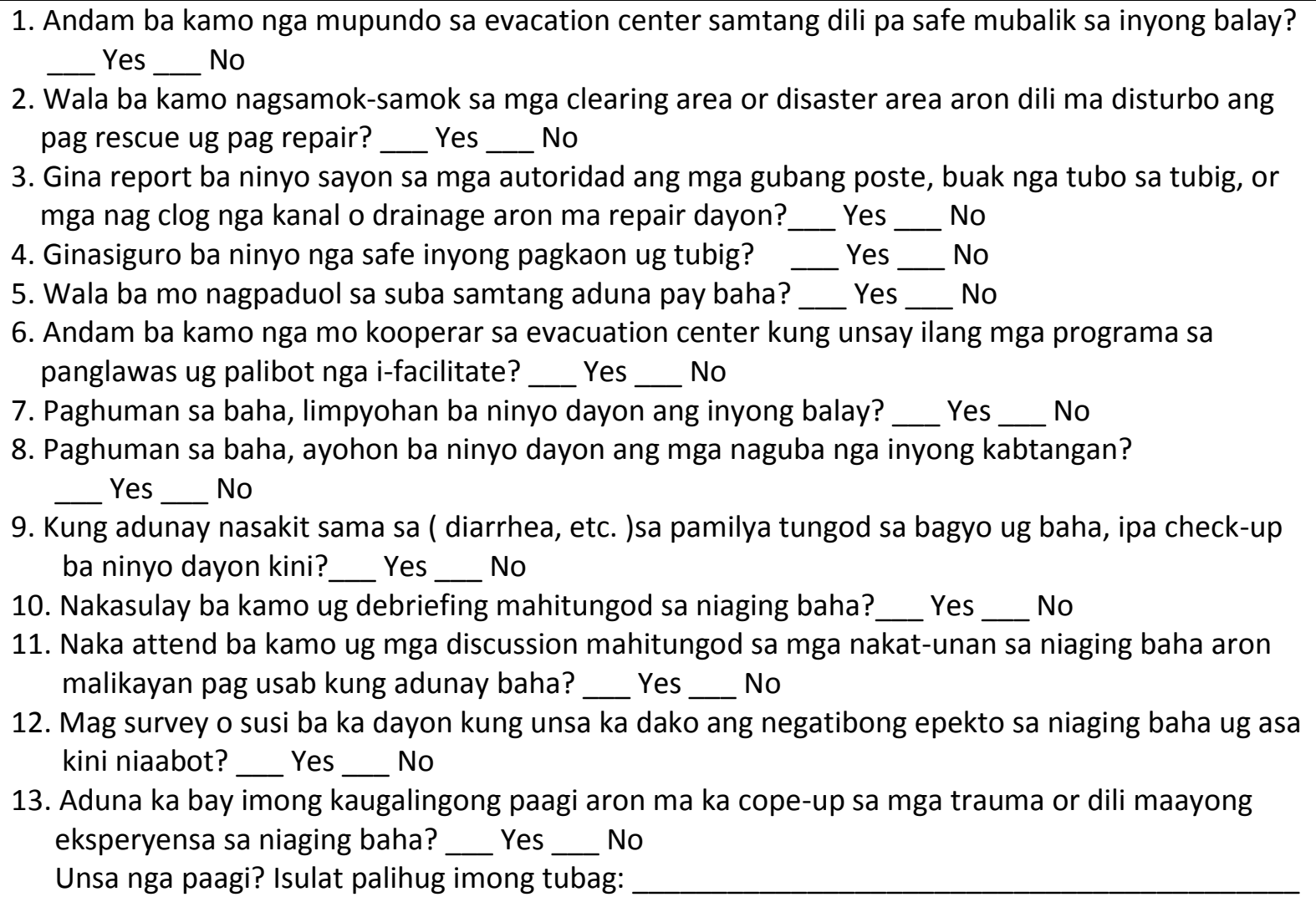 \\
\hline COORDINATION & $\begin{array}{l}\text { 1. Nikooperar o mo koopearar ba ka sa coordination procedures aron hapsay ang pag pasilidad sa } \\
\text { mga LGU's sa resilience program sa baha?_ Yes__ No } \\
\text { 2. Andam ka bang mo paambit o share sa impormasyon sa imong silingan kung nag issue na ug flood } \\
\text { warning? Y Yes_ No }\end{array}$ \\
\hline $\begin{array}{l}\text { Adaptation } \\
\text { Strategies }\end{array}$ & $\begin{array}{l}\text { 1. Uyon ka ba sa mga adaptation strategies o programa nga gibuhat sa LGU's ug NGO's nga adunay } \\
\text { kalambigitan sa baha ug uban pang kalamidad? __ Yes__ No } \\
\text { 2. Naka tambong ka ba sa mga panagtigum kabahin nianang mga programaha?__ Yes__ No }\end{array}$ \\
\hline
\end{tabular}


KAP of Household Respondents on Environmental Microbial Health Risks

(E. coli, Leptospira spp., Dengue Fever Mosquito)

KAHIBALO (KNOWLDEGE) on Environmental Microbial Health Risks

1. Nakadungog naba kamo sa mga sumusunod nga bacteria/kagaw ug virus: Escherichia coli or E. coli? Leptospira spp.? Yes No

Dengue Fever causing mosquito? Yes No

2. Kahibalo ba kamo nga adunay mga bacteria or kagaw nga nagdala ug sakit nga atong makuha dinhas sa tubig nga atong gi-inom or naa sa suba? __ Yes _ No

3. Nasayod ba kamo nga ang kaning mga maong kagaw sama sa (E. coli, Leptospira spp. \& Dengue Fever mosquito) puedeng maka matay? __ Yes __ No

4. Nasayod ba kamo kung sa unsang paagi nato kini puede makuha o matakod? __ Yes __ No E. coli or Kagaw/Bacteria sa tubig __ Yes __ No

Kung ang imong tubag YES, palihug ug butang ug check dinha sa linya sa ilalom kung sa imong huna-huna mao nay paagi nga makuha matakod nato ang maong kagaw:

kung dili manghinaw pag-ayo unya gikan naghikap ug hayop or nakahikap sa tae sa hayop unya dili mugamit ug sabon ug tubig

ang pag inom sa hugaw ug kontaminado nga tubig

ang pagkaligo sa hugaw ug kontaminado nga suba bisan tuod dyutay mang ganing ra ang kagaw nga naa sa suba aksidente nga pag inom sa kontaminadong tubig nga gikan sa suba, gripo, atabay o tubod

Leptospira spp. or Kagaw nga naa sa ihi sa ilaga or balagtok__ Yes __ No

Kung ang imong tubag YES, palihug ug butang ug check dinha sa linya sa ilalom kung sa imong huna-huna mao nay paagi nga makuha nato ang maong kagaw:

maglakaw nga walay sanilas, sapatos o boots sa baha nga tubig o suba nya naa kay samad nga gamay kaayo pagkaligo sa suba o atabay pag tusnob-tusnob sa baha

Lamok nga nagdala ug Dengue Fever ___ Yes __ No

Kung ang imong tubag YES, palihug ug butang ug check dinha sa linya sa ilalom kung sa imong huna-huna mao nay paagi nga makuha nato ang maong kagaw: __ paak sa lamok nga Aedes spp. nag nagdala ug dengue fever

5. Nasayod ka ba nga ang kaning maong mga sakit nga dala ani nga mga kagaw puede nato malikayan? __ Yes No

Kung ang imong tubag yes palihug ug butang ug check dinha sa linya sa ilalom kung sa imong huna-huna makatabang kana nga puede nato malikayan:

E.coli or Kagaw/Bacteria sa tubig

ang paghugas maayo sa kamot gamit ang tubig ug sabon

___ ang pagdili sa mga hayop nga maduol sa tubig/suba/atabay pagpabukal sa tubig sulod sa 10 minutos ang pag gamit ug chorine sa pag disinfect sa tubig

Leptospirosis spp.or Kagaw nga naa sa ihi sa ilaga or balagtok ang dili pag basa-basa sa baha or pagkaligo sa baha nga tubig hilabi na kung adunay samad sa tiil o lawas 


_ ang paggamit ug boots kung timpong ulan-ulan ug baha
ang pag sigurado sa lugar nga walay mga ilaga sa palibot
Lamok nga nagdala ug Dengue Fever
pagpatay or control sa mga lamok
_ pag gamit ug chemical sa pagpatay sa larva sa lamok ${ }_{\text {_ }}^{\text {ang pag sigurado nga walay tubig nga nagpundo sa container nga abre }}$
ang pag wala sa mga basa-basa sa palibot or mga punong-punong sa palibot
ang paggamit ug isda sa pagpatay sa larva sa lamok nga naa sa mga kanal-kanal
ang pag protektar sa kaugalingun pinaagi sa paggamit tag-as nga sanina/karsones/long sleeve/midyas ug mga

6. Nasayod ka ba sa mga sintomas sa E.coli infection sama sa diarrhea/kalibanga? __ Yes __ No

Kung ang imong tubag yes palihug ug butang ug check dinha sa linya sa ilalom kung sa imong huna-huna mao ka na ang mga sintomas: __ grabe nga sakit sa tiyan __ murag puro tubig ang diarrhea __ pagsuka __ hilanat _ _ complications sa utok usahay adunay dugo ang diarrhea
Nasayod ka ba sa mga sintomas sa Leptospirosis infection? HUS (acute visceral failure, hemolytic anemia)
Kung ang imong tubag yes palihug ug butang ug check dinha sa linya sa ilalom kung sa imong huna-huna mao ka na ang mga sintomas:
_ lipong-lipong __ pagsuka __ sakit sa tiyan __ diarrhea __ sakit ang mga joints __ labad ang ulo
_ grabe nga kakapoy, wala nay kusog _ sakit ang mga muscles labi na ang bagtak

Nasayod ka ba sa mga sintomas sa Dengue Fever infection? __ Yes __ No

Kung ang imong tubag yes palihug ug butang ug check dinha sa linya sa ilalom kung sa imong huna-huna mao ka na ang mga sintomas:

__ taas ug kali tang hilanat __ adunay mga pasa-pasa sa lawas __ nihubag ang atay __ daling mo dugo shock

_ _ sakit ang mga musclesug joints sakit ang mata, luyo, lawas ug ulo adunay mga pamlog or hubag-hubag lipong-lipong ug suka colds and flu

7. Nasayod ka ba nga ang mga sakit nga dala sa E. coli, Leptospira spp. \& Dengue Fever mosquito puedeng makamatay? _ Yes__ No

8. Nasayod ka ba nga ang mga sakit nga dala sa E. coli, Leptospira spp. \& Dengue Fever mosquito puede matambalan? Yes__ No

9. Di-in nimo nahibal-an ang mga kabahin niining mga kagaw ug sakit nga E.coli/diarrhea, Liptospirosis ug

Dengue Fever? Palihug ug butang ug check sa imong tubag. TV _ radio programs _ newspapers _ libro sa Barangay __ health care personel internet/online post discussions sa eskelahan pamilya Barangay officials___kaugalingong experience ibutang kung asa pa mobile/cellphone messages

Unsay imong paghatag ug IMPORTANSYA (Attitude) kabahin sa E.coli diarrhea sa mga sumusunod nga items: Palihug ug butangi ug check ang linya sa imong tubag.

$\begin{array}{llll}\text { Gibaliwala } & \text { Medyo } & \text { Medyo } & \text { Giseryoso } \\ \text { Kaayo } & \text { Gibaliwala } & \text { Seryoso } & \text { Kaayo }\end{array}$
a. Ang Kabahin sa E.coli (Nature)
b. Ang Pagtakod o Pagsulod sa Lawas
c. PREVENTION o Paglikay 
d. Mga Sintomas

e. Nga Makapatay

f. Ang Pagpatambal o Tambal

g. Ang Bayad sa Pagpatambal

h. Ang sakit mismo

i. Information Drive o

Mga Pagpahibalo

Unsay imong paghatag ug IMPORTANSYA (Attitude) kabahin sa Liptospirosis nga sakit sa mga sumusunod nga items: : Palihug ug butangi ug check ang linya sa imong tubag.

$\begin{array}{llll}\text { Gibaliwala } & \text { Medyo } & \text { Medyo } & \text { Giseryoso } \\ \text { Kaayo } & \text { Gibaliwala } & \text { Seryoso } & \text { Kaayo }\end{array}$

a. Ang Kabahin sa Liptospirosis

b. Ang Pagtakod o Pagsulod sa Lawas

c. PREVENTION o Paglikay

d. Mga Sintomas

e. Nga Makapatay

f. Ang Pagpatambal o Tambal

g. Ang Bayad sa Pagpatambal

h. Ang sakit mismo

i. Information Drive o

Mga Pagpahibalo
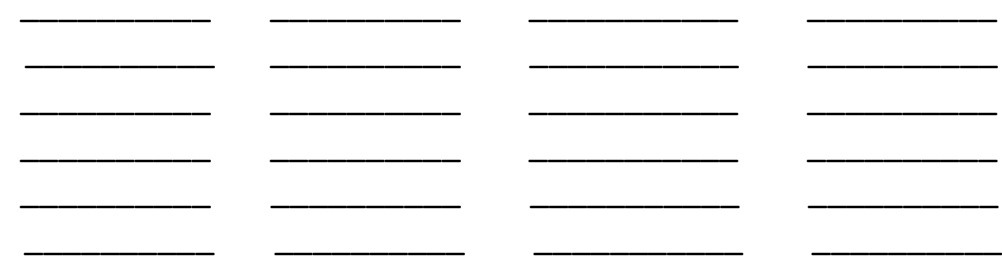

Unsay imong paghatag ug IMPORTANSYA (Attitude) kabahin sa Dengue Fever nga sakit sa mga sumusunod nga items: : Palihug ug butangi ug check ang linya sa imong tubag.

$\begin{array}{llll}\text { Gibaliwala } & \text { Medyo } & \text { Medyo } & \text { Giseryoso } \\ \text { Kaayo } & \text { Gibaliwala } & \text { Seryoso } & \text { Kaayo }\end{array}$
a. Ang Kabahin sa Dengue Fever
b. Ang Pagtakod o Pagsulod sa Lawas
c. PREVENTION o Paglikay
d. Mga Sintomas
e. Nga Makapatay
f. Ang Pagpatambal o Tambal
g. Ang Bayad sa Pagpatambal
h. Ang sakit mismo
i. Information Drive o
Mga Pagpahibalo

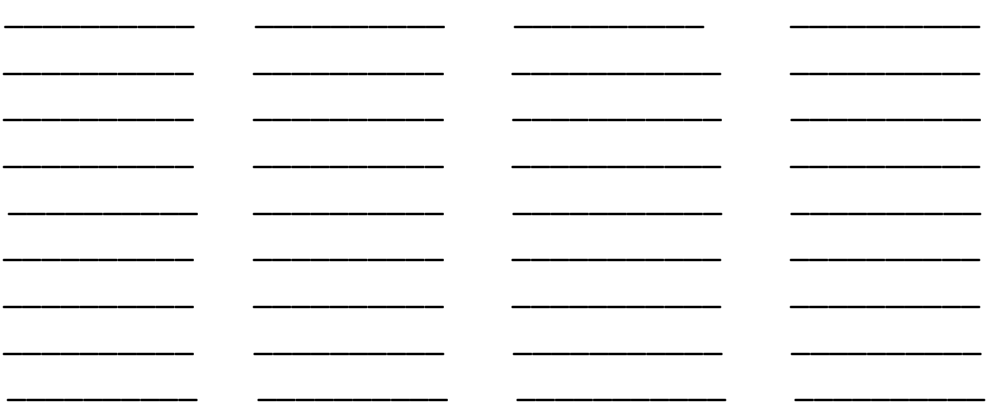

Mga PRACTICES nga adunay kalambigitan sa $E$. coli infection/diarrhea sa mga sumusunod nga items:

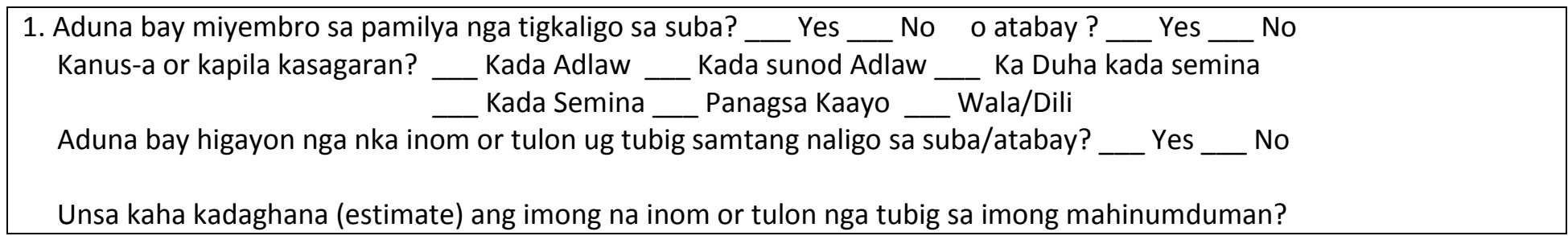




\section{Community-Based Flood Vulnerability Index for Urban Flooding: Understanding \\ Social Vulnerabilities and Risks}

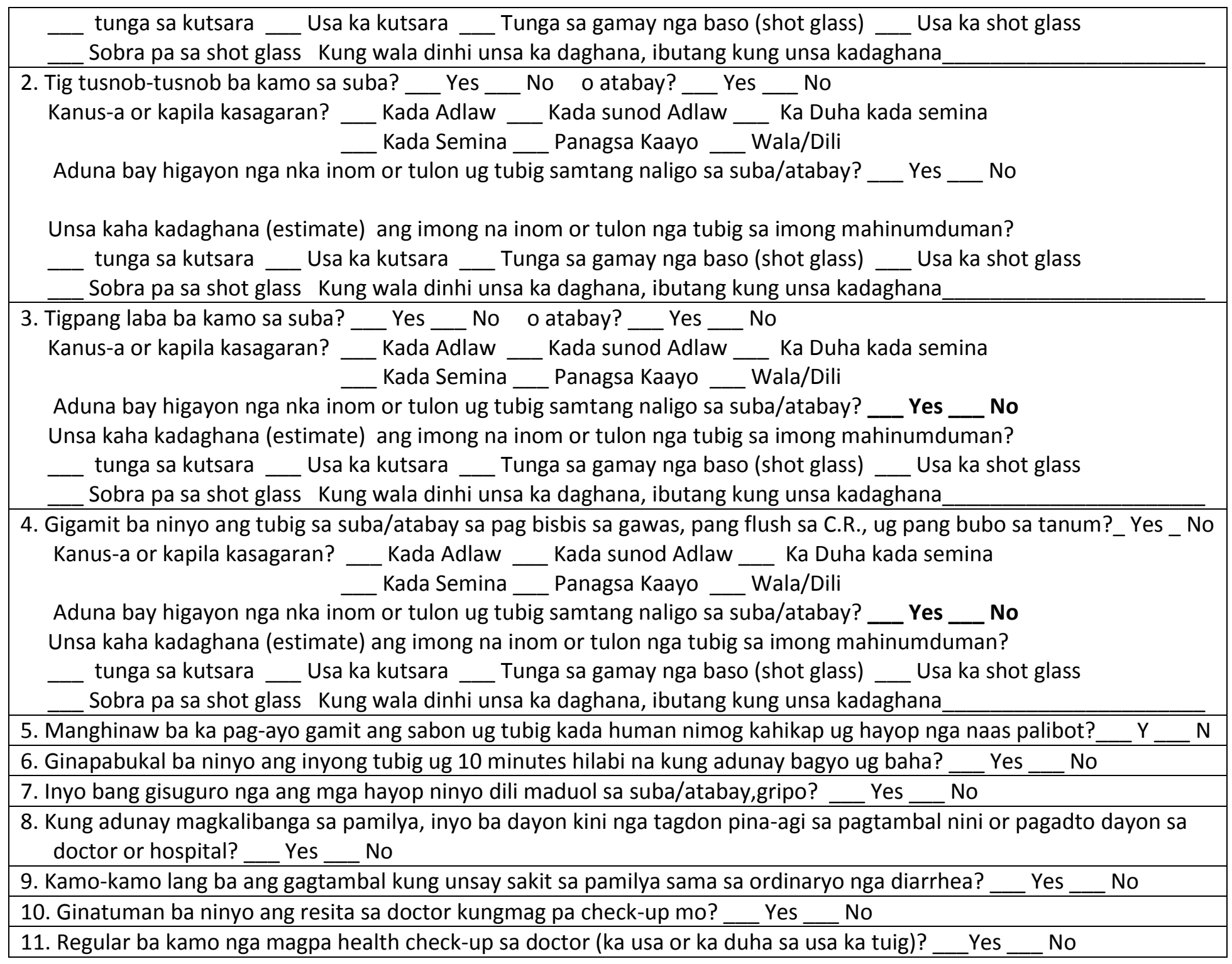

\section{Mga PRACTICES nga adunay kalambigitan sa Liptospirosis infection sa mga sumusunod nga items:}

Similar Questions for Leptospirosis Infection from E.coli questions(Numbers 1-4; 15-17)

1. Kung adunay gihilantan sa pamilya, ipa check-up ba dayon ninyo? __ Yes __ No

2. Nagamit ba kamo ug rubber boots panahon sa bagyo ug baha? __ Yes _ _ No

3. Nag-inom ba kamo ug antibiotic nga Doxycyline para dili magka Liptospirosis hilabi na panahon sa bagyo ug baha?

Yes _ No

\section{Mga PRACTICES nga adunay kalambigitan sa Dengue Fever infection sa mga sumusunod nga items:}

1. Kanunay ba kamo naga panglimpyo sa inyong balay ug palibot ug gisiguro nga walay tubig nga

napundo sa mga lugar nag nka lista sa ilalom nga kasagarang puy-an sa mga lamok? _ Yes

No 


\section{Community-Based Flood Vulnerability Index for Urban Flooding: Understanding Social Vulnerabilities and Risks}

Kung ang imong tubag yes, butangi ug check ang items nga naa sa ilalom nga maoy imong tubag.

mga kaang sa tanum mga nigahi nga yuta sa mga tanum collar sa toilet bowl gutter sa atop mga gagmay kanal-kanal gully trap wala na gigamit nga water tank flower pot plate road side drain tubo sa mga drainage gikan sa atop

2. Kanunay ba kamo naga panglimpyo sa inyong balay ug palibot ug gisiguro nga walay tubig nga napundo sa mga lugar nag nka lista sa ilalom nga dili kasagarang puy-an sa mga lamok? __ Yes No

Kung ang imong tubag yes, butangi ug check ang items nga naa sa ilalom nga maoy imong tubag.

_ mga bangag sa kahoy _ mga tanum _ aircon tray _ BBQ pit _ canvass sheet

Mga wala gigamit or gilabay nga mga receptacles, containers sama sa:

_ ligid __ plastic caps __ bagol sa lubi _ mga botilya __ lata _ _ baldi __ jars _ _ stocked-up nga gutters tarpulins drums

3. Gisiguro ba ninyo nga ang inyong balay ang hangin makagawas ug sulod? __ Yes _ _ No

4. Naa bay mga screen inyong portahan ug binatana? __ Yes __ No

5. Inyo bang ginasigurado nga kada human ninyong gamit sa drum/tangke sa tubig inyo kining gisirado?

_. Yes _ No _ W Wala

6. Ang inyo bang tubig maabtan ug semana sa mga gibutangan ninyo sama sa drum or baldi ug uban pa?

7. Ok lang ba ninyo nga adunay mga tubig nga napundo sulod ug gawas sa inyong balay? __ Yes __ No

8. Gipasagdan ba ninyo ang tubig sa mga flower pot or vases nga muabot ug usa ka semana? __ Yes __ No

9. Adunay bay fogging nga gihimo sa inyong balay or Barangay? __ Yes __ No

10. Nakagamit ba kamo ug chemical sa pagpatay sa mga larva sa lamok? __ Yes __ No

11. Nakagamit ba kamo ug biological nga paagi sama sa pag gamit ug isda sa pagpatay sa mga larva sa lamok? $\mathrm{Y}$ __ N

Assessment on Flood Resilience \& Health Program of the Local Government Units and NGO's

Sa imong mga panglantaw ug panghuna-huna base sa imong na experensya ug nakita o nadungog, kung unsa ka maayo ang mga programa sa gobyerno ug NGO. Palihug ug butang ug check sa linya nga maoy imong tubag.

Maayo Kaayo Maayo Ok Lang Dili Maayo Dili Dyud Maayo

(Excellent) (Very Well) (Good) (Poor) (Very Poor)

1. Ang pag implementar ug monitor sa mga polisiya, plano ug programa para sa mga kalimidad sama sa bagyo ug baha.

2. Nga matinud-anon ang gobyerno sa mga budget ug donasyon nga para sa mga katawhan nga naapektahan sa maong mga kalamidad.

3. Sa mga livelihood o tabang pinansyal aron maka negosyo ug makabangon sa epekto sa baha ug bagyo.

4. Sa mga polisiya ug programa para sa pag protektar sa atong suba.

5. Ang inyong pag kooperar aron ma-protektaran ang atong suba gikan sa kadaut niini.

6. Ang mga drainage system

7. Ang mga dike system

8. Ang mga bridge system/taytayan

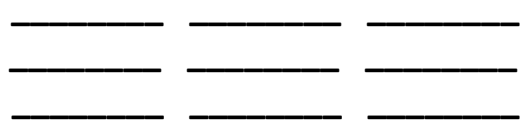


Community-Based Flood Vulnerability Index for Urban Flooding: Understanding Social Vulnerabilities and Risks

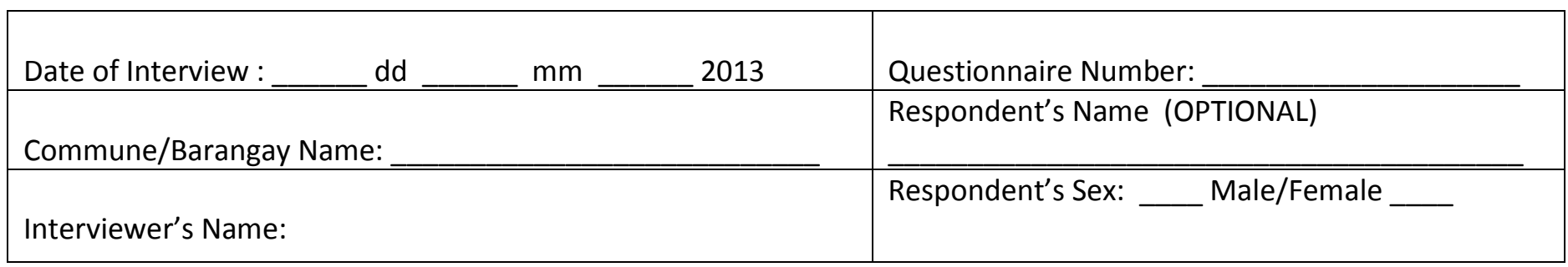

9. Ang mga flood hazard maps

10. Ang pag limpyo o kabkab/kalot sa suba kung dili na maayo ang pag flow sa tubig niini.

11. Ang mga pag apud-apud sa donations, goods and relief

12. Ang pagpanghatag ug information drive brochures o mga balasahon nga makatabang mahitangud sa paglikay sa epekto sa baha o bagyo ug ang pagbangon gikan niini.

13. Ang mga early flood warning systems

14. Ang mga pagbansay-bansay (preparedness and drills) aron maandam sa unsa nga mga kalimidad hilabi na sa bagyo ug baha

15. Ang mga organisasyon ug volunteers sa gobyerno o NGO's nga motabang ug mo- responder sa panahon sa bagyo ug baha.

16. Ang mga basic emergency and relief services sama sa pagkaon, tubig, sanitation, transportasyon, komunikasyon, medical help, provisional repairs o pag-ayo sa mga naguba o damage nga property sa gobyerno, pribado o sa mga katawhan dinhi sa barangay.

17. Ang pag clean-up (limpyo) sa mga lugar nga apektado, ang paghatag ug insurance, claims (tabang pinansyal), traumatic and psychological stress debriefings (pag check-up ug paghatag ug advice sa mga na shock sa mga nanghitabo sa baha o bagyo.

18. Ang mga gitagana nga relocation area sa gobyerno para sa mga katawhan nga naa sa flood prone area.

19. Ang mga programa sa diarrhea

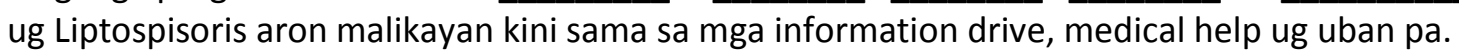

20. Ang mga programa sa pagsumpo sa sakit nga Dengue Fever sama sa fogging, chemical/biological control, information drive brochures ug lectures, clean-up ug uban pang mga paagi dinhi sa Barangay. 
Community-Based Flood Vulnerability Index for Urban Flooding: Understanding Social Vulnerabilities and Risks

\section{Appendix 3 LOCAL GOVERNMENT UNITS (LGU'S) and NONGOVERMENTAL ORGANIZATIONS (NGO's)}

In this appendix the following form of questionnaires used in the survey is presented as follows:

1. Local Government Units (LGU's) and Non-governmental Organizations (NGO's) Assessments on Flood Resilience interms of:
A. Governance
B. Sustainable Community Livelihood
C. The River's Natural Resources and Natural Features Management
D. Land Use Management and Structural Design
E. Post-Risk Assessment and Integration
F. Warning and Evacuation
G. Emergency Response
H. Disaster Recovery

SURVEY FORM QUESTIONNAIRE

ASSESSMENTS ON FLOOD RESILIENCE IN THE FOLLOWING ITEMS:

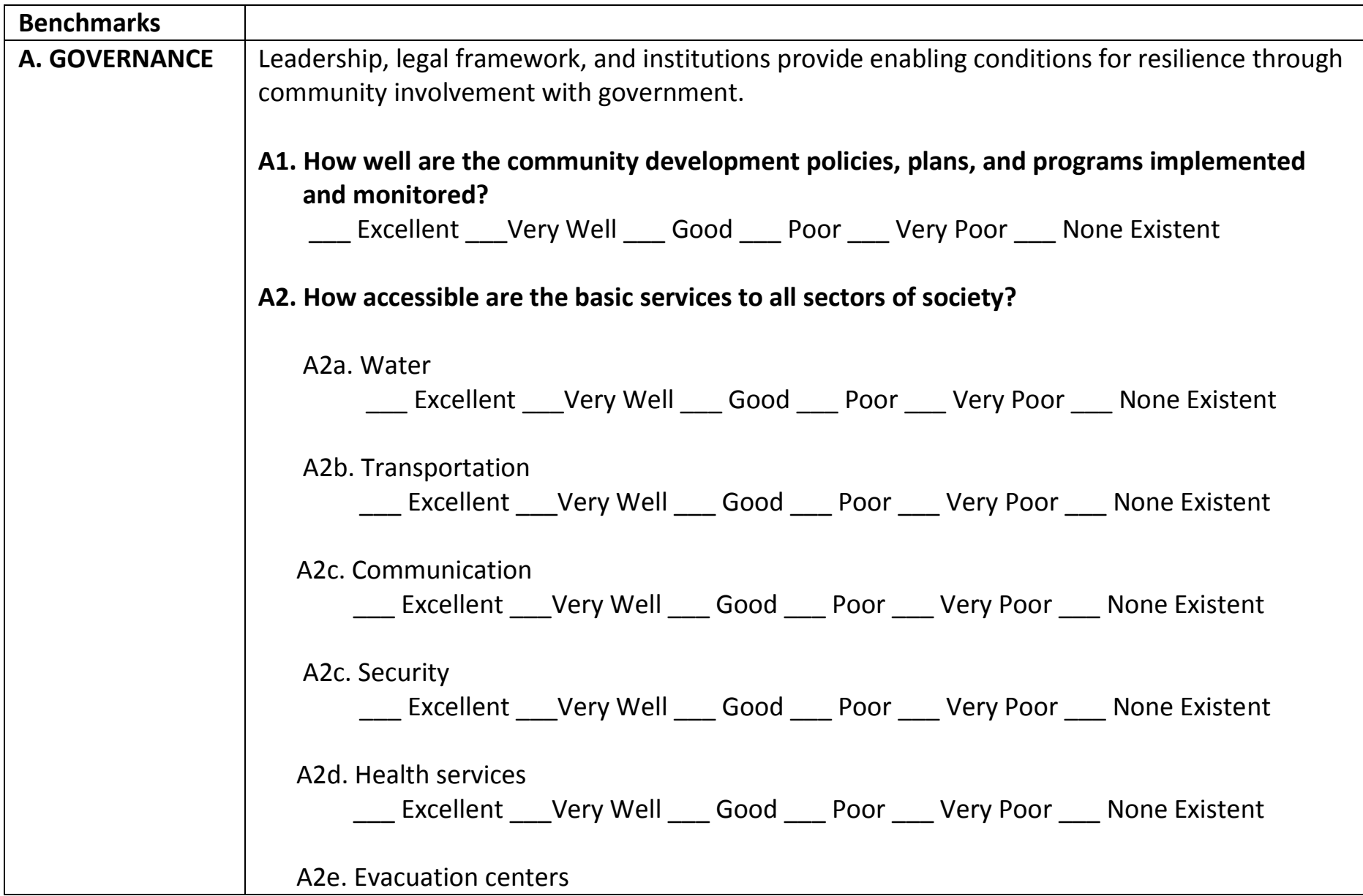




\begin{tabular}{|c|c|}
\hline & 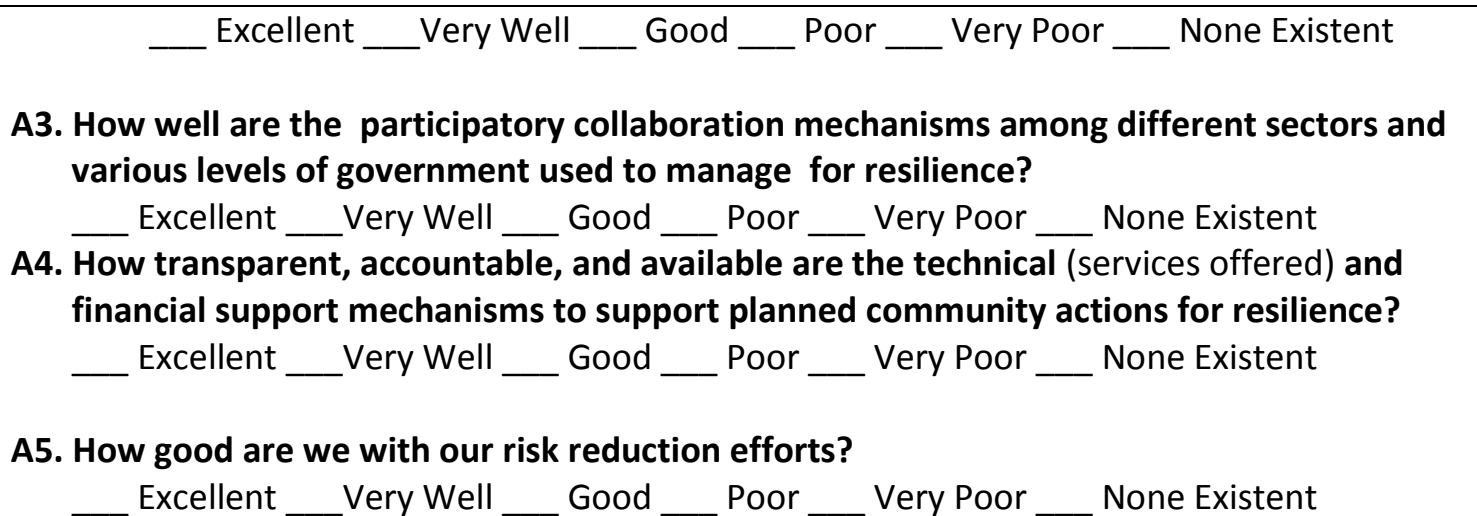 \\
\hline $\begin{array}{l}\text { B. SUSTAINABLE } \\
\text { COMMUNITY } \\
\text { LIVELIHOOD }\end{array}$ & 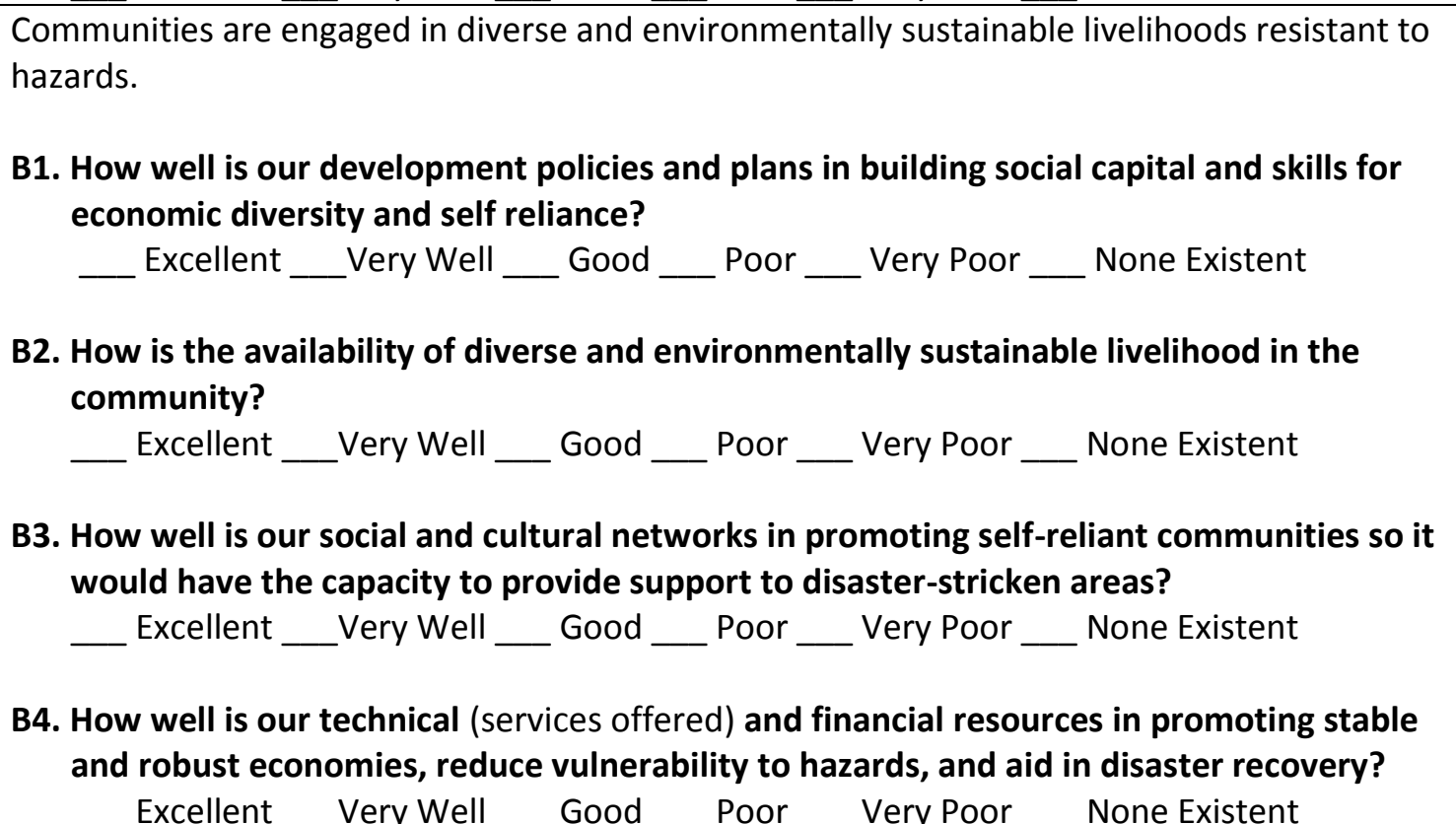 \\
\hline $\begin{array}{l}\text { C. THE RIVER'S } \\
\text { NATURAL } \\
\text { RESOURCES \& } \\
\text { NATURAL } \\
\text { FEATURES' } \\
\text { MANAGEMENT }\end{array}$ & 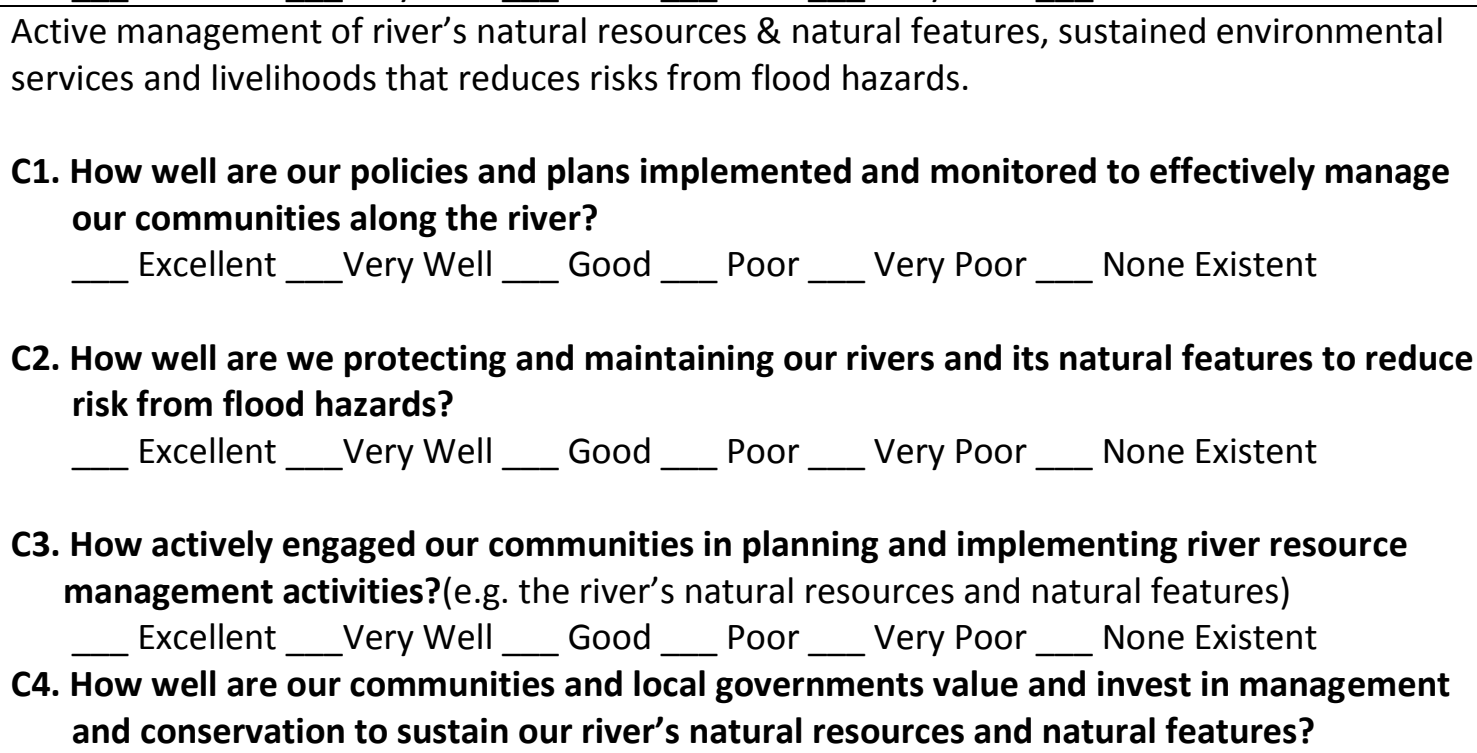 \\
\hline
\end{tabular}


Community-Based Flood Vulnerability Index for Urban Flooding: Understanding Social Vulnerabilities and Risks

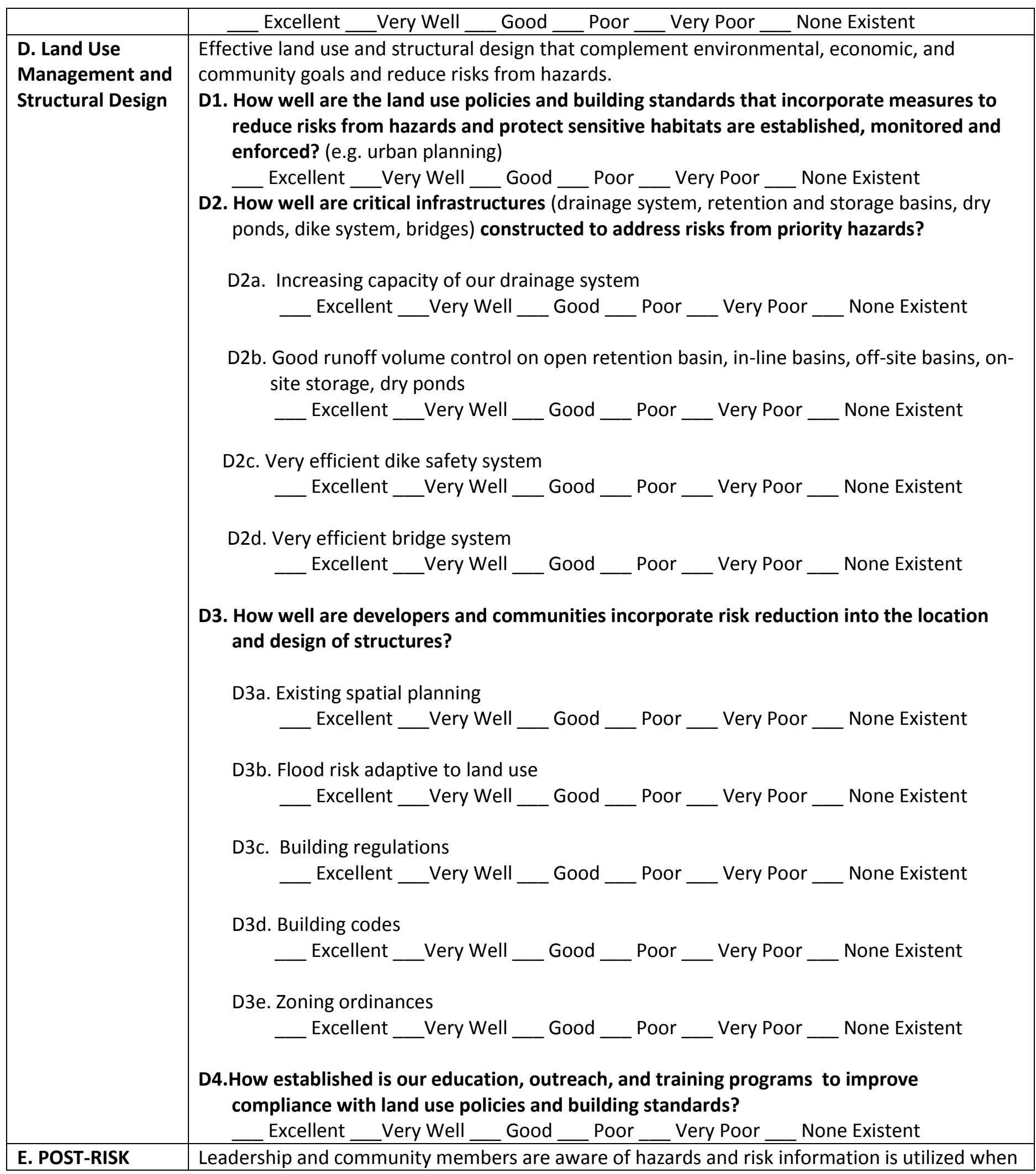




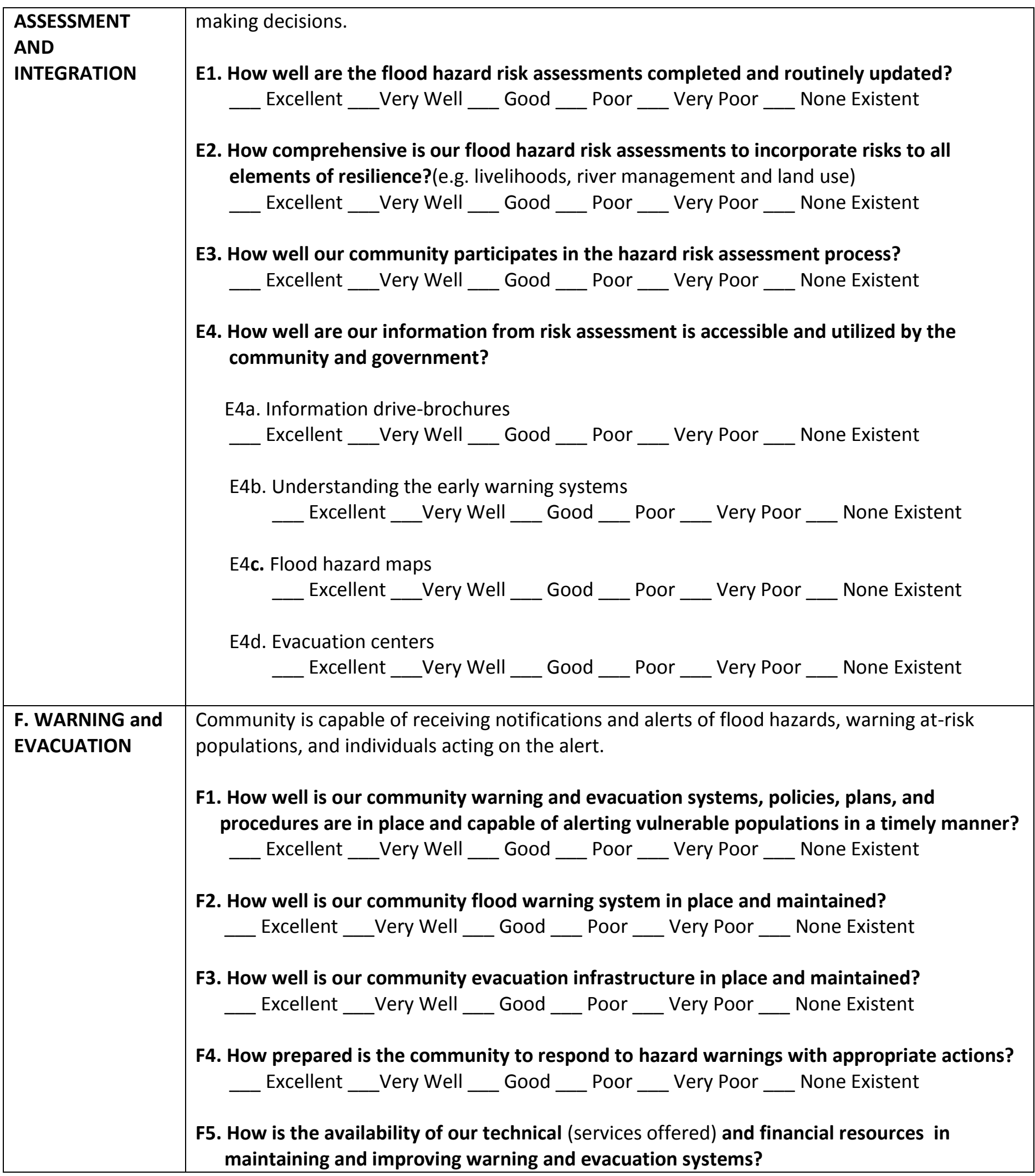


Community-Based Flood Vulnerability Index for Urban Flooding: Understanding Social Vulnerabilities and Risks

\begin{tabular}{|c|c|}
\hline & _Excellent __ Very Well__ Good__ Poor __ Very Poor __ None Existent \\
\hline $\begin{array}{l}\text { G. EMERGENCY } \\
\text { RESPONSE }\end{array}$ & 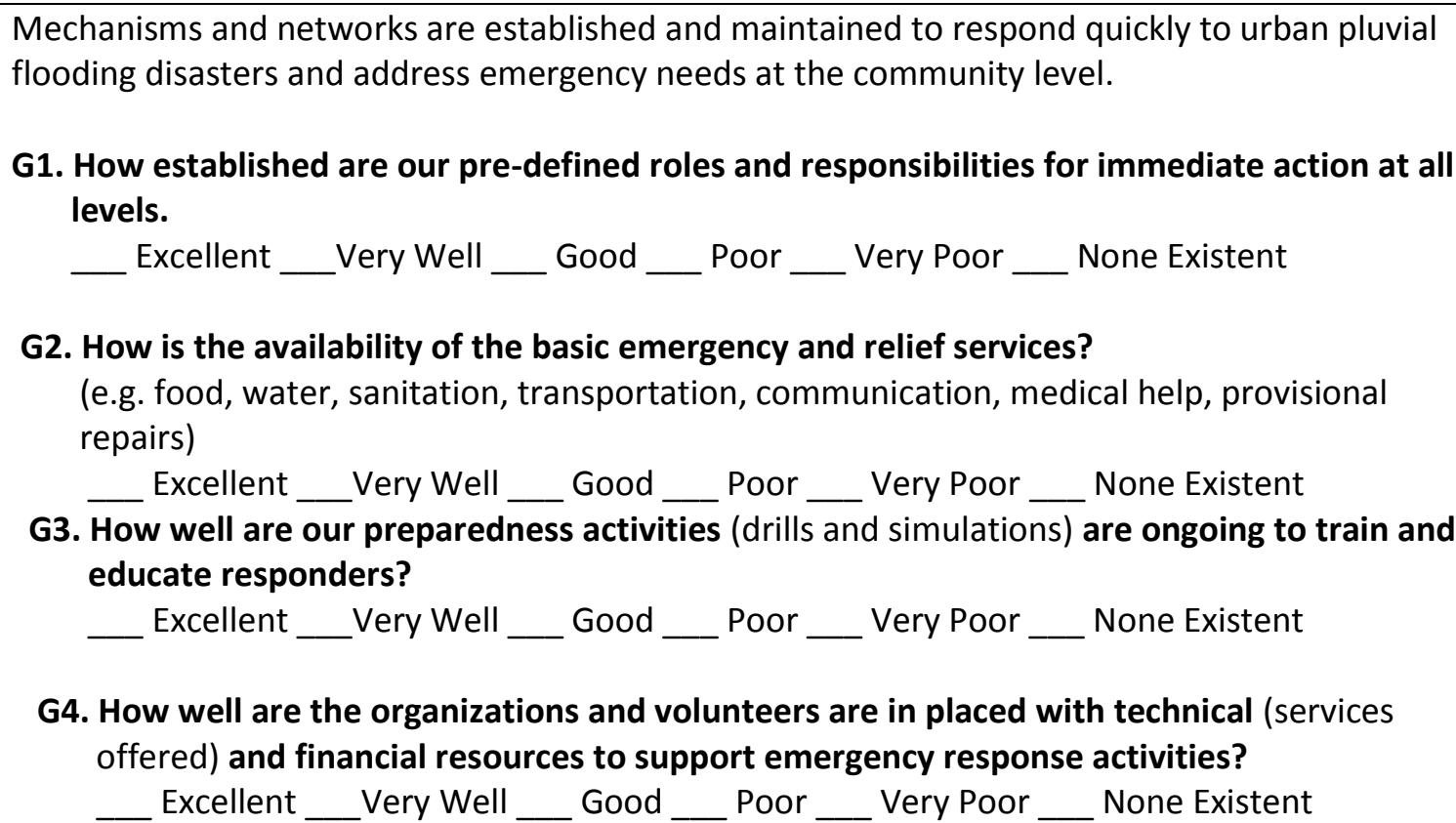 \\
\hline $\begin{array}{l}\text { H. DISASTER } \\
\text { RECOVERY }\end{array}$ & 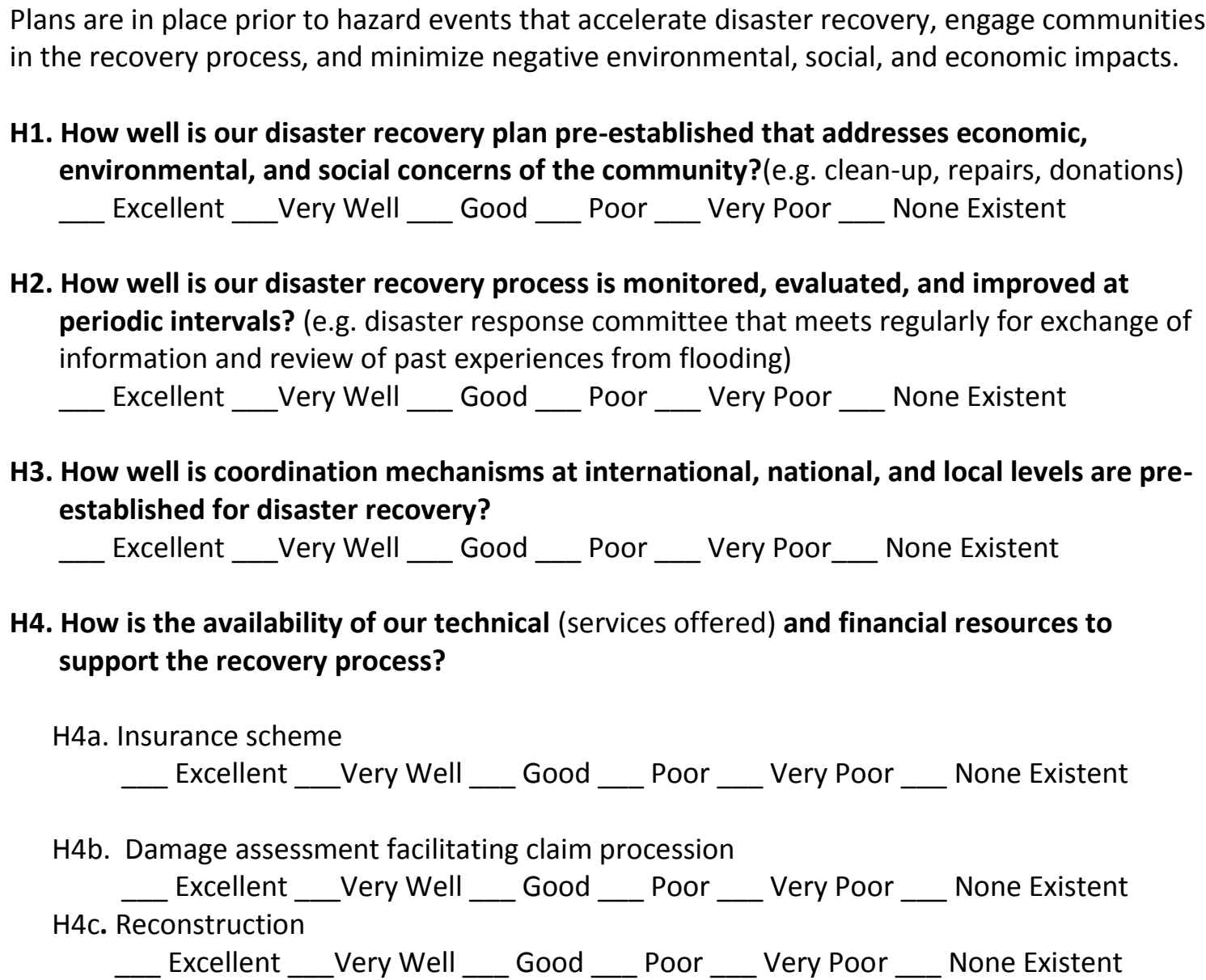 \\
\hline
\end{tabular}


Community-Based Flood Vulnerability Index for Urban Flooding: Understanding Social Vulnerabilities and Risks

\begin{tabular}{|c|c|}
\hline & 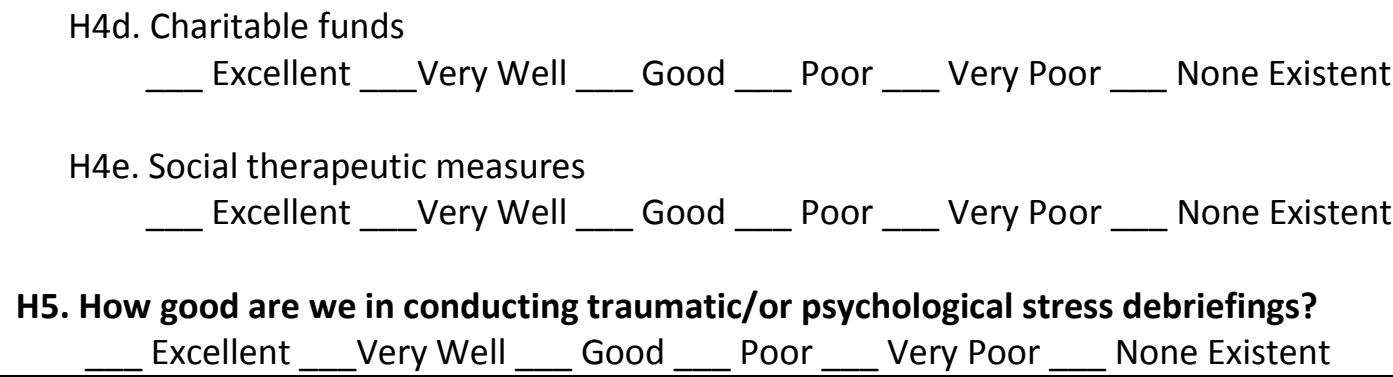 \\
\hline $\begin{array}{l}\text { FOR COMMENTS } \\
\text { \& SUGGESTIONS }\end{array}$ & \\
\hline
\end{tabular}




\section{APPENDIX 4 RESULTS for the Respondent's Profile}

In this appendix the results of the surveyed questionnaires from the household respondents is presented as follows:

1. Results of the household respondents profile on socio-demographic, socio-economic, physical and social environment

2. Results on the Knowledge, Attitude, and Practices (KAP) on Community Flood Resilient Assessment

3. Results on the KAP of Household Respondents on Environmental Microbial Health Risks (E. coli, Leptospira spp., Dengue Fever Mosquito)

4. Results on the Assessment on Flood Resilience \& Health Program of the Local Government Units and NGO's

\section{Age and Sex Distribution}

\begin{tabular}{|c|c|c|c|c|c|c|c|c|}
\hline \multirow{3}{*}{ Barangay } & \multirow{3}{*}{$\begin{array}{c}\text { Number of } \\
\text { Respondents }\end{array}$} & \multicolumn{4}{|c|}{ Gender } & \multicolumn{3}{|c|}{ Age } \\
\hline & & \multicolumn{2}{|c|}{ Female } & \multicolumn{2}{|c|}{ Male } & \multirow{2}{*}{ Mean } & \multicolumn{2}{|c|}{ Range } \\
\hline & & Number & $\%$ & Number & $\%$ & & Minimum & Maximum \\
\hline Tabuc-tubig & 10 & 7 & 77.78 & 2 & 22.22 & 38.75 & 25 & 65 \\
\hline Junob & 16 & 15 & 93.75 & 1 & 6.25 & 39.75 & 19 & 63 \\
\hline Poblacion 1 & 22 & 14 & 77.78 & 4 & 22.22 & 45.00 & 17 & 86 \\
\hline Batinguel & 38 & 24 & 82.76 & 5 & 17.24 & 37.55 & 22 & 60 \\
\hline Candua-ay & 72 & 51 & 79.69 & 13 & 20.31 & 38.21 & 18 & 70 \\
\hline Taclobo & 63 & 40 & 81.63 & 9 & 18.37 & 40.50 & 19 & 82 \\
\hline Bagacay & 30 & 20 & 76.92 & 6 & 23.08 & 35.23 & 18 & 62 \\
\hline Cadawinonan & 25 & 14 & 82.35 & 3 & 17.65 & 40.76 & 24 & 65 \\
\hline Poblacion 8 & 29 & 21 & 91.30 & 2 & 8.70 & 44.88 & 20 & 79 \\
\hline Barangay 2 & 16 & 11 & 78.57 & 3 & 21.43 & 40.08 & 25 & 62 \\
\hline Balugo & 17 & 8 & 61.54 & 5 & 38.46 & 45.50 & 23 & 70 \\
\hline Calindagan & 23 & 17 & 80.95 & 4 & 19.05 & 39.05 & 22 & 76 \\
\hline Overall & 361 & 242 & 80.94 & 57 & 19.06 & 39.84 & 17 & 86 \\
\hline
\end{tabular}


Community-Based Flood Vulnerability Index for Urban Flooding: Understanding

Social Vulnerabilities and Risks

\section{Educational Attainment}

\begin{tabular}{|c|c|c|c|c|c|c|c|c|c|c|}
\hline \multirow{2}{*}{$\begin{array}{l}\text { Educational } \\
\text { Attainment }\end{array}$} & \multicolumn{2}{|c|}{ Tabuc-tubig } & \multicolumn{2}{|c|}{ Junob } & \multicolumn{2}{|c|}{ Poblacion 1} & \multicolumn{2}{|c|}{ Batinguel } & \multicolumn{2}{|c|}{ Candua-ay } \\
\hline & Number & $\%$ & Number & $\%$ & Number & $\%$ & Number & $\%$ & Number & $\%$ \\
\hline Graduate School & 1 & 10.00 & 0 & 0.00 & 0 & 0.00 & 0 & 0.00 & 0 & 0.00 \\
\hline College Graduate & 0 & 0.00 & 1 & 6.25 & 5 & 22.73 & 2 & 5.26 & 6 & 8.33 \\
\hline College Level & 0 & 0.00 & 3 & 18.75 & 3 & 13.64 & 7 & 18.42 & 15 & 20.83 \\
\hline Vocational & 0 & 0.00 & 0 & 0.00 & 0 & 0.00 & 0 & 0.00 & 0 & 0.00 \\
\hline $\begin{array}{l}\text { High School } \\
\text { Graduate }\end{array}$ & 0 & 0.00 & 7 & 43.75 & 4 & 18.18 & 5 & 13.16 & 12 & 16.67 \\
\hline High School Level & 3 & 30.00 & 2 & 12.50 & 3 & 13.64 & 6 & 15.79 & 18 & 25.00 \\
\hline $\begin{array}{l}\text { Elementary } \\
\text { Graduate }\end{array}$ & 0 & 0.00 & 0 & 0.00 & 2 & 9.09 & 2 & 5.26 & 0 & 0.00 \\
\hline Elementary Level & 2 & 20.00 & 3 & 18.75 & 3 & 13.64 & 10 & 26.32 & 10 & 13.89 \\
\hline Did not indicate & 4 & 40.00 & 0 & 0.00 & 2 & 9.09 & 6 & 15.79 & 11 & 15.28 \\
\hline Total & 10 & 100.00 & 16 & 100.00 & 22 & 100.00 & 38 & 100.00 & 72 & 100.00 \\
\hline
\end{tabular}


Community-Based Flood Vulnerability Index for Urban Flooding: Understanding Social Vulnerabilities and Risks

\begin{tabular}{|c|c|c|c|c|c|c|c|c|c|c|}
\hline \multirow{2}{*}{$\begin{array}{l}\text { Educational } \\
\text { Attainment }\end{array}$} & \multicolumn{2}{|c|}{ Taclobo } & \multicolumn{2}{|c|}{ Bagacay } & \multicolumn{2}{|c|}{ Cadawinonan } & \multicolumn{2}{|c|}{ Poblacion 8} & \multicolumn{2}{|c|}{ Barangay 2} \\
\hline & Number & $\%$ & Number & $\%$ & Number & $\%$ & Number & $\%$ & Number & $\%$ \\
\hline Graduate School & 0 & 0.00 & 0 & 0.00 & 0 & 0.00 & 0 & 0.00 & 0 & 0.00 \\
\hline College Graduate & 11 & 17.46 & 0 & 0.00 & 3 & 12.00 & 1 & 3.45 & 2 & 12.50 \\
\hline College Level & 16 & 25.40 & 5 & 16.67 & 5 & 20.00 & 7 & 24.14 & 5 & 31.25 \\
\hline Vocational & 1 & 1.59 & 0 & 0.00 & 0 & 0.00 & 0 & 0.00 & 0 & 0.00 \\
\hline $\begin{array}{ll}\text { High } & \text { School } \\
\text { Graduate } & \\
\end{array}$ & 5 & 7.94 & 5 & 16.67 & 2 & 8.00 & 3 & 10.34 & 2 & 12.50 \\
\hline High School Level & 9 & 14.29 & 4 & 13.33 & 8 & 32.00 & 8 & 27.59 & 2 & 12.50 \\
\hline $\begin{array}{l}\text { Elementary } \\
\text { Graduate }\end{array}$ & 2 & 3.17 & 3 & 10.00 & 1 & 4.00 & 1 & 3.45 & 0 & 0.00 \\
\hline Elementary Level & 8 & 12.70 & 5 & 16.67 & 4 & 16.00 & 5 & 17.24 & 0 & 0.00 \\
\hline Did not indicate & 11 & 17.46 & 8 & 26.67 & 2 & 8.00 & 4 & 13.79 & 5 & 31.25 \\
\hline Total & 63 & 100.00 & 30 & 100.00 & 25 & 100.00 & 29 & 100.00 & 16 & 100.00 \\
\hline
\end{tabular}

Educational Attainment ... continued

\begin{tabular}{|c|c|c|c|c|c|c|}
\hline \multirow{2}{*}{ Educational Attainment } & \multicolumn{2}{|c|}{ Balugo } & \multicolumn{2}{|c|}{ Calindagan } & \multicolumn{2}{|c|}{ Overall } \\
\hline & Number & $\%$ & Number & $\%$ & Number & $\%$ \\
\hline Graduate School & 0 & 0.00 & 0 & 0.00 & 1 & 0.28 \\
\hline College Graduate & 2 & 11.76 & 3 & 13.04 & 36 & 9.97 \\
\hline College Level & 1 & 5.88 & 1 & 4.35 & 68 & 18.84 \\
\hline Vocational & 0 & 0.00 & 0 & 0.00 & 1 & 0.28 \\
\hline High School Graduate & 2 & 11.76 & 7 & 30.43 & 54 & 14.96 \\
\hline High School Level & 3 & 17.65 & 8 & 34.78 & 74 & 20.50 \\
\hline Elementary Graduate & 2 & 11.76 & 0 & 0.00 & 13 & 3.60 \\
\hline Elementary Level & 6 & 35.29 & 3 & 13.04 & 59 & 16.34 \\
\hline Did not indicate & 1 & 5.88 & 1 & 4.35 & 55 & 15.24 \\
\hline Total & 17 & 100.00 & 23 & 100.00 & 361 & 100.00 \\
\hline
\end{tabular}


Community-Based Flood Vulnerability Index for Urban Flooding: Understanding Social Vulnerabilities and Risks

\section{Household Profile}

\section{Number of Family Members}

\begin{tabular}{|c|c|c|c|c|c|c|c|c|}
\hline \multirow[t]{2}{*}{ Barangay } & \multicolumn{3}{|c|}{ Total Number of Family Members } & \multicolumn{3}{|c|}{ Number of Extended Family Members } & \multicolumn{2}{|c|}{$\begin{array}{l}\text { Mean Gender } \\
\text { Distribution (\%) }\end{array}$} \\
\hline & Average & Minimum & Maximum & Average & Minimum & Maximum & Female & Male \\
\hline Tabuc-tubig & 5.30 & 3 & 9 & 1.10 & 0.00 & 5.00 & 47.17 & 52.83 \\
\hline Junob & 4.73 & 2 & 6 & 0.40 & 0.00 & 4.00 & 50.95 & 49.05 \\
\hline Poblacion 1 & 8.14 & 3 & 16 & 3.19 & 0.00 & 12.00 & 52.05 & 47.95 \\
\hline Batinguel & 5.15 & 2 & 12 & 0.76 & 0.00 & 5.00 & 53.13 & 46.88 \\
\hline Candua-ay & 6.04 & 3 & 16 & 1.24 & 0.00 & 9.00 & 52.15 & 47.85 \\
\hline Taclobo & 6.16 & 2 & 13 & 1.69 & 0.00 & 8.00 & 50.71 & 49.29 \\
\hline Bagacay & 5.55 & 3 & 13 & 1.34 & 0.00 & 6.00 & 49.32 & 50.68 \\
\hline Cadawinonan & 6.64 & 3 & 13 & 1.59 & 0.00 & 5.00 & 51.16 & 48.84 \\
\hline Poblacion 8 & 6.89 & 2 & 12 & 1.63 & 0.00 & 12.00 & 56.32 & 43.68 \\
\hline Barangay 2 & 5.38 & 2 & 10 & 1.62 & 0.00 & 6.00 & 44.59 & 55.41 \\
\hline Balugo & 6.53 & 4 & 13 & 2.00 & 0.00 & 7.00 & 47.17 & 52.83 \\
\hline Calindagan & 5.78 & 1 & 13 & 1.09 & 0.00 & 6.00 & 56.62 & 43.38 \\
\hline Overall & 6.07 & 1 & 16 & 1.46 & 0.00 & 12.00 & 51.68 & 48.32 \\
\hline
\end{tabular}


Community-Based Flood Vulnerability Index for Urban Flooding: Understanding

Social Vulnerabilities and Risks

\section{Recent Typhoon/Flood ("Sendong") Affected Households}

\begin{tabular}{|c|c|c|c|c|}
\hline \multirow{3}{*}{ Barangay } & \multicolumn{4}{|c|}{ Typhoon/Flood "Sendong" Victim } \\
\hline & \multicolumn{2}{|c|}{ Yes } & \multicolumn{2}{|c|}{ No } \\
\hline & Number & $\%$ & Number & $\%$ \\
\hline Tabuc-tubig & 6 & 60.00 & 4 & 40.00 \\
\hline Junob & 14 & 87.50 & 2 & 12.50 \\
\hline Poblacion 1 & 13 & 59.09 & 9 & 40.91 \\
\hline Batinguel & 31 & 81.58 & 6 & 15.79 \\
\hline Candua-ay & 60 & 83.33 & 12 & 16.67 \\
\hline Taclobo & 30 & 47.62 & 33 & 52.38 \\
\hline Bagacay & 23 & 76.67 & 7 & 23.33 \\
\hline Cadawinonan & 15 & 60.00 & 10 & 40.00 \\
\hline Poblacion 8 & 25 & 86.21 & 4 & 13.79 \\
\hline Barangay 2 & 14 & 87.50 & 2 & 12.50 \\
\hline Balugo & 11 & 64.71 & 6 & 35.29 \\
\hline Calindagan & 15 & 65.22 & 8 & 34.78 \\
\hline Total & 257 & 71.19 & 103 & 28.53 \\
\hline
\end{tabular}


Community-Based Flood Vulnerability Index for Urban Flooding: Understanding

Social Vulnerabilities and Risks

\section{Diarrhea Experience}

\begin{tabular}{|c|c|c|c|c|c|}
\hline \multirow{3}{*}{ Barangay } & \multicolumn{4}{|c|}{ Experienced Diarrhea } & \multirow{3}{*}{$\begin{array}{l}\text { Mean Number of Family } \\
\text { Members that } \\
\text { Experienced Diarrhea }\end{array}$} \\
\hline & \multicolumn{2}{|c|}{ Yes } & \multicolumn{2}{|c|}{ No } & \\
\hline & Number & $\%$ & Number & $\%$ & \\
\hline Tabuc-tubig & 5 & 50.00 & 5 & 50.00 & 3.50 \\
\hline Junob & 4 & 25.00 & 12 & 75.00 & 4.25 \\
\hline Poblacion 1 & 12 & 54.55 & 10 & 45.45 & 3.67 \\
\hline Batinguel & 24 & 63.16 & 14 & 36.84 & 2.55 \\
\hline Candua-ay & 27 & 37.50 & 45 & 62.50 & 2.81 \\
\hline Taclobo & 24 & 38.10 & 39 & 61.90 & 2.65 \\
\hline Bagacay & 10 & 33.33 & 20 & 66.67 & 4.10 \\
\hline Cadawinonan & 10 & 40.00 & 15 & 60.00 & 2.25 \\
\hline Poblacion 8 & 19 & 65.52 & 10 & 34.48 & 3.45 \\
\hline Barangay 2 & 8 & 50.00 & 8 & 50.00 & 2.38 \\
\hline Balugo & 9 & 52.94 & 8 & 47.06 & 3.67 \\
\hline Calindagan & 9 & 39.13 & 14 & 60.87 & 2.22 \\
\hline Total & 161 & 44.60 & 200 & 55.40 & 3.00 \\
\hline
\end{tabular}


Community-Based Flood Vulnerability Index for Urban Flooding: Understanding

Social Vulnerabilities and Risks

\section{Dengue Experience}

\begin{tabular}{|c|c|c|c|c|c|}
\hline \multirow{3}{*}{ Barangay } & \multicolumn{4}{|c|}{ Experienced Dengue } & \multirow{3}{*}{$\begin{array}{c}\text { Mean Number of Family } \\
\text { Members that } \\
\text { Experienced Dengue }\end{array}$} \\
\hline & \multicolumn{2}{|c|}{ Yes } & \multicolumn{2}{|c|}{ No } & \\
\hline & Number & $\%$ & Number & $\%$ & \\
\hline Tabuc-tubig & 0 & 0.00 & 10 & 100.00 & 0.00 \\
\hline Junob & 2 & 12.50 & 14 & 87.50 & 2.00 \\
\hline Poblacion 1 & 9 & 40.91 & 13 & 59.09 & 2.00 \\
\hline Batinguel & 8 & 21.05 & 30 & 78.95 & 1.38 \\
\hline Candua-ay & 10 & 13.89 & 62 & 86.11 & 1.30 \\
\hline Taclobo & 12 & 19.05 & 51 & 80.95 & 1.54 \\
\hline Bagacay & 3 & 10.00 & 27 & 90.00 & 1.33 \\
\hline Cadawinonan & 5 & 20.00 & 20 & 80.00 & 1.00 \\
\hline Poblacion 8 & 8 & 27.59 & 21 & 72.41 & 1.25 \\
\hline Barangay 2 & 4 & 25.00 & 12 & 75.00 & 1.00 \\
\hline Balugo & 2 & 11.76 & 15 & 88.24 & 1.00 \\
\hline Calindagan & 4 & 17.39 & 19 & 82.61 & 1.50 \\
\hline Total & 67 & 18.56 & 294 & 81.44 & 1.42 \\
\hline
\end{tabular}


Community-Based Flood Vulnerability Index for Urban Flooding: Understanding

Social Vulnerabilities and Risks

\section{Liptospirosis Experience}

\begin{tabular}{|c|c|c|c|c|c|}
\hline \multirow{3}{*}{ Barangay } & \multicolumn{4}{|c|}{ Experienced Liptospirosis } & \multirow{3}{*}{$\begin{array}{l}\text { Mean Number of Family } \\
\text { Members that } \\
\text { Experienced Liptospirosis }\end{array}$} \\
\hline & \multicolumn{2}{|c|}{ Yes } & \multicolumn{2}{|l|}{ No } & \\
\hline & Number & $\%$ & Number & $\%$ & \\
\hline Tabuc-tubig & 0 & 0.00 & 10 & 100.00 & 0.00 \\
\hline Junob & 0 & 0.00 & 16 & 100.00 & 0.00 \\
\hline Poblacion 1 & 1 & 4.55 & 21 & 95.45 & 2.00 \\
\hline Batinguel & 0 & 0.00 & 38 & 100.00 & 0.00 \\
\hline Candua-ay & 2 & 2.78 & 70 & 97.22 & 1.00 \\
\hline Taclobo & 1 & 1.59 & 62 & 98.41 & 4.00 \\
\hline Bagacay & 1 & 3.33 & 29 & 96.67 & 3.00 \\
\hline Cadawinonan & 0 & 0.00 & 25 & 100.00 & 0.00 \\
\hline Poblacion 8 & 2 & 6.90 & 27 & 93.10 & 1.50 \\
\hline Barangay 2 & 0 & 0.00 & 16 & 100.00 & 0.00 \\
\hline Balugo & 1 & 5.88 & 16 & 94.12 & 1.00 \\
\hline Calindagan & 0 & 0.00 & 23 & 100.00 & 0.00 \\
\hline Total & 8 & 2.22 & 353 & 97.78 & 1.42 \\
\hline
\end{tabular}


Community-Based Flood Vulnerability Index for Urban Flooding: Understanding Social Vulnerabilities and Risks

\section{SOCIO-ECONOMIC}

\section{Occupation}

\begin{tabular}{|c|c|c|c|c|c|c|c|c|c|c|}
\hline \multirow{2}{*}{ Occupation } & \multicolumn{2}{|c|}{ Tabuc-tubig } & \multicolumn{2}{|c|}{ Junob } & \multicolumn{2}{|c|}{ Poblacion 1} & \multicolumn{2}{|c|}{ Batinguel } & \multicolumn{2}{|c|}{ Candua-ay } \\
\hline & Number & $\%$ & Number & $\%$ & Number & $\%$ & Number & $\%$ & Number & $\%$ \\
\hline Fishermen & 0 & 0.00 & 0 & 0.00 & 2 & 9.09 & 0 & 0.00 & 1 & 1.39 \\
\hline Skilled Worker & 0 & 0.00 & 1 & 6.25 & 2 & 9.09 & 3 & 7.89 & 8 & 11.11 \\
\hline Laborer/Helper & 2 & 20.00 & 2 & 12.50 & 2 & 9.09 & 5 & 13.16 & 16 & 22.22 \\
\hline Saleslady/Salesman & 3 & 30.00 & 3 & 18.75 & 4 & 18.18 & 7 & 18.42 & 12 & 16.67 \\
\hline Public Employee & 0 & 0.00 & 1 & 6.25 & 3 & 13.64 & 2 & 5.26 & 5 & 6.94 \\
\hline Private Employee & 0 & 0.00 & 0 & 0.00 & 4 & 18.18 & 7 & 18.42 & 22 & 30.56 \\
\hline Pedicab/Easyride Driver & 1 & 10.00 & 1 & 6.25 & 0 & 0.00 & 3 & 7.89 & 11 & 15.28 \\
\hline Private Driver & 0 & 0.00 & 0 & 0.00 & 0 & 0.00 & 4 & 10.53 & 0 & 0.00 \\
\hline Laundry & 0 & 0.00 & 1 & 6.25 & 0 & 0.00 & 4 & 10.53 & 1 & 1.39 \\
\hline Others & 2 & 20.00 & 4 & 25.00 & 5 & 22.73 & 0 & 0.00 & 3 & 4.17 \\
\hline No Work & 0 & 0.00 & 1 & 6.25 & 1 & 4.55 & 2 & 5.26 & 1 & 1.39 \\
\hline Did not specify & 2 & 20.00 & 2 & 12.50 & 1 & 4.55 & 3 & 7.89 & 3 & 4.17 \\
\hline
\end{tabular}


Community-Based Flood Vulnerability Index for Urban Flooding: Understanding Social Vulnerabilities and Risks

Occupation ... continued

\begin{tabular}{|c|c|c|c|c|c|c|c|c|c|c|}
\hline \multirow{2}{*}{ Occupation } & \multicolumn{2}{|c|}{ Taclobo } & \multicolumn{2}{|c|}{ Bagacay } & \multicolumn{2}{|c|}{ Cadawinonan } & \multicolumn{2}{|c|}{ Poblacion 8} & \multicolumn{2}{|c|}{ Barangay 2} \\
\hline & Number & $\%$ & Number & $\%$ & Number & $\%$ & Number & $\%$ & Number & $\%$ \\
\hline Fishermen & 1 & 1.59 & 1 & 3.33 & 2 & 8.00 & 0 & 0.00 & 0 & 0.00 \\
\hline Skilled Worker & 2 & 3.17 & 5 & 16.67 & 4 & 16.00 & 2 & 6.90 & 2 & 12.50 \\
\hline Laborer/Helper & 9 & 14.29 & 6 & 20.00 & 7 & 28.00 & 6 & 20.69 & 1 & 6.25 \\
\hline Saleslady/Salesman & 16 & 25.40 & 6 & 20.00 & 3 & 12.00 & 7 & 24.14 & 1 & 6.25 \\
\hline Public Employee & 7 & 11.11 & 3 & 10.00 & 8 & 32.00 & 4 & 13.79 & 3 & 18.75 \\
\hline Private Employee & 17 & 26.98 & 6 & 20.00 & 7 & 28.00 & 2 & 6.90 & 3 & 18.75 \\
\hline Pedicab/Easyride Driver & 2 & 3.17 & 0 & 0.00 & 2 & 8.00 & 4 & 13.79 & 0 & 0.00 \\
\hline Private Driver & 0 & 0.00 & 0 & 0.00 & 0 & 0.00 & 2 & 6.90 & 2 & 12.50 \\
\hline Laundry & 0 & 0.00 & 1 & 3.33 & 5 & 20.00 & 2 & 6.90 & 0 & 0.00 \\
\hline Others & 7 & 11.11 & 1 & 3.33 & 0 & 0.00 & 6 & 20.69 & 3 & 18.75 \\
\hline No Work & 1 & 1.59 & 0 & 0.00 & 0 & 0.00 & 0 & 0.00 & 0 & 0.00 \\
\hline Did not specify & 6 & 9.52 & 4 & 13.33 & 1 & 4.00 & 1 & 3.45 & 1 & 6.25 \\
\hline
\end{tabular}


Community-Based Flood Vulnerability Index for Urban Flooding: Understanding Social Vulnerabilities and Risks

Occupation ... continued

\begin{tabular}{|l|r|r|r|r|r|r|}
\hline \multirow{2}{*}{ Occupation } & \multicolumn{2}{|c|}{ Balugo } & \multicolumn{2}{c|}{ Calindagan } & \multicolumn{2}{c|}{ Overall } \\
\cline { 2 - 7 } & Number & \multicolumn{1}{|c}{$\%$} & Number & \multicolumn{1}{c|}{$\%$} & Number & \multicolumn{1}{c|}{$\%$} \\
\hline Fishermen & 0 & 0.00 & 5 & 21.74 & 12 & 3.32 \\
\hline Skilled Worker & 2 & 11.76 & 3 & 13.04 & 34 & 9.42 \\
\hline Laborer/Helper & 4 & 23.53 & 3 & 13.04 & 63 & 17.45 \\
\hline Saleslady/Salesman & 0 & 0.00 & 6 & 26.09 & 68 & 18.84 \\
\hline Public Employee & 3 & 17.65 & 1 & 4.35 & 40 & 11.08 \\
\hline Private Employee & 1 & 5.88 & 6 & 26.09 & 75 & 20.78 \\
\hline Pedicab/Easyride Driver & 2 & 11.76 & 2 & 8.70 & 28 & 7.76 \\
\hline Private Driver & 0 & 0.00 & 1 & 4.35 & 9 & 2.49 \\
\hline Laundry & 1 & 5.88 & 0 & 0.00 & 15 & 4.16 \\
\hline Others & 3 & 17.65 & 2 & 8.70 & 36 & 9.97 \\
\hline No Work & 0 & 0.00 & 0 & 0.00 & 6 & 1.66 \\
\hline Did not specify & 2 & 11.76 & 1 & 4.35 & 27 & 7.48 \\
\hline
\end{tabular}


Community-Based Flood Vulnerability Index for Urban Flooding: Understanding Social Vulnerabilities and Risks

\section{Family Income}

\begin{tabular}{|l|r|r|r|r|r|r|r|r|r|r|}
\hline \multirow{2}{*}{ Income } & \multicolumn{2}{|c|}{ Tabuc-tubig } & \multicolumn{2}{c|}{ Junob } & \multicolumn{2}{c|}{ Poblacion 1 } & \multicolumn{2}{c|}{ Batinguel } & \multicolumn{2}{c|}{ Candua-ay } \\
\cline { 2 - 11 } & Number & \multicolumn{1}{|c|}{$\%$} & Number & \multicolumn{1}{c|}{$\%$} & Number & \multicolumn{1}{c|}{$\%$} & Number & \multicolumn{1}{c|}{$\%$} & Number & $\%$ \\
\hline Below 3,000 & 2 & 20.00 & 6 & 37.50 & 6 & 27.27 & 16 & 42.11 & 18 & 25.00 \\
\hline 3001-10,000 & 4 & 40.00 & 5 & 31.25 & 6 & 27.27 & 15 & 39.47 & 34 & 47.22 \\
\hline 10,001 and above & 2 & 20.00 & 3 & 18.75 & 7 & 31.82 & 2 & 5.26 & 13 & 18.06 \\
\hline No Income & 0 & 0.00 & 0 & 0.00 & 0 & 0.00 & 0 & 0.00 & 0 & 0.00 \\
\hline Did not specify & 2 & 20.00 & 2 & 12.50 & 3 & 13.64 & 5 & 13.16 & 7 & 9.72 \\
\hline
\end{tabular}

\begin{tabular}{|l|r|r|r|r|r|r|r|r|r|r|}
\hline \multirow{2}{*}{ Income } & \multicolumn{2}{|c|}{ Taclobo } & \multicolumn{2}{c|}{ Bagacay } & \multicolumn{2}{c|}{ Cadawinonan } & \multicolumn{2}{c|}{ Poblacion 8 } & \multicolumn{2}{c|}{ Barangay 2 } \\
\cline { 2 - 11 } & Number & \multicolumn{1}{|c|}{ \% } & Number & \% & Number & \multicolumn{1}{c|}{$\%$} & Number & \multicolumn{1}{c|}{$\%$} & Number & $\%$ \\
\hline Below 3000 & 18 & 28.57 & 12 & 40.00 & 4 & 16.00 & 14 & 48.28 & 6 & 37.50 \\
\hline 3001-10,000 & 28 & 44.44 & 14 & 46.67 & 12 & 48.00 & 11 & 37.93 & 8 & 50.00 \\
\hline 10,001 and above & 13 & 20.63 & 1 & 3.33 & 6 & 24.00 & 2 & 6.90 & 2 & 12.50 \\
\hline No Income & 0 & 0.00 & 0 & 0.00 & 0 & 0.00 & 2 & 6.90 & 0 & 0.00 \\
\hline Did not specify & 4 & 6.35 & 3 & 10.00 & 3 & 12.00 & 0 & 0.00 & 0 & 0.00 \\
\hline
\end{tabular}

\begin{tabular}{|l|r|r|r|r|r|r|}
\hline \multirow{2}{*}{ Income } & \multicolumn{2}{|c|}{ Balugo } & \multicolumn{2}{c|}{ Calindagan } & \multicolumn{2}{c|}{ Overall } \\
\cline { 2 - 7 } & Number & \multicolumn{1}{c|}{$\%$} & Number & \multicolumn{1}{c|}{$\%$} & Number & \multicolumn{1}{c|}{$\%$} \\
\hline Below 3000 & 4 & 23.53 & 6 & 26.09 & 112 & 31.02 \\
\hline $3001-10,000$ & 8 & 47.06 & 12 & 52.17 & 157 & 43.49 \\
\hline 10,001 and above & 2 & 11.76 & 3 & 13.04 & 56 & 15.51 \\
\hline No Income & 0 & 0.00 & 0 & 0.00 & 2 & 0.55 \\
\hline Did not specify & 3 & 17.65 & 2 & 8.70 & 34 & 9.42 \\
\hline
\end{tabular}


Community-Based Flood Vulnerability Index for Urban Flooding: Understanding Social Vulnerabilities and Risks

\section{Residential House and Lot Ownership}

\begin{tabular}{|l|r|r|r|r|r|r|r|r|r|r|}
\hline \multirow{2}{*}{ Ownership } & \multicolumn{2}{|c|}{ Tabuc-tubig } & \multicolumn{2}{c|}{ Junob } & \multicolumn{2}{c|}{ Poblacion 1 } & \multicolumn{2}{c|}{ Batinguel } & \multicolumn{2}{c|}{ Candua-ay } \\
\cline { 2 - 11 } & Number & \multicolumn{1}{|c|}{$\%$} & Number & \% & Number & \multicolumn{1}{c|}{$\%$} & Number & \% & Number & \% \\
\hline House and Lot & 1 & 10.00 & 0 & 0.00 & 5 & 22.73 & 7 & 18.42 & 19 & 26.39 \\
\hline House Only & 8 & 80.00 & 10 & 62.50 & 11 & 50.00 & 24 & 63.16 & 25 & 34.72 \\
\hline Lot Only & 1 & 10.00 & 2 & 12.50 & 2 & 9.09 & 2 & 5.26 & 6 & 8.33 \\
\hline Do Own any Property & 0 & 0.00 & 4 & 25.00 & 4 & 18.18 & 5 & 13.16 & 16 & 22.22 \\
\hline Did not specify & 0 & 0.00 & 0 & 0.00 & 0 & 0.00 & 0 & 0.00 & 6 & 8.33 \\
\hline
\end{tabular}

\begin{tabular}{|c|c|c|c|c|c|c|c|c|c|c|}
\hline \multirow{2}{*}{ Ownership } & \multicolumn{2}{|c|}{ Taclobo } & \multicolumn{2}{|c|}{ Bagacay } & \multicolumn{2}{|c|}{ Cadawinonan } & \multicolumn{2}{|c|}{ Poblacion 8} & \multicolumn{2}{|c|}{ Barangay 2} \\
\hline & Number & $\%$ & Number & $\%$ & Number & $\%$ & Number & $\%$ & Number & $\%$ \\
\hline House and Lot & 24 & 38.10 & 2 & 6.67 & 16 & 64.00 & 7 & 24.14 & 2 & 12.50 \\
\hline House Only & 19 & 30.16 & 21 & 70.00 & 4 & 16.00 & 13 & 44.83 & 8 & 50.00 \\
\hline Lot Only & 11 & 17.46 & 2 & 6.67 & 1 & 4.00 & 6 & 20.69 & 3 & 18.75 \\
\hline Do Own any Property & 9 & 14.29 & 5 & 16.67 & 4 & 16.00 & 3 & 10.34 & 2 & 12.50 \\
\hline Did not specify & 0 & 0.00 & 0 & 0.00 & 0 & 0.00 & 0 & 0.00 & 1 & 6.25 \\
\hline
\end{tabular}

\begin{tabular}{|l|r|r|r|r|r|r|}
\hline \multirow{2}{*}{ Ownership } & \multicolumn{2}{|c|}{ Balugo } & \multicolumn{2}{c|}{ Calindagan } & \multicolumn{2}{c|}{ Overall } \\
\cline { 2 - 7 } & Number & \multicolumn{1}{c|}{$\%$} & Number & \multicolumn{1}{c|}{$\%$} & Number & \multicolumn{1}{c|}{$\%$} \\
\hline House and Lot & 4 & 23.53 & 6 & 26.09 & 93 & 25.76 \\
\hline House Only & 2 & 11.76 & 3 & 13.04 & 148 & 41.00 \\
\hline Lot Only & 0 & 0.00 & 0 & 0.00 & 36 & 9.97 \\
\hline Do Own any Property & 8 & 47.06 & 12 & 52.17 & 72 & 19.94 \\
\hline Did not specify & 3 & 17.65 & 2 & 8.70 & 12 & 3.32 \\
\hline
\end{tabular}


Community-Based Flood Vulnerability Index for Urban Flooding: Understanding Social Vulnerabilities and Risks

Property Insurance

\begin{tabular}{|l|r|r|r|r|r|r|}
\hline \multirow{2}{*}{ Barangay } & \multicolumn{7}{|c|}{ Insured } \\
\cline { 2 - 8 } & \multicolumn{2}{|c|}{ Yes } & \multicolumn{2}{c|}{ No } & \multicolumn{2}{c|}{ Not Specified } \\
\cline { 2 - 8 } & Number & \multicolumn{1}{c|}{ Number } & \multicolumn{1}{c|}{$\%$} & Number & \multicolumn{1}{c|}{$\%$} \\
\hline Tabuc-tubig & 0 & 0.00 & 10 & 100.00 & 0 & 0.00 \\
\hline Junob & 0 & 0.00 & 16 & 100.00 & 0 & 0.00 \\
\hline Poblacion 1 & 3 & 13.64 & 19 & 86.36 & 0 & 0.00 \\
\hline Batinguel & 2 & 5.26 & 36 & 94.74 & 0 & 0.00 \\
\hline Candua-ay & 12 & 16.67 & 51 & 70.83 & 9 & 12.50 \\
\hline Taclobo & 11 & 17.46 & 43 & 68.25 & 9 & 14.29 \\
\hline Bagacay & 4 & 13.33 & 22 & 73.33 & 4 & 13.33 \\
\hline Cadawinonan & 7 & 28.00 & 16 & 64.00 & 2 & 8.00 \\
\hline Poblacion 8 & 2 & 6.90 & 25 & 86.21 & 2 & 6.90 \\
\hline Barangay 2 & 1 & 6.25 & 12 & 75.00 & 3 & 18.75 \\
\hline Balugo & 0 & 0.00 & 17 & 100.00 & 0 & 0.00 \\
\hline Calindagan & 2 & 8.70 & 21 & 91.30 & 0 & 0.00 \\
\hline \multicolumn{1}{|c|}{ Overall } & 44 & 12.19 & 288 & 79.78 & 29 & 8.03 \\
\hline
\end{tabular}


Community-Based Flood Vulnerability Index for Urban Flooding: Understanding Social Vulnerabilities and Risks

\section{Housing Materials}

\begin{tabular}{|c|c|c|c|c|c|c|c|c|c|c|}
\hline \multirow{2}{*}{ Material } & \multicolumn{2}{|c|}{ Tabuc-tubig } & \multicolumn{2}{|c|}{ Junob } & \multicolumn{2}{|c|}{ Poblacion 1} & \multicolumn{2}{|c|}{ Batinguel } & \multicolumn{2}{|c|}{ Candua-ay } \\
\hline & Number & $\%$ & Number & $\%$ & Number & $\%$ & Number & $\%$ & Number & $\%$ \\
\hline Concrete & 0 & 0.00 & 0 & 0.00 & 2 & 9.09 & 4 & 10.53 & 6 & 8.33 \\
\hline Semi-Concrete & 5 & 50.00 & 3 & 18.75 & 10 & 45.45 & 5 & 13.16 & 32 & 44.44 \\
\hline $\begin{array}{l}\text { Semi-Concrete with Light } \\
\text { Roofing Materials }\end{array}$ & 2 & 20.00 & 0 & 0.00 & 1 & 4.55 & 1 & 2.63 & 3 & 4.17 \\
\hline Wood & 1 & 10.00 & 1 & 6.25 & 5 & 22.73 & 14 & 36.84 & 15 & 20.83 \\
\hline $\begin{array}{l}\text { Wood with Light Roofing } \\
\text { Materials }\end{array}$ & 1 & 10.00 & 4 & 25.00 & 4 & 18.18 & 10 & 26.32 & 8 & 11.11 \\
\hline Light Materials & 1 & 10.00 & 5 & 31.25 & 0 & 0.00 & 2 & 5.26 & 7 & 9.72 \\
\hline Tent/Plastic & 0 & 0.00 & 3 & 18.75 & 0 & 0.00 & 2 & 5.26 & 0 & 0.00 \\
\hline Did not specify & 0 & 0.00 & 0 & 0.00 & 0 & 0.00 & 0 & 0.00 & 1 & 1.39 \\
\hline
\end{tabular}

\begin{tabular}{|c|c|c|c|c|c|c|c|c|c|c|}
\hline \multirow{2}{*}{ Material } & \multicolumn{2}{|c|}{ Taclobo } & \multicolumn{2}{|c|}{ Bagacay } & \multicolumn{2}{|c|}{ Cadawinonan } & \multicolumn{2}{|c|}{ Poblacion 8} & \multicolumn{2}{|c|}{ Barangay 2} \\
\hline & Number & $\%$ & Number & $\%$ & Number & $\%$ & Number & $\%$ & Number & $\%$ \\
\hline Concrete & 6 & 9.52 & 3 & 10.00 & 6 & 24.00 & 1 & 3.45 & 1 & 6.25 \\
\hline Semi-Concrete & 21 & 33.33 & 5 & 16.67 & 11 & 44.00 & 11 & 37.93 & 2 & 12.50 \\
\hline $\begin{array}{l}\text { Semi-Concrete with Light } \\
\text { Roofing Materials }\end{array}$ & 0 & 0.00 & 2 & 6.67 & 3 & 12.00 & 2 & 6.90 & 2 & 12.50 \\
\hline Wood & 21 & 33.33 & 10 & 33.33 & 5 & 20.00 & 9 & 31.03 & 7 & 43.75 \\
\hline $\begin{array}{l}\text { Wood with Light Roofing } \\
\text { Materials }\end{array}$ & 7 & 11.11 & 8 & 26.67 & 0 & 0.00 & 6 & 20.69 & 2 & 12.50 \\
\hline Light Materials & 3 & 4.76 & 2 & 6.67 & 0 & 0.00 & 0 & 0.00 & 2 & 12.50 \\
\hline Tent/Plastic & 1 & 1.59 & 0 & 0.00 & 0 & 0.00 & 0 & 0.00 & 0 & 0.00 \\
\hline Did not specify & 4 & 6.35 & 0 & 0.00 & 0 & 0.00 & 0 & 0.00 & 0 & 0.00 \\
\hline
\end{tabular}


Community-Based Flood Vulnerability Index for Urban Flooding: Understanding Social Vulnerabilities and Risks

Housing Materials ... continued

\begin{tabular}{|l|r|r|r|r|r|r|}
\hline \multirow{2}{*}{ Material } & \multicolumn{2}{|c|}{ Balugo } & \multicolumn{2}{c|}{ Calindagan } & \multicolumn{2}{c|}{ Overall } \\
\cline { 2 - 8 } & Number & \multicolumn{1}{c|}{$\%$} & Number & \multicolumn{1}{c|}{$\%$} & Number & \multicolumn{1}{c|}{$\%$} \\
\hline Concrete & 1 & 5.88 & 2 & 8.70 & 32 & 8.86 \\
\hline Semi-Concrete wight & 3 & 17.65 & 13 & 56.52 & 121 & 33.52 \\
\hline $\begin{array}{l}\text { Semi-Concrete with Lighting Materials } \\
\text { Roofing }\end{array}$ & 0 & 0.00 & 1 & 4.35 & 17 & 4.71 \\
\hline Wood & 5 & 29.41 & 3 & 13.04 & 96 & 26.59 \\
\hline $\begin{array}{l}\text { Wood with Light Roofing } \\
\text { Materials }\end{array}$ & 3 & 17.65 & 3 & 13.04 & 56 & 15.51 \\
\hline Light Materials & 5 & 29.41 & 1 & 4.35 & 28 & 7.76 \\
\hline Tent/Plastic & 0 & 0.00 & 0 & 0.00 & 6 & 1.66 \\
\hline Did not specify & 0 & 0.00 & 0 & 0.00 & 5 & 1.39 \\
\hline
\end{tabular}

Notes: Semi-Concrete: concrete and wood; Light Roofing Materials: coconut/nipa shingles,

Light Materials: bamboo, cartoon and scavenged materials, coconut/nipa shingles. 
Community-Based Flood Vulnerability Index for Urban Flooding: Understanding Social Vulnerabilities and Risks

Physical Environment

\section{Flooding Frequency in Place}

\begin{tabular}{|l|r|r|r|r|r|r|r|r|r|r|}
\hline \multirow{2}{*}{ Frequency } & \multicolumn{2}{|c|}{ Tabuc-tubig } & \multicolumn{2}{c|}{ Junob } & \multicolumn{2}{c|}{ Poblacion 1 } & \multicolumn{2}{c|}{ Batinguel } & \multicolumn{2}{c|}{ Candua-ay } \\
\cline { 2 - 12 } & Number & \multicolumn{1}{|c|}{$\%$} & Number & \% & Number & \multicolumn{1}{c|}{$\%$} & Number & $\%$ & Number & \% \\
\hline Every month & 0 & 0.00 & 0 & 0.00 & 2 & 9.09 & 3 & 7.89 & 8 & 11.11 \\
\hline Every 4 months & 1 & 10.00 & 2 & 12.50 & 0 & 0.00 & 8 & 21.05 & 2 & 2.78 \\
\hline Every 6 months & 3 & 30.00 & 2 & 12.50 & 0 & 0.00 & 4 & 10.53 & 4 & 5.56 \\
\hline Every year & 3 & 30.00 & 5 & 31.25 & 8 & 36.36 & 11 & 28.95 & 15 & 20.83 \\
\hline Sometimes & 3 & 30.00 & 2 & 12.50 & 6 & 27.27 & 7 & 18.42 & 17 & 23.61 \\
\hline Rarely & 0 & 0.00 & 4 & 25.00 & 2 & 9.09 & 4 & 10.53 & 20 & 27.78 \\
\hline Never & 0 & 0.00 & 1 & 6.25 & 3 & 13.64 & 1 & 2.63 & 4 & 5.56 \\
\hline Did not Specify & 0 & 0.00 & 0 & 0.00 & 1 & 4.55 & 0 & 0.00 & 2 & 2.78 \\
\hline
\end{tabular}

\begin{tabular}{|c|c|c|c|c|c|c|c|c|c|c|}
\hline \multirow{2}{*}{ Frequency } & \multicolumn{2}{|c|}{ Taclobo } & \multicolumn{2}{|c|}{ Bagacay } & \multicolumn{2}{|c|}{ Cadawinonan } & \multicolumn{2}{|c|}{ Poblacion 8} & \multicolumn{2}{|c|}{ Barangay 2} \\
\hline & Number & $\%$ & Number & $\%$ & Number & $\%$ & Number & $\%$ & Number & $\%$ \\
\hline Every month & 1 & 1.59 & 0 & 0.00 & 1 & 4.00 & 0 & 0.00 & 0 & 0.00 \\
\hline Every 4 months & 5 & 7.94 & 5 & 16.67 & 0 & 0.00 & 4 & 13.79 & 0 & 0.00 \\
\hline Every 6 months & 2 & 3.17 & 1 & 3.33 & 0 & 0.00 & 1 & 3.45 & 1 & 6.25 \\
\hline Every year & 11 & 17.46 & 8 & 26.67 & 7 & 28.00 & 9 & 31.03 & 6 & 37.50 \\
\hline Sometimes & 18 & 28.57 & 7 & 23.33 & 6 & 24.00 & 7 & 24.14 & 3 & 18.75 \\
\hline Rarely & 17 & 26.98 & 9 & 30.00 & 7 & 28.00 & 8 & 27.59 & 6 & 37.50 \\
\hline Never & 9 & 14.29 & 0 & 0.00 & 2 & 8.00 & 0 & 0.00 & 0 & 0.00 \\
\hline Did not Specify & 0 & 0.00 & 0 & 0.00 & 2 & 8.00 & 0 & 0.00 & 0 & 0.00 \\
\hline
\end{tabular}


Community-Based Flood Vulnerability Index for Urban Flooding: Understanding Social Vulnerabilities and Risks

Flooding Frequency in Place ... continued

\begin{tabular}{|l|r|r|r|r|r|r|}
\hline \multirow{2}{*}{\multicolumn{1}{|c|}{ Frequency }} & \multicolumn{2}{|c|}{ Balugo } & \multicolumn{2}{c|}{ Calindagan } & \multicolumn{2}{c|}{ Overall } \\
\cline { 2 - 7 } & Number & \multicolumn{1}{c|}{$\%$} & Number & \multicolumn{1}{c|}{$\%$} & Number & \multicolumn{1}{c|}{$\%$} \\
\hline Every month & 0 & 0.00 & 1 & 4.35 & 16 & 4.43 \\
\hline Every 4 months & 0 & 0.00 & 1 & 4.35 & 28 & 7.76 \\
\hline Every 6 months & 0 & 0.00 & 1 & 4.35 & 19 & 5.26 \\
\hline Every year & 5 & 29.41 & 3 & 13.04 & 91 & 25.21 \\
\hline Sometimes & 9 & 52.94 & 7 & 30.43 & 92 & 25.48 \\
\hline Rarely & 2 & 11.76 & 7 & 30.43 & 86 & 23.82 \\
\hline Never & 0 & 0.00 & 3 & 13.04 & 23 & 6.37 \\
\hline Did not Specify & 1 & 5.88 & 0 & 0.00 & 6 & 1.66 \\
\hline
\end{tabular}


Community-Based Flood Vulnerability Index for Urban Flooding: Understanding Social Vulnerabilities and Risks

\section{Number of Houses Reached by Flooding}

\begin{tabular}{|c|c|c|c|c|c|c|c|c|c|c|}
\hline \multirow{2}{*}{ Reached by Flooding } & \multicolumn{2}{|c|}{ Tabuc-tubig } & \multicolumn{2}{|c|}{ Junob } & \multicolumn{2}{|c|}{ Poblacion 1} & \multicolumn{2}{|c|}{ Batinguel } & \multicolumn{2}{|c|}{ Candua-ay } \\
\hline & Number & $\%$ & Number & $\%$ & Number & $\%$ & Number & $\%$ & Number & $\%$ \\
\hline Yes & 6 & 60.00 & 13 & 81.25 & 13 & 59.09 & 31 & 81.58 & 59 & 81.94 \\
\hline No & 4 & 40.00 & 3 & 18.75 & 9 & 40.91 & 7 & 18.42 & 13 & 18.06 \\
\hline Did not Specify & 0 & 0.00 & 0 & 0.00 & 0 & 0.00 & 0 & 0.00 & 0 & 0.00 \\
\hline
\end{tabular}

\begin{tabular}{|l|r|r|r|r|r|r|r|r|r|r|}
\hline \multirow{2}{*}{ Reached by Flooding } & \multicolumn{2}{|c|}{ Taclobo } & \multicolumn{2}{|c|}{ Bagacay } & \multicolumn{2}{c|}{ Cadawinonan } & \multicolumn{2}{c|}{ Poblacion 8 } & \multicolumn{2}{c|}{ Barangay 2} \\
\cline { 2 - 12 } & Number & \multicolumn{1}{|c|}{$\%$} & Number & \multicolumn{1}{c|}{$\%$} & Number & \% & Number & $\%$ & Number & \% \\
\hline Yes & 30 & 47.62 & 23 & 76.67 & 15 & 60.00 & 24 & 82.76 & 14 & 87.50 \\
\hline No & 32 & 50.79 & 7 & 23.33 & 10 & 40.00 & 5 & 17.24 & 2 & 12.50 \\
\hline Did not Specify & 1 & 1.59 & 0 & 0.00 & 0 & 0.00 & 0 & 0.00 & 0 & 0.00 \\
\hline
\end{tabular}

\begin{tabular}{|l|r|r|r|r|r|r|}
\hline \multirow{2}{*}{ Reached by Flooding } & \multicolumn{2}{|c|}{ Balugo } & \multicolumn{2}{c|}{ Calindagan } & \multicolumn{2}{c|}{ Overall } \\
\cline { 2 - 7 } & Number & \multicolumn{1}{c|}{$\%$} & Number & \multicolumn{1}{c|}{$\%$} & Number & \multicolumn{1}{c|}{$\%$} \\
\hline Yes & 10 & 58.82 & 16 & 69.57 & 254 & 70.36 \\
\hline No & 7 & 41.18 & 7 & 30.43 & 106 & 29.36 \\
\hline Did not Specify & 0 & 0.00 & 0 & 0.00 & 1 & 0.28 \\
\hline
\end{tabular}


Community-Based Flood Vulnerability Index for Urban Flooding: Understanding Social Vulnerabilities and Risks

Depth of Flood Waters in the Immediate Surroundings

\begin{tabular}{|l|r|r|r|r|r|r|r|r|r|r|}
\hline \multirow{2}{*}{ Depth } & \multicolumn{2}{|c|}{ Tabuc-tubig } & \multicolumn{2}{c|}{ Junob } & \multicolumn{2}{c|}{ Poblacion 1 } & \multicolumn{2}{c|}{ Batinguel } & \multicolumn{2}{c|}{ Candua-ay } \\
\cline { 2 - 11 } & Number & \% & Number & \% & Number & \% & Number & \% & Number & \% \\
\hline Ankle High & 0 & 0.00 & 0 & 0.00 & 7 & 31.82 & 8 & 21.05 & 13 & 18.06 \\
\hline Knee High & 0 & 0.00 & 3 & 18.75 & 8 & 36.36 & 5 & 13.16 & 16 & 22.22 \\
\hline Waist High & 0 & 0.00 & 0 & 0.00 & 4 & 18.18 & 9 & 23.68 & 18 & 25.00 \\
\hline Shoulder High & 1 & 10.00 & 1 & 6.25 & 2 & 9.09 & 2 & 5.26 & 11 & 15.28 \\
\hline Above the Head & 3 & 30.00 & 4 & 25.00 & 0 & 0.00 & 5 & 13.16 & 5 & 6.94 \\
\hline Roof High & 2 & 20.00 & 3 & 18.75 & 0 & 0.00 & 2 & 5.26 & 3 & 4.17 \\
\hline Beyond the Reef & 0 & 0.00 & 2 & 12.50 & 0 & 0.00 & 4 & 10.53 & 0 & 0.00 \\
\hline Did not Specify & 4 & 40.00 & 3 & 18.75 & 1 & 4.55 & 3 & 7.89 & 6 & 8.33 \\
\hline
\end{tabular}

\begin{tabular}{|l|r|r|r|r|r|r|r|r|r|r|}
\hline \multirow{2}{*}{ Depth } & \multicolumn{2}{|c|}{ Taclobo } & \multicolumn{2}{c|}{ Bagacay } & \multicolumn{2}{c|}{ Cadawinonan } & \multicolumn{2}{c|}{ Poblacion 8 } & \multicolumn{2}{c|}{ Barangay 2 } \\
\cline { 2 - 12 } & Number & \multicolumn{1}{c|}{ \% } & Number & \multicolumn{1}{c|}{ \% } & Number & \multicolumn{1}{c|}{ \% } & Number & \multicolumn{1}{c|}{$\%$} & Number & \% \\
\hline Ankle High & 22 & 34.92 & 5 & 16.67 & 6 & 24.00 & 3 & 10.34 & 4 & 25.00 \\
\hline Knee High & 7 & 11.11 & 2 & 6.67 & 4 & 16.00 & 5 & 17.24 & 3 & 18.75 \\
\hline Waist High & 5 & 7.94 & 5 & 16.67 & 2 & 8.00 & 2 & 6.90 & 2 & 12.50 \\
\hline Shoulder High & 4 & 6.35 & 4 & 13.33 & 4 & 16.00 & 2 & 6.90 & 2 & 12.50 \\
\hline Above the Head & 5 & 7.94 & 8 & 26.67 & 3 & 12.00 & 8 & 27.59 & 4 & 25.00 \\
\hline Roof High & 5 & 7.94 & 1 & 3.33 & 0 & 0.00 & 3 & 10.34 & 1 & 6.25 \\
\hline Beyond the Reef & 0 & 0.00 & 0 & 0.00 & 0 & 0.00 & 3 & 10.34 & 0 & 0.00 \\
\hline Did not Specify & 15 & 23.81 & 5 & 16.67 & 6 & 24.00 & 3 & 10.34 & 0 & 0.00 \\
\hline
\end{tabular}


Community-Based Flood Vulnerability Index for Urban Flooding: Understanding Social Vulnerabilities and Risks

Depth of Flood Waters in the Immediate Surroundings ... continued

\begin{tabular}{|l|r|r|r|r|r|r|}
\hline \multirow{2}{*}{ Depth } & \multicolumn{2}{c|}{ Balugo } & \multicolumn{2}{c|}{ Calindagan } & \multicolumn{2}{c|}{ Overall } \\
\cline { 2 - 7 } & Number & \multicolumn{1}{c|}{$\%$} & Number & \multicolumn{1}{c|}{$\%$} & Number & \multicolumn{1}{c|}{$\%$} \\
\hline Ankle High & 5 & 29.41 & 9 & 39.13 & 82 & 22.71 \\
\hline Knee High & 3 & 17.65 & 6 & 26.09 & 62 & 17.17 \\
\hline Waist High & 4 & 23.53 & 3 & 13.04 & 54 & 14.96 \\
\hline Shoulder High & 1 & 5.88 & 1 & 4.35 & 35 & 9.70 \\
\hline Above the Head & 0 & 0.00 & 1 & 4.35 & 46 & 12.74 \\
\hline Roof High & 1 & 5.88 & 0 & 0.00 & 21 & 5.82 \\
\hline Beyond the Reef & 1 & 5.88 & 0 & 0.00 & 10 & 2.77 \\
\hline Did not Specify & 2 & 11.76 & 3 & 13.04 & 51 & 14.13 \\
\hline
\end{tabular}


Community-Based Flood Vulnerability Index for Urban Flooding: Understanding Social Vulnerabilities and Risks

\section{Immediate Surrounding Cleanliness}

\begin{tabular}{|c|c|c|c|c|c|c|c|c|c|c|}
\hline \multirow{2}{*}{ Frequency } & \multicolumn{2}{|c|}{ Tabuc-tubig } & \multicolumn{2}{|c|}{ Junob } & \multicolumn{2}{|c|}{ Poblacion 1} & \multicolumn{2}{|c|}{ Batinguel } & \multicolumn{2}{|c|}{ Candua-ay } \\
\hline & Number & $\%$ & Number & $\%$ & Number & $\%$ & Number & $\%$ & Number & $\%$ \\
\hline Yes & 10 & 100.00 & 14 & 87.50 & 15 & 68.18 & 31 & 81.58 & 57 & 79.17 \\
\hline No & 0 & 0.00 & 2 & 12.50 & 7 & 31.82 & 7 & 18.42 & 15 & 20.83 \\
\hline Did not Specify & 0 & 0.00 & 0 & 0.00 & 0 & 0.00 & 0 & 0.00 & 0 & 0.00 \\
\hline
\end{tabular}

\begin{tabular}{|l|r|r|r|r|r|r|r|r|r|r|}
\hline \multirow{2}{*}{ Frequency } & \multicolumn{2}{|c|}{ Taclobo } & \multicolumn{2}{c|}{ Bagacay } & \multicolumn{2}{c|}{ Cadawinonan } & \multicolumn{2}{c|}{ Poblacion 8 } & \multicolumn{2}{c|}{ Barangay 2 } \\
\cline { 2 - 12 } & Number & \multicolumn{1}{|c|}{$\%$} & Number & \multicolumn{1}{c|}{$\%$} & Number & \multicolumn{1}{c|}{$\%$} & Number & \% & Number & \% \\
\hline Yes & 53 & 84.13 & 23 & 76.67 & 23 & 92.00 & 25 & 86.21 & 12 & 75.00 \\
\hline No & 10 & 15.87 & 6 & 20.00 & 2 & 8.00 & 4 & 13.79 & 4 & 25.00 \\
\hline Did not Specify & 0 & 0.00 & 1 & 3.33 & 0 & 0.00 & 0 & 0.00 & 0 & 0.00 \\
\hline
\end{tabular}

\begin{tabular}{|l|r|r|r|r|r|r|}
\hline \multirow{2}{*}{ Frequency } & \multicolumn{2}{|c|}{ Balugo } & \multicolumn{2}{c|}{ Calindagan } & \multicolumn{2}{c|}{ Overall } \\
\cline { 2 - 7 } & Number & \multicolumn{1}{c|}{$\%$} & Number & \multicolumn{1}{c|}{$\%$} & Number & \multicolumn{1}{c|}{$\%$} \\
\hline Yes & 15 & 88.24 & 15 & 65.22 & 293 & 81.16 \\
\hline No & 2 & 11.76 & 8 & 34.78 & 67 & 18.56 \\
\hline Did not Specify & 0 & 0.00 & 0 & 0.00 & 1 & 0.28 \\
\hline
\end{tabular}


Community-Based Flood Vulnerability Index for Urban Flooding: Understanding

Social Vulnerabilities and Risks

\section{Presence of Water Logged Areas in Surroundings}

\begin{tabular}{|l|r|r|r|r|r|r|r|r|r|r|}
\hline \multirow{2}{*}{ Frequency } & \multicolumn{2}{|c|}{ Tabuc-tubig } & \multicolumn{2}{c|}{ Junob } & \multicolumn{2}{c|}{ Poblacion 1 } & \multicolumn{2}{c|}{ Batinguel } & \multicolumn{2}{c|}{ Candua-ay } \\
\cline { 2 - 11 } & Number & \multicolumn{1}{c|}{$\%$} & Number & \multicolumn{1}{c|}{$\%$} & Number & \multicolumn{1}{c|}{$\%$} & \multicolumn{1}{c|}{ Number } & \multicolumn{1}{c|}{ \% } & Number & \multicolumn{1}{c|}{$\%$} \\
\hline Yes & 9 & 90.00 & 4 & 25.00 & 14 & 63.64 & 16 & 42.11 & 32 & 44.44 \\
\hline No & 1 & 10.00 & 12 & 75.00 & 8 & 36.36 & 22 & 57.89 & 39 & 54.17 \\
\hline Did not Specify & 0 & 0.00 & 0 & 0.00 & 0 & 0.00 & 0 & 0.00 & 1 & 1.39 \\
\hline
\end{tabular}

\begin{tabular}{|c|c|c|c|c|c|c|c|c|c|c|}
\hline \multirow{2}{*}{ Frequency } & \multicolumn{2}{|c|}{ Taclobo } & \multicolumn{2}{|c|}{ Bagacay } & \multicolumn{2}{|c|}{ Cadawinonan } & \multicolumn{2}{|c|}{ Poblacion 8} & \multicolumn{2}{|c|}{ Barangay 2} \\
\hline & Number & $\%$ & Number & $\%$ & Number & $\%$ & Number & $\%$ & Number & $\%$ \\
\hline Yes & 31 & 49.21 & 14 & 46.67 & 8 & 32.00 & 12 & 41.38 & 6 & 37.50 \\
\hline No & 32 & 50.79 & 16 & 53.33 & 17 & 68.00 & 17 & 58.62 & 10 & 62.50 \\
\hline Did not Specify & 0 & 0.00 & 0 & 0.00 & 0 & 0.00 & 0 & 0.00 & 0 & 0.00 \\
\hline
\end{tabular}

\begin{tabular}{|l|r|r|r|r|r|r|}
\hline \multirow{2}{*}{ Frequency } & \multicolumn{2}{|c|}{ Balugo } & \multicolumn{2}{c|}{ Calindagan } & \multicolumn{2}{c|}{ Overall } \\
\cline { 2 - 7 } & Number & \multicolumn{1}{c|}{$\%$} & Number & \multicolumn{1}{c|}{$\%$} & Number & \multicolumn{1}{c|}{$\%$} \\
\hline Yes & 5 & 29.41 & 14 & 60.87 & 165 & 45.71 \\
\hline No & 11 & 64.71 & 9 & 39.13 & 194 & 53.74 \\
\hline Did not Specify & 1 & 5.88 & 0 & 0.00 & 2 & 0.55 \\
\hline
\end{tabular}


Community-Based Flood Vulnerability Index for Urban Flooding: Understanding

Social Vulnerabilities and Risks

Presence of Open Sewage or Canal in Surroundings

\begin{tabular}{|l|r|r|r|r|r|r|r|r|r|r|}
\hline \multirow{2}{*}{ Frequency } & \multicolumn{2}{|c|}{ Tabuc-tubig } & \multicolumn{2}{c|}{ Junob } & \multicolumn{2}{c|}{ Poblacion 1 } & \multicolumn{2}{c|}{ Batinguel } & \multicolumn{2}{c|}{ Candua-ay } \\
\cline { 2 - 11 } & Number & \multicolumn{1}{|c|}{$\%$} & Number & \multicolumn{1}{c|}{$\%$} & Number & \multicolumn{1}{c|}{$\%$} & Number & $\%$ & Number & \% \\
\hline Yes & 9 & 90.00 & 4 & 25.00 & 15 & 68.18 & 16 & 42.11 & 35 & 48.61 \\
\hline No & 1 & 10.00 & 12 & 75.00 & 7 & 31.82 & 22 & 57.89 & 37 & 51.39 \\
\hline Did not Specify & 0 & 0.00 & 0 & 0.00 & 0 & 0.00 & 0 & 0.00 & 0 & 0.00 \\
\hline
\end{tabular}

\begin{tabular}{|l|r|r|r|r|r|r|r|r|r|r|}
\hline \multirow{2}{*}{ Frequency } & \multicolumn{2}{|c|}{ Taclobo } & \multicolumn{2}{c|}{ Bagacay } & \multicolumn{2}{c|}{ Cadawinonan } & \multicolumn{2}{c|}{ Poblacion 8 } & \multicolumn{2}{c|}{ Barangay 2 } \\
\cline { 2 - 12 } & Number & \multicolumn{1}{|c|}{$\%$} & Number & \multicolumn{1}{c|}{$\%$} & Number & \% & Number & \% & Number & \% \\
\hline Yes & 32 & 50.79 & 16 & 53.33 & 12 & 48.00 & 15 & 51.72 & 9 & 56.25 \\
\hline No & 30 & 47.62 & 14 & 46.67 & 13 & 52.00 & 13 & 44.83 & 7 & 43.75 \\
\hline Did not Specify & 1 & 1.59 & 0 & 0.00 & 0 & 0.00 & 1 & 3.45 & 0 & 0.00 \\
\hline
\end{tabular}

\begin{tabular}{|l|r|r|r|r|r|r|}
\hline \multirow{2}{*}{ Frequency } & \multicolumn{2}{|c|}{ Balugo } & \multicolumn{2}{c|}{ Calindagan } & \multicolumn{2}{c|}{ Overall } \\
\cline { 2 - 7 } & Number & \multicolumn{1}{|c|}{$\%$} & Number & \multicolumn{1}{c|}{$\%$} & Number & \multicolumn{1}{c|}{$\%$} \\
\hline Yes & 5 & 29.41 & 18 & 78.26 & 186 & 51.52 \\
\hline No & 12 & 70.59 & 5 & 21.74 & 173 & 47.92 \\
\hline Did not Specify & 0 & 0.00 & 0 & 0.00 & 2 & 0.55 \\
\hline
\end{tabular}


Community-Based Flood Vulnerability Index for Urban Flooding: Understanding Social Vulnerabilities and Risks

\section{Proximity of House to Bodies of Water}

\begin{tabular}{|l|r|r|r|r|r|r|r|r|r|r|}
\hline \multirow{2}{*}{ Body of Water } & \multicolumn{2}{|c|}{ Tabuc-tubig } & \multicolumn{2}{c|}{ Junob } & \multicolumn{2}{c|}{ Poblacion 1 } & \multicolumn{2}{c|}{ Batinguel } & \multicolumn{2}{c|}{ Candua-ay } \\
\cline { 2 - 11 } & Number & \multicolumn{1}{|c|}{$\%$} & Number & \multicolumn{1}{c|}{$\%$} & Number & \multicolumn{1}{c|}{$\%$} & Number & $\%$ & Number & $\%$ \\
\hline River & 10 & 100 & 14 & 87.50 & 14 & 63.64 & 31 & 81.58 & 46 & 63.89 \\
\hline Creek/Pond & 0 & 0.00 & 0 & 0.00 & 0 & 0.00 & 2 & 5.26 & 4 & 5.56 \\
\hline Coastal & 0 & 0.00 & 0 & 0.00 & 4 & 18.18 & 0 & 0.00 & 4 & 5.56 \\
\hline Far from Water System & 0 & 0.00 & 0 & 0.00 & 1 & 4.55 & 0 & 0.00 & 2 & 2.78 \\
\hline Did not Specify & 0 & 0.00 & 2 & 12.50 & 3 & 13.64 & 5 & 13.16 & 16 & 22.22 \\
\hline
\end{tabular}

\begin{tabular}{|l|r|r|r|r|r|r|r|r|r|r|}
\hline \multirow{2}{*}{ Body of Water } & \multicolumn{2}{|c|}{ Taclobo } & \multicolumn{2}{c|}{ Bagacay } & \multicolumn{2}{c|}{ Cadawinonan } & \multicolumn{2}{c|}{ Poblacion 8 } & \multicolumn{2}{c|}{ Barangay 2 } \\
\cline { 2 - 11 } & Number & \multicolumn{1}{|c|}{$\%$} & Number & \multicolumn{1}{c|}{$\%$} & Number & \multicolumn{1}{c|}{ \% } & Number & \% & Number & \% \\
\hline River & 28 & 44.44 & 19 & 63.33 & 16 & 64.00 & 19 & 65.52 & 10 & 62.50 \\
\hline Creek/Pond & 2 & 3.17 & 0 & 0.00 & 0 & 0.00 & 0 & 0.00 & 0 & 0.00 \\
\hline Coastal & 0 & 0.00 & 0 & 0.00 & 0 & 0.00 & 1 & 3.45 & 2 & 12.50 \\
\hline Far from Water System & 2 & 3.17 & 1 & 3.33 & 0 & 0.00 & 5 & 17.24 & 3 & 18.75 \\
\hline Did not Specify & 31 & 49.21 & 10 & 33.33 & 9 & 36.00 & 4 & 13.79 & 1 & 6.25 \\
\hline
\end{tabular}

\begin{tabular}{|l|r|r|r|r|r|r|}
\hline \multirow{2}{*}{ Body of Water } & \multicolumn{2}{|c|}{ Balugo } & \multicolumn{2}{c|}{ Calindagan } & \multicolumn{2}{c|}{ Overall } \\
\cline { 2 - 7 } & Number & \multicolumn{1}{c|}{$\%$} & Number & \multicolumn{1}{c|}{$\%$} & Number & \multicolumn{1}{c|}{$\%$} \\
\hline River & 7 & 41.18 & 10 & 43.48 & 224 & 62.05 \\
\hline Creek/Pond & 0 & 0.00 & 1 & 4.35 & 9 & 2.49 \\
\hline Coastal & 0 & 0.00 & 8 & 34.78 & 19 & 5.26 \\
\hline Far from Water System & 1 & 5.88 & 0 & 0.00 & 15 & 4.16 \\
\hline Did not Specify & 9 & 52.94 & 4 & 17.39 & 94 & 26.04 \\
\hline
\end{tabular}


Community-Based Flood Vulnerability Index for Urban Flooding: Understanding Social Vulnerabilities and Risks

\section{Location of House in Elevated Areas}

\begin{tabular}{|c|c|c|c|c|c|c|c|c|c|c|}
\hline \multirow[t]{2}{*}{ Frequency } & \multicolumn{2}{|c|}{ Tabuc-tubig } & \multicolumn{2}{|c|}{ Junob } & \multicolumn{2}{|c|}{ Poblacion 1} & \multicolumn{2}{|c|}{ Batinguel } & \multicolumn{2}{|c|}{ Candua-ay } \\
\hline & Number & $\%$ & Number & $\%$ & Number & $\%$ & Number & $\%$ & Number & $\%$ \\
\hline Yes & 5 & 50.00 & 7 & 43.75 & 6 & 27.27 & 12 & 31.58 & 31 & 43.06 \\
\hline No & 5 & 50.00 & 9 & 56.25 & 16 & 72.73 & 26 & 68.42 & 39 & 54.17 \\
\hline Did not Specify & 0 & 0.00 & 0 & 0.00 & 0 & 0.00 & 0 & 0.00 & 2 & 2.78 \\
\hline
\end{tabular}

\begin{tabular}{|c|c|c|c|c|c|c|c|c|c|c|}
\hline \multirow{2}{*}{ Frequency } & \multicolumn{2}{|c|}{ Taclobo } & \multicolumn{2}{|c|}{ Bagacay } & \multicolumn{2}{|c|}{ Cadawinonan } & \multicolumn{2}{|c|}{ Poblacion 8} & \multicolumn{2}{|c|}{ Barangay 2} \\
\hline & Number & $\%$ & Number & $\%$ & Number & $\%$ & Number & $\%$ & Number & $\%$ \\
\hline Yes & 32 & 50.79 & 24 & 80.00 & 14 & 56.00 & 10 & 34.48 & 6 & 37.50 \\
\hline No & 31 & 49.21 & 6 & 20.00 & 9 & 36.00 & 19 & 65.52 & 10 & 62.50 \\
\hline Did not Specify & 0 & 0.00 & 0 & 0.00 & 2 & 8.00 & 0 & 0.00 & 0 & 0.00 \\
\hline
\end{tabular}

\begin{tabular}{|l|r|r|r|r|r|r|}
\hline \multirow{2}{*}{ Frequency } & \multicolumn{2}{|c|}{ Balugo } & \multicolumn{2}{c|}{ Calindagan } & \multicolumn{2}{c|}{ Overall } \\
\cline { 2 - 8 } & Number & \multicolumn{1}{c|}{$\%$} & Number & \multicolumn{1}{c|}{$\%$} & Number & $\%$ \\
\hline Yes & 16 & 94.12 & 4 & 17.39 & 167 & 46.26 \\
\hline No & 1 & 5.88 & 19 & 82.61 & 190 & 52.63 \\
\hline Did not Specify & 0 & 0.00 & 0 & 0.00 & 4 & 1.11 \\
\hline
\end{tabular}


Community-Based Flood Vulnerability Index for Urban Flooding: Understanding Social Vulnerabilities and Risks

\section{Place Where Children/Adult Defecate}

\begin{tabular}{|c|c|c|c|c|c|c|c|c|c|c|}
\hline \multirow{2}{*}{ Place } & \multicolumn{2}{|c|}{ Tabuc-tubig } & \multicolumn{2}{|c|}{ Junob } & \multicolumn{2}{|c|}{ Poblacion 1} & \multicolumn{2}{|c|}{ Batinguel } & \multicolumn{2}{|c|}{ Candua-ay } \\
\hline & Number & $\%$ & Number & $\%$ & Number & $\%$ & Number & $\%$ & Number & $\%$ \\
\hline Own Latrine & 10 & 100.00 & 12 & 75.00 & 19 & 86.36 & 34 & 89.47 & 68 & 94.44 \\
\hline Neighbors Latrine & 0 & 0.00 & 3 & 18.75 & 0 & 0.00 & 3 & 7.89 & 1 & 1.39 \\
\hline Public Latrine & 0 & 0.00 & 1 & 6.25 & 2 & 9.09 & 0 & 0.00 & 0 & 0.00 \\
\hline On the Ground & 0 & 0.00 & 0 & 0.00 & 1 & 4.55 & 0 & 0.00 & 1 & 1.39 \\
\hline Water Body & 0 & 0.00 & 0 & 0.00 & 0 & 0.00 & 0 & 0.00 & 0 & 0.00 \\
\hline Anywhere & 0 & 0.00 & 0 & 0.00 & 0 & 0.00 & 1 & 2.63 & 2 & 2.78 \\
\hline Did not Specify & 0 & 0.00 & 0 & 0.00 & 0 & 0.00 & 0 & 0.00 & 0 & 0.00 \\
\hline
\end{tabular}

\begin{tabular}{|c|c|c|c|c|c|c|c|c|c|c|}
\hline \multirow{2}{*}{ Place } & \multicolumn{2}{|c|}{ Taclobo } & \multicolumn{2}{|c|}{ Bagacay } & \multicolumn{2}{|c|}{ Cadawinonan } & \multicolumn{2}{|c|}{ Poblacion 8} & \multicolumn{2}{|c|}{ Barangay 2} \\
\hline & Number & $\%$ & Number & $\%$ & Number & $\%$ & Number & $\%$ & Number & $\%$ \\
\hline Own Latrine & 59 & 93.65 & 28 & 93.33 & 24 & 96.00 & 28 & 96.55 & 16 & 100.00 \\
\hline Neighbors Latrine & 1 & 1.59 & 1 & 3.33 & 1 & 4.00 & 0 & 0.00 & 0 & 0.00 \\
\hline Public Latrine & 0 & 0.00 & 1 & 3.33 & 0 & 0.00 & 0 & 0.00 & 0 & 0.00 \\
\hline On the Ground & 3 & 4.76 & 0 & 0.00 & 0 & 0.00 & 1 & 3.45 & 0 & 0.00 \\
\hline Water Body & 0 & 0.00 & 0 & 0.00 & 0 & 0.00 & 0 & 0.00 & 0 & 0.00 \\
\hline Anywhere & 0 & 0.00 & 0 & 0.00 & 0 & 0.00 & 0 & 0.00 & 0 & 0.00 \\
\hline Did not Specify & 0 & 0.00 & 0 & 0.00 & 0 & 0.00 & 0 & 0.00 & 0 & 0.00 \\
\hline
\end{tabular}


Community-Based Flood Vulnerability Index for Urban Flooding: Understanding Social Vulnerabilities and Risks

Place Where Children/Adult Defecate ... continued

\begin{tabular}{|l|r|r|r|r|r|r|}
\hline \multirow{2}{*}{ Place } & \multicolumn{2}{|c|}{ Balugo } & \multicolumn{2}{c|}{ Calindagan } & \multicolumn{2}{c|}{ Overall } \\
\cline { 2 - 7 } & Number & \multicolumn{1}{c|}{$\%$} & Number & \multicolumn{1}{c|}{$\%$} & Number & \multicolumn{1}{c|}{$\%$} \\
\hline Own Latrine & 13 & 76.47 & 21 & 91.30 & 332 & 91.97 \\
\hline Neighbors Latrine & 2 & 11.76 & 0 & 0.00 & 12 & 3.32 \\
\hline Public Latrine & 1 & 5.88 & 1 & 4.35 & 6 & 1.66 \\
\hline On the Ground & 1 & 5.88 & 1 & 4.35 & 8 & 2.22 \\
\hline Water Body & 0 & 0.00 & 0 & 0.00 & 0 & 0.00 \\
\hline Anywhere & 0 & 0.00 & 0 & 0.00 & 3 & 0.83 \\
\hline Did not Specify & 0 & 0.00 & 0 & 0.00 & 0 & 0.00 \\
\hline
\end{tabular}

\section{Type of Latrine}

\begin{tabular}{|c|c|c|c|c|c|c|c|c|c|c|}
\hline \multirow{2}{*}{ Type } & \multicolumn{2}{|c|}{ Tabuc-tubig } & \multicolumn{2}{|c|}{ Junob } & \multicolumn{2}{|c|}{ Poblacion 1} & \multicolumn{2}{|c|}{ Batinguel } & \multicolumn{2}{|c|}{ Candua-ay } \\
\hline & Number & $\%$ & Number & $\%$ & Number & $\%$ & Number & $\%$ & Number & $\%$ \\
\hline Water Sealed & 10 & 100.00 & 4 & 25.00 & 10 & 45.45 & 18 & 47.37 & 36 & 50.00 \\
\hline Antipolo Type & 0 & 0.00 & 1 & 6.25 & 0 & 0.00 & 3 & 7.89 & 9 & 12.50 \\
\hline Pour Flushed & 0 & 0.00 & 9 & 56.25 & 11 & 50.00 & 13 & 34.21 & 18 & 25.00 \\
\hline No Latrine & 0 & 0.00 & 2 & 12.50 & 1 & 4.55 & 4 & 10.53 & 3 & 4.17 \\
\hline Did not Specify & 0 & 0.00 & 0 & 0.00 & 0 & 0.00 & 0 & 0.00 & 6 & 8.33 \\
\hline
\end{tabular}


Community-Based Flood Vulnerability Index for Urban Flooding: Understanding Social Vulnerabilities and Risks

\begin{tabular}{|c|c|c|c|c|c|c|c|c|c|c|}
\hline \multirow{2}{*}{ Type } & \multicolumn{2}{|c|}{ Taclobo } & \multicolumn{2}{|c|}{ Bagacay } & \multicolumn{2}{|c|}{ Cadawinonan } & \multicolumn{2}{|c|}{ Poblacion 8} & \multicolumn{2}{|c|}{ Barangay 2} \\
\hline & Number & $\%$ & Number & $\%$ & Number & $\%$ & Number & $\%$ & Number & $\%$ \\
\hline Water Sealed & 30 & 47.62 & 17 & 56.67 & 10 & 40.00 & 11 & 37.93 & 9 & 56.25 \\
\hline Antipolo Type & 4 & 6.35 & 0 & 0.00 & 1 & 4.00 & 3 & 10.34 & 1 & 6.25 \\
\hline Pour Flushed & 24 & 38.10 & 9 & 30.00 & 11 & 44.00 & 15 & 51.72 & 6 & 37.50 \\
\hline No Latrine & 1 & 1.59 & 0 & 0.00 & 2 & 8.00 & 0 & 0.00 & 0 & 0.00 \\
\hline Did not Specify & 4 & 6.35 & 4 & 13.33 & 1 & 4.00 & 0 & 0.00 & 0 & 0.00 \\
\hline
\end{tabular}

\begin{tabular}{|l|r|r|r|r|r|r|}
\hline \multirow{2}{*}{ Type } & \multicolumn{2}{|c|}{ Balugo } & \multicolumn{2}{c|}{ Calindagan } & \multicolumn{2}{c|}{ Overall } \\
\cline { 2 - 7 } & Number & \multicolumn{1}{c|}{$\%$} & Number & \multicolumn{1}{c|}{$\%$} & Number & \multicolumn{1}{c|}{$\%$} \\
\hline Water Sealed & 7 & 41.18 & 11 & 47.83 & 173 & 47.92 \\
\hline Antipolo Type & 1 & 5.88 & 0 & 0.00 & 23 & 6.37 \\
\hline Pour Flushed & 6 & 35.29 & 11 & 47.83 & 133 & 36.84 \\
\hline No Latrine & 3 & 17.65 & 0 & 0.00 & 16 & 4.43 \\
\hline Did not Specify & 0 & 0.00 & 1 & 4.35 & 16 & 4.43 \\
\hline
\end{tabular}

\section{Sewage Drain}

\begin{tabular}{|c|c|c|c|c|c|c|c|c|c|c|}
\hline \multirow[t]{2}{*}{ Sewage Drain } & \multicolumn{2}{|c|}{ Tabuc-tubig } & \multicolumn{2}{|c|}{ Junob } & \multicolumn{2}{|c|}{ Poblacion 1} & \multicolumn{2}{|c|}{ Batinguel } & \multicolumn{2}{|c|}{ Candua-ay } \\
\hline & Number & $\%$ & Number & $\%$ & Number & $\%$ & Number & $\%$ & Number & $\%$ \\
\hline Septic Tank & 2 & 20.00 & 3 & 18.75 & 5 & 22.73 & 7 & 18.42 & 19 & 26.39 \\
\hline Barangay Drainage & 8 & 80.00 & 4 & 25.00 & 9 & 40.91 & 8 & 21.05 & 16 & 22.22 \\
\hline Pit & 0 & 0.00 & 8 & 50.00 & 7 & 31.82 & 20 & 52.63 & 33 & 45.83 \\
\hline Anywhere & 0 & 0.00 & 1 & 6.25 & 0 & 0.00 & 1 & 2.63 & 1 & 1.39 \\
\hline River & 0 & 0.00 & 0 & 0.00 & 1 & 4.55 & 1 & 2.63 & 0 & 0.00 \\
\hline Did not Specify & 0 & 0.00 & 0 & 0.00 & 0 & 0.00 & 1 & 2.63 & 3 & 4.17 \\
\hline
\end{tabular}


Community-Based Flood Vulnerability Index for Urban Flooding: Understanding Social Vulnerabilities and Risks

\begin{tabular}{|c|c|c|c|c|c|c|c|c|c|c|}
\hline \multirow[t]{2}{*}{ Sewage Drain } & \multicolumn{2}{|c|}{ Taclobo } & \multicolumn{2}{|c|}{ Bagacay } & \multicolumn{2}{|c|}{ Cadawinonan } & \multicolumn{2}{|c|}{ Poblacion 8} & \multicolumn{2}{|c|}{ Barangay 2} \\
\hline & Number & $\%$ & Number & $\%$ & Number & $\%$ & Number & $\%$ & Number & $\%$ \\
\hline Septic Tank & 19 & 30.16 & 6 & 20.00 & 3 & 12.00 & 11 & 37.93 & 4 & 25.00 \\
\hline Barangay Drainage & 10 & 15.87 & 3 & 10.00 & 8 & 32.00 & 11 & 37.93 & 4 & 25.00 \\
\hline Pit & 24 & 38.10 & 16 & 53.33 & 8 & 32.00 & 4 & 13.79 & 5 & 31.25 \\
\hline Anywhere & 3 & 4.76 & 1 & 3.33 & 4 & 16.00 & 1 & 3.45 & 0 & 0.00 \\
\hline River & 1 & 1.59 & 2 & 6.67 & 1 & 4.00 & 0 & 0.00 & 3 & 18.75 \\
\hline Did not Specify & 6 & 9.52 & 2 & 6.67 & 1 & 4.00 & 2 & 6.90 & 0 & 0.00 \\
\hline
\end{tabular}

Sewage Drain ... continued

\begin{tabular}{|l|r|r|r|r|r|r|}
\hline \multirow{2}{*}{ Sewage Drain } & \multicolumn{2}{|c|}{ Balugo } & \multicolumn{2}{c|}{ Calindagan } & \multicolumn{2}{c|}{ Overall } \\
\cline { 2 - 7 } & Number & \multicolumn{1}{c|}{$\%$} & Number & \multicolumn{1}{c|}{$\%$} & Number & $\%$ \\
\hline Septic Tank & 6 & 35.29 & 7 & 30.43 & 92 & 25.48 \\
\hline Barangay Drainage & 2 & 11.76 & 7 & 30.43 & 90 & 24.93 \\
\hline Pit & 6 & 35.29 & 9 & 39.13 & 140 & 38.78 \\
\hline Anywhere & 2 & 11.76 & 0 & 0.00 & 14 & 3.88 \\
\hline River & 0 & 0.00 & 0 & 0.00 & 9 & 2.49 \\
\hline Did not Specify & 1 & 5.88 & 0 & 0.00 & 16 & 4.43 \\
\hline
\end{tabular}


Community-Based Flood Vulnerability Index for Urban Flooding: Understanding

Social Vulnerabilities and Risks

\section{Solid Waste Disposal}

\begin{tabular}{|c|c|c|c|c|c|c|c|c|c|c|}
\hline \multirow{2}{*}{ Place of Disposal } & \multicolumn{2}{|c|}{ Tabuc-tubig } & \multicolumn{2}{|c|}{ Junob } & \multicolumn{2}{|c|}{ Poblacion 1} & \multicolumn{2}{|c|}{ Batinguel } & \multicolumn{2}{|c|}{ Candua-ay } \\
\hline & Number & $\%$ & Number & $\%$ & Number & $\%$ & Number & $\%$ & Number & $\%$ \\
\hline Collected by LGU & 10 & 100.00 & 4 & 25.00 & 20 & 90.91 & 15 & 39.47 & 28 & 38.89 \\
\hline Composting & 1 & 10.00 & 0 & 0.00 & 0 & 0.00 & 4 & 10.53 & 12 & 16.67 \\
\hline Burying in the Ground & 1 & 10.00 & 5 & 31.25 & 1 & 4.55 & 5 & 13.16 & 14 & 19.44 \\
\hline Burning & 0 & 0.00 & 6 & 37.50 & 2 & 9.09 & 16 & 42.11 & 19 & 26.39 \\
\hline Throwing into the River & 0 & 0.00 & 2 & 12.50 & 0 & 0.00 & 1 & 2.63 & 2 & 2.78 \\
\hline Did not Specify & 0 & 0.00 & 0 & 0.00 & 0 & 0.00 & 0 & 0.00 & 4 & 5.56 \\
\hline
\end{tabular}

\begin{tabular}{|l|r|r|r|r|r|r|r|r|r|r|}
\hline \multirow{2}{*}{ Place of Disposal } & \multicolumn{2}{|c|}{ Taclobo } & \multicolumn{2}{c|}{ Bagacay } & \multicolumn{2}{c|}{ Cadawinonan } & \multicolumn{2}{c|}{ Poblacion 8 } & \multicolumn{2}{c|}{ Barangay 2 } \\
\cline { 2 - 11 } & Number & \multicolumn{1}{c|}{$\%$} & Number & \multicolumn{1}{c|}{$\%$} & Number & \multicolumn{1}{c|}{ \% } & Number & \% & Number & \multicolumn{1}{c|}{$\%$} \\
\hline Collected by LGU & 50 & 79.37 & 18 & 60.00 & 18 & 72.00 & 28 & 96.55 & 16 & 100.00 \\
\hline Composting & 2 & 3.17 & 1 & 3.33 & 4 & 16.00 & 0 & 0.00 & 0 & 0.00 \\
\hline Burying in the Ground & 2 & 3.17 & 5 & 16.67 & 4 & 16.00 & 0 & 0.00 & 0 & 0.00 \\
\hline Burning & 9 & 14.29 & 8 & 26.67 & 0 & 0.00 & 0 & 0.00 & 0 & 0.00 \\
\hline Throwing into the River & 1 & 1.59 & 1 & 3.33 & 0 & 0.00 & 1 & 3.45 & 0 & 0.00 \\
\hline Did not Specify & 0 & 0.00 & 0 & 0.00 & 1 & 4.00 & 0 & 0.00 & 0 & 0.00 \\
\hline
\end{tabular}


Community-Based Flood Vulnerability Index for Urban Flooding: Understanding Social Vulnerabilities and Risks

Solid Waste Disposal ... continued

\begin{tabular}{|l|r|r|r|r|r|r|}
\hline \multirow{2}{*}{ Place of Disposal } & \multicolumn{2}{|c|}{ Balugo } & \multicolumn{2}{c|}{ Calindagan } & \multicolumn{2}{c|}{ Overall } \\
\cline { 2 - 7 } & Number & \multicolumn{1}{c|}{$\%$} & Number & \multicolumn{1}{c|}{$\%$} & Number & $\%$ \\
\hline Collected by LGU & 11 & 64.71 & 17 & 73.91 & 235 & 65.10 \\
\hline Composting & 1 & 5.88 & 0 & 0.00 & 25 & 6.93 \\
\hline Burying in the Ground & 2 & 11.76 & 5 & 21.74 & 44 & 12.19 \\
\hline Burning & 3 & 17.65 & 0 & 0.00 & 63 & 17.45 \\
\hline Throwing into the River & 0 & 0.00 & 1 & 4.35 & 9 & 2.49 \\
\hline Did not Specify & 0 & 0.00 & 0 & 0.00 & 5 & 1.39 \\
\hline
\end{tabular}

\section{Practicing Solid Waste Segregation}

\begin{tabular}{|c|c|c|c|c|c|c|c|c|c|c|}
\hline \multirow{2}{*}{ Frequency } & \multicolumn{2}{|c|}{ Tabuc-tubig } & \multicolumn{2}{|c|}{ Junob } & \multicolumn{2}{|c|}{ Poblacion 1} & \multicolumn{2}{|c|}{ Batinguel } & \multicolumn{2}{|c|}{ Candua-ay } \\
\hline & Number & $\%$ & Number & $\%$ & Number & $\%$ & Number & $\%$ & Number & $\%$ \\
\hline Yes & 9 & 90.00 & 8 & 50.00 & 13 & 59.09 & 23 & 60.53 & 38 & 52.78 \\
\hline No & 1 & 10.00 & 8 & 50.00 & 8 & 36.36 & 15 & 39.47 & 30 & 41.67 \\
\hline Did not Specify & 0 & 0.00 & 0 & 0.00 & 1 & 4.55 & 0 & 0.00 & 4 & 5.56 \\
\hline
\end{tabular}

\begin{tabular}{|c|c|c|c|c|c|c|c|c|c|c|}
\hline \multirow{2}{*}{ Frequency } & \multicolumn{2}{|c|}{ Taclobo } & \multicolumn{2}{|c|}{ Bagacay } & \multicolumn{2}{|c|}{ Cadawinonan } & \multicolumn{2}{|c|}{ Poblacion 8} & \multicolumn{2}{|c|}{ Barangay 2} \\
\hline & Number & $\%$ & Number & $\%$ & Number & $\%$ & Number & $\%$ & Number & $\%$ \\
\hline Yes & 29 & 46.03 & 15 & 50.00 & 18 & 72.00 & 17 & 58.62 & 10 & 62.50 \\
\hline No & 33 & 52.38 & 15 & 50.00 & 6 & 24.00 & 12 & 41.38 & 6 & 37.50 \\
\hline Did not Specify & 1 & 1.59 & 0 & 0.00 & 1 & 4.00 & 0 & 0.00 & 0 & 0.00 \\
\hline
\end{tabular}


Community-Based Flood Vulnerability Index for Urban Flooding: Understanding Social Vulnerabilities and Risks

\begin{tabular}{|l|r|r|r|r|r|r|}
\hline \multirow{2}{*}{ Frequency } & \multicolumn{2}{|c|}{ Balugo } & \multicolumn{2}{c|}{ Calindagan } & \multicolumn{2}{c|}{ Overall } \\
\cline { 2 - 7 } & Number & \multicolumn{1}{c|}{$\%$} & Number & \multicolumn{1}{c|}{$\%$} & Number & \multicolumn{1}{c|}{$\%$} \\
\hline Yes & 11 & 64.71 & 12 & 52.17 & 203 & 56.23 \\
\hline No & 6 & 35.29 & 10 & 43.48 & 150 & 41.55 \\
\hline Did not Specify & 0 & 0.00 & 1 & 4.35 & 8 & 2.22 \\
\hline
\end{tabular}

\section{Source of Drinking Water (Ordinary Days)}

\begin{tabular}{|c|c|c|c|c|c|c|c|c|c|c|}
\hline \multirow[t]{2}{*}{ Source } & \multicolumn{2}{|c|}{ Tabuc-tubig } & \multicolumn{2}{|c|}{ Junob } & \multicolumn{2}{|c|}{ Poblacion 1} & \multicolumn{2}{|c|}{ Batinguel } & \multicolumn{2}{|c|}{ Candua-ay } \\
\hline & Number & $\%$ & Number & $\%$ & Number & $\%$ & Number & $\%$ & Number & $\%$ \\
\hline Communal Faucet & 1 & 10.00 & 1 & 6.25 & 1 & 4.55 & 6 & 15.79 & 11 & 15.28 \\
\hline House to House Connection & 5 & 50.00 & 7 & 43.75 & 15 & 68.18 & 21 & 55.26 & 50 & 69.44 \\
\hline Spring & 1 & 10.00 & 2 & 12.50 & 1 & 4.55 & 1 & 2.63 & 1 & 1.39 \\
\hline Well & 0 & 0.00 & 1 & 6.25 & 0 & 0.00 & 5 & 13.16 & 0 & 0.00 \\
\hline River & 0 & 0.00 & 0 & 0.00 & 0 & 0.00 & 0 & 0.00 & 1 & 1.39 \\
\hline Water Pump & 4 & 40.00 & 1 & 6.25 & 3 & 13.64 & 2 & 5.26 & 6 & 8.33 \\
\hline Commercial Water Dispensers & 0 & 0.00 & 4 & 25.00 & 5 & 22.73 & 0 & 0.00 & 5 & 6.94 \\
\hline Bottled Water & 0 & 0.00 & 0 & 0.00 & 0 & 0.00 & 2 & 5.26 & 2 & 2.78 \\
\hline Did not Specify & 0 & 0.00 & 0 & 0.00 & 0 & 0.00 & 3 & 7.89 & 3 & 4.17 \\
\hline
\end{tabular}


Community-Based Flood Vulnerability Index for Urban Flooding: Understanding Social Vulnerabilities and Risks

\begin{tabular}{|c|c|c|c|c|c|c|c|c|c|c|}
\hline \multirow[t]{2}{*}{ Source } & \multicolumn{2}{|c|}{ Taclobo } & \multicolumn{2}{|c|}{ Bagacay } & \multicolumn{2}{|c|}{ Cadawinonan } & \multicolumn{2}{|c|}{ Poblacion 8} & \multicolumn{2}{|c|}{ Barangay 2} \\
\hline & Number & $\%$ & Number & $\%$ & Number & $\%$ & Number & $\%$ & Number & $\%$ \\
\hline Communal Faucet & 7 & 11.11 & 2 & 6.67 & 1 & 4.00 & 15 & 51.72 & 3 & 18.75 \\
\hline House to House Connection & 37 & 58.73 & 13 & 43.33 & 17 & 68.00 & 12 & 41.38 & 10 & 62.50 \\
\hline Spring & 1 & 1.59 & 0 & 0.00 & 1 & 4.00 & 0 & 0.00 & 0 & 0.00 \\
\hline Well & 0 & 0.00 & 0 & 0.00 & 0 & 0.00 & 0 & 0.00 & 0 & 0.00 \\
\hline River & 4 & 6.35 & 9 & 30.00 & 0 & 0.00 & 0 & 0.00 & 0 & 0.00 \\
\hline Water Pump & 10 & 15.87 & 5 & 16.67 & 3 & 12.00 & 0 & 0.00 & 0 & 0.00 \\
\hline Commercial Water Dispensers & 7 & 11.11 & 0 & 0.00 & 5 & 20.00 & 3 & 10.34 & 3 & 18.75 \\
\hline Bottled Water & 0 & 0.00 & 0 & 0.00 & 0 & 0.00 & 0 & 0.00 & 0 & 0.00 \\
\hline Did not Specify & 2 & 3.17 & 2 & 6.67 & 0 & 0.00 & 0 & 0.00 & 1 & 6.25 \\
\hline
\end{tabular}

\section{Source of Drinking Water (Ordinary Days) ... continued}

\begin{tabular}{|l|r|r|r|r|r|r|}
\hline \multirow{2}{*}{ Source } & \multicolumn{2}{|c|}{ Balugo } & \multicolumn{2}{c|}{ Calindagan } & \multicolumn{2}{c|}{ Overall } \\
\cline { 2 - 7 } & Number & \multicolumn{1}{c|}{$\%$} & Number & \multicolumn{1}{c|}{$\%$} & Number & \multicolumn{1}{c|}{$\%$} \\
\hline Communal Faucet & 5 & 29.41 & 2 & 8.70 & 55 & 15.24 \\
\hline House to House Connection & 9 & 52.94 & 18 & 78.26 & 214 & 59.28 \\
\hline Spring & 1 & 5.88 & 0 & 0.00 & 9 & 2.49 \\
\hline Well & 0 & 0.00 & 0 & 0.00 & 6 & 1.66 \\
\hline River & 0 & 0.00 & 0 & 0.00 & 14 & 3.88 \\
\hline Water Pump & 0 & 0.00 & 1 & 4.35 & 35 & 9.70 \\
\hline Commercial Water Dispensers & 3 & 17.65 & 1 & 4.35 & 36 & 9.97 \\
\hline Bottled Water & 0 & 0.00 & 1 & 4.35 & 5 & 1.39 \\
\hline Did not Specify & 0 & 0.00 & 0 & 0.00 & 11 & 3.05 \\
\hline
\end{tabular}


Community-Based Flood Vulnerability Index for Urban Flooding: Understanding

\section{Social Vulnerabilities and Risks}

\section{Source of Drinking Water (During Heavy Rains or Flood)}

\begin{tabular}{|c|c|c|c|c|c|c|c|c|c|c|}
\hline \multirow{2}{*}{ Source } & \multicolumn{2}{|c|}{ Tabuc-tubig } & \multicolumn{2}{|c|}{ Junob } & \multicolumn{2}{|c|}{ Poblacion 1} & \multicolumn{2}{|c|}{ Batinguel } & \multicolumn{2}{|c|}{ Candua-ay } \\
\hline & Number & $\%$ & Number & $\%$ & Number & $\%$ & Number & $\%$ & Number & $\%$ \\
\hline Communal Faucet & 1 & 10.00 & 1 & 6.25 & 0 & 0.00 & 6 & 15.79 & 1 & 1.39 \\
\hline House to House Connection & 6 & 60.00 & 6 & 37.50 & 16 & 72.73 & 14 & 36.84 & 42 & 58.33 \\
\hline Spring & 1 & 10.00 & 1 & 6.25 & 1 & 4.55 & 1 & 2.63 & 0 & 0.00 \\
\hline Donations & 1 & 10.00 & 1 & 6.25 & 1 & 4.55 & 6 & 15.79 & 5 & 6.94 \\
\hline Well & 0 & 0.00 & 0 & 0.00 & 0 & 0.00 & 1 & 2.63 & 2 & 2.78 \\
\hline River & 1 & 10.00 & 0 & 0.00 & 0 & 0.00 & 0 & 0.00 & 0 & 0.00 \\
\hline Water Pump & 0 & 0.00 & 2 & 12.50 & 1 & 4.55 & 1 & 2.63 & 3 & 4.17 \\
\hline Commercial Water Dispensers & 0 & 0.00 & 4 & 25.00 & 5 & 22.73 & 5 & 13.16 & 16 & 22.22 \\
\hline Bottled Water & 1 & 10.00 & 0 & 0.00 & 3 & 13.64 & 5 & 13.16 & 6 & 8.33 \\
\hline Did not Specify & 0 & 0.00 & 1 & 6.25 & 0 & 0.00 & 0 & 0.00 & 1 & 1.39 \\
\hline
\end{tabular}

\begin{tabular}{|c|c|c|c|c|c|c|c|c|c|c|}
\hline \multirow{2}{*}{ Source } & \multicolumn{2}{|c|}{ Taclobo } & \multicolumn{2}{|c|}{ Bagacay } & \multicolumn{2}{|c|}{ Cadawinonan } & \multicolumn{2}{|c|}{ Poblacion 8} & \multicolumn{2}{|c|}{ Barangay 2} \\
\hline & Number & $\%$ & Number & $\%$ & Number & $\%$ & Number & $\%$ & Number & $\%$ \\
\hline Communal Faucet & 4 & 6.35 & 1 & 3.33 & 1 & 4.00 & 5 & 17.24 & 1 & 6.25 \\
\hline House to House Connection & 21 & 33.33 & 13 & 43.33 & 14 & 56.00 & 8 & 27.59 & 7 & 43.75 \\
\hline Spring & 3 & 4.76 & 0 & 0.00 & 1 & 4.00 & 1 & 3.45 & 0 & 0.00 \\
\hline Donations & 1 & 1.59 & 2 & 6.67 & 1 & 4.00 & 7 & 24.14 & 1 & 6.25 \\
\hline Well & 0 & 0.00 & 0 & 0.00 & 0 & 0.00 & 1 & 3.45 & 0 & 0.00 \\
\hline River & 0 & 0.00 & 0 & 0.00 & 0 & 0.00 & 0 & 0.00 & 0 & 0.00 \\
\hline Water Pump & 6 & 9.52 & 12 & 40.00 & 0 & 0.00 & 0 & 0.00 & 2 & 12.50 \\
\hline Commercial Water Dispensers & 21 & 33.33 & 2 & 6.67 & 6 & 24.00 & 5 & 17.24 & 5 & 31.25 \\
\hline Bottled Water & 7 & 11.11 & 2 & 6.67 & 1 & 4.00 & 4 & 13.79 & 2 & 12.50 \\
\hline Did not Specify & 3 & 4.76 & 1 & 3.33 & 1 & 4.00 & 0 & 0.00 & 0 & 0.00 \\
\hline
\end{tabular}


Community-Based Flood Vulnerability Index for Urban Flooding: Understanding Social Vulnerabilities and Risks

Source of Drinking Water (During Heavy Rains or Flood) ... continued

\begin{tabular}{|l|r|r|r|r|r|r|}
\hline \multirow{2}{*}{ Source } & \multicolumn{2}{c|}{ Balugo } & \multicolumn{2}{c|}{ Calindagan } & \multicolumn{2}{c|}{ Overall } \\
\cline { 2 - 7 } & Number & \multicolumn{1}{c|}{$\%$} & Number & \multicolumn{1}{c|}{$\%$} & \multicolumn{1}{c|}{ Number } & \% \\
\hline Communal Faucet & 6 & 35.29 & 3 & 13.04 & 30 & 8.31 \\
\hline House to House Connection & 6 & 35.29 & 13 & 56.52 & 166 & 45.98 \\
\hline Spring & 2 & 11.76 & 1 & 4.35 & 12 & 3.32 \\
\hline Donations & 1 & 5.88 & 1 & 4.35 & 28 & 7.76 \\
\hline Well & 0 & 0.00 & 0 & 0.00 & 4 & 1.11 \\
\hline River & 0 & 0.00 & 0 & 0.00 & 1 & 0.28 \\
\hline Water Pump & 0 & 0.00 & 1 & 4.35 & 28 & 7.76 \\
\hline Commercial Water Dispensers & 2 & 11.76 & 3 & 13.04 & 74 & 20.50 \\
\hline Bottled Water & 1 & 5.88 & 1 & 4.35 & 33 & 9.14 \\
\hline Did not Specify & 0 & 0.00 & 0 & 0.00 & 7 & 1.94 \\
\hline
\end{tabular}

\section{Perception on Cleanliness of Water}

\begin{tabular}{|c|c|c|c|c|c|c|c|c|c|c|}
\hline \multirow{2}{*}{ Frequency } & \multicolumn{2}{|c|}{ Tabuc-tubig } & \multicolumn{2}{|c|}{ Junob } & \multicolumn{2}{|c|}{ Poblacion 1} & \multicolumn{2}{|c|}{ Batinguel } & \multicolumn{2}{|c|}{ Candua-ay } \\
\hline & Number & $\%$ & Number & $\%$ & Number & $\%$ & Number & $\%$ & Number & $\%$ \\
\hline Yes & 8 & 80.00 & 14 & 87.50 & 19 & 86.36 & 32 & 84.21 & 59 & 81.94 \\
\hline No & 2 & 20.00 & 2 & 12.50 & 2 & 9.09 & 6 & 15.79 & 11 & 15.28 \\
\hline Did not Specify & 0 & 0.00 & 0 & 0.00 & 1 & 4.55 & 0 & 0.00 & 2 & 2.78 \\
\hline
\end{tabular}


Community-Based Flood Vulnerability Index for Urban Flooding: Understanding Social Vulnerabilities and Risks

\begin{tabular}{|c|c|c|c|c|c|c|c|c|c|c|}
\hline \multirow{2}{*}{ Frequency } & \multicolumn{2}{|c|}{ Taclobo } & \multicolumn{2}{|c|}{ Bagacay } & \multicolumn{2}{|c|}{ Cadawinonan } & \multicolumn{2}{|c|}{ Poblacion 8} & \multicolumn{2}{|c|}{ Barangay 2} \\
\hline & Number & $\%$ & Number & $\%$ & Number & $\%$ & Number & $\%$ & Number & $\%$ \\
\hline Yes & 47 & 74.60 & 24 & 80.00 & 23 & 92.00 & 19 & 65.52 & 13 & 81.25 \\
\hline No & 14 & 22.22 & 4 & 13.33 & 2 & 8.00 & 10 & 34.48 & 3 & 18.75 \\
\hline Did not Specify & 2 & 3.17 & 2 & 6.67 & 0 & 0.00 & 0 & 0.00 & 0 & 0.00 \\
\hline
\end{tabular}

\begin{tabular}{|l|r|r|r|r|r|r|}
\hline \multirow{2}{*}{ Frequency } & \multicolumn{2}{|c|}{ Balugo } & \multicolumn{2}{c|}{ Calindagan } & \multicolumn{2}{c|}{ Overall } \\
\cline { 2 - 7 } & Number & \multicolumn{1}{c|}{$\%$} & Number & \multicolumn{1}{c|}{$\%$} & Number & \multicolumn{1}{c|}{$\%$} \\
\hline Yes & 13 & 76.47 & 16 & 69.57 & 287 & 79.50 \\
\hline No & 4 & 23.53 & 7 & 30.43 & 67 & 18.56 \\
\hline Did not Specify & 0 & 0.00 & 0 & 0.00 & 7 & 1.94 \\
\hline
\end{tabular}

\section{Home Water Treatment or Sterilization Process}

\begin{tabular}{|c|c|c|c|c|c|c|c|c|c|c|}
\hline \multirow{2}{*}{ Process } & \multicolumn{2}{|c|}{ Tabuc-tubig } & \multicolumn{2}{|c|}{ Junob } & \multicolumn{2}{|c|}{ Poblacion 1} & \multicolumn{2}{|c|}{ Batinguel } & \multicolumn{2}{|c|}{ Candua-ay } \\
\hline & Number & $\%$ & Number & $\%$ & Number & $\%$ & Number & $\%$ & Number & $\%$ \\
\hline Boiling in less than 10 minutes & 0 & 0.00 & 1 & 6.25 & 3 & 13.64 & 4 & 10.53 & 12 & 16.67 \\
\hline Boiling in 10 minutes & 2 & 20.00 & 6 & 37.50 & 11 & 50.00 & 15 & 39.47 & 13 & 18.06 \\
\hline Chlorination & 0 & 0.00 & 2 & 12.50 & 0 & 0.00 & 4 & 10.53 & 5 & 6.94 \\
\hline Settling & 0 & 0.00 & 0 & 0.00 & 1 & 4.55 & 1 & 2.63 & 0 & 0.00 \\
\hline Filter & 0 & 0.00 & 1 & 6.25 & 1 & 4.55 & 2 & 5.26 & 4 & 5.56 \\
\hline Nothing & 8 & 80.00 & 7 & 43.75 & 5 & 22.73 & 11 & 28.95 & 22 & 30.56 \\
\hline Did not Specify & 0 & 0.00 & 0 & 0.00 & 1 & 4.55 & 1 & 2.63 & 16 & 22.22 \\
\hline
\end{tabular}


Community-Based Flood Vulnerability Index for Urban Flooding: Understanding Social Vulnerabilities and Risks

\begin{tabular}{|c|c|c|c|c|c|c|c|c|c|c|}
\hline \multirow{2}{*}{ Process } & \multicolumn{2}{|c|}{ Taclobo } & \multicolumn{2}{|c|}{ Bagacay } & \multicolumn{2}{|c|}{ Cadawinonan } & \multicolumn{2}{|c|}{ Poblacion 8} & \multicolumn{2}{|c|}{ Barangay 2} \\
\hline & Number & $\%$ & Number & $\%$ & Number & $\%$ & Number & $\%$ & Number & $\%$ \\
\hline Boiling in less than 10 minutes & 9 & 14.29 & 3 & 10.00 & 3 & 12.00 & 4 & 13.79 & 2 & 12.50 \\
\hline Boiling in 10 minutes & 19 & 30.16 & 12 & 40.00 & 6 & 24.00 & 14 & 48.28 & 4 & 25.00 \\
\hline Chlorination & 5 & 7.94 & 3 & 10.00 & 3 & 12.00 & 2 & 6.90 & 2 & 12.50 \\
\hline Settling & 2 & 3.17 & 0 & 0.00 & 0 & 0.00 & 0 & 0.00 & 1 & 6.25 \\
\hline Filter & 7 & 11.11 & 0 & 0.00 & 1 & 4.00 & 0 & 0.00 & 1 & 6.25 \\
\hline Nothing & 17 & 26.98 & 10 & 33.33 & 10 & 40.00 & 5 & 17.24 & 6 & 37.50 \\
\hline Did not Specify & 4 & 6.35 & 3 & 10.00 & 2 & 8.00 & 4 & 13.79 & 1 & 6.25 \\
\hline
\end{tabular}

\section{Home Water Treatment or Sterilization Process ... continued}

\begin{tabular}{|c|c|c|c|c|c|c|}
\hline \multirow{2}{*}{ Process } & \multicolumn{2}{|c|}{ Balugo } & \multicolumn{2}{|c|}{ Calindagan } & \multicolumn{2}{|c|}{ Overall } \\
\hline & Number & $\%$ & Number & $\%$ & Number & $\%$ \\
\hline Boiling in less than 10 minutes & 1 & 5.88 & 1 & 4.35 & 43 & 11.91 \\
\hline Boiling in 10 minutes & 6 & 35.29 & 12 & 52.17 & 120 & 33.24 \\
\hline Chlorination & 0 & 0.00 & 1 & 4.35 & 27 & 7.48 \\
\hline Settling & 0 & 0.00 & 0 & 0.00 & 5 & 1.39 \\
\hline Filter & 1 & 5.88 & 1 & 4.35 & 19 & 5.26 \\
\hline Nothing & 9 & 52.94 & 7 & 30.43 & 117 & 32.41 \\
\hline Did not Specify & 0 & 0.00 & 1 & 4.35 & 33 & 9.14 \\
\hline
\end{tabular}


Community-Based Flood Vulnerability Index for Urban Flooding: Understanding Social Vulnerabilities and Risks

\section{Owned Domesticated Animals}

\begin{tabular}{|c|c|c|c|c|c|c|c|c|c|c|}
\hline \multirow{2}{*}{ Animal } & \multicolumn{2}{|c|}{ Tabuc-tubig } & \multicolumn{2}{|c|}{ Junob } & \multicolumn{2}{|c|}{ Poblacion 1} & \multicolumn{2}{|c|}{ Batinguel } & \multicolumn{2}{|c|}{ Candua-ay } \\
\hline & Number & $\%$ & Number & $\%$ & Number & $\%$ & Number & $\%$ & Number & $\%$ \\
\hline Pig & 2 & 20.00 & 2 & 12.50 & 2 & 9.09 & 9 & 23.68 & 14 & 19.44 \\
\hline Cow & 1 & 10.00 & 2 & 12.50 & 0 & 0.00 & 2 & 5.26 & 2 & 2.78 \\
\hline Chicken & 4 & 40.00 & 4 & 25.00 & 3 & 13.64 & 14 & 36.84 & 29 & 40.28 \\
\hline Goats & 0 & 0.00 & 1 & 6.25 & 2 & 9.09 & 0 & 0.00 & 5 & 6.94 \\
\hline Birds & 0 & 0.00 & 0 & 0.00 & 1 & 4.55 & 0 & 0.00 & 2 & 2.78 \\
\hline Doves & 0 & 0.00 & 0 & 0.00 & 1 & 4.55 & 1 & 2.63 & 1 & 1.39 \\
\hline Cats & 5 & 50.00 & 4 & 25.00 & 7 & 31.82 & 6 & 15.79 & 14 & 19.44 \\
\hline Dogs & 5 & 50.00 & 5 & 31.25 & 3 & 13.64 & 15 & 39.47 & 17 & 23.61 \\
\hline Horse & 0 & 0.00 & 1 & 6.25 & 1 & 4.55 & 2 & 5.26 & 3 & 4.17 \\
\hline Did not Specify & 1 & 10.00 & 7 & 43.75 & 8 & 36.36 & 8 & 21.05 & 20 & 27.78 \\
\hline
\end{tabular}

\begin{tabular}{|c|c|c|c|c|c|c|c|c|c|c|}
\hline \multirow{2}{*}{ Animal } & \multicolumn{2}{|c|}{ Taclobo } & \multicolumn{2}{|c|}{ Bagacay } & \multicolumn{2}{|c|}{ Cadawinonan } & \multicolumn{2}{|c|}{ Poblacion 8} & \multicolumn{2}{|c|}{ Barangay 2} \\
\hline & Number & $\%$ & Number & $\%$ & Number & $\%$ & Number & $\%$ & Number & $\%$ \\
\hline Pig & 7 & 11.11 & 3 & 10.00 & 9 & 36.00 & 3 & 10.34 & 2 & 12.50 \\
\hline Cow & 2 & 3.17 & 1 & 3.33 & 3 & 12.00 & 0 & 0.00 & 1 & 6.25 \\
\hline Chicken & 16 & 25.40 & 10 & 33.33 & 1 & 4.00 & 4 & 13.79 & 5 & 31.25 \\
\hline Goats & 0 & 0.00 & 1 & 3.33 & 1 & 4.00 & 0 & 0.00 & 0 & 0.00 \\
\hline Birds & 1 & 1.59 & 0 & 0.00 & 1 & 4.00 & 0 & 0.00 & 1 & 6.25 \\
\hline Doves & 2 & 3.17 & 1 & 3.33 & 2 & 8.00 & 0 & 0.00 & 0 & 0.00 \\
\hline Cats & 27 & 42.86 & 3 & 10.00 & 6 & 24.00 & 5 & 17.24 & 3 & 18.75 \\
\hline Dogs & 24 & 38.10 & 9 & 30.00 & 9 & 36.00 & 5 & 17.24 & 2 & 12.50 \\
\hline Horse & 2 & 3.17 & 1 & 3.33 & 0 & 0.00 & 0 & 0.00 & 1 & 6.25 \\
\hline Did not Specify & 16 & 25.40 & 9 & 30.00 & 4 & 16.00 & 19 & 65.52 & 3 & 18.75 \\
\hline
\end{tabular}


Community-Based Flood Vulnerability Index for Urban Flooding: Understanding

Social Vulnerabilities and Risks

Owned Domesticated Animals ... continued

\begin{tabular}{|c|c|c|c|c|c|c|}
\hline \multirow{2}{*}{ Animal } & \multicolumn{2}{|c|}{ Balugo } & \multicolumn{2}{|c|}{ Calindagan } & \multicolumn{2}{|c|}{ Overall } \\
\hline & Number & $\%$ & Number & $\%$ & Number & $\%$ \\
\hline Pig & 5 & 29.41 & 5 & 21.74 & 63 & 17.45 \\
\hline Cow & 4 & 23.53 & 0 & 0.00 & 18 & 4.99 \\
\hline Chicken & 12 & 70.59 & 4 & 17.39 & 106 & 29.36 \\
\hline Goats & 1 & 5.88 & 1 & 4.35 & 12 & 3.32 \\
\hline Birds & 0 & 0.00 & 0 & 0.00 & 6 & 1.66 \\
\hline Doves & 0 & 0.00 & 1 & 4.35 & 9 & 2.49 \\
\hline Cats & 4 & 23.53 & 6 & 26.09 & 20 & 5.54 \\
\hline Dogs & 5 & 29.41 & 6 & 26.09 & 58 & 16.07 \\
\hline Horse & 0 & 0.00 & 0 & 0.00 & 52 & 14.40 \\
\hline Did not Specify & 2 & 11.76 & 12 & 52.17 & 109 & 30.19 \\
\hline
\end{tabular}

\section{Domestic Animal Fecal Materials Disposal}

\begin{tabular}{|c|c|c|c|c|c|c|c|c|c|c|}
\hline \multirow[t]{2}{*}{ Place } & \multicolumn{2}{|c|}{ Tabuc-tubig } & \multicolumn{2}{|c|}{ Junob } & \multicolumn{2}{|c|}{ Poblacion 1} & \multicolumn{2}{|c|}{ Batinguel } & \multicolumn{2}{|c|}{ Candua-ay } \\
\hline & Number & $\%$ & Number & $\%$ & Number & $\%$ & Number & $\%$ & Number & $\%$ \\
\hline Own Latrine & 0 & 0.00 & 1 & 6.25 & 0 & 0.00 & 2 & 5.26 & 2 & 2.78 \\
\hline Neighbors Latrine & 0 & 0.00 & 0 & 0.00 & 0 & 0.00 & 0 & 0.00 & 0 & 0.00 \\
\hline Public Latrine & 0 & 0.00 & 0 & 0.00 & 0 & 0.00 & 1 & 2.63 & 0 & 0.00 \\
\hline On the Ground & 8 & 80.00 & 7 & 43.75 & 11 & 50.00 & 23 & 60.53 & 39 & 54.17 \\
\hline Water Body & 1 & 10.00 & 1 & 6.25 & 2 & 9.09 & 0 & 0.00 & 1 & 1.39 \\
\hline Pit & 0 & 0.00 & 0 & 0.00 & 2 & 9.09 & 2 & 5.26 & 2 & 2.78 \\
\hline Anywhere & 0 & 0.00 & 0 & 0.00 & 0 & 0.00 & 0 & 0.00 & 0 & 0.00 \\
\hline Did not Specify & 1 & 10.00 & 7 & 43.75 & 7 & 31.82 & 10 & 26.32 & 28 & 38.89 \\
\hline
\end{tabular}


Community-Based Flood Vulnerability Index for Urban Flooding: Understanding

Social Vulnerabilities and Risks

\begin{tabular}{|l|r|r|r|r|r|r|r|r|r|r|}
\hline \multirow{2}{*}{ Place } & \multicolumn{2}{c|}{ Taclobo } & \multicolumn{2}{c|}{ Bagacay } & \multicolumn{2}{c|}{ Cadawinonan } & \multicolumn{2}{c|}{ Poblacion 8 } & \multicolumn{2}{c|}{ Barangay 2 } \\
\cline { 2 - 10 } & Number & \multicolumn{1}{|c|}{$\%$} & Number & \multicolumn{1}{c|}{$\%$} & Number & \multicolumn{1}{c|}{$\%$} & Number & \% & Number & \% \\
\hline Own Latrine & 3 & 4.76 & 1 & 3.33 & 2 & 8.00 & 0 & 0.00 & 1 & 6.25 \\
\hline Neighbors Latrine & 0 & 0.00 & 0 & 0.00 & 0 & 0.00 & 0 & 0.00 & 1 & 6.25 \\
\hline Public Latrine & 0 & 0.00 & 1 & 3.33 & 0 & 0.00 & 0 & 0.00 & 0 & 0.00 \\
\hline On the Ground & 29 & 46.03 & 15 & 50.00 & 13 & 52.00 & 10 & 34.48 & 7 & 43.75 \\
\hline Water Body & 3 & 4.76 & 0 & 0.00 & 0 & 0.00 & 0 & 0.00 & 2 & 12.50 \\
\hline Pit & 0 & 0.00 & 1 & 3.33 & 1 & 4.00 & 0 & 0.00 & 1 & 6.25 \\
\hline Anywhere & 0 & 0.00 & 0 & 0.00 & 0 & 0.00 & 0 & 0.00 & 0 & 0.00 \\
\hline Did not Specify & 28 & 44.44 & 12 & 40.00 & 9 & 36.00 & 19 & 65.52 & 4 & 25.00 \\
\hline
\end{tabular}

\section{Domestic Animal Fecal Materials Disposal}

\begin{tabular}{|c|c|c|c|c|c|c|}
\hline \multirow{2}{*}{ Place } & \multicolumn{2}{|c|}{ Balugo } & \multicolumn{2}{|c|}{ Calindagan } & \multicolumn{2}{|c|}{ Overall } \\
\hline & Number & $\%$ & Number & $\%$ & Number & $\%$ \\
\hline Own Latrine & 2 & 11.76 & 1 & 4.35 & 15 & 4.16 \\
\hline Neighbors Latrine & 0 & 0.00 & 0 & 0.00 & 1 & 0.28 \\
\hline Public Latrine & 1 & 5.88 & 0 & 0.00 & 3 & 0.83 \\
\hline On the Ground & 7 & 41.18 & 5 & 21.74 & 174 & 48.20 \\
\hline Water Body & 1 & 5.88 & 2 & 8.70 & 13 & 3.60 \\
\hline Pit & 2 & 11.76 & 2 & 8.70 & 13 & 3.60 \\
\hline Anywhere & 0 & 0.00 & 0 & 0.00 & 0 & 0.00 \\
\hline Did not Specify & 4 & 23.53 & 13 & 56.52 & 142 & 39.34 \\
\hline
\end{tabular}


Community-Based Flood Vulnerability Index for Urban Flooding: Understanding

Social Vulnerabilities and Risks

\section{Neighbor Owned Domesticated Animals}

\begin{tabular}{|l|r|r|r|r|r|r|r|r|r|r|}
\hline \multirow{2}{*}{ Animal } & \multicolumn{2}{|c|}{ Tabuc-tubig } & \multicolumn{2}{c|}{ Junob } & \multicolumn{2}{c|}{ Poblacion 1 } & \multicolumn{2}{c|}{ Batinguel } & \multicolumn{2}{c|}{ Candua-ay } \\
\cline { 2 - 11 } & Number & \multicolumn{1}{|c|}{$\%$} & Number & \multicolumn{1}{c|}{$\%$} & Number & \multicolumn{1}{c|}{$\%$} & \multicolumn{1}{c|}{ Number } & \multicolumn{1}{c|}{ \% } & Number & \multicolumn{1}{c|}{$\%$} \\
\hline Pig & 2 & 20.00 & 10 & 62.50 & 6 & 27.27 & 7 & 18.42 & 37 & 51.39 \\
\hline Cow & 0 & 0.00 & 4 & 25.00 & 0 & 0.00 & 6 & 15.79 & 23 & 31.94 \\
\hline Chicken & 5 & 50.00 & 12 & 75.00 & 9 & 40.91 & 27 & 71.05 & 50 & 69.44 \\
\hline Goats & 0 & 0.00 & 8 & 50.00 & 0 & 0.00 & 11 & 28.95 & 29 & 40.28 \\
\hline Birds & 0 & 0.00 & 5 & 31.25 & 2 & 9.09 & 0 & 0.00 & 7 & 9.72 \\
\hline Doves & 0 & 0.00 & 4 & 25.00 & 1 & 4.55 & 5 & 13.16 & 6 & 8.33 \\
\hline Cats & 7 & 70.00 & 9 & 56.25 & 6 & 27.27 & 9 & 23.68 & 41 & 56.94 \\
\hline Dogs & 9 & 90.00 & 10 & 62.50 & 16 & 72.73 & 30 & 78.95 & 43 & 59.72 \\
\hline Horse & 0 & 0.00 & 0 & 0.00 & 1 & 4.55 & 0 & 0.00 & 8 & 11.11 \\
\hline Did not Specify & 0 & 0.00 & 0 & 0.00 & 0 & 0.00 & 0 & 0.00 & 4 & 5.56 \\
\hline
\end{tabular}

\begin{tabular}{|c|c|c|c|c|c|c|c|c|c|c|}
\hline \multirow{2}{*}{ Animal } & \multicolumn{2}{|c|}{ Taclobo } & \multicolumn{2}{|c|}{ Bagacay } & \multicolumn{2}{|c|}{ Cadawinonan } & \multicolumn{2}{|c|}{ Poblacion 8} & \multicolumn{2}{|c|}{ Barangay 2} \\
\hline & Number & $\%$ & Number & $\%$ & Number & $\%$ & Number & $\%$ & Number & $\%$ \\
\hline Pig & 20 & 31.75 & 13 & 43.33 & 17 & 68.00 & 8 & 27.59 & 9 & 56.25 \\
\hline Cow & 3 & 4.76 & 3 & 10.00 & 8 & 32.00 & 0 & 0.00 & 0 & 0.00 \\
\hline Chicken & 25 & 39.68 & 19 & 63.33 & 11 & 44.00 & 20 & 68.97 & 9 & 56.25 \\
\hline Goats & 7 & 11.11 & 5 & 16.67 & 5 & 20.00 & 1 & 3.45 & 1 & 6.25 \\
\hline Birds & 1 & 1.59 & 0 & 0.00 & 3 & 12.00 & 1 & 3.45 & 1 & 6.25 \\
\hline Doves & 5 & 7.94 & 1 & 3.33 & 4 & 16.00 & 0 & 0.00 & 2 & 12.50 \\
\hline Cats & 32 & 50.79 & 12 & 40.00 & 17 & 68.00 & 20 & 68.97 & 8 & 50.00 \\
\hline Dogs & 42 & 66.67 & 14 & 46.67 & 9 & 36.00 & 23 & 79.31 & 5 & 31.25 \\
\hline Horse & 1 & 1.59 & 1 & 3.33 & 0 & 0.00 & 1 & 3.45 & 0 & 0.00 \\
\hline Did not Specify & 5 & 7.94 & 3 & 10.00 & 0 & 0.00 & 3 & 10.34 & 0 & 0.00 \\
\hline
\end{tabular}


Community-Based Flood Vulnerability Index for Urban Flooding: Understanding Social Vulnerabilities and Risks

\section{Neighbor Owned Domesticated Animals ... continued}

\begin{tabular}{|l|r|r|r|r|r|r|}
\hline \multirow{2}{*}{ Animal } & \multicolumn{2}{|c|}{ Balugo } & \multicolumn{2}{c|}{ Calindagan } & \multicolumn{2}{c|}{ Overall } \\
\cline { 2 - 7 } & Number & \multicolumn{1}{c}{$\%$} & Number & \multicolumn{1}{c|}{$\%$} & Number & $\%$ \\
\hline Pig & 9 & 52.94 & 12 & 52.17 & 150 & 41.55 \\
\hline Cow & 4 & 23.53 & 1 & 4.35 & 52 & 14.40 \\
\hline Chicken & 10 & 58.82 & 16 & 69.57 & 213 & 59.00 \\
\hline Goats & 2 & 11.76 & 3 & 13.04 & 72 & 19.94 \\
\hline Birds & 0 & 0.00 & 2 & 8.70 & 22 & 6.09 \\
\hline Doves & 0 & 0.00 & 4 & 17.39 & 32 & 8.86 \\
\hline Cats & 7 & 41.18 & 14 & 60.87 & 88 & 24.38 \\
\hline Dogs & 11 & 64.71 & 14 & 60.87 & 128 & 35.46 \\
\hline Horse & 0 & 0.00 & 3 & 13.04 & 112 & 31.02 \\
\hline Did not Specify & 1 & 5.88 & 1 & 4.35 & 17 & 4.71 \\
\hline
\end{tabular}

\section{Perception on the Allowing of Raising Animals in the Community}

\begin{tabular}{|c|c|c|c|c|c|c|c|c|c|c|}
\hline \multirow{2}{*}{ Frequency } & \multicolumn{2}{|c|}{ Tabuc-tubig } & \multicolumn{2}{|c|}{ Junob } & \multicolumn{2}{|c|}{ Poblacion 1} & \multicolumn{2}{|c|}{ Batinguel } & \multicolumn{2}{|c|}{ Candua-ay } \\
\hline & Number & $\%$ & Number & $\%$ & Number & $\%$ & Number & $\%$ & Number & $\%$ \\
\hline Yes & 10 & 100.00 & 15 & 93.75 & 20 & 90.91 & 38 & 100.00 & 51 & 70.83 \\
\hline No & 0 & 0.00 & 1 & 6.25 & 0 & 0.00 & 0 & 0.00 & 13 & 18.06 \\
\hline Did not Specify & 0 & 0.00 & 0 & 0.00 & 2 & 9.09 & 0 & 0.00 & 8 & 11.11 \\
\hline
\end{tabular}


Community-Based Flood Vulnerability Index for Urban Flooding: Understanding

\section{Social Vulnerabilities and Risks}

\begin{tabular}{|c|c|c|c|c|c|c|c|c|c|c|}
\hline \multirow{2}{*}{ Frequency } & \multicolumn{2}{|c|}{ Taclobo } & \multicolumn{2}{|c|}{ Bagacay } & \multicolumn{2}{|c|}{ Cadawinonan } & \multicolumn{2}{|c|}{ Poblacion 8} & \multicolumn{2}{|c|}{ Barangay 2} \\
\hline & Number & $\%$ & Number & $\%$ & Number & $\%$ & Number & $\%$ & Number & $\%$ \\
\hline Yes & 53 & 84.13 & 26 & 86.67 & 19 & 76.00 & 25 & 86.21 & 14 & 87.50 \\
\hline No & 9 & 14.29 & 2 & 6.67 & 3 & 12.00 & 2 & 6.90 & 2 & 12.50 \\
\hline Did not Specify & 1 & 1.59 & 2 & 6.67 & 3 & 12.00 & 2 & 6.90 & 0 & 0.00 \\
\hline
\end{tabular}

\begin{tabular}{|l|r|r|r|r|r|r|}
\hline \multirow{2}{*}{ Frequency } & \multicolumn{2}{|c|}{ Balugo } & \multicolumn{2}{c|}{ Calindagan } & \multicolumn{2}{c|}{ Overall } \\
\cline { 2 - 7 } & Number & \multicolumn{1}{c|}{$\%$} & Number & \multicolumn{1}{c|}{$\%$} & Number & \multicolumn{1}{c|}{$\%$} \\
\hline Yes & 15 & 88.24 & 19 & 82.61 & 305 & 84.49 \\
\hline No & 1 & 5.88 & 4 & 17.39 & 37 & 10.25 \\
\hline Did not Specify & 1 & 5.88 & 0 & 0.00 & 19 & 5.26 \\
\hline
\end{tabular}

\section{Presence of Rats in the House}

\begin{tabular}{|c|c|c|c|c|c|c|c|c|c|c|}
\hline \multirow{2}{*}{ Frequency } & \multicolumn{2}{|c|}{ Tabuc-tubig } & \multicolumn{2}{|c|}{ Junob } & \multicolumn{2}{|c|}{ Poblacion 1} & \multicolumn{2}{|c|}{ Batinguel } & \multicolumn{2}{|c|}{ Candua-ay } \\
\hline & Number & $\%$ & Number & $\%$ & Number & $\%$ & Number & $\%$ & Number & $\%$ \\
\hline Yes & 10 & 100.00 & 15 & 93.75 & 22 & 100.00 & 35 & 92.11 & 62 & 86.11 \\
\hline No & 0 & 0.00 & 1 & 6.25 & 0 & 0.00 & 3 & 7.89 & 10 & 13.89 \\
\hline Did not Specify & 0 & 0.00 & 0 & 0.00 & 0 & 0.00 & 0 & 0.00 & 0 & 0.00 \\
\hline
\end{tabular}

\begin{tabular}{|c|c|c|c|c|c|c|c|c|c|c|}
\hline \multirow{2}{*}{ Frequency } & \multicolumn{2}{|c|}{ Taclobo } & \multicolumn{2}{|c|}{ Bagacay } & \multicolumn{2}{|c|}{ Cadawinonan } & \multicolumn{2}{|c|}{ Poblacion 8} & \multicolumn{2}{|c|}{ Barangay 2} \\
\hline & Number & $\%$ & Number & $\%$ & Number & $\%$ & Number & $\%$ & Number & $\%$ \\
\hline Yes & 61 & 96.83 & 28 & 93.33 & 21 & 84.00 & 28 & 96.55 & 16 & 100.00 \\
\hline No & 2 & 3.17 & 2 & 6.67 & 3 & 12.00 & 1 & 3.45 & 0 & 0.00 \\
\hline Did not Specify & 0 & 0.00 & 0 & 0.00 & 1 & 4.00 & 0 & 0.00 & 0 & 0.00 \\
\hline
\end{tabular}


Community-Based Flood Vulnerability Index for Urban Flooding: Understanding Social Vulnerabilities and Risks

\begin{tabular}{|c|c|c|c|c|c|c|}
\hline \multirow{2}{*}{ Frequency } & \multicolumn{2}{|c|}{ Balugo } & \multicolumn{2}{|c|}{ Calindagan } & \multicolumn{2}{|c|}{ Overall } \\
\hline & Number & $\%$ & Number & $\%$ & Number & $\%$ \\
\hline Yes & 15 & 88.24 & 23 & 100.00 & 336 & 93.07 \\
\hline No & 2 & 11.76 & 0 & 0.00 & 24 & 6.65 \\
\hline Did not Specify & 0 & 0.00 & 0 & 0.00 & 1 & 0.28 \\
\hline
\end{tabular}

\section{Presence of Rats in the Neighborhood}

\begin{tabular}{|c|c|c|c|c|c|c|c|c|c|c|}
\hline \multirow{2}{*}{ Frequency } & \multicolumn{2}{|c|}{ Tabuc-tubig } & \multicolumn{2}{|c|}{ Junob } & \multicolumn{2}{|c|}{ Poblacion 1} & \multicolumn{2}{|c|}{ Batinguel } & \multicolumn{2}{|c|}{ Candua-ay } \\
\hline & Number & $\%$ & Number & $\%$ & Number & $\%$ & Number & $\%$ & Number & $\%$ \\
\hline Yes & 10 & 100.00 & 13 & 81.25 & 22 & 100.00 & 31 & 81.58 & 57 & 79.17 \\
\hline No & 0 & 0.00 & 3 & 18.75 & 0 & 0.00 & 7 & 18.42 & 15 & 20.83 \\
\hline Did not Specify & 0 & 0.00 & 0 & 0.00 & 0 & 0.00 & 0 & 0.00 & 0 & 0.00 \\
\hline
\end{tabular}

\begin{tabular}{|c|c|c|c|c|c|c|c|c|c|c|}
\hline \multirow{2}{*}{ Frequency } & \multicolumn{2}{|c|}{ Taclobo } & \multicolumn{2}{|c|}{ Bagacay } & \multicolumn{2}{|c|}{ Cadawinonan } & \multicolumn{2}{|c|}{ Poblacion 8} & \multicolumn{2}{|c|}{ Barangay 2} \\
\hline & Number & $\%$ & Number & $\%$ & Number & $\%$ & Number & $\%$ & Number & $\%$ \\
\hline Yes & 57 & 90.48 & 26 & 86.67 & 21 & 84.00 & 28 & 96.55 & 15 & 93.75 \\
\hline No & 6 & 9.52 & 4 & 13.33 & 3 & 12.00 & 1 & 3.45 & 1 & 6.25 \\
\hline Did not Specify & 0 & 0.00 & 0 & 0.00 & 1 & 4.00 & 0 & 0.00 & 0 & 0.00 \\
\hline
\end{tabular}

\begin{tabular}{|c|c|c|c|c|c|c|}
\hline \multirow{2}{*}{ Frequency } & \multicolumn{2}{|c|}{ Balugo } & \multicolumn{2}{|c|}{ Calindagan } & \multicolumn{2}{|c|}{ Overall } \\
\hline & Number & $\%$ & Number & $\%$ & Number & $\%$ \\
\hline Yes & 12 & 70.59 & 23 & 100.00 & 315 & 87.26 \\
\hline No & 5 & 29.41 & 0 & 0.00 & 45 & 12.47 \\
\hline Did not Specify & 0 & 0.00 & 0 & 0.00 & 1 & 0.28 \\
\hline
\end{tabular}


Community-Based Flood Vulnerability Index for Urban Flooding: Understanding

Social Vulnerabilities and Risks

\section{Presence of Stray Animals in the Neighborhood}

\begin{tabular}{|c|c|c|c|c|c|c|c|c|c|c|}
\hline \multirow{2}{*}{ Frequency } & \multicolumn{2}{|c|}{ Tabuc-tubig } & \multicolumn{2}{|c|}{ Junob } & \multicolumn{2}{|c|}{ Poblacion 1} & \multicolumn{2}{|c|}{ Batinguel } & \multicolumn{2}{|c|}{ Candua-ay } \\
\hline & Number & $\%$ & Number & $\%$ & Number & $\%$ & Number & $\%$ & Number & $\%$ \\
\hline Yes & 7 & 70.00 & 9 & 56.25 & 15 & 68.18 & 20 & 52.63 & 41 & 56.94 \\
\hline No & 3 & 30.00 & 7 & 43.75 & 7 & 31.82 & 18 & 47.37 & 27 & 37.50 \\
\hline Did not Specify & 0 & 0.00 & 0 & 0.00 & 0 & 0.00 & 0 & 0.00 & 4 & 5.56 \\
\hline
\end{tabular}

\begin{tabular}{|c|c|c|c|c|c|c|c|c|c|c|}
\hline \multirow{2}{*}{ Frequency } & \multicolumn{2}{|c|}{ Taclobo } & \multicolumn{2}{|c|}{ Bagacay } & \multicolumn{2}{|c|}{ Cadawinonan } & \multicolumn{2}{|c|}{ Poblacion 8} & \multicolumn{2}{|c|}{ Barangay 2} \\
\hline & Number & $\%$ & Number & $\%$ & Number & $\%$ & Number & $\%$ & Number & $\%$ \\
\hline Yes & 42 & 66.67 & 16 & 53.33 & 16 & 64.00 & 15 & 51.72 & 11 & 68.75 \\
\hline No & 21 & 33.33 & 14 & 46.67 & 7 & 28.00 & 12 & 41.38 & 5 & 31.25 \\
\hline Did not Specify & 0 & 0.00 & 0 & 0.00 & 2 & 8.00 & 2 & 6.90 & 0 & 0.00 \\
\hline
\end{tabular}

\begin{tabular}{|c|c|c|c|c|c|c|}
\hline \multirow{2}{*}{ Frequency } & \multicolumn{2}{|c|}{ Balugo } & \multicolumn{2}{|c|}{ Calindagan } & \multicolumn{2}{|c|}{ Overall } \\
\hline & Number & $\%$ & Number & $\%$ & Number & $\%$ \\
\hline Yes & 5 & 29.41 & 14 & 60.87 & 211 & 58.45 \\
\hline No & 12 & 70.59 & 9 & 39.13 & 142 & 39.34 \\
\hline Did not Specify & 0 & 0.00 & 0 & 0.00 & 8 & 2.22 \\
\hline
\end{tabular}


Community-Based Flood Vulnerability Index for Urban Flooding: Understanding Social Vulnerabilities and Risks

\section{Awareness of Programs on Sanitation and Hygiene}

\begin{tabular}{|c|c|c|c|c|c|c|c|c|c|c|}
\hline \multirow{2}{*}{ Program } & \multicolumn{2}{|c|}{ Tabuc-tubig } & \multicolumn{2}{|c|}{ Junob } & \multicolumn{2}{|c|}{ Poblacion 1} & \multicolumn{2}{|c|}{ Batinguel } & \multicolumn{2}{|c|}{ Candua-ay } \\
\hline & Number & $\%$ & Number & $\%$ & Number & $\%$ & Number & $\%$ & Number & $\%$ \\
\hline Water Safety & 2 & 20.00 & 10 & 62.50 & 7 & 31.82 & 12 & 31.58 & 33 & 45.83 \\
\hline Environmental Sanitation & 1 & 10.00 & 9 & 56.25 & 16 & 72.73 & 16 & 42.11 & 44 & 61.11 \\
\hline Garbage Segregation & 7 & 70.00 & 15 & 93.75 & 11 & 50.00 & 21 & 55.26 & 48 & 66.67 \\
\hline Disease Outbreaks & 4 & 40.00 & 12 & 75.00 & 9 & 40.91 & 13 & 34.21 & 34 & 47.22 \\
\hline Right Way of Washing Hands & 1 & 10.00 & 11 & 68.75 & 8 & 36.36 & 15 & 39.47 & 39 & 54.17 \\
\hline Owning a Latrine & 2 & 20.00 & 9 & 56.25 & 7 & 31.82 & 12 & 31.58 & 28 & 38.89 \\
\hline Did not specify & 1 & 10.00 & 2 & 12.50 & 1 & 4.55 & 1 & 2.63 & 8 & 11.11 \\
\hline
\end{tabular}

\begin{tabular}{|c|c|c|c|c|c|c|c|c|c|c|}
\hline \multirow{2}{*}{ Program } & \multicolumn{2}{|c|}{ Taclobo } & \multicolumn{2}{|c|}{ Bagacay } & \multicolumn{2}{|c|}{ Cadawinonan } & \multicolumn{2}{|c|}{ Poblacion 8} & \multicolumn{2}{|c|}{ Barangay 2} \\
\hline & Number & $\%$ & Number & $\%$ & Number & $\%$ & Number & $\%$ & Number & $\%$ \\
\hline Water Safety & 17 & 26.98 & 15 & 50.00 & 7 & 28.00 & 19 & 65.52 & 5 & 31.25 \\
\hline Environmental Sanitation & 26 & 41.27 & 14 & 46.67 & 15 & 60.00 & 18 & 62.07 & 4 & 25.00 \\
\hline Garbage Segregation & 28 & 44.44 & 15 & 50.00 & 16 & 64.00 & 18 & 62.07 & 9 & 56.25 \\
\hline Disease Outbreaks & 23 & 36.51 & 13 & 43.33 & 11 & 44.00 & 16 & 55.17 & 4 & 25.00 \\
\hline Right Way of Washing Hands & 14 & 22.22 & 13 & 43.33 & 11 & 44.00 & 19 & 65.52 & 2 & 12.50 \\
\hline Owning a Latrine & 14 & 22.22 & 10 & 33.33 & 7 & 28.00 & 15 & 51.72 & 2 & 12.50 \\
\hline Did not specify & 7 & 11.11 & 3 & 10.00 & 1 & 4.00 & 4 & 13.79 & 1 & 6.25 \\
\hline
\end{tabular}


Community-Based Flood Vulnerability Index for Urban Flooding: Understanding

Social Vulnerabilities and Risks

Awareness of Programs on Sanitation and Hygiene ... continued

\begin{tabular}{|c|c|c|c|c|c|c|}
\hline \multirow{2}{*}{ Program } & \multicolumn{2}{|c|}{ Balugo } & \multicolumn{2}{|c|}{ Calindagan } & \multicolumn{2}{|c|}{ Overall } \\
\hline & Number & $\%$ & Number & $\%$ & Number & $\%$ \\
\hline Water Safety & 4 & 23.53 & 6 & 26.09 & 137 & 37.95 \\
\hline Environmental Sanitation & 3 & 17.65 & 10 & 43.48 & 176 & 48.75 \\
\hline Garbage Segregation & 8 & 47.06 & 16 & 69.57 & 212 & 58.73 \\
\hline Disease Outbreaks & 3 & 17.65 & 10 & 43.48 & 152 & 42.11 \\
\hline Right Way of Washing Hands & 2 & 11.76 & 10 & 43.48 & 145 & 40.17 \\
\hline Owning a Latrine & 3 & 17.65 & 8 & 34.78 & 117 & 32.41 \\
\hline Did not specify & 4 & 23.53 & 1 & 4.35 & 34 & 9.42 \\
\hline
\end{tabular}


Community-Based Flood Vulnerability Index for Urban Flooding: Understanding Social Vulnerabilities and Risks

\section{Sources of Information About the Sanitation and Hygiene Programs}

\begin{tabular}{|c|c|c|c|c|c|c|c|c|c|c|}
\hline \multirow{2}{*}{ Source } & \multicolumn{2}{|c|}{ Tabuc-tubig } & \multicolumn{2}{|c|}{ Junob } & \multicolumn{2}{|c|}{ Poblacion 1} & \multicolumn{2}{|c|}{ Batinguel } & \multicolumn{2}{|c|}{ Candua-ay } \\
\hline & Number & $\%$ & Number & $\%$ & Number & $\%$ & Number & $\%$ & Number & $\%$ \\
\hline Own Family & 0 & 0.00 & 2 & 12.50 & 4 & 18.18 & 4 & 10.53 & 8 & 11.11 \\
\hline Neighbors & 0 & 0.00 & 1 & 6.25 & 1 & 4.55 & 2 & 5.26 & 9 & 12.50 \\
\hline NGO Worker & 1 & 10.00 & 0 & 0.00 & 0 & 0.00 & 5 & 13.16 & 9 & 12.50 \\
\hline LGUs & 0 & 0.00 & 4 & 25.00 & 1 & 4.55 & 10 & 26.32 & 11 & 15.28 \\
\hline Health Center & 5 & 50.00 & 5 & 31.25 & 9 & 40.91 & 15 & 39.47 & 29 & 40.28 \\
\hline Barangay Officials & 6 & 60.00 & 2 & 12.50 & 8 & 36.36 & 10 & 26.32 & 28 & 38.89 \\
\hline Barangay Health Worker & 5 & 50.00 & 7 & 43.75 & 11 & 50.00 & 11 & 28.95 & 40 & 55.56 \\
\hline School/Teacher & 3 & 30.00 & 5 & 31.25 & 9 & 40.91 & 8 & 21.05 & 23 & 31.94 \\
\hline Religious Groups & 0 & 0.00 & 2 & 12.50 & 0 & 0.00 & 7 & 18.42 & 9 & 12.50 \\
\hline TV & 2 & 20.00 & 7 & 43.75 & 8 & 36.36 & 15 & 39.47 & 18 & 25.00 \\
\hline Radio & 1 & 10.00 & 6 & 37.50 & 4 & 18.18 & 3 & 7.89 & 16 & 22.22 \\
\hline Newspaper/Magazines & 0 & 0.00 & 3 & 18.75 & 2 & 9.09 & 2 & 5.26 & 7 & 9.72 \\
\hline Bill Board & 0 & 0.00 & 1 & 6.25 & 1 & 4.55 & 0 & 0.00 & 3 & 4.17 \\
\hline Did not specify & 1 & 10.00 & 0 & 0.00 & 1 & 4.55 & 2 & 5.26 & 5 & 6.94 \\
\hline
\end{tabular}


Community-Based Flood Vulnerability Index for Urban Flooding: Understanding Social Vulnerabilities and Risks

\section{Sources of Information About the Sanitation and Hygiene Programs ... continued}

\begin{tabular}{|c|c|c|c|c|c|c|c|c|c|c|}
\hline \multirow{2}{*}{ Source } & \multicolumn{2}{|c|}{ Taclobo } & \multicolumn{2}{|c|}{ Bagacay } & \multicolumn{2}{|c|}{ Cadawinonan } & \multicolumn{2}{|c|}{ Poblacion 8} & \multicolumn{2}{|c|}{ Barangay 2} \\
\hline & Number & $\%$ & Number & $\%$ & Number & $\%$ & Number & $\%$ & Number & $\%$ \\
\hline Own Family & 4 & 6.35 & 1 & 3.33 & 3 & 12.00 & 1 & 3.45 & 1 & 6.25 \\
\hline Neighbors & 6 & 9.52 & 1 & 3.33 & 3 & 12.00 & 0 & 0.00 & 0 & 0.00 \\
\hline NGO Worker & 7 & 11.11 & 2 & 6.67 & 2 & 8.00 & 8 & 27.59 & 2 & 12.50 \\
\hline LGUs & 5 & 7.94 & 2 & 6.67 & 6 & 24.00 & 8 & 27.59 & 1 & 6.25 \\
\hline Health Center & 22 & 34.92 & 9 & 30.00 & 10 & 40.00 & 12 & 41.38 & 4 & 25.00 \\
\hline Barangay Officials & 21 & 33.33 & 7 & 23.33 & 10 & 40.00 & 18 & 62.07 & 6 & 37.50 \\
\hline Barangay Health Worker & 20 & 31.75 & 19 & 63.33 & 9 & 36.00 & 17 & 58.62 & 6 & 37.50 \\
\hline School/Teacher & 20 & 31.75 & 5 & 16.67 & 4 & 16.00 & 5 & 17.24 & 3 & 18.75 \\
\hline Religious Groups & 9 & 14.29 & 2 & 6.67 & 3 & 12.00 & 6 & 20.69 & 2 & 12.50 \\
\hline TV & 14 & 22.22 & 4 & 13.33 & 11 & 44.00 & 12 & 41.38 & 5 & 31.25 \\
\hline Radio & 10 & 15.87 & 3 & 10.00 & 6 & 24.00 & 10 & 34.48 & 1 & 6.25 \\
\hline Newspaper/Magazines & 4 & 6.35 & 1 & 3.33 & 6 & 24.00 & 7 & 24.14 & 4 & 25.00 \\
\hline Bill Board & 1 & 1.59 & 0 & 0.00 & 1 & 4.00 & 4 & 13.79 & 0 & 0.00 \\
\hline Did not specify & 6 & 9.52 & 2 & 6.67 & 1 & 4.00 & 2 & 6.90 & 0 & 0.00 \\
\hline
\end{tabular}


Community-Based Flood Vulnerability Index for Urban Flooding: Understanding

Social Vulnerabilities and Risks

\section{Sources of Information About the Sanitation and Hygiene Programs ... continued}

\begin{tabular}{|c|c|c|c|c|c|c|}
\hline \multirow{2}{*}{ Source } & \multicolumn{2}{|c|}{ Balugo } & \multicolumn{2}{|c|}{ Calindagan } & \multicolumn{2}{|c|}{ Overall } \\
\hline & Number & $\%$ & Number & $\%$ & Number & $\%$ \\
\hline Own Family & 1 & 5.88 & 0 & 0.00 & 29 & 8.03 \\
\hline Neighbors & 1 & 5.88 & 0 & 0.00 & 24 & 6.65 \\
\hline NGO Worker & 2 & 11.76 & 1 & 4.35 & 39 & 10.80 \\
\hline LGUs & 0 & 0.00 & 1 & 4.35 & 49 & 13.57 \\
\hline Health Center & 5 & 29.41 & 7 & 30.43 & 132 & 36.57 \\
\hline Barangay Officials & 2 & 11.76 & 10 & 43.48 & 128 & 35.46 \\
\hline Barangay Health Worker & 3 & 17.65 & 13 & 56.52 & 161 & 44.60 \\
\hline School/Teacher & 1 & 5.88 & 6 & 26.09 & 92 & 25.48 \\
\hline Religious Groups & 1 & 5.88 & 1 & 4.35 & 42 & 11.63 \\
\hline TV & 4 & 23.53 & 8 & 34.78 & 108 & 29.92 \\
\hline Radio & 3 & 17.65 & 6 & 26.09 & 69 & 19.11 \\
\hline Newspaper/Magazines & 0 & 0.00 & 1 & 4.35 & 37 & 10.25 \\
\hline Bill Board & 0 & 0.00 & 0 & 0.00 & 11 & 3.05 \\
\hline Did not specify & 4 & 23.53 & 1 & 4.35 & 25 & 6.93 \\
\hline
\end{tabular}


Community-Based Flood Vulnerability Index for Urban Flooding: Understanding

Social Vulnerabilities and Risks

\section{SOCIAL ENVIRONMENT}

\section{Friends with Neighbors}

\begin{tabular}{|l|r|r|r|r|r|r|r|r|r|r|}
\hline \multirow{2}{*}{ Frequency } & \multicolumn{2}{|c|}{ Tabuc-tubig } & \multicolumn{2}{c|}{ Junob } & \multicolumn{2}{c|}{ Poblacion 1 } & \multicolumn{2}{c|}{ Batinguel } & \multicolumn{2}{c|}{ Candua-ay } \\
\cline { 2 - 11 } & Number & \multicolumn{1}{|c|}{$\%$} & Number & \multicolumn{1}{c|}{$\%$} & Number & \multicolumn{1}{c|}{ Number } & \multicolumn{1}{c|}{ Number } & \% \\
\hline Yes & 9 & 90.00 & 14 & 87.50 & 22 & 100.00 & 38 & 100.00 & 68 & 94.44 \\
\hline No & 1 & 10.00 & 2 & 12.50 & 0 & 0.00 & 0 & 0.00 & 4 & 5.56 \\
\hline Did not Specify & 0 & 0.00 & 0 & 0.00 & 0 & 0.00 & 0 & 0.00 & 0 & 0.00 \\
\hline
\end{tabular}

\begin{tabular}{|c|c|c|c|c|c|c|c|c|c|c|}
\hline \multirow{2}{*}{ Frequency } & \multicolumn{2}{|c|}{ Taclobo } & \multicolumn{2}{|c|}{ Bagacay } & \multicolumn{2}{|c|}{ Cadawinonan } & \multicolumn{2}{|c|}{ Poblacion 8} & \multicolumn{2}{|c|}{ Barangay 2} \\
\hline & Number & $\%$ & Number & $\%$ & Number & $\%$ & Number & $\%$ & Number & $\%$ \\
\hline Yes & 60 & 95.24 & 29 & 96.67 & 24 & 96.00 & 28 & 96.55 & 14 & 87.50 \\
\hline No & 3 & 4.76 & 1 & 3.33 & 1 & 4.00 & 1 & 3.45 & 2 & 12.50 \\
\hline Did not Specify & 0 & 0.00 & 0 & 0.00 & 0 & 0.00 & 0 & 0.00 & 0 & 0.00 \\
\hline
\end{tabular}

\begin{tabular}{|l|r|r|r|r|r|r|}
\hline \multirow{2}{*}{ Frequency } & \multicolumn{2}{c|}{ Balugo } & \multicolumn{2}{c|}{ Calindagan } & \multicolumn{2}{c|}{ Overall } \\
\cline { 2 - 7 } & Number & \multicolumn{1}{c|}{$\%$} & \multicolumn{1}{c|}{ Number } & \multicolumn{1}{c|}{ \% } & Number & \multicolumn{1}{c|}{$\%$} \\
\hline Yes & 16 & 94.12 & 22 & 95.65 & 344 & 95.29 \\
\hline No & 1 & 5.88 & 1 & 4.35 & 17 & 4.71 \\
\hline Did not Specify & 0 & 0.00 & 0 & 0.00 & 0 \\
\hline
\end{tabular}


Community-Based Flood Vulnerability Index for Urban Flooding: Understanding

Social Vulnerabilities and Risks

\section{Willingness to Help Neighbors}

\begin{tabular}{|l|r|r|r|r|r|r|r|r|r|r|}
\hline \multirow{2}{*}{ Frequency } & \multicolumn{2}{|c|}{ Tabuc-tubig } & \multicolumn{2}{c|}{ Junob } & \multicolumn{2}{c|}{ Poblacion 1 } & \multicolumn{2}{c|}{ Batinguel } & \multicolumn{2}{c|}{ Candua-ay } \\
\cline { 2 - 11 } & Number & \multicolumn{1}{c|}{$\%$} & Number & \multicolumn{1}{c|}{$\%$} & Number & \multicolumn{1}{c|}{$\%$} & Number & \multicolumn{1}{c|}{$\%$} & Number & \multicolumn{1}{c|}{$\%$} \\
\hline Yes & 10 & 100 & 15 & 93.75 & 22 & 100.00 & 38 & 100.00 & 70 & 97.22 \\
\hline No & 0 & 0.00 & 1 & 6.25 & 0 & 0.00 & 0 & 0.00 & 2 & 2.78 \\
\hline Did not Specify & 0 & 0.00 & 0 & 0.00 & 0 & 0.00 & 0 & 0.00 & 0 & 0.00 \\
\hline
\end{tabular}

\begin{tabular}{|c|c|c|c|c|c|c|c|c|c|c|}
\hline \multirow{2}{*}{ Frequency } & \multicolumn{2}{|c|}{ Taclobo } & \multicolumn{2}{|c|}{ Bagacay } & \multicolumn{2}{|c|}{ Cadawinonan } & \multicolumn{2}{|c|}{ Poblacion 8} & \multicolumn{2}{|c|}{ Barangay 2} \\
\hline & Number & $\%$ & Number & $\%$ & Number & $\%$ & Number & $\%$ & Number & $\%$ \\
\hline Yes & 60 & 95.24 & 26 & 86.67 & 25 & 100.00 & 26 & 89.66 & 15 & 93.75 \\
\hline No & 3 & 4.76 & 2 & 6.67 & 0 & 0.00 & 3 & 10.34 & 1 & 6.25 \\
\hline Did not Specify & 0 & 0.00 & 2 & 6.67 & 0 & 0.00 & 0 & 0.00 & 0 & 0.00 \\
\hline
\end{tabular}

\begin{tabular}{|l|r|r|r|r|r|r|}
\hline \multirow{2}{*}{ Frequency } & \multicolumn{2}{|c|}{ Balugo } & \multicolumn{2}{c|}{ Calindagan } & \multicolumn{2}{c|}{ Overall } \\
\cline { 2 - 7 } & Number & \multicolumn{1}{c|}{$\%$} & \multicolumn{1}{c|}{ Number } & \multicolumn{1}{c|}{ Number } & \multicolumn{1}{c|}{$\%$} \\
\hline Yes & 16 & 94.12 & 23 & 100.00 & 346 & 95.84 \\
\hline No & 0 & 0.00 & 0 & 0.00 & 12 & 3.32 \\
\hline Did not Specify & 1 & 5.88 & 0 & 0.00 & 3 \\
\hline
\end{tabular}


Community-Based Flood Vulnerability Index for Urban Flooding: Understanding Social Vulnerabilities and Risks

\section{Knowledge on the Holding of Health Related Meetings in the Community}

\begin{tabular}{|c|c|c|c|c|c|c|c|c|c|c|}
\hline \multirow{2}{*}{ Frequency } & \multicolumn{2}{|c|}{ Tabuc-tubig } & \multicolumn{2}{|c|}{ Junob } & \multicolumn{2}{|c|}{ Poblacion 1} & \multicolumn{2}{|c|}{ Batinguel } & \multicolumn{2}{|c|}{ Candua-ay } \\
\hline & Number & $\%$ & Number & $\%$ & Number & $\%$ & Number & $\%$ & Number & $\%$ \\
\hline Yes & 10 & 100.00 & 15 & 93.75 & 20 & 90.91 & 23 & 60.53 & 52 & 72.22 \\
\hline No & 0 & 0.00 & 1 & 6.25 & 1 & 4.55 & 15 & 39.47 & 16 & 22.22 \\
\hline Did not Specify & 0 & 0.00 & 0 & 0.00 & 1 & 4.55 & 0 & 0.00 & 4 & 5.56 \\
\hline
\end{tabular}

\begin{tabular}{|c|c|c|c|c|c|c|c|c|c|c|}
\hline \multirow{2}{*}{ Frequency } & \multicolumn{2}{|c|}{ Taclobo } & \multicolumn{2}{|c|}{ Bagacay } & \multicolumn{2}{|c|}{ Cadawinonan } & \multicolumn{2}{|c|}{ Poblacion 8} & \multicolumn{2}{|c|}{ Barangay 2} \\
\hline & Number & $\%$ & Number & $\%$ & Number & $\%$ & Number & $\%$ & Number & $\%$ \\
\hline Yes & 45 & 71.43 & 25 & 83.33 & 20 & 80.00 & 26 & 89.66 & 11 & 68.75 \\
\hline No & 17 & 26.98 & 4 & 13.33 & 3 & 12.00 & 0 & 0.00 & 4 & 25.00 \\
\hline Did not Specify & 1 & 1.59 & 1 & 3.33 & 2 & 8.00 & 3 & 10.34 & 1 & 6.25 \\
\hline
\end{tabular}

\begin{tabular}{|c|c|c|c|c|c|c|}
\hline \multirow{2}{*}{ Frequency } & \multicolumn{2}{|c|}{ Balugo } & \multicolumn{2}{|c|}{ Calindagan } & \multicolumn{2}{|c|}{ Overall } \\
\hline & Number & $\%$ & Number & $\%$ & Number & $\%$ \\
\hline Yes & 10 & 58.82 & 22 & 95.65 & 279 & 77.29 \\
\hline No & 7 & 41.18 & 1 & 4.35 & 69 & 19.11 \\
\hline Did not Specify & 0 & 0.00 & 0 & 0.00 & 13 & 3.60 \\
\hline
\end{tabular}

\section{Attendance to Held Related Meetings Conducted in the Community}

\begin{tabular}{|c|c|c|c|c|c|c|c|c|c|c|}
\hline \multirow{2}{*}{ Frequency } & \multicolumn{2}{|c|}{ Tabuc-tubig } & \multicolumn{2}{|c|}{ Junob } & \multicolumn{2}{|c|}{ Poblacion 1} & \multicolumn{2}{|c|}{ Batinguel } & \multicolumn{2}{|c|}{ Candua-ay } \\
\hline & Number & $\%$ & Number & $\%$ & Number & $\%$ & Number & $\%$ & Number & $\%$ \\
\hline Yes & 8 & 80.00 & 11 & 68.75 & 14 & 63.64 & 15 & 39.47 & 39 & 54.17 \\
\hline No & 2 & 20.00 & 5 & 31.25 & 8 & 36.36 & 23 & 60.53 & 28 & 38.89 \\
\hline Did not Specify & 0 & 0.00 & 0 & 0.00 & 0 & 0.00 & 0 & 0.00 & 5 & 6.94 \\
\hline
\end{tabular}


Community-Based Flood Vulnerability Index for Urban Flooding: Understanding

\begin{tabular}{|c|c|c|c|c|c|c|c|c|c|c|}
\hline \multirow{2}{*}{ Frequency } & \multicolumn{2}{|c|}{ Taclobo } & \multicolumn{2}{|c|}{ Bagacay } & \multicolumn{2}{|c|}{ Cadawinonan } & \multicolumn{2}{|c|}{ Poblacion 8} & \multicolumn{2}{|c|}{ Barangay 2} \\
\hline & Number & $\%$ & Number & $\%$ & Number & $\%$ & Number & $\%$ & Number & $\%$ \\
\hline Yes & 24 & 38.10 & 21 & 70.00 & 15 & 60.00 & 19 & 65.52 & 6 & 37.50 \\
\hline No & 37 & 58.73 & 5 & 16.67 & 9 & 36.00 & 9 & 31.03 & 10 & 62.50 \\
\hline Did not Specify & 2 & 3.17 & 4 & 13.33 & 1 & 4.00 & 1 & 3.45 & 0 & 0.00 \\
\hline
\end{tabular}

\begin{tabular}{|l|r|r|r|r|r|r|}
\hline \multirow{2}{*}{ Frequency } & \multicolumn{2}{|c|}{ Balugo } & \multicolumn{2}{c|}{ Calindagan } & \multicolumn{2}{c|}{ Overall } \\
\cline { 2 - 7 } & Number & \multicolumn{1}{c|}{$\%$} & Number & \multicolumn{1}{c|}{$\%$} & \multicolumn{1}{c|}{ Number } & \multicolumn{1}{c|}{$\%$} \\
\hline Yes & 5 & 29.41 & 17 & 73.91 & 194 & 53.74 \\
\hline No & 11 & 64.71 & 5 & 21.74 & 152 & 42.11 \\
\hline Did not Specify & 1 & 5.88 & 1 & 4.35 & 15 & 4.16 \\
\hline
\end{tabular}

Witnessed Neighbors Assisting Neighbors in Times of Need During Typhoons/Flooding

\begin{tabular}{|c|c|c|c|c|c|c|c|c|c|c|}
\hline \multirow{2}{*}{ Frequency } & \multicolumn{2}{|c|}{ Tabuc-tubig } & \multicolumn{2}{|c|}{ Junob } & \multicolumn{2}{|c|}{ Poblacion 1} & \multicolumn{2}{|c|}{ Batinguel } & \multicolumn{2}{|c|}{ Candua-ay } \\
\hline & Number & $\%$ & Number & $\%$ & Number & $\%$ & Number & $\%$ & Number & $\%$ \\
\hline Yes & 10 & 100.00 & 16 & 100.00 & 18 & 81.82 & 32 & 84.21 & 66 & 91.67 \\
\hline No & 0 & 0.00 & 0 & 0.00 & 4 & 18.18 & 6 & 15.79 & 5 & 6.94 \\
\hline Did not Specify & 0 & 0.00 & 0 & 0.00 & 0 & 0.00 & 0 & 0.00 & 1 & 1.39 \\
\hline
\end{tabular}

\begin{tabular}{|l|r|r|r|r|r|r|r|r|r|r|}
\hline \multirow{2}{*}{ Frequency } & \multicolumn{2}{|c|}{ Taclobo } & \multicolumn{2}{c|}{ Bagacay } & \multicolumn{2}{c|}{ Cadawinonan } & \multicolumn{2}{c|}{ Poblacion 8 } & \multicolumn{2}{c|}{ Barangay 2 } \\
\cline { 2 - 11 } & Number & \multicolumn{1}{c|}{$\%$} & Number & \multicolumn{1}{c|}{$\%$} & Number & \multicolumn{1}{c|}{$\%$} & Number & \% & \multicolumn{1}{c|}{ Number } & \multicolumn{1}{c|}{$\%$} \\
\hline Yes & 60 & 95.24 & 27 & 90.00 & 22 & 88.00 & 25 & 86.21 & 15 & 93.75 \\
\hline No & 3 & 4.76 & 1 & 3.33 & 1 & 4.00 & 4 & 13.79 & 0 & 0.00 \\
\hline Did not Specify & 0 & 0.00 & 2 & 6.67 & 2 & 8.00 & 0 & 0.00 & 1 & 6.25 \\
\hline
\end{tabular}


Community-Based Flood Vulnerability Index for Urban Flooding: Understanding

Social Vulnerabilities and Risks

\begin{tabular}{|l|r|r|r|r|r|r|}
\hline \multirow{2}{*}{ Frequency } & \multicolumn{2}{c|}{ Balugo } & \multicolumn{2}{c|}{ Calindagan } & \multicolumn{2}{c|}{ Overall } \\
\cline { 2 - 7 } & Number & \multicolumn{1}{c|}{$\%$} & Number & \multicolumn{1}{c|}{ \% } & \multicolumn{1}{c|}{ Number } & \multicolumn{1}{c}{ \% } \\
\hline Yes & 12 & 70.59 & 22 & 95.65 & 90.03 \\
\hline No & 2 & 11.76 & 1 & 4.35 & 27 & 7.48 \\
\hline Did not Specify & 3 & 17.65 & 0 & 0.00 & 9 & 2.49 \\
\hline
\end{tabular}

\section{Knowledge on the Risk Flooding}

\begin{tabular}{|l|r|r|r|r|r|r|r|r|r|r|}
\hline \multirow{2}{*}{ Frequency } & \multicolumn{2}{|c|}{ Tabuc-tubig } & \multicolumn{2}{c|}{ Junob } & \multicolumn{2}{c|}{ Poblacion 1 } & \multicolumn{2}{c|}{ Batinguel } & \multicolumn{2}{c|}{ Candua-ay } \\
\cline { 2 - 10 } & Number & \multicolumn{1}{c|}{$\%$} & Number & \multicolumn{1}{c|}{$\%$} & Number & \multicolumn{1}{c|}{$\%$} & \multicolumn{1}{c|}{ Number } & \multicolumn{1}{c|}{$\%$} & \multicolumn{1}{c|}{ Number } & \multicolumn{1}{c|}{$\%$} \\
\hline Yes & 10 & 100.00 & 15 & 93.75 & 18 & 81.82 & 36 & 94.74 & 62 & 86.11 \\
\hline No & 0 & 0.00 & 1 & 6.25 & 4 & 18.18 & 2 & 5.26 & 9 & 12.50 \\
\hline Did not Specify & 0 & 0.00 & 0 & 0.00 & 0 & 0.00 & 0 & 0.00 & 1 & 1.39 \\
\hline
\end{tabular}

\begin{tabular}{|c|c|c|c|c|c|c|c|c|c|c|}
\hline \multirow[t]{2}{*}{ Frequency } & \multicolumn{2}{|c|}{ Taclobo } & \multicolumn{2}{|c|}{ Bagacay } & \multicolumn{2}{|c|}{ Cadawinonan } & \multicolumn{2}{|c|}{ Poblacion 8} & \multicolumn{2}{|c|}{ Barangay 2} \\
\hline & Number & $\%$ & Number & $\%$ & Number & $\%$ & Number & $\%$ & Number & $\%$ \\
\hline Yes & 59 & 93.65 & 27 & 90.00 & 21 & 84.00 & 27 & 93.10 & 16 & 100.00 \\
\hline No & 2 & 3.17 & 2 & 6.67 & 4 & 16.00 & 2 & 6.90 & 0 & 0.00 \\
\hline Did not Specify & 2 & 3.17 & 1 & 3.33 & 0 & 0.00 & 0 & 0.00 & 0 & 0.00 \\
\hline
\end{tabular}

\begin{tabular}{|l|r|r|r|r|r|r|}
\hline \multirow{2}{*}{ Frequency } & \multicolumn{2}{|c|}{ Balugo } & \multicolumn{2}{c|}{ Calindagan } & \multicolumn{2}{c|}{ Overall } \\
\cline { 2 - 7 } & Number & \multicolumn{1}{|c|}{$\%$} & Number & \multicolumn{1}{c|}{$\%$} & Number & \multicolumn{1}{c|}{$\%$} \\
\hline Yes & 13 & 76.47 & 21 & 91.30 & 325 & 90.03 \\
\hline No & 4 & 23.53 & 2 & 8.70 & 32 & 8.86 \\
\hline Did not Specify & 0 & 0.00 & 0 & 0.00 & 4 & 1.11 \\
\hline
\end{tabular}


Community-Based Flood Vulnerability Index for Urban Flooding: Understanding Social Vulnerabilities and Risks

Willingness to Vacate and be Relocated

\begin{tabular}{|c|c|c|c|c|c|c|c|c|c|c|}
\hline \multirow{2}{*}{ Frequency } & \multicolumn{2}{|c|}{ Tabuc-tubig } & \multicolumn{2}{|c|}{ Junob } & \multicolumn{2}{|c|}{ Poblacion 1} & \multicolumn{2}{|c|}{ Batinguel } & \multicolumn{2}{|c|}{ Candua-ay } \\
\hline & Number & $\%$ & Number & $\%$ & Number & $\%$ & Number & $\%$ & Number & $\%$ \\
\hline Yes & 10 & 100.00 & 14 & 87.50 & 14 & 63.64 & 25 & 65.79 & 45 & 62.50 \\
\hline No & 0 & 0.00 & 2 & 12.50 & 7 & 31.82 & 13 & 34.21 & 24 & 33.33 \\
\hline Did not Specify & 0 & 0.00 & 0 & 0.00 & 1 & 4.55 & 0 & 0.00 & 3 & 4.17 \\
\hline
\end{tabular}

\begin{tabular}{|c|c|c|c|c|c|c|c|c|c|c|}
\hline \multirow{2}{*}{ Frequency } & \multicolumn{2}{|c|}{ Taclobo } & \multicolumn{2}{|c|}{ Bagacay } & \multicolumn{2}{|c|}{ Cadawinonan } & \multicolumn{2}{|c|}{ Poblacion 8} & \multicolumn{2}{|c|}{ Barangay 2} \\
\hline & Number & $\%$ & Number & $\%$ & Number & $\%$ & Number & $\%$ & Number & $\%$ \\
\hline Yes & 45 & 71.43 & 23 & 76.67 & 19 & 76.00 & 19 & 65.52 & 10 & 62.50 \\
\hline No & 13 & 20.63 & 4 & 13.33 & 5 & 20.00 & 9 & 31.03 & 6 & 37.50 \\
\hline Did not Specify & 5 & 7.94 & 3 & 10.00 & 1 & 4.00 & 1 & 3.45 & 0 & 0.00 \\
\hline
\end{tabular}

\begin{tabular}{|l|r|r|r|r|r|r|}
\hline \multirow{2}{*}{ Frequency } & \multicolumn{2}{|c|}{ Balugo } & \multicolumn{2}{c|}{ Calindagan } & \multicolumn{2}{c|}{ Overall } \\
\cline { 2 - 7 } & Number & \multicolumn{1}{|c}{$\%$} & Number & \multicolumn{1}{c|}{$\%$} & Number & \multicolumn{1}{c|}{$\%$} \\
\hline Yes & 15 & 88.24 & 19 & 82.61 & 258 & 71.47 \\
\hline No & 2 & 11.76 & 4 & 17.39 & 89 & 24.65 \\
\hline Did not Specify & 0 & 0.00 & 0 & 0.00 & 14 & 3.88 \\
\hline
\end{tabular}


Community-Based Flood Vulnerability Index for Urban Flooding: Understanding

Social Vulnerabilities and Risks

\section{Reasons for Acceding to Vacate}

\begin{tabular}{|c|c|c|c|c|c|c|c|c|c|c|}
\hline \multirow{2}{*}{ Reasons } & \multicolumn{2}{|c|}{ Tabuc-tubig } & \multicolumn{2}{|c|}{ Junob } & \multicolumn{2}{|c|}{ Poblacion 1} & \multicolumn{2}{|c|}{ Batinguel } & \multicolumn{2}{|c|}{ Candua-ay } \\
\hline & Number & $\%$ & Number & $\%$ & Number & $\%$ & Number & $\%$ & Number & $\%$ \\
\hline Availability of relocation site & 0 & 0.00 & 0 & 0.00 & 3 & 13.64 & 5 & 13.16 & 6 & 8.33 \\
\hline Avoid further losses & 0 & 0.00 & 0 & 0.00 & 0 & 0.00 & 0 & 0.00 & 0 & 0.00 \\
\hline Avoid recurrence of being flooded & 0 & 0.00 & 1 & 6.25 & 2 & 9.09 & 0 & 0.00 & 0 & 0.00 \\
\hline High risk area & 1 & 10.00 & 1 & 6.25 & 0 & 0.00 & 2 & 5.26 & 2 & 2.78 \\
\hline Property owned by government & 1 & 10.00 & 0 & 0.00 & 0 & 0.00 & 0 & 0.00 & 0 & 0.00 \\
\hline Safety of family & 5 & 50.00 & 7 & 43.75 & 5 & 22.73 & 16 & 42.11 & 28 & 38.89 \\
\hline Trust in LGU advisory & 0 & 0.00 & 0 & 0.00 & 0 & 0.00 & 0 & 0.00 & 0 & 0.00 \\
\hline Did not Specify & 1 & 10.00 & 3 & 18.75 & 3 & 13.64 & 4 & 10.53 & 11 & 15.28 \\
\hline
\end{tabular}

\begin{tabular}{|c|c|c|c|c|c|c|c|c|c|c|}
\hline \multirow{2}{*}{ Reasons } & \multicolumn{2}{|c|}{ Taclobo } & \multicolumn{2}{|c|}{ Bagacay } & \multicolumn{2}{|c|}{ Cadawinonan } & \multicolumn{2}{|c|}{ Poblacion 8} & \multicolumn{2}{|c|}{ Barangay 2} \\
\hline & Number & $\%$ & Number & $\%$ & Number & $\%$ & Number & $\%$ & Number & $\%$ \\
\hline Availability of relocation site & 6 & 9.52 & 1 & 3.33 & 3 & 12.00 & 3 & 10.34 & 0 & 0.00 \\
\hline Avoid further losses & 0 & 0.00 & 1 & 3.33 & 0 & 0.00 & 0 & 0.00 & 0 & 0.00 \\
\hline Avoid recurrence of being flooded & 1 & 1.59 & 1 & 3.33 & 3 & 12.00 & 1 & 3.45 & 1 & 6.25 \\
\hline High risk area & 1 & 1.59 & 2 & 6.67 & 2 & 8.00 & 2 & 6.90 & 2 & 12.50 \\
\hline Property owned by government & 0 & 0.00 & 0 & 0.00 & 0 & 0.00 & 0 & 0.00 & 0 & 0.00 \\
\hline Safety of family & 29 & 46.03 & 10 & 33.33 & 11 & 44.00 & 11 & 37.93 & 7 & 43.75 \\
\hline Trust in LGU advisory & 0 & 0.00 & 0 & 0.00 & 0 & 0.00 & 0 & 0.00 & 0 & 0.00 \\
\hline Did not Specify & 3 & 4.76 & 4 & 13.33 & 2 & 8.00 & 3 & 10.34 & 1 & 6.25 \\
\hline
\end{tabular}


Community-Based Flood Vulnerability Index for Urban Flooding: Understanding Social Vulnerabilities and Risks

\section{Reasons for Acceding to Vacate ... continued}

\begin{tabular}{|l|r|r|r|r|r|r|}
\hline \multirow{2}{*}{ Reasons } & \multicolumn{2}{|c|}{ Balugo } & \multicolumn{2}{c|}{ Calindagan } & \multicolumn{2}{c|}{ Overall } \\
\cline { 2 - 7 } & Number & \multicolumn{1}{c|}{$\%$} & Number & \multicolumn{1}{c|}{$\%$} & Number & \multicolumn{1}{c|}{$\%$} \\
\hline Availability of relocation site & 2 & 11.76 & 2 & 8.70 & 31 & 8.59 \\
\hline Avoid further losses & 0 & 0.00 & 0 & 0.00 & 1 & 0.28 \\
\hline Avoid recurrence of being flooded & 0 & 0.00 & 0 & 0.00 & 10 & 2.77 \\
\hline High risk area & 1 & 5.88 & 0 & 0.00 & 16 & 4.43 \\
\hline Property owned by government & 0 & 0.00 & 0 & 0.00 & 1 & 0.28 \\
\hline Safety of family & 9 & 52.94 & 13 & 56.52 & 151 & 41.83 \\
\hline Trust in LGU advisory & 0 & 0.00 & 0 & 0.00 & 0 & 0.00 \\
\hline Did not Specify & 2 & 11.76 & 2 & 8.70 & 39 & 10.80 \\
\hline
\end{tabular}

\section{Reasons for Not Acceding to Vacate}

\begin{tabular}{|c|c|c|c|c|c|c|c|c|c|c|}
\hline \multirow{2}{*}{ Reasons } & \multicolumn{2}{|c|}{ Tabuc-tubig } & \multicolumn{2}{|c|}{ Junob } & \multicolumn{2}{|c|}{ Poblacion 1} & \multicolumn{2}{|c|}{ Batinguel } & \multicolumn{2}{|c|}{ Candua-ay } \\
\hline & Number & $\%$ & Number & $\%$ & Number & $\%$ & Number & $\%$ & Number & $\%$ \\
\hline Being ready and alert & 0 & 0.00 & 0 & 0.00 & 0 & 0.00 & 0 & 0.00 & 0 & 0.00 \\
\hline Dikes are in place & 0 & 0.00 & 0 & 0.00 & 0 & 0.00 & 1 & 2.63 & 0 & 0.00 \\
\hline Dont trust the LGU & 0 & 0.00 & 0 & 0.00 & 1 & 4.55 & 0 & 0.00 & 1 & 1.39 \\
\hline No relocation site & 0 & 0.00 & 0 & 0.00 & 2 & 9.09 & 5 & 13.16 & 8 & 11.11 \\
\hline No threat & 0 & 0.00 & 0 & 0.00 & 1 & 4.55 & 1 & 2.63 & 2 & 2.78 \\
\hline Not ready & 0 & 0.00 & 0 & 0.00 & 0 & 0.00 & 0 & 0.00 & 0 & 0.00 \\
\hline Proximity of source of livelihood & 0 & 0.00 & 1 & 6.25 & 0 & 0.00 & 1 & 2.63 & 2 & 2.78 \\
\hline Secure our property & 0 & 0.00 & 1 & 6.25 & 0 & 0.00 & 0 & 0.00 & 1 & 1.39 \\
\hline Sentimental reasons & 0 & 0.00 & 0 & 0.00 & 0 & 0.00 & 1 & 2.63 & 2 & 2.78 \\
\hline Did not Specify & 4 & 40.00 & 1 & 6.25 & 6 & 27.27 & 5 & 13.16 & 11 & 15.28 \\
\hline
\end{tabular}


Community-Based Flood Vulnerability Index for Urban Flooding: Understanding Social Vulnerabilities and Risks

\begin{tabular}{|c|c|c|c|c|c|c|c|c|c|c|}
\hline \multirow{2}{*}{ Reasons } & \multicolumn{2}{|c|}{ Taclobo } & \multicolumn{2}{|c|}{ Bagacay } & \multicolumn{2}{|c|}{ Cadawinonan } & \multicolumn{2}{|c|}{ Poblacion 8} & \multicolumn{2}{|c|}{ Barangay 2} \\
\hline & Number & $\%$ & Number & $\%$ & Number & $\%$ & Number & $\%$ & Number & $\%$ \\
\hline Being ready and alert & 0 & 0.00 & 0 & 0.00 & 2 & 8.00 & 0 & 0.00 & 0 & 0.00 \\
\hline Dikes are in place & 1 & 1.59 & 0 & 0.00 & 0 & 0.00 & 0 & 0.00 & 0 & 0.00 \\
\hline Dont trust the LGU & 0 & 0.00 & 0 & 0.00 & 0 & 0.00 & 0 & 0.00 & 0 & 0.00 \\
\hline No relocation site & 5 & 7.94 & 5 & 16.67 & 0 & 0.00 & 2 & 6.90 & 3 & 18.75 \\
\hline No threat & 2 & 3.17 & 0 & 0.00 & 0 & 0.00 & 1 & 3.45 & 0 & 0.00 \\
\hline Not ready & 1 & 1.59 & 0 & 0.00 & 0 & 0.00 & 0 & 0.00 & 0 & 0.00 \\
\hline Proximity of source of livelihood & 0 & 0.00 & 1 & 3.33 & 0 & 0.00 & 3 & 10.34 & 2 & 12.50 \\
\hline Secure our property & 0 & 0.00 & 1 & 3.33 & 0 & 0.00 & 1 & 3.45 & 0 & 0.00 \\
\hline Sentimental reasons & 2 & 3.17 & 0 & 0.00 & 2 & 8.00 & 1 & 3.45 & 1 & 6.25 \\
\hline Did not Specify & 10 & 15.87 & 2 & 6.67 & 4 & 16.00 & 3 & 10.34 & 3 & 18.75 \\
\hline
\end{tabular}

\section{Reasons for Not Acceding to Vacate ... continued}

\begin{tabular}{|l|r|r|r|r|r|r|}
\hline \multirow{2}{*}{ Reasons } & \multicolumn{2}{|c|}{ Balugo } & \multicolumn{2}{c|}{ Calindagan } & \multicolumn{2}{c|}{ Overall } \\
\cline { 2 - 7 } & Number & \multicolumn{1}{|c|}{$\%$} & Number & $\%$ & Number & $\%$ \\
\hline Being ready and alert & 0 & 0.00 & 0 & 0.00 & 2 & 0.55 \\
\hline Dikes are in place & 0 & 0.00 & 0 & 0.00 & 2 & 0.55 \\
\hline Dont trust the LGU & 0 & 0.00 & 0 & 0.00 & 2 & 0.55 \\
\hline No relocation site & 0 & 0.00 & 2 & 8.70 & 32 & 8.86 \\
\hline No threat & 1 & 5.88 & 0 & 0.00 & 8 & 2.22 \\
\hline Not ready & 0 & 0.00 & 0 & 0.00 & 1 & 0.28 \\
\hline Proximity of source of livelihood & 0 & 0.00 & 1 & 4.35 & 11 & 3.05 \\
\hline Secure our property & 0 & 0.00 & 1 & 4.35 & 5 & 1.39 \\
\hline Sentimental reasons & 0 & 0.00 & 0 & 0.00 & 9 & 2.49 \\
\hline Did not Specify & 4 & 23.53 & 4 & 17.39 & 57 & 15.79 \\
\hline
\end{tabular}


Social Vulnerabilities and Risks

\section{Appendix 5 Knowledge, Attitude, and Practices (KAP) on Flood Resilience}

In this appendix the results from Knowledge, Attitude, and Practices (KAP) on Flood Resilience of the surveyed questionnaires from the household respondents is presented as follows:

A. Flood Resilience

1. Hazard

2. Risks

3. Exposure

4. Preparedness

5. Response

6. Recovery

7. Coordination

8. Adaptation Strategies 
Community-Based Flood Vulnerability Index for Urban Flooding: Understanding

Social Vulnerabilities and Risks

\section{Flood Resilience: KNOWLEDGE}

\begin{tabular}{|c|c|c|c|c|c|c|c|c|c|c|}
\hline \multirow{2}{*}{\begin{tabular}{l}
\multicolumn{1}{c}{ Item: HAZARD } \\
Questions
\end{tabular}} & \multicolumn{2}{|c|}{ Tabuc-tubig } & \multicolumn{2}{|c|}{ Junob } & \multicolumn{2}{|c|}{ Poblacion 1} & \multicolumn{2}{|c|}{ Calindagan } & \multicolumn{2}{|c|}{ Balugo } \\
\hline & $\mathbf{F}$ & $\%$ & $\mathbf{F}$ & $\%$ & $\mathbf{F}$ & $\%$ & $\mathbf{F}$ & $\%$ & $\mathbf{F}$ & $\%$ \\
\hline $\begin{array}{l}\text { 1. Are you aware that your area } \\
\text { is a flood hazard zone and you } \\
\text { are at high risks? }\end{array}$ & 6 & 60.00 & 13 & 81.25 & 16 & 72.73 & 8 & 34.78 & 7 & 41.18 \\
\hline $\begin{array}{l}\text { 2. Do you know the nature and } \\
\text { capacity of floods? }\end{array}$ & 10 & 100.00 & 11 & 68.75 & 14 & 63.64 & 8 & 34.78 & 9 & 52.94 \\
\hline $\begin{array}{l}\text { 3. Have you experienced } \\
\text { flooding in this area and still } \\
\text { continue to live here? }\end{array}$ & 9 & 90.00 & 12 & 75.00 & 20 & 90.91 & 4 & 17.39 & 10 & 58.82 \\
\hline $\begin{array}{l}\text { 4. Have you seen presence of } \\
\text { overloaded drainage } \\
\text { infrastructures during heavy } \\
\text { rains/typhoons and have seen } \\
\text { its potential risks? }\end{array}$ & 8 & 80.00 & 11 & 68.75 & 20 & 90.91 & 5 & 21.74 & 10 & 58.82 \\
\hline $\begin{array}{l}\text { 5. Have you seen debris from all } \\
\text { kinds during and after } \\
\text { flooding? }\end{array}$ & 10 & 100.00 & 16 & 100.00 & 20 & 90.91 & 9 & 39.13 & 13 & 76.47 \\
\hline $\begin{array}{l}\text { 6. Do you know if there are flood } \\
\text { hazard maps available for your } \\
\text { locality? }\end{array}$ & 3 & 30.00 & 6 & 37.50 & 7 & 31.82 & 1 & 4.35 & 2 & 11.76 \\
\hline Item Summary & Mean & S.D. & Mean & S.D. & Mean & S.D. & Mean & S.D. & Mean & S.D. \\
\hline Mean Score & 4.60 & 1.26 & 4.50 & 1.20 & 4.41 & 1.37 & 4.35 & 1.70 & 3.00 & 1.58 \\
\hline Percentage Score & 76.67 & 21.08 & 71.88 & 19.92 & 73.48 & 22.81 & 72.46 & 28.25 & 50.00 & 26.35 \\
\hline
\end{tabular}

*F values are frequency of "yes" answers 
Community-Based Flood Vulnerability Index for Urban Flooding: Understanding

Social Vulnerabilities and Risks

Flood Resilience: KNOWLEDGE ... continued

\begin{tabular}{|c|c|c|c|c|c|c|c|c|c|c|}
\hline \multirow{2}{*}{$\begin{array}{l}\text { Item: HAZARD } \\
\text { Questions }\end{array}$} & \multicolumn{2}{|c|}{ Barangay 2} & \multicolumn{2}{|c|}{ Poblacion 8} & \multicolumn{2}{|c|}{ Cadawinonan } & \multicolumn{2}{|c|}{ Bagacay } & \multicolumn{2}{|c|}{ Taclobo } \\
\hline & $\mathbf{F}$ & $\%$ & $\mathbf{F}$ & $\%$ & $\mathbf{F}$ & $\%$ & $\mathbf{F}$ & $\%$ & $\mathbf{F}$ & $\%$ \\
\hline $\begin{array}{l}\text { 1. Are you aware that your area } \\
\text { is a flood hazard zone and you } \\
\text { are at high risks? }\end{array}$ & 15 & 93.75 & 24 & 82.76 & 17 & 70.83 & 24 & 80.00 & 45 & 73.77 \\
\hline $\begin{array}{l}\text { 2. Do you know the nature and } \\
\text { capacity of floods? }\end{array}$ & 14 & 87.50 & 27 & 93.10 & 20 & 83.33 & 21 & 70.00 & 54 & 88.52 \\
\hline $\begin{array}{l}\text { 3. Have you experienced } \\
\text { flooding in this area and still } \\
\text { continue to live here? }\end{array}$ & 13 & 81.25 & 29 & 100.00 & 15 & 62.50 & 26 & 86.67 & 42 & 68.85 \\
\hline $\begin{array}{l}\text { 4. Have you seen presence of } \\
\text { overloaded drainage } \\
\text { infrastructures during heavy } \\
\text { rains/typhoons and have seen } \\
\text { its potential risks? }\end{array}$ & 14 & 87.50 & 29 & 100.00 & 21 & 87.50 & 22 & 73.33 & 52 & 85.25 \\
\hline $\begin{array}{l}\text { 5. Have you seen debris from all } \\
\text { kinds during and after } \\
\text { flooding? }\end{array}$ & 15 & 93.75 & 29 & 100.00 & 24 & 100.00 & 30 & 100.00 & 53 & 86.89 \\
\hline $\begin{array}{l}\text { 6. Do you know if there are } \\
\text { flood hazard maps available } \\
\text { for your locality? }\end{array}$ & 9 & 56.25 & 15 & 51.72 & 11 & 45.83 & 2 & 6.67 & 19 & 31.15 \\
\hline Item Summary & Mean & S.D. & Mean & S.D. & Mean & S.D. & Mean & S.D. & Mean & S.D. \\
\hline Mean Score & 5.00 & 1.41 & 5.28 & 0.92 & 4.32 & 1.38 & 4.17 & 0.99 & 4.21 & 1.55 \\
\hline Percentage Score & 83.33 & 23.57 & 87.93 & 15.36 & 72.00 & 22.93 & 69.44 & 16.43 & 70.11 & 25.78 \\
\hline
\end{tabular}


Community-Based Flood Vulnerability Index for Urban Flooding: Understanding

Social Vulnerabilities and Risks

Flood Resilience: KNOWLEDGE ... continued

\begin{tabular}{|c|c|c|c|c|c|c|}
\hline Item: HAZARD & Canc & & Bat & & Ove & \\
\hline Questions & $\mathbf{F}$ & $\%$ & $\mathbf{F}$ & $\%$ & $\mathbf{F}$ & $\%$ \\
\hline $\begin{array}{l}\text { 1. Are you aware that your area is a flood hazard } \\
\text { zone and you are at high risks? }\end{array}$ & 58 & 80.56 & 32 & 84.21 & 265 & 73.41 \\
\hline $\begin{array}{l}\text { 2. Do you know the nature and capacity of } \\
\text { floods? }\end{array}$ & 57 & 79.17 & 31 & 81.58 & 276 & 76.45 \\
\hline $\begin{array}{l}\text { 3. Have you experienced flooding in this area } \\
\text { and still continue to live here? }\end{array}$ & 63 & 87.50 & 32 & 84.21 & 275 & 76.18 \\
\hline $\begin{array}{l}\text { 4. Have you seen presence of overloaded } \\
\text { drainage infrastructures during heavy } \\
\text { rains/typhoons and have seen its potential } \\
\text { risks? }\end{array}$ & 55 & 76.39 & 29 & 76.32 & 276 & 76.45 \\
\hline $\begin{array}{l}\text { 5. Have you seen debris from all kinds during } \\
\text { and after flooding? }\end{array}$ & 63 & 87.50 & 32 & 84.21 & 314 & 86.98 \\
\hline $\begin{array}{l}\text { 6. Do you know if there are flood hazard maps } \\
\text { available for your locality? }\end{array}$ & 28 & 38.89 & 16 & 42.11 & 119 & 32.96 \\
\hline Item Summary & Mean & S.D. & Mean & S.D. & Mean & S.D. \\
\hline Mean Score & 4.50 & 1.56 & 4.53 & 1.47 & 4.40 & 1.47 \\
\hline Percentage Score & 75.00 & 25.94 & 75.44 & 24.43 & 73.41 & 24.42 \\
\hline
\end{tabular}


Community-Based Flood Vulnerability Index for Urban Flooding: Understanding

Social Vulnerabilities and Risks

Flood Resilience: KNOWLEDGE ... continued

\begin{tabular}{|c|c|c|c|c|c|c|c|c|c|c|}
\hline \multirow{2}{*}{$\begin{array}{l}\text { Item: RISK } \\
\text { Questions }\end{array}$} & \multicolumn{2}{|c|}{ Tabuc-tubig } & \multicolumn{2}{|c|}{ Junob } & \multicolumn{2}{|c|}{ Poblacion 1} & \multicolumn{2}{|c|}{ Calindagan } & \multicolumn{2}{|c|}{ Balugo } \\
\hline & $\mathbf{F}$ & $\%$ & $\mathbf{F}$ & $\%$ & $\mathbf{F}$ & $\%$ & $\mathbf{F}$ & $\%$ & $\mathbf{F}$ & $\%$ \\
\hline $\begin{array}{l}\text { 1. Are you aware that flooding } \\
\text { can occur during and after } \\
\text { heavy downpour? }\end{array}$ & 10 & 100.00 & 16 & 100.00 & 18 & 81.82 & 10 & 43.48 & 13 & 76.47 \\
\hline $\begin{array}{l}\text { 2. Are you aware of the } \\
\text { limitation and level of } \\
\text { protection of the flood control } \\
\text { barriers? }\end{array}$ & 8 & 80.00 & 10 & 62.50 & 10 & 45.45 & 7 & 30.43 & 8 & 47.06 \\
\hline $\begin{array}{l}\text { 3. Do you know what time of the } \\
\text { year flooding can usually } \\
\text { occur? }\end{array}$ & 6 & 60.00 & 13 & 81.25 & 10 & 45.45 & 3 & 13.04 & 4 & 23.53 \\
\hline $\begin{array}{l}\text { 4. Do you think It can also } \\
\text { happen at any time and one } \\
\text { just needs to be ready all the } \\
\text { time? }\end{array}$ & 10 & 100.00 & 14 & 87.50 & 21 & 95.45 & 9 & 39.13 & 15 & 88.24 \\
\hline Item Summary & Mean & S.D. & Mean & S.D. & Mean & S.D. & Mean & S.D. & Mean & S.D. \\
\hline Mean Score & 3.40 & 0.84 & 3.50 & 0.79 & 2.68 & 0.99 & 3.04 & 0.88 & 2.35 & 1.22 \\
\hline Percentage Score & 85.00 & 21.08 & 82.81 & 19.83 & 67.05 & 24.86 & 76.09 & 21.95 & 58.82 & 30.54 \\
\hline
\end{tabular}


Community-Based Flood Vulnerability Index for Urban Flooding: Understanding

Social Vulnerabilities and Risks

Flood Resilience: KNOWLEDGE ... continued

\begin{tabular}{|c|c|c|c|c|c|c|c|c|c|c|}
\hline Item: RISK & Barar & gay 2 & Pobl & ion 8 & Cadaw & onan & Bag & & Tac & \\
\hline Questions & $\mathbf{F}$ & $\%$ & $\mathbf{F}$ & $\%$ & $\mathbf{F}$ & $\%$ & $\mathbf{F}$ & $\%$ & $\mathbf{F}$ & $\%$ \\
\hline $\begin{array}{l}\text { 1. Are you aware that flooding } \\
\text { can occur during and after } \\
\text { heavy downpour? }\end{array}$ & 14 & 87.50 & 25 & 86.21 & 22 & 91.67 & 29 & 96.67 & 59 & 96.72 \\
\hline $\begin{array}{l}\text { 2. Are you aware of the limitation } \\
\text { and level of protection of the } \\
\text { flood control barriers? }\end{array}$ & 12 & 75.00 & 18 & 62.07 & 18 & 75.00 & 17 & 56.67 & 43 & 70.49 \\
\hline $\begin{array}{l}\text { 3. Do you know what time of the } \\
\text { year flooding can usually occur? }\end{array}$ & 6 & 37.50 & 17 & 58.62 & 15 & 62.50 & 14 & 46.67 & 34 & 55.74 \\
\hline $\begin{array}{l}\text { 4. Do you think It can also happen } \\
\text { at any time and one just needs } \\
\text { to be ready all the time? }\end{array}$ & 16 & 100.00 & 28 & 96.55 & 24 & 100.00 & 29 & 96.67 & 61 & 100.00 \\
\hline Item Summary & Mean & S.D. & Mean & S.D. & Mean & S.D. & Mean & S.D. & Mean & S.D. \\
\hline Mean Score & 3.00 & 0.97 & 3.03 & 0.98 & 3.16 & 1.11 & 2.97 & 1.03 & 3.13 & 0.91 \\
\hline Percentage Score & 75.00 & 24.15 & 75.86 & 24.53 & 79.00 & 27.65 & 74.17 & 25.83 & 78.17 & 22.67 \\
\hline
\end{tabular}


Community-Based Flood Vulnerability Index for Urban Flooding: Understanding Social Vulnerabilities and Risks

Flood Resilience: KNOWLEDGE ... continued

\begin{tabular}{|c|c|c|c|c|c|c|}
\hline \multirow{2}{*}{$\begin{array}{l}\text { Item: RISK } \\
\text { Questions }\end{array}$} & \multicolumn{2}{|c|}{ Candau-ay } & \multicolumn{2}{|c|}{ Batinguel } & \multicolumn{2}{|c|}{ Overall } \\
\hline & $\mathbf{F}$ & $\%$ & $\mathbf{F}$ & $\%$ & $\mathbf{F}$ & $\%$ \\
\hline $\begin{array}{l}\text { 1. Are you aware that flooding } \\
\text { can occur during and after } \\
\text { heavy downpour? }\end{array}$ & 63 & 87.50 & 36 & 94.74 & 315 & 87.26 \\
\hline $\begin{array}{l}\text { 2. Are you aware of the } \\
\text { limitation and level of } \\
\text { protection of the flood } \\
\text { control barriers? }\end{array}$ & 63 & 87.50 & 28 & 73.68 & 242 & 67.04 \\
\hline $\begin{array}{l}\text { 3. Do you know what time of } \\
\text { the year flooding can usually } \\
\text { occur? }\end{array}$ & 39 & 54.17 & 24 & 63.16 & 185 & 51.25 \\
\hline $\begin{array}{l}\text { 4. Do you think It can also } \\
\text { happen at any time and one } \\
\text { just needs to be ready all the } \\
\text { time? }\end{array}$ & 66 & 91.67 & 29 & 76.32 & 322 & 89.20 \\
\hline Item Summary & Mean & S.D. & Mean & S.D. & Mean & S.D. \\
\hline Mean Score & 3.21 & 1.64 & 3.08 & 0.91 & 3.06 & 1.14 \\
\hline Percentage Score & 80.21 & 40.88 & 76.97 & 22.80 & 76.52 & 28.46 \\
\hline
\end{tabular}


Community-Based Flood Vulnerability Index for Urban Flooding: Understanding

Social Vulnerabilities and Risks

Flood Resilience: KNOWLEDGE ... continued

\begin{tabular}{|c|c|c|c|c|c|c|c|c|c|c|}
\hline \multirow{2}{*}{$\begin{array}{l}\text { Item: EXPOSURE } \\
\text { Questions }\end{array}$} & \multicolumn{2}{|c|}{ Tabuc-tubig } & \multicolumn{2}{|c|}{ Junob } & \multicolumn{2}{|c|}{ Poblacion 1} & \multicolumn{2}{|c|}{ Calindagan } & \multicolumn{2}{|c|}{ Balugo } \\
\hline & $\mathbf{F}$ & $\%$ & $\mathbf{F}$ & $\%$ & $\mathbf{F}$ & $\%$ & $\mathbf{F}$ & $\%$ & $\mathbf{F}$ & $\%$ \\
\hline $\begin{array}{l}\text { 1. Are you aware of the negative } \\
\text { impacts of flooding? }\end{array}$ & 10 & 100.00 & 16 & 100.00 & 22 & 100.00 & 10 & 43.48 & 13 & 76.47 \\
\hline $\begin{array}{l}\text { 2. Have you or anyone in the } \\
\text { household have been exposed } \\
\text { to flooding before? }\end{array}$ & 6 & 60.00 & 12 & 75.00 & 20 & 90.91 & 6 & 26.09 & 9 & 52.94 \\
\hline $\begin{array}{l}\text { 3. Have you or anyone in the } \\
\text { household have been injured } \\
\text { from the previous flooding? }\end{array}$ & 3 & 30.00 & 6 & 37.50 & 12 & 54.55 & 3 & 13.04 & 4 & 23.53 \\
\hline $\begin{array}{l}\text { 4. Have you or anyone in the } \\
\text { household have been sick } \\
\text { during or after flooding/rainy } \\
\text { season? }\end{array}$ & 5 & 50.00 & 7 & 43.75 & 9 & 40.91 & 3 & 13.04 & 4 & 23.53 \\
\hline $\begin{array}{l}\text { 5. Have your household have } \\
\text { experienced loss of love ones } \\
\text { due to flooding and the impacts } \\
\text { it has brought such as injury and } \\
\text { infection? }\end{array}$ & 3 & 30.00 & 5 & 31.25 & 2 & 9.09 & 0 & 0.00 & 2 & 11.76 \\
\hline $\begin{array}{l}\text { 6. Have you lost any of your } \\
\text { property from the previous } \\
\text { flooding? }\end{array}$ & 7 & 70.00 & 14 & 87.50 & 7 & 31.82 & 1 & 4.35 & 6 & 35.29 \\
\hline Item Summary & Mean & S.D. & Mean & S.D. & Mean & S.D. & Mean & S.D. & Mean & S.D. \\
\hline Mean Score & 3.40 & 1.71 & 3.80 & 1.18 & 3.27 & 1.35 & 2.04 & 1.07 & 2.24 & 1.86 \\
\hline Percentage Score & 56.67 & 28.54 & 62.50 & 19.72 & 54.55 & 22.53 & 34.06 & 17.75 & 37.25 & 30.92 \\
\hline
\end{tabular}


Community-Based Flood Vulnerability Index for Urban Flooding: Understanding

\section{Social Vulnerabilities and Risks}

\begin{tabular}{|c|c|c|c|c|c|c|c|c|c|c|}
\hline \multirow{2}{*}{$\begin{array}{l}\text { Item: EXPOSURE } \\
\text { Questions }\end{array}$} & \multicolumn{2}{|c|}{ Barangay 2} & \multicolumn{2}{|c|}{ Poblacion 8} & \multicolumn{2}{|c|}{ Cadawinonan } & \multicolumn{2}{|c|}{ Bagacay } & \multicolumn{2}{|c|}{ Taclobo } \\
\hline & $F$ & $\%$ & $F$ & $\%$ & $\mathbf{F}$ & $\%$ & $\mathbf{F}$ & $\%$ & $\mathbf{F}$ & $\%$ \\
\hline $\begin{array}{l}\text { 1. Are you aware of the negative } \\
\text { impacts of flooding? }\end{array}$ & 16 & 100.00 & 29 & 100.00 & 23 & 95.83 & 29 & 96.67 & 60 & 98.36 \\
\hline $\begin{array}{l}\text { 2. Have you or anyone in the } \\
\text { household have been exposed } \\
\text { to flooding before? }\end{array}$ & 13 & 81.25 & 28 & 96.55 & 19 & 79.17 & 27 & 90.00 & 44 & 72.13 \\
\hline $\begin{array}{l}\text { 3. Have you or anyone in the } \\
\text { household have been injured } \\
\text { from the previous flooding? }\end{array}$ & 7 & 43.75 & 13 & 44.83 & 8 & 33.33 & 9 & 30.00 & 17 & 27.87 \\
\hline $\begin{array}{l}\text { 4. Have you or anyone in the } \\
\text { household have been sick } \\
\text { during or after flooding/rainy } \\
\text { season? }\end{array}$ & 5 & 31.25 & 16 & 55.17 & 7 & 29.17 & 11 & 36.67 & 15 & 24.59 \\
\hline $\begin{array}{l}\text { 5. Have your household have } \\
\text { experienced loss of love ones } \\
\text { due to flooding and the impacts } \\
\text { it has brought such as injury and } \\
\text { infection? }\end{array}$ & 1 & 6.25 & 8 & 27.59 & 2 & 8.33 & 5 & 16.67 & 4 & 6.56 \\
\hline $\begin{array}{l}\text { 6. Have you lost any of your } \\
\text { property from the previous } \\
\text { flooding? }\end{array}$ & 12 & 75.00 & 20 & 68.97 & 8 & 33.33 & 20 & 66.67 & 27 & 44.26 \\
\hline Item Summary & Mean & S.D. & Mean & S.D. & Mean & S.D. & Mean & S.D. & Mean & S.D. \\
\hline Mean Score & 3.38 & 1.41 & 3.93 & 1.46 & 2.68 & 1.38 & 3.37 & 1.27 & 2.65 & 1.43 \\
\hline Percentage Score & 56.25 & 23.47 & 65.52 & 24.37 & 44.67 & 22.93 & 56.11 & 21.21 & 44.18 & 23.79 \\
\hline
\end{tabular}


Community-Based Flood Vulnerability Index for Urban Flooding: Understanding Social Vulnerabilities and Risks

\begin{tabular}{|l|r|r|r|r|r|c|}
\hline Item: EXPOSURE & \multicolumn{2}{|c|}{ Candau-ay } & \multicolumn{2}{c|}{ Batinguel } & \multicolumn{2}{c|}{ Overall } \\
\hline Questions & \multicolumn{1}{|c|}{ F } & \multicolumn{1}{c|}{ \% } & \multicolumn{1}{c|}{ F } & \multicolumn{1}{c|}{ \% } & \multicolumn{1}{c|}{ F } \\
\hline $\begin{array}{l}\text { 1. Are you aware of the } \\
\text { negative impacts of flooding? }\end{array}$ & 65 & 90.28 & 37 & 97.37 & 330 & 91.41 \\
\hline $\begin{array}{l}\text { 2. Have you or anyone in the } \\
\text { household have been } \\
\text { exposed to flooding before? }\end{array}$ & 59 & 81.94 & 36 & 94.74 & 279 & 77.29 \\
\hline $\begin{array}{l}\text { 3. Have you or anyone in the } \\
\text { household have been injured } \\
\text { from the previous flooding? }\end{array}$ & 24 & 33.33 & 18 & 47.37 & 124 & 34.35 \\
\hline $\begin{array}{l}\text { 4. Have you or anyone in the } \\
\text { household have been sick } \\
\text { during or after flooding/rainy } \\
\text { season? }\end{array}$ & 22 & 30.56 & 16 & 42.11 & 120 & 33.24 \\
\hline $\begin{array}{l}\text { 5. Have your household have } \\
\text { experienced loss of love ones } \\
\text { due to flooding and the } \\
\text { impacts it has brought such } \\
\text { as injury and infection? }\end{array}$ & 10 & 13.89 & 5 & 13.16 & 47 & 13.02 \\
\hline $\begin{array}{l}\text { 6. Have you lost any of your } \\
\text { property from the previous } \\
\text { flooding? }\end{array}$ & 39 & 54.17 & 33 & 86.84 & 194 & 53.74 \\
\hline Item Summary & Mean & S.D. & Mean & S.D. & Mean & S.D. \\
\hline Mean Score & 3.04 & 1.46 & 3.82 & 1.23 & 3.10 & 1.48 \\
\hline Percentage Score & 50.69 & 24.30 & 63.60 & 20.45 & 51.62 & 24.65 \\
\hline
\end{tabular}


Community-Based Flood Vulnerability Index for Urban Flooding: Understanding

Social Vulnerabilities and Risks

Flood Resilience: KNOWLEDGE ... continued

\begin{tabular}{|c|c|c|c|c|c|c|c|c|c|c|}
\hline \multirow{2}{*}{$\begin{array}{l}\text { Item: PREPAREDNESS } \\
\text { Questions }\end{array}$} & \multicolumn{2}{|c|}{ Tabuc-tubig } & \multicolumn{2}{|c|}{ Junob } & \multicolumn{2}{|c|}{ Poblacion 1} & \multicolumn{2}{|c|}{ Calindagan } & \multicolumn{2}{|c|}{ Balugo } \\
\hline & $\mathbf{F}$ & $\%$ & $\mathbf{F}$ & $\%$ & $\mathbf{F}$ & $\%$ & $\mathbf{F}$ & $\%$ & $\mathbf{F}$ & $\%$ \\
\hline $\begin{array}{l}\text { 1. Have you heard about the } \\
\text { presence of flood early warning } \\
\text { systems in your community? }\end{array}$ & 7 & 70.00 & 13 & 81.25 & 9 & 40.91 & 4 & 17.39 & 8 & 47.06 \\
\hline $\begin{array}{l}\text { 2. Do you know how to interpret } \\
\text { it? }\end{array}$ & 6 & 60.00 & 9 & 56.25 & 12 & 54.55 & 4 & 17.39 & 7 & 41.18 \\
\hline $\begin{array}{l}\text { 3. Were you aware if there were } \\
\text { any lectures on Early Warning } \\
\text { Systems in your community? }\end{array}$ & 6 & 60.00 & 10 & 62.50 & 11 & 50.00 & 4 & 17.39 & 5 & 29.41 \\
\hline $\begin{array}{l}\text { 4. Were you aware if there were } \\
\text { any drills on Early Warning } \\
\text { Systems in your community? }\end{array}$ & 5 & 50.00 & 5 & 31.25 & 13 & 59.09 & 2 & 8.70 & 3 & 17.65 \\
\hline $\begin{array}{l}\text { 5. Do you know about the } \\
\text { information drive on flood } \\
\text { prevention spread around in your } \\
\text { community? }\end{array}$ & 10 & 100.00 & 11 & 68.75 & 20 & 90.91 & 5 & 21.74 & 9 & 52.94 \\
\hline Item Summary & Mean & S.D. & Mean & S.D. & Mean & S.D. & Mean & S.D. & Mean & S.D. \\
\hline Mean Score & 3.40 & 1.65 & 2.50 & 1.75 & 2.95 & 1.81 & 2.39 & 1.73 & 1.88 & 1.80 \\
\hline Percentage Score & 68.00 & 32.93 & 60.00 & 35.02 & 59.09 & 36.24 & 47.83 & 34.50 & 37.65 & 35.97 \\
\hline
\end{tabular}


Community-Based Flood Vulnerability Index for Urban Flooding: Understanding

Social Vulnerabilities and Risks

Flood Resilience: KNOWLEDGE ... continued

\begin{tabular}{|c|c|c|c|c|c|c|c|c|c|c|}
\hline \multirow{2}{*}{$\begin{array}{l}\text { Item: PREPAREDNESS } \\
\text { Questions }\end{array}$} & \multicolumn{2}{|c|}{ Barangay 2} & \multicolumn{2}{|c|}{ Poblacion 8} & \multicolumn{2}{|c|}{ Cadawinonan } & \multicolumn{2}{|c|}{ Bagacay } & \multicolumn{2}{|c|}{ Taclobo } \\
\hline & $\mathbf{F}$ & $\%$ & $\mathbf{F}$ & $\%$ & $\mathbf{F}$ & $\%$ & $\mathbf{F}$ & $\%$ & $\mathbf{F}$ & $\%$ \\
\hline $\begin{array}{l}\text { 1. Have you heard about the } \\
\text { presence of flood early warning } \\
\text { systems in your community? }\end{array}$ & 9 & 56.25 & 23 & 79.31 & 19 & 79.17 & 24 & 80.00 & 37 & 60.66 \\
\hline $\begin{array}{l}\text { 2. Do you know how to interpret } \\
\text { it? }\end{array}$ & 8 & 50.00 & 20 & 68.97 & 15 & 62.50 & 17 & 56.67 & 44 & 72.13 \\
\hline $\begin{array}{l}\text { 3. Were you aware if there were } \\
\text { any lectures on Early Warning } \\
\text { Systems in your community? }\end{array}$ & 7 & 43.75 & 18 & 62.07 & 12 & 50.00 & 16 & 53.33 & 28 & 45.90 \\
\hline $\begin{array}{l}\text { 4. Were you aware if there were } \\
\text { any drills on Early Warning } \\
\text { Systems in your community? }\end{array}$ & 6 & 37.50 & 21 & 72.41 & 11 & 45.83 & 12 & 40.00 & 20 & 32.79 \\
\hline $\begin{array}{l}\text { 5. Do you know about the } \\
\text { information drive on flood } \\
\text { prevention spread around in your } \\
\text { community? }\end{array}$ & 11 & 68.75 & 25 & 86.21 & 18 & 75.00 & 19 & 63.33 & 36 & 59.02 \\
\hline Item Summary & Mean & S.D. & Mean & S.D. & Mean & S.D. & Mean & S.D. & Mean & S.D. \\
\hline Mean Score & 2.56 & 1.79 & 3.69 & 1.69 & 3.00 & 1.85 & 2.93 & 1.48 & 2.62 & 1.61 \\
\hline Percentage Score & 51.25 & 35.75 & 73.79 & 33.85 & 60.00 & 36.97 & 58.67 & 29.68 & 52.38 & 32.21 \\
\hline
\end{tabular}


Community-Based Flood Vulnerability Index for Urban Flooding: Understanding Social Vulnerabilities and Risks

Flood Resilience: KNOWLEDGE ... continued

\begin{tabular}{|l|c|c|c|c|c|c|}
\hline \multicolumn{1}{|c|}{ Item: PREPAREDNESS } & \multicolumn{2}{|c|}{ Candau-ay } & \multicolumn{2}{c|}{ Batinguel } & \multicolumn{2}{c|}{ Overall } \\
\hline Questions & F & $\%$ & F & $\%$ & F & $\%$ \\
\hline $\begin{array}{l}\text { 1. Have you heard about the } \\
\text { presence of flood early warning } \\
\text { systems in your community? }\end{array}$ & 52 & 72.22 & 33 & 86.84 & 238 & 65.93 \\
\hline $\begin{array}{l}\text { 2. Do you know how to } \\
\text { interpret it? }\end{array}$ & 52 & 72.22 & 31 & 81.58 & 225 & 62.33 \\
\hline $\begin{array}{l}\text { 3. Were you aware if there } \\
\text { were any lectures on Early } \\
\text { Warning Systems in your } \\
\text { community? }\end{array}$ & 37 & 51.39 & 19 & 50.00 & 173 & 47.92 \\
\hline $\begin{array}{l}\text { 4. Were you aware if there } \\
\text { were any drills on Early } \\
\text { Warning Systems in your } \\
\text { community? }\end{array}$ & 40 & 55.56 & 16 & 42.11 & 154 & 42.66 \\
\hline $\begin{array}{l}\text { 5. Do you know about the } \\
\text { information drive on flood } \\
\text { prevention spread around in } \\
\text { your community? }\end{array}$ & 50 & 69.44 & 28 & 73.68 & 242 & 67.04 \\
\hline Item Summary & Mean & S.D. & Mean & S.D. & Mean & S.D. \\
\hline Mean Score & 3.21 & 1.89 & 3.34 & 1.66 & 2.96 & 1.76 \\
\hline Percentage Score & 64.17 & 37.82 & 66.84 & 33.30 & 59.17 & 35.16 \\
\hline
\end{tabular}


Community-Based Flood Vulnerability Index for Urban Flooding: Understanding

Social Vulnerabilities and Risks

Flood Resilience: KNOWLEDGE ... continued

\begin{tabular}{|c|c|c|c|c|c|c|c|c|c|c|}
\hline \multirow{2}{*}{$\begin{array}{c}\text { Source of Preparedness } \\
\text { Information }\end{array}$} & \multicolumn{2}{|c|}{ Tabuc-tubig } & \multicolumn{2}{|c|}{ Junob } & \multicolumn{2}{|c|}{ Poblacion 1} & \multicolumn{2}{|c|}{ Calindagan } & \multicolumn{2}{|c|}{ Balugo } \\
\hline & $\mathbf{F}$ & $\%$ & $\mathbf{F}$ & $\%$ & $\mathbf{F}$ & $\%$ & $\mathbf{F}$ & $\%$ & $\mathbf{F}$ & $\%$ \\
\hline Own family & 0 & 0.00 & 2 & 12.50 & 1 & 4.55 & 0 & 0.00 & 0 & 0.00 \\
\hline Other villagers & 1 & 10.00 & 1 & 6.25 & 1 & 4.55 & 0 & 0.00 & 1 & 5.88 \\
\hline NGO worker & 0 & 0.00 & 1 & 6.25 & 0 & 0.00 & 0 & 0.00 & 0 & 0.00 \\
\hline LGU's & 1 & 10.00 & 0 & 0.00 & 3 & 13.64 & 1 & 4.35 & 1 & 5.88 \\
\hline Health Center & 1 & 10.00 & 2 & 12.50 & 2 & 9.09 & 1 & 4.35 & 1 & 5.88 \\
\hline Barangay Officials & 5 & 50.00 & 6 & 37.50 & 10 & 45.45 & 7 & 30.43 & 4 & 23.53 \\
\hline Barangay Health Workers & 1 & 10.00 & 2 & 12.50 & 1 & 4.55 & 4 & 17.39 & 2 & 11.76 \\
\hline Physicians/Nurses/ Pharmacist & 0 & 0.00 & 1 & 6.25 & 3 & 13.64 & 2 & 8.70 & 1 & 5.88 \\
\hline School/Teachers & 1 & 10.00 & 0 & 0.00 & 0 & 0.00 & 1 & 4.35 & 1 & 5.88 \\
\hline Religious Groups & 3 & 30.00 & 4 & 25.00 & 9 & 40.91 & 8 & 34.78 & 3 & 17.65 \\
\hline TV & 1 & 10.00 & 6 & 37.50 & 8 & 36.36 & 5 & 21.74 & 4 & 23.53 \\
\hline Radio & 1 & 10.00 & 4 & 25.00 & 1 & 4.55 & 1 & 4.35 & 3 & 17.65 \\
\hline Newspaper/Magazines & 0 & 0.00 & 0 & 0.00 & 0 & 0.00 & 0 & 0.00 & 0 & 0.00 \\
\hline Billboard & 0 & 0.00 & 0 & 0.00 & 0 & 0.00 & 0 & 0.00 & 0 & 0.00 \\
\hline
\end{tabular}


Community-Based Flood Vulnerability Index for Urban Flooding: Understanding

Social Vulnerabilities and Risks

Flood Resilience: KNOWLEDGE ... continued

\begin{tabular}{|c|c|c|c|c|c|c|c|c|c|c|}
\hline \multirow{2}{*}{$\begin{array}{l}\text { Source of Preparedness } \\
\text { Information }\end{array}$} & \multicolumn{2}{|c|}{ Barangay 2} & \multicolumn{2}{|c|}{ Poblacion 8} & \multicolumn{2}{|c|}{ Cadawinonan } & \multicolumn{2}{|c|}{ Bagacay } & \multicolumn{2}{|c|}{ Taclobo } \\
\hline & $\mathbf{F}$ & $\%$ & $\mathbf{F}$ & $\%$ & $F$ & $\%$ & $F$ & $\%$ & $F$ & $\%$ \\
\hline Own family & 0 & 0.00 & 1 & 3.45 & 2 & 8.33 & 1 & 3.33 & 3 & 4.92 \\
\hline Other villagers & 2 & 12.50 & 2 & 6.90 & 4 & 16.67 & 2 & 6.67 & 4 & 6.56 \\
\hline NGO worker & 2 & 12.50 & 4 & 13.79 & 3 & 12.50 & 1 & 3.33 & 7 & 11.48 \\
\hline LGU'S & 0 & 0.00 & 4 & 13.79 & 6 & 25.00 & 3 & 10.00 & 0 & 0.00 \\
\hline Health Center & 1 & 6.25 & 5 & 17.24 & 6 & 25.00 & 3 & 10.00 & 5 & 8.20 \\
\hline Barangay Officials & 6 & 37.50 & 19 & 65.52 & 8 & 33.33 & 5 & 16.67 & 14 & 22.95 \\
\hline Barangay Health Workers & 3 & 18.75 & 3 & 10.34 & 1 & 4.17 & 3 & 10.00 & 6 & 9.84 \\
\hline Physicians/Nurses/ Pharmacist & 2 & 12.50 & 3 & 10.34 & 4 & 16.67 & 3 & 10.00 & 5 & 8.20 \\
\hline School/Teachers & 1 & 6.25 & 0 & 0.00 & 1 & 4.17 & 3 & 10.00 & 4 & 6.56 \\
\hline Religious Groups & 2 & 12.50 & 5 & 17.24 & 8 & 33.33 & 6 & 20.00 & 12 & 19.67 \\
\hline TV & 2 & 12.50 & 4 & 13.79 & 7 & 29.17 & 7 & 23.33 & 14 & 22.95 \\
\hline Radio & 1 & 6.25 & 1 & 3.45 & 2 & 8.33 & 2 & 6.67 & 6 & 9.84 \\
\hline Newspaper/Magazines & 0 & 0.00 & 1 & 3.45 & 1 & 4.17 & 0 & 0.00 & 0 & 0.00 \\
\hline Billboard & 0 & 0.00 & 0 & 0.00 & 0 & 0.00 & 0 & 0.00 & 0 & 0.00 \\
\hline
\end{tabular}


Community-Based Flood Vulnerability Index for Urban Flooding: Understanding Social Vulnerabilities and Risks

Flood Resilience: KNOWLEDGE ... continued

\begin{tabular}{|c|c|c|c|c|c|c|}
\hline \multirow{2}{*}{$\begin{array}{l}\text { Source of Preparedness } \\
\text { Information }\end{array}$} & \multicolumn{2}{|c|}{ Candau-ay } & \multicolumn{2}{|c|}{ Batinguel } & \multicolumn{2}{|c|}{ Overall } \\
\hline & $\mathbf{F}$ & $\%$ & $\mathbf{F}$ & $\%$ & $\mathbf{F}$ & $\%$ \\
\hline Own family & 8 & 11.11 & 5 & 13.16 & 23 & 6.37 \\
\hline Other villagers & 6 & 8.33 & 3 & 7.89 & 27 & 7.48 \\
\hline NGO worker & 13 & 18.06 & 7 & 18.42 & 38 & 10.53 \\
\hline LGU's & 11 & 15.28 & 4 & 10.53 & 34 & 9.42 \\
\hline Health Center & 12 & 16.67 & 5 & 13.16 & 44 & 12.19 \\
\hline Barangay Officials & 31 & 43.06 & 13 & 34.21 & 128 & 35.46 \\
\hline Barangay Health Workers & 18 & 25.00 & 6 & 15.79 & 50 & 13.85 \\
\hline $\begin{array}{l}\text { Physicians/Nurses/ } \\
\text { Pharmacist }\end{array}$ & 9 & 12.50 & 2 & 5.26 & 35 & 9.70 \\
\hline School/Teachers & 9 & 12.50 & 1 & 2.63 & 22 & 6.09 \\
\hline Religious Groups & 22 & 30.56 & 13 & 34.21 & 95 & 26.32 \\
\hline TV & 23 & 31.94 & 10 & 26.32 & 91 & 25.21 \\
\hline Radio & 5 & 6.94 & 3 & 7.89 & 30 & 8.31 \\
\hline Newspaper/Magazines & 2 & 2.78 & 0 & 0.00 & 4 & 1.11 \\
\hline Billboard & 0 & 0.00 & 0 & 0.00 & 0 & 0.00 \\
\hline
\end{tabular}


Community-Based Flood Vulnerability Index for Urban Flooding: Understanding Social Vulnerabilities and Risks

Flood Resilience: KNOWLEDGE ... continued

\begin{tabular}{|c|c|c|c|c|c|c|c|c|c|c|}
\hline Item: RESPONSE & Tabuc-tul & & Junob & & Poblacior & & Calindaga & & Balugo & \\
\hline Questions & $\mathbf{F}$ & $\%$ & $\mathbf{F}$ & $\%$ & $\mathbf{F}$ & $\%$ & $\mathbf{F}$ & $\%$ & $\mathbf{F}$ & $\%$ \\
\hline $\begin{array}{l}\text { 1. Are you aware that we have a } \\
\text { local emergency response group } \\
\text { in our community and city? }\end{array}$ & 9 & 90.00 & 11 & 68.75 & 18 & 81.82 & 7 & 30.43 & 12 & 70.59 \\
\hline $\begin{array}{l}\text { 2. Do you know the locations of } \\
\text { the evacuation centers? }\end{array}$ & 10 & 100.00 & 13 & 81.25 & 16 & 72.73 & 5 & 21.74 & 7 & 41.18 \\
\hline Item Summary & Mean & S.D. & Mean & S.D. & Mean & S.D. & Mean & S.D. & Mean & S.D. \\
\hline Mean Score & 1.90 & 0.32 & 1.30 & 0.82 & 1.55 & 0.67 & 1.48 & 0.85 & 1.12 & 0.78 \\
\hline Percentage Score & 95.00 & 15.81 & 75.00 & 40.82 & 77.27 & 33.55 & 73.91 & 42.29 & 55.88 & 39.06 \\
\hline
\end{tabular}

\begin{tabular}{|c|c|c|c|c|c|c|c|c|c|c|}
\hline \multirow{2}{*}{$\begin{array}{l}\text { Item: RESPONSE } \\
\text { Questions }\end{array}$} & \multicolumn{2}{|c|}{ Barangay 2} & \multicolumn{2}{|c|}{ Poblacion 8} & \multicolumn{2}{|c|}{ Cadawinonan } & \multicolumn{2}{|c|}{ Bagacay } & \multicolumn{2}{|c|}{ Taclobo } \\
\hline & $\mathbf{F}$ & $\%$ & $\mathbf{F}$ & $\%$ & $\mathbf{F}$ & $\%$ & $\mathbf{F}$ & $\%$ & $\mathbf{F}$ & $\%$ \\
\hline $\begin{array}{l}\text { 1. Are you aware that we have a } \\
\text { local emergency response group } \\
\text { in our community and city? }\end{array}$ & 12 & 75.00 & 24 & 82.76 & 21 & 87.50 & 26 & 86.67 & 49 & 80.33 \\
\hline $\begin{array}{l}\text { 2. Do you know the locations of } \\
\text { the evacuation centers? }\end{array}$ & 12 & 75.00 & 25 & 86.21 & 20 & 83.33 & 21 & 70.00 & 46 & 75.41 \\
\hline Item Summary & Mean & S.D. & Mean & S.D. & Mean & S.D. & Mean & S.D. & Mean & S.D. \\
\hline Mean Score & 1.50 & 0.82 & 1.69 & 0.60 & 1.64 & 0.70 & 1.57 & 0.63 & 1.51 & 0.72 \\
\hline Percentage Score & 75.00 & 40.82 & 84.48 & 30.19 & 82.00 & 35.00 & 78.33 & 31.30 & 75.40 & 35.78 \\
\hline
\end{tabular}


Community-Based Flood Vulnerability Index for Urban Flooding: Understanding Social Vulnerabilities and Risks

Flood Resilience: KNOWLEDGE ... continued

\begin{tabular}{|l|r|r|r|r|r|c|}
\hline \multicolumn{1}{|c|}{ Item: RESPONSE } & \multicolumn{2}{|c|}{ Candau-ay } & \multicolumn{2}{c|}{ Batinguel } & \multicolumn{2}{c|}{ Overall } \\
\hline Questions & \multicolumn{1}{c|}{ F } & \multicolumn{1}{c|}{ \% } & F & \multicolumn{1}{c|}{$\%$} & F & \multicolumn{1}{c|}{$\%$} \\
\hline $\begin{array}{l}\text { 1. Are you aware that we have } \\
\text { a local emergency response } \\
\text { group in our community and } \\
\text { city? }\end{array}$ & 51 & 70.83 & 29 & 76.32 & 269 & 74.52 \\
\hline $\begin{array}{l}\text { 2. Do you know the locations of } \\
\text { the evacuation centers? }\end{array}$ & 57 & 79.17 & 31 & 81.58 & 263 & 72.85 \\
\hline Item Summary & Mean & S.D. & Mean & S.D. & Mean & S.D. \\
\hline Mean Score & 1.50 & 0.79 & 1.58 & 0.68 & 1.53 & 0.72 \\
\hline Percentage Score & 75.00 & 39.36 & 78.95 & 34.15 & 76.73 & 36.11 \\
\hline
\end{tabular}


Community-Based Flood Vulnerability Index for Urban Flooding: Understanding

Social Vulnerabilities and Risks

Flood Resilience: KNOWLEDGE ... continued

\begin{tabular}{|c|c|c|c|c|c|c|c|c|c|c|}
\hline \multirow{2}{*}{$\begin{array}{l}\text { Item: RECOVERY } \\
\text { Questions }\end{array}$} & \multicolumn{2}{|c|}{ Tabuc-tubig } & \multicolumn{2}{|c|}{ Junob } & \multicolumn{2}{|c|}{ Poblacion 1} & \multicolumn{2}{|c|}{ Calindagan } & \multicolumn{2}{|c|}{ Balugo } \\
\hline & $\mathbf{F}$ & $\%$ & $\mathbf{F}$ & $\%$ & $\mathbf{F}$ & $\%$ & \begin{tabular}{l|l|}
$\mathbf{F}$ \\
\end{tabular} & $\%$ & $\mathbf{F}$ & $\%$ \\
\hline $\begin{array}{l}\text { 1. Do you know how to conduct } \\
\text { yourself in the evacuation } \\
\text { centers? }\end{array}$ & 10 & 100.00 & 12 & 75.00 & 16 & 72.73 & 4 & 17.39 & 12 & 70.59 \\
\hline $\begin{array}{l}\text { 2. Are you aware of the different } \\
\text { programs of the local government } \\
\text { in times of calamities? }\end{array}$ & 10 & 100.00 & 9 & 56.25 & 16 & 72.73 & 5 & 21.74 & 10 & 58.82 \\
\hline Item Summary & Mean & S.D. & Mean & S.D. & Mean & S.D. & Mean & S.D. & Mean & S.D. \\
\hline Mean Score & 2.00 & 0.00 & 1.10 & 0.87 & 1.45 & 0.74 & 1.13 & 0.87 & 1.29 & 0.77 \\
\hline Percentage Score & 100.00 & 0.00 & 65.63 & 43.66 & 72.73 & 36.93 & 56.52 & 43.44 & 64.71 & 38.59 \\
\hline
\end{tabular}

\begin{tabular}{|c|c|c|c|c|c|c|c|c|c|c|}
\hline \multirow{2}{*}{$\begin{array}{l}\text { Item: RECOVERY } \\
\text { Questions }\end{array}$} & \multicolumn{2}{|c|}{ Barangay 2} & \multicolumn{2}{|c|}{ Poblacion 8} & \multicolumn{2}{|c|}{ Cadawinonan } & \multicolumn{2}{|c|}{ Bagacay } & \multicolumn{2}{|c|}{ Taclobo } \\
\hline & $\mathbf{F}$ & $\%$ & $\mathbf{F}$ & $\%$ & $\mathbf{F}$ & $\%$ & \begin{tabular}{l|l}
$\mathbf{F}$ \\
\end{tabular} & $\%$ & $\mathbf{F}$ & $\%$ \\
\hline $\begin{array}{l}\text { 1. Do you know how to conduct } \\
\text { yourself in the evacuation } \\
\text { centers? }\end{array}$ & 13 & 81.25 & 24 & 82.76 & 23 & 95.83 & 23 & 76.67 & 56 & 91.80 \\
\hline $\begin{array}{l}\text { 2. Are you aware of the different } \\
\text { programs of the local government } \\
\text { in times of calamities? }\end{array}$ & 8 & 50.00 & 21 & 72.41 & 17 & 70.83 & 19 & 63.33 & 41 & 67.21 \\
\hline Item Summary & Mean & S.D. & Mean & S.D. & Mean & S.D. & Mean & S.D. & Mean & S.D. \\
\hline Mean Score & 1.31 & 0.79 & 1.55 & 0.78 & 1.60 & 0.65 & 1.40 & 0.81 & 1.54 & 0.64 \\
\hline Percentage Score & 65.63 & 39.66 & 77.59 & 39.16 & 80.00 & 32.27 & 70.00 & 40.68 & 76.98 & 32.16 \\
\hline
\end{tabular}


Community-Based Flood Vulnerability Index for Urban Flooding: Understanding Social Vulnerabilities and Risks

Flood Resilience: KNOWLEDGE ... continued

\begin{tabular}{|l|r|r|r|r|r|r|}
\hline \multicolumn{1}{|c|}{ Item: RECOVERY } & \multicolumn{2}{c|}{ Candau-ay } & \multicolumn{2}{c|}{ Batinguel } & \multicolumn{2}{c|}{ Overall } \\
\hline Questions & F & \multicolumn{1}{c|}{ \% } & F & \multicolumn{1}{c|}{ \% } & \\
\hline $\begin{array}{l}\text { 1. Do you know how to conduct } \\
\text { yourself in the evacuation } \\
\text { centers? }\end{array}$ & 58 & 80.56 & 34 & 89.47 & 285 & 78.95 \\
\hline $\begin{array}{l}\text { 2. Are you aware of the } \\
\text { different programs of the local } \\
\text { government in times of } \\
\text { calamities? }\end{array}$ & 45 & 62.50 & 31 & 81.58 & 232 & 64.27 \\
\hline $\begin{array}{l}\text { Item Summary } \\
\text { Mean Score }\end{array}$ & Mean & S.D. & Mean & S.D. & Mean & S.D. \\
\hline Percentage Score & 71.43 & 0.78 & 1.71 & 0.52 & 1.48 & 0.73 \\
\hline
\end{tabular}

Flood Resilience: KNOWLEDGE ... continued

\begin{tabular}{|c|c|c|c|c|c|c|c|c|c|c|}
\hline Item: COORDINATION & \multicolumn{2}{|c|}{ Tabuc-tubig } & \multicolumn{2}{|c|}{ Junob } & \multicolumn{2}{|c|}{ Poblacion 1} & \multicolumn{2}{|c|}{ Calindagan } & \multicolumn{2}{|c|}{ Balugo } \\
\hline Questions & $\mathbf{F}$ & $\%$ & $\mathbf{F}$ & $\%$ & $\mathbf{F}$ & $\%$ & $\mathbf{F}$ & $\%$ & $\mathbf{F}$ & $\%$ \\
\hline $\begin{array}{l}\text { 1. Are you aware that the } \\
\text { emergency response team and } \\
\text { the rest of the units work in a } \\
\text { coordinated manner? }\end{array}$ & 9 & 90.00 & 11 & 68.75 & 16 & 72.73 & 5 & 21.74 & 12 & 70.59 \\
\hline $\begin{array}{l}\text { 2. Do you know the Standard } \\
\text { Operating Procedures during } \\
\text { response and evacuations events } \\
\text { so coordination is facilitated? }\end{array}$ & 8 & 80.00 & 10 & 62.50 & 16 & 72.73 & 5 & 21.74 & 7 & 41.18 \\
\hline Item Summary & Mean & S.D. & Mean & S.D. & Mean & S.D. & Mean & S.D. & Mean & S.D. \\
\hline Mean Score & 1.70 & 0.48 & 1.10 & 0.87 & 1.45 & 0.74 & 1.09 & 0.95 & 1.12 & 0.78 \\
\hline Percentage Score & 85.00 & 24.15 & 65.63 & 43.66 & 72.73 & 36.93 & 54.35 & 47.47 & 55.88 & 39.06 \\
\hline
\end{tabular}


Community-Based Flood Vulnerability Index for Urban Flooding: Understanding

Social Vulnerabilities and Risks

Flood Resilience: KNOWLEDGE ... continued

\begin{tabular}{|c|c|c|c|c|c|c|c|c|c|c|}
\hline \multirow{2}{*}{$\begin{array}{l}\text { Item: COORDINATION } \\
\text { Questions }\end{array}$} & \multicolumn{2}{|c|}{ Barangay 2} & \multicolumn{2}{|c|}{ Poblacion 8} & \multicolumn{2}{|c|}{ Cadawinonan } & \multicolumn{2}{|c|}{ Bagacay } & \multicolumn{2}{|c|}{ Taclobo } \\
\hline & $\mathbf{F}$ & $\%$ & $\mathbf{F}$ & $\%$ & $\mathbf{F}$ & $\%$ & $\mathbf{F}$ & $\%$ & $\mathbf{F}$ & $\%$ \\
\hline $\begin{array}{l}\text { 1. Are you aware that the } \\
\text { emergency response team and } \\
\text { the rest of the units work in a } \\
\text { coordinated manner? }\end{array}$ & 11 & 68.75 & 21 & 72.41 & 20 & 83.33 & 19 & 63.33 & 43 & 70.49 \\
\hline $\begin{array}{l}\text { 2. Do you know the Standard } \\
\text { Operating Procedures during } \\
\text { response and evacuations events } \\
\text { so coordination is facilitated? }\end{array}$ & 11 & 68.75 & 20 & 68.97 & 18 & 75.00 & 16 & 53.33 & 41 & 67.21 \\
\hline Item Summary & Mean & S.D. & Mean & S.D. & Mean & S.D. & Mean & S.D. & Mean & S.D. \\
\hline Mean Score & 1.38 & 0.89 & 1.41 & 0.82 & 1.52 & 0.71 & 1.17 & 0.83 & 1.33 & 0.82 \\
\hline Percentage Score & 68.75 & 44.25 & 70.69 & 41.23 & 76.00 & 35.71 & 58.33 & 41.70 & 66.67 & 41.15 \\
\hline
\end{tabular}


Community-Based Flood Vulnerability Index for Urban Flooding: Understanding Social Vulnerabilities and Risks

Flood Resilience: KNOWLEDGE ... continued

\begin{tabular}{|c|c|c|c|c|c|c|}
\hline Item: COORDINATION & Cand & I-ay & Bati & uel & Ov & \\
\hline Questions & $\mathbf{F}$ & $\%$ & $\mathbf{F}$ & $\%$ & $\mathbf{F}$ & $\%$ \\
\hline $\begin{array}{l}\text { 1. Are you aware that the } \\
\text { emergency response team and } \\
\text { the rest of the units work in a } \\
\text { coordinated manner? }\end{array}$ & 46 & 63.89 & 30 & 78.95 & 243 & 67.31 \\
\hline $\begin{array}{l}\text { 2. Do you know the Standard } \\
\text { Operating Procedures during } \\
\text { response and evacuations } \\
\text { events so coordination is } \\
\text { facilitated? }\end{array}$ & 48 & 66.67 & 26 & 68.42 & 226 & 62.60 \\
\hline Item Summary & Mean & S.D. & Mean & S.D. & Mean & S.D. \\
\hline Mean Score & 1.31 & 65.28 & 1.47 & 0.76 & 1.34 & 0.81 \\
\hline Percentage Score & 0.85 & 42.49 & 73.68 & 38.09 & 67.04 & 40.75 \\
\hline
\end{tabular}


Community-Based Flood Vulnerability Index for Urban Flooding: Understanding

Social Vulnerabilities and Risks

\section{Flood Resilience: KNOWLEDGE PERCENT SCORE SUMMARY}

\begin{tabular}{|c|c|c|c|c|c|c|c|c|c|c|}
\hline \multirow{2}{*}{ Items } & \multicolumn{2}{|c|}{ Tabuc-tubig } & \multicolumn{2}{|c|}{ Junob } & \multicolumn{2}{|c|}{ Poblacion 1} & \multicolumn{2}{|c|}{ Calindagan } & \multicolumn{2}{|c|}{ Balugo } \\
\hline & Mean & S.D. & Mean & S.D. & Mean & S.D. & Mean & S.D. & Mean & S.D. \\
\hline Hazard & 76.67 & 21.08 & 71.88 & 19.92 & 73.48 & 22.81 & 72.46 & 28.25 & 50.00 & 26.35 \\
\hline Risk & 85.00 & 21.08 & 82.81 & 19.83 & 67.05 & 24.86 & 76.09 & 21.95 & 58.82 & 30.54 \\
\hline Exposure & 56.67 & 28.54 & 62.50 & 19.72 & 54.55 & 22.53 & 34.06 & 17.75 & 37.25 & 30.92 \\
\hline Preparedness & 68.00 & 32.93 & 60.00 & 35.02 & 59.09 & 36.24 & 47.83 & 34.50 & 37.65 & 35.97 \\
\hline Response & 95.00 & 15.81 & 75.00 & 40.82 & 77.27 & 33.55 & 73.91 & 42.29 & 55.88 & 39.06 \\
\hline Recovery & 100.00 & 0.00 & 65.63 & 43.66 & 72.73 & 36.93 & 56.52 & 43.44 & 64.71 & 38.59 \\
\hline Coordination & 85.00 & 24.15 & 65.63 & 43.66 & 72.73 & 36.93 & 54.35 & 47.47 & 55.88 & 39.06 \\
\hline Adaptation Strategies & 80.00 & 42.16 & 68.75 & 47.87 & 45.45 & 50.96 & 30.43 & 47.05 & 47.06 & 51.45 \\
\hline Overall & 80.79 & 13.99 & 69.02 & 7.38 & 65.29 & 11.16 & 55.71 & 17.73 & 50.91 & 9.86 \\
\hline
\end{tabular}

\begin{tabular}{|c|c|c|c|c|c|c|c|c|c|c|}
\hline \multirow{2}{*}{ Items } & \multicolumn{2}{|c|}{ Barangay 2} & \multicolumn{2}{|c|}{ Poblacion 8} & \multicolumn{2}{|c|}{ Cadawinonan } & \multicolumn{2}{|c|}{ Bagacay } & \multicolumn{2}{|c|}{ Taclobo } \\
\hline & Mean & S.D. & Mean & S.D. & Mean & S.D. & Mean & S.D. & Mean & S.D. \\
\hline Hazard & 83.33 & 23.57 & 87.93 & 15.36 & 72.00 & 22.93 & 69.44 & 16.43 & 70.11 & 25.78 \\
\hline Risk & 75.00 & 24.15 & 75.86 & 24.53 & 79.00 & 27.65 & 74.17 & 25.83 & 78.17 & 22.67 \\
\hline Exposure & 56.25 & 23.47 & 65.52 & 24.37 & 44.67 & 22.93 & 56.11 & 21.21 & 44.18 & 23.79 \\
\hline Preparedness & 51.25 & 35.75 & 73.79 & 33.85 & 60.00 & 36.97 & 58.67 & 29.68 & 52.38 & 32.21 \\
\hline Response & 75.00 & 40.82 & 84.48 & 30.19 & 82.00 & 35.00 & 78.33 & 31.30 & 75.40 & 35.78 \\
\hline Recovery & 65.63 & 39.66 & 77.59 & 39.16 & 80.00 & 32.27 & 70.00 & 40.68 & 76.98 & 32.16 \\
\hline Coordination & 68.75 & 44.25 & 70.69 & 41.23 & 76.00 & 35.71 & 58.33 & 41.70 & 66.67 & 41.15 \\
\hline Adaptation Strategies & 62.50 & 50.00 & 68.97 & 47.08 & 72.00 & 45.83 & 36.67 & 49.01 & 55.56 & 50.09 \\
\hline Overall & 67.21 & 10.58 & 75.60 & 7.63 & 70.71 & 12.57 & 62.72 & 13.26 & 64.93 & 12.74 \\
\hline
\end{tabular}


Community-Based Flood Vulnerability Index for Urban Flooding: Understanding Social Vulnerabilities and Risks

\begin{tabular}{|l|r|r|r|r|r|r|}
\hline \multirow{2}{*}{ Items } & \multicolumn{2}{|c|}{ Candau-ay } & \multicolumn{2}{c|}{ Batinguel } & \multicolumn{2}{c|}{ Overall } \\
\cline { 2 - 7 } & \multicolumn{1}{c|}{ Mean } & \multicolumn{1}{c|}{ S.D. } & \multicolumn{1}{c|}{ Mean } & \multicolumn{1}{c|}{ S.D. } & \multicolumn{1}{c|}{ Mean } & \multicolumn{1}{c|}{ S.D. } \\
\hline Hazard & 75.00 & 25.94 & 75.44 & 24.43 & 73.41 & 24.42 \\
\hline Risk & 80.21 & 40.88 & 76.97 & 22.80 & 76.52 & 28.46 \\
\hline Exposure & 50.69 & 24.30 & 63.60 & 20.45 & 51.62 & 24.65 \\
\hline Preparedness & 64.17 & 37.82 & 66.84 & 33.30 & 59.17 & 35.16 \\
\hline Response & 75.00 & 39.36 & 78.95 & 34.15 & 76.73 & 36.11 \\
\hline Recovery & 71.53 & 39.21 & 85.53 & 25.75 & 73.96 & 36.71 \\
\hline Coordination & 65.28 & 42.49 & 73.68 & 38.09 & 67.04 & 40.75 \\
\hline Adaptation Strategies & 51.39 & 50.33 & 55.26 & 50.39 & 54.29 & 49.88 \\
\hline Overall & 66.66 & 10.97 & 72.03 & 9.62 & 66.59 & 10.23 \\
\hline
\end{tabular}

Flood Resilience: ATTITUDE PERCENT SCORE SUMMARY

\begin{tabular}{|c|c|c|c|c|c|c|c|c|c|c|}
\hline \multirow{2}{*}{ Items } & \multicolumn{2}{|c|}{ Tabuc-tubig } & \multicolumn{2}{|c|}{ Junob } & \multicolumn{2}{|c|}{ Poblacion 1} & \multicolumn{2}{|c|}{ Calindagan } & \multicolumn{2}{|c|}{ Balugo } \\
\hline & Mean & S.D. & Mean & S.D. & Mean & S.D. & Mean & S.D. & Mean & S.D. \\
\hline Hazard & 3.50 & 0.71 & 2.75 & 1.18 & 3.05 & 0.84 & 3.04 & 0.98 & 2.94 & 0.97 \\
\hline Risk & 2.60 & 1.17 & 3.00 & 0.97 & 3.18 & 0.80 & 3.04 & 1.11 & 3.00 & 1.00 \\
\hline Exposure & 2.40 & 1.07 & 2.56 & 1.15 & 3.18 & 0.80 & 2.74 & 1.05 & 2.71 & 1.16 \\
\hline Preparedness & 3.30 & 0.95 & 3.25 & 1.00 & 3.10 & 0.89 & 3.04 & 1.02 & 3.06 & 0.90 \\
\hline Response & 3.60 & 0.52 & 3.25 & 0.77 & 3.41 & 0.80 & 3.09 & 1.04 & 3.25 & 0.77 \\
\hline Recovery & 3.50 & 0.71 & 3.38 & 0.81 & 3.27 & 0.77 & 3.17 & 1.03 & 3.24 & 0.90 \\
\hline Coordination & 3.50 & 0.53 & 3.38 & 0.72 & 3.36 & 0.73 & 2.96 & 1.02 & 2.94 & 1.03 \\
\hline Adaptation Strategies & 3.00 & 1.05 & 3.19 & 0.75 & 3.00 & 0.82 & 2.68 & 0.95 & 2.71 & 1.05 \\
\hline \multicolumn{11}{|l|}{ Overall } \\
\hline Mean Score & 3.18 & 0.46 & 3.09 & 0.30 & 3.19 & 0.15 & 2.97 & 0.17 & 2.98 & 0.21 \\
\hline Mean Percent Score & 79.38 & 12.94 & 77.34 & 12.42 & 79.40 & 14.99 & 73.91 & 22.94 & 73.90 & 18.55 \\
\hline
\end{tabular}


Community-Based Flood Vulnerability Index for Urban Flooding: Understanding

Social Vulnerabilities and Risks

Flood Resilience: ATTITUDE PERCENT SCORE SUMMARY . . continued

\begin{tabular}{|c|c|c|c|c|c|c|c|c|c|c|}
\hline \multirow{2}{*}{ Items } & \multicolumn{2}{|c|}{ Barangay 2} & \multicolumn{2}{|c|}{ Poblacion 8} & \multicolumn{2}{|c|}{ Cadawinonan } & \multicolumn{2}{|c|}{ Bagacay } & \multicolumn{2}{|c|}{ Taclobo } \\
\hline & Mean & S.D. & Mean & S.D. & Mean & S.D. & Mean & S.D. & Mean & S.D. \\
\hline Hazard & 3.38 & 0.81 & 2.93 & 1.04 & 3.20 & 1.00 & 2.67 & 1.15 & 2.83 & 1.14 \\
\hline Risk & 3.25 & 0.86 & 2.75 & 0.97 & 3.20 & 0.91 & 2.62 & 1.21 & 2.81 & 1.08 \\
\hline Exposure & 3.15 & 1.07 & 2.85 & 0.95 & 3.13 & 1.12 & 2.41 & 1.09 & 2.81 & 1.02 \\
\hline Preparedness & 3.38 & 0.62 & 2.89 & 1.03 & 3.32 & 0.90 & 2.80 & 1.13 & 2.80 & 0.96 \\
\hline Response & 3.50 & 0.82 & 3.14 & 1.01 & 3.20 & 1.00 & 2.87 & 1.11 & 3.14 & 0.95 \\
\hline Recovery & 3.38 & 0.89 & 3.11 & 0.96 & 3.36 & 0.91 & 2.70 & 1.09 & 3.06 & 0.95 \\
\hline Coordination & 3.06 & 1.00 & 3.00 & 1.02 & 3.04 & 1.02 & 2.77 & 0.97 & 2.90 & 1.01 \\
\hline Adaptation Strategies & 3.19 & 0.75 & 2.93 & 1.04 & 3.08 & 1.10 & 2.70 & 0.95 & 2.89 & 1.01 \\
\hline \multicolumn{11}{|l|}{ Overall } \\
\hline Mean Score & 3.28 & 0.15 & 2.95 & 0.13 & 3.19 & 0.11 & 2.69 & 0.14 & 2.91 & 0.13 \\
\hline Mean Percent Score & 80.27 & 16.95 & 70.26 & 24.94 & 79.00 & 21.87 & 66.77 & 22.21 & 72.07 & 20.22 \\
\hline
\end{tabular}


Community-Based Flood Vulnerability Index for Urban Flooding: Understanding Social Vulnerabilities and Risks

Flood Resilience: ATTITUDE PERCENT SCORE SUMMARY . . . continued

\begin{tabular}{|l|r|r|r|r|r|r|}
\hline \multirow{2}{*}{ Items } & \multicolumn{2}{|c|}{ Candau-ay } & \multicolumn{2}{c|}{ Batinguel } & \multicolumn{2}{c|}{ Overall } \\
\cline { 2 - 7 } & Mean & \multicolumn{1}{c|}{ S.D. } & \multicolumn{1}{c|}{ Mean } & \multicolumn{1}{c|}{ S.D. } & \multicolumn{1}{c|}{ Mean } & \multicolumn{1}{c|}{ S.D. } \\
\hline Hazard & 2.92 & 1.16 & 3.00 & 1.14 & 2.99 & 0.24 \\
\hline Risk & 2.86 & 1.03 & 2.76 & 1.12 & 2.89 & 0.24 \\
\hline Exposure & 2.58 & 1.20 & 2.66 & 1.02 & 2.80 & 0.27 \\
\hline Preparedness & 2.91 & 1.06 & 2.97 & 1.08 & 3.01 & 0.24 \\
\hline Response & 3.09 & 0.96 & 3.22 & 1.11 & 3.16 & 0.19 \\
\hline Recovery & 3.10 & 1.07 & 3.17 & 1.06 & 3.12 & 0.23 \\
\hline Coordination & 2.93 & 1.12 & 3.00 & 1.09 & 2.96 & 0.10 \\
\hline Adaptation Strategies & 2.77 & 1.13 & 2.86 & 0.98 & 2.92 & 0.17 \\
\hline Overall & & & & & & \\
\hline \multicolumn{1}{|c|}{ Mean Score } & 2.89 & 0.17 & 2.95 & 0.19 & 2.98 & 0.12 \\
\hline Mean Percent Score & 69.62 & 24.87 & 72.62 & 21.46 & 72.94 & 4.96 \\
\hline
\end{tabular}


Community-Based Flood Vulnerability Index for Urban Flooding: Understanding Social Vulnerabilities and Risks

Flood Resilience: PRACTICE

\begin{tabular}{|c|c|c|c|c|c|c|c|c|c|c|}
\hline Item: HAZARD* & Tabuc & ibig & & & Pobla & n 1 & Calin & & $\mathrm{Ba}$ & \\
\hline Questions & $\mathbf{F}$ & $\%$ & $\mathbf{F}$ & $\%$ & $\mathbf{F}$ & $\%$ & $\mathbf{F}$ & $\%$ & $\mathbf{F}$ & $\%$ \\
\hline $\begin{array}{l}\text { If you know that your house is in a } \\
\text { flood prone area, would you still } \\
\text { continue to live there? }\end{array}$ & 5 & 50.00 & 14 & 87.50 & 6 & 27.27 & 15 & 65.22 & 12 & 70.59 \\
\hline Item Summary & Mean & S.D. & Mean & S.D. & Mean & S.D. & Mean & S.D. & Mean & S.D. \\
\hline Mean Score & 0.50 & 0.53 & 0.88 & 0.34 & 0.27 & 0.46 & 0.65 & 0.49 & 0.71 & 0.47 \\
\hline Percentage Score & 50.00 & 50.00 & 87.50 & 34.16 & 27.27 & 45.58 & 65.22 & 48.70 & 70.59 & 46.97 \\
\hline
\end{tabular}

*F values are for the "NO" answers (desirable)

\begin{tabular}{|c|c|c|c|c|c|c|c|c|c|c|}
\hline \multirow{2}{*}{$\begin{array}{l}\text { Item: HAZARD } \\
\text { Questions }\end{array}$} & \multicolumn{2}{|c|}{ Barangay 2} & \multicolumn{2}{|c|}{ Poblacion 8} & \multicolumn{2}{|c|}{ Cadawinonan } & \multicolumn{2}{|c|}{ Bagacay } & \multicolumn{2}{|c|}{ Taclobo } \\
\hline & $\mathbf{F}$ & $\%$ & $\mathbf{F}$ & $\%$ & $\mathbf{F}$ & $\%$ & $\mathbf{F}$ & $\%$ & $\mathbf{F}$ & $\%$ \\
\hline $\begin{array}{l}\text { If you know that your house is in a } \\
\text { flood prone area, would you still } \\
\text { continue to live there? }\end{array}$ & 5 & 31.25 & 8 & 27.59 & 9 & 37.50 & 23 & 76.67 & 36 & 59.02 \\
\hline Item Summary & Mean & S.D. & Mean & S.D. & Mean & S.D. & Mean & S.D. & Mean & S.D. \\
\hline Mean Score & 0.31 & 0.48 & 0.29 & 0.46 & 0.36 & 0.49 & 0.77 & 0.43 & 0.61 & 0.49 \\
\hline Percentage Score & 31.25 & 47.87 & 28.57 & 46.00 & 36.00 & 48.99 & 76.67 & 43.02 & 61.02 & 49.19 \\
\hline
\end{tabular}


Community-Based Flood Vulnerability Index for Urban Flooding: Understanding

Social Vulnerabilities and Risks

Flood Resilience: PRACTICE ... continued

\begin{tabular}{|c|c|c|c|c|c|c|}
\hline Item: HAZARD & Cand & & Bati & & Ov & \\
\hline Questions & $\mathbf{F}$ & $\%$ & $\mathbf{F}$ & $\%$ & $\mathbf{F}$ & $\%$ \\
\hline $\begin{array}{l}\text { If you know that your house is in a flood prone area, } \\
\text { would you still continue to live there? }\end{array}$ & 21 & 29.17 & 13 & 34.21 & 172 & 47.65 \\
\hline Item Summary & Mean & S.D. & Mean & S.D. & Mean & S.D. \\
\hline Mean Score & 0.30 & 0.46 & 0.34 & 0.48 & 0.47 & 0.50 \\
\hline Percentage Score & 29.58 & 45.96 & 34.21 & 48.08 & 47.04 & 49.98 \\
\hline
\end{tabular}

Reasons for not relocating

\begin{tabular}{|c|c|c|c|c|c|c|c|c|c|c|}
\hline \multirow{2}{*}{ Reasons } & \multicolumn{2}{|c|}{ Tabuc-tubig } & \multicolumn{2}{|c|}{ Junob } & \multicolumn{2}{|c|}{ Poblacion 1} & \multicolumn{2}{|c|}{ Calindagan } & \multicolumn{2}{|c|}{ Balugo } \\
\hline & $\mathbf{F}$ & $\%$ & $\mathbf{F}$ & $\%$ & $\mathbf{F}$ & $\%$ & $\mathbf{F}$ & $\%$ & $\mathbf{F}$ & $\%$ \\
\hline 1. No safer place to transfer & 3 & 30.00 & 3 & 18.75 & 9 & 40.91 & 6 & 26.09 & 5 & 29.41 \\
\hline 2. Like the current place & 2 & 20.00 & 0 & 0.00 & 0 & 0.00 & 0 & 0.00 & 0 & 0.00 \\
\hline $\begin{array}{l}\text { 3. Have been here for long and used } \\
\text { to flooding }\end{array}$ & 0 & 0.00 & 1 & 6.25 & 1 & 4.55 & 1 & 4.35 & 0 & 0.00 \\
\hline 4. Hard to build a new home & 0 & 0.00 & 0 & 0.00 & 2 & 9.09 & 0 & 0.00 & 0 & 0.00 \\
\hline 5. Tolerable flooding/not frequent & 0 & 0.00 & 0 & 0.00 & 2 & 9.09 & 1 & 4.35 & 1 & 5.88 \\
\hline $\begin{array}{l}\text { 6. Relocation site is far from } \\
\text { livelihood/school }\end{array}$ & 0 & 0.00 & 0 & 0.00 & 0 & 0.00 & 1 & 4.35 & 0 & 0.00 \\
\hline 7. Dike is in place & 0 & 0.00 & 0 & 0.00 & 0 & 0.00 & 0 & 0.00 & 1 & 5.88 \\
\hline $\begin{array}{l}\text { 8. Location is elevated/far from river } \\
\text { banks }\end{array}$ & 0 & 0.00 & 0 & 0.00 & 0 & 0.00 & 0 & 0.00 & 0 & 0.00 \\
\hline
\end{tabular}


Community-Based Flood Vulnerability Index for Urban Flooding: Understanding Social Vulnerabilities and Risks

Flood Resilience: PRACTICE ... continued

Reasons for not relocating

\begin{tabular}{|c|c|c|c|c|c|c|c|c|c|c|}
\hline \multirow{2}{*}{ Reasons } & \multicolumn{2}{|c|}{ Barangay 2} & \multicolumn{2}{|c|}{ Poblacion 8} & \multicolumn{2}{|c|}{ Cadawinonan } & \multicolumn{2}{|c|}{ Bagacay } & \multicolumn{2}{|c|}{ Taclobo } \\
\hline & $\mathbf{F}$ & $\%$ & $\mathbf{F}$ & $\%$ & $\mathbf{F}$ & $\%$ & $\mathbf{F}$ & $\%$ & $\mathbf{F}$ & $\%$ \\
\hline 1. No safer place to transfer & 7 & 43.75 & 9 & 31.03 & 6 & 25.00 & 9 & 30.00 & 18 & 29.51 \\
\hline 2. Like the current place & 0 & 0.00 & 1 & 3.45 & 1 & 4.17 & 0 & 0.00 & 0 & 0.00 \\
\hline $\begin{array}{l}\text { 3. Have been here for long and used } \\
\text { to flooding }\end{array}$ & 0 & 0.00 & 5 & 17.24 & 1 & 4.17 & 0 & 0.00 & 0 & 0.00 \\
\hline 4. Hard to build a new home & 0 & 0.00 & 0 & 0.00 & 0 & 0.00 & 0 & 0.00 & 0 & 0.00 \\
\hline 5. Tolerable flooding/not frequent & 0 & 0.00 & 1 & 3.45 & 0 & 0.00 & 0 & 0.00 & 2 & 3.28 \\
\hline $\begin{array}{l}\text { 6. Relocation site is far from } \\
\text { livelihood/school }\end{array}$ & 2 & 12.50 & 2 & 6.90 & 0 & 0.00 & 1 & 3.33 & 2 & 3.28 \\
\hline 7. Dike is in place & 0 & 0.00 & 0 & 0.00 & 1 & 4.17 & 0 & 0.00 & 0 & 0.00 \\
\hline $\begin{array}{l}\text { 8. Location is elevated/far from river } \\
\text { banks }\end{array}$ & 1 & 6.25 & 0 & 0.00 & 1 & 4.17 & 0 & 0.00 & 1 & 1.64 \\
\hline
\end{tabular}


Community-Based Flood Vulnerability Index for Urban Flooding: Understanding Social Vulnerabilities and Risks

Flood Resilience: PRACTICE ... continued

Reasons for not relocating

\begin{tabular}{|c|c|c|c|c|c|c|}
\hline \multirow{2}{*}{ Reasons } & \multicolumn{2}{|c|}{ Candau-ay } & \multicolumn{2}{|c|}{ Batinguel } & \multicolumn{2}{|c|}{ Overall } \\
\hline & $\mathbf{F}$ & $\%$ & $\mathbf{F}$ & $\%$ & $\mathbf{F}$ & $\%$ \\
\hline 1. No safer place to transfer & 31 & 43.06 & 20 & 52.63 & 126 & 34.90 \\
\hline 2. Like the current place & 0 & 0.00 & 0 & 0.00 & 4 & 1.11 \\
\hline 3. Have been here for long and used to flooding & 5 & 6.94 & 1 & 2.63 & 15 & 4.16 \\
\hline 4. Hard to build a new home & 0 & 0.00 & 0 & 0.00 & 2 & 0.55 \\
\hline 5. Tolerable flooding/not frequent & 2 & 2.78 & 0 & 0.00 & 9 & 2.49 \\
\hline 6. Relocation site is far from livelihood/school & 2 & 2.78 & 1 & 2.63 & 11 & 3.05 \\
\hline 7. Dike is in place & 2 & 2.78 & 1 & 2.63 & 5 & 1.39 \\
\hline 8. Location is elevated/far from river banks & 5 & 6.94 & 0 & 0.00 & 8 & 2.22 \\
\hline
\end{tabular}

Flood Resilience: PRACTICE . . . continued

Reasons for opting to relocate

\begin{tabular}{|c|c|c|c|c|c|c|c|c|c|c|}
\hline \multirow{2}{*}{ Reasons } & \multicolumn{2}{|c|}{ Tabuc-tubig } & \multicolumn{2}{|c|}{ Junob } & \multicolumn{2}{|c|}{ Poblacion 1} & \multicolumn{2}{|c|}{ Calindagan } & \multicolumn{2}{|c|}{ Balugo } \\
\hline & $\mathbf{F}$ & $\%$ & $\mathbf{F}$ & $\%$ & $\mathbf{F}$ & $\%$ & $\mathbf{F}$ & $\%$ & $\mathbf{F}$ & $\%$ \\
\hline 1. Safety & 1 & 10.00 & 4 & 25.00 & 3 & 13.64 & 8 & 34.78 & 7 & 41.18 \\
\hline $\begin{array}{l}\text { 2. Bad previous experience with } \\
\text { flooding }\end{array}$ & 0 & 0.00 & 3 & 18.75 & 0 & 0.00 & 0 & 0.00 & 0 & 0.00 \\
\hline 3. Risk/uncertainly of flooding & 0 & 0.00 & 1 & 6.25 & 0 & 0.00 & 0 & 0.00 & 0 & 0.00 \\
\hline
\end{tabular}


Community-Based Flood Vulnerability Index for Urban Flooding: Understanding Social Vulnerabilities and Risks

\begin{tabular}{|c|c|c|c|c|c|c|c|c|c|c|}
\hline \multirow{2}{*}{ Reasons } & \multicolumn{2}{|c|}{ Barangay 2} & \multicolumn{2}{|c|}{ Poblacion 8} & \multicolumn{2}{|c|}{ Cadawinonan } & \multicolumn{2}{|c|}{ Bagacay } & \multicolumn{2}{|c|}{ Taclobo } \\
\hline & $\mathbf{F}$ & $\%$ & $\mathbf{F}$ & $\%$ & $\mathbf{F}$ & $\%$ & $\mathbf{F}$ & $\%$ & $\mathbf{F}$ & $\%$ \\
\hline 1. Safety & 5 & 31.25 & 7 & 24.14 & 5 & 20.83 & 11 & 36.67 & 11 & 18.03 \\
\hline $\begin{array}{l}\text { 2. Bad previous experience with } \\
\text { flooding }\end{array}$ & 0 & 0.00 & 0 & 0.00 & 0 & 0.00 & 2 & 6.67 & 3 & 4.92 \\
\hline 3. Risk/uncertainly of flooding & 0 & 0.00 & 0 & 0.00 & 0 & 0.00 & 1 & 3.33 & 6 & 9.84 \\
\hline
\end{tabular}

\begin{tabular}{|c|c|c|c|c|c|c|}
\hline \multirow{2}{*}{ Reasons } & \multicolumn{2}{|c|}{ Candau-ay } & \multicolumn{2}{|c|}{ Batinguel } & \multicolumn{2}{|c|}{ Overall } \\
\hline & $\mathbf{F}$ & $\%$ & $\mathbf{F}$ & $\%$ & $\mathbf{F}$ & $\%$ \\
\hline 1. Safety & 6 & 8.33 & 5 & 13.16 & 73 & 20.22 \\
\hline 2. Bad previous experience with flooding & 2 & 2.78 & 1 & 2.63 & 11 & 3.05 \\
\hline 3. Risk/uncertainly of flooding & 1 & 1.39 & 1 & 2.63 & 10 & 2.77 \\
\hline
\end{tabular}

Flood Resilience: PRACTICE ... continued

\begin{tabular}{|c|c|c|c|c|c|c|c|c|c|c|}
\hline Item: RISK & \multicolumn{2}{|c|}{ Tabuc-tubig } & \multicolumn{2}{|c|}{ Junob } & \multicolumn{2}{|c|}{ Poblacion 1} & \multicolumn{2}{|c|}{ Calindagan } & \multicolumn{2}{|c|}{ Balugo } \\
\hline Questions & $\mathbf{F}$ & $\%$ & $\mathbf{F}$ & $\%$ & $\mathbf{F}$ & $\%$ & $\mathbf{F}$ & $\%$ & $\mathbf{F}$ & $\%$ \\
\hline $\begin{array}{l}\text { 1. Do you consider or give } \\
\text { importance to the hazards involved } \\
\text { in flooding? }\end{array}$ & 10 & 100.00 & 13 & 81.25 & 18 & 81.82 & 20 & 86.96 & 16 & 94.12 \\
\hline $\begin{array}{l}\text { 2. Do you consider or give } \\
\text { importance to the risks involved in } \\
\text { flooding? }\end{array}$ & 10 & 100.00 & 11 & 68.75 & 16 & 72.73 & 19 & 82.61 & 11 & 64.71 \\
\hline Item Summary & Mean & S.D. & Mean & S.D. & Mean & S.D. & Mean & S.D. & Mean & S.D. \\
\hline Mean Score & 2.00 & 0.00 & 1.50 & 0.82 & 1.55 & 0.80 & 1.70 & 0.56 & 1.59 & 0.62 \\
\hline Percentage Score & 100.00 & 0.00 & 75.00 & 40.82 & 77.27 & 40.02 & 84.78 & 27.94 & 79.41 & 30.92 \\
\hline
\end{tabular}


Community-Based Flood Vulnerability Index for Urban Flooding: Understanding Social Vulnerabilities and Risks

\begin{tabular}{|c|c|c|c|c|c|c|c|c|c|c|}
\hline Item: RISK & Bara & y 2 & Pobla & on 8 & Cadaw & nan & Bag & & Tac & \\
\hline Questions & $\mathbf{F}$ & $\%$ & $\mathbf{F}$ & $\%$ & $\mathbf{F}$ & $\%$ & $\mathbf{F}$ & $\%$ & $\mathbf{F}$ & $\%$ \\
\hline $\begin{array}{l}\text { 1. Do you consider or give } \\
\text { importance to the hazards involved } \\
\text { in flooding? }\end{array}$ & 15 & 93.75 & 24 & 82.76 & 24 & 100.00 & 21 & 70.00 & 53 & 86.89 \\
\hline $\begin{array}{l}\text { 2. Do you consider or give } \\
\text { importance to the risks involved in } \\
\text { flooding? }\end{array}$ & 14 & 87.50 & 24 & 82.76 & 22 & 91.67 & 15 & 50.00 & 47 & 77.05 \\
\hline Item Summary & Mean & S.D. & Mean & S.D. & Mean & S.D. & Mean & S.D. & Mean & S.D. \\
\hline Mean Score & 1.81 & 0.40 & 1.66 & 0.72 & 1.84 & 0.37 & 1.20 & 0.85 & 1.59 & 0.75 \\
\hline Percentage Score & 90.63 & 20.16 & 82.76 & 36.05 & 92.00 & 18.71 & 60.00 & 42.35 & 79.37 & 37.71 \\
\hline
\end{tabular}

Flood Resilience: PRACTICE ... continued

\begin{tabular}{|c|c|c|c|c|c|c|}
\hline Item: RISK & Cand & d-ay & Bati & & & \\
\hline Questions & $\mathbf{F}$ & $\%$ & $\mathbf{F}$ & $\%$ & $\mathbf{F}$ & $\%$ \\
\hline $\begin{array}{l}\text { 1. Do you consider or give } \\
\text { importance to the hazards } \\
\text { involved in flooding? }\end{array}$ & 61 & 84.72 & 31 & 81.58 & 316 & 87.53 \\
\hline $\begin{array}{l}\text { 2. Do you consider or give } \\
\text { importance to the risks } \\
\text { involved in flooding? }\end{array}$ & 51 & 70.83 & 31 & 81.58 & 281 & 77.84 \\
\hline Item Summary & Mean & S.D. & Mean & S.D. & Mean & S.D. \\
\hline Mean Score & 1.56 & 0.75 & 1.63 & 0.71 & 1.60 & 0.71 \\
\hline Percentage Score & 77.78 & 37.42 & 81.58 & 35.68 & 79.92 & 35.43 \\
\hline
\end{tabular}


Community-Based Flood Vulnerability Index for Urban Flooding: Understanding Social Vulnerabilities and Risks

Flood Resilience: PRACTICE ... continued

\begin{tabular}{|c|c|c|c|c|c|c|c|c|c|c|}
\hline \multirow{2}{*}{$\begin{array}{l}\text { Item: EXPOSURE } \\
\text { Questions }\end{array}$} & \multicolumn{2}{|c|}{ Tabuc-tubig } & \multicolumn{2}{|c|}{ Junob } & \multicolumn{2}{|c|}{ Poblacion 1} & \multicolumn{2}{|c|}{ Calindagan } & \multicolumn{2}{|c|}{ Balugo } \\
\hline & $\mathbf{F}$ & $\%$ & $\mathbf{F}$ & $\%$ & $\mathbf{F}$ & $\%$ & $\mathbf{F}$ & $\%$ & $\mathbf{F}$ & $\%$ \\
\hline $\begin{array}{l}\text { 1. Do you wear protective clothing } \\
\text { (raincoat) and sturdy shoes( boots) } \\
\text { during typhoons and flooding? }\end{array}$ & 5 & 50.00 & 8 & 50.00 & 13 & 59.09 & 12 & 52.17 & 10 & 58.82 \\
\hline $\begin{array}{l}\text { 2. Would you immediately evacuate } \\
\text { to designated areas when a flood } \\
\text { warning announcement is given by } \\
\text { those in authority? }\end{array}$ & 10 & 100.00 & 13 & 81.25 & 19 & 86.36 & 23 & 100.00 & 16 & 94.12 \\
\hline $\begin{array}{l}\text { 3. Would you tend to watch and stay } \\
\text { near the flowing water while } \\
\text { flooding? }\end{array}$ & 2 & 20.00 & 5 & 31.25 & 7 & 31.82 & 4 & 17.39 & 4 & 23.53 \\
\hline $\begin{array}{l}\text { 4. Would you tend to pick up } \\
\text { floating and stocked debris during } \\
\text { flooding? }\end{array}$ & 0 & 0.00 & 1 & 6.25 & 6 & 27.27 & 1 & 4.35 & 1 & 5.88 \\
\hline Item Summary & Mean & S.D. & Mean & S.D. & Mean & S.D. & Mean & S.D. & Mean & S.D. \\
\hline Mean Score & 1.70 & 0.82 & 1.69 & 0.79 & 2.05 & 0.84 & 1.74 & 0.69 & 1.82 & 0.64 \\
\hline Percentage Score & 42.50 & 20.58 & 42.19 & 19.83 & 51.14 & 21.10 & 43.48 & 17.22 & 45.59 & 15.90 \\
\hline
\end{tabular}


Community-Based Flood Vulnerability Index for Urban Flooding: Understanding Social Vulnerabilities and Risks

Flood Resilience: PRACTICE ... continued

\begin{tabular}{|c|c|c|c|c|c|c|c|c|c|c|}
\hline \multirow{2}{*}{$\begin{array}{l}\text { Item: EXPOSURE } \\
\text { Questions }\end{array}$} & \multicolumn{2}{|c|}{ Barangay 2} & \multicolumn{2}{|c|}{ Poblacion 8} & \multicolumn{2}{|c|}{ Cadawinonan } & \multicolumn{2}{|c|}{ Bagacay } & \multicolumn{2}{|c|}{ Taclobo } \\
\hline & $\mathbf{F}$ & $\%$ & $\mathbf{F}$ & $\%$ & $\mathbf{F}$ & $\%$ & $\mathbf{F}$ & $\%$ & $\mathbf{F}$ & $\%$ \\
\hline $\begin{array}{l}\text { 1. Do you wear protective clothing } \\
\text { (raincoat) and sturdy shoes( boots) } \\
\text { during typhoons and flooding? }\end{array}$ & 7 & 43.75 & 9 & 31.03 & 17 & 70.83 & 13 & 43.33 & 41 & 67.21 \\
\hline $\begin{array}{l}\text { 2. Would you immediately evacuate } \\
\text { to designated areas when a flood } \\
\text { warning announcement is given by } \\
\text { those in authority? }\end{array}$ & 16 & 100.00 & 28 & 96.55 & 25 & 104.17 & 30 & 100.00 & 59 & 96.72 \\
\hline $\begin{array}{l}\text { 3. Would you tend to watch and stay } \\
\text { near the flowing water while } \\
\text { flooding? }\end{array}$ & 1 & 6.25 & 6 & 20.69 & 4 & 16.67 & 6 & 20.00 & 10 & 16.39 \\
\hline $\begin{array}{l}\text { 4. Would you tend to pick up } \\
\text { floating and stocked debris during } \\
\text { flooding? }\end{array}$ & 1 & 6.25 & 5 & 17.24 & 4 & 16.67 & 1 & 3.33 & 3 & 4.92 \\
\hline Item Summary & Mean & S.D. & Mean & S.D. & Mean & S.D. & Mean & S.D. & Mean & S.D. \\
\hline Mean Score & 1.56 & 0.63 & 1.66 & 0.72 & 2.00 & 0.71 & 1.67 & 0.71 & 1.79 & 0.79 \\
\hline Percentage Score & 39.06 & 15.73 & 41.38 & 18.02 & 50.00 & 17.68 & 41.67 & 17.78 & 44.84 & 19.65 \\
\hline
\end{tabular}


Community-Based Flood Vulnerability Index for Urban Flooding: Understanding Social Vulnerabilities and Risks

Flood Resilience: PRACTICE . . . continued

\begin{tabular}{|c|c|c|c|c|c|c|}
\hline \multirow{2}{*}{$\begin{array}{ll} & \text { Item: EXPOSURE } \\
\text { Questions } & \end{array}$} & \multicolumn{2}{|c|}{ Candau-ay } & \multicolumn{2}{|c|}{ Batinguel } & \multicolumn{2}{|c|}{ Overall } \\
\hline & $\mathbf{F}$ & $\%$ & $\mathbf{F}$ & $\%$ & $\mathbf{F}$ & $\%$ \\
\hline $\begin{array}{l}\text { 1. Do you wear protective clothing (raincoat) and } \\
\text { sturdy shoes( boots) during typhoons and flooding? }\end{array}$ & 42 & 58.33 & 20 & 52.63 & 202 & 55.96 \\
\hline $\begin{array}{l}\text { 2. Would you immediately evacuate to designated } \\
\text { areas when a flood warning announcement is given } \\
\text { by those in authority? }\end{array}$ & 60 & 83.33 & 35 & 92.11 & 344 & 95.29 \\
\hline $\begin{array}{l}\text { 3. Would you tend to watch and stay near the } \\
\text { flowing water while flooding? }\end{array}$ & 12 & 16.67 & 11 & 28.95 & 74 & 20.50 \\
\hline $\begin{array}{l}\text { 4. Would you tend to pick up floating and stocked } \\
\text { debris during flooding? }\end{array}$ & 7 & 9.72 & 7 & 18.42 & 37 & 10.25 \\
\hline Item Summary & Mean & S.D. & Mean & S.D. & Mean & S.D. \\
\hline Mean Score & 1.68 & 0.77 & 1.92 & 0.82 & 1.77 & 0.76 \\
\hline Percentage Score & 42.01 & 19.15 & 48.03 & 20.45 & 44.32 & 18.88 \\
\hline
\end{tabular}


Community-Based Flood Vulnerability Index for Urban Flooding: Understanding Social Vulnerabilities and Risks

Flood Resilience: PRACTICE . . . continued

\begin{tabular}{|c|c|c|c|c|c|c|c|c|c|c|}
\hline Item: PREPAREDNESS & Tabu & ubig & JuI & & Pobla & n 1 & Calin & & Bal & \\
\hline Questions & $\mathbf{F}$ & $\%$ & $\mathbf{F}$ & $\%$ & $\mathbf{F}$ & $\%$ & $\mathbf{F}$ & $\%$ & $\mathbf{F}$ & $\%$ \\
\hline $\begin{array}{l}\text { 1. Do you prepare matches, } \\
\text { lighters, candles, traditional lamp } \\
\text { and chargeable lamp and other } \\
\text { things ready and safe during } \\
\text { heavy rains or expected flooding? }\end{array}$ & 10 & 100.00 & 14 & 87.50 & 20 & 90.91 & 21 & 91.30 & 16 & 94.12 \\
\hline $\begin{array}{l}\text { 2. Do you unplug all appliances } \\
\text { including the main switch when } \\
\text { heavy rain and typhoon is } \\
\text { coming? }\end{array}$ & 10 & 100.00 & 12 & 75.00 & 19 & 86.36 & 21 & 91.30 & 15 & 88.24 \\
\hline $\begin{array}{l}\text { 3. If you do not have any } \\
\text { transportation, do you make } \\
\text { arrangements with relatives, } \\
\text { friends, or the local government? }\end{array}$ & 6 & 60.00 & 9 & 56.25 & 15 & 68.18 & 18 & 78.26 & 13 & 76.47 \\
\hline $\begin{array}{l}\text { 4. Do you gather water, food, } \\
\text { clothing, and emergency supplies } \\
\text { before any typhoon and flooding } \\
\text { occurs? }\end{array}$ & 8 & 80.00 & 13 & 81.25 & 16 & 72.73 & 21 & 91.30 & 15 & 88.24 \\
\hline
\end{tabular}


Community-Based Flood Vulnerability Index for Urban Flooding: Understanding Social Vulnerabilities and Risks

Flood Resilience: PRACTICE ... continued

\begin{tabular}{|c|c|c|c|c|c|c|c|c|c|c|}
\hline Item: PREPAREDNESS & Tabuc & ubig & Jun & & Pobla & on 1 & Calin & gan & Bal & \\
\hline Questions & $\mathbf{F}$ & $\%$ & $\mathbf{F}$ & $\%$ & $\mathbf{F}$ & $\%$ & $\mathbf{F}$ & $\%$ & $\mathbf{F}$ & $\%$ \\
\hline $\begin{array}{l}\text { 5. Do you secure your house by } \\
\text { boarding or placing shutter on all } \\
\text { windows/doors and all loose } \\
\text { items such as garbage can lids, } \\
\text { empty drums, gardening tools, } \\
\text { and any other material that could } \\
\text { become airborne during high } \\
\text { winds? }\end{array}$ & 7 & 70.00 & 15 & 93.75 & 20 & 90.91 & 21 & 91.30 & 14 & 82.35 \\
\hline $\begin{array}{l}\text { 6. Do you fuel your motorbikes, } \\
\text { tricycles or car prior to the } \\
\text { typhoon and flooding? }\end{array}$ & 7 & 70 & 14 & 87.5 & 17 & 77.27 & 16 & 69.57 & 12 & 70.59 \\
\hline $\begin{array}{l}\text { 7. Did you participate in an Early } \\
\text { Warning System lectures in your } \\
\text { community? }\end{array}$ & 8 & 80 & 9 & 56.25 & 7 & 31.82 & 8 & 34.78 & 3 & 17.65 \\
\hline $\begin{array}{l}\text { 8. Did you participate in drills } \\
\text { related to evacuation and } \\
\text { response? }\end{array}$ & 7 & 70 & 9 & 56.25 & 7 & 31.82 & 9 & 39.13 & 4 & 23.53 \\
\hline Item Summary & Mean & S.D. & Mean & S.D. & Mean & S.D. & Mean & S.D. & Mean & S.D. \\
\hline Mean Score & 6.30 & 2.06 & 5.94 & 1.77 & 5.50 & 1.92 & 5.87 & 1.69 & 5.41 & 1.54 \\
\hline Percentage Score & 78.75 & 25.72 & 74.22 & 22.11 & 68.75 & 24.01 & 73.37 & 21.09 & 67.65 & 19.29 \\
\hline
\end{tabular}


Community-Based Flood Vulnerability Index for Urban Flooding: Understanding Social Vulnerabilities and Risks

Flood Resilience: PRACTICE ... continued

\begin{tabular}{|c|c|c|c|c|c|c|c|c|c|c|}
\hline \multirow{2}{*}{$\begin{array}{l}\text { Item: PREPAREDNESS } \\
\text { Questions }\end{array}$} & \multicolumn{2}{|c|}{ Barangay 2} & \multicolumn{2}{|c|}{ Poblacion 8} & \multicolumn{2}{|c|}{ Cadawinonan } & \multicolumn{2}{|c|}{ Bagacay } & \multicolumn{2}{|c|}{ Taclobo } \\
\hline & $\mathbf{F}$ & $\%$ & $\mathbf{F}$ & $\%$ & $\mathbf{F}$ & $\%$ & $\mathbf{F}$ & $\%$ & $\mathbf{F}$ & $\%$ \\
\hline $\begin{array}{l}\text { 1. Do you prepare matches, } \\
\text { lighters, candles, traditional lamp } \\
\text { and chargeable lamp and other } \\
\text { things ready and safe during } \\
\text { heavy rains or expected flooding? }\end{array}$ & 15 & 93.75 & 28 & 96.55 & 24 & 100.00 & 30 & 100.00 & 57 & 93.44 \\
\hline $\begin{array}{l}\text { 2. Do you unplug all appliances } \\
\text { including the main switch when } \\
\text { heavy rain and typhoon is } \\
\text { coming? }\end{array}$ & 15 & 93.75 & 26 & 89.66 & 21 & 87.50 & 28 & 93.33 & 55 & 90.16 \\
\hline $\begin{array}{l}\text { 3. If you do not have any } \\
\text { transportation, do you make } \\
\text { arrangements with relatives, } \\
\text { friends, or the local government? }\end{array}$ & 9 & 56.25 & 21 & 72.41 & 17 & 70.83 & 18 & 60.00 & 49 & 80.33 \\
\hline $\begin{array}{l}\text { 4. Do you gather water, food, } \\
\text { clothing, and emergency supplies } \\
\text { before any typhoon and flooding } \\
\text { occurs? }\end{array}$ & 14 & 87.50 & 23 & 79.31 & 22 & 91.67 & 21 & 70.00 & 56 & 91.80 \\
\hline
\end{tabular}


Community-Based Flood Vulnerability Index for Urban Flooding: Understanding Social Vulnerabilities and Risks

Flood Resilience: PRACTICE ... continued

\begin{tabular}{|c|c|c|c|c|c|c|c|c|c|c|}
\hline Item: PREPAREDNESS & Baran & 2 & Pobla & in 8 & Cadau & onan & Bag & & Tac & \\
\hline Questions & $\mathbf{F}$ & $\%$ & $\mathbf{F}$ & $\%$ & $\mathbf{F}$ & $\%$ & $\mathbf{F}$ & $\%$ & $F$ & $\%$ \\
\hline $\begin{array}{l}\text { 5. Do you secure your house by } \\
\text { boarding or placing shutter on all } \\
\text { windows/doors and all loose } \\
\text { items such as garbage can lids, } \\
\text { empty drums, gardening tools, } \\
\text { and any other material that could } \\
\text { become airborne during high } \\
\text { winds? }\end{array}$ & 14 & 87.50 & 22 & 75.86 & 19 & 79.17 & 23 & 76.67 & 52 & 85.25 \\
\hline $\begin{array}{l}\text { 6. Do you fuel your motorbikes, } \\
\text { tricycles or car prior to the } \\
\text { typhoon and flooding? }\end{array}$ & 10 & 62.5 & 18 & 62.07 & 20 & 83.33 & 23 & 76.67 & 50 & 81.97 \\
\hline $\begin{array}{l}\text { 7. Did you participate in an Early } \\
\text { Warning System lectures in your } \\
\text { community? }\end{array}$ & 5 & 31.25 & 18 & 62.07 & 13 & 54.17 & 12 & 40.00 & 29 & 47.54 \\
\hline $\begin{array}{l}\text { 8. Did you participate in drills } \\
\text { related to evacuation and } \\
\text { response? }\end{array}$ & 4 & 25 & 19 & 65.52 & 12 & 50.00 & 8 & 26.67 & 21 & 34.43 \\
\hline Item Summary & Mean & S.D. & Mean & S.D. & Mean & S.D. & Mean & S.D. & Mean & S.D. \\
\hline Mean Score & 5.38 & 2.19 & 6.03 & 2.21 & 5.92 & 2.22 & 5.43 & 1.81 & 5.86 & 1.63 \\
\hline Percentage Score & 67.19 & 27.34 & 75.43 & 27.65 & 74.00 & 27.70 & 67.92 & 22.67 & 73.21 & 20.44 \\
\hline
\end{tabular}


Community-Based Flood Vulnerability Index for Urban Flooding: Understanding

Social Vulnerabilities and Risks

Flood Resilience: PRACTICE . . . continued

\begin{tabular}{|c|c|c|c|c|c|c|}
\hline Item: PREPAREDNESS & Cand & & Batin & & Ove & \\
\hline Questions & $F$ & $\%$ & $\mathbf{F}$ & $\%$ & $\mathbf{F}$ & $\%$ \\
\hline $\begin{array}{l}\text { 1. Do you prepare matches, lighters, candles, } \\
\text { traditional lamp and chargeable lamp and other } \\
\text { things ready and safe during heavy rains or } \\
\text { expected flooding? }\end{array}$ & 65 & 90.28 & 34 & 89.47 & 344 & 95.29 \\
\hline $\begin{array}{l}\text { 2. Do you unplug all appliances including the } \\
\text { main switch when heavy rain and typhoon is } \\
\text { coming? }\end{array}$ & 60 & 83.33 & 33 & 86.84 & 325 & 90.03 \\
\hline $\begin{array}{l}\text { 3. If you do not have any transportation, do you } \\
\text { make arrangements with relatives, friends, or the } \\
\text { local government? }\end{array}$ & 54 & 75.00 & 28 & 73.68 & 263 & 72.85 \\
\hline $\begin{array}{l}\text { 4. Do you gather water, food, clothing, and } \\
\text { emergency supplies before any typhoon and } \\
\text { flooding occurs? }\end{array}$ & 60 & 83.33 & 36 & 94.74 & 313 & 86.70 \\
\hline
\end{tabular}


Community-Based Flood Vulnerability Index for Urban Flooding: Understanding Social Vulnerabilities and Risks

Flood Resilience: PRACTICE . . . continued

\begin{tabular}{|c|c|c|c|c|c|c|}
\hline Item: PREPAREDNESS & Cand & & Bati & & Ov & \\
\hline Questions & $\mathbf{F}$ & $\%$ & $\mathbf{F}$ & $\%$ & $\mathbf{F}$ & $\%$ \\
\hline $\begin{array}{l}\text { 5. Do you secure your house by boarding or } \\
\text { placing shutter on all windows/doors and all } \\
\text { loose items such as garbage can lids, empty } \\
\text { drums, gardening tools, and any other material } \\
\text { that could become airborne during high winds? }\end{array}$ & 54 & 75.00 & 34 & 89.47 & 302 & 83.66 \\
\hline $\begin{array}{l}\text { 6. Do you fuel your motorbikes, tricycles or car } \\
\text { prior to the typhoon and flooding? }\end{array}$ & 57 & 79.17 & 30 & 78.95 & 281 & 77.84 \\
\hline $\begin{array}{l}\text { 7. Did you participate in an Early Warning System } \\
\text { lectures in your community? }\end{array}$ & 33 & 45.83 & 18 & 47.37 & 171 & 47.37 \\
\hline $\begin{array}{l}\text { 8. Did you participate in drills related to } \\
\text { evacuation and response? }\end{array}$ & 35 & 48.61 & 19 & 50.00 & 161 & 44.60 \\
\hline Item Summary & Mean & S.D. & Mean & S.D. & Mean & S.D. \\
\hline Mean Score & 5.81 & 2.42 & 6.11 & 1.72 & 5.81 & 1.97 \\
\hline Percentage Score & 72.57 & 30.30 & 76.32 & 21.51 & 72.61 & 24.63 \\
\hline
\end{tabular}


Community-Based Flood Vulnerability Index for Urban Flooding: Understanding Social Vulnerabilities and Risks

Flood Resilience: PRACTICE ... continued

\begin{tabular}{|c|c|c|c|c|c|c|c|c|c|c|}
\hline \multirow{2}{*}{$\begin{array}{l}\text { Item: RESPONSE } \\
\text { Questions }\end{array}$} & \multicolumn{2}{|c|}{ Tabuc-tubig } & \multicolumn{2}{|c|}{ Junob } & \multicolumn{2}{|c|}{ Poblacion 1} & \multicolumn{2}{|c|}{ Calindagan } & \multicolumn{2}{|c|}{ Balugo } \\
\hline & $\mathbf{F}$ & $\%$ & $\mathbf{F}$ & $\%$ & $\mathbf{F}$ & $\%$ & $\mathbf{F}$ & $\%$ & $\mathbf{F}$ & $\%$ \\
\hline $\begin{array}{l}\text { 1. Are you always alert all the time } \\
\text { for possible flooding especially if it } \\
\text { rains hard for several hours? }\end{array}$ & 10 & 100.00 & 15 & 93.75 & 18 & 81.82 & 23 & 100.00 & 15 & 88.24 \\
\hline $\begin{array}{l}\text { 2. Do you listen to the radio, watch } \\
\text { the TV, read the newspaper, keep } \\
\text { track online updates and mobile text } \\
\text { messages and call authorities for } \\
\text { further information and warning } \\
\text { during heavy rains, typhoons and } \\
\text { flooding events? }\end{array}$ & 10 & 100.00 & 16 & 100.00 & 19 & 86.36 & 21 & 91.30 & 16 & 94.12 \\
\hline $\begin{array}{l}\text { 3. Do you have neighborhood } \\
\text { associations or support members in } \\
\text { times of need during flooding? }\end{array}$ & 8 & 80.00 & 13 & 81.25 & 14 & 63.64 & 15 & 65.22 & 13 & 76.47 \\
\hline $\begin{array}{l}\text { 4. Do you check from time to time } \\
\text { the water levels of the river near } \\
\text { you whenever there is a heavy rain? }\end{array}$ & 8 & 80.00 & 14 & 87.50 & 16 & 72.73 & 19 & 82.61 & 12 & 70.59 \\
\hline $\begin{array}{l}\text { 5. Do you have contacts from people } \\
\text { further up to your area (Balugo or } \\
\text { Valencia) so you will know the water } \\
\text { levels there? }\end{array}$ & 7 & 70.00 & 5 & 31.25 & 13 & 59.09 & 9 & 39.13 & 12 & 70.59 \\
\hline
\end{tabular}


Community-Based Flood Vulnerability Index for Urban Flooding: Understanding Social Vulnerabilities and Risks

Flood Resilience: PRACTICE ... continued

\begin{tabular}{|c|c|c|c|c|c|c|c|c|c|c|}
\hline \multirow{2}{*}{$\begin{array}{l}\text { Item: RESPONSE } \\
\text { Questions }\end{array}$} & \multicolumn{2}{|c|}{ Tabuc-tubig } & \multicolumn{2}{|c|}{ Junob } & \multicolumn{2}{|c|}{ Poblacion 1} & \multicolumn{2}{|c|}{ Calindagan } & \multicolumn{2}{|c|}{ Balugo } \\
\hline & $\mathbf{F}$ & $\%$ & $\mathbf{F}$ & $\%$ & $\mathbf{F}$ & $\%$ & $\mathbf{F}$ & $\%$ & $\mathbf{F}$ & $\%$ \\
\hline $\begin{array}{l}\text { 6. Would you be ready to cooperate } \\
\text { if local officials and rescue } \\
\text { operations directing evacuation } \\
\text { routes? }\end{array}$ & 10 & 100 & 15 & 93.75 & 20 & 90.91 & 22 & 95.65 & 17 & 100.00 \\
\hline Item Summary & Mean & S.D. & Mean & S.D. & Mean & S.D. & Mean & S.D. & Mean & S.D. \\
\hline Mean Score & 5.30 & 0.82 & 4.88 & 0.89 & 4.55 & 1.44 & 4.74 & 1.10 & 5.00 & 1.00 \\
\hline Percentage Score & 88.33 & 13.72 & 81.25 & 14.75 & 75.76 & 23.97 & 78.99 & 18.27 & 83.33 & 16.67 \\
\hline
\end{tabular}


Community-Based Flood Vulnerability Index for Urban Flooding: Understanding Social Vulnerabilities and Risks

Flood Resilience: PRACTICE ... continued

\begin{tabular}{|c|c|c|c|c|c|c|c|c|c|c|}
\hline \multirow{2}{*}{$\begin{array}{l}\text { Item: RESPONSE } \\
\text { Questions }\end{array}$} & \multicolumn{2}{|c|}{ Barangay 2} & \multicolumn{2}{|c|}{ Poblacion 8} & \multicolumn{2}{|c|}{ Cadawinonan } & \multicolumn{2}{|c|}{ Bagacay } & \multicolumn{2}{|c|}{ Taclobo } \\
\hline & $\mathbf{F}$ & $\%$ & $\mathbf{F}$ & $\%$ & $\mathbf{F}$ & $\%$ & $\mathbf{F}$ & $\%$ & $\mathbf{F}$ & $\%$ \\
\hline $\begin{array}{l}\text { 1. Are you always alert all the time } \\
\text { for possible flooding especially if it } \\
\text { rains hard for several hours? }\end{array}$ & 15 & 93.75 & 28 & 96.55 & 21 & 87.50 & 28 & 93.33 & 54 & 88.52 \\
\hline $\begin{array}{l}\text { 2. Do you listen to the radio, watch } \\
\text { the TV, read the newspaper, keep } \\
\text { track online updates and mobile } \\
\text { text messages and call authorities } \\
\text { for further information and warning } \\
\text { during heavy rains, typhoons and } \\
\text { flooding events? }\end{array}$ & 16 & 100.00 & 26 & 89.66 & 21 & 87.50 & 28 & 93.33 & 58 & 95.08 \\
\hline $\begin{array}{l}\text { 3. Do you have neighborhood } \\
\text { associations or support members in } \\
\text { times of need during flooding? }\end{array}$ & 12 & 75.00 & 26 & 89.66 & 19 & 79.17 & 17 & 56.67 & 38 & 62.30 \\
\hline $\begin{array}{l}\text { 4. Do you check from time to time } \\
\text { the water levels of the river near } \\
\text { you whenever there is a heavy rain? }\end{array}$ & 13 & 81.25 & 23 & 79.31 & 20 & 83.33 & 26 & 86.67 & 56 & 91.80 \\
\hline $\begin{array}{l}\text { 5. Do you have contacts from } \\
\text { people further up to your area } \\
\text { (Balugo or Valencia) so you will } \\
\text { know the water levels there? }\end{array}$ & 9 & 56.25 & 21 & 72.41 & 16 & 66.67 & 8 & 26.67 & 34 & 55.74 \\
\hline
\end{tabular}


Community-Based Flood Vulnerability Index for Urban Flooding: Understanding

Social Vulnerabilities and Risks

Flood Resilience: PRACTICE . . . continued

\begin{tabular}{|c|c|c|c|c|c|c|c|c|c|c|}
\hline Item: RESPONSE & Bara & & Pobla & & Cadaw & nan & Bag & & Tacl & \\
\hline Questions & $\mathbf{F}$ & $\%$ & $\mathbf{F}$ & $\%$ & $\mathbf{F}$ & $\%$ & $\mathbf{F}$ & $\%$ & $\mathbf{F}$ & $\%$ \\
\hline $\begin{array}{l}\text { 6. Would you be ready to cooperate } \\
\text { if local officials and rescue } \\
\text { operations directing evacuation } \\
\text { routes? }\end{array}$ & 16 & 100 & 27 & 93.10 & 23 & 95.83 & 29 & 96.67 & 57 & 93.44 \\
\hline Item Summary & Mean & S.D. & Mean & S.D. & Mean & S.D. & Mean & S.D. & Mean & S.D. \\
\hline Mean Score & 5.06 & 0.93 & 5.21 & 1.45 & 4.80 & 1.85 & 4.53 & 1.31 & 4.71 & 1.21 \\
\hline Percentage Score & 84.38 & 15.48 & 86.78 & 24.14 & 80.00 & 30.81 & 75.56 & 21.77 & 78.57 & 20.18 \\
\hline
\end{tabular}


Community-Based Flood Vulnerability Index for Urban Flooding: Understanding Social Vulnerabilities and Risks

Flood Resilience: PRACTICE ... continued

\begin{tabular}{|l|c|c|c|c|c|c|}
\hline \multicolumn{1}{|c|}{ Item: RESPONSE } & \multicolumn{2}{|c|}{ Candau-ay } & \multicolumn{2}{c|}{ Batinguel } & \multicolumn{2}{c|}{ Overall } \\
\hline Questions & F & \% & F & \% & F & \% \\
\hline $\begin{array}{l}\text { 1. Are you always alert all the } \\
\text { time for possible flooding } \\
\text { especially if it rains hard for } \\
\text { several hours? }\end{array}$ & 62 & 86.11 & 36 & 94.74 & 335 & 92.80 \\
\hline $\begin{array}{l}\text { 2. Do you listen to the radio, } \\
\text { watch the TV read the } \\
\text { newspaper, keep track online } \\
\text { updates and mobile text } \\
\text { messages and call authorities } \\
\text { for further information and } \\
\text { warning during heavy rains, } \\
\text { typhoons and flooding events? }\end{array}$ & 59 & 81.94 & 32 & 84.21 & 332 & 91.97 \\
\hline $\begin{array}{l}\text { 3. Do you have neighborhood } \\
\text { associations or support } \\
\text { members in times of need } \\
\text { during flooding? }\end{array}$ & 48 & 66.67 & 18 & 47.37 & 249 & 68.98 \\
\hline $\begin{array}{l}\text { 4. Do you check from time to } \\
\text { time the water levels of the } \\
\text { river near you whenever there } \\
\text { is a heavy rain? }\end{array}$ & 55 & 76.39 & 33 & 86.84 & 303 & 83.93 \\
\hline $\begin{array}{l}\text { 5. Do you have contacts from } \\
\text { people further up to your area } \\
\text { (Balugo or Valencia) so you will } \\
\text { know the water levels there? }\end{array}$ & 39 & 54.17 & 17 & 44.74 & 197 & 54.57 \\
\hline
\end{tabular}


Community-Based Flood Vulnerability Index for Urban Flooding: Understanding Social Vulnerabilities and Risks

Flood Resilience: PRACTICE . . . continued

\begin{tabular}{|l|r|r|r|r|r|r|}
\hline \multicolumn{1}{|c|}{ Item: RESPONSE } & \multicolumn{2}{c|}{ Candau-ay } & \multicolumn{2}{c|}{ Batinguel } & \multicolumn{2}{c|}{ Overall } \\
\hline Questions & \multicolumn{1}{c|}{ F } & \multicolumn{1}{c|}{$\%$} & F & \multicolumn{1}{c|}{$\%$} & \multicolumn{1}{c|}{ F } & \\
\hline $\begin{array}{l}\text { 6. Would you be ready to } \\
\text { cooperate if local officials and } \\
\text { rescue operations directing } \\
\text { evacuation routes? }\end{array}$ & 60 & 83.33 & 34 & 89.47 & 340 & 94.18 \\
\hline Item Summary & Mean & S.D. & Mean & S.D. & Mean & S.D. \\
\hline Mean Score & 4.49 & 1.89 & 4.47 & 1.35 & 4.72 & 1.43 \\
\hline Percentage Score & 74.77 & 31.52 & 74.56 & 22.51 & 78.62 & 23.91 \\
\hline
\end{tabular}


Community-Based Flood Vulnerability Index for Urban Flooding: Understanding

Social Vulnerabilities and Risks

Flood Resilience: PRACTICE ... continued

\begin{tabular}{|c|c|c|c|c|c|c|c|c|c|c|}
\hline Item: RECOVERY & Tabu & abig & Jur & & Poble & on 1 & Calin & & $\mathrm{Ba}$ & \\
\hline Questions & $\mathbf{F}$ & $\%$ & $\mathbf{F}$ & $\%$ & $\mathbf{F}$ & $\%$ & $\mathbf{F}$ & $\%$ & $\mathbf{F}$ & $\%$ \\
\hline $\begin{array}{l}\text { 1. Do you remain in the evacuation } \\
\text { center, until informed by local } \\
\text { authorities that it is safe to leave? }\end{array}$ & 10 & 100.00 & 16 & 100.00 & 20 & 90.91 & 21 & 91.30 & 16 & 94.12 \\
\hline $\begin{array}{l}\text { 2. Do you stay away from disaster } \\
\text { areas? }\end{array}$ & 7 & 70.00 & 11 & 68.75 & 16 & 72.73 & 20 & 86.96 & 13 & 76.47 \\
\hline $\begin{array}{l}\text { 3. Do you avoid loose or dangling } \\
\text { power wires, broken sewer or water } \\
\text { mains and report them immediately } \\
\text { to local officials? }\end{array}$ & 8 & 80.00 & 15 & 93.75 & 22 & 100.00 & 20 & 86.96 & 12 & 70.59 \\
\hline $\begin{array}{l}\text { 4. Do you check food for spoilage } \\
\text { and other food supply including } \\
\text { water that is safe to eat and DRINK? }\end{array}$ & 10 & 100.00 & 16 & 100.00 & 22 & 100.00 & 21 & 91.30 & 15 & 88.24 \\
\hline $\begin{array}{l}\text { 5. Do you stay away from river } \\
\text { banks until all potential flooding has } \\
\text { passed? }\end{array}$ & 8 & 80.00 & 13 & 81.25 & 17 & 77.27 & 19 & 82.61 & 16 & 94.12 \\
\hline $\begin{array}{l}\text { 6. Would you be willing to stay and } \\
\text { cooperate to whatever programs } \\
\text { and procedures (health, sanitation } \\
\text { practices) that they will facilitate in } \\
\text { the evacuation center during } \\
\text { flooding calamity? }\end{array}$ & 8 & 80 & 16 & 100 & 21 & 95.45 & 21 & 91.30 & 16 & 94.12 \\
\hline
\end{tabular}


Community-Based Flood Vulnerability Index for Urban Flooding: Understanding Social Vulnerabilities and Risks

Flood Resilience: PRACTICE ... continued

\begin{tabular}{|c|c|c|c|c|c|c|c|c|c|c|}
\hline \multirow{2}{*}{$\begin{array}{l}\text { Item: RECOVERY } \\
\text { Questions }\end{array}$} & \multicolumn{2}{|c|}{ Tabuc-tubig } & \multicolumn{2}{|c|}{ Junob } & \multicolumn{2}{|c|}{ Poblacion 1} & \multicolumn{2}{|c|}{ Calindagan } & \multicolumn{2}{|c|}{ Balugo } \\
\hline & $\mathbf{F}$ & $\%$ & $\mathbf{F}$ & $\%$ & $\mathbf{F}$ & $\%$ & $\mathbf{F}$ & $\%$ & $\mathbf{F}$ & $\%$ \\
\hline $\begin{array}{l}\text { 7. Do you immediately clean up your } \\
\text { house after a flooding event? }\end{array}$ & 10 & 100 & 14 & 87.5 & 19 & 86.36 & 21 & 91.30 & 17 & 100.00 \\
\hline $\begin{array}{l}\text { 8. Do you immediately repair } \\
\text { whatever damage to your property } \\
\text { after a flooding event? }\end{array}$ & 10 & 100 & 11 & 68.75 & 20 & 90.91 & 19 & 82.61 & 16 & 94.12 \\
\hline $\begin{array}{l}\text { 9. Do you immediately go for a } \\
\text { medical check-up if one is sick from } \\
\text { diarrhea in your family especially } \\
\text { during or after a typhoon or flooding } \\
\text { events? }\end{array}$ & 10 & 100 & 14 & 87.5 & 22 & 100.00 & 18 & 78.26 & 14 & 82.35 \\
\hline $\begin{array}{l}\text { 10. Have you been given or have } \\
\text { you attended some debriefing } \\
\text { session of the past flooding event? }\end{array}$ & 5 & 50 & 10 & 62.5 & 10 & 45.45 & 6 & 26.09 & 3 & 17.65 \\
\hline $\begin{array}{l}\text { 11. Have you attended to some } \\
\text { discussions of lessons learned from } \\
\text { the past flooding event? }\end{array}$ & 7 & 70 & 13 & 81.25 & 10 & 45.45 & 8 & 34.78 & 6 & 35.29 \\
\hline $\begin{array}{l}\text { 12. Do you usually do a survey by } \\
\text { yourself of the scope of the } \\
\text { damaged the past flooding has } \\
\text { brought? }\end{array}$ & 10 & 100 & 14 & 87.5 & 14 & 63.64 & 19 & 82.61 & 13 & 76.47 \\
\hline
\end{tabular}


Community-Based Flood Vulnerability Index for Urban Flooding: Understanding

Social Vulnerabilities and Risks

Flood Resilience: PRACTICE . . . continued

\begin{tabular}{|c|c|c|c|c|c|c|c|c|c|c|}
\hline Item: RECOVERY & Tabuc & abig & Jur & & Pobla & on 1 & Calin & & Bal & \\
\hline Questions & $\mathbf{F}$ & $\%$ & $\mathbf{F}$ & $\%$ & $\mathbf{F}$ & $\%$ & $\mathbf{F}$ & $\%$ & $\mathbf{F}$ & $\%$ \\
\hline $\begin{array}{l}\text { 13. Do you find ways to cope from } \\
\text { the last flooding incident? }\end{array}$ & 7 & 70 & 14 & 87.5 & 17 & 77.27 & 13 & 56.52 & 6 & 35.29 \\
\hline Item Summary & Mean & S.D. & Mean & S.D. & Mean & S.D. & Mean & S.D. & Mean & S.D. \\
\hline Mean Score & 11.00 & 1.70 & 11.06 & 1.39 & 10.45 & 2.09 & 9.83 & 2.93 & 9.59 & 2.12 \\
\hline Percentage Score & 84.62 & 13.07 & 85.10 & 10.68 & 80.42 & 16.05 & 75.59 & 22.56 & 73.76 & 16.33 \\
\hline
\end{tabular}


Community-Based Flood Vulnerability Index for Urban Flooding: Understanding

Social Vulnerabilities and Risks

Flood Resilience: PRACTICE ... continued

\begin{tabular}{|c|c|c|c|c|c|c|c|c|c|c|}
\hline \multirow{2}{*}{$\begin{array}{l}\text { Item: RECOVERY } \\
\text { Questions }\end{array}$} & \multicolumn{2}{|c|}{ Barangay 2} & \multicolumn{2}{|c|}{ Poblacion 8} & \multicolumn{2}{|c|}{ Cadawinonan } & \multicolumn{2}{|c|}{ Bagacay } & \multicolumn{2}{|c|}{ Taclobo } \\
\hline & $\mathbf{F}$ & $\%$ & $\mathbf{F}$ & $\%$ & $F$ & $\%$ & $\mathbf{F}$ & $\%$ & $\mathbf{F}$ & $\%$ \\
\hline $\begin{array}{l}\text { 1. Do you remain in the evacuation } \\
\text { center, until informed by local } \\
\text { authorities that it is safe to leave? }\end{array}$ & 15 & 93.75 & 28 & 96.55 & 23 & 95.83 & 29 & 96.67 & 54 & 88.52 \\
\hline $\begin{array}{l}\text { 2. Do you stay away from disaster } \\
\text { areas? }\end{array}$ & 13 & 81.25 & 24 & 82.76 & 21 & 87.50 & 22 & 73.33 & 47 & 77.05 \\
\hline $\begin{array}{l}\text { 3. Do you avoid loose or dangling } \\
\text { power wires, broken sewer or water } \\
\text { mains and report them immediately } \\
\text { to local officials? }\end{array}$ & 16 & 100.00 & 25 & 86.21 & 20 & 83.33 & 28 & 93.33 & 54 & 88.52 \\
\hline $\begin{array}{l}\text { 4. Do you check food for spoilage } \\
\text { and other food supply including } \\
\text { water that is safe to eat and DRINK? }\end{array}$ & 16 & 100.00 & 28 & 96.55 & 24 & 100.00 & 29 & 96.67 & 62 & 101.64 \\
\hline $\begin{array}{l}\text { 5. Do you stay away from river } \\
\text { banks until all potential flooding has } \\
\text { passed? }\end{array}$ & 13 & 81.25 & 24 & 82.76 & 20 & 83.33 & 23 & 76.67 & 51 & 83.61 \\
\hline $\begin{array}{l}\text { 6. Would you be willing to stay and } \\
\text { cooperate to whatever programs } \\
\text { and procedures (health, sanitation } \\
\text { practices) that they will facilitate in } \\
\text { the evacuation center during } \\
\text { flooding calamity? }\end{array}$ & 15 & 93.75 & 27 & 93.10 & 24 & 100.00 & 30 & 100.00 & 60 & 98.36 \\
\hline
\end{tabular}


Community-Based Flood Vulnerability Index for Urban Flooding: Understanding Social Vulnerabilities and Risks

Flood Resilience: PRACTICE ... continued

\begin{tabular}{|c|c|c|c|c|c|c|c|c|c|c|}
\hline \multirow{2}{*}{$\begin{array}{l}\text { Item: RECOVERY } \\
\text { Questions }\end{array}$} & \multicolumn{2}{|c|}{ Barangay 2} & \multicolumn{2}{|c|}{ Poblacion 8} & \multicolumn{2}{|c|}{ Cadawinonan } & \multicolumn{2}{|c|}{ Bagacay } & \multicolumn{2}{|c|}{ Taclobo } \\
\hline & $\mathbf{F}$ & $\%$ & $\mathbf{F}$ & $\%$ & $\mathbf{F}$ & $\%$ & $\mathbf{F}$ & $\%$ & $\mathbf{F}$ & $\%$ \\
\hline $\begin{array}{l}\text { 7. Do you immediately clean up your } \\
\text { house after a flooding event? }\end{array}$ & 16 & 100 & 39 & 134.48 & 23 & 95.83 & 27 & 90.00 & 62 & 101.64 \\
\hline $\begin{array}{l}\text { 8. Do you immediately repair } \\
\text { whatever damage to your property } \\
\text { after a flooding event? }\end{array}$ & 16 & 100 & 24 & 82.76 & 21 & 87.50 & 26 & 86.67 & 55 & 90.16 \\
\hline $\begin{array}{l}\text { 9. Do you immediately go for a } \\
\text { medical check-up if one is sick from } \\
\text { diarrhea in your family especially } \\
\text { during or after a typhoon or } \\
\text { flooding events? }\end{array}$ & 16 & 100 & 25 & 86.21 & 19 & 79.17 & 29 & 96.67 & 64 & 104.92 \\
\hline $\begin{array}{l}\text { 10. Have you been given or have } \\
\text { you attended some debriefing } \\
\text { session of the past flooding event? }\end{array}$ & 6 & 37.5 & 16 & 55.17 & 12 & 50.00 & 5 & 16.67 & 22 & 36.07 \\
\hline $\begin{array}{l}\text { 11. Have you attended to some } \\
\text { discussions of lessons learned from } \\
\text { the past flooding event? }\end{array}$ & 6 & 37.5 & 23 & 79.31 & 13 & 54.17 & 21 & 70.00 & 25 & 40.98 \\
\hline $\begin{array}{l}\text { 12. Do you usually do a survey by } \\
\text { yourself of the scope of the } \\
\text { damaged the past flooding has } \\
\text { brought? }\end{array}$ & 15 & 93.75 & 27 & 93.10 & 19 & 79.17 & 26 & 86.67 & 52 & 85.25 \\
\hline
\end{tabular}


Community-Based Flood Vulnerability Index for Urban Flooding: Understanding

Social Vulnerabilities and Risks

Flood Resilience: PRACTICE ... continued

\begin{tabular}{|c|c|c|c|c|c|c|c|c|c|c|}
\hline Item: RECOVERY & Barar & & Pobla & n 8 & Cadaw & nan & Bag & & Tac & \\
\hline Questions & $\mathbf{F}$ & $\%$ & $\mathbf{F}$ & $\%$ & $\mathbf{F}$ & $\%$ & $\mathbf{F}$ & $\%$ & $\mathbf{F}$ & $\%$ \\
\hline $\begin{array}{l}\text { 13. Do you find ways to cope from } \\
\text { the last flooding incident? }\end{array}$ & 13 & 81.25 & 26 & 89.66 & 23 & 95.83 & 16 & 53.33 & 41 & 67.21 \\
\hline Item Summary & Mean & S.D. & Mean & S.D. & Mean & S.D. & Mean & S.D. & Mean & S.D. \\
\hline Mean Score & 11.00 & 1.32 & 11.59 & 3.06 & 10.48 & 2.43 & 10.37 & 2.01 & 10.30 & 2.53 \\
\hline Percentage Score & 84.62 & 10.13 & 89.12 & 23.58 & 80.62 & 18.73 & 79.74 & 15.45 & 79.24 & 19.47 \\
\hline
\end{tabular}

Flood Resilience: PRACTICE ... continued

\begin{tabular}{|c|c|c|c|c|c|c|}
\hline Item: RECOVERY & Cand & & Bati & & Ov & \\
\hline Questions & $\mathbf{F}$ & $\%$ & $\mathbf{F}$ & $\%$ & $\mathbf{F}$ & $\%$ \\
\hline $\begin{array}{l}\text { 1. Do you remain in the evacuation center, until } \\
\text { informed by local authorities that it is safe to leave? }\end{array}$ & 66 & 91.67 & 36 & 94.74 & 344 & 95.29 \\
\hline 2. Do you stay away from disaster areas? & 63 & 87.50 & 34 & 89.47 & 298 & 82.55 \\
\hline $\begin{array}{l}\text { 3. Do you avoid loose or dangling power wires, } \\
\text { broken sewer or water mains and report them } \\
\text { immediately to local officials? }\end{array}$ & 60 & 83.33 & 33 & 86.84 & 321 & 88.92 \\
\hline $\begin{array}{l}\text { 4. Do you check food for spoilage and other food } \\
\text { supply including water that is safe to eat and DRINK? }\end{array}$ & 70 & 97.22 & 36 & 94.74 & 359 & 99.45 \\
\hline $\begin{array}{l}\text { 5. Do you stay away from river banks until all } \\
\text { potential flooding has passed? }\end{array}$ & 58 & 80.56 & 30 & 78.95 & 300 & 83.10 \\
\hline $\begin{array}{l}\text { 6. Would you be willing to stay and cooperate to } \\
\text { whatever programs and procedures (health, } \\
\text { sanitation practices) that they will facilitate in the } \\
\text { evacuation center during flooding calamity? }\end{array}$ & 62 & 86.11 & 35 & 92.11 & 343 & 95.01 \\
\hline
\end{tabular}

Flood Resilience: PRACTICE ... continued 
Community-Based Flood Vulnerability Index for Urban Flooding: Understanding

Social Vulnerabilities and Risks

\begin{tabular}{|c|c|c|c|c|c|c|}
\hline Item: RECOVERY & Canda & & Batir & & Ove & \\
\hline Questions & $\mathbf{F}$ & $\%$ & $\mathbf{F}$ & $\%$ & $\mathbf{F}$ & $\%$ \\
\hline $\begin{array}{l}\text { 7. Do you immediately clean up your house after a } \\
\text { flooding event? }\end{array}$ & 64 & 88.89 & 37 & 97.37 & 359 & 99.45 \\
\hline $\begin{array}{l}\text { 8. Do you immediately repair whatever damage to } \\
\text { your property after a flooding event? }\end{array}$ & 59 & 81.94 & 30 & 78.95 & 317 & 87.81 \\
\hline $\begin{array}{l}\text { 9. Do you immediately go for a medical check-up if } \\
\text { one is sick from diarrhea in your family especially } \\
\text { during or after a typhoon or flooding events? }\end{array}$ & 67 & 93.06 & 45 & 118.42 & 353 & 97.78 \\
\hline $\begin{array}{l}\text { 10. Have you been given or have you attended some } \\
\text { debriefing session of the past flooding event? }\end{array}$ & 28 & 38.89 & 23 & 60.53 & 151 & 41.83 \\
\hline $\begin{array}{l}\text { 11. Have you attended to some discussions of } \\
\text { lessons learned from the past flooding event? }\end{array}$ & 39 & 54.17 & 30 & 78.95 & 208 & 57.62 \\
\hline $\begin{array}{l}\text { 12. Do you usually do a survey by yourself of the } \\
\text { scope of the damaged the past flooding has } \\
\text { brought? }\end{array}$ & 60 & 83.33 & 32 & 84.21 & 311 & 86.15 \\
\hline
\end{tabular}

Flood Resilience: PRACTICE . . . continued

\begin{tabular}{|c|c|c|c|c|c|c|}
\hline \multirow{2}{*}{$\begin{array}{ll} & \text { Item: RECOVERY } \\
\text { Questions } & \end{array}$} & \multicolumn{2}{|c|}{ Candau-ay } & \multicolumn{2}{|c|}{ Batinguel } & \multicolumn{2}{|c|}{ Overall } \\
\hline & $\mathbf{F}$ & $\%$ & $\mathbf{F}$ & $\%$ & $\mathbf{F}$ & $\%$ \\
\hline $\begin{array}{l}\text { 13. Do you find ways to cope from the last flooding } \\
\text { incident? }\end{array}$ & 56 & 77.78 & 29 & 76.32 & 268 & 74.24 \\
\hline Item Summary & Mean & S.D. & Mean & S.D. & Mean & S.D. \\
\hline Mean Score & 10.44 & 3.31 & 11.32 & 2.91 & 10.59 & 2.66 \\
\hline Percentage Score & 80.34 & 25.49 & 87.04 & 22.42 & 81.44 & 20.45 \\
\hline
\end{tabular}


Community-Based Flood Vulnerability Index for Urban Flooding: Understanding Social Vulnerabilities and Risks

Flood Resilience: PRACTICE ... continued

Coping Mechanisms

\begin{tabular}{|c|c|c|c|c|c|c|c|c|c|c|}
\hline \multirow{2}{*}{ Coping Mechanism } & \multicolumn{2}{|c|}{ Tabuc-tubig } & \multicolumn{2}{|c|}{ Junob } & \multicolumn{2}{|c|}{ Poblacion 1} & \multicolumn{2}{|c|}{ Calindagan } & \multicolumn{2}{|c|}{ Balugo } \\
\hline & $\mathbf{F}$ & $\%$ & $\mathbf{F}$ & $\%$ & $\mathbf{F}$ & $\%$ & $\mathbf{F}$ & $\%$ & $\mathbf{F}$ & $\%$ \\
\hline 1. Counseling & 1 & 10.00 & 0 & 0.00 & 0 & 0.00 & 0 & 0.00 & 0 & 0.00 \\
\hline $\begin{array}{l}\text { 2. Not mentioning/forgetting the } \\
\text { unfortunate event }\end{array}$ & 1 & 10.00 & 0 & 0.00 & 0 & 0.00 & 0 & 0.00 & 0 & 0.00 \\
\hline 3. Staying Calm & 1 & 10.00 & 0 & 0.00 & 2 & 9.09 & 3 & 13.04 & 1 & 5.88 \\
\hline 4. Prayers/attending church & 0 & 0.00 & 3 & 18.75 & 1 & 4.55 & 1 & 4.35 & 0 & 0.00 \\
\hline 5. Evacuating/relocating & 0 & 0.00 & 2 & 12.50 & 0 & 0.00 & 1 & 4.35 & 0 & 0.00 \\
\hline 6. Work harder & 0 & 0.00 & 1 & 6.25 & 0 & 0.00 & 0 & 0.00 & 0 & 0.00 \\
\hline 7. Accepting reality & 0 & 0.00 & 0 & 0.00 & 1 & 4.55 & 0 & 0.00 & 0 & 0.00 \\
\hline 8. Soliciting help from health center & 0 & 0.00 & 0 & 0.00 & 1 & 4.55 & 0 & 0.00 & 0 & 0.00 \\
\hline 9. Listening to advice of others & 0 & 0.00 & 0 & 0.00 & 1 & 4.55 & 0 & 0.00 & 0 & 0.00 \\
\hline 10. Family bond & 0 & 0.00 & 0 & 0.00 & 2 & 9.09 & 0 & 0.00 & 0 & 0.00 \\
\hline 11. Being alert/ready & 0 & 0.00 & 0 & 0.00 & 0 & 0.00 & 0 & 0.00 & 0 & 0.00 \\
\hline 12. Listening to radio/tv & 0 & 0.00 & 0 & 0.00 & 0 & 0.00 & 0 & 0.00 & 0 & 0.00 \\
\hline
\end{tabular}


Community-Based Flood Vulnerability Index for Urban Flooding: Understanding Social Vulnerabilities and Risks

Flood Resilience: PRACTICE . . . continued

\begin{tabular}{|c|c|c|c|c|c|c|c|c|c|c|}
\hline \multirow{2}{*}{ Coping Mechanism } & \multicolumn{2}{|c|}{ Barangay 2} & \multicolumn{2}{|c|}{ Poblacion 8} & \multicolumn{2}{|c|}{ Cadawinonan } & \multicolumn{2}{|c|}{ Bagacay } & \multicolumn{2}{|c|}{ Taclobo } \\
\hline & $\mathbf{F}$ & $\%$ & $\mathbf{F}$ & $\%$ & $\mathbf{F}$ & $\%$ & $\mathbf{F}$ & $\%$ & $\mathbf{F}$ & $\%$ \\
\hline 1. Counseling & 1 & 6.25 & 0 & 0.00 & 0 & 0.00 & 0 & 0.00 & 0 & 0.00 \\
\hline $\begin{array}{l}\text { 2. Not mentioning/forgetting the } \\
\text { unfortunate event }\end{array}$ & 1 & 6.25 & 1 & 3.45 & 2 & 8.33 & 0 & 0.00 & 0 & 0.00 \\
\hline 3. Staying Calm & 0 & 0.00 & 3 & 10.34 & 1 & 4.17 & 0 & 0.00 & 0 & 0.00 \\
\hline 4. Prayers/attending church & 1 & 6.25 & 0 & 0.00 & 3 & 12.50 & 0 & 0.00 & 1 & 1.64 \\
\hline 5. Evacuating/relocating & 0 & 0.00 & 1 & 3.45 & 0 & 0.00 & 0 & 0.00 & 0 & 0.00 \\
\hline 6. Work harder & 0 & 0.00 & 0 & 0.00 & 0 & 0.00 & 0 & 0.00 & 0 & 0.00 \\
\hline 7. Accepting reality & 1 & 6.25 & 0 & 0.00 & 0 & 0.00 & 0 & 0.00 & 0 & 0.00 \\
\hline 8. Soliciting help from health center & 0 & 0.00 & 0 & 0.00 & 2 & 8.33 & 0 & 0.00 & 1 & 1.64 \\
\hline 9. Listenting to advice of others & 0 & 0.00 & 0 & 0.00 & 0 & 0.00 & 0 & 0.00 & 0 & 0.00 \\
\hline 10. Family bond & 0 & 0.00 & 0 & 0.00 & 0 & 0.00 & 0 & 0.00 & 0 & 0.00 \\
\hline 11. Being alert/ready & 0 & 0.00 & 2 & 6.90 & 0 & 0.00 & 0 & 0.00 & 0 & 0.00 \\
\hline 12. Listening to radio/tv & 0 & 0.00 & 0 & 0.00 & 0 & 0.00 & 0 & 0.00 & 1 & 1.64 \\
\hline
\end{tabular}


Community-Based Flood Vulnerability Index for Urban Flooding: Understanding

401 Social Vulnerabilities and Risks

Flood Resilience: PRACTICE ... continued

\begin{tabular}{|c|c|c|c|c|c|c|}
\hline \multirow{2}{*}{ Coping Mechanism } & \multicolumn{2}{|c|}{ Candau-ay } & \multicolumn{2}{|c|}{ Batinguel } & \multicolumn{2}{|c|}{ Overall } \\
\hline & $\mathbf{F}$ & $\%$ & $\mathbf{F}$ & $\%$ & $\mathbf{F}$ & $\%$ \\
\hline 1. Counseling & 0 & 0.00 & 0 & 0.00 & 2 & 0.55 \\
\hline 2. Not mentioning/forgetting the unfortunate event & 1 & 1.39 & 2 & 5.26 & 8 & 2.22 \\
\hline 3. Staying Calm & 3 & 4.17 & 2 & 5.26 & 16 & 4.43 \\
\hline 4. Prayers/attending church & 5 & 6.94 & 1 & 2.63 & 16 & 4.43 \\
\hline 5. Evacuating/relocating & 1 & 1.39 & 1 & 2.63 & 6 & 1.66 \\
\hline 6. Work harder & 0 & 0.00 & 0 & 0.00 & 1 & 0.28 \\
\hline 7. Accepting reality & 1 & 1.39 & 0 & 0.00 & 3 & 0.83 \\
\hline 8. Soliciting help from health center & 0 & 0.00 & 0 & 0.00 & 4 & 1.11 \\
\hline 9. Listenting to advice of others & 0 & 0.00 & 0 & 0.00 & 1 & 0.28 \\
\hline 10. Family bond & 0 & 0.00 & 1 & 2.63 & 3 & 0.83 \\
\hline 11. Being alert/ready & 1 & 1.39 & 0 & 0.00 & 3 & 0.83 \\
\hline 12. Listening to radio/tv & 0 & 0.00 & 0 & 0.00 & 1 & 0.28 \\
\hline
\end{tabular}


Community-Based Flood Vulnerability Index for Urban Flooding: Understanding

Social Vulnerabilities and Risks

Flood Resilience: PRACTICE . . . continued

\begin{tabular}{|c|c|c|c|c|c|c|c|c|c|c|}
\hline \multirow{2}{*}{$\begin{array}{l}\text { Item: COORDINATION } \\
\text { Questions }\end{array}$} & \multicolumn{2}{|c|}{ Tabuc-tubig } & \multicolumn{2}{|c|}{ Junob } & \multicolumn{2}{|c|}{ Poblacion 1} & \multicolumn{2}{|c|}{ Calindagan } & \multicolumn{2}{|c|}{ Balugo } \\
\hline & $\mathbf{F}$ & $\%$ & $\mathbf{F}$ & $\%$ & $\mathbf{F}$ & $\%$ & $\mathbf{F}$ & $\%$ & $\mathbf{F}$ & $\%$ \\
\hline $\begin{array}{l}\text { 1. Do you cooperate with the } \\
\text { coordination procedures of the local } \\
\text { government for the resilience } \\
\text { program in your community? }\end{array}$ & 8 & 80.00 & 14 & 87.50 & 17 & 77.27 & 16 & 69.57 & 12 & 70.59 \\
\hline $\begin{array}{l}\text { 2. Would you share your information } \\
\text { to your neighbors about your } \\
\text { knowledge of an issued flood } \\
\text { warning? }\end{array}$ & 10 & 100.00 & 16 & 100.00 & 21 & 95.45 & 19 & 82.61 & 15 & 88.24 \\
\hline Item Summary & Mean & S.D. & Mean & S.D. & Mean & S.D. & Mean & S.D. & Mean & S.D. \\
\hline Mean Score & 1.80 & 0.42 & 1.88 & 0.34 & 1.73 & 0.46 & 1.52 & 0.73 & 1.59 & 0.71 \\
\hline Percentage Score & 90.00 & 21.08 & 93.75 & 17.08 & 86.36 & 22.79 & 76.09 & 36.52 & 79.41 & 35.61 \\
\hline
\end{tabular}


Community-Based Flood Vulnerability Index for Urban Flooding: Understanding

Social Vulnerabilities and Risks

Flood Resilience: PRACTICE ... continued

\begin{tabular}{|c|c|c|c|c|c|c|c|c|c|c|}
\hline Item: COORDINATION & \multicolumn{2}{|c|}{ Barangay 2} & \multicolumn{2}{|c|}{ Poblacion 8} & \multicolumn{2}{|c|}{ Cadawinonan } & \multicolumn{2}{|c|}{ Bagacay } & \multicolumn{2}{|c|}{ Taclobo } \\
\hline Questions & $\mathbf{F}$ & $\%$ & $\mathbf{F}$ & $\%$ & $\mathbf{F}$ & $\%$ & $\mathbf{F}$ & $\%$ & $\mathbf{F}$ & $\%$ \\
\hline $\begin{array}{l}\text { 1. Do you cooperate with the } \\
\text { coordination procedures of the local } \\
\text { government for the resilience } \\
\text { program in your community? }\end{array}$ & 14 & 87.50 & 26 & 89.66 & 16 & 66.67 & 26 & 86.67 & 47 & 77.05 \\
\hline $\begin{array}{l}\text { 2. Would you share your } \\
\text { information to your neighbors about } \\
\text { your knowledge of an issued flood } \\
\text { warning? }\end{array}$ & 16 & 100.00 & 27 & 93.10 & 22 & 91.67 & 30 & 100.00 & 58 & 95.08 \\
\hline Item Summary & Mean & S.D. & Mean & S.D. & Mean & S.D. & Mean & S.D. & Mean & S.D. \\
\hline Mean Score & 1.88 & 0.34 & 1.83 & 0.54 & 1.52 & 0.71 & 1.87 & 0.35 & 1.67 & 0.60 \\
\hline Percentage Score & 93.75 & 17.08 & 91.38 & 26.96 & 76.00 & 35.71 & 93.33 & 17.29 & 83.33 & 29.78 \\
\hline
\end{tabular}

Flood Resilience: PRACTICE ... continued

\begin{tabular}{|c|c|c|c|c|c|c|}
\hline Item: COORDINATION & Cand & & Bati & & Ove & \\
\hline Questions & $\mathbf{F}$ & $\%$ & $\mathbf{F}$ & $\%$ & $\mathbf{F}$ & $\%$ \\
\hline $\begin{array}{l}\text { 1. Do you cooperate with the coordination } \\
\text { procedures of the local government for the resilience } \\
\text { program in your community? }\end{array}$ & 50 & 69.44 & 30 & 78.95 & 284 & 78.67 \\
\hline $\begin{array}{l}\text { 2. Would you share your information to your } \\
\text { neighbors about your knowledge of an issued flood } \\
\text { warning? }\end{array}$ & 58 & 80.56 & 34 & 89.47 & 336 & 93.07 \\
\hline Item Summary & Mean & S.D. & Mean & S.D. & Mean & S.D. \\
\hline Mean Score & 1.50 & 0.80 & 1.68 & 0.62 & 1.67 & 0.63 \\
\hline Percentage Score & 75.00 & 40.25 & 84.21 & 30.99 & 83.38 & 31.41 \\
\hline
\end{tabular}


Community-Based Flood Vulnerability Index for Urban Flooding: Understanding Social Vulnerabilities and Risks

Flood Resilience: PRACTICE ... continued

\begin{tabular}{|c|c|c|c|c|c|c|c|c|c|c|}
\hline \multirow{2}{*}{$\begin{array}{c}\text { Item: } \\
\text { ADAPTATION STRATEGIES } \\
\text { Questions }\end{array}$} & \multicolumn{2}{|c|}{ Tabuc-tubig } & \multicolumn{2}{|c|}{ Junob } & \multicolumn{2}{|c|}{ Poblacion 1} & \multicolumn{2}{|c|}{ Calindagan } & \multicolumn{2}{|c|}{ Balugo } \\
\hline & $\mathbf{F}$ & $\%$ & $\mathbf{F}$ & $\%$ & $\mathbf{F}$ & $\%$ & $\mathbf{F}$ & $\%$ & $\mathbf{F}$ & $\%$ \\
\hline $\begin{array}{l}\text { 1. Are you in favor of whatever } \\
\text { adaptation strategies the local } \\
\text { government is implementing or } \\
\text { planned? }\end{array}$ & 10 & 100.00 & 16 & 100.00 & 19 & 86.36 & 20 & 86.96 & 15 & 88.24 \\
\hline $\begin{array}{l}\text { 2. Have you participated to any } \\
\text { adaptation strategies facilitated by } \\
\text { the LGU's? }\end{array}$ & 5 & 50.00 & 14 & 87.50 & 11 & 50.00 & 5 & 21.74 & 4 & 23.53 \\
\hline $\begin{array}{l}\text { 3. Have you applied what you have } \\
\text { learned from the adaptation } \\
\text { strategies? }\end{array}$ & 6 & 60 & 10 & 62.5 & 15 & 68.18 & 9 & 39.13 & 6 & 35.29 \\
\hline Item Summary & Mean & S.D. & Mean & S.D. & Mean & S.D. & Mean & S.D. & Mean & S.D. \\
\hline Mean Score & 2.10 & 0.99 & 2.50 & 0.73 & 2.05 & 1.05 & 1.48 & 0.99 & 1.47 & 1.01 \\
\hline Percentage Score & 70.00 & 33.15 & 83.33 & 24.34 & 68.18 & 34.85 & 49.28 & 33.14 & 49.02 & 33.58 \\
\hline
\end{tabular}


Community-Based Flood Vulnerability Index for Urban Flooding: Understanding

Social Vulnerabilities and Risks

Flood Resilience: PRACTICE ... continued

\begin{tabular}{|c|c|c|c|c|c|c|c|c|c|c|}
\hline $\begin{array}{c}\text { Item: } \\
\text { ADAPTATION STRATEGIES }\end{array}$ & Barar & & Pobla & n 8 & Cadaw & onan & Bag & & Tac & \\
\hline Questions & $\mathbf{F}$ & $\%$ & $\mathbf{F}$ & $\%$ & $\mathbf{F}$ & $\%$ & $\mathbf{F}$ & $\%$ & $\mathbf{F}$ & $\%$ \\
\hline $\begin{array}{l}\text { 1. Are you in favor of whatever } \\
\text { adaptation strategies the local } \\
\text { government is implementing or in } \\
\text { planned? }\end{array}$ & 14 & 87.50 & 22 & 75.86 & 20 & 83.33 & 25 & 83.33 & 54 & 88.52 \\
\hline $\begin{array}{l}\text { 2. Have you participated to any } \\
\text { adaptation strategies facilitated by } \\
\text { the LGU's? }\end{array}$ & 6 & 37.50 & 19 & 65.52 & 11 & 45.83 & 13 & 43.33 & 25 & 40.98 \\
\hline $\begin{array}{l}\text { 3. Have you applied what you have } \\
\text { learned from the adaptation } \\
\text { strategies? }\end{array}$ & 12 & 75.00 & 22 & 75.86 & 15 & 62.50 & 17 & 56.67 & 31 & 50.82 \\
\hline Item Summary & Mean & S.D. & Mean & S.D. & Mean & S.D. & Mean & S.D. & Mean & S.D. \\
\hline Mean Score & 2.00 & 0.82 & 2.17 & 1.20 & 1.84 & 1.21 & 1.83 & 1.09 & 1.75 & 1.06 \\
\hline Percentage Score & 66.67 & 27.22 & 72.41 & 39.91 & 61.33 & 40.46 & 61.11 & 36.18 & 58.20 & 35.40 \\
\hline
\end{tabular}


Community-Based Flood Vulnerability Index for Urban Flooding: Understanding

Social Vulnerabilities and Risks

Flood Resilience: PRACTICE ... continued

\begin{tabular}{|c|c|c|c|c|c|c|}
\hline Item: ADAPTATION STRATEGIES & Cand & & Bati & & Ov & \\
\hline Questions & $\mathbf{F}$ & $\%$ & $\mathbf{F}$ & $\%$ & $\mathbf{F}$ & $\%$ \\
\hline $\begin{array}{l}\text { 1. Are you in favor of whatever adaptation strategies } \\
\text { the local government is implementing or in planned? }\end{array}$ & 57 & 79.17 & 35 & 92.11 & 317 & 87.81 \\
\hline $\begin{array}{l}\text { 2. Have you participated to any adaptation strategies } \\
\text { facilitated by the LGU's? }\end{array}$ & 31 & 43.06 & 25 & 65.79 & 174 & 48.20 \\
\hline $\begin{array}{l}\text { 3. Have you applied what you have learned from the } \\
\text { adaptation strategies? }\end{array}$ & 43 & 59.72 & 27 & 71.05 & 219 & 60.66 \\
\hline Item Summary & Mean & S.D. & Mean & S.D. & Mean & S.D. \\
\hline Mean Score & 1.82 & 1.19 & 2.29 & 1.01 & 1.91 & 1.09 \\
\hline Percentage Score & 60.65 & 39.69 & 76.32 & 33.70 & 63.62 & 36.43 \\
\hline
\end{tabular}

\section{Flood Resilience: PRACTICE PERCENT SCORE SUMMARY}

\begin{tabular}{|c|c|c|c|c|c|c|c|c|c|c|}
\hline \multirow{2}{*}{ Items } & \multicolumn{2}{|c|}{ Tabuc-tubig } & \multicolumn{2}{|c|}{ Junob } & \multicolumn{2}{|c|}{ Poblacion 1} & \multicolumn{2}{|c|}{ Calindagan } & \multicolumn{2}{|c|}{ Balugo } \\
\hline & Mean & S.D. & Mean & S.D. & Mean & S.D. & Mean & S.D. & Mean & S.D. \\
\hline Hazard & 50.00 & 50.00 & 87.50 & 34.16 & 27.27 & 45.58 & 65.22 & 48.70 & 70.59 & 46.97 \\
\hline Risk & 100.00 & 0.00 & 75.00 & 40.82 & 77.27 & 40.02 & 84.78 & 27.94 & 79.41 & 30.92 \\
\hline Exposure & 42.50 & 20.58 & 42.19 & 19.83 & 51.14 & 21.10 & 43.48 & 17.22 & 45.59 & 15.90 \\
\hline Preparedness & 78.75 & 25.72 & 74.22 & 22.11 & 68.75 & 24.01 & 73.37 & 21.09 & 67.65 & 19.29 \\
\hline Response & 88.33 & 13.72 & 81.25 & 14.75 & 75.76 & 23.97 & 78.99 & 18.27 & 83.33 & 16.67 \\
\hline Recovery & 84.62 & 13.07 & 85.10 & 10.68 & 80.42 & 16.05 & 75.59 & 22.56 & 73.76 & 16.33 \\
\hline Coordination & 90.00 & 21.08 & 93.75 & 17.08 & 86.36 & 22.79 & 76.09 & 36.52 & 79.41 & 35.61 \\
\hline Adaptation Strategies & 70.00 & 33.15 & 83.33 & 24.34 & 68.18 & 34.85 & 49.28 & 33.14 & 49.02 & 33.58 \\
\hline Overall & 75.52 & 20.14 & 77.79 & 15.74 & 66.89 & 19.17 & 68.35 & 14.70 & 68.59 & 14.12 \\
\hline
\end{tabular}


Community-Based Flood Vulnerability Index for Urban Flooding: Understanding

\section{Social Vulnerabilities and Risks}

\begin{tabular}{|c|c|c|c|c|c|c|c|c|c|c|}
\hline \multirow{2}{*}{ Items } & \multicolumn{2}{|c|}{ Barangay 2} & \multicolumn{2}{|c|}{ Poblacion 8} & \multicolumn{2}{|c|}{ Cadawinonan } & \multicolumn{2}{|c|}{ Bagacay } & \multicolumn{2}{|c|}{ Taclobo } \\
\hline & Mean & S.D. & Mean & S.D. & Mean & S.D. & Mean & S.D. & Mean & S.D. \\
\hline Hazard & 31.25 & 47.87 & 28.57 & 46.00 & 36.00 & 48.99 & 76.67 & 43.02 & 61.02 & 49.19 \\
\hline Risk & 90.63 & 20.16 & 82.76 & 36.05 & 92.00 & 18.71 & 60.00 & 42.35 & 79.37 & 37.71 \\
\hline Exposure & 39.06 & 15.73 & 41.38 & 18.02 & 50.00 & 17.68 & 41.67 & 17.78 & 44.84 & 19.65 \\
\hline Preparedness & 67.19 & 27.34 & 75.43 & 27.65 & 74.00 & 27.70 & 67.92 & 22.67 & 73.21 & 20.44 \\
\hline Response & 84.38 & 15.48 & 86.78 & 24.14 & 80.00 & 30.81 & 75.56 & 21.77 & 78.57 & 20.18 \\
\hline Recovery & 84.62 & 10.13 & 89.12 & 23.58 & 80.62 & 18.73 & 79.74 & 15.45 & 79.24 & 19.47 \\
\hline Coordination & 93.75 & 17.08 & 91.38 & 26.96 & 76.00 & 35.71 & 93.33 & 17.29 & 83.33 & 29.78 \\
\hline Adaptation Strategies & 66.67 & 27.22 & 72.41 & 39.91 & 61.33 & 40.46 & 61.11 & 36.18 & 58.20 & 35.40 \\
\hline Overall & 69.69 & 23.56 & 70.98 & 23.39 & 68.74 & 18.39 & 69.50 & 15.58 & 69.72 & 13.56 \\
\hline
\end{tabular}

Flood Resilience: PRACTICE PERCENT SCORE SUMMARY . . . continued

\begin{tabular}{|c|c|c|c|c|c|c|}
\hline \multirow{2}{*}{ Items } & \multicolumn{2}{|c|}{ Candau-ay } & \multicolumn{2}{|c|}{ Batinguel } & \multicolumn{2}{|c|}{ Overall } \\
\hline & Mean & S.D. & Mean & S.D. & Mean & S.D. \\
\hline Hazard & 29.58 & 45.96 & 34.21 & 48.08 & 47.04 & 49.98 \\
\hline Risk & 77.78 & 37.42 & 81.58 & 35.68 & 79.92 & 35.43 \\
\hline Exposure & 42.01 & 19.15 & 48.03 & 20.45 & 44.32 & 18.88 \\
\hline Preparedness & 72.57 & 30.30 & 76.32 & 21.51 & 72.61 & 24.63 \\
\hline Response & 74.77 & 31.52 & 74.56 & 22.51 & 78.62 & 23.91 \\
\hline Recovery & 80.34 & 25.49 & 87.04 & 22.42 & 81.44 & 20.45 \\
\hline Coordination & 75.00 & 40.25 & 84.21 & 30.99 & 83.38 & 31.41 \\
\hline Adaptation Strategies & 60.65 & 39.69 & 76.32 & 33.70 & 63.62 & 36.43 \\
\hline Overall & 64.09 & 18.70 & 70.28 & 18.86 & 68.87 & 15.61 \\
\hline
\end{tabular}




\section{APPENDIX 6 Knowledge, Attitude, and Practices (KAP) on Environmental Microbial Health Risks}

In this appendix the results from Knowledge, Attitude, and Practices (KAP) on Environmental Microbial Health Risks of the surveyed questionnaires from the household respondents is presented as follows:

A. Environmental Microbial Health Risks

1. Nature of E.coli, Leptospirosis, and Dengue Fever moaquito

2. Mode of transmission

3. Prevention

4. Signs and Symptoms

5. It is fatal

6. Treatment

7. Financial Cost of Treatment

Environmental Microbial Health Risks: KNOWLEDGE

\begin{tabular}{|c|c|c|c|c|c|c|c|c|c|c|}
\hline Questions & \multicolumn{2}{|c|}{ Tabuc-tubig } & \multicolumn{2}{|c|}{ Junob } & \multicolumn{2}{|c|}{ Poblacion 1} & \multicolumn{2}{|c|}{ Calindagan } & \multicolumn{2}{|c|}{ Balugo } \\
\hline $\begin{array}{l}\text { 1. Have you heard about the } \\
\text { following bacteria and virus: }\end{array}$ & $\mathbf{F}$ & $\%$ & $\mathbf{F}$ & $\%$ & $\mathbf{F}$ & $\%$ & $\mathbf{F}$ & $\%$ & $\mathbf{F}$ & $\%$ \\
\hline Escherichia coli or E. coli? & 8 & 80.00 & 13 & 81.25 & 16 & 72.73 & 18 & 78.26 & 13 & 76.47 \\
\hline Leptospira spp. ? & 6 & 60.00 & 12 & 75.00 & 18 & 81.82 & 19 & 82.61 & 15 & 88.24 \\
\hline Dengue Fever causing mosquito? & 8 & 80.00 & 14 & 87.50 & 22 & 100.00 & 22 & 95.65 & 15 & 88.24 \\
\hline Item Summary & Mean & S.D. & Mean & S.D. & Mean & S.D. & Mean & S.D. & Mean & S.D. \\
\hline Mean Score & 2.20 & 0.79 & 2.44 & 0.96 & 2.55 & 0.67 & 2.57 & 0.79 & 2.53 & 0.62 \\
\hline Percentage Score & 73.33 & 26.29 & 81.25 & 32.13 & 84.85 & 22.37 & 85.51 & 26.26 & 84.31 & 20.81 \\
\hline
\end{tabular}


Community-Based Flood Vulnerability Index for Urban Flooding: Understanding Social Vulnerabilities and Risks

\begin{tabular}{|c|c|c|c|c|c|c|c|c|c|c|}
\hline Questions & \multicolumn{2}{|c|}{ Barangay 2} & \multicolumn{2}{|c|}{ Poblacion 8} & \multicolumn{2}{|c|}{ Cadawinonan } & \multicolumn{2}{|l|}{ Bagacay } & \multicolumn{2}{|l|}{ Taclobo } \\
\hline $\begin{array}{l}\text { 1. Have you heard about the } \\
\text { following bacteria and virus: }\end{array}$ & $\mathbf{F}$ & $\%$ & $\mathbf{F}$ & $\%$ & $\mathbf{F}$ & $\%$ & $\mathbf{F}$ & $\%$ & $\mathbf{F}$ & $\%$ \\
\hline Escherichia coli or E. coli? & 14 & 87.50 & 25 & 86.21 & 16 & 64.00 & 23 & 76.67 & 48 & 78.69 \\
\hline Leptospira spp. ? & 16 & 100.00 & 24 & 82.76 & 22 & 88.00 & 21 & 70.00 & 48 & 78.69 \\
\hline Dengue Fever causing mosquito? & 16 & 100.00 & 27 & 93.10 & 25 & 100.00 & 27 & 90.00 & 55 & 90.16 \\
\hline Item Summary & Mean & S.D. & Mean & S.D. & Mean & S.D. & Mean & S.D. & Mean & S.D. \\
\hline Mean Score & 2.88 & 0.34 & 2.62 & 0.78 & 2.52 & 0.65 & 2.37 & 0.89 & 2.40 & 0.79 \\
\hline Percentage Score & 95.83 & 11.39 & 87.36 & 25.84 & 84.00 & 21.77 & 78.89 & 29.66 & 79.89 & 26.46 \\
\hline
\end{tabular}

Environmental Microbial Health Risks: KNOWLEDGE . . . continued

\begin{tabular}{|c|c|c|c|c|c|c|}
\hline Questions & \multicolumn{2}{|c|}{ Candau-ay } & \multicolumn{2}{|c|}{ Batinguel } & \multicolumn{2}{|c|}{ Overall } \\
\hline $\begin{array}{l}\text { 1. Have you heard about the } \\
\text { following bacteria and virus: }\end{array}$ & $\mathbf{F}$ & $\%$ & $\mathbf{F}$ & $\%$ & $\mathbf{F}$ & $\%$ \\
\hline Escherichia coli or E. coli? & 56 & 77.78 & 28 & 73.68 & 278 & 77.01 \\
\hline Leptospira spp. ? & 61 & 84.72 & 35 & 92.11 & 297 & 82.27 \\
\hline $\begin{array}{lll}\text { Dengue } & \text { Fever causing } \\
\text { mosquito? } & & \\
\end{array}$ & 66 & 91.67 & 36 & 94.74 & 333 & 92.24 \\
\hline Item Summary & Mean & S.D. & Mean & S.D. & Mean & S.D. \\
\hline Mean Score & 2.54 & 0.79 & 2.61 & 0.79 & 2.52 & 0.16 \\
\hline Percentage Score & 84.72 & 26.20 & 86.84 & 26.33 & 83.90 & 5.45 \\
\hline
\end{tabular}


Community-Based Flood Vulnerability Index for Urban Flooding: Understanding

Social Vulnerabilities and Risks

Environmental Microbial Health Risks: KNOWLEDGE . . . continued

\begin{tabular}{|c|c|c|c|c|c|c|c|c|c|c|}
\hline \multirow{2}{*}{ Questions } & \multicolumn{2}{|c|}{ Tabuc-tubig } & \multicolumn{2}{|c|}{ Junob } & \multicolumn{2}{|c|}{ Poblacion 1} & \multicolumn{2}{|c|}{ Calindagan } & \multicolumn{2}{|c|}{ Balugo } \\
\hline & $\mathbf{F}$ & $\%$ & $\mathbf{F}$ & $\%$ & $\mathbf{F}$ & $\%$ & $\mathbf{F}$ & $\%$ & $\mathbf{F}$ & $\%$ \\
\hline $\begin{array}{l}\text { 2. Have you heard about that there } \\
\text { are bad and dangerous bacteria in } \\
\text { water? }\end{array}$ & 10 & 100.00 & 15 & 93.75 & 21 & 95.45 & 23 & 100.00 & 16 & 94.12 \\
\hline Item Summary & Mean & S.D. & Mean & S.D. & Mean & S.D. & Mean & S.D. & Mean & S.D. \\
\hline Mean Score & 1.00 & 0.00 & 0.94 & 0.25 & 0.95 & 0.21 & 1.00 & 0.00 & 0.94 & 0.24 \\
\hline Percentage Score & 100.00 & 0.00 & 93.75 & 25.00 & 95.45 & 21.32 & 100.00 & 0.00 & 94.12 & 24.25 \\
\hline
\end{tabular}

\begin{tabular}{|c|c|c|c|c|c|c|c|c|c|c|}
\hline \multirow{2}{*}{ Questions } & \multicolumn{2}{|c|}{ Barangay 2} & \multicolumn{2}{|c|}{ Poblacion 8} & \multicolumn{2}{|c|}{ Cadawinonan } & \multicolumn{2}{|c|}{ Bagacay } & \multicolumn{2}{|c|}{ Taclobo } \\
\hline & $\mathbf{F}$ & $\%$ & $\mathbf{F}$ & $\%$ & $\mathbf{F}$ & $\%$ & $\mathbf{F}$ & $\%$ & $\mathbf{F}$ & $\%$ \\
\hline $\begin{array}{l}\text { 2. Have you heard about that there } \\
\text { are bad and dangerous bacteria in } \\
\text { water? }\end{array}$ & 16 & 100.00 & 26 & 89.66 & 23 & 92.00 & 26 & 86.67 & 61 & 100.00 \\
\hline Item Summary & Mean & S.D. & Mean & S.D. & Mean & S.D. & Mean & S.D. & Mean & S.D. \\
\hline Mean Score & 1.00 & 0.00 & 0.90 & 0.31 & 0.92 & 0.28 & 0.87 & 0.35 & 0.97 & 0.18 \\
\hline Percentage Score & 100.00 & 0.00 & 89.66 & 30.99 & 30.67 & 9.23 & 86.67 & 34.57 & 96.83 & 17.67 \\
\hline
\end{tabular}

Environmental Microbial Health Risks: KNOWLEDGE ... continued

\begin{tabular}{|c|c|c|c|c|c|c|}
\hline \multirow{2}{*}{ Questions } & \multicolumn{2}{|c|}{ Candau-ay } & \multicolumn{2}{|c|}{ Batinguel } & \multicolumn{2}{|c|}{ Overall } \\
\hline & $\mathbf{F}$ & $\%$ & $\mathbf{F}$ & $\%$ & $\mathbf{F}$ & $\%$ \\
\hline $\begin{array}{l}\text { 2. Have you heard about that there are bad and } \\
\text { dangerous bacteria in water? }\end{array}$ & 68 & 94.44 & 35 & 92.11 & 340 & 94.18 \\
\hline Item Summary & Mean & S.D. & Mean & S.D. & Mean & S.D. \\
\hline Mean Score & 0.94 & 0.23 & 0.92 & 0.27 & 0.95 & 0.04 \\
\hline Percentage Score & 94.44 & 23.07 & 92.11 & 27.33 & 89.47 & 18.97 \\
\hline
\end{tabular}


Community-Based Flood Vulnerability Index for Urban Flooding: Understanding

Social Vulnerabilities and Risks

Environmental Microbial Health Risks: KNOWLEDGE . . . continued

\begin{tabular}{|c|c|c|c|c|c|c|c|c|c|c|}
\hline \multirow{2}{*}{ Questions } & \multicolumn{2}{|c|}{ Tabuc-tubig } & \multicolumn{2}{|c|}{ Junob } & \multicolumn{2}{|c|}{ Poblacion 1} & \multicolumn{2}{|c|}{ Calindagan } & \multicolumn{2}{|c|}{ Balugo } \\
\hline & $\mathbf{F}$ & $\%$ & $F$ & $\%$ & $\mathbf{F}$ & $\%$ & $\mathbf{F}$ & $\%$ & $\mathbf{F}$ & $\%$ \\
\hline $\begin{array}{l}\text { 3. Are you aware that E. coli, } \\
\text { Leptospira spp. \& Dengue Fever } \\
\text { mosquito can be deadly? }\end{array}$ & 9 & 90.00 & 14 & 87.50 & 21 & 95.45 & 23 & 100.00 & 16 & 94.12 \\
\hline Item Summary & Mean & S.D. & Mean & S.D. & Mean & S.D. & Mean & S.D. & Mean & S.D. \\
\hline Mean Score & 0.90 & 0.32 & 0.88 & 0.34 & 0.95 & 0.21 & 1.00 & 0.00 & 0.94 & 0.24 \\
\hline Percentage Score & 90.00 & 31.62 & 87.50 & 34.16 & 95.45 & 21.32 & 100.00 & 0.00 & 94.12 & 24.25 \\
\hline
\end{tabular}

\begin{tabular}{|c|c|c|c|c|c|c|c|c|c|c|}
\hline \multirow{2}{*}{ Questions } & \multicolumn{2}{|c|}{ Barangay 2} & \multicolumn{2}{|c|}{ Poblacion 8} & \multicolumn{2}{|c|}{ Cadawinonan } & \multicolumn{2}{|c|}{ Bagacay } & \multicolumn{2}{|c|}{ Taclobo } \\
\hline & $\mathbf{F}$ & $\%$ & $\mathbf{F}$ & $\%$ & $\mathbf{F}$ & $\%$ & $\mathbf{F}$ & $\%$ & $\mathbf{F}$ & $\%$ \\
\hline $\begin{array}{l}\text { 3. Are you aware that E. coli, } \\
\text { Leptospira spp. \& Dengue Fever } \\
\text { mosquito can be deadly? }\end{array}$ & 15 & 93.75 & 27 & 93.10 & 24 & 96.00 & 26 & 86.67 & 59 & 96.72 \\
\hline Item Summary & Mean & S.D. & Mean & S.D. & Mean & S.D. & Mean & S.D. & Mean & S.D. \\
\hline Mean Score & 0.94 & 0.25 & 0.93 & 0.26 & 0.96 & 0.20 & 0.87 & 0.35 & 0.94 & 0.25 \\
\hline Percentage Score & 93.75 & 25.00 & 93.10 & 25.79 & 96.00 & 20.00 & 86.67 & 34.57 & 93.65 & 24.58 \\
\hline
\end{tabular}


Community-Based Flood Vulnerability Index for Urban Flooding: Understanding Social Vulnerabilities and Risks

\begin{tabular}{|l|r|r|r|r|r|c|}
\hline \multicolumn{2}{|c|}{ Questions } & \multicolumn{2}{|c|}{ Candau-ay } & \multicolumn{2}{c|}{ Batinguel } & \multicolumn{2}{c|}{ Overall } \\
\cline { 2 - 7 } & F & \multicolumn{1}{c|}{$\%$} & F & \multicolumn{1}{c|}{$\%$} & F & $\%$ \\
\hline $\begin{array}{l}\text { 3. Are you aware that E. coli, } \\
\text { Leptospira spp. \& Dengue } \\
\begin{array}{l}\text { Fever mosquito can be } \\
\text { deadly? }\end{array}\end{array}$ & 71 & 98.61 & 36 & 94.74 & 341 & 94.46 \\
\hline Item Summary & Mean & S.D. & Mean & S.D. & Mean & S.D. \\
\hline Mean Score & 0.99 & 0.12 & 0.95 & 0.23 & 0.94 & 0.04 \\
\hline Percentage Score & 98.61 & 11.79 & 94.74 & 22.63 & 93.63 & 3.99 \\
\hline
\end{tabular}

\begin{tabular}{|c|c|c|c|c|c|c|c|c|c|c|}
\hline \multicolumn{3}{|c|}{ Tabuc-tubig } & \multicolumn{2}{|c|}{ Junob } & \multicolumn{2}{|c|}{ Poblacion 1} & \multicolumn{2}{|c|}{ Calindagan } & \multicolumn{2}{|c|}{ Balugo } \\
\hline $\begin{array}{l}\text { 4. Do you know how the } \\
\text { following bacteria and virus can } \\
\text { be transmitted? }\end{array}$ & $\mathbf{F}$ & $\%$ & $\mathbf{F}$ & $\%$ & $\mathbf{F}$ & $\%$ & $\mathbf{F}$ & $\%$ & $\mathbf{F}$ & $\%$ \\
\hline \multicolumn{11}{|l|}{ E. coli } \\
\hline $\begin{array}{l}\text { failure to wash hands thoroughly } \\
\text { with soap and water following } \\
\text { contact with animals or animal } \\
\text { waste }\end{array}$ & 6 & 60.00 & 6 & 37.50 & 14 & 63.64 & 11 & 47.83 & 8 & 47.06 \\
\hline drinking contaminated water & 6 & 60.00 & 10 & 62.50 & 19 & 86.36 & 19 & 82.61 & 14 & 82.35 \\
\hline $\begin{array}{l}\text { swimming in water even with very } \\
\text { low levels of sewage } \\
\text { contamination }\end{array}$ & 7 & 70.00 & 5 & 31.25 & 11 & 50.00 & 11 & 47.83 & 8 & 47.06 \\
\hline $\begin{array}{l}\text { accidental ingestion of } \\
\text { contaminated water }\end{array}$ & 7 & 70.00 & 11 & 68.75 & 12 & 54.55 & 12 & 52.17 & 9 & 52.94 \\
\hline Item Summary & Mean & S.D. & Mean & S.D. & Mean & S.D. & Mean & S.D. & Mean & S.D. \\
\hline Mean Score & 2.60 & 1.71 & 2.00 & 1.41 & 2.55 & 1.63 & 2.30 & 1.52 & 2.29 & 1.69 \\
\hline Percentage Score & 65.00 & 42.82 & 50.00 & 35.36 & 63.64 & 40.63 & 57.61 & 38.02 & 57.35 & 42.17 \\
\hline
\end{tabular}


Community-Based Flood Vulnerability Index for Urban Flooding: Understanding

Social Vulnerabilities and Risks

Environmental Microbial Health Risks: KNOWLEDGE . . . continued

\begin{tabular}{|c|c|c|c|c|c|c|c|c|c|c|}
\hline Questions & \multicolumn{2}{|c|}{ Tabuc-tubig } & \multicolumn{2}{|c|}{ Junob } & \multicolumn{2}{|c|}{ Poblacion 1} & \multicolumn{2}{|c|}{ Calindagan } & \multicolumn{2}{|c|}{ Balugo } \\
\hline $\begin{array}{l}\text { 4. Do you know how the } \\
\text { following bacteria and virus can } \\
\text { be transmitted? }\end{array}$ & $\mathbf{F}$ & $\%$ & $\mathbf{F}$ & $\%$ & $\mathbf{F}$ & $\%$ & $\mathbf{F}$ & $\%$ & $\mathbf{F}$ & $\%$ \\
\hline \multicolumn{11}{|l|}{ Leptospira spp. } \\
\hline $\begin{array}{l}\text { walking barefoot in flood waters; } \\
\text { contacts of mucous membranes } \\
\text { or broken skin with water } \\
\text { (swimming or immersion) } \\
\text { contaminated with the urine of } \\
\text { infected animals }\end{array}$ & 6 & 60.00 & 12 & 75.00 & 17 & 77.27 & 19 & 82.61 & 14 & 82.35 \\
\hline swimming in water & 7 & 70.00 & 7 & 43.75 & 9 & 40.91 & 10 & 43.48 & 9 & 52.94 \\
\hline wading in flood waters & 7 & 70.00 & 9 & 56.25 & 10 & 45.45 & 9 & 39.13 & 8 & 47.06 \\
\hline Item Summary & Mean & S.D. & Mean & S.D. & Mean & S.D. & Mean & S.D. & Mean & S.D. \\
\hline Mean Score & 2.00 & 1.33 & 1.75 & 1.24 & 1.64 & 1.22 & 1.65 & 1.11 & 1.82 & 1.07 \\
\hline \multirow[t]{2}{*}{ Percentage Score } & 66.67 & 44.44 & 58.33 & 41.28 & 54.55 & 40.56 & 55.07 & 37.08 & 60.78 & 35.81 \\
\hline & $\mathbf{F}$ & $\%$ & $\mathbf{F}$ & $\%$ & $\mathbf{F}$ & $\%$ & $\mathbf{F}$ & $\%$ & $\mathbf{F}$ & $\%$ \\
\hline \multicolumn{11}{|l|}{ Dengue Fever causing mosquito } \\
\hline $\begin{array}{l}\text { mosquito bite infected from } \\
\text { Aedes spp. }\end{array}$ & 7 & 70 & 15 & 93.75 & 19 & 86.36 & 23 & 100 & 16 & 94.12 \\
\hline Item Summary & Mean & S.D. & Mean & S.D. & Mean & S.D. & Mean & S.D. & Mean & S.D. \\
\hline Mean Score & 0.70 & 0.48 & 0.94 & 0.25 & 0.86 & 0.35 & 1.00 & 0.00 & 0.94 & 0.24 \\
\hline Percentage Score & 70.00 & 48.30 & 93.75 & 25.00 & 86.36 & 35.13 & 100.00 & 0.00 & 94.12 & 24.25 \\
\hline Overall Summary & Mean & S.D. & Mean & S.D. & Mean & S.D. & Mean & S.D. & Mean & S.D. \\
\hline Mean Score & 5.30 & 3.43 & 4.69 & 2.52 & 5.05 & 2.70 & 4.96 & 2.38 & 5.06 & 2.66 \\
\hline Percentage Score & 66.25 & 42.92 & 58.59 & 31.53 & 63.07 & 33.74 & 61.96 & 29.79 & 63.24 & 33.21 \\
\hline
\end{tabular}


Community-Based Flood Vulnerability Index for Urban Flooding: Understanding Social Vulnerabilities and Risks

Environmental Microbial Health Risks: KNOWLEDGE . . . continued

\begin{tabular}{|c|c|c|c|c|c|c|c|c|c|c|}
\hline \multirow{2}{*}{$\begin{array}{l}\text { Questions } \\
\text { 4. Do you know how the following } \\
\text { bacteria and virus can be } \\
\text { transmitted? }\end{array}$} & \multicolumn{2}{|c|}{ Barangay 2} & \multicolumn{2}{|c|}{ Poblacion 8} & \multicolumn{2}{|c|}{ Cadawinonan } & \multicolumn{2}{|c|}{ Bagacay } & \multicolumn{2}{|c|}{ Taclobo } \\
\hline & $\mathbf{F}$ & $\%$ & $\mathbf{F}$ & $\%$ & $\mathbf{F}$ & $\%$ & $\mathbf{F}$ & $\%$ & $\mathbf{F}$ & $\%$ \\
\hline \multicolumn{11}{|l|}{ E. coli } \\
\hline $\begin{array}{l}\text { failure to wash hands thoroughly } \\
\text { with soap and water following } \\
\text { contact with animals or animal } \\
\text { waste }\end{array}$ & 10 & 62.50 & 15 & 51.72 & 15 & 60.00 & 16 & 53.33 & 28 & 45.90 \\
\hline drinking contaminated water & 15 & 93.75 & 24 & 82.76 & 19 & 76.00 & 19 & 63.33 & 44 & 72.13 \\
\hline $\begin{array}{l}\text { swimming in water even with very } \\
\text { low levels of sewage contamination }\end{array}$ & 11 & 68.75 & 11 & 37.93 & 12 & 48.00 & 16 & 53.33 & 25 & 40.98 \\
\hline $\begin{array}{l}\text { accidental ingestion of contaminated } \\
\text { water }\end{array}$ & 11 & 68.75 & 12 & 41.38 & 12 & 48.00 & 14 & 46.67 & 33 & 54.10 \\
\hline Item Summary & Mean & S.D. & Mean & S.D. & Mean & S.D. & Mean & S.D. & Mean & S.D. \\
\hline Mean Score & 2.94 & 1.44 & 2.14 & 1.43 & 2.32 & 1.55 & 2.17 & 1.68 & 2.06 & 1.51 \\
\hline Percentage Score & 73.44 & 35.90 & 53.45 & 35.81 & 58.00 & 38.68 & 54.17 & 42.08 & 51.59 & 37.80 \\
\hline
\end{tabular}


Community-Based Flood Vulnerability Index for Urban Flooding: Understanding

Social Vulnerabilities and Risks

Environmental Microbial Health Risks: KNOWLEDGE . . . continued

\begin{tabular}{|c|c|c|c|c|c|c|c|c|c|c|}
\hline \multirow{2}{*}{$\begin{array}{l}\text { Questions } \\
\text { 4. Do you know how the following } \\
\text { bacteria and virus can be } \\
\text { transmitted? }\end{array}$} & \multicolumn{2}{|c|}{ Barangay 2} & \multicolumn{2}{|c|}{ Poblacion 8} & \multicolumn{2}{|c|}{ Cadawinonan } & \multicolumn{2}{|c|}{ Bagacay } & \multicolumn{2}{|c|}{ Taclobo } \\
\hline & $\mathbf{F}$ & $\%$ & $\mathbf{F}$ & $\%$ & $\mathbf{F}$ & $\%$ & $\mathbf{F}$ & $\%$ & $\mathbf{F}$ & $\%$ \\
\hline \multicolumn{11}{|l|}{ Leptospira spp. } \\
\hline $\begin{array}{l}\text { walking barefoot in flood waters; } \\
\text { contacts of mucous membranes or } \\
\text { broken skin with water (swimming } \\
\text { or immersion) contaminated with } \\
\text { the urine of infected animals }\end{array}$ & 13 & 81.25 & 26 & 89.66 & 19 & 76.00 & 21 & 70.00 & 50 & 81.97 \\
\hline swimming in water & 8 & 50.00 & 9 & 31.03 & 12 & 48.00 & 10 & 33.33 & 26 & 42.62 \\
\hline wading in flood waters & 9 & 56.25 & 12 & 41.38 & 14 & 56.00 & 14 & 46.67 & 25 & 40.98 \\
\hline Item Summary & Mean & S.D. & Mean & S.D. & Mean & S.D. & Mean & S.D. & Mean & S.D. \\
\hline Mean Score & 1.88 & 1.15 & 1.62 & 1.01 & 1.80 & 0.96 & 1.50 & 1.07 & 1.60 & 1.11 \\
\hline \multirow[t]{2}{*}{ Percentage Score } & 62.50 & 38.25 & 54.02 & 33.82 & 60.00 & 31.91 & 50.00 & 35.83 & 53.44 & 37.17 \\
\hline & $\mathbf{F}$ & $\%$ & $\mathbf{F}$ & $\%$ & $\mathbf{F}$ & $\%$ & $\mathbf{F}$ & $\%$ & $\mathbf{F}$ & $\%$ \\
\hline \multicolumn{11}{|l|}{ Dengue Fever causing mosquito } \\
\hline $\begin{array}{l}\text { mosquito bite infected from Aedes } \\
\text { spp. }\end{array}$ & 12 & 75.00 & 28 & 96.55 & 20 & 80.00 & 25 & 83.33 & 58 & 95.08 \\
\hline Item Summary & Mean & S.D. & Mean & S.D. & Mean & S.D. & Mean & S.D. & Mean & S.D. \\
\hline Mean Score & 0.75 & 0.45 & 0.97 & 0.19 & 0.80 & 0.41 & 0.83 & 0.38 & 0.92 & 0.27 \\
\hline Percentage Score & 75.00 & 44.72 & 96.55 & 18.57 & 80.00 & 40.82 & 83.33 & 37.90 & 92.06 & 27.25 \\
\hline Overall Summary & Mean & S.D. & Mean & S.D. & Mean & S.D. & Mean & S.D. & Mean & S.D. \\
\hline Mean Score & 5.56 & 2.63 & 4.72 & 2.22 & 4.92 & 2.63 & 4.50 & 2.79 & 4.59 & 2.56 \\
\hline Percentage Score & 69.53 & 32.90 & 59.05 & 27.73 & 61.50 & 32.86 & 56.25 & 34.86 & 57.34 & 32.04 \\
\hline
\end{tabular}


Community-Based Flood Vulnerability Index for Urban Flooding: Understanding Social Vulnerabilities and Risks

Environmental Microbial Health Risks: KNOWLEDGE . . . continued

\begin{tabular}{|c|c|c|c|c|c|c|}
\hline \multirow{2}{*}{$\begin{array}{l}\text { Questions } \\
\text { 4. Do you know how the following bacteria and virus } \\
\text { can be transmitted? }\end{array}$} & \multicolumn{2}{|c|}{ Candau-ay } & \multicolumn{2}{|c|}{ Batinguel } & \multicolumn{2}{|c|}{ Overall } \\
\hline & $\mathbf{F}$ & $\%$ & $\mathbf{F}$ & $\%$ & $\mathbf{F}$ & $\%$ \\
\hline \multicolumn{7}{|l|}{ E. coli } \\
\hline $\begin{array}{l}\text { failure to wash hands thoroughly with soap and } \\
\text { water following contact with animals or animal waste }\end{array}$ & 47 & 65.28 & 18 & 47.37 & 194 & 53.74 \\
\hline drinking contaminated water & 51 & 70.83 & 27 & 71.05 & 267 & 73.96 \\
\hline $\begin{array}{l}\text { swimming in water even with very low levels of } \\
\text { sewage contamination }\end{array}$ & 47 & 65.28 & 15 & 39.47 & 179 & 49.58 \\
\hline accidental ingestion of contaminated water & 43 & 59.72 & 16 & 42.11 & 192 & 53.19 \\
\hline Item Summary & Mean & S.D. & Mean & S.D. & Mean & S.D. \\
\hline Mean Score & 2.61 & 1.60 & 2.00 & 1.51 & 2.33 & 0.29 \\
\hline Percentage Score & 65.28 & 39.93 & 50.00 & 37.67 & 58.29 & 7.24 \\
\hline
\end{tabular}


Community-Based Flood Vulnerability Index for Urban Flooding: Understanding Social Vulnerabilities and Risks

Environmental Microbial Health Risks: KNOWLEDGE . . . continued

\begin{tabular}{|c|c|c|c|c|c|c|}
\hline Questions & \multicolumn{2}{|c|}{ Candau-ay } & \multicolumn{2}{|c|}{ Batinguel } & \multicolumn{2}{|c|}{ Overall } \\
\hline $\begin{array}{l}\text { 4. Do you know how the following bacteria and } \\
\text { virus can be transmitted? }\end{array}$ & $\mathbf{F}$ & $\%$ & $\mathbf{F}$ & $\%$ & $\mathbf{F}$ & $\%$ \\
\hline \multicolumn{7}{|l|}{ Leptospira spp. } \\
\hline $\begin{array}{l}\text { walking barefoot in flood waters; contacts of } \\
\text { mucous membranes or broken skin with water } \\
\text { (swimming or immersion) contaminated with the } \\
\text { urine of infected animals }\end{array}$ & 57 & 79.17 & 30 & 78.95 & 284 & 78.67 \\
\hline swimming in water & 41 & 56.94 & 15 & 39.47 & 163 & 45.15 \\
\hline wading in flood waters & 46 & 63.89 & 15 & 39.47 & 178 & 49.31 \\
\hline Item Summary & Mean & S.D. & Mean & S.D. & Mean & S.D. \\
\hline Mean Score & 2.00 & 1.14 & 1.58 & 1.03 & 1.74 & 0.16 \\
\hline \multirow[t]{2}{*}{ Percentage Score } & 66.67 & 37.94 & 52.63 & 34.34 & 57.89 & 5.49 \\
\hline & $\mathbf{F}$ & $\%$ & $\mathbf{F}$ & $\%$ & $\mathbf{F}$ & $\%$ \\
\hline \multicolumn{7}{|l|}{ Dengue Fever causing mosquito } \\
\hline mosquito bite infected from Aedes spp. & 66 & 91.67 & 30 & 78.95 & 319 & 88.37 \\
\hline Item Summary & Mean & S.D. & Mean & S.D. & Mean & S.D. \\
\hline Mean Score & 0.92 & 0.28 & 0.79 & 0.41 & 0.87 & 0.09 \\
\hline Percentage Score & 91.67 & 27.83 & 78.95 & 41.32 & 86.82 & 9.36 \\
\hline Overall Summary & Mean & S.D. & Mean & S.D. & Mean & S.D. \\
\hline Mean Score & 5.53 & 2.63 & 4.37 & 2.51 & 4.94 & 0.39 \\
\hline Percentage Score & 69.10 & 32.90 & 54.61 & 31.36 & 61.71 & 4.83 \\
\hline
\end{tabular}


Community-Based Flood Vulnerability Index for Urban Flooding: Understanding Social Vulnerabilities and Risks

Environmental Microbial Health Risks: KNOWLEDGE . . . continued

\begin{tabular}{|c|c|c|c|c|c|c|c|c|c|c|}
\hline \multirow{2}{*}{$\begin{array}{l}\text { Questions } \\
\text { 5. Have you heard that infections } \\
\text { brought about by these bacteria } \\
\text { and virus can be prevented? }\end{array}$} & \multicolumn{2}{|c|}{ Tabuc-tubig } & \multicolumn{2}{|c|}{ Junob } & \multicolumn{2}{|c|}{ Poblacion 1} & \multicolumn{2}{|c|}{ Calindagan } & \multicolumn{2}{|c|}{ Balugo } \\
\hline & $\mathbf{F}$ & $\%$ & $\mathbf{F}$ & $\%$ & $\mathbf{F}$ & $\%$ & $\mathbf{F}$ & $\%$ & $\mathbf{F}$ & $\%$ \\
\hline \multicolumn{11}{|l|}{ E. coli } \\
\hline $\begin{array}{l}\text { washing of hands thoroughly with } \\
\text { soap and water }\end{array}$ & 7 & 70.00 & 12 & 75.00 & 17 & 77.27 & 16 & 69.57 & 12 & 70.59 \\
\hline $\begin{array}{l}\text { boiling of water at } 100 \text { degrees } \\
\text { celcius for } 10 \text { minutes }\end{array}$ & 6 & 60.00 & 10 & 62.50 & 13 & 59.09 & 15 & 65.22 & 11 & 64.71 \\
\hline $\begin{array}{l}\text { prohibiting animals near bodies of } \\
\text { water }\end{array}$ & 7 & 70.00 & 7 & 43.75 & 13 & 59.09 & 11 & 47.83 & 8 & 47.06 \\
\hline treating water with chlorine & 6 & 60.00 & 9 & 56.25 & 10 & 45.45 & 9 & 39.13 & 9 & 52.94 \\
\hline $\begin{array}{l}\text { avoid swimming in fecally } \\
\text { contaminated waters }\end{array}$ & 6 & 60 & 12 & 75 & 12 & 54.55 & 14 & 60.87 & 9 & 52.94 \\
\hline Item Summary & Mean & S.D. & Mean & S.D. & Mean & S.D. & Mean & S.D. & Mean & S.D. \\
\hline Mean Score & 3.20 & 2.10 & 3.13 & 1.86 & 2.95 & 1.79 & 2.83 & 1.83 & 2.88 & 2.06 \\
\hline Percentage Score & 64.00 & 41.95 & 62.50 & 37.15 & 59.09 & 35.71 & 56.52 & 36.51 & 57.65 & 41.16 \\
\hline
\end{tabular}


Community-Based Flood Vulnerability Index for Urban Flooding: Understanding Social Vulnerabilities and Risks

Environmental Microbial Health Risks: KNOWLEDGE . . . continued

\begin{tabular}{|c|c|c|c|c|c|c|c|c|c|c|}
\hline \multirow{2}{*}{$\begin{array}{l}\text { Questions } \\
\text { 5. Have you heard that infections } \\
\text { brought about by these bacteria } \\
\text { and virus can be prevented? }\end{array}$} & \multicolumn{2}{|c|}{ Tabuc-tubig } & \multicolumn{2}{|c|}{ Junob } & \multicolumn{2}{|c|}{ Poblacion 1} & \multicolumn{2}{|c|}{ Calindagan } & \multicolumn{2}{|c|}{ Balugo } \\
\hline & $\mathbf{F}$ & $\%$ & $\mathbf{F}$ & $\%$ & $\mathbf{F}$ & $\%$ & $\mathbf{F}$ & $\%$ & $\mathbf{F}$ & $\%$ \\
\hline \multicolumn{11}{|l|}{ Leptospira spp. } \\
\hline $\begin{array}{l}\text { avoid contact with flood waters by } \\
\text { swimming or immersion with an } \\
\text { open wound }\end{array}$ & 8 & 80.00 & 13 & 81.25 & 17 & 77.27 & 13 & 56.52 & 13 & 76.47 \\
\hline $\begin{array}{l}\text { use of sturdy boots during heavy } \\
\text { rains and flooding }\end{array}$ & 7 & 70.00 & 12 & 75.00 & 15 & 68.18 & 17 & 73.91 & 12 & 70.59 \\
\hline avoid walking barefoot & 6 & 60.00 & 12 & 75.00 & 14 & 63.64 & 17 & 73.91 & 11 & 64.71 \\
\hline $\begin{array}{l}\text { securing the environment free from } \\
\text { its reservoir and fecal contamination }\end{array}$ & 7 & 70.00 & 8 & 50.00 & 15 & 68.18 & 12 & 52.17 & 9 & 52.94 \\
\hline Item Summary & Mean & S.D. & Mean & S.D. & Mean & S.D. & Mean & S.D. & Mean & S.D. \\
\hline Mean Score & 2.80 & 1.75 & 2.81 & 1.47 & 2.77 & 1.54 & 2.57 & 1.59 & 2.65 & 1.50 \\
\hline Percentage Score & 70.00 & 43.78 & 70.31 & 36.76 & 69.32 & 38.52 & 64.13 & 39.76 & 66.18 & 37.44 \\
\hline
\end{tabular}


Community-Based Flood Vulnerability Index for Urban Flooding: Understanding

Social Vulnerabilities and Risks

Environmental Microbial Health Risks: KNOWLEDGE . . . continued

\begin{tabular}{|c|c|c|c|c|c|c|c|c|c|c|}
\hline \multicolumn{3}{|c|}{ Tabuc-tubig } & \multicolumn{2}{|c|}{ Junob } & \multicolumn{2}{|c|}{ Poblacion 1} & \multicolumn{2}{|c|}{ Calindagan } & \multicolumn{2}{|c|}{ Balugo } \\
\hline $\begin{array}{l}\text { 5. Have you heard that infections } \\
\text { brought about by these bacteria } \\
\text { and virus can be prevented? }\end{array}$ & $\mathbf{F}$ & $\%$ & $\mathbf{F}$ & $\%$ & $\mathbf{F}$ & $\%$ & $\mathbf{F}$ & $\%$ & $\mathbf{F}$ & $\%$ \\
\hline \multicolumn{11}{|l|}{ Dengue Fever causing mosquito } \\
\hline $\begin{array}{ll}\text { mosquito control } & \text { (eradicate } \\
\text { mosquitoes as possible) } & \end{array}$ & 14 & 56.00 & 11 & 68.75 & 13 & 59.09 & 14 & 60.87 & 10 & 58.82 \\
\hline $\begin{array}{l}\text { solid waste management (proper } \\
\text { disposal of waste) }\end{array}$ & 13 & 52.00 & 8 & 50.00 & 12 & 54.55 & 11 & 47.83 & 7 & 41.18 \\
\hline chemical control & 14 & 56.00 & 8 & 50.00 & 10 & 45.45 & 13 & 56.52 & 11 & 64.71 \\
\hline $\begin{array}{l}\text { improvement of water supply and } \\
\text { storage (putting all unused } \\
\text { containers upside down) }\end{array}$ & 16 & 64.00 & 13 & 81.25 & 19 & 86.36 & 15 & 65.22 & 12 & 70.59 \\
\hline $\begin{array}{l}\text { modification of man-made larval } \\
\text { habitats (discourage presence of } \\
\text { water-logged areas) }\end{array}$ & 15 & 60.00 & 10 & 62.50 & 14 & 63.64 & 13 & 56.52 & 10 & 58.82 \\
\hline $\begin{array}{l}\text { biological control (use of } \\
\text { larvivoparous fish) }\end{array}$ & 11 & 44.00 & 8 & 50.00 & 7 & 31.82 & 11 & 47.83 & 8 & 47.06 \\
\hline $\begin{array}{l}\text { personal protection (use of insect } \\
\text { repellent and appropriate clothing) }\end{array}$ & 16 & 64.00 & 12 & 75.00 & 12 & 54.55 & 15 & 65.22 & 10 & 58.82 \\
\hline Item Summary & Mean & S.D. & Mean & S.D. & Mean & S.D. & Mean & S.D. & Mean & S.D. \\
\hline Mean Score & 3.96 & 2.88 & 4.38 & 2.68 & 3.95 & 2.52 & 4.00 & 2.80 & 4.00 & 2.65 \\
\hline Percentage Score & 56.57 & 41.13 & 62.50 & 38.29 & 56.49 & 35.95 & 57.14 & 39.94 & 57.14 & 37.80 \\
\hline
\end{tabular}


Community-Based Flood Vulnerability Index for Urban Flooding: Understanding Social Vulnerabilities and Risks

Environmental Microbial Health Risks: KNOWLEDGE . . . continued

\begin{tabular}{|c|c|c|c|c|c|c|c|c|c|c|}
\hline Questions & \multicolumn{2}{|c|}{ Tabuc-tubig } & \multicolumn{2}{|c|}{ Junob } & \multicolumn{2}{|c|}{ Poblacion 1} & \multicolumn{2}{|c|}{ Calindagan } & \multicolumn{2}{|c|}{ Balugo } \\
\hline $\begin{array}{l}\text { 5. Have you heard that } \\
\text { infections brought about by } \\
\text { these bacteria and virus can be } \\
\text { prevented? }\end{array}$ & & & & & & & & & & \\
\hline Overall Summary & Mean & S.D. & Mean & S.D. & Mean & S.D. & Mean & S.D. & Mean & S.D. \\
\hline Mean Score & 9.24 & 6.19 & 10.31 & 5.70 & 9.68 & 5.43 & 9.39 & 6.03 & 9.53 & 5.98 \\
\hline Percentage Score & 57.75 & 38.67 & 64.45 & 35.63 & 60.51 & 33.93 & 58.70 & 37.68 & 59.56 & 37.38 \\
\hline
\end{tabular}


Community-Based Flood Vulnerability Index for Urban Flooding: Understanding

Social Vulnerabilities and Risks

Environmental Microbial Health Risks: KNOWLEDGE . . . continued

\begin{tabular}{|c|c|c|c|c|c|c|c|c|c|c|}
\hline \multirow{2}{*}{$\begin{array}{l}\text { Questions } \\
\text { 5. Have you heard that infections } \\
\text { brought about by these bacteria } \\
\text { and virus can be prevented? }\end{array}$} & \multicolumn{2}{|c|}{ Barangay 2} & \multicolumn{2}{|c|}{ Poblacion 8} & \multicolumn{2}{|c|}{ Cadawinonan } & \multicolumn{2}{|c|}{ Bagacay } & \multicolumn{2}{|c|}{ Taclobo } \\
\hline & $\mathbf{F}$ & $\%$ & $\mathbf{F}$ & $\%$ & $\mathbf{F}$ & $\%$ & $\mathbf{F}$ & $\%$ & $\mathbf{F}$ & $\%$ \\
\hline \multicolumn{11}{|l|}{ E. coli } \\
\hline $\begin{array}{l}\text { washing of hands thoroughly with } \\
\text { soap and water }\end{array}$ & 12 & 75.00 & 21 & 72.41 & 17 & 68.00 & 19 & 63.33 & 41 & 67.21 \\
\hline $\begin{array}{l}\text { boiling of water at } 100 \text { degrees } \\
\text { celcius for } 10 \text { minutes }\end{array}$ & 15 & 93.75 & 20 & 68.97 & 18 & 72.00 & 20 & 66.67 & 45 & 73.77 \\
\hline $\begin{array}{l}\text { prohibiting animals near bodies of } \\
\text { water }\end{array}$ & 11 & 68.75 & 15 & 51.72 & 11 & 44.00 & 16 & 53.33 & 23 & 37.70 \\
\hline treating water with chlorine & 11 & 68.75 & 11 & 37.93 & 13 & 52.00 & 16 & 53.33 & 29 & 47.54 \\
\hline $\begin{array}{lccc}\text { avoid swimming in fecally } \\
\text { contaminated waters }\end{array}$ & 11 & 68.75 & 15 & 51.72 & 14 & 56 & 17 & 56.67 & 28 & 45.90 \\
\hline Item Summary & Mean & S.D. & Mean & S.D. & Mean & S.D. & Mean & S.D. & Mean & S.D. \\
\hline Mean Score & 3.75 & 1.88 & 2.83 & 1.97 & 2.92 & 1.91 & 2.93 & 2.07 & 2.63 & 1.91 \\
\hline Percentage Score & 75.00 & 37.59 & 56.55 & 39.30 & 58.40 & 38.26 & 58.67 & 41.33 & 52.70 & 38.24 \\
\hline
\end{tabular}


Community-Based Flood Vulnerability Index for Urban Flooding: Understanding Social Vulnerabilities and Risks

Environmental Microbial Health Risks: KNOWLEDGE . . . continued

\begin{tabular}{|c|c|c|c|c|c|c|c|c|c|c|}
\hline \multirow{2}{*}{$\begin{array}{l}\text { Questions } \\
\text { 5. Have you heard that infections } \\
\text { brought about by these bacteria } \\
\text { and virus can be prevented? }\end{array}$} & \multicolumn{2}{|c|}{ Barangay 2} & \multicolumn{2}{|c|}{ Poblacion 8} & \multicolumn{2}{|c|}{ Cadawinonan } & \multicolumn{2}{|c|}{ Bagacay } & \multicolumn{2}{|c|}{ Taclobo } \\
\hline & $\mathbf{F}$ & $\%$ & $\mathbf{F}$ & $\%$ & $\mathbf{F}$ & $\%$ & $\mathbf{F}$ & $\%$ & $\mathbf{F}$ & $\%$ \\
\hline \multicolumn{11}{|l|}{ Leptospira spp. } \\
\hline $\begin{array}{l}\text { avoid contact with flood waters by } \\
\text { swimming or immersion with an } \\
\text { open wound }\end{array}$ & 13 & 81.25 & 20 & 68.97 & 18 & 72.00 & 20 & 66.67 & 44 & 72.13 \\
\hline $\begin{array}{l}\text { use of sturdy boots during heavy } \\
\text { rains and flooding }\end{array}$ & 12 & 75.00 & 18 & 62.07 & 14 & 56.00 & 15 & 50.00 & 36 & 59.02 \\
\hline avoid walking barefoot & 13 & 81.25 & 16 & 55.17 & 13 & 52.00 & 15 & 50.00 & 33 & 54.10 \\
\hline $\begin{array}{l}\text { securing the environment free from } \\
\text { its reservoir and fecal contamination }\end{array}$ & 10 & 62.5 & 11 & 37.93 & 14 & 56.00 & 15 & 50.00 & 33 & 54.10 \\
\hline Item Summary & Mean & S.D. & Mean & S.D. & Mean & S.D. & Mean & S.D. & Mean & S.D. \\
\hline Mean Score & 3.00 & 1.46 & 2.24 & 1.60 & 2.36 & 1.63 & 2.17 & 1.72 & 2.32 & 1.57 \\
\hline Percentage Score & 75.00 & 36.51 & 56.03 & 39.90 & 59.00 & 40.75 & 54.17 & 43.09 & 57.94 & 39.36 \\
\hline
\end{tabular}


Community-Based Flood Vulnerability Index for Urban Flooding: Understanding Social Vulnerabilities and Risks

Environmental Microbial Health Risks: KNOWLEDGE . . . continued

\begin{tabular}{|c|c|c|c|c|c|c|c|c|c|c|}
\hline \multirow{2}{*}{$\begin{array}{l}\text { Questions } \\
\text { 5. Have you heard that infections } \\
\text { brought about by these bacteria } \\
\text { and virus can be prevented? }\end{array}$} & \multicolumn{2}{|c|}{ Barangay 2} & \multicolumn{2}{|c|}{ Poblacion 8} & \multicolumn{2}{|c|}{ Cadawinonan } & \multicolumn{2}{|c|}{ Bagacay } & \multicolumn{2}{|c|}{ Taclobo } \\
\hline & $\mathbf{F}$ & $\%$ & $\mathbf{F}$ & $\%$ & $\mathbf{F}$ & $\%$ & $\mathbf{F}$ & $\%$ & $\mathbf{F}$ & $\%$ \\
\hline \multicolumn{11}{|l|}{ Dengue Fever causing mosquito } \\
\hline $\begin{array}{ll}\text { mosquito control } & \text { (eradicate } \\
\text { mosquitoes as possible) } & \end{array}$ & 10 & 62.50 & 15 & 51.72 & 14 & 56.00 & 15 & 50.00 & 41 & 67.21 \\
\hline $\begin{array}{l}\text { solid waste management (proper } \\
\text { disposal of waste) }\end{array}$ & 9 & 56.25 & 13 & 44.83 & 13 & 52.00 & 16 & 53.33 & 28 & 45.90 \\
\hline chemical control & 11 & 68.75 & 14 & 48.28 & 14 & 56.00 & 17 & 56.67 & 29 & 47.54 \\
\hline $\begin{array}{l}\text { improvement of water supply and } \\
\text { storage (putting all unused } \\
\text { containers upside down) }\end{array}$ & 14 & 87.50 & 23 & 79.31 & 16 & 64.00 & 21 & 70.00 & 48 & 78.69 \\
\hline $\begin{array}{l}\text { modification of man-made larval } \\
\text { habitats (discourage presence of } \\
\text { water-logged areas) }\end{array}$ & 10 & 62.50 & 16 & 55.17 & 15 & 60.00 & 18 & 60.00 & 36 & 59.02 \\
\hline $\begin{array}{l}\text { biological control (use of } \\
\text { larvivoparous fish) }\end{array}$ & 9 & 56.25 & 13 & 44.83 & 11 & 44.00 & 14 & 46.67 & 29 & 47.54 \\
\hline $\begin{array}{l}\text { personal protection (use of insect } \\
\text { repellent and appropriate clothing) }\end{array}$ & 10 & 62.50 & 15 & 51.72 & 16 & 64.00 & 18 & 60.00 & 37 & 60.66 \\
\hline
\end{tabular}


Community-Based Flood Vulnerability Index for Urban Flooding: Understanding Social Vulnerabilities and Risks

Environmental Microbial Health Risks: KNOWLEDGE . . . continued

\begin{tabular}{|c|c|c|c|c|c|c|c|c|c|c|}
\hline Questions & \multicolumn{2}{|c|}{ Barangay 2} & \multicolumn{2}{|c|}{ Poblacion 8} & \multicolumn{2}{|c|}{ Cadawinonan } & \multicolumn{2}{|c|}{ Bagacay } & \multicolumn{2}{|c|}{ Taclobo } \\
\hline $\begin{array}{l}\text { 5. Have you heard that } \\
\text { infections brought about by } \\
\text { these bacteria and virus can be } \\
\text { prevented? }\end{array}$ & & & & & & & & & & \\
\hline Item Summary & Mean & S.D. & Mean & S.D. & Mean & S.D. & Mean & S.D. & Mean & S.D. \\
\hline Mean Score & 4.56 & 2.94 & 3.76 & 2.85 & 3.96 & 2.88 & 3.97 & 2.94 & 3.94 & 3.22 \\
\hline Percentage Score & 65.18 & 42.05 & 53.69 & 40.70 & 56.57 & 41.13 & 56.67 & 42.03 & 56.24 & 46.03 \\
\hline Overall Summary & Mean & S.D. & Mean & S.D. & Mean & S.D. & Mean & S.D. & Mean & S.D. \\
\hline Mean Score & 11.31 & 70.70 & 8.83 & 6.19 & 9.24 & 6.19 & 9.07 & 6.57 & 8.89 & 6.39 \\
\hline Percentage Score & 5.97 & 37.34 & 55.17 & 38.71 & 57.75 & 38.67 & 56.67 & 41.06 & 55.56 & 39.94 \\
\hline
\end{tabular}


Community-Based Flood Vulnerability Index for Urban Flooding: Understanding Social Vulnerabilities and Risks

Environmental Microbial Health Risks: KNOWLEDGE . . . continued

\begin{tabular}{|c|c|c|c|c|c|c|}
\hline \multirow{2}{*}{$\begin{array}{l}\text { Questions } \\
\text { 5. Have you heard that infections brought about by } \\
\text { these bacteria and virus can be prevented? }\end{array}$} & \multicolumn{2}{|c|}{ Candau-ay } & \multicolumn{2}{|c|}{ Batinguel } & \multicolumn{2}{|c|}{ Overall } \\
\hline & $\mathbf{F}$ & $\%$ & $\mathbf{F}$ & $\%$ & $\mathbf{F}$ & $\%$ \\
\hline \multicolumn{7}{|l|}{ E. coli } \\
\hline washing of hands thoroughly with soap and water & 49 & 68.06 & 23 & 60.53 & 246 & 68.14 \\
\hline boiling of water at 100 degrees celcius for 10 minutes & 48 & 66.67 & 27 & 71.05 & 248 & 68.70 \\
\hline prohibiting animals near bodies of water & 45 & 62.50 & 15 & 39.47 & 182 & 50.42 \\
\hline treating water with chlorine & 44 & 61.11 & 21 & 55.26 & 188 & 52.08 \\
\hline avoid swimming in fecally contaminated waters & 48 & 66.67 & 21 & 55.26 & 207 & 57.34 \\
\hline Item Summary & Mean & S.D. & Mean & S.D. & Mean & S.D. \\
\hline Mean Score & 3.25 & 2.03 & 2.82 & 2.01 & 3.01 & 0.29 \\
\hline Percentage Score & 65.00 & 40.66 & 56.32 & 40.23 & 60.20 & 5.83 \\
\hline
\end{tabular}


Community-Based Flood Vulnerability Index for Urban Flooding: Understanding

Social Vulnerabilities and Risks

Environmental Microbial Health Risks: KNOWLEDGE . . . continued

\begin{tabular}{|c|c|c|c|c|c|c|}
\hline \multirow{2}{*}{$\begin{array}{l}\text { Questions } \\
\text { 5. Have you heard that infections brought about by } \\
\text { these bacteria and virus can be prevented? }\end{array}$} & \multicolumn{2}{|c|}{ Candau-ay } & \multicolumn{2}{|c|}{ Batinguel } & \multicolumn{2}{|c|}{ Overall } \\
\hline & $\mathbf{F}$ & $\%$ & $\mathbf{F}$ & $\%$ & $\mathbf{F}$ & $\%$ \\
\hline \multicolumn{7}{|l|}{ Leptospira spp. } \\
\hline $\begin{array}{l}\text { avoid contact with flood waters by swimming or } \\
\text { immersion with an open wound }\end{array}$ & 51 & 70.83 & 24 & 63.16 & 254 & 70.36 \\
\hline use of sturdy boots during heavy rains and flooding & 48 & 66.67 & 24 & 63.16 & 230 & 63.71 \\
\hline avoid walking barefoot & 49 & 68.06 & 22 & 57.89 & 221 & 61.22 \\
\hline $\begin{array}{l}\text { securing the environment free from its reservoir and } \\
\text { fecal contamination }\end{array}$ & 43 & 59.72 & 20 & 52.63 & 197 & 54.57 \\
\hline Item Summary & Mean & S.D. & Mean & S.D. & Mean & S.D. \\
\hline Mean Score & 2.65 & 1.70 & 2.37 & 1.63 & 2.56 & 0.26 \\
\hline Percentage Score & 66.32 & 42.41 & 59.21 & 40.86 & 63.97 & 6.61 \\
\hline
\end{tabular}


Community-Based Flood Vulnerability Index for Urban Flooding: Understanding

Social Vulnerabilities and Risks

Environmental Microbial Health Risks: KNOWLEDGE ... continued

\begin{tabular}{|c|c|c|c|c|c|c|}
\hline \multirow{2}{*}{$\begin{array}{l}\text { Questions } \\
\text { 5. Have you heard that infections brought about by } \\
\text { these bacteria and virus can be prevented? }\end{array}$} & \multicolumn{2}{|c|}{ Candau-ay } & \multicolumn{2}{|c|}{ Batinguel } & \multicolumn{2}{|c|}{ Overall } \\
\hline & $\mathbf{F}$ & $\%$ & $\mathbf{F}$ & $\%$ & $\mathbf{F}$ & $\%$ \\
\hline \multicolumn{7}{|l|}{ Dengue Fever causing mosquito } \\
\hline mosquito control (eradicate mosquitoes as possible) & 48 & 66.67 & 18 & 47.37 & 215 & 59.56 \\
\hline solid waste management (proper disposal of waste) & 41 & 56.94 & 17 & 44.74 & 182 & 50.42 \\
\hline chemical control & 40 & 55.56 & 16 & 42.11 & 189 & 52.35 \\
\hline $\begin{array}{l}\text { improvement of water supply and storage (putting all } \\
\text { unused containers upside down) }\end{array}$ & 54 & 75.00 & 25 & 65.79 & 267 & 73.96 \\
\hline $\begin{array}{l}\text { modification of man-made larval habitats (discourage } \\
\text { presence of water-logged areas) }\end{array}$ & 46 & 63.89 & 24 & 63.16 & 219 & 60.66 \\
\hline biological control (use of larvivoparous fish) & 35 & 48.61 & 17 & 44.74 & 169 & 46.81 \\
\hline $\begin{array}{l}\text { personal protection (use of insect repellent and } \\
\text { appropriate clothing) }\end{array}$ & 46 & 63.89 & 24 & 63.16 & 220 & 60.94 \\
\hline Item Summary & Mean & S.D. & Mean & S.D. & Mean & S.D. \\
\hline Mean Score & 4.31 & 2.85 & 3.71 & 2.89 & 4.09 & 0.28 \\
\hline Percentage Score & 61.51 & 40.66 & 53.01 & 41.34 & 58.37 & 4.00 \\
\hline
\end{tabular}

Environmental Microbial Health Risks: KNOWLEDGE . . . continued

\begin{tabular}{|l|r|r|r|r|r|r|}
\hline \multicolumn{1}{|c|}{ Questions } & \multicolumn{2}{|c|}{ Candau-ay } & \multicolumn{2}{c|}{ Batinguel } & \multicolumn{2}{c|}{ Overall } \\
\hline $\begin{array}{l}\text { 5. Have you heard that } \\
\text { infections brought about by } \\
\text { these bacteria and virus can be } \\
\text { prevented? }\end{array}$ & & & & & & \\
\hline Overall Summary & Mean & \multicolumn{1}{|c|}{ S.D. } & Mean & S.D. & Mean & \multicolumn{1}{c|}{ S.D. } \\
\hline Mean Score & 10.21 & 6.32 & 8.89 & 6.39 & 9.65 & 0.78 \\
\hline Percentage Score & 63.80 & 39.50 & 55.59 & 39.92 & 60.34 & 4.86 \\
\hline
\end{tabular}


Community-Based Flood Vulnerability Index for Urban Flooding: Understanding

Social Vulnerabilities and Risks

Environmental Microbial Health Risks: KNOWLEDGE . . . continued

\begin{tabular}{|c|c|c|c|c|c|c|c|c|c|c|}
\hline Questions & \multicolumn{2}{|c|}{ Tabuc-tubig } & \multicolumn{2}{|c|}{ Junob } & \multicolumn{2}{|c|}{ Poblacion 1} & \multicolumn{2}{|c|}{ Calindagan } & \multicolumn{2}{|c|}{ Balugo } \\
\hline $\begin{array}{l}\text { 6. Do you know the signs and } \\
\text { symptoms of infection of : }\end{array}$ & $\mathbf{F}$ & $\%$ & $\mathbf{F}$ & $\%$ & $\mathbf{F}$ & $\%$ & $\mathbf{F}$ & $\%$ & $\mathbf{F}$ & $\%$ \\
\hline \multicolumn{11}{|l|}{ E. coli } \\
\hline severe abdominal cramps & 7 & 70.00 & 11 & 68.75 & 17 & 77.27 & 14 & 60.87 & 10 & 58.82 \\
\hline watery diarrhea & 6 & 60.00 & 8 & 50.00 & 13 & 59.09 & 17 & 73.91 & 10 & 58.82 \\
\hline vomiting & 5 & 50.00 & 8 & 50.00 & 11 & 50.00 & 13 & 56.52 & 8 & 47.06 \\
\hline fever & 6 & 60.00 & 7 & 43.75 & 11 & 50.00 & 10 & 43.48 & 7 & 41.18 \\
\hline severe neurological complications & 3 & 30.00 & 6 & 37.50 & 3 & 13.64 & 6 & 26.09 & 4 & 23.53 \\
\hline sometimes bloody diarrhea & 4 & 40.00 & 8 & 50.00 & 6 & 27.27 & 8 & 34.78 & 6 & 35.29 \\
\hline $\begin{array}{l}\text { HUS (acute visceral failure, } \\
\text { hemolytic anemia) }\end{array}$ & 3 & 30.00 & 5 & 31.25 & 3 & 13.64 & 6 & 26.09 & 3 & 17.65 \\
\hline Item Summary & Mean & S.D. & Mean & S.D. & Mean & S.D. & Mean & S.D. & Mean & S.D. \\
\hline Mean Score & 3.40 & 2.32 & 3.31 & 2.18 & 2.91 & 2.33 & 3.22 & 2.59 & 2.82 & 2.53 \\
\hline \multirow[t]{2}{*}{ Percentage Score } & 48.57 & 33.13 & 47.32 & 31.18 & 41.56 & 33.26 & 45.96 & 37.04 & 40.34 & 36.15 \\
\hline & $\mathbf{F}$ & $\%$ & $\mathbf{F}$ & $\%$ & $\mathbf{F}$ & $\%$ & $\mathbf{F}$ & $\%$ & $\mathbf{F}$ & $\%$ \\
\hline \multicolumn{11}{|l|}{ Leptospira spp. } \\
\hline nausea & 5 & 50.00 & 8 & 50.00 & 11 & 50.00 & 8 & 34.78 & 7 & 41.18 \\
\hline vomiting & 5 & 50.00 & 9 & 56.25 & 8 & 36.36 & 9 & 39.13 & 5 & 29.41 \\
\hline abdominal pain & 5 & 50.00 & 8 & 50.00 & 7 & 31.82 & 7 & 30.43 & 7 & 41.18 \\
\hline diarrhea & 6 & 60.00 & 9 & 56.25 & 8 & 36.36 & 12 & 52.17 & 7 & 41.18 \\
\hline arthralgia & 5 & 50.00 & 12 & 75.00 & 11 & 50.00 & 7 & 30.43 & 5 & 29.41 \\
\hline headache & 6 & 60.00 & 11 & 68.75 & 8 & 36.36 & 10 & 43.48 & 5 & 29.41 \\
\hline prostration & 5 & 50.00 & 10 & 62.50 & 11 & 50.00 & 7 & 30.43 & 7 & 41.18 \\
\hline myalgia (particularly calf muscles) & 6 & 60.00 & 9 & 56.25 & 10 & 45.45 & 8 & 34.78 & 5 & 29.41 \\
\hline
\end{tabular}


Community-Based Flood Vulnerability Index for Urban Flooding: Understanding Social Vulnerabilities and Risks

Environmental Microbial Health Risks: KNOWLEDGE . . . continued

\begin{tabular}{|c|c|c|c|c|c|c|c|c|c|c|}
\hline Questions & \multicolumn{2}{|c|}{ Tabuc-tubig } & \multicolumn{2}{|c|}{ Junob } & \multicolumn{2}{|c|}{ Poblacion 1} & \multicolumn{2}{|c|}{ Calindagan } & \multicolumn{2}{|c|}{ Balugo } \\
\hline $\begin{array}{l}\text { 6. Do you know the signs and } \\
\text { symptoms of infection of : }\end{array}$ & & & & & & & & & & \\
\hline Item Summary & Mean & S.D. & Mean & S.D. & Mean & S.D. & Mean & S.D. & Mean & S.D. \\
\hline Mean Score & 4.30 & 3.80 & 4.75 & 3.13 & 3.36 & 3.39 & 2.96 & 3.27 & 2.82 & 3.41 \\
\hline \multirow[t]{2}{*}{ Percentage Score } & 53.75 & 47.53 & 59.38 & 39.13 & 42.05 & 42.35 & 36.96 & 40.85 & 35.29 & 42.67 \\
\hline & $\mathbf{F}$ & $\%$ & $\mathbf{F}$ & $\%$ & $\mathbf{F}$ & $\%$ & $\mathbf{F}$ & $\%$ & $\mathbf{F}$ & $\%$ \\
\hline \multicolumn{11}{|l|}{ Dengue Fever causing mosquito } \\
\hline high fever of acute onset & 6 & 60.00 & 13 & 81.25 & 17 & 77.27 & 20 & 86.96 & 13 & 76.47 \\
\hline $\begin{array}{l}\text { hemorrhagic manifestations } \\
\text { (presence of spots on the body) }\end{array}$ & 5 & 50.00 & 10 & 62.50 & 12 & 54.55 & 10 & 43.48 & 9 & 52.94 \\
\hline hepatomegally & 3 & 30.00 & 2 & 12.50 & 6 & 27.27 & 6 & 26.09 & 4 & 23.53 \\
\hline bleeding & 2 & 20.00 & 5 & 31.25 & 9 & 40.91 & 6 & 26.09 & 4 & 23.53 \\
\hline shock & 1 & 10.00 & 2 & 12.50 & 4 & 18.18 & 5 & 21.74 & 2 & 11.76 \\
\hline $\begin{array}{l}\text { myalgia and arthralgia (severe joint } \\
\text { and muscle pain) }\end{array}$ & 4 & 40.00 & 8 & 50.00 & 9 & 40.91 & 10 & 43.48 & 6 & 35.29 \\
\hline lymphadenopathy & 6 & 60.00 & 4 & 25.00 & 6 & 27.27 & 6 & 26.09 & 3 & 17.65 \\
\hline nausea and vomiting & 7 & 70.00 & 9 & 56.25 & 10 & 45.45 & 12 & 52.17 & 6 & 35.29 \\
\hline pain in eyeballs & 6 & 60.00 & 6 & 37.50 & 8 & 36.36 & 7 & 30.43 & 5 & 29.41 \\
\hline pain in back, body and joints & 4 & 40.00 & 5 & 31.25 & 11 & 50.00 & 13 & 56.52 & 6 & 35.29 \\
\hline \multicolumn{11}{|l|}{ severe headache } \\
\hline colds and flu & & & & & & & & & & \\
\hline
\end{tabular}


Community-Based Flood Vulnerability Index for Urban Flooding: Understanding Social Vulnerabilities and Risks

Environmental Microbial Health Risks: KNOWLEDGE . . . continued

\begin{tabular}{|c|c|c|c|c|c|c|c|c|c|c|}
\hline Questions & \multicolumn{2}{|c|}{ Tabuc-tubig } & \multicolumn{2}{|c|}{ Junob } & \multicolumn{2}{|c|}{ Poblacion 1} & \multicolumn{2}{|c|}{ Calindagan } & \multicolumn{2}{|c|}{ Balugo } \\
\hline $\begin{array}{l}\text { 6. Do you know the signs and } \\
\text { symptoms of infection of : }\end{array}$ & & & & & & & & & & \\
\hline Item Summary & Mean & S.D. & Mean & S.D. & Mean & S.D. & Mean & S.D. & Mean & S.D. \\
\hline Mean Score & 4.40 & 3.37 & 4.00 & 2.76 & 4.18 & 3.63 & 4.13 & 3.38 & 3.41 & 3.00 \\
\hline Percentage Score & 44.00 & 33.73 & 40.00 & 27.57 & 41.82 & 36.34 & 41.30 & 33.75 & 34.12 & 30.01 \\
\hline Overall Summary & Mean & S.D. & Mean & S.D. & Mean & S.D. & Mean & S.D. & Mean & S.D. \\
\hline Mean Score & 12.10 & 9.00 & 12.06 & 7.58 & 10.45 & 8.97 & 10.30 & 8.56 & 9.06 & 8.30 \\
\hline Percentage Score & 48.40 & 36.00 & 48.25 & 30.30 & 41.82 & 35.88 & 41.22 & 34.23 & 36.24 & 33.18 \\
\hline
\end{tabular}


Community-Based Flood Vulnerability Index for Urban Flooding: Understanding

Social Vulnerabilities and Risks

Environmental Microbial Health Risks: KNOWLEDGE ... continued

\begin{tabular}{|c|c|c|c|c|c|c|c|c|c|c|}
\hline Questions & \multicolumn{2}{|c|}{ Barangay 2} & \multicolumn{2}{|c|}{ Poblacion 8} & \multicolumn{2}{|c|}{ Cadawinonan } & \multicolumn{2}{|c|}{ Bagacay } & \multicolumn{2}{|c|}{ Taclobo } \\
\hline $\begin{array}{l}\text { 6. Do you know the signs and } \\
\text { symptoms of infection of : }\end{array}$ & $\mathbf{F}$ & $\%$ & $\mathbf{F}$ & $\%$ & $\mathbf{F}$ & $\%$ & $\mathbf{F}$ & $\%$ & $\mathbf{F}$ & $\%$ \\
\hline \multicolumn{11}{|l|}{ E. coli } \\
\hline severe abdominal cramps & 11 & 68.75 & 16 & 55.17 & 17 & 68.00 & 22 & 73.33 & 40 & 65.57 \\
\hline watery diarrhea & 12 & 75.00 & 14 & 48.28 & 18 & 72.00 & 17 & 56.67 & 39 & 63.93 \\
\hline vomiting & 18 & 112.50 & 13 & 44.83 & 14 & 56.00 & 16 & 53.33 & 30 & 49.18 \\
\hline fever & 8 & 50.00 & 14 & 48.28 & 13 & 52.00 & 14 & 46.67 & 31 & 50.82 \\
\hline severe neurological complications & 8 & 50.00 & 9 & 31.03 & 7 & 28.00 & 10 & 33.33 & 19 & 31.15 \\
\hline sometimes bloody diarrhea & 9 & 56.25 & 11 & 37.93 & 11 & 44.00 & 13 & 43.33 & 25 & 40.98 \\
\hline $\begin{array}{l}\text { HUS (acute visceral failure, } \\
\text { hemolytic anemia) }\end{array}$ & 7 & 43.75 & 9 & 31.03 & 10 & 40.00 & 7 & 23.33 & 16 & 26.23 \\
\hline Item Summary & Mean & S.D. & Mean & S.D. & Mean & S.D. & Mean & S.D. & Mean & S.D. \\
\hline Mean Score & 4.56 & 4.00 & 2.97 & 2.88 & 3.60 & 2.77 & 3.30 & 2.76 & 3.17 & 2.66 \\
\hline \multirow[t]{2}{*}{ Percentage Score } & 65.18 & 57.14 & 42.36 & 41.21 & 51.43 & 39.56 & 47.14 & 39.37 & 45.35 & 37.93 \\
\hline & $\mathbf{F}$ & $\%$ & $\mathbf{F}$ & $\%$ & $\mathbf{F}$ & $\%$ & $\mathbf{F}$ & $\%$ & $\mathbf{F}$ & $\%$ \\
\hline \multicolumn{11}{|l|}{ Leptospira spp. } \\
\hline nausea & 8 & 50.00 & 13 & 44.83 & 8 & 32.00 & 11 & 36.67 & 24 & 39.34 \\
\hline vomiting & 7 & 43.75 & 13 & 44.83 & 9 & 36.00 & 12 & 40.00 & 29 & 47.54 \\
\hline abdominal pain & 8 & 50.00 & 12 & 41.38 & 9 & 36.00 & 13 & 43.33 & 25 & 40.98 \\
\hline diarrhea & 8 & 50.00 & 14 & 48.28 & 20 & 80.00 & 14 & 46.67 & 23 & 37.70 \\
\hline arthralgia & 12 & 75.00 & 14 & 48.28 & 10 & 40.00 & 13 & 43.33 & 26 & 42.62 \\
\hline headache & 8 & 50.00 & 16 & 55.17 & 21 & 84.00 & 13 & 43.33 & 26 & 42.62 \\
\hline prostration & 10 & 62.50 & 14 & 48.28 & 11 & 44.00 & 13 & 43.33 & 26 & 42.62 \\
\hline myalgia (particularly calf muscles) & 9 & 56.25 & 13 & 44.83 & 10 & 40.00 & 13 & 43.33 & 23 & 37.70 \\
\hline
\end{tabular}


Community-Based Flood Vulnerability Index for Urban Flooding: Understanding Social Vulnerabilities and Risks

Environmental Microbial Health Risks: KNOWLEDGE . . . continued

\begin{tabular}{|c|c|c|c|c|c|c|c|c|c|c|}
\hline Questions & \multicolumn{2}{|c|}{ Barangay 2} & \multicolumn{2}{|c|}{ Poblacion 8} & \multicolumn{2}{|c|}{ Cadawinonan } & \multicolumn{2}{|c|}{ Bagacay } & \multicolumn{2}{|c|}{ Taclobo } \\
\hline $\begin{array}{l}\text { 6. Do you know the signs and } \\
\text { symptoms of infection of : }\end{array}$ & & & & & & & & & & \\
\hline Item Summary & Mean & S.D. & Mean & S.D. & Mean & S.D. & Mean & S.D. & Mean & S.D. \\
\hline Mean Score & 4.38 & 3.40 & 3.76 & 3.73 & 3.92 & 4.48 & 3.40 & 3.55 & 3.21 & 3.41 \\
\hline \multirow[t]{2}{*}{ Percentage Score } & 54.69 & 42.54 & 46.98 & 46.61 & 49.00 & 56.01 & 42.50 & 44.36 & 40.08 & 42.61 \\
\hline & $\mathbf{F}$ & $\%$ & $\mathbf{F}$ & $\%$ & $\mathbf{F}$ & $\%$ & $\mathbf{F}$ & $\%$ & $\mathbf{F}$ & $\%$ \\
\hline \multicolumn{11}{|l|}{ Dengue Fever causing mosquito } \\
\hline high fever of acute onset & 13 & 81.25 & 25 & 86.21 & 20 & 80.00 & 26 & 86.67 & 56 & 91.80 \\
\hline $\begin{array}{l}\text { hemorrhagic manifestations } \\
\text { (presence of spots on the body) }\end{array}$ & 11 & 68.75 & 12 & 41.38 & 13 & 52.00 & 20 & 66.67 & 30 & 49.18 \\
\hline hepatomegally & 4 & 25.00 & 5 & 17.24 & 6 & 24.00 & 11 & 36.67 & 16 & 26.23 \\
\hline bleeding & 5 & 31.25 & 11 & 37.93 & 9 & 36.00 & 13 & 43.33 & 20 & 32.79 \\
\hline shock & 5 & 31.25 & 5 & 17.24 & 5 & 20.00 & 10 & 33.33 & 14 & 22.95 \\
\hline $\begin{array}{l}\text { myalgia and arthralgia (severe joint } \\
\text { and muscle pain) }\end{array}$ & 8 & 50.00 & 13 & 44.83 & 7 & 28.00 & 13 & 43.33 & 27 & 44.26 \\
\hline lymphadenopathy & 7 & 43.75 & 6 & 20.69 & 4 & 16.00 & 12 & 40.00 & 21 & 34.43 \\
\hline nausea and vomiting & 6 & 37.50 & 13 & 44.83 & 8 & 32.00 & 14 & 46.67 & 27 & 44.26 \\
\hline pain in eyeballs & 7 & 43.75 & 9 & 31.03 & 8 & 32.00 & 12 & 40.00 & 26 & 42.62 \\
\hline pain in back, body and joints & 10 & 62.50 & 11 & 37.93 & 9 & 36.00 & 14 & 46.67 & 23 & 37.70 \\
\hline \multicolumn{11}{|l|}{ severe headache } \\
\hline colds and flu & & & & & & & & & & \\
\hline
\end{tabular}


Community-Based Flood Vulnerability Index for Urban Flooding: Understanding Social Vulnerabilities and Risks

Environmental Microbial Health Risks: KNOWLEDGE . . . continued

\begin{tabular}{|c|c|c|c|c|c|c|c|c|c|c|}
\hline Questions & \multicolumn{2}{|c|}{ Barangay 2} & \multicolumn{2}{|c|}{ Poblacion 8} & \multicolumn{2}{|c|}{ Cadawinonan } & \multicolumn{2}{|c|}{ Bagacay } & \multicolumn{2}{|c|}{ Taclobo } \\
\hline $\begin{array}{l}\text { 6. Do you know the signs and } \\
\text { symptoms of infection of : }\end{array}$ & & & & & & & & & & \\
\hline Item Summary & Mean & S.D. & Mean & S.D. & Mean & S.D. & Mean & S.D. & Mean & S.D. \\
\hline Mean Score & 4.75 & 3.28 & 3.79 & 3.44 & 3.56 & 3.22 & 4.83 & 3.96 & 4.13 & 3.62 \\
\hline Percentage Score & 47.50 & 32.76 & 37.93 & 34.37 & 35.60 & 32.16 & 48.33 & 39.57 & 41.27 & 36.17 \\
\hline Overall Summary & Mean & S.D. & Mean & S.D. & Mean & S.D. & Mean & S.D. & Mean & S.D. \\
\hline Mean Score & 13.69 & 9.05 & 10.52 & 9.71 & 11.08 & 9.26 & 11.53 & 9.37 & 10.51 & 8.97 \\
\hline Percentage Score & 54.75 & 36.21 & 42.07 & 38.83 & 44.32 & 37.04 & 46.13 & 37.49 & 42.03 & 35.86 \\
\hline
\end{tabular}


Community-Based Flood Vulnerability Index for Urban Flooding: Understanding

Social Vulnerabilities and Risks

Environmental Microbial Health Risks: KNOWLEDGE ... continued

\begin{tabular}{|c|c|c|c|c|c|c|}
\hline \multirow{2}{*}{$\begin{array}{l}\text { Questions } \\
\begin{array}{l}\text { 6. Do you know the signs and symptoms of infection } \\
\text { of : }\end{array}\end{array}$} & \multicolumn{2}{|c|}{ Candau-ay } & \multicolumn{2}{|c|}{ Batinguel } & \multicolumn{2}{|c|}{ Overall } \\
\hline & $\mathbf{F}$ & $\%$ & $\mathbf{F}$ & $\%$ & $\mathbf{F}$ & $\%$ \\
\hline \multicolumn{7}{|l|}{ E. coli } \\
\hline severe abdominal cramps & 48 & 66.67 & 27 & 71.05 & 240 & 66.48 \\
\hline watery diarrhea & 46 & 63.89 & 21 & 55.26 & 221 & 61.22 \\
\hline vomiting & 41 & 56.94 & 18 & 47.37 & 195 & 54.02 \\
\hline fever & 43 & 59.72 & 19 & 50.00 & 183 & 50.69 \\
\hline severe neurological complications & 29 & 40.28 & 10 & 26.32 & 114 & 31.58 \\
\hline sometimes bloody diarrhea & 31 & 43.06 & 15 & 39.47 & 147 & 40.72 \\
\hline HUS (acute visceral failure, hemolytic anemia) & 27 & 37.5 & 12 & 31.58 & 108 & 29.9169 \\
\hline Item Summary & Mean & S.D. & Mean & S.D. & Mean & S.D. \\
\hline Mean Score & 3.68 & 2.86 & 3.21 & 2.70 & 3.35 & 0.46 \\
\hline \multirow[t]{2}{*}{ Percentage Score } & 52.58 & 40.82 & 45.86 & 38.61 & 47.81 & 6.58 \\
\hline & $\mathbf{F}$ & $\%$ & $\mathbf{F}$ & $\%$ & $\mathbf{F}$ & $\%$ \\
\hline \multicolumn{7}{|l|}{ Leptospira spp. } \\
\hline nausea & 28 & 38.89 & 14 & 36.84 & 145 & 40.17 \\
\hline vomiting & 30 & 41.67 & 13 & 34.21 & 149 & 41.27 \\
\hline abdominal pain & 32 & 44.44 & 15 & 39.47 & 148 & 41.00 \\
\hline diarrhea & 31 & 43.06 & 20 & 52.63 & 172 & 47.65 \\
\hline arthralgia & 31 & 43.06 & 13 & 34.21 & 159 & 44.04 \\
\hline headache & 35 & 48.61 & 11 & 28.95 & 170 & 47.09 \\
\hline prostration & 32 & 44.44 & 13 & 34.21 & 159 & 44.04 \\
\hline myalgia (particularly calf muscles) & 31 & 43.06 & 10 & 26.32 & 147 & 40.72 \\
\hline
\end{tabular}


Community-Based Flood Vulnerability Index for Urban Flooding: Understanding Social Vulnerabilities and Risks

Environmental Microbial Health Risks: KNOWLEDGE . . . continued

\begin{tabular}{|c|c|c|c|c|c|c|}
\hline \multirow{2}{*}{$\begin{array}{l}\text { Questions } \\
\begin{array}{l}\text { 6. Do you know the signs and symptoms of infection } \\
\text { of : }\end{array}\end{array}$} & \multicolumn{2}{|c|}{ Candau-ay } & \multicolumn{2}{|c|}{ Batinguel } & \multicolumn{2}{|c|}{ Overall } \\
\hline & & & & & & \\
\hline Item Summary & Mean & S.D. & Mean & S.D. & Mean & S.D. \\
\hline Mean Score & 3.47 & 3.44 & 2.87 & 3.18 & 3.60 & 0.63 \\
\hline \multirow[t]{2}{*}{ Percentage Score } & 43.40 & 43.04 & 35.86 & 39.76 & 44.99 & 7.87 \\
\hline & $\mathbf{F}$ & $\%$ & $\mathbf{F}$ & $\%$ & $\mathbf{F}$ & $\%$ \\
\hline \multicolumn{7}{|l|}{ Dengue Fever causing mosquito } \\
\hline high fever of acute onset & 62 & 86.11 & 29 & 76.32 & 300 & 83.10 \\
\hline $\begin{array}{l}\text { hemorrhagic manifestations (presence of spots on } \\
\text { the body) }\end{array}$ & 38 & 52.78 & 18 & 47.37 & 188 & 52.08 \\
\hline hepatomegally & 19 & 26.39 & 8 & 21.05 & 90 & 24.93 \\
\hline bleeding & 25 & 34.72 & 15 & 39.47 & 124 & 34.35 \\
\hline shock & 13 & 18.06 & 4 & 10.53 & 70 & 19.39 \\
\hline myalgia and arthralgia (severe joint and muscle pain) & 26 & 36.11 & 12 & 31.58 & 143 & 39.61 \\
\hline lymphadenopathy & 17 & 23.61 & 7 & 18.42 & 99 & 27.42 \\
\hline nausea and vomiting & 28 & 38.89 & 10 & 26.32 & 150 & 41.55 \\
\hline pain in eyeballs & 30 & 41.67 & 13 & 34.21 & 137 & 37.95 \\
\hline pain in back, body and joints & 34 & 47.22 & 13 & 34.21 & 153 & 42.38 \\
\hline \multicolumn{7}{|l|}{ severe headache } \\
\hline colds and flu & & & & & & \\
\hline
\end{tabular}


Community-Based Flood Vulnerability Index for Urban Flooding: Understanding

Social Vulnerabilities and Risks

Environmental Microbial Health Risks: KNOWLEDGE . . . continued

\begin{tabular}{|c|c|c|c|c|c|c|}
\hline \multirow{2}{*}{$\begin{array}{l}\text { Questions } \\
\text { 6. Do you know the signs and symptoms of infection } \\
\text { of : }\end{array}$} & \multicolumn{2}{|c|}{ Candau-ay } & \multicolumn{2}{|c|}{ Batinguel } & \multicolumn{2}{|c|}{ Overall } \\
\hline & & & & & & \\
\hline Item Summary & Mean & S.D. & Mean & S.D. & Mean & S.D. \\
\hline Mean Score & 4.06 & 3.44 & 3.39 & 3.17 & 4.05 & 0.47 \\
\hline Percentage Score & 40.56 & 34.35 & 33.95 & 31.67 & 40.53 & 4.67 \\
\hline Overall Summary & Mean & S.D. & Mean & S.D. & Mean & S.D. \\
\hline Mean Score & 11.21 & 9.00 & 9.47 & 8.35 & 11.00 & 1.25 \\
\hline Percentage Score & 44.83 & 35.98 & 37.89 & 33.41 & 44.00 & 5.01 \\
\hline
\end{tabular}

Environmental Microbial Health Risks: KNOWLEDGE . . . continued

\begin{tabular}{|c|c|c|c|c|c|c|c|c|c|c|}
\hline \multirow[t]{2}{*}{ Questions } & \multicolumn{2}{|c|}{ Tabuc-tubig } & \multicolumn{2}{|c|}{ Junob } & \multicolumn{2}{|c|}{ Poblacion 1} & \multicolumn{2}{|c|}{ Calindagan } & \multicolumn{2}{|c|}{ Balugo } \\
\hline & $\mathbf{F}$ & $\%$ & $\mathbf{F}$ & $\%$ & $\mathbf{F}$ & $\%$ & $\mathbf{F}$ & $\%$ & $\mathbf{F}$ & $\%$ \\
\hline $\begin{array}{l}\text { 7. Do you know how E. coli } \\
\text { infection, Liptospira spp. and } \\
\text { Dengue Fever infection can be } \\
\text { fatal? }\end{array}$ & 9 & 90.00 & 16 & 100.00 & 18 & 81.82 & 23 & 100.00 & 17 & 100.00 \\
\hline Item Summary & Mean & S.D. & Mean & S.D. & Mean & S.D. & Mean & S.D. & Mean & S.D. \\
\hline Mean Score & 0.90 & 0.32 & 1.00 & 0.00 & 0.82 & 0.39 & 1.00 & 0.00 & 1.00 & 0.00 \\
\hline Percentage Score & 90.00 & 31.62 & 100.00 & 0.00 & 81.82 & 39.48 & 100.00 & 0.00 & 100.00 & 0.00 \\
\hline
\end{tabular}


Community-Based Flood Vulnerability Index for Urban Flooding: Understanding Social Vulnerabilities and Risks

\begin{tabular}{|c|c|c|c|c|c|c|c|c|c|c|}
\hline \multirow{2}{*}{ Questions } & \multicolumn{2}{|c|}{ Barangay 2} & \multicolumn{2}{|c|}{ Poblacion 8} & \multicolumn{2}{|c|}{ Cadawinonan } & \multicolumn{2}{|c|}{ Bagacay } & \multicolumn{2}{|c|}{ Taclobo } \\
\hline & $\mathbf{F}$ & $\%$ & $\mathbf{F}$ & $\%$ & $\mathbf{F}$ & $\%$ & $\mathbf{F}$ & $\%$ & $\mathbf{F}$ & $\%$ \\
\hline $\begin{array}{l}\text { 7. Do you know how E. coli } \\
\text { infection, Liptospira spp. and } \\
\text { Dengue Fever infection can be } \\
\text { fatal? }\end{array}$ & 15 & 93.75 & 28 & 96.55 & 20 & 80.00 & 27 & 90.00 & 55 & 90.16 \\
\hline Item Summary & Mean & S.D. & Mean & S.D. & Mean & S.D. & Mean & S.D. & Mean & S.D. \\
\hline Mean Score & 0.94 & 0.25 & 0.97 & 0.19 & 0.80 & 0.41 & 0.90 & 0.31 & 0.87 & 0.34 \\
\hline Percentage Score & 93.75 & 25.00 & 96.55 & 18.57 & 80.00 & 40.82 & 90.00 & 30.51 & 87.30 & 33.56 \\
\hline
\end{tabular}

Environmental Microbial Health Risks: KNOWLEDGE . . . continued

\begin{tabular}{|c|c|c|c|c|c|c|}
\hline \multirow{2}{*}{ Questions } & \multicolumn{2}{|c|}{ Candau-ay } & \multicolumn{2}{|c|}{ Batinguel } & \multicolumn{2}{|c|}{ Overall } \\
\hline & $\mathbf{F}$ & $\%$ & $\mathbf{F}$ & $\%$ & $\mathbf{F}$ & $\%$ \\
\hline $\begin{array}{l}\text { 7. Do you know how E. coli infection, Liptospira spp. } \\
\text { and Dengue Fever infection can be fatal? }\end{array}$ & 71 & 98.61 & 35 & 92.11 & 334 & 92.52 \\
\hline Item Summary & Mean & S.D. & Mean & S.D. & Mean & S.D. \\
\hline Mean Score & 0.99 & 0.12 & 0.92 & 0.27 & 0.93 & 0.07 \\
\hline Percentage Score & 98.61 & 11.79 & 92.11 & 27.33 & 92.51 & 6.97 \\
\hline
\end{tabular}


Community-Based Flood Vulnerability Index for Urban Flooding: Understanding

Social Vulnerabilities and Risks

Environmental Microbial Health Risks: KNOWLEDGE . . . continued

\begin{tabular}{|c|c|c|c|c|c|c|c|c|c|c|}
\hline \multirow{2}{*}{ Questions } & \multicolumn{2}{|c|}{ Tabuc-tubig } & \multicolumn{2}{|c|}{ Junob } & \multicolumn{2}{|c|}{ Poblacion 1} & \multicolumn{2}{|c|}{ Calindagan } & \multicolumn{2}{|c|}{ Balugo } \\
\hline & $\mathbf{F}$ & $\%$ & $\mathbf{F}$ & $\%$ & $\mathbf{F}$ & $\%$ & $\mathbf{F}$ & $\%$ & $\mathbf{F}$ & $\%$ \\
\hline $\begin{array}{l}\text { 8. Do you know that E. coli, } \\
\text { Leptospira spp. \& Dengue Fever } \\
\text { mosquito can also be treated? }\end{array}$ & 8 & 80.00 & 11 & 68.75 & 18 & 81.82 & 23 & 100.00 & 15 & 88.24 \\
\hline Item Summary & Mean & S.D. & Mean & S.D. & Mean & S.D. & Mean & S.D. & Mean & S.D. \\
\hline Mean Score & 0.80 & 0.42 & 0.69 & 0.48 & 0.82 & 0.39 & 1.00 & 0.00 & 0.88 & 0.33 \\
\hline Percentage Score & 80.00 & 42.16 & 68.75 & 47.87 & 81.82 & 39.48 & 100.00 & 0.00 & 88.24 & 33.21 \\
\hline
\end{tabular}

\begin{tabular}{|c|c|c|c|c|c|c|c|c|c|c|}
\hline \multirow{2}{*}{ Questions } & \multicolumn{2}{|c|}{ Barangay 2} & \multicolumn{2}{|c|}{ Poblacion 8} & \multicolumn{2}{|c|}{ Cadawinonan } & \multicolumn{2}{|c|}{ Bagacay } & \multicolumn{2}{|c|}{ Taclobo } \\
\hline & $\mathbf{F}$ & $\%$ & $\mathbf{F}$ & $\%$ & $\mathbf{F}$ & $\%$ & $\mathbf{F}$ & $\%$ & $\mathbf{F}$ & $\%$ \\
\hline $\begin{array}{l}\text { 8. Do you know that E. coli, } \\
\text { Leptospira spp. \& Dengue Fever } \\
\text { mosquito can also be treated? }\end{array}$ & 15 & 93.75 & 29 & 100.00 & 21 & 84.00 & 25 & 83.33 & 59 & 96.72 \\
\hline Item Summary & Mean & S.D. & Mean & S.D. & Mean & S.D. & Mean & S.D. & Mean & S.D. \\
\hline Mean Score & 0.94 & 0.25 & 1.00 & 0.00 & 0.84 & 0.37 & 0.83 & 0.38 & 0.94 & 0.25 \\
\hline Percentage Score & 93.75 & 25.00 & 100.00 & 0.00 & 84.00 & 37.42 & 83.33 & 37.90 & 93.65 & 24.58 \\
\hline
\end{tabular}

\begin{tabular}{|c|c|c|c|c|c|c|}
\hline \multirow{2}{*}{ Questions } & \multicolumn{2}{|c|}{ Candau-ay } & \multicolumn{2}{|c|}{ Batinguel } & \multicolumn{2}{|c|}{ Overall } \\
\hline & $\mathbf{F}$ & $\%$ & $\mathbf{F}$ & $\%$ & $\mathbf{F}$ & $\%$ \\
\hline $\begin{array}{l}\text { 8. Do you know that E. coli, Leptospira spp. \& } \\
\text { Dengue Fever mosquito can also be treated? }\end{array}$ & 67 & 93.06 & 35 & 92.11 & 326 & 90.30 \\
\hline Item Summary & Mean & S.D. & Mean & S.D. & Mean & S.D. \\
\hline Mean Score & 0.93 & 93.06 & 0.92 & 0.27 & 0.88 & 0.09 \\
\hline Percentage Score & 0.26 & 25.60 & 92.11 & 27.33 & 88.22 & 9.07 \\
\hline
\end{tabular}


Community-Based Flood Vulnerability Index for Urban Flooding: Understanding Social Vulnerabilities and Risks

9. Where did you get your sources of information on E. coli infection, Liptospira spp. and Dengue Fever infection?

\begin{tabular}{|c|c|c|c|c|c|c|c|c|c|c|}
\hline \multirow{2}{*}{ Source } & \multicolumn{2}{|c|}{ Tabuc-tubig } & \multicolumn{2}{|l|}{ Junob } & \multicolumn{2}{|c|}{ Poblacion 1} & \multicolumn{2}{|l|}{ Calindagan } & \multicolumn{2}{|l|}{ Balugo } \\
\hline & $\mathbf{F}$ & $\%$ & $\mathbf{F}$ & $\%$ & $\mathbf{F}$ & $\%$ & $\mathbf{F}$ & $\%$ & $\mathbf{F}$ & $\%$ \\
\hline TV & 8 & 80.00 & 15 & 93.75 & 13 & 59.09 & 18 & 78.26 & 14 & 82.35 \\
\hline radio programs & 2 & 20.00 & 9 & 56.25 & 8 & 36.36 & 9 & 39.13 & 9 & 52.94 \\
\hline newspapers & 3 & 30.00 & 5 & 31.25 & 8 & 36.36 & 6 & 26.09 & 5 & 29.41 \\
\hline books & 3 & 30.00 & 3 & 18.75 & 6 & 27.27 & 3 & 13.04 & 2 & 11.76 \\
\hline school discussions & 3 & 30.00 & 8 & 50.00 & 9 & 40.91 & 9 & 39.13 & 6 & 35.29 \\
\hline Family & 2 & 20.00 & 1 & 6.25 & 9 & 40.91 & 4 & 17.39 & 3 & 17.65 \\
\hline Brgy. Discussions & 2 & 20.00 & 6 & 37.50 & 7 & 31.82 & 9 & 39.13 & 3 & 17.65 \\
\hline health care personal & 3 & 30.00 & 8 & 50.00 & 10 & 45.45 & 14 & 60.87 & 7 & 41.18 \\
\hline internet/online post & 0 & 0.00 & 1 & 6.25 & 7 & 31.82 & 5 & 21.74 & 4 & 23.53 \\
\hline mobile messages & 1 & 10.00 & 1 & 6.25 & 2 & 9.09 & 1 & 4.35 & 13 & 76.47 \\
\hline Brgy. Officials & 1 & 10.00 & 5 & 31.25 & 7 & 31.82 & 6 & 26.09 & 2 & 11.76 \\
\hline Personal experience & 2 & 20.00 & 4 & 25.00 & 5 & 22.73 & 2 & 8.70 & 2 & 11.76 \\
\hline
\end{tabular}


Community-Based Flood Vulnerability Index for Urban Flooding: Understanding

441 Social Vulnerabilities and Risks

9. Where did you get your sources of information on E. coli infection, Liptospira spp. and Dengue Fever infection? ... continued

\begin{tabular}{|c|c|c|c|c|c|c|c|c|c|c|}
\hline \multirow{2}{*}{ Source } & \multicolumn{2}{|c|}{ Barangay 2} & \multicolumn{2}{|c|}{ Poblacion 8} & \multicolumn{2}{|c|}{ Cadawinonan } & \multicolumn{2}{|c|}{ Bagacay } & \multicolumn{2}{|c|}{ Taclobo } \\
\hline & $\mathbf{F}$ & $\%$ & $\mathbf{F}$ & $\%$ & $\mathbf{F}$ & $\%$ & $\mathbf{F}$ & $\%$ & $\mathbf{F}$ & $\%$ \\
\hline TV & 14 & 87.50 & 27 & 93.10 & 21 & 84.00 & 20 & 66.67 & 50 & 81.97 \\
\hline radio programs & 4 & 25.00 & 15 & 51.72 & 12 & 48.00 & 11 & 36.67 & 29 & 47.54 \\
\hline newspapers & 5 & 31.25 & 8 & 27.59 & 9 & 36.00 & 4 & 13.33 & 20 & 32.79 \\
\hline books & 4 & 25.00 & 6 & 20.69 & 3 & 12.00 & 4 & 13.33 & 18 & 29.51 \\
\hline school discussions & 4 & 25.00 & 10 & 34.48 & 6 & 24.00 & 8 & 26.67 & 21 & 34.43 \\
\hline Family & 2 & 12.50 & 6 & 20.69 & 3 & 12.00 & 4 & 13.33 & 15 & 24.59 \\
\hline Brgy. Discussions & 4 & 25.00 & 15 & 51.72 & 5 & 20.00 & 7 & 23.33 & 14 & 22.95 \\
\hline health care personal & 5 & 31.25 & 15 & 51.72 & 10 & 40.00 & 18 & 60.00 & 25 & 40.98 \\
\hline internet/online post & 5 & 31.25 & 6 & 20.69 & 4 & 16.00 & 3 & 10.00 & 16 & 26.23 \\
\hline mobile messages & 1 & 6.25 & 4 & 13.79 & 3 & 12.00 & 2 & 6.67 & 8 & 13.11 \\
\hline Brgy. Officials & 1 & 6.25 & 11 & 37.93 & 5 & 20.00 & 3 & 10.00 & 10 & 16.39 \\
\hline Personal experience & 3 & 18.75 & 4 & 13.79 & 5 & 20.00 & 1 & 3.33 & 6 & 9.84 \\
\hline
\end{tabular}


Community-Based Flood Vulnerability Index for Urban Flooding: Understanding Social Vulnerabilities and Risks

442

9. Where did you get your sources of information on E. coli infection, Liptospira spp. and Dengue Fever infection? ... continued

\begin{tabular}{|c|c|c|c|c|c|c|}
\hline \multirow{2}{*}{ Source } & \multicolumn{2}{|c|}{ Candau-ay } & \multicolumn{2}{|c|}{ Batinguel } & \multicolumn{2}{|c|}{ Overall } \\
\hline & $\mathbf{F}$ & $\%$ & $\mathbf{F}$ & $\%$ & $\mathbf{F}$ & $\%$ \\
\hline TV & 60 & 83.33 & 33 & 86.84 & 293 & 81.16 \\
\hline radio programs & 41 & 56.94 & 14 & 36.84 & 163 & 45.15 \\
\hline newspapers & 24 & 33.33 & 9 & 23.68 & 106 & 29.36 \\
\hline books & 17 & 23.61 & 9 & 23.68 & 78 & 21.61 \\
\hline school discussions & 25 & 34.72 & 13 & 34.21 & 122 & 33.80 \\
\hline Family & 22 & 30.56 & 6 & 15.79 & 77 & 21.33 \\
\hline Brgy. Discussions & 16 & 22.22 & 6 & 15.79 & 94 & 26.04 \\
\hline health care personal & 32 & 44.44 & 13 & 34.21 & 160 & 44.32 \\
\hline internet/online post & 16 & 22.22 & 5 & 13.16 & 72 & 19.94 \\
\hline mobile messages & 11 & 15.28 & 3 & 7.89 & 50 & 13.85 \\
\hline Brgy. Officials & 17 & 23.61 & 6 & 15.79 & 74 & 20.50 \\
\hline Personal experience & 11 & 15.28 & 7 & 18.42 & 52 & 14.40 \\
\hline
\end{tabular}


Community-Based Flood Vulnerability Index for Urban Flooding: Understanding

Social Vulnerabilities and Risks

Environmental Microbial Health Risks: KNOWLEDGE PERCENT SCORE SUMMARY

\begin{tabular}{|c|c|c|c|c|c|c|c|c|c|c|}
\hline \multirow{2}{*}{ Questions } & \multicolumn{2}{|c|}{ Tabuc-tubig } & \multicolumn{2}{|c|}{ Junob } & \multicolumn{2}{|c|}{ Poblacion 1} & \multicolumn{2}{|c|}{ Calindagan } & \multicolumn{2}{|c|}{ Balugo } \\
\hline & Mean & S.D. & Mean & S.D. & Mean & S.D. & Mean & S.D. & Mean & S.D. \\
\hline $\begin{array}{l}\text { 1. Have you heard about the } \\
\text { following bacteria and virus: E. coli, } \\
\text { Leptospira spp., Dengue Fever } \\
\text { Mosquito? }\end{array}$ & 73.33 & 26.29 & 81.25 & 32.13 & 84.85 & 22.37 & 85.51 & 26.26 & 84.31 & 20.81 \\
\hline $\begin{array}{l}\text { 2. Have you heard about that there } \\
\text { are bad and dangerous bacteria in } \\
\text { water? }\end{array}$ & 100.00 & 0.00 & 93.75 & 25.00 & 95.45 & 21.32 & 100.00 & 0.00 & 94.12 & 24.25 \\
\hline $\begin{array}{l}\text { 3. Are you aware that E. coli, } \\
\text { Leptospira spp. \& Dengue Fever } \\
\text { mosquito can be deadly? }\end{array}$ & 90.00 & 31.62 & 87.50 & 34.16 & 95.45 & 21.32 & 100.00 & 0.00 & 94.12 & 24.25 \\
\hline $\begin{array}{l}\text { 4. Do you know how the following } \\
\text { bacteria and virus (E. coli, Leptospira } \\
\text { spp., Dengue Fever Mosquito) can } \\
\text { be transmitted? }\end{array}$ & 66.25 & 42.92 & 58.59 & 31.53 & 63.07 & 33.74 & 61.96 & 29.79 & 63.24 & 33.21 \\
\hline $\begin{array}{l}\text { 5. Have you heard that infections } \\
\text { brought about by these bacteria and } \\
\text { virus (E. coli, Leptospira spp., } \\
\text { Dengue Fever Mosquito) can be } \\
\text { prevented? }\end{array}$ & 57.75 & 38.67 & 64.45 & 35.63 & 60.51 & 33.93 & 58.70 & 37.68 & 59.56 & 37.38 \\
\hline $\begin{array}{l}\text { 6. Do you know the signs and } \\
\text { symptoms of infection of E. coli, } \\
\text { Leptospira spp., Dengue Fever } \\
\text { Mosquito? }\end{array}$ & 48.40 & 36.00 & 48.25 & 30.30 & 41.82 & 35.88 & 41.22 & 34.23 & 36.24 & 33.18 \\
\hline
\end{tabular}


Community-Based Flood Vulnerability Index for Urban Flooding: Understanding

Social Vulnerabilities and Risks

Environmental Microbial Health Risks: KNOWLEDGE PERCENT SCORE SUMMARY . . continued

\begin{tabular}{|c|c|c|c|c|c|c|c|c|c|c|}
\hline \multirow{2}{*}{ Questions } & \multicolumn{2}{|c|}{ Tabuc-tubig } & \multicolumn{2}{|c|}{ Junob } & \multicolumn{2}{|c|}{ Poblacion 1} & \multicolumn{2}{|c|}{ Calindagan } & \multicolumn{2}{|c|}{ Balugo } \\
\hline & Mean & S.D. & Mean & S.D. & Mean & S.D. & Mean & S.D. & Mean & S.D. \\
\hline $\begin{array}{l}\text { 7. Do you know how E. coli infection, } \\
\text { Liptospira spp. and Dengue Fever } \\
\text { infection can be fatal? }\end{array}$ & 90.00 & 31.62 & 100.00 & 0.00 & 81.82 & 39.48 & 100.00 & 0.00 & 100.00 & 0.00 \\
\hline $\begin{array}{l}\text { 8. Do you know that E. coli, } \\
\text { Leptospira spp. \& Dengue Fever } \\
\text { mosquito can also be treated? }\end{array}$ & 80.00 & 42.16 & 68.75 & 47.87 & 81.82 & 39.48 & 100.00 & 0.00 & 88.24 & 33.21 \\
\hline Overall & 75.72 & 17.65 & 75.32 & 18.15 & 75.60 & 18.81 & 80.92 & 23.63 & 77.48 & 22.20 \\
\hline
\end{tabular}


Community-Based Flood Vulnerability Index for Urban Flooding: Understanding

Social Vulnerabilities and Risks

Environmental Microbial Health Risks: KNOWLEDGE PERCENT SCORE SUMMARY . . . continued

\begin{tabular}{|c|c|c|c|c|c|c|c|c|c|c|}
\hline \multirow{2}{*}{ Questions } & \multicolumn{2}{|c|}{ Barangay 2} & \multicolumn{2}{|c|}{ Poblacion 8} & \multicolumn{2}{|c|}{ Cadawinonan } & \multicolumn{2}{|l|}{ Bagacay } & \multicolumn{2}{|l|}{ Taclobo } \\
\hline & Mean & S.D. & Mean & S.D. & Mean & S.D. & Mean & S.D. & Mean & S.D. \\
\hline $\begin{array}{l}\text { 1. Have you heard about the } \\
\text { following bacteria and virus: E. coli, } \\
\text { Leptospira spp., Dengue Fever } \\
\text { Mosquito? }\end{array}$ & 95.83 & 11.39 & 87.36 & 25.84 & 84.00 & 21.77 & 78.89 & 29.66 & 79.89 & 26.46 \\
\hline $\begin{array}{l}\text { 2. Have you heard about that there } \\
\text { are bad and dangerous bacteria in } \\
\text { water? }\end{array}$ & 100.00 & 0.00 & 89.66 & 30.99 & 30.67 & 9.23 & 86.67 & 34.57 & 96.83 & 17.67 \\
\hline $\begin{array}{l}\text { 3. Are you aware that E. coli, } \\
\text { Leptospira spp. \& Dengue Fever } \\
\text { mosquito can be deadly? }\end{array}$ & 93.75 & 25.00 & 93.10 & 25.79 & 96.00 & 20.00 & 86.67 & 34.57 & 93.65 & 24.58 \\
\hline $\begin{array}{l}\text { 4. Do you know how the following } \\
\text { bacteria and virus (E. coli, Leptospira } \\
\text { spp., Dengue Fever Mosquito) can } \\
\text { be transmitted? }\end{array}$ & 69.53 & 32.90 & 59.05 & 27.73 & 61.50 & 32.86 & 56.25 & 34.86 & 57.34 & 32.04 \\
\hline $\begin{array}{l}\text { 5. Have you heard that infections } \\
\text { brought about by these bacteria and } \\
\text { virus (E. coli, Leptospira spp., } \\
\text { Dengue Fever Mosquito) can be } \\
\text { prevented? }\end{array}$ & 5.97 & 37.34 & 55.17 & 38.71 & 57.75 & 38.67 & 56.67 & 41.06 & 55.56 & 39.94 \\
\hline $\begin{array}{l}\text { 6. Do you know the signs and } \\
\text { symptoms of infection of E. coli, } \\
\text { Leptospira spp., Dengue Fever } \\
\text { Mosquito? }\end{array}$ & 54.75 & 36.21 & 42.07 & 38.83 & 44.32 & 37.04 & 46.13 & 37.49 & 42.03 & 35.86 \\
\hline
\end{tabular}


Community-Based Flood Vulnerability Index for Urban Flooding: Understanding Social Vulnerabilities and Risks

Environmental Microbial Health Risks: KNOWLEDGE PERCENT SCORE SUMMARY . . . continued

\begin{tabular}{|c|c|c|c|c|c|c|c|c|c|c|}
\hline \multirow{2}{*}{ Questions } & \multicolumn{2}{|c|}{ Barangay 2} & \multicolumn{2}{|c|}{ Poblacion 8} & \multicolumn{2}{|c|}{ Cadawinonan } & \multicolumn{2}{|l|}{ Bagacay } & \multicolumn{2}{|l|}{ Taclobo } \\
\hline & Mean & S.D. & Mean & S.D. & Mean & S.D. & Mean & S.D. & Mean & S.D. \\
\hline $\begin{array}{l}\text { 7. Do you know how E. coli infection, } \\
\text { Liptospira spp. and Dengue Fever } \\
\text { infection can be fatal? }\end{array}$ & 93.75 & 25.00 & 96.55 & 18.57 & 80.00 & 40.82 & 90.00 & 30.51 & 87.30 & 33.56 \\
\hline $\begin{array}{l}\text { 8. Do you know that E. coli, } \\
\text { Leptospira spp. \& Dengue Fever } \\
\text { mosquito can also be treated? }\end{array}$ & 93.75 & 25.00 & 100.00 & 0.00 & 84.00 & 37.42 & 83.33 & 37.90 & 93.65 & 24.58 \\
\hline Overall & 75.92 & 32.32 & 77.87 & 22.20 & 67.28 & 22.48 & 73.08 & 17.21 & 75.78 & 21.11 \\
\hline
\end{tabular}


Community-Based Flood Vulnerability Index for Urban Flooding: Understanding

Social Vulnerabilities and Risks

Environmental Microbial Health Risks: KNOWLEDGE PERCENT SCORE SUMMARY . . . continued

\begin{tabular}{|c|c|c|c|c|c|c|}
\hline \multirow{2}{*}{ Questions } & \multicolumn{2}{|c|}{ Candau-ay } & \multicolumn{2}{|c|}{ Batinguel } & \multicolumn{2}{|c|}{ Overall } \\
\hline & Mean & S.D. & Mean & S.D. & Mean & S.D. \\
\hline $\begin{array}{l}\text { 1. Have you heard about the following bacteria and } \\
\text { virus: E. coli, Leptospira spp., Dengue Fever } \\
\text { Mosquito? }\end{array}$ & 84.72 & 26.20 & 86.84 & 26.33 & 83.90 & 5.45 \\
\hline $\begin{array}{l}\text { 2. Have you heard about that there are bad and } \\
\text { dangerous bacteria in water? }\end{array}$ & 94.44 & 23.07 & 92.11 & 27.33 & 89.47 & 18.97 \\
\hline $\begin{array}{l}\text { 3. Are you aware that E. coli, Leptospira spp. \& } \\
\text { Dengue Fever mosquito can be deadly? }\end{array}$ & 98.61 & 11.79 & 94.74 & 22.63 & 93.63 & 3.99 \\
\hline $\begin{array}{l}\text { 4. Do you know how the following bacteria and virus } \\
\text { (E. coli, Leptospira spp., Dengue Fever Mosquito) can } \\
\text { be transmitted? }\end{array}$ & 69.10 & 32.90 & 54.61 & 31.36 & 61.71 & 4.83 \\
\hline $\begin{array}{l}\text { 5. Have you heard that infections brought about by } \\
\text { these bacteria and virus (E. coli, Leptospira spp., } \\
\text { Dengue Fever Mosquito) can be prevented? }\end{array}$ & 63.80 & 39.50 & 55.59 & 39.92 & 60.34 & 4.86 \\
\hline $\begin{array}{l}\text { 6. Do you know the signs and symptoms of infection } \\
\text { of E. coli, Leptospira spp., Dengue Fever Mosquito? }\end{array}$ & 43.40 & 43.04 & 35.86 & 39.76 & 44.99 & 7.87 \\
\hline
\end{tabular}

Environmental Microbial Health Risks: KNOWLEDGE PERCENT SCORE SUMMARY . . continued

\begin{tabular}{|l|r|r|r|r|r|}
\hline \multicolumn{1}{|c|}{ Questions } & \multicolumn{2}{|c|}{ Candau-ay } & \multicolumn{2}{|c|}{ Batinguel } & \multicolumn{2}{c|}{ Overall } \\
\cline { 2 - 6 } & \multicolumn{1}{|c|}{ Mean } & \multicolumn{1}{|c|}{ S.D. } & \multicolumn{1}{c|}{ Mean } & \multicolumn{1}{c|}{ S.D. } & \\
\hline $\begin{array}{l}\text { 7. Do you know how E. coli infection, Liptospira spp. } \\
\text { and Dengue Fever infection can be fatal? }\end{array}$ & 98.61 & 11.79 & 92.11 & 27.33 & 92.51 \\
\hline $\begin{array}{l}\text { 8. Do you know that E. coli, Leptospira spp. \& } \\
\text { Dengue Fever mosquito can also be treated? }\end{array}$ & 0.26 & 25.60 & 92.11 & 27.33 & 88.22 \\
\hline Overall & $\mathbf{6 9 . 1 2}$ & $\mathbf{3 3 . 9 2}$ & $\mathbf{7 5 . 4 9}$ & $\mathbf{2 3 . 0 9}$ & $\mathbf{7 6 . 8 5}$ \\
\hline
\end{tabular}


Community-Based Flood Vulnerability Index for Urban Flooding: Understanding

Social Vulnerabilities and Risks

Health Risk: E. coli ATTITUDE PERCENT SCORE SUMMARY

\begin{tabular}{|c|c|c|c|c|c|c|c|c|c|c|}
\hline \multirow[t]{2}{*}{ Items } & \multicolumn{2}{|c|}{ Tabuc-tubig } & \multicolumn{2}{|c|}{ Junob } & \multicolumn{2}{|c|}{ Poblacion 1} & \multicolumn{2}{|c|}{ Calindagan } & \multicolumn{2}{|c|}{ Balugo } \\
\hline & Mean & S.D. & Mean & S.D. & Mean & S.D. & Mean & S.D. & Mean & S.D. \\
\hline The nature of E.coli & 3.00 & 1.25 & 3.38 & 1.09 & 3.18 & 0.85 & 3.04 & 0.98 & 3.06 & 1.20 \\
\hline Mode of transmission & 3.50 & 0.71 & 3.50 & 1.03 & 3.09 & 1.02 & 3.09 & 0.97 & 3.18 & 1.13 \\
\hline Prevention & 2.90 & 1.37 & 3.38 & 1.02 & 3.38 & 1.02 & 3.17 & 0.98 & 3.12 & 1.22 \\
\hline Signs and symptoms & 3.10 & 0.99 & 3.25 & 1.18 & 3.41 & 0.67 & 3.04 & 0.93 & 3.35 & 0.93 \\
\hline It is fatal & 3.70 & 0.48 & 3.56 & 1.03 & 3.50 & 0.86 & 3.32 & 0.95 & 3.41 & 1.00 \\
\hline Treatment & 3.50 & 0.85 & 3.38 & 1.02 & 3.27 & 0.94 & 3.17 & 0.94 & 3.29 & 1.10 \\
\hline Financial cost of treatment & 3.30 & 0.95 & 3.69 & 0.79 & 3.14 & 0.99 & 3.30 & 0.88 & 3.35 & 0.93 \\
\hline The infection itself & 3.40 & 1.26 & 3.63 & 0.81 & 3.48 & 0.68 & 3.17 & 0.94 & 3.24 & 1.03 \\
\hline Information drive & 3.80 & 0.63 & 3.38 & 1.02 & 3.32 & 0.89 & 3.04 & 1.07 & 3.24 & 1.09 \\
\hline \multicolumn{11}{|l|}{ Overall } \\
\hline Mean Score & 3.36 & 0.70 & 3.46 & 0.81 & 3.27 & 0.74 & 3.12 & 0.86 & 3.25 & 0.88 \\
\hline Mean Percent Score & 83.89 & 17.51 & 86.46 & 20.18 & 81.82 & 18.52 & 78.02 & 21.40 & 81.21 & 21.88 \\
\hline
\end{tabular}


Community-Based Flood Vulnerability Index for Urban Flooding: Understanding

Social Vulnerabilities and Risks

Health Risk: E. coli ATTITUDE PERCENT SCORE SUMMARY ... continued

\begin{tabular}{|c|c|c|c|c|c|c|c|c|c|c|}
\hline \multirow{2}{*}{ Items } & \multicolumn{2}{|c|}{ Barangay 2} & \multicolumn{2}{|c|}{ Poblacion 8} & \multicolumn{2}{|c|}{ Cadawinonan } & \multicolumn{2}{|c|}{ Bagacay } & \multicolumn{2}{|c|}{ Taclobo } \\
\hline & Mean & S.D. & Mean & S.D. & Mean & S.D. & Mean & S.D. & Mean & S.D. \\
\hline The nature of E.coli & 3.00 & 1.10 & 2.86 & 0.99 & 2.83 & 1.17 & 2.66 & 1.14 & 2.94 & 1.20 \\
\hline Mode of transmission & 3.06 & 1.06 & 3.00 & 1.04 & 3.00 & 1.18 & 2.80 & 1.10 & 3.02 & 1.17 \\
\hline Prevention & 3.44 & 0.96 & 3.17 & 1.04 & 2.96 & 1.16 & 2.97 & 1.16 & 3.19 & 1.20 \\
\hline Signs and symptoms & 3.25 & 0.86 & 3.10 & 1.05 & 3.08 & 1.06 & 2.77 & 1.17 & 3.08 & 1.20 \\
\hline It is fatal & 3.69 & 0.60 & 3.25 & 1.00 & 3.33 & 0.92 & 2.97 & 1.16 & 3.11 & 1.17 \\
\hline Treatment & 3.50 & 0.89 & 3.21 & 0.99 & 2.96 & 1.12 & 2.90 & 1.12 & 3.17 & 1.13 \\
\hline Financial cost of treatment & 3.31 & 0.95 & 3.10 & 0.98 & 3.00 & 1.06 & 2.90 & 1.12 & 3.11 & 1.14 \\
\hline The infection itself & 3.38 & 1.09 & 3.24 & 0.99 & 3.04 & 1.20 & 2.90 & 1.12 & 3.14 & 1.15 \\
\hline Information drive & 3.06 & 1.06 & 2.93 & 1.03 & 2.92 & 1.14 & 2.87 & 1.20 & 3.02 & 1.17 \\
\hline \multicolumn{11}{|l|}{ Overall } \\
\hline Mean Score & 3.30 & 0.75 & 3.07 & 0.94 & 2.89 & 1.16 & 2.85 & 1.05 & 3.09 & 1.09 \\
\hline Mean Percent Score & 82.47 & 18.80 & 76.82 & 23.48 & 72.33 & 28.90 & 71.20 & 26.16 & 77.16 & 27.15 \\
\hline
\end{tabular}


Community-Based Flood Vulnerability Index for Urban Flooding: Understanding

Social Vulnerabilities and Risks

Health Risk: E. coli ATTITUDE PERCENT SCORE SUMMARY . . continued

\begin{tabular}{|c|c|c|c|c|c|c|}
\hline \multirow{2}{*}{ Items } & \multicolumn{2}{|c|}{ Candau-ay } & \multicolumn{2}{|c|}{ Batinguel } & \multicolumn{2}{|c|}{ Overall } \\
\hline & Mean & S.D. & Mean & S.D. & Mean & S.D. \\
\hline The nature of E.coli & 2.71 & 1.34 & 3.11 & 1.16 & 2.98 & 0.20 \\
\hline Mode of transmission & 2.68 & 1.32 & 3.11 & 1.11 & 3.09 & 0.24 \\
\hline Prevention & 2.71 & 1.36 & 3.16 & 1.15 & 3.13 & 0.22 \\
\hline Signs and symptoms & 2.82 & 1.25 & 3.24 & 1.05 & 3.12 & 0.19 \\
\hline It is fatal & 2.94 & 1.25 & 3.29 & 1.04 & 3.34 & 0.25 \\
\hline Treatment & 2.90 & 1.18 & 3.32 & 0.96 & 3.22 & 0.21 \\
\hline Financial cost of treatment & 2.72 & 1.20 & 3.21 & 0.91 & 3.18 & 0.25 \\
\hline The infection itself & 2.79 & 1.23 & 3.18 & 0.98 & 3.22 & 0.24 \\
\hline Information drive & 2.52 & 1.32 & 3.03 & 1.08 & 3.09 & 0.32 \\
\hline \multicolumn{7}{|l|}{ Overall } \\
\hline Mean Score & 2.75 & 1.17 & 3.18 & 0.95 & 3.13 & 0.22 \\
\hline Mean Percent Score & 68.67 & 29.27 & 79.53 & 23.85 & 78.30 & 5.39 \\
\hline
\end{tabular}


Community-Based Flood Vulnerability Index for Urban Flooding: Understanding

Social Vulnerabilities and Risks

Health Risk: Liptospirosis ATTITUDE PERCENT SCORE SUMMARY

\begin{tabular}{|c|c|c|c|c|c|c|c|c|c|c|}
\hline \multirow{2}{*}{ Items } & \multicolumn{2}{|c|}{ Tabuc-tubig } & \multicolumn{2}{|c|}{ Junob } & \multicolumn{2}{|c|}{ Poblacion 1} & \multicolumn{2}{|c|}{ Calindagan } & \multicolumn{2}{|c|}{ Balugo } \\
\hline & Mean & S.D. & Mean & S.D. & Mean & S.D. & Mean & S.D. & Mean & S.D. \\
\hline The nature of Liptospirosis & 3.60 & 0.52 & 3.44 & 1.03 & 3.36 & 0.90 & 3.30 & 0.93 & 3.41 & 0.71 \\
\hline Mode of transmission & 3.50 & 0.85 & 3.50 & 1.03 & 3.41 & 0.73 & 3.22 & 1.04 & 2.94 & 1.14 \\
\hline Prevention & 3.80 & 0.42 & 3.25 & 1.18 & 3.62 & 0.59 & 3.36 & 1.05 & 3.18 & 1.07 \\
\hline Signs and symptoms & 3.40 & 0.97 & 3.44 & 1.03 & 3.23 & 0.75 & 3.39 & 0.99 & 3.06 & 1.14 \\
\hline It is fatal & 3.50 & 0.85 & 3.44 & 1.21 & 3.43 & 0.87 & 3.57 & 0.84 & 3.29 & 1.05 \\
\hline Treatment & 3.60 & 0.84 & 3.25 & 1.18 & 3.32 & 0.89 & 3.48 & 0.85 & 3.41 & 0.80 \\
\hline Financial cost of treatment & 3.40 & 0.97 & 3.25 & 1.18 & 3.33 & 0.97 & 3.43 & 0.79 & 3.47 & 0.62 \\
\hline The infection itself & 3.60 & 0.84 & 3.56 & 1.03 & 3.36 & 0.85 & 3.41 & 0.91 & 3.00 & 0.79 \\
\hline Information drive & 3.50 & 0.85 & 3.38 & 1.02 & 3.36 & 0.90 & 3.22 & 1.09 & 3.29 & 0.92 \\
\hline \multicolumn{11}{|l|}{ Overall } \\
\hline Mean Score & 3.54 & 0.57 & 3.39 & 0.98 & 3.33 & 0.72 & 3.34 & 0.84 & 3.23 & 0.71 \\
\hline Mean Percent Score & 88.61 & 14.37 & 84.72 & 24.55 & 83.21 & 18.03 & 83.57 & 21.09 & 80.72 & 17.69 \\
\hline
\end{tabular}


Community-Based Flood Vulnerability Index for Urban Flooding: Understanding

Social Vulnerabilities and Risks

Health Risk: Liptospirosis ATTITUDE PERCENT SCORE SUMMARY . . continued

\begin{tabular}{|c|c|c|c|c|c|c|c|c|c|c|}
\hline \multirow{2}{*}{ Items } & \multicolumn{2}{|c|}{ Barangay 2} & \multicolumn{2}{|c|}{ Poblacion 8} & \multicolumn{2}{|c|}{ Cadawinonan } & \multicolumn{2}{|c|}{ Bagacay } & \multicolumn{2}{|c|}{ Taclobo } \\
\hline & Mean & S.D. & Mean & S.D. & Mean & S.D. & Mean & S.D. & Mean & S.D. \\
\hline The nature of Liptospirosis & 3.69 & 0.60 & 2.93 & 1.07 & 2.92 & 1.35 & 2.73 & 1.20 & 3.00 & 1.22 \\
\hline Mode of transmission & 3.69 & 0.60 & 3.07 & 1.13 & 2.83 & 1.34 & 2.67 & 1.24 & 3.08 & 1.17 \\
\hline Prevention & 3.69 & 0.79 & 3.10 & 1.11 & 2.79 & 1.38 & 2.83 & 1.21 & 3.14 & 1.22 \\
\hline Signs and symptoms & 3.44 & 0.89 & 3.07 & 1.07 & 2.88 & 1.26 & 2.80 & 1.16 & 3.11 & 1.19 \\
\hline It is fatal & 3.80 & 0.56 & 3.28 & 0.96 & 2.92 & 1.28 & 2.83 & 1.23 & 3.11 & 1.23 \\
\hline Treatment & 3.75 & 0.58 & 3.21 & 0.96 & 2.88 & 1.26 & 2.83 & 1.18 & 3.06 & 1.22 \\
\hline Financial cost of treatment & 3.53 & 0.74 & 3.14 & 0.92 & 2.92 & 1.28 & 2.90 & 1.24 & 2.95 & 1.22 \\
\hline The infection itself & 3.80 & 0.41 & 3.29 & 0.98 & 2.96 & 1.27 & 2.87 & 1.14 & 3.15 & 1.19 \\
\hline Information drive & 3.63 & 0.72 & 3.17 & 1.04 & 3.00 & 1.29 & 2.70 & 1.18 & 3.00 & 1.23 \\
\hline \multicolumn{11}{|l|}{ Overall } \\
\hline Mean Score & 3.59 & 0.60 & 3.11 & 0.95 & 2.78 & 1.34 & 2.80 & 1.12 & 3.06 & 1.14 \\
\hline Mean Percent Score & 89.76 & 15.10 & 77.87 & 23.81 & 69.56 & 33.56 & 69.91 & 27.90 & 76.41 & 28.39 \\
\hline
\end{tabular}


Community-Based Flood Vulnerability Index for Urban Flooding: Understanding

Social Vulnerabilities and Risks

Health Risk: Liptospirosis ATTITUDE PERCENT SCORE SUMMARY . . continued

\begin{tabular}{|c|c|c|c|c|c|c|}
\hline \multirow{2}{*}{ Items } & \multicolumn{2}{|c|}{ Candau-ay } & \multicolumn{2}{|c|}{ Batinguel } & \multicolumn{2}{|c|}{ Overall } \\
\hline & Mean & S.D. & Mean & S.D. & Mean & S.D. \\
\hline The nature of Liptospirosis & 2.57 & 1.32 & 3.26 & 1.18 & 3.18 & 0.35 \\
\hline Mode of transmission & 2.69 & 1.32 & 3.24 & 1.20 & 3.15 & 0.33 \\
\hline Prevention & 2.67 & 1.34 & 3.21 & 1.14 & 3.22 & 0.36 \\
\hline Signs and symptoms & 2.79 & 1.30 & 3.11 & 1.16 & 3.14 & 0.24 \\
\hline It is fatal & 2.88 & 1.24 & 3.21 & 1.12 & 3.27 & 0.30 \\
\hline Treatment & 2.83 & 1.24 & 3.21 & 1.12 & 3.24 & 0.30 \\
\hline Financial cost of treatment & 2.79 & 1.22 & 3.08 & 1.10 & 3.18 & 0.25 \\
\hline The infection itself & 2.82 & 1.25 & 3.21 & 1.09 & 3.25 & 0.31 \\
\hline Information drive & 2.51 & 1.34 & 3.18 & 1.18 & 3.16 & 0.32 \\
\hline \multicolumn{7}{|l|}{ Overall } \\
\hline Mean Score & 2.72 & 1.21 & 3.19 & 1.09 & 3.17 & 0.29 \\
\hline Mean Percent Score & 68.09 & 30.27 & 79.75 & 27.28 & 79.35 & 7.26 \\
\hline
\end{tabular}


Community-Based Flood Vulnerability Index for Urban Flooding: Understanding

Social Vulnerabilities and Risks

Health Risk: Dengue Fever ATTITUDE PERCENT SCORE SUMMARY

\begin{tabular}{|c|c|c|c|c|c|c|c|c|c|c|}
\hline \multirow{2}{*}{ Items } & \multicolumn{2}{|c|}{ Tabuc-tubig } & \multicolumn{2}{|c|}{ Junob } & \multicolumn{2}{|c|}{ Poblacion 1} & \multicolumn{2}{|c|}{ Calindagan } & \multicolumn{2}{|c|}{ Balugo } \\
\hline & Mean & S.D. & Mean & S.D. & Mean & S.D. & Mean & S.D. & Mean & S.D. \\
\hline The nature of Dengue Fever & 3.70 & 0.67 & 3.75 & 0.77 & 3.45 & 0.86 & 3.83 & 0.39 & 3.65 & 0.61 \\
\hline Mode of transmission & 4.00 & 0.00 & 3.75 & 0.77 & 3.41 & 0.80 & 3.61 & 0.50 & 3.47 & 0.62 \\
\hline Prevention & 3.60 & 0.70 & 3.50 & 1.03 & 3.57 & 0.81 & 3.70 & 0.56 & 3.41 & 0.71 \\
\hline Signs and symptoms & 3.60 & 0.70 & 3.50 & 0.89 & 3.41 & 0.80 & 3.74 & 0.45 & 3.56 & 0.51 \\
\hline It is fatal & 4.00 & 0.00 & 3.63 & 0.89 & 3.50 & 0.86 & 3.87 & 0.34 & 3.41 & 1.00 \\
\hline Treatment & 3.60 & 0.84 & 3.44 & 0.89 & 3.55 & 0.80 & 3.74 & 0.45 & 3.00 & 1.17 \\
\hline Financial cost of treatment & 3.80 & 0.63 & 3.38 & 1.02 & 3.36 & 1.00 & 3.65 & 0.49 & 3.53 & 0.51 \\
\hline The infection itself & 3.90 & 0.32 & 3.75 & 0.77 & 3.64 & 0.73 & 3.74 & 0.45 & 3.47 & 0.62 \\
\hline Information drive & 3.90 & 0.32 & 3.56 & 0.81 & 3.32 & 1.09 & 3.57 & 0.66 & 3.47 & 0.72 \\
\hline \multicolumn{11}{|l|}{ Overall } \\
\hline Mean Score & 3.79 & 0.37 & 3.58 & 0.76 & 3.45 & 0.79 & 3.71 & 0.37 & 3.42 & 0.49 \\
\hline Mean Percent Score & 94.72 & 9.21 & 89.58 & 18.96 & 86.24 & 19.65 & 92.87 & 9.17 & 85.46 & 12.21 \\
\hline
\end{tabular}


Community-Based Flood Vulnerability Index for Urban Flooding: Understanding Social Vulnerabilities and Risks

Health Risk: Dengue Fever ATTITUDE PERCENT SCORE SUMMARY . . continued

\begin{tabular}{|c|c|c|c|c|c|c|c|c|c|c|}
\hline \multirow{2}{*}{ Items } & \multicolumn{2}{|c|}{ Barangay 2} & \multicolumn{2}{|c|}{ Poblacion 8} & \multicolumn{2}{|c|}{ Cadawinonan } & \multicolumn{2}{|c|}{ Bagacay } & \multicolumn{2}{|c|}{ Taclobo } \\
\hline & Mean & S.D. & Mean & S.D. & Mean & S.D. & Mean & S.D. & Mean & S.D. \\
\hline The nature of Dengue Fever & 3.94 & 0.25 & 3.62 & 0.56 & 3.52 & 0.82 & 3.10 & 0.92 & 3.48 & 0.86 \\
\hline Mode of transmission & 3.81 & 0.40 & 3.66 & 0.48 & 3.40 & 0.82 & 3.10 & 0.82 & 3.42 & 0.84 \\
\hline Prevention & 3.75 & 0.58 & 3.62 & 0.49 & 3.28 & 0.98 & 3.23 & 0.86 & 3.49 & 0.80 \\
\hline Signs and symptoms & 3.56 & 0.63 & 3.66 & 0.48 & 3.32 & 0.85 & 3.13 & 0.68 & 3.49 & 0.76 \\
\hline It is fatal & 3.81 & 0.40 & 3.72 & 0.45 & 3.52 & 0.92 & 3.27 & 0.78 & 3.54 & 0.80 \\
\hline Treatment & 3.75 & 0.45 & 3.59 & 0.57 & 3.32 & 0.95 & 3.13 & 0.78 & 3.38 & 0.85 \\
\hline Financial cost of treatment & 3.53 & 0.83 & 3.52 & 0.57 & 3.44 & 0.82 & 3.23 & 0.63 & 3.37 & 0.92 \\
\hline The infection itself & 3.75 & 0.45 & 3.66 & 0.55 & 3.40 & 1.00 & 3.30 & 0.60 & 3.49 & 0.84 \\
\hline Information drive & 3.63 & 0.72 & 3.45 & 0.69 & 3.42 & 1.02 & 3.00 & 0.83 & 3.32 & 0.93 \\
\hline \multicolumn{11}{|l|}{ Overall } \\
\hline Mean Score & 3.70 & 0.45 & 3.61 & 0.44 & 3.39 & 0.78 & 3.16 & 0.63 & 3.44 & 0.76 \\
\hline Mean Percent Score & 92.53 & 11.37 & 90.23 & 10.90 & 84.67 & 19.51 & 78.89 & 15.71 & 85.89 & 19.03 \\
\hline
\end{tabular}


Community-Based Flood Vulnerability Index for Urban Flooding: Understanding

Social Vulnerabilities and Risks

Health Risk: Dengue Fever ATTITUDE PERCENT SCORE SUMMARY . . continued

\begin{tabular}{|c|c|c|c|c|c|c|}
\hline \multirow{2}{*}{ Items } & \multicolumn{2}{|c|}{ Candau-ay } & \multicolumn{2}{|c|}{ Batinguel } & \multicolumn{2}{|c|}{ Overall } \\
\hline & Mean & S.D. & Mean & S.D. & Mean & S.D. \\
\hline The nature of Dengue Fever & 3.44 & 0.86 & 3.65 & 0.63 & 3.59 & 0.22 \\
\hline Mode of transmission & 3.41 & 0.81 & 3.66 & 0.53 & 3.56 & 0.24 \\
\hline Prevention & 3.32 & 0.87 & 3.66 & 0.53 & 3.51 & 0.17 \\
\hline Signs and symptoms & 3.44 & 0.89 & 3.63 & 0.54 & 3.50 & 0.16 \\
\hline It is fatal & 3.44 & 0.84 & 3.76 & 0.43 & 3.62 & 0.21 \\
\hline Treatment & 3.35 & 0.86 & 3.55 & 0.50 & 3.45 & 0.23 \\
\hline Financial cost of treatment & 3.21 & 0.88 & 3.53 & 0.51 & 3.46 & 0.17 \\
\hline The infection itself & 3.37 & 0.91 & 3.58 & 0.50 & 3.59 & 0.18 \\
\hline Information drive & 3.06 & 1.05 & 3.47 & 0.60 & 3.43 & 0.24 \\
\hline \multicolumn{7}{|l|}{ Overall } \\
\hline Mean Score & 3.29 & 0.88 & 3.60 & 0.42 & 3.51 & 0.19 \\
\hline Mean Percent Score & 82.14 & 22.01 & 89.99 & 10.48 & 87.77 & 4.70 \\
\hline
\end{tabular}


Community-Based Flood Vulnerability Index for Urban Flooding: Understanding Social Vulnerabilities and Risks

Health Risk: ATTITUDE PERCENT SCORE SUMMARY

\begin{tabular}{|c|c|c|c|c|c|c|c|c|c|c|}
\hline \multirow{2}{*}{ Item } & \multicolumn{2}{|c|}{ Tabuc-tubig } & \multicolumn{2}{|c|}{ Junob } & \multicolumn{2}{|c|}{ Poblacion 1} & \multicolumn{2}{|c|}{ Calindagan } & \multicolumn{2}{|c|}{ Balugo } \\
\hline & Mean & S.D. & Mean & S.D. & Mean & S.D. & Mean & S.D. & Mean & S.D. \\
\hline E.coli & 83.89 & 17.51 & 86.46 & 20.18 & 81.82 & 18.52 & 78.02 & 21.40 & 81.21 & 21.88 \\
\hline Liptospirosis & 88.61 & 14.37 & 84.72 & 24.55 & 83.21 & 18.03 & 83.57 & 21.09 & 80.72 & 17.69 \\
\hline Dengue Fever & 94.72 & 9.21 & 89.58 & 18.96 & 86.24 & 19.65 & 92.87 & 9.17 & 85.46 & 12.21 \\
\hline $\begin{array}{l}\text { Overall } \\
\text { Mean Percent Score }\end{array}$ & 89.07 & 5.43 & 86.92 & 2.46 & 83.75 & 2.26 & 84.82 & 7.51 & 82.46 & 2.61 \\
\hline
\end{tabular}

\begin{tabular}{|c|c|c|c|c|c|c|c|c|c|c|}
\hline \multirow{2}{*}{ Items } & \multicolumn{2}{|c|}{ Barangay 2} & \multicolumn{2}{|c|}{ Poblacion 8} & \multicolumn{2}{|c|}{ Cadawinonan } & \multicolumn{2}{|c|}{ Bagacay } & \multicolumn{2}{|c|}{ Taclobo } \\
\hline & Mean & S.D. & Mean & S.D. & Mean & S.D. & Mean & S.D. & Mean & S.D. \\
\hline E.coli & 82.47 & 18.80 & 76.82 & 23.48 & 72.33 & 28.90 & 71.20 & 26.16 & 77.16 & 27.15 \\
\hline Liptospirosis & 89.76 & 15.10 & 77.87 & 23.81 & 69.56 & 33.56 & 69.91 & 27.90 & 76.41 & 28.39 \\
\hline Dengue Fever & 92.53 & 11.37 & 90.23 & 10.90 & 84.67 & 19.51 & 78.89 & 15.71 & 85.89 & 19.03 \\
\hline $\begin{array}{l}\text { Overall } \\
\quad \text { Mean Percent Score }\end{array}$ & 88.25 & 5.20 & 81.64 & 7.46 & 75.52 & 8.04 & 73.33 & 4.85 & 79.82 & 5.27 \\
\hline
\end{tabular}

\begin{tabular}{|l|r|r|r|r|r|r|}
\hline \multirow{2}{*}{ Items } & \multicolumn{2}{|c|}{ Candau-ay } & \multicolumn{2}{c|}{ Batinguel } & \multicolumn{2}{c|}{ Overall } \\
\cline { 2 - 7 } & \multicolumn{1}{|c|}{ Mean } & \multicolumn{1}{c|}{ S.D. } & \multicolumn{1}{c|}{ Mean } & \multicolumn{1}{c|}{ S.D. } & \multicolumn{1}{c|}{ Mean } & \multicolumn{1}{c|}{ S.D. } \\
\hline E.coli & 68.67 & 29.27 & 79.53 & 23.85 & 78.30 & 5.39 \\
\hline Liptospirosis & 68.09 & 30.27 & 79.75 & 27.28 & 79.35 & 7.26 \\
\hline Dengue Fever & 82.14 & 22.01 & 89.99 & 10.48 & 87.77 & 4.70 \\
\hline $\begin{array}{l}\text { Overall } \\
\text { Mean Percent Score }\end{array}$ & 72.97 & 7.95 & 83.09 & 5.97 & 81.80 & 5.19 \\
\hline
\end{tabular}


Community-Based Flood Vulnerability Index for Urban Flooding: Understanding Social Vulnerabilities and Risks

Health Risk: E. coli Practice

\begin{tabular}{|c|c|c|c|c|c|c|c|c|c|c|}
\hline \multirow{2}{*}{ Questions } & \multicolumn{2}{|c|}{ Tabuc-tubig } & \multicolumn{2}{|c|}{ Junob } & \multicolumn{2}{|c|}{ Poblacion 1} & \multicolumn{2}{|c|}{ Calindagan } & \multicolumn{2}{|c|}{ Balugo } \\
\hline & $\mathbf{F}$ & $\%$ & $\mathbf{F}$ & $\%$ & $\mathbf{F}$ & $\%$ & $\mathbf{F}$ & $\%$ & $\mathbf{F}$ & $\%$ \\
\hline \multirow[t]{2}{*}{$\begin{array}{l}\text { 1a. Do you or other members in } \\
\text { the family go swimming or } \\
\text { bathing in the river? }\end{array}$} & 6 & 60.00 & 6 & 37.50 & 19 & 86.36 & 19 & 82.61 & 8 & 47.06 \\
\hline & Mean & S.D. & Mean & S.D. & Mean & S.D. & Mean & S.D. & Mean & S.D. \\
\hline Mean Score & 0.60 & 0.52 & 0.38 & 0.50 & 0.86 & 0.35 & 0.83 & 0.39 & 0.47 & 0.51 \\
\hline \multirow[t]{2}{*}{ Percentage Score } & 60.00 & 51.64 & 37.50 & 50.00 & 86.36 & 35.13 & 82.61 & 38.76 & 47.06 & 51.45 \\
\hline & Mean & S.D. & Mean & S.D. & Mean & S.D. & Mean & S.D. & Mean & S.D. \\
\hline \multicolumn{11}{|l|}{ Frequency of swimming } \\
\hline Mean Score & 5.40 & 1.58 & 3.57 & 2.34 & 5.60 & 1.14 & 5.78 & 0.52 & 3.47 & 2.50 \\
\hline \multirow[t]{2}{*}{ Percentage Score } & 90.00 & 26.29 & 52.08 & 41.67 & 93.33 & 19.04 & 96.38 & 8.64 & 57.84 & 41.72 \\
\hline & $\mathbf{F}$ & $\%$ & $\mathbf{F}$ & $\%$ & $\mathbf{F}$ & $\%$ & $\mathbf{F}$ & $\%$ & $\mathbf{F}$ & $\%$ \\
\hline \multirow[t]{2}{*}{$\begin{array}{l}\text { 1b. Were there any chances that } \\
\text { you have accidentally swallowed } \\
\text { the water from the river? }\end{array}$} & 9 & 90.00 & 10 & 62.5 & 18 & 81.82 & 20 & 86.96 & 11 & 64.71 \\
\hline & Mean & S.D. & Mean & S.D. & Mean & S.D. & Mean & S.D. & Mean & S.D. \\
\hline Mean Score & 0.90 & 0.32 & 0.63 & 0.50 & 0.86 & 0.36 & 0.87 & 0.34 & 0.65 & 0.49 \\
\hline \multirow[t]{2}{*}{ Percentage Score } & 90.00 & 31.62 & 62.50 & 50.00 & 85.71 & 35.86 & 86.96 & 34.44 & 64.71 & 49.26 \\
\hline & Mean & S.D. & Mean & S.D. & Mean & S.D. & Mean & S.D. & Mean & S.D. \\
\hline \multicolumn{11}{|c|}{ Estimated amount of water swallowed } \\
\hline Mean Score & 5.60 & 1.26 & 5.13 & 1.36 & 5.50 & 1.37 & 5.74 & 1.05 & 5.41 & 0.94 \\
\hline Percentage Score & 93.33 & 21.08 & 85.42 & 22.67 & 91.67 & 22.86 & 95.65 & 17.56 & 90.20 & 15.66 \\
\hline Q1 Item Summary & Mean & S.D. & Mean & S.D. & Mean & S.D. & Mean & S.D. & Mean & S.D. \\
\hline Percentage Score & 83.33 & 15.63 & 59.38 & 20.16 & 89.27 & 3.80 & 90.40 & 6.73 & 64.95 & 18.33 \\
\hline
\end{tabular}


Community-Based Flood Vulnerability Index for Urban Flooding: Understanding

\section{Social Vulnerabilities and Risks}

Health Risk: E. coli Practice ... . continued

\begin{tabular}{|c|c|c|c|c|c|c|c|c|c|c|}
\hline \multirow{2}{*}{ Questions } & \multicolumn{2}{|c|}{ Barangay 2} & \multicolumn{2}{|c|}{ Poblacion 8} & \multicolumn{2}{|c|}{ Cadawinonan } & \multicolumn{2}{|c|}{ Bagacay } & \multicolumn{2}{|c|}{ Taclobo } \\
\hline & $\mathbf{F}$ & $\%$ & $\mathbf{F}$ & $\%$ & $\mathbf{F}$ & $\%$ & $\mathbf{F}$ & $\%$ & $\mathbf{F}$ & $\%$ \\
\hline \multirow[t]{2}{*}{$\begin{array}{l}\text { 1a. Do you or other members in } \\
\text { the family go swimming or } \\
\text { bathing in the river? }\end{array}$} & 11 & 68.75 & 17 & 58.62 & 17 & 68.00 & 15 & 50.00 & 42 & 68.85 \\
\hline & Mean & S.D. & Mean & S.D. & Mean & S.D. & Mean & S.D. & Mean & S.D. \\
\hline Mean Score & 0.69 & 0.48 & 0.59 & 0.50 & 0.68 & 0.48 & 0.50 & 0.51 & 0.73 & 0.45 \\
\hline \multirow[t]{2}{*}{ Percentage Score } & 68.75 & 47.87 & 58.62 & 50.12 & 68.00 & 47.61 & 50.00 & 50.85 & 73.02 & 44.74 \\
\hline & Mean & S.D. & Mean & S.D. & Mean & S.D. & Mean & S.D. & Mean & S.D. \\
\hline \multicolumn{11}{|l|}{ Frequency of swimming } \\
\hline Mean Score & 5.31 & 1.40 & 4.83 & 1.81 & 5.64 & 0.57 & 5.13 & 1.41 & 5.30 & 1.44 \\
\hline \multirow[t]{2}{*}{ Percentage Score } & 88.54 & 23.35 & 80.46 & 30.23 & 94.00 & 9.48 & 85.56 & 23.46 & 88.36 & 24.07 \\
\hline & $\mathbf{F}$ & $\%$ & $\mathbf{F}$ & $\%$ & $\mathbf{F}$ & $\%$ & $\mathbf{F}$ & $\%$ & $\mathbf{F}$ & $\%$ \\
\hline \multirow[t]{2}{*}{$\begin{array}{l}\text { 1b. Were there any chances that } \\
\text { you have accidentally swallowed } \\
\text { the water from the river? }\end{array}$} & 11 & 68.75 & 19 & 65.52 & 17 & 68.00 & 22 & 73.33 & 44 & 72.13 \\
\hline & Mean & S.D. & Mean & S.D. & Mean & S.D. & Mean & S.D. & Mean & S.D. \\
\hline Mean Score & 0.79 & 0.43 & 0.66 & 0.48 & 0.68 & 0.48 & 0.73 & 0.45 & 0.76 & 0.43 \\
\hline \multirow[t]{2}{*}{ Percentage Score } & 78.57 & 42.58 & 65.52 & 48.37 & 68.00 & 47.61 & 73.33 & 44.98 & 76.19 & 42.93 \\
\hline & Mean & S.D. & Mean & S.D. & Mean & S.D. & Mean & S.D. & Mean & S.D. \\
\hline \multicolumn{11}{|c|}{ Estimated amount of water swallowed } \\
\hline Mean Score & 5.69 & 0.70 & 5.03 & 1.55 & 4.96 & 1.70 & 5.40 & 90.00 & 5.38 & 1.35 \\
\hline Percentage Score & 94.79 & 11.74 & 83.91 & 25.77 & 82.67 & 28.25 & 1.22 & 20.34 & 89.68 & 22.49 \\
\hline Q1 Item Summary & Mean & S.D. & Mean & S.D. & Mean & S.D. & Mean & S.D. & Mean & S.D. \\
\hline Percentage Score & 82.66 & 11.43 & 72.13 & 12.03 & 78.17 & 12.62 & 52.53 & 37.25 & 81.81 & 8.44 \\
\hline
\end{tabular}


Community-Based Flood Vulnerability Index for Urban Flooding: Understanding Social Vulnerabilities and Risks

Health Risk: E. coli Practice ... . continued

\begin{tabular}{|c|c|c|c|c|c|c|}
\hline \multirow{2}{*}{ Questions } & \multicolumn{2}{|c|}{ Candau-ay } & \multicolumn{2}{|c|}{ Batinguel } & \multicolumn{2}{|c|}{ Overall } \\
\hline & $\mathbf{F}$ & $\%$ & $\mathbf{F}$ & $\%$ & $\mathbf{F}$ & $\%$ \\
\hline \multirow[t]{2}{*}{$\begin{array}{l}\text { 1a. Do you or other members in the } \\
\text { family go swimming or bathing in } \\
\text { the river? }\end{array}$} & 47 & 65.28 & 16 & 42.11 & 223 & 61.77 \\
\hline & Mean & S.D. & Mean & S.D. & Mean & S.D. \\
\hline Mean Score & 0.65 & 0.48 & 0.42 & 0.50 & 0.62 & 0.15 \\
\hline \multirow[t]{2}{*}{ Percentage Score } & 65.28 & 47.94 & 42.11 & 50.04 & 61.61 & 15.40 \\
\hline & Mean & S.D. & Mean & S.D. & Mean & S.D. \\
\hline \multicolumn{7}{|l|}{ Frequency of swimming } \\
\hline Mean Score & 5.15 & 1.59 & 4.21 & 2.12 & 4.95 & 0.78 \\
\hline \multirow[t]{2}{*}{ Percentage Score } & 85.88 & 26.49 & 70.18 & 35.34 & 69.07 & 34.45 \\
\hline & $\mathbf{F}$ & $\%$ & $\mathbf{F}$ & $\%$ & $\mathbf{F}$ & $\%$ \\
\hline \multirow[t]{2}{*}{$\begin{array}{l}\text { 1b. Were there any chances that } \\
\text { you have accidentally swallowed the } \\
\text { water from the river? }\end{array}$} & 60 & 83.33 & 24 & 63.16 & 265 & 73.41 \\
\hline & Mean & S.D. & Mean & S.D. & Mean & S.D. \\
\hline Mean Score & 0.83 & 0.38 & 0.63 & 0.49 & 0.75 & 0.10 \\
\hline \multirow[t]{2}{*}{ Percentage Score } & 83.33 & 37.53 & 63.16 & 48.89 & 74.83 & 10.05 \\
\hline & Mean & S.D. & Mean & S.D. & Mean & S.D. \\
\hline \multicolumn{7}{|l|}{ Estimated amount of water swallowed } \\
\hline Mean Score & 5.56 & 1.12 & 5.26 & 1.18 & 5.39 & 0.25 \\
\hline Percentage Score & 92.59 & 18.74 & 87.72 & 19.64 & 89.80 & 4.18 \\
\hline Q1 Item Summary & Mean & S.D. & Mean & S.D. & Mean & S.D. \\
\hline Percentage Score & 81.77 & 11.67 & 65.79 & 18.87 & 73.83 & 11.95 \\
\hline
\end{tabular}


Community-Based Flood Vulnerability Index for Urban Flooding: Understanding Social Vulnerabilities and Risks

Health Risk: E. coli Practice ... continued

\begin{tabular}{|c|c|c|c|c|c|c|c|c|c|c|}
\hline \multirow{2}{*}{ Questions } & \multicolumn{2}{|c|}{ Tabuc-tubig } & \multicolumn{2}{|c|}{ Junob } & \multicolumn{2}{|c|}{ Poblacion 1} & \multicolumn{2}{|c|}{ Calindagan } & \multicolumn{2}{|c|}{ Balugo } \\
\hline & $F$ & $\%$ & $\mathbf{F}$ & $\%$ & $F$ & $\%$ & $F$ & $\%$ & $F$ & $\%$ \\
\hline \multirow[t]{2}{*}{$\begin{array}{l}\text { 2a. Do you immerse yourself } \\
\text { other members in the family into } \\
\text { the river? }\end{array}$} & 7 & 70.00 & 5 & 31.25 & 17 & 77.27 & 18 & 78.26 & 8 & 47.06 \\
\hline & Mean & S.D. & Mean & S.D. & Mean & S.D. & Mean & S.D. & Mean & S.D. \\
\hline Mean Score & 0.70 & 0.48 & 0.31 & 0.48 & 0.77 & 0.43 & 0.82 & 0.39 & 0.47 & 0.51 \\
\hline \multirow[t]{2}{*}{ Percentage Score } & 70.00 & 48.30 & 31.25 & 47.87 & 77.27 & 42.89 & 81.82 & 39.48 & 47.06 & 51.45 \\
\hline & Mean & S.D. & Mean & S.D. & Mean & S.D. & Mean & S.D. & Mean & S.D. \\
\hline \multicolumn{11}{|l|}{ Frequency of immersion } \\
\hline Mean Score & 5.30 & 1.57 & 3.13 & 2.22 & 5.55 & 1.15 & 5.83 & 0.39 & 4.35 & 2.15 \\
\hline \multirow[t]{2}{*}{ Percentage Score } & 88.33 & 26.12 & 52.08 & 36.96 & 92.50 & 19.10 & 97.10 & 6.46 & 72.55 & 35.81 \\
\hline & $\mathbf{F}$ & $\%$ & $\mathbf{F}$ & $\%$ & $\mathbf{F}$ & $\%$ & $\mathbf{F}$ & $\%$ & $\mathbf{F}$ & $\%$ \\
\hline \multirow[t]{2}{*}{$\begin{array}{l}2 \mathrm{~b} . \text { Were there any chances that } \\
\text { you have accidentally swallowed } \\
\text { the water from the river? }\end{array}$} & 10 & 100.00 & 5 & 31.25 & 17 & 77.27 & 21 & 91.30 & 12 & 70.59 \\
\hline & Mean & S.D. & Mean & S.D. & Mean & S.D. & Mean & S.D. & Mean & S.D. \\
\hline Mean Score & 1.00 & 0.00 & 0.31 & 0.48 & 0.85 & 0.37 & 0.91 & 0.29 & 0.71 & 0.47 \\
\hline \multirow[t]{2}{*}{ Percentage Score } & 100.00 & 0.00 & 31.25 & 47.87 & 85.00 & 36.63 & 91.30 & 28.81 & 70.59 & 46.97 \\
\hline & Mean & S.D. & Mean & S.D. & Mean & S.D. & Mean & S.D. & Mean & S.D. \\
\hline \multicolumn{11}{|c|}{ Estimated amount of water swallowed } \\
\hline Mean Score & 6.00 & 0.00 & 4.94 & 1.44 & 5.55 & 1.34 & 5.74 & 1.05 & 5.53 & 0.87 \\
\hline Percentage Score & 100.00 & 0.00 & 3.13 & 2.22 & 92.42 & 22.26 & 95.65 & 17.56 & 92.16 & 14.57 \\
\hline Q2 Item Summary & Mean & S.D. & Mean & S.D. & Mean & S.D. & Mean & S.D. & Mean & S.D. \\
\hline Percentage Score & 89.58 & 14.17 & 29.43 & 20.10 & 86.80 & 7.26 & 91.47 & 6.89 & 70.59 & 18.46 \\
\hline
\end{tabular}


Community-Based Flood Vulnerability Index for Urban Flooding: Understanding

Social Vulnerabilities and Risks

Health Risk: E. coli Practice ... continued

\begin{tabular}{|c|c|c|c|c|c|c|c|c|c|c|}
\hline \multirow{2}{*}{ Questions } & \multicolumn{2}{|c|}{ Barangay 2} & \multicolumn{2}{|c|}{ Poblacion 8} & \multicolumn{2}{|c|}{ Cadawinonan } & \multicolumn{2}{|c|}{ Bagacay } & \multicolumn{2}{|c|}{ Taclobo } \\
\hline & $\mathbf{F}$ & $\%$ & $\mathbf{F}$ & $\%$ & $\mathbf{F}$ & $\%$ & $\mathbf{F}$ & $\%$ & $\mathbf{F}$ & $\%$ \\
\hline \multirow[t]{2}{*}{$\begin{array}{l}\text { 2a. Do you immerse yourself } \\
\text { other members in the family into } \\
\text { the river? }\end{array}$} & 13 & 81.25 & 17 & 58.62 & 15 & 60.00 & 6 & 20.00 & 32 & 52.46 \\
\hline & Mean & S.D. & Mean & S.D. & Mean & S.D. & Mean & S.D. & Mean & S.D. \\
\hline Mean Score & 0.81 & 0.40 & 0.61 & 0.50 & 0.60 & 0.50 & 0.21 & 0.41 & 0.56 & 0.50 \\
\hline \multirow[t]{2}{*}{ Percentage Score } & 81.25 & 40.31 & 60.71 & 49.73 & 60.00 & 50.00 & 20.69 & 41.23 & 55.56 & 50.09 \\
\hline & Mean & S.D. & Mean & S.D. & Mean & S.D. & Mean & S.D. & Mean & S.D. \\
\hline \multicolumn{11}{|l|}{ Frequency of immersion } \\
\hline Mean Score & 5.56 & 1.26 & 5.07 & 1.53 & 5.64 & 0.57 & 4.66 & 1.54 & 5.05 & 1.63 \\
\hline \multirow[t]{2}{*}{ Percentage Score } & 92.71 & 21.05 & 84.48 & 25.56 & 94.00 & 9.48 & 77.59 & 25.70 & 84.13 & 27.18 \\
\hline & $\mathbf{F}$ & $\%$ & $\mathbf{F}$ & $\%$ & $\mathbf{F}$ & $\%$ & $\mathbf{F}$ & $\%$ & $\mathbf{F}$ & $\%$ \\
\hline \multirow[t]{2}{*}{$\begin{array}{l}\text { 2b. Were there any chances that } \\
\text { you have accidentally swallowed } \\
\text { the water from the river? }\end{array}$} & 13 & 81.25 & 21 & 72.41 & 20 & 80.00 & 23 & 76.67 & 47 & 77.05 \\
\hline & Mean & S.D. & Mean & S.D. & Mean & S.D. & Mean & S.D. & Mean & S.D. \\
\hline Mean Score & 0.87 & 0.35 & 0.72 & 0.45 & 0.80 & 0.41 & 0.79 & 0.41 & 0.84 & 0.37 \\
\hline \multirow[t]{2}{*}{ Percentage Score } & 86.67 & 35.19 & 72.41 & 45.49 & 80.00 & 40.82 & 79.31 & 41.23 & 84.13 & 36.84 \\
\hline & Mean & S.D. & Mean & S.D. & Mean & S.D. & Mean & S.D. & Mean & S.D. \\
\hline \multicolumn{11}{|l|}{ Estimated amount of water swallowed } \\
\hline Mean Score & 5.81 & 0.54 & 5.45 & 1.15 & 5.44 & 1.42 & 5.53 & 1.14 & 5.63 & 1.07 \\
\hline Percentage Score & 96.88 & 9.07 & 90.80 & 19.20 & 90.67 & 23.61 & 92.22 & 18.94 & 93.92 & 17.79 \\
\hline Q2 Item Summary & Mean & S.D. & Mean & S.D. & Mean & S.D. & Mean & S.D. & Mean & S.D. \\
\hline Percentage Score & 89.38 & 6.85 & 77.10 & 13.33 & 81.17 & 15.32 & 67.45 & 31.85 & 79.43 & 16.57 \\
\hline
\end{tabular}


Community-Based Flood Vulnerability Index for Urban Flooding: Understanding Social Vulnerabilities and Risks

Health Risk: E. coli Practice ... continued

\begin{tabular}{|c|c|c|c|c|c|c|}
\hline \multirow[b]{2}{*}{ Questions } & \multicolumn{2}{|c|}{ Candau-ay } & \multicolumn{2}{|c|}{ Batinguel } & \multicolumn{2}{|c|}{ Overall } \\
\hline & $\mathbf{F}$ & $\%$ & $\mathbf{F}$ & $\%$ & $\mathbf{F}$ & $\%$ \\
\hline \multirow[t]{2}{*}{$\begin{array}{l}\text { 2a. Do you immerse yourself } \\
\text { other members in the family } \\
\text { into the river? }\end{array}$} & 33 & 45.83 & 16 & 42.11 & 187 & 51.80 \\
\hline & Mean & S.D. & Mean & S.D. & Mean & S.D. \\
\hline Mean Score & 0.46 & 0.50 & 0.42 & 0.50 & 0.56 & 0.20 \\
\hline \multirow[t]{2}{*}{ Percentage Score } & 45.83 & 50.18 & 42.11 & 50.04 & 56.13 & 19.60 \\
\hline & Mean & S.D. & Mean & S.D. & Mean & S.D. \\
\hline \multicolumn{7}{|l|}{ Frequency of immersion } \\
\hline Mean Score & 4.89 & 1.57 & 4.26 & 2.18 & 4.94 & 0.76 \\
\hline \multirow[t]{2}{*}{ Percentage Score } & 80.32 & 27.74 & 71.05 & 36.28 & 82.24 & 12.70 \\
\hline & $\mathbf{F}$ & $\%$ & $\mathbf{F}$ & $\%$ & $\mathbf{F}$ & $\%$ \\
\hline \multirow[t]{2}{*}{$\begin{array}{l}2 \mathrm{~b} \text {. Were there any chances } \\
\text { that you have accidentally } \\
\text { swallowed the water from the } \\
\text { river? }\end{array}$} & 62 & 86.11 & 28 & 73.68 & 274 & 75.90 \\
\hline & Mean & S.D. & Mean & S.D. & Mean & S.D. \\
\hline Mean Score & 0.86 & 0.35 & 0.74 & 0.45 & 0.83 & 0.09 \\
\hline \multirow[t]{2}{*}{ Percentage Score } & 86.11 & 34.83 & 73.68 & 44.63 & 82.66 & 8.72 \\
\hline & Mean & S.D. & Mean & S.D. & Mean & S.D. \\
\hline \multicolumn{7}{|c|}{ Estimated amount of water swallowed } \\
\hline Mean Score & 5.67 & 1.01 & 5.53 & 0.80 & 5.63 & 0.17 \\
\hline Percentage Score & 94.44 & 16.78 & 92.11 & 13.28 & 93.75 & 2.84 \\
\hline Q2 Item Summary & Mean & S.D. & Mean & S.D. & Mean & S.D. \\
\hline Percentage Score & 76.68 & 21.36 & 69.74 & 20.67 & 78.69 & 15.96 \\
\hline
\end{tabular}


Community-Based Flood Vulnerability Index for Urban Flooding: Understanding Social Vulnerabilities and Risks

Health Risk: E. coli Practice ... continued

\begin{tabular}{|c|c|c|c|c|c|c|c|c|c|c|}
\hline \multirow{2}{*}{ Questions } & \multicolumn{2}{|c|}{ Tabuc-tubig } & \multicolumn{2}{|c|}{ Junob } & \multicolumn{2}{|c|}{ Poblacion 1} & \multicolumn{2}{|c|}{ Calindagan } & \multicolumn{2}{|c|}{ Balugo } \\
\hline & $\mathbf{F}$ & $\%$ & $\mathbf{F}$ & $\%$ & $\mathbf{F}$ & $\%$ & $\mathbf{F}$ & $\%$ & $\mathbf{F}$ & $\%$ \\
\hline \multirow[t]{2}{*}{$\begin{array}{l}\text { 3a. Do you wash your clothes in } \\
\text { the river? }\end{array}$} & 8 & 80.00 & 10 & 62.50 & 21 & 95.45 & 23 & 100.00 & 4 & 23.53 \\
\hline & Mean & S.D. & Mean & S.D. & Mean & S.D. & Mean & S.D. & Mean & S.D. \\
\hline Mean Score & 0.80 & 0.42 & 0.63 & 0.50 & 0.95 & 0.21 & 1.00 & 0.00 & 0.24 & 0.44 \\
\hline \multirow[t]{2}{*}{ Percentage Score } & 80.00 & 42.16 & 62.50 & 50.00 & 95.45 & 21.32 & 100.00 & 0.00 & 23.53 & 43.72 \\
\hline & Mean & S.D. & Mean & S.D. & Mean & S.D. & Mean & S.D. & Mean & S.D. \\
\hline \multicolumn{11}{|l|}{ Frequency of washing } \\
\hline Mean Score & 5.30 & 1.16 & 3.00 & 1.71 & 5.56 & 1.04 & 5.96 & 0.21 & 3.82 & 1.94 \\
\hline \multirow[t]{2}{*}{ Percentage Score } & 88.33 & 19.33 & 50.00 & 28.50 & 92.59 & 17.36 & 99.28 & 3.48 & 63.73 & 32.40 \\
\hline & $\mathbf{F}$ & $\%$ & $\mathbf{F}$ & $\%$ & $\mathbf{F}$ & $\%$ & $\mathbf{F}$ & $\%$ & $\mathbf{F}$ & $\%$ \\
\hline \multirow[t]{2}{*}{$\begin{array}{l}\text { 3b. Were there any chances that } \\
\text { you have accidentally swallowed } \\
\text { the water from the river? }\end{array}$} & 10 & 100.00 & 6 & 37.5 & 19 & 86.36 & 22 & 95.65 & 9 & 52.94 \\
\hline & Mean & S.D. & Mean & S.D. & Mean & S.D. & Mean & S.D. & Mean & S.D. \\
\hline Mean Score & 1.00 & 0.00 & 0.38 & 0.50 & 0.90 & 0.30 & 0.96 & 0.21 & 0.53 & 0.51 \\
\hline \multirow[t]{2}{*}{ Percentage Score } & 100.00 & 0.00 & 37.50 & 50.00 & 90.48 & 30.08 & 95.65 & 20.85 & 52.94 & 51.45 \\
\hline & Mean & S.D. & Mean & S.D. & Mean & S.D. & Mean & S.D. & Mean & S.D. \\
\hline \multicolumn{11}{|c|}{ Estimated amount of water swallowed } \\
\hline Mean Score & 6.00 & 0.00 & 5.31 & 1.25 & 5.59 & 1.33 & 5.96 & 0.21 & 5.29 & 0.92 \\
\hline Percentage Score & 100.00 & 0.00 & 88.54 & 20.83 & 93.18 & 22.22 & 99.28 & 3.48 & 88.24 & 15.33 \\
\hline Q3 Item Summary & Mean & S.D. & Mean & S.D. & Mean & S.D. & Mean & S.D. & Mean & S.D. \\
\hline Percentage Score & 92.08 & 9.75 & 59.64 & 21.81 & 92.93 & 2.05 & 98.55 & 1.96 & 57.11 & 26.82 \\
\hline
\end{tabular}


Community-Based Flood Vulnerability Index for Urban Flooding: Understanding

Social Vulnerabilities and Risks

Health Risk: E. coli Practice ... continued

\begin{tabular}{|c|c|c|c|c|c|c|c|c|c|c|}
\hline \multirow{2}{*}{ Questions } & \multicolumn{2}{|c|}{ Barangay 2} & \multicolumn{2}{|c|}{ Poblacion 8} & \multicolumn{2}{|c|}{ Cadawinonan } & \multicolumn{2}{|c|}{ Bagacay } & \multicolumn{2}{|c|}{ Taclobo } \\
\hline & $\mathbf{F}$ & $\%$ & $\mathbf{F}$ & $\%$ & $\mathbf{F}$ & $\%$ & $\mathbf{F}$ & $\%$ & $\mathbf{F}$ & $\%$ \\
\hline \multirow[t]{2}{*}{$\begin{array}{l}\text { 3a. Do you wash your clothes in } \\
\text { the river? }\end{array}$} & 16 & 100.00 & 21 & 72.41 & 17 & 68.00 & 18 & 60.00 & 40 & 65.57 \\
\hline & Mean & S.D. & Mean & S.D. & Mean & S.D. & Mean & S.D. & Mean & S.D. \\
\hline Mean Score & 1.00 & 0.00 & 0.72 & 0.45 & 0.68 & 0.48 & 0.60 & 0.50 & 0.70 & 0.46 \\
\hline \multirow[t]{2}{*}{ Percentage Score } & 100.00 & 0.00 & 72.41 & 45.49 & 68.00 & 47.61 & 60.00 & 49.83 & 69.84 & 46.26 \\
\hline & Mean & S.D. & Mean & S.D. & Mean & S.D. & Mean & S.D. & Mean & S.D. \\
\hline \multicolumn{11}{|l|}{ Frequency of washing } \\
\hline Mean Score & 6.00 & 0.00 & 4.96 & 1.58 & 5.40 & 1.12 & 5.27 & 1.17 & 5.25 & 1.37 \\
\hline \multirow[t]{2}{*}{ Percentage Score } & 100.00 & 0.00 & 77.01 & 33.16 & 90.00 & 18.63 & 87.78 & 19.54 & 87.57 & 22.79 \\
\hline & $F$ & $\%$ & $\mathbf{F}$ & $\%$ & $\mathbf{F}$ & $\%$ & $\mathbf{F}$ & $\%$ & $\mathbf{F}$ & $\%$ \\
\hline \multirow[t]{2}{*}{$\begin{array}{l}\text { 3b. Were there any chances that } \\
\text { you have accidentally swallowed } \\
\text { the water from the river? }\end{array}$} & 13 & 81.25 & 23 & 79.31 & 21 & 84.00 & 25 & 83.33 & 49 & 80.33 \\
\hline & Mean & S.D. & Mean & S.D. & Mean & S.D. & Mean & S.D. & Mean & S.D. \\
\hline Mean Score & 0.93 & 0.27 & 0.79 & 0.41 & 0.84 & 0.37 & 0.83 & 0.38 & 0.86 & 0.35 \\
\hline \multirow[t]{2}{*}{ Percentage Score } & 92.86 & 26.73 & 79.31 & 41.23 & 84.00 & 37.42 & 83.33 & 37.90 & 85.71 & 35.27 \\
\hline & Mean & S.D. & Mean & S.D. & Mean & S.D. & Mean & S.D. & Mean & S.D. \\
\hline \multicolumn{11}{|c|}{ Estimated amount of water swallowed } \\
\hline Mean Score & 5.94 & 0.25 & 5.55 & 0.99 & 5.67 & 0.92 & 5.60 & 1.10 & 5.63 & 1.08 \\
\hline Percentage Score & 98.96 & 4.17 & 92.53 & 16.42 & 90.67 & 24.09 & 93.33 & 18.36 & 93.92 & 18.04 \\
\hline Q3 Item Summary & Mean & S.D. & Mean & S.D. & Mean & S.D. & Mean & S.D. & Mean & S.D. \\
\hline Percentage Score & 97.95 & 3.43 & 80.32 & 8.63 & 83.17 & 10.55 & 81.11 & 14.66 & 84.26 & 10.23 \\
\hline
\end{tabular}


Community-Based Flood Vulnerability Index for Urban Flooding: Understanding Social Vulnerabilities and Risks

Health Risk: E. coli Practice ... continued

\begin{tabular}{|l|r|r|r|r|r|c|}
\hline \multirow{2}{*}{ Questions } & \multicolumn{2}{|c|}{ Candau-ay } & \multicolumn{2}{c|}{ Batinguel } & \multicolumn{2}{c|}{ Overall } \\
\cline { 2 - 7 } & \multicolumn{1}{c|}{$\mathbf{F}$} & \multicolumn{1}{c|}{$\%$} & \multicolumn{1}{c|}{ F } & \multicolumn{1}{c|}{$\%$} & \multicolumn{1}{c|}{ F } & \multicolumn{1}{c|}{$\%$} \\
\hline $\begin{array}{l}\text { 3a. Do you wash your clothes in } \\
\text { the river? }\end{array}$ & 42 & 58.33 & 12 & 31.58 & 222 & 61.50 \\
\hline & Mean & S.D. & Mean & S.D. & Mean & S.D. \\
\hline Mean Score & 0.58 & 0.50 & 0.32 & 0.47 & 0.69 & 0.25 \\
\hline Percentage Score & 58.33 & 49.65 & 31.58 & 47.11 & 69.01 & 25.34 \\
\hline & Mean & S.D. & Mean & S.D. & Mean & S.D. \\
\hline
\end{tabular}

\begin{tabular}{|c|c|c|c|c|c|c|}
\hline \multicolumn{7}{|l|}{ Frequency of washing } \\
\hline Mean Score & 5.07 & 1.44 & 4.16 & 1.87 & 5.16 & 0.67 \\
\hline \multirow[t]{2}{*}{ Percentage Score } & 84.49 & 23.95 & 69.30 & 31.13 & 85.46 & 11.39 \\
\hline & $\mathbf{F}$ & $\%$ & $\mathbf{F}$ & $\%$ & $\mathbf{F}$ & $\%$ \\
\hline \multirow[t]{2}{*}{$\begin{array}{l}3 \mathrm{~b} \text {. Were there any chances } \\
\text { that you have accidentally } \\
\text { swallowed the water from the } \\
\text { river? }\end{array}$} & 62 & 86.11 & 27 & 71.05 & 280 & 77.56 \\
\hline & Mean & S.D. & Mean & S.D. & Mean & S.D. \\
\hline Mean Score & 0.86 & 0.35 & 0.71 & 0.46 & 0.84 & 0.13 \\
\hline \multirow[t]{2}{*}{ Percentage Score } & 86.11 & 34.83 & 71.05 & 45.96 & 83.77 & 12.94 \\
\hline & Mean & S.D. & Mean & S.D. & Mean & S.D. \\
\hline
\end{tabular}

Estimated amount of water swallowed

\begin{tabular}{|l|r|r|r|r|r|c|}
\hline Mean Score & 5.64 & 1.05 & 5.34 & 1.19 & 5.66 & 0.23 \\
\hline Percentage Score & 93.98 & 17.54 & 89.04 & 19.86 & 93.92 & 4.01 \\
\hline Q3 Item Summary & Mean & S.D. & Mean & S.D. & Mean & S.D. \\
\hline Percentage Score & 80.73 & 15.50 & 65.24 & 24.15 & 83.04 & 10.35 \\
\hline
\end{tabular}


Community-Based Flood Vulnerability Index for Urban Flooding: Understanding

\section{Social Vulnerabilities and Risks}

Health Risk: E. coli Practice ... continued

\begin{tabular}{|c|c|c|c|c|c|c|c|c|c|c|}
\hline \multirow{2}{*}{ Questions } & \multicolumn{2}{|c|}{ Tabuc-tubig } & \multicolumn{2}{|c|}{ Junob } & \multicolumn{2}{|c|}{ Poblacion 1} & \multicolumn{2}{|c|}{ Calindagan } & \multicolumn{2}{|c|}{ Balugo } \\
\hline & $\mathbf{F}$ & $\%$ & $\mathbf{F}$ & $\%$ & $\mathbf{F}$ & $\%$ & $\mathbf{F}$ & $\%$ & $\mathbf{F}$ & $\%$ \\
\hline \multirow[t]{2}{*}{$\begin{array}{l}\text { 4a. Do you use water from the } \\
\text { river/deep well to wet your } \\
\text { ground, flush your toilet, and } \\
\text { water your plants? }\end{array}$} & 7 & 70.00 & 11 & 68.75 & 19 & 86.36 & 22 & 95.65 & 6 & 35.29 \\
\hline & Mean & S.D. & Mean & S.D. & Mean & S.D. & Mean & S.D. & Mean & S.D. \\
\hline Mean Score & 0.70 & 0.48 & 0.38 & 0.50 & 0.86 & 0.35 & 0.96 & 0.21 & 0.35 & 0.49 \\
\hline \multirow[t]{2}{*}{ Percentage Score } & 70.00 & 48.30 & 37.50 & 50.00 & 86.36 & 35.13 & 95.65 & 20.85 & 35.29 & 49.26 \\
\hline & Mean & S.D. & Mean & S.D. & Mean & S.D. & Mean & S.D. & Mean & S.D. \\
\hline \multicolumn{11}{|c|}{ Frequency of use of water from river } \\
\hline Mean Score & 4.90 & 1.91 & 5.31 & 1.25 & 5.55 & 1.34 & 5.96 & 0.21 & 3.18 & 2.43 \\
\hline \multirow[t]{2}{*}{ Percentage Score } & 81.67 & 31.87 & 88.54 & 20.83 & 92.42 & 22.26 & 99.28 & 3.48 & 52.94 & 40.50 \\
\hline & $\mathbf{F}$ & $\%$ & $\mathbf{F}$ & $\%$ & $\mathbf{F}$ & $\%$ & $\mathbf{F}$ & $\%$ & $\mathbf{F}$ & $\%$ \\
\hline \multirow[t]{2}{*}{$\begin{array}{l}\text { 4b. Were there any chances that } \\
\text { you have accidentally swallowed } \\
\text { the water from the river? }\end{array}$} & 10 & 100.00 & 11 & 68.75 & 20 & 90.91 & 23 & 100.00 & 10 & 58.82 \\
\hline & Mean & S.D. & Mean & S.D. & Mean & S.D. & Mean & S.D. & Mean & S.D. \\
\hline Mean Score & 1.00 & 0.00 & 0.69 & 0.48 & 0.91 & 0.29 & 1.00 & 0.00 & 0.59 & 0.51 \\
\hline \multirow[t]{2}{*}{ Percentage Score } & 100.00 & 0.00 & 68.75 & 47.87 & 90.91 & 29.42 & 100.00 & 0.00 & 58.82 & 50.73 \\
\hline & Mean & S.D. & Mean & S.D. & Mean & S.D. & Mean & S.D. & Mean & S.D. \\
\hline \multicolumn{11}{|c|}{ Estimated amount of water swallowed } \\
\hline Mean Score & 6.00 & 0.00 & 5.25 & 1.39 & 5.68 & 1.13 & 6.00 & 0.00 & 5.29 & 0.92 \\
\hline Percentage Score & 100.00 & 0.00 & 87.50 & 23.17 & 94.70 & 18.82 & 100.00 & 0.00 & 88.24 & 15.33 \\
\hline Q4 Item Summary & Mean & S.D. & Mean & S.D. & Mean & S.D. & Mean & S.D. & Mean & S.D. \\
\hline Percentage Score & 87.92 & 14.74 & 70.57 & 23.85 & 91.10 & 3.52 & 98.73 & 2.08 & 58.82 & 22.01 \\
\hline
\end{tabular}


Community-Based Flood Vulnerability Index for Urban Flooding: Understanding Social Vulnerabilities and Risks

Health Risk: E. coli Practice ... continued

\begin{tabular}{|c|c|c|c|c|c|c|c|c|c|c|}
\hline \multirow{2}{*}{ Questions } & \multicolumn{2}{|c|}{ Barangay 2} & \multicolumn{2}{|c|}{ Poblacion 8} & \multicolumn{2}{|c|}{ Cadawinonan } & \multicolumn{2}{|c|}{ Bagacay } & \multicolumn{2}{|c|}{ Taclobo } \\
\hline & $\mathbf{F}$ & $\%$ & $\mathbf{F}$ & $\%$ & $\mathbf{F}$ & $\%$ & $\mathbf{F}$ & $\%$ & $\mathbf{F}$ & $\%$ \\
\hline \multirow[t]{2}{*}{$\begin{array}{l}\text { 4a. Do you use water from the } \\
\text { river/deep well to wet your } \\
\text { ground, flush your toilet, and } \\
\text { water your plants? }\end{array}$} & 12 & 75.00 & 21 & 72.41 & 24 & 96.00 & 19 & 63.33 & 41 & 67.21 \\
\hline & Mean & S.D. & Mean & S.D. & Mean & S.D. & Mean & S.D. & Mean & S.D. \\
\hline Mean Score & 0.75 & 0.45 & 0.72 & 0.45 & 0.96 & 0.20 & 0.63 & 0.49 & 0.71 & 0.46 \\
\hline \multirow[t]{2}{*}{ Percentage Score } & 75.00 & 44.72 & 72.41 & 45.49 & 96.00 & 20.00 & 63.33 & 49.01 & 71.43 & 45.54 \\
\hline & Mean & S.D. & Mean & S.D. & Mean & S.D. & Mean & S.D. & Mean & S.D. \\
\hline \multicolumn{11}{|l|}{ Frequency of use of water from river } \\
\hline Mean Score & 5.63 & 1.02 & 4.97 & 1.84 & 5.96 & 0.20 & 4.70 & 2.05 & 5.03 & 1.89 \\
\hline \multirow[t]{2}{*}{ Percentage Score } & 93.75 & 17.08 & 82.76 & 30.69 & 99.33 & 3.33 & 78.33 & 34.23 & 83.86 & 31.53 \\
\hline & $\mathbf{F}$ & $\%$ & $\mathbf{F}$ & $\%$ & $\mathbf{F}$ & $\%$ & $\mathbf{F}$ & $\%$ & $\mathbf{F}$ & $\%$ \\
\hline \multirow[t]{2}{*}{$\begin{array}{l}\text { 4b. Were there any chances that } \\
\text { you have accidentally swallowed } \\
\text { the water from the river? }\end{array}$} & 15 & 93.75 & 25 & 86.21 & 25 & 100.00 & 26 & 86.67 & 49 & 80.33 \\
\hline & Mean & S.D. & Mean & S.D. & Mean & S.D. & Mean & S.D. & Mean & S.D. \\
\hline Mean Score & 0.94 & 0.25 & 0.89 & 0.31 & 1.00 & 0.00 & 0.87 & 0.35 & 0.86 & 0.35 \\
\hline \multirow[t]{2}{*}{ Percentage Score } & 93.75 & 25.00 & 89.29 & 31.50 & 100.00 & 0.00 & 86.67 & 34.57 & 85.71 & 35.27 \\
\hline & Mean & S.D. & Mean & S.D. & Mean & S.D. & Mean & S.D. & Mean & S.D. \\
\hline \multicolumn{11}{|c|}{ Estimated amount of water swallowed } \\
\hline Mean Score & 5.88 & 0.34 & 5.66 & 1.04 & 6.00 & 0.00 & 5.83 & 0.59 & 5.60 & 1.20 \\
\hline Percentage Score & 97.92 & 5.69 & 94.25 & 17.41 & 100.00 & 0.00 & 97.22 & 9.87 & 93.39 & 19.98 \\
\hline Q4 Item Summary & Mean & S.D. & Mean & S.D. & Mean & S.D. & Mean & S.D. & Mean & S.D. \\
\hline Percentage Score & 90.10 & 10.26 & 84.68 & 9.43 & 98.83 & 1.91 & 81.39 & 14.30 & 83.60 & 9.10 \\
\hline
\end{tabular}


Community-Based Flood Vulnerability Index for Urban Flooding: Understanding Social Vulnerabilities and Risks

Health Risk: E. coli Practice ... continued

\begin{tabular}{|c|c|c|c|c|c|c|}
\hline \multirow{2}{*}{ Questions } & \multicolumn{2}{|c|}{ Candau-ay } & \multicolumn{2}{|c|}{ Batinguel } & \multicolumn{2}{|c|}{ Overall } \\
\hline & $\mathbf{F}$ & $\%$ & $\mathbf{F}$ & $\%$ & $\mathbf{F}$ & $\%$ \\
\hline \multirow[t]{2}{*}{$\begin{array}{l}\text { 4a. Do you use water from the } \\
\text { river/deep well to wet your } \\
\text { ground, flush your toilet, and } \\
\text { water your plants? }\end{array}$} & 54 & 75.00 & 21 & 55.26 & 246 & 68.14 \\
\hline & Mean & S.D. & Mean & S.D. & Mean & S.D. \\
\hline Mean Score & 0.75 & 0.44 & 0.55 & 0.50 & 0.72 & 0.18 \\
\hline \multirow[t]{2}{*}{ Percentage Score } & 75.00 & 43.61 & 55.26 & 50.39 & 72.34 & 17.51 \\
\hline & Mean & S.D. & Mean & S.D. & Mean & S.D. \\
\hline \multicolumn{7}{|l|}{ Frequency of use of water from river } \\
\hline Mean Score & 5.19 & 1.70 & 4.16 & 2.21 & 5.02 & 0.82 \\
\hline \multirow[t]{2}{*}{ Percentage Score } & 86.57 & 28.34 & 69.30 & 36.87 & 83.66 & 13.64 \\
\hline & $\mathbf{F}$ & $\%$ & $\mathbf{F}$ & $\%$ & $\mathbf{F}$ & $\%$ \\
\hline \multirow{2}{*}{$\begin{array}{l}\text { 4b. Were there any chances } \\
\text { that you have accidentally } \\
\text { swallowed the water from the } \\
\text { river? }\end{array}$} & 65 & 90.28 & 27 & 71.05 & 295 & 81.72 \\
\hline & Mean & S.D. & Mean & S.D. & Mean & S.D. \\
\hline Mean Score & 0.90 & 0.30 & 0.71 & 0.46 & 0.88 & 0.13 \\
\hline \multirow[t]{2}{*}{ Percentage Score } & 90.28 & 29.83 & 71.05 & 45.96 & 87.86 & 12.75 \\
\hline & Mean & S.D. & Mean & S.D. & Mean & S.D. \\
\hline \multicolumn{7}{|c|}{ Estimated amount of water swallowed } \\
\hline Mean Score & 5.71 & 1.01 & 5.37 & 1.17 & 5.73 & 0.24 \\
\hline Percentage Score & 95.14 & 16.89 & 89.47 & 19.54 & 95.48 & 4.07 \\
\hline Q4 Item Summary & Mean & S.D. & Mean & S.D. & Mean & S.D. \\
\hline Percentage Score & 86.75 & 8.58 & 71.27 & 14.04 & 84.84 & 9.66 \\
\hline
\end{tabular}


Community-Based Flood Vulnerability Index for Urban Flooding: Understanding Social Vulnerabilities and Risks

Health Risk: E. coli Practice ... continued

\begin{tabular}{|c|c|c|c|c|c|c|c|c|c|c|}
\hline \multirow{2}{*}{ Questions } & \multicolumn{2}{|c|}{ Tabuc-tubig } & \multicolumn{2}{|c|}{ Junob } & \multicolumn{2}{|c|}{ Poblacion 1} & \multicolumn{2}{|c|}{ Calindagan } & \multicolumn{2}{|c|}{ Balugo } \\
\hline & $\mathbf{F}$ & $\%$ & $F$ & $\%$ & $\mathbf{F}$ & $\%$ & $\mathbf{F}$ & $\%$ & $\mathbf{F}$ & $\%$ \\
\hline $\begin{array}{l}\text { 5. Do you wash your hands with } \\
\text { soap and water thoroughly after } \\
\text { contact with domesticated } \\
\text { animals? }\end{array}$ & 10 & 100.00 & 16 & 100.00 & 20 & 90.91 & 19 & 82.61 & 14 & 82.35 \\
\hline Q5 Item Summary & Mean & S.D. & Mean & S.D. & Mean & S.D. & Mean & S.D. & Mean & S.D. \\
\hline Mean Score & 1.00 & 0.00 & 1.00 & 0.00 & 0.91 & 0.29 & 0.83 & 0.39 & 0.82 & 0.39 \\
\hline Percentage Score & 100.00 & 0.00 & 100.00 & 0.00 & 90.91 & 29.42 & 82.61 & 38.76 & 82.35 & 39.30 \\
\hline
\end{tabular}

\begin{tabular}{|c|c|c|c|c|c|c|c|c|c|c|}
\hline \multirow{2}{*}{ Questions } & \multicolumn{2}{|c|}{ Barangay 2} & \multicolumn{2}{|c|}{ Poblacion 8} & \multicolumn{2}{|c|}{ Cadawinonan } & \multicolumn{2}{|c|}{ Bagacay } & \multicolumn{2}{|c|}{ Taclobo } \\
\hline & $\mathbf{F}$ & $\%$ & $\mathbf{F}$ & $\%$ & $\mathbf{F}$ & $\%$ & $\mathbf{F}$ & $\%$ & $\mathbf{F}$ & $\%$ \\
\hline $\begin{array}{l}\text { 5. Do you wash your hands with } \\
\text { soap and water thoroughly after } \\
\text { contact with domesticated } \\
\text { animals? }\end{array}$ & 14 & 87.50 & 22 & 75.86 & 19 & 76.00 & 23 & 76.67 & 47 & 77.05 \\
\hline Q5 Item Summary & Mean & S.D. & Mean & S.D. & Mean & S.D. & Mean & S.D. & Mean & S.D. \\
\hline Mean Score & 0.88 & 0.34 & 0.76 & 0.44 & 0.76 & 0.44 & 0.77 & 0.43 & 0.87 & 0.34 \\
\hline Percentage Score & 87.50 & 34.16 & 75.86 & 43.55 & 76.00 & 43.59 & 76.67 & 43.02 & 86.89 & 34.04 \\
\hline
\end{tabular}


Community-Based Flood Vulnerability Index for Urban Flooding: Understanding Social Vulnerabilities and Risks

Health Risk: E. coli Practice ... continued

\begin{tabular}{|c|c|c|c|c|c|c|}
\hline \multirow{2}{*}{ Questions } & \multicolumn{2}{|c|}{ Candau-ay } & \multicolumn{2}{|c|}{ Batinguel } & \multicolumn{2}{|c|}{ Overall } \\
\hline & $\mathbf{F}$ & $\%$ & $\mathbf{F}$ & $\%$ & $\mathbf{F}$ & $\%$ \\
\hline $\begin{array}{l}\text { 5. Do you wash your hands with } \\
\text { soap and water thoroughly } \\
\text { after contact with } \\
\text { domesticated animals? }\end{array}$ & 50 & 69.44 & 33 & 86.84 & 271 & 75.07 \\
\hline Q5 Item Summary & Mean & S.D. & Mean & S.D. & Mean & S.D. \\
\hline Mean Score & 0.69 & 0.46 & 0.87 & 0.34 & 0.83 & 0.09 \\
\hline Percentage Score & 69.44 & 46.39 & 86.84 & 34.26 & 83.19 & 8.52 \\
\hline
\end{tabular}

Health Risk: E. coli Practice ... continued

\begin{tabular}{|c|c|c|c|c|c|c|c|c|c|c|}
\hline \multirow[b]{2}{*}{ Questions } & \multicolumn{2}{|c|}{ Tabuc-tubig } & \multicolumn{2}{|l|}{ Junob } & \multicolumn{2}{|c|}{ Poblacion 1} & \multicolumn{2}{|c|}{ Calindagan } & \multicolumn{2}{|l|}{ Balugo } \\
\hline & $\mathbf{F}$ & $\%$ & $\mathbf{F}$ & $\%$ & $\mathbf{F}$ & $\%$ & $\mathbf{F}$ & $\%$ & $\mathbf{F}$ & $\%$ \\
\hline $\begin{array}{l}\text { 6. Do you boil your water for } 10 \\
\text { minutes during unusual events } \\
\text { such as during typhoons \& } \\
\text { flooding? }\end{array}$ & 8 & 80.00 & 14 & 87.50 & 18 & 81.82 & 13 & 56.52 & 12 & 70.59 \\
\hline Q6 Item Summary & Mean & S.D. & Mean & S.D. & Mean & S.D. & Mean & S.D. & Mean & S.D. \\
\hline Mean Score & 0.80 & 0.42 & 0.88 & 0.34 & 0.86 & 0.36 & 0.57 & 0.51 & 0.71 & 0.47 \\
\hline Percentage Score & 80.00 & 42.16 & 87.50 & 34.16 & 85.71 & 35.86 & 56.52 & 50.69 & 70.59 & 46.97 \\
\hline
\end{tabular}


Community-Based Flood Vulnerability Index for Urban Flooding: Understanding

472 Social Vulnerabilities and Risks

\begin{tabular}{|c|c|c|c|c|c|c|c|c|c|c|}
\hline \multirow{2}{*}{ Questions } & \multicolumn{2}{|c|}{ Barangay 2} & \multicolumn{2}{|c|}{ Poblacion 8} & \multicolumn{2}{|c|}{ Cadawinonan } & \multicolumn{2}{|c|}{ Bagacay } & \multicolumn{2}{|c|}{ Taclobo } \\
\hline & $F$ & $\%$ & $\mathbf{F}$ & $\%$ & $\mathbf{F}$ & $\%$ & $F$ & $\%$ & $\mathbf{F}$ & $\%$ \\
\hline $\begin{array}{l}\text { 6. Do you boil your water for } 10 \\
\text { minutes during unusual events } \\
\text { such as during typhoons \& } \\
\text { flooding? }\end{array}$ & 10 & 62.50 & 19 & 65.52 & 18 & 72.00 & 18 & 60.00 & 42 & 68.85 \\
\hline Q6 Item Summary & Mean & S.D. & Mean & S.D. & Mean & S.D. & Mean & S.D. & Mean & S.D. \\
\hline Mean Score & 0.63 & 0.50 & 0.66 & 0.48 & 0.72 & 0.46 & 0.60 & 0.50 & 0.74 & 0.44 \\
\hline Percentage Score & 62.50 & 50.00 & 65.52 & 48.37 & 72.00 & 45.83 & 60.00 & 49.83 & 74.19 & 44.11 \\
\hline
\end{tabular}

Health Risk: E. coli Practice ... continued

\begin{tabular}{|c|c|c|c|c|c|c|}
\hline \multirow{2}{*}{ Questions } & \multicolumn{2}{|c|}{ Candau-ay } & \multicolumn{2}{|c|}{ Batinguel } & \multicolumn{2}{|c|}{ Overall } \\
\hline & $\mathbf{F}$ & $\%$ & $\mathbf{F}$ & $\%$ & $\mathbf{F}$ & $\%$ \\
\hline $\begin{array}{l}\text { 6. Do you boil your water for } 10 \text { minutes during } \\
\text { unusual events such as during typhoons \& } \\
\text { flooding? }\end{array}$ & 40 & 55.56 & 30 & 78.95 & 228 & 63.16 \\
\hline Q6 Item Summary & Mean & S.D. & Mean & S.D. & Mean & S.D. \\
\hline Mean Score & 0.56 & 0.50 & 0.79 & 0.41 & 0.69 & 0.10 \\
\hline Percentage Score & 55.56 & 50.04 & 78.95 & 41.32 & 69.23 & 10.05 \\
\hline
\end{tabular}


Community-Based Flood Vulnerability Index for Urban Flooding: Understanding

Social Vulnerabilities and Risks

Health Risk: E. coli Practice ... continued

\begin{tabular}{|c|c|c|c|c|c|c|c|c|c|c|}
\hline \multirow{2}{*}{ Questions } & \multicolumn{2}{|c|}{ Tabuc-tubig } & \multicolumn{2}{|c|}{ Junob } & \multicolumn{2}{|c|}{ Poblacion 1} & \multicolumn{2}{|c|}{ Calindagan } & \multicolumn{2}{|c|}{ Balugo } \\
\hline & $\mathbf{F}$ & $\%$ & $\mathbf{F}$ & $\%$ & $\mathbf{F}$ & $\%$ & $\mathbf{F}$ & $\%$ & $\mathbf{F}$ & $\%$ \\
\hline $\begin{array}{l}\text { 7. Do you keep your animals away } \\
\text { from bodies of water? }\end{array}$ & 6 & 60.00 & 8 & 80.00 & 8 & 80.00 & 15 & 65.22 & 10 & 58.82 \\
\hline Q7 Item Summary & Mean & S.D. & Mean & S.D. & Mean & S.D. & Mean & S.D. & Mean & S.D. \\
\hline Mean Score & 0.60 & 0.52 & 0.80 & 0.42 & 0.89 & 0.33 & 0.71 & 0.46 & 0.59 & 0.51 \\
\hline Percentage Score & 60.00 & 51.64 & 80.00 & 42.16 & 88.89 & 33.33 & 71.43 & 46.29 & 58.82 & 50.73 \\
\hline
\end{tabular}

\begin{tabular}{|c|c|c|c|c|c|c|c|c|c|c|}
\hline \multirow{2}{*}{ Questions } & \multicolumn{2}{|c|}{ Barangay 2} & \multicolumn{2}{|c|}{ Poblacion 8} & \multicolumn{2}{|c|}{ Cadawinonan } & \multicolumn{2}{|c|}{ Bagacay } & \multicolumn{2}{|c|}{ Taclobo } \\
\hline & $\mathbf{F}$ & $\%$ & $\mathbf{F}$ & $\%$ & $\mathbf{F}$ & $\%$ & $\mathbf{F}$ & $\%$ & $\mathbf{F}$ & $\%$ \\
\hline $\begin{array}{l}\text { 7. Do you keep your animals away } \\
\text { from bodies of water? }\end{array}$ & 10 & 62.50 & 15 & 51.72 & 13 & 52.00 & 20 & 66.67 & 41 & 67.21 \\
\hline Q7 Item Summary & Mean & S.D. & Mean & S.D. & Mean & S.D. & Mean & S.D. & Mean & S.D. \\
\hline Mean Score & 0.63 & 0.50 & 0.52 & 0.51 & 0.54 & 0.51 & 0.69 & 0.47 & 0.74 & 0.44 \\
\hline Percentage Score & 62.50 & 50.00 & 51.72 & 50.85 & 54.17 & 50.90 & 68.97 & 47.08 & 74.19 & 44.11 \\
\hline
\end{tabular}

\begin{tabular}{|c|c|c|c|c|c|c|}
\hline \multirow{2}{*}{ Questions } & \multicolumn{2}{|c|}{ Candau-ay } & \multicolumn{2}{|c|}{ Batinguel } & \multicolumn{2}{|c|}{ Overall } \\
\hline & $\mathbf{F}$ & $\%$ & $\mathbf{F}$ & $\%$ & $\mathbf{F}$ & $\%$ \\
\hline $\begin{array}{l}\text { 7. Do you keep your animals away from bodies of } \\
\text { water? }\end{array}$ & 45 & 62.50 & 25 & 65.79 & 208 & 57.62 \\
\hline Q7 Item Summary & Mean & S.D. & Mean & S.D. & Mean & S.D. \\
\hline Mean Score & 0.64 & 0.48 & 0.66 & 0.48 & 0.66 & 0.10 \\
\hline Percentage Score & 64.29 & 48.26 & 65.79 & 48.08 & 65.52 & 10.36 \\
\hline
\end{tabular}


Community-Based Flood Vulnerability Index for Urban Flooding: Understanding Social Vulnerabilities and Risks

Health Risk: E. coli Practice ... continued

\begin{tabular}{|c|c|c|c|c|c|c|c|c|c|c|}
\hline \multirow{2}{*}{ Questions } & \multicolumn{2}{|c|}{ Tabuc-tubig } & \multicolumn{2}{|c|}{ Junob } & \multicolumn{2}{|c|}{ Poblacion 1} & \multicolumn{2}{|c|}{ Calindagan } & \multicolumn{2}{|c|}{ Balugo } \\
\hline & $\mathbf{F}$ & $\%$ & $\mathbf{F}$ & $\%$ & $\mathbf{F}$ & $\%$ & $\mathbf{F}$ & $\%$ & $\mathbf{F}$ & $\%$ \\
\hline $\begin{array}{l}\text { 8. If one is sick from severe } \\
\text { diarrhea in the family, do you } \\
\text { immediately sick for medical } \\
\text { help? }\end{array}$ & 10 & 100.00 & 7 & 70.00 & 9 & 90.00 & 19 & 82.61 & 14 & 82.35 \\
\hline Q8 Item Summary & Mean & S.D. & Mean & S.D. & Mean & S.D. & Mean & S.D. & Mean & S.D. \\
\hline Mean Score & 1.00 & 0.00 & 0.70 & 0.48 & 0.90 & 0.32 & 0.83 & 0.39 & 0.82 & 0.39 \\
\hline Percentage Score & 100.00 & 0.00 & 70.00 & 48.30 & 90.00 & 31.62 & 82.61 & 38.76 & 82.35 & 39.30 \\
\hline
\end{tabular}

\begin{tabular}{|c|c|c|c|c|c|c|c|c|c|c|}
\hline \multirow{2}{*}{ Questions } & \multicolumn{2}{|c|}{ Barangay 2} & \multicolumn{2}{|c|}{ Poblacion 8} & \multicolumn{2}{|c|}{ Cadawinonan } & \multicolumn{2}{|c|}{ Bagacay } & \multicolumn{2}{|c|}{ Taclobo } \\
\hline & $\mathbf{F}$ & $\%$ & $\mathbf{F}$ & $\%$ & $\mathbf{F}$ & $\%$ & $\mathbf{F}$ & $\%$ & $\mathbf{F}$ & $\%$ \\
\hline $\begin{array}{l}\text { 8. If one is sick from severe } \\
\text { diarrhea in the family, do you } \\
\text { immediately sick for medical } \\
\text { help? }\end{array}$ & 13 & 81.25 & 22 & 75.86 & 17 & 68.00 & 22 & 73.33 & 43 & 70.49 \\
\hline Q8 Item Summary & Mean & S.D. & Mean & S.D. & Mean & S.D. & Mean & S.D. & Mean & S.D. \\
\hline Mean Score & 0.81 & 0.40 & 0.76 & 0.44 & 0.68 & 0.48 & 0.73 & 0.45 & 0.81 & 0.40 \\
\hline Percentage Score & 81.25 & 40.31 & 75.86 & 43.55 & 68.00 & 47.61 & 73.33 & 44.98 & 80.65 & 39.83 \\
\hline
\end{tabular}

\begin{tabular}{|c|c|c|c|c|c|c|}
\hline \multirow{2}{*}{ Questions } & \multicolumn{2}{|c|}{ Candau-ay } & \multicolumn{2}{|c|}{ Batinguel } & \multicolumn{2}{|c|}{ Overall } \\
\hline & $\mathbf{F}$ & $\%$ & $\mathbf{F}$ & $\%$ & $\mathbf{F}$ & $\%$ \\
\hline $\begin{array}{l}\text { 8. If one is sick from severe diarrhea in the family, } \\
\text { do you immediately sick for medical help? }\end{array}$ & 49 & 68.06 & 34 & 89.47 & 252 & 69.81 \\
\hline Q8 Item Summary & Mean & S.D. & Mean & S.D. & Mean & S.D. \\
\hline Mean Score & 0.68 & 0.47 & 0.89 & 0.31 & 0.81 & 0.10 \\
\hline Percentage Score & 68.06 & 46.95 & 89.47 & 31.10 & 81.05 & 9.70 \\
\hline
\end{tabular}


Community-Based Flood Vulnerability Index for Urban Flooding: Understanding Social Vulnerabilities and Risks

Health Risk: E. coli Practice ... continued

\begin{tabular}{|c|c|c|c|c|c|c|c|c|c|c|}
\hline \multirow{2}{*}{ Questions } & \multicolumn{2}{|c|}{ Tabuc-tubig } & \multicolumn{2}{|c|}{ Junob } & \multicolumn{2}{|c|}{ Poblacion 1} & \multicolumn{2}{|c|}{ Calindagan } & \multicolumn{2}{|c|}{ Balugo } \\
\hline & $\mathbf{F}$ & $\%$ & $\mathbf{F}$ & $\%$ & $\mathbf{F}$ & $\%$ & $\mathbf{F}$ & $\%$ & $\mathbf{F}$ & $\%$ \\
\hline 9. Do you self-medicate? & 6 & 60.00 & 8 & 50.00 & 10 & 45.45 & 14 & 60.87 & 11 & 64.71 \\
\hline Q9 Item Summary & Mean & S.D. & Mean & S.D. & Mean & S.D. & Mean & S.D. & Mean & S.D. \\
\hline Mean Score & 0.60 & 0.52 & 0.50 & 0.52 & 0.45 & 0.51 & 0.61 & 0.50 & 0.69 & 0.48 \\
\hline Percentage Score & 60.00 & 51.64 & 50.00 & 51.64 & 45.45 & 50.96 & 60.87 & 49.90 & 68.75 & 47.87 \\
\hline
\end{tabular}

\begin{tabular}{|c|c|c|c|c|c|c|c|c|c|c|}
\hline \multirow{2}{*}{ Questions } & \multicolumn{2}{|c|}{ Barangay 2} & \multicolumn{2}{|c|}{ Poblacion 8} & \multicolumn{2}{|c|}{ Cadawinonan } & \multicolumn{2}{|c|}{ Bagacay } & \multicolumn{2}{|c|}{ Taclobo } \\
\hline & $\mathbf{F}$ & $\%$ & $\mathbf{F}$ & $\%$ & $\mathbf{F}$ & $\%$ & $\mathbf{F}$ & $\%$ & $\mathbf{F}$ & $\%$ \\
\hline 9. Do you self-medicate? & 8 & 50.00 & 18 & 62.07 & 11 & 44.00 & 9 & 30.00 & 27 & 44.26 \\
\hline Q9 Item Summary & Mean & S.D. & Mean & S.D. & Mean & S.D. & Mean & S.D. & Mean & S.D. \\
\hline Mean Score & 0.50 & 0.52 & 0.62 & 0.49 & 0.44 & 0.51 & 0.30 & 0.47 & 0.46 & 0.50 \\
\hline Percentage Score & 50.00 & 51.64 & 62.07 & 49.38 & 44.00 & 50.66 & 30.00 & 46.61 & 45.90 & 50.25 \\
\hline
\end{tabular}

\begin{tabular}{|c|c|c|c|c|c|c|}
\hline \multirow{2}{*}{ Questions } & \multicolumn{2}{|c|}{ Candau-ay } & \multicolumn{2}{|c|}{ Batinguel } & \multicolumn{2}{|c|}{ Overall } \\
\hline & $\mathbf{F}$ & $\%$ & $\mathbf{F}$ & $\%$ & $\mathbf{F}$ & $\%$ \\
\hline 9. Do you self-medicate? & 28 & 38.89 & 13 & 34.21 & 155 & 42.94 \\
\hline Q9 Item Summary & Mean & S.D. & Mean & S.D. & Mean & S.D. \\
\hline Mean Score & 0.40 & 0.49 & 0.34 & 0.48 & 0.49 & 0.12 \\
\hline Percentage Score & 40.00 & 49.34 & 34.21 & 48.08 & 49.21 & 12.37 \\
\hline
\end{tabular}


Community-Based Flood Vulnerability Index for Urban Flooding: Understanding

Social Vulnerabilities and Risks

Health Risk: E. coli Practice ... continued

\begin{tabular}{|c|c|c|c|c|c|c|c|c|c|c|}
\hline \multirow{2}{*}{ Questions } & \multicolumn{2}{|c|}{ Tabuc-tubig } & \multicolumn{2}{|c|}{ Junob } & \multicolumn{2}{|c|}{ Poblacion 1} & \multicolumn{2}{|c|}{ Calindagan } & \multicolumn{2}{|c|}{ Balugo } \\
\hline & $\mathbf{F}$ & $\%$ & $\mathbf{F}$ & $\%$ & $\mathbf{F}$ & $\%$ & $\mathbf{F}$ & $\%$ & $F$ & $\%$ \\
\hline $\begin{array}{l}\text { 10. Do you follow the prescription } \\
\text { given? }\end{array}$ & 10 & 100.00 & 13 & 81.25 & 20 & 90.91 & 18 & 78.26 & 15 & 88.24 \\
\hline Q10 Item Summary & Mean & S.D. & Mean & S.D. & Mean & S.D. & Mean & S.D. & Mean & S.D. \\
\hline Mean Score & 1.00 & 0.00 & 0.81 & 0.40 & 0.91 & 0.29 & 0.78 & 0.42 & 0.88 & 0.33 \\
\hline Percentage Score & 100.00 & 0.00 & 81.25 & 40.31 & 90.91 & 29.42 & 78.26 & 42.17 & 88.24 & 33.21 \\
\hline
\end{tabular}

\begin{tabular}{|c|c|c|c|c|c|c|c|c|c|c|}
\hline \multirow{2}{*}{ Questions } & \multicolumn{2}{|c|}{ Barangay 2} & \multicolumn{2}{|c|}{ Poblacion 8} & \multicolumn{2}{|c|}{ Cadawinonan } & \multicolumn{2}{|c|}{ Bagacay } & \multicolumn{2}{|c|}{ Taclobo } \\
\hline & $\mathbf{F}$ & $\%$ & $\mathbf{F}$ & $\%$ & $\mathbf{F}$ & $\%$ & $\mathbf{F}$ & $\%$ & $\mathbf{F}$ & $\%$ \\
\hline $\begin{array}{l}\text { 10. Do you follow the prescription } \\
\text { given? }\end{array}$ & 14 & 87.50 & 21 & 72.41 & 18 & 72.00 & 25 & 83.33 & 48 & 78.69 \\
\hline Q10 Item Summary & Mean & S.D. & Mean & S.D. & Mean & S.D. & Mean & S.D. & Mean & S.D. \\
\hline Mean Score & 0.88 & 0.34 & 0.75 & 0.44 & 0.72 & 0.46 & 0.83 & 0.38 & 0.90 & 0.30 \\
\hline Percentage Score & 87.50 & 34.16 & 75.00 & 44.10 & 72.00 & 45.83 & 83.33 & 37.90 & 90.16 & 30.03 \\
\hline
\end{tabular}

\begin{tabular}{|c|c|c|c|c|c|c|}
\hline \multirow{2}{*}{ Questions } & \multicolumn{2}{|c|}{ Candau-ay } & \multicolumn{2}{|c|}{ Batinguel } & \multicolumn{2}{|c|}{ Overall } \\
\hline & $\mathbf{F}$ & $\%$ & $\mathbf{F}$ & $\%$ & $\mathbf{F}$ & $\%$ \\
\hline 10. Do you follow the prescription given? & 50 & 69.44 & 31 & 81.58 & 270 & 74.79 \\
\hline Q10 Item Summary & Mean & S.D. & Mean & S.D. & Mean & S.D. \\
\hline Mean Score & 0.69 & 0.46 & 0.82 & 0.39 & 0.83 & 0.09 \\
\hline Percentage Score & 69.44 & 46.39 & 81.58 & 39.29 & 83.31 & 9.18 \\
\hline
\end{tabular}


Community-Based Flood Vulnerability Index for Urban Flooding: Understanding Social Vulnerabilities and Risks

Health Risk: E. coli Practice ... continued

\begin{tabular}{|c|c|c|c|c|c|c|c|c|c|c|}
\hline \multirow{2}{*}{ Questions } & \multicolumn{2}{|c|}{ Tabuc-tubig } & \multicolumn{2}{|c|}{ Junob } & \multicolumn{2}{|c|}{ Poblacion 1} & \multicolumn{2}{|c|}{ Calindagan } & \multicolumn{2}{|c|}{ Balugo } \\
\hline & $\mathbf{F}$ & $\%$ & $\mathbf{F}$ & $\%$ & $\mathbf{F}$ & $\%$ & $\mathbf{F}$ & $\%$ & $\mathbf{F}$ & $\%$ \\
\hline $\begin{array}{l}\text { 11. Do you go for a regular health } \\
\text { check up? }\end{array}$ & 9 & 90.00 & 9 & 56.25 & 15 & 68.18 & 13 & 56.52 & 12 & 70.59 \\
\hline Q11 Item Summary & Mean & S.D. & Mean & S.D. & Mean & S.D. & Mean & S.D. & Mean & S.D. \\
\hline Mean Score & 0.90 & 0.32 & 0.56 & 0.51 & 0.68 & 0.48 & 0.57 & 0.51 & 0.71 & 0.47 \\
\hline Percentage Score & 90.00 & 31.62 & 56.25 & 51.23 & 68.18 & 47.67 & 56.52 & 50.69 & 76.47 & 43.72 \\
\hline
\end{tabular}

\begin{tabular}{|c|c|c|c|c|c|c|c|c|c|c|}
\hline \multirow{2}{*}{ Questions } & \multicolumn{2}{|c|}{ Barangay 2} & \multicolumn{2}{|c|}{ Poblacion 8} & \multicolumn{2}{|c|}{ Cadawinonan } & \multicolumn{2}{|c|}{ Bagacay } & \multicolumn{2}{|c|}{ Taclobo } \\
\hline & $\mathbf{F}$ & $\%$ & $\mathbf{F}$ & $\%$ & $\mathbf{F}$ & $\%$ & $\mathbf{F}$ & $\%$ & $\mathbf{F}$ & $\%$ \\
\hline $\begin{array}{l}\text { 11. Do you go for a regular health } \\
\text { check up? }\end{array}$ & 8 & 50.00 & 15 & 51.72 & 14 & 56.00 & 17 & 56.67 & 37 & 60.66 \\
\hline Q11 Item Summary & Mean & S.D. & Mean & S.D. & Mean & S.D. & Mean & S.D. & Mean & S.D. \\
\hline Mean Score & 0.50 & 0.52 & 0.54 & 0.51 & 0.56 & 0.51 & 0.59 & 0.50 & 0.67 & 0.47 \\
\hline Percentage Score & 50.00 & 51.64 & 53.57 & 50.79 & 56.00 & 50.66 & 58.62 & 50.12 & 67.21 & 47.33 \\
\hline
\end{tabular}

\begin{tabular}{|c|c|c|c|c|c|c|}
\hline \multirow{2}{*}{ Questions } & \multicolumn{2}{|c|}{ Candau-ay } & \multicolumn{2}{|c|}{ Batinguel } & \multicolumn{2}{|c|}{ Overall } \\
\hline & \begin{tabular}{l|l|}
$\mathbf{F}$ \\
\end{tabular} & $\%$ & $\mathbf{F}$ & $\%$ & $\mathbf{F}$ & $\%$ \\
\hline 11. Do you go for a regular health check-up? & 29 & 40.28 & 23 & 60.53 & 192 & 53.19 \\
\hline Q11 Item Summary & Mean & S.D. & Mean & S.D. & Mean & S.D. \\
\hline Mean Score & 0.40 & 0.49 & 0.61 & 0.50 & 0.61 & 0.13 \\
\hline Percentage Score & 40.28 & 49.39 & 60.53 & 49.54 & 61.58 & 13.50 \\
\hline
\end{tabular}


Community-Based Flood Vulnerability Index for Urban Flooding: Understanding

\section{Social Vulnerabilities and Risks}

\section{Health Risk: E. coli Practice SUMMARY}

\begin{tabular}{|c|c|c|c|c|c|c|c|c|c|c|}
\hline \multirow{2}{*}{ Questions } & \multicolumn{2}{|c|}{ Tabuc-tubig } & \multicolumn{2}{|c|}{ Junob } & \multicolumn{2}{|c|}{ Poblacion 1} & \multicolumn{2}{|c|}{ Calindagan } & \multicolumn{2}{|c|}{ Balugo } \\
\hline & Mean & S.D. & Mean & S.D. & Mean & S.D. & Mean & S.D. & Mean & S.D. \\
\hline $\begin{array}{l}\text { 1. Do you or other members in } \\
\text { the family go swimming or } \\
\text { bathing in the river? }\end{array}$ & 83.33 & 15.63 & 59.38 & 20.16 & 89.27 & 3.80 & 90.40 & 6.73 & 64.95 & 18.33 \\
\hline $\begin{array}{l}\text { 2. Do you immerse yourself other } \\
\text { members in the family into the } \\
\text { river? }\end{array}$ & 89.58 & 14.17 & 29.43 & 20.10 & 86.80 & 7.26 & 91.47 & 6.89 & 70.59 & 18.46 \\
\hline $\begin{array}{l}\text { 3. Do you wash your clothes in the } \\
\text { river? }\end{array}$ & 92.08 & 9.75 & 59.64 & 21.81 & 92.93 & 2.05 & 98.55 & 1.96 & 57.11 & 26.82 \\
\hline $\begin{array}{l}\text { 4. Do you use water from the } \\
\text { river/deep well to wet your } \\
\text { ground, flush your toilet, and } \\
\text { water your plants? }\end{array}$ & 87.92 & 14.74 & 70.57 & 23.85 & 91.10 & 3.52 & 98.73 & 2.08 & 58.82 & 22.01 \\
\hline $\begin{array}{l}\text { 5. Do you wash your hands with } \\
\text { soap and water thoroughly after } \\
\text { contact with domesticated } \\
\text { animals? }\end{array}$ & 100.00 & 0.00 & 100.00 & 0.00 & 90.91 & 29.42 & 82.61 & 38.76 & 82.35 & 39.30 \\
\hline $\begin{array}{l}\text { 6. Do you boil your water for } 10 \\
\text { minutes during unusual events } \\
\text { such as during typhoons \& } \\
\text { flooding? }\end{array}$ & 80.00 & 42.16 & 87.50 & 34.16 & 85.71 & 35.86 & 56.52 & 50.69 & 70.59 & 46.97 \\
\hline $\begin{array}{l}\text { 7. Do you keep your animals away } \\
\text { from bodies of water? }\end{array}$ & 60.00 & 51.64 & 80.00 & 42.16 & 88.89 & 33.33 & 71.43 & 46.29 & 58.82 & 50.73 \\
\hline $\begin{array}{l}\text { 8. If one is sick from severe } \\
\text { diarrhea in the family, do you } \\
\text { immediately sick for medical } \\
\text { help? }\end{array}$ & 100.00 & 0.00 & 70.00 & 48.30 & 90.00 & 31.62 & 82.61 & 38.76 & 82.35 & 39.30 \\
\hline
\end{tabular}


Community-Based Flood Vulnerability Index for Urban Flooding: Understanding

Social Vulnerabilities and Risks

Health Risk: E. coli Practice SUMMARY . . continued

\begin{tabular}{|c|c|c|c|c|c|c|c|c|c|c|}
\hline \multirow{2}{*}{ Questions } & \multicolumn{2}{|c|}{ Tabuc-tubig } & \multicolumn{2}{|c|}{ Junob } & \multicolumn{2}{|c|}{ Poblacion 1} & \multicolumn{2}{|c|}{ Calindagan } & \multicolumn{2}{|c|}{ Balugo } \\
\hline & Mean & S.D. & Mean & S.D. & Mean & S.D. & Mean & S.D. & Mean & S.D. \\
\hline 9. Do you self-medicate? & 60.00 & 51.64 & 50.00 & 51.64 & 45.45 & 50.96 & 60.87 & 49.90 & 68.75 & 47.87 \\
\hline $\begin{array}{l}\text { 10. Do you follow the prescription } \\
\text { given? }\end{array}$ & 100.00 & 0.00 & 81.25 & 40.31 & 90.91 & 29.42 & 78.26 & 42.17 & 88.24 & 33.21 \\
\hline $\begin{array}{l}\text { 11. Do you go for a regular health } \\
\text { check-up? }\end{array}$ & 90.00 & 31.62 & 56.25 & 51.23 & 68.18 & 47.67 & 56.52 & 50.69 & 76.47 & 43.72 \\
\hline Overall Summary & 85.72 & 14.32 & 67.64 & 19.56 & 83.65 & 14.35 & 78.91 & 15.75 & 70.82 & 10.56 \\
\hline
\end{tabular}


Community-Based Flood Vulnerability Index for Urban Flooding: Understanding

Social Vulnerabilities and Risks

Health Risk: E. coli Practice SUMMARY . . continued

\begin{tabular}{|c|c|c|c|c|c|c|c|c|c|c|}
\hline \multirow{2}{*}{ Questions } & \multicolumn{2}{|c|}{ Barangay 2} & \multicolumn{2}{|c|}{ Poblacion 8} & \multicolumn{2}{|c|}{ Cadawinonan } & \multicolumn{2}{|c|}{ Bagacay } & \multicolumn{2}{|c|}{ Taclobo } \\
\hline & Mean & S.D. & Mean & S.D. & Mean & S.D. & Mean & S.D. & Mean & S.D. \\
\hline $\begin{array}{l}\text { 1. Do you or other members in } \\
\text { the family go swimming or } \\
\text { bathing in the river? }\end{array}$ & 82.66 & 11.43 & 72.13 & 12.03 & 78.17 & 12.62 & 52.53 & 37.25 & 81.81 & 8.44 \\
\hline $\begin{array}{l}\text { 2. Do you immerse yourself other } \\
\text { members in the family into the } \\
\text { river? }\end{array}$ & 89.38 & 6.85 & 77.10 & 13.33 & 81.17 & 15.32 & 67.45 & 31.85 & 79.43 & 16.57 \\
\hline $\begin{array}{l}\text { 3. Do you wash your clothes in } \\
\text { the river? }\end{array}$ & 97.95 & 3.43 & 80.32 & 8.63 & 83.17 & 10.55 & 81.11 & 14.66 & 84.26 & 10.23 \\
\hline $\begin{array}{l}\text { 4. Do you use water from the } \\
\text { river/deep well to wet your } \\
\text { ground, flush your toilet, and } \\
\text { water your plants? }\end{array}$ & 90.10 & 10.26 & 84.68 & 9.43 & 98.83 & 1.91 & 81.39 & 14.30 & 83.60 & 9.10 \\
\hline $\begin{array}{l}\text { 5. Do you wash your hands with } \\
\text { soap and water thoroughly after } \\
\text { contact with domesticated } \\
\text { animals? }\end{array}$ & 87.50 & 34.16 & 75.86 & 43.55 & 76.00 & 43.59 & 76.67 & 43.02 & 86.89 & 34.04 \\
\hline $\begin{array}{l}\text { 6. Do you boil your water for } 10 \\
\text { minutes during unusual events } \\
\text { such as during typhoons \& } \\
\text { flooding? }\end{array}$ & 62.50 & 50.00 & 65.52 & 48.37 & 72.00 & 45.83 & 60.00 & 49.83 & 74.19 & 44.11 \\
\hline $\begin{array}{l}\text { 7. Do you keep your animals away } \\
\text { from bodies of water? }\end{array}$ & 62.50 & 50.00 & 51.72 & 50.85 & 54.17 & 50.90 & 68.97 & 47.08 & 74.19 & 44.11 \\
\hline $\begin{array}{l}\text { 8. If one is sick from severe } \\
\text { diarrhea in the family, do you } \\
\text { immediately sick for medical } \\
\text { help? }\end{array}$ & 81.25 & 40.31 & 75.86 & 43.55 & 68.00 & 47.61 & 73.33 & 44.98 & 80.65 & 39.83 \\
\hline
\end{tabular}


Community-Based Flood Vulnerability Index for Urban Flooding: Understanding

Social Vulnerabilities and Risks

Health Risk: E. coli Practice SUMMARY . . . continued

\begin{tabular}{|c|c|c|c|c|c|c|c|c|c|c|}
\hline \multirow{2}{*}{ Questions } & \multicolumn{2}{|c|}{ Barangay 2} & \multicolumn{2}{|c|}{ Poblacion 8} & \multicolumn{2}{|c|}{ Cadawinonan } & \multicolumn{2}{|c|}{ Bagacay } & \multicolumn{2}{|c|}{ Taclobo } \\
\hline & Mean & S.D. & Mean & S.D. & Mean & S.D. & Mean & S.D. & Mean & S.D. \\
\hline 9. Do you self-medicate? & 50.00 & 51.64 & 62.07 & 49.38 & 44.00 & 50.66 & 30.00 & 46.61 & 45.90 & 50.25 \\
\hline $\begin{array}{l}\text { 10. Do you follow the prescription } \\
\text { given? }\end{array}$ & 87.50 & 34.16 & 75.00 & 44.10 & 72.00 & 45.83 & 83.33 & 37.90 & 90.16 & 30.03 \\
\hline $\begin{array}{l}\text { 11. Do you go for a regular health } \\
\text { check up? }\end{array}$ & 50.00 & 51.64 & 53.57 & 50.79 & 56.00 & 50.66 & 58.62 & 50.12 & 67.21 & 47.33 \\
\hline Overall Summary & 76.49 & 17.06 & 70.35 & 10.75 & 71.23 & 15.33 & 66.67 & 15.83 & 77.12 & 12.20 \\
\hline
\end{tabular}


Community-Based Flood Vulnerability Index for Urban Flooding: Understanding

Social Vulnerabilities and Risks

Health Risk: E. coli Practice SUMMARY . . continued

\begin{tabular}{|c|c|c|c|c|c|c|}
\hline \multirow{2}{*}{ Questions } & \multicolumn{2}{|c|}{ Candau-ay } & \multicolumn{2}{|c|}{ Batinguel } & \multicolumn{2}{|c|}{ Overall } \\
\hline & Mean & S.D. & Mean & S.D. & Mean & S.D. \\
\hline $\begin{array}{l}\text { 1. Do you or other members in the family go } \\
\text { swimming or bathing in the river? }\end{array}$ & 81.77 & 11.67 & 65.79 & 18.87 & 73.83 & 11.95 \\
\hline $\begin{array}{l}\text { 2. Do you immerse yourself other members in the } \\
\text { family into the river? }\end{array}$ & 76.68 & 21.36 & 69.74 & 20.67 & 78.69 & 15.96 \\
\hline 3. Do you wash your clothes in the river? & 80.73 & 15.50 & 65.24 & 24.15 & 83.04 & 10.35 \\
\hline $\begin{array}{l}\text { 4. Do you use water from the river/deep well to } \\
\text { wet your ground, flush your toilet, and water } \\
\text { your plants? }\end{array}$ & 86.75 & 8.58 & 71.27 & 14.04 & 84.84 & 9.66 \\
\hline $\begin{array}{l}\text { 5. Do you wash your hands with soap and water } \\
\text { thoroughly after contact with domesticated } \\
\text { animals? }\end{array}$ & 69.44 & 46.39 & 86.84 & 34.26 & 83.19 & 8.52 \\
\hline $\begin{array}{l}\text { 6. Do you boil your water for } 10 \text { minutes during } \\
\text { unusual events such as during typhoons \& } \\
\text { flooding? }\end{array}$ & 55.56 & 50.04 & 78.95 & 41.32 & 69.23 & 10.05 \\
\hline $\begin{array}{l}\text { 7. Do you keep your animals away from bodies of } \\
\text { water? }\end{array}$ & 64.29 & 48.26 & 65.79 & 48.08 & 65.52 & 10.36 \\
\hline $\begin{array}{l}\text { 8. If one is sick from severe diarrhea in the family, } \\
\text { do you immediately sick for medical help? }\end{array}$ & 68.06 & 46.95 & 89.47 & 31.10 & 81.05 & 9.70 \\
\hline
\end{tabular}

Health Risk: E. coli Practice SUMMARY . . . continued

\begin{tabular}{|l|r|r|r|r|r|r|}
\hline \multirow{2}{*}{ Questions } & \multicolumn{2}{c|}{ Candau-ay } & \multicolumn{2}{c|}{ Batinguel } & \multicolumn{2}{c|}{ Overall } \\
\cline { 2 - 6 } & \multicolumn{1}{|c|}{ Mean } & \multicolumn{1}{c|}{ S.D. } & \multicolumn{1}{c|}{ Mean } & \multicolumn{1}{c|}{ S.D. } & \multicolumn{1}{c|}{ Mean } & \multicolumn{1}{c|}{ S.D. } \\
\hline 9. Do you self-medicate? & 40.00 & 49.34 & 34.21 & 48.08 & 49.21 & 12.37 \\
\hline 10. Do you follow the prescription given? & 69.44 & 46.39 & 81.58 & 39.29 & 83.31 & 9.18 \\
\hline 11. Do you go for a regular health check up? & 40.28 & 49.39 & 60.53 & 49.54 & 61.58 & 13.50 \\
\hline Overall Summary & $\mathbf{6 6 . 6 4}$ & $\mathbf{1 5 . 7 6}$ & $\mathbf{6 9 . 9 5}$ & $\mathbf{1 5 . 1 9}$ & $\mathbf{7 3 . 9 5}$ & $\mathbf{1 1 . 4 3}$ \\
\hline
\end{tabular}


Community-Based Flood Vulnerability Index for Urban Flooding: Understanding Social Vulnerabilities and Risks

Health Risk: Leptospirosis Practice

\begin{tabular}{|c|c|c|c|c|c|c|c|c|c|c|}
\hline \multirow[b]{2}{*}{ Questions } & \multicolumn{2}{|c|}{ Tabuc-tubig } & \multicolumn{2}{|l|}{ Junob } & \multicolumn{2}{|c|}{ Poblacion 1} & \multicolumn{2}{|c|}{ Calindagan } & \multicolumn{2}{|l|}{ Balugo } \\
\hline & $\mathbf{F}$ & $\%$ & $\mathbf{F}$ & $\%$ & $\mathbf{F}$ & $\%$ & $\mathbf{F}$ & $\%$ & $\mathbf{F}$ & $\%$ \\
\hline $\begin{array}{l}\text { 1. If one is sick from severe fever } \\
\text { in the family, do you immediately } \\
\text { sick for medical help? }\end{array}$ & 9 & 90.00 & 9 & 56.25 & 17 & 77.27 & 16 & 69.57 & 13 & 76.47 \\
\hline Q1 Item Summary & Mean & S.D. & Mean & S.D. & Mean & S.D. & Mean & S.D. & Mean & S.D. \\
\hline Mean Score & 0.90 & 0.32 & 0.56 & 0.51 & 0.77 & 0.43 & 0.70 & 0.47 & 0.76 & 0.44 \\
\hline Percentage Score & 90.00 & 31.62 & 56.25 & 51.23 & 77.27 & 42.89 & 69.57 & 47.05 & 76.47 & 43.72 \\
\hline
\end{tabular}

\begin{tabular}{|c|c|c|c|c|c|c|c|c|c|c|}
\hline \multirow[t]{2}{*}{ Questions } & \multicolumn{2}{|c|}{ Barangay 2} & \multicolumn{2}{|c|}{ Poblacion 8} & \multicolumn{2}{|c|}{ Cadawinonan } & \multicolumn{2}{|c|}{ Bagacay } & \multicolumn{2}{|c|}{ Taclobo } \\
\hline & $\mathbf{F}$ & $\%$ & $\mathbf{F}$ & $\%$ & $\mathbf{F}$ & $\%$ & $\mathbf{F}$ & $\%$ & $\mathbf{F}$ & $\%$ \\
\hline $\begin{array}{l}\text { 1. If one is sick from severe fever } \\
\text { in the family, do you immediately } \\
\text { sick for medical help? }\end{array}$ & 12 & 75.00 & 17 & 58.62 & 15 & 60.00 & 22 & 73.33 & 40 & 65.57 \\
\hline Q1 Item Summary & Mean & S.D. & Mean & S.D. & Mean & S.D. & Mean & S.D. & Mean & S.D. \\
\hline Mean Score & 0.75 & 0.45 & 0.59 & 0.50 & 0.60 & 0.50 & 0.73 & 0.45 & 0.74 & 0.44 \\
\hline Percentage Score & 75.00 & 44.72 & 58.62 & 50.12 & 60.00 & 50.00 & 73.33 & 44.98 & 74.19 & 44.11 \\
\hline
\end{tabular}


Community-Based Flood Vulnerability Index for Urban Flooding: Understanding

Social Vulnerabilities and Risks

Health Risk: Leptospirosis Practice ... continued

\begin{tabular}{|c|c|c|c|c|c|c|}
\hline \multirow{2}{*}{ Questions } & \multicolumn{2}{|c|}{ Candau-ay } & \multicolumn{2}{|c|}{ Batinguel } & \multicolumn{2}{|c|}{ Overall } \\
\hline & $\mathbf{F}$ & $\%$ & $\mathbf{F}$ & $\%$ & $\mathbf{F}$ & $\%$ \\
\hline $\begin{array}{l}\text { 1. If one is sick from severe fever in the family, do } \\
\text { you immediately sick for medical help? }\end{array}$ & 42 & 58.33 & 29 & 76.32 & 232 & 64.27 \\
\hline Q1 Item Summary & Mean & S.D. & Mean & S.D. & Mean & S.D. \\
\hline Mean Score & 0.58 & 0.50 & 0.76 & 0.43 & 0.72 & 0.10 \\
\hline Percentage Score & 58.33 & 49.65 & 76.32 & 43.09 & 71.74 & 9.60 \\
\hline
\end{tabular}

Health Risk: Leptospirosis Practice ... continued

\begin{tabular}{|c|c|c|c|c|c|c|c|c|c|c|}
\hline \multirow{2}{*}{ Questions } & \multicolumn{2}{|c|}{ Tabuc-tubig } & \multicolumn{2}{|c|}{ Junob } & \multicolumn{2}{|c|}{ Poblacion 1} & \multicolumn{2}{|c|}{ Calindagan } & \multicolumn{2}{|c|}{ Balugo } \\
\hline & $\mathbf{F}$ & $\%$ & $\mathbf{F}$ & $\%$ & $\mathbf{F}$ & $\%$ & \begin{tabular}{l|l|}
$\mathbf{F}$ \\
\end{tabular} & $\%$ & $\mathbf{F}$ & $\%$ \\
\hline $\begin{array}{l}\text { 2. Do you use rubber boots during } \\
\text { heavy rains, typhoons or flooding? }\end{array}$ & 4 & 40.00 & 6 & 37.50 & 7 & 31.82 & 7 & 30.43 & 8 & 47.06 \\
\hline Q2 Item Summary & Mean & S.D. & Mean & S.D. & Mean & S.D. & Mean & S.D. & Mean & S.D. \\
\hline Mean Score & 0.40 & 0.52 & 0.38 & 0.50 & 0.32 & 0.48 & 0.30 & 0.47 & 0.47 & 0.51 \\
\hline Percentage Score & 40.00 & 51.64 & 37.50 & 50.00 & 31.82 & 47.67 & 30.43 & 47.05 & 47.06 & 51.45 \\
\hline
\end{tabular}

\begin{tabular}{|c|c|c|c|c|c|c|c|c|c|c|}
\hline \multirow{2}{*}{ Questions } & \multicolumn{2}{|c|}{ Barangay 2} & \multicolumn{2}{|c|}{ Poblacion 8} & \multicolumn{2}{|c|}{ Cadawinonan } & \multicolumn{2}{|c|}{ Bagacay } & \multicolumn{2}{|c|}{ Taclobo } \\
\hline & $\mathbf{F}$ & $\%$ & $\mathbf{F}$ & $\%$ & $\mathbf{F}$ & $\%$ & $\mathbf{F}$ & $\%$ & $\mathbf{F}$ & $\%$ \\
\hline $\begin{array}{l}\text { 2. Do you use rubber boots during } \\
\text { heavy rains, typhoons or flooding? }\end{array}$ & 9 & 56.25 & 8 & 27.59 & 8 & 32.00 & 4 & 13.33 & 21 & 34.43 \\
\hline Q2 Item Summary & Mean & S.D. & Mean & S.D. & Mean & S.D. & Mean & S.D. & Mean & S.D. \\
\hline Mean Score & 0.56 & 0.51 & 0.28 & 0.45 & 0.32 & 0.48 & 0.13 & 0.35 & 0.37 & 0.49 \\
\hline Percentage Score & 56.25 & 51.23 & 27.59 & 45.49 & 32.00 & 47.61 & 13.33 & 34.57 & 37.10 & 48.70 \\
\hline
\end{tabular}


Community-Based Flood Vulnerability Index for Urban Flooding: Understanding

Social Vulnerabilities and Risks

Health Risk: Leptospirosis Practice ... continued

\begin{tabular}{|c|c|c|c|c|c|c|}
\hline \multirow{2}{*}{ Questions } & \multicolumn{2}{|c|}{ Candau-ay } & \multicolumn{2}{|c|}{ Batinguel } & \multicolumn{2}{|c|}{ Overall } \\
\hline & $\mathbf{F}$ & $\%$ & $\mathbf{F}$ & $\%$ & $\mathbf{F}$ & $\%$ \\
\hline $\begin{array}{l}\text { 2. Do you use rubber boots during heavy rains, } \\
\text { typhoons or flooding? }\end{array}$ & 22 & 30.56 & 12 & 31.58 & 110 & 30.47 \\
\hline Q3 Item Summary & Mean & S.D. & Mean & S.D. & Mean & S.D. \\
\hline Mean Score & 0.31 & 0.46 & 0.32 & 0.47 & 0.34 & 0.11 \\
\hline Percentage Score & 30.56 & 46.39 & 31.58 & 47.11 & 34.34 & 11.03 \\
\hline
\end{tabular}

Health Risk: Leptospirosis Practice ... continued

\begin{tabular}{|c|c|c|c|c|c|c|c|c|c|c|}
\hline \multirow{2}{*}{ Questions } & \multicolumn{2}{|c|}{ Tabuc-tubig } & \multicolumn{2}{|c|}{ Junob } & \multicolumn{2}{|c|}{ Poblacion 1} & \multicolumn{2}{|c|}{ Calindagan } & \multicolumn{2}{|c|}{ Balugo } \\
\hline & $\mathbf{F}$ & $\%$ & $\mathbf{F}$ & $\%$ & $\mathbf{F}$ & $\%$ & $\mathbf{F}$ & $\%$ & $\mathbf{F}$ & $\%$ \\
\hline $\begin{array}{l}\text { 3. Do you take Doxycyline } \\
\text { antibiotics as prevention during } \\
\text { rainy or flooding season? }\end{array}$ & 4 & 40.00 & 3 & 18.75 & 1 & 4.55 & 4 & 17.39 & 3 & 17.65 \\
\hline Mean Score & 0.40 & 0.52 & 0.19 & 0.40 & 0.05 & 0.21 & 0.17 & 0.39 & 0.18 & 0.39 \\
\hline Percentage Score & 40.00 & 51.64 & 18.75 & 40.31 & 4.55 & 21.32 & 17.39 & 38.76 & 17.65 & 39.30 \\
\hline
\end{tabular}

\begin{tabular}{|c|c|c|c|c|c|c|c|c|c|c|}
\hline \multirow{2}{*}{ Questions } & \multicolumn{2}{|c|}{ Barangay 2} & \multicolumn{2}{|c|}{ Poblacion 8} & \multicolumn{2}{|c|}{ Cadawinonan } & \multicolumn{2}{|c|}{ Bagacay } & \multicolumn{2}{|c|}{ Taclobo } \\
\hline & $\mathbf{F}$ & $\%$ & $\mathbf{F}$ & $\%$ & $\mathbf{F}$ & $\%$ & $\mathbf{F}$ & $\%$ & $\mathbf{F}$ & $\%$ \\
\hline $\begin{array}{l}\text { 3. Do you take Doxycyline } \\
\text { antibiotics as prevention during } \\
\text { rainy or flooding season? }\end{array}$ & 3 & 18.75 & 5 & 17.24 & 4 & 16.00 & 0 & 0.00 & 20 & 32.79 \\
\hline Q10 Item Summary & Mean & S.D. & Mean & S.D. & Mean & S.D. & Mean & S.D. & Mean & S.D. \\
\hline Mean Score & 0.19 & 0.40 & 0.17 & 0.38 & 0.16 & 0.37 & 0 & 0.00 & 0.34 & 0.48 \\
\hline Percentage Score & 18.75 & 40.31 & 17.24 & 38.44 & 16.00 & 37.42 & 0 & 0.00 & 33.87 & 47.71 \\
\hline
\end{tabular}


Community-Based Flood Vulnerability Index for Urban Flooding: Understanding

Social Vulnerabilities and Risks

Health Risk: Leptospirosis Practice ... continued

\begin{tabular}{|c|c|c|c|c|c|c|}
\hline \multirow[t]{2}{*}{ Questions } & \multicolumn{2}{|c|}{ Candau-ay } & \multicolumn{2}{|c|}{ Batinguel } & \multicolumn{2}{|c|}{ Overall } \\
\hline & $\mathbf{F}$ & $\%$ & $\mathbf{F}$ & $\%$ & $\mathbf{F}$ & $\%$ \\
\hline $\begin{array}{l}\text { 3. Do you take Doxycyline antibiotics as } \\
\text { prevention during rainy or flooding season? }\end{array}$ & 15 & 20.83 & 12 & 31.58 & 71 & 19.67 \\
\hline Q10 Item Summary & Mean & S.D. & Mean & S.D. & Mean & S.D. \\
\hline Mean Score & 0.21 & 0.41 & 0.32 & 0.47 & 0.20 & 0.12 \\
\hline Percentage Score & 20.83 & 40.90 & 31.58 & 47.11 & 19.81 & 11.85 \\
\hline
\end{tabular}


Community-Based Flood Vulnerability Index for Urban Flooding: Understanding

\section{Social Vulnerabilities and Risks}

\section{Health Risk: Leptospirosis Practice SUMMARY}

\begin{tabular}{|c|c|c|c|c|c|c|c|c|c|c|}
\hline \multirow{2}{*}{$\begin{array}{r}\text { Questions } \\
\text { From } E \text { coli questions }\end{array}$} & \multicolumn{2}{|c|}{ Tabuc-tubig } & \multicolumn{2}{|c|}{ Junob } & \multicolumn{2}{|c|}{ Poblacion 1} & \multicolumn{2}{|c|}{ Calindagan } & \multicolumn{2}{|c|}{ Balugo } \\
\hline & Mean & S.D. & Mean & S.D. & Mean & S.D. & Mean & S.D. & Mean & S.D. \\
\hline $\begin{array}{l}\text { 1. Do you or other members in } \\
\text { the family go swimming or } \\
\text { bathing in the river? }\end{array}$ & 83.33 & 15.63 & 59.38 & 20.16 & 89.27 & 3.80 & 90.40 & 6.73 & 64.95 & 18.33 \\
\hline $\begin{array}{l}\text { 2. Do you immerse yourself other } \\
\text { members in the family into the } \\
\text { river? }\end{array}$ & 89.58 & 14.17 & 29.43 & 20.10 & 86.80 & 7.26 & 91.47 & 6.89 & 70.59 & 18.46 \\
\hline $\begin{array}{l}\text { 3. Do you wash your clothes in the } \\
\text { river? }\end{array}$ & 92.08 & 9.75 & 59.64 & 21.81 & 92.93 & 2.05 & 98.55 & 1.96 & 57.11 & 26.82 \\
\hline $\begin{array}{l}\text { 4. Do you use water from the } \\
\text { river/deep well to wet your } \\
\text { ground, flush your toilet, and } \\
\text { water your plants? }\end{array}$ & 87.92 & 14.74 & 70.57 & 23.85 & 91.10 & 3.52 & 98.73 & 2.08 & 58.82 & 22.01 \\
\hline Leptospirosis questions & & & & & & & & & & \\
\hline $\begin{array}{l}\text { 1. If one is sick from severe fever } \\
\text { in the family, do you immediately } \\
\text { sick for medical help? }\end{array}$ & 90.00 & 31.62 & 56.25 & 51.23 & 77.27 & 42.89 & 69.57 & 47.05 & 76.47 & 43.72 \\
\hline $\begin{array}{l}\text { 2. Do you use rubber boots during } \\
\text { heavy rains, typhoons or } \\
\text { flooding? }\end{array}$ & 40.00 & 51.64 & 37.50 & 50.00 & 31.82 & 47.67 & 30.43 & 47.05 & 47.06 & 51.45 \\
\hline $\begin{array}{l}\text { 3. Do you take Doxycyline } \\
\text { antibiotics as prevention during } \\
\text { rainy or flooding season? }\end{array}$ & 40.00 & 51.64 & 18.75 & 40.31 & 4.55 & 21.32 & 17.39 & 38.76 & 17.65 & 39.30 \\
\hline Overall Summary & 74.70 & 23.86 & 47.36 & 18.93 & 67.68 & 35.07 & 70.93 & 33.78 & 56.09 & 19.46 \\
\hline
\end{tabular}


Community-Based Flood Vulnerability Index for Urban Flooding: Understanding

Social Vulnerabilities and Risks

Health Risk: Leptospirosis Practice SUMMARY . . continued

\begin{tabular}{|c|c|c|c|c|c|c|c|c|c|c|}
\hline \multirow{2}{*}{$\begin{array}{r}\text { Questions } \\
\text { From } E \text { coli questions }\end{array}$} & \multicolumn{2}{|c|}{ Barangay 2} & \multicolumn{2}{|c|}{ Poblacion 8} & \multicolumn{2}{|c|}{ Cadawinonan } & \multicolumn{2}{|c|}{ Bagacay } & \multicolumn{2}{|c|}{ Taclobo } \\
\hline & Mean & S.D. & Mean & S.D. & Mean & S.D. & Mean & S.D. & Mean & S.D. \\
\hline $\begin{array}{l}\text { 1. Do you or other members in } \\
\text { the family go swimming or } \\
\text { bathing in the river? }\end{array}$ & 82.66 & 11.43 & 72.13 & 12.03 & 78.17 & 12.62 & 52.53 & 37.25 & 81.81 & 8.44 \\
\hline $\begin{array}{l}\text { 2. Do you immerse yourself other } \\
\text { members in the family into the } \\
\text { river? }\end{array}$ & 89.38 & 6.85 & 77.10 & 13.33 & 81.17 & 15.32 & 67.45 & 31.85 & 79.43 & 16.57 \\
\hline $\begin{array}{l}\text { 3. Do you wash your clothes in } \\
\text { the river? }\end{array}$ & 97.95 & 3.43 & 80.32 & 8.63 & 83.17 & 10.55 & 81.11 & 14.66 & 84.26 & 10.23 \\
\hline $\begin{array}{l}\text { 4. Do you use water from the } \\
\text { river/deep well to wet your } \\
\text { ground, flush your toilet, and } \\
\text { water your plants? }\end{array}$ & 90.10 & 10.26 & 84.68 & 9.43 & 98.83 & 1.91 & 81.39 & 14.30 & 83.60 & 9.10 \\
\hline Leptospirosis questions & & & & & & & & & & \\
\hline $\begin{array}{l}\text { 1. If one is sick from severe fever } \\
\text { in the family, do you immediately } \\
\text { sick for medical help? }\end{array}$ & 75.00 & 44.72 & 58.62 & 50.12 & 60.00 & 50.00 & 73.33 & 44.98 & 74.19 & 44.11 \\
\hline $\begin{array}{l}\text { 2. Do you use rubber boots during } \\
\text { heavy rains, typhoons or } \\
\text { flooding? }\end{array}$ & 56.25 & 51.23 & 27.59 & 45.49 & 32.00 & 47.61 & 13.33 & 34.57 & 37.10 & 48.70 \\
\hline $\begin{array}{l}\text { 3. Do you take Doxycyline } \\
\text { antibiotics as prevention during } \\
\text { rainy or flooding season? }\end{array}$ & 18.75 & 40.31 & 17.24 & 38.44 & 16.00 & 37.42 & 0 & 0.00 & 33.87 & 47.71 \\
\hline Overall Summary & 72.87 & 27.40 & 59.67 & 26.90 & 64.19 & 30.06 & 52.74 & 33.17 & 67.75 & 22.31 \\
\hline
\end{tabular}


Community-Based Flood Vulnerability Index for Urban Flooding: Understanding

Social Vulnerabilities and Risks

Health Risk: Leptospirosis Practice SUMMARY . . continued

\begin{tabular}{|c|c|c|c|c|c|c|}
\hline Questions & \multicolumn{2}{|c|}{ Candau-ay } & \multicolumn{2}{|c|}{ Batinguel } & \multicolumn{2}{|c|}{ Overall } \\
\hline From $E$ coli questions & Mean & S.D. & Mean & S.D. & Mean & S.D. \\
\hline $\begin{array}{l}\text { 1. Do you or other members in the family go } \\
\text { swimming or bathing in the river? }\end{array}$ & 81.77 & 11.67 & 65.79 & 18.87 & 73.83 & 11.95 \\
\hline $\begin{array}{l}\text { 2. Do you immerse yourself other members in the } \\
\text { family into the river? }\end{array}$ & 76.68 & 21.36 & 69.74 & 20.67 & 78.69 & 15.96 \\
\hline 3. Do you wash your clothes in the river? & 80.73 & 15.50 & 65.24 & 24.15 & 83.04 & 10.35 \\
\hline $\begin{array}{l}\text { 4. Do you use water from the river/deep well to } \\
\text { wet your ground, flush your toilet, and water } \\
\text { your plants? }\end{array}$ & 86.75 & 8.58 & 71.27 & 14.04 & 84.84 & 9.66 \\
\hline \multicolumn{7}{|l|}{ Leptospirosis questions } \\
\hline $\begin{array}{l}\text { 1. If one is sick from severe fever in the family, do } \\
\text { you immediately sick for medical help? }\end{array}$ & 58.33 & 49.65 & 76.32 & 43.09 & 71.74 & 9.60 \\
\hline $\begin{array}{l}\text { 2. Do you use rubber boots during heavy rains, } \\
\text { typhoons or flooding? }\end{array}$ & 30.56 & 46.39 & 31.58 & 47.11 & 34.34 & 11.03 \\
\hline $\begin{array}{l}\text { 3. Do you take Doxycyline antibiotics as } \\
\text { prevention during rainy or flooding season? }\end{array}$ & 20.83 & 40.90 & 31.58 & 47.11 & 19.81 & 11.85 \\
\hline Overall Summary & 62.24 & 26.66 & 58.79 & 18.95 & 63.75 & 25.83 \\
\hline
\end{tabular}


Community-Based Flood Vulnerability Index for Urban Flooding: Understanding

Social Vulnerabilities and Risks

Health Risk: Dengue Practice

\begin{tabular}{|c|c|c|c|c|c|c|c|c|c|c|}
\hline \multirow{2}{*}{ Questions } & \multicolumn{2}{|c|}{ Tabuc-tubig } & \multicolumn{2}{|c|}{ Junob } & \multicolumn{2}{|c|}{ Poblacion 1} & \multicolumn{2}{|c|}{ Calindagan } & \multicolumn{2}{|c|}{ Balugo } \\
\hline & $\mathbf{F}$ & $\%$ & $\mathbf{F}$ & $\%$ & $\mathbf{F}$ & $\%$ & $\mathbf{F}$ & $\%$ & $\mathbf{F}$ & $\%$ \\
\hline $\begin{array}{l}\text { 1. Do you clean your immediate } \\
\text { surroundings and empty from the } \\
\text { following usual mosquito } \\
\text { breeding sites? }\end{array}$ & 9 & 90.00 & 9 & 56.25 & 20 & 90.91 & 21 & 91.30 & 14 & 82.35 \\
\hline Q1 Item Summary & Mean & S.D. & Mean & S.D. & Mean & S.D. & Mean & S.D. & Mean & S.D. \\
\hline Mean Score & 0.90 & 0.32 & 0.56 & 0.51 & 0.91 & 0.29 & 0.91 & 0.29 & 0.82 & 0.39 \\
\hline Percentage Score & 90.00 & 31.62 & 56.25 & 51.23 & 90.91 & 29.42 & 91.30 & 28.81 & 82.35 & 39.30 \\
\hline
\end{tabular}

\begin{tabular}{|c|c|c|c|c|c|c|c|c|c|c|}
\hline \multirow{2}{*}{ Questions } & \multicolumn{2}{|c|}{ Barangay 2} & \multicolumn{2}{|c|}{ Poblacion 8} & \multicolumn{2}{|c|}{ Cadawinonan } & \multicolumn{2}{|c|}{ Bagacay } & \multicolumn{2}{|c|}{ Taclobo } \\
\hline & $\mathbf{F}$ & $\%$ & $\mathbf{F}$ & $\%$ & $\mathbf{F}$ & $\%$ & $\mathbf{F}$ & $\%$ & $\mathbf{F}$ & $\%$ \\
\hline $\begin{array}{l}\text { 1. Do you clean your immediate } \\
\text { surroundings and empty from the } \\
\text { following usual mosquito } \\
\text { breeding sites? }\end{array}$ & 15 & 93.75 & 26 & 89.66 & 22 & 88.00 & 27 & 90.00 & 50 & 81.97 \\
\hline Q1 Item Summary & Mean & S.D. & Mean & S.D. & Mean & S.D. & Mean & S.D. & Mean & S.D. \\
\hline Mean Score & 0.94 & 0.25 & 0.90 & 0.31 & 0.88 & 0.33 & 0.90 & 0.31 & 0.92 & 0.27 \\
\hline Percentage Score & 93.75 & 25.00 & 89.66 & 30.99 & 88.00 & 33.17 & 90.00 & 30.51 & 91.94 & 27.45 \\
\hline
\end{tabular}


Community-Based Flood Vulnerability Index for Urban Flooding: Understanding

491 Social Vulnerabilities and Risks

\begin{tabular}{|c|c|c|c|c|c|c|}
\hline \multirow{2}{*}{ Questions } & \multicolumn{2}{|c|}{ Candau-ay } & \multicolumn{2}{|c|}{ Batinguel } & \multicolumn{2}{|c|}{ Overall } \\
\hline & $\mathbf{F}$ & $\%$ & $\mathbf{F}$ & $\%$ & $\mathbf{F}$ & $\%$ \\
\hline $\begin{array}{l}\text { 1. Do you clean your immediate surroundings and } \\
\text { empty from the following usual mosquito } \\
\text { breeding sites? }\end{array}$ & 56 & 77.78 & 37 & 97.37 & 301 & 83.38 \\
\hline Q1 Item Summary & Mean & S.D. & Mean & S.D. & Mean & S.D. \\
\hline Mean Score & 0.78 & 0.42 & 0.97 & 0.16 & 3.58 & 7.14 \\
\hline Percentage Score & 77.78 & 41.87 & 97.37 & 16.22 & 82.25 & 25.16 \\
\hline
\end{tabular}

Mosquito breeding sites being cleaned

\begin{tabular}{|c|c|c|c|c|c|c|c|c|c|c|}
\hline \multirow{2}{*}{ Breeding Sites } & \multicolumn{2}{|c|}{ Tabuc-tubig } & \multicolumn{2}{|c|}{ Junob } & \multicolumn{2}{|c|}{ Poblacion 1} & \multicolumn{2}{|c|}{ Calindagan } & \multicolumn{2}{|c|}{ Balugo } \\
\hline & $\mathbf{F}$ & $\%$ & $\mathbf{F}$ & $\%$ & $\mathbf{F}$ & $\%$ & $\mathbf{F}$ & $\%$ & $\mathbf{F}$ & $\%$ \\
\hline flower pot & 7 & 70.00 & 9 & 56.25 & 17 & 77.27 & 15 & 65.22 & 10 & 58.82 \\
\hline hardened soil of potted plants & 4 & 40.00 & 6 & 37.50 & 7 & 31.82 & 5 & 21.74 & 2 & 11.76 \\
\hline collar of toilet bowl & 5 & 50.00 & 5 & 31.25 & 8 & 36.36 & 6 & 26.09 & 3 & 17.65 \\
\hline gully trap & 5 & 50.00 & 4 & 25.00 & 3 & 13.64 & 11 & 47.83 & 5 & 29.41 \\
\hline roof gutter & 6 & 60.00 & 7 & 43.75 & 9 & 40.91 & 12 & 52.17 & 5 & 29.41 \\
\hline flower pot plat & 3 & 30.00 & 4 & 25.00 & 4 & 18.18 & 5 & 21.74 & 2 & 11.76 \\
\hline road side drain & 8 & 80.00 & 6 & 37.50 & 12 & 54.55 & 10 & 43.48 & 5 & 29.41 \\
\hline scupper drain & 3 & 30.00 & 2 & 12.50 & 6 & 27.27 & 7 & 30.43 & 4 & 23.53 \\
\hline abandoned water tank & 7 & 70.00 & 4 & 25.00 & 9 & 40.91 & 9 & 39.13 & 3 & 17.65 \\
\hline
\end{tabular}


Community-Based Flood Vulnerability Index for Urban Flooding: Understanding

Social Vulnerabilities and Risks

Mosquito breeding sites being cleaned ... continued

\begin{tabular}{|c|c|c|c|c|c|c|c|c|c|c|}
\hline \multirow{2}{*}{ Breeding Sites } & \multicolumn{2}{|c|}{ Barangay 2} & \multicolumn{2}{|c|}{ Poblacion 8} & \multicolumn{2}{|c|}{ Cadawinonan } & \multicolumn{2}{|c|}{ Bagacay } & \multicolumn{2}{|c|}{ Taclobo } \\
\hline & $\mathbf{F}$ & $\%$ & $\mathbf{F}$ & $\%$ & $\mathbf{F}$ & $\%$ & $\mathbf{F}$ & $\%$ & $\mathbf{F}$ & $\%$ \\
\hline flower pot & 12 & 75.00 & 18 & 62.07 & 16 & 64.00 & 18 & 60.00 & 34 & 55.74 \\
\hline hardened soil of potted plants & 5 & 31.25 & 12 & 41.38 & 8 & 32.00 & 10 & 33.33 & 17 & 27.87 \\
\hline collar of toilet bowl & 4 & 25.00 & 12 & 41.38 & 8 & 32.00 & 11 & 36.67 & 22 & 36.07 \\
\hline gully trap & 4 & 25.00 & 7 & 24.14 & 7 & 28.00 & 8 & 26.67 & 22 & 36.07 \\
\hline roof gutter & 7 & 43.75 & 17 & 58.62 & 11 & 44.00 & 14 & 46.67 & 25 & 40.98 \\
\hline flower pot plat & 6 & 37.50 & 9 & 31.03 & 5 & 20.00 & 9 & 30.00 & 23 & 37.70 \\
\hline road side drain & 8 & 50.00 & 13 & 44.83 & 12 & 48.00 & 13 & 43.33 & 24 & 39.34 \\
\hline scupper drain & 2 & 12.50 & 10 & 34.48 & 6 & 24.00 & 9 & 30.00 & 15 & 24.59 \\
\hline abandoned water tank & 6 & 37.50 & 11 & 37.93 & 7 & 28.00 & 7 & 23.33 & 21 & 34.43 \\
\hline
\end{tabular}

\begin{tabular}{|c|c|c|c|c|c|c|}
\hline \multirow{2}{*}{ Breeding Sites } & \multicolumn{2}{|c|}{ Candau-ay } & \multicolumn{2}{|c|}{ Batinguel } & \multicolumn{2}{|c|}{ Overall } \\
\hline & $\mathbf{F}$ & $\%$ & $\mathbf{F}$ & $\%$ & $\mathbf{F}$ & $\%$ \\
\hline flower pot & 44 & 61.11 & 23 & 60.53 & 223 & 61.77 \\
\hline hardened soil of potted plants & 18 & 25.00 & 10 & 26.32 & 104 & 28.81 \\
\hline collar of toilet bowl & 28 & 38.89 & 10 & 26.32 & 122 & 33.80 \\
\hline gully trap & 21 & 29.17 & 13 & 34.21 & 110 & 30.47 \\
\hline roof gutter & 35 & 48.61 & 16 & 42.11 & 164 & 45.43 \\
\hline flower pot plat & 25 & 34.72 & 9 & 23.68 & 104 & 28.81 \\
\hline road side drain & 36 & 50.00 & 15 & 39.47 & 162 & 44.88 \\
\hline scupper drain & 23 & 31.94 & 9 & 23.68 & 96 & 26.59 \\
\hline abandoned water tank & 26 & 36.11 & 9 & 23.68 & 119 & 32.96 \\
\hline
\end{tabular}


Community-Based Flood Vulnerability Index for Urban Flooding: Understanding Social Vulnerabilities and Risks

Health Risk: Dengue Practice... continued

\begin{tabular}{|c|c|c|c|c|c|c|c|c|c|c|}
\hline \multirow{2}{*}{ Questions } & \multicolumn{2}{|c|}{ Tabuc-tubig } & \multicolumn{2}{|c|}{ Junob } & \multicolumn{2}{|c|}{ Poblacion 1} & \multicolumn{2}{|c|}{ Calindagan } & \multicolumn{2}{|c|}{ Balugo } \\
\hline & $\mathbf{F}$ & $\%$ & $\mathbf{F}$ & $\%$ & $\mathbf{F}$ & $\%$ & $\mathbf{F}$ & $\%$ & $\mathbf{F}$ & $\%$ \\
\hline $\begin{array}{l}\text { 2. Do you clean your immediate } \\
\text { surroundings and empty from the } \\
\text { following unusual/uncommon } \\
\text { mosquito breeding Sites? }\end{array}$ & 8 & 80.00 & 13 & 81.25 & 19 & 86.36 & 20 & 86.96 & 16 & 94.12 \\
\hline Q2 Item Summary & Mean & S.D. & Mean & S.D. & Mean & S.D. & Mean & S.D. & Mean & S.D. \\
\hline Mean Score & 0.80 & 0.42 & 0.81 & 0.40 & 0.90 & 0.30 & 0.87 & 0.34 & 0.94 & 0.24 \\
\hline Percentage Score & 80.00 & 42.16 & 81.25 & 40.31 & 90.48 & 30.08 & 86.96 & 34.44 & 94.12 & 24.25 \\
\hline
\end{tabular}

\begin{tabular}{|c|c|c|c|c|c|c|c|c|c|c|}
\hline \multirow{2}{*}{ Questions } & \multicolumn{2}{|c|}{ Barangay 2} & \multicolumn{2}{|c|}{ Poblacion 8} & \multicolumn{2}{|c|}{ Cadawinonan } & \multicolumn{2}{|c|}{ Bagacay } & \multicolumn{2}{|c|}{ Taclobo } \\
\hline & $\mathbf{F}$ & $\%$ & $\mathbf{F}$ & $\%$ & $\mathbf{F}$ & $\%$ & $\mathbf{F}$ & $\%$ & $\mathbf{F}$ & $\%$ \\
\hline $\begin{array}{l}\text { 2. Do you clean your immediate } \\
\text { surroundings and empty from the } \\
\text { following unusual/uncommon } \\
\text { mosquito breeding Sites? }\end{array}$ & 13 & 81.25 & 25 & 86.21 & 23 & 92.00 & 25 & 83.33 & 48 & 78.69 \\
\hline Q2 Item Summary & Mean & S.D. & Mean & S.D. & Mean & S.D. & Mean & S.D. & Mean & S.D. \\
\hline Mean Score & 0.81 & 0.40 & 0.89 & 0.31 & 0.92 & 0.28 & 0.83 & 0.38 & 0.87 & 0.34 \\
\hline Percentage Score & 81.25 & 40.31 & 89.29 & 31.50 & 92.00 & 27.69 & 83.33 & 37.90 & 87.10 & 33.80 \\
\hline
\end{tabular}


Community-Based Flood Vulnerability Index for Urban Flooding: Understanding Social Vulnerabilities and Risks

Health Risk: Dengue Practice ... continued

\begin{tabular}{|c|c|c|c|c|c|c|}
\hline \multirow{2}{*}{ Questions } & \multicolumn{2}{|c|}{ Candau-ay } & \multicolumn{2}{|c|}{ Batinguel } & \multicolumn{2}{|c|}{ Overall } \\
\hline & $\mathbf{F}$ & $\%$ & $\mathbf{F}$ & $\%$ & $\mathbf{F}$ & $\%$ \\
\hline $\begin{array}{l}\text { 2. Do you clean your immediate surroundings and } \\
\text { empty from the following unusual/uncommon } \\
\text { mosquito breeding Sites? }\end{array}$ & 55 & 76.39 & 32 & 84.21 & 284 & 78.67 \\
\hline Q2 Item Summary & Mean & S.D. & Mean & S.D. & Mean & S.D. \\
\hline Mean Score & 0.76 & 0.43 & 0.84 & 0.37 & 0.86 & 0.05 \\
\hline Percentage Score & 76.39 & 42.77 & 84.21 & 36.95 & 85.92 & 5.44 \\
\hline
\end{tabular}


Community-Based Flood Vulnerability Index for Urban Flooding: Understanding Social Vulnerabilities and Risks

Unusual/uncommon mosquito breeding sites

\begin{tabular}{|c|c|c|c|c|c|c|c|c|c|c|}
\hline \multirow{2}{*}{ Breeding Sites } & \multicolumn{2}{|c|}{ Tabuc-tubig } & \multicolumn{2}{|c|}{ Junob } & \multicolumn{2}{|c|}{ Poblacion 1} & \multicolumn{2}{|c|}{ Calindagan } & \multicolumn{2}{|c|}{ Balugo } \\
\hline & $\mathbf{F}$ & $\%$ & $\mathbf{F}$ & $\%$ & $\mathbf{F}$ & $\%$ & $\mathbf{F}$ & $\%$ & $\mathbf{F}$ & $\%$ \\
\hline tree hole & 4 & 40.00 & 5 & 31.25 & 10 & 45.45 & 11 & 47.83 & 7 & 41.18 \\
\hline plant axil & 7 & 70.00 & 16 & 100.00 & 16 & 72.73 & 16 & 69.57 & 10 & 58.82 \\
\hline aircon tray & 3 & 30.00 & 1 & 6.25 & 2 & 9.09 & 4 & 17.39 & 3 & 17.65 \\
\hline BBQ pit & 4 & 40.00 & 1 & 6.25 & 3 & 13.64 & 4 & 17.39 & 2 & 11.76 \\
\hline canvass sheet & 3 & 30.00 & 2 & 12.50 & 3 & 13.64 & 3 & 13.04 & 2 & 11.76 \\
\hline \multicolumn{11}{|c|}{ discarded receptacles such as: } \\
\hline tire & 10 & 100.00 & 7 & 43.75 & 11 & 50.00 & 12 & 52.17 & 6 & 35.29 \\
\hline plastic cap & 9 & 90.00 & 5 & 31.25 & 9 & 40.91 & 12 & 52.17 & 5 & 29.41 \\
\hline coconut shells & 3 & 30.00 & 7 & 43.75 & 10 & 45.45 & 11 & 47.83 & 7 & 41.18 \\
\hline empty bottles & 9 & 90.00 & 9 & 56.25 & 11 & 50.00 & 16 & 69.57 & 10 & 58.82 \\
\hline cans & 6 & 60.00 & 10 & 62.50 & 12 & 54.55 & 17 & 73.91 & 9 & 52.94 \\
\hline buckets & 5 & 50.00 & 8 & 50.00 & 8 & 36.36 & 12 & 52.17 & 4 & 23.53 \\
\hline jars & 4 & 40.00 & 8 & 50.00 & 7 & 31.82 & 11 & 47.83 & 4 & 23.53 \\
\hline blocked roof gutters & 4 & 40.00 & 8 & 50.00 & 6 & 27.27 & 9 & 39.13 & 2 & 11.76 \\
\hline tarps & 4 & 40.00 & 2 & 12.50 & 3 & 13.64 & 7 & 30.43 & 2 & 11.76 \\
\hline drums & 4 & 40.00 & 4 & 25.00 & 8 & 36.36 & 9 & 39.13 & 3 & 17.65 \\
\hline
\end{tabular}


Community-Based Flood Vulnerability Index for Urban Flooding: Understanding Social Vulnerabilities and Risks

Unusual/uncommon mosquito breeding sites ... continued

\begin{tabular}{|c|c|c|c|c|c|c|c|c|c|c|}
\hline \multirow[b]{2}{*}{ Breeding Sites } & \multicolumn{2}{|c|}{ Barangay 2} & \multicolumn{2}{|c|}{ Poblacion 8} & \multicolumn{2}{|c|}{ Cadawinonan } & \multicolumn{2}{|c|}{ Bagacay } & \multicolumn{2}{|c|}{ Taclobo } \\
\hline & $\mathbf{F}$ & $\%$ & $\mathbf{F}$ & $\%$ & $\mathbf{F}$ & $\%$ & $\mathbf{F}$ & $\%$ & $\mathbf{F}$ & $\%$ \\
\hline tree hole & 8 & 50.00 & 15 & 51.72 & 11 & 44.00 & 11 & 36.67 & 25 & 40.98 \\
\hline plant axil & 9 & 56.25 & 16 & 55.17 & 19 & 76.00 & 24 & 80.00 & 39 & 63.93 \\
\hline aircon tray & 0 & 0.00 & 2 & 6.90 & 3 & 12.00 & 7 & 23.33 & 15 & 24.59 \\
\hline BBQ pit & 1 & 6.25 & 2 & 6.90 & 3 & 12.00 & 6 & 20.00 & 10 & 16.39 \\
\hline canvass sheet & 2 & 12.50 & 6 & 20.69 & 2 & 8.00 & 6 & 20.00 & 8 & 13.11 \\
\hline \multicolumn{11}{|c|}{ discarded receptacles such as: } \\
\hline tire & 6 & 37.50 & 11 & 37.93 & 9 & 36.00 & 15 & 50.00 & 27 & 44.26 \\
\hline plastic cap & 6 & 37.50 & 12 & 41.38 & 9 & 36.00 & 16 & 53.33 & 27 & 44.26 \\
\hline coconut shells & 8 & 50.00 & 10 & 34.48 & 11 & 44.00 & 16 & 53.33 & 23 & 37.70 \\
\hline empty bottles & 14 & 87.50 & 19 & 65.52 & 14 & 56.00 & 35 & 116.67 & 34 & 55.74 \\
\hline cans & 13 & 81.25 & 20 & 68.97 & 14 & 56.00 & 21 & 70.00 & 32 & 52.46 \\
\hline buckets & 5 & 31.25 & 11 & 37.93 & 8 & 32.00 & 12 & 40.00 & 26 & 42.62 \\
\hline jars & 4 & 25.00 & 8 & 27.59 & 7 & 28.00 & 7 & 23.33 & 20 & 32.79 \\
\hline blocked roof gutters & 1 & 6.25 & 8 & 27.59 & 6 & 24.00 & 8 & 26.67 & 16 & 26.23 \\
\hline tarps & 2 & 12.50 & 7 & 24.14 & 5 & 20.00 & 5 & 16.67 & 12 & 19.67 \\
\hline drums & 2 & 12.50 & 7 & 24.14 & 4 & 16.00 & 7 & 23.33 & 16 & 26.23 \\
\hline
\end{tabular}


Community-Based Flood Vulnerability Index for Urban Flooding: Understanding Social Vulnerabilities and Risks

Unusual/uncommon mosquito breeding sites ... continued

\begin{tabular}{|c|c|c|c|c|c|c|}
\hline \multirow{2}{*}{ Breeding Sites } & \multicolumn{2}{|c|}{ Candau-ay } & \multicolumn{2}{|c|}{ Batinguel } & \multicolumn{2}{|c|}{ Overall } \\
\hline & $\mathbf{F}$ & $\%$ & $\mathbf{F}$ & $\%$ & $\mathbf{F}$ & $\%$ \\
\hline tree hole & 33 & 45.83 & 17 & 44.74 & 157 & 43.49 \\
\hline aircon tray & 11 & 15.28 & 4 & 10.53 & 55 & 15.24 \\
\hline BBQ pit & 11 & 15.28 & 3 & 7.89 & 50 & 13.85 \\
\hline \multicolumn{7}{|l|}{ discarded receptacles such as: } \\
\hline tire & 33 & 45.83 & 21 & 55.26 & 168 & 46.54 \\
\hline plastic cap & 32 & 44.44 & 19 & 50.00 & 161 & 44.60 \\
\hline coconut shells & 28 & 38.89 & 19 & 50.00 & 153 & 42.38 \\
\hline jars & 25 & 34.72 & 11 & 28.95 & 116 & 32.13 \\
\hline blocked roof gutters & 19 & 26.39 & 10 & 26.32 & 97 & 26.87 \\
\hline tarps & 21 & 29.17 & 9 & 23.68 & 79 & 21.88 \\
\hline drums & 25 & 34.72 & 12 & 31.58 & 101 & 27.98 \\
\hline
\end{tabular}


Community-Based Flood Vulnerability Index for Urban Flooding: Understanding

Social Vulnerabilities and Risks

Health Risk: Dengue Practice ... continued

\begin{tabular}{|c|c|c|c|c|c|c|c|c|c|c|}
\hline \multirow{2}{*}{ Questions } & \multicolumn{2}{|c|}{ Tabuc-tubig } & \multicolumn{2}{|c|}{ Junob } & \multicolumn{2}{|c|}{ Poblacion 1} & \multicolumn{2}{|c|}{ Calindagan } & \multicolumn{2}{|c|}{ Balugo } \\
\hline & $\mathbf{F}$ & $\%$ & $\mathbf{F}$ & $\%$ & $\mathbf{F}$ & $\%$ & $\mathbf{F}$ & $\%$ & $\mathbf{F}$ & $\%$ \\
\hline $\begin{array}{l}\text { 3. Do you make sure that your } \\
\text { home is airy, bright, and safe from } \\
\text { moisture? }\end{array}$ & 10 & 100.00 & 14 & 87.50 & 22 & 100.00 & 20 & 86.96 & 15 & 88.24 \\
\hline Q3 Item Summary & Mean & S.D. & Mean & S.D. & Mean & S.D. & Mean & S.D. & Mean & S.D. \\
\hline Mean Score & 1.00 & 0.00 & 0.88 & 0.34 & 1.00 & 0.00 & 0.87 & 0.34 & 0.94 & 0.25 \\
\hline Percentage Score & 100.00 & 0.00 & 87.50 & 34.16 & 100.00 & 0.00 & 86.96 & 34.44 & 93.75 & 25.00 \\
\hline
\end{tabular}

\begin{tabular}{|c|c|c|c|c|c|c|c|c|c|c|}
\hline \multirow{2}{*}{ Questions } & \multicolumn{2}{|c|}{ Barangay 2} & \multicolumn{2}{|c|}{ Poblacion 8} & \multicolumn{2}{|c|}{ Cadawinonan } & \multicolumn{2}{|c|}{ Bagacay } & \multicolumn{2}{|c|}{ Taclobo } \\
\hline & $\mathbf{F}$ & $\%$ & $\mathbf{F}$ & $\%$ & $\mathbf{F}$ & $\%$ & $\mathbf{F}$ & $\%$ & $\mathbf{F}$ & $\%$ \\
\hline $\begin{array}{l}\text { 3. Do you make sure that your } \\
\text { home is airy, bright, and safe } \\
\text { from moisture? }\end{array}$ & 16 & 100.00 & 19 & 65.52 & 18 & 72.00 & 21 & 70 & 48 & 78.69 \\
\hline Q3 Item Summary & Mean & S.D. & Mean & S.D. & Mean & S.D. & Mean & S.D. & Mean & S.D. \\
\hline Mean Score & 1.00 & 0.63 & 0.70 & 0.47 & 0.72 & 0.46 & 0.70 & 70.00 & 0.85 & 0.36 \\
\hline Percentage Score & 100.00 & 63.25 & 70.37 & 46.53 & 72.00 & 45.83 & 0.47 & 46.61 & 85.48 & 35.51 \\
\hline
\end{tabular}


Community-Based Flood Vulnerability Index for Urban Flooding: Understanding Social Vulnerabilities and Risks

Health Risk: Dengue Practice... continued

\begin{tabular}{|c|c|c|c|c|c|c|}
\hline \multirow{2}{*}{ Questions } & \multicolumn{2}{|c|}{ Candau-ay } & \multicolumn{2}{|c|}{ Batinguel } & \multicolumn{2}{|c|}{ Overall } \\
\hline & $\mathbf{F}$ & $\%$ & $\mathbf{F}$ & $\%$ & $\mathbf{F}$ & $\%$ \\
\hline $\begin{array}{l}\text { 3. Do you make sure that your home is airy, } \\
\text { bright, and safe from moisture? }\end{array}$ & 47 & 65.28 & 31 & 81.58 & 267 & 73.96 \\
\hline Q3 Item Summary & Mean & S.D. & Mean & S.D. & Mean & S.D. \\
\hline Mean Score & 0.66 & 0.48 & 0.82 & 0.39 & 0.84 & 0.13 \\
\hline Percentage Score & 66.20 & 47.64 & 81.58 & 39.29 & 84.21 & 13.12 \\
\hline
\end{tabular}

Health Risk: Dengue Practice ... continued

\begin{tabular}{|c|c|c|c|c|c|c|c|c|c|c|}
\hline \multirow{2}{*}{ Questions } & \multicolumn{2}{|c|}{ Tabuc-tubig } & \multicolumn{2}{|c|}{ Junob } & \multicolumn{2}{|c|}{ Poblacion 1} & \multicolumn{2}{|c|}{ Calindagan } & \multicolumn{2}{|c|}{ Balugo } \\
\hline & $\mathbf{F}$ & $\%$ & $\mathbf{F}$ & $\%$ & $\mathbf{F}$ & $\%$ & $\mathbf{F}$ & $\%$ & $\mathbf{F}$ & $\%$ \\
\hline $\begin{array}{l}\text { 4. Do you have fixed net on doors } \\
\text { and windows? }\end{array}$ & 0 & 0.00 & 0 & 0.00 & 7 & 31.82 & 1 & 4.35 & 2 & 11.76 \\
\hline Q4 Item Summary & Mean & S.D. & Mean & S.D. & Mean & S.D. & Mean & S.D. & Mean & S.D. \\
\hline Mean Score & 0.00 & 0.00 & 0.00 & 0.00 & 0.32 & 0.48 & 0.04 & 0.21 & 0.13 & 0.34 \\
\hline Percentage Score & 0.00 & 0.00 & 0.00 & 0.00 & 31.82 & 47.67 & 4.35 & 20.85 & 12.50 & 34.16 \\
\hline
\end{tabular}

\begin{tabular}{|c|c|c|c|c|c|c|c|c|c|c|}
\hline \multirow{2}{*}{ Questions } & \multicolumn{2}{|c|}{ Barangay 2} & \multicolumn{2}{|c|}{ Poblacion 8} & \multicolumn{2}{|c|}{ Cadawinonan } & \multicolumn{2}{|l|}{ Bagacay } & \multicolumn{2}{|l|}{ Taclobo } \\
\hline & $\mathbf{F}$ & $\%$ & $\mathbf{F}$ & $\%$ & $\mathbf{F}$ & $\%$ & $\mathbf{F}$ & $\%$ & $\mathbf{F}$ & $\%$ \\
\hline $\begin{array}{l}\text { 4. Do you have fixed net on doors } \\
\text { and windows? }\end{array}$ & 1 & 6.25 & 4 & 13.79 & 1 & 4.00 & 4 & 13.33 & 14 & 22.95 \\
\hline Q4 Item Summary & Mean & S.D. & Mean & S.D. & Mean & S.D. & Mean & S.D. & Mean & S.D. \\
\hline Mean Score & 0.06 & 0.25 & 0.14 & 0.36 & 0.04 & 0.20 & 0.13 & 0.35 & 0.25 & 0.43 \\
\hline Percentage Score & 6.25 & 25.00 & 14.29 & 35.63 & 4.00 & 20.00 & 13.33 & 34.57 & 24.59 & 43.42 \\
\hline
\end{tabular}


Community-Based Flood Vulnerability Index for Urban Flooding: Understanding Social Vulnerabilities and Risks

\begin{tabular}{|c|c|c|c|c|c|c|}
\hline \multirow{2}{*}{ Questions } & \multicolumn{2}{|c|}{ Candau-ay } & \multicolumn{2}{|c|}{ Batinguel } & \multicolumn{2}{|c|}{ Overall } \\
\hline & $\mathbf{F}$ & $\%$ & $\mathbf{F}$ & $\%$ & $\mathbf{F}$ & $\%$ \\
\hline 4. Do you have fixed net on doors and windows? & 4 & 5.56 & 7 & 18.42 & 45 & 12.47 \\
\hline Q4 Item Summary & Mean & S.D. & Mean & S.D. & Mean & S.D. \\
\hline Mean Score & 0.06 & 0.23 & 0.18 & 0.39 & 0.12 & 0.10 \\
\hline Percentage Score & 5.63 & 23.22 & 18.42 & 39.29 & 12.29 & 9.69 \\
\hline
\end{tabular}

Health Risk: Dengue Practice ... continued

\begin{tabular}{|c|c|c|c|c|c|c|c|c|c|c|}
\hline \multirow{2}{*}{ Questions } & \multicolumn{2}{|c|}{ Tabuc-tubig } & \multicolumn{2}{|c|}{ Junob } & \multicolumn{2}{|c|}{ Poblacion 1} & \multicolumn{2}{|c|}{ Calindagan } & \multicolumn{2}{|c|}{ Balugo } \\
\hline & $\mathbf{F}$ & $\%$ & $\mathbf{F}$ & $\%$ & $\mathbf{F}$ & $\%$ & $\mathbf{F}$ & $\%$ & $\mathbf{F}$ & $\%$ \\
\hline $\begin{array}{l}\text { 5. Do you close the overhead } \\
\text { tanks after using? }\end{array}$ & 10 & 100.00 & 11 & 68.75 & 16 & 72.73 & 16 & 69.57 & 8 & 47.06 \\
\hline Q5 Item Summary & Mean & S.D. & Mean & S.D. & Mean & S.D. & Mean & S.D. & Mean & S.D. \\
\hline Mean Score & 1.00 & 0.00 & 0.69 & 0.48 & 0.73 & 0.46 & 0.73 & 0.46 & 0.47 & 0.51 \\
\hline Percentage Score & 100.00 & 0.00 & 68.75 & 47.87 & 72.73 & 45.58 & 72.73 & 45.58 & 47.06 & 51.45 \\
\hline
\end{tabular}

\begin{tabular}{|c|c|c|c|c|c|c|c|c|c|c|}
\hline \multirow{2}{*}{ Questions } & \multicolumn{2}{|c|}{ Barangay 2} & \multicolumn{2}{|c|}{ Poblacion 8} & \multicolumn{2}{|c|}{ Cadawinonan } & \multicolumn{2}{|c|}{ Bagacay } & \multicolumn{2}{|c|}{ Taclobo } \\
\hline & $\mathbf{F}$ & $\%$ & $\mathbf{F}$ & $\%$ & $\mathbf{F}$ & $\%$ & $\mathbf{F}$ & $\%$ & $\mathbf{F}$ & $\%$ \\
\hline $\begin{array}{l}\text { 5. Do you close the overhead } \\
\text { tanks after using? }\end{array}$ & 11 & 68.75 & 15 & 51.72 & 18 & 72.00 & 19 & 63.33 & 40 & 65.57 \\
\hline Q5 Item Summary & Mean & S.D. & Mean & S.D. & Mean & S.D. & Mean & S.D. & Mean & S.D. \\
\hline Mean Score & 0.69 & 0.48 & 0.52 & 0.51 & 0.72 & 0.46 & 0.63 & 0.49 & 0.68 & 0.47 \\
\hline Percentage Score & 68.75 & 47.87 & 51.72 & 50.85 & 72.00 & 45.83 & 63.33 & 49.01 & 67.74 & 47.13 \\
\hline
\end{tabular}


Community-Based Flood Vulnerability Index for Urban Flooding: Understanding Social Vulnerabilities and Risks

\begin{tabular}{|c|c|c|c|c|c|c|}
\hline \multirow{2}{*}{ Questions } & \multicolumn{2}{|c|}{ Candau-ay } & \multicolumn{2}{|c|}{ Batinguel } & \multicolumn{2}{|c|}{ Overall } \\
\hline & $\mathbf{F}$ & $\%$ & $\mathbf{F}$ & $\%$ & $\mathbf{F}$ & $\%$ \\
\hline 5. Do you close the overhead tanks after using? & 42 & 58.33 & 29 & 76.32 & 224 & 62.05 \\
\hline Q5 Item Summary & Mean & S.D. & Mean & S.D. & Mean & S.D. \\
\hline Mean Score & 0.58 & 0.50 & 0.76 & 0.43 & 0.68 & 0.14 \\
\hline Percentage Score & 58.33 & 49.65 & 76.32 & 43.09 & 68.25 & 14.04 \\
\hline
\end{tabular}

Health Risk: Dengue Practice ... continued

\begin{tabular}{|c|c|c|c|c|c|c|c|c|c|c|}
\hline \multirow{2}{*}{ Questions } & \multicolumn{2}{|c|}{ Tabuc-tubig } & \multicolumn{2}{|c|}{ Junob } & \multicolumn{2}{|c|}{ Poblacion 1} & \multicolumn{2}{|c|}{ Calindagan } & \multicolumn{2}{|c|}{ Balugo } \\
\hline & $\mathbf{F}$ & $\%$ & $\mathbf{F}$ & $\%$ & $\mathbf{F}$ & $\%$ & $\mathbf{F}$ & $\%$ & $\mathbf{F}$ & $\%$ \\
\hline $\begin{array}{l}\text { 6. Do you keep your water in } \\
\text { water containers for a week? }\end{array}$ & 7 & 70.00 & 13 & 81.25 & 18 & 81.82 & 22 & 95.65 & 14 & 82.35 \\
\hline Q6 Item Summary & Mean & S.D. & Mean & S.D. & Mean & S.D. & Mean & S.D. & Mean & S.D. \\
\hline Mean Score & 0.70 & 0.48 & 0.81 & 0.40 & 0.82 & 0.39 & 0.96 & 0.21 & 0.82 & 0.39 \\
\hline Percentage Score & 70.00 & 48.30 & 81.25 & 40.31 & 81.82 & 39.48 & 95.65 & 20.85 & 82.35 & 39.30 \\
\hline
\end{tabular}

\begin{tabular}{|c|c|c|c|c|c|c|c|c|c|c|}
\hline \multirow{2}{*}{ Questions } & \multicolumn{2}{|c|}{ Barangay 2} & \multicolumn{2}{|c|}{ Poblacion 8} & \multicolumn{2}{|c|}{ Cadawinonan } & \multicolumn{2}{|c|}{ Bagacay } & \multicolumn{2}{|c|}{ Taclobo } \\
\hline & $\mathbf{F}$ & $\%$ & $\mathbf{F}$ & $\%$ & $\mathbf{F}$ & $\%$ & $\mathbf{F}$ & $\%$ & $\mathbf{F}$ & $\%$ \\
\hline $\begin{array}{l}\text { 6. Do you keep your water in } \\
\text { water containers for a week? }\end{array}$ & 4 & 25.00 & 26 & 89.66 & 22 & 88.00 & 27 & 90.00 & 47 & 77.05 \\
\hline Q6 Item Summary & Mean & S.D. & Mean & S.D. & Mean & S.D. & Mean & S.D. & Mean & S.D. \\
\hline Mean Score & 0.88 & 0.34 & 0.90 & 0.31 & 0.88 & 0.33 & 0.90 & 0.31 & 0.85 & 0.36 \\
\hline Percentage Score & 87.50 & 34.16 & 89.66 & 30.99 & 88.00 & 33.17 & 90.00 & 30.51 & 85.48 & 35.51 \\
\hline
\end{tabular}


Community-Based Flood Vulnerability Index for Urban Flooding: Understanding Social Vulnerabilities and Risks

\begin{tabular}{|c|c|c|c|c|c|c|}
\hline \multirow{2}{*}{ Questions } & \multicolumn{2}{|c|}{ Candau-ay } & \multicolumn{2}{|c|}{ Batinguel } & \multicolumn{2}{|c|}{ Overall } \\
\hline & $\mathbf{F}$ & $\%$ & $\mathbf{F}$ & $\%$ & $\mathbf{F}$ & $\%$ \\
\hline $\begin{array}{l}\text { 6. Do you keep your water in water containers for } \\
\text { a week? }\end{array}$ & 69 & 95.83 & 36 & 94.74 & 292 & 80.89 \\
\hline Q6 Item Summary & Mean & S.D. & Mean & S.D. & Mean & S.D. \\
\hline Mean Score & 0.96 & 0.20 & 0.95 & 0.23 & 0.87 & 0.08 \\
\hline Percentage Score & 95.83 & 20.12 & 94.74 & 22.63 & 87.37 & 7.54 \\
\hline
\end{tabular}

Health Risk: Dengue Practice ... continued

\begin{tabular}{|c|c|c|c|c|c|c|c|c|c|c|}
\hline \multirow{2}{*}{ Questions } & \multicolumn{2}{|c|}{ Tabuc-tubig } & \multicolumn{2}{|c|}{ Junob } & \multicolumn{2}{|c|}{ Poblacion 1} & \multicolumn{2}{|c|}{ Calindagan } & \multicolumn{2}{|c|}{ Balugo } \\
\hline & $\mathbf{F}$ & $\%$ & $\mathbf{F}$ & $\%$ & $\mathbf{F}$ & $\%$ & $\mathbf{F}$ & $\%$ & $\mathbf{F}$ & $\%$ \\
\hline $\begin{array}{l}\text { 7. Do you let water to accumulate } \\
\text { inside and outside your home? }\end{array}$ & 10 & 100.00 & 15 & 93.75 & 18 & 81.82 & 18 & 78.26 & 11 & 64.71 \\
\hline Q7 Item Summary & Mean & S.D. & Mean & S.D. & Mean & S.D. & Mean & S.D. & Mean & S.D. \\
\hline Mean Score & 1.00 & 0.00 & 0.94 & 0.25 & 0.82 & 0.39 & 0.78 & 0.42 & 0.65 & 0.49 \\
\hline Percentage Score & 100.00 & 0.00 & 93.75 & 25.00 & 81.82 & 39.48 & 78.26 & 42.17 & 64.71 & 49.26 \\
\hline
\end{tabular}

\begin{tabular}{|c|c|c|c|c|c|c|c|c|c|c|}
\hline \multirow{2}{*}{ Questions } & \multicolumn{2}{|c|}{ Barangay 2} & \multicolumn{2}{|c|}{ Poblacion 8} & \multicolumn{2}{|c|}{ Cadawinonan } & \multicolumn{2}{|c|}{ Bagacay } & \multicolumn{2}{|c|}{ Taclobo } \\
\hline & $\mathbf{F}$ & $\%$ & $\mathbf{F}$ & $\%$ & $\mathbf{F}$ & $\%$ & $\mathbf{F}$ & $\%$ & $\mathbf{F}$ & $\%$ \\
\hline $\begin{array}{l}\text { 7. Do you let water to accumulate } \\
\text { inside and outside your home? }\end{array}$ & 4 & 25.00 & 25 & 86.21 & 22 & 88.00 & 29 & 96.67 & 47 & 77.05 \\
\hline Q7 Item Summary & Mean & S.D. & Mean & S.D. & Mean & S.D. & Mean & S.D. & Mean & S.D. \\
\hline Mean Score & 0.88 & 0.34 & 0.86 & 0.35 & 0.88 & 0.33 & 0.96 & 0.20 & 0.85 & 0.36 \\
\hline Percentage Score & 87.50 & 34.16 & 86.21 & 35.09 & 88.00 & 33.17 & 96.00 & 20.00 & 85.48 & 35.51 \\
\hline
\end{tabular}


Community-Based Flood Vulnerability Index for Urban Flooding: Understanding Social Vulnerabilities and Risks

Health Risk: Dengue Practice... continued

\begin{tabular}{|c|c|c|c|c|c|c|}
\hline \multirow{2}{*}{ Questions } & \multicolumn{2}{|c|}{ Candau-ay } & \multicolumn{2}{|c|}{ Batinguel } & \multicolumn{2}{|c|}{ Overall } \\
\hline & $\mathbf{F}$ & $\%$ & $\mathbf{F}$ & $\%$ & $\mathbf{F}$ & $\%$ \\
\hline $\begin{array}{l}\text { 7. Do you let water to accumulate inside and } \\
\text { outside your home? }\end{array}$ & 67 & 93.06 & 34 & 89.47 & 283 & 78.39 \\
\hline Q7 Item Summary & Mean & S.D. & Mean & S.D. & Mean & S.D. \\
\hline Mean Score & 0.93 & 0.26 & 0.89 & 0.31 & 0.85 & 0.08 \\
\hline Percentage Score & 93.06 & 25.60 & 89.47 & 31.10 & 84.59 & 8.45 \\
\hline
\end{tabular}

Health Risk: Dengue Practice ... continued

\begin{tabular}{|c|c|c|c|c|c|c|c|c|c|c|}
\hline \multirow{2}{*}{ Questions } & \multicolumn{2}{|c|}{ Tabuc-tubig } & \multicolumn{2}{|c|}{ Junob } & \multicolumn{2}{|c|}{ Poblacion 1} & \multicolumn{2}{|c|}{ Calindagan } & \multicolumn{2}{|c|}{ Balugo } \\
\hline & $\mathbf{F}$ & $\%$ & $\mathbf{F}$ & $\%$ & $\mathbf{F}$ & $\%$ & $\mathbf{F}$ & $\%$ & $\mathbf{F}$ & $\%$ \\
\hline $\begin{array}{l}\text { 8. Do you let water to stay in the } \\
\text { flower pots or vases for a week? }\end{array}$ & 10 & 100.00 & 15 & 93.75 & 21 & 95.45 & 19 & 82.61 & 15 & 88.24 \\
\hline Q8 Item Summary & Mean & S.D. & Mean & S.D. & Mean & S.D. & Mean & S.D. & Mean & S.D. \\
\hline Mean Score & 1.00 & 0.00 & 0.94 & 0.25 & 0.95 & 0.21 & 0.86 & 0.35 & 0.88 & 0.33 \\
\hline Percentage Score & 100.00 & 0.00 & 93.75 & 25.00 & 95.45 & 21.32 & 86.36 & 35.13 & 88.24 & 33.21 \\
\hline
\end{tabular}

\begin{tabular}{|c|c|c|c|c|c|c|c|c|c|c|}
\hline \multirow{2}{*}{ Questions } & \multicolumn{2}{|c|}{ Barangay 2} & \multicolumn{2}{|c|}{ Poblacion 8} & \multicolumn{2}{|c|}{ Cadawinonan } & \multicolumn{2}{|c|}{ Bagacay } & \multicolumn{2}{|c|}{ Taclobo } \\
\hline & $\mathbf{F}$ & $\%$ & $\mathbf{F}$ & $\%$ & $\mathbf{F}$ & $\%$ & \begin{tabular}{|l|l}
$\mathbf{F}$ & \\
\end{tabular} & $\%$ & $\mathbf{F}$ & $\%$ \\
\hline $\begin{array}{l}\text { 8. Do you let water to stay in the } \\
\text { flower pots or vases for a week? }\end{array}$ & 5 & 31.25 & 26 & 89.66 & 23 & 92.00 & 28 & 93.33 & 47 & 77.05 \\
\hline Q8 Item Summary & Mean & S.D. & Mean & S.D. & Mean & S.D. & Mean & S.D. & Mean & S.D. \\
\hline Mean Score & 0.81 & 0.40 & 0.90 & 0.31 & 0.92 & 0.28 & 0.92 & 0.28 & 0.85 & 0.36 \\
\hline Percentage Score & 81.25 & 40.31 & 89.66 & 30.99 & 92.00 & 27.69 & 92.00 & 27.69 & 85.48 & 35.51 \\
\hline
\end{tabular}


Community-Based Flood Vulnerability Index for Urban Flooding: Understanding Social Vulnerabilities and Risks

Health Risk: Dengue Practice... continued

\begin{tabular}{|c|c|c|c|c|c|c|}
\hline \multirow[t]{2}{*}{ Questions } & \multicolumn{2}{|l|}{ Candau-ay } & \multicolumn{2}{|l|}{ Batinguel } & \multicolumn{2}{|l|}{ Overall } \\
\hline & $\mathbf{F}$ & $\%$ & $\mathbf{F}$ & $\%$ & $\mathbf{F}$ & $\%$ \\
\hline $\begin{array}{l}\text { 8. Do you let water to stay in the flower pots or } \\
\text { vases for a week? }\end{array}$ & 72 & 100.00 & 37 & 97.37 & 303 & 83.93 \\
\hline Q8 Item Summary & Mean & S.D. & Mean & S.D. & Mean & S.D. \\
\hline Mean Score & 1.00 & 0.00 & 0.97 & 0.16 & 0.92 & 0.06 \\
\hline Percentage Score & 100.00 & 0.00 & 97.37 & 16.22 & 91.62 & 6.14 \\
\hline
\end{tabular}

Health Risk: Dengue Practice ... continued

\begin{tabular}{|c|c|c|c|c|c|c|c|c|c|c|}
\hline \multirow{2}{*}{ Questions } & \multicolumn{2}{|c|}{ Tabuc-tubig } & \multicolumn{2}{|c|}{ Junob } & \multicolumn{2}{|c|}{ Poblacion 1} & \multicolumn{2}{|c|}{ Calindagan } & \multicolumn{2}{|c|}{ Balugo } \\
\hline & $\mathbf{F}$ & $\%$ & $\mathbf{F}$ & $\%$ & \begin{tabular}{l|l|}
$\mathbf{F}$ \\
\end{tabular} & $\%$ & $\mathbf{F}$ & $\%$ & $\mathbf{F}$ & $\%$ \\
\hline $\begin{array}{l}\text { 9. Have you had fogging activities } \\
\text { in your home or community? }\end{array}$ & 7 & 70.00 & 7 & 43.75 & 9 & 40.91 & 5 & 21.74 & 6 & 35.29 \\
\hline Q9 Item Summary & Mean & S.D. & Mean & S.D. & Mean & S.D. & Mean & S.D. & Mean & S.D. \\
\hline Mean Score & 0.70 & 0.48 & 0.44 & 0.51 & 0.41 & 0.50 & 0.22 & 0.42 & 0.35 & 0.49 \\
\hline Percentage Score & 70.00 & 48.30 & 43.75 & 51.23 & 40.91 & 50.32 & 21.74 & 42.17 & 35.29 & 49.26 \\
\hline
\end{tabular}

\begin{tabular}{|c|c|c|c|c|c|c|c|c|c|c|}
\hline \multirow{2}{*}{ Questions } & \multicolumn{2}{|c|}{ Barangay 2} & \multicolumn{2}{|c|}{ Poblacion 8} & \multicolumn{2}{|c|}{ Cadawinonan } & \multicolumn{2}{|c|}{ Bagacay } & \multicolumn{2}{|c|}{ Taclobo } \\
\hline & $\mathbf{F}$ & $\%$ & $\mathbf{F}$ & $\%$ & $\mathbf{F}$ & $\%$ & $\mathbf{F}$ & $\%$ & $\mathbf{F}$ & $\%$ \\
\hline $\begin{array}{l}\text { 9. Have you had fogging activities } \\
\text { in your home or community? }\end{array}$ & 5 & 31.25 & 11 & 37.93 & 9 & 36.00 & 9 & 36.00 & 20 & 32.79 \\
\hline Q9 Item Summary & Mean & S.D. & Mean & S.D. & Mean & S.D. & Mean & S.D. & Mean & S.D. \\
\hline Mean Score & 0.31 & 0.48 & 0.38 & 0.49 & 0.36 & 0.49 & 0.36 & 0.49 & 0.38 & 0.49 \\
\hline Percentage Score & 31.25 & 47.87 & 37.93 & 49.38 & 36.00 & 48.99 & 36.00 & 48.99 & 37.70 & 48.87 \\
\hline
\end{tabular}


Community-Based Flood Vulnerability Index for Urban Flooding: Understanding Social Vulnerabilities and Risks

Health Risk: Dengue Practice ... continued

\begin{tabular}{|c|c|c|c|c|c|c|}
\hline \multirow{2}{*}{ Questions } & \multicolumn{2}{|l|}{ Candau-ay } & \multicolumn{2}{|l|}{ Batinguel } & \multicolumn{2}{|l|}{ Overall } \\
\hline & $\mathbf{F}$ & $\%$ & $\mathbf{F}$ & $\%$ & $\mathbf{F}$ & $\%$ \\
\hline $\begin{array}{l}\text { 9. Have you had fogging activities in your home or } \\
\text { community? }\end{array}$ & 19 & 26.39 & 15 & 39.47 & 115 & 31.86 \\
\hline Q9 Item Summary & Mean & S.D. & Mean & S.D. & Mean & S.D. \\
\hline Mean Score & 0.26 & 0.44 & 0.39 & 0.50 & 0.38 & 0.12 \\
\hline Percentage Score & 26.39 & 44.38 & 39.47 & 49.54 & 37.52 & 12.22 \\
\hline
\end{tabular}

Health Risk: Dengue Practice ... continued

\begin{tabular}{|c|c|c|c|c|c|c|c|c|c|c|}
\hline \multirow{2}{*}{ Questions } & \multicolumn{2}{|c|}{ Tabuc-tubig } & \multicolumn{2}{|c|}{ Junob } & \multicolumn{2}{|c|}{ Poblacion 1} & \multicolumn{2}{|c|}{ Calindagan } & \multicolumn{2}{|c|}{ Balugo } \\
\hline & $\mathbf{F}$ & $\%$ & $\mathbf{F}$ & $\%$ & $\mathbf{F}$ & $\%$ & $\mathbf{F}$ & $\%$ & $\mathbf{F}$ & $\%$ \\
\hline $\begin{array}{l}\text { 10. Have you had apply chemical } \\
\text { control against larval stages of } \\
\text { dengue mosquitoes? }\end{array}$ & 6 & 60.00 & 3 & 18.75 & 6 & 27.27 & 6 & 26.09 & 4 & 23.53 \\
\hline Q10 Item Summary & Mean & S.D. & Mean & S.D. & Mean & S.D. & Mean & S.D. & Mean & S.D. \\
\hline Mean Score & 0.60 & 0.52 & 0.19 & 0.40 & 0.27 & 0.46 & 0.26 & 0.45 & 0.24 & 0.44 \\
\hline Percentage Score & 60.00 & 51.64 & 18.75 & 40.31 & 27.27 & 45.58 & 26.09 & 44.90 & 23.53 & 43.72 \\
\hline
\end{tabular}

\begin{tabular}{|c|c|c|c|c|c|c|c|c|c|c|}
\hline \multirow{2}{*}{ Questions } & \multicolumn{2}{|c|}{ Barangay 2} & \multicolumn{2}{|c|}{ Poblacion 8} & \multicolumn{2}{|c|}{ Cadawinonan } & \multicolumn{2}{|c|}{ Bagacay } & \multicolumn{2}{|c|}{ Taclobo } \\
\hline & $\mathbf{F}$ & $\%$ & $\mathbf{F}$ & $\%$ & $\mathbf{F}$ & $\%$ & $\mathbf{F}$ & $\%$ & $\mathbf{F}$ & $\%$ \\
\hline $\begin{array}{l}\text { 10. Have you had apply chemical } \\
\text { control against larval stages of } \\
\text { dengue mosquitoes? }\end{array}$ & 4 & 25.00 & 5 & 17.24 & 8 & 32.00 & 7 & 28.00 & 19 & 31.15 \\
\hline Q10 Item Summary & Mean & S.D. & Mean & S.D. & Mean & S.D. & Mean & S.D. & Mean & S.D. \\
\hline Mean Score & 0.25 & 0.45 & 0.17 & 0.38 & 0.32 & 0.48 & 0.28 & 0.46 & 0.34 & 0.48 \\
\hline Percentage Score & 25.00 & 44.72 & 17.24 & 38.44 & 32.00 & 47.61 & 28.00 & 45.83 & 33.87 & 47.71 \\
\hline
\end{tabular}


Community-Based Flood Vulnerability Index for Urban Flooding: Understanding Social Vulnerabilities and Risks

Health Risk: Dengue Practice ... continued

\begin{tabular}{|c|c|c|c|c|c|c|}
\hline \multirow{2}{*}{ Questions } & \multicolumn{2}{|c|}{ Candau-ay } & \multicolumn{2}{|c|}{ Batinguel } & \multicolumn{2}{|c|}{ Overall } \\
\hline & $\mathbf{F}$ & $\%$ & $\mathbf{F}$ & $\%$ & $\mathbf{F}$ & $\%$ \\
\hline $\begin{array}{l}\text { 10. Have you had apply chemical control against } \\
\text { larval stages of dengue mosquitoes? }\end{array}$ & 11 & 15.28 & 11 & 28.95 & 87 & 24.10 \\
\hline Q10 Item Summary & Mean & S.D. & Mean & S.D. & Mean & S.D. \\
\hline Mean Score & 0.15 & 0.36 & 0.29 & 0.46 & 0.29 & 0.12 \\
\hline Percentage Score & 15.28 & 36.23 & 28.95 & 45.96 & 28.84 & 11.74 \\
\hline
\end{tabular}

Health Risk: Dengue Practice ... continued

\begin{tabular}{|c|c|c|c|c|c|c|c|c|c|c|}
\hline \multirow{2}{*}{ Questions } & \multicolumn{2}{|c|}{ Tabuc-tubig } & \multicolumn{2}{|c|}{ Junob } & \multicolumn{2}{|c|}{ Poblacion 1} & \multicolumn{2}{|c|}{ Calindagan } & \multicolumn{2}{|c|}{ Balugo } \\
\hline & $\mathbf{F}$ & $\%$ & $\mathbf{F}$ & $\%$ & $\mathbf{F}$ & $\%$ & $\mathbf{F}$ & $\%$ & $\mathbf{F}$ & $\%$ \\
\hline $\begin{array}{l}\text { 11. Have you had apply biological } \\
\text { control against larval stages of } \\
\text { dengue mosquitoes? }\end{array}$ & 3 & 30.00 & 2 & 12.50 & 4 & 18.18 & 0 & 0.00 & 3 & 17.65 \\
\hline Q11 Item Summary & Mean & S.D. & Mean & S.D. & Mean & S.D. & Mean & S.D. & Mean & S.D. \\
\hline Mean Score & 0.30 & 0.48 & 0.13 & 0.34 & 0.18 & 0.39 & 0.00 & 0.00 & 0.18 & 0.39 \\
\hline Percentage Score & 30.00 & 48.30 & 12.50 & 34.16 & 18.18 & 39.48 & 0.00 & 0.00 & 17.65 & 39.30 \\
\hline
\end{tabular}


Community-Based Flood Vulnerability Index for Urban Flooding: Understanding Social Vulnerabilities and Risks

\begin{tabular}{|c|c|c|c|c|c|c|c|c|c|c|}
\hline \multirow[b]{2}{*}{ Questions } & \multicolumn{2}{|c|}{ Barangay 2} & \multicolumn{2}{|c|}{ Poblacion 8} & \multicolumn{2}{|c|}{ Cadawinonan } & \multicolumn{2}{|l|}{ Bagacay } & \multicolumn{2}{|l|}{ Taclobo } \\
\hline & $\mathbf{F}$ & $\%$ & $\mathbf{F}$ & $\%$ & $\mathbf{F}$ & $\%$ & $\mathbf{F}$ & $\%$ & $\mathbf{F}$ & $\%$ \\
\hline $\begin{array}{l}\text { 11. Have you had apply biological } \\
\text { control against larval stages of } \\
\text { dengue mosquitoes? }\end{array}$ & 3 & 18.75 & 7 & 24.14 & 9 & 36.00 & 2 & 8.00 & 13 & 21.31 \\
\hline Q11 Item Summary & Mean & S.D. & Mean & S.D. & Mean & S.D. & Mean & S.D. & Mean & S.D. \\
\hline Mean Score & 0.19 & 0.40 & 0.24 & 0.44 & 0.36 & 0.49 & 0.08 & 0.28 & 0.24 & 0.43 \\
\hline Percentage Score & 18.75 & 40.31 & 24.14 & 43.55 & 36.00 & 48.99 & 8.33 & 28.23 & 24.19 & 43.18 \\
\hline
\end{tabular}

Health Risk: Dengue Practice ... continued

\begin{tabular}{|c|c|c|c|c|c|c|}
\hline \multirow{2}{*}{ Questions } & \multicolumn{2}{|c|}{ Candau-ay } & \multicolumn{2}{|c|}{ Batinguel } & \multicolumn{2}{|c|}{ Overall } \\
\hline & $\mathbf{F}$ & $\%$ & $\mathbf{F}$ & $\%$ & $\mathbf{F}$ & $\%$ \\
\hline $\begin{array}{l}\text { 11. Have you had apply biological control } \\
\text { against larval stages of dengue } \\
\text { mosquitoes? }\end{array}$ & 11 & 15.28 & 4 & 10.53 & 59 & 16.34 \\
\hline Q11 Item Summary & Mean & S.D. & Mean & S.D. & Mean & S.D. \\
\hline Mean Score & 0.15 & 0.36 & 0.11 & 0.31 & 0.18 & 0.10 \\
\hline Percentage Score & 15.28 & 36.23 & 10.53 & 31.10 & 18.46 & 10.12 \\
\hline
\end{tabular}


Community-Based Flood Vulnerability Index for Urban Flooding: Understanding Social Vulnerabilities and Risks

Health Risk: Dengue Practice SUMMARY

\begin{tabular}{|c|c|c|c|c|c|c|c|c|c|c|}
\hline \multirow{2}{*}{ Questions } & \multicolumn{2}{|c|}{ Tabuc-tubig } & \multicolumn{2}{|c|}{ Junob } & \multicolumn{2}{|c|}{ Poblacion 1} & \multicolumn{2}{|c|}{ Calindagan } & \multicolumn{2}{|c|}{ Balugo } \\
\hline & Mean & S.D. & Mean & S.D. & Mean & S.D. & Mean & S.D. & Mean & S.D. \\
\hline $\begin{array}{l}\text { 1. Do you clean your } \\
\text { immediate surroundings } \\
\text { and empty from the } \\
\text { following usual mosquito } \\
\text { breeding sites? }\end{array}$ & 90.00 & 31.62 & 56.25 & 51.23 & 90.91 & 29.42 & 91.30 & 28.81 & 82.35 & 39.30 \\
\hline $\begin{array}{l}\text { 2. Do you clean your } \\
\text { immediate surroundings } \\
\text { and empty from the } \\
\text { following } \\
\text { unusual/uncommon } \\
\text { mosquito breeding Sites? }\end{array}$ & 80.00 & 42.16 & 81.25 & 40.31 & 90.48 & 30.08 & 86.96 & 34.44 & 94.12 & 24.25 \\
\hline $\begin{array}{l}\text { 3. Do you make sure that } \\
\text { your home is airy, bright, } \\
\text { and safe from moisture? }\end{array}$ & 100.00 & 0.00 & 87.50 & 34.16 & 100.00 & 0.00 & 86.96 & 34.44 & 93.75 & 25.00 \\
\hline $\begin{array}{l}\text { 4. Do you have fixed net on } \\
\text { doors and windows? }\end{array}$ & 0.00 & 0.00 & 0.00 & 0.00 & 31.82 & 47.67 & 4.35 & 20.85 & 12.50 & 34.16 \\
\hline $\begin{array}{l}\text { 5. Do you close the } \\
\text { overhead tanks after } \\
\text { using? }\end{array}$ & 100.00 & 0.00 & 68.75 & 47.87 & 72.73 & 45.58 & 72.73 & 45.58 & 47.06 & 51.45 \\
\hline $\begin{array}{l}\text { 6. Do you keep your water } \\
\text { in water containers for a } \\
\text { week? }\end{array}$ & 70.00 & 48.30 & 81.25 & 40.31 & 81.82 & 39.48 & 95.65 & 20.85 & 82.35 & 39.30 \\
\hline $\begin{array}{l}\text { 7. Do you let water to } \\
\text { accumulate inside and } \\
\text { outside your home? }\end{array}$ & 100.00 & 0.00 & 93.75 & 25.00 & 81.82 & 39.48 & 78.26 & 42.17 & 64.71 & 49.26 \\
\hline
\end{tabular}


Community-Based Flood Vulnerability Index for Urban Flooding: Understanding

Social Vulnerabilities and Risks

\begin{tabular}{|c|c|c|c|c|c|c|c|c|c|c|}
\hline $\begin{array}{l}\text { 8. Do you let water to stay } \\
\text { in the flower pots or vases } \\
\text { for a week? }\end{array}$ & 100.00 & 0.00 & 93.75 & 25.00 & 95.45 & 21.32 & 86.36 & 35.13 & 88.24 & 33.21 \\
\hline $\begin{array}{l}\text { 9. Have you had fogging } \\
\text { activities in your home or } \\
\text { community? }\end{array}$ & 70.00 & 48.30 & 43.75 & 51.23 & 40.91 & 50.32 & 21.74 & 42.17 & 35.29 & 49.26 \\
\hline
\end{tabular}

Health Risk: Dengue Practice SUMMARY . . . continued

\begin{tabular}{|c|c|c|c|c|c|c|c|c|c|c|}
\hline \multirow{2}{*}{ Questions } & \multicolumn{2}{|c|}{ Tabuc-tubig } & \multicolumn{2}{|c|}{ Junob } & \multicolumn{2}{|c|}{ Poblacion 1} & \multicolumn{2}{|c|}{ Calindagan } & \multicolumn{2}{|c|}{ Balugo } \\
\hline & Mean & S.D. & Mean & S.D. & Mean & S.D. & Mean & S.D. & Mean & S.D. \\
\hline $\begin{array}{l}\text { 10. Have you had apply } \\
\text { chemical control against } \\
\text { larval stages of dengue } \\
\text { mosquitoes? }\end{array}$ & 60.00 & 51.64 & 18.75 & 40.31 & 27.27 & 45.58 & 26.09 & 44.90 & 23.53 & 43.72 \\
\hline $\begin{array}{l}\text { 11. Have you had apply } \\
\text { biological control against } \\
\text { larval stages of dengue } \\
\text { mosquitoes? }\end{array}$ & 30.00 & 48.30 & 12.50 & 34.16 & 18.18 & 39.48 & 0.00 & 0.00 & 17.65 & 39.30 \\
\hline Overall Summary & 72.73 & 32.59 & 57.95 & 34.36 & 66.49 & 30.61 & 59.13 & 37.68 & 58.32 & 32.01 \\
\hline
\end{tabular}


Community-Based Flood Vulnerability Index for Urban Flooding: Understanding Social Vulnerabilities and Risks

\begin{tabular}{|c|c|c|c|c|c|c|c|c|c|c|}
\hline \multirow{2}{*}{ Questions } & \multicolumn{2}{|c|}{ Barangay 2} & \multicolumn{2}{|c|}{ Poblacion 8} & \multicolumn{2}{|c|}{ Cadawinonan } & \multicolumn{2}{|c|}{ Bagacay } & \multicolumn{2}{|c|}{ Taclobo } \\
\hline & Mean & S.D. & Mean & S.D. & Mean & S.D. & Mean & S.D. & Mean & S.D. \\
\hline $\begin{array}{l}\text { 1. Do you clean your } \\
\text { immediate surroundings and } \\
\text { empty from the following } \\
\text { usual mosquito breeding } \\
\text { sites? }\end{array}$ & 93.75 & 25.00 & 89.66 & 30.99 & 88.00 & 33.17 & 90.00 & 30.51 & 91.94 & 27.45 \\
\hline $\begin{array}{l}\text { 2. Do you clean your } \\
\text { immediate surroundings and } \\
\text { empty from the following } \\
\text { unusual/uncommon } \\
\text { mosquito breeding Sites? }\end{array}$ & 81.25 & 40.31 & 89.29 & 31.50 & 92.00 & 27.69 & 83.33 & 37.90 & 87.10 & 33.80 \\
\hline $\begin{array}{l}\text { 3. Do you make sure that } \\
\text { your home is airy, bright, and } \\
\text { safe from moisture? }\end{array}$ & 100.00 & 63.25 & 70.37 & 46.53 & 72.00 & 45.83 & 0.47 & 46.61 & 85.48 & 35.51 \\
\hline $\begin{array}{l}\text { 4. Do you have fixed net on } \\
\text { doors and windows? }\end{array}$ & 6.25 & 25.00 & 14.29 & 35.63 & 4.00 & 20.00 & 13.33 & 34.57 & 24.59 & 43.42 \\
\hline
\end{tabular}


Community-Based Flood Vulnerability Index for Urban Flooding: Understanding Social Vulnerabilities and Risks

Health Risk: Dengue Practice SUMMARY . . . continued

\begin{tabular}{|c|c|c|c|c|c|c|c|c|c|c|}
\hline \multirow{2}{*}{ Questions } & \multicolumn{2}{|c|}{ Barangay 2} & \multicolumn{2}{|c|}{ Poblacion 8} & \multicolumn{2}{|c|}{ Cadawinonan } & \multicolumn{2}{|c|}{ Bagacay } & \multicolumn{2}{|c|}{ Taclobo } \\
\hline & Mean & S.D. & Mean & S.D. & Mean & S.D. & Mean & S.D. & Mean & S.D. \\
\hline $\begin{array}{l}\text { 5. Do you close the overhead } \\
\text { tanks after using? }\end{array}$ & 68.75 & 47.87 & 51.72 & 50.85 & 72.00 & 45.83 & 63.33 & 49.01 & 67.74 & 47.13 \\
\hline $\begin{array}{l}\text { 6. Do you keep your water in } \\
\text { water containers for a week? }\end{array}$ & 87.50 & 34.16 & 89.66 & 30.99 & 88.00 & 33.17 & 90.00 & 30.51 & 85.48 & 35.51 \\
\hline $\begin{array}{l}\text { 7. Do you let water to } \\
\text { accumulate inside and } \\
\text { outside your home? }\end{array}$ & 87.50 & 34.16 & 86.21 & 35.09 & 88.00 & 33.17 & 96.00 & 20.00 & 85.48 & 35.51 \\
\hline $\begin{array}{l}\text { 8. Do you let water to stay in } \\
\text { the flower pots or vases for a } \\
\text { week? }\end{array}$ & 81.25 & 40.31 & 89.66 & 30.99 & 92.00 & 27.69 & 92.00 & 27.69 & 85.48 & 35.51 \\
\hline $\begin{array}{l}\text { 9. Have you had fogging } \\
\text { activities in your home or } \\
\text { community? }\end{array}$ & 31.25 & 47.87 & 37.93 & 49.38 & 36.00 & 48.99 & 36.00 & 48.99 & 37.70 & 48.87 \\
\hline $\begin{array}{l}\text { 10. Have you had apply } \\
\text { chemical control against } \\
\text { larval stages of dengue } \\
\text { mosquitoes? }\end{array}$ & 25.00 & 44.72 & 17.24 & 38.44 & 32.00 & 47.61 & 28.00 & 45.83 & 33.87 & 47.71 \\
\hline $\begin{array}{l}\text { 11. Have you had apply } \\
\text { biological control against } \\
\text { larval stages of dengue } \\
\text { mosquitoes? }\end{array}$ & 18.75 & 40.31 & 24.14 & 43.55 & 36.00 & 48.99 & 8.33 & 28.23 & 24.19 & 43.18 \\
\hline Overall Summary & 61.93 & 34.40 & 60.01 & 31.70 & 63.64 & 31.01 & 54.62 & 37.88 & 64.46 & 28.12 \\
\hline
\end{tabular}


Community-Based Flood Vulnerability Index for Urban Flooding: Understanding Social Vulnerabilities and Risks

Health Risk: Dengue Practice SUMMARY . . . continued

\begin{tabular}{|c|c|c|c|c|c|c|}
\hline \multirow{2}{*}{ Questions } & \multicolumn{2}{|c|}{ Candau-ay } & \multicolumn{2}{|c|}{ Batinguel } & \multicolumn{2}{|c|}{ Overall } \\
\hline & Mean & S.D. & Mean & S.D. & Mean & S.D. \\
\hline $\begin{array}{l}\text { 1. Do you clean your immediate surroundings } \\
\text { and empty from the following usual mosquito } \\
\text { breeding sites? }\end{array}$ & 77.78 & 41.87 & 97.37 & 16.22 & 82.25 & 25.16 \\
\hline $\begin{array}{l}\text { 2. Do you clean your immediate surroundings } \\
\text { and empty from the following } \\
\text { unusual/uncommon mosquito breeding Sites? }\end{array}$ & 76.39 & 42.77 & 84.21 & 36.95 & 85.92 & 5.44 \\
\hline $\begin{array}{l}\text { 3. Do you make sure that your home is airy, } \\
\text { bright, and safe from moisture? }\end{array}$ & 66.20 & 47.64 & 81.58 & 39.29 & 84.21 & 13.12 \\
\hline 4. Do you have fixed net on doors and windows? & 5.63 & 23.22 & 18.42 & 39.29 & 12.29 & 9.69 \\
\hline 5. Do you close the overhead tanks after using? & 58.33 & 49.65 & 76.32 & 43.09 & 68.25 & 14.04 \\
\hline $\begin{array}{l}\text { 6. Do you keep your water in water containers } \\
\text { for a week? }\end{array}$ & 95.83 & 20.12 & 94.74 & 22.63 & 87.37 & 7.54 \\
\hline $\begin{array}{l}\text { 7. Do you let water to accumulate inside and } \\
\text { outside your home? }\end{array}$ & 93.06 & 25.60 & 89.47 & 31.10 & 84.59 & 8.45 \\
\hline $\begin{array}{l}\text { 8. Do you let water to stay in the flower pots or } \\
\text { vases for a week? }\end{array}$ & 100.00 & 0.00 & 97.37 & 16.22 & 91.62 & 6.14 \\
\hline $\begin{array}{l}\text { 9. Have you had fogging activities in your home } \\
\text { or community? }\end{array}$ & 26.39 & 44.38 & 39.47 & 49.54 & 37.52 & 12.22 \\
\hline
\end{tabular}

\begin{tabular}{|c|c|c|c|c|c|c|}
\hline \multirow{2}{*}{ Questions } & \multicolumn{2}{|c|}{ Candau-ay } & \multicolumn{2}{|c|}{ Batinguel } & \multicolumn{2}{|c|}{ Overall } \\
\hline & Mean & S.D. & Mean & S.D. & Mean & S.D. \\
\hline $\begin{array}{l}\text { 10. Have you had apply chemical control against } \\
\text { larval stages of dengue mosquitoes? }\end{array}$ & 15.28 & 36.23 & 28.95 & 45.96 & 28.84 & 11.74 \\
\hline $\begin{array}{l}\text { 11. Have you had apply biological control against } \\
\text { larval stages of dengue mosquitoes? }\end{array}$ & 15.28 & 36.23 & 10.53 & 31.10 & 18.46 & 10.12 \\
\hline Overall Summary & 57.29 & 35.51 & 65.31 & 33.82 & 61.94 & 31.00 \\
\hline
\end{tabular}




\section{Appendix 7 LOCAL GOVERNMENT UNITS and NON-GOVERNMENTAL ORGANIZATION MATRIX (SUMMARY)}

In this appendix the results of the survey from the Local Government Units (LGU's) and Non-governmental Organizations (NGO's) in terms of the following is presented as follows:
1. Governance
2. Sustainable Community Livelihood
3. The River's Natural Resources and Natural Features Management
4. Land Use Management and Structural Design
5. Post-Risk Assessment and Integration
6. Warning and Evacuation
7. Emergency Response
8. Disaster Recovery 
Community-Based Flood Vulnerability Index for Urban Flooding: Understanding Social Vulnerabilities and Risks

LOCAL GOVERNMENT UNITS and NON-GOVERNMENTAL ORGANIZATION MATRIX (SUMMARY)

\begin{tabular}{|c|c|c|c|c|c|c|c|c|c|c|}
\hline \multirow{3}{*}{$\begin{array}{l}\text { Local Government } \\
\text { Unit/NGO }\end{array}$} & \multicolumn{10}{|c|}{ BENCHMARK } \\
\hline & \multicolumn{2}{|c|}{ A. Governance } & \multicolumn{2}{|c|}{$\begin{array}{l}\text { B. Society and } \\
\text { Economy }\end{array}$} & \multicolumn{2}{|c|}{ 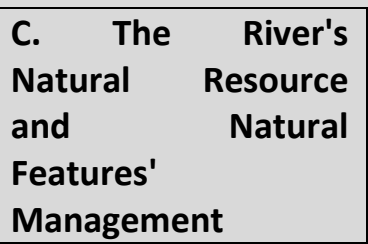 } & \multicolumn{2}{|c|}{$\begin{array}{l}\text { D. Land Use and } \\
\text { Management and } \\
\text { Structural Design }\end{array}$} & \multicolumn{2}{|c|}{ E. Risk Knowledge } \\
\hline & Average & Percent & Average & Percent & Average & Percent & Average & Percent & Average & Percent \\
\hline Poblacion 1 (Tinago) & 3.23 & 64.67 & 2.88 & 57.50 & 3.13 & 62.50 & 3.09 & 62.34 & 3.41 & 63.33 \\
\hline $\begin{array}{ll}\begin{array}{l}\text { Poblacion } \\
\text { (Lukewright) }\end{array} & 2 \\
\end{array}$ & 2.30 & 46.00 & 2.00 & 40.00 & 2.38 & 47.50 & 2.69 & 54.69 & 2.56 & 48.67 \\
\hline Poblacion 8 & 3.00 & 60.00 & 2.38 & 47.50 & 2.13 & 42.50 & 2.66 & 56.41 & 2.97 & 51.31 \\
\hline Tabuc-tubig & 2.58 & 51.67 & 1.88 & 37.50 & 1.50 & 30.00 & 1.85 & 38.75 & 2.13 & 45.63 \\
\hline Calindagan & 4.33 & 86.67 & 4.00 & 80.00 & 4.25 & 85.00 & 4.31 & 87.81 & 4.44 & 90.25 \\
\hline Taclobo & 3.25 & 65.00 & 2.88 & 57.50 & 2.88 & 57.50 & 2.45 & 46.25 & 2.88 & 58.31 \\
\hline Bagacay & 3.65 & 73.00 & 3.38 & 67.50 & 3.50 & 70.00 & 2.95 & 56.25 & 3.91 & 66.91 \\
\hline Junob & 3.85 & 77.00 & 3.13 & 62.50 & 3.38 & 67.50 & 3.56 & 71.56 & 3.56 & 71.40 \\
\hline Batinguel & 3.12 & 62.33 & 3.25 & 65.00 & 3.13 & 62.50 & 3.08 & 61.88 & 3.38 & 65.67 \\
\hline Cadawinonan & 3.57 & 71.33 & 3.13 & 62.50 & 3.63 & 72.50 & 3.03 & 58.28 & 3.09 & 63.06 \\
\hline Balugo & 2.85 & 57.00 & 2.38 & 47.50 & 2.38 & 47.50 & 2.04 & 38.44 & 2.13 & 46.64 \\
\hline Candau-ay & 3.48 & 69.67 & 3.25 & 65.00 & 3.63 & 72.50 & 3.43 & 68.13 & 3.59 & 69.13 \\
\hline PDRRMC & 4.00 & 80.00 & 3.75 & 75.00 & 3.00 & 60.00 & 3.11 & 62.81 & 4.00 & 73.32 \\
\hline DRRMC & 3.50 & 70.00 & 3.25 & 65.00 & 4.00 & 80.00 & 4.10 & 82.50 & 3.00 & 70.71 \\
\hline NGO & 2.70 & 54.00 & 3.00 & 60.00 & 2.38 & 47.50 & 2.69 & 53.57 & 2.34 & 53.46 \\
\hline OVERALL & 3.29 & 65.89 & 2.97 & 59.33 & 3.02 & 60.33 & 3.00 & 59.98 & 3.16 & 62.52 \\
\hline
\end{tabular}


Community-Based Flood Vulnerability Index for Urban Flooding: Understanding Social Vulnerabilities and Risks

LOCAL GOVERNMENT UNITS and NON-GOVERNMENTAL ORGANIZATION MATRIX (SUMMARY) ... continued

\begin{tabular}{|c|c|c|c|c|c|c|c|c|}
\hline \multirow{3}{*}{$\begin{array}{l}\text { Local Government } \\
\text { Unit/NGO }\end{array}$} & \multicolumn{6}{|c|}{ BENCHMARK } & & \\
\hline & \multicolumn{2}{|c|}{$\begin{array}{l}\text { F. Warning and } \\
\text { Evacuation }\end{array}$} & \multicolumn{2}{|c|}{ G. Emergency Response } & \multicolumn{2}{|c|}{ H. Disaster Recovery } & \multicolumn{2}{|c|}{ OVERALL } \\
\hline & Average & Percent & Average & Percent & Average & Percent & Average & Percent \\
\hline Poblacion 1 (Tinago) & 3.50 & 70.00 & 3.25 & 65.00 & 2.85 & 45.00 & 3.17 & 63.33 \\
\hline Poblacion 2 (Lukewright) & 3.00 & 60.00 & 2.63 & 52.50 & 1.92 & 30.33 & 2.43 & 48.67 \\
\hline Poblacion 8 & 2.30 & 46.00 & 2.75 & 55.00 & 2.35 & 37.00 & 2.57 & 51.31 \\
\hline Tabuc-tubig & 2.90 & 58.00 & 2.75 & 55.00 & 2.67 & 43.33 & 2.28 & 45.63 \\
\hline Calindagan & 5.00 & 100.00 & 5.00 & 100.00 & 4.77 & 75.33 & 4.51 & 90.25 \\
\hline Taclobo & 3.00 & 60.00 & 3.00 & 60.00 & 3.00 & 48.00 & 2.92 & 58.31 \\
\hline Bagacay & 3.60 & 72.00 & 3.25 & 65.00 & 2.53 & 40.67 & 3.35 & 66.91 \\
\hline Junob & 3.60 & 72.00 & 3.75 & 75.00 & 3.73 & 60.67 & 3.57 & 71.40 \\
\hline Batinguel & 3.50 & 70.00 & 3.38 & 67.50 & 3.45 & 55.00 & 3.28 & 65.67 \\
\hline Cadawinonan & 3.10 & 62.00 & 3.25 & 65.00 & 2.43 & 36.67 & 3.15 & 63.06 \\
\hline Balugo & 1.90 & 38.00 & 2.63 & 52.50 & 2.37 & 37.33 & 2.33 & 46.64 \\
\hline Candau-ay & 3.80 & 76.00 & 4.13 & 82.50 & 2.35 & 31.00 & 3.46 & 69.13 \\
\hline PDRRMC & 3.80 & 76.00 & 4.00 & 80.00 & 3.67 & 61.33 & 3.67 & 73.32 \\
\hline DRRMC & 3.40 & 68.00 & 4.00 & 80.00 & 3.03 & 48.67 & 3.54 & 70.71 \\
\hline NGO & 2.70 & 54.00 & 3.06 & 61.25 & 2.51 & 39.17 & 2.67 & 53.46 \\
\hline OVERALL & 3.27 & 65.47 & 3.39 & 67.75 & 2.91 & 45.97 & 3.13 & 62.52 \\
\hline
\end{tabular}


Community-Based Flood Vulnerability Index for Urban Flooding: Understanding

Social Vulnerabilities and Risks

\section{LOCAL GOVERNMENT UNITS and NON-GOVERNMENTAL ORGANIZATION MATRIX}

\begin{tabular}{|c|c|c|c|c|}
\hline \multirow[b]{2}{*}{ Benchmarks } & \multicolumn{4}{|c|}{ LOCAL GOVERNMENT UNIT } \\
\hline & $\begin{array}{l}\text { Poblacion } 1 \\
\text { (Tinago) }\end{array}$ & $\begin{array}{l}\text { Poblacion } 2 \\
\text { (Lukewright) }\end{array}$ & Poblacion 8 & Tabuc-tubig \\
\hline A. Governance & 3.23 & 2.30 & 3.00 & 2.58 \\
\hline $\begin{array}{l}\text { A1. How well are the community development policies, plans, } \\
\text { and programs implemented and monitored? }\end{array}$ & 3.00 & 2.50 & 3.00 & 3.00 \\
\hline A2. How accessible are the basic services to all sectors of society? & 3.67 & 2.50 & 3.50 & 3.42 \\
\hline A2a. Water & 3.50 & 3.00 & 4.00 & 3.50 \\
\hline A2b. Transportation & 3.50 & 2.00 & 3.50 & 3.00 \\
\hline A2c. Communication & 4.00 & 3.00 & 4.00 & 3.50 \\
\hline A2d. Security & 3.50 & 2.50 & 3.00 & 3.50 \\
\hline A2e. Health services & 3.50 & 2.00 & 3.50 & 3.50 \\
\hline A2f. Evacuation centers & 4.00 & 2.50 & 3.00 & 3.50 \\
\hline $\begin{array}{l}\text { A3. How well are the participatory collaboration mechanisms } \\
\text { among different sectors and various levels of government } \\
\text { used to manage for resilience? }\end{array}$ & 3.50 & 2.50 & 3.00 & 2.50 \\
\hline $\begin{array}{l}\text { A4. transparent, accountable, and available are the technical } \\
\text { and financial support mechanisms to support planned }\end{array}$ & 3.00 & 2.00 & 2.50 & 2.00 \\
\hline A.5 How good are we with our risk reduction efforts? & 3.00 & 2.00 & 3.00 & 2.00 \\
\hline $\begin{array}{l}\text { Percent Score } \\
\end{array}$ & 64.67 & 46.00 & 60.00 & 51.67 \\
\hline B. Society and Economy & 2.88 & 2.00 & 2.38 & 1.88 \\
\hline $\begin{array}{l}\text { B1. How well is our development policies and plans in building } \\
\text { social capital and skills for economic diversity and self- } \\
\text { reliance? }\end{array}$ & 3.00 & 2.00 & 2.50 & 2.00 \\
\hline $\begin{array}{l}\text { B2. How is the availability of diverse and environmentally } \\
\text { sustainable livelihood in the community? }\end{array}$ & 2.50 & 1.00 & 2.00 & 1.50 \\
\hline
\end{tabular}


Community-Based Flood Vulnerability Index for Urban Flooding: Understanding

Social Vulnerabilities and Risks

LOCAL GOVERNMENT UNITS and NON-GOVERNMENTAL ORGANIZATION MATRIX ... continued

\begin{tabular}{|c|c|c|c|c|}
\hline \multirow[b]{2}{*}{ Benchmarks } & \multicolumn{4}{|c|}{ LOCAL GOVERNMENT UNIT } \\
\hline & $\begin{array}{l}\text { Poblacion } 1 \\
\text { (Tinago) }\end{array}$ & $\begin{array}{l}\text { Poblacion } 2 \\
\text { (Lukewright) }\end{array}$ & Poblacion 8 & Tabuc-tubig \\
\hline $\begin{array}{l}\text { B3. How well is our technical and financial resources in promoting } \\
\text { self-reliant communities so it would have the capacity to } \\
\text { provide support to disaster-stricken areas? }\end{array}$ & 3.00 & 2.50 & 2.50 & 2.00 \\
\hline $\begin{array}{l}\text { B4. How well is our technical and financial resources in promoting } \\
\text { stable and robust economies, reduce vulnerability to hazards, } \\
\text { and aid in disaster recovery? }\end{array}$ & 3.00 & 2.50 & 2.50 & 2.00 \\
\hline $\begin{array}{r}\text { Percent Score } \\
\end{array}$ & $\mathbf{5 7 . 5 0}$ & 40.00 & 47.50 & 37.50 \\
\hline C. The River's Natural Resource and Natural Features' Management & 3.13 & 2.38 & 2.13 & 1.50 \\
\hline $\begin{array}{l}\text { C1. How well are our policies and plans implemented and } \\
\text { monitored to effectively manage our communities along the } \\
\text { river? }\end{array}$ & 3.50 & 2.50 & 2.50 & 2.50 \\
\hline $\begin{array}{l}\text { C2. How well are the protecting and maintaining our river and its } \\
\text { natural features to reduce risk from flood hazards? }\end{array}$ & 3.00 & 2.50 & 2.00 & 0.50 \\
\hline $\begin{array}{l}\text { C3. How actively engaged are our communities in planning and } \\
\text { and implementing river resource management activities? }\end{array}$ & 3.00 & 2.00 & 2.00 & 1.00 \\
\hline $\begin{array}{l}\text { C4. How well are our communities and local governments value } \\
\text { and invest in management and conservation to sustain our } \\
\text { river's natural resources and natural features? }\end{array}$ & 3.00 & 2.50 & 2.00 & 2.00 \\
\hline Percent Score & 62.50 & 47.50 & 42.50 & 30.00 \\
\hline
\end{tabular}


Community-Based Flood Vulnerability Index for Urban Flooding: Understanding Social Vulnerabilities and Risks

LOCAL GOVERNMENT UNITS and NON-GOVERNMENTAL ORGANIZATION MATRIX ... continued

\begin{tabular}{|c|c|c|c|c|}
\hline \multirow[b]{2}{*}{ Benchmarks } & \multicolumn{4}{|c|}{ LOCAL GOVERNMENT UNIT } \\
\hline & $\begin{array}{l}\text { Poblacion } 1 \\
\text { (Tinago) }\end{array}$ & $\begin{array}{l}\text { Poblacion } 2 \\
\text { (Lukewright) }\end{array}$ & Poblacion 8 & Tabuc-tubig \\
\hline D. Land Use and Management and Structural Design & 3.09 & 2.69 & 2.66 & 1.85 \\
\hline $\begin{array}{l}\text { D1. How well are the land use policies and building Standards that } \\
\text { incorporate measures to reduce risks from hazards and } \\
\text { protect sensitive habitats are established, monitored and } \\
\text { enforced? }\end{array}$ & 3.00 & 2.50 & 2.00 & 1.50 \\
\hline $\begin{array}{l}\text { D2. How well are the critical infrastructures constructed to } \\
\text { address risks from priority hazards? }\end{array}$ & 3.38 & 2.75 & 3.13 & 3.00 \\
\hline D2a. Increasing capacity of our drainage system & 4.00 & 2.50 & 3.50 & 3.00 \\
\hline $\begin{array}{l}\text { D2b. Good runoff volume control on open retention basin, } \\
\text { in-line basins, off-site basins, on site storage, dry ponds }\end{array}$ & 1.50 & 1.00 & 3.00 & 1.00 \\
\hline D2c. Very efficient dike safety system & 4.00 & 3.50 & 3.00 & 4.00 \\
\hline D2d. Very efficient bridge system & 4.00 & 4.00 & 3.00 & 4.00 \\
\hline $\begin{array}{l}\text { D3. How well are developers and communities incorporate risk } \\
\text { reduction into the location and design of structures? }\end{array}$ & 3.00 & 2.50 & 2.50 & 1.90 \\
\hline D3a. Existing spatial planning & 3.00 & 3.00 & 3.00 & 3.00 \\
\hline D3b. Flood risk adaptive to land use & 3.00 & 1.50 & 2.50 & 2.00 \\
\hline D3c. Building regulations & 3.00 & 2.50 & 2.50 & 2.00 \\
\hline D3d. Building codes & 3.00 & 2.50 & 2.50 & 1.50 \\
\hline D3e. Zoning ordinances & 3.00 & 3.00 & 2.00 & 1.00 \\
\hline $\begin{array}{l}\text { D4. How established is our education, outreach, and training } \\
\text { programs to improve compliance with land use policies and } \\
\text { building standards? }\end{array}$ & 3.00 & 3.00 & 3.00 & 1.00 \\
\hline Percent Score & 62.34 & 54.69 & 56.41 & 38.75 \\
\hline
\end{tabular}


Community-Based Flood Vulnerability Index for Urban Flooding: Understanding

Social Vulnerabilities and Risks

LOCAL GOVERNMENT UNITS and NON-GOVERNMENTAL ORGANIZATION MATRIX ... continued

\begin{tabular}{|c|c|c|c|c|}
\hline \multirow[b]{2}{*}{ Benchmarks } & \multicolumn{4}{|c|}{ LOCAL GOVERNMENT UNIT } \\
\hline & $\begin{array}{l}\text { Poblacion } 1 \\
\text { (Tinago) }\end{array}$ & $\begin{array}{l}\text { Poblacion } 2 \\
\text { (Lukewright) }\end{array}$ & Poblacion 8 & Tabuc-tubig \\
\hline E. Risk Knowledge & 3.41 & 2.56 & 2.97 & 2.13 \\
\hline $\begin{array}{l}\text { E1. How well are the flood hazard risk assessments completed } \\
\text { and routinely updated? }\end{array}$ & 3.50 & 2.50 & 3.00 & 1.50 \\
\hline $\begin{array}{l}\text { E2. How comprehensive is our flood hazard risk assessments } \\
\text { to incorporate risks to all elements of resilience? }\end{array}$ & 3.50 & 2.50 & 3.00 & 1.50 \\
\hline $\begin{array}{l}\text { E3. How well our community participates in the hazard risk } \\
\text { assessment process? }\end{array}$ & 3.00 & 2.50 & 3.00 & 2.50 \\
\hline $\begin{array}{l}\text { E4. How well are our information from risk assessment is } \\
\text { accessible and utilized by the community and government? }\end{array}$ & 3.63 & 2.75 & 2.88 & 3.00 \\
\hline E4a. Information drive-brochures & 3.50 & 3.00 & 2.50 & 2.50 \\
\hline E4b. Understanding the early warning systems & 3.50 & 3.00 & 2.50 & 3.50 \\
\hline E4c. Flood hazard maps & 3.50 & 2.00 & 2.50 & 2.50 \\
\hline E4d. Evacuation centers & 4.00 & 3.00 & 4.00 & 3.50 \\
\hline Percent Score & 68.13 & 51.25 & 59.38 & 42.50 \\
\hline F. Warning and Evacuation & 3.50 & 3.00 & 2.30 & 2.90 \\
\hline $\begin{array}{l}\text { F1. How well is our community warning and evacuation systems, } \\
\text { policies, plans, and procedures are in place and capable of } \\
\text { alerting vulnerable populations in a timely manner? }\end{array}$ & 4.00 & 3.00 & 2.50 & 2.00 \\
\hline $\begin{array}{l}\text { F2. How well is our community flood warning system in place } \\
\text { and maintained? }\end{array}$ & 3.50 & 3.00 & 2.00 & 3.50 \\
\hline $\begin{array}{l}\text { F3. How well is our community evacuation infrastructure in } \\
\text { place and maintained? }\end{array}$ & 4.00 & 3.00 & 2.50 & 3.00 \\
\hline
\end{tabular}


Community-Based Flood Vulnerability Index for Urban Flooding: Understanding

Social Vulnerabilities and Risks

LOCAL GOVERNMENT UNITS and NON-GOVERNMENTAL ORGANIZATION MATRIX ... continued

\begin{tabular}{|c|c|c|c|c|}
\hline \multirow[b]{2}{*}{ Benchmarks } & \multicolumn{4}{|c|}{ LOCAL GOVERNMENT UNIT } \\
\hline & $\begin{array}{l}\text { Poblacion } 1 \\
\text { (Tinago) }\end{array}$ & $\begin{array}{l}\text { Poblacion } 2 \\
\text { (Lukewright) }\end{array}$ & Poblacion 8 & Tabuc-tubig \\
\hline $\begin{array}{l}\text { F4. How prepared is the community to respond to hazard } \\
\text { warnings with appropriate actions? }\end{array}$ & 3.00 & 3.00 & 2.00 & 3.50 \\
\hline $\begin{array}{l}\text { F5. How is the availability of our technical (services offered) } \\
\text { and financial resources in maintaining and improving } \\
\text { warning and evacuation systems? }\end{array}$ & 3.00 & 3.00 & 2.50 & 2.50 \\
\hline $\begin{array}{l}\text { Percent Score } \\
\end{array}$ & 70.00 & 60.00 & 46.00 & 58.00 \\
\hline G. Emergency Response & 3.25 & 2.63 & 2.75 & 2.75 \\
\hline $\begin{array}{l}\text { G1. How established are our pre-defined roles and } \\
\text { responsibilities for immediate action at all levels. }\end{array}$ & 3.50 & 3.00 & 3.00 & 2.50 \\
\hline $\begin{array}{l}\text { G2. How is the availability of the basic emergency and } \\
\text { relief services? }\end{array}$ & 3.50 & 3.00 & 3.00 & 3.00 \\
\hline $\begin{array}{l}\text { G3. How well are our preparedness activities (drills and } \\
\text { simulations) are ongoing to train and educate responders? }\end{array}$ & 3.00 & 2.00 & 2.00 & 2.50 \\
\hline $\begin{array}{l}\text { G4. How well are the organizations and volunteers are in } \\
\text { placed with technical (services offered) and financial } \\
\text { resources to support emergency response activities? }\end{array}$ & 3.00 & 2.50 & 3.00 & 3.00 \\
\hline Percent Score & 65.00 & 52.50 & 55.00 & 55.00 \\
\hline H. Disaster Recovery & 2.85 & 1.92 & 2.35 & 2.67 \\
\hline $\begin{array}{l}\text { H1. How well is our disaster recovery plan pre-established that } \\
\text { addresses economic, environmental, and social concerns } \\
\text { of the community? }\end{array}$ & 3.00 & 2.50 & 2.50 & 3.00 \\
\hline $\begin{array}{l}\text { H2. How well is our disaster recovery process is monitored, } \\
\text { and improved at periodic intervals? }\end{array}$ & 3.00 & 2.00 & 2.50 & 3.00 \\
\hline
\end{tabular}


Community-Based Flood Vulnerability Index for Urban Flooding: Understanding Social Vulnerabilities and Risks

LOCAL GOVERNMENT UNITS and NON-GOVERNMENTAL ORGANIZATION MATRIX ... continued

\begin{tabular}{|c|c|c|c|c|}
\hline \multirow[b]{2}{*}{ Benchmarks } & \multicolumn{4}{|c|}{ LOCAL GOVERNMENT UNIT } \\
\hline & $\begin{array}{c}\text { Poblacion } 1 \\
\text { (Tinago) }\end{array}$ & $\begin{array}{l}\text { Poblacion } 2 \\
\text { (Lukewright) }\end{array}$ & Poblacion 8 & Tabuc-tubig \\
\hline $\begin{array}{l}\text { H3. How well is coordination mechanisms at international, } \\
\text { national, and local levels are pre-established for disaster } \\
\text { recovery? }\end{array}$ & 3.00 & 2.00 & 2.50 & 2.50 \\
\hline $\begin{array}{l}\text { H4. How is the availability of our technical (services offered) } \\
\text { and financial resources to support the recovery process? }\end{array}$ & 2.75 & 2.08 & 2.25 & 2.33 \\
\hline H4a. Insurance scheme & 1.50 & 2.00 & 1.50 & 3.00 \\
\hline H4b. Damage assessment facilitating claim procession & 3.00 & 2.50 & 2.50 & 2.00 \\
\hline H4c. Reconstruction & 3.00 & 2.00 & 2.00 & 2.00 \\
\hline H4d. Charitable funds & 3.00 & 2.00 & 2.50 & 2.00 \\
\hline H4e. Social therapeutic measures & 3.00 & 2.00 & 2.50 & 2.00 \\
\hline H4f. Rescue equipment and tools & 3.00 & 2.00 & 2.50 & 3.00 \\
\hline $\begin{array}{l}\text { H5. How good are we in conducting traumatic/or psychological } \\
\text { stress debriefings? }\end{array}$ & 2.50 & 1.00 & 2.00 & 2.50 \\
\hline Percent Score & 45.00 & 30.33 & 37.00 & 43.33 \\
\hline AVERAGE RATING (RAW) & 3.17 & 2.43 & 2.57 & 2.28 \\
\hline OVERALL ALL PERCENT SCORE & 63.33 & 48.67 & 51.31 & 45.63 \\
\hline
\end{tabular}


Community-Based Flood Vulnerability Index for Urban Flooding: Understanding

Social Vulnerabilities and Risks

LOCAL GOVERNMENT UNITS and NON-GOVERNMENTAL ORGANIZATION MATRIX ... continued

\begin{tabular}{|c|c|c|c|c|}
\hline \multirow{2}{*}{ Benchmarks } & \multicolumn{4}{|c|}{ LOCAL GOVERNMENT UNIT } \\
\hline & Calindagan & Taclobo & Bagacay & Junob \\
\hline A. Governance & 4.33 & 3.25 & 3.65 & 3.85 \\
\hline $\begin{array}{l}\text { A1. How well are the community development policies, plans, } \\
\text { and programs implemented and monitored? }\end{array}$ & 4.00 & 3.50 & 2.50 & 3.50 \\
\hline A2. How accessible are the basic services to all sectors of society? & 4.67 & 3.75 & 3.25 & 3.75 \\
\hline A2a. Water & 4.00 & 4.00 & 3.00 & 3.50 \\
\hline A2b. Transportation & 4.00 & 4.00 & 4.00 & 4.00 \\
\hline A2c. Communication & 5.00 & 4.00 & 3.00 & 4.00 \\
\hline A2d. Security & 5.00 & 3.50 & 3.00 & 3.50 \\
\hline A2e. Health services & 5.00 & 3.50 & 4.00 & 4.00 \\
\hline A2f. Evacuation centers & 5.00 & 3.50 & 2.50 & 3.50 \\
\hline $\begin{array}{l}\text { A3. How well are the participatory collaboration mechanisms } \\
\text { among different sectors and various levels of government } \\
\text { used to manage for resilience? }\end{array}$ & 4.00 & 3.00 & 3.50 & 4.00 \\
\hline $\begin{array}{l}\text { A4. transparent, accountable, and available are the technical } \\
\text { and financial support mechanisms to support planned }\end{array}$ & 4.00 & 3.00 & 4.00 & 4.00 \\
\hline A.5 How good are we with our risk reduction efforts? & 5.00 & 3.00 & 5.00 & 4.00 \\
\hline $\begin{array}{l}\text { Percent Score } \\
\end{array}$ & 86.67 & 65.00 & 73.00 & 77.00 \\
\hline B. Society and Economy & 4.00 & 2.88 & 3.38 & 3.13 \\
\hline $\begin{array}{l}\text { B1. How well is our development policies and plans in building } \\
\text { social capital and skills for economic diversity and self- } \\
\text { reliance? }\end{array}$ & 4.00 & 3.00 & 3.00 & 3.00 \\
\hline $\begin{array}{l}\text { B2. How is the availability of diverse and environmentally } \\
\text { sustainable livelihood in the community? }\end{array}$ & 4.00 & 2.50 & 3.00 & 3.00 \\
\hline
\end{tabular}


Community-Based Flood Vulnerability Index for Urban Flooding: Understanding

Social Vulnerabilities and Risks

LOCAL GOVERNMENT UNITS and NON-GOVERNMENTAL ORGANIZATION MATRIX ... continued

\begin{tabular}{|c|c|c|c|c|}
\hline \multirow{2}{*}{ Benchmarks } & \multicolumn{4}{|c|}{ LOCAL GOVERNMENT UNIT } \\
\hline & Calindagan & Taclobo & Bagacay & Junob \\
\hline $\begin{array}{l}\text { B3. How well is our technical and financial resources in promoting } \\
\text { self-reliant communities so it would have the capacity to } \\
\text { provide support to disaster-stricken areas? }\end{array}$ & 4.00 & 3.00 & 4.00 & 3.00 \\
\hline $\begin{array}{l}\text { B4. How well is our technical and financial resources in promoting } \\
\text { stable and robust economies, reduce vulnerability to hazards, } \\
\text { and aid in disaster recovery? }\end{array}$ & 4.00 & 3.00 & 3.50 & 3.50 \\
\hline Percent Score & 80.00 & 57.50 & 67.50 & 62.50 \\
\hline C. The River's Natural Resource and Natural Features' Management & 4.25 & 2.88 & 3.50 & 3.38 \\
\hline $\begin{array}{l}\text { C1. How well are our policies and plans implemented and } \\
\text { monitored to effectively manage our communities along the } \\
\text { river? }\end{array}$ & 5.00 & 2.50 & 4.00 & 3.50 \\
\hline $\begin{array}{l}\text { C2. How well are the protecting and maintaining our river and its } \\
\text { natural features to reduce risk from flood hazards? }\end{array}$ & 4.00 & 3.00 & 3.50 & 3.00 \\
\hline $\begin{array}{l}\text { C3. How actively engaged are our communities in planning and } \\
\text { and implementing river resource management activities? }\end{array}$ & 4.00 & 3.00 & 3.50 & 3.50 \\
\hline $\begin{array}{l}\text { C4. How well are our communities and local governments value } \\
\text { and invest in management and conservation to sustain our } \\
\text { river's natural resources and natural features? }\end{array}$ & 4.00 & 3.00 & 3.00 & 3.50 \\
\hline Percent Score & 85.00 & 57.50 & 70.00 & 67.50 \\
\hline
\end{tabular}


LOCAL GOVERNMENT UNITS and NON-GOVERNMENTAL ORGANIZATION MATRIX ... continued

\begin{tabular}{|c|c|c|c|c|}
\hline \multirow{2}{*}{ Benchmarks } & \multicolumn{4}{|c|}{ LOCAL GOVERNMENT UNIT } \\
\hline & Calindagan & Taclobo & Bagacay & Junob \\
\hline D. Land Use and Management and Structural Design & 4.31 & 2.45 & 2.95 & 3.56 \\
\hline $\begin{array}{l}\text { D1. How well are the land use policies and building Standards that } \\
\text { incorporate measures to reduce risks from hazards and } \\
\text { protect sensitive habitats are established, monitored and } \\
\text { enforced? }\end{array}$ & 4.00 & 3.00 & 3.50 & 3.50 \\
\hline $\begin{array}{l}\text { D2. How well are the critical infrastructures constructed to } \\
\text { address risks from priority hazards? }\end{array}$ & 4.25 & 2.50 & 2.50 & 3.75 \\
\hline D2a. Increasing capacity of our drainage system & 4.00 & 3.00 & 2.50 & 4.00 \\
\hline $\begin{array}{l}\text { D2b. Good runoff volume control on open retention basin, } \\
\text { in-line basins, off-site basins, on site storage, dry ponds }\end{array}$ & 4.00 & 3.00 & 2.50 & 3.50 \\
\hline D2c. Very efficient dike safety system & 4.00 & 2.00 & 3.00 & 4.00 \\
\hline D2d. Very efficient bridge system & 5.00 & 2.00 & 2.00 & 3.50 \\
\hline $\begin{array}{l}\text { D3. How well are developers and communities incorporate risk } \\
\text { reduction into the location and design of structures? }\end{array}$ & 4.00 & 2.80 & 2.80 & 3.50 \\
\hline D3a. Existing spatial planning & 4.00 & 3.00 & 3.50 & 4.00 \\
\hline D3b. Flood risk adaptive to land use & 4.00 & 2.50 & 3.00 & 3.50 \\
\hline D3c. Building regulations & 4.00 & 3.50 & 3.00 & 3.00 \\
\hline D3d. Building codes & 4.00 & 2.50 & 2.50 & 3.00 \\
\hline D3e. Zoning ordinances & 4.00 & 2.50 & 2.00 & 4.00 \\
\hline $\begin{array}{l}\text { D4. How established is our education, outreach, and training } \\
\text { programs to improve compliance with land use policies and } \\
\text { building standards? }\end{array}$ & 5.00 & 1.50 & 3.00 & 3.50 \\
\hline Percent Score & 87.81 & 46.25 & 56.25 & 71.56 \\
\hline
\end{tabular}


Community-Based Flood Vulnerability Index for Urban Flooding: Understanding

Social Vulnerabilities and Risks

LOCAL GOVERNMENT UNITS and NON-GOVERNMENTAL ORGANIZATION MATRIX ... continued

\begin{tabular}{|c|c|c|c|c|}
\hline \multirow{2}{*}{ Benchmarks } & \multicolumn{4}{|c|}{ LOCAL GOVERNMENT UNIT } \\
\hline & Calindagan & Taclobo & Bagacay & Junob \\
\hline E. Risk Knowledge & 4.44 & 2.88 & 3.91 & 3.56 \\
\hline $\begin{array}{l}\text { E1. How well are the flood hazard risk assessments completed } \\
\text { and routinely updated? }\end{array}$ & 5.00 & 3.00 & 4.00 & 3.50 \\
\hline $\begin{array}{l}\text { E2. How comprehensive is our flood hazard risk assessments } \\
\text { to incorporate risks to all elements of resilience? }\end{array}$ & 4.00 & 3.00 & 3.50 & 3.50 \\
\hline $\begin{array}{l}\text { E3. How well our community participates in the hazard risk } \\
\text { assessment process? }\end{array}$ & 4.00 & 3.00 & 4.50 & 3.50 \\
\hline $\begin{array}{l}\text { E4. How well are our information from risk assessment is } \\
\text { accessible and utilized by the community and government? }\end{array}$ & 4.75 & 2.50 & 3.63 & 3.75 \\
\hline E4a. Information drive-brochures & 5.00 & 0.00 & 3.50 & 3.50 \\
\hline E4b. Understanding the early warning systems & 5.00 & 3.00 & 4.00 & 4.00 \\
\hline E4c. Flood hazard maps & 4.00 & 3.50 & 4.50 & 4.00 \\
\hline E4d. Evacuation centers & 5.00 & 3.50 & 2.50 & 3.50 \\
\hline Percent Score & 88.75 & $\mathbf{5 7 . 5 0}$ & 78.13 & 71.25 \\
\hline F. Warning and Evacuation & 5.00 & 3.00 & 3.60 & 3.60 \\
\hline $\begin{array}{l}\text { F1. How well is our community warning and evacuation systems, } \\
\text { policies, plans, and procedures are in place and capable of } \\
\text { alerting vulnerable populations in a timely manner? }\end{array}$ & 5.00 & 3.00 & 3.50 & 4.00 \\
\hline $\begin{array}{l}\text { F2. How well is our community flood warning system in place } \\
\text { and maintained? }\end{array}$ & 5.00 & 3.00 & 3.50 & 3.50 \\
\hline $\begin{array}{l}\text { F3. How well is our community evacuation infrastructure in } \\
\text { place and maintained? }\end{array}$ & 5.00 & 3.00 & 3.50 & 3.00 \\
\hline
\end{tabular}


Community-Based Flood Vulnerability Index for Urban Flooding: Understanding Social Vulnerabilities and Risks

LOCAL GOVERNMENT UNITS and NON-GOVERNMENTAL ORGANIZATION MATRIX ... continued

\begin{tabular}{|c|c|c|c|c|}
\hline \multirow{2}{*}{ Benchmarks } & \multicolumn{4}{|c|}{ LOCAL GOVERNMENT UNIT } \\
\hline & Calindagan & Taclobo & Bagacay & Junob \\
\hline $\begin{array}{l}\text { F4. How prepared is the community to respond to hazard } \\
\text { warnings with appropriate actions? }\end{array}$ & 5.00 & 3.00 & 4.00 & 4.00 \\
\hline $\begin{array}{l}\text { F5. How is the availability of our technical (services offered) } \\
\text { and financial resources in maintaining and improving } \\
\text { warning and evacuation systems? }\end{array}$ & 5.00 & 3.00 & 3.50 & 3.50 \\
\hline $\begin{array}{l}\text { Percent Score } \\
\end{array}$ & 100.00 & 60.00 & 72.00 & 72.00 \\
\hline G. Emergency Response & 5.00 & 3.00 & 3.25 & 3.75 \\
\hline $\begin{array}{l}\text { G1. How established are our pre-defined roles and } \\
\text { responsibilities for immediate action at all levels. }\end{array}$ & 5.00 & 3.00 & 3.00 & 4.00 \\
\hline $\begin{array}{l}\text { G2. How is the availability of the basic emergency and } \\
\text { relief services? }\end{array}$ & 5.00 & 3.00 & 3.50 & 3.50 \\
\hline $\begin{array}{l}\text { G3. How well are our preparedness activities (drills and } \\
\text { simulations) are ongoing to train and educate responders? }\end{array}$ & 5.00 & 3.00 & 4.00 & 4.00 \\
\hline $\begin{array}{l}\text { G4. How well are the organizations and volunteers are in } \\
\text { placed with technical (services offered) and financial } \\
\text { resources to support emergency response activities? }\end{array}$ & 5.00 & 3.00 & 2.50 & 3.50 \\
\hline Percent Score & 100.00 & 60.00 & 65.00 & 75.00 \\
\hline H. Disaster Recovery & 4.77 & 3.00 & 2.53 & 3.73 \\
\hline $\begin{array}{l}\text { H1. How well is our disaster recovery plan pre-established that } \\
\text { addresses economic, environmental, and social concerns } \\
\text { of the community? }\end{array}$ & 5.00 & 3.00 & 2.50 & 3.50 \\
\hline $\begin{array}{l}\text { H2. How well is our disaster recovery process is monitored, } \\
\text { and improved at periodic intervals? }\end{array}$ & 5.00 & 3.00 & 2.50 & 4.00 \\
\hline
\end{tabular}


Community-Based Flood Vulnerability Index for Urban Flooding: Understanding

Social Vulnerabilities and Risks

LOCAL GOVERNMENT UNITS and NON-GOVERNMENTAL ORGANIZATION MATRIX ... continued

\begin{tabular}{|c|c|c|c|c|}
\hline \multirow{2}{*}{ Benchmarks } & \multicolumn{4}{|c|}{ LOCAL GOVERNMENT UNIT } \\
\hline & Calindagan & Taclobo & Bagacay & Junob \\
\hline $\begin{array}{l}\text { H3. How well is coordination mechanisms at international, } \\
\text { national, and local levels are pre-established for disaster } \\
\text { recovery? }\end{array}$ & 5.00 & 3.00 & 2.50 & 3.50 \\
\hline $\begin{array}{l}\text { H4. How is the availability of our technical (services offered) } \\
\text { and financial resources to support the recovery process? }\end{array}$ & 4.83 & 3.00 & 2.67 & 3.67 \\
\hline H4a. Insurance scheme & 5.00 & 3.00 & 2.50 & 2.00 \\
\hline H4b. Damage assessment facilitating claim procession & 5.00 & 3.00 & 2.50 & 4.00 \\
\hline H4c. Reconstruction & 4.00 & 3.00 & 2.50 & 4.00 \\
\hline H4d. Charitable funds & 5.00 & 3.00 & 2.50 & 4.00 \\
\hline H4e. Social therapeutic measures & 5.00 & 3.00 & 3.00 & 4.00 \\
\hline H4f. Rescue equipment and tools & 5.00 & 3.00 & 3.00 & 4.00 \\
\hline $\begin{array}{l}\text { H5. How good are we in conducting traumatic/or psychological } \\
\text { stress debriefings? }\end{array}$ & 4.00 & 3.00 & 2.50 & 4.00 \\
\hline Percent Score & 75.33 & 48.00 & 40.67 & 60.67 \\
\hline AVERAGE RATING (RAW) & 4.51 & 2.92 & 3.35 & 3.57 \\
\hline OVERALL ALL PERCENT SCORE & 90.25 & 58.31 & 66.91 & 71.40 \\
\hline
\end{tabular}


Community-Based Flood Vulnerability Index for Urban Flooding: Understanding

Social Vulnerabilities and Risks

LOCAL GOVERNMENT UNITS and NON-GOVERNMENTAL ORGANIZATION MATRIX ... continued

\begin{tabular}{|c|c|c|c|c|}
\hline \multirow{2}{*}{ Benchmarks } & \multicolumn{4}{|c|}{ LOCAL GOVERNMENT UNIT } \\
\hline & Batinguel & Cadawinonan & Balugo & Candau-ay \\
\hline A. Governance & 3.12 & 3.57 & 2.85 & 3.48 \\
\hline $\begin{array}{l}\text { A1. How well are the community development policies, plans, } \\
\text { and programs implemented and monitored? }\end{array}$ & 3.00 & 3.50 & 3.50 & 3.50 \\
\hline A2. How accessible are the basic services to all sectors of society? & 3.58 & 3.83 & 3.25 & 3.92 \\
\hline A2a. Water & 4.00 & 4.00 & 3.50 & 3.50 \\
\hline A2b. Transportation & 4.00 & 4.00 & 3.50 & 4.50 \\
\hline A2c. Communication & 3.50 & 4.00 & 3.50 & 4.50 \\
\hline A2d. Security & 3.00 & 3.50 & 3.00 & 3.50 \\
\hline A2e. Health services & 3.50 & 3.50 & 3.50 & 4.00 \\
\hline A2f. Evacuation centers & 3.50 & 4.00 & 2.50 & 3.50 \\
\hline $\begin{array}{l}\text { A3. How well are the participatory collaboration mechanisms } \\
\text { among different sectors and various levels of government } \\
\text { used to manage for resilience? }\end{array}$ & 3.00 & 3.50 & 3.00 & 3.50 \\
\hline $\begin{array}{l}\text { A4. transparent, accountable, and available are the technical } \\
\text { and financial support mechanisms to support planned }\end{array}$ & 3.00 & 3.50 & 2.00 & 3.00 \\
\hline A.5 How good are we with our risk reduction efforts? & 3.00 & 3.50 & 2.50 & 3.50 \\
\hline Percent Score & 62.33 & 71.33 & $\mathbf{5 7 . 0 0}$ & 69.67 \\
\hline B. Society and Economy & 3.25 & 3.13 & 2.38 & 3.25 \\
\hline $\begin{array}{l}\text { B1. How well is our development policies and plans in building } \\
\text { social capital and skills for economic diversity and self- } \\
\text { reliance? }\end{array}$ & 3.00 & 3.50 & 2.50 & 3.00 \\
\hline $\begin{array}{l}\text { B2. How is the availability of diverse and environmentally } \\
\text { sustainable livelihood in the community? }\end{array}$ & 3.00 & 2.50 & 2.50 & 3.50 \\
\hline
\end{tabular}


LOCAL GOVERNMENT UNITS and NON-GOVERNMENTAL ORGANIZATION MATRIX ... continued

\begin{tabular}{|c|c|c|c|c|}
\hline \multirow{2}{*}{ Benchmarks } & \multicolumn{4}{|c|}{ LOCAL GOVERNMENT UNIT } \\
\hline & Batinguel & Cadawinonan & Balugo & Candau-ay \\
\hline $\begin{array}{l}\text { B3. How well is our technical and financial resources in promoting } \\
\text { self-reliant communities so it would have the capacity to } \\
\text { provide support to disaster-stricken areas? }\end{array}$ & 3.50 & 3.50 & 2.00 & 3.00 \\
\hline $\begin{array}{l}\text { B4. How well is our technical and financial resources in promoting } \\
\text { stable and robust economies, reduce vulnerability to hazards, } \\
\text { and aid in disaster recovery? }\end{array}$ & 3.50 & 3.00 & 2.50 & 3.50 \\
\hline $\begin{array}{l}\text { Percent Score } \\
\end{array}$ & 65.00 & 62.50 & 47.50 & 65.00 \\
\hline C. The River's Natural Resource and Natural Features' Management & 3.13 & 3.63 & 2.38 & 3.63 \\
\hline $\begin{array}{l}\text { C1. How well are our policies and plans implemented and } \\
\text { monitored to effectively manage our communities along the } \\
\text { river? }\end{array}$ & 3.50 & 3.50 & 3.00 & 4.00 \\
\hline $\begin{array}{l}\text { C2. How well are the protecting and maintaining our river and its } \\
\text { natural features to reduce risk from flood hazards? }\end{array}$ & 3.00 & 3.50 & 3.00 & 3.50 \\
\hline $\begin{array}{l}\text { C3. How actively engaged are our communities in planning and } \\
\text { and implementing river resource management activities? }\end{array}$ & 3.00 & 4.00 & 1.50 & 3.50 \\
\hline $\begin{array}{l}\text { C4. How well are our communities and local governments value } \\
\text { and invest in management and conservation to sustain our } \\
\text { river's natural resources and natural features? }\end{array}$ & 3.00 & 3.50 & 2.00 & 3.50 \\
\hline $\begin{array}{l}\text { Percent Score } \\
\end{array}$ & 62.50 & 72.50 & 47.50 & 72.50 \\
\hline
\end{tabular}


LOCAL GOVERNMENT UNITS and NON-GOVERNMENTAL ORGANIZATION MATRIX ... continued

\begin{tabular}{|c|c|c|c|c|}
\hline \multirow{2}{*}{ Benchmarks } & \multicolumn{4}{|c|}{ LOCAL GOVERNMENT UNIT } \\
\hline & Batinguel & Cadawinonan & Balugo & Candau-ay \\
\hline D. Land Use and Management and Structural Design & 3.08 & 3.03 & 2.04 & 3.43 \\
\hline $\begin{array}{l}\text { D1. How well are the land use policies and building Standards that } \\
\text { incorporate measures to reduce risks from hazards and } \\
\text { protect sensitive habitats are established, monitored and } \\
\text { enforced? }\end{array}$ & 3.00 & 3.50 & 2.50 & 3.50 \\
\hline $\begin{array}{l}\text { D2. How well are the critical infrastructures constructed to } \\
\text { address risks from priority hazards? }\end{array}$ & 3.00 & 2.63 & 2.25 & 3.00 \\
\hline D2a. Increasing capacity of our drainage system & 3.50 & 3.00 & 3.00 & 4.00 \\
\hline $\begin{array}{l}\text { D2b. Good runoff volume control on open retention basin, } \\
\text { in-line basins, off-site basins, on site storage, dry ponds }\end{array}$ & 2.50 & 3.00 & 0.00 & 2.00 \\
\hline D2c. Very efficient dike safety system & 3.00 & 2.00 & 3.00 & 3.00 \\
\hline D2d. Very efficient bridge system & 3.00 & 2.50 & 3.00 & 3.00 \\
\hline $\begin{array}{l}\text { D3. How well are developers and communities incorporate risk } \\
\text { reduction into the location and design of structures? }\end{array}$ & 3.30 & 3.00 & 1.40 & 3.20 \\
\hline D3a. Existing spatial planning & 3.00 & 3.00 & 2.00 & 3.00 \\
\hline D3b. Flood risk adaptive to land use & 3.00 & 2.50 & 2.00 & 3.50 \\
\hline D3c. Building regulations & 3.50 & 3.00 & 1.00 & 3.50 \\
\hline D3d. Building codes & 3.50 & 3.00 & 1.00 & 3.00 \\
\hline D3e. Zoning ordinances & 3.50 & 3.50 & 1.00 & 3.00 \\
\hline $\begin{array}{l}\text { D4. How established is our education, outreach, and training } \\
\text { programs to improve compliance with land use policies and } \\
\text { building standards? }\end{array}$ & 3.00 & 3.00 & 2.00 & 4.00 \\
\hline Percent Score & 61.88 & 58.28 & 38.44 & 68.13 \\
\hline
\end{tabular}


Community-Based Flood Vulnerability Index for Urban Flooding: Understanding

Social Vulnerabilities and Risks

LOCAL GOVERNMENT UNITS and NON-GOVERNMENTAL ORGANIZATION MATRIX ... continued

\begin{tabular}{|c|c|c|c|c|}
\hline \multirow{2}{*}{ Benchmarks } & \multicolumn{4}{|c|}{ LOCAL GOVERNMENT UNIT } \\
\hline & Batinguel & Cadawinonan & Balugo & Candau-ay \\
\hline E. Risk Knowledge & 3.38 & 3.09 & 2.13 & 3.59 \\
\hline $\begin{array}{l}\text { E1. How well are the flood hazard risk assessments completed } \\
\text { and routinely updated? }\end{array}$ & 3.50 & 3.00 & 2.00 & 3.50 \\
\hline $\begin{array}{l}\text { E2. How comprehensive is our flood hazard risk assessments } \\
\text { to incorporate risks to all elements of resilience? }\end{array}$ & 3.00 & 3.00 & 2.00 & 3.00 \\
\hline $\begin{array}{l}\text { E3. How well our community participates in the hazard risk } \\
\text { assessment process? }\end{array}$ & 3.50 & 3.00 & 2.00 & 4.50 \\
\hline $\begin{array}{l}\text { E4. How well are our information from risk assessment is } \\
\text { accessible and utilized by the community and government? }\end{array}$ & 3.50 & 3.38 & 2.50 & 3.38 \\
\hline E4a. Information drive-brochures & 4.00 & 3.50 & 2.50 & 3.00 \\
\hline E4b. Understanding the early warning systems & 3.50 & 3.00 & 2.50 & 3.50 \\
\hline E4c. Flood hazard maps & 3.00 & 3.00 & 3.00 & 3.50 \\
\hline E4d. Evacuation centers & 3.50 & 4.00 & 2.00 & 3.50 \\
\hline Percent Score & 67.50 & 61.88 & 42.50 & 71.88 \\
\hline F. Warning and Evacuation & 3.50 & 3.10 & 1.90 & 3.80 \\
\hline $\begin{array}{l}\text { F1. How well is our community warning and evacuation systems, } \\
\text { policies, plans, and procedures are in place and capable of } \\
\text { alerting vulnerable populations in a timely manner? }\end{array}$ & 3.50 & 3.00 & 3.00 & 4.50 \\
\hline $\begin{array}{l}\text { F2. How well is our community flood warning system in place } \\
\text { and maintained? }\end{array}$ & 3.50 & 2.50 & 1.50 & 4.00 \\
\hline $\begin{array}{l}\text { F3. How well is our community evacuation infrastructure in } \\
\text { place and maintained? }\end{array}$ & 4.00 & 3.50 & 2.00 & 3.50 \\
\hline
\end{tabular}


Community-Based Flood Vulnerability Index for Urban Flooding: Understanding

Social Vulnerabilities and Risks

LOCAL GOVERNMENT UNITS and NON-GOVERNMENTAL ORGANIZATION MATRIX ... continued

\begin{tabular}{|c|c|c|c|c|}
\hline \multirow{2}{*}{ Benchmarks } & \multicolumn{4}{|c|}{ LOCAL GOVERNMENT UNIT } \\
\hline & Batinguel & Cadawinonan & Balugo & Candau-ay \\
\hline $\begin{array}{l}\text { F4. How prepared is the community to respond to hazard } \\
\text { warnings with appropriate actions? }\end{array}$ & 3.50 & 3.50 & 1.50 & 3.50 \\
\hline $\begin{array}{l}\text { F5. How is the availability of our technical (services offered) } \\
\text { and financial resources in maintaining and improving } \\
\text { warning and evacuation systems? }\end{array}$ & 3.00 & 3.00 & 1.50 & 3.50 \\
\hline Percent Score & 70.00 & 62.00 & 38.00 & 76.00 \\
\hline G. Emergency Response & 3.38 & 3.25 & 2.63 & 4.13 \\
\hline $\begin{array}{l}\text { G1. How established are our pre-defined roles and } \\
\text { responsibilities for immediate action at all levels. }\end{array}$ & 3.00 & 3.50 & 2.50 & 4.00 \\
\hline $\begin{array}{l}\text { G2. How is the availability of the basic emergency and } \\
\text { relief services? }\end{array}$ & 3.50 & 3.50 & 3.00 & 4.00 \\
\hline $\begin{array}{l}\text { G3. How well are our preparedness activities (drills and } \\
\text { simulations) are ongoing to train and educate responders? }\end{array}$ & 3.50 & 2.50 & 2.50 & 4.50 \\
\hline $\begin{array}{l}\text { G4. How well are the organizations and volunteers are in } \\
\text { placed with technical (services offered) and financial } \\
\text { resources to support emergency response activities? }\end{array}$ & 3.50 & 3.50 & 2.50 & 4.00 \\
\hline $\begin{array}{l}\text { Percent Score } \\
\end{array}$ & 67.50 & 65.00 & 52.50 & 82.50 \\
\hline H. Disaster Recovery & 3.45 & 2.43 & 2.37 & 2.35 \\
\hline $\begin{array}{l}\text { H1. How well is our disaster recovery plan pre-established that } \\
\text { addresses economic, environmental, and social concerns } \\
\text { of the community? }\end{array}$ & 3.50 & 2.50 & 2.50 & 3.50 \\
\hline $\begin{array}{l}\text { H2. How well is our disaster recovery process is monitored, } \\
\text { and improved at periodic intervals? }\end{array}$ & 3.00 & 2.50 & 2.00 & 3.50 \\
\hline
\end{tabular}


Community-Based Flood Vulnerability Index for Urban Flooding: Understanding

Social Vulnerabilities and Risks

LOCAL GOVERNMENT UNITS and NON-GOVERNMENTAL ORGANIZATION MATRIX ... continued

\begin{tabular}{|c|c|c|c|c|}
\hline \multirow{2}{*}{ Benchmarks } & \multicolumn{4}{|c|}{ LOCAL GOVERNMENT UNIT } \\
\hline & Batinguel & Cadawinonan & Balugo & Candau-ay \\
\hline $\begin{array}{l}\text { H3. How well is coordination mechanisms at international, } \\
\text { national, and local levels are pre-established for disaster } \\
\text { recovery? }\end{array}$ & 3.50 & 3.00 & 2.50 & 4.00 \\
\hline $\begin{array}{l}\text { H4. How is the availability of our technical (services offered) } \\
\text { and financial resources to support the recovery process? }\end{array}$ & 3.75 & 2.17 & 2.33 & 0.75 \\
\hline H4a. Insurance scheme & 3.50 & 1.00 & 2.50 & 0.00 \\
\hline H4b. Damage assessment facilitating claim procession & 3.50 & 1.50 & 2.50 & 0.00 \\
\hline H4c. Reconstruction & 4.00 & 2.50 & 2.00 & 0.00 \\
\hline H4d. Charitable funds & 4.00 & 3.00 & 2.50 & 0.00 \\
\hline H4e. Social therapeutic measures & 3.50 & 2.50 & 2.00 & 1.50 \\
\hline H4f. Rescue equipment and tools & 4.00 & 2.50 & 2.50 & 3.00 \\
\hline $\begin{array}{l}\text { H5. How good are we in conducting traumatic/or psychological } \\
\text { stress debriefings? }\end{array}$ & 3.50 & 2.00 & 2.50 & 0.00 \\
\hline $\begin{array}{l}\text { Percent Score } \\
\end{array}$ & 55.00 & 36.67 & 37.33 & 31.00 \\
\hline AVERAGE RATING (RAW) & 3.28 & 3.15 & 2.33 & 3.46 \\
\hline OVERALL ALL PERCENT SCORE & 65.67 & 63.06 & 46.64 & 69.13 \\
\hline
\end{tabular}


Community-Based Flood Vulnerability Index for Urban Flooding: Understanding

Social Vulnerabilities and Risks

LOCAL GOVERNMENT UNITS and NON-GOVERNMENTAL ORGANIZATION MATRIX ... continued

\begin{tabular}{|c|c|c|c|c|}
\hline \multirow{2}{*}{ Benchmarks } & \multicolumn{3}{|c|}{ LGU/NON-GOVERNMENTAL ORGANIZATION } & \multirow{2}{*}{ Overall } \\
\hline & PDRRMC & DRRMC & NGO & \\
\hline A. Governance & 4.00 & 3.50 & 2.70 & 3.29 \\
\hline $\begin{array}{l}\text { A1. How well are the community development policies, plans, } \\
\text { and programs implemented and monitored? }\end{array}$ & 4.00 & 3.00 & 2.50 & 3.20 \\
\hline A2. How accessible are the basic services to all sectors of society? & 4.00 & 3.50 & 3.00 & 3.57 \\
\hline A2a. Water & 4.00 & 4.00 & 3.33 & 3.66 \\
\hline A2b. Transportation & 4.00 & 3.00 & 3.50 & 3.63 \\
\hline A2c. Communication & 4.00 & 4.00 & 3.25 & 3.82 \\
\hline A2d. Security & 4.00 & 3.00 & 2.67 & 3.34 \\
\hline A2e. Health services & 4.00 & 3.00 & 3.00 & 3.57 \\
\hline A2f. Evacuation centers & 4.00 & 4.00 & 2.25 & 3.42 \\
\hline $\begin{array}{l}\text { A3. How well are the participatory collaboration mechanisms } \\
\text { among different sectors and various levels of government } \\
\text { used to manage for resilience? }\end{array}$ & 4.00 & 3.00 & 2.50 & 3.23 \\
\hline $\begin{array}{l}\text { A4. transparent, accountable, and available are the technical } \\
\text { and financial support mechanisms to support planned }\end{array}$ & 4.00 & 4.00 & 2.75 & 3.12 \\
\hline A.5 How good are we with our risk reduction efforts? & 4.00 & 4.00 & 2.75 & 3.35 \\
\hline $\begin{array}{l}\text { Percent Score } \\
\end{array}$ & 80.00 & 70.00 & 54.00 & 65.89 \\
\hline B. Society and Economy & 3.75 & 3.25 & 3.00 & 2.97 \\
\hline $\begin{array}{l}\text { B1. How well is our development policies and plans in building } \\
\text { social capital and skills for economic diversity and self- } \\
\text { reliance? }\end{array}$ & 4.00 & 3.00 & 3.33 & 2.99 \\
\hline $\begin{array}{l}\text { B2. How is the availability of diverse and environmentally } \\
\text { sustainable livelihood in the community? }\end{array}$ & 3.00 & 3.00 & 3.00 & 2.67 \\
\hline
\end{tabular}


Community-Based Flood Vulnerability Index for Urban Flooding: Understanding

Social Vulnerabilities and Risks

LOCAL GOVERNMENT UNITS and NON-GOVERNMENTAL ORGANIZATION MATRIX ... continued

\begin{tabular}{|c|c|c|c|c|}
\hline \multirow{2}{*}{ Benchmarks } & \multicolumn{3}{|c|}{ LGU/NON-GOVERNMENTAL ORGANIZATION } & \multirow{2}{*}{ Overall } \\
\hline & PDRRMC & DRRMC & NGO & \\
\hline $\begin{array}{l}\text { B3. How well is our technical and financial resources in promoting } \\
\text { self-reliant communities so it would have the capacity to } \\
\text { provide support to disaster-stricken areas? }\end{array}$ & 4.00 & 4.00 & 3.00 & 3.13 \\
\hline $\begin{array}{l}\text { B4. How well is our technical and financial resources in promoting } \\
\text { stable and robust economies, reduce vulnerability to hazards, } \\
\text { and aid in disaster recovery? }\end{array}$ & 4.00 & 3.00 & 2.67 & 3.08 \\
\hline Percent Score & 75.00 & 65.00 & 60.00 & 59.33 \\
\hline C. The River's Natural Resource and Natural Features' Management & 3.00 & 4.00 & 2.38 & 3.02 \\
\hline $\begin{array}{l}\text { C1. How well are our policies and plans implemented and } \\
\text { monitored to effectively manage our communities along the } \\
\text { river? }\end{array}$ & 3.00 & 4.00 & 2.25 & 3.28 \\
\hline $\begin{array}{l}\text { C2. How well are the protecting and maintaining our river and its } \\
\text { natural features to reduce risk from flood hazards? }\end{array}$ & 3.00 & 4.00 & 2.25 & 2.92 \\
\hline $\begin{array}{l}\text { C3. How actively engaged are our communities in planning and } \\
\text { and implementing river resource management activities? }\end{array}$ & 3.00 & 4.00 & 2.50 & 2.90 \\
\hline $\begin{array}{l}\text { C4. How well are our communities and local governments value } \\
\text { and invest in management and conservation to sustain our } \\
\text { river's natural resources and natural features? }\end{array}$ & 3.00 & 4.00 & 2.50 & 2.97 \\
\hline Percent Score & 60.00 & 80.00 & 47.50 & 60.33 \\
\hline
\end{tabular}


Community-Based Flood Vulnerability Index for Urban Flooding: Understanding

Social Vulnerabilities and Risks

LOCAL GOVERNMENT UNITS and NON-GOVERNMENTAL ORGANIZATION MATRIX ... continued

\begin{tabular}{|c|c|c|c|c|}
\hline \multirow{2}{*}{ Benchmarks } & \multicolumn{3}{|c|}{ LGU/NON-GOVERNMENTAL ORGANIZATION } & \multirow{2}{*}{ Overall } \\
\hline & PDRRMC & DRRMC & NGO & \\
\hline D. Land Use and Management and Structural Design & 3.11 & 4.10 & 2.69 & 3.00 \\
\hline $\begin{array}{l}\text { D1. How well are the land use policies and building Standards that } \\
\text { incorporate measures to reduce risks from hazards and } \\
\text { protect sensitive habitats are established, monitored and } \\
\text { enforced? }\end{array}$ & 3.00 & 4.00 & 2.75 & 3.02 \\
\hline $\begin{array}{l}\text { D2. How well are the critical infrastructures constructed to } \\
\text { address risks from priority hazards? }\end{array}$ & 3.25 & 4.00 & 2.44 & 3.05 \\
\hline D2a. Increasing capacity of our drainage system & 4.00 & 4.00 & 2.50 & 3.37 \\
\hline $\begin{array}{l}\text { D2b. Good runoff volume control on open retention basin, } \\
\text { in-line basins, off-site basins, on site storage, dry ponds }\end{array}$ & 3.00 & 3.00 & 2.25 & 2.35 \\
\hline D2c. Very efficient dike safety system & 3.00 & 4.00 & 2.50 & 3.20 \\
\hline D2d. Very efficient bridge system & 3.00 & 5.00 & 2.50 & 3.30 \\
\hline $\begin{array}{l}\text { D3. How well are developers and communities incorporate risk } \\
\text { reduction into the location and design of structures? }\end{array}$ & 3.20 & 4.40 & 2.58 & 2.94 \\
\hline D3a. Existing spatial planning & 4.00 & 4.00 & 2.33 & 3.19 \\
\hline D3b. Flood risk adaptive to land use & 3.00 & 4.00 & 2.25 & 2.82 \\
\hline D3c. Building regulations & 3.00 & 4.00 & 2.33 & 2.92 \\
\hline D3d. Building codes & 3.00 & 5.00 & 3.00 & 2.87 \\
\hline D3e. Zoning ordinances & 3.00 & 5.00 & 3.00 & 2.90 \\
\hline $\begin{array}{l}\text { D4. How established is our education, outreach, and training } \\
\text { programs to improve compliance with land use policies and } \\
\text { building standards? }\end{array}$ & 3.00 & 4.00 & 3.00 & 3.00 \\
\hline Percent Score & 62.81 & 82.50 & 53.57 & 59.98 \\
\hline
\end{tabular}


Community-Based Flood Vulnerability Index for Urban Flooding: Understanding

Social Vulnerabilities and Risks

LOCAL GOVERNMENT UNITS and NON-GOVERNMENTAL ORGANIZATION MATRIX ... continued

\begin{tabular}{|c|c|c|c|c|}
\hline \multirow{2}{*}{ Benchmarks } & \multicolumn{3}{|c|}{ LGU/NON-GOVERNMENTAL ORGANIZATION } & \multirow{2}{*}{ Overall } \\
\hline & PDRRMC & DRRMC & NGO & \\
\hline E. Risk Knowledge & 4.00 & 3.00 & 2.34 & 3.16 \\
\hline $\begin{array}{l}\text { E1. How well are the flood hazard risk assessments completed } \\
\text { and routinely updated? }\end{array}$ & 4.00 & 3.00 & 2.25 & 3.15 \\
\hline $\begin{array}{l}\text { E2. How comprehensive is our flood hazard risk assessments } \\
\text { to incorporate risks to all elements of resilience? }\end{array}$ & 4.00 & 3.00 & 2.75 & 3.02 \\
\hline $\begin{array}{l}\text { E3. How well our community participates in the hazard risk } \\
\text { assessment process? }\end{array}$ & 4.00 & 3.00 & 2.25 & 3.22 \\
\hline $\begin{array}{l}\text { E4. How well are our information from risk assessment is } \\
\text { accessible and utilized by the community and government? }\end{array}$ & 4.00 & 3.00 & 2.13 & 3.25 \\
\hline E4a. Information drive-brochures & 4.00 & 3.00 & 2.50 & 3.07 \\
\hline E4b. Understanding the early warning systems & 4.00 & 3.00 & 1.25 & 3.28 \\
\hline E4c. Flood hazard maps & 4.00 & 3.00 & 2.25 & 3.22 \\
\hline E4d. Evacuation centers & 4.00 & 3.00 & 2.50 & 3.43 \\
\hline Percent Score & 80.00 & 60.00 & 46.88 & 63.17 \\
\hline F. Warning and Evacuation & 3.80 & 3.40 & 2.70 & 3.27 \\
\hline $\begin{array}{l}\text { F1. How well is our community warning and evacuation systems, } \\
\text { policies, plans, and procedures are in place and capable of } \\
\text { alerting vulnerable populations in a timely manner? }\end{array}$ & 4.00 & 4.00 & 2.75 & 3.45 \\
\hline $\begin{array}{l}\text { F2. How well is our community flood warning system in place } \\
\text { and maintained? }\end{array}$ & 4.00 & 3.00 & 1.75 & 3.15 \\
\hline $\begin{array}{l}\text { F3. How well is our community evacuation infrastructure in } \\
\text { place and maintained? }\end{array}$ & 3.00 & 3.00 & 2.50 & 3.23 \\
\hline
\end{tabular}


Community-Based Flood Vulnerability Index for Urban Flooding: Understanding

Social Vulnerabilities and Risks

LOCAL GOVERNMENT UNITS and NON-GOVERNMENTAL ORGANIZATION MATRIX ... continued

\begin{tabular}{|c|c|c|c|c|}
\hline \multirow{2}{*}{ Benchmarks } & \multicolumn{3}{|c|}{ LGU/NON-GOVERNMENTAL ORGANIZATION } & \multirow{2}{*}{ Overall } \\
\hline & PDRRMC & DRRMC & NGO & \\
\hline $\begin{array}{l}\text { F4. How prepared is the community to respond to hazard } \\
\text { warnings with appropriate actions? }\end{array}$ & 4.00 & 4.00 & 3.00 & 3.37 \\
\hline $\begin{array}{l}\text { F5. How is the availability of our technical (services offered) } \\
\text { and financial resources in maintaining and improving } \\
\text { warning and evacuation systems? }\end{array}$ & 4.00 & 3.00 & 3.50 & 3.17 \\
\hline Percent Score & 76.00 & 68.00 & 54.00 & 65.47 \\
\hline G. Emergency Response & 4.00 & 4.00 & 3.06 & 3.39 \\
\hline $\begin{array}{l}\text { G1. How established are our pre-defined roles and } \\
\text { responsibilities for immediate action at all levels. }\end{array}$ & 4.00 & 4.00 & 2.50 & 3.37 \\
\hline $\begin{array}{l}\text { G2. How is the availability of the basic emergency and } \\
\text { relief services? }\end{array}$ & 4.00 & 4.00 & 3.00 & 3.50 \\
\hline $\begin{array}{l}\text { G3. How well are our preparedness activities (drills and } \\
\text { simulations) are ongoing to train and educate responders? }\end{array}$ & 4.00 & 4.00 & 3.25 & 3.32 \\
\hline $\begin{array}{l}\text { G4. How well are the organizations and volunteers are in } \\
\text { placed with technical (services offered) and financial } \\
\text { resources to support emergency response activities? }\end{array}$ & 4.00 & 4.00 & 3.50 & 3.37 \\
\hline Percent Score & 80.00 & 80.00 & 61.25 & 67.75 \\
\hline H. Disaster Recovery & 3.67 & 3.03 & 2.51 & 2.91 \\
\hline $\begin{array}{l}\text { H1. How well is our disaster recovery plan pre-established that } \\
\text { addresses economic, environmental, and social concerns } \\
\text { of the community? }\end{array}$ & 4.00 & 3.00 & 2.25 & 3.08 \\
\hline $\begin{array}{l}\text { H2. How well is our disaster recovery process is monitored, } \\
\text { and improved at periodic intervals? }\end{array}$ & 4.00 & 3.00 & 2.25 & 3.02 \\
\hline
\end{tabular}


Community-Based Flood Vulnerability Index for Urban Flooding: Understanding

Social Vulnerabilities and Risks

LOCAL GOVERNMENT UNITS and NON-GOVERNMENTAL ORGANIZATION MATRIX ... continued

\begin{tabular}{|c|c|c|c|c|}
\hline \multirow{2}{*}{ Benchmarks } & \multicolumn{3}{|c|}{ LGU/NON-GOVERNMENTAL ORGANIZATION } & \multirow{2}{*}{ Overall } \\
\hline & PDRRMC & DRRMC & NGO & \\
\hline $\begin{array}{l}\text { H3. How well is coordination mechanisms at international, } \\
\text { national, and local levels are pre-established for disaster } \\
\text { recovery? }\end{array}$ & 3.00 & 3.00 & 2.75 & 3.05 \\
\hline $\begin{array}{l}\text { H4. How is the availability of our technical (services offered) } \\
\text { and financial resources to support the recovery process? }\end{array}$ & 3.33 & 3.17 & 2.79 & 2.79 \\
\hline H4a. Insurance scheme & 3.00 & 3.00 & 2.00 & 2.37 \\
\hline H4b. Damage assessment facilitating claim procession & 3.00 & 3.00 & 2.50 & 2.70 \\
\hline H4c. Reconstruction & 4.00 & 4.00 & 3.25 & 2.82 \\
\hline $\mathrm{H} 4 \mathrm{~d}$. Charitable funds & 3.00 & 3.00 & 3.25 & 2.85 \\
\hline H4e. Social therapeutic measures & 3.00 & 3.00 & 2.75 & 2.85 \\
\hline H4f. Rescue equipment and tools & 4.00 & 3.00 & 3.00 & 3.17 \\
\hline $\begin{array}{l}\text { H5. How good are we in conducting traumatic/or psychological } \\
\text { stress debriefings? }\end{array}$ & 4.00 & 3.00 & 2.50 & 2.60 \\
\hline Percent Score & 61.33 & 48.67 & 39.17 & 45.97 \\
\hline AVERAGE RATING (RAW) & 3.67 & 3.54 & 2.67 & 3.13 \\
\hline OVERALL ALL PERCENT SCORE & 73.32 & 70.71 & 53.46 & 62.52 \\
\hline
\end{tabular}




\section{APPENDIX 8 Assessment on Flood Resilience and Health Program the Local Government Units and NGO's}

The appendix presents the results from the household respondents on the assessment on flood resilience and health programs administered and facilitated by the LGU's and NGO's.

Assessment on Flood Resilience and Health Program the Local Government Units and NGO's

\begin{tabular}{|c|c|c|c|c|c|c|c|c|c|c|}
\hline \multirow{2}{*}{ Items } & \multicolumn{2}{|c|}{ Tabuc-tubig } & \multicolumn{2}{|c|}{ Junob } & \multicolumn{2}{|c|}{ Poblacion 1} & \multicolumn{2}{|c|}{ Calindagan } & \multicolumn{2}{|c|}{ Balugo } \\
\hline & Mean & S.D. & Mean & S.D. & Mean & S.D. & Mean & S.D. & Mean & S.D. \\
\hline $\begin{array}{l}\text { 1. The implementation and } \\
\text { monitoring of the policies, plans, } \\
\text { and programs for the different } \\
\text { natural calamities particularly } \\
\text { typhoon and flooding events. }\end{array}$ & 4.40 & 0.70 & 3.50 & 1.32 & 3.77 & 1.02 & 3.65 & 1.40 & 3.65 & 1.22 \\
\hline $\begin{array}{l}\text { 2. The transparency and } \\
\text { trustworthiness of the LGU in } \\
\text { terms of the facilitation and } \\
\text { distribution of the budget and } \\
\text { donations for the affected } \\
\text { population in the community. }\end{array}$ & 4.60 & 0.84 & 3.13 & 1.50 & 3.45 & 1.30 & 3.00 & 1.45 & 2.65 & 1.46 \\
\hline $\begin{array}{l}\text { 3. For the livelihood or financial } \\
\text { aid for the community people to } \\
\text { recover again from such calamity. }\end{array}$ & 3.80 & 1.23 & 3.06 & 1.44 & 3.45 & 1.18 & 2.91 & 1.68 & 2.31 & 1.58 \\
\hline $\begin{array}{l}\text { 4. For the programs and policies in saving } \\
\text { and protecting the BANICA River. }\end{array}$ & 3.70 & 1.25 & 3.06 & 1.57 & 3.55 & 1.18 & 3.23 & 1.48 & 2.41 & 1.12 \\
\hline $\begin{array}{l}\text { 5. The cooperation of the } \\
\text { community people including you in } \\
\text { protecting the Banica river. }\end{array}$ & 4.30 & 0.82 & 3.50 & 1.32 & 3.76 & 0.94 & 3.57 & 1.27 & 3.35 & 0.86 \\
\hline 6. The drainage systems & 3.20 & 1.62 & 2.44 & 1.50 & 3.55 & 1.34 & 3.26 & 1.42 & 2.59 & 1.62 \\
\hline 7. The dike systems & 3.10 & 1.37 & 3.19 & 1.38 & 3.73 & 1.03 & 3.41 & 1.37 & 3.24 & 1.48 \\
\hline 8. The bridge systems & 4.20 & 1.14 & 3.31 & 1.25 & 4.05 & 1.00 & 3.48 & 1.27 & 3.07 & 1.22 \\
\hline 9. The flood hazard maps & 3.50 & 1.43 & 3.00 & 1.26 & 3.57 & 1.16 & 3.35 & 1.19 & 3.24 & 1.03 \\
\hline
\end{tabular}


Community-Based Flood Vulnerability Index for Urban Flooding: Understanding Social Vulnerabilities and Risks

Assessment on Flood Resilience and Health Program the Local Government Units and NGO's ... continued

\begin{tabular}{|c|c|c|c|c|c|c|c|c|c|c|}
\hline \multirow{2}{*}{ Items } & \multicolumn{2}{|c|}{ Tabuc-tubig } & \multicolumn{2}{|c|}{ Junob } & \multicolumn{2}{|c|}{ Poblacion 1} & \multicolumn{2}{|c|}{ Calindagan } & \multicolumn{2}{|c|}{ Balugo } \\
\hline & Mean & S.D. & Mean & S.D. & Mean & S.D. & Mean & S.D. & Mean & S.D. \\
\hline $\begin{array}{l}\text { 10. The use of backhoe in cleaning } \\
\text { the Banica river especially when } \\
\text { the normal flow is blocked. }\end{array}$ & 3.90 & 1.20 & 2.88 & 1.54 & 3.05 & 1.25 & 3.09 & 1.31 & 2.94 & 1.68 \\
\hline $\begin{array}{l}\text { 11. The distribution of donations, } \\
\text { goods and relief. }\end{array}$ & 4.40 & 0.70 & 3.25 & 1.34 & 3.41 & 1.40 & 2.78 & 1.51 & 2.81 & 1.87 \\
\hline $\begin{array}{l}\text { 12. The distribution of brochures } \\
\text { and the information drive that } \\
\text { would increase knowledge on the } \\
\text { negative impacts from typhoon } \\
\text { and flooding events for the } \\
\text { purposes of prevention and } \\
\text { recovery. }\end{array}$ & 4.10 & 1.20 & 3.38 & 1.45 & 3.50 & 1.14 & 3.43 & 1.38 & 3.24 & 1.15 \\
\hline 13. Flood early warning systems & 4.10 & 0.88 & 3.25 & 1.44 & 3.55 & 1.22 & 3.52 & 1.16 & 3.53 & 1.18 \\
\hline $\begin{array}{l}\text { 14. Preparedness and drill to } \\
\text { increase resilience from typhoons } \\
\text { and floods. }\end{array}$ & 4.20 & 0.92 & 3.25 & 1.39 & 3.38 & 1.43 & 3.30 & 1.15 & 2.94 & 1.34 \\
\hline $\begin{array}{l}\text { 15. The response and } \\
\text { preparedness of the DRRMC, } \\
\text { PDRRMC and other NGO } \\
\text { volunteers during rescue events. }\end{array}$ & 4.00 & 0.82 & 3.75 & 1.24 & 3.62 & 1.16 & 3.87 & 1.06 & 4.06 & 1.14 \\
\hline
\end{tabular}


Community-Based Flood Vulnerability Index for Urban Flooding: Understanding Social Vulnerabilities and Risks

Assessment on Flood Resilience and Health Program the Local Government Units and NGO's ... continued

\begin{tabular}{|c|c|c|c|c|c|c|c|c|c|c|}
\hline \multirow{2}{*}{ Items } & \multicolumn{2}{|c|}{ Tabuc-tubig } & \multicolumn{2}{|c|}{ Junob } & \multicolumn{2}{|c|}{ Poblacion 1} & \multicolumn{2}{|c|}{ Calindagan } & \multicolumn{2}{|c|}{ Balugo } \\
\hline & Mean & S.D. & Mean & S.D. & Mean & S.D. & Mean & S.D. & Mean & S.D. \\
\hline $\begin{array}{l}\text { 16. The basic emergency and relief } \\
\text { services such as food, water, } \\
\text { sanitation, transportation, } \\
\text { communication, medical help, } \\
\text { provisional repairs of damaged } \\
\text { properties. }\end{array}$ & 4.10 & 0.99 & 3.06 & 1.53 & 3.68 & 1.21 & 3.57 & 1.20 & 3.88 & 1.17 \\
\hline $\begin{array}{l}\text { 17. The operation clean-up } \\
\text { affected places, giving of } \\
\text { insurances, claims, financial aids, } \\
\text { traumatic and psychological stress } \\
\text { debriefings. }\end{array}$ & 4.50 & 0.71 & 3.25 & 1.48 & 3.64 & 1.22 & 3.13 & 1.52 & 3.24 & 1.56 \\
\hline $\begin{array}{l}\text { 18. The relocation sites provided } \\
\text { by the LGU's to those who were } \\
\text { affected from the last flooding and } \\
\text { to those who live in the flood } \\
\text { prone area. }\end{array}$ & 4.30 & 0.95 & 3.19 & 1.56 & 3.68 & 1.25 & 3.43 & 1.24 & 3.82 & 1.01 \\
\hline $\begin{array}{l}\text { 19. The health programs for } \\
\text { diarrhea and Liptospirosis such as } \\
\text { medical help, information drive } \\
\text { and among others so outbreaks } \\
\text { can be prevented. }\end{array}$ & 4.30 & 0.95 & 3.31 & 1.30 & 3.55 & 1.26 & 3.35 & 1.19 & 3.18 & 1.19 \\
\hline
\end{tabular}


Community-Based Flood Vulnerability Index for Urban Flooding: Understanding

Social Vulnerabilities and Risks

Assessment on Flood Resilience and Health Program the Local Government Units and NGO's ... continued

\begin{tabular}{|c|c|c|c|c|c|c|c|c|c|c|}
\hline \multirow{2}{*}{ Items } & \multicolumn{2}{|c|}{ Tabuc-tubig } & \multicolumn{2}{|c|}{ Junob } & \multicolumn{2}{|c|}{ Poblacion 1} & \multicolumn{2}{|c|}{ Calindagan } & \multicolumn{2}{|c|}{ Balugo } \\
\hline & Mean & S.D. & Mean & S.D. & Mean & S.D. & Mean & S.D. & Mean & S.D. \\
\hline $\begin{array}{l}\text { 20. The different prevention and } \\
\text { control programs for Dengue Fever } \\
\text { infection such as fogging, } \\
\text { chemical/biological control, } \\
\text { information drive brochures, } \\
\text { lectures, clean-up and other } \\
\text { similar means at the community } \\
\text { level. }\end{array}$ & 4.40 & 0.84 & 3.63 & 1.36 & 3.64 & 1.14 & 3.43 & 1.44 & 3.47 & 1.07 \\
\hline Overall & & & & & & & & & & \\
\hline Mean Score & 81.10 & 13.79 & 64.38 & 23.92 & 70.91 & 20.59 & 66.48 & 21.97 & 62.94 & 19.92 \\
\hline Mean Percent Score & 81.10 & 13.79 & 64.38 & 23.92 & 70.91 & 20.59 & 66.48 & 21.97 & 62.94 & 19.92 \\
\hline
\end{tabular}


Community-Based Flood Vulnerability Index for Urban Flooding: Understanding Social Vulnerabilities and Risks

Assessment on Flood Resilience and Health Program the Local Government Units and NGO's ... continued

\begin{tabular}{|c|c|c|c|c|c|c|c|c|c|c|}
\hline \multirow{2}{*}{ Items } & \multicolumn{2}{|c|}{ Barangay 2} & \multicolumn{2}{|c|}{ Poblacion 8} & \multicolumn{2}{|c|}{ Cadawinonan } & \multicolumn{2}{|c|}{ Bagacay } & \multicolumn{2}{|c|}{ Taclobo } \\
\hline & Mean & S.D. & Mean & S.D. & Mean & S.D. & Mean & S.D. & Mean & S.D. \\
\hline $\begin{array}{l}\text { 1. The implementation and } \\
\text { monitoring of the policies, plans, } \\
\text { and programs for the different } \\
\text { natural calamities particularly } \\
\text { typhoon and flooding events. }\end{array}$ & 3.81 & 1.05 & 3.45 & 1.18 & 3.64 & 1.11 & 3.77 & 1.19 & 3.59 & 1.13 \\
\hline $\begin{array}{l}2 . \quad \text { The transparency and } \\
\text { trustworthiness of the LGU in } \\
\text { terms of the facilitation and } \\
\text { distribution of the budget and } \\
\text { donations for the affected } \\
\text { population in the community. }\end{array}$ & 2.88 & 1.26 & 3.10 & 1.23 & 3.44 & 1.39 & 3.10 & 1.37 & 3.33 & 1.19 \\
\hline $\begin{array}{l}\text { 3. For the livelihood or financial } \\
\text { aid for the community people to } \\
\text { recover again from such calamity. }\end{array}$ & 2.81 & 1.42 & 3.28 & 1.36 & 3.13 & 1.39 & 3.20 & 1.32 & 3.08 & 1.17 \\
\hline $\begin{array}{l}\text { 4. For the programs and policies in } \\
\text { saving and protecting the BANICA } \\
\text { River. }\end{array}$ & 3.00 & 1.36 & 3.46 & 1.23 & 3.50 & 1.35 & 3.37 & 1.45 & 3.29 & 1.21 \\
\hline $\begin{array}{l}\text { 5. The cooperation of the } \\
\text { community people including you } \\
\text { in protecting the Banica river. }\end{array}$ & 3.44 & 1.21 & 3.52 & 1.09 & 3.64 & 1.11 & 3.43 & 1.14 & 3.56 & 1.07 \\
\hline 6. The drainage systems & 3.19 & 1.33 & 3.28 & 1.36 & 3.24 & 1.42 & 3.28 & 1.13 & 3.17 & 1.16 \\
\hline 7. The dike systems & 3.25 & 1.13 & 3.32 & 1.22 & 3.52 & 1.33 & 3.57 & 1.17 & 3.16 & 1.02 \\
\hline 8. The bridge systems & 3.38 & 1.20 & 3.61 & 1.07 & 3.52 & 1.23 & 3.50 & 0.94 & 3.16 & 1.00 \\
\hline
\end{tabular}


Community-Based Flood Vulnerability Index for Urban Flooding: Understanding Social Vulnerabilities and Risks

Assessment on Flood Resilience and Health Program the Local Government Units and NGO's ... continued

\begin{tabular}{|c|c|c|c|c|c|c|c|c|c|c|}
\hline \multirow{2}{*}{ Items } & \multicolumn{2}{|c|}{ Barangay 2} & \multicolumn{2}{|c|}{ Poblacion 8} & \multicolumn{2}{|c|}{ Cadawinonan } & \multicolumn{2}{|c|}{ Bagacay } & \multicolumn{2}{|c|}{ Taclobo } \\
\hline & Mean & S.D. & Mean & S.D. & Mean & S.D. & Mean & S.D. & Mean & S.D. \\
\hline 9. The flood hazard maps & 3.25 & 1.18 & 3.48 & 1.12 & 3.52 & 1.16 & 3.24 & 0.99 & 3.08 & 1.06 \\
\hline $\begin{array}{l}\text { 10. The use of backhoe in cleaning } \\
\text { the Banica river especially when } \\
\text { the normal flow is blocked. }\end{array}$ & 2.63 & 1.31 & 3.17 & 1.39 & 3.16 & 1.40 & 3.24 & 1.38 & 2.98 & 1.16 \\
\hline $\begin{array}{l}\text { 11. The distribution of donations, } \\
\text { goods and relief. }\end{array}$ & 3.00 & 1.26 & 3.41 & 1.40 & 3.44 & 1.47 & 3.17 & 1.21 & 3.24 & 1.25 \\
\hline $\begin{array}{l}\text { 12. The distribution of brochures } \\
\text { and the information drive that } \\
\text { would increase knowledge on the } \\
\text { negative impacts from typhoon } \\
\text { and flooding events for the } \\
\text { purposes of prevention and } \\
\text { recovery. }\end{array}$ & 3.00 & 1.37 & 3.66 & 1.04 & 3.50 & 1.32 & 3.37 & 1.13 & 3.41 & 1.17 \\
\hline 13. Flood early warning systems & 3.44 & 1.15 & 3.66 & 1.14 & 3.79 & 1.06 & 3.23 & 1.28 & 3.27 & 1.12 \\
\hline $\begin{array}{l}\text { 14. Preparedness and drill to } \\
\text { increase resilience from typhoons } \\
\text { and floods. }\end{array}$ & 3.25 & 1.39 & 3.41 & 1.38 & 3.54 & 1.50 & 3.30 & 1.39 & 3.16 & 1.19 \\
\hline $\begin{array}{l}\text { 15. The response and } \\
\text { preparedness of the DRRMC, } \\
\text { PDRRMC and other NGO } \\
\text { volunteers during rescue events. }\end{array}$ & 3.86 & 0.86 & 4.04 & 0.84 & 3.78 & 1.20 & 4.21 & 0.74 & 3.79 & 1.00 \\
\hline
\end{tabular}


Community-Based Flood Vulnerability Index for Urban Flooding: Understanding Social Vulnerabilities and Risks

Assessment on Flood Resilience and Health Program the Local Government Units and NGO's ... continued

\begin{tabular}{|c|c|c|c|c|c|c|c|c|c|c|}
\hline \multirow{2}{*}{ Items } & \multicolumn{2}{|c|}{ Barangay 2} & \multicolumn{2}{|c|}{ Poblacion 8} & \multicolumn{2}{|c|}{ Cadawinonan } & \multicolumn{2}{|c|}{ Bagacay } & \multicolumn{2}{|c|}{ Taclobo } \\
\hline & Mean & S.D. & Mean & S.D. & Mean & S.D. & Mean & S.D. & Mean & S.D. \\
\hline $\begin{array}{l}\text { 16. The basic emergency and } \\
\text { relief services such as food, water, } \\
\text { sanitation, transportation, } \\
\text { communication, medical help, } \\
\text { provisional repairs of damaged } \\
\text { properties. }\end{array}$ & 3.60 & 1.24 & 3.97 & 0.87 & 3.84 & 0.90 & 3.77 & 0.86 & 3.63 & 1.00 \\
\hline $\begin{array}{l}\text { 17. The operation clean-up } \\
\text { affected places, giving of } \\
\text { insurances, claims, financial aids, } \\
\text { traumatic and psychological stress } \\
\text { debriefings. }\end{array}$ & 3.19 & 1.28 & 3.69 & 1.14 & 3.60 & 1.00 & 3.33 & 1.06 & 3.43 & 1.07 \\
\hline $\begin{array}{l}\text { 18. The relocation sites provided } \\
\text { by the LGU's to those who were } \\
\text { affected from the last flooding and } \\
\text { to those who live in the flood } \\
\text { prone area. }\end{array}$ & 3.31 & 1.40 & 3.72 & 0.96 & 3.84 & 1.03 & 2.72 & 1.19 & 3.41 & 1.01 \\
\hline $\begin{array}{l}\text { 19. The health programs for } \\
\text { diarrhea and Liptospirosis such as } \\
\text { medical help, information drive } \\
\text { and among others so outbreaks } \\
\text { can be prevented. }\end{array}$ & 3.31 & 1.25 & 3.56 & 1.01 & 3.92 & 0.86 & 3.53 & 1.01 & 3.40 & 1.01 \\
\hline
\end{tabular}


Community-Based Flood Vulnerability Index for Urban Flooding: Understanding Social Vulnerabilities and Risks

Assessment on Flood Resilience and Health Program the Local Government Units and NGO's ... continued

\begin{tabular}{|c|c|c|c|c|c|c|c|c|c|c|}
\hline \multirow{2}{*}{ Items } & \multicolumn{2}{|c|}{ Barangay 2} & \multicolumn{2}{|c|}{ Poblacion 8} & \multicolumn{2}{|c|}{ Cadawinonan } & \multicolumn{2}{|c|}{ Bagacay } & \multicolumn{2}{|c|}{ Taclobo } \\
\hline & Mean & S.D. & Mean & S.D. & Mean & S.D. & Mean & S.D. & Mean & S.D. \\
\hline $\begin{array}{l}\text { 20. The different prevention and } \\
\text { control programs for Dengue } \\
\text { Fever infection such as fogging, } \\
\text { chemical/biological control, } \\
\text { information drive brochures, } \\
\text { lectures, clean-up and other } \\
\text { similar means at the community } \\
\text { level. }\end{array}$ & 3.31 & 1.25 & 3.79 & 1.08 & 3.92 & 0.91 & 3.90 & 0.80 & 3.75 & 1.03 \\
\hline Overall & & & & & & & & & & \\
\hline Mean Score & 64.00 & 20.99 & 69.83 & 19.98 & 70.48 & 19.61 & 67.53 & 15.74 & 66.75 & 17.14 \\
\hline Mean Percent Score & 64.00 & 20.99 & 69.83 & 19.98 & 70.48 & 19.61 & 67.53 & 15.74 & 66.75 & 17.14 \\
\hline
\end{tabular}


Community-Based Flood Vulnerability Index for Urban Flooding: Understanding Social Vulnerabilities and Risks

Assessment on Flood Resilience and Health Program the Local Government Units and NGO's ... continued

\begin{tabular}{|c|c|c|c|c|c|c|}
\hline \multirow{2}{*}{ Items } & \multicolumn{2}{|c|}{ Candau-ay } & \multicolumn{2}{|c|}{ Batinguel } & \multicolumn{2}{|c|}{ Overall } \\
\hline & Mean & S.D. & Mean & S.D. & Mean & S.D. \\
\hline $\begin{array}{l}\text { 1. The implementation and monitoring of the } \\
\text { policies, plans, and programs for the different } \\
\text { natural calamities particularly typhoon and } \\
\text { flooding events. }\end{array}$ & 3.54 & 1.24 & 3.82 & 1.35 & 3.72 & 0.25 \\
\hline $\begin{array}{l}\text { 2. The transparency and trustworthiness of the } \\
\text { LGU in terms of the facilitation and distribution of } \\
\text { the budget and donations for the affected } \\
\text { population in the community. }\end{array}$ & 3.03 & 1.26 & 3.03 & 1.40 & 3.23 & 0.49 \\
\hline $\begin{array}{l}\text { 3. For the livelihood or financial aid for the } \\
\text { community people to recover again from such } \\
\text { calamity. }\end{array}$ & 3.04 & 1.24 & 2.97 & 1.35 & 3.09 & 0.36 \\
\hline $\begin{array}{l}\text { 4. For the programs and policies in saving and } \\
\text { protecting the BANICA River. }\end{array}$ & 3.15 & 1.21 & 3.53 & 1.43 & 3.27 & 0.34 \\
\hline $\begin{array}{l}\text { 5. The cooperation of the community people } \\
\text { including you in protecting the Banica river. }\end{array}$ & 3.51 & 1.11 & 3.79 & 1.17 & 3.61 & 0.25 \\
\hline 6. The drainage systems & 2.90 & 1.25 & 3.13 & 1.19 & 3.10 & 0.31 \\
\hline 7. The dike systems & 3.11 & 1.24 & 3.42 & 1.22 & 3.33 & 0.20 \\
\hline 8. The bridge systems & 3.10 & 1.24 & 3.34 & 1.07 & 3.48 & 0.35 \\
\hline 9. The flood hazard maps & 2.87 & 1.34 & 3.00 & 1.36 & 3.26 & 0.23 \\
\hline
\end{tabular}


Community-Based Flood Vulnerability Index for Urban Flooding: Understanding

Social Vulnerabilities and Risks

Assessment on Flood Resilience and Health Program the Local Government Units and NGO's ... continued

\begin{tabular}{|c|c|c|c|c|c|c|}
\hline \multirow{2}{*}{ Items } & \multicolumn{2}{|c|}{ Candau-ay } & \multicolumn{2}{|c|}{ Batinguel } & \multicolumn{2}{|c|}{ Overall } \\
\hline & Mean & S.D. & Mean & S.D. & Mean & S.D. \\
\hline $\begin{array}{l}\text { 10. The use of backhoe in cleaning the Banica } \\
\text { river especially when the normal flow is blocked. }\end{array}$ & 2.94 & 1.46 & 2.71 & 1.37 & 3.06 & 0.32 \\
\hline $\begin{array}{l}\text { 11. The distribution of donations, goods and } \\
\text { relief. }\end{array}$ & 3.11 & 1.33 & 2.89 & 1.52 & 3.24 & 0.43 \\
\hline $\begin{array}{l}\text { 12. The distribution of brochures and the } \\
\text { information drive that would increase knowledge } \\
\text { on the negative impacts from typhoon and } \\
\text { flooding events for the purposes of prevention } \\
\text { and recovery. }\end{array}$ & 3.32 & 1.11 & 3.26 & 1.35 & 3.43 & 0.27 \\
\hline 13. Flood early warning systems & 3.25 & 1.35 & 3.22 & 1.42 & 3.48 & 0.27 \\
\hline $\begin{array}{l}\text { 14. Preparedness and drill to increase resilience } \\
\text { from typhoons and floods. }\end{array}$ & 3.19 & 1.32 & 2.95 & 1.41 & 3.32 & 0.33 \\
\hline $\begin{array}{l}\text { 15. The response and preparedness of the } \\
\text { DRRMC, PDRRMC and other NGO volunteers } \\
\text { during rescue events. }\end{array}$ & 3.86 & 1.04 & 3.71 & 1.29 & 3.88 & 0.17 \\
\hline
\end{tabular}


Community-Based Flood Vulnerability Index for Urban Flooding: Understanding Social Vulnerabilities and Risks

Assessment on Flood Resilience and Health Program the Local Government Units and NGO's ... continued

\begin{tabular}{|c|c|c|c|c|c|c|}
\hline \multirow{2}{*}{ Items } & \multicolumn{2}{|c|}{ Candau-ay } & \multicolumn{2}{|c|}{ Batinguel } & \multicolumn{2}{|c|}{ Overall } \\
\hline & Mean & S.D. & Mean & S.D. & Mean & S.D. \\
\hline $\begin{array}{l}\text { 16. The basic emergency and relief services such } \\
\text { as food, water, sanitation, transportation, } \\
\text { communication, medical help, provisional repairs } \\
\text { of damaged properties. }\end{array}$ & 3.75 & 0.99 & 3.47 & 1.20 & 3.69 & 0.27 \\
\hline $\begin{array}{l}\text { 17. The operation clean-up affected places, giving } \\
\text { of insurances, claims, financial aids, traumatic and } \\
\text { psychological stress debriefings. }\end{array}$ & 3.49 & 1.01 & 3.16 & 1.31 & 3.47 & 0.38 \\
\hline $\begin{array}{l}\text { 18. The relocation sites provided by the LGU's to } \\
\text { those who were affected from the last flooding } \\
\text { and to those who live in the flood prone area. }\end{array}$ & 3.28 & 1.06 & 3.08 & 1.40 & 3.48 & 0.42 \\
\hline $\begin{array}{l}\text { 19. The health programs for diarrhea and } \\
\text { Liptospirosis such as medical help, information } \\
\text { drive and among others so outbreaks can be } \\
\text { prevented. }\end{array}$ & 3.31 & 1.02 & 3.24 & 1.26 & 3.50 & 0.32 \\
\hline
\end{tabular}

Assessment on Flood Resilience and Health Program the Local Government Units and NGO's ... continued

\begin{tabular}{|c|c|c|c|c|c|c|}
\hline \multirow{2}{*}{ Items } & \multicolumn{2}{|c|}{ Candau-ay } & \multicolumn{2}{|c|}{ Batinguel } & \multicolumn{2}{|c|}{ Overall } \\
\hline & Mean & S.D. & Mean & S.D. & Mean & S.D. \\
\hline $\begin{array}{l}\text { 20. The different prevention and control programs } \\
\text { for Dengue Fever infection such as fogging, } \\
\text { chemical/biological control, information drive } \\
\text { brochures, lectures, clean-up and other similar } \\
\text { means at the community level. }\end{array}$ & 3.67 & 1.01 & 3.13 & 1.40 & 3.67 & 0.33 \\
\hline \multicolumn{7}{|l|}{ Overall } \\
\hline Mean Score & 65.31 & 18.03 & 64.76 & 20.97 & 67.87 & 4.92 \\
\hline Mean Percent Score & 65.31 & 18.03 & 64.76 & 20.97 & 67.87 & 4.92 \\
\hline
\end{tabular}


Community-Based Flood Vulnerability Index for Urban Flooding: Understanding Social Vulnerabilities and Risks 